\title{
The Size Effect and Strain Effect in Reinforced Masonry
}

A thesis submitted to the Faculty of Graduate and Postdoctoral Affairs in partial fulfillment of the requirements for the degree of

\section{Doctor of Philosophy in Civil Engineering}

\author{
by
}

\section{Salah R Sarhat}

The Ottawa-Carleton Institute for

Civil and Environmental Engineering (OCICEE)

Department of Civil and Environmental Engineering

Carleton University

Ottawa, Ontario, Canada

(C) 2016 Salah Sarhat 


\begin{abstract}
The research described in this thesis focuses on improving our understanding of the behaviour of reinforced concrete masonry subjected to shear. All shear design methods in current masonry building codes are empirically based, and have been shown to produce widely varying predictions of shear strengths of masonry walls, beams and columns. Furthermore, the research community acknowledges that there is little to no consensus on the exact mechanisms of shear transfer in masonry elements, thereby slowing the replacement of empirical design expressions with more rational approaches. Given that shear failures can be brittle and sudden, with little to no warning of impending failure; experimental research focusing on these two issues is of primary importance.
\end{abstract}

An extensive experimental program consisting load-testing fifteen large-scale reinforced masonry beams is presented in this thesis. The results definitively show that principles that govern the shear design of reinforced concrete beams in Canada can be applied to reinforced masonry beams. Various phenomena that have been observed in reinforced concrete subjected to shear were also observed in these tests, includes "the size effect" and "the strain effect". It is shown that design codes that do not account for these effects exhibit higher variability and in the case of size effect, may produce unsafe designs.

Detailed instrumentation of the test specimens showed that aggregate interlock is the major mechanism of shear transfer in masonry beams, and as such this mechanism can explain much of the observed experimental behaviour. The size effect, wherein the failure shear stress decreases as the effective depth increases, can be explained by the reduced aggregate interlock capacity. 
Likewise, the strain effect, wherein the failure shear stress decrease as longitudinal strains increase, can be explained based on reduced aggregate interlock. It is also found that stirrups and longitudinal reinforcement distributed over the height of the beam have highly beneficial effects on shear behaviour of reinforced masonry.

It is found that the general method of shear design from the CSA A23.3for reinforced concrete can be used to design reinforced masonry, and is more accurate and reliable than current masonry codes. It is concluded that masonry design codes should be updated to account for the size effect and strain effect. The test results of this research were used to justify the use of the CSA A23.3 as a base to revise the shear provisions in of CSA S304-2014 masonry code.

A series of side studies focused on the compressive strength of masonry $\left(\mathrm{f}_{\mathrm{m}}\right)$ were also performed. A large database of compressive tests on ungrouted and grouted masonry prisms reported in the literature was assembled and analyzed to develop simple formulae to predict $f_{m}$. The predictive capability of the formulae proposed in this thesis was compared to five international masonry design codes, and it was found that they gave the most accurate predictions of compressive strength of masonry with the least variation. The proposed equations to calculate $\mathrm{f}_{\mathrm{m}}$ can serve as replacements for current code methods. 


\section{Acknowledgements}

\section{"He has not thanked Allah who has not thanked people."}

-The Prophet Mohammed, peace and blessings be upon him

I would like to thank all who have contributed to make this journey a success. First of all, I would like to sincerely thank my supervisor, Dr. Ted Sherwood for his encouragement and invaluable help throughout my graduate career at Carleton University. Without his expertise, mentoring, genial assistance and constructive criticism, this research could not have been completed. Dr. Sherwood has been a constant source of support that has proven to be truly invaluable in all the time of research. I had the great fortune to have him as a supervisor and I thank him greatly.

My experimental work would never have happened without the help of staff members in the structural lab at Carleton University. Stanley Conley was the focal character in setting up the experimental setup and testing the masonry beams, Pierre Trudel crafted with his golden hands the instrumentation parts required for the testing. Kenneth Akhiwu and Jason Arnott were very helpful in the materials testing. Special thanks have to go to my friend Bishoy Alfa Samy for his vital help in completing the experimental work. Without his help, I would be probably still stuck in the laboratory. I would like to thank John Grimes, Megan Potts, Mohammed Al-Kadaumi, Mitra Khaja, Seyed Mohammed Musavi and Joshua Woods for their helping hands in conducting the experimental program. 
I wish to thank Mr. David Stubbs of the Canada Masonry Design Centre as well as instructor Tim and his team of masons for all their help in constructing my specimens. I want to thank Dr. Bennett Banting for teaching me everything he knows about image correlation analysis. The financial support of the Natural Sciences and Engineering Research Council (NSERC) of Canada is greatly appreciated. The additional financial support of the Canada Masonry Design Centre, Canadian Masonry Contractors Association, Ontario Masonry Contractors Association and Canadian Concrete Masonry Producers Association is also gratefully appreciated. The supply of materials by Permacon, Merkley Supply LTD, Essroc Italcementi Group, and Pultrall CO is greatly acknowledged.

I must express my heart-felt appreciation to my wife Hajera and my children Mohammed, Ali, Aya and Mustafa for providing me with unfailing love and continuous encouragement throughout my years of study. Without their support I would have really gone insane a long time ago. This thesis is dedicated in loving memory of my father, Rifaat Sarhat. This thesis is also dedicated to my mother Dawlet Rustom for her endless encouragement. 


\section{Table of Contents}

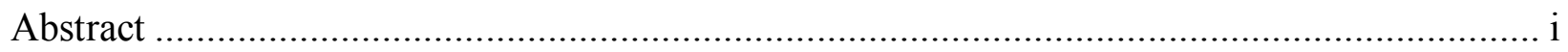

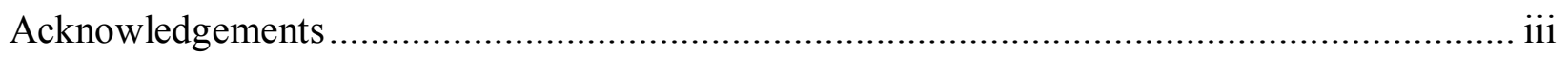

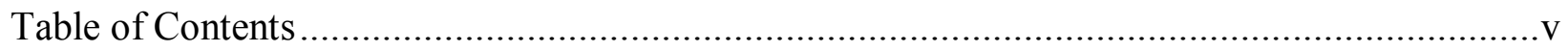

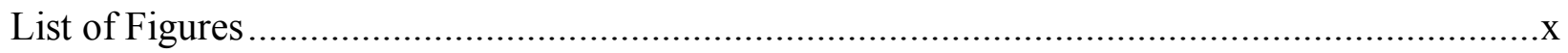

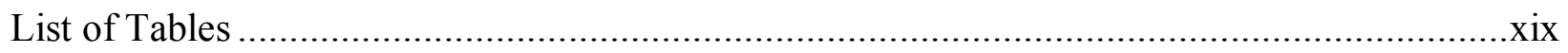

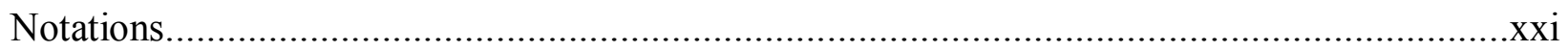

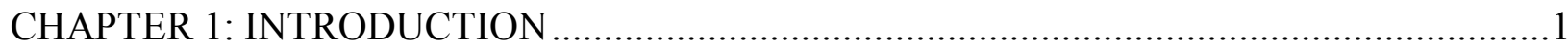

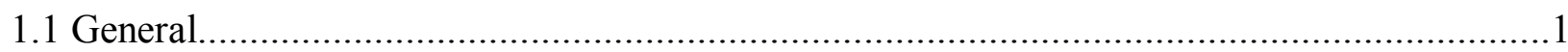

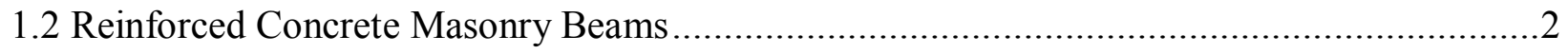

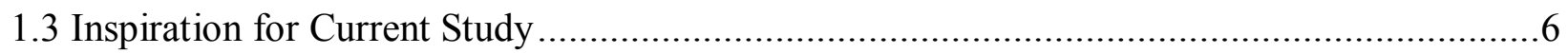

1.4 Compressive Strength of Masonry .................................................................. 11

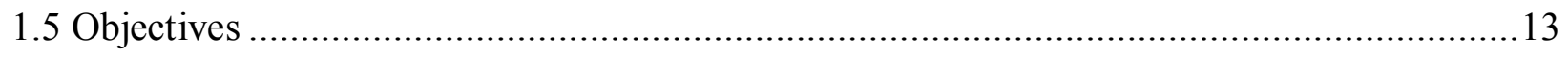

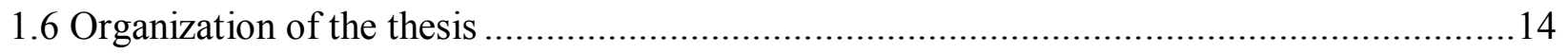

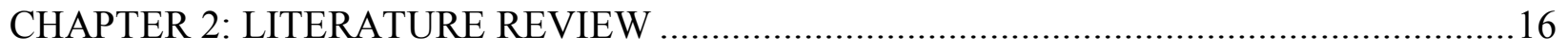

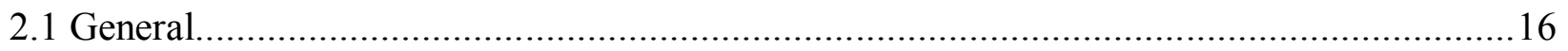

2.2 Shear Behaviour of Reinforced Concrete Beams......................................................... 17

2.2.1 Shear Behaviour of RC Beams before Cracking ...................................................... 17

2.2.2 Shear Behaviour of RC Beams after Cracking .................................................20

2.2.3 Mechanisms of Shear Transfer in Reinforced Concrete .............................................24

2.2.4 Effect of a/d Ratio and Modes of Failure ...............................................................2 27

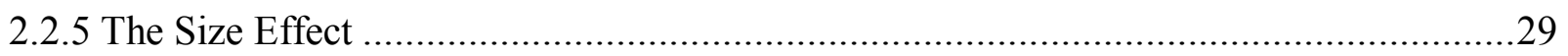

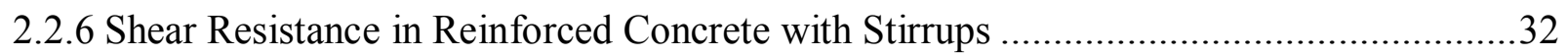

2.2.7 The ACI Shear Design Method .....................................................................33

2.2.8 CSA A23.3-04 General Method of Shear Design for Reinforced Concrete Beams.........35

2.3 Shear Behaviour of Reinforced Concrete Masonry Beams .........................................45

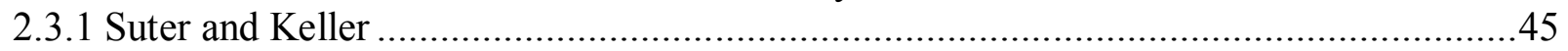

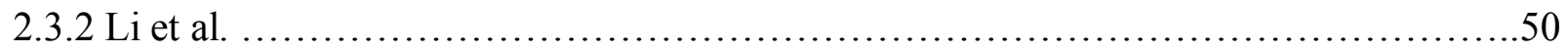

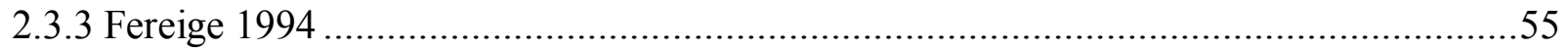

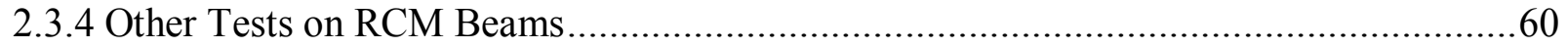

2.4 Performance of the Various Code Shear Provisions for RCM Beams...............................62 


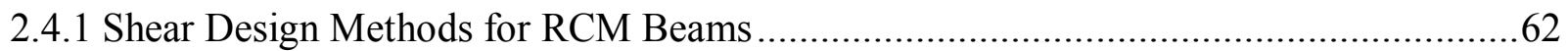

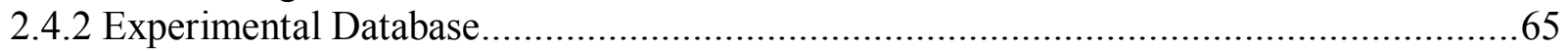

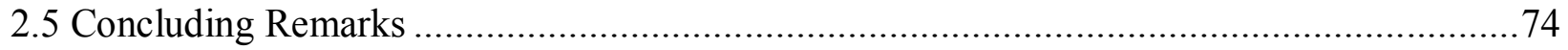

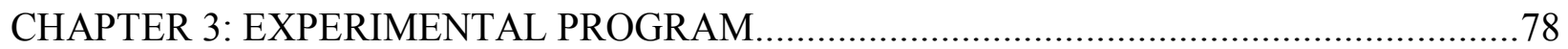

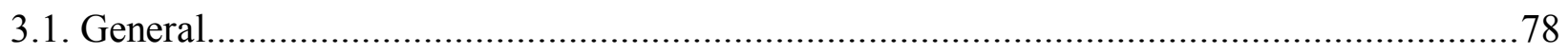

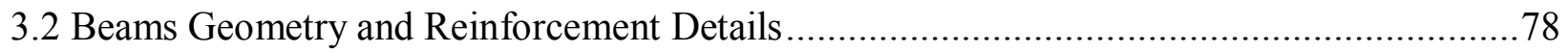

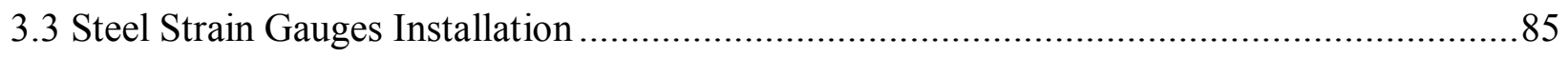

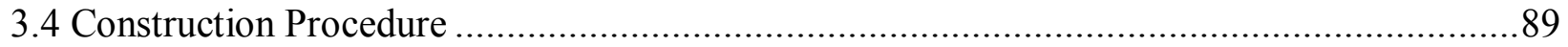

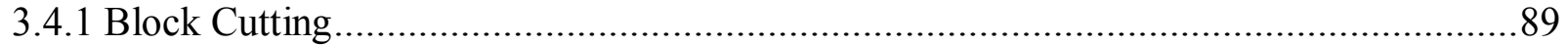

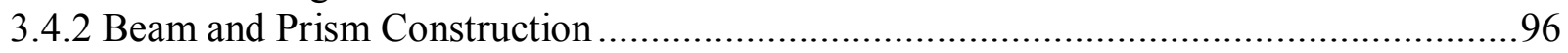

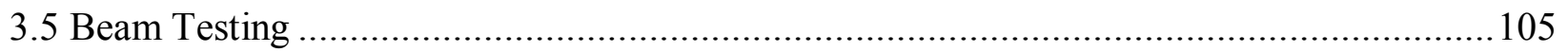

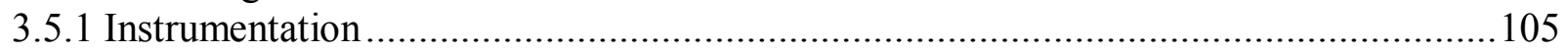

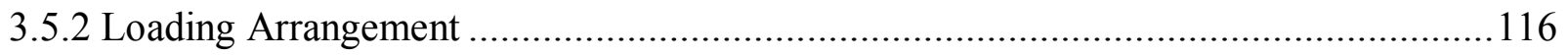

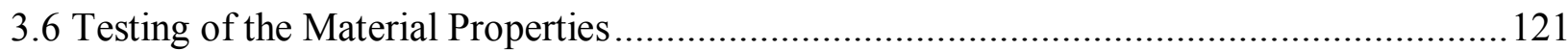

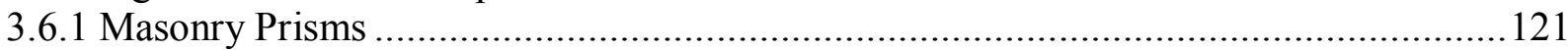

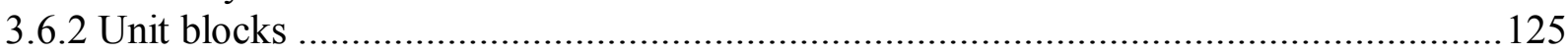

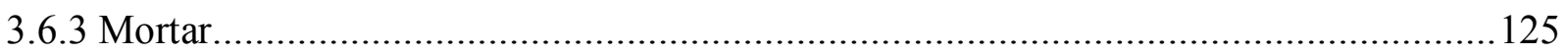

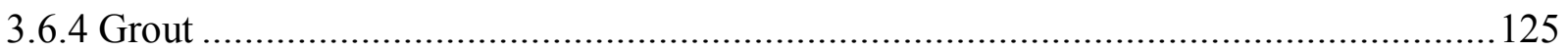

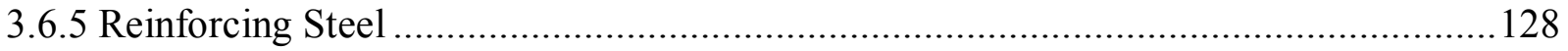

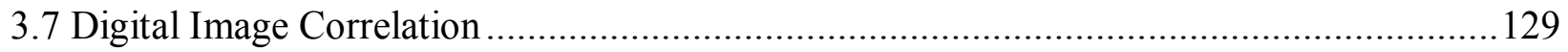

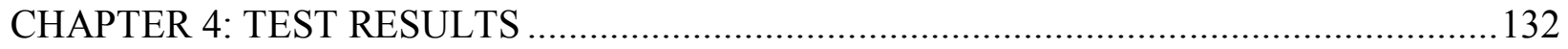

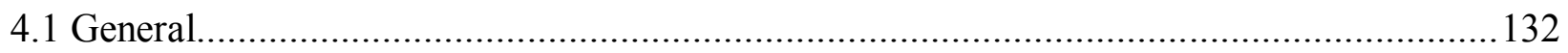

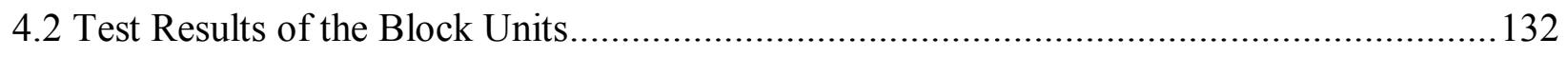

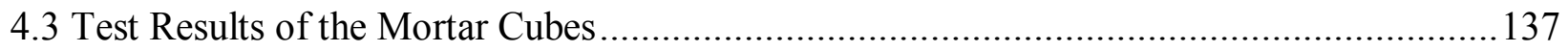

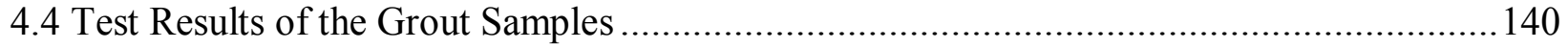

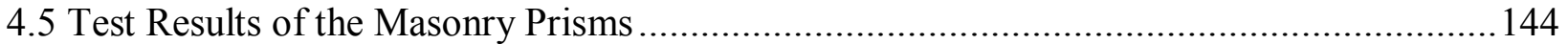

4.5.1 Masonry Prisms Loaded Normal to Bed Joints ..........................................................146

4.5.2 Masonry Prisms Loaded Parallel to Bed Joint ...........................................................155

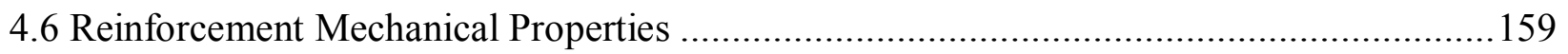

4.7 Experimental Results of the Reinforced Masonry Beams................................................... 163 


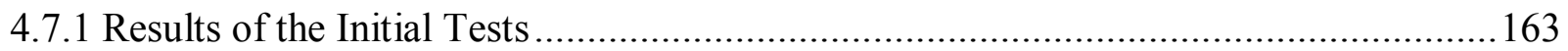

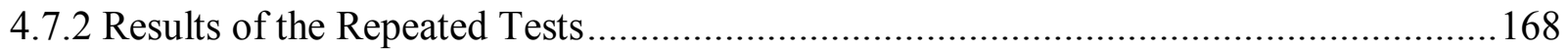

CHAPTER 5: SIZE EFFECT IN REINFORCED MASONRY ………................................170

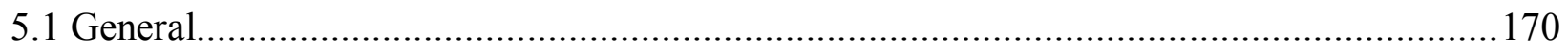

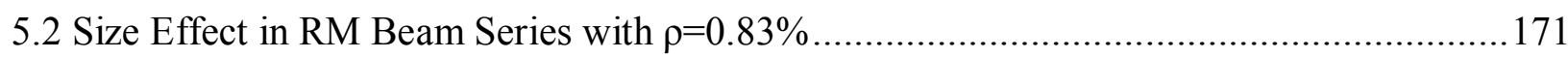

5.2.1 Failure Mechanisms and Load-Deflection Behaviour .................................................171

5.2.2 The Progression of Shear Failure in RMB Series with $\rho=0.83 \% \ldots \ldots \ldots \ldots \ldots \ldots \ldots \ldots \ldots \ldots \ldots \ldots . . .174$

5.2.2 Crack Spacing and Crack Widths ..............................................................................189

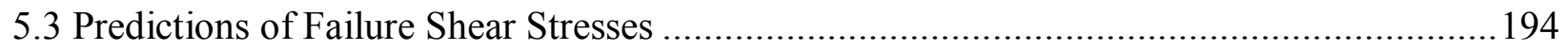

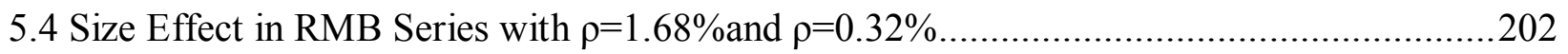

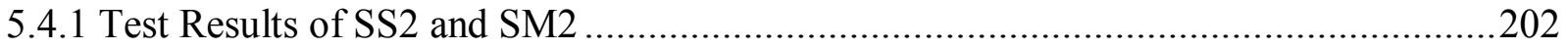

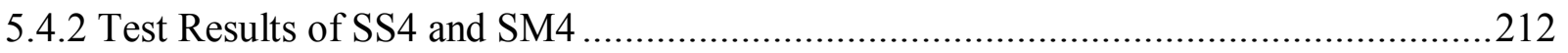

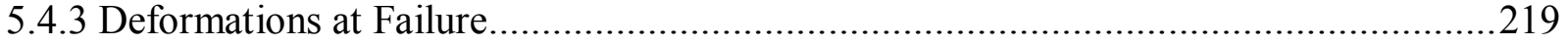

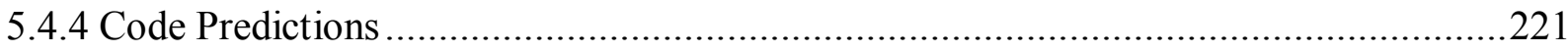

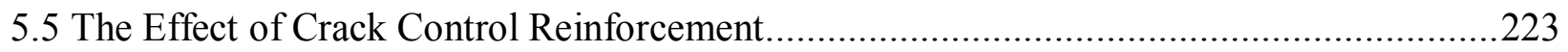

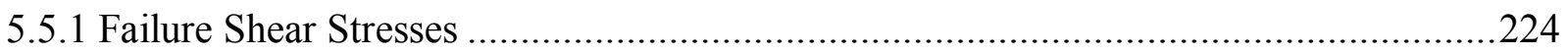

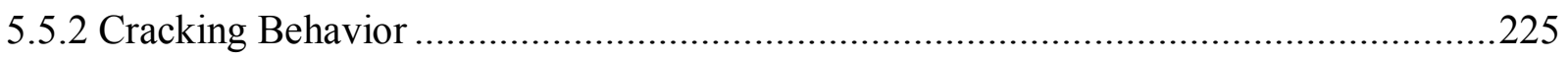

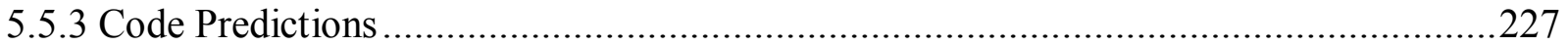

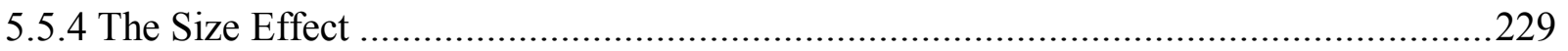

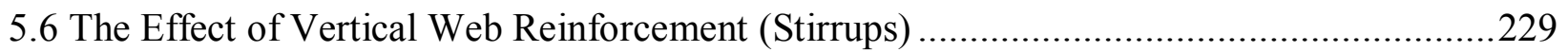

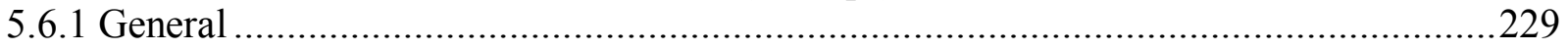

5.6.2 Load-Displacement Response of Specimens SS2 and SS3 ......................................2230

5.6.4 Load-Displacement Response of Specimen SM3 ....................................................23

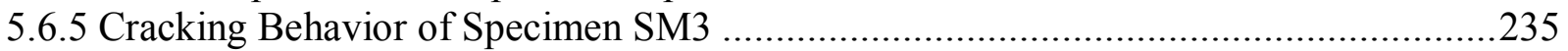

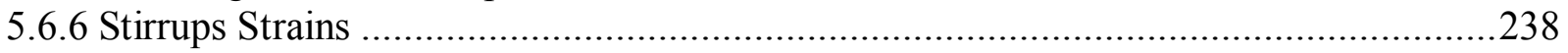

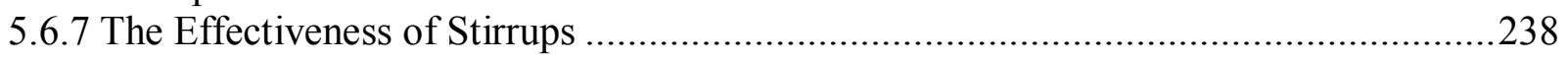

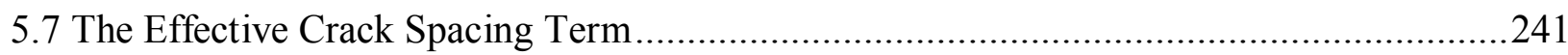

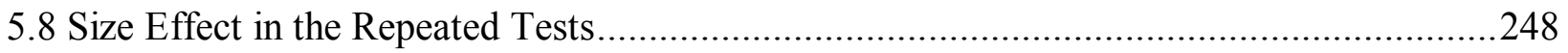

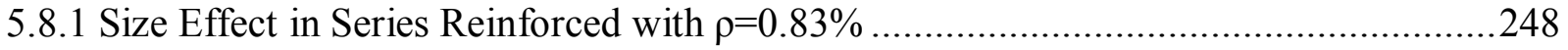

5.8.2 Cracking Behaviour of Repeated Test Series with $\rho=0.83 \% \ldots \ldots \ldots \ldots \ldots \ldots \ldots \ldots \ldots \ldots \ldots \ldots \ldots . . .249$

5.8.4 Size Effect in the Repeated Tests of Series with $\rho=0.32 \% \ldots \ldots \ldots \ldots \ldots \ldots \ldots \ldots \ldots \ldots \ldots \ldots \ldots \ldots . . .257$

5.8.5 Cracking Behaviour of Repeated Test Series with $\rho=0.32 \% \ldots \ldots \ldots \ldots \ldots \ldots \ldots \ldots \ldots \ldots \ldots \ldots \ldots . . .257$

5.8.6 Failure Shear Stress Predictions of the Repeated Tests .................................................260

5.9 Size Effect in RMB Series Reinforced with FRP Bars ....................................................263

5.10 Shear Stress Transmitted in Compression Zone ……....................................................266

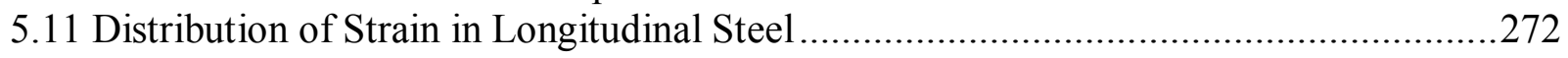




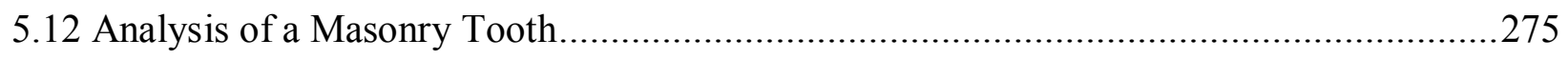

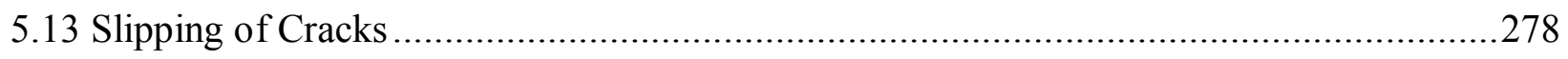

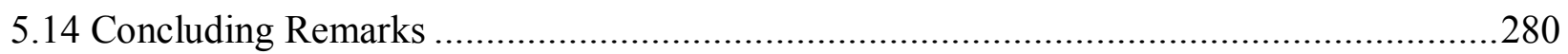

CHAPTER 6: THE STRAIN EFFECT IN REINFORCED MASONRY .................................282

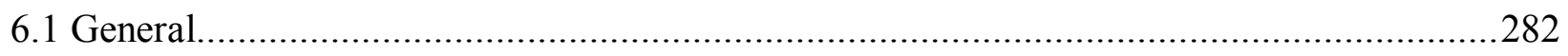

6.2 Effect of $\rho$ on Shear Strength of Reinforced Masonry .....................................................283

6.2.1 Effect of $\rho$ on Shear Strength of Small Size Series ..................................................2.28

6.2.2 Effect of $\rho$ on Shear Strength of Medium Size Series ................................................294

6.3 The Effect of Reinforcement Stiffness, E, on Shear Strength of Reinforced Masonry ........307

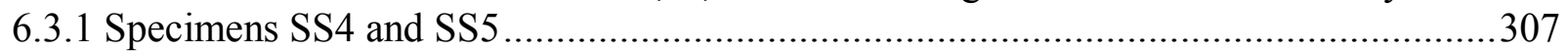

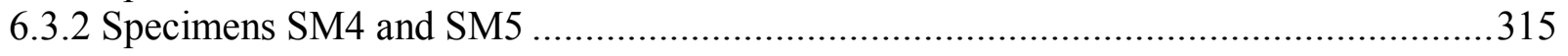

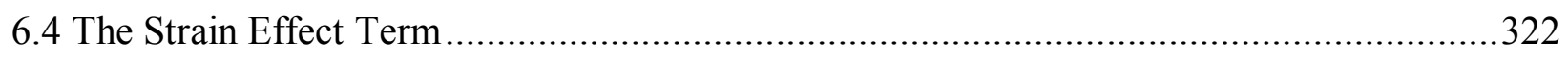

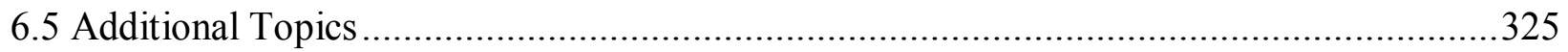

6.5.1 The Effect of Crack Control Reinforcement on Flexural Cracks ...................................325

6.5.2 Accuracy of Image Correlation Analysis in Reinforced Masonry ..................................331

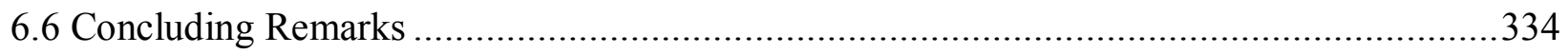

CHAPTER 7: PREDICTION OF COMPRESSIVE STRENGTH OF HOLLOW CONCRETE

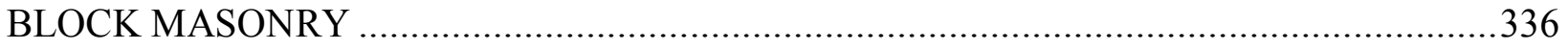

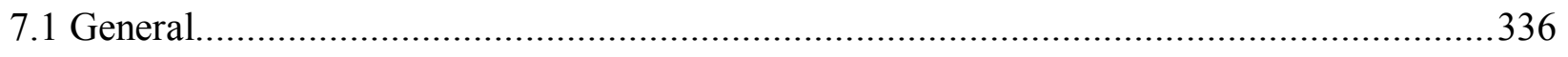

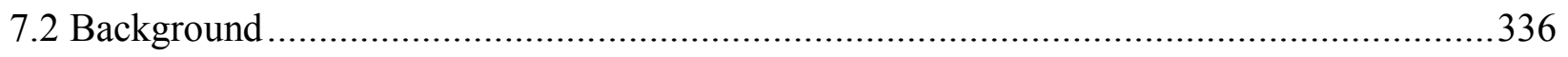

7.3 Prediction of Compressive Strength of Ungrouted Masonry................................................339

7.3.1 Factors Affecting $\mathrm{f}_{\mathrm{m}}$ of Ungrouted Masonry ………....................................................34

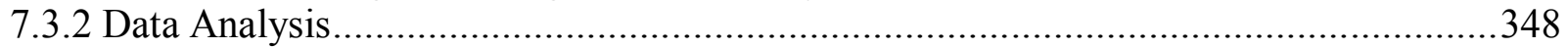

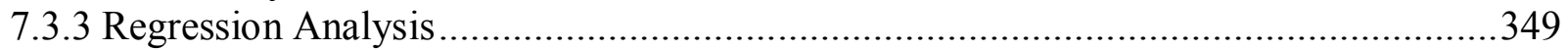

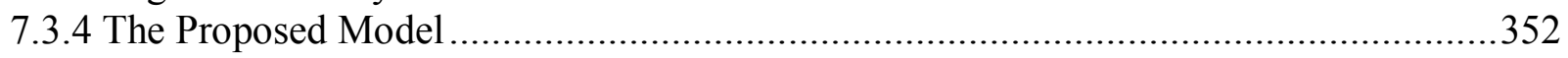

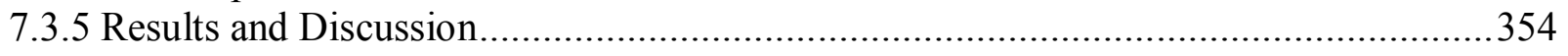

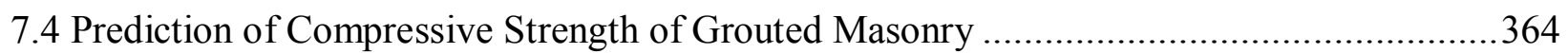

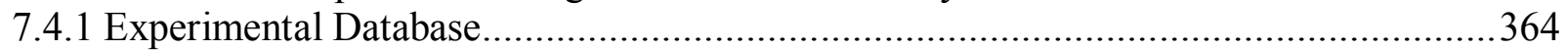

7.4.2 Factors Influencing $\mathrm{f}_{\mathrm{m}}$ of Grouted Concrete Block Masonry …….................................366

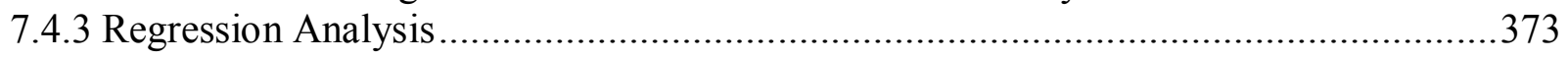

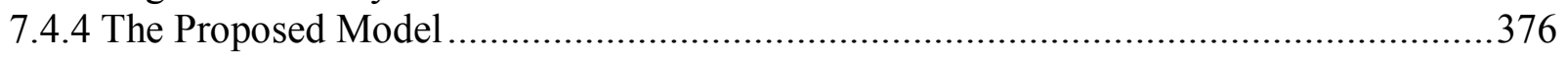

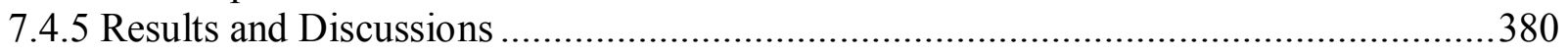




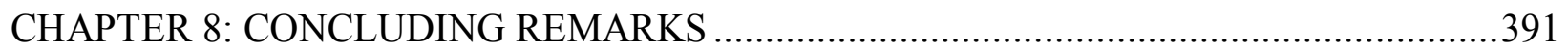

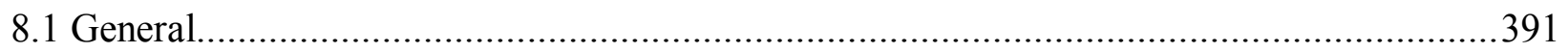

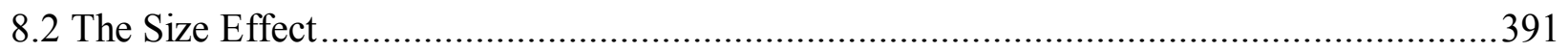

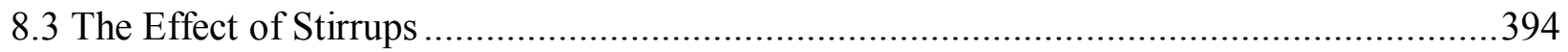

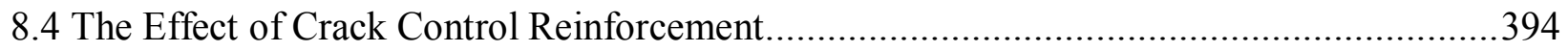

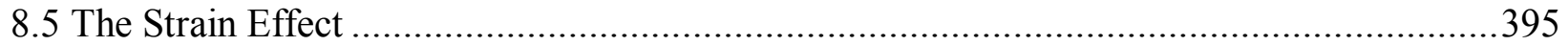

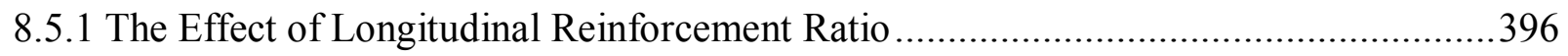

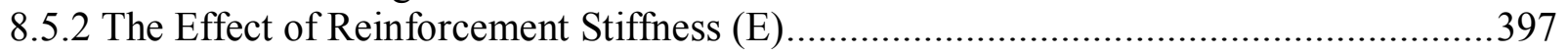

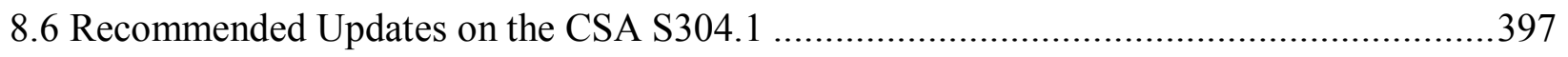

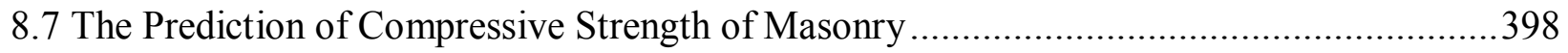

8.7.1 The Compressive Strength of Ungrouted Masonry ...............................................398

8.7.2 The Compressive Strength of Grouted Masonry .................................................399

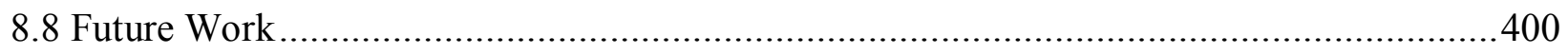

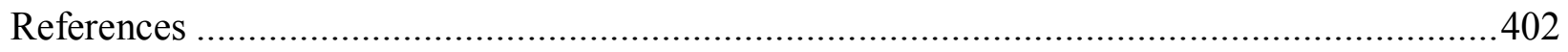

Appendix A: Tests Results of the Reinforced Masonry Beams..........................413

Appendix B: Sample of Calculations for the Shear Strength Prediction of a Reinforced Masonry

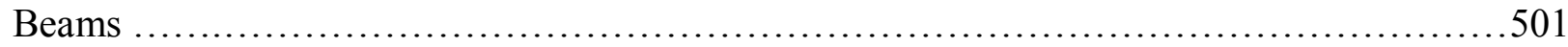

Appendix C Database of the Compressive Tests for Ungrouted Hollow Block Masonry Prisms

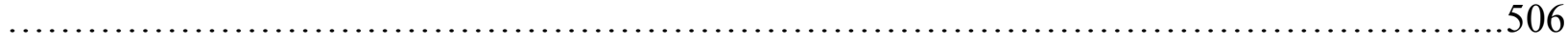

Appendix D: Database of the Compressive Tests for Grouted Hollow Block Masonry Prisms 516 


\section{List of Figures}

Figure 1-1: Reinforced Masonry Beams ……….............................................................

Figure 1-2: Shear Strength Predictions of TMS 402 and CSA S304.1 Codes for RCM Beams of

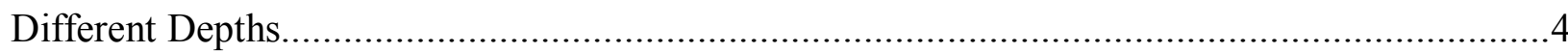

Figure 1-3: Illustration of the Size Effect in Shear for Reinforced Concrete Beams without

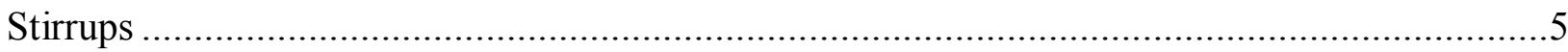

Figure 1-4: Shear Strength Predictions of TMS 402, CSA S304.1, AS3700 and BS5628 Codes

for Reinforced Masonry Beams with Different Reinforcement Ratios .......................................5

Figure 1-5: A Reinforced Brick Masonry Girder in the St. Hedwig's Church in St. Louis,

Missouri, USA (Reproduced from Technical Notes 17M) ......................................................

Figure 1-6: A Reinforced Brick Masonry Girder in Maryland City Shopping Center, Missouri,

USA (Reproduced from Technical Notes 17M) .............................................................

Figure 1-7: A Reinforced Concrete Masonry Beam at Meadows Mall in Lake St. Louis, USA

(Reproduced from Grant et al. 2009) ............................................................................... 10

Figure 1-8: Configurations of Concrete Block Masonry Prisms .................................................12

Figure 2-1: Shear Stress Distribution in an Un-Cracked Reinforced Concrete Beam...................19

Figure 2-2: Shear Stress Distribution in a Cracked Reinforced Concrete Beam...........................21

Figure 2-3: Mechanisms of Shear Transfer in Reinforced Concrete without Stirrups ..................24

Figure 2-4: Measurement of Shear in the Compression Zone (Kani et. al. (1979)) ....................26

Figure 2-5: Measurement of Shear Carried in Compression Zone of Beam L-10N2 (Sherwood et

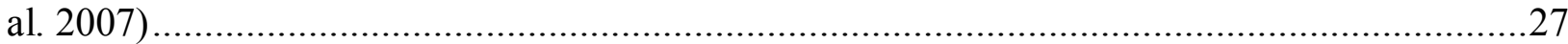

Figure 2-6: Effect of a/d on Shear Strength (Adopted from Collins et. al. (2007)) …….............28

Figure 2-7: Kani's Size Effect Tests (Reproduced from Sherwood (2007)) ..............................30

Figure 2-8: Shimizu-Kajima and University of Toronto tests (Sherwood et al. (2008)) ..............32

Figure 2-9: Mechanisms of Shear Transfer in Reinforced Concrete with Stirrups .......................33

Figure 2-10: Relationships of the Modified Compression Field Theory ......................................36

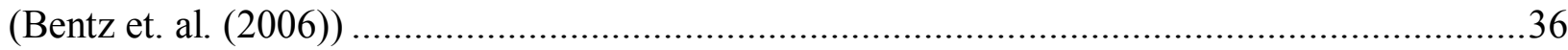

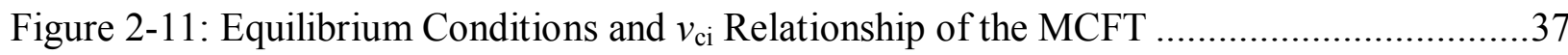

Figure 2-12: Aggregate Interlock Mechanism....................................................................

Figure 2-13: Definition of the Crack Spacing Parameter, $\mathrm{s}_{\mathrm{x}}$ in in the CSA A23.3 General Method (Collins and Mitchell (1997)) .........................................................................................42

Figure 2-14: Flow Chart for the Iterative Analysis Process in the CSA A23.3-04 General Method

Figure 2-15: Reinforced Masonry Beams Tested by Suter and Keller (Stretcher Units) ..............46

Figure 2-16: Reinforced Masonry Beams Tested by Suter and Keller (Solider Unit Series) ........47

Figure 2-17: Effect of a/d on Shear Strength of RCM Beams (Suter and Keller 1980, 1984)......48

Figure 2-18: Effect of $(\rho)$ on Shear Strength of RCM Beams (Suter and Keller $(1980,1984)$ ) ....48

Figure 2-19: Effect of Effective Depth on Shear Strength of RCM Beams (Suter and

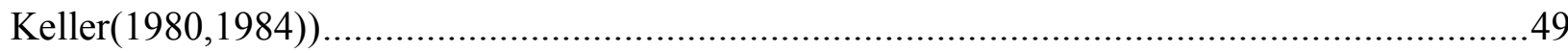


Figure 2-20: Effect of Grout Type on Shear Strength of RCM Beams (Suter and Keller

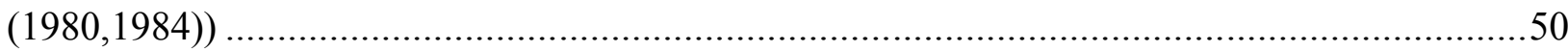

Figure 2-21: Reinforced Masonry Beams Tested by Li et al. (One Course Series) ....................51

Figure 2-22: Reinforced Masonry Beams Tested by Li et al. (Two-Course Series) ...................52

Figure 2-23: Effect of a/d on Shear Strength of RCM Beams (Li et al. (1994)) .........................53

Figure 2-24: Effect of Flexural Reinforcement Ratio on Shear Strength of RCM Beams (Li et al. (1994))

Figure 2-25: Effect of Masonry Compressive Strength on Shear Strength of RCM Beams (Li et al. (1994)) .55

Figure 2-26: Reinforced Masonry Beams Tested by Ferieg ...............................................57

Figure 2-27: Effect of $\rho$ on Shear Strength of RCM Beams (Ferieg(1994)) .............................58

Figure 2-28: Effect of (a/d) on Shear Strength of RCM Beams (Ferieg (1994)) .......................59

Figure 2-29: Illustration of the Strain Effect ................................................................69

Figure 2-30: Code Predictions of the Strain Effect............................................................ 70

Figure 2-31: Effect of Fill on Failure Shear Stress ....................................................... 71

Figure 2-32: Comparison of CSA A23.3 and CSA S304.1 Shear Strength Predictions ...............74

Figure 2-33: Comparison of CSA A23.3 and TMS 402-2011 Shear Strength Predictions ..........74

Figure 3-1: Reinforced Masonry Beams without Web Reinforcement ...................................79

Figure 3-2: Reinforced Masonry Beams with Web Reinforcement .........................................80

Figure 3-3: Cross-Section and Reinforcement Details of the Reinforced Masonry Beams (As

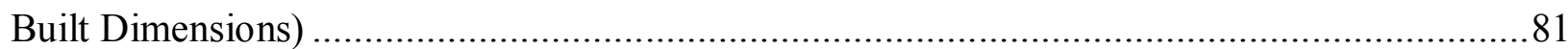

Figure 3-4: Steel Strain Gauge Locations for Small and Large Beam Series ...........................87

Figure 3-5: Steel Strain Gauge Locations for Medium Beam Series......................................8 88

Figure 3-6: Configurations of Unit Blocks Used in Construction of Small and Medium Beam

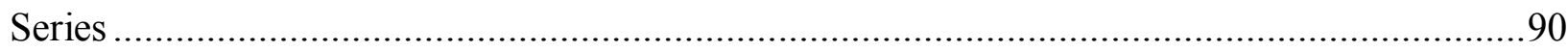

Figure 3-7: Configurations of Unit Blocks Used in Construction of Large Beam Series............91

Figure 3-8: Photos of the Unit Blocks Used in the Current Investigation ................................92

Figure 3-9: Block Cutting for Small and Medium Beam Series ........................................... 93

Figure 3-10: Block Cutting for Large Beam Series .......................................................... 94

Figure 3-11: Wet Saw Used for Block Cutting and Samples of Block Cuts............................95

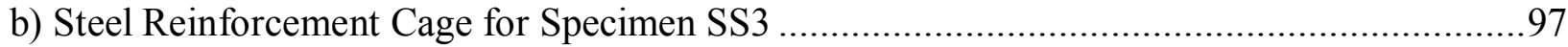

Figure 3-12: Steel Reinforcement Cages........................................................................ 97

Figure 3-13: Construction of the Medium Beams ....................................................... 98

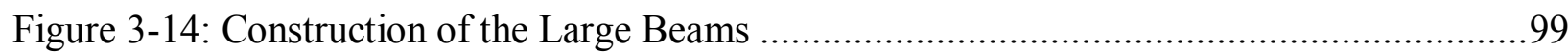

Figure 3-15: Production of the Mortar ......................................................................... 100

Figure 3-16: Sealing the Sides of the Beams and Prisms before Grouting ............................. 101

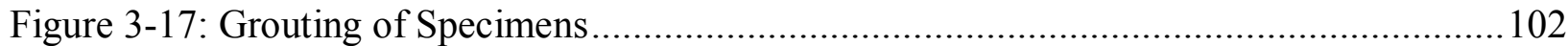

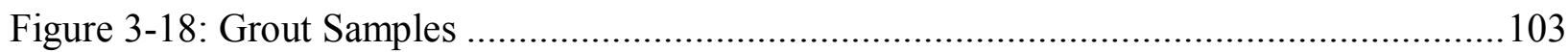

Figure 3-19: Curing of the Specimens ............................................................................ 104

Figure 3-20: Diagrams of Side Mounted LVDTs Attached to the Beams ..............................106 


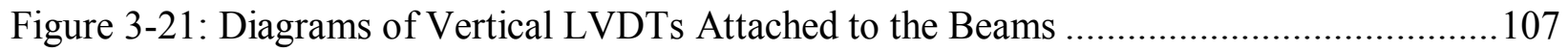

Figure 3-22: Photos of LVDTs Attached to the Large, Medium and Small Size Beams ...........108

Figure 3-23: Procedure of Attaching the Side-Mounted LVDTs to the Beams ........................ 109

Figure 3-24: Diagram of the Demec Rosettes and the Demec Gauges along the Reinforcement

Level.

Figure 3-25: Photo Showing Demec Rosettes and Demec Gauges at the Reinforcement Level 111

Figure 3-26: Concrete Strain Gauges installed in compression zone of the Large Beams .........113

Figure 3-27: Photo of Concrete Strain Gauges installed in the Compression Zone of the Large

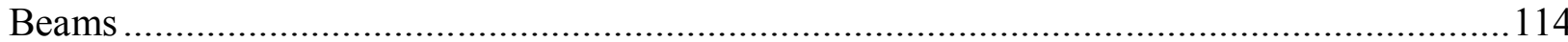

Figure 3-28: Diagram of Concrete Strain Gauges Installed in the Compression Zone of SS1, SS5

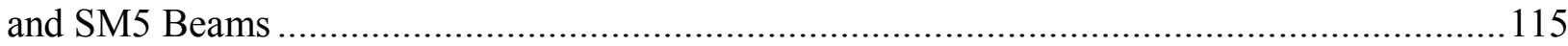

Figure 3-29: Test Setup of the Large and Medium Beams ............................................. 117

Figure 3-30: Photos of the Test Set up of the of the Large and Medium Beams ...................... 118

Figure 3-31: Test Setup of the Small Beams ............................................................. 119

Figure 3-32: Testing of the Repeated Sides of the Beams ................................................ 120

Figure 3-33: Painting and Capping of the Prisms ............................................................. 122

Figure 3-34: A Diagram Showing the Test Set up for the Prisms .........................................123

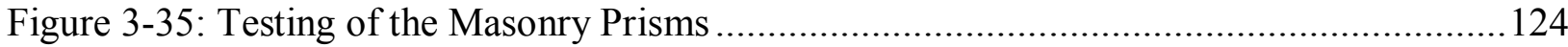

Figure 3-36: Capping and Testing of the Unit Blocks .................................................. 126

Figure 3-37: Testing of the Mortar and Grout ........................................................... 127

Figure 3-38: Pull Tests of the Steel Reinforcing Rebars ............................................... 128

Figure 3-39: Specimen Preparation for the DIC Measurement ..........................................131

Figure 4-1: Effective Capped Areas of the Unit Blocks .................................................... 135

Figure 4-2: Failure Patterns of Unit Blocks Tested in Compression ......................................136

Figure 4-3: Stress- Strain Curves for the Masonry Units ............................................... 137

Figure 4-4: Failure Patterns of the Mortar Cubes ............................................................... 140

Figure 4-5: Failure Patterns of the Grout Samples ............................................................. 142

Figure 4-6: A Typical Stress-Strain Curve for the Cylinder Grout Samples ............................ 143

Figure 4-7: Gross Areas of the Normal to Bed Joint Prisms ................................................ 146

Figure 4-8: Typical Failure Patterns of $190 \mathrm{~mm}$ Masonry Prisms Loaded Normal to the Bed Joint

Figure 4-9: Typical Failure Patterns of $240 \mathrm{~mm}$ Masonry Prisms Loaded Normal to the Bed Joint

Figure 4-10: Stress-Strain Curves for Prism PN9 and its Block Unit and Grout Sample.......... 150 Figure 4-11 Typical Stress-Strain Curves of the Masonry Prisms Tested Normal and Parallel to the Bed Joint ..................................................................................................... 152

Figure 4-12: The VIC-2D Analysis for a Masonry Prism Tested Normal to the Bed Joints ...... 153 Figure 4-13: Stress-Strain Curve for Masonry Prism (PN9) Tested Normal to the Bed Joint ... 154 Figure 4-14: Gross Areas of Prisms Loaded Parallel to the Bed Joints ................................ 155 
Figure 4-15: Typical Failure Patterns of 190 mm Masonry Prisms Loaded Parallel to the Bed Joint

Figure 4-16: Typical Failure Patterns of $240 \mathrm{~mm}$ Masonry Prisms Loaded Parallel to the Bed

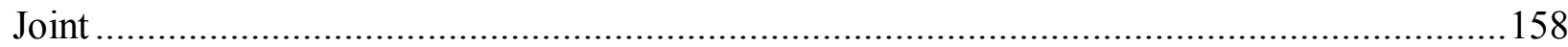

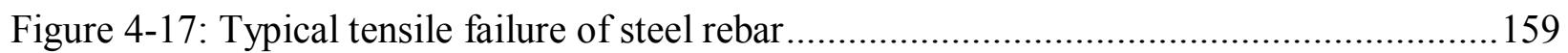

Figure 4-18 Typical Stress-Strain Curves for the 10M, 20M, 25M and 30M rebars ................161

Figure 4-19 Typical Stress-Strain Curves for the 5/16in and 15M rebars ..............................162

Figure 4-20: A schematic Diagram for the Key Experimental Results for the Small Beams .....164

Figure 4-21: A Schematic Diagram for the Key Experimental Results for the Medium Beams 165

Figure 4-22: A Schematic Diagram for the Key Experimental Results for the Large Beams ....165

Figure 5-1: Load-Deflections Curves of Specimens SS1, SM1, SM1D, SL1 and SL2 ….........172

Figure 5-2: Relative Deflections of Specimens SS1 and SL1 ..............................................173

Figure 5-3: Ultimate Shear Strain in first failed Sides of Specimens SS1, SM1, SM1D, SL1 and

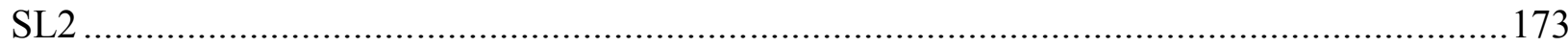

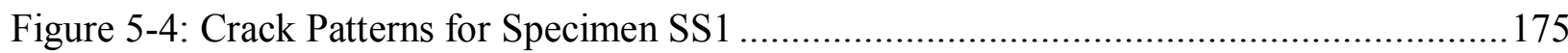

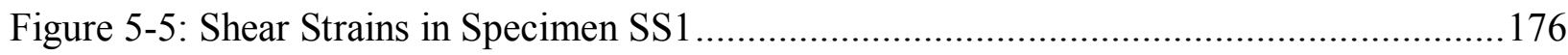

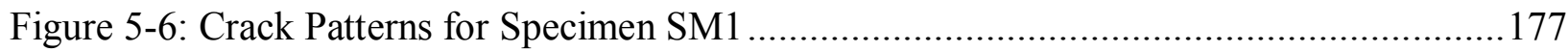

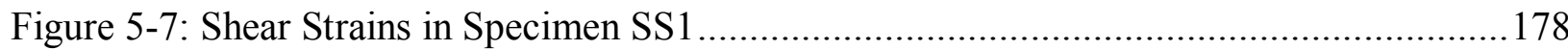

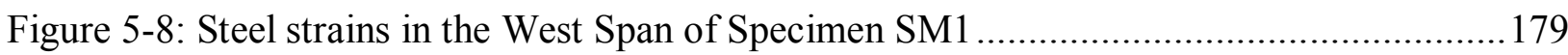

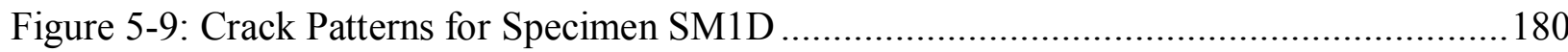

Figure 5-10: Shear Strains Measured in the East Span of Specimen SM1D ……….................181

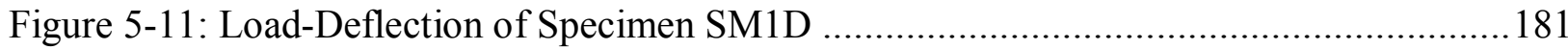

Figure 5-12: An assumed Strut and Tie Model for Specimen SM1D.......................................182

Figure 5-13: Interlocking across the Crack in Specimen SM1D after an Initial Breakdown of

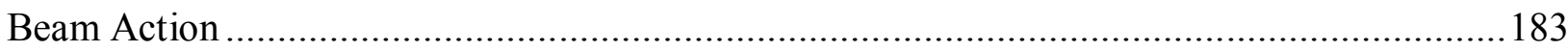

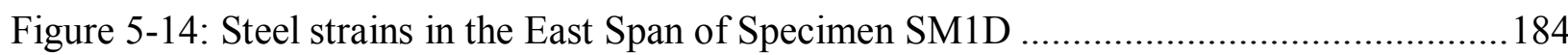

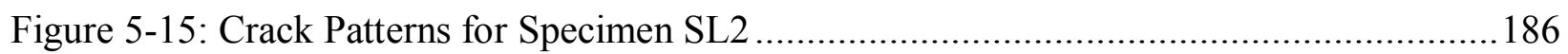

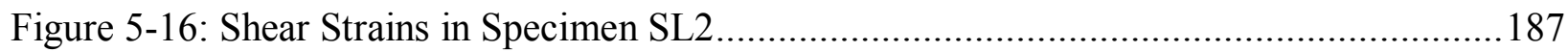

Figure 5-17: Failure Pattern of SS1, SM1, SMD1, SL1 and SL2 Beams ...............................188

Figure 5-18: Crack Patterns in North Face of SS1, SM1 and SL2 at Shear Stress of 0.51 MPa 190

Figure 5-19: Crack Patterns in South Faces of SS1, SM1 and SL2 at Shear Stress of 0.51 MPa

Figure 5-20: Crack Spacing at Mid-depth of SS1, SM1 and SL2 Beams as a Function of $d$ at

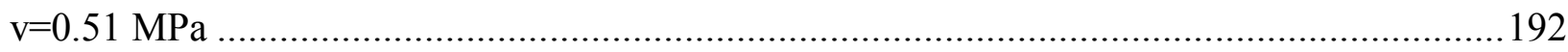

Figure 5-21: Crack Spacing at Mid-Depth of SS1, SM1 and SL2 Beams at v=0.51 MPa .........192 Figure 5-22: Average and Maximum Crack Widths at Mid-Depth of SS1, SM1 and SL2 Beams

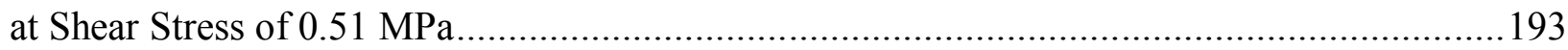

Figure 5-23: Failure Shear Stress for RMC Beams with Different Depths................................197

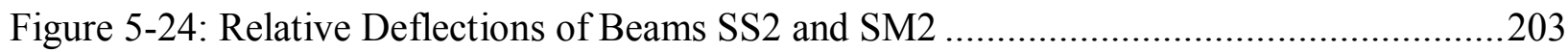

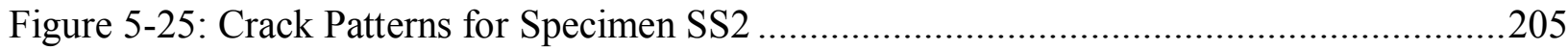


Figure 5-26: Shear Strains in Specimen SS2 ..........................................................206

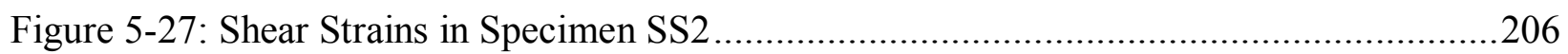

Figure 5-28: Crack Patterns for Specimen SM2 …......................................................208

Figure 5-29: Shear Strains in Specimen SS2 .............................................................209

Figure 5-30: Steel Strains in the West Span of Specimen SM2 .........................................209

Figure 5-31: Crack Patterns in South Faces of SS2 and SM2 at Shear Stress of 0.68 MPa ......211

Figure 5-32: Average and Maximum Crack Widths in SS2 and SM2 Beams at a Shear Stress of

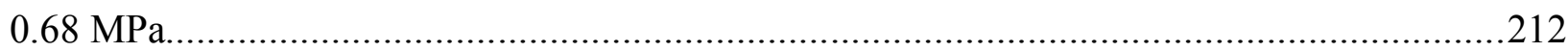

Figure 5-33: Relative Deflections of Beams SS4 and SM4 .............................................2 213

Figure 5-34: Crack Patterns for Specimen SS4 ...........................................................214

Figure 5-35: Shear Strains in Specimen SS4 ...............................................................2 215

Figure 5-36: Crack Patterns for Specimen SM4 …..........................................................216

Figure 5-37: Crack Patterns in South Faces of SS4 and SM4 at Shear Stress of 0.34 MPa ......218

Figure 5-38: Average and Maximum Crack Widths in SS4 and SM4 at Shear Stress of 0.34 MPa

Figure 5-39: Ultimate Shear Strain in first failed Spans of Specimens SS2, SM2, SS4 and SM4

Figure 5-40: Maximum Steel Strains in Specimens SS2 and SM2 SS4 and SM4 ..................220

Figure 5-41: Failure Shear Stress for Specimens SS2, SM2, SS4 and SM4 ..........................222

Figure 5-42: Relative Displacements in SS1, SM1D and SM6 ........................................224

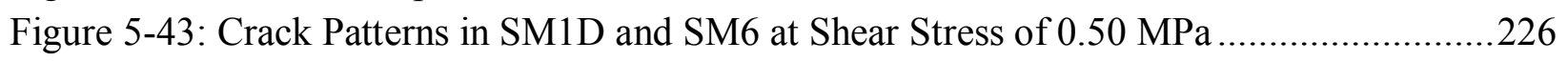

Figure 5-44: Maximum and Average Crack widths in SMID and SM6 at 0.5 MPa ...............227

Figure 5-45: Failure Crack Patterns of SM1D and SM6 (Crack Widths Are for the Last Load stage Before Failure) ..................................................................................................22

Figure 5-46: Failure Shear Stresses of SS1, SM1D and SM6 ............................................228

Figure 5-47: Load vs Displacements of Specimens SS3 and SS2 ...................................231

Figure 5-48: Crack Patterns of Specimens SS3 and SS2 Prior to Failure...............................2232

Figure 5-49: Failure Crack Patterns of Specimens SS3 and SS2 (Crack Widths Measured at Last

Load Stage before Failure) ..........................................................................232

Figure 5-50: Contours of Horizontal Displacements and Shear Strains in Specimens SS2 and SS3 using Image Correlation Analysis.....................................................234

Figure 5-51: Relative Displacements of Specimens SS2, SM2 and SM3 ............................235

Figure 5-52: Crack Patterns of Specimens SM2 and SM3 Prior to Failure ..............................2236

Figure 5-53: Failure Crack Patterns of Specimens SM2 and SM3 .....................................237

Figure 5-54: Failure Shear Strains of Specimens SM2 and SM3 .....................................237

Figure 5-55: Stirrup Strains at Different Load Stages ....................................................239

Figure 5-56: Failure Shear Stress Predictions for RM Beams Reinforced with Stirrup ............240

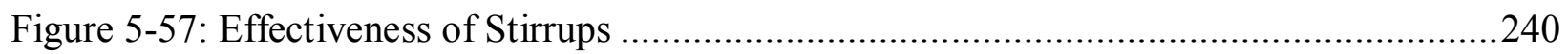

Figure 5-58: The CSA 2004 Size Effect Term .................................................................242

Figure 5-59: Maximum Aggregate Size in Specimen SM2 ..............................................24 
Figure 5-60 Calculations of Equivalent Aggregate Size for the CSA A23.3 Prediction of the

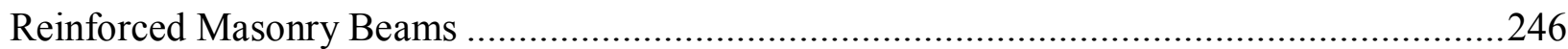

Figure 5-61: Surface of Major Diagonal Crack in Beam SL2 ............................................247

Figure 5-62: Relative Displacements of SS1R, SM1R and SL2R ......................................248

Figure 5-63: Crack Patterns of Specimen SS1R ............................................................250

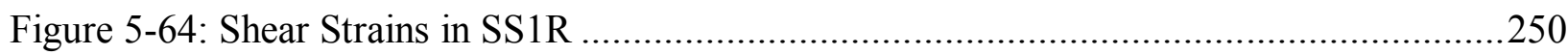

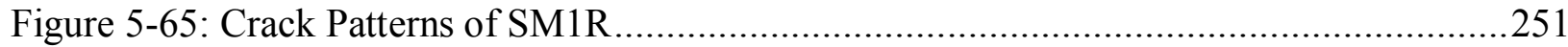

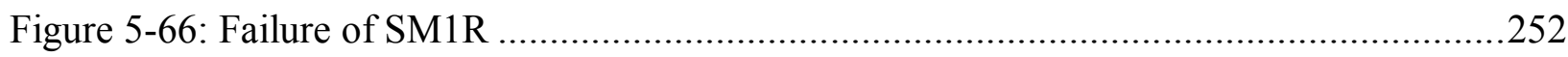

Figure 5-67: Crack Patterns of SL2R .........................................................................253

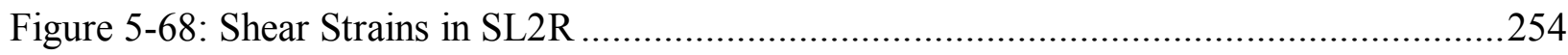

Figure 5-69: Crack Patterns of SM1DR ......................................................................25

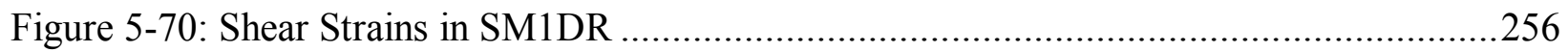

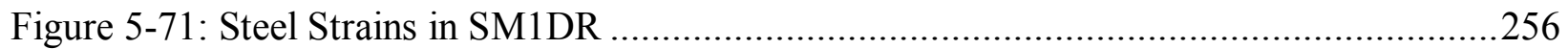

Figure 5-72: Relative Displacements of SS1R, SM1R and SL2R ......................................257

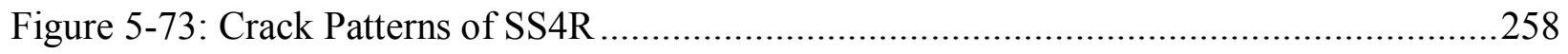

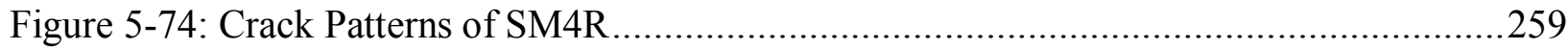

Figure 5-75: Shear Strains in SM4R ...........................................................................260

Figure 5-76: Failure Shear Stresses of Specimens SS1R, SM1DR, SM1D, SL1 and SL2 ........262

Figure 5-77: Failure Shear Stresses of Specimens SS4R and SM4R ..................................262

Figure 5-78: Crack Patterns in SS5 and SM5 at Shear Stress of 0.21 MPa ...........................264

Figure 5-79: Average and Maximum Crack Widths in SS5 and SM5 Beams at Shear Stress of

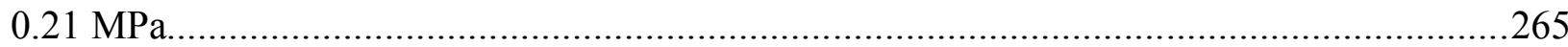

Figure 5-80: Failure Shear Stresses in RMB reinforced with GFRP bars ..............................266

Figure 5-81 Measurement of Shear Transfer Portion by Compression Zone in Specimen SL2 .268 Figure 5-82: A Masonry Prism Instrumented with Strain Gauges and Tested Parallel to Bed

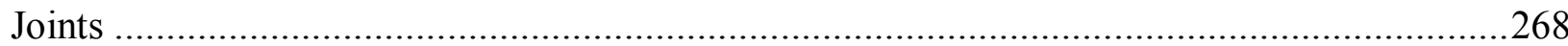

Figure 5-83: Stress -Strain Curve of the Companion Prism and Load-Deflection Curve of.....269 Specimen SL2 .................................................................................................269

Figure 5-84 Measurement of Compression Zone Contribution to Shear Resistance in Specimen

SL1 ...................................................................................................2 270

Figure 5-85: Measurement of Shear Transfer Portion by Compression Zone in Specimen SM5

Figure 5-86: Measurement of Shear Transfer Contribution by Compression Zone in Specimen

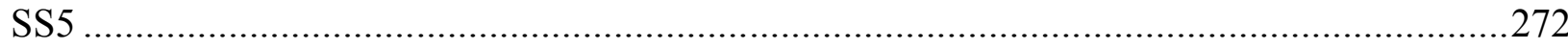

Figure 5-87: Strains at Level of Longitudinal Steel in Specimens SM1 and SM1D ...............273

Figure 5-88: Strains at Level of Longitudinal Steel in Specimens SL1 and SL2 ....................274

Figure 5-89: Strains at Level of Longitudinal Steel in Specimens SS4 ................................274

Figure 5-90: A Masonry Tooth in Specimen SL1 ........................................................2275

Figure 5-91: Analysis of a Masonry Tooth in Specimen SL1 ........................................2276

Figure 5-92: Shear Failure in Specimen SL1 due to Breakdown in Aggregate Interlock .........277 
Figure 5-93: Slippage along One of the Major Shear Cracks in Specimen SL2 279

Figure 6-1: Relative Displacement with Different Reinforcement Ratios in Specimens SS1, SS2,

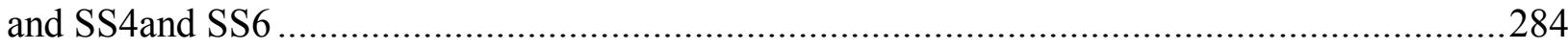

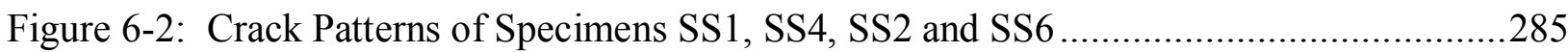

Figure 6-3: Average Crack Widths at $\mathrm{P}=70 \mathrm{kN}$ in Specimen SS1, SS2, SS4 and SS6 ............286

Figure 6-4: Steel Strains at Mid-Span of Specimens SS1, SS2, SS4 and SS6 .......................286

Figure 6-5: Longitudinal Strains, $\varepsilon_{x}$, in Specimens SS1, SS2, SS4 and SS6 ...........................287

Figure 6-6: Steel Strains at Mid-Span of Specimens SS1, SS2, SS4 and SS6 .........................28

Figure 6-7: Longitudinal Strains at Various Levels in Specimens SS1 ................................289

Figure 6-8: Crack Patterns of Specimens SS1, SS2, SS4 and SS6 Prior to initial Breakdown of

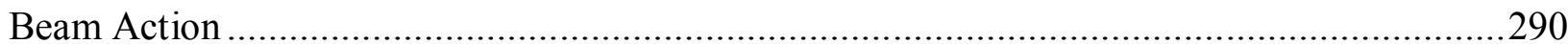

Figure 6-9: Failure Crack Patterns of Specimens SS1, SS2, SS4 and SS6 …........................291

Figure 6-10: Load-Deflection Responses for Specimens SS1R, SS2R, SS4R and SS6R ..........292

Figure 6-11: Failure Shear Stresses for Small Reinforced Masonry Beams with Different $\rho$...294

Figure 6-12: Load-Deflection Curves of Specimens SM1, SM1D, SM2 and SM4 ..................295

Figure 6-13: Crack Patterns in specimens SM1D, SM2 and SM4 at an applied load of 100 kN297

Figure 6-14: Mid-Height Steel Strains in Specimens SM1, SM1D, SM2 and SM4 .................297

Figure 6-15: Mid-height Longitudinal Strains in Specimens SM1, SM1D, SM2 and SM4 .......298

Figure 6-16: Crack Patterns in Specimens SM1D, SM2 and SM4 and Prior to Breakdown of

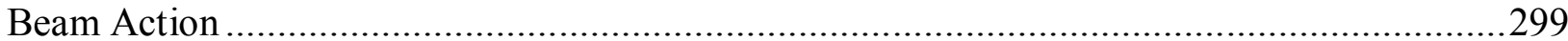

Figure 6-17: Failure Crack Patterns on south faces of Specimens SM1, SM1D, SM2 and SM4300

Figure 6-18: Failure Shear Stresses of specimens SM1, SM1D, SM2 and SM4 .....................302

Figure 6-19: Crack Patterns of Specimens SM1D and SM2 at the Same Longitudinal Strain ..305

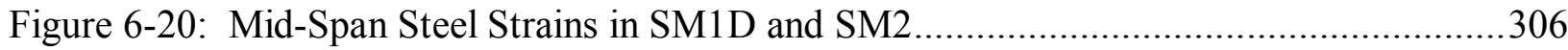

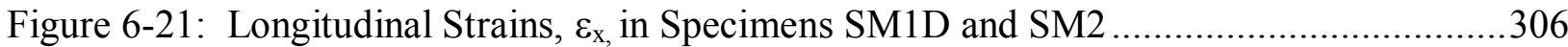

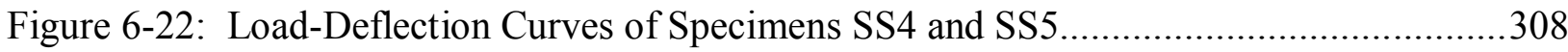

Figure 6-23: Crack Patterns of Specimens SS4 and SS5 at shear Stress of 0.34 MPa ...............309

Figure 6-24: Mid-Span Steel Strains of Specimens SS4 and SS5 ……............................... 310

Figure 6-25: Longitudinal Strains at mid-depths of Specimens SS4 and SS5 .........................311

Figure 6-26: Longitudinal Strains $(\mu \varepsilon)$ in Specimens SS4 and SS5 using Image Correlation

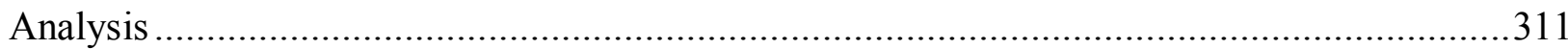

Figure 6-27: The Average and Maximum Crack Widths at Different Depths in SS4 and SS5...312 Figure 6-28: Failure Crack Patterns of Specimens SS4 and SS5 (Crack Widths Measured at

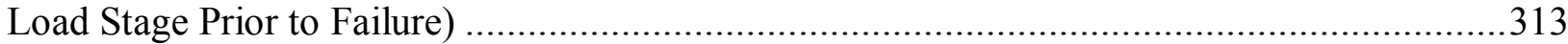

Figure 6-29: Load-Deflection Curves of Specimens SS4 and SS5 .......................................... 314

Figure 6-30: Crack Patterns of Specimens SS4R and SS5R prior to Failure ............................314

Figure 6-31: Load-Deflection Curves of Specimens SS4 and SS5 ...................................... 315

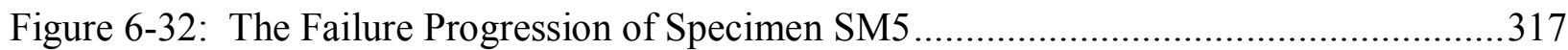

Figure 6-33: The Inspection of Possible Arch Action Engagement in Specimen SM5 ..............318

Figure 6-34: Steel Strains in the East Side of Specimen SM5 .............................................318 
Figure 6-35: Shear Strain in the East Side of Specimen SM5 ................................................ 319

Figure 6-36: Crack Patterns of Specimens SM4 and SM5 at an Applied of 60kN .................320

Figure 6-37: Longitudinal Strains, $\varepsilon_{\mathrm{x}}$, in specimens SM4 and SM5 ....................................320

Figure 6-38: Failure Crack Patterns of Specimens SM4 and SM5 (Crack Widths Measured at

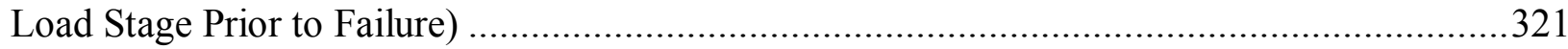

Figure 6-39: Failure Shear Stresses of RMB with Different Reinforcement Types..................322

Figure 6-40: The CSA 2004 Strain Effect Term...............................................................324

Figure 6-41: Crack Patterns on the South Faces of Specimen SL1 and SL2 ..........................326

Figure 6-42: Maximum Crack Widths on the South Faces of Specimen SL1 and SL2 .............327

Figure 6-43: Crack Patterns on the North Faces of Specimen SL1 and SL2 ..........................329

Figure 6-44: Maximum Crack Widths on the North Faces of Specimen SL1 and SL2 .............330

Figure 6-45: Load- Deflection Curve of Specimen SS5 ...................................................332

Figure 6-46: Vertical Displacement Contours of Specimens SS5 at Various Load Stages .......333

Figure 7-1: Configurations of Hollow Concrete Block Masonry Prisms..................................338

Figure 7-2: Effect of Unit Strength on Compressive Strength of Ungrouted Concrete Block

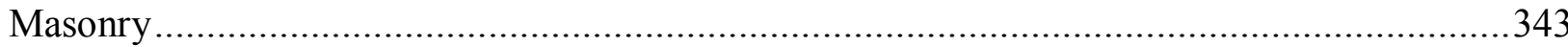

Figure 7-3: Effect of Mortar Strength on Compressive Strength of Ungrouted Concrete Block

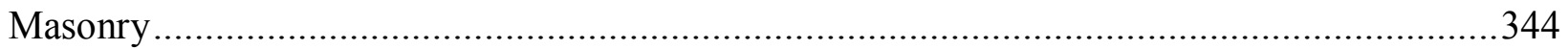

Figure 7-4: Bedding Types in Concrete Masonry ..............................................................345

Figure 7-5: Effect of h/t Ratio on the Compressive Strength of Ungrouted Concrete Block

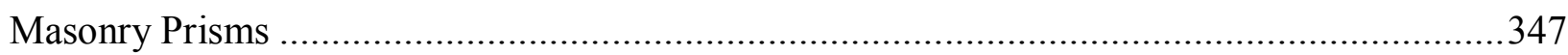

Figure 7-6: Correction Factors for h/t Ratios of Ungrouted Concrete Block Masonry Prisms in

Various Masonry Design Codes ..................................................................... 347

Figure 7-7: Predictive Ability of Equation (7-1): a) the Coefficient of Determination and b)

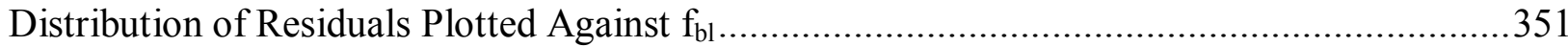

Figure 7-8: Application of the 95\% Confidence Lower Limit to the Proposed Model for

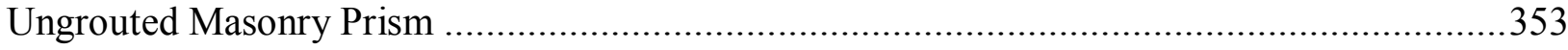

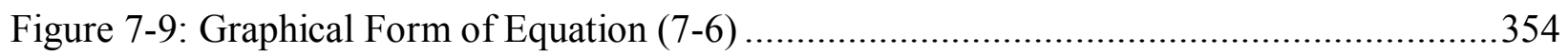

Figure 7-10: Comparison of Predictive Abilities of the AS 3700, CSA S304.1, TMS 402 Codes

and Equation (7-6) for the Entire Database of Ungrouted Prisms ........................................359

Figure 7-11: Comparison of Predictive Abilities of the AS 3700, CSA S304.1, TMS 402 Codes

and Equation (7-6) for Face-shell Bedded Ungrouted Masonry .......................................360

Figure 7-12: Comparison of Predictive Abilities of the BS5826-2, Eurocode 6 and Equation (7-6)

for Fully Bedded Ungrouted Masonry ....................................................................... 361

Figure 7-13: Comparison of Predictive Abilities of the CSA S304.1-2004 Code and Equation (7-

6) For N Type Mortar and S Type Mortar Ungrouted Prisms .......................................... 362

Figure 7-14: Comparison of Predictive Ability of Equation (7-6) and CSA S304.1-2004 Based on

Specified Compressive Strength of Ungrouted Prisms ......................................................363

Figure 7-15: Effect of h/t Ratio on the Compressive Strength of Grouted Concrete Block

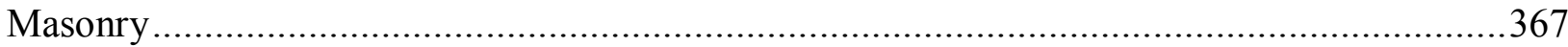


Figure 7-16: Correction Factors for $\mathrm{h} / \mathrm{t}$ Ratios of Grouted Concrete Block Masonry in Different

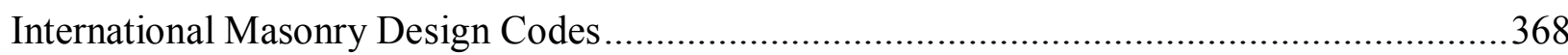

Figure 7-17: Effect of Unit strength on the Compressive Strength of Grouted Concrete Block

Masonry .369

Figure 7-18: Effect of Mortar Strength on the Compressive Strength of Grouted Concrete Block

Masonry 371

Figure 7-19: Effect of Grout Strength on the Compressive Strength of Grouted Concrete Block

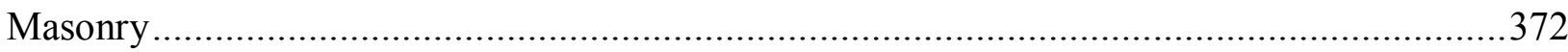

Figure 7-20: Adequacy of Equation (7-11) Compared to the Unit Strength Model....................376

Figure 7-21: Distribution of Residuals of Equation (7-11) Plotted Against $\mathrm{f}_{\mathrm{bl}}$...........................376

Figure 7-22: Application of the 90\% confidence lower limit to the proposed model .................377

Figure 7-23: Graphical Form for the Proposed Formula......................................................... 379

Figure 7-24: Comparison of Predictive Abilities of the AS 3700, CSA S304.1, TMS 402 Codes and Equation (7-12) for the Entire Database of Grouted Prisms .384 Figure 7-25: Comparison of Predictive Performance for Equation (7-11) and Khalaf et al.'s Model .385

Figure 7-26: Comparison of Predictive Abilities of the CSA S304.1-2004 Code and Equation (712) For N Type Mortar and S Type Mortar grouted Prisms. 386 Figure 7-27: Comparison of Predictive Performance for the Proposed Model, AS 3700 and TMS 402 Codes for the Range of Grout Strength 387

Figure 7-28: Comparison of Predictive Ability of Equation (7-12) and CSA S304.1-2004 Based on Specified Compressive Strength of grouted Prisms 388 


\section{List of Tables}

Table 2-1: Database of 117 Shear-Critical RCM Beams without Web Reinforcement ..............67

Table 2-2: Summary of Shear Design Methods for RCM Beams ............................................72

Table 3-1: Geometry and Reinforcement Details of the Reinforced Masonry Beams ................82

Table 4-1: The Matrix of the Experimental Program ............................................................ 133

Table 4-2: Unit Test Matrix................................................................................................ 134

Table 4-3: Test Results of Mortars ................................................................................ 138

Table 4-4: Compressive Strength Results for the Grout Samples .........................................141

Table 4-5: Compressive Strength Results for the Masonry Prisms ........................................ 145

Table 4-6: The Summary of Reinforcement Properties ...................................................... 160

Table 4-7: Summary of Experimental Observations for the Initial Tests of the Masonry Beams

Table 4-8: Summary of Longitudinal Strains $\varepsilon_{\mathrm{x}}$ and Shear strains $\gamma_{\mathrm{xy}}$ for the Initial Tests of the Masonry Beams

Table 4-9: Summary of Experimental Observations for the Repeated Tests of the Masonry

Beams

Table 5-1: Experimental Observation of the Initial Tests of the Size Effect Series Beams with North American Codes Predictions.

Table 5-2: Shear Strength Predictions by the BS5628 and AS 3700 Codes and Empirical Models by Li et al., Feriege and Dhanasekar et al.

Table 5-3: North American Codes Predictions Based on the Specified Masonry Compressive

Strength

Table 5-4: Comparisons of Predictions of North American Codes Based on the Specified

Masonry Compressive Strength and the Prisms Compressive Strength.....

Table 5-5: Experimental Observation of the Repeated Tests of the Size Effect Series Beams with

North American Codes Predictions.

Table 5-6 Experimental Observations of the RMB Reinforced with GFRP Bars with North

American Codes Predictions .263

Table 6-1: Experimental Observation of the Initial Tests of $\rho$ Effect Series with Codes

Predictions 303

Table 7-1 Summary of the Experimental Investigations Conducted on the Main Factors Affecting the Compressive Strength of Ungrouted Hollow Concrete Block Masonry ..... .340

Table 7-2 Ranges of the Values of the Main Factors Affecting the Compressive Strength of Ungrouted Masonry Covered in the Assembled Database. 341

Table 7-3: The Coefficients of Multiple Determination Factor for Different Statistical Model of

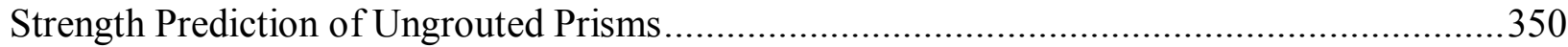

Table 7.4: Sample of Calculations for Determination of $\mathrm{f}^{\prime}{ }_{\mathrm{m}}$ for Ungrouted Masonry ...............355 Table 7-5: Values of Mean (f'm Exp/ f'm Pred), Standard Deviation, Coefficient of Variation and IAE for the Proposed Formula and Major International Masonry Codes .356 
Table 7-6: Summary of Experimental Investigations Conducted on the Main Factors Affecting the Compressive Strength of Grouted Hollow Concrete Block Masonry

Table 7-7: Ranges of the Values of the Main Factors Affecting $f^{\prime}{ }_{m}$ of Grouted Masonry Covered in the Assembled Database

Table 7-8: Coefficients of Multiple Determination for Different Statistical Models of Grouted

Prisms

Table 7-9: Sample of Calculations for determination of $\mathrm{f}^{\prime} \mathrm{m}$ for grouted masonry

Table 7-10: Values of mean ( $\mathrm{f}_{\mathrm{m} \text { Exp }} / \mathrm{f}_{\mathrm{m} \text { Pred }}$ ), standard deviation, coefficient of variation, IAE, number and percentage of over- predicted data for the proposed formula and major international masonry codes.

Table 7-11: Results of the Masonry Prisms Tested Normal to Bed Joint in the Current Investigation with the Predictions of the Proposed Equation (7-12) .389 


\section{Notations}

$\rho=$ longitudinal tensile steel reinforcement ratio $\left(=A_{s} / b_{w} d\right)$

$\mathrm{a}=$ shear span

$\mathrm{A}_{\mathrm{b}}=$ the bedded area of ungrouted masonry

$\mathrm{A}_{\mathrm{c}}=$ the area of the grout

$\mathrm{a}_{\mathrm{g}}=$ maximum coarse aggregate size

$\mathrm{A}_{\mathrm{g}}=$ the gross area of the unit

$\mathrm{A}_{\mathrm{n}}=$ net cross-sectional area of beam

$\mathrm{A}_{\mathrm{p}}=$ area of prestressed tension zone reinforcement

$\mathrm{A}_{\mathrm{s}}=$ area of non-prestressed tension zone reinforcement

$\mathrm{b}_{\mathrm{w}}=$ beam width

$\mathrm{C}_{\mathrm{b}}=$ factor used in Equation 7-2 to account for bedding type.

$\mathrm{C}_{\mathrm{h}}$ = factor used in Equation 7-2 to account for the ratio of a prism height to its thickness.

$\mathrm{C}_{\mathrm{hg}}=$ factor used in Equation 7-13 to account for the ratio of a prism height to its thickness.

$\mathrm{d}=$ effective depth of the beam (distance from extreme compression fibre to centroid of longitudinal steel)

$\mathrm{d}_{\mathrm{g}} \quad=$ Maximum lateral dimension of the grout prism

$\mathrm{dg}=$ maximum lateral dimension of the moulded grout prism

$\mathrm{d}_{\mathrm{v}}=$ flexural lever arm, effective shear depth

$\mathrm{E}_{\mathrm{p}}=$ elastic modulus of prestressed reinforcement

$\mathrm{E}_{\mathrm{s}}=$ elastic modulus of non-prestressed reinforcement

$\mathrm{f}^{\prime}{ }_{\mathrm{m}}=$ masonry compressive strength

$\mathrm{f}_{\mathrm{m} \text { Exp }}=$ experimentally determined masonry compressive strength, normalized for the $\mathrm{h} / \mathrm{t}$ ratio of prism

$\mathrm{f}^{\prime}{ }_{\mathrm{m} \text { Pred }}=$ predicted masonry compressive strength, normalized for the $\mathrm{h} / \mathrm{t}$ ratio of prism.

$\mathrm{f}^{\prime}{ }_{\mathrm{vm}}=$ characteristic shear strength of reinforced masonry

$\mathrm{f}_{\mathrm{bl}}=$ the compressive strength of the masonry unit based on its net area

$f_{b l n}=$ normalised compressive strength of 100x100 masonry units (Eurocode 6).

$\mathrm{f}_{\mathrm{c}}=$ concrete compressive strength

$f_{g}=$ cube compressive strength of mortar.

$\mathrm{f}_{\mathrm{gr}}=$ grout cylinder compressive strength

$\mathrm{f}_{\mathrm{mr}}=$ mortar compressive strength.

$f_{m r}=$ cube compressive strength of mortar, and

$\mathrm{f}_{\mathrm{mr}}=$ mortar cube compressive strength

$\mathrm{f}_{\mathrm{po}}=$ stress in prestressing tendon when strain in surrounding concrete is zero

$\mathrm{f}_{\mathrm{vS}}=$ design shear strength of the main longitudinal reinforcement

$f_{y v}=$ yield strength of the stirrups

$\mathrm{h} / \mathrm{t}=$ ratio of prism height to its thickness

$\mathrm{h}_{\mathrm{g}}=$ height of the grout moulded prism

$\mathrm{I}=$ moment of inertia of the cross section

$\mathrm{K}, \alpha$ and $\beta=$ constants used in Eurocode 6 to predict $\mathrm{f}_{\mathrm{m}}$ 
$\mathrm{k}_{\mathrm{h}}=$ factor used in the AS 3700 code to account for the ratio of unit height to mortar joint thickness.

$\mathrm{k}_{\mathrm{m}}=$ factor used in the AS 3700 code to account for bedding type.

$\mathrm{M}=$ applied moment

$\mathrm{N}$ = applied axial load (tension positive)

$\mathrm{P}_{\mathrm{g}} \quad=$ Grout prism compressive strength

$\mathrm{Q}=$ first moment of area at point where $v$ is calculated

$\mathrm{s}_{\mathrm{x}}\left(\mathrm{s}_{\mathrm{z}}\right)=$ crack spacing parameter

$\mathrm{s}_{\mathrm{xe}}\left(\mathrm{s}_{\mathrm{ze}}\right)=$ equivalent crack spacing factor

$\mathrm{V}=$ applied shear

$\mathrm{V}_{\mathrm{c}}=$ shear strength of concrete (force)

$\mathrm{Vl}=$ volume of the moulded grout prism

$\mathrm{V}_{\mathrm{m}}=$ shear strength of masonry (stress)

$\mathrm{V}_{\mathrm{m}}=$ shear strength of masonry (force)

$\mathrm{V}_{\mathrm{p}}=$ vertical component of effective prestressing force

$\mathrm{y}=$ distance from the neutral axis

$\beta=$ parameter describing ability of cracked concrete to transfer shear stress by aggregate Interlock

$\varepsilon_{\mathrm{x}}=$ longitudinal strain at mid-depth of beam 


\section{CHAPTER 1: INTRODUCTION}

\subsection{General}

Masonry is a structural material of major importance in Canada that is commonly used in a wide range of buildings, ranging from low to moderate-rise residential construction to larger structures such as schools and hospitals. The main reasons for this importance are masonry's attractive appearance, minimum maintenance and economy. Furthermore, its inherent thermal storage qualities assist in reducing internal temperature variations and peak loads on heating and cooling systems thus providing long-term energy savings. The mass properties of masonry make the system an effective barrier to sound. It provides architectural freedom and versatility with significant aesthetic appeal. Fire safety is another inherent attribute of masonry construction which has long been recognized.

Masonry structures, while having these benefits, still represent a challenge to structural analysis because of their complicated, multifaceted mechanical behaviour. This behaviour is made even more difficult to quantitatively predict by significant scatter in experimental data from tests conducted to investigate its behaviour. This difficulty in understanding the behaviour of masonry increases the competition the masonry industry faces from other building materials such as concrete, steel and wood.

An aspect of the structural behaviour of masonry that is still poorly understood is its response to shear forces. Unlike flexural failures, shear failures in masonry structures are brittle and sudden. If they occur, they do so with little or no warning. Furthermore, they are considerably more 
difficult to predict than flexural failures due to the fact that flexure involves longitudinal stresses while shear involves both longitudinal and transverse stresses. Flexural design provisions for masonry elements are based on the assumptions that plane cross sections of the element remain plane after bending and this assumption is effective for many different flexural elements. On the other hand, there is considerable debate concerning the mechanisms that govern shear failure in masonry. Existing design procedures are empirical or semi-empirical at best and have generally been developed by a best fit analysis through experimental results. As such, it is important to conduct research that will lead to masonry design procedures for shear that are as accurate and rational as those for flexure procedures. As a first step, this can be done by focussing on reinforced masonry beams, since these are among the simplest of masonry structural elements.

\subsection{Reinforced Concrete Masonry Beams}

Reinforced concrete masonry ( $\mathrm{RCM}$ ) beams are common structural elements in masonry buildings. RCM beams are used to span various openings, such as doors, windows and passages (see Figure 1-1). Although it is possible to use other material elements like steel beams, the most economical and aesthetically pleasing elements are often reinforced concrete masonry. Also, RCM beams are often used as part of masonry walls. Reinforced masonry walls may be shearresisting members, or "shear walls", which are part of the lateral load-resisting system of a building. In such a structural system, RCM beams may be used as connections between shear walls or piers. Such beams are called coupling beams because they "couple" the shear walls or piers (BIA Technical Note No.17B 1999). 

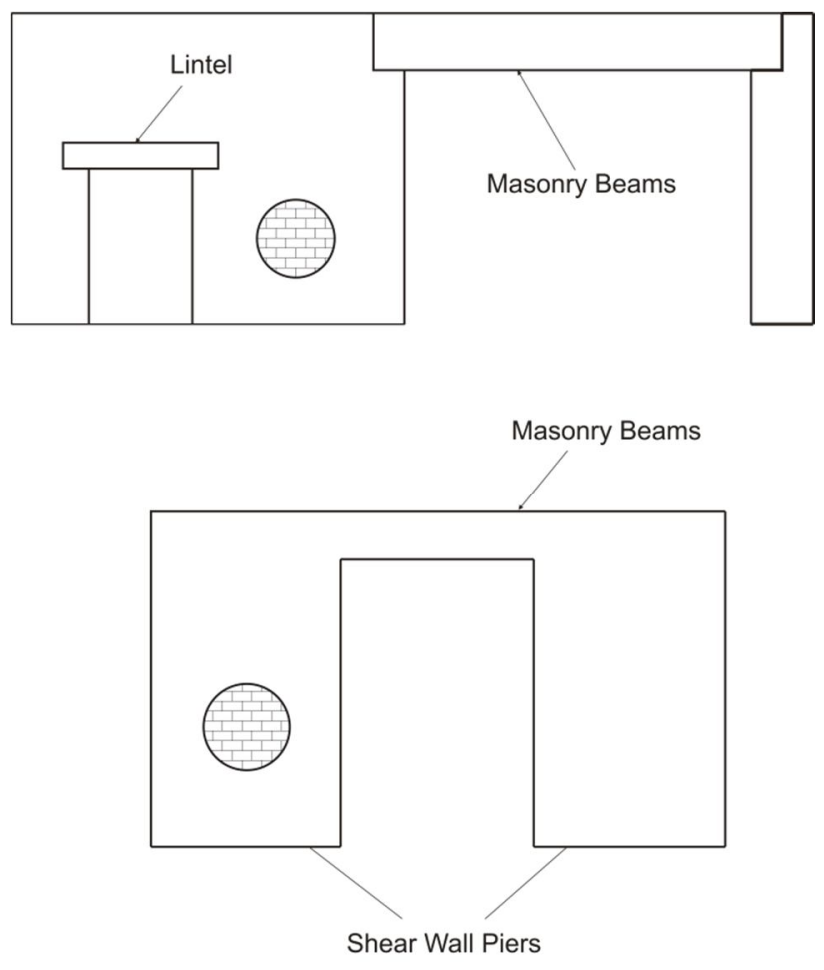

Figure 1-1: Reinforced Masonry Beams

The shear strength may determine the ultimate load-carrying capacity of a masonry beam and thus shear strength is a critical property of masonry. However, besides the limited amount of experiments dedicated to study the shear behaviour of reinforced masonry beams (compared to reinforced concrete (RC) beams), there is great discrepancy between design codes of different countries. For example, the TMS 402-2011 code (USA) does not account for some of the basic factors affecting the shear capacity of masonry members. The Canadian masonry design code (CSA S304.1-2004), on the other hand, is the only design code that account for the size effect (change in effective depth) of on the failure shear stress of masonry beams. However, it does not account for other important factors, such as the flexural reinforcement ratio $(\rho)$. Predictions of failure shear stress as the depth increases for reinforced masonry beams without stirrups are presented in Figure 1-2 for both the TMS MSJC and CSA S304.1 codes. 


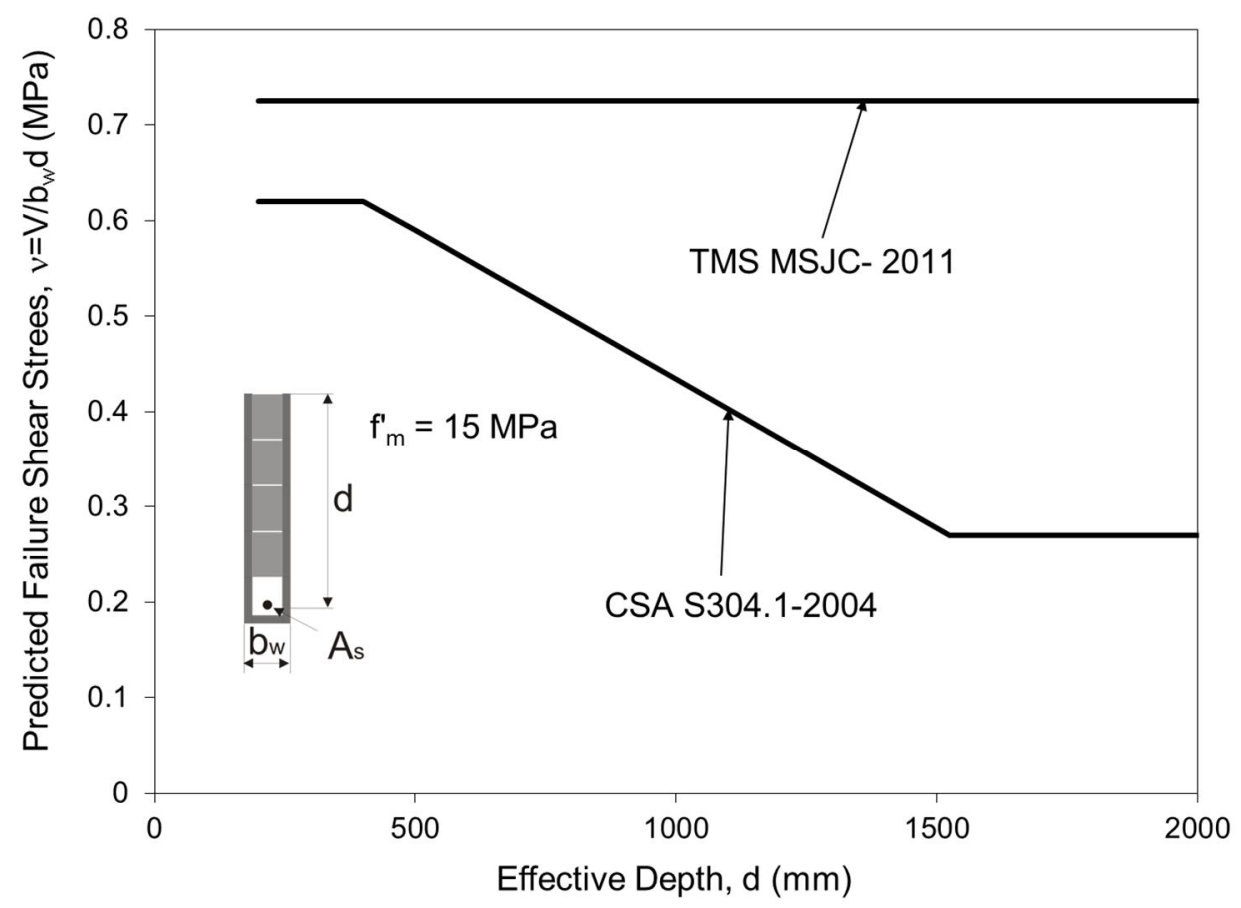

Figure 1-2: Shear Strength Predictions of TMS 402 and CSA S304.1 Codes for RCM Beams of Different Depths

The failure shear stress of reinforced concrete beams without shear reinforcement decreases as the effective depth increases (see Figure 1-3). This phenomenon is known as the "size effect," and numerous investigations have been conducted over the past few decades on this important topic. As the similarity between reinforced concrete and masonry beams is widely recognized, it is expected the TMS 402 code will be non-conservative at large effective depths (Figure 1-4). This is a very worthwhile and important aspect for further study.

Another example of the differences between masonry design codes is illustrated in Figure 1-4. The AS 3700-2001 (Australia) and BS5628-2005 (UK) accounts for the main reinforcement ratio, whereas the TMS MSJC and CSA S304.1 provisions are not sensitive to the change of reinforcement ratio. 

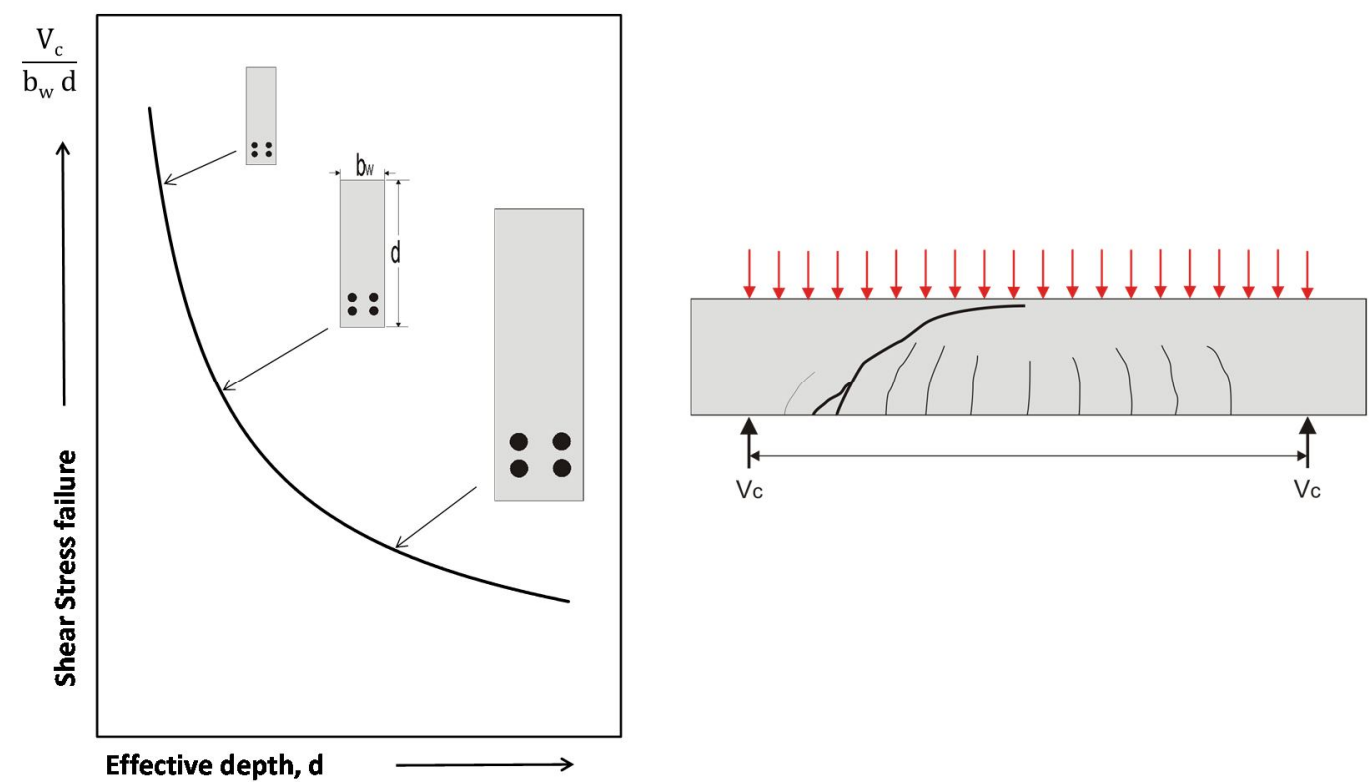

Figure 1-3: Illustration of the Size Effect in Shear for Reinforced Concrete Beams without Stirrups

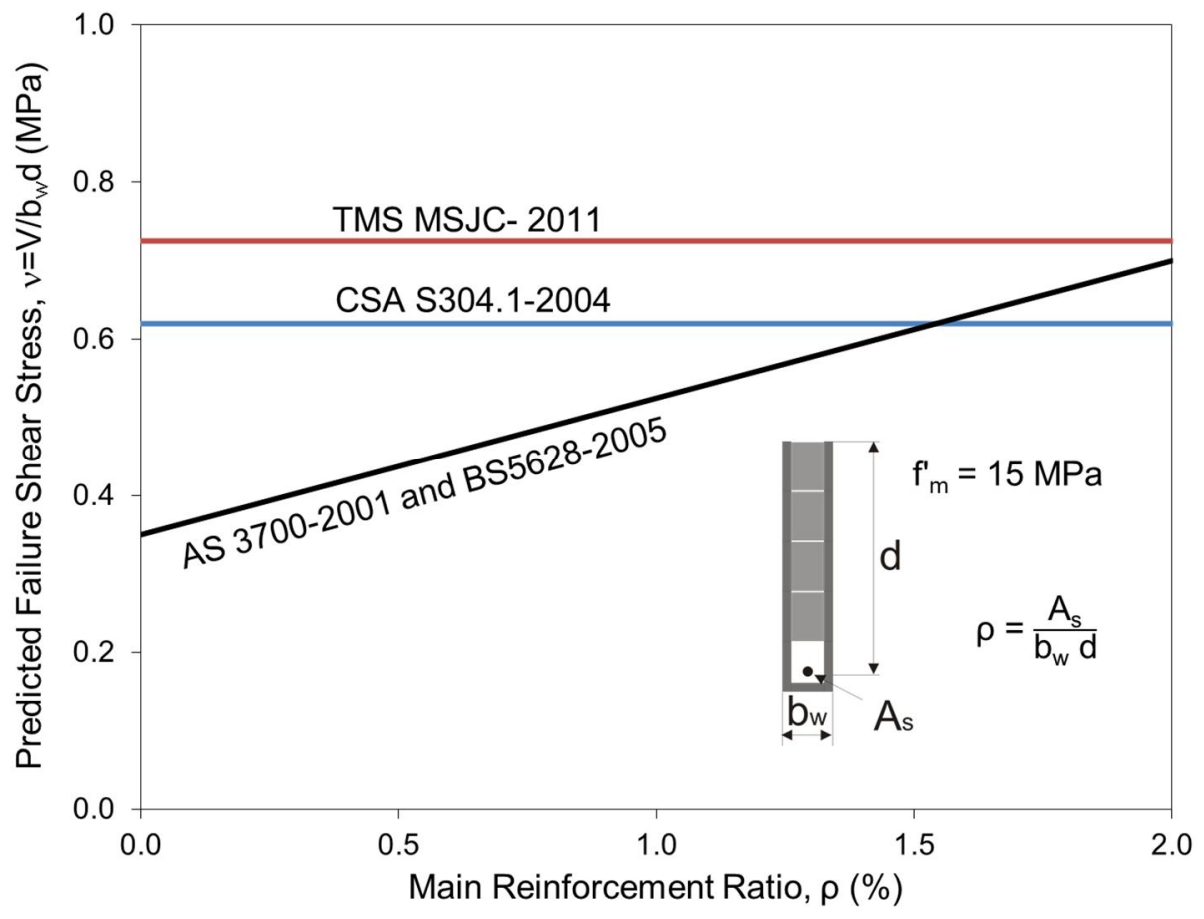

Figure 1-4: Shear Strength Predictions of TMS 402, CSA S304.1, AS3700 and BS5628 Codes for Reinforced Masonry Beams with Different Reinforcement Ratios 
Ensuring RCM has adequate shear strength is an important aspect of structural design. Masonry beams without web reinforcement can experience brittle failure with very little deformation to warn of impending failure (Drysdale and Hamid 2005). Furthermore, since it is difficult to provide web reinforcement in masonry, often reinforced masonry beams are often constructed without any web reinforcement (Dhanasekar 2001). Therefore, the design provisions used to determine shear strength of masonry beams without web reinforcement must be accurate, safe, and rational. Furthermore, improving design provisions for beams will lead to improve shear design provisions for other structural elements such as walls, pilasters and columns.

\subsection{Inspiration for Current Study}

The work described in this thesis was inspired by various design situations where large masonry girders were used in commercial, residential, or health-related structures, as architects commonly desire open, column-free spaces.

Figure 1-5 shows a plan of St. Hedwig's Church in St. Louis, Missouri, built in 1957. The design incorporated a modified clerestory that extends the length of the church from front to rear. To provide adequate sightlines (i.e. have a space free of interior columns), the side space walls of the clerestory were supported only at the ends. Structural members, $65 \mathrm{ft}$ long, were required to carry the roof load from above and part of the loads from the side roofs. Golabowski and Herrmann (Technical Notes 17M) examined three types of girders for this structure: prestressed concrete, brick-encased steel plate, and reinforced brick masonry (RBM) girders. 


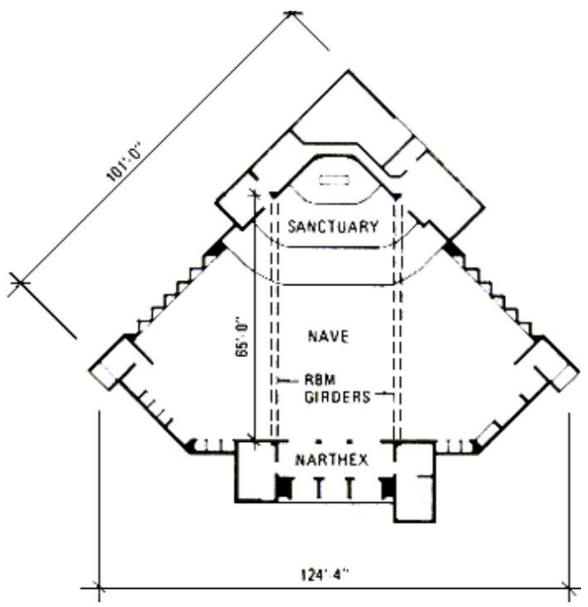

a) Church Plan

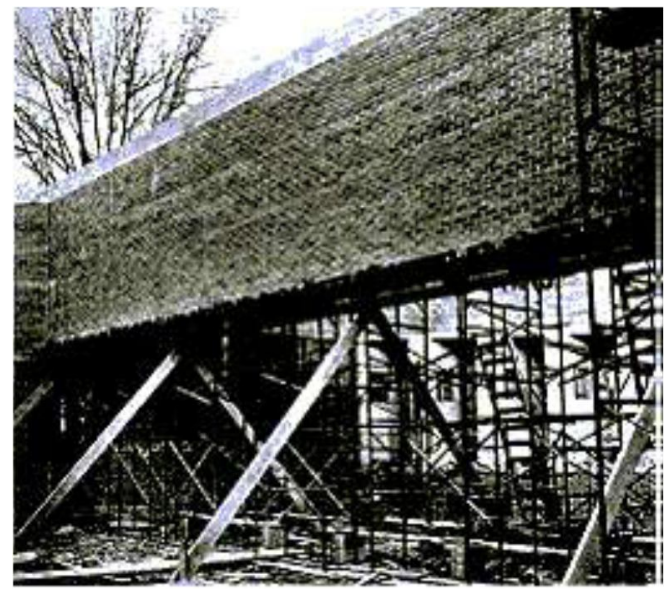

b) The RBM Girder under Construction

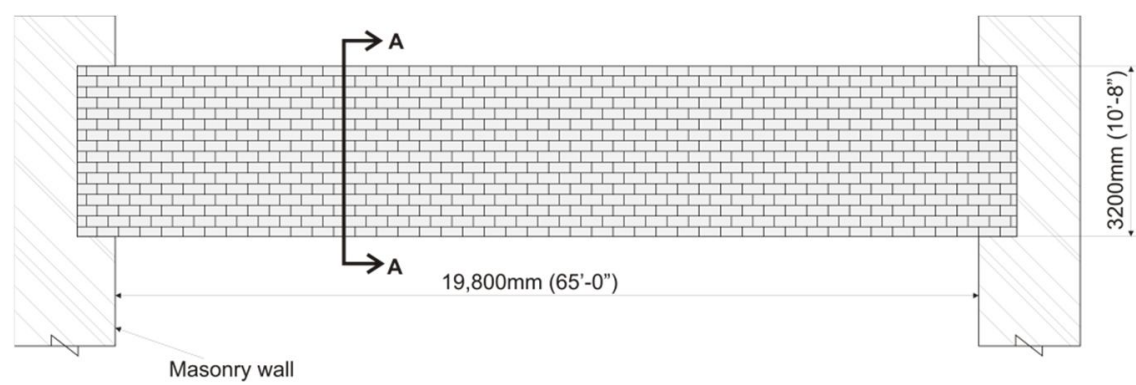

c) RBM Girder Elevation

d) Section A-A

$$
\begin{aligned}
& \text { Precast } \\
& \text { concrete joist }
\end{aligned}
$$

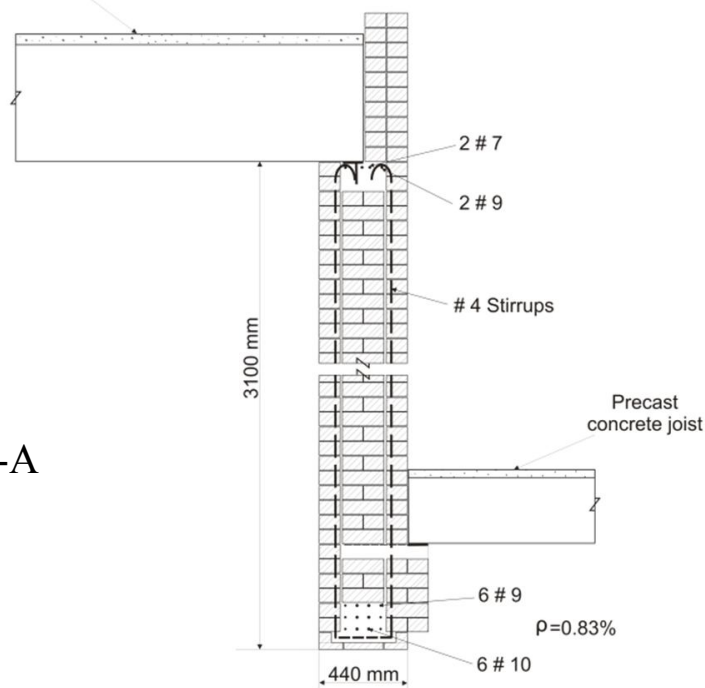

Figure 1-5: A Reinforced Brick Masonry Girder in the St. Hedwig's Church in St. Louis, Missouri, USA (Reproduced from Technical Notes 17M) 
The prestressed concrete girders were eliminated because, with masonry on both sides, they would be too thick for the desired appearance. The option of brick-encased steel plate girders was eliminated too because these girder would have been end-supported on steel columns built into the masonry walls. Golabowski and Herrmann selected RBM girders because exposed brick was used extensively both outside and inside the church. The church contractor, C. Rallo Contracting Company, Inc., reported that the total cost of the two RBM girders and supporting columns was only $\$ 8000$ (1957 dollars); columns alone cost $\$ 600$ (Technical Notes 17M). The bid figures showed that two steel plate girders and four steel columns would have cost $\$ 8200$ without the brick encasing.

Another example of extensive use of large brick masonry beams is the Maryland City Shopping Center in Missouri (Architecture: Anthony F. Musolino \& Associate, Structural Engineer: Lugi Iacono). The RBM girder illustrated in Figure 1-6 is supported on RBM columns spaced at $23 \mathrm{ft}$ 4 in. $(7120 \mathrm{~mm})$ on center. It carries half of the arcade roof load transmitted to it by a beam located $6 \mathrm{ft} 8 \mathrm{in}$. from one support. Other girders are loaded similarly by beams at varying distances from the girder support. 


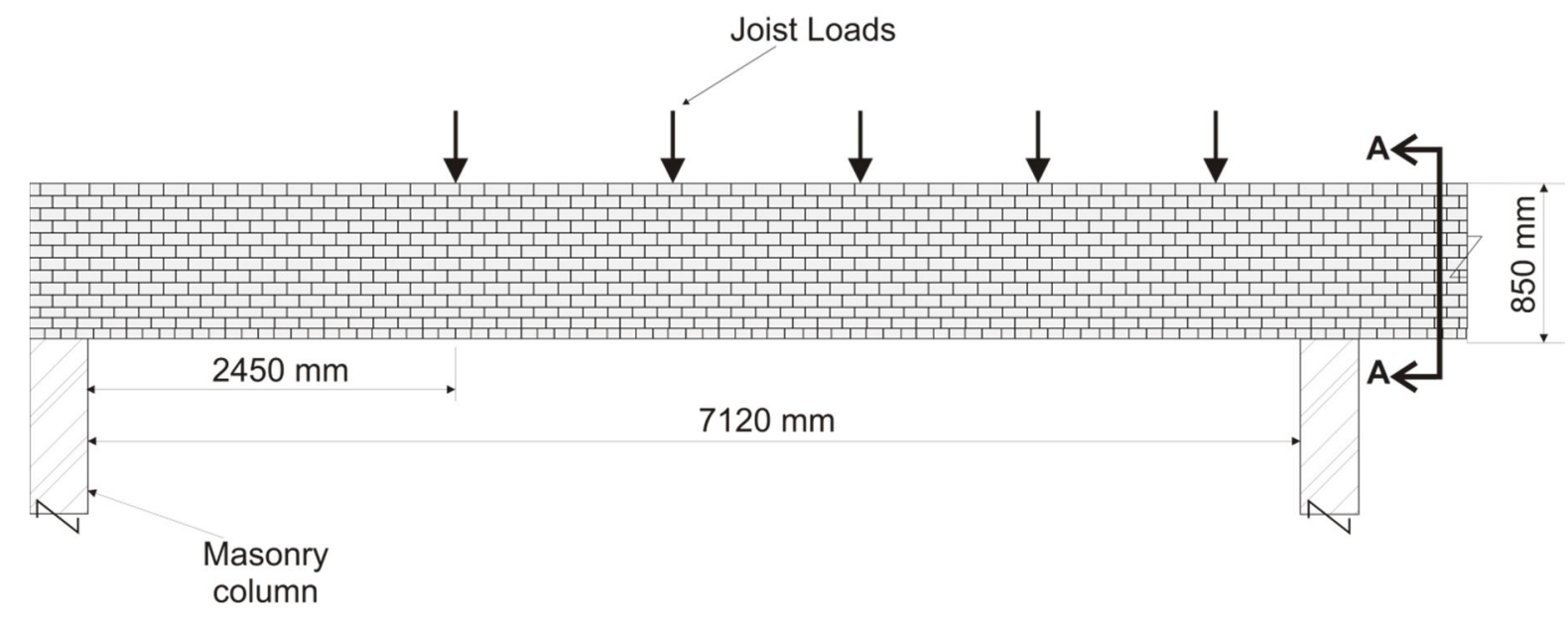

a) RBM Girder Elevation

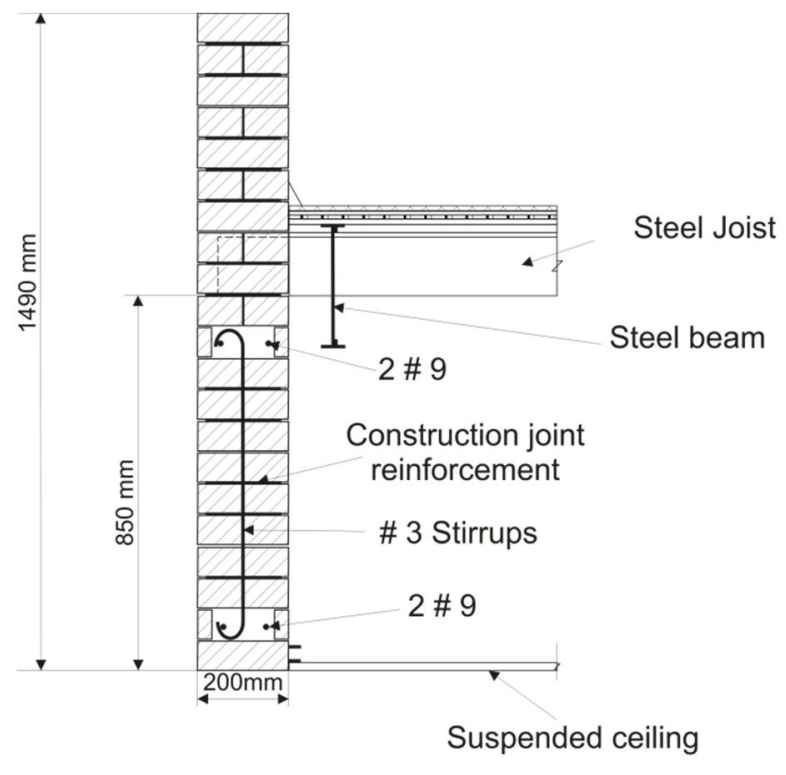

b) Section A-A

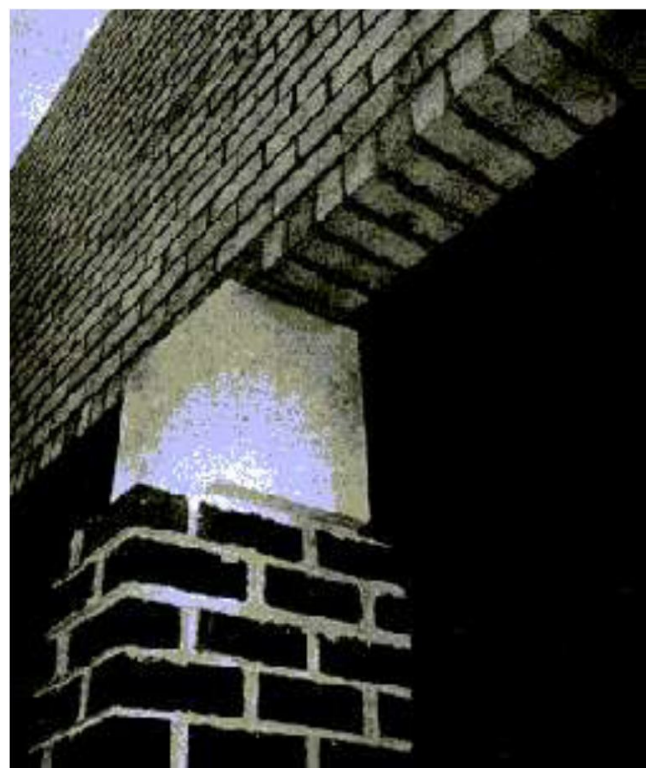

c) A photo of the RBM

Figure 1-6: A Reinforced Brick Masonry Girder in Maryland City Shopping Center, Missouri, USA (Reproduced from Technical Notes 17M)

The Meadows Mall at Lake St. Louis, USA, consists of six buildings totaling over 260,000 sq ft. All were built with 8 in. concrete masonry units. The structural elements included load bearing 
masonry, masonry columns, moment frame walls and masonry beams (Grant et al. 2009). While the engineer`s original plan for the Meadows at Lake St. Louis was to construct the front sides of the building with a moment-resisting frame of steel beams and columns with a façade of brick veneer and steel stud backup, one of the project's developers mandated the use of load bearing masonry throughout. As such, no perimeter steel columns were used. Figure 1-7 (Grant et al. 2009) shows a photo of the front side of one of the six building in the Meadows mall with the reinforcement details of the masonry moment resisting frame.
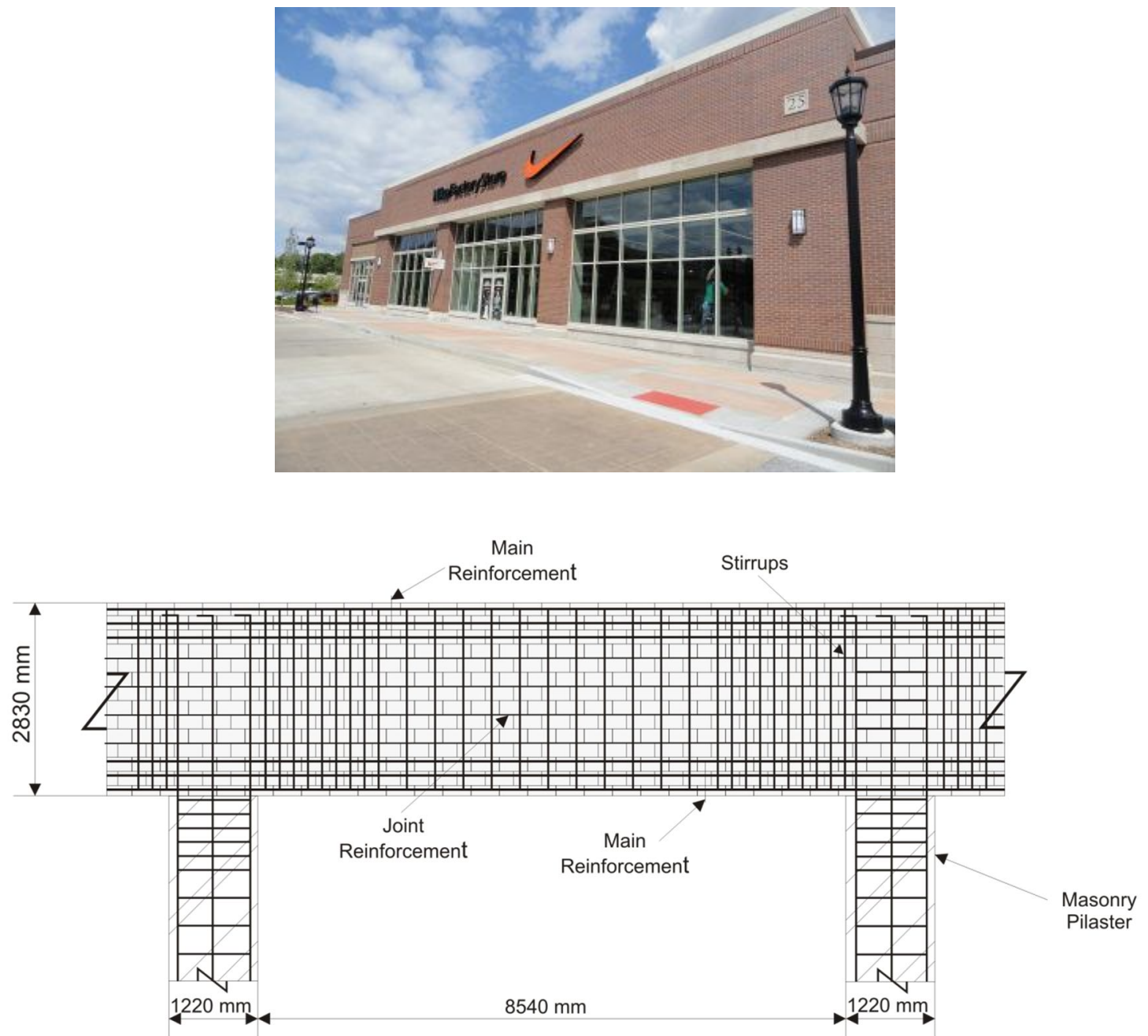

Figure 1-7: A Reinforced Concrete Masonry Beam at Meadows Mall in Lake St. Louis, USA (Reproduced from Grant et al. 2009) 
The main tensile steel rebar was placed in the top three courses and the bottom three courses of the masonry storefront beam. The beams were heavily reinforced by vertical reinforcement (stirrups) and horizontal reinforcement (joint and rebar).

The effective depths of these large masonry beams range from 1.5 to 5 times beyond the size of typical laboratory shear tests, and at that range of depth, the size effect can be expected to dominate shear response. As such, design code equations should accurately account for the size effect in shear. The key question is "Do masonry design codes give accurate predictions of the failure shear stress of these large masonry beams?"

\subsection{Compressive Strength of Masonry}

The compressive strength of a building material is one of the most important mechanical properties that engineers use when designing a structure. As with other materials, the measurement of compressive strength is the basic test for ensuring quality control of masonry construction. However, there is still considerable debate as to how to measure the compressive strength of masonry and how to choose a test specimen configuration that best represents the insitu construction.

Masonry design codes generally adopt two approaches to determine the compressive strength of masonry $\left(\mathrm{f}_{\mathrm{m}}^{\prime}\right)$. The first approach involves testing of masonry prisms or wallets (as shown in Figure 1-8) built from the same materials used in actual construction. The measured compressive strengths from these tests are then related to the strength of the masonry structure 
by factors that account for the size of the tested samples (i.e. the height to thickness ratio). This method is usually not practical at the design stage. Furthermore, it may not be possible during the construction phase due to the time and cost involved, including the lack of local availability of high capacity testing machines and the complexities of transporting samples.

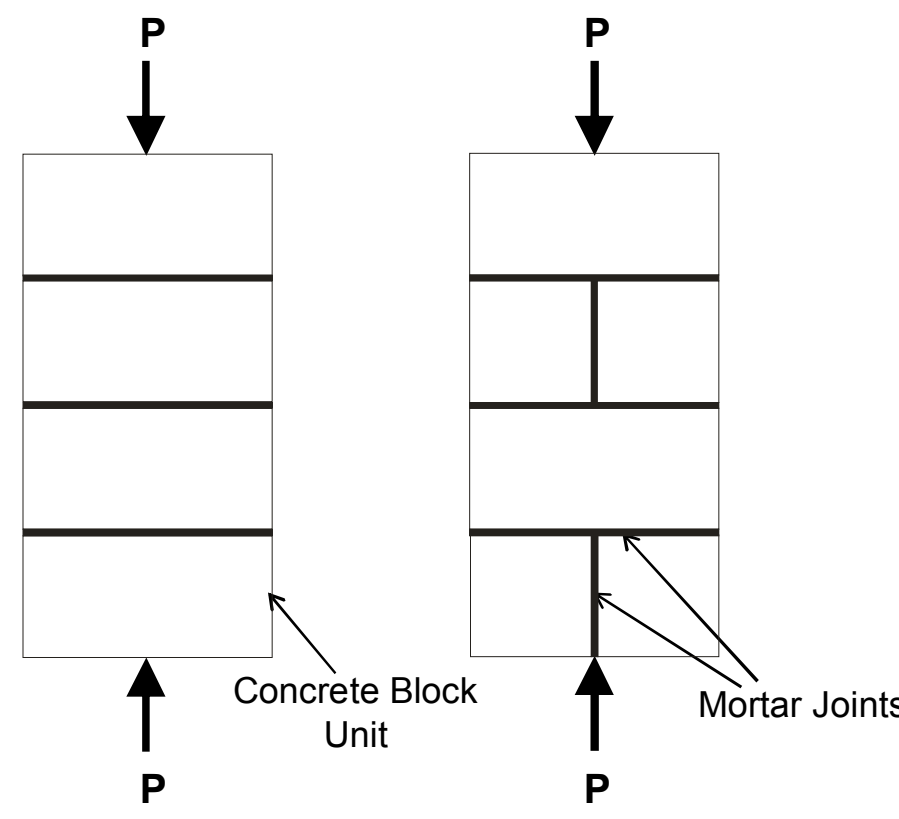

Stack Bond Prism

Running Bond Prism

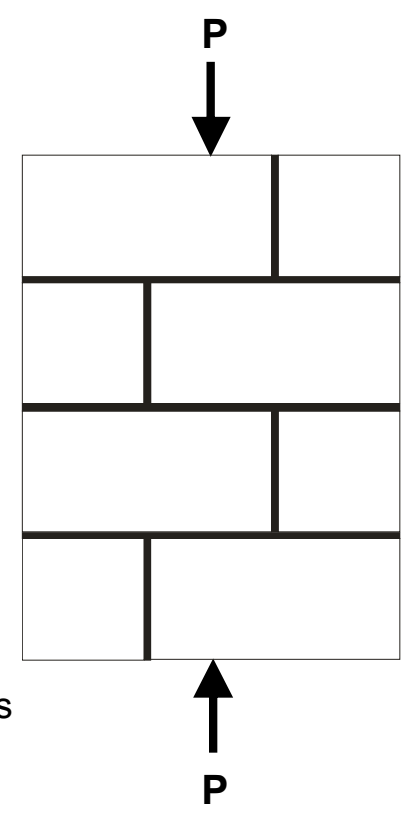

Wallet

Figure 1-8: Configurations of Concrete Block Masonry Prisms

In the second approach, known as unit strength method, masonry design codes provide tabulated values based on the compressive strength of the block and the type of mortar, are used to determine the specified compressive strength $\left(\mathrm{f}_{\mathrm{m}}\right)$. These tables, commonly found in building codes, have been derived from empirical relationships, though often based on limited numbers of test results. Since these tables are reported to be conservative (Drysdale and Hamid 2005, Korany and Glanville 2004, Gayed and Korany 2011, Ross and Korany 2012), it is worthwhile to continuously re-evaluate the tabulated of $\mathrm{f}_{\mathrm{m}}$ as more test results become available. 


\subsection{Objectives}

This thesis reports the test results of an extensive experimental program consisting of fifteen tests on full scale reinforced concrete masonry beams. Three sizes of test specimens were studied: small, medium and large. They range in heights from $390 \mathrm{~mm}$ to 1.59 metres, in widths from 190 $\mathrm{mm}$ to $240 \mathrm{~mm}$, and in mass from $560 \mathrm{~kg}$ to 10 tonnes. The test specimens were designed to study the size effect and the strain effect in reinforced masonry beams. Effective depth, main reinforcement ratio, use of vertical reinforcement (stirrups), use of horizontal crack control reinforcement, the use of GFRP reinforcement and the use of high strength steel are the main experimental variables. Also, the experimental work included construction of 41 masonry prisms, 90 mortar cubes, 24 grout moulded prisms and 24 grout cylinders. These along with samples of unit blocks were tested as the material test samples of the beams.

The overall objective of this research is to study the shear behaviour of fully grouted reinforced concrete masonry beams, particularly those constructed without shear reinforcement. Specifically, the work investigates and attempts to quantify the following:

- The significance of the size effect on shear behaviour of reinforced masonry beams, including how best to account for it in masonry design codes;

- The significance of the strain effect on shear behaviour of reinforced masonry beams, including the effect of the main reinforcement ratio and the use of reinforcement with different stiffnesses or yield strength (GFRP or high strength regular steel); and

- The mechanisms of shear failure in reinforced concrete masonry beams. 
It is hoped that the experimental data and resulting analysis will assist in the development of rational, theoretically-sound shear design provisions, the application of which will ensure appropriate levels of safety for the types of large-scale structural elements shown in Figures $1-5$ to $1-7$;

As testing of compressive strength of masonry control prisms is a substantial part of the experimental program, it was decided to engage in a side study to develop simple and accurate empirical formulae to predict compressive strengths of concrete block masonry. The objectives of studying the compressive strength can be explained as follows:

- A large database of compressive test results on ungrouted and grouted masonry prisms reported in the literature were assembled;

- The collected database was analyzed to develop simple and accurate empirical formulae to predict the compressive strength of masonry; and

- The predictive capabilities of the proposed formulae were compared to those of major international masonry design codes.

\subsection{Organization of the thesis}

This thesis is organized into eight chapters. Chapter 2 is a review of the literature on shear in reinforced masonry and concrete beams, focusing on areas most relevant to the research reported in the thesis. Chapter 3 describes the experimental program that investigates the size effect and strain effect on shear strength of reinforced masonry beams. Chapter 4 
presents the test results of the RM beams presents along with the results of tests conducted on various material properties associated with these beams. Chapter 5 discusses the results of the experimental program described in chapters 3 and 4 in the context of the size effect in shear. The purpose of Chapter 6 is to investigate the significance of the strain effect in reinforced masonry. Additional topics such as the application of image correlation analysis for reinforced masonry and the effect of horizontal reinforcement on flexural cracks will be discussed in Chapter 6 as well. Chapter 7 reports the development of simple and accurate formulae to predict the compressive strength of ungrouted and grouted concrete block masonry through regression analysis on a large database of compressive test results collected from the literature. Chapter 8 includes the main concluding remarks and recommendations for future work. 


\section{CHAPTER 2: LITERATURE REVIEW}

This chapter is intended to serve as a detailed review of the shear behaviour of reinforced concrete masonry beams (RCM). As the similarity of reinforced masonry and reinforced concrete beams is widely appreciated (Drysdale and Hamid (2005)), the topics covered by this literature review begin with an overview of the shear behaviour of reinforced concrete (RC) beams, followed by an overview of shear design provisions of reinforced concrete beams in the ACI (US) and the CSA (Canada) codes. Subsequently, a critical review of the previous studies on shear behaviour of reinforced concrete masonry beams is presented. The shear strength results for 117 RCM beams without shear reinforcement were collected from these previous studies. The collected database was used to analyze shear design provisions of current masonry codes for RCM beams to assess their safety and predictive capabilities. The four codes include: CSA S304.1-04 (Canada), ACI 530-08 (US), AS 3700-2001 (Australia), and BS 5628-2:2005 (UK). A fifth set of shear design provisions was chosen -the general method of shear design from the CSA A23.3-04 code for reinforced concrete (CSA Committee A23.3 (2004)).

\subsection{General}

Reinforced concrete and reinforced concrete masonry beams without stirrups can experience brittle and sudden shear failures with little or no warning. As such, ensuring that these beams have adequate shear strength is a critical aspect of structural design of these elements to avoid possible catastrophic results.

A well-designed beam should be critical in flexure rather than shear. In such a beam, considerable warning of imminent structural failure can be expected as the steel yields, leading 
to wide cracks and large deformations. Furthermore, actual flexural failure loads in excess of those expected can be achieved due to strain hardening and membrane action. Shear failures of beams without stirrups are not associated with such warning or hidden factors of safety. As such, designers must rely on accurate, rational and safe code provisions to design beams with adequate safety against shear failure.

\subsection{Shear Behaviour of Reinforced Concrete Beams}

\subsubsection{Shear Behaviour of RC Beams before Cracking}

Given the brittle nature of shear failure, a critical aspect of structural design of a concrete element is ensuring that the element has adequate shear strength. It is worthwhile to briefly discuss the behaviour of typical reinforced concrete beams used in experimental studies on shear. Consider the simply-supported beam shown in Fig. 2-1, subjected to a single point load at midspan. Before cracking, the beam will act as elastic material and the flexural stresses $(\sigma)$ and shear stresses $(v)$ can be calculated from familiar expressions:

$$
\begin{gathered}
\sigma=\frac{\mathrm{My}}{\mathrm{I}} \\
v=\frac{\mathrm{VQ}}{\mathrm{Ib}}
\end{gathered}
$$

Where:

$\mathrm{M}=$ bending moment acting at the section

$y=$ distance from the neutral axis

$I=$ moment of inertia of the cross section

$\mathrm{V}=$ shear force acting at the section 
$\mathrm{Q}=$ first moment of area at point where $v$ is calculated

$b_{w}=$ width of the section

Both flexural and shear stresses vary along the span and the cross-section of the beam. At any section of the beam, the flexural stresses are at maximum in the extreme fibers of the beams and zero at the neutral axis. The shear stresses, on the other hand, are at maximum at the neutral axis and zero at the extreme fibers. For instance, consider elements A and B located at the very top and very bottom of the section at the middle of the shear span (quarter of the beam). Element A is under flexural compression stress only, while element B is subjected to tensile flexural stress only. At an element located neither at the extreme fibers nor at the neutral axis of the beam, such as element $\mathrm{C}$, is subjected to both flexural as well as shear stresses. These stresses combine to result in principle compressive $\left(f_{2}\right)$ and tensile $\left(f_{1}\right)$ stresses.

$\mathrm{f}_{1,2}=\frac{\sigma}{2} \pm \sqrt{\left(\frac{\sigma}{2}\right)+v^{2}}$

These stresses are inclined with respect to the beam's axis and the inclination angle can be calculated as follows:

$\theta=\frac{2 v}{\sigma}$

The principle tensile stresses are commonly called diagonal tensile stresses because of their directionality. When the diagonal tensile stress reaches the tensile strength of concrete, a diagonal crack develops. At the neutral axis, where the flexural stresses are zero, an element 
(such as element D) is in the state of pure shear, and the principal stresses act at a $45^{\circ}$ angle to the horizontal.
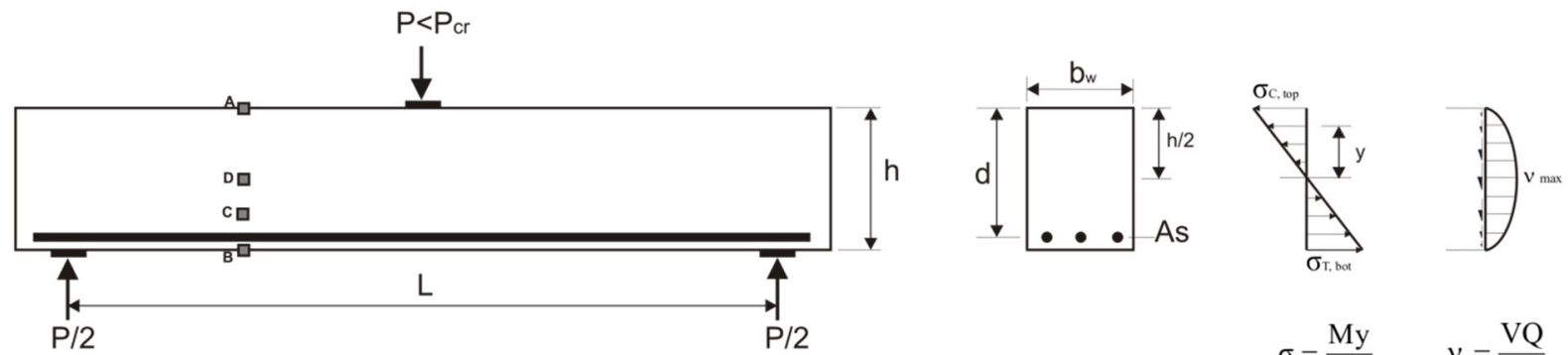

$\mathrm{P} / 2$

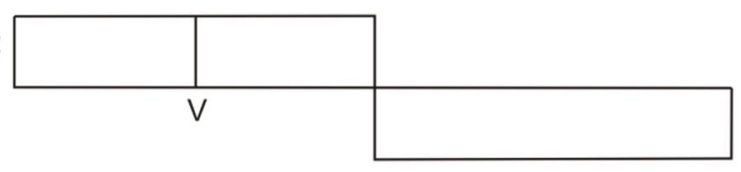

Shear Force Diagram

$$
\sigma=\frac{\mathrm{My}}{\mathrm{I}} \quad v=\frac{\mathrm{VQ}}{\mathrm{Ib}}
$$

$\mathrm{A}^{\prime}$
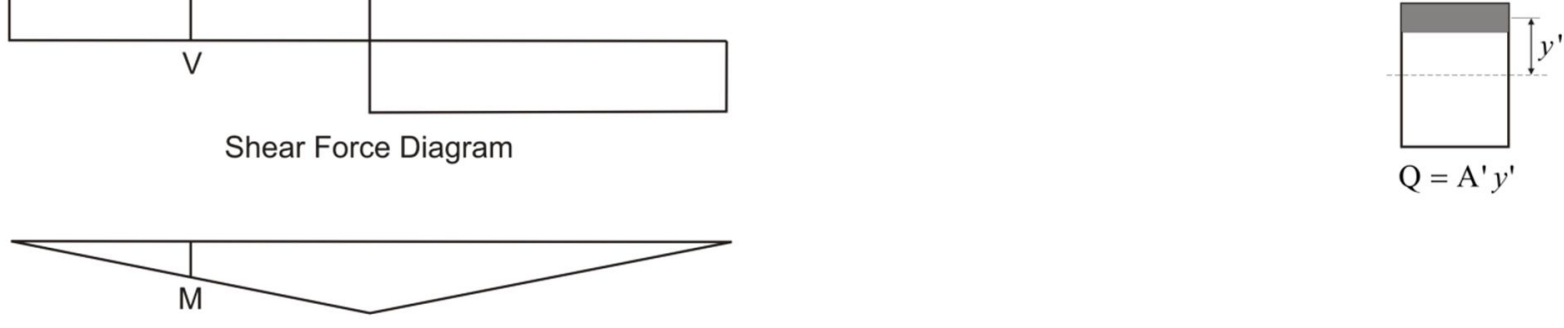

Bending Moment Diagram
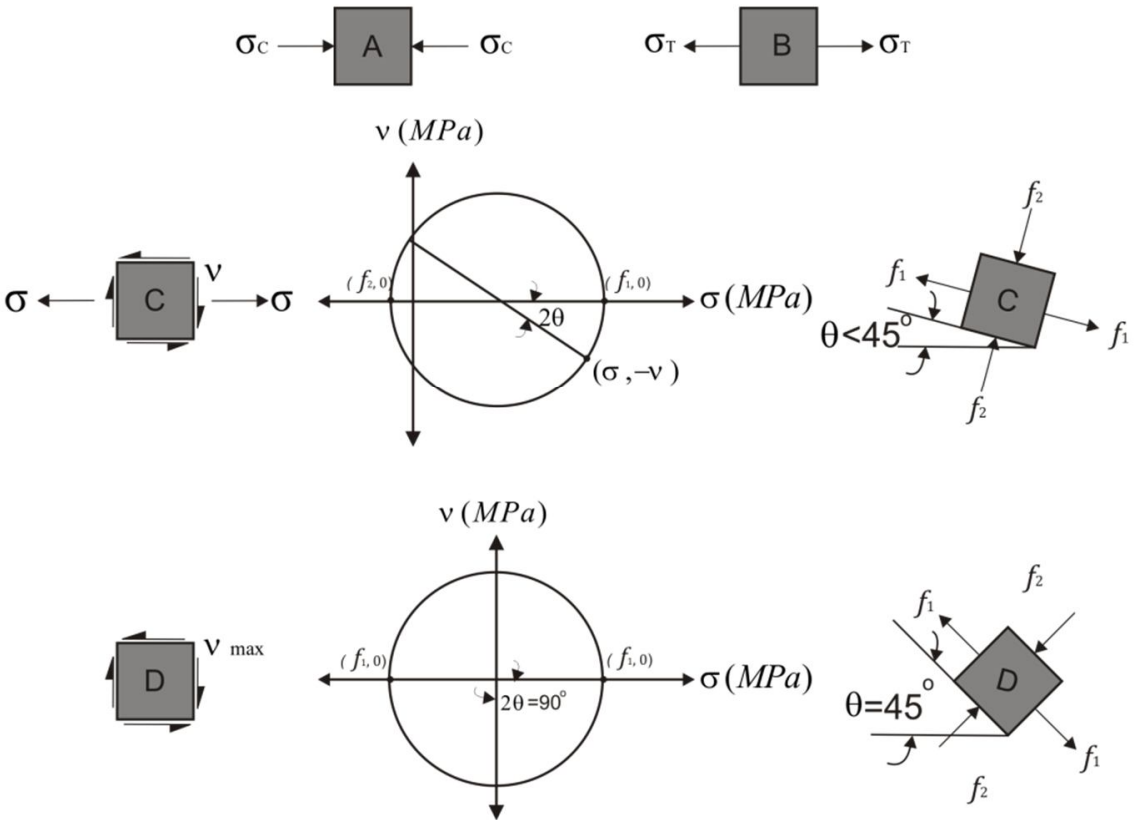

Figure 2-1: Shear Stress Distribution in an Un-Cracked Reinforced Concrete Beam 


\subsubsection{Shear Behaviour of RC Beams after Cracking}

When the applied load exceeds the cracking load, two major types of cracks develop. First, vertical flexural cracks occur and start at the bottom of the beam where the flexural stresses are large. These flexural cracks extend up the beams, and in regions of pure moment remain vertical. In regions of combined moment and shear, these cracks will incline as they extend up the beam due to the reorientation of the principle stresses caused by increasing shear stress.

In cracked concrete, the internal shear stress distribution can no longer be described using Equation (2-2). Mörsch (1909) found that the vertical shear stress distribution could be determined at a section giving that that the adjacent flexural stresses were known. He showed that shear stress distribution in a cracked member consisted of two regions: a parabolic distribution above the neutral axis (in the un-cracked compression zone), increasing from zero at the top fiber in compression to a maximum value at the neutral axis, and a constant shear stress region below the neutral axis. To explore Mörsch`s shear stress distribution, consider the cracked reinforced concrete beam without stirrups of width $b_{w}$ shown in Figure 2-2a). The segment between two cracks is shown in Figure 2-2b), along with the horizontal forces resulting from flexural stresses and vertical forces resulting from shear acting on the section. The moment on the right face is higher than that on the left, resulting in different concrete compressive forces and steel tensile forces from left to right. For simplicity, it is assumed that the flexural lever arm jd does not change over the distance $\mathrm{dx}$. The segment between two cracks consists of three areas, the flexural compression zone, flexural tensile zone and tensile steel area. 


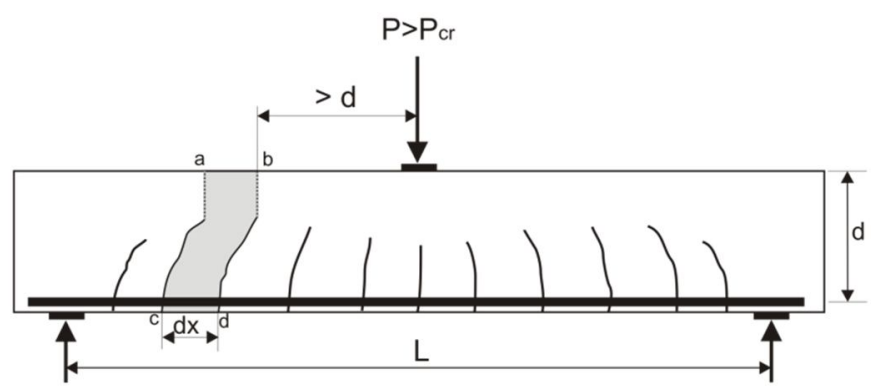

a) Cracked Reinforced Concrete Beam

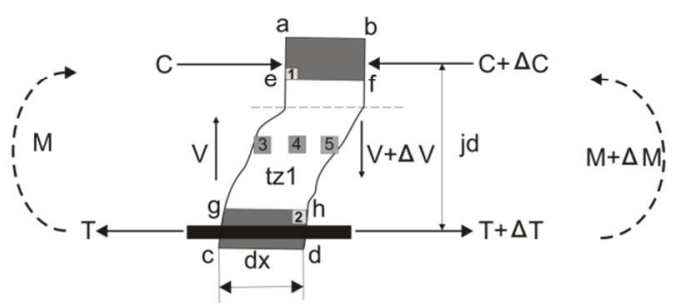

b) Section between Two Cracks
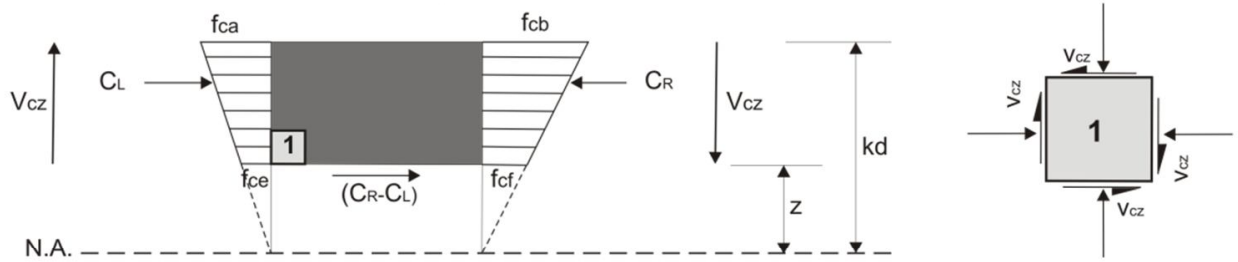

c) Shear Stress in the Flexural Compression Zone

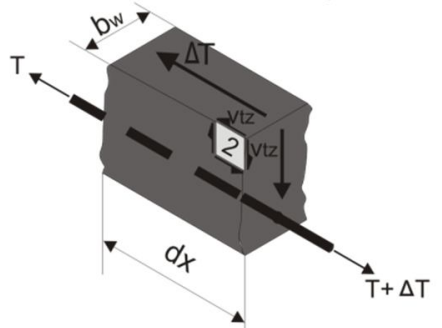

d) Section at Tensile Steel Level

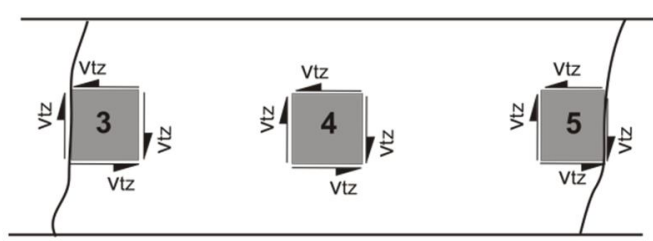

e) Section in the Flexural Tension Zone

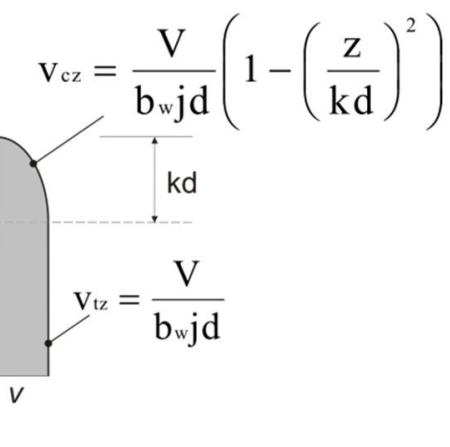

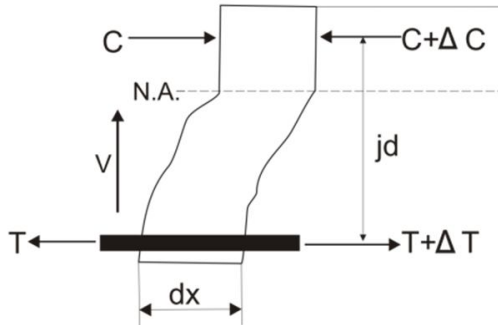

f) Distribution of Shear Stress in Section between Two Cracks

Figure 2-2: Shear Stress Distribution in a Cracked Reinforced Concrete Beam 
For the flexural compression zone, consider the segment a-b-e-f in the compression zone (shown in Figure 2-2c), where the horizontal face e-f is located at a distance $\mathrm{z}$ from the neutral axis. Left side a-e and right side $b$-f are subjected to trapezoidal horizontal stress blocks, forming horizontal compressive forces $C_{L}$ and $C_{R}$. As $C_{R}$ is slightly larger than $C_{L}$, a horizontal force of $\left(C_{R}-C_{L}\right)$ must act on the horizontal plane e- $\mathrm{f}$ (Jourawski (1856)) to maintain equilibrium. The compressive force $\mathrm{C}_{\mathrm{L}}$ can be found by:

$\mathrm{C}_{\mathrm{L}}=\frac{1}{2}\left(\mathrm{f}_{\mathrm{ca}}+\mathrm{f}_{\mathrm{ce}}\right)(\mathrm{kd}-\mathrm{z}) \mathrm{b}_{\mathrm{w}}$

Where $\quad f_{c e}=\frac{z}{k d} f_{c e}$

Hence, $C_{L}=\frac{1}{2}\left(f c a+\frac{z}{k d} f c a\right)(k d-z) b_{w}$

Resulting in $\mathrm{C}_{\mathrm{L}}=\frac{1}{2} \mathrm{f}_{\mathrm{ca}}\left(1-\left(\frac{\mathrm{z}}{\mathrm{kd}}\right)^{2}\right)(\mathrm{kd}-\mathrm{z}) \mathrm{b}_{\mathrm{w}}$

Similarly, $C_{R}=\frac{1}{2} f_{c b}\left(1-\left(\frac{z}{k d}\right)^{2}\right)(k d-z) b_{w}$

Now consider the entire triangular flexural stress block on the left and right sides.

Moment $\mathrm{M}$ on the left at a and moment $\mathrm{M}+\Delta \mathrm{M}$ on the right can be found as

$\mathrm{M}_{\mathrm{L}}=\frac{1}{2} \mathrm{f}_{\mathrm{ca}} \mathrm{b}_{\mathrm{w}}(\mathrm{kd}) \mathrm{jd}$ 


$$
\mathrm{M}+\Delta \mathrm{M}=\frac{1}{2} \mathrm{f}_{\mathrm{cb}} \mathrm{b}_{\mathrm{w}}(\mathrm{kd}) \mathrm{jd}
$$

By substituting (2-6) into (2-5), the following relationships for $C_{L}$ and $C_{R}$ are determined:

$$
\mathrm{C}_{\mathrm{L}}=\frac{\mathrm{ML}_{\mathrm{L}}}{\mathrm{jd}} \mathrm{f}_{\mathrm{ca}}\left(1-\left(\frac{\mathrm{z}}{\mathrm{kd}}\right)^{2}\right)
$$

$$
\mathrm{C}_{\mathrm{R}}=\frac{\mathrm{M}_{\mathrm{R}}}{\mathrm{jd}} \mathrm{f}_{\mathrm{cb}}\left(1-\left(\frac{\mathrm{z}}{\mathrm{kd}}\right)^{2}\right)
$$

The horizontal shear force on the face e-f can be then calculated as follows:

$$
\mathrm{V}_{\mathrm{ef}}=\frac{\left(\mathrm{C}_{\mathrm{R}}-\mathrm{C}_{\mathrm{L}}\right)}{\mathrm{b}_{\mathrm{w}} \mathrm{dx}}=\frac{\left(\mathrm{M}_{\mathrm{R}}-\mathrm{M}_{\mathrm{L}}\right) \mathrm{M}_{\mathrm{R}}}{\mathrm{b}_{\mathrm{w}}(\mathrm{dx}) \mathrm{jd}}\left(1-\left(\frac{\mathrm{z}}{\mathrm{kd}}\right)^{2}\right)=\frac{\mathrm{V}}{\mathrm{b}_{\mathrm{wj}} \mathrm{d}}\left(1-\left(\frac{\mathrm{z}}{\mathrm{kd}}\right)^{2}\right)
$$

Equation (2-8) yields a parabolic shear stress distribution in the compression zone with a value of zero at $\mathrm{z}=\mathrm{kd}$ (top of the beam) to a maximum value of $\frac{\mathrm{v}}{\mathrm{b}_{\mathrm{wjd}}}$ at $\mathrm{z}=0$. Horizontal equilibrium of the small element 1 (Figure 2-2c) requires that horizontal shear stress on e-f to be equal to the vertical shear stress at $\mathrm{z}$ from neutral axis.

To determine vertical shear distribution in the tension zone $\mathrm{vtz}$, consider the block of concrete at the steel level h-g-c-d (Figure 2-2d). The difference in tensile force in the steel from left to right, $\Delta \mathrm{T}$, must be resisted by horizontal shear stresses on the face $\mathrm{h}-\mathrm{g}$, which are equal to $\frac{\Delta \mathrm{T}}{\mathrm{b}_{\mathrm{w} j \mathrm{~d}}}$. $\Delta \mathrm{T}=\frac{\Delta \mathrm{M}}{\mathrm{jd}}=\frac{\mathrm{Vdx}}{\mathrm{jd}}$

Hence, $v t z=\frac{\Delta T}{b_{w j d}}=\frac{V d x}{b_{w}(d x) j d}=\frac{V}{b_{w j d}}$ 
To achieve the rotational equilibrium, the horizontal shear stress on face h-g must be equal to the vertical shear stress on hd and gc. As the horizontal shear stress on face h-g is not a function of the distance between this face and the steel, shear stress in the tension zone, $\mathrm{v}_{\mathrm{tz}}$, is constant within this region and is equal to the maximum shear stress at the neutral axis from equation (28). Rotational equilibrium in elements 3,4 and 5 in the tension zone (Figure 2-2e) requires that vertical shear in tension zone be transferred across cracks. The complete shear stress distribution as determined by Mörsch is shown in Figure 2-2f.

\subsubsection{Mechanisms of Shear Transfer in Reinforced Concrete}

It can be seen from Figure 2-3 that in reinforced concrete member without transverse reinforcement, the total shear force $\left(\mathrm{V}_{\mathrm{c}}\right)$ is resisted by three major components:

- the force in the compression zone $\left(\mathrm{V}_{\mathrm{cz}}\right)$

- the vertical component of the aggregate interlock shear stress, $v_{\mathrm{a}}$, and

- the dowel force $\left(\mathrm{V}_{\mathrm{d}}\right)$ in the tensile steel

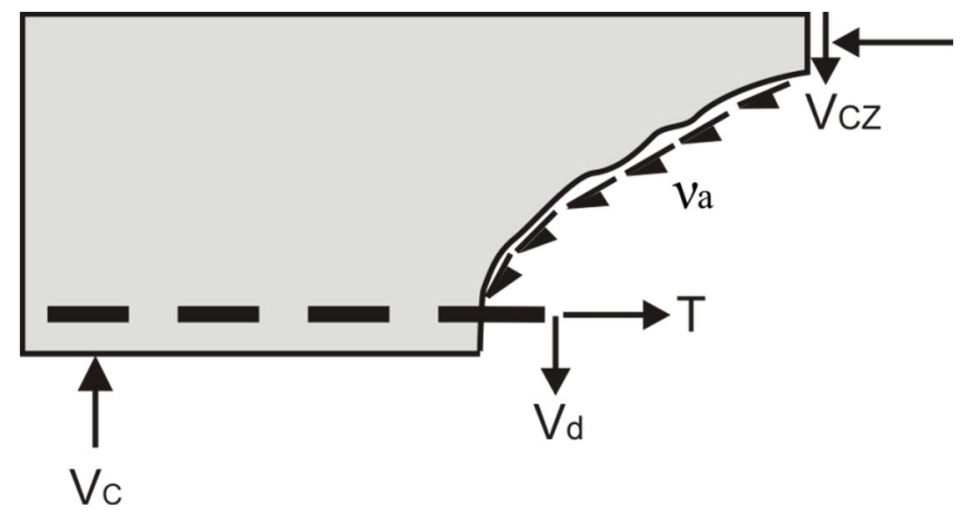

Figure 2-3: Mechanisms of Shear Transfer in Reinforced Concrete without Stirrups 
A large number of studies and investigations have been conducted over the years to determine the relative proportions of each of these components; however, these proportions still represent a source of debate. Many factors can affect the relative proportions of these components, and these factors include:

- shear span to depth ratio $(\mathrm{a} / \mathrm{d})$

- reinforcement ratio

- reinforcement stiffness and distribution

- crack width and roughness, and

- concrete strength and cover thickness.

There are two major schools of thoughts regarding the relative proportions of these components. First, in early attempts at developing shear design provisions, researchers neglected the role of aggregate interlock (Zwoyer and Siess (1954), Moretto (1955), Moody et. al. (1954), Hanson (1958), Bresler and Pister (1958) and Walther (1962)) believing that in members without shear reinforcement once cracking occurred, all the vertical shear force was carried only within the uncracked compression zone. Many current international concrete and masonry design codes are based on this assumption. As research progressed, it was realized that aggregate interlock has substantial effect on shear behaviour of reinforced concrete. Several investigations (Moe (1962), Fenwick and Paulay (1964, 1968), MacGregor (1964), Taylor (1970), MacGregor and Walters (1967), Kani et. al. (1979) and Sherwood et. al. (2007)) have shown that up to $75 \%$ of the vertical shear force is transferred by the aggregate interlock mechanism. In these tests, the contribution of aggregate interlock to the shear resistance was evaluated through careful instrumentation of cracked beams or other elements in a way that allowed the quantification of each component. For instance, Kani et al. (1979) found that at three adjacent cracks, the shear in 
the compression zone were $19 \%, 32 \%$ and $17 \%$ of the total shear (see Figure 2-4). They also found that the dowel action component was quite small, resulting in about $71 \%, 58 \%$, and $73 \%$ of the shear force being carried by aggregate interlock.

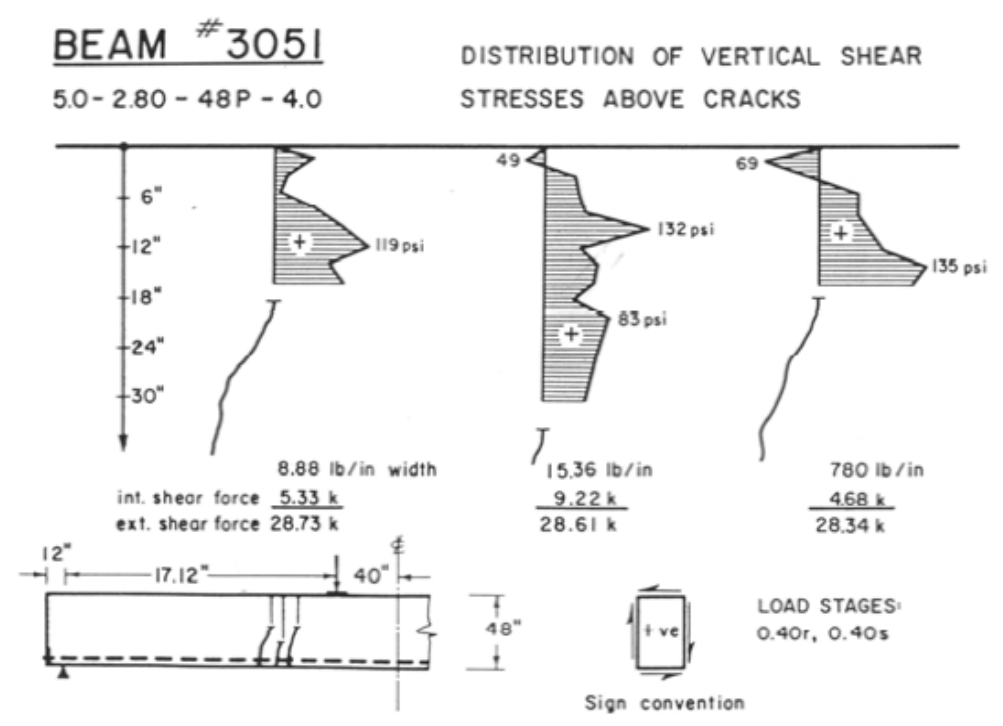

Figure 2-4: Measurement of Shear in the Compression Zone (Kani et. al. (1979))

In Beam L-10N2 tested by Sherwood et al. (2007) (see Figure 2-5), two columns of horizontal strain gauges were applied at the head of the crack at a load of $420 \mathrm{kN}$ and the resulting longitudinal strains were recorded. The Young's modulus determined from companion compressive cylinder tests following similar load histories was used to convert the longitudinal concrete strains to longitudinal concrete stresses. By integrating the resulting shear stress distribution, Sherwood et al (2007) found that only $24 \%$ of the total shear force at the section was carried by the uncracked compression zone. This indicates that the majority of the vertical shear in L-10N1 was resisted by aggregate interlock across the crack in the web of the beam. 


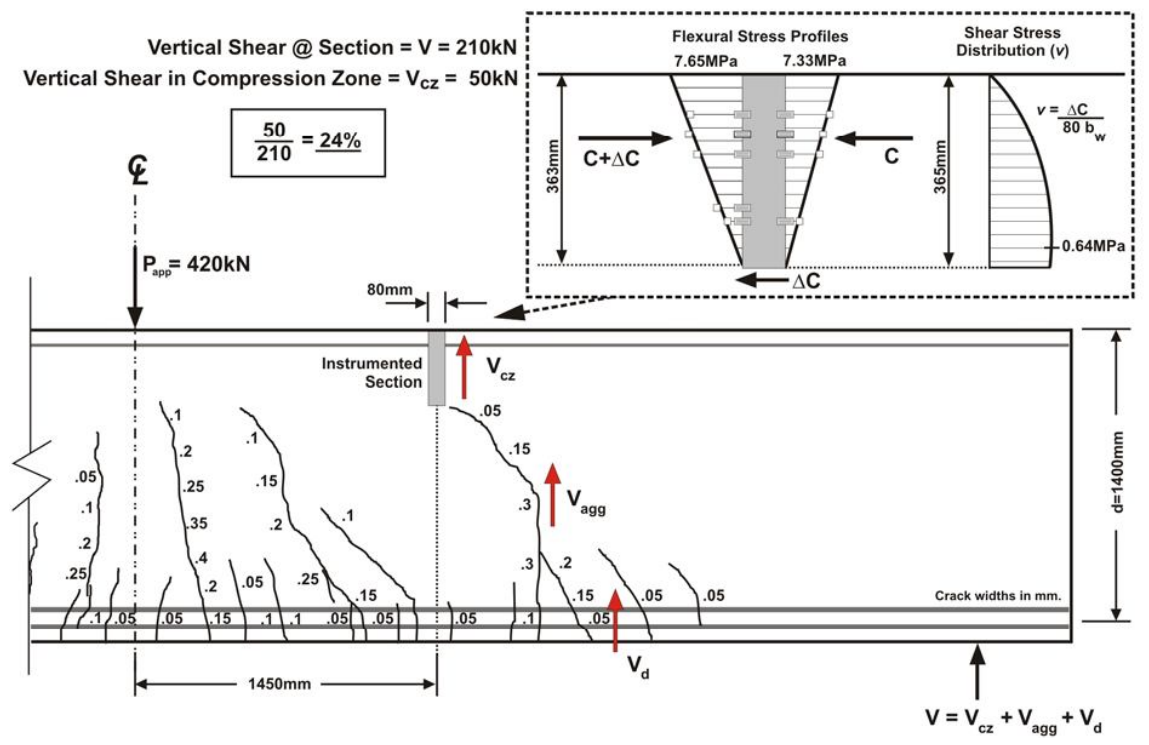

Figure 2-5: Measurement of Shear Carried in Compression Zone of Beam L-10N2 (Sherwood et al. 2007)

ASCE-ACI committee 426 (1973) reported the work done by Gregely (1969) who confirmed that the contribution of various mechanisms to the shear resistance of cracked reinforced concrete are as follows: $20-40 \%$ by compression zone, $33-50 \%$ aggregate interlock and 15 to 25\% by dowel action. Other researchers (Krefeld and Thurston (1966), Parmelee (1961), and Baumann (1968)) found similar proportions of the shear to be carried by dowel action. Finally, although ASCE-ACI committee 445 highlighted that the residual tension across the crack can contribute to shear resistance this component is likely small compared to other components.

\subsubsection{Effect of a/d Ratio and Modes of Failure}

The shear span to effective depth ratio $(\mathrm{a} / \mathrm{d})$ is a very influential factor in determining the shear strength of reinforced concrete beams. One of the primary effects of the a/d ratio is that it determines whether arch action can engage after beam action breaks down (see Figure 2-6). In so-called slender RC members (wherein a/d is greater than about 2.5), the shear behaviour is 
dominated by beam action. In these beams, when the aggregate interlock breaks down on a crack, beam action can no longer be maintained and strut and tie action cannot be engaged. Shear failure in slender members is characterized by a sudden formation of an inclined flexureshear crack. In $\mathrm{RC}$ members with a/d less than about 2.5 , the shear behaviour is governed by arch action, wherein shear is sustained by inclined concrete compression struts between the applied load and the support even after aggregate interlock breaks down on a crack. Shear failure in deep beams is characterized by one or more of crushing of the strut, tension in the top face of the strut, anchorage failure and splitting at the level of the steel. Shear strength in deep beams can be evaluated using a strut and tie model.

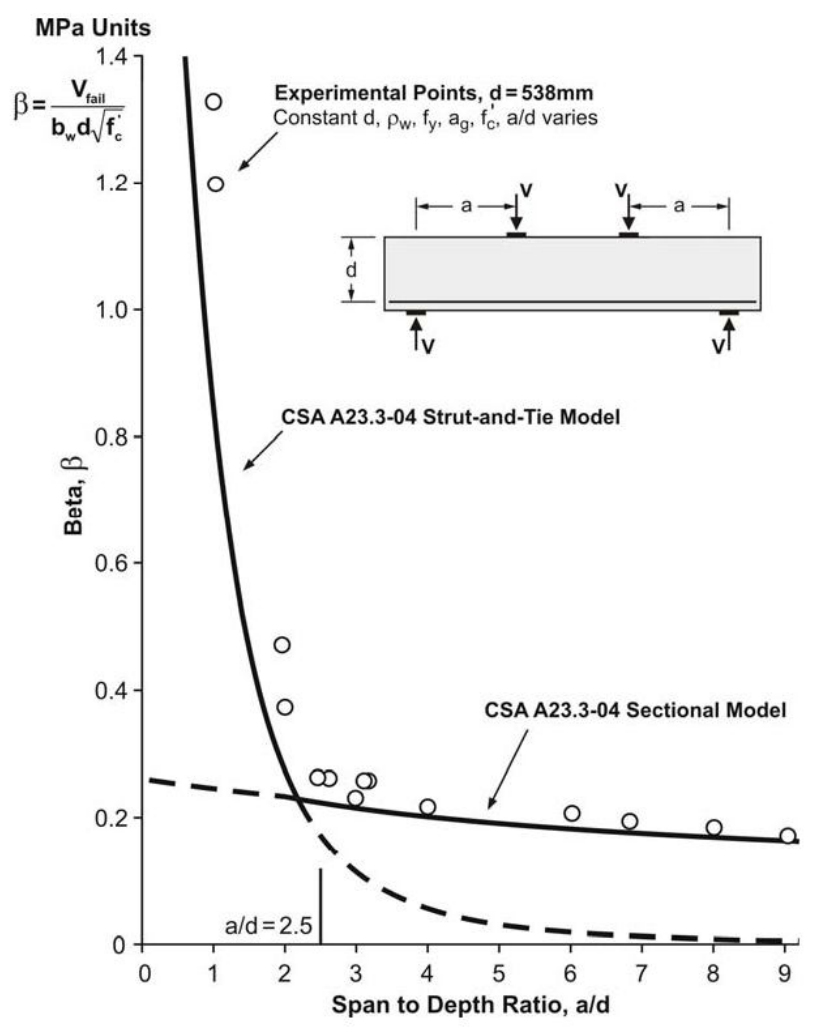

Figure 2-6: Effect of a/d on Shear Strength (Adopted from Collins et. al. (2007)) 


\subsubsection{The Size Effect}

The failure shear stress of reinforced concrete (RC) beams without shear reinforcement decreases as the effective depth increases. This phenomenon is known as the "size effect," and numerous experimental investigations have been conducted on this phenomenon over the past few decades (Kani 1967, Shioya 1989, Shioya et. al. 1989, Ghannoum 1998, Yoshida 2000, ShanCao 2001and Sherwood 2008)).

Shear tests are normally conducted on relatively small beams and most code design equations were developed statistically based on experimental databases consisting primarily of these small beams. However, these design provisions are often used to design beams much larger than the specimens tested in laboratories. For instance, the mean beam depth in the database used to derive the ACI 318 Equations (11-3) and (11-5) (Equations (2-9) and (2-10) below) for $\mathrm{V}_{\mathrm{c}}$ was 13.4 in. $(340 \mathrm{~mm})$.

$$
\begin{aligned}
& \mathrm{V}_{\mathrm{c}}=0.167 \sqrt{\mathrm{f}^{\prime} \mathrm{c}} \mathrm{b}_{\mathrm{w}} \mathrm{d} \\
& \mathrm{V}_{\mathrm{c}}=2 \sqrt{\mathrm{f}^{\prime} \mathrm{c}} \mathrm{b}_{\mathrm{w}} \mathrm{d} \\
& \frac{\mathrm{V}_{\mathrm{c}}}{\mathrm{b}_{\mathrm{w}} \mathrm{d}}=\frac{1}{7} \sqrt{\mathrm{f}^{\prime} \mathrm{c}}+17 \frac{\rho_{\mathrm{w}} \mathrm{V}_{\mathrm{d}}}{\mathrm{M}} \leq 0.29 \sqrt{\mathrm{f}^{\prime} \mathrm{c}}
\end{aligned}
$$

As a result, this equation design does not account for the size effect in shear. In the 50 years since the $\mathrm{ACI}$ equation for $\mathrm{V}_{\mathrm{c}}$ was developed, relatively few tests on slender beams with large effective depths have been performed. For example, Collins et. al. (2007) collected a large database of 1849 shear test results in which only about $1.2 \%$ of the tests were slender beams 
$(\mathrm{a} / \mathrm{d}>2.5)$ with very large effective depths $(1000 \mathrm{~mm}$ or more). Furthermore, $84 \%$ of the shear failures reported in the literature occurred in small beams (with an effective depth less $406 \mathrm{~mm}$ ).

Kani (1967 and 1969) was among the first to study the effect of absolute member size on concrete shear strength after a major shear failure of an Air force warehouse in Ohio in 1955 (Anderson (1957), Collins and Mitchell (1997)). He conducted tests on large number of reinforced concrete beams without stirrups in which the a/d ratio and effective depth, $d$, were varied in order to evaluate the effect of beam depth. Kani's essential finding that the failure shear stress, v, decreases as the effective depth, d, increases. Sherwood (2008) highlighted the results of two of Kani's beams (1969) (see Figure 2-7) in which a 42.9in. deep beam without stirrups, at an a/d ratio of 3.1 and a reinforcement ratio of $0.80 \%$ failed at a shear stress correspond to 0.67 of the estimated shear strength both Equations (11-3) and (11-5) of the ACI 318 code (Figure 27).

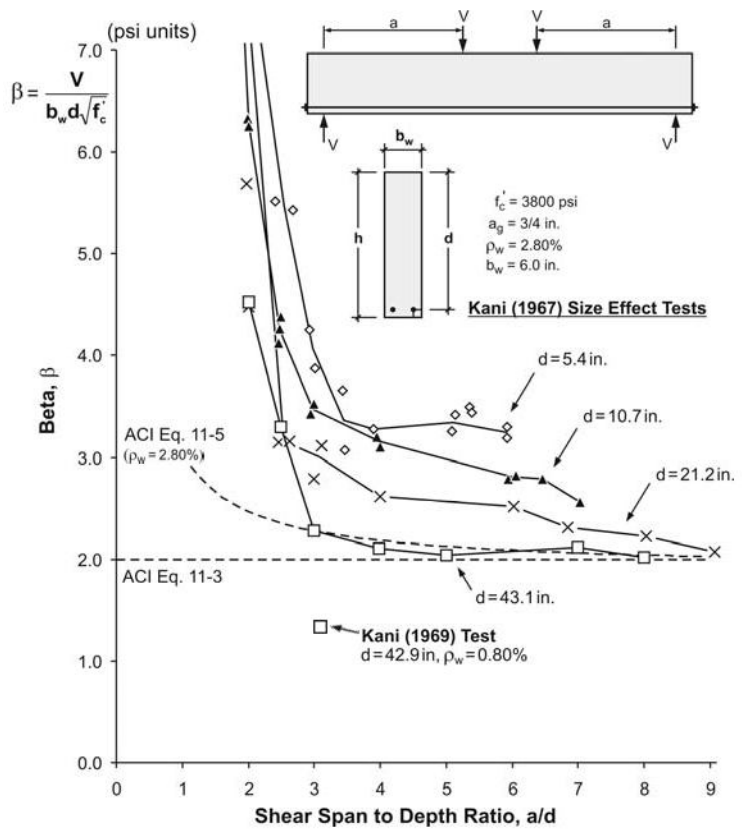

Figure 2-7: Kani's Size Effect Tests (Reproduced from Sherwood (2007)) 
Shioya et. al. (1989) and Shioya (1989) conducted a number of tests on large-scale beams in which the influence of member depth and aggregate size on shear strength was investigated. In this study, a series of lightly reinforced concrete beams were loaded to shear failure, with depths varying between $100 \mathrm{~mm}$ to $3000 \mathrm{~mm}$ and maximum aggregate sizes ranging from $1 \mathrm{~mm}$ to $25 \mathrm{~mm}$. Shioya et. al. found that the shear stress at failure decreased as the member depth increased and as the aggregate size decreased. The size effect in shear was explained by the authors as a result of a combination of two actions: size effect in concrete and "shear transfer" across surfaces of the shear cracks.

Ghannoum (1998) tested two geometrically similar series of beams of different concrete strengths. Beam heights in each of the series ranged from $90 \mathrm{~mm}$ to $960 \mathrm{~mm}$ and all the beams had a constant a/d ratio of 2.5. Results showed a strong "size-effect" in the behaviour of concrete beam or one-way slab elements subjected to shear, where deeper members have smaller shear stresses at failure than shallower ones.

Extensive tests have been conducted at the University of Toronto on the size effect in shear (Collins and Kuchma (1999), Yoshida (2000), ShanCao (2001), Sherwood (2008)). A total of 23 reinforced concrete beams without stirrups were constructed with an effective depth greater than $890 \mathrm{~mm}$. These tests have confirmed the existence of size effect, and shown that the ACI code was unable to safely predict their shear strengths. Sherwood et al. (2008) combined the results of Shimizu-Kajima tests and University of Toronto tests in Figure 2-8. It can be seen in the figure that the shear stress decreased as the effective depth increases. The inability of ACI Equation 113 (Equation (2-9)) to accurately and safely predict the shear strength of the largest members is clearly observed. 


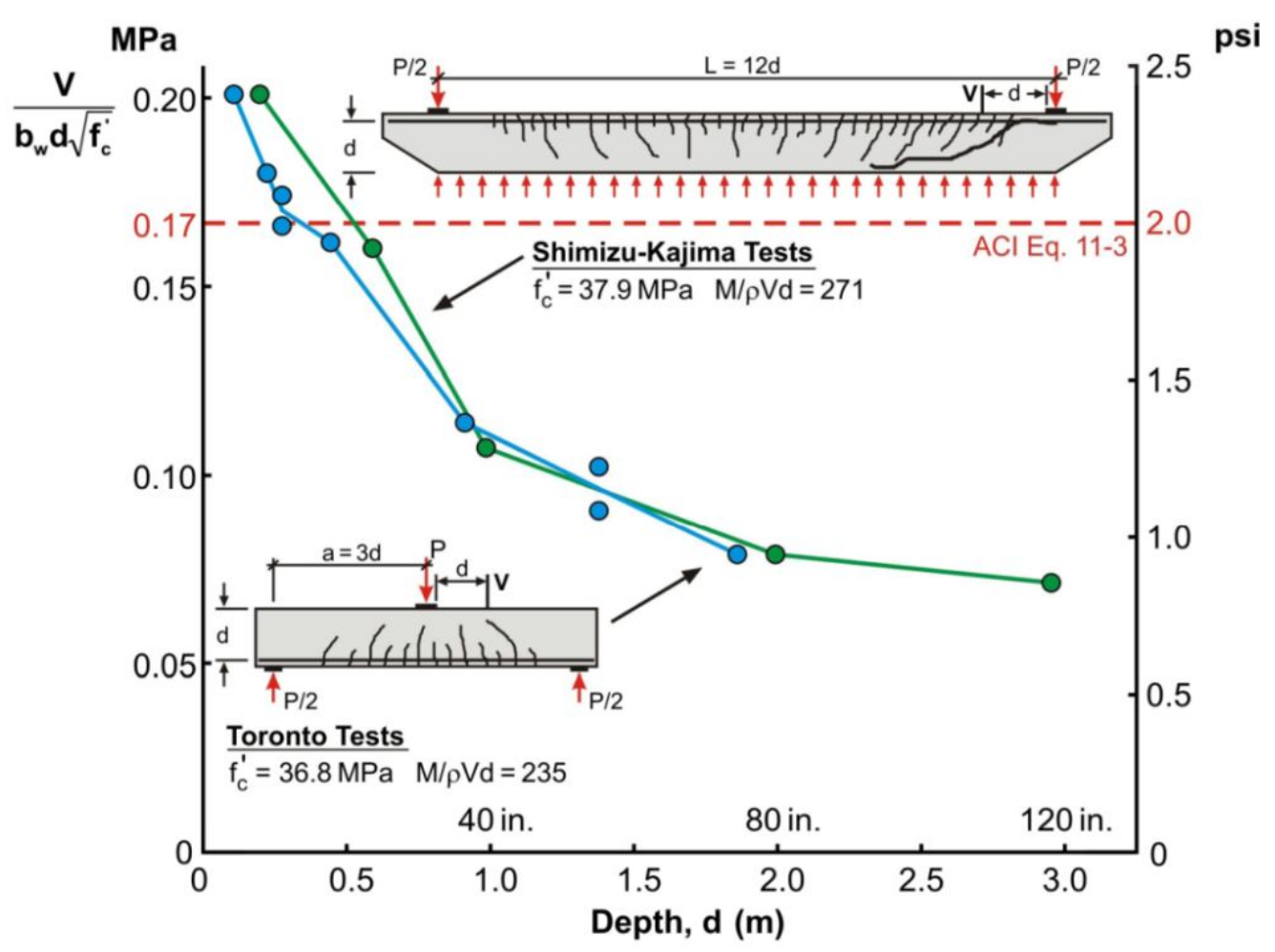

Figure 2-8: Shimizu-Kajima and University of Toronto tests (Sherwood et al. (2008))

\subsubsection{Shear Resistance in Reinforced Concrete with Stirrups}

The presence of stirrups provides an additional vertical force $\left(\mathrm{V}_{\mathrm{s}}\right)$ which contributes to the shear resistance besides the other basic shear mechanisms. In designing reinforced concrete beams with stirrups, it is common to assume that stirrups are yielding at the crack and that the stirrups do not prevent the formation of diagonal cracks, but rather become effective after the formation of the diagonal cracks. Figure 2-9 shows the shear resistance mechanisms in reinforced concrete with stirrups. 


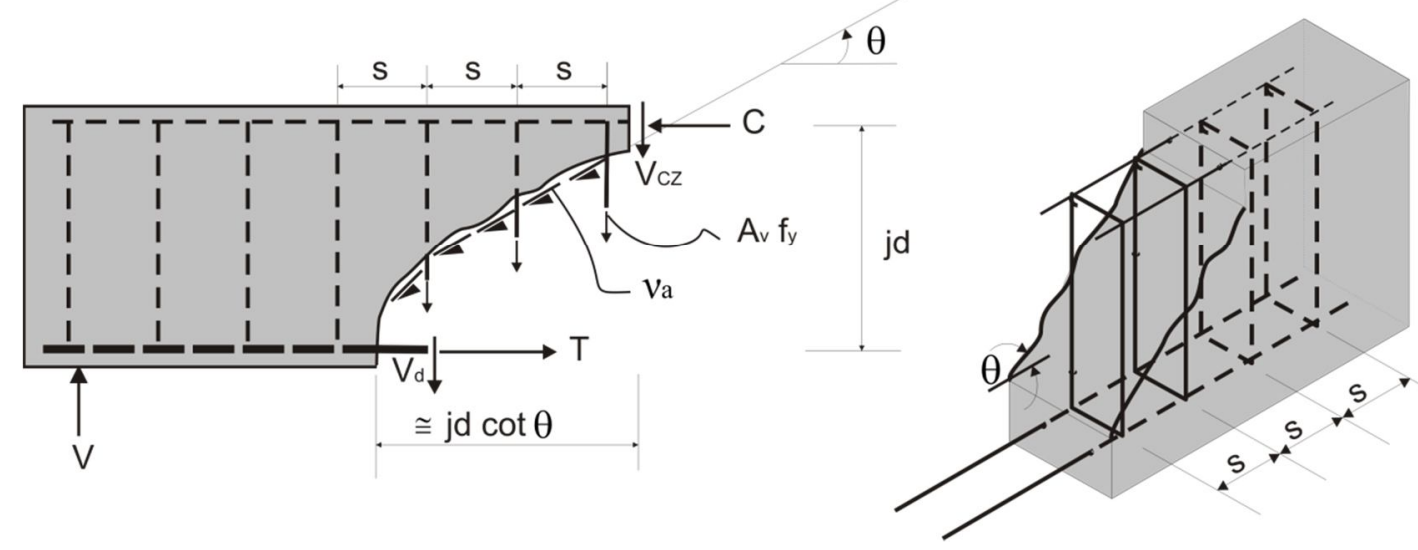

Figure 2-9: Mechanisms of Shear Transfer in Reinforced Concrete with Stirrups

\subsubsection{The ACI Shear Design Method}

The design provisions for shear in many concrete design codes, including the TMS 402 design code, originated from the $45^{\circ}$ truss model developed by Ritter 1899 and Mörsch 1909. In this model, it is assumed that shear cracks form at an angle of $45^{\circ}$ and that shear is transferred in the cracked section by a flow of forces that can be approximated as a truss model. The diagonal compressive stress in concrete struts act as the diagonal members of the truss while the stirrups act as the vertical tension members. The longitudinal tension reinforcement represents the bottom chord of the truss while the flexural compression zone of the beam acts as the top chord. Furthermore, the truss model assumes that only transverse reinforcement is effective at carrying shear, thereby predicting that a section without stirrups has no shear strength.

Considering Figure 2-9, the expression for the shear strength of a concrete section by this model can be explained as follows:

$\sum F_{y}=0 \rightarrow V-A_{v} f_{y} \frac{j d \cot \theta}{s}$ 
$\mathrm{V}=\frac{\mathrm{A}_{\mathrm{v}} \mathrm{f}_{\mathrm{y}}}{\mathrm{s}} \mathrm{jd} \cot \theta$

$v=\frac{V}{b_{w j d}}=\frac{A_{v} f_{y}}{b_{w S}} \cot \theta$

For the $45^{\circ}$ model, $\quad \cot \theta=1$, thus

$v=\frac{A_{v} f_{y}}{b_{w S}}$

Although Mörsch recognized that shear crack did not necessarily form at $45^{\circ}$, he could not derive a reasonable way to determine the actual inclination. The basic equation in that ACI code for shear strength of reinforced beams (Equation (2-12)) consists of two components: a concrete contribution $\left(\mathrm{V}_{\mathrm{c}}\right)$ and transverse reinforcement contribution $\left(\mathrm{V}_{\mathrm{s}}\right)$ predicted by the $45^{\circ}$ truss model.

$\mathrm{V}=\mathrm{V}_{\mathrm{c}}+\mathrm{V}_{\mathrm{s}}$

The concrete contribution to shear resistance $\left(V_{c}\right)$ was first set at an empirically safe derived working stress of $\mathrm{V}_{\mathrm{d}} \mathrm{b}_{\mathrm{w}} \mathrm{d}=\mathrm{v}_{\mathrm{c}}=0.03 \mathrm{f}_{\mathrm{c}}$. In 1962, ACI Committee 326 (1962) suggested the use of Equation (2-10). This equation was derived based on a curve-fit through 194 experimental data points. This well-known expression (Equation 2-10) has remained unchanged since that time and is currently Equation (11-5) of the ACI 318 design code. The use of the term $\left(\mathrm{M} / \rho_{\mathrm{w}} \mathrm{Vd}\right)$ in Equation (2-10) can be considered as a major innovation, as the stress in the longitudinal flexural steel at shear failure is directly related to this parameter. Thus, as the stress, $\mathrm{f}_{\mathrm{s}}$, in the longitudinal flexural steel decreases, the shear stress at failure increases. 
Equation (2-10) can be further simplified to Equation (2-9) which gives a safe lower bound to the experimental database used to derive Equation (2-10). Equation (2-9) is currently Equation (113) of the ACI 318 design code, and it is being used more than Equation (2-10) due to its simplicity. Most of masonry design codes use equations similar to Equations (2-9) and (2-10) for shear design of reinforced masonry elements.

\subsubsection{CSA A23.3-04 General Method of Shear Design for Reinforced Concrete Beams}

The development of the CSA A23.3-2004 general shear design provisions can be considered as a significant breakthrough in the modelling of shear behaviour of reinforced concrete. Unlike most

of the shear design equations for reinforced concrete which are empirically derived from curve fits of experimental data, the General Method of shear design is based on a rational theory. This theory is known as the Modified Compression Field Theory (MCFT) (Vecchio and Collins (1986)). In the MCFT, it is assumed that crack width is the product of the crack spacing in the principal tensile direction, $\mathrm{s}_{\theta}$, and the principal tensile strain, $\varepsilon_{1}$ (see Figure 2-10). The principle stresses are related to the principle strains by a set of equilibrium, compatibility and stress-strain relationships. The term $s_{\theta}$ is a function of the ability of the reinforcement in the $\mathrm{x}$ and $\mathrm{z}-$ directions to control crack spacings in the $\mathrm{x}$ and $\mathrm{z}$-directions, respectively (Equation 10 in Figure $(2-10))$.

Shear stresses $\left(v_{\mathrm{ci}}\right)$ on the crack are resisted by aggregate interlock. Equation (2-13) predicts the aggregate interlock shear capacity at a crack, $\mathrm{v}_{\mathrm{ci}}$, and was developed based on the experimental data of Walraven (1981). Walraven found that wider cracks will be associated with lower the 
aggregate interlock. As such, any action that lead to increase the crack width in Equation (2-13) by either increasing the crack spacing, $s_{\theta}$, or the principal tensile strain, $\varepsilon_{1}$, will result in a reduced aggregate interlock capacity.

$$
\text { vci } \leq \frac{0.18 \sqrt{\mathrm{f}^{\prime} \mathrm{c}}}{\left(0.31+\frac{24 \mathrm{~s}_{\ominus} \varepsilon_{1}}{\mathrm{ag}+16}\right)} \quad(\mathrm{MPa}, \mathrm{mm})
$$

\begin{tabular}{|c|c|c|}
\hline $\begin{array}{l}\text { Equilibrium } \\
\text { Conditions }\end{array}$ & $\begin{array}{l}\text { Average Stresses } \\
\text { 1. } f_{\mathrm{x}}=\rho_{\mathrm{x}} f_{\mathrm{sx}}+f_{2}-v \cot \theta \\
\text { 2. } f_{\mathrm{z}}=\rho_{\rho_{2}} f_{\mathrm{z}}+f_{2}-v \tan \theta \\
\text { 3. } v=\left(f_{1}+f_{2}\right) /(\tan \theta+\cot \theta) \\
\text { Stresses at Cracks } \\
\text { 4. } f_{\text {sccr }}=\left(f_{\mathrm{x}}+v \cot \theta+v_{c i} \cot \theta\right) / \rho_{x} \\
\text { 5. } f_{\mathrm{scc}}=\left(f_{z}+v \tan \theta-v_{c i} \tan \theta\right) / \rho_{z}\end{array}$ & 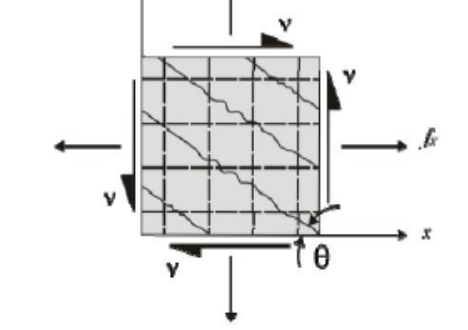 \\
\hline $\begin{array}{l}\text { Geometric } \\
\text { Conditions }\end{array}$ & $\begin{array}{l}\text { Average Strains } \\
\text { 6. } \tan ^{2} \theta=\frac{\left(\varepsilon_{\mathrm{x}}+\varepsilon_{2}\right)}{\left(\varepsilon_{\mathrm{z}}+\varepsilon_{2}\right)} \\
\text { 7. } \varepsilon_{1}=\varepsilon_{\mathrm{X}}+\varepsilon_{2}+\varepsilon_{2} \\
\text { 8. } \gamma_{\mathrm{z} z}=2\left(\varepsilon_{\mathrm{X}}+\varepsilon_{2}\right) \cot \theta \\
\text { Crack widths } \\
\text { 9. } w=s_{\theta} \varepsilon_{1} \\
\text { 10. } s_{\theta}=1 /\left(\frac{\sin \theta}{s_{z}}+\frac{\cos \theta}{s_{z}}\right)\end{array}$ & \\
\hline $\begin{array}{l}\text { Stress-Strain } \\
\text { Relationships }\end{array}$ & $\begin{array}{l}\text { Reinforcement } \\
\text { 11. } f_{\mathrm{sx}}=E_{\mathrm{s}} \varepsilon_{\mathrm{x}} \leq f_{\mathrm{yx}} \\
\text { 12. } f_{\mathrm{sx}}=E_{\mathrm{s}} \varepsilon_{2} \leq f_{\mathrm{yz}} \\
\text { Concrete } \\
\text { 13. } f_{2}=\frac{f^{\prime} c}{0.8+170 \varepsilon_{\mathrm{1}}}\left[2 \frac{\varepsilon_{2}}{\varepsilon_{\mathrm{c}}^{\prime}}-\left(\frac{\varepsilon_{2}}{\varepsilon_{\mathrm{c}}}\right)^{2}\right] \\
\text { 14. } f_{1}=0.33 \sqrt{f^{\prime} c} /\left(1+\sqrt{500 \varepsilon_{1}}\right) \mathrm{MPa} \\
\text { 15. } v_{\mathrm{ci}} \leq 0.18 \sqrt{f^{\prime} c} /\left(0.31+\frac{24 w}{a_{\mathrm{v}}+16}\right) \mathrm{MPa}, \mathrm{mm}\end{array}$ & 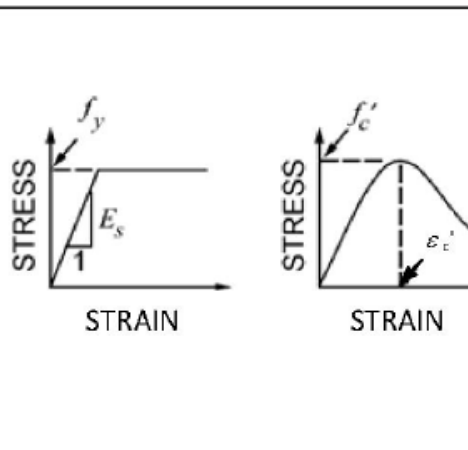 \\
\hline
\end{tabular}

Figure 2-10: Relationships of the Modified Compression Field Theory (Bentz et. al. (2006)) 
In Figure 2-11, the equilibrium conditions on average and at a crack are illustrated. For the area between the cracks, there is a tensile stress $f_{1}$ in the principal direction, with average stresses in the steel $\mathrm{f}_{\mathrm{sx}}$ and $\mathrm{f}_{\mathrm{sz}}$. At a crack, equilibrium necessitates that the stresses increase in the steel, and it may even require that a shear stress $\mathrm{v}_{\mathrm{ci}}$ act across the crack. If $\mathrm{v}_{\mathrm{ci}}$ exceeds the aggregate interlock capacity, failure will occur due to sliding on the crack, and this is often the case when the steel is yielding in one or both directions and in case the steel exists in one direction only.
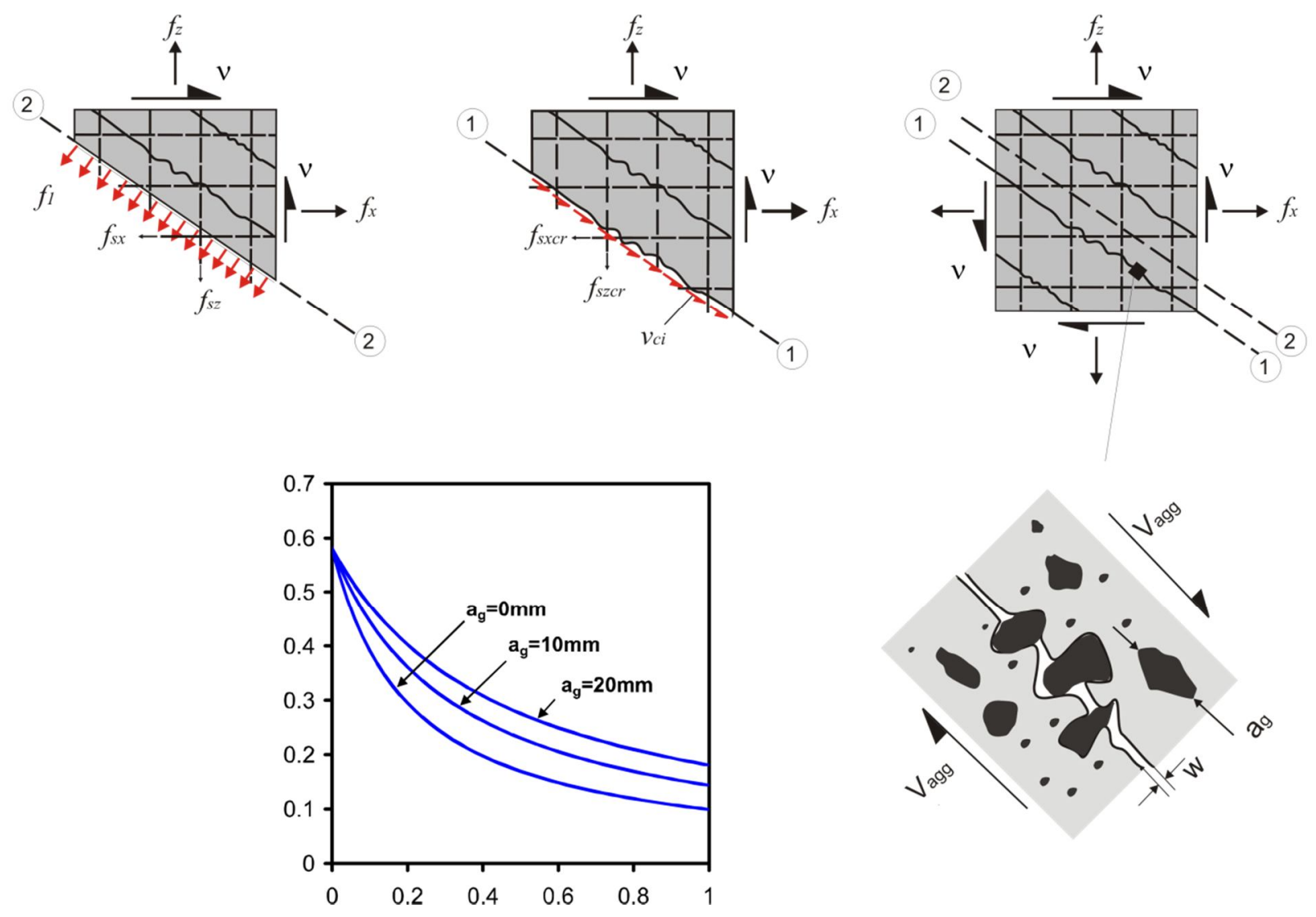

Figure 2-11: Equilibrium Conditions and $v_{\mathrm{ci}}$ Relationship of the MCFT

A full analysis using the MCFT to predict shear strength of a membrane element involves solving the 15 equations in Fig. 2-10. Collins and Mitchell (1991) simplified the MCFT and it was first implemented in the 1994 version of the CSA A23.3 concrete design code. Similar shear 
provisions to the CSA 1994 general method were also adopted by Ontario and Canadian Highway Bridge Design codes (OHBDC (1993), CHBDC (2000)) and the US AASHTO-LRFD Bridge Design Specifications (AASHTO 1994). Despite the advantages of the CSA 1994 general method, there remained difficulties with its practical use by designers. The 2004 CSA A23.3 general shear design method was derived from the Simplified Modified Compression Field Theory (Bentz et. al. (2006)) which is a simplification of the Modified Compression Field Theory aimed at simplifying the day-to-day use of the general method.

The basic equation in the 2004 CSA A23.3 general shear design method to calculate shear strength of reinforced concrete beams is as follows:

$$
V_{c}=\beta \sqrt{f^{\prime} c} b_{w} d_{v}+\frac{A_{v} f_{y}}{s} d_{v} \cot \theta
$$

In deriving the CSA A23.3 shear design equations for slender beams, the rational assumption was made that the majority of the shear in a concrete section without web reinforcement is transferred by interlocking of aggregate particles at cracks below the neutral axis. This assumption has been confirmed by a number of studies on slender beams (Fenwick and Pauley (1968), Taylor (1970), Kani et. al. (1979), Sherwood et. al. (2007), Sherwood (2008)), and it follows from this assumption that aggregate interlock capacity governs the shear strength of slender members. This is accounted for by the $\beta$ term in Eq. (2-14) and Eq. (2-15).

$$
\mathrm{V}_{\mathrm{c}}=\beta \sqrt{\mathrm{f}_{\mathrm{c}}} \mathrm{b}_{\mathrm{w}} \mathrm{d}_{\mathrm{v}}
$$


The term $\beta$ describes the ability of cracked concrete to resist shear stresses by aggregate interlock, in that low values of $\beta$ refers to low aggregate interlock capacity. Action that serves to reduce aggregate interlock capacity will decrease shear strength. These actions that result in decreasing beam shear strength can include: a) axial tension, b) decreasing the reinforcement ratio, c) increasing the ratio of moment to shear at the section or d) the use of lower stiffness reinforcement (such as FRP) as each of these lead to wider cracks. Similarly, prestressing and axial compression will lead to narrower cracks, higher aggregate interlock capacity and enhanced shear strengths. These actions are collectively termed the "strain effect" as each affects the longitudinal strain at the section.

The failure shear stress of beams without stirrups can also be reduced due to increasing the effective depth, d. This reduction in failure shear stress with increasing depth can be attributed to the fact that the longitudinal spacing of cracks at the RC beam mid-depth is usually constant at $0.5 \mathrm{~d}$, regardless of the beam depth. As the depth is increased, the spacing increases as well. This in turn will cause crack width to increase. These wider cracks precipitate shear failure at a lower shear stress due to reduced aggregate interlock capacity. The use of distributed layers of longitudinal steel in the beam web as crack control reinforcement can result in more closely spaced, and thus narrower, cracks. Test results by Sherwood (2008) have shown that beams with sufficient quantity of crack control reinforcement had higher shear strength, and this increase can be accounted for by the CSA A23.3 code. Furthermore, Sherwood et al. (2007) have shown that beam shear strength is directly related to aggregate size. Reducing the maximum aggregate size will lead to lower shear strengths as the cracks become smoother and less shear stresses can be transferred through aggregate interlock. 
All of these effects are combined and accounted for through the use of the $\beta$ term in Eq. (2-16). The term $\beta$ is calculated by an expression consisting of a strain effect term and a size effect term:

$\beta=\frac{0.4}{\left(1+1500 \varepsilon_{\mathrm{x}}\right)} \cdot \frac{1300}{\left(1000+\mathrm{sxe}_{\mathrm{xe}}\right)}=($ Strain effect term $) \cdot($ Size effect term $)$

The longitudinal strain at the mid-depth of a beam web, $\varepsilon_{x}$, is conservatively assumed to be equal to one-half the strain in the longitudinal tensile reinforcing steel (see Figure 2-12). The full expression for calculating $\varepsilon_{\mathrm{x}}$ is as follows:

$\varepsilon_{x}=\frac{M_{f} / d_{v}+V_{f}-V_{p}+0.5 N_{f}-A_{p} f_{p o}}{2\left(E_{s} A_{s}+E_{p} A_{p}\right)}$

Where:-

$\mathrm{M}_{\mathrm{f}}=$ factored applied moment,

$\mathrm{V}_{\mathrm{f}}=$ factored applied shear,

$\mathrm{d}_{\mathrm{v}}=$ flexural lever arm (equal to $0.9 \mathrm{~d}$ or $0.72 \mathrm{~h}$, whichever is greater, where $\mathrm{h}$ is the beam height), $\mathrm{V}_{\mathrm{f}}=$ factored applied shear, $\mathrm{V}_{\mathrm{p}}=$ vertical component of effective prestressing force, $\mathrm{N}_{\mathrm{f}}=$ factored applied axial load (tension positive), $f_{p o}=$ stress in prestressing tendon when strain in surrounding concrete is zero, $E_{s}, E_{p}=$ elastic modulus of non-prestressed and prestressed reinforcement, respectively $A_{s}, A_{p}=$ area of non-prestressed and prestressed tension zone reinforcement, respectively.

For sections that are not prestressed or subjected to axial loads, $\varepsilon_{\mathrm{x}}$ is calculated as: 
$\varepsilon_{\mathrm{x}}=\frac{\mathrm{Mf}_{\mathrm{f}} / \mathrm{d}_{\mathrm{v}}+\mathrm{V}_{\mathrm{f}}}{2 \mathrm{E}_{\mathrm{s}} \mathrm{As}_{\mathrm{s}}}$
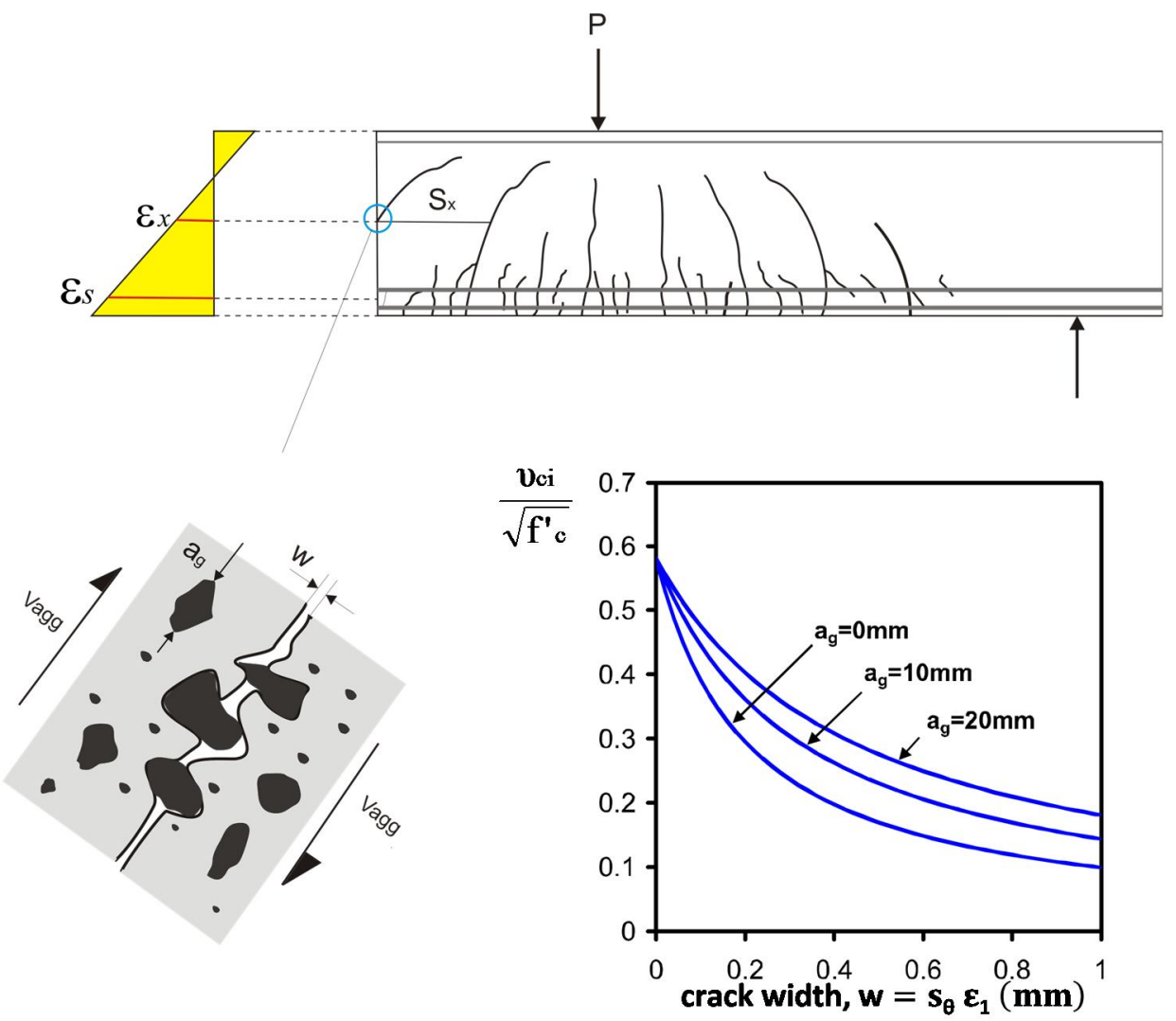

Figure 2-12: Aggregate Interlock Mechanism

The crack spacing parameter, $\mathrm{s}_{\mathrm{x}}\left(\mathrm{s}_{\mathrm{z}}\right)$, accounts for the effect of the crack spacing at the beam middepth. This parameter is equal to the flexural lever arm $d_{v}\left(d_{v}=0.9 d\right.$ or $0.72 h$, whichever is greater) or the maximum distance between layers of longitudinal steel distributed along the height of the web, whichever is less. Each layer of such reinforcement shall have an area at least equal to $0.003 b_{w} s_{z}$ (see Figure 2-13). The effect of the maximum coarse aggregate size $\left(a_{g}\right)$ is included in the size effect term through the equivalent crack spacing factor term, $\mathrm{s}_{\mathrm{xe}}$ :

$\mathrm{Sxe}=\frac{35 \mathrm{sx}}{15+\mathrm{ag}} \geq 0.85 \mathrm{Sx}$ 
For sections containing at least the minimum transverse reinforcement of $0.006 \sqrt{f^{\prime} c} \frac{b_{w} s}{f_{y}}$, the equivalent crack spacing factor $\mathrm{s}_{\mathrm{xe}},\left(\mathrm{s}_{\mathrm{ze}}\right)$ is taken as equal to $300 \mathrm{~mm}$ (see Figure 2-13).
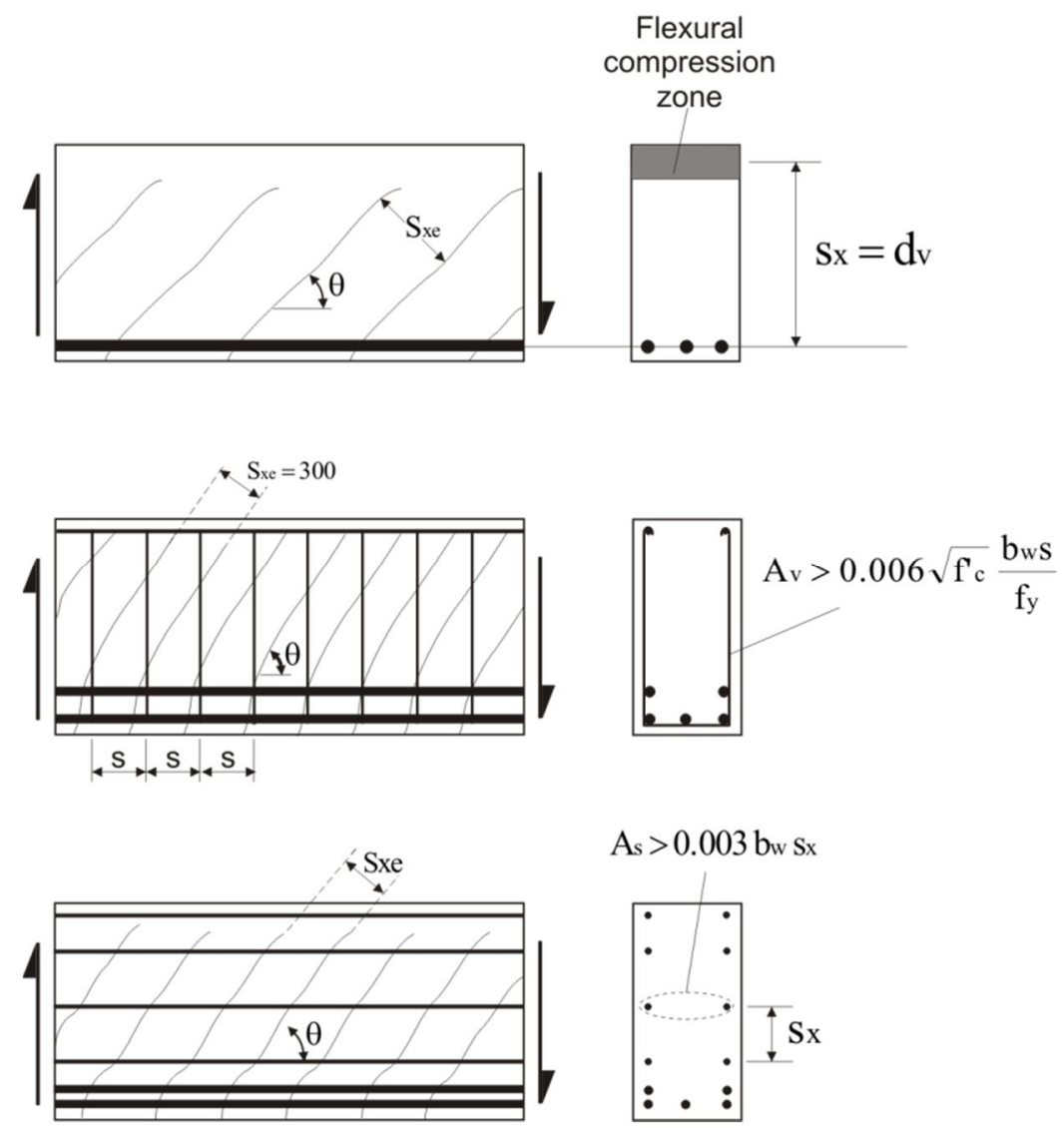

Figure 2-13: Definition of the Crack Spacing Parameter, $s_{x}$ in in the CSA A23.3 General Method (Collins and Mitchell (1997))

To calculate the experimental shear strength of beams using the general method, Equations (215) through (2-18) must be solved by a quadratic equation or using an iterative approach by hand or in a single line of a spreadsheet. Figure 2-14 shows a flow chart for the iterative process. For typical simply-supported point-loaded beams, such as those used in current experimental programs, the critical section can be taken at a distance $d$ away from the applied load (location of 
maximum moment). This allows the effect of the moment on crack widths to be rationally taken into account, and lead to more accurate shear strength predictions.

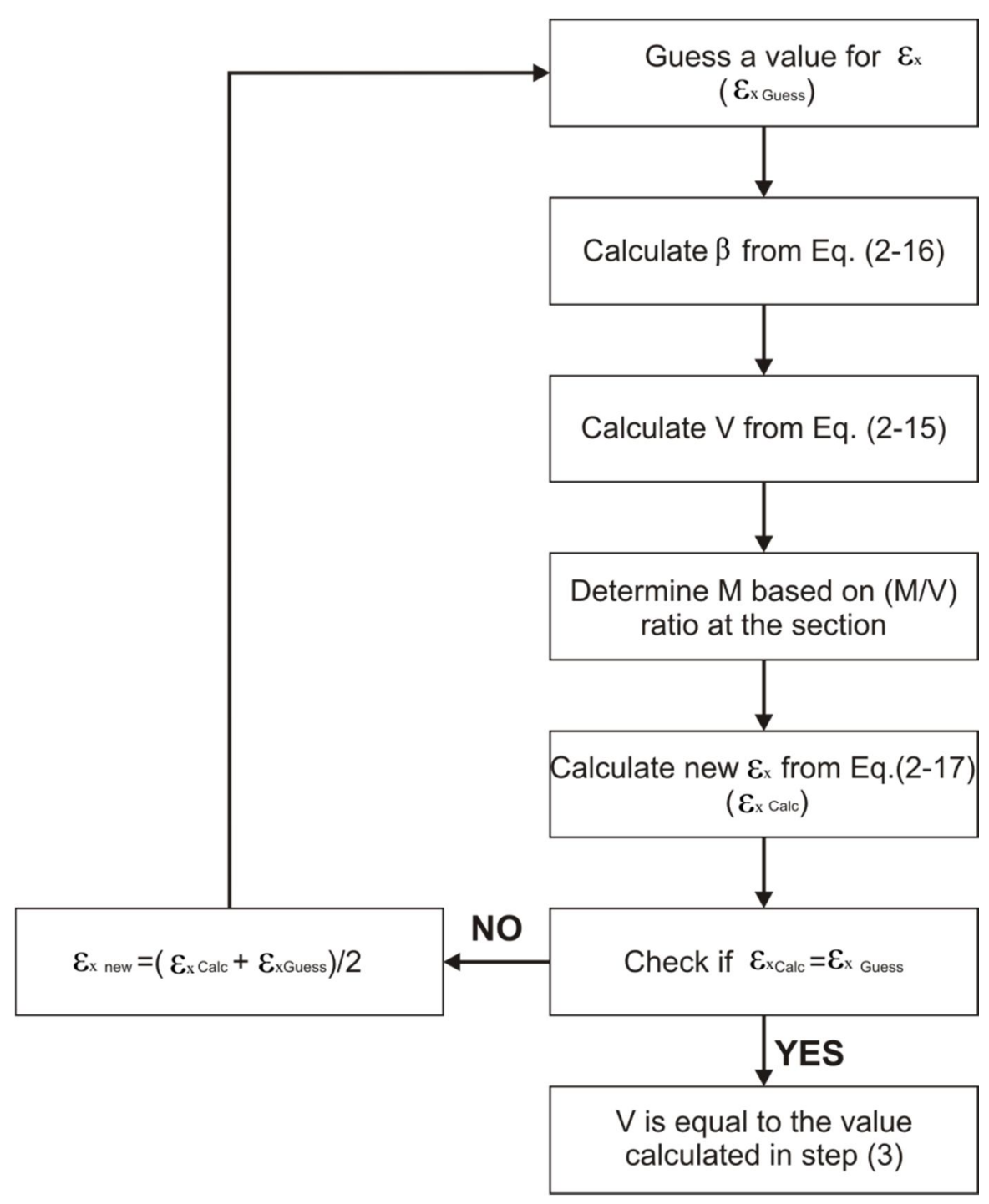

Figure 2-14: Flow Chart for the Iterative Analysis Process in the CSA A23.3-04 General Method

It is worth mentioning that Equation (2-16) was optimized for the magnitudes of longitudinal strains exhibited by concrete reinforced with conventional 400MPa steel. Members reinforced with low-reinforcement ratios of high-strength and steel members reinforced with FRP rebars 
will also exhibit large longitudinal strains. In these cases Equation (2-16) will conservatively predict the shear strengths. Hoult et al (2008) proposed a more accurate version of Equation (219) specifically intended for members with high-strains (reinforced with very low reinforcement ratios or with low stiffness reinforcement). The equation is as follows:

$\beta=\frac{0.3}{(0.15+1000 \varepsilon x)^{0.7}} \cdot \frac{1300}{(1000+\text { Sxe })}$

This equation can be used as a direct substitute for Equation (2-16). It yields slightly more accurate shear strength predictions of normally-reinforced beams, and considerably more accurate predictions for beams reinforced with FRP-reinforced or with very low reinforcement ratios. 


\subsection{Shear Behaviour of Reinforced Concrete Masonry Beams}

This section presents a review of previous studies conducted on the shear behaviour of RCM beams. Experimental research efforts on the shear behaviour of RCM beams have been somewhat limited, and are far less numerous that for reinforced concrete. Only a few experimental investigations have been reported in the literature. In this section, these studies will be critically reviewed. Also, the configurations of the tested beams with their reinforcement details are presented and discussed.

\subsubsection{Suter and Keller}

Suter and Keller $(1980,1984)$ conducted an extensive experimental investigation to study the ultimate shear strength of reinforced masonry beams. The investigation was carried out over many years and comprised over 70 reinforced masonry beams, 36 of which were slender beams $(\mathrm{a} / \mathrm{d}>2.5)$ with rest considered as deep beams $(\mathrm{a} / \mathrm{d}<2.5)$ (see Figure $2-15$ and $2-16)$. Only the results of the slender beams will be referenced in this chapter. The experimental investigation studied the effect of number of key parameters on shear capacity of masonry. The studied parameters were shear span to depth ratio $(\mathrm{a} / \mathrm{d})$, flexural reinforcement ratio $(\rho)$, type of fill (grout fill versus mortar fill), joint spacing, beam coursing (single course versus two course), and effective depth.

Suter and Keller's test results showed that reinforced masonry beams exhibit many similarities in behaviour. It can be seen from Figure 2-17 that increasing shear span to depth ratio (a/d) results in reduction of shear strength. This reduction is more pronounced in two-course beams (Series CU162-164 and Series CU167-169). Figure 2-17 can also be used to demonstrate the effect of 
beam coursing on shear strength. For example, beams of series CU140-142 and series CU162-

164 are identical except for the fact that CU140-142 beams were built in single course while

CU162-164 were two course beams. It can be seen that the average shear failure lines are parallel and the two course masonry beams have shear capacities comparable to single course beams.

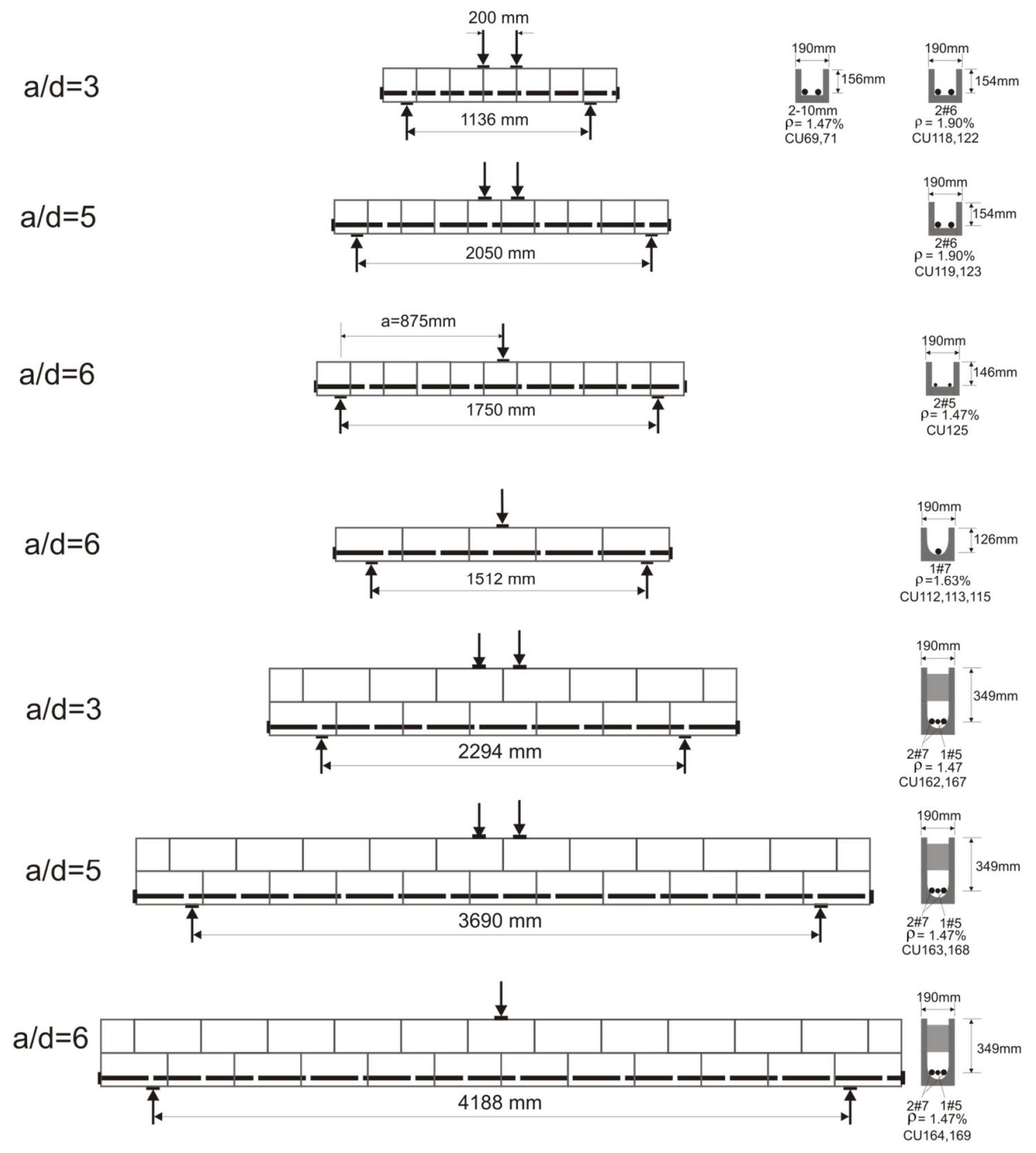

Figure 2-15: Reinforced Masonry Beams Tested by Suter and Keller (Stretcher Units) 


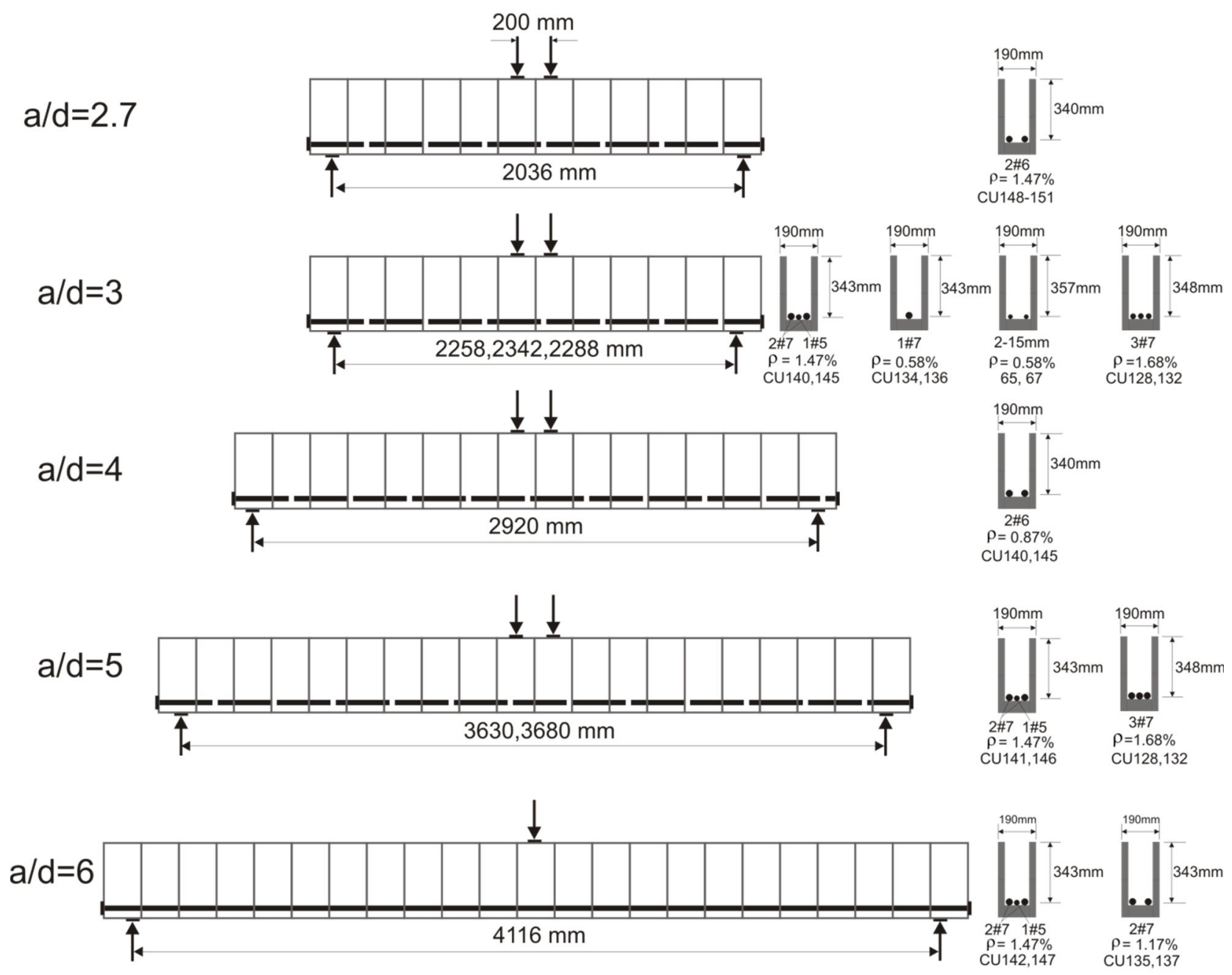

Figure 2-16: Reinforced Masonry Beams Tested by Suter and Keller (Solider Unit Series)

The test results also showed that at $\mathrm{a} / \mathrm{d}=3$, a three-fold increase in $\rho$ resulted in an increase in shear strength of about $42 \%$ in masonry beams (see Figure 2-18). Suter and Keller found that this range of increase in shear strength of concrete masonry beams lie between that of reinforced concrete beams and reinforced brick beams. 


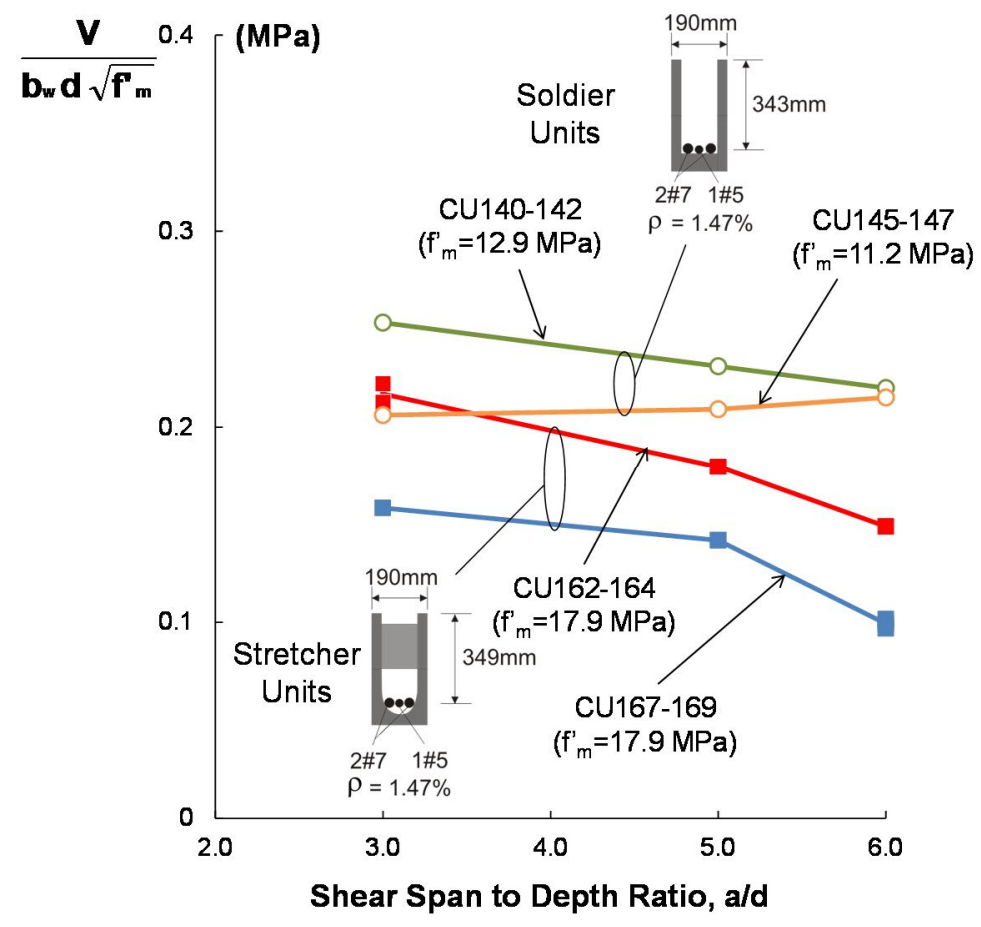

Figure 2-17: Effect of a/d on Shear Strength of RCM Beams (Suter and Keller 1980, 1984)

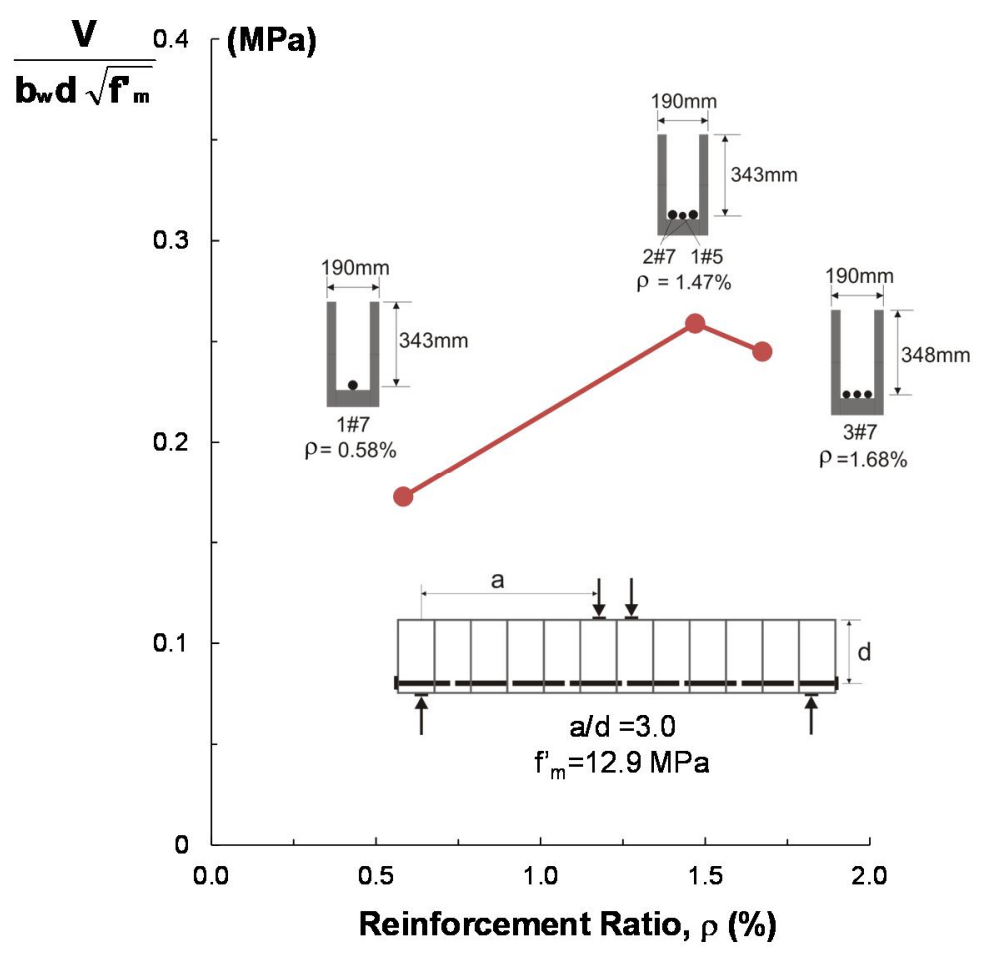

Figure 2-18: Effect of ( $\rho)$ on Shear Strength of RCM Beams (Suter and Keller $(1980,1984))$ 
Suter and Keller investigated the influence of effective depth on shear capacity of reinforced masonry beams. Figure 2-19 shows that the shallow beams obtained higher shear strength than the deeper beams. Doubling the beam depth resulted in an average decrease in failure shear stress of $46 \%$. Suter and Keller noted that this reduction is significantly greater than that for reinforced concrete beams. As Suter and Keller's tests were conducted on one or two course beams only, it is important to study the size effect on larger beams (more than two-course beams) such those discussed in Chapter 1 (Figures (1-5) through (1-7)).

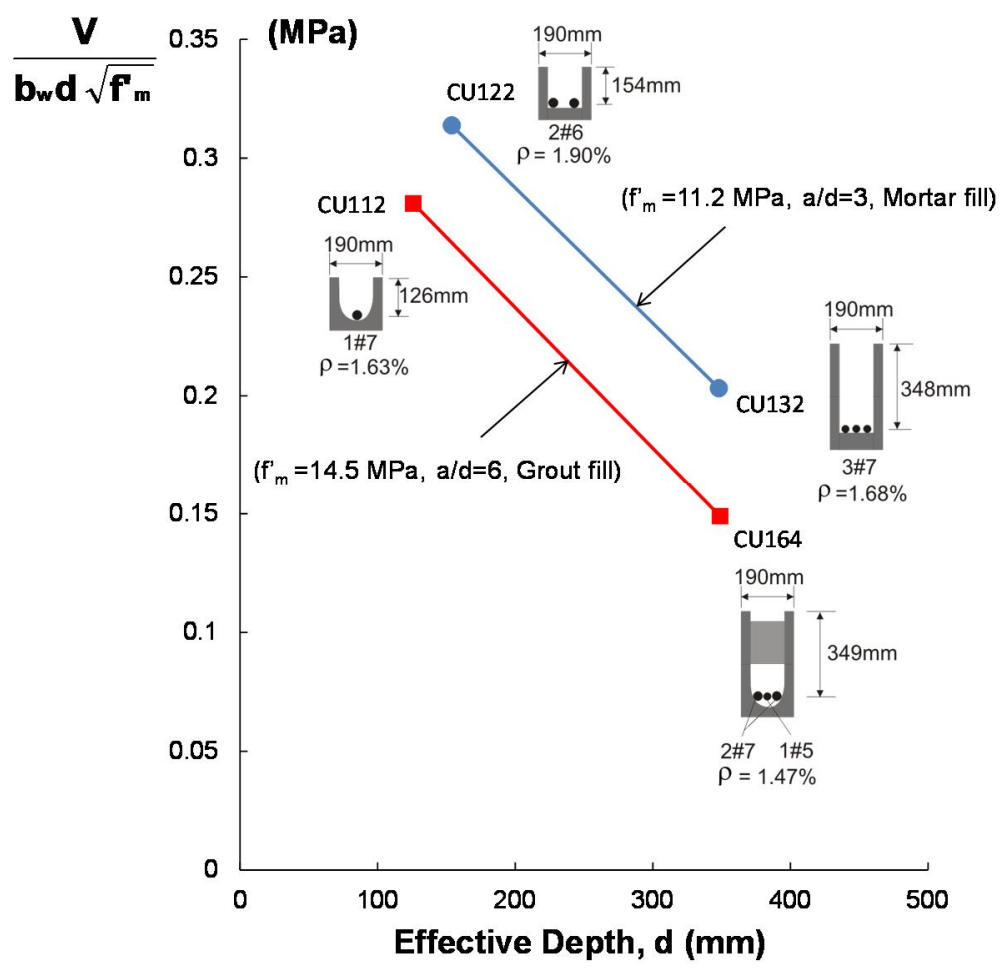

Figure 2-19: Effect of Effective Depth on Shear Strength of RCM Beams (Suter and Keller(1980,1984))

Figure 2-20 shows the shear strengths of four sets of beams (CU140-142, CU145-147, CU162164, and CU167-169). Each set comprises three beams. CU140-142 and CU145-147 series were built in single course in which CU140-142 beams were built with coarse grout while 
CU145-147 beams were built with mortar. On the other hand, CU162-164 and CU167-169 were built in two courses, CU162-164 with grout fill and CU167-169 with mortar. It can be seen that the beams with grout fill have higher strength than those built with mortar fill. The effect of type of fill was more significant in two course beams. Suter and Keller related the increase in shear strength of grout-filled beams compared to the mortar-filled ones to the increase in the compressive strength of grout to that of the mortar. They did not consider the fact the grout has a larger aggregate size than mortar which leads to having higher aggregate interlock and higher shear strength.

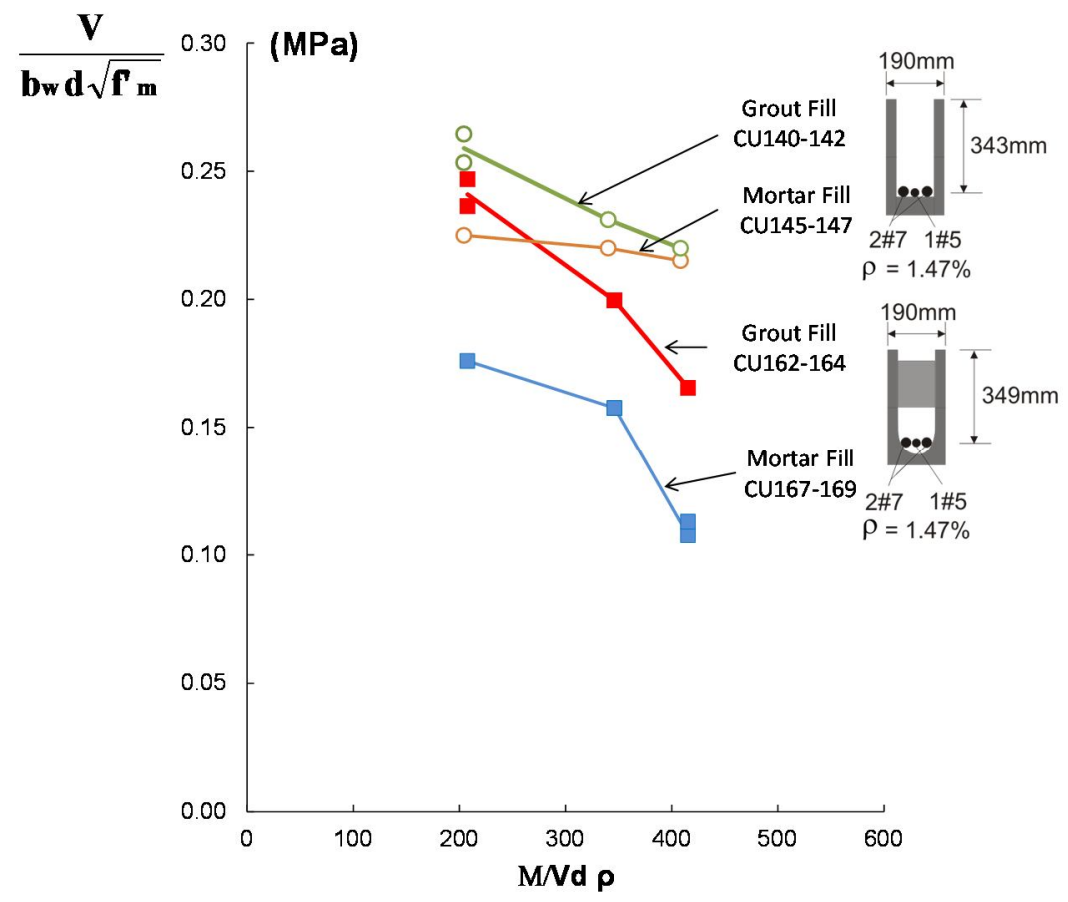

Figure 2-20: Effect of Grout Type on Shear Strength of RCM Beams (Suter and Keller $(1980,1984))$

\subsubsection{Li et al.}

Li et al. (1994) reported on research carried out at the British Cement Association. The program included 38 specimens (of which twenty four beams had an a/d ratio greater than 2.5) tested to failure using a two point loading system. The configuration and the details of the tested beams 
are shown in Figures 2-21 and 2-22. Single, double and soldier course beam were used to investigate the effect of the amount of tension reinforcement, masonry compressive strength and $\mathrm{a} / \mathrm{d}$ ratio on the shear strength of these beams. The beams were tested on simple supports and the load was applied through two points set $900 \mathrm{~mm}$ apart in the centre of the beam.

$$
\mathrm{a} / \mathrm{d}=2.5
$$

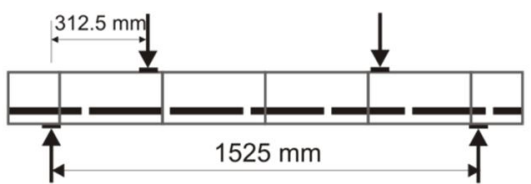

$\mathrm{a} / \mathrm{d}=3.5$

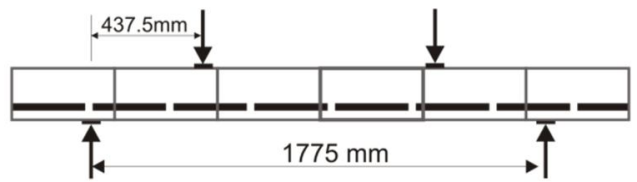

$\mathrm{a} / \mathrm{d}=4.5$

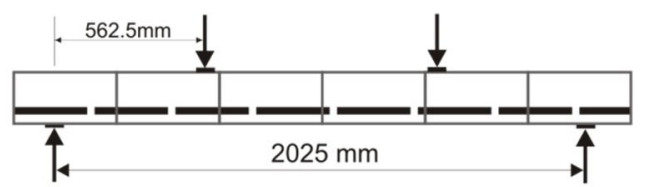

$\mathrm{a} / \mathrm{d}=5.5$

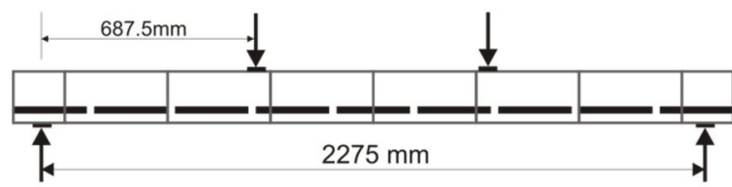

$\mathrm{a} / \mathrm{d}=2.5$
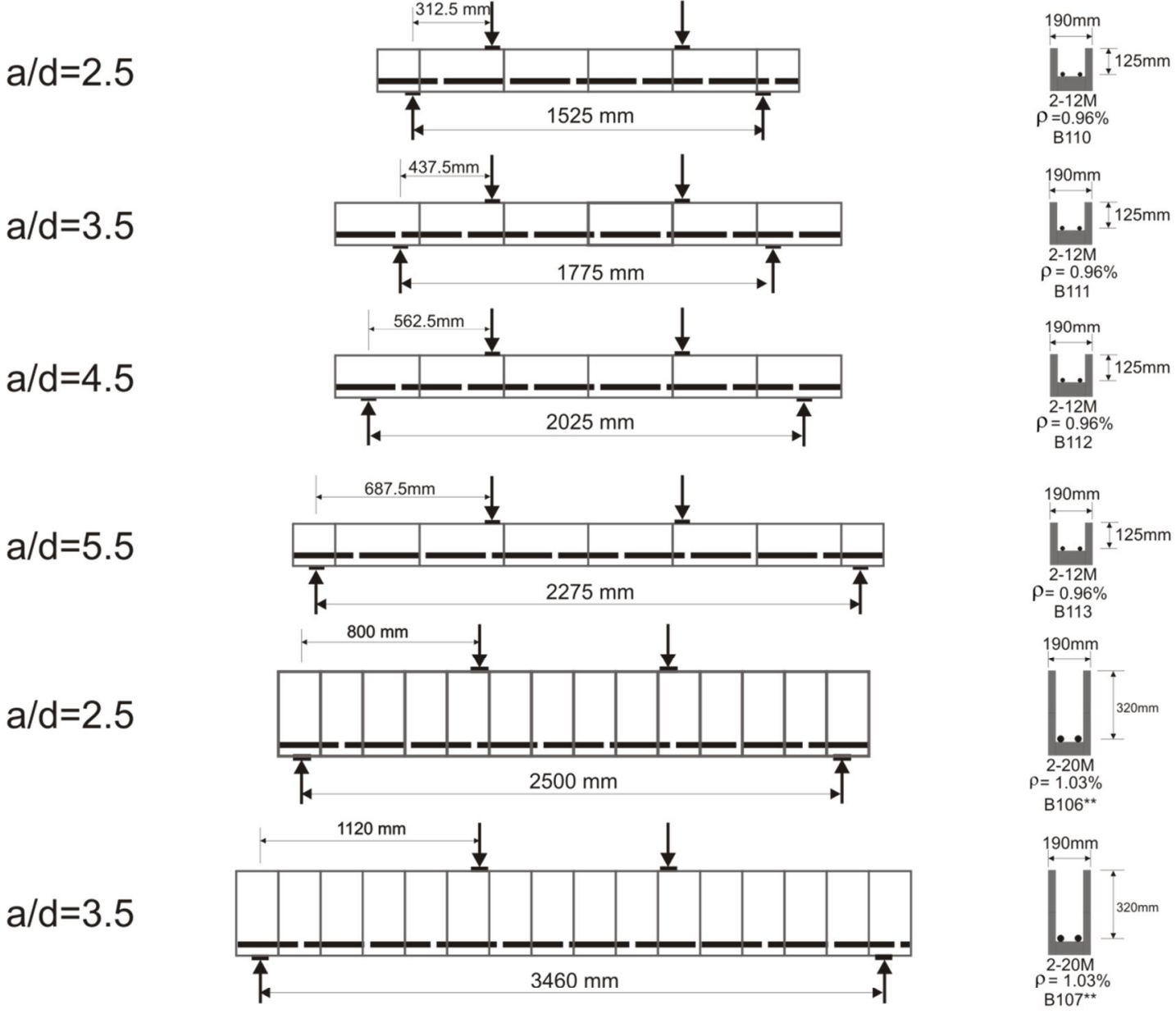

$\mathrm{a} / \mathrm{d}=2.5$

$\mathrm{a} / \mathrm{d}=3.5$
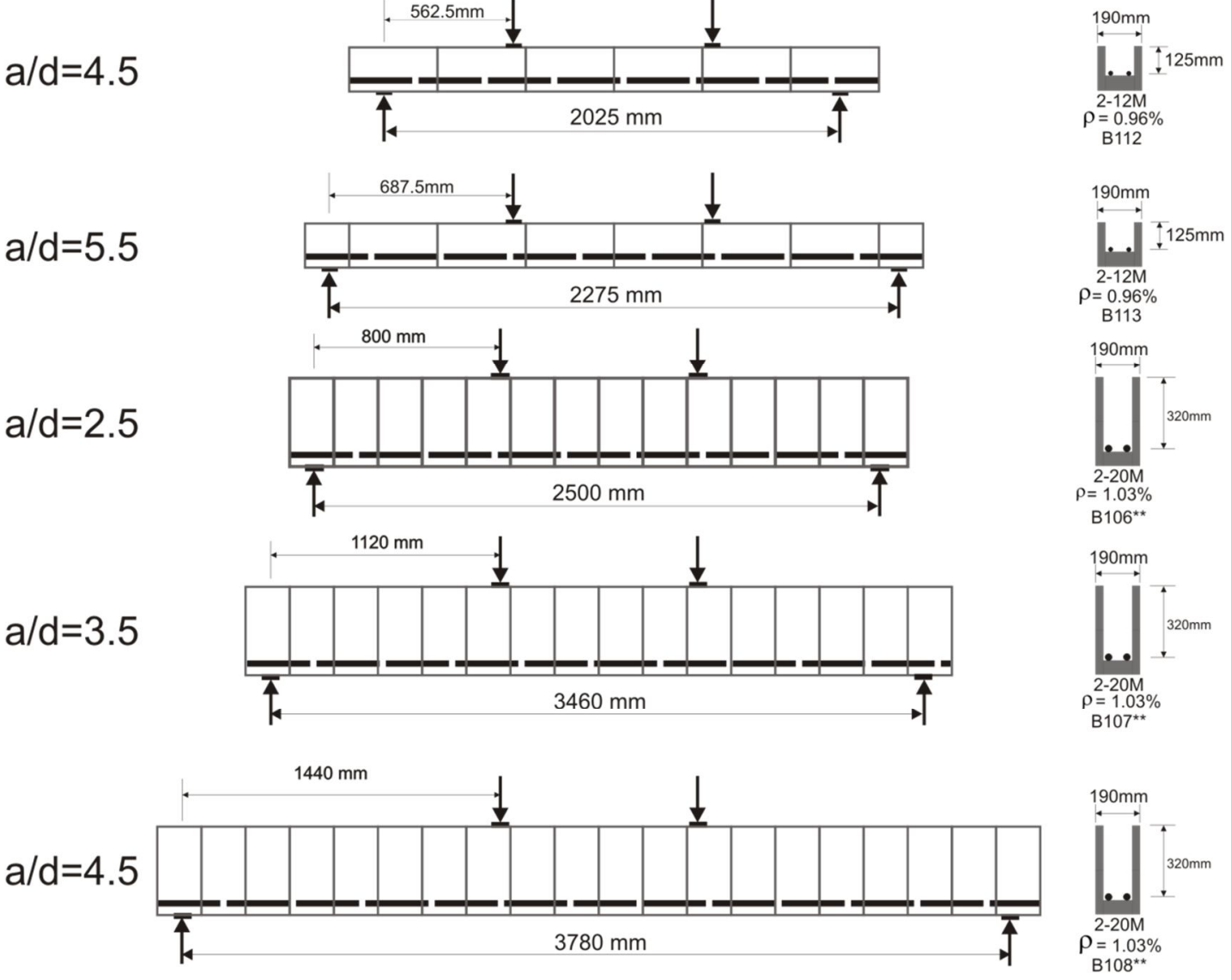

**Made out of high strength block

Figure 2-21: Reinforced Masonry Beams Tested by Li et al. (One Course Series) 


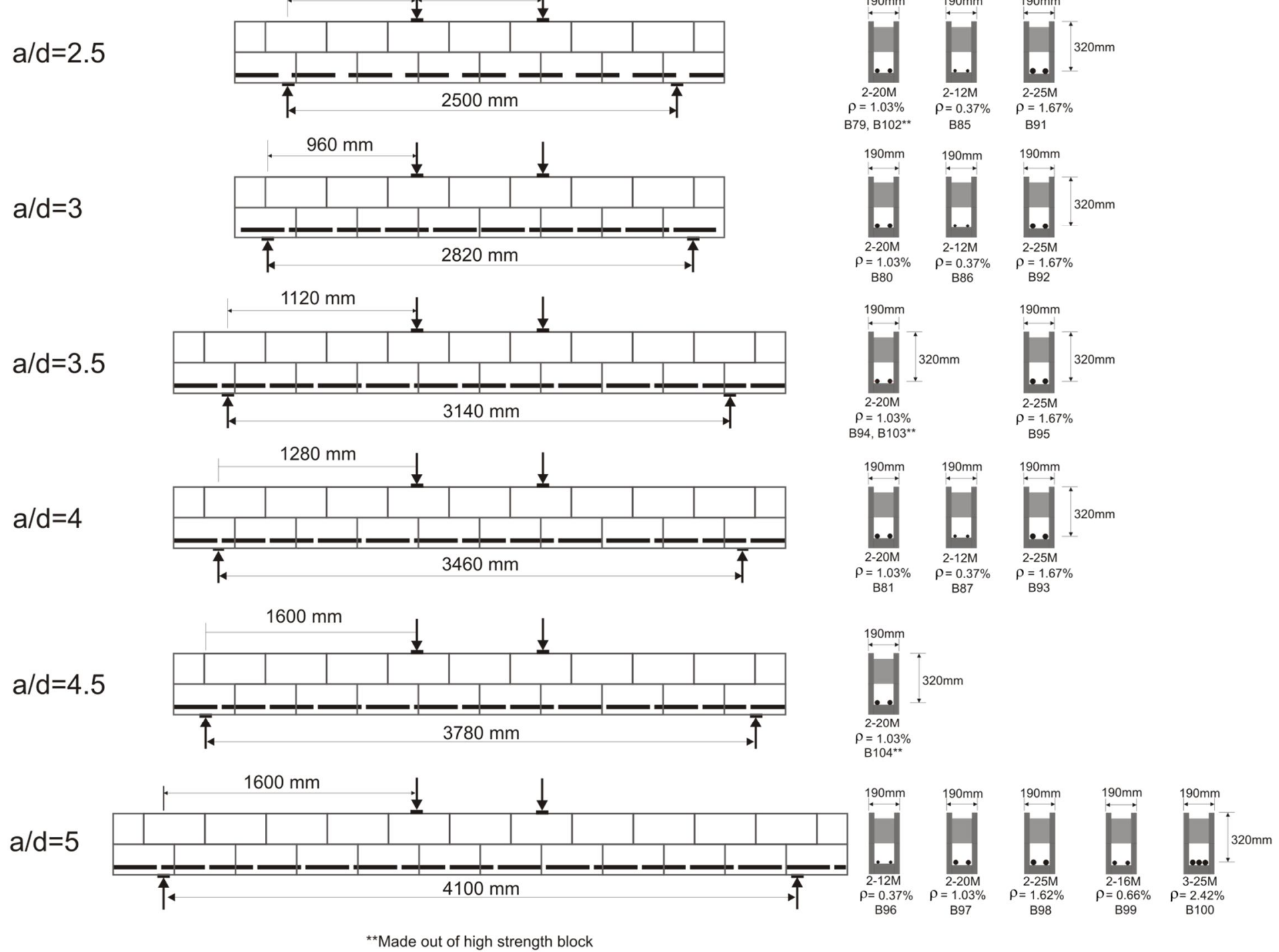

Figure 2-22: Reinforced Masonry Beams Tested by Li et al. (Two-Course Series) 
The effect of a/d on shear strength was more influential in the tests of Li et al. than those of Suter and Keller. Figure 2-23 shows that the results indicated a significant decrease in ultimate shear stress occurred with increasing a/d in the range of 3 to 6 .

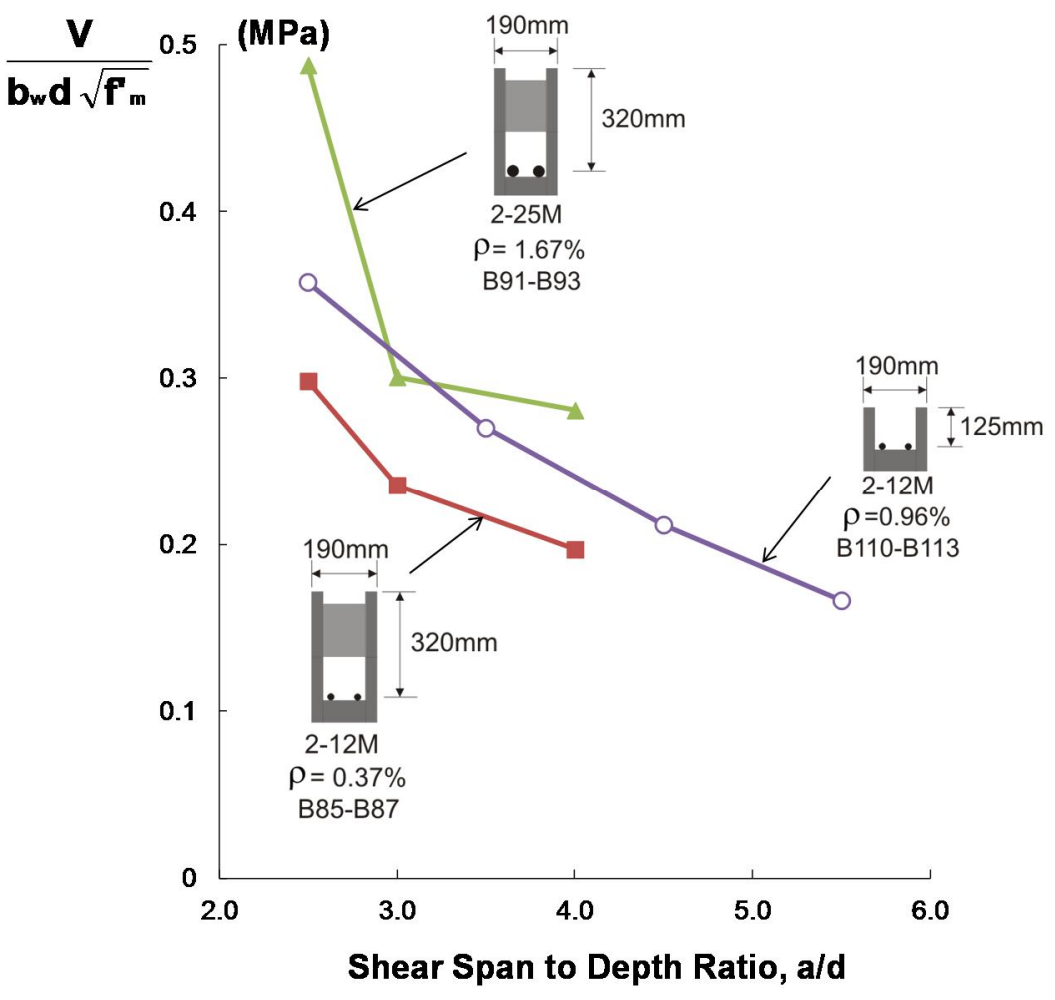

Figure 2-23: Effect of a/d on Shear Strength of RCM Beams (Li et al. (1994))

Figure 2-24 shows the normalized shear strength of masonry beams with different flexural reinforcement ratios. Increasing the reinforcement ratio from 0.37 to 1.67 led to an increase of about $65 \%$ in ultimate shear strength, with the increase being higher for beams with shear/span to depth ratio of 2.5. It can be also seen that increasing the reinforcement ratio beyond the ratio of $1.67 \%$ to $2.24 \%$ had only a marginal effect on shear strength. 


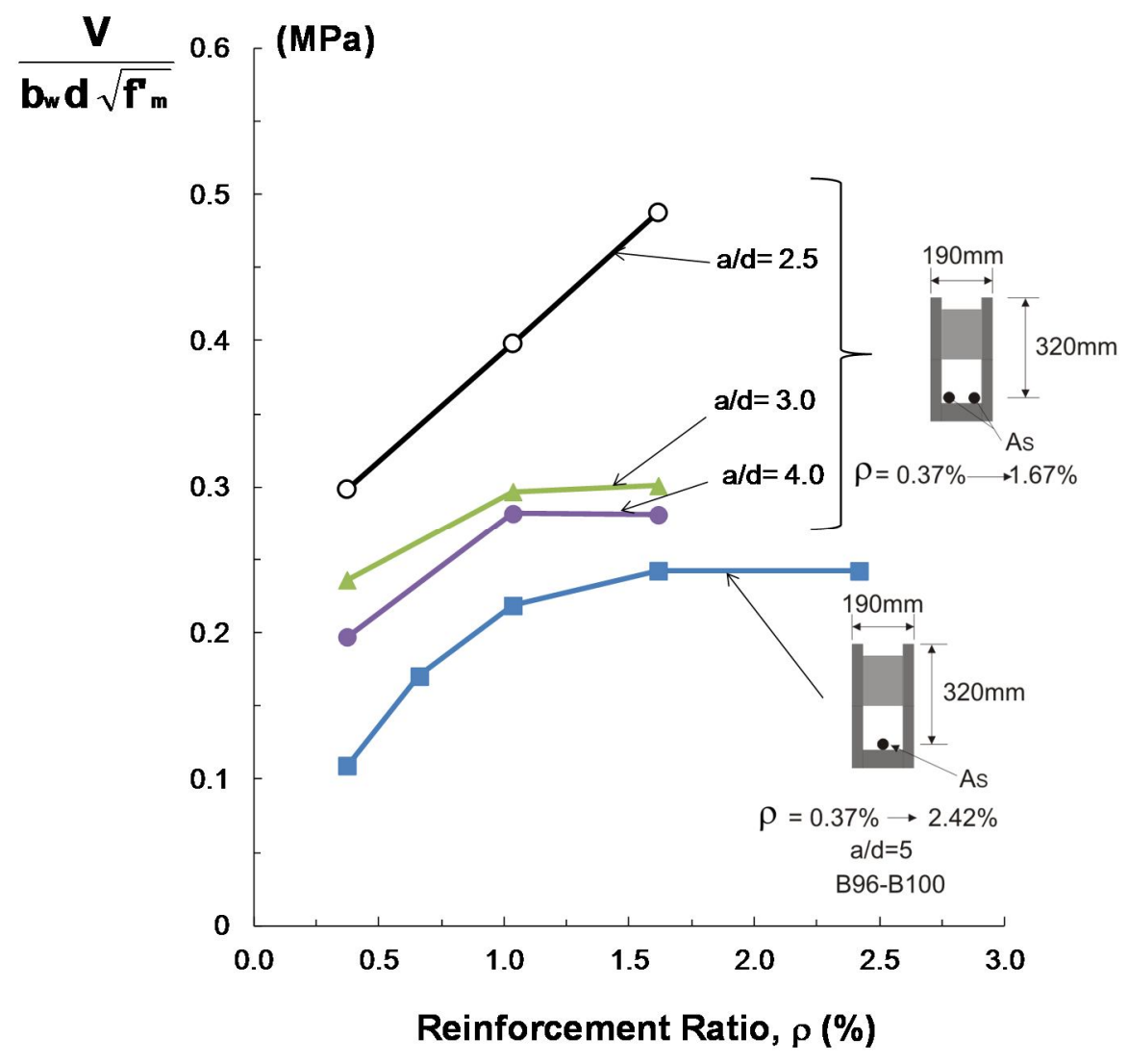

Figure 2-24: Effect of Flexural Reinforcement Ratio on Shear Strength of RCM Beams (Li et al. (1994))

Li et al. investigated the effect masonry compressive strength on shear strength of masonry beams through varying the block, mortar and grout strength. They did not determine $\mathrm{f}_{\mathrm{m}}$ by conducting prism tests, but rather individual compressive tests on unit, mortar samples and grout samples. It can be seen from Figure 2-25 that the increase in masonry compressive strength had only a moderate effect on shear strength of masonry beams. It is worth mentioning that the masonry compressive strengths of these beams were estimated based on Khalaf et al.'s equation (1994) which will be discussed later in Chapter 5 of this thesis. 


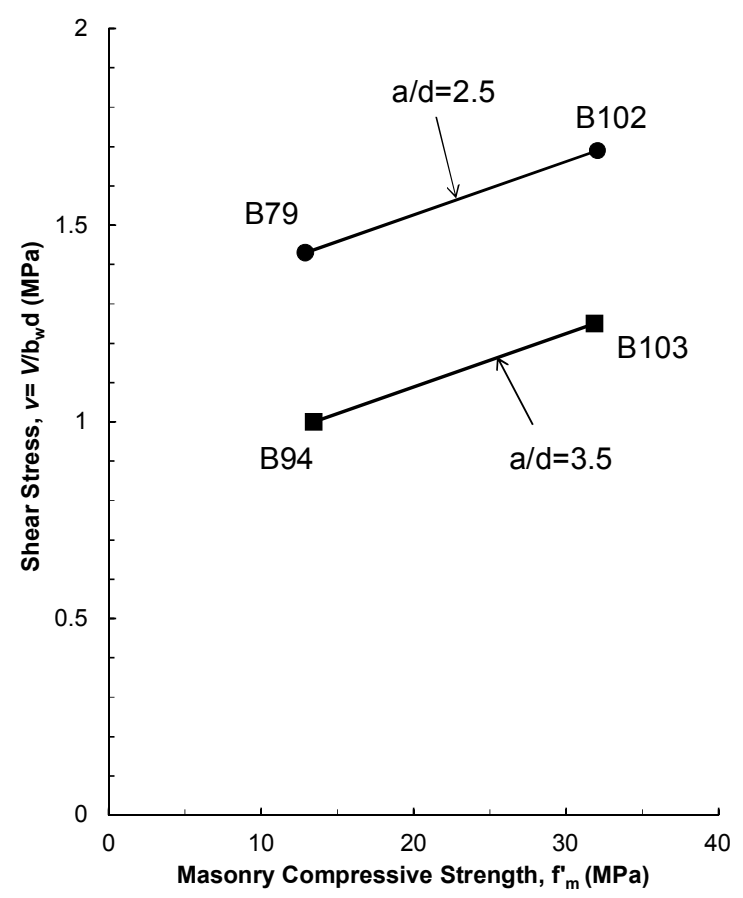

Figure 2-25: Effect of Masonry Compressive Strength on Shear Strength of RCM Beams (Li et al. (1994))

$\mathrm{Li}$ et al. recommended the formula shown in equation (2-20) for the prediction of shear capacity of reinforced masonry beams:

$V_{m}=\left[1.996-0.994 \ln \left(\frac{a}{d}\right)\right]\left[0.173+0.056 \ln \left(\frac{A_{s} f_{y}}{f_{m}^{\prime} b_{w d} d}\right)\right] f_{m}^{\prime}$

\subsubsection{Fereige 1994}

Fereige investigated and reported on the shear strength of reinforced masonry beams. The purpose of the tests was to determine how the beam shear strength was influenced by a/d and $\rho$. Fereige tested a total of 49 reinforced concrete masonry beams without web reinforcement of which twenty four of these beams had $\mathrm{a} / \mathrm{d}>2.5$. All the beams were of $190 \mathrm{~mm}$ width but varied in height, being constructed of either one or two courses. The one-course beam consisted of 
regular bond beam units while the two-course beams were constructed with bond beam units in the first course and stretcher units in the second course. The beams were constructed out of unit blocks with average strength of 9.6 MPa, type S mortar with average strength of 16.4MPa and coarse aggregate grout with an average strength of $18.7 \mathrm{MPa}$. The configuration of these beams and the details of their reinforcement are presented in Figure 2-26. 


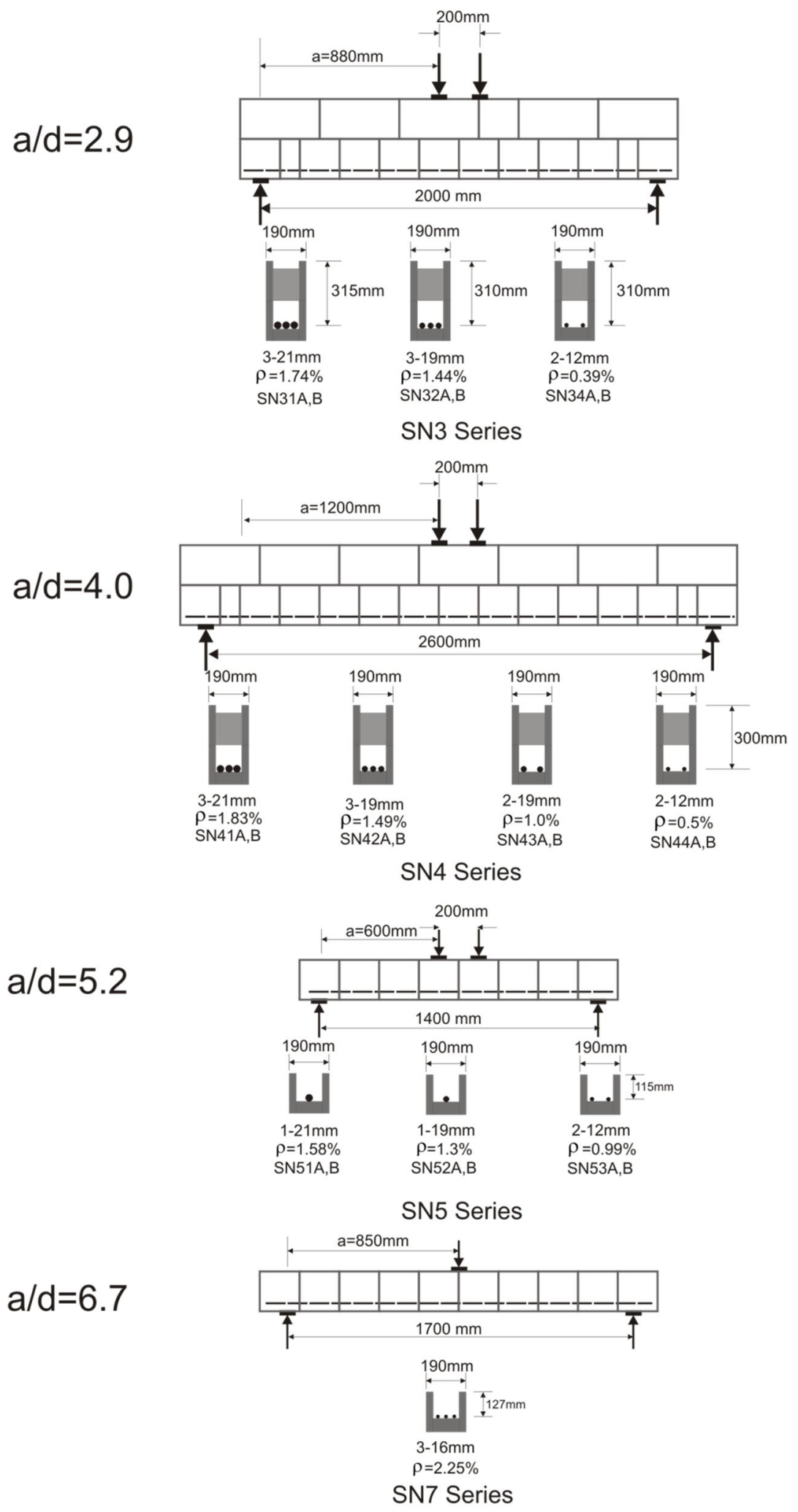

Figure 2-26: Reinforced Masonry Beams Tested by Ferieg 
Ferieg (1994) noted that reinforced masonry beams failed suddenly in shear in a similar fashion to reinforced concrete beams, except that cracks in masonry beams strongly tend to propagate through the joint (horizontal and vertical). This alters the crack patterns from equivalent RC beams. Fergie's test results show that there was no consistent pattern of increase in shear strength of reinforced masonry beams with the main reinforcement ratio ( $\rho$ ) (see Figure 2-27). This finding somewhat agrees with Suter and Keller's test results, but is in clear conflict with the test results of Li et al.

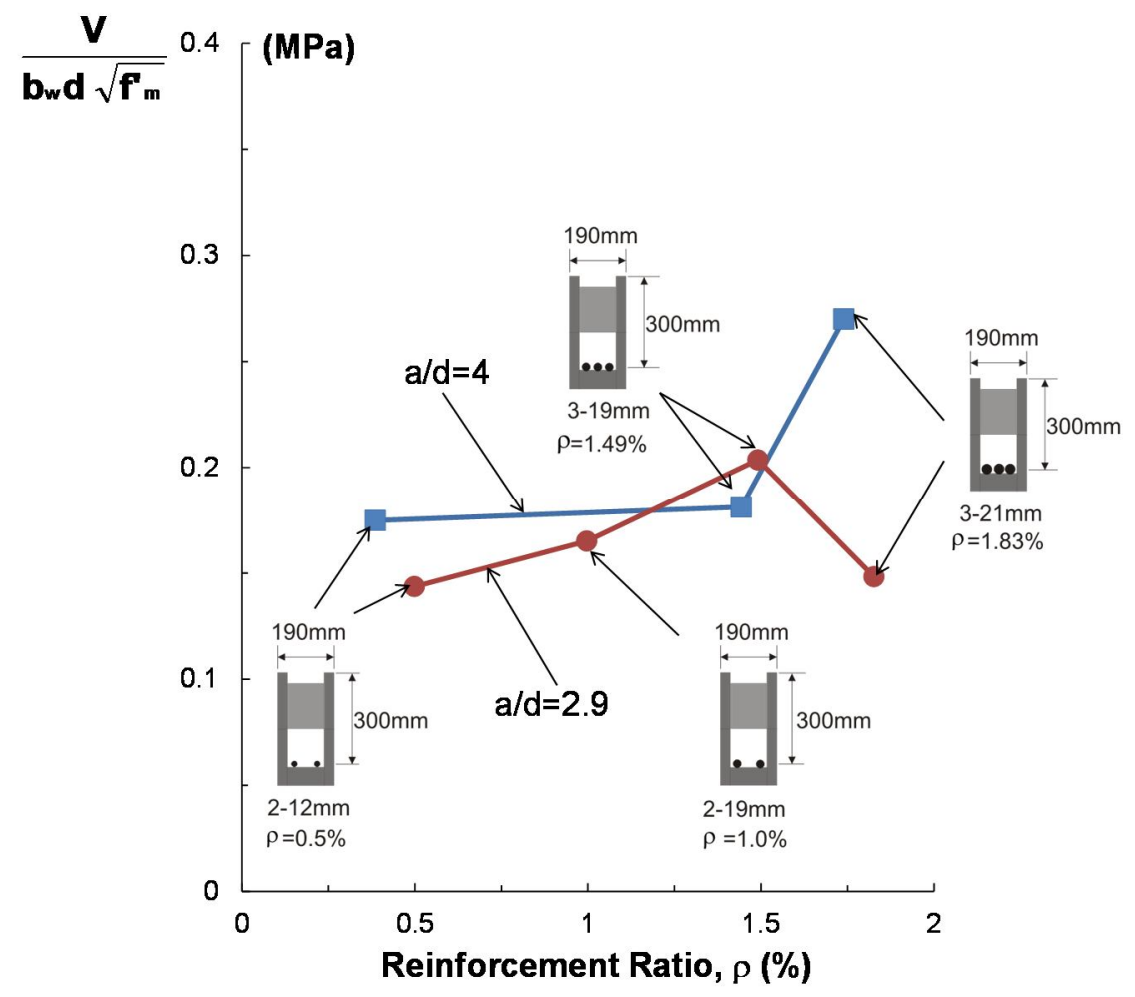

Figure 2-27: Effect of $\rho$ on Shear Strength of RCM Beams (Ferieg(1994))

Fereig's test results revealed another conflict with the results of Li et al. and Suter and Keller. It can be seen from Figure 2-28 that the shear span to depth ratio had only a very small effect on 
shear strength. Fereig concluded that for slender beams $(a / d>2.5)$, the effect of span to depth ratio and reinforcement ratio are not significant and can be ignored.

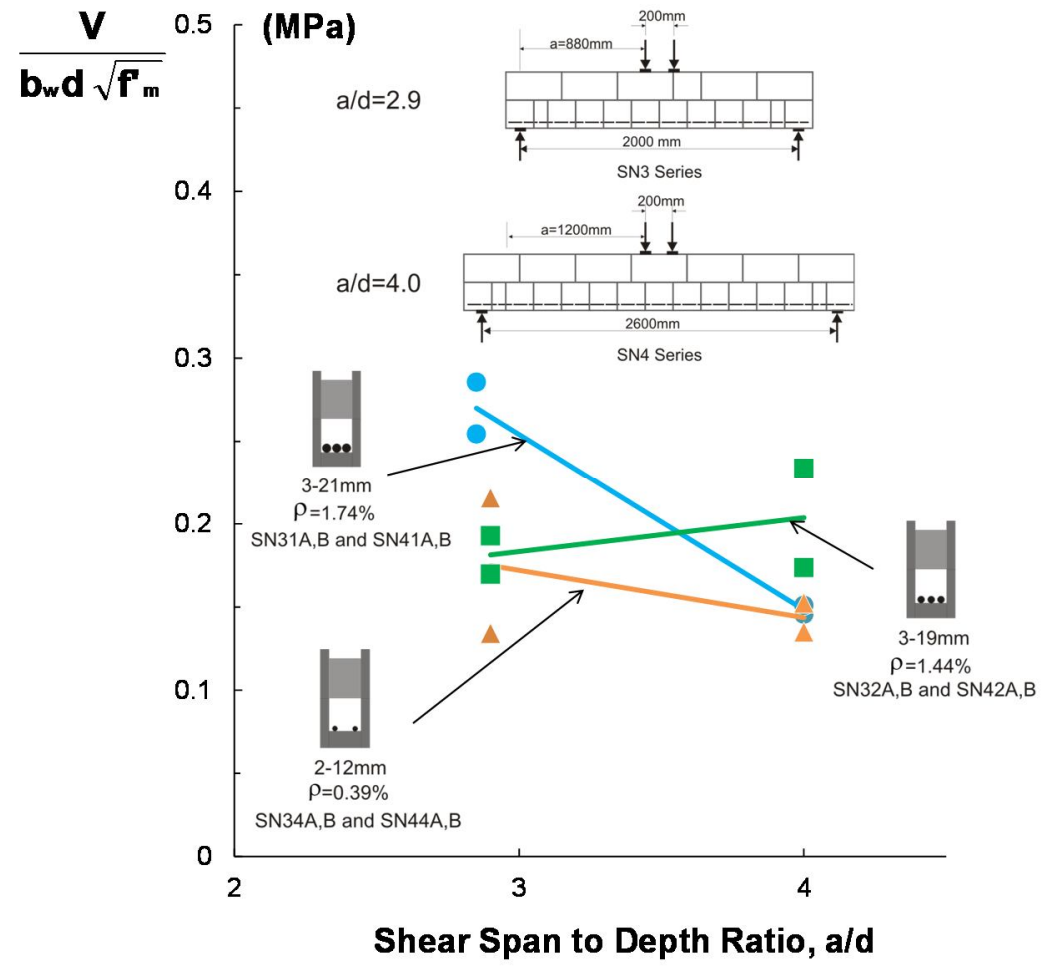

Figure 2-28: Effect of (a/d) on Shear Strength of RCM Beams (Ferieg (1994))

Based on his experimental results, Ferieg suggested the following equations to predict the nominal shear strength of masonry beams without web reinforcement

$$
\begin{array}{ll}
\mathrm{V}_{\mathrm{m}}=\frac{1}{12}\left[11.86-4.14\left(\frac{\mathrm{a}}{\mathrm{d}}\right)\right] \sqrt{\mathrm{f}^{\prime} \mathrm{m}} \mathrm{b}_{\mathrm{w}} \mathrm{d} & \text { for }(\mathrm{a} / \mathrm{d}) \leq 2.0 \\
\mathrm{~V}_{\mathrm{m}}=\frac{1}{12}\left[3.6-0.12\left(\frac{\mathrm{a}}{\mathrm{d}}\right)\right] \sqrt{\mathrm{f}^{\prime} \mathrm{m}} b_{\mathrm{w}} \mathrm{d} & \text { for }(\mathrm{a} / \mathrm{d})>2.0
\end{array}
$$




\subsubsection{Other Tests on RCM Beams}

Dhanasekar and Wong (2001) tested seventy stack bonded fully grouted concrete block and brick block masonry beams. Dhanasekar and Wong did not report any detailed information about the dimensions, reinforcement or the test results of the beams. Instead, they reported the range of the parameters considered in their tests. Unfortunately, the author was not able to have access to the database of these results even after contacting the first author of the paper. The $(\mathrm{a} / \mathrm{d})$ ratio of the tested beams ranged between 0.16 to 3.2 in 24 steps. The span of the beams varied from $240 \mathrm{~mm}$ to $740 \mathrm{~mm}$ while overall depth of the beams were $150 \mathrm{~mm}$ or $310 \mathrm{~mm}$ for the clay brick block masonry beams and $190 \mathrm{~mm}$ or $390 \mathrm{~mm}$ for the clay brick block masonry beams. Dhanasekar and Wong noticed that the failure of the of masonry beams occurred suddenly with cracks grew through vertical joints (as the beams were stack bonded) until they reached close to the point load and then deviated away towards the point load and the support. Dhanasekar and Wong found out that the shear strength reinforced masonry beams is significantly affected by both the (a/d) ratio and depth (d) of the beam (size effect). As the depth of the beam increases, the shear strength decreases. Similarly, the shear strength decreases as (a/d) increases. However, Dhanasekar and Wong have noticed that the effect of size effect on shear strength of reinforced masonry beams is more pronounced than the effect of $(\mathrm{a} / \mathrm{d})$.

Based on a multiple regression analysis conducted on their test results and test results by Suter and Keller, Li et al. and Ferieg, Dhanasekar and Wong proposed the formula in Equation (2-22) 


$$
\begin{array}{ll}
\operatorname{Vm}=\left(4.0\left[\sqrt{\frac{\mathrm{Le}}{\mathrm{d}}} \times \sqrt{\frac{\mathrm{ag}}{\mathrm{h}}} \times \sqrt[4]{\mathrm{fy}_{\mathrm{y}} \times \rho \times \mathrm{f}^{\prime} \mathrm{m}}\right]\right)^{2} & \text { for }(\mathrm{a} / \mathrm{d}) \leq 2.0 \\
\mathrm{Vm}=\left(1.2\left[\frac{\mathrm{a}}{\mathrm{d}}\right]^{-0.8}\left[\sqrt{\frac{\mathrm{Le}}{\mathrm{d}}} \times \sqrt{\frac{\mathrm{ag}}{\mathrm{h}}} \times \sqrt[4]{\mathrm{fy}_{\mathrm{y}} \times \rho \times \mathrm{f}^{\prime} \mathrm{m}}\right]\right)^{2} & \text { for }(\mathrm{a} / \mathrm{d})>2.0
\end{array}
$$

Where:

Le : the effective span length

Brzev (2006) conducted an experimental program on using FRP sheets to retrofit RCM beams that had failed in shear. She tested six RCM beams without stirrups as reference beams. Five of these reference beams failed in shear. No companion prisms were tested and the results of the shear failure of the beams were used as reference values to evaluate the effectiveness of the FRP retrofitting.

Fereig (1994b) tested a total of fourteen two-course RCM beams with stirrups, six of which had an a/d ratio of 3.8 , with the rest having a/d ratio of 1.9 . The purpose was to study the effectiveness of stirrups in masonry beams. Three different web reinforcements were used in this program. Fereig (1994b) concluded that the nature of the crack propagation in RCM limits the effectiveness of vertical web reinforcement. He also concluded that the truss analogy overestimates the contribution of the vertical web reinforcement. It is worth mentioning that Fereig (1994b) did not test reference beams (beams without web reinforcement) in his experimental program. 


\subsection{Performance of the Various Code Shear Provisions for RCM Beams}

\subsubsection{Shear Design Methods for RCM Beams}

In this section, the reliability and predictive capabilities of shear design provisions from various masonry codes and the CSA general method for reinforced concrete are assessed in terms of a database of 117 shear tests reported in the literature. The shear design provisions of four international masonry codes will be reviewed and these include: CSA S304.1-04 (Canada), TMS MSJC (ACI 530-11) (US), AS 3700-2001 (Australia), and BS 5628-2:2005 (UK).

\section{TMS MSJC-2011(ACI 530-11)}

The nominal shear strength provided by masonry is computed using Equation 2-23 (in psi units):

$$
\mathrm{V}_{\mathrm{m}}=\left[4.0-1.75\left(\mathrm{Mu}_{\mathrm{u}} / \mathrm{Vud}_{\mathrm{v}}\right)\right] \mathrm{A}_{\mathrm{n}} \sqrt{\mathrm{f}^{\prime} \mathrm{m}}
$$

Where:

$\mathrm{M}_{\mathrm{u}} / \mathrm{V}_{\mathrm{u}} \mathrm{d}_{\mathrm{v}}=\mathrm{a} / \mathrm{d}$ for point-loaded beams, and need not be greater than 1.0,

$A_{n}=$ net cross-sectional area of beam (taken as $\left.b_{w} d\right)$,

$b_{w}=$ the width of the beam,

$\mathrm{d}=$ effective depth of the beam (distance from extreme compression fibre to centroid of longitudinal steel), and $\mathrm{f}_{\mathrm{m}}=$ masonry compressive strength.

For beams with $\mathrm{a} / \mathrm{d}>1$ the formula can be simplified to the following:

$$
\begin{aligned}
& V_{m}=V_{m} / b_{w d} d=2.25 \sqrt{f^{\prime} m} \quad \text { (psi units) } \\
& V_{m}=V_{m} / b_{w} d=0.187 \sqrt{f^{\prime} m} \quad \text { (MPa units) }
\end{aligned}
$$


Thus TMS 402 predicts that masonry beams without stirrups are $1.125\left(\frac{2.25}{2}=1.125\right)$ times stronger than equivalent reinforced concrete beams.For masonry beams reinforced with stirrups, TMS 402 uses the following equation:

$\mathrm{VR}_{\mathrm{R}}=\left[4.0-1.75\left(\mathrm{Mu} / \mathrm{Vud}_{\mathrm{v}}\right)\right] \mathrm{An}_{\mathrm{n}} \sqrt{\mathrm{f}^{\prime} \mathrm{m}}+0.5\left(\frac{\mathrm{Av}_{\mathrm{v}}}{\mathrm{s}}\right) \mathrm{f}_{\mathrm{yv}} \mathrm{d}$

Where:

$\mathrm{A}_{\mathrm{V}}=$ area of the stirrup $\left(\mathrm{mm}^{2}\right)$

$\mathrm{f}_{\mathrm{yv}}=$ yield strength of the stirrups $\left(\mathrm{N} / \mathrm{mm}^{2}\right)$

This means that TMS 402 determines the shear strength of reinforced masonry as the full masonry contribution plus one-half of the theoretical contribution of the stirrups.

\section{AS 3700-2001 (Australia)}

The Australian code suggests the following equation to calculate the shear strength of RCM beams without stirrups:

$V_{m}=f^{\prime} v m b_{w} d+f_{v s} A s$

Where:-

$\mathrm{f}_{\mathrm{vm}}=$ characteristic shear strength of reinforced masonry $=0.35 \mathrm{MPa}$.

$\mathrm{f}_{\mathrm{vs}}=$ design shear strength of the main longitudinal reinforcement $=17.5 \mathrm{MPa}$.

$\mathrm{A}_{\mathrm{s}}=$ the cross-sectional area of fully anchored longitudinal reinforcement in the tension zone of the cross-section under consideration, limited to $0.02 b_{\mathrm{w}} \mathrm{d}$ 


\section{BS 5628-2:2005 (UK)}

In this code the shear strength of masonry beams without stirrups is determined using equation (2-27):

$V_{m}=\left(0.35+17.5 \mathrm{As} / \mathrm{b}_{w d}\right) \cdot(2.5-0.25 \mathrm{a} / \mathrm{d}) \mathrm{b}_{\mathrm{w}} \mathrm{d}$

\section{CSA S304.1-04 (Canada)}

The nominal shear resistance of reinforced beams of grouted, normal density concrete block masonry is calculated as follows:

$V_{m}=0.16 \sqrt{f^{\prime} m}\left(1.0-\frac{d-400}{2000}\right) b_{w} d$

Where $\mathrm{v}_{\mathrm{m}}$ should neither be taken greater than $0.16\left(\mathrm{f}_{\mathrm{m}}\right)^{0.5}$ nor less than $0.07\left(\mathrm{f}_{\mathrm{m}}\right)^{0.5}$.

For grouted brick masonry constructed with solid units, the CSA S304.1-04 suggests the following equation for $\mathrm{v}_{\mathrm{m}}$ :

$\mathrm{Vm}_{\mathrm{m}}=0.056 \sqrt{\mathrm{f}^{\mathrm{m}}}\left(1.0-\frac{\mathrm{d}-400}{2000}\right)$

but $\mathrm{v}_{\mathrm{m}}$ should not be greater than $0.056\left(\mathrm{f}_{\mathrm{m}}\right)^{0.5}$.

The nominal shear resistance of beams of reinforced brick masonry of solid units is taken as $50 \%$ of the value for reinforced grouted brick masonry of solid units.

The CSA S304.1 uses Equation (2-30) to determine the nominal shear contribution provided by shear reinforcement (stirrups). To determine the factored shear resistance, $V_{R}, V_{m}$ from (2-29) is added to $\mathrm{V}_{\mathrm{S}}$ from Equation (2-30). As opposed to the TMS 402code (Equation (2-25)), the full stirrup contribution is used. 
$\mathrm{V}_{\mathrm{s}}=\left(\frac{\mathrm{Av}_{\mathrm{v}}}{\mathrm{s}}\right) \mathrm{f}_{\mathrm{yv}} \mathrm{d}$

\subsubsection{Experimental Database}

Test results for 117 shear-critical RCM beams without shear reinforcement assembled from published literature (Suter and Keller (1980), Suter and Keller (1984), Li et al. (1994), Ferieg (1994) and Brzev (2006)) are summarized in Table 1. The database comprises RCM beams having $\mathrm{f}_{\mathrm{m}}$ values ranging from 8.6 to $30 \mathrm{MPa}$, a/d ratios varying between 2.5 and $6.7, \rho$ ratios ranging from $0.37 \%$ to $2.5 \%$ and depths varying between 109 and $349 \mathrm{~mm}$. Only beams having $\mathrm{a} / \mathrm{d}$ ratios of 2.5 or greater are considered here as the current investigation is concerned only with beams where arch action cannot be engaged after beam action breaks down. It is worth mentioning that $\mathrm{f}^{\prime} \mathrm{m}$ values used by Suter and Keller and Ferieg were obtained from companion prism tests. Li et. al. and Brzev rather conducted individual component tests on the blocks, mortar and grout. The $\mathrm{f}^{\prime} \mathrm{m}$ values for $\mathrm{Li}$ et. al. and Brzev were calculated based on the equation proposed by Khalaf et. al. (1994):

$\mathrm{f}^{\prime} \mathrm{m}=0.3 \mathrm{fbl}+0.20 \mathrm{fmr}+0.25 \mathrm{fgr}$

Where:-

$\mathrm{f}_{\mathrm{bl}}=$ compressive strength of unfilled full-block unit,

$\mathrm{f}_{\mathrm{mr}}=$ cube compressive strength of mortar, and

$\mathrm{f}_{\mathrm{gr}}=$ cube compressive strength of grout.

For $\mathrm{RCM}$ beams, $\mathrm{V}_{\mathrm{m}}$ and $\mathrm{f}_{\mathrm{m}}$ can replace $\mathrm{V}_{\mathrm{C}}$ and $\mathrm{f}_{\mathrm{c}}$ directly. A crack in a $\mathrm{RCM}$ beam travels diagonally through grout, block (each of which may have a different maximum aggregate size) and horizontally or vertically through mortar joints (with fine aggregate). Furthermore, cracks in 
RCM form at predefined paths (mortar joints), giving the cracks a more jagged appearance than in RC beams. This may result in the formation of shear keys at corners of masonry units that will permit shear stresses to be resisted by interlocking of adjacent blocks, a phenomenon not generally observed in concrete. Lastly, as researchers rarely report the aggregate size used in the grout and blocks, it was found that acceptable shear strength predictions can be achieved by setting $\mathrm{a}_{\mathrm{g}}=10 \mathrm{~mm}$ for beams filled with grout, and $\mathrm{a}_{\mathrm{g}}=0 \mathrm{~mm}$ for beams filled with mortar. Further work is needed on how to rationally account for the effect of aggregate size in reinforced masonry.

As an example of calculating the shear strength of a RCM beam by the CSA A23.3-04 General Method, consider beam CU158, tested by Suter and Keller (1980), with the following properties: $b_{w}=194 \mathrm{~mm}, \mathrm{~d}=345 \mathrm{~mm}, \mathrm{f}_{\mathrm{m}}=9.2 \mathrm{MPa}, \mathrm{A}_{\mathrm{s}}=562 \mathrm{~mm}^{2}, \mathrm{a} / \mathrm{d}=4, \mathrm{a}_{\mathrm{g}}=10 \mathrm{~mm}$ and a shear span of a $=1.38 \mathrm{~m}$. For $\mathrm{d}_{\mathrm{v}}=0.9 \mathrm{~d}=311 \mathrm{~mm}, \mathrm{~s}_{\mathrm{xe}}=434 \mathrm{~mm}$ from Equation (2-18). Guessing that $\varepsilon_{\mathrm{x}}=0.5$ $\mathrm{x} 10^{-3}$ will lead to a value for $\beta$ of 0.207 , and Equation (2-15) yields a shear strength of $37.8 \mathrm{kN}$. At a distance $\mathrm{d}$ away from the point load(critical section for shear), the shear strength of $37.8 \mathrm{kN}$ would be associated with a moment of $(\mathrm{a}-\mathrm{d}) \times \mathrm{V}=(1.38-0.345) \times 37.8=39.1 \mathrm{kN}-\mathrm{m}$. Equation (2-17)) can be calculated, giving $\varepsilon_{\mathrm{x}}=0.729 \times 10^{-3}$. This value is not equal to the guessed value of $\varepsilon_{\mathrm{x}}$. Thus a new value will be tried as the average of the old and new estimate, $\varepsilon_{\mathrm{x}}=(0.5+0.729) \mathrm{x}$ $10^{-3} / 2=0.615 \times 10^{-3}$. A good convergence is attained when $\varepsilon_{\mathrm{x}}=0.648 \times 10^{-3}$ and Equation $(2-15)$ yields a shear force of $33.6 \mathrm{kN}$. The specimen failed at a shear force of $52.8 \mathrm{kN}$ leading to a $\mathrm{V}_{\text {exp }} / \mathrm{V}_{\text {pred }}$ ratio of 1.56. 
Table 2-1: Database of 112 Shear-Critical RCM Beams without Web Reinforcement

\begin{tabular}{|c|c|c|c|c|c|c|c|c|c|c|c|c|c|}
\hline \multirow{2}{*}{$\#$} & \multirow{2}{*}{ Authors } & \multicolumn{6}{|c|}{ Experimental Details } & \multicolumn{6}{|c|}{$\begin{array}{l}\text { Ratio of Experimental to Predicted Shear Strength } \\
\qquad\left(\mathrm{v}_{\mathrm{exp}} / \mathrm{N}_{\text {pred }}\right)\end{array}$} \\
\hline & & $\begin{array}{l}\text { Beam } \\
\text { ID }\end{array}$ & $\begin{array}{c}\mathrm{d} \\
(\mathrm{mm})\end{array}$ & $\begin{array}{c}\rho \\
(\%)\end{array}$ & $\mathrm{a} / \mathrm{d}$ & $\begin{array}{c}f_{m}^{\prime} \\
(\mathrm{MPa})\end{array}$ & $\begin{array}{l}\mathrm{V}_{\exp }^{1} \\
(\mathrm{MPa})\end{array}$ & $\begin{array}{c}\mathrm{ACl} \\
530-08\end{array}$ & $\begin{array}{c}\text { AS } 3700- \\
01\end{array}$ & $\begin{array}{c}\text { BS } 5628 \\
2: 2005\end{array}$ & $\begin{array}{c}\text { CSA } \\
\text { S304.1 }\end{array}$ & $\begin{array}{c}\text { CSA } \\
\text { A23.3-04 }\end{array}$ & $\begin{array}{l}\text { Hoult } \\
\text { et. al. }\end{array}$ \\
\hline 1 & Suter \& Keller & CU118a & 154 & 1.90 & 3.0 & 12.9 & 1.28 & 1.92 & 1.88 & 107 & 2.23 & 1.42 & 1.39 \\
\hline 2 & $(1980)$ & Cu118b & 154 & 1.90 & 3.0 & 12.9 & 1.34 & 2.01 & 1.96 & 112 & 2.33 & 1.49 & 1.46 \\
\hline 3 & & CU119 & 154 & 1.90 & 5.0 & 12.9 & 0.99 & 1.48 & 145 & 116 & 1.72 & 1.28 & 1.22 \\
\hline 4 & & Cu122a & 154 & 1.90 & 3.0 & 11.2 & 1.05 & 1.69 & 154 & 0.88 & 1.96 & 1.26 & 1.25 \\
\hline 5 & & Cu122b & 154 & 1.90 & 3.0 & 11.2 & 1.36 & 2.18 & 199 & 114 & 2.54 & 1.64 & 1.61 \\
\hline 6 & & Cu123a & 154 & 1.90 & 5.0 & 11.2 & 0.92 & 1.48 & 135 & 108 & 1.72 & 1.28 & 1.23 \\
\hline 7 & & cu123b & 154 & 1.90 & 5.0 & 11.2 & 0.92 & 1.48 & 1.35 & 108 & 1.72 & 1.28 & 1.23 \\
\hline 8 & & Cu115 & 126 & 1.59 & 6.0 & 11.2 & 0.74 & 1.19 & 1.18 & 118 & 1.38 & 1.13 & 1.06 \\
\hline 9 & & Cu125 & 146 & 1.38 & 6.0 & 11.2 & 0.71 & 1.14 & 1.20 & 1.20 & 1.33 & 1.16 & 1.08 \\
\hline 10 & & Cu128 & 348 & 1.67 & 3.0 & 12.9 & 0.88 & 1.32 & 1.37 & 0.78 & 1.53 & 1.15 & 1.14 \\
\hline 11 & & Cu129 & 348 & 1.67 & 5.0 & 12.9 & 0.90 & 1.35 & 140 & 112 & 1.57 & 1.37 & 1.32 \\
\hline 12 & & CU132 & 348 & 1.67 & 3.0 & 11.2 & 0.68 & 1.09 & 1.06 & 0.60 & 1.27 & 0.99 & 0.99 \\
\hline 13 & & CU133 & 348 & 1.67 & 5.0 & 11.2 & 0.54 & 0.87 & 0.84 & 0.67 & 1.01 & 0.91 & 0.88 \\
\hline 14 & & CU134 & 343 & 0.58 & 3.0 & 12.9 & 0.62 & 0.93 & 1.37 & 0.78 & 1.08 & 1.12 & 1.04 \\
\hline 15 & & Cu135 & 343 & 1.15 & 6.0 & 12.9 & 0.77 & 1.15 & 140 & 140 & 1.34 & 1.41 & 1.31 \\
\hline 16 & & CU136a & 343 & 0.58 & 3.0 & 11.2 & 0.55 & 0.88 & 122 & 0.70 & 1.03 & 1.09 & 1.03 \\
\hline 17 & & cu136b & 343 & 0.58 & 3.0 & 11.2 & 0.59 & 0.95 & 131 & 0.75 & 1.10 & 1.17 & 1.10 \\
\hline 18 & & Cu137 & 343 & 1.15 & 6.0 & 11.2 & 0.62 & 1.00 & 113 & 113 & 1.16 & 1.24 & 1.17 \\
\hline 19 & & CU140a & 343 & 1.47 & 3.0 & 12.9 & 0.91 & 1.36 & 150 & 0.86 & 1.58 & 1.23 & 1.21 \\
\hline 20 & & CU140b & 343 & 1.47 & 3.0 & 12.9 & 0.95 & 1.42 & 156 & 0.89 & 1.65 & 1.29 & 1.26 \\
\hline 21 & & CU141a & 343 & 1.47 & 5.0 & 12.9 & 0.83 & 1.24 & 1.37 & 109 & 1.44 & 1.31 & 1.25 \\
\hline 22 & & Cu141b & 343 & 1.47 & 5.0 & 12.9 & 0.83 & 1.24 & 1.37 & 109 & 1.44 & 1.31 & 1.25 \\
\hline 23 & & CU113 & 126 & 1.55 & 6.0 & 11.2 & 0.97 & 1.56 & 156 & 156 & 1.81 & 1.46 & 1.37 \\
\hline 24 & & CU142 & 343 & 1.47 & 6.0 & 12.9 & 0.79 & 1.18 & 1.30 & 130 & 1.37 & 1.33 & 1.25 \\
\hline 25 & & CU145a & 343 & 1.47 & 3.0 & 11.2 & 0.69 & 1.11 & 114 & 0.65 & 1.20 & 1.03 & 1.02 \\
\hline 26 & & CU145b & 343 & 1.47 & 3.0 & 11.2 & 0.82 & 1.32 & 1.35 & 0.77 & 1.53 & 1.23 & 1.22 \\
\hline 27 & & CU146a & 343 & 1.47 & 5.0 & 11.2 & 0.70 & 1.12 & 1.15 & 0.92 & 1.31 & 1.22 & 1.18 \\
\hline 28 & & CU146b & 343 & 1.47 & 5.0 & 11.2 & 0.81 & 1.30 & 133 & 107 & 1.51 & 1.41 & 1.36 \\
\hline 29 & & CU147a & 343 & 1.47 & 6.0 & 11.2 & 0.72 & 1.16 & 1.19 & 119 & 1.34 & 1.33 & 1.27 \\
\hline 30 & & CU147b & 343 & 1.47 & 6.0 & 11.2 & 0.72 & 1.16 & 1.19 & 1.19 & 1.34 & 1.33 & 1.27 \\
\hline 31 & & CU148 & 343 & 0.85 & 2.7 & 9.2 & 0.88 & 1.56 & 176 & 0.97 & 1.81 & 1.52 & 1.47 \\
\hline 32 & & CU112 & 126 & 1.55 & 6.0 & 11.2 & 0.94 & 1.51 & 151 & 151 & 1.76 & 1.42 & 1.32 \\
\hline 33 & & Cu149a & 340 & 0.85 & 2.7 & 9.2 & 0.79 & 1.40 & 158 & 0.87 & 1.63 & 1.36 & 1.32 \\
\hline 34 & & cu149b & 340 & 0.85 & 2.7 & 9.2 & 0.83 & 1.47 & 166 & 0.91 & 1.71 & 1.43 & 1.39 \\
\hline 35 & & CU150a & 340 & 0.85 & 2.7 & 9.2 & 0.76 & 1.35 & 152 & 0.83 & 1.57 & 1.31 & 1.27 \\
\hline 36 & & CU150b & 340 & 0.85 & 2.7 & 9.2 & 0.85 & 1.51 & 170 & 0.93 & 1.75 & 1.47 & 1.42 \\
\hline 37 & & Cu151 & 340 & 0.85 & 2.7 & 9.2 & 0.80 & 1.42 & 160 & 0.88 & 1.65 & 1.38 & 1.34 \\
\hline 38 & & CU154a & 340 & 0.85 & 4.0 & 9.2 & 0.68 & 1.21 & 136 & 0.91 & 1.40 & 1.33 & 1.26 \\
\hline 39 & & CU154b & 340 & 0.85 & 4.0 & 9.2 & 0.76 & 1.35 & 152 & 102 & 1.57 & 1.49 & 1.41 \\
\hline 40 & & CU155a & 345 & 0.84 & 4.0 & 9.2 & 0.73 & 1.29 & 147 & 0.98 & 1.50 & 1.44 & 1.36 \\
\hline 41 & & Cu155b & 345 & 0.84 & 4.0 & 9.2 & 0.79 & 1.40 & 159 & 1.06 & 1.63 & 1.56 & 1.48 \\
\hline 42 & & CU156a & 345 & 0.84 & 4.0 & 9.2 & 0.73 & 1.29 & 147 & 0.98 & 1.50 & 1.44 & 1.36 \\
\hline 43 & & Cu156b & 345 & 0.84 & 4.0 & 9.2 & 0.72 & 1.28 & 145 & 0.97 & 1.48 & 1.42 & 1.34 \\
\hline 44 & & CU157a & 345 & 0.84 & 4.0 & 9.2 & 0.80 & 1.42 & 161 & 107 & 1.65 & 1.58 & 1.49 \\
\hline 45 & & CU157b & 345 & 0.84 & 4.0 & 9.2 & 0.77 & 1.36 & 155 & 103 & 1.59 & 1.52 & 1.44 \\
\hline 46 & & Cu158 & 345 & 0.84 & 4.0 & 9.2 & 0.79 & 1.40 & 159 & 106 & 1.63 & 1.56 & 1.48 \\
\hline 47 & & Cu159 & 345 & 0.84 & 4.0 & 9.2 & 0.83 & 1.47 & 167 & 1.11 & 1.71 & 1.64 & 1.55 \\
\hline 48 & & CU162a & 349 & 1.44 & 3.0 & 17.9 & 0.90 & 1.14 & 1.49 & 0.85 & 1.33 & 1.09 & 1.06 \\
\hline 49 & & CU162b & 349 & 1.44 & 3.0 & 17.9 & 0.94 & 1.19 & 156 & 0.89 & 1.39 & 1.14 & 1.11 \\
\hline 50 & & CU163a & 349 & 1.44 & 5.0 & 17.9 & 0.76 & 0.97 & 126 & 101 & 1.12 & 1.09 & 1.03 \\
\hline 51 & & CU163a & 349 & 1.44 & 5.0 & 17.9 & 0.76 & 0.97 & 126 & 101 & 1.12 & 1.09 & 1.03 \\
\hline 52 & & CU105 & 109 & 2.24 & 5.0 & 11.2 & 1.28 & 2.06 & 173 & 1.38 & 2.39 & 1.60 & 1.54 \\
\hline 53 & & CU164 & 349 & 1.44 & 6.0 & 17.9 & 0.63 & 0.80 & 105 & 105 & 0.93 & 0.96 & 0.89 \\
\hline 54 & & CU167 & 349 & 1.44 & 3.0 & 17.9 & 0.67 & 0.85 & 111 & 0.64 & 0.99 & 0.81 & 0.79 \\
\hline 55 & & CU168a & 349 & 1.44 & 5.0 & 17.9 & 0.60 & 0.76 & 100 & 0.80 & 0.89 & 0.90 & 0.85 \\
\hline 56 & & CU168b & 349 & 1.44 & 5.0 & 17.9 & 0.60 & 0.76 & 100 & 0.80 & 0.89 & 0.90 & 0.85 \\
\hline 57 & & CU169a & 349 & 1.44 & 6.0 & 17.9 & 0.41 & 0.52 & 0.68 & 0.68 & 0.61 & 0.65 & 0.61 \\
\hline 58 & & cu169b & 349 & 1.44 & 6.0 & 17.9 & 0.43 & 0.55 & 0.71 & 0.71 & 0.64 & 0.68 & 0.64 \\
\hline
\end{tabular}




\begin{tabular}{|c|c|c|c|c|c|c|c|c|c|c|c|c|c|}
\hline \multirow{2}{*}{ \# } & \multirow{2}{*}{ Authors } & \multicolumn{6}{|c|}{ Experimental Details } & \multicolumn{6}{|c|}{$\begin{array}{l}\text { Ratio of Experimental to Predicted Shear Strength } \\
\qquad\left(v_{\text {exp }} / v_{\text {pred }}\right)\end{array}$} \\
\hline & & $\begin{array}{l}\text { Beam } \\
\text { ID }\end{array}$ & $\begin{array}{c}\mathrm{d} \\
(\mathrm{mm})\end{array}$ & $\begin{array}{c}\rho \\
(\%)\end{array}$ & $\mathrm{a} / \mathrm{d}$ & $\begin{array}{c}f^{\prime} m \\
(\mathrm{MPa})\end{array}$ & $\begin{array}{c}V_{\exp }^{1} \\
(\mathrm{MPa})\end{array}$ & $\begin{array}{c}\mathrm{ACl} \\
530-08\end{array}$ & $\begin{array}{c}\text { AS } 3700- \\
01\end{array}$ & \begin{tabular}{|c|} 
BS $5628-$ \\
$2: 2005$
\end{tabular} & $\begin{array}{c}\text { CSA } \\
\text { S304.1 }\end{array}$ & $\begin{array}{c}\text { CSA } \\
\text { A23.3-04 }\end{array}$ & $\begin{array}{l}\text { Hoult } \\
\text { et. al. }\end{array}$ \\
\hline 59 & \multirow{4}{*}{$\begin{array}{l}\text { Suter \& Keller } \\
\quad(1984)\end{array}$} & 65 & 357 & 0.58 & 3.0 & 12.6 & 0.71 & 1.07 & 1.57 & 0.90 & 1.25 & 1.30 & 121 \\
\hline 60 & & 67 & 357 & 0.58 & 3.0 & 18.9 & 0.87 & 1.08 & 1.93 & 1.10 & 1.25 & 1.41 & 129 \\
\hline 61 & & 69 & 156 & 0.66 & 3.0 & 12.2 & 0.88 & 1.35 & 1.88 & 1.08 & 1.57 & 1.38 & 1.28 \\
\hline 62 & & 71 & 156 & 0.66 & 3.0 & 18.9 & 0.88 & 1.08 & 1.88 & 1.08 & 1.26 & 1.20 & 109 \\
\hline 63 & \multirow[t]{26}{*}{ Li et al.(1994) } & 879 & 320 & 1.03 & 2.5 & 11.9 & 1.43 & 2.22 & 2.69 & 1.43 & 2.59 & 2.05 & 200 \\
\hline 64 & & $B 80$ & 320 & 1.03 & 3.0 & 11.8 & 1.02 & 1.59 & 1.92 & 1.10 & 1.85 & 1.55 & 150 \\
\hline 65 & & $B 81$ & 320 & 1.03 & 4.0 & 11.6 & 0.96 & 1.51 & 1.80 & 1.20 & 1.76 & 1.61 & 153 \\
\hline 66 & & $B 85$ & 320 & 0.37 & 2.5 & 12.9 & 1.03 & 1.54 & 2.48 & 1.32 & 1.80 & 2.02 & 184 \\
\hline 67 & & 886 & 320 & 0.37 & 3.0 & 11.2 & 0.79 & 1.26 & 1.89 & 1.08 & 1.47 & 1.72 & 156 \\
\hline 68 & & $B 87$ & 320 & 0.37 & 4.0 & 11.2 & 0.66 & 1.06 & 1.58 & 1.05 & 1.23 & 1.61 & 143 \\
\hline 69 & & B91 & 320 & 1.62 & 2.5 & 12.3 & 1.71 & 2.62 & 2.70 & 1.44 & 3.05 & 2.15 & 214 \\
\hline 70 & & 892 & 320 & 1.62 & 3.0 & 12.4 & 1.16 & 1.77 & 1.83 & 1.05 & 2.06 & 1.53 & 151 \\
\hline 71 & & $B 93$ & 320 & 1.62 & 4.0 & 12.1 & 0.99 & 1.53 & 1.56 & 1.04 & 1.78 & 1.43 & 139 \\
\hline 72 & & 894 & 320 & 1.03 & 3.5 & 13.5 & 1.00 & 1.46 & 1.88 & 1.16 & 1.70 & 1.53 & 1.46 \\
\hline 73 & & 895 & 320 & 1.62 & 3.5 & 12.7 & 1.08 & 1.63 & 1.71 & 1.05 & 1.89 & 1.47 & 144 \\
\hline 74 & & $B 96$ & 320 & 0.37 & 5.0 & 12.7 & 0.39 & 0.59 & 0.94 & 0.75 & 0.68 & 1.01 & 0.87 \\
\hline 75 & & $B 97$ & 320 & 1.03 & 5.0 & 13.4 & 0.80 & 1.17 & 1.51 & 1.21 & 1.37 & 1.39 & 129 \\
\hline 76 & & 898 & 320 & 1.62 & 5.0 & 12.6 & 0.86 & 1.30 & 1.36 & 1.08 & 1.51 & 1.31 & 126 \\
\hline 77 & & $B 99$ & 320 & 0.66 & 5.0 & 12.4 & 0.60 & 0.91 & 1.28 & 1.02 & 1.06 & 1.24 & 112 \\
\hline 78 & & B100 & 320 & 2.42 & 5.0 & 13.2 & 0.88 & 1.30 & 1.13 & 0.90 & 1.51 & 1.17 & 114 \\
\hline 79 & & B102 & 320 & 1.03 & 2.5 & 32.1 & 1.69 & 1.60 & 3.18 & 1.70 & 1.87 & 1.72 & 163 \\
\hline 80 & & B103 & 320 & 1.03 & 3.5 & 31.9 & 1.25 & 1.19 & 2.35 & 1.45 & 1.38 & 1.44 & 133 \\
\hline 81 & & B104 & 320 & 1.03 & 4.5 & 30.4 & 1.05 & 1.02 & 1.98 & 1.44 & 1.19 & 1.35 & 123 \\
\hline 82 & & B106 & 320 & 1.03 & 2.5 & 32.6 & 1.59 & 1.50 & 3.00 & 1.60 & 1.74 & 1.62 & 153 \\
\hline 83 & & B107 & 320 & 1.03 & 3.5 & 30.2 & 1.53 & 1.50 & 2.88 & 1.77 & 1.74 & 1.79 & 166 \\
\hline 84 & & B108 & 320 & 1.03 & 4.5 & 28.9 & 1.13 & 1.13 & 2.13 & 1.55 & 1.31 & 1.47 & 134 \\
\hline 85 & & B110 & 125 & 0.96 & 2.5 & 31.3 & 2.00 & 1.92 & 3.87 & 2.06 & 2.23 & 1.87 & 173 \\
\hline 86 & & B111 & 125 & 0.96 & 3.5 & 30.0 & 1.48 & 1.45 & 2.86 & 1.76 & 1.69 & 1.58 & 144 \\
\hline 87 & & B112 & 125 & 0.96 & 4.5 & 28.5 & 1.13 & 1.14 & 2.18 & 1.59 & 1.32 & 1.35 & 1.21 \\
\hline 88 & & $\mathrm{~B} 113$ & 125 & 0.96 & 5.5 & 30.6 & 0.92 & 0.89 & 1.78 & 1.58 & 1.04 & 1.17 & 102 \\
\hline 89 & \multirow[t]{24}{*}{ Ferieg (1994) } & SN31A & 315 & 1.74 & 2.9 & 8.9 & 0.85 & 1.54 & 1.30 & 0.73 & 1.78 & 1.23 & 1.22 \\
\hline 90 & & SN31B & 315 & 1.74 & 2.9 & 11.0 & 0.84 & 1.37 & 1.29 & 0.72 & 1.59 & 1.12 & 111 \\
\hline 91 & & SN32A & 310 & 1.44 & 2.9 & 11.5 & 0.65 & 1.04 & 1.09 & 0.61 & 1.21 & 0.90 & 0.88 \\
\hline 92 & & SN32B & 310 & 1.44 & 2.9 & 11.6 & 0.58 & 0.91 & 0.96 & 0.54 & 1.06 & 0.79 & 0.78 \\
\hline 93 & & SN34A & 310 & 0.39 & 2.9 & 12.3 & 0.76 & 1.16 & 1.81 & 1.02 & 1.35 & 1.56 & 1.41 \\
\hline 94 & & SN34B & 310 & 0.39 & 2.9 & 11.5 & 0.46 & 0.72 & 1.09 & 0.61 & 0.84 & 0.96 & 0.87 \\
\hline 95 & & SN41A & 300 & 1.83 & 4.0 & 11.5 & 0.49 & 0.78 & 0.74 & 0.49 & 0.91 & 0.69 & 0.68 \\
\hline 96 & & SN41B & 300 & 1.83 & 4.0 & 11.1 & 0.50 & 0.81 & 0.75 & 0.50 & 0.94 & 0.72 & 0.70 \\
\hline 97 & & SN42A & 300 & 1.49 & 4.0 & 11.3 & 0.58 & 0.93 & 0.96 & 0.64 & 1.09 & 0.87 & 0.85 \\
\hline 98 & & SN42B & 300 & 1.49 & 4.0 & 11.0 & 0.78 & 1.26 & 1.27 & 0.85 & 1.46 & 1.17 & 1.13 \\
\hline 99 & & SN43A & 300 & 1.00 & 4.0 & 8.6 & 0.50 & 0.91 & 0.94 & 0.63 & 1.05 & 0.92 & 0.88 \\
\hline 100 & & SN43B & 300 & 1.00 & 4.0 & 11.1 & 0.54 & 0.87 & 1.03 & 0.68 & 1.01 & 0.92 & 0.87 \\
\hline 101 & & SN44A & 300 & 0.50 & 4.0 & 10.9 & 0.50 & 0.82 & 1.15 & 0.77 & 0.95 & 1.10 & 100 \\
\hline 102 & & SN44B & 300 & 0.50 & 4.0 & 10.2 & 0.43 & 0.73 & 0.99 & 0.66 & 0.84 & 0.97 & 0.87 \\
\hline 103 & & SN51A & 115 & 1.58 & 5.2 & 15.0 & 1.10 & 1.53 & 1.75 & 1.47 & 1.78 & 1.42 & 132 \\
\hline 104 & & SN51B & 115 & 1.58 & 5.2 & 11.0 & 1.03 & 1.67 & 1.64 & 1.37 & 1.94 & 1.47 & 1.38 \\
\hline 105 & & SN52A & 115 & 1.30 & 5.2 & 11.1 & 1.01 & 1.63 & 1.75 & 1.47 & 1.90 & 1.54 & 143 \\
\hline 106 & & SN52B & 115 & 1.30 & 5.2 & 10.7 & 0.90 & 1.47 & 1.55 & 1.30 & 1.71 & 1.38 & 129 \\
\hline 107 & & SN53A & 120 & 0.99 & 5.0 & 10.7 & 0.90 & 1.48 & 1.72 & 1.38 & 1.72 & 1.50 & 1.38 \\
\hline 108 & & SN53B & 120 & 0.99 & 5.0 & 10.4 & 0.42 & 0.70 & 0.80 & 0.64 & 0.81 & 0.71 & 0.65 \\
\hline 109 & & SN70A & 127 & 2.50 & 6.7 & 10.8 & 0.88 & 1.44 & 1.12 & 1.12 & 1.67 & 1.19 & 114 \\
\hline 110 & & SN70B & 127 & 2.50 & 6.7 & 10.6 & 0.90 & 1.49 & 1.14 & 1.14 & 1.73 & 1.23 & 118 \\
\hline 111 & & SN70C & 127 & 2.50 & 6.7 & 10.0 & 0.86 & 1.46 & 1.09 & 1.09 & 1.70 & 1.20 & 1.15 \\
\hline 112 & & SN70D & 127 & 2.50 & 6.7 & 10.1 & 0.92 & 1.52 & 1.14 & 1.14 & 1.77 & 1.25 & 1.27 \\
\hline 113 & \multirow[t]{5}{*}{ Brzev (2006) } & L1 & 250 & 0.84 & 4.2 & 17.1 & 0.89 & 1.16 & 1.80 & 1.24 & 1.35 & 1.39 & 138 \\
\hline 114 & & L2 & 250 & 0.84 & 4.2 & 17.1 & 0.97 & 1.26 & 1.95 & 1.35 & 1.47 & 1.50 & 105 \\
\hline 115 & & B1 & 250 & 0.84 & 4.2 & 17.1 & 0.74 & 0.96 & 1.49 & 1.03 & 1.12 & 1.14 & 115 \\
\hline 116 & & 82 & 250 & 0.84 & 4.2 & 17.1 & 0.81 & 1.05 & 1.63 & 1.12 & 1.22 & 1.25 & 1.13 \\
\hline 117 & & \$1 & 250 & 0.84 & 4.2 & 17.1 & 0.80 & 1.04 & 1.61 & 1.11 & 1.21 & 1.24 & 1.15 \\
\hline & & & & & & & Average & 1.28 & 1.54 & 1.05 & 1.49 & 1.33 & 1.25 \\
\hline & & & & & & & STDEV: & 0.36 & 0.52 & 0.30 & 0.41 & 0.28 & 0.26 \\
\hline & & & & & & $1 \mathrm{~s}$ & 'ercentile: & 0.45 & 0.31 & 0.34 & 0.52 & 0.68 & 0.63 \\
\hline
\end{tabular}




\section{The Strain Effect}

In Figure 2-29 the 117 experimentally determined failure shear stresses (normalized by the square-root of the masonry strength) are plotted versus $\mathrm{M} / \rho \mathrm{Vd}$ values. In this figure the strain effect can be very clearly seen, in that the failure shear stresses generally decrease with an increase in $\mathrm{M} / \mathrm{\rho Vd}$. Two series of beams by Li et al. (1994) are highlighted that in particular show the strain effect. In one of the series $\rho$ was kept constant with varying a/d while in the other series a/d was kept constant with varying $\rho$. It appears that RCM beams have exhibited similar behaviour to reinforced concrete beams in which failure shear stresses decrease with decreasing reinforcement ratio and increasing a/d ratio. It can be seen that both the TMS 402 and CSA masonry codes are not sensitive to the change in $\mathrm{M} / \rho \mathrm{Vd}$ as both predict constant values of normalized failure shear stress.

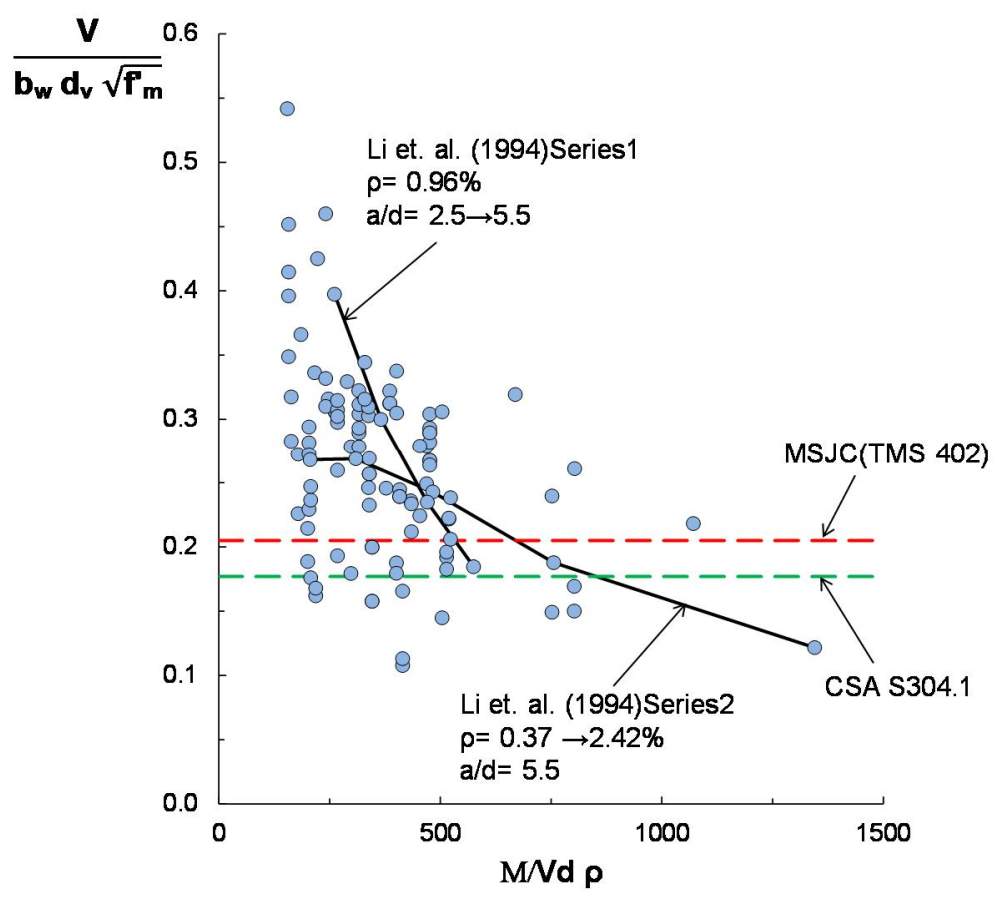

Figure 2-29: Illustration of the Strain Effect 
Figure 2-30 shows that the degree of conservatism of the TMS 402 and CSA S304.1 codes decreased as $\mathrm{M} / \rho \mathrm{Vd}$ increased. In this figure the failure shear stresses of the Li et. al. series of beams in which $\rho$ was varied are reported, along with the predicted failure shear stresses of the TMS 402, CSA S304.1 and the CSA A23.3 codes. Clearly, the CSA A23.3 code was able to captures the experimental behaviour of the series of beams quite effectively, and far better than the TMS 402 and CSA masonry codes. It is interesting that a design code specifically intended for reinforced concrete can accurately account for the effect of $\rho$ and a/d in masonry beams. Furthermore, as this code is formulated based on the assumption that aggregate interlock capacity of concrete at cracks governs shear strength, it would seem that, like RC beams, RCM beams transfer considerable shear stress across cracks below the neutral axis.

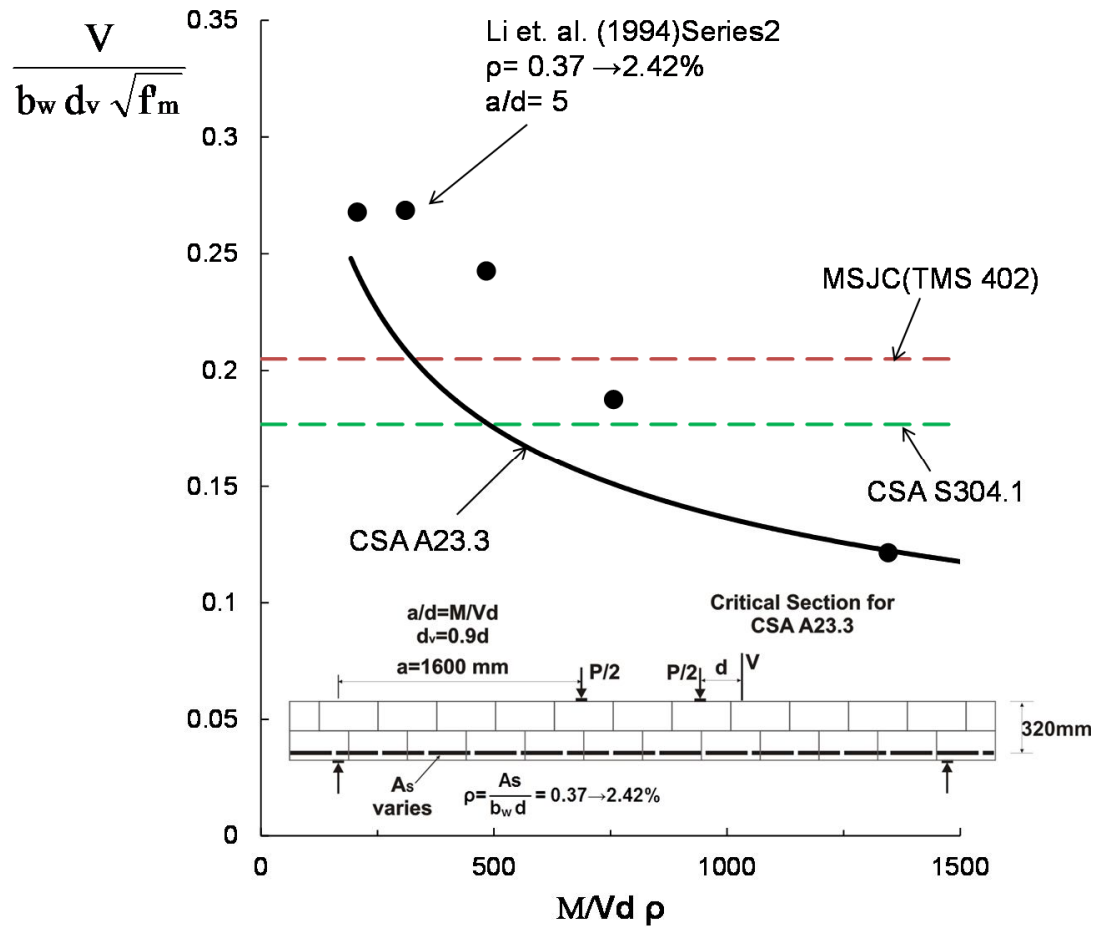

Figure 2-30: Code Predictions of the Strain Effect 
It is expected that the frictional characteristics of the cracks in reinforced masonry would affect the beam shear strength. One such characteristic would be the type of grout. In Figure 2-31, data from Suter et. al. (1984) is reproduced, in which beams with different fills (mortar or grout) were tested. All beams had a constant effective depth and $\rho$, with a varying a/d. The specimens indicated with the hollow points were filled with mortar (sand aggregate) while the specimens indicated by the solid points were filled with grout (mixed with sand and large aggregate). Clearly, the specimens with grout exhibited generally higher shear strengths than those grouted with mortar. The simplest explanation for this behaviour is that the cracks in the mortar-filled beams were smoother than those cracks in the beams with grout. It can be clearly seen that the General Method can account for the differences in shear strength of the use of different grout types.

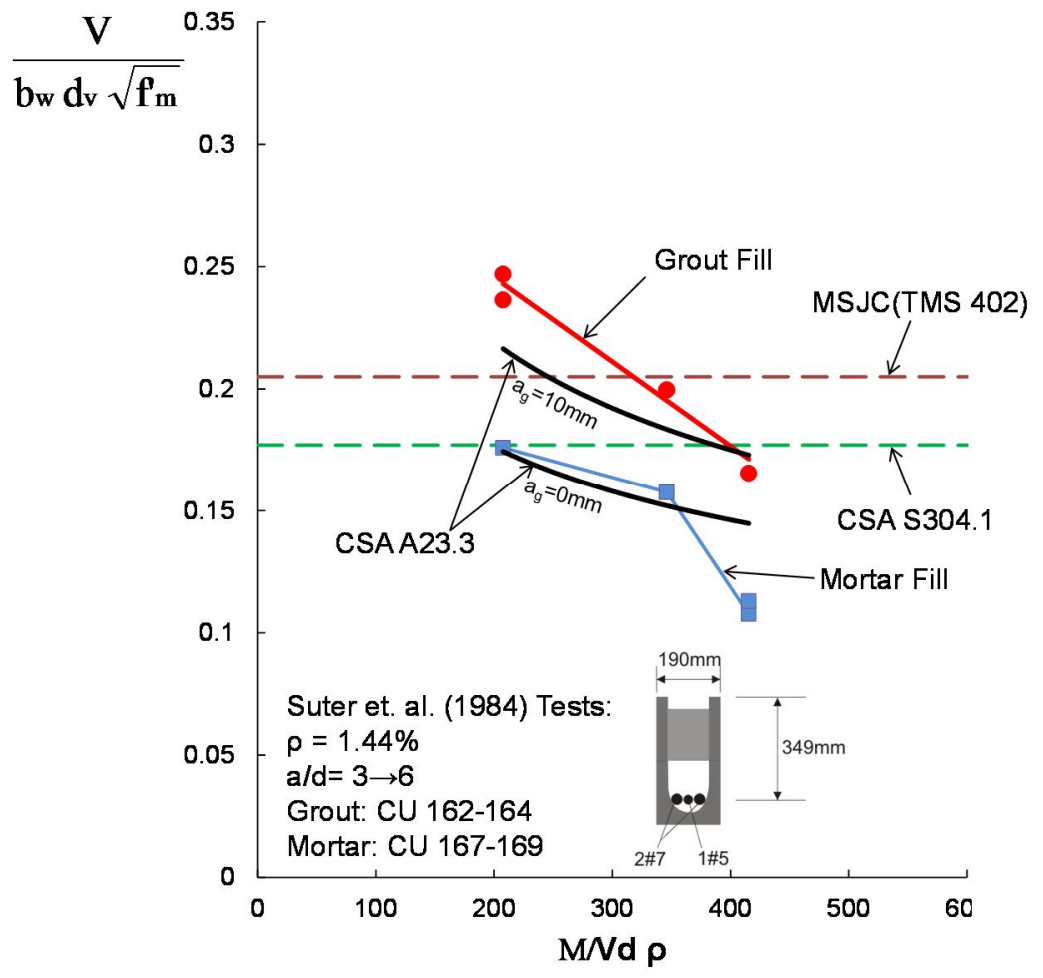

Figure 2-31: Effect of Fill on Failure Shear Stress 


\section{Accuracy and Safety of Code Predictions}

Tables 2-1 and 2-2 summarize the average ratios of experimental to predicted strengths, the standard deviations and the coefficient of variation values (COV). It can be seen in these tables that the British code had the lowest average $\mathrm{V}_{\text {exp }} / \mathrm{V}_{\text {pred }}$ ratio, the TMS 402 (ACI 530) code had an average value of 1.28 and both the Australian and Canadian codes had the highest average values.

Table 2-2: Summary of Shear Design Methods for RCM Beams

\begin{tabular}{|c|c|c|c|c|c|c|c|c|c|c|}
\hline \multirow{3}{*}{ Design Method } & \multirow{3}{*}{ Intended Use } & \multicolumn{5}{|c|}{ Key Parameters } & \multicolumn{4}{|c|}{ Predictive Ability } \\
\hline & & \multirow{2}{*}{$\mathrm{f}_{\mathrm{m}}$} & \multicolumn{3}{|c|}{ Strain Effect } & \multirow{2}{*}{$\begin{array}{l}\text { Size } \\
\text { Effect }\end{array}$} & \multirow{2}{*}{$\begin{array}{c}\text { Average } \\
\mathrm{V}_{\text {exp }} / \mathrm{V}_{\text {Pred }}\end{array}$} & \multirow{2}{*}{ STDV } & \multirow{2}{*}{$\mathrm{COV}$} & \multirow{2}{*}{$\begin{array}{c}1_{\text {st }} \\
\text { Percentile }\end{array}$} \\
\hline & & & $\mathbf{M} / \mathbf{V}$ & $\rho$ & $\mathbf{E}$ & & & & & \\
\hline TMS 402-2011 & Masonry-Steel Reinforced & $\mathrm{X}$ & & & & & 1.28 & 0.36 & 0.28 & 0.44 \\
\hline AS3700-2001 & Masonry-Steel Reinforced & & & $\mathrm{x}$ & & & 1.54 & 0.52 & 0.34 & 0.33 \\
\hline BS5628-2005 & Masonry-Steel Reinforced & & $\mathrm{X}$ & $\mathrm{X}$ & & & 1.05 & 0.30 & 0.29 & 0.35 \\
\hline CSA S304.1-2004 & Masonry-Steel Reinforced & $\mathrm{X}$ & & & & $\mathrm{X}$ & 1.49 & 0.41 & 0.28 & 0.53 \\
\hline CSA A23.3-General Method & Masonry-Steel Reinforced & $\mathbf{X}$ & $\mathbf{X}$ & $\mathbf{X}$ & $\mathbf{X}$ & $\mathbf{X}$ & 1.33 & 0.28 & 0.21 & 0.68 \\
\hline Hoult et al. & Masonry-FRP Reinforced & $\mathbf{X}$ & $\mathbf{X}$ & $\mathbf{X}$ & $\mathbf{X}$ & $\mathbf{X}$ & 1.25 & 0.26 & 0.21 & 0.64 \\
\hline
\end{tabular}

Another important and well-known parameter summarized in the tables is the "1st-percentile value," which has been traditionally used as an estimate of the required shear strength reduction factor (MacGregor and Bartlett (2000)) to achieve an appropriately safe design equation. That is, the shear strength reduction factor should be equal to or less than the $1^{\text {st }}$ percentile value for the design equation to be considered of sufficient safety. Assuming a normal distribution, the first percentile value is equal to 2.33 standard deviations from the mean.

In the case of the BS 5628-2:2005 method, for example, the first percentile value is equal to $1.05-2.33(0.30)=0.35$. It can thus be expected that $99 \%$ of the tested shear strengths will exceed 
0.35 times the strength calculated by Equation (2-27). Thus, while it would appear that the British code can accurately predict beam shear strength (due to its low average $\mathrm{V}_{\text {exp }} / \mathrm{V}_{\text {pred }}$ ratio) its high variation requires a very low material strength reduction factor in order to apply the code safely. This factor of 0.35 is smaller than the partial material reduction factor of 0.5 suggested by BS 5628-2:2005. Likewise, the $1^{\text {st }}$ percentile value of 0.33 for AS $3700-2001$ is well below the reduction factor of 0.75 used in this code. This can raise serious concerns about the safety of these codes when designing RCM beams. The $1^{\text {st }}$ percentile value for the CSA S304.1-04 of 0.53 is lower than the reduction factor of 0.6 adopted in the code. As the $0.681^{\text {st }}$ percentile value calculated above is greater than the reduction factor in CSA S304.1-04, it can be concluded that the CSA A23.3 general method would provide both the safest and most accurate designs of RCM beams in Canada. It is interesting also to note that the Hoult et al. modified equation for $\beta$ (Equation (2-19)) provides marginally more accurate shear strength predictions, with a $1^{\text {st }}$ percentile value that remains above 0.6.

To further demonstrate the accuracy of the general method, consider Figure 2-32 and Figure 2-33 in which the values of the $\mathrm{V}_{\text {exp }} / \mathrm{V}_{\text {pred }}$ ratios for the 117 beam database are plotted for the CSA S304.1, TMS 402 and CSA A23.3 codes. Compared with the shear strength predictions generated by TMS 402 and CSA S304.1, it can be seen that the CSA A23.3 code provides a consistent level of safety over the range of $\rho$ and a/d considered. 

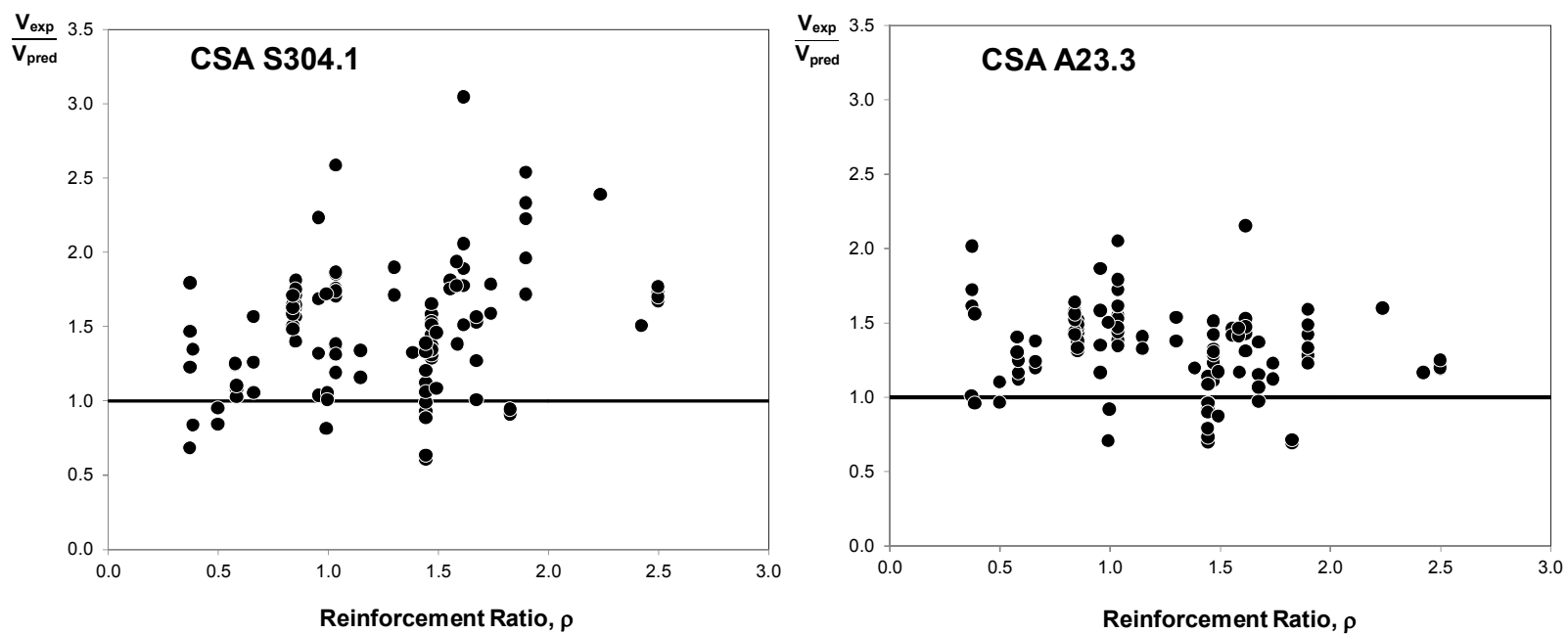

Figure 2-32: Comparison of CSA A23.3 and CSA S304.1 Shear Strength Predictions
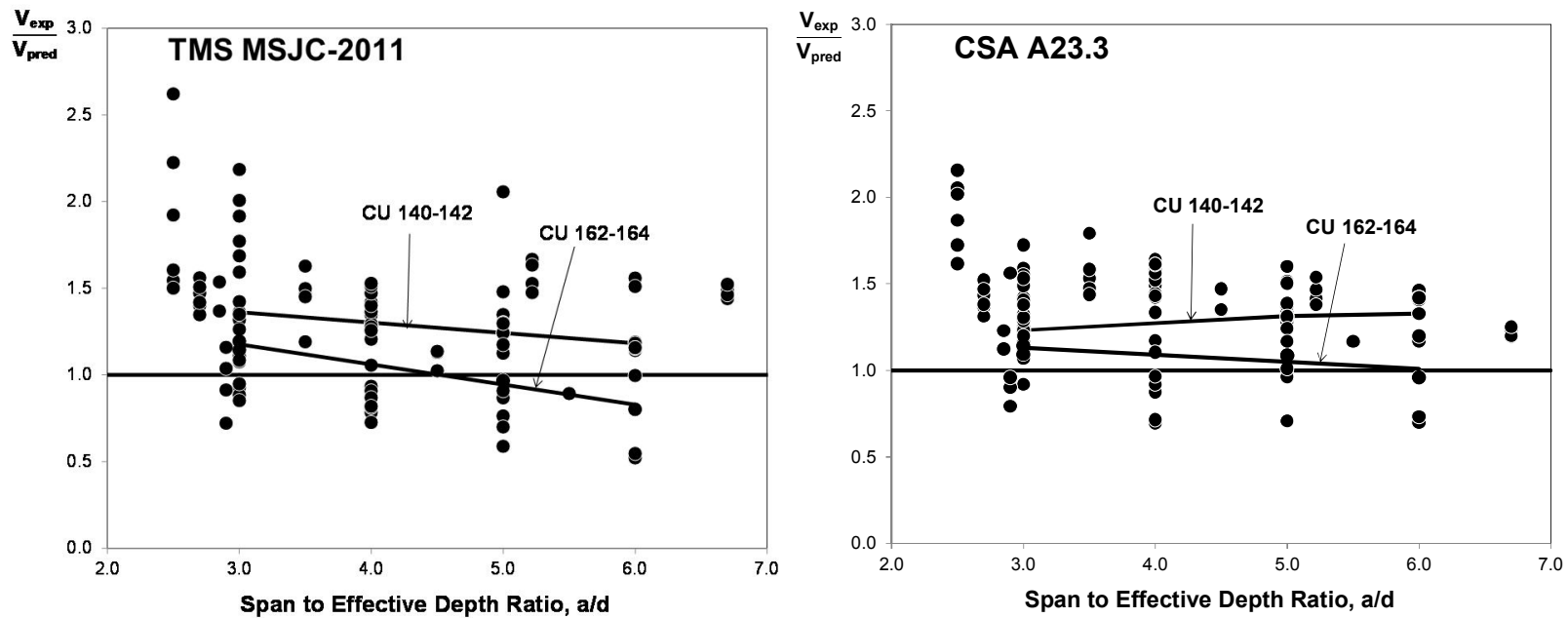

Figure 2-33: Comparison of CSA A23.3 and TMS 402-2011 Shear Strength Predictions

\subsection{Concluding Remarks}

Few investigations have been conducted on the shear behaviour of reinforced masonry beams.

These investigations did not cover all the factors affecting the shear strength of reinforced 
masonry, such as the size effect. Furthermore, these investigations yielded conflicting results for some of the factors that are known to be significantly influential on the shear strength of reinforced concrete beams. In general, the following major gaps in the existing literature on shear behaviour can be identified:

1- Although Suter and Keller (1980) were the first to identify the existence of the size effect in masonry, this factor has not been studied thoroughly. Suter and Keller (1980) made their observation only on one and two course beams. Masonry beams with more than two courses, such those discussed in Chapter 1, have not been tested in shear. There is a very serious risk to public safety when dealing with shear design methods that do not account for the size effect (Sherwood et. al. (2007)). There is a clear need for experimental data and analysis on beams that are very deep. This will assist in the development of rational, theoretically-sound shear design provisions, the application of which will ensure appropriate levels of safety for the types of large-scale structural elements shown in Figures 1-5 to 1-7.

2- The strain effect on shear strength in reinforced masonry has been studied, however conflicting results were reached. While Feriege suggests $\rho$ and $a / d$ have no effect on shear strength of RCM beams, Li et al. showed that these factors are very influential. Suter and Kellers $(1980,1984)$ found that $\rho$ and $a / d$ have an effect, but the effect was less significant in masonry than in concrete. Neither the TMS MSJC-2011 nor CSA S304.1 codes accounts for the strain effect in their shear equations. 
The strain effect can be expected to dominate the behavior of reinforced masonry walls. As such it is important to further study the strain effect in reinforced masonry. This importance was confirmed by Banting and El-Dakhakhni (2012) who used test results of eight full scale reinforced masonry walls tested by Miller et al. (2005) to evaluate the application of Modified Compression Field Theory to predict the shear strength of reinforced masonry walls. The General Method of the CSA A23.3-2004 resulted in more accurate estimate of shear strength predict the shear strength of reinforced masonry walls compared to the CSA S04.1-2004.

3- The mechanisms of shear resistance in reinforced concrete have been the focus of many studies. Moe (1962), Fenwick and Paulay (1964, 1968), MacGregor (1964), Taylor (1970), MacGregor and Walters (1967), Kani et al. (1979), Sherwood et. al. (2007) and Sherwood (2008) have convincingly confirmed that the majority of the shear in a concrete section without web reinforcement is transferred by interlocking of aggregate particles at cracks below the neutral axis. To the author's best knowledge, the mechanisms of shear resistance in reinforced masonry has not been studied yet to such a degree. Furthermore, the well accepted mechanism of "aggregate interlock" is not considered in the shear equations in the different masonry design codes. It is worthwhile to study the shear resistance mechanisms in RCM beams.

4-Besides being limited, the previous investigations on shear behaviour of RCM beams have only focused on the ultimate shear strength. Less attention has been paid to cracking behaviour of reinforced masonry. A detailed measurement and analysis of cracks widths and spacing in small and large masonry beams can help in studying how shear cracking and flexural-shear cracking affect the shear capacity of reinforced masonry. To the author's knowledge this has not been done for reinforced masonry. 
5- The comparative study of the predictive abilities of different masonry design codes showed that these codes are conservative in predicting shear strength of RCM beams. This conservatism, however, is associated with high coefficients of variation. The $1^{\text {st }}$ percentile values of all four of the masonry codes analyzed were lower than the shear strength reduction factors adopted in the codes. As such, it appears worthwhile to review these equations for future editions of the codes. It is most interesting, and indeed quite promising, that shear design methods based on the Modified Compression Field Theory work so well with reinforced masonry. It appears possible to develop a comprehensive, rational theory for shear in reinforced masonry based on the Modified Compression Field Theory that will apply to elements in addition to beams, such as walls, pilasters and columns. The advantage of formulating shear design expressions based on an accurate theory rather than curve fitting to experiments is that accurate predictions of shear strengths can be made where no experimental data exist. 


\section{CHAPTER 3: EXPERIMENTAL PROGRAM}

\subsection{General}

This chapter presents an explanation of the experimental portion of this research. A total of fifteen reinforced masonry beams, thirteen without stirrups and two with stirrups, were constructed and loaded to failure in the John Adjeleian Laboratory at Carleton University. These beams were designed to investigate the effects of the following factors on the shear behaviour of reinforced masonry: the effective depth, $d$, (size effect), the longitudinal reinforcement ratio $(\rho)$, the longitudinal reinforcement stiffness (steel rebars versus GFRP), the existence of distributed longitudinal reinforcement, and transverse reinforcement (stirrups).

\subsection{Beams Geometry and Reinforcement Details}

A summary of the fifteen specimens is presented in Figures 3-1 to 3-2 and Table 3-1. It can be seen that the beams are classified into three groups based on their size: Large beams made with eight courses of $240 \mathrm{~mm}$ wide concrete block units, Medium beams made of five courses of 190 mm wide concrete block units and small beams made out of two courses of $190 \mathrm{~mm}$ wide concrete block units. The beams are labeled according to their size and the reinforcement contents in them. Three notations were used in labeling the beams. The first notation is the letter $\mathrm{S}$ which refers to the first letter of the last name of the author. The second notation refers to the size of the beam: $\mathrm{L}$ for large, $\mathrm{M}$ for middle and $\mathrm{S}$ for small. The third notation is a number that refers to the reinforcement ratio or type. 


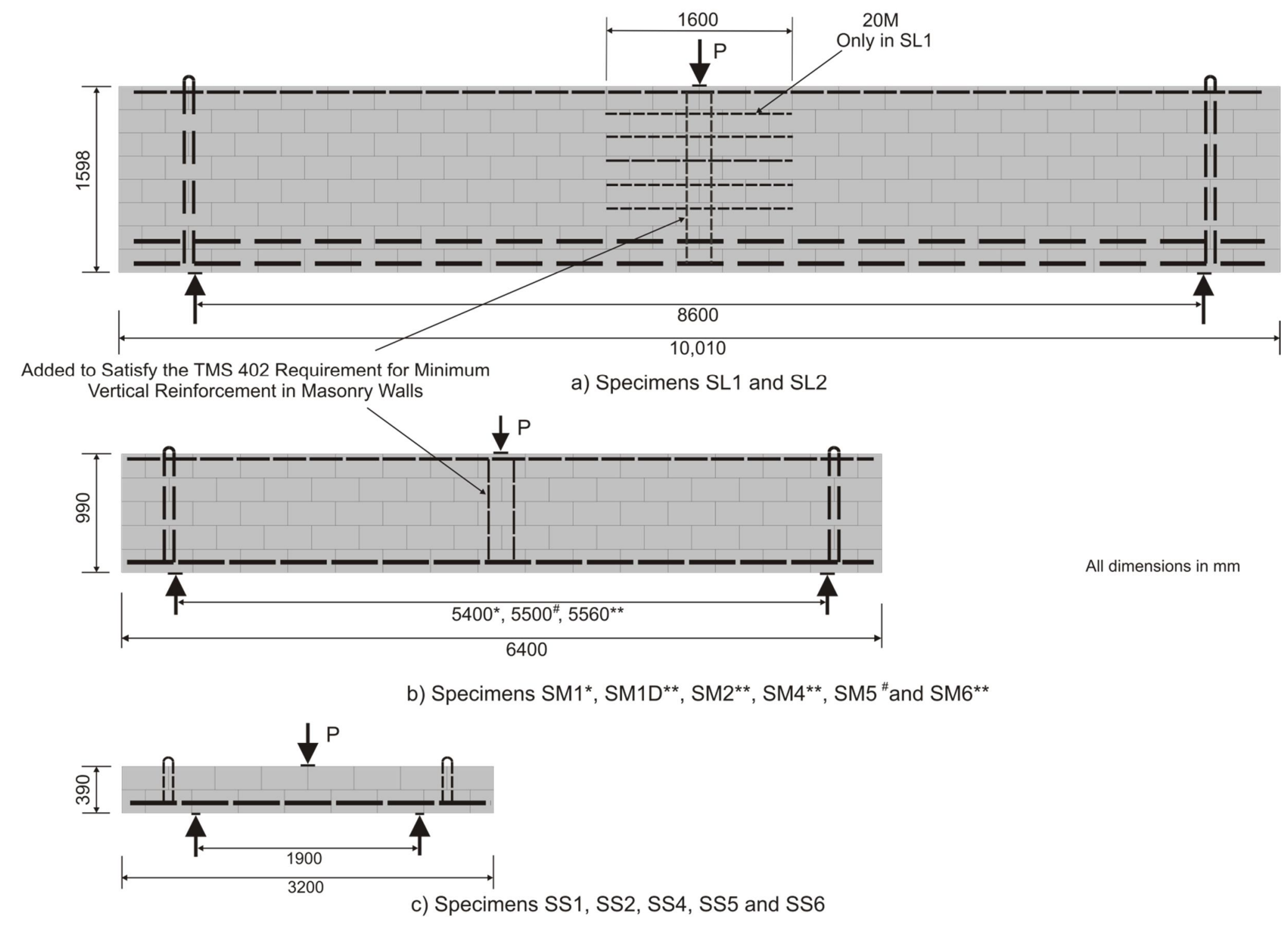

Figure 3-1: Reinforced Masonry Beams without Web Reinforcement 


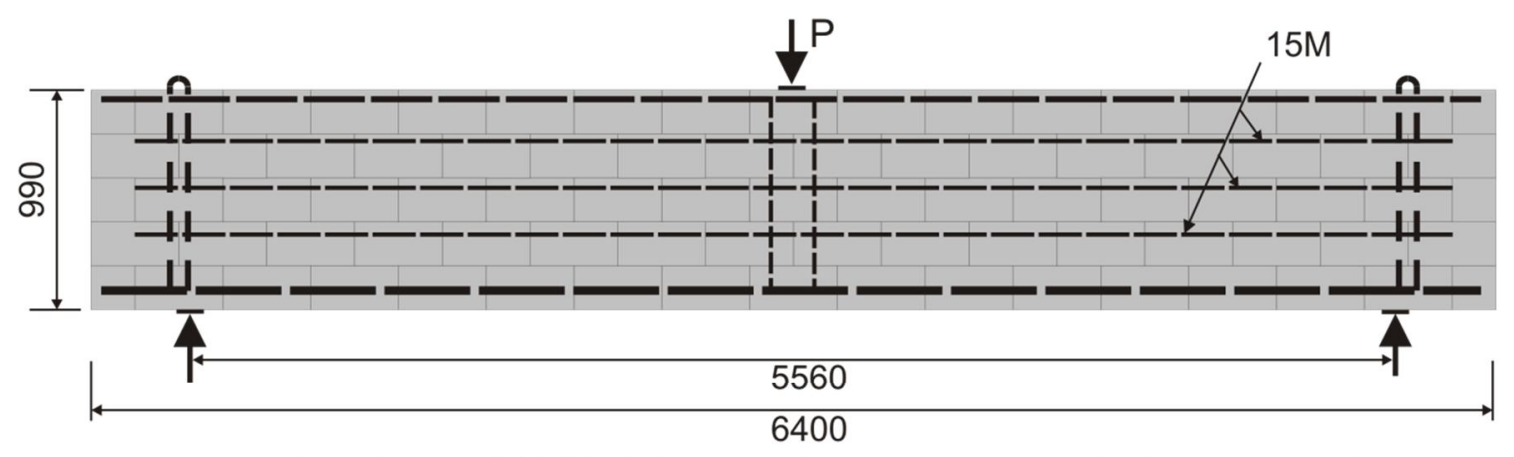

a) Specimen SM6 (Reinforced with Horizontally Distributed Steel)

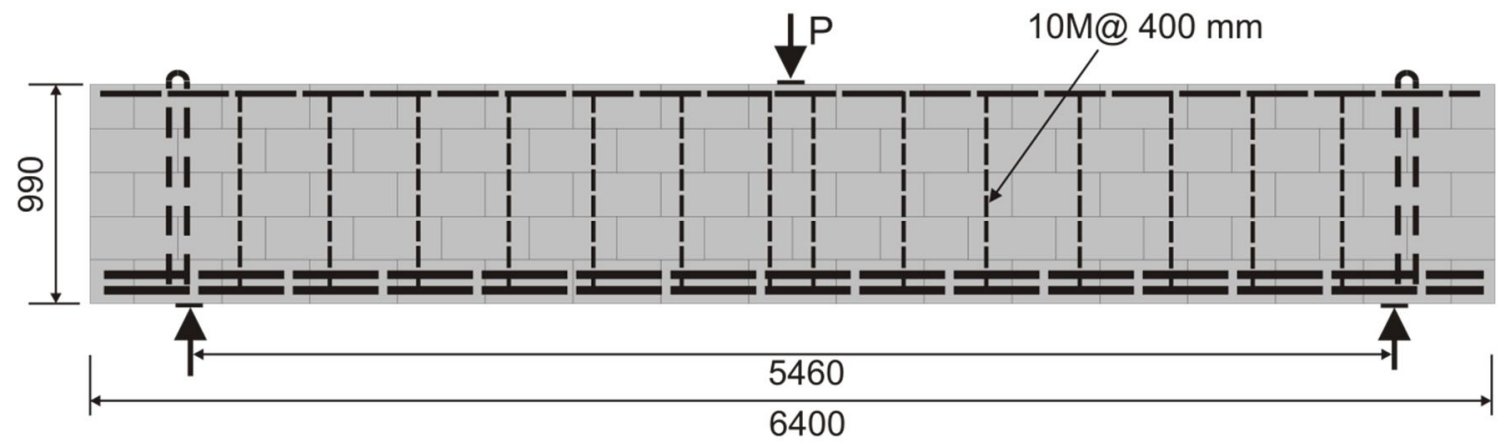

b) Specimen SM3 (Reinforced with Stirrups)

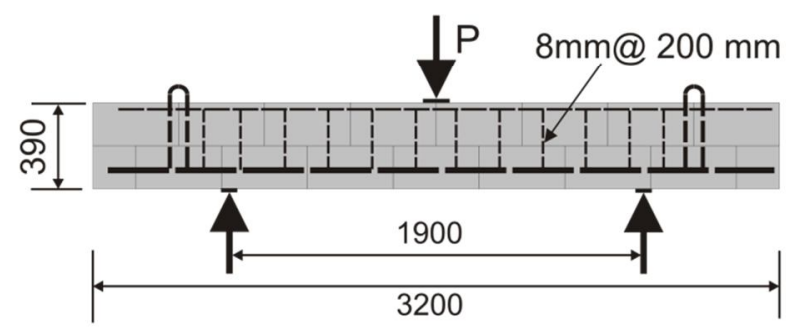

All dimensions in $\mathrm{mm}$

c) Specimen SS3 (Reinforced with Stirrups)

Figure 3-2: Reinforced Masonry Beams with Web Reinforcement 


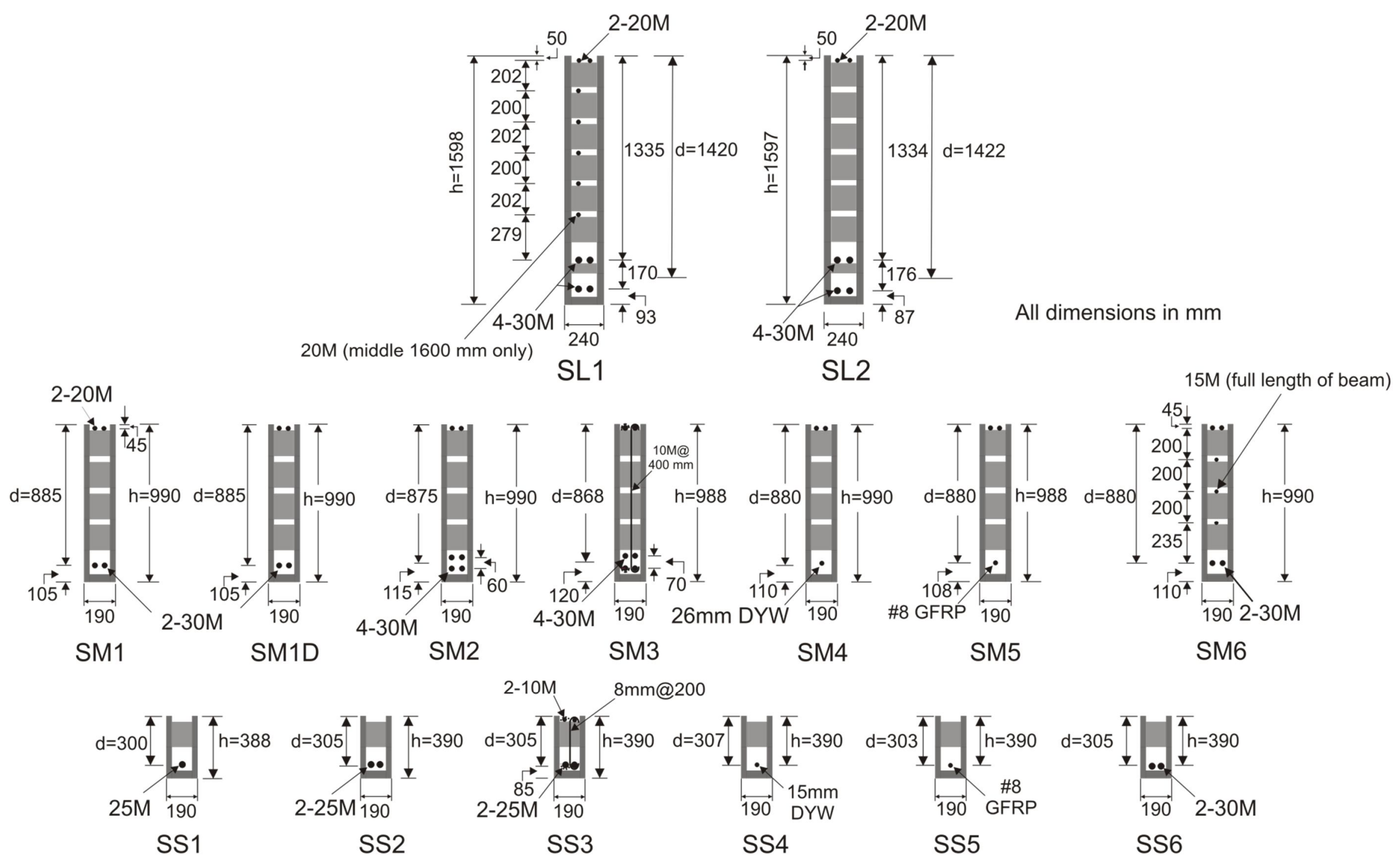

Figure 3-3: Cross-Section and Reinforcement Details of the Reinforced Masonry Beams (As Built Dimensions) 
Table 3-1: Geometry and Reinforcement Details of the Reinforced Masonry Beams

\begin{tabular}{|c|c|c|c|c|c|c|c|c|c|c|c|c|}
\hline \multirow{2}{*}{$\begin{array}{l}\text { Beam } \\
\text { Name }\end{array}$} & \multicolumn{6}{|c|}{ Geometry (As-Built Dimensions)* } & \multicolumn{4}{|c|}{ Main Reinforcement } & \multirow{2}{*}{$\begin{array}{c}\text { Crack } \\
\text { Control } \\
\text { Steel }\end{array}$} & \multirow{2}{*}{ Stirrups } \\
\hline & $\stackrel{\mathrm{L}}{(\mathrm{mm})}$ & $\begin{array}{c}\mathrm{h} \\
(\mathrm{mm})\end{array}$ & $\begin{array}{l}\text { Shear } \\
\text { span } \\
(\mathrm{mm})\end{array}$ & $\underset{(\mathrm{mm})}{\mathrm{d}}$ & $\mathrm{a} / \mathrm{d}$ & $b_{w}$ & Rebars & Type & $\begin{array}{c}\mathrm{As} \\
\left(\mathrm{mm}^{2}\right)\end{array}$ & $\rho(\%)$ & & \\
\hline SS1 & 3202 & 388 & 950 & 300 & 3.17 & 190 & $25 \mathrm{M}$ & S & 500 & 0.88 & - & - \\
\hline SS2 & 3200 & 390 & 950 & 305 & 3.11 & 190 & $2-25 \mathrm{M}$ & $\mathrm{S}$ & 1000 & 1.73 & - & - \\
\hline SS3 & 3200 & 390 & 950 & 305 & 3.14 & 190 & $2-25 \mathrm{M}$ & $\mathrm{S}$ & 1000 & 1.74 & - & $\begin{array}{c}8 \mathrm{~mm} @ \\
200\end{array}$ \\
\hline SS4 & 3200 & 390 & 950 & 307 & 3.10 & 190 & $15.6 \mathrm{~mm}$ & DYW & 177 & 0.30 & - & - \\
\hline SS5 & 3200 & 390 & 950 & 303 & 3.14 & 190 & $\# 5$ & GFRP & 197 & 0.34 & - & - \\
\hline SS6 & 3200 & 390 & 950 & 305 & 3.11 & 190 & $2-30 \mathrm{M}$ & S & 1400 & 2.45 & - & - \\
\hline SM1 & 6400 & 990 & 2700 & 885 & 3.05 & 190 & $2-30 \mathrm{M}$ & S & 1400 & 0.83 & - & - \\
\hline SM1D & 6400 & 990 & 2780 & 885 & 3.14 & 190 & $2-30 \mathrm{M}$ & S & 1400 & 0.83 & - & - \\
\hline SM2 & 6400 & 990 & 2780 & 875 & 3.18 & 190 & $4-30 \mathrm{M}$ & S & 2800 & 1.68 & - & - \\
\hline SM3 & 6400 & 988 & 2730 & 868 & 3.15 & 190 & 4-30M & S & 2800 & 1.70 & - & $\begin{array}{c}10 \mathrm{M} @ \\
400\end{array}$ \\
\hline SM4 & 6400 & 990 & 2780 & 880 & 3.16 & 190 & $26 \mathrm{~mm}$ & DYW & 548 & 0.33 & - & - \\
\hline SM5 & 6400 & 988 & 2750 & 880 & 3.13 & 190 & $\# 8$ & GFRP & 507 & 0.30 & - & - \\
\hline SM6 & 6400 & 990 & 2780 & 880 & 3.16 & 190 & $2-30 \mathrm{M}$ & S & 1400 & 0.83 & (1) & - \\
\hline SL1 & 10010 & 1598 & 4300 & 1420 & 3.03 & 240 & 4-30M & S & 2800 & 0.82 & (2) & - \\
\hline SL2 & 10010 & 1597 & 4300 & 1422 & 3.02 & 240 & 4-30M & S & 2800 & 0.82 & - & - \\
\hline
\end{tabular}

* Final dimensions after construction and grouting of the beams. The reinforcement depth (d) was re-measured after testing the beams.

(1) $15 \mathrm{M}$ each course (full length of beam)

(2) $20 \mathrm{M}$ each course (middle $1600 \mathrm{~mm}$ of beam only)

Two beams were constructed in the large series: SL1 and SL2. The nominal dimensions of these eight course beams were $240 \mathrm{~mm}$ wide, $1590 \mathrm{~mm}$ high and 10,000 $\mathrm{mm}$ long. Both beams were 
reinforced with four $30 \mathrm{M}$ conventional steel bars (giving a main reinforcement ratio $(\rho)$ of $0.82 \%$ ) and two $20 \mathrm{M}$ rebars as the top course. Both beams are identical except that SL1 was additionally reinforced with $20 \mathrm{M}$ rebars in the third to the seventh courses over a distance of 1.6 $m$ in the center of the beam.

The middle size series consisted of seven beams with nominal dimensions of $190 \mathrm{~mm}$ wide, 990 $\mathrm{mm}$ high, and $6400 \mathrm{~mm}$ long. Three of the specimens (SM1, SM1D (duplicate of SM1) and SM6) were reinforced in flexure with two 30M conventional steel bars with SM6 additionally reinforced with one $15 \mathrm{M}$ longitudinal steel bar distributed in each of the three middle courses. Specimens SM2 and SM3 were reinforced with four 30M conventional steel bars with SM3 additionally reinforced with $10 \mathrm{M}$ single leg stirrups every $400 \mathrm{~mm}$. Specimen SM4 was reinforced with a single $26 \mathrm{~mm}$ Dywidag bar (with a cross-sectional area of $548 \mathrm{~mm}^{2}$, a yield strength of $830 \mathrm{MPa}$ ) while Specimen SM5, on the other hand, was reinforced with a \#8 GFRP bar (with a cross-sectional area of $507 \mathrm{~mm}^{2}$, a Young's modulus of 51,900MPa and a yield strength of $675 \mathrm{MPa}$ ). All beams in this series were reinforced with two $20 \mathrm{M}$ bars in the upper course as compression reinforcement.

The small size series consists of six beams made out of two courses with nominal dimensions of $190 \mathrm{~mm}$ width, height $390 \mathrm{~mm}$ height, and $3200 \mathrm{~mm}$ length. Specimen SS1was reinforced with a single 25M conventional steel bar. Specimens SS2 and SS3 were reinforced in flexure with two $25 \mathrm{M}$ conventional steel bars with SS3 additionally reinforced with $8 \mathrm{~mm}$ single leg stirrups every $200 \mathrm{~mm}$ and two 10M bars in compression to hold the stirrups in place. Specimen SS4 was reinforced with a $15 \mathrm{~mm}$ Dywidag bar (with a cross-sectional area of $177 \mathrm{~mm}^{2}$ and a yield 
strength of $900 \mathrm{MPa}$ ) while SS5 was reinforced with a \#5 GFRP bar (with a cross-sectional area of $197 \mathrm{~mm}^{2}$, a Young's modulus of 48,200MPa and a yield strength of $675 \mathrm{MPa}$ ). Lastly, Specimen SS6 was reinforced with two 30M conventional steel bars.

The effect of size on failure shear stress of reinforced masonry beams can be studied by direct comparison between the results of specimens SS1 (of d=300 mm), SM1and SM1D (of d=885 $\mathrm{mm})$, and SL1 and SL2 ( $\mathrm{d}=1420 \mathrm{~mm}$ and $1422 \mathrm{~mm})$. These beams have approximately constant reinforcement ratios $(\rho)$ ranging from 0.82 to of $0.88 \%$. The effect of size on failure shear stress can also be studied by comparing the results of SS2 $(\mathrm{d}=305 \mathrm{~mm})$ to $\mathrm{SM} 2(\mathrm{~d}=875 \mathrm{~mm})$ for an average $\rho$ of $1.71 \%$, SS4 (of $d=307 \mathrm{~mm})$ to SM4 $(\mathrm{d}=880 \mathrm{~mm})$ for an average $\rho$ of $0.32 \%$ and SS5 $(d=303 \mathrm{~mm})$ to SM5 $(d=880 \mathrm{~mm})$ for an average $\rho$ of $0.32 \%$. The a/d ratios for all these beams are approximately constant at 3.10 , ranging from to 3.02 to 3.18 .

The strain effect on failure shear stress can be studied by direct comparison between the results of the beams within each series of middle and small beams. The effect of using different reinforcement ratios can be studied by comparing the results of SS1 $(\rho=0.88 \%)$, SS2 $(\rho=1.74 \%)$, SS4 $(\rho=0.30 \%)$ and SS6 $(\rho=2.42 \%)$. Likewise, the effect of reinforcement ratio can be studied by examining SM1 and SM1D $(\rho=0.83 \%)$, SM2 $(\rho=1.68 \%)$ and SM4 $(\rho=0.33 \%)$. The effect of using different reinforcement stiffnesses on shear strength can be investigated by comparing the results of SS4 (reinforced with a $15 \mathrm{~mm}$ Dywidag bar with Young's modulus of 205,000MPa) to SS5 (reinforced with a \#5 GFRP bar with Young's modulus of 48,200MPa) and SM4 (reinforced 
with a $26 \mathrm{~mm}$ Dywidag bar with Young's modulus of 205,000MPa) to SM5 (reinforced with a \#8 GFRP bar with Young's modulus of 51,900MPa).

To study the effect of using horizontally distributed steel on the shear strength of reinforced masonry, test results of specimen SM6 (reinforced with one 15M longitudinal steel bar distributed in each of the three middle courses) will be compared to those of specimen SM1D which has the same $\rho$ and $(\mathrm{a} / \mathrm{d})$ ratios. The effect of the skin reinforcement on flexural crack widths in reinforced masonry will be investigated by comparing the crack patterns and width of specimens SL1 and SL2. These two beams are identical except for SL1 being additionally reinforced with five $20 \mathrm{M}$ steel rebars (one in each course from third to seventh course) in the center of south face over $1600 \mathrm{~mm}$.

The effect of using stirrups on failure shear stress can be studied by comparing results of specimens SS2 versus SS3 that are identical except for that SS3 is reinforced with stirrups. The effect of stirrups on shear behaviour of RMB can also be investigated in the medium size series by comparing the results of specimens SM2 to those of SM3.

\subsection{Steel Strain Gauges Installation}

In order to determine and record the reinforcement strains during the loading, various rebars were instrumented with strain gauges at different locations. The locations of the strain gauges are outlined in Figures 3-4 and 3-5. The labeling of the strain gages installed on the main reinforcement rebars depends on the location of the strain gauges inside the beam (center of the 
beam $(M)$, quarters $(\mathrm{Q})$ and ends $(\mathrm{E})$ of the beams. For example, strain gauge QNW refers to a strain gauge located at the north face of the west quarter of the beam. Twenty four strain gauges installed were installed on the stirrups of strain gauges specimen SM3, twelve in each span: East and West.

The installation procedures of the strain gauges consisted of multiple steps:

- To attach the strain gauges properly, a smooth surface was made. The ribs of the steel in the location of installation were removed using a cutting disc. In the case of the GFRP rebar, a small piece of steel plate with sharp teeth was used to carefully remove the thin sand layer from the location of installation. A dynafile abrasive belt was used after that to make the smooth surface.

- The strain gauges were installed using M-Bond 200 adhesive. To obtain the proper results, the installation procedures as outlined in the installation Bulletin of M-bond 200 adhesive were followed.

- After installation, lead wires were soldered to the strain gauges and their resistances were checked using a switch and balances unit. The lead were tied to the bar using zip-ties to avoid any movements during the grouting.

- The next step was covering the installation area with adequate protective coatings. To examine protection against humid exposure during grouting, the whole surface of the installation area was covered by wax. The wax then was covered by proofing tape. 


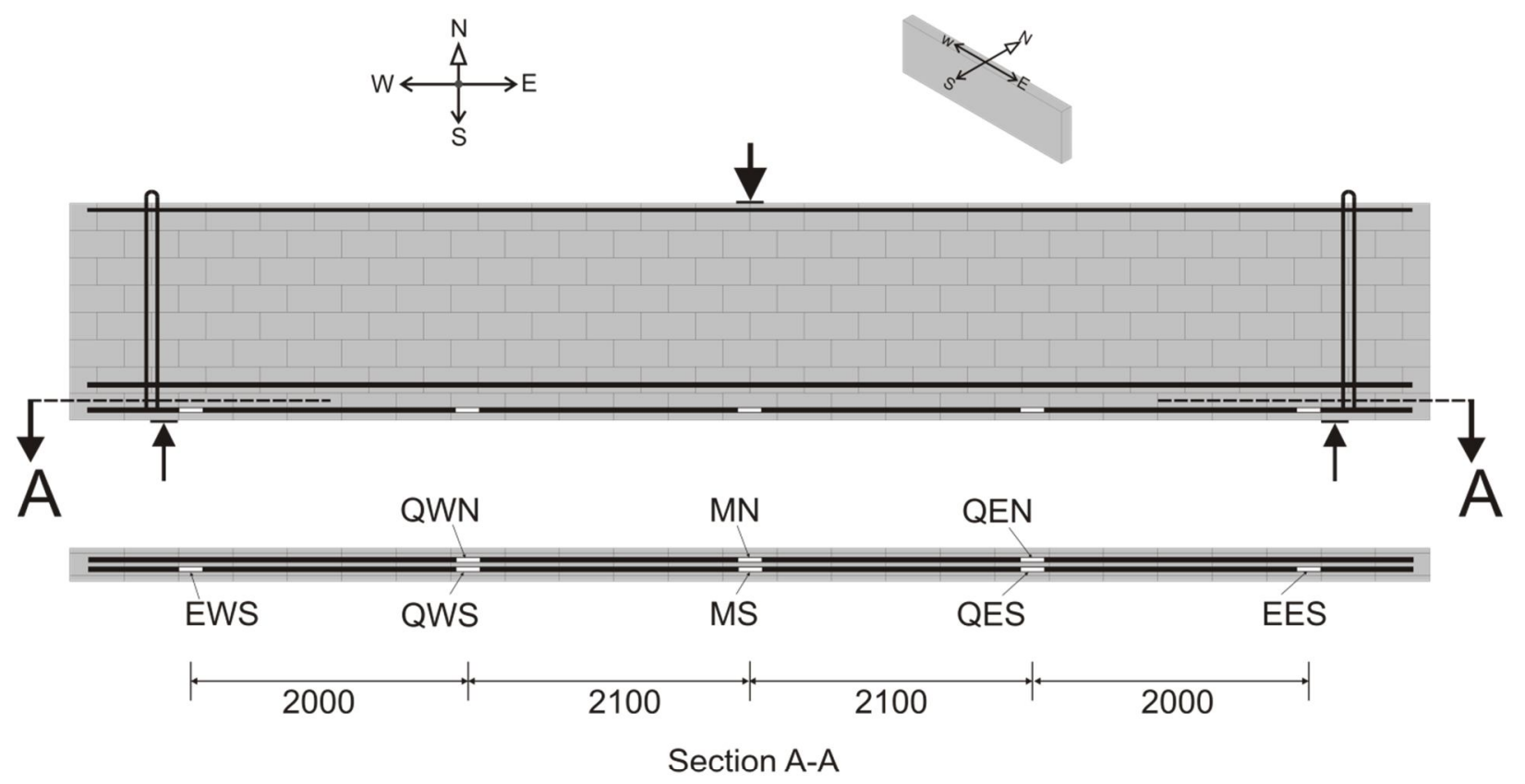

Locations of steel strain gauges in SL1 and SL2

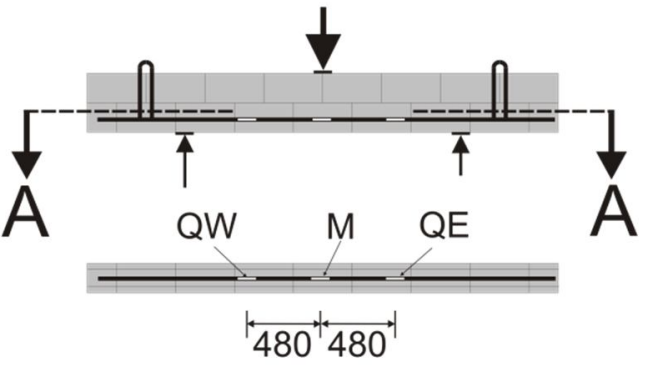

Locations of steel strain gauges in SS1, SS4 and SS5

QWS MS QWN

Locations of steel strain gauges in SS2, SS3 and SS6

Section A-A

Figure 3-4: Steel Strain Gauge Locations for Small and Large Beam Series 


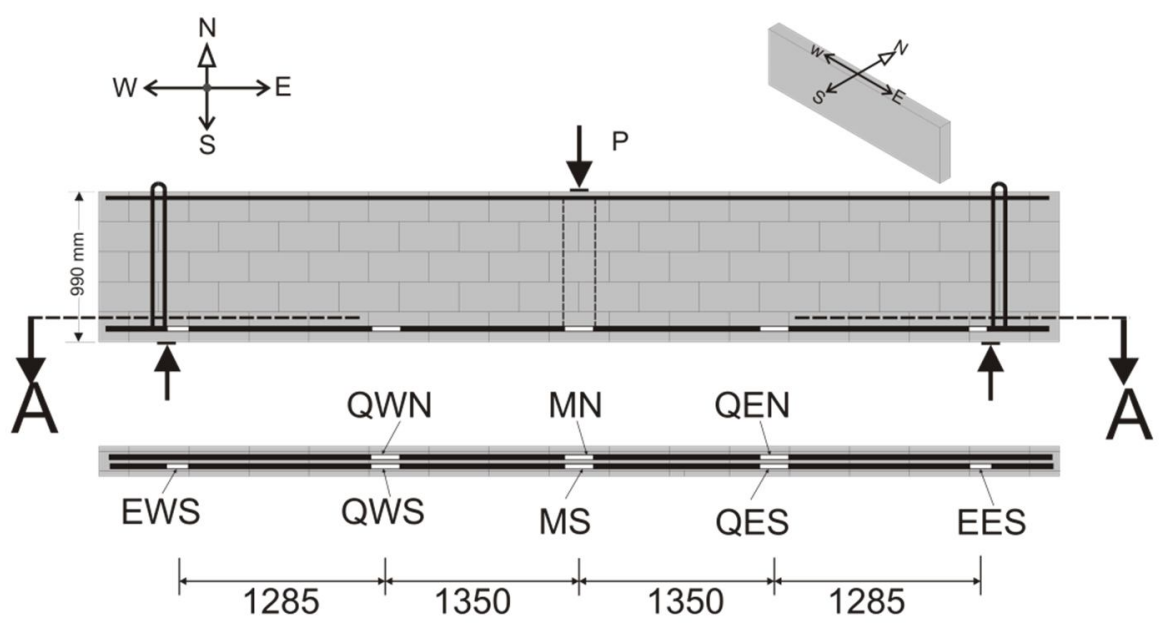

Locations of steel strain gauges in SM1, SM1D and SM6

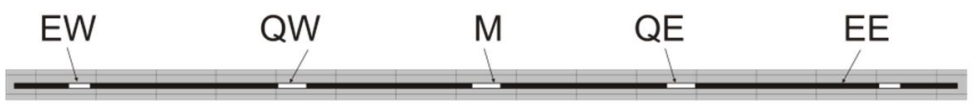

Locations of steel strain gauges in SM4 and SM5

Section A-A

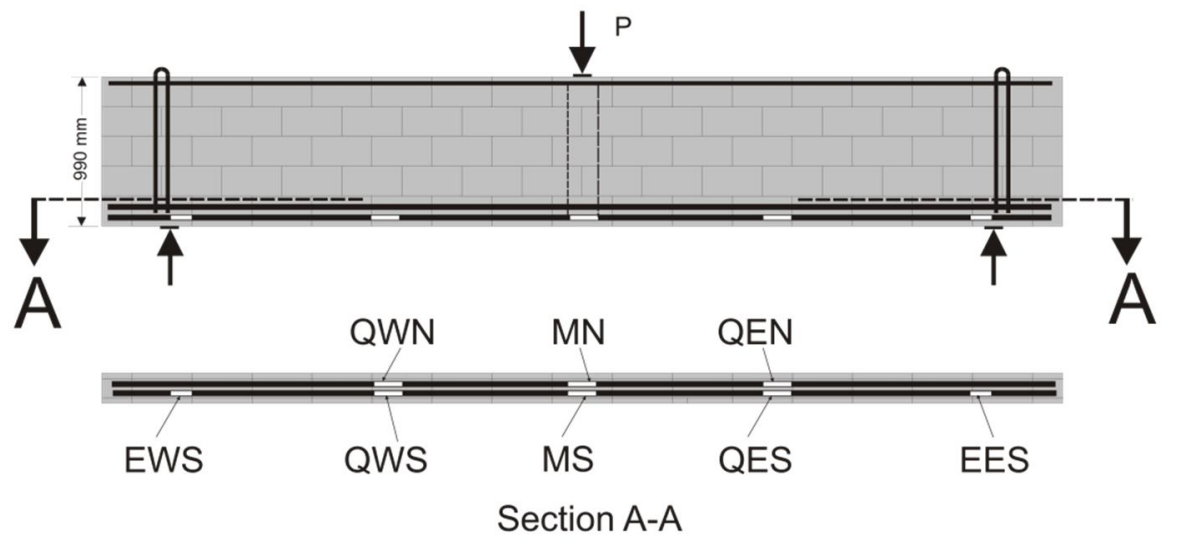

Locations of steel strain gauges in SM2

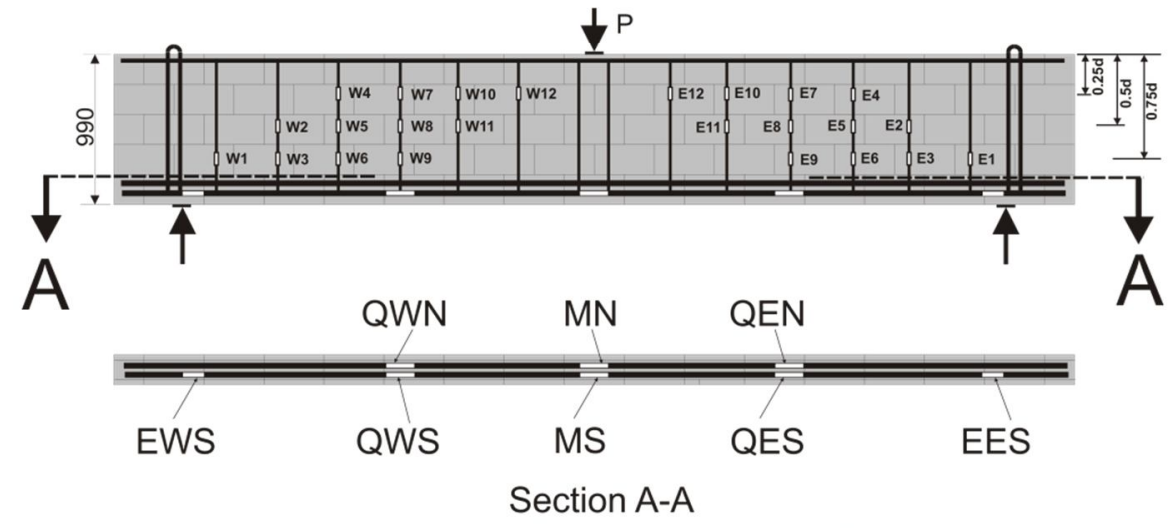

Locations of steel strain gauges in SM3

Figure 3-5: Steel Strain Gauge Locations for Medium Beam Series 


\subsection{Construction Procedure}

The experimental program encompasses construction of 15 reinforced masonry beams and 41 masonry prisms. In all beams bond beam units were used in the first course and depressed web units in the upper courses. The small and medium series were built with $190 \mathrm{~mm}$ unit blocks while the large beams were built with $240 \mathrm{~mm}$ unit blocks. Figures 3-6 to 3-8 present the configurations of the unit blocks used in the current investigation. These prisms were built and tested to determine compressive strength and the modulus of elasticity of the masonry. Each prism is identified with a name. Prims built with $190 \mathrm{~mm}$ blocks have three letter names: the first term denotes that it is a prism $(\mathrm{P})$, the second term indicates the direction of the applied load ( $\mathrm{N}$ for normal to the bed joint and $\mathrm{P}$ for parallel to the bed joint) and the third term is a numerical designation (given in the order of their testing sequence). Prisms built with $240 \mathrm{~mm}$ blocks have four letter names: the first two terms denotes that it is a large prism (PL), the third term indicates the direction of the applied load ( $\mathrm{N}$ for normal to the bed joint and $\mathrm{L}$ for parallel to the bed joint) and the fourth term is a number showing the order of their testing sequence. The construction process consists of many steps: block cutting, block laying and construction of the beams and the associated prisms and grouting the beams and the prisms.

\subsubsection{Block Cutting}

The configuration of the beams and the prisms required that many block units be cut into different shapes. Figures 3-9 and 3-10 show different block cuts used to construct the small, middle, and large size beams with their associated masonry prisms. An electric wet saw with a $500 \mathrm{~mm}$ diameter diamond blade was used to cut units (Figure 3-11). 

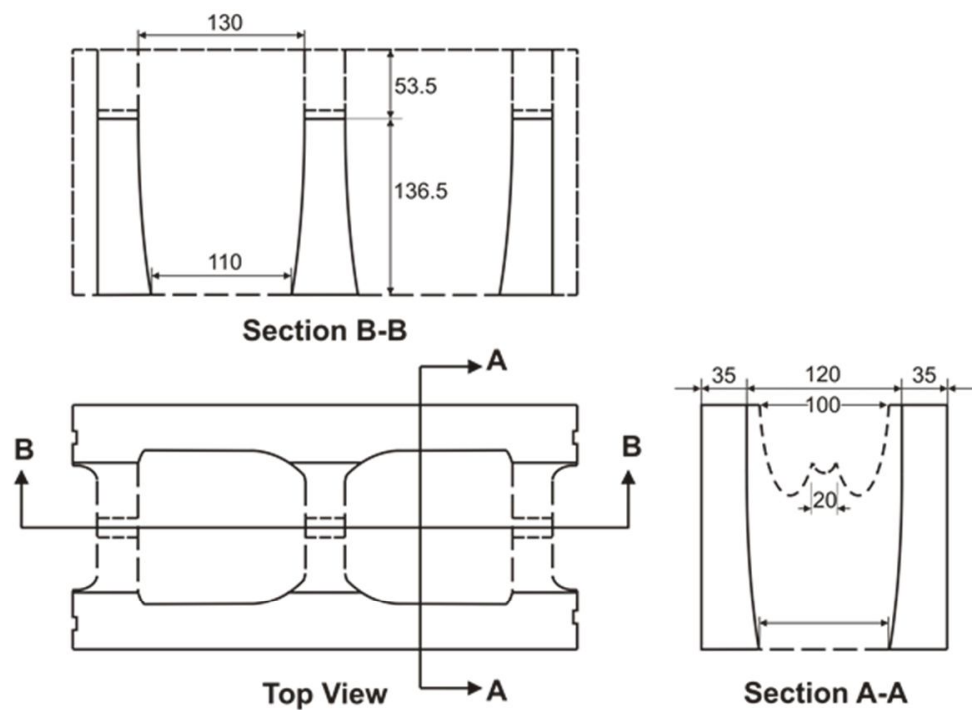

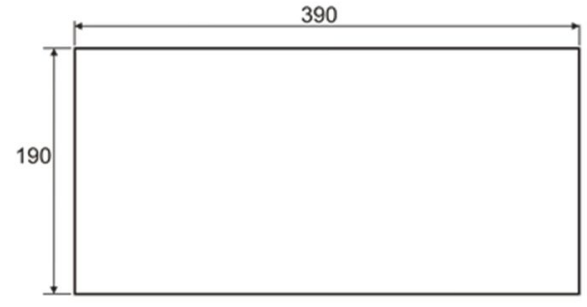

Front View

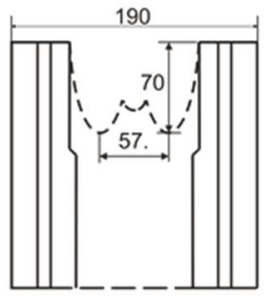

End View

a) $190 \mathrm{~mm}$ Depressed Web Unit

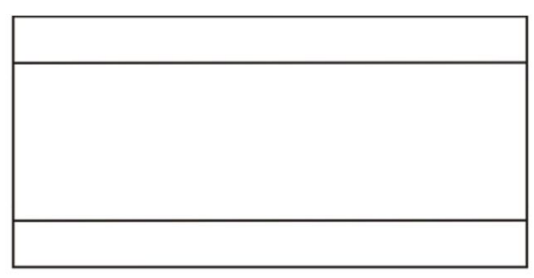

Top View

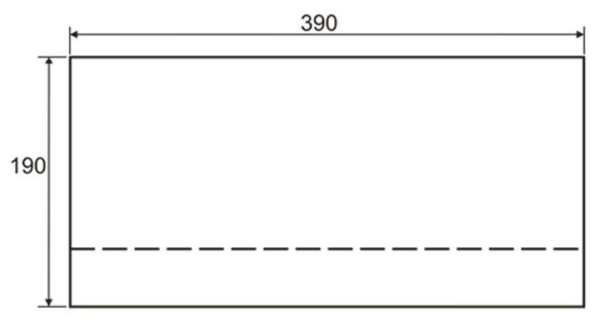

Front View

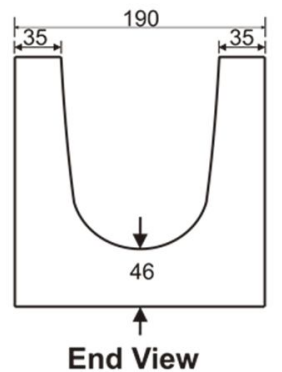

b) $190 \mathrm{~mm}$ Lintel (Bond) Unit

Figure 3-6: Configurations of Unit Blocks Used in Construction of Small and Medium Beam Series 

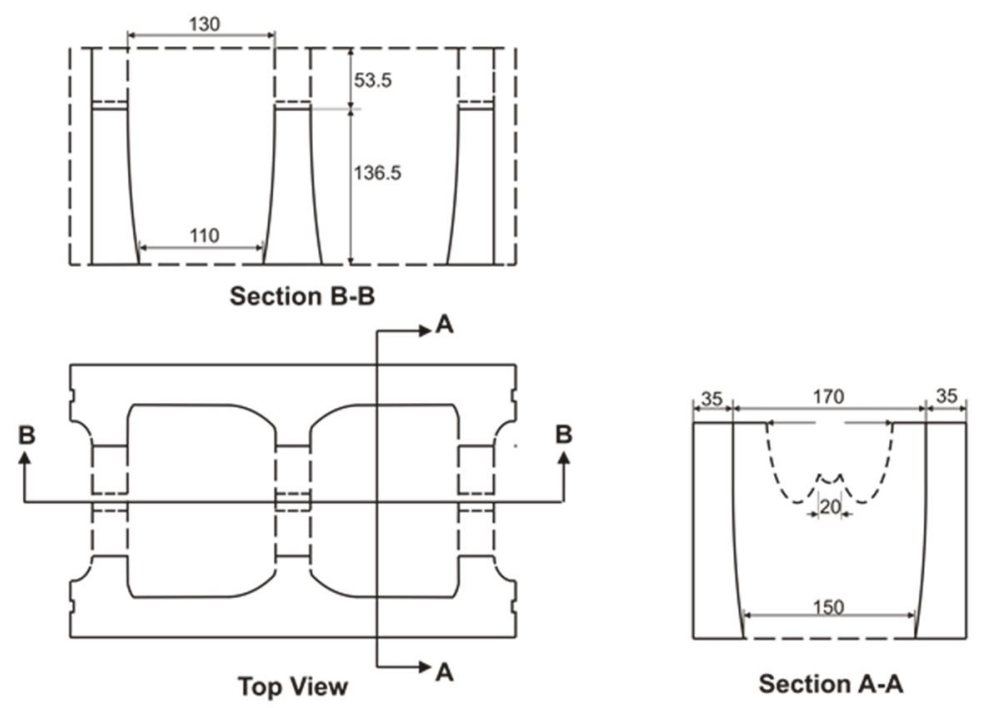

Section A-A
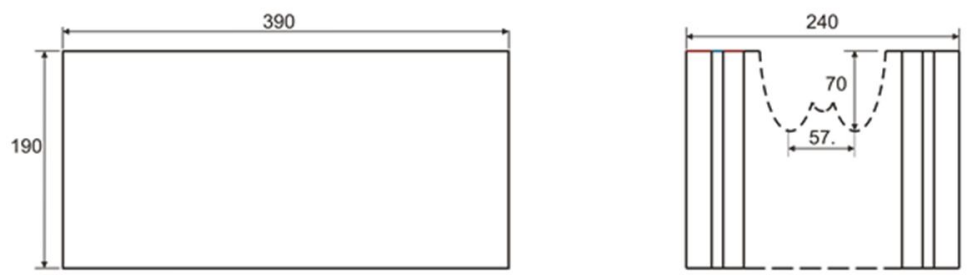

Front View

End View

a) $240 \mathrm{~mm}$ Depressed Web Unit

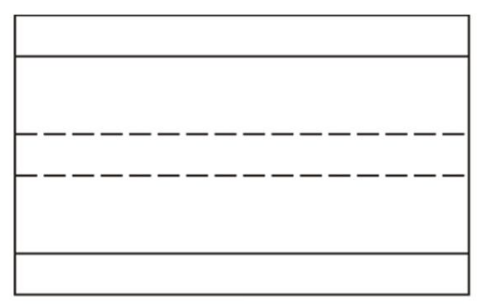

Top View

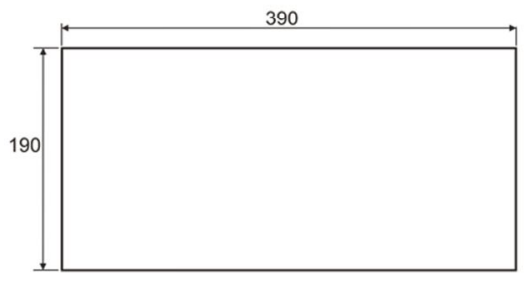

Front View

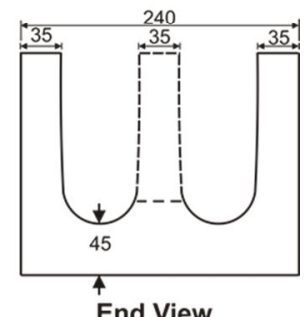

b) $240 \mathrm{~mm}$ Lintel (Bond) Unit

Figure 3-7: Configurations of Unit Blocks Used in Construction of Large Beam Series 


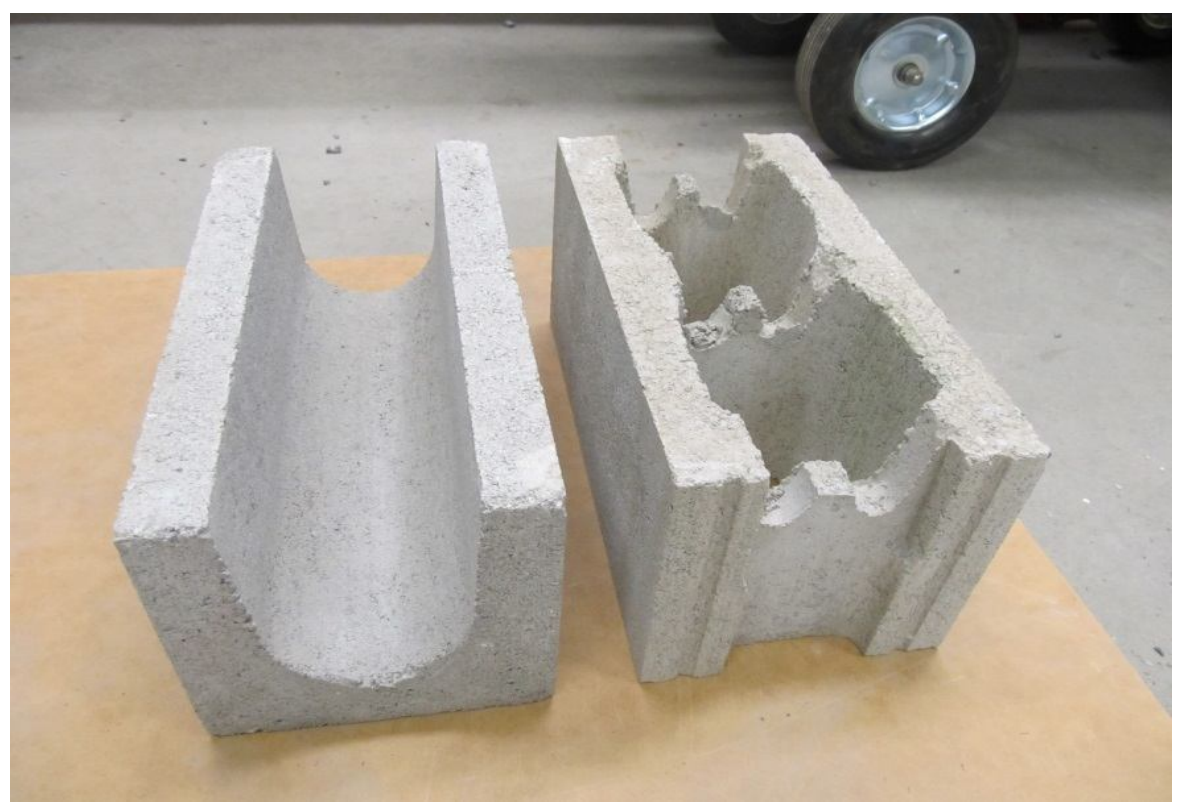

a) 190mm Unit blocks (Lintel Block (Left) and Depressed-Web (Right))

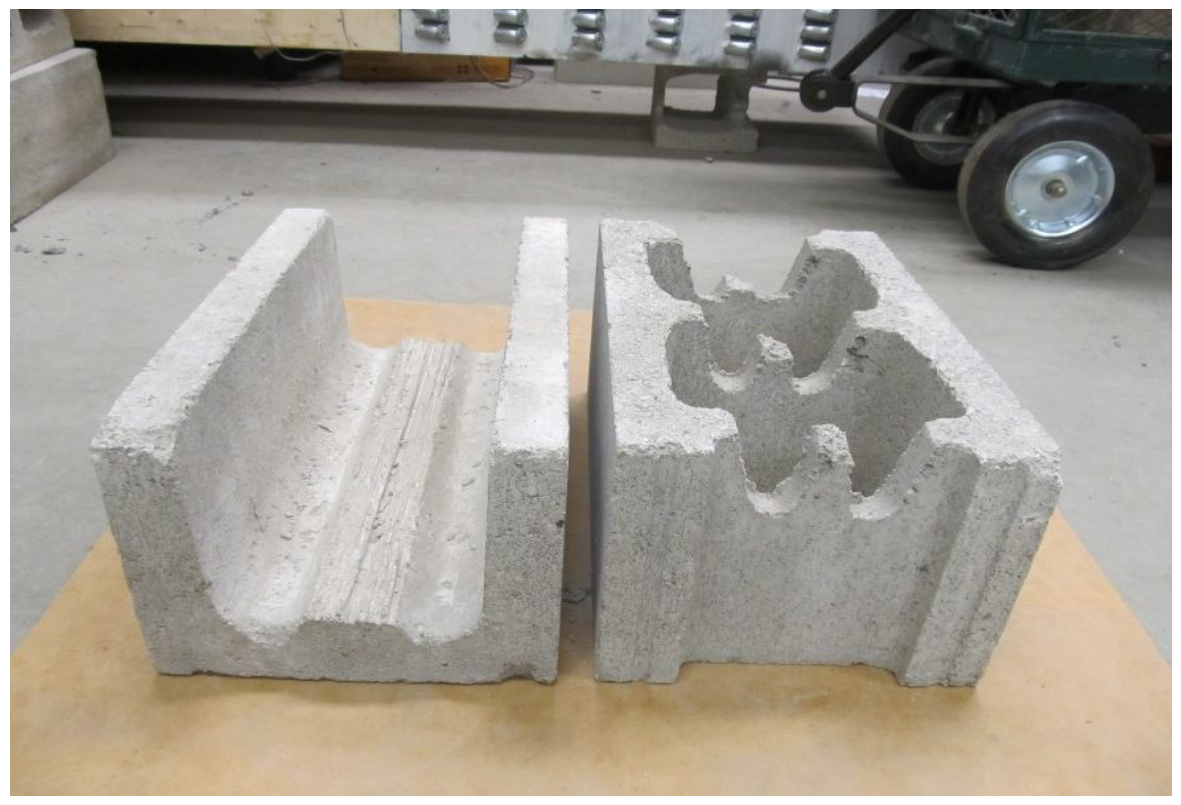

b) $240 \mathrm{~mm}$ Unit blocks (Lintel Block (Left) and Depressed-Web (Right))

Figure 3-8: Photos of the Unit Blocks Used in the Current Investigation 

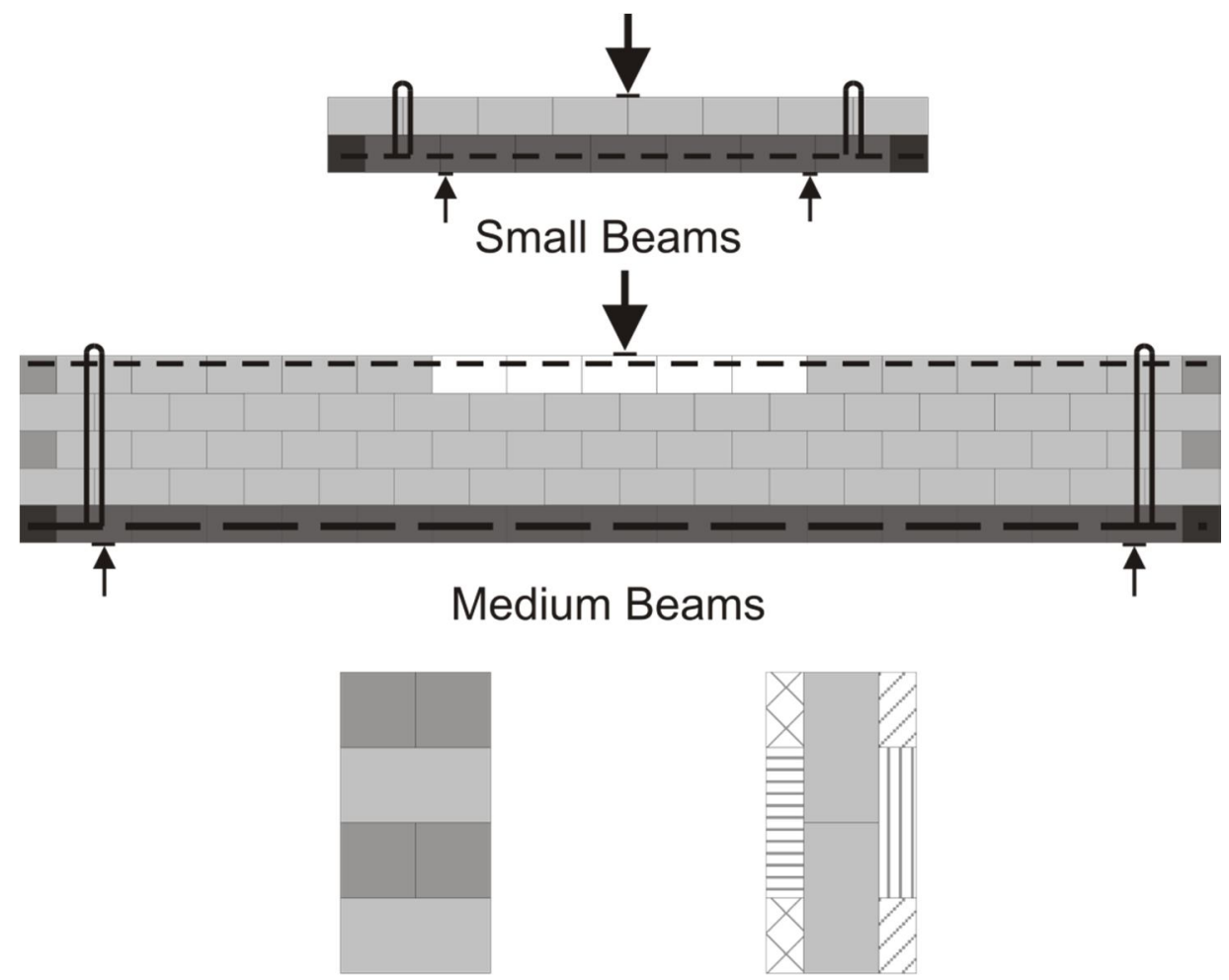

Prisms PN1 to PN20

Prisms PL1 to PL12
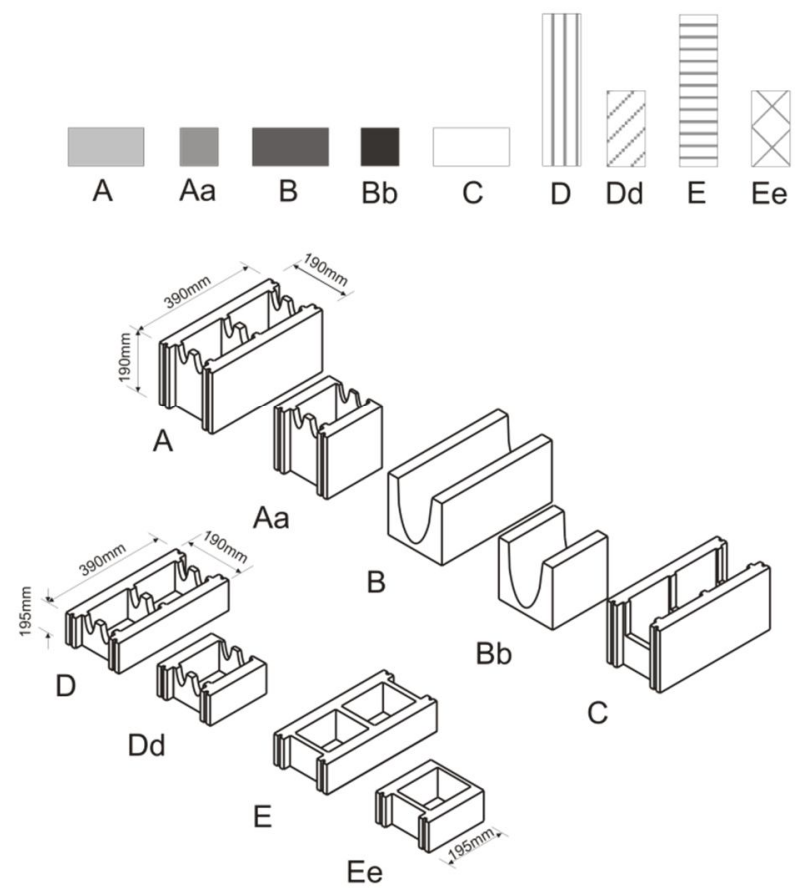

Figure 3-9: Block Cutting for Small and Medium Beam Series 

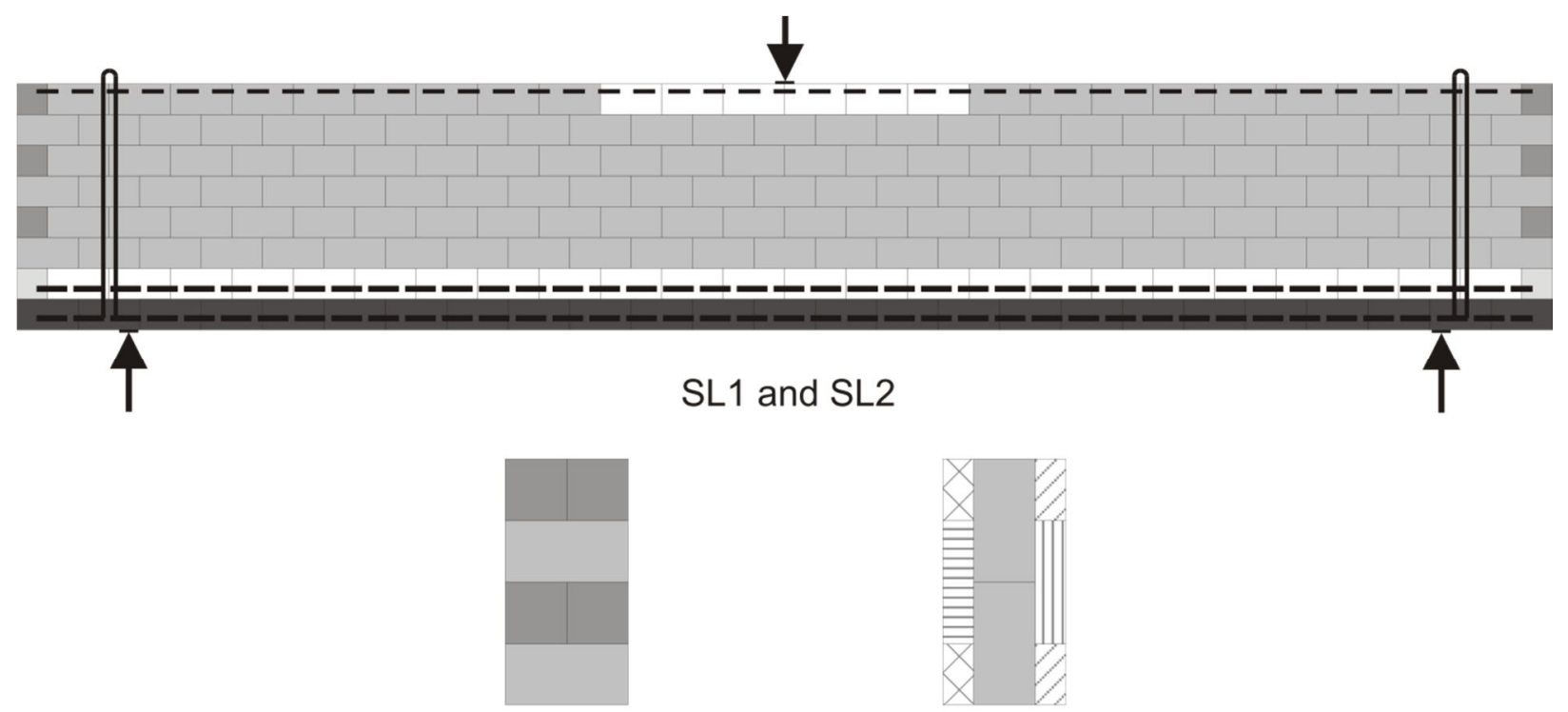

Prisms PLN1 to PLN5

Prisms PLL1 to PLL3
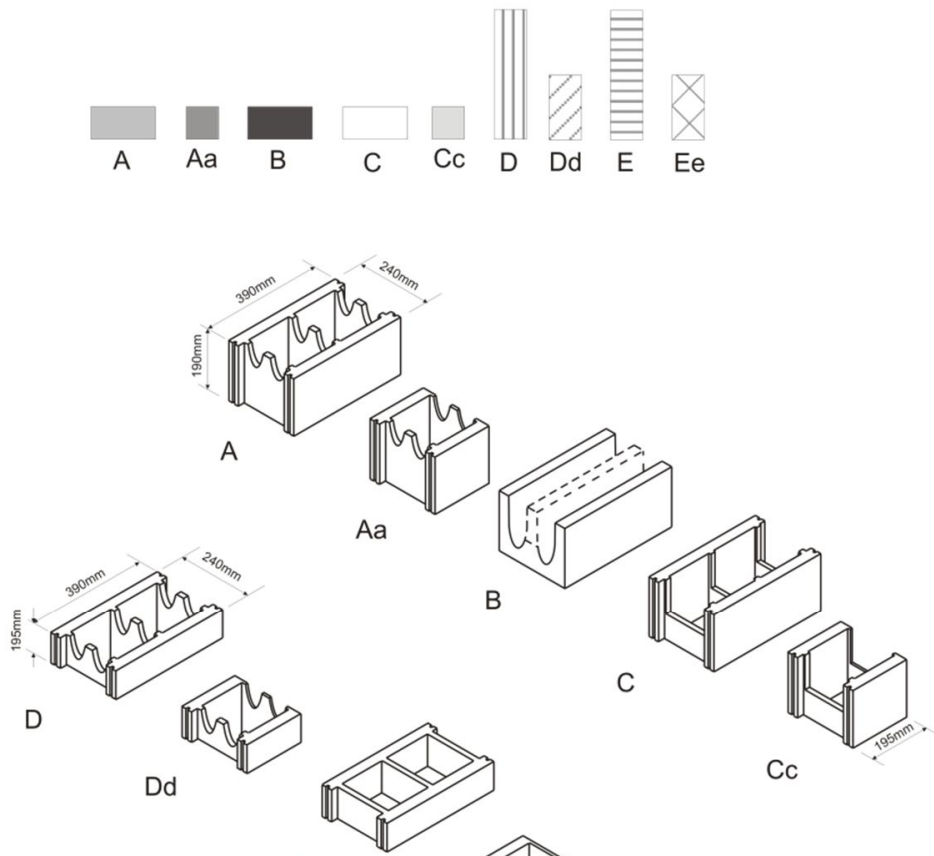

E

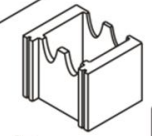

Aa

$\mathrm{Ee}$

Figure 3-10: Block Cutting for Large Beam Series 


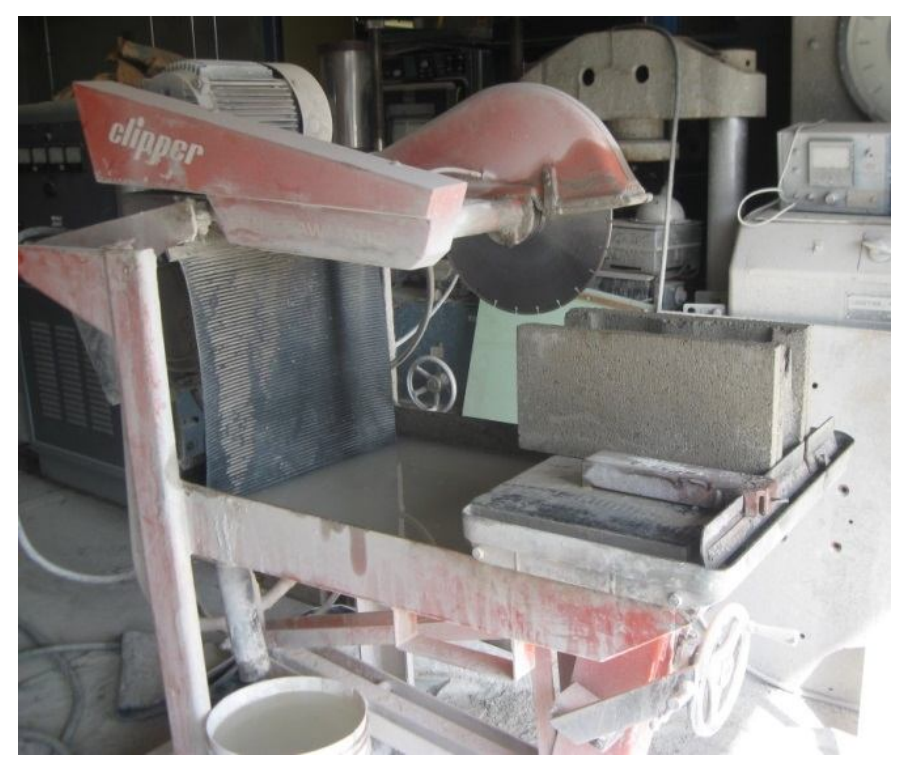

a) Wet Saw
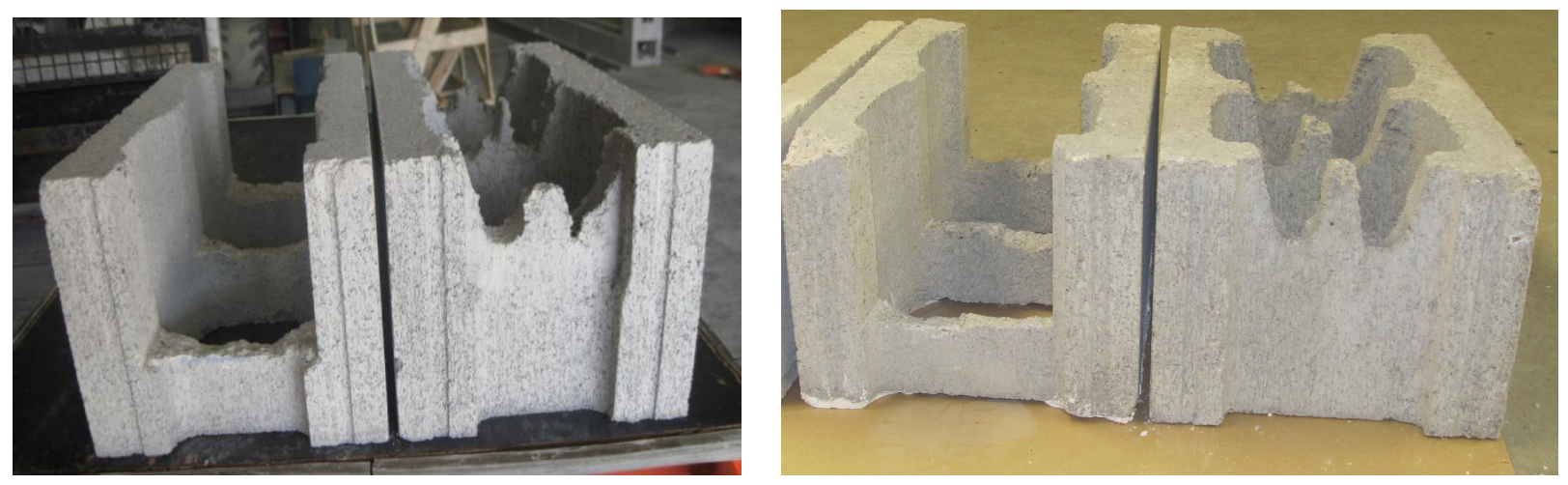

b) Removal of Part of the Web from a 190 mm Units

c) Removal of the Middle Web from a 240 mm Units

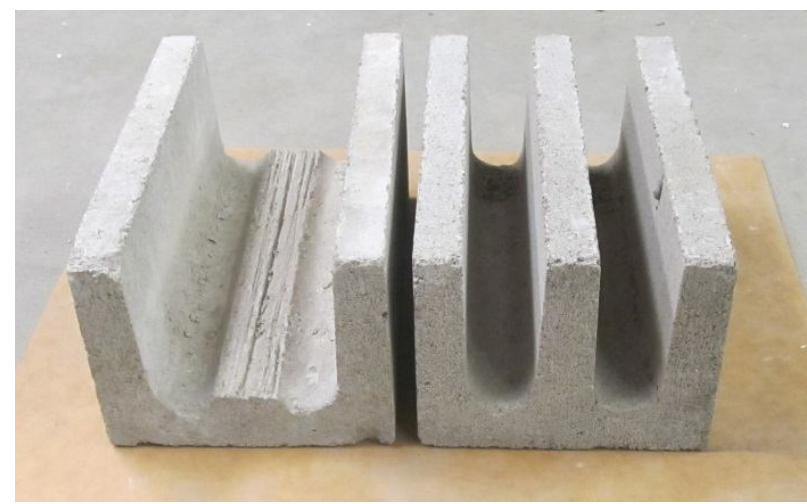

d) Removal of Part of the Web from a $240 \mathrm{~mm}$ Bond Beam Units

Figure 3-11: Wet Saw Used for Block Cutting and Samples of Block Cuts 


\subsubsection{Beam and Prism Construction}

Bond beam units (lintel units) were used in the bottom courses of all beams while the rest of the courses were built from depressed web units. The following construction sequence was used: first, the bottom course was laid and then the reinforcing cages (see Figure 3-12) were placed and firmly tied at the ends of the beams to prevent shifting during grouting. Then, the top courses were laid. Face shell bedding was used throughout the program. To facilitate moving of the beams, 2-20M steel lifting hooks were cast in the portions that lie outside the test region. Figures 3-13 and 3-14 show the construction procedure. In order to obtain compressive strength of the masonry beams, prisms were constructed at the same as the beams. Type S mortar was used throughout the program. The mix proportions by weight were 1:0.21:3.53 for Portland cement:lime:sand respectively (see Figure 3-15 for the mortar mixing). Water was added to achieve the desired spread (100-115\%) determined using a mortar flow table (see Figure 3-15b). The targeted average of mortar strength was $25 \mathrm{MPa}$. A total of ninety $50 \mathrm{~mm} \times 50 \mathrm{mmx} 50 \mathrm{~mm}$ mortar cubes were cast from different mortar batches used in construction of different beams and prisms. A detailed table of these mortar cubes will be provided in Chapter 4. 


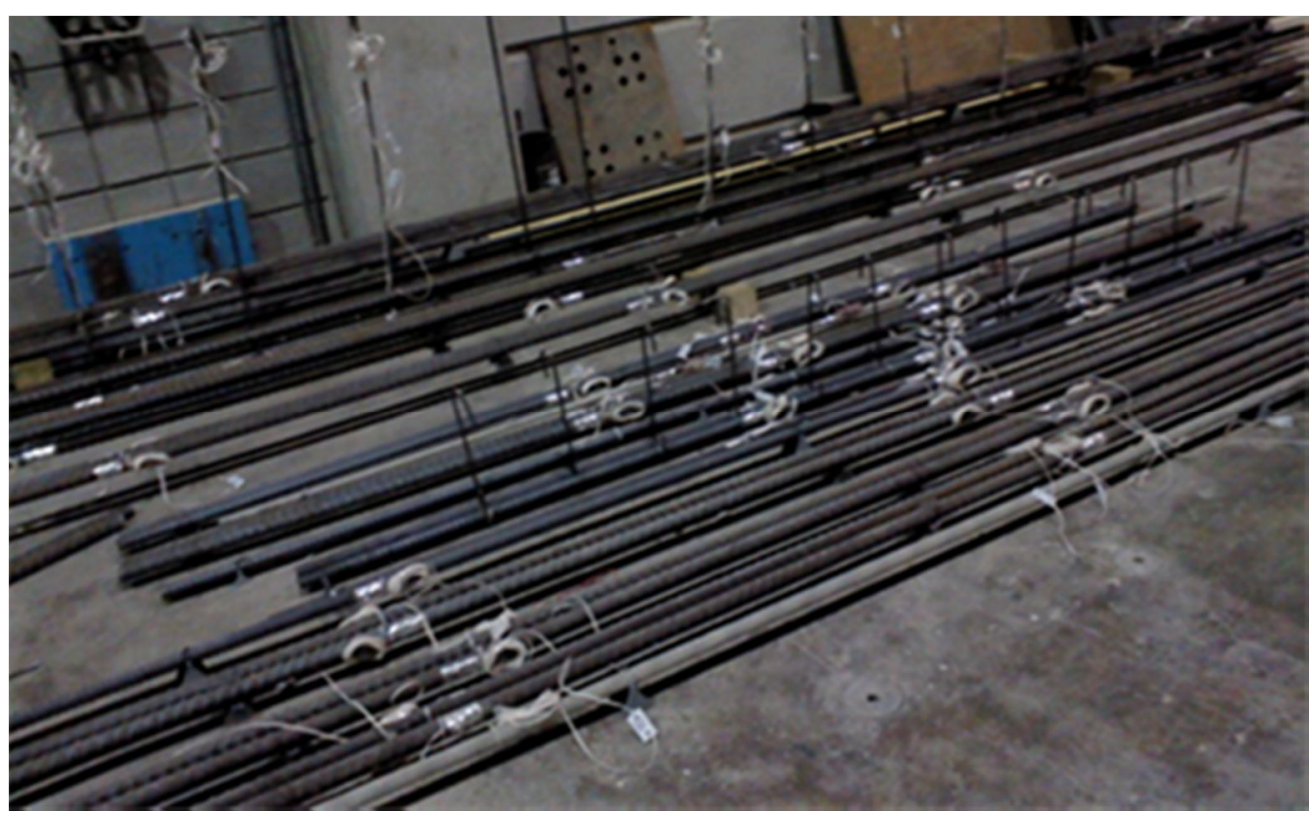

a) Steel Reinforcement Cages Prepared for Construction

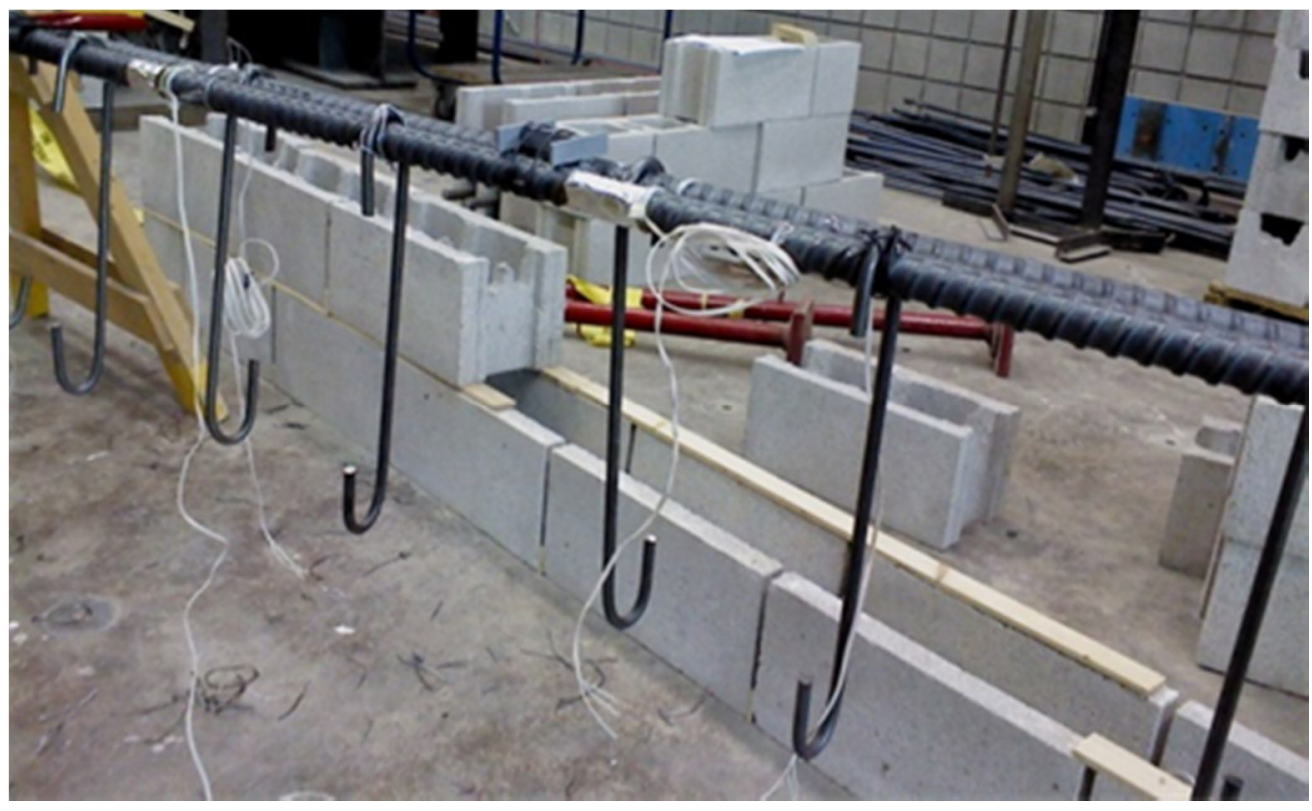

b) Steel Reinforcement Cage for Specimen SS3

Figure 3-12: Steel Reinforcement Cages 


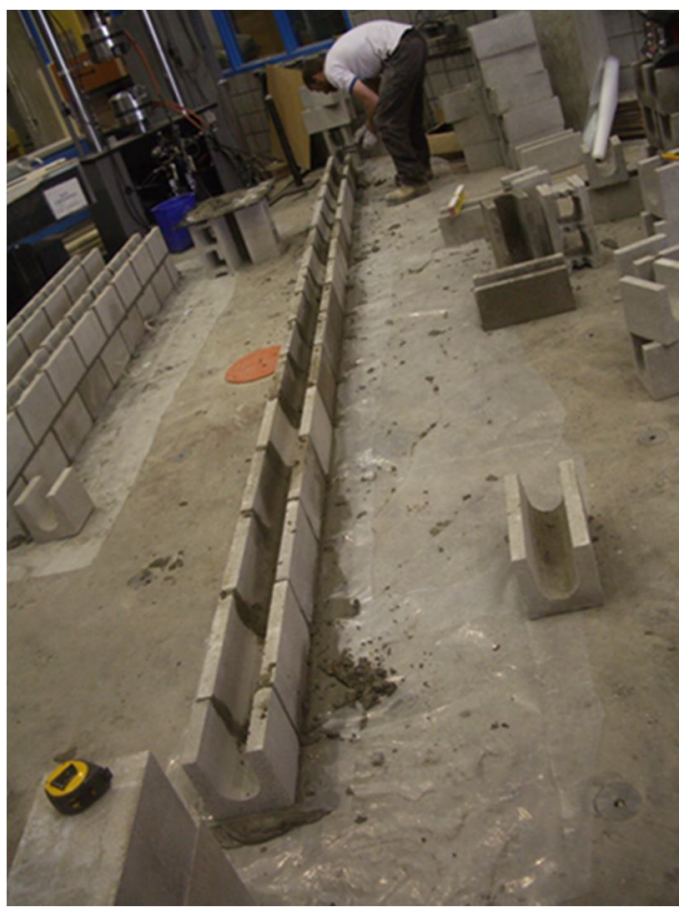

a) Laying $190 \mathrm{~mm}$ Bond Beam Units in the Bottom Course

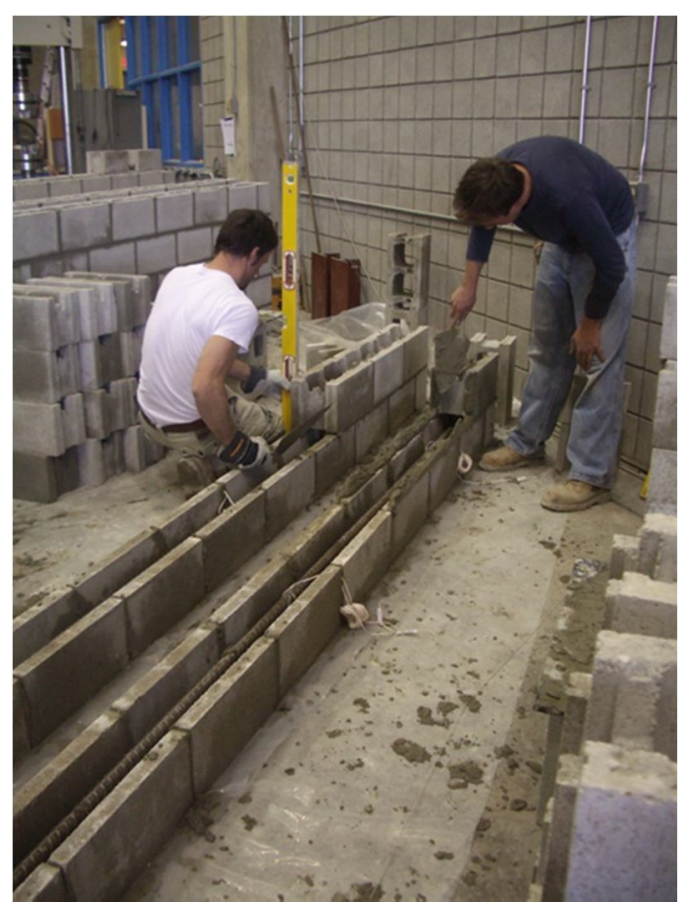

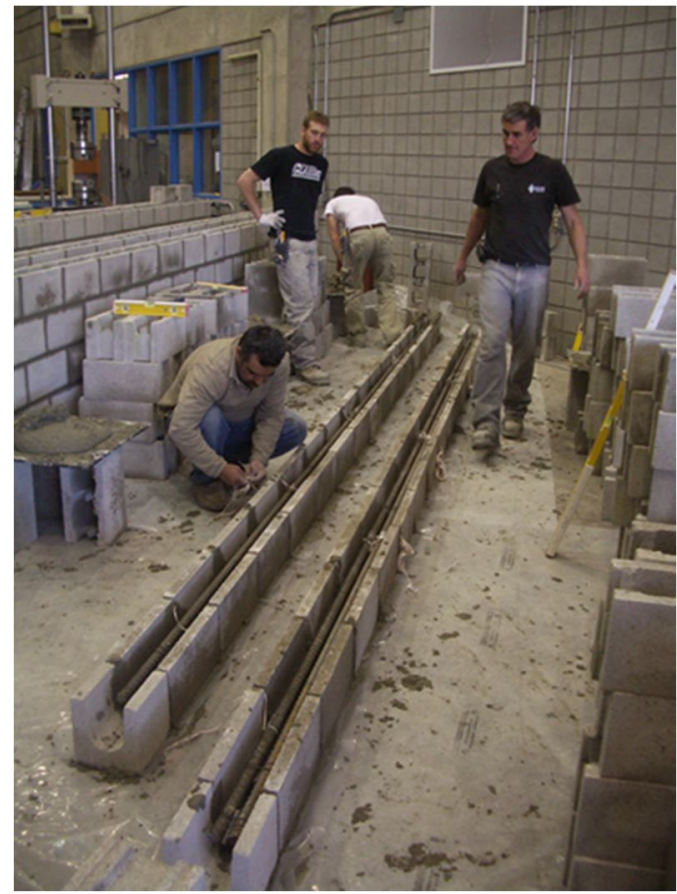

b) Laying the Reinforcement Cages in the Bottom Courses

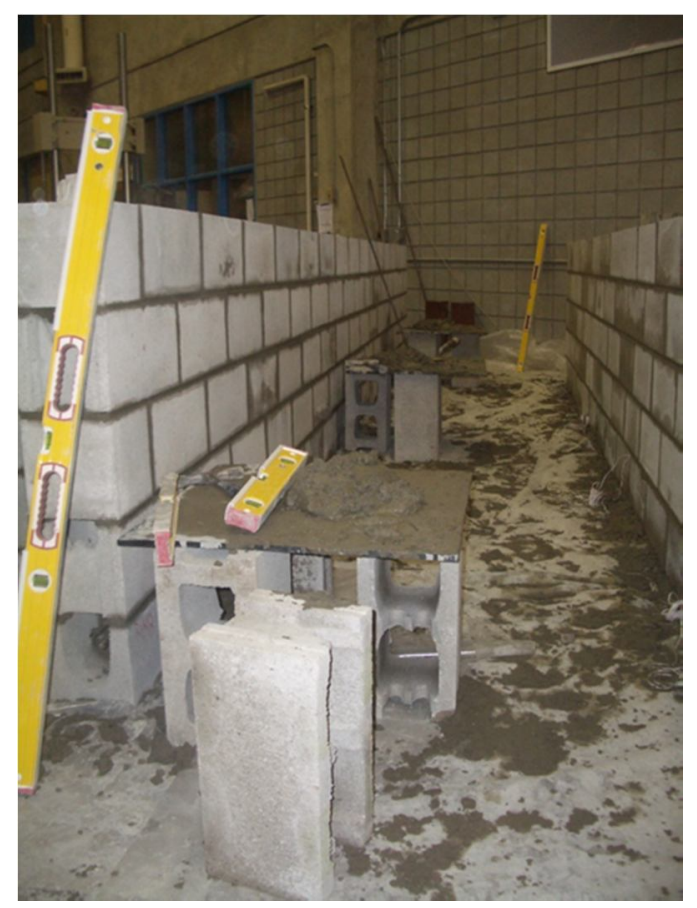

c) Laying the Depressed Web Units in the Top Courses with Face Shell

Figure 3-13: Construction of the Medium Beams 


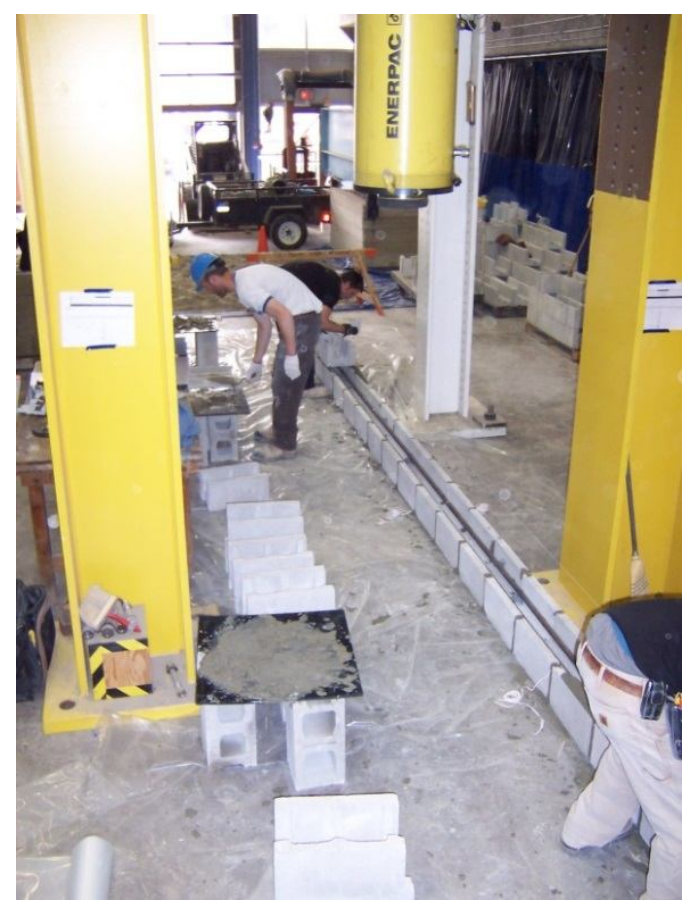

a) Laying $240 \mathrm{~mm}$ Bond Beam Units in the Bottom Course

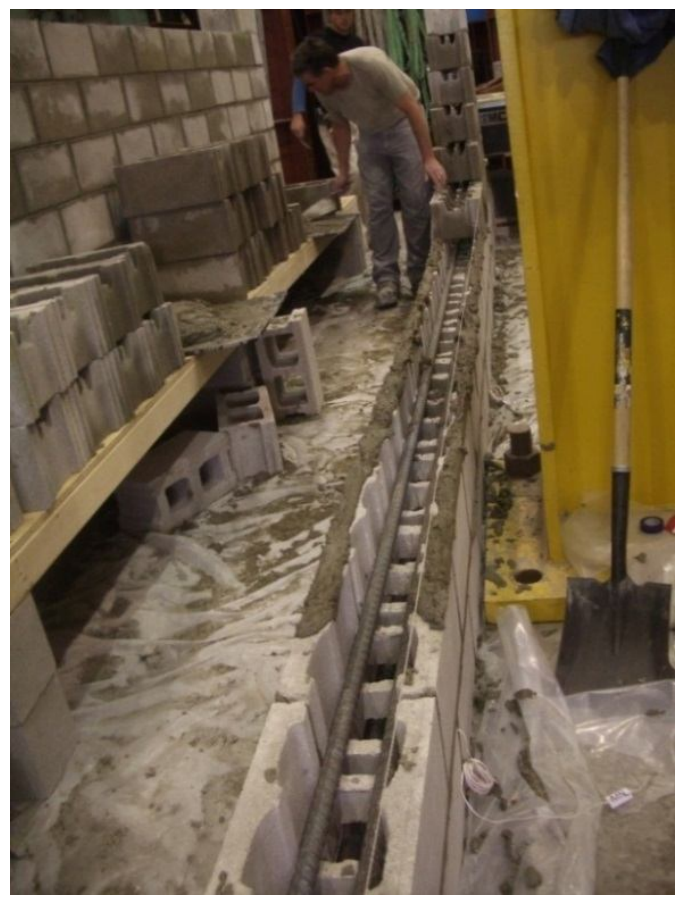

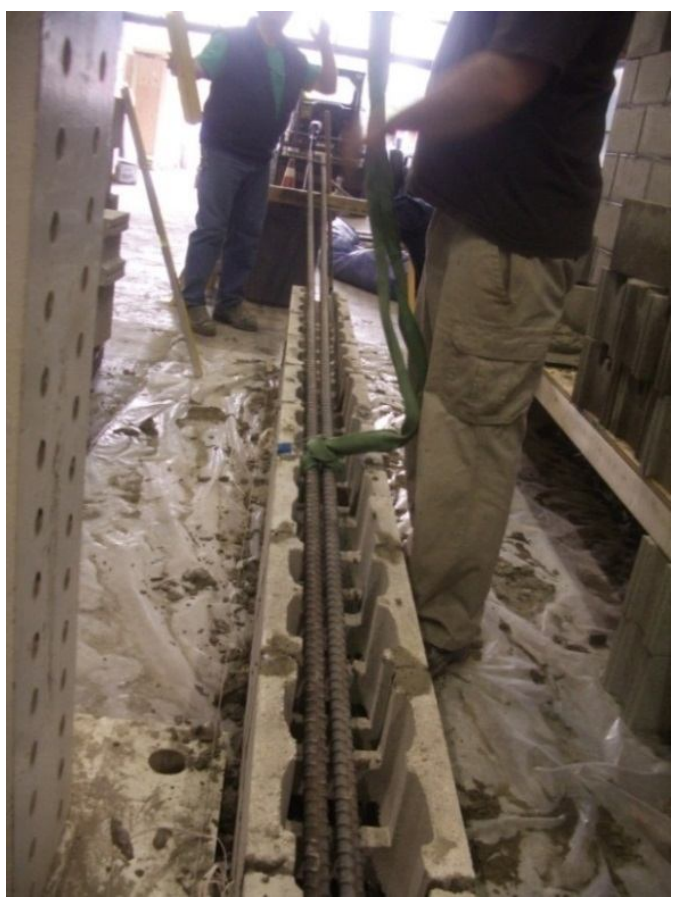

b) Laying the Second Course of the Beam with Partially Removed Webs

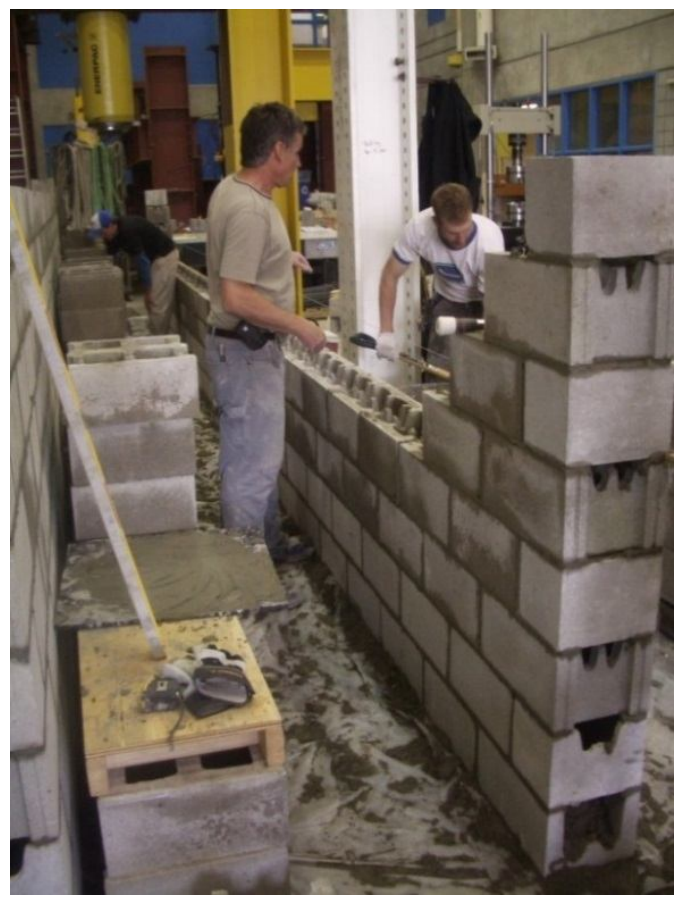

c) Laying the Depressed Web Units in the Top Courses with Face Shell

Figure 3-14: Construction of the Large Beams 

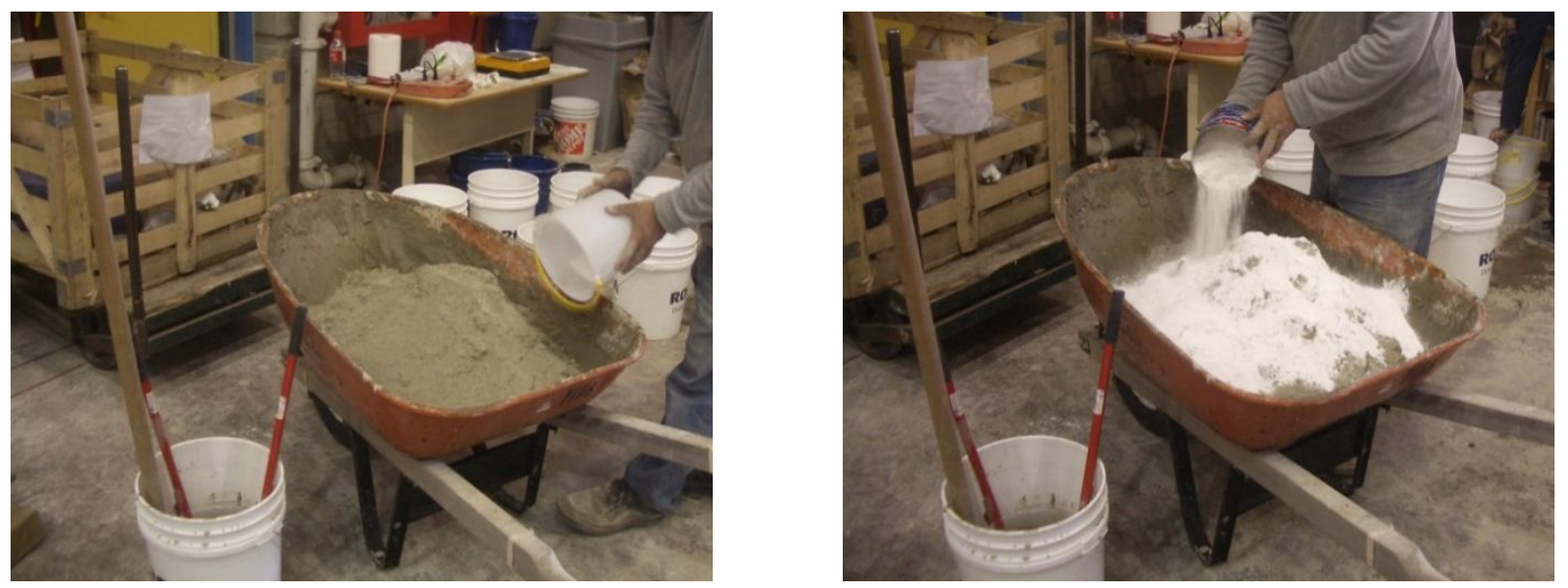

a) Mixing the Mortar

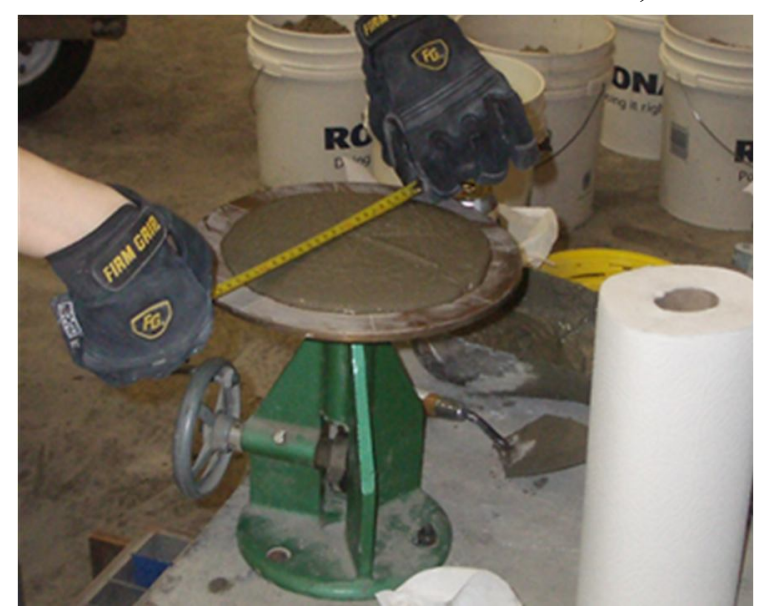

b) Mortar Flow Test

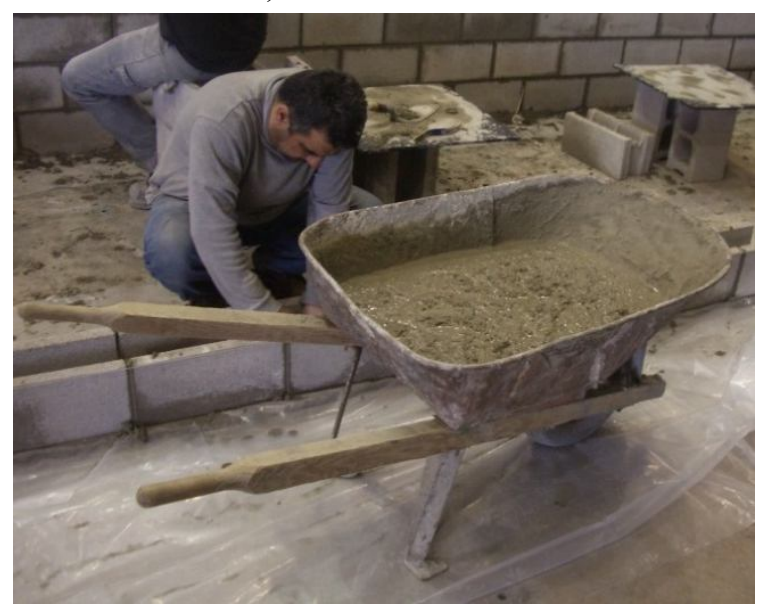

d) Moving the Mortar to the Beams

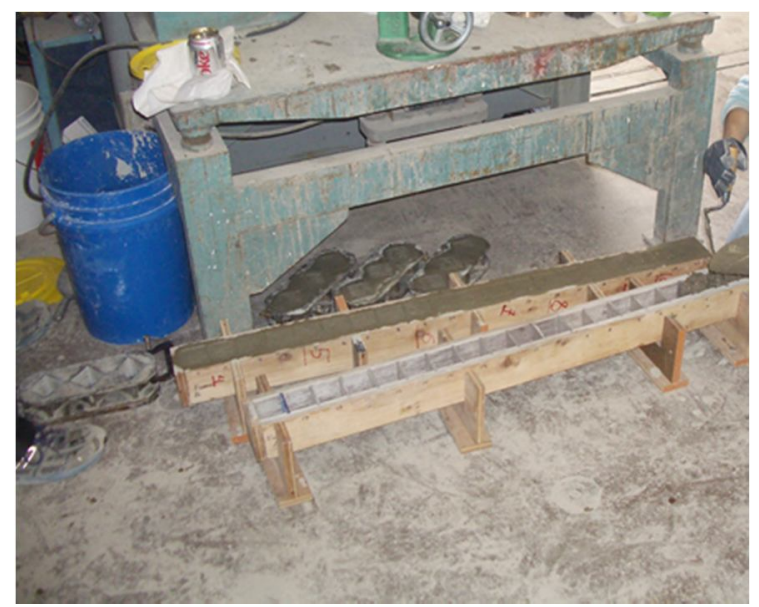

c) Mortar Cube Samples

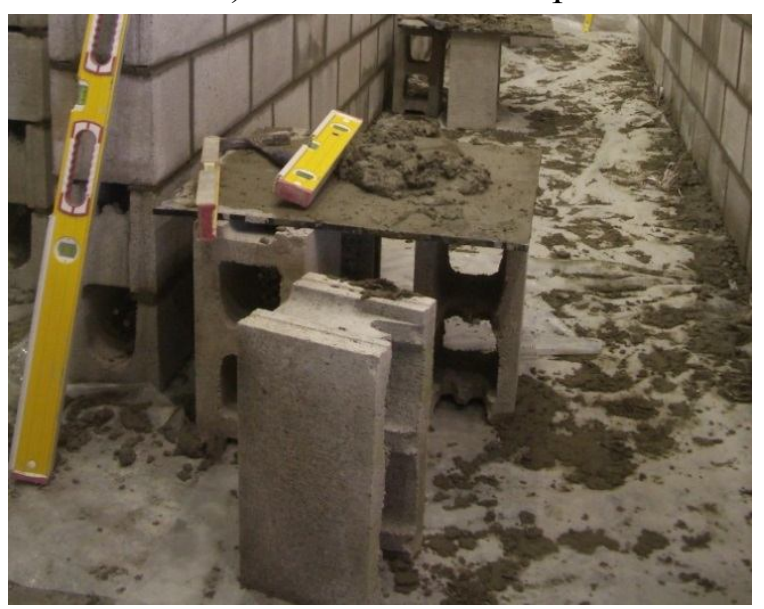

e) Mortar put on Table Ready to be Used in Construction

Figure 3-15: Production of the Mortar 
After the construction of the beams and the prisms, the ends of the beams and the sides of prisms were sealed with plywood (see Figure 3-16).

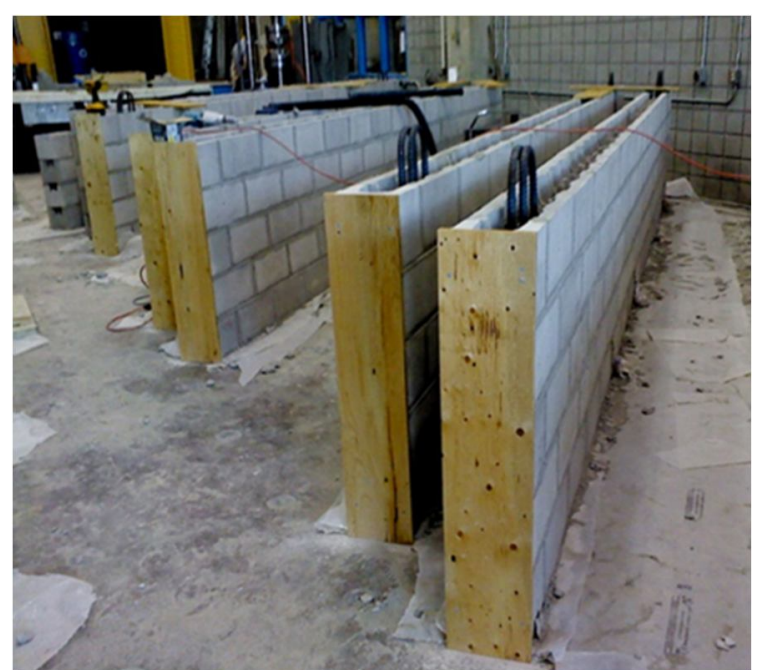

a) Ends of the Medium Beams Sealed with Plywood

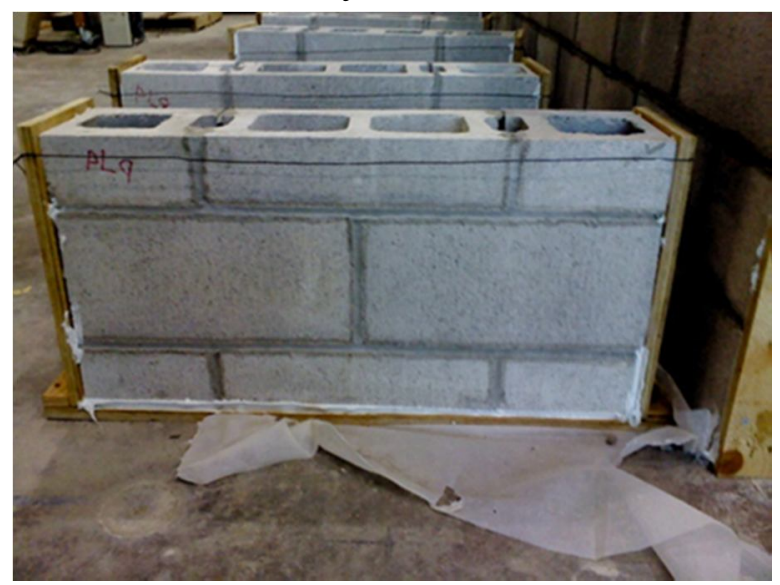

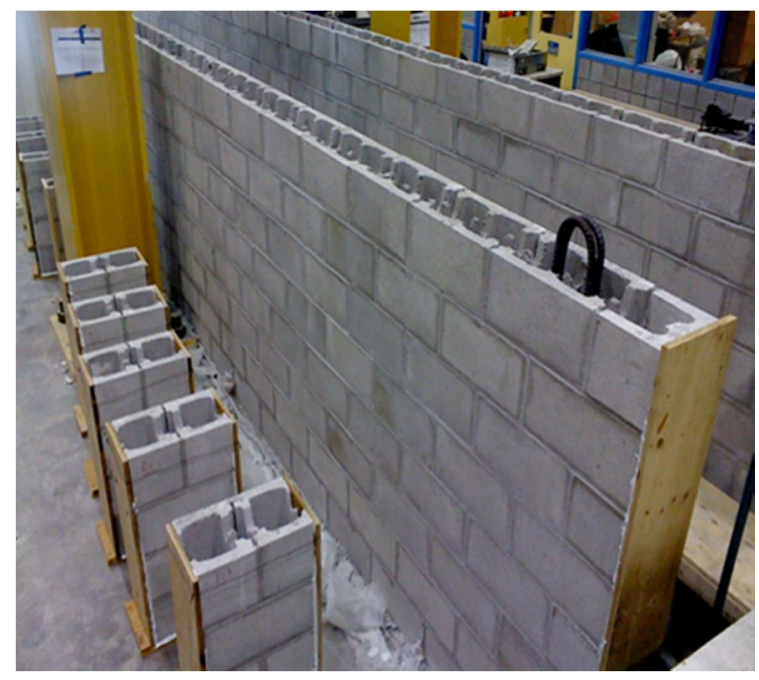

b) Ends of the Large Beams Sealed with Plywood

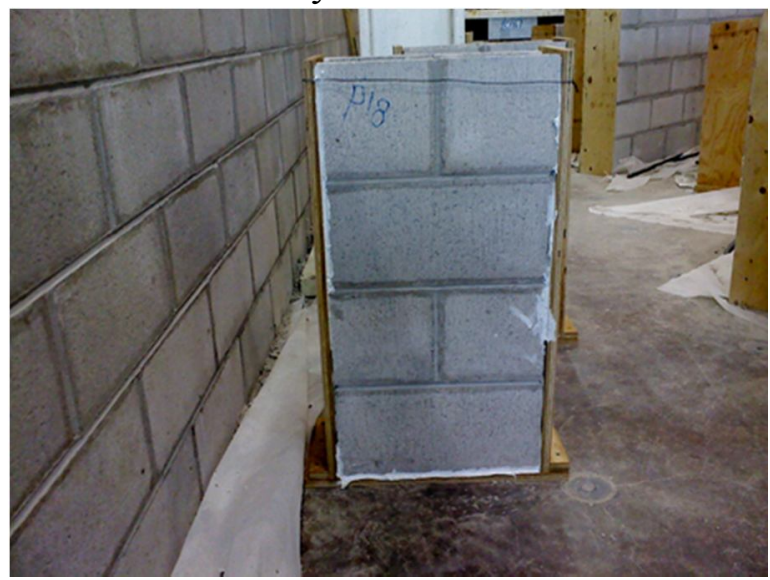

c) Ends of the Prisms Sealed with Plywood

Figure 3-16: Sealing the Sides of the Beams and Prisms before Grouting

Following the sealing of ends of the beams and prisms, the specimens were fully grouted using fine grout supplied by a local ready mix company. The slump ranged from 200 to $240 \mathrm{~mm}$.

Figure 3-17 shows the photos taken in the day of grouting. The grout was pumped into place and carefully vibrated using needle vibrators with no segregation observed. 


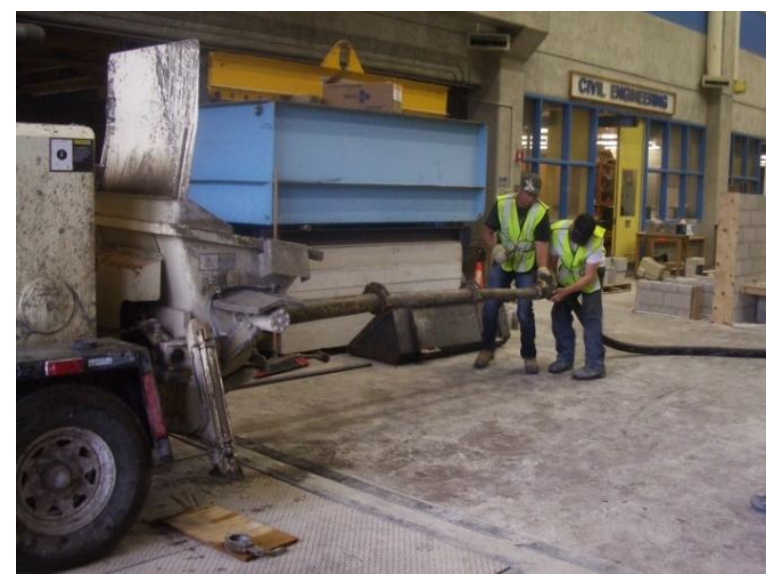

a) Installing the Trailer Pump

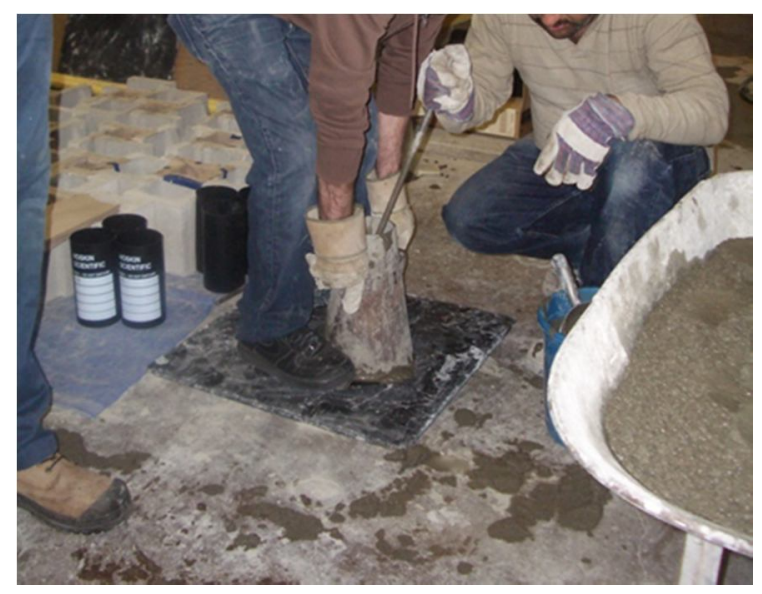

c) Measuring the Slump of the Grout

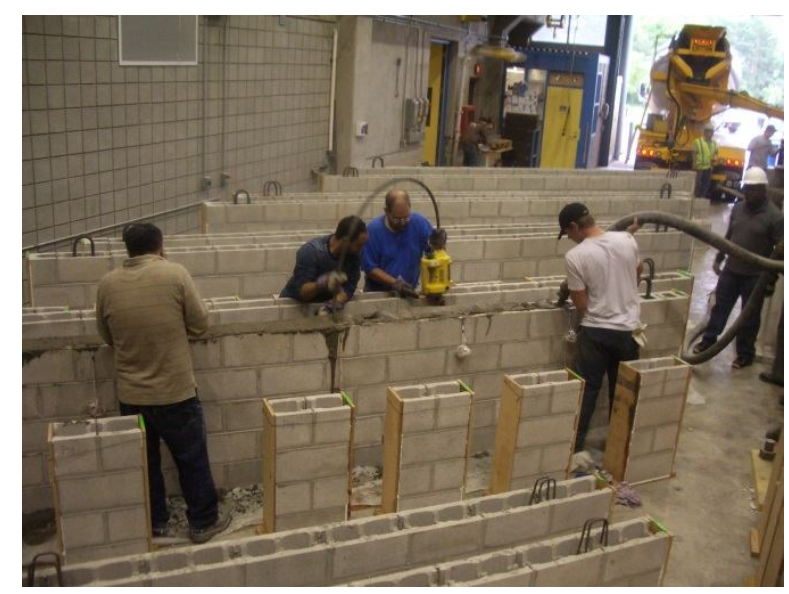

e) Vibration of the Gout

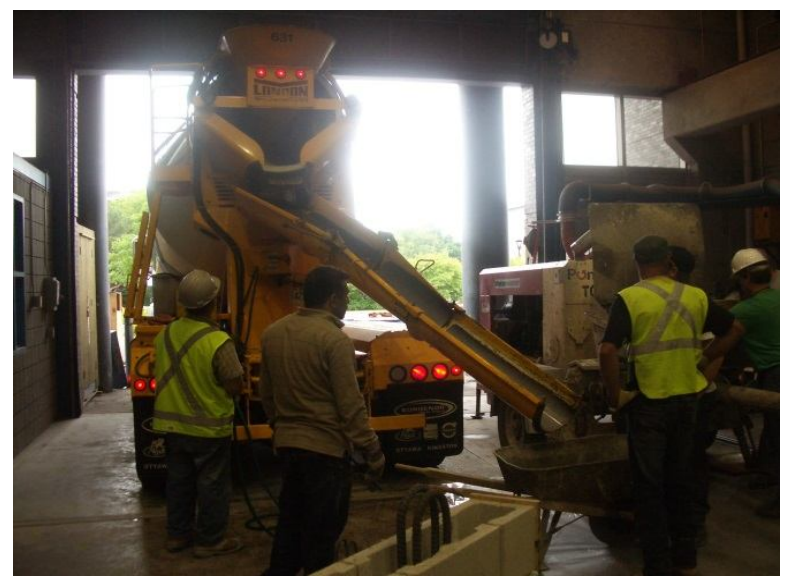

b ) Ready Mix Truck

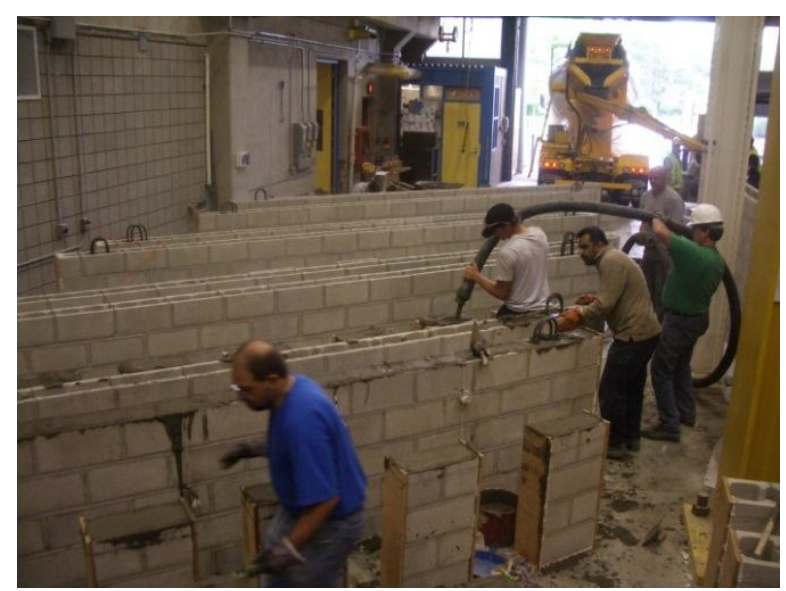

d) Grouting the Beams and the Prisms

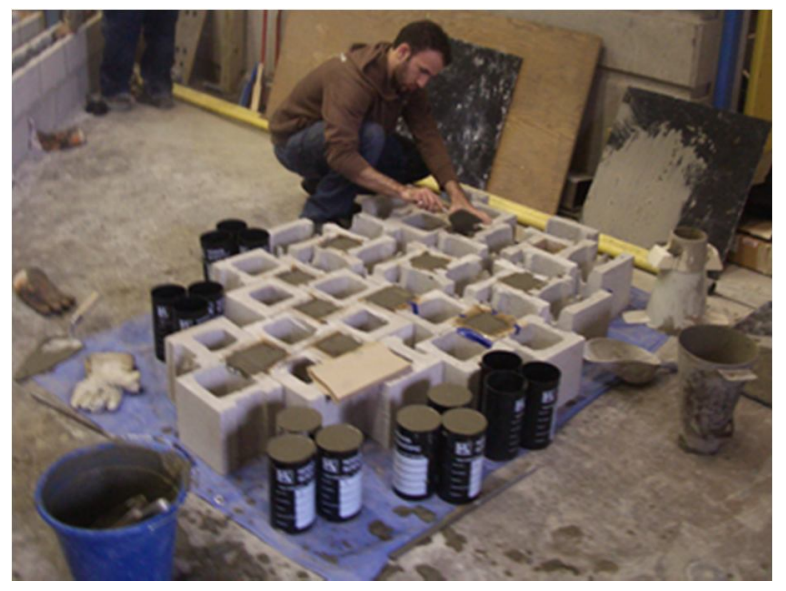

f) Grout Samples

Figure 3-17: Grouting of Specimens 
The grout was well consolidated and fully surrounded the reinforcement even for the heavily reinforced beams. This was verified after testing the beams and the masonry prisms. A total of twenty four $100 \mathrm{~mm}$ x $200 \mathrm{~mm}$ cylinders and twenty four $90 \mathrm{~mm}$ x $90 \mathrm{~mm}$ x $175 \mathrm{~mm}$ block molded prisms were cast at the time of grouting different beams and prisms (see Figure 3-18).

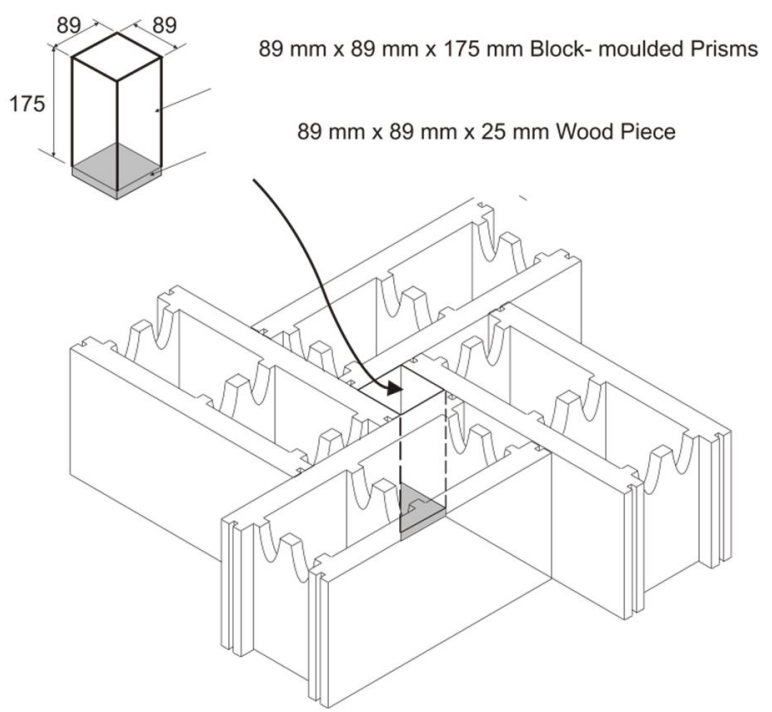

a) $89 \mathrm{~mm} \times 89 \mathrm{~mm} \times 175 \mathrm{~mm}$ Block- moulded Prisms
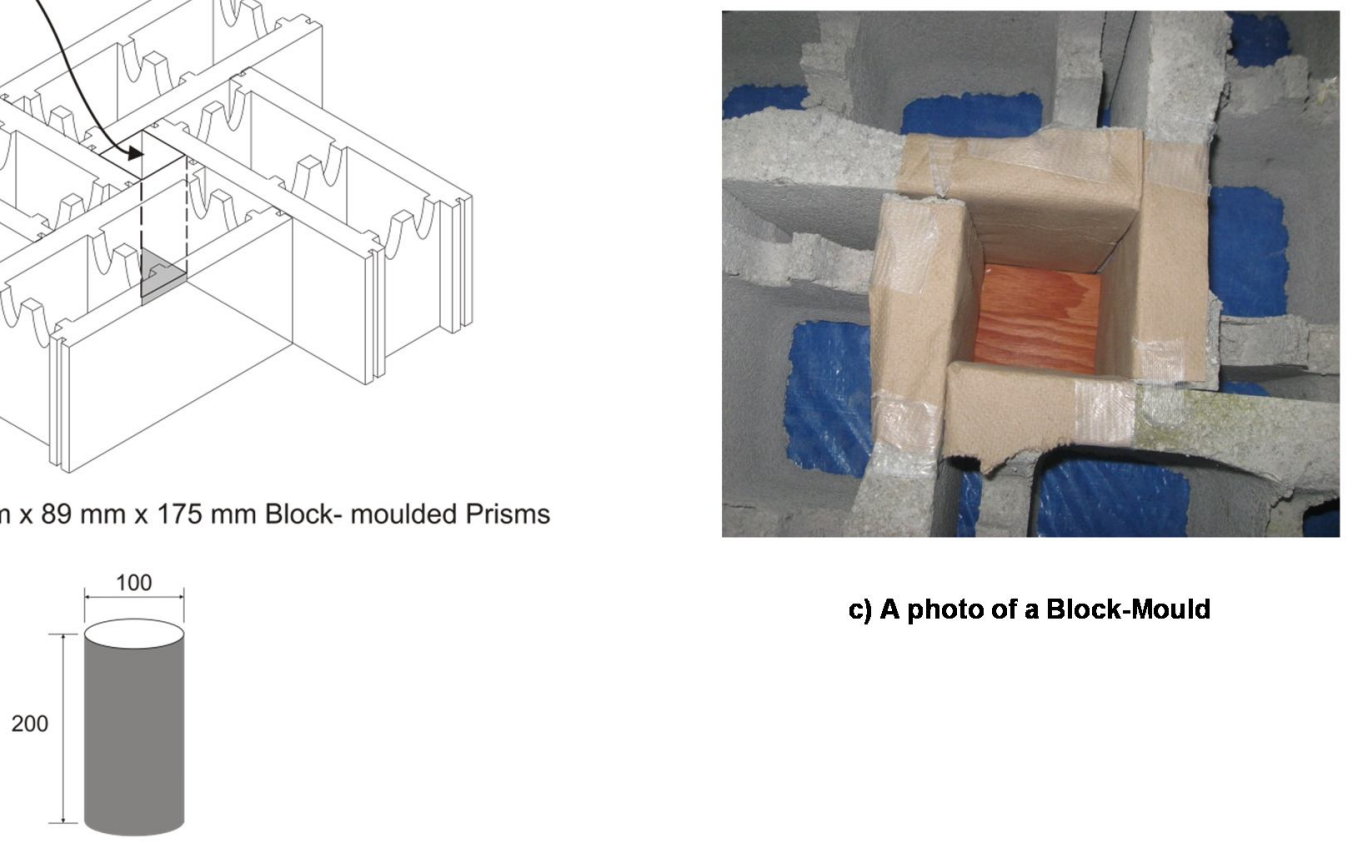

c) A photo of a Block-Mould

b) $100 \mathrm{~mm} \times 200 \mathrm{~mm}$ Non-Absorbent Plastic Cylinder Moulds

Figure 3-18: Grout Samples 
The top surface of the specimens were trowelled smoothly and covered with plastic sheeting for seven days at room temperature (see Figure 3-19). After uncovering, the specimens remained in ambient lab conditions to cure until testing.

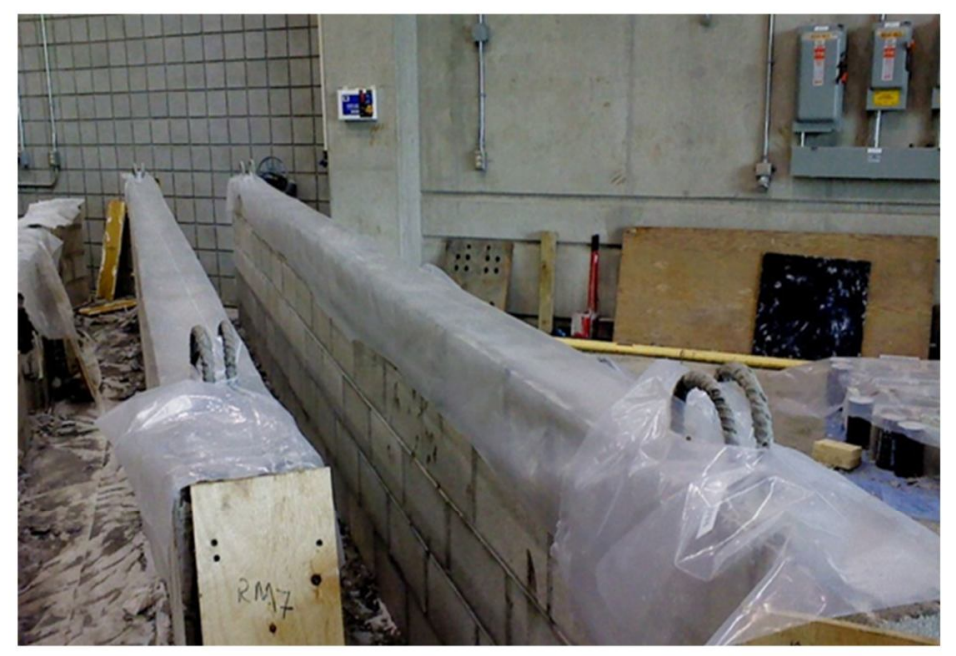

a) Plastic Sheets on Top of the Beams

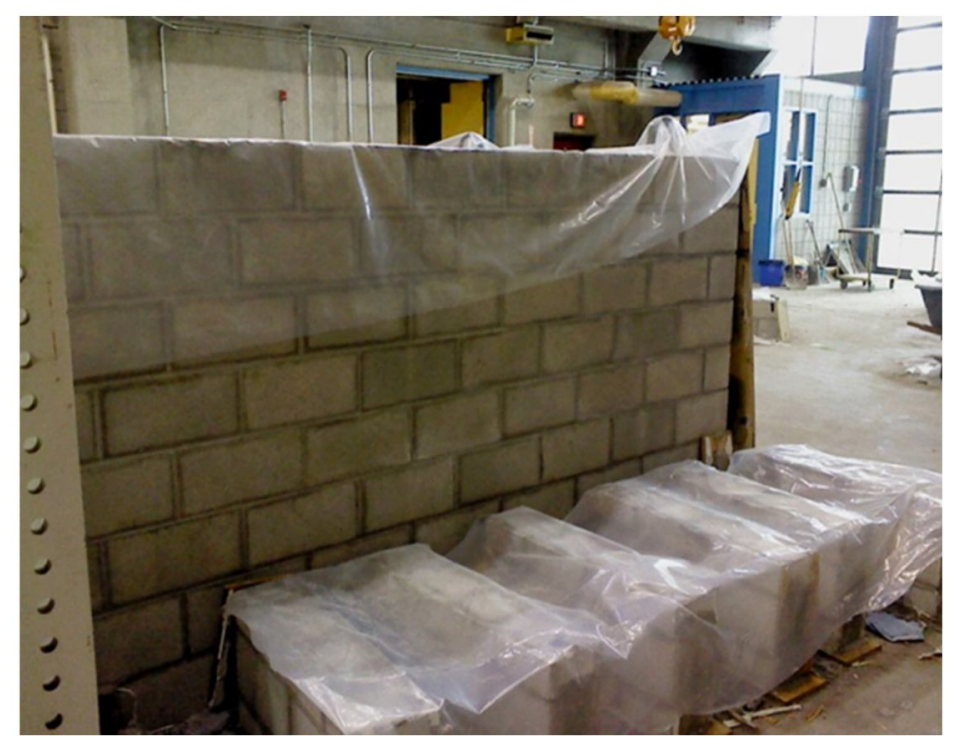

b) Plastic Sheets on Top of the Beams and the Prisms

Figure 3-19: Curing of the Specimens 


\subsection{Beam Testing}

This section presents a description of the test set up of the beams. All beams were tested at ages of more than 365 days. Prior to testing, the beams were painted with diluted white latex paint to make it easy to see cracks when they formed during testing.

\subsubsection{Instrumentation}

Besides the strain gauges embedded inside the beams, different external instrumentations were used during testing of the beams

\section{Linear-Variable Displacement Transducers (LVDTs)}

Linear-Variable Displacement Transducers (LVDTs) were used in three forms: side-mounted LVDTs, vertical LVDTs and out of plane LVDTs. The side-mounted LVDTs were installed on one side of the beam in order to measure the horizontal axial strains at the mid-depth of the beam and the shear strains in the shear span. For the large and middle size beams, six sets of LVDTs were installed on one side of each the beams, three sets in each shear span. Each set consisted of three LVDTs: one horizontal LVDT to measure the longitudinal strain at the mid depth of the beams and two LVDTs in a large $\pm 45^{\circ}$ cross to measure the shear strain at that section of the beam. For the small beams series, two sets of LVDTs were attached to one side of the beams, one set in each shear span. Each set consisted of 5 LVDTs, one horizontal LVDT and 4 diagonal LVDTs in $45^{\circ}$ crosses. Figure 3-20 show the locations of these side-mounted LVDTs. 


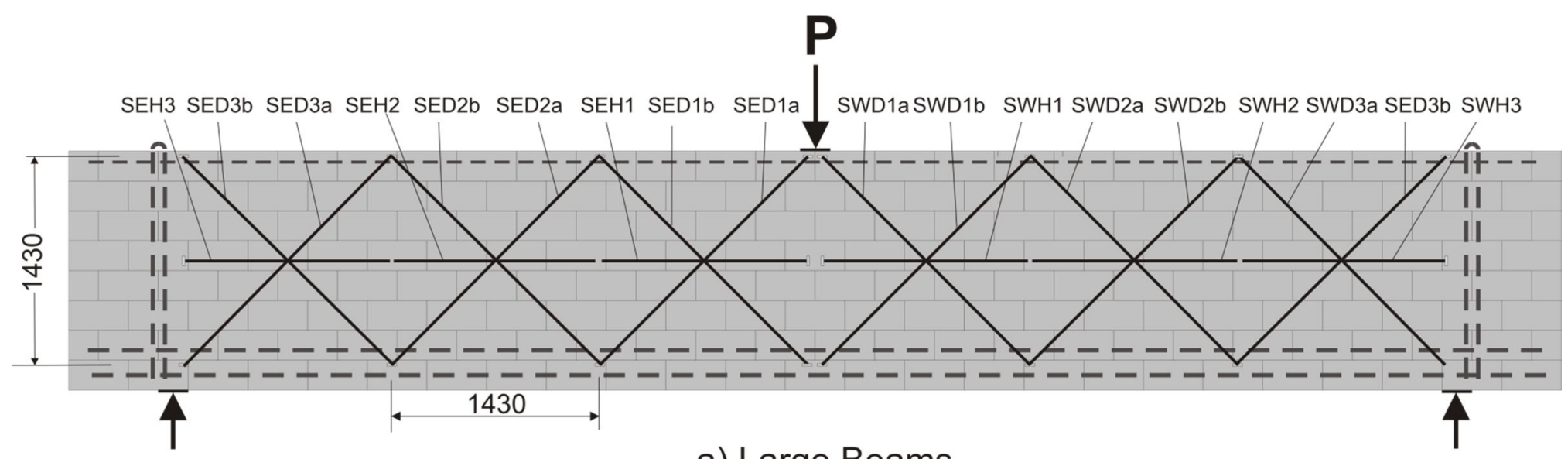

a) Large Beams

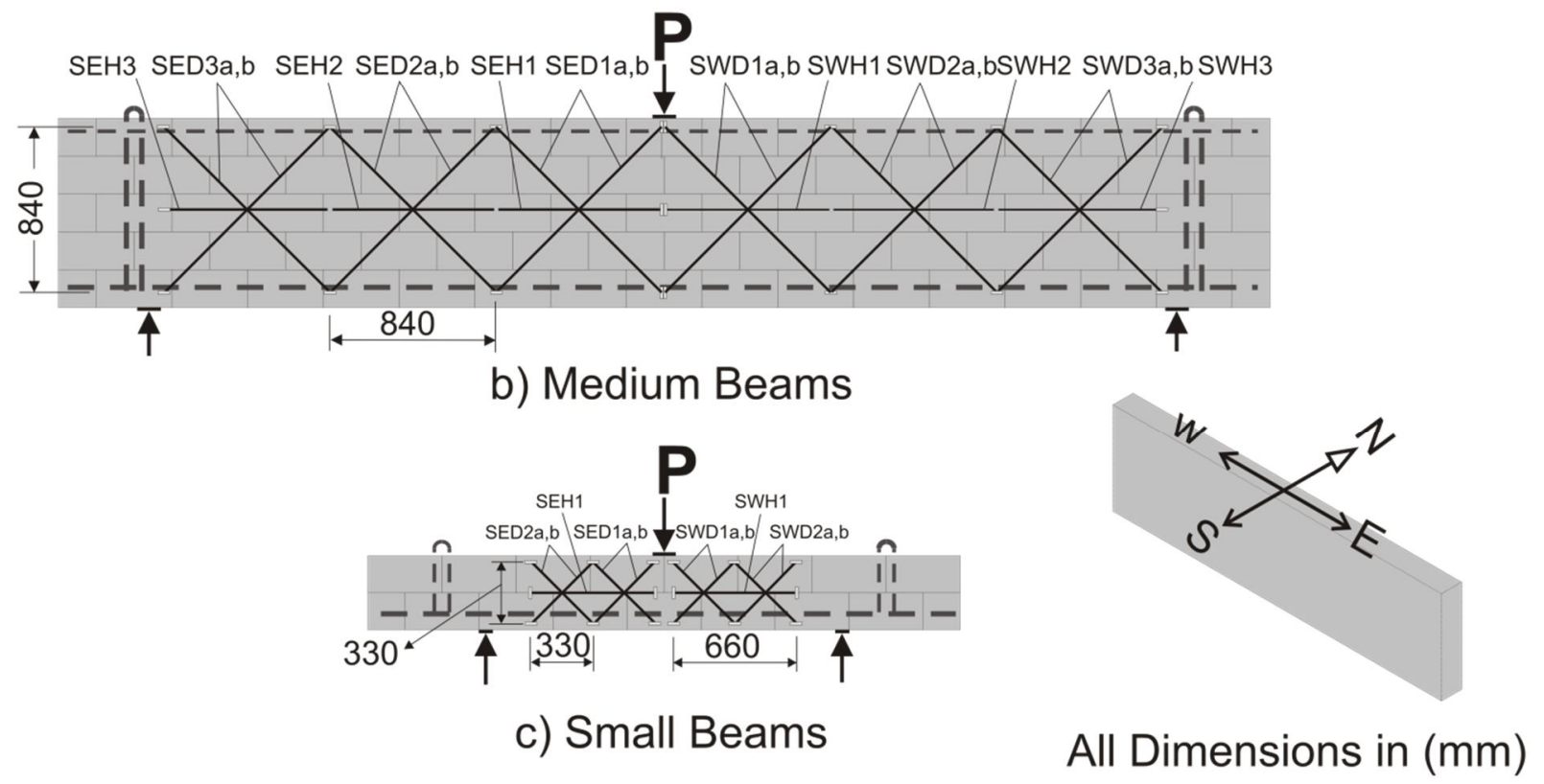

Figure 3-20: Diagrams of Side Mounted LVDTs Attached to the Beams 
Vertical LVDTs were installed below the beams to measure vertical displacements during loading, as shown in Figure 3-21. In addition to these, two sets of LVDTs were installed out of plane at the end of the beams, one set at each end. Figure 3-22 shows photos of the LVDTs, whereas Figure 3-23 shows the process of attaching the LVDTs to the surface of the beams.

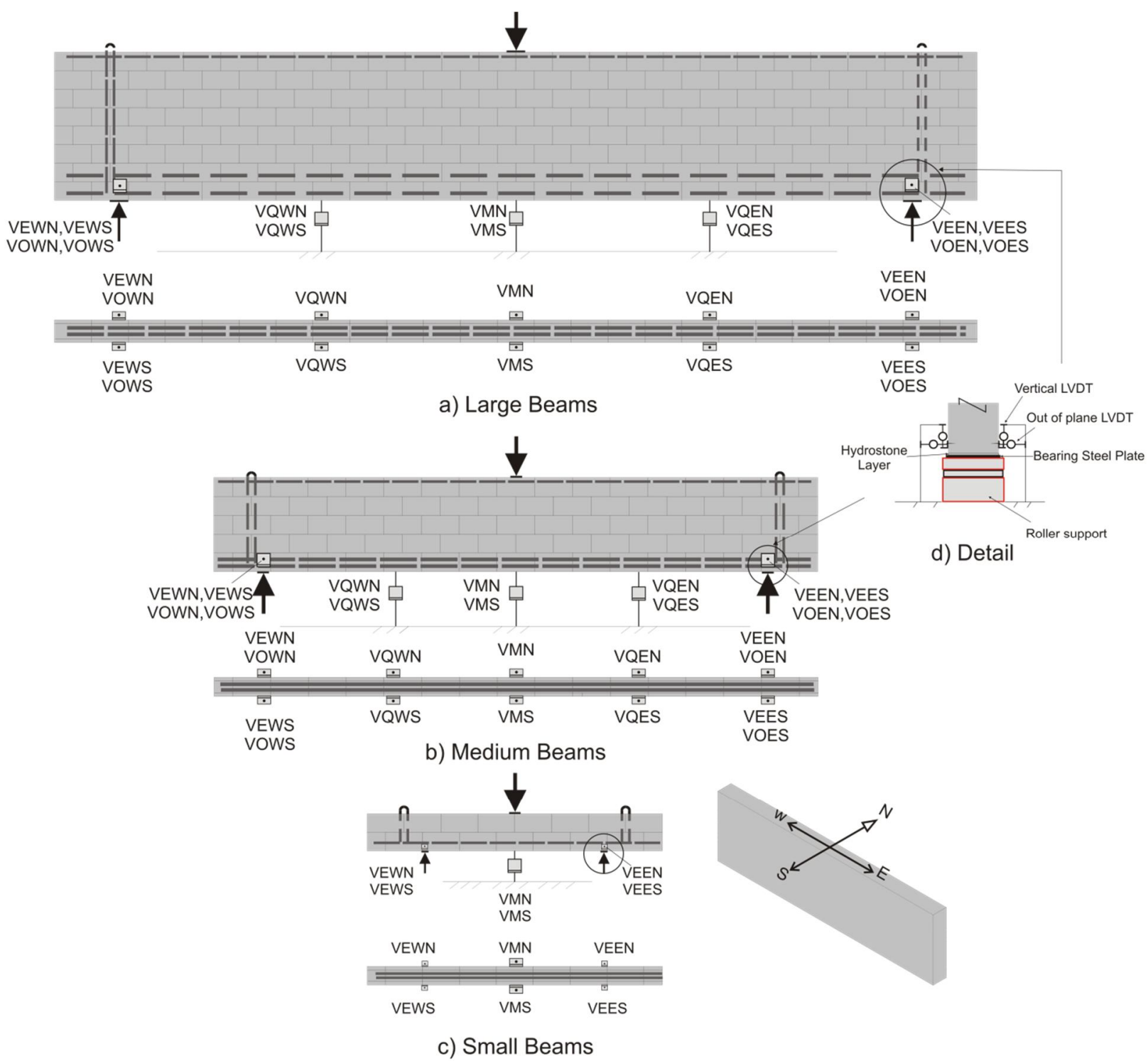

Figure 3-21: Diagrams of Vertical LVDTs Attached to the Beams 
a) LVDTs Attached to the Large Beams

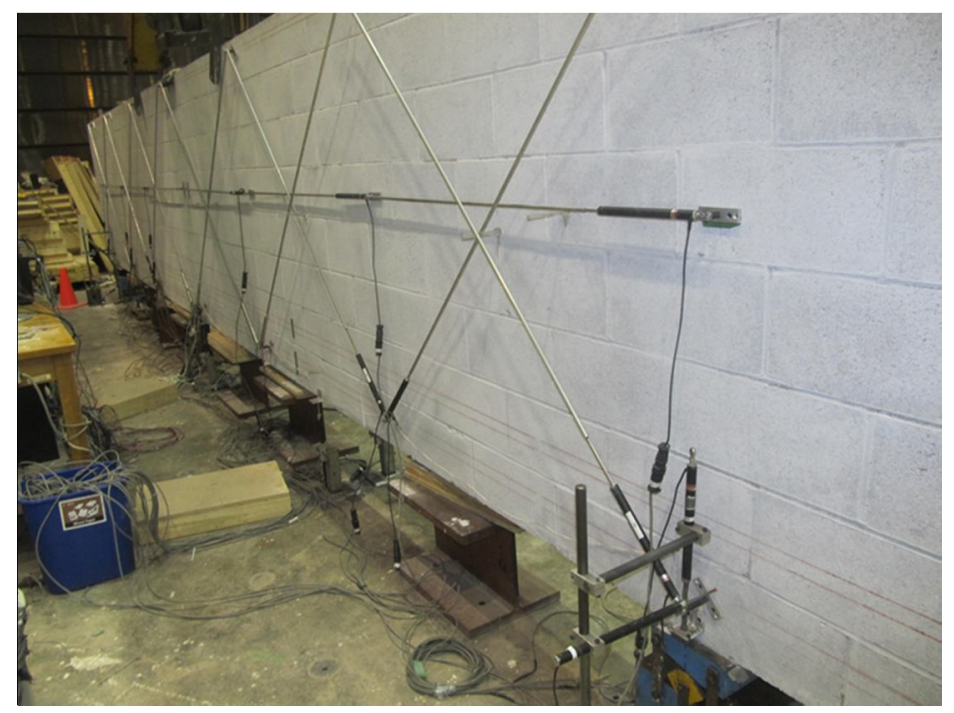

b) LVDTs Attached to the Medium Beams

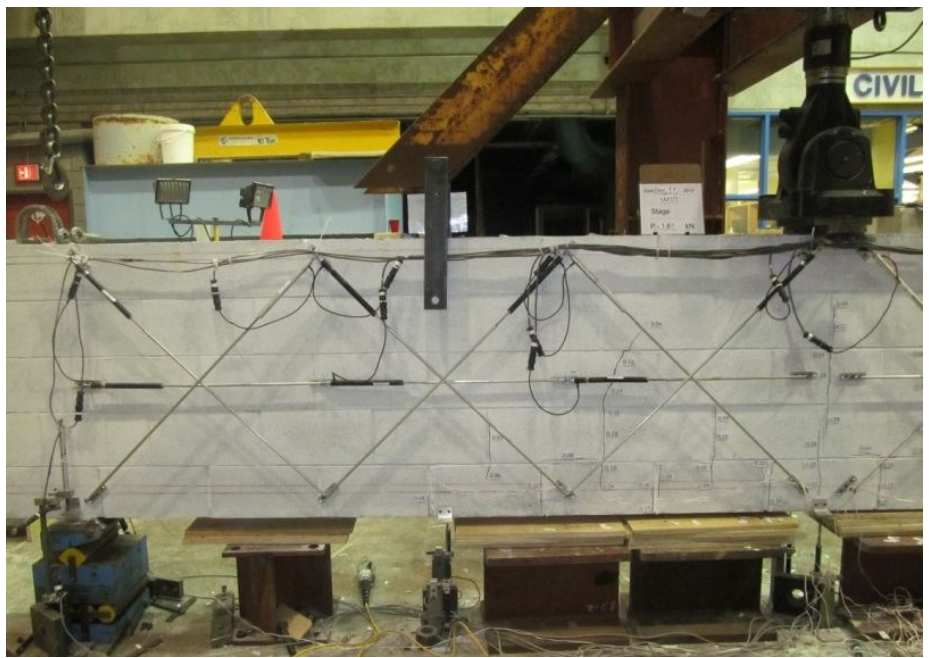

c) LVDTs Attached to the Small Beams

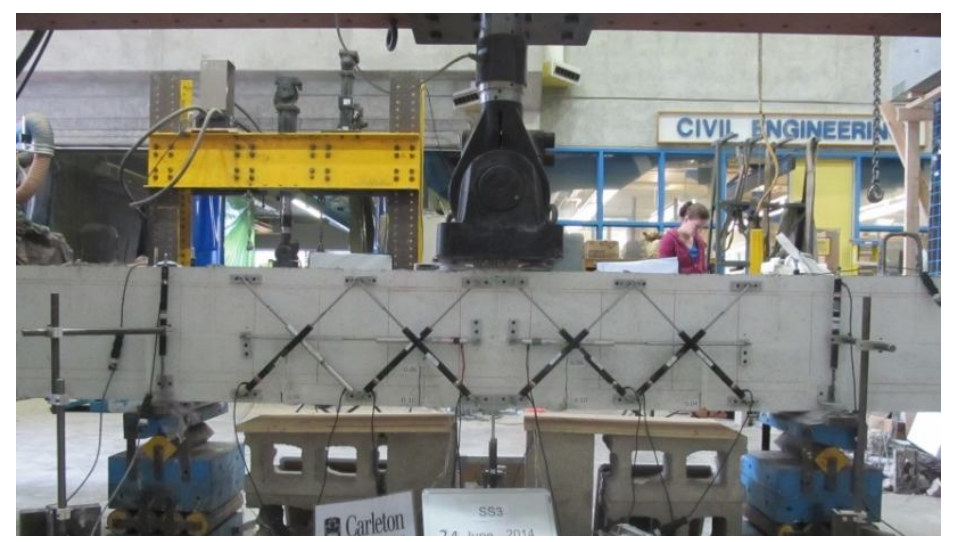

Figure 3-22: Photos of LVDTs Attached to the Large, Medium and Small Size Beams 


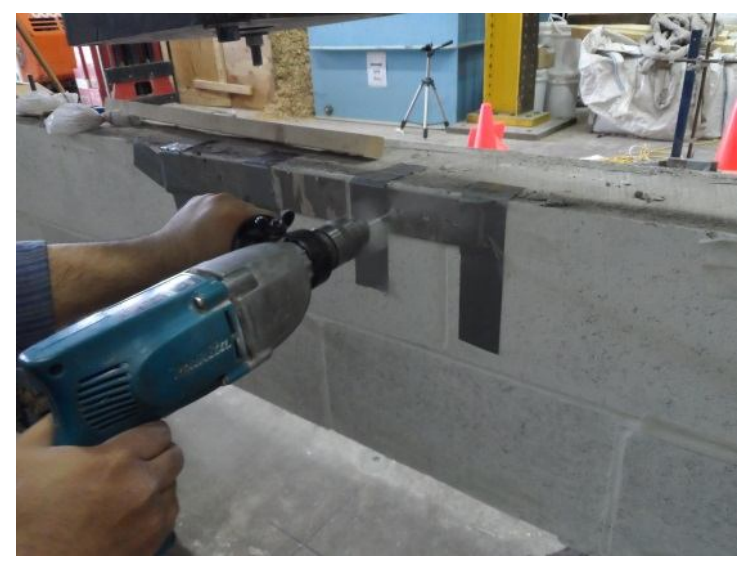

a) Drilling the Holes

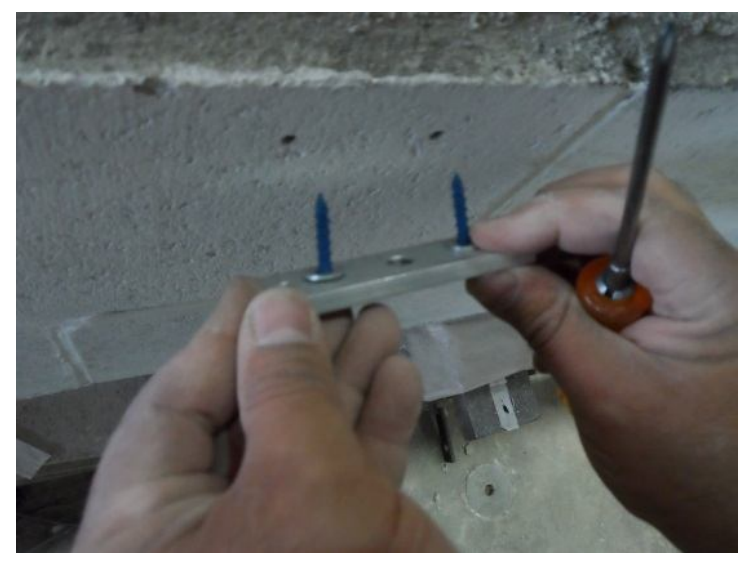

c) Attaching Aluminum brackets to the Beam Surface
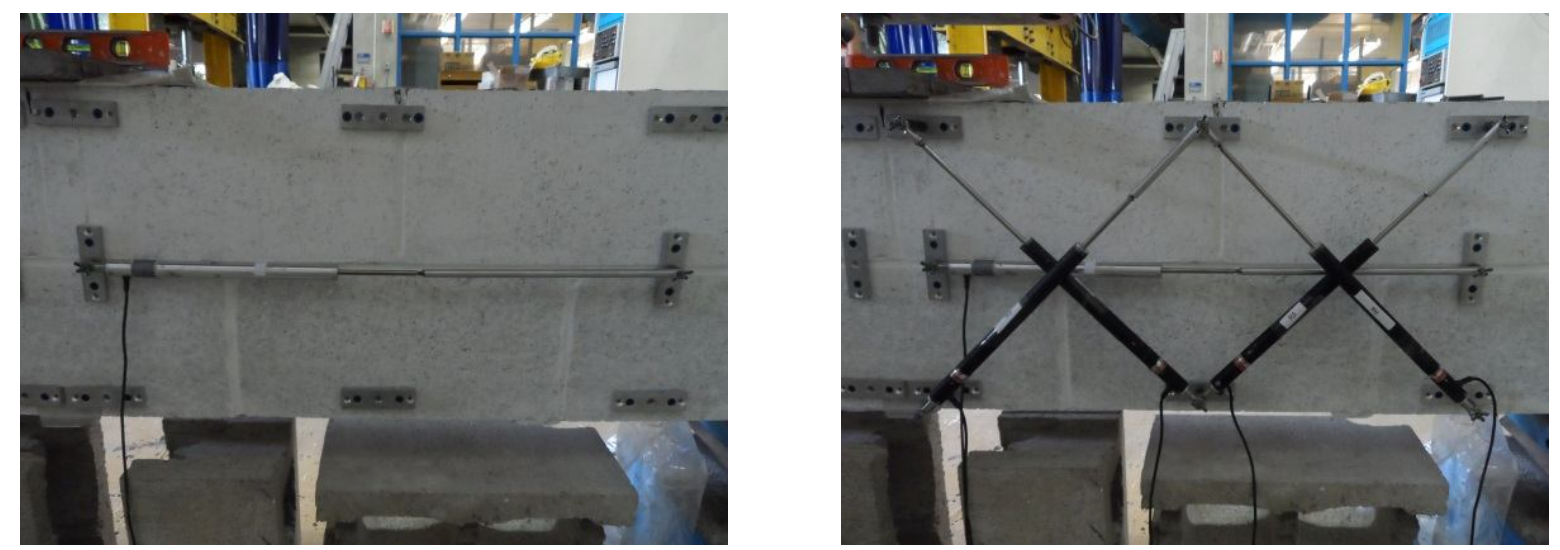

e) Attaching the LVDT Sets to the Beams

Figure 3-23: Procedure of Attaching the Side-Mounted LVDTs to the Beams 


\section{Demountable Mechanical Gauges (Demec Gauges)}

Three configurations of demountable mechanical demec gauges were used to measure the concrete strains in the middle and large beams:

1. Demec points were attached to the beam surface spread at $200 \mathrm{~mm}$ along the main reinforcement steel

2. At various locations, demec guages were attached to the surface in rosette form to assess strain coordinations at the tips of cracks

It is worth mentioning that the demec gauges in form 1 were attached prior to testing, whereas the demec gauges in forms 2 were attached during the testing. Figure 3-24 and 3-25 show a diagram and a photo of these forms of demec gauges. 


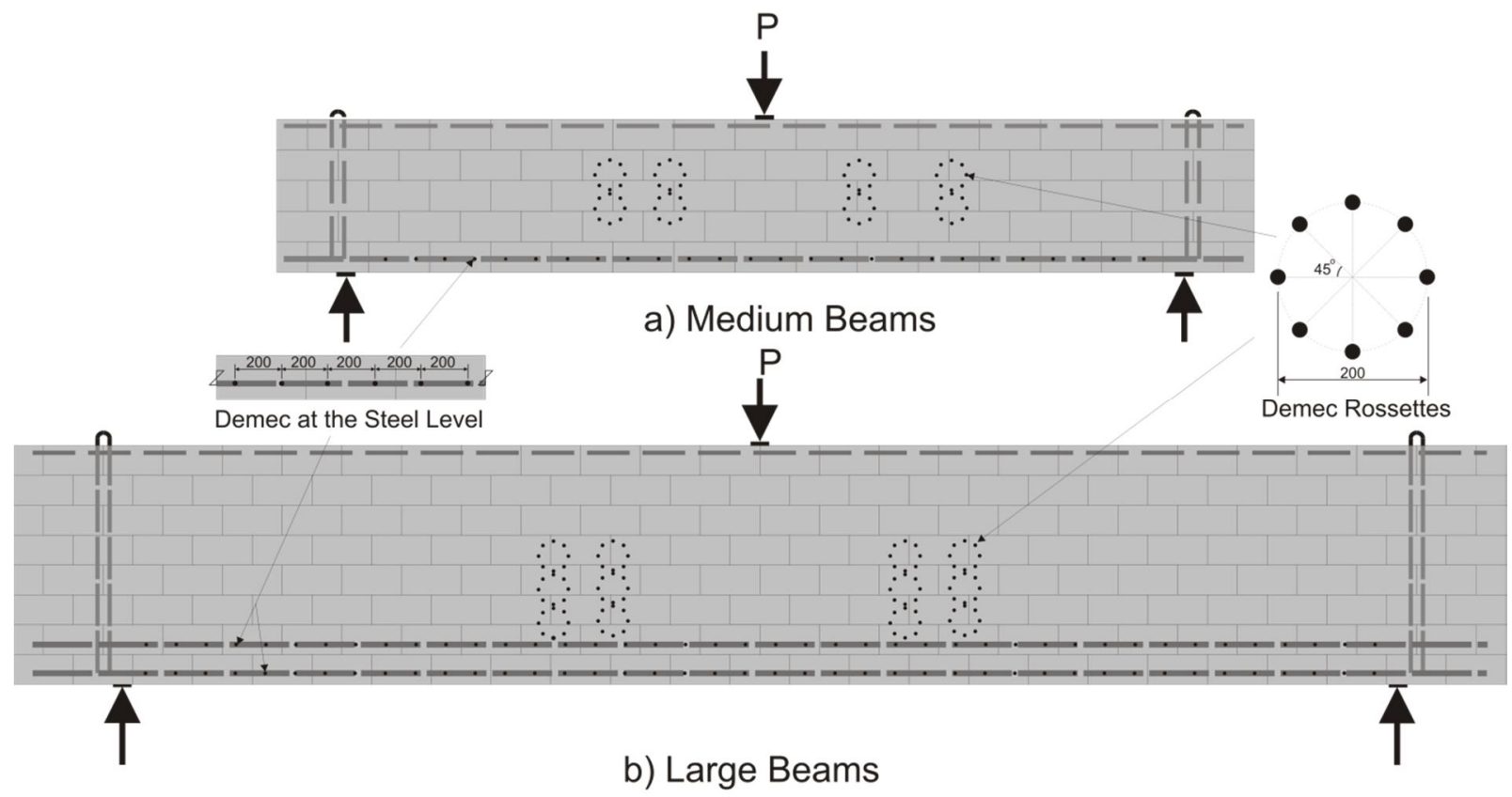

Figure 3-24: Diagram of the Demec Rosettes and the Demec Gauges along the Reinforcement Level

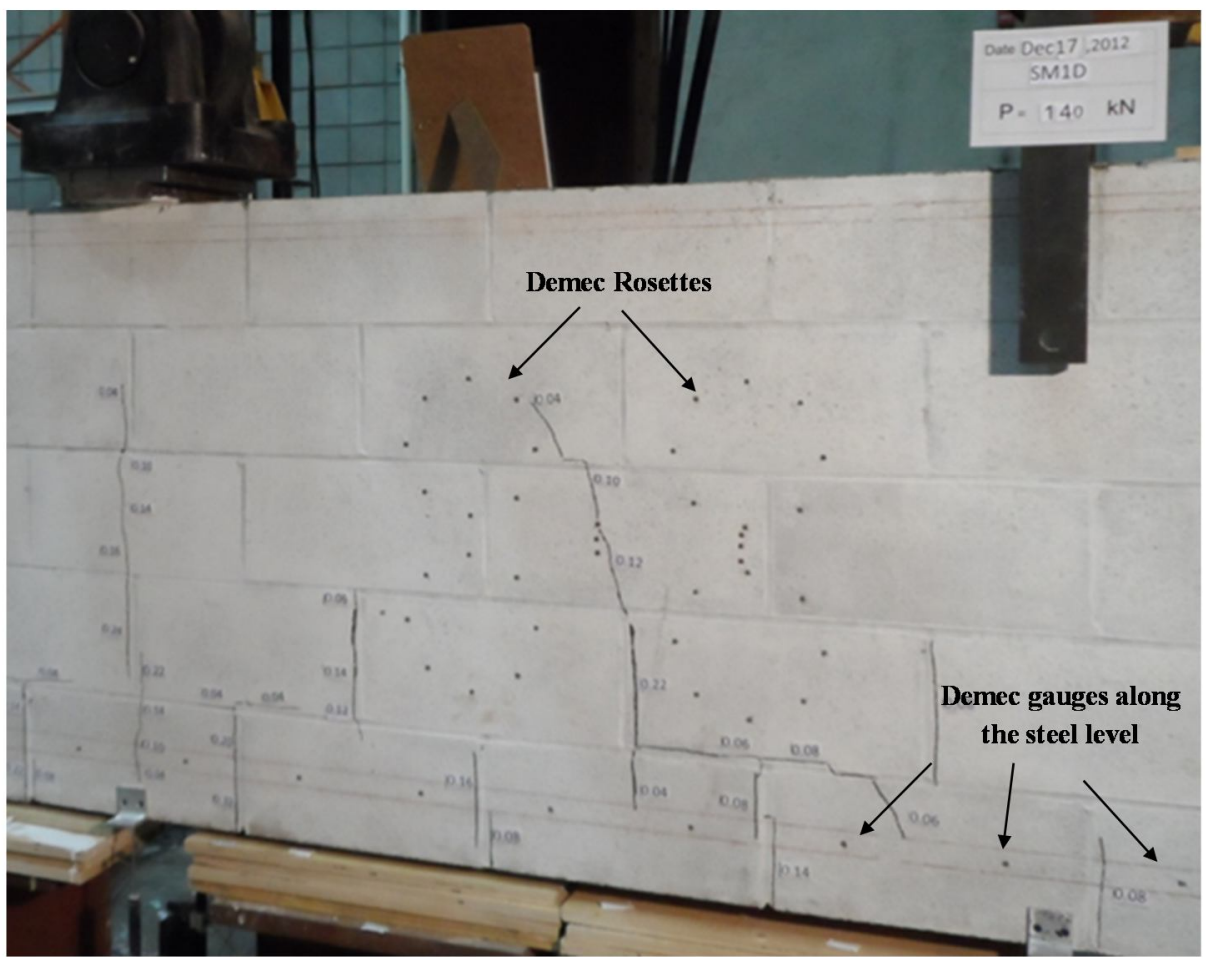

Figure 3-25: Photo Showing Demec Rosettes and Demec Gauges at the Reinforcement Level 


\section{Concrete Strain gauges}

In each of specimens SS1, SS5, SM5, SL1 and SL2, two sets of concrete strain gauges were installed in the compression zone of one of the shear spans at a distance equal to or greater than the effective depth $\mathrm{d}$ from the point load (except for SL1 and SL2 where the distances were less d). Figures 3-26 to 3-27 show the diagrams and photos of theses beams. These gauges were installed at various load stages to measure the shear force carried in the uncracked compression zone. In all these beams and after reaching a specific load stage, the applied load was reduced to zero and two columns of horizontal strain gauges were applied at the head of one of the cracks in the eastern span of the south face of the beam. The load was then reapplied and the resulting longitudinal strains recorded.

To attach the strain gauges on the surface of the concrete, the paint was first removed using the grinder. Compressed air was then used to remove all dust to create a clean surface. To make a smooth surface to install the strain gauges, bugholes in the masonry surface were filled by Mbond 10 adhesive which was left for one day to dry; a grinder was again used to remove the layer of dried epoxy. After installing the strain gauges, the resistances of all gauges were checked with a switch-and-balance unit. 

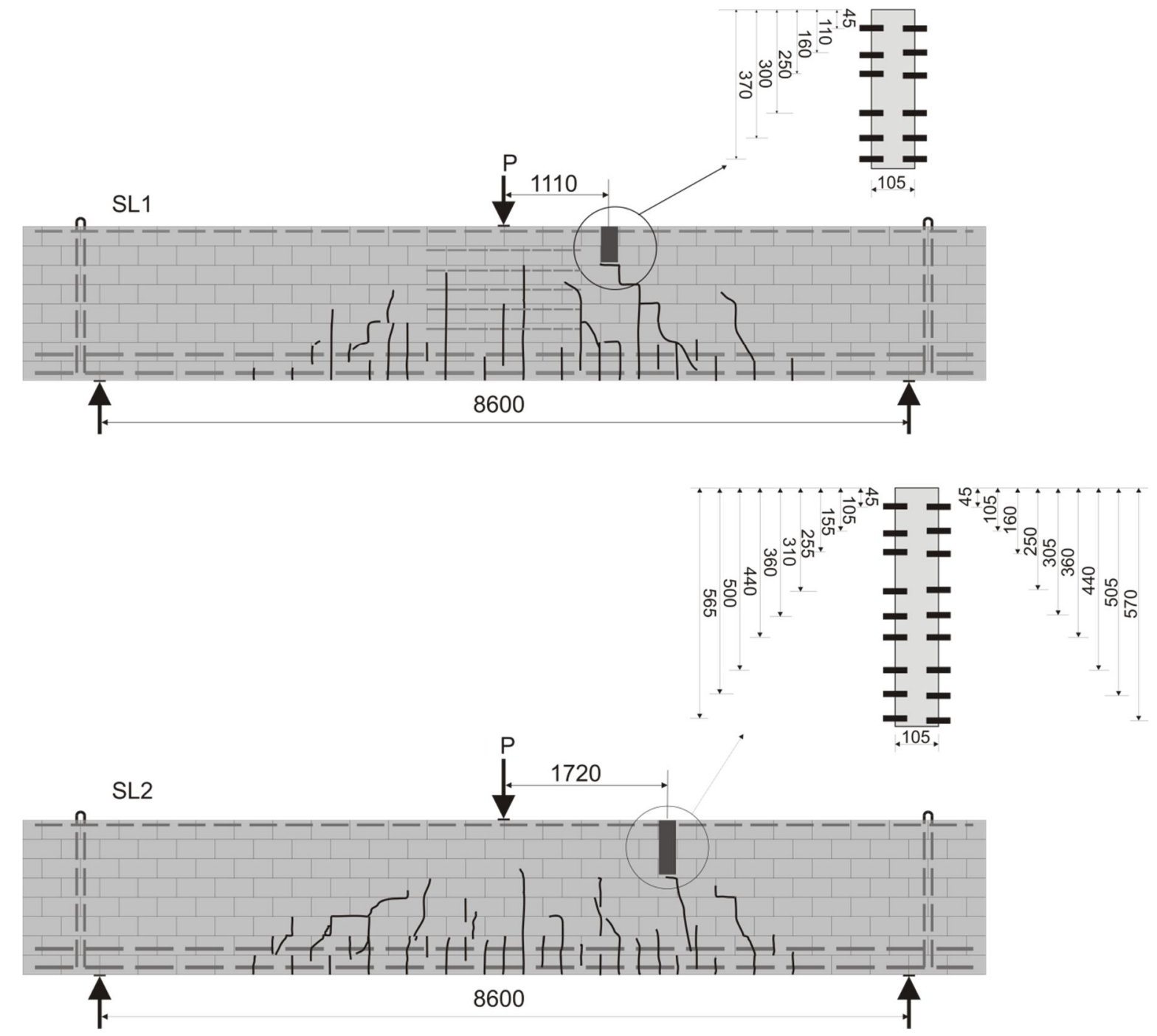

Figure 3-26: Concrete Strain Gauges installed in compression zone of the Large Beams 


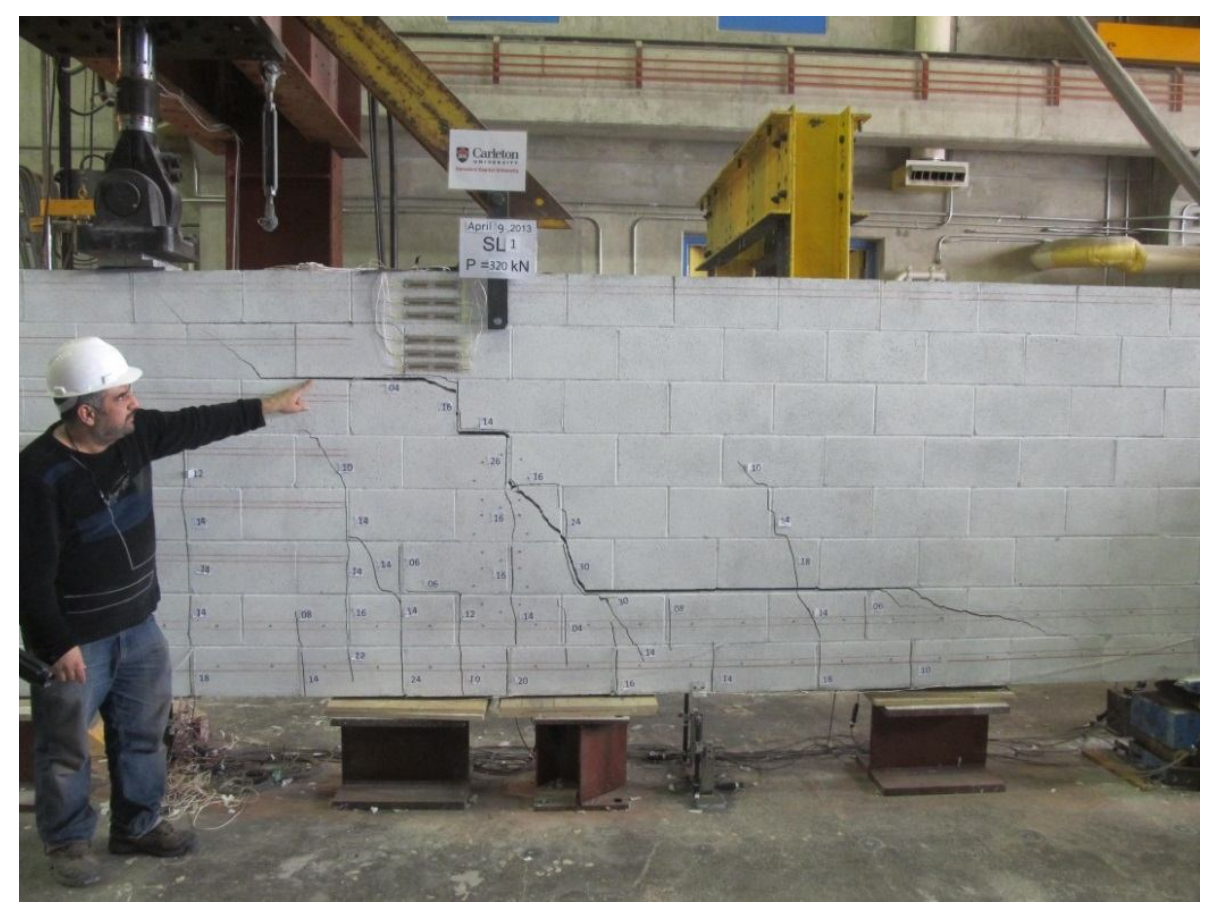

a) Concrete Strain Gauges Installed in the Compression Zone of SL1

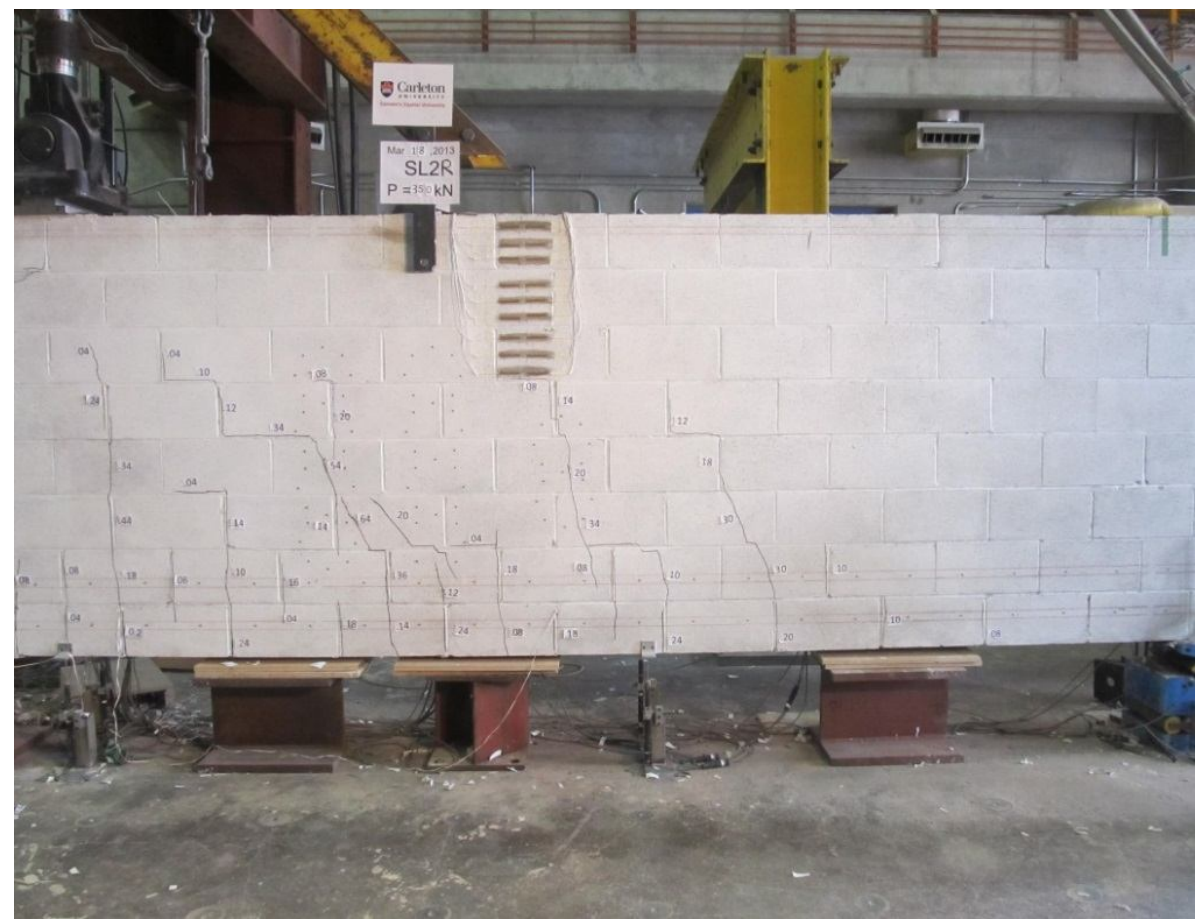

b) Concrete Strain Gauges Installed in the Compression Zone of SL2

Figure 3-27: Photo of Concrete Strain Gauges installed in the Compression Zone of the Large Beams 


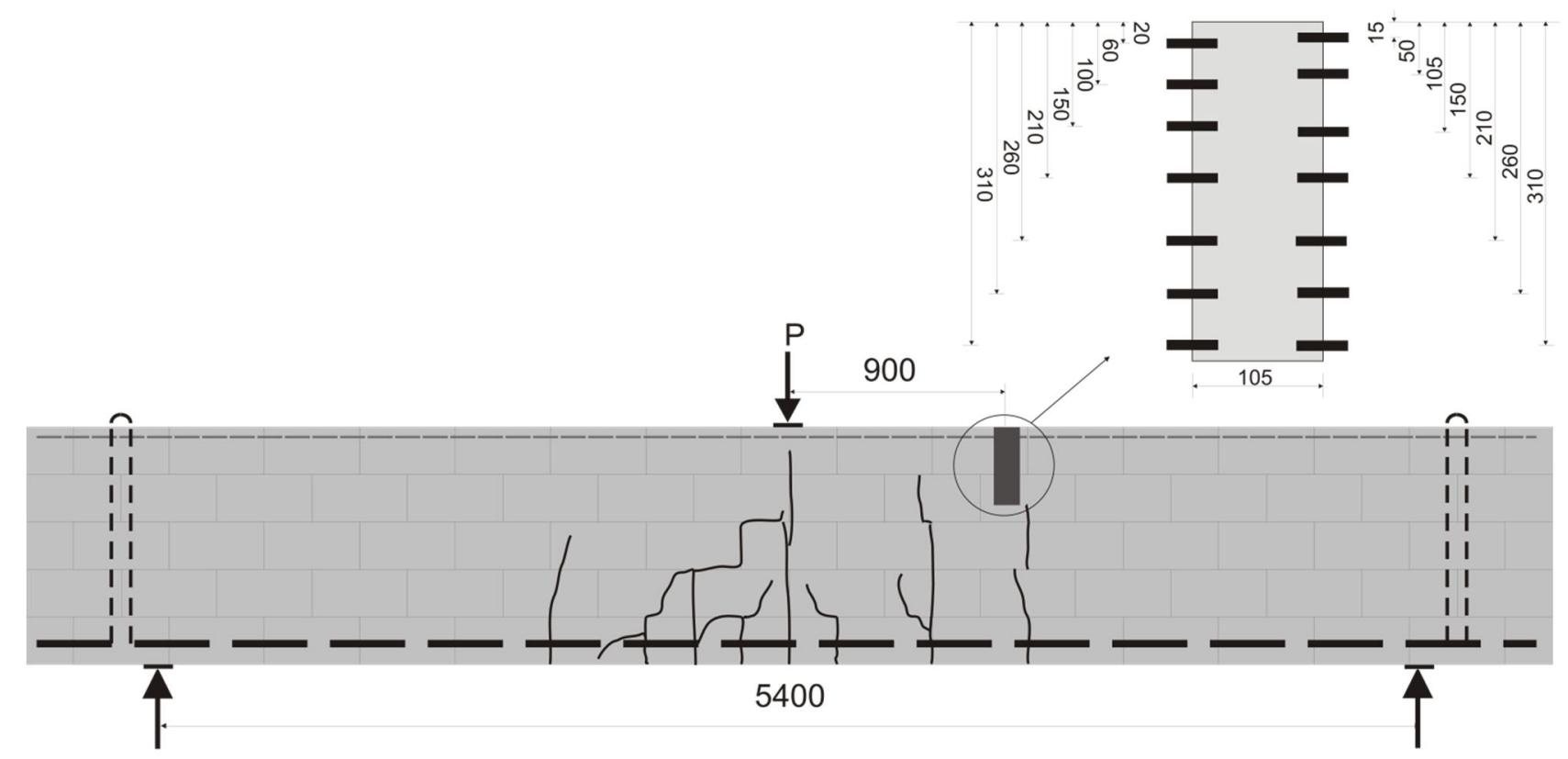

a) Medium Beam SM5

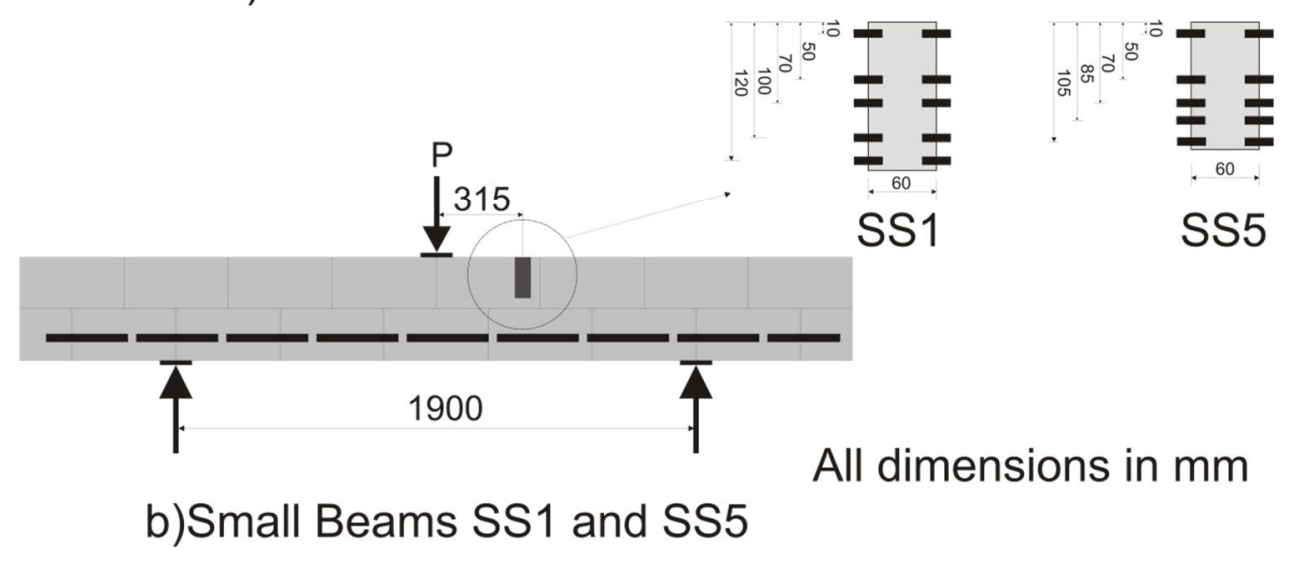

Figure 3-28: Diagram of Concrete Strain Gauges Installed in the Compression Zone of SS1, SS5 and SM5 Beams 


\subsubsection{Loading Arrangement}

Prior to testing, the specimens were painted with diluted white latex paint to aid in seeing cracks when they formed during testing. The specimens were tested in three-point bending under monotonic load until shear failure occurred (see Figures 3-29 to 3-31). The beams were supported on a pair of roller supports through $25 \mathrm{~mm}$ thick bearing steel plates covering the entire width of beam. The load was applied to the beams through a $25 \mathrm{~mm}$ thick plate. Thin layers of hydrostone were placed between the steel loading/bearing plates and the beam to ensure uniform bearing stresses. Except for specimen SM3, loading was applied by a $500 \mathrm{kN}$ capacity machine for all the beams. A $1000 \mathrm{kN}$ capacity machine was used to apply the loading in specimen SM3. During the testing loading was paused at various stages to permit detailed investigation of the cracking patterns, including marking the cracks with a felt-tip pen, measuring crack widths to a precision of $0.025 \mathrm{~mm}$ and photographing the beams. At load stages, the load was reduced by $10 \%$ for safety. When shear failure occurred in one side was clamped using steel plates and high strength threaded rods and the beams was reloaded to failure in the opposite side (repeated side) (see Figure 3-32). 


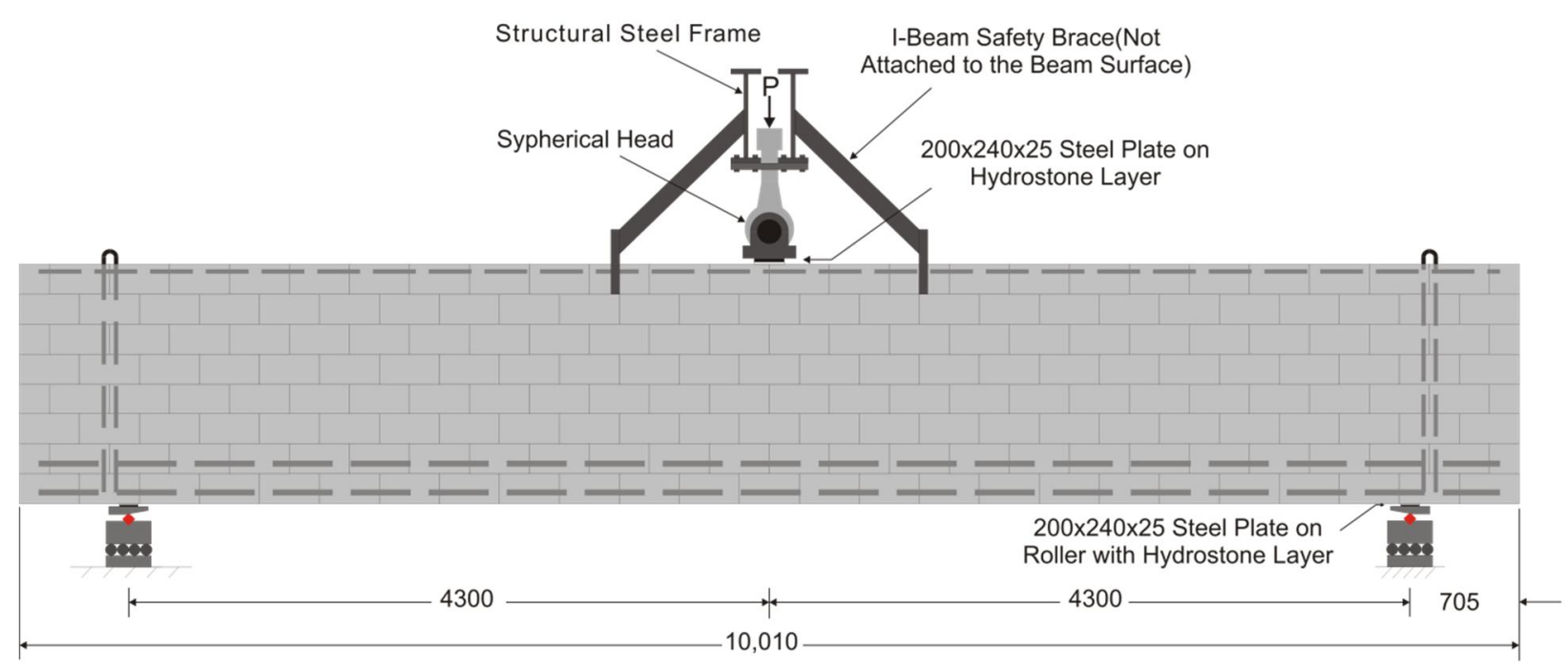

a) Specimens SL1 and SL2

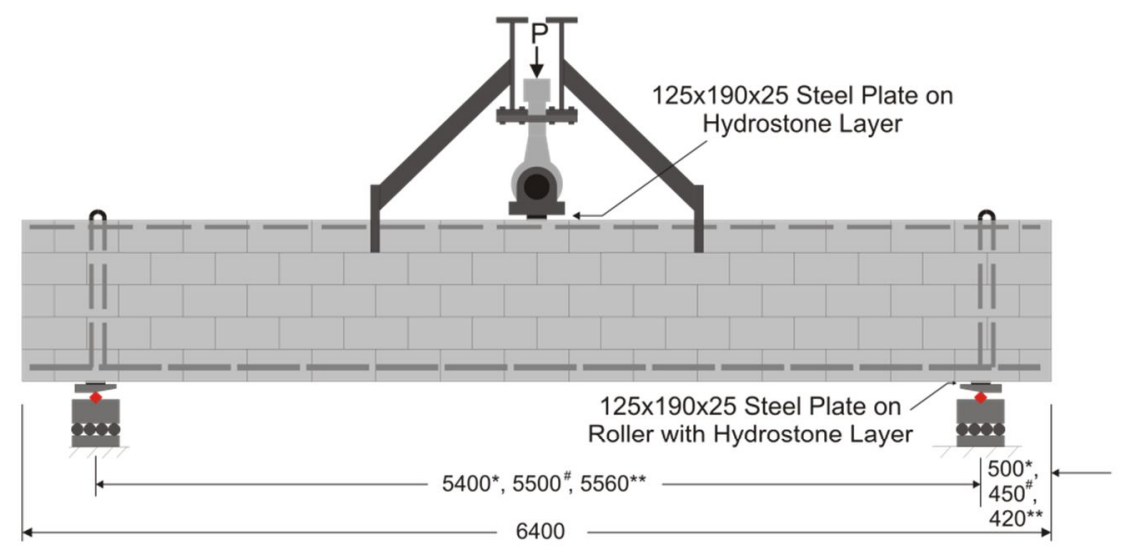

b) Specimens SM1*, SM1D**, SM2**, SM4 ${ }^{* *}, \mathrm{SM}^{*}$ and SM6**

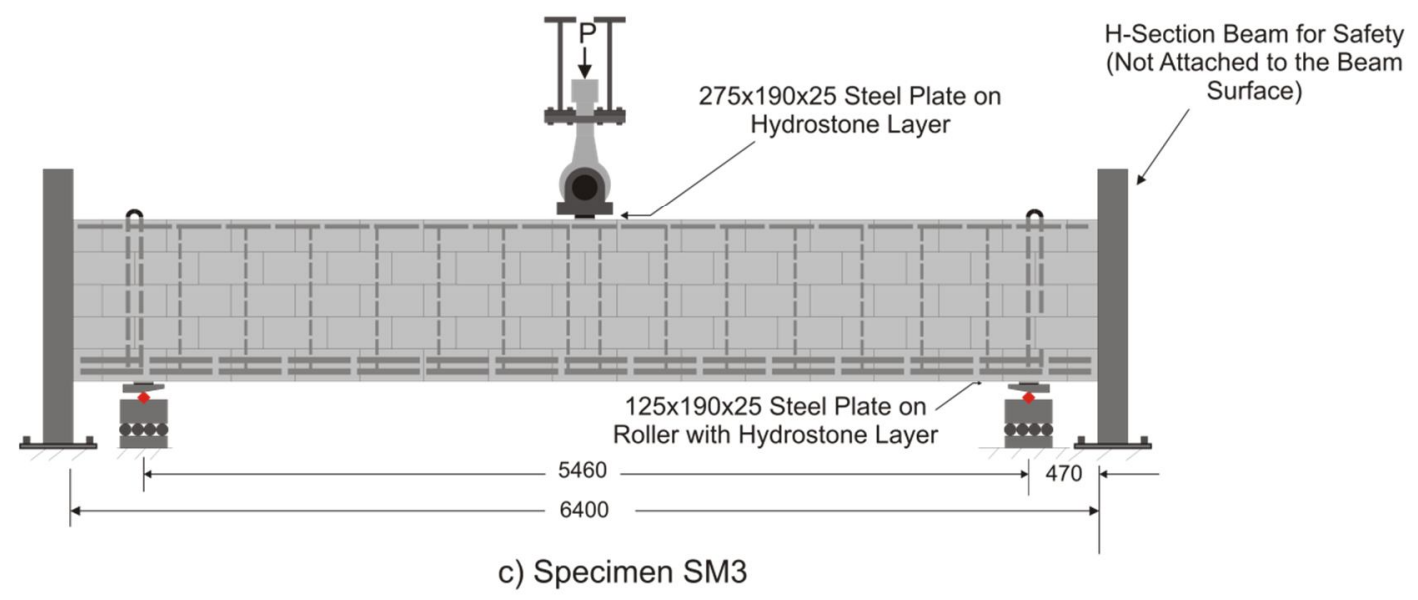

Figure 3-29: Test Setup of the Large and Medium Beams 


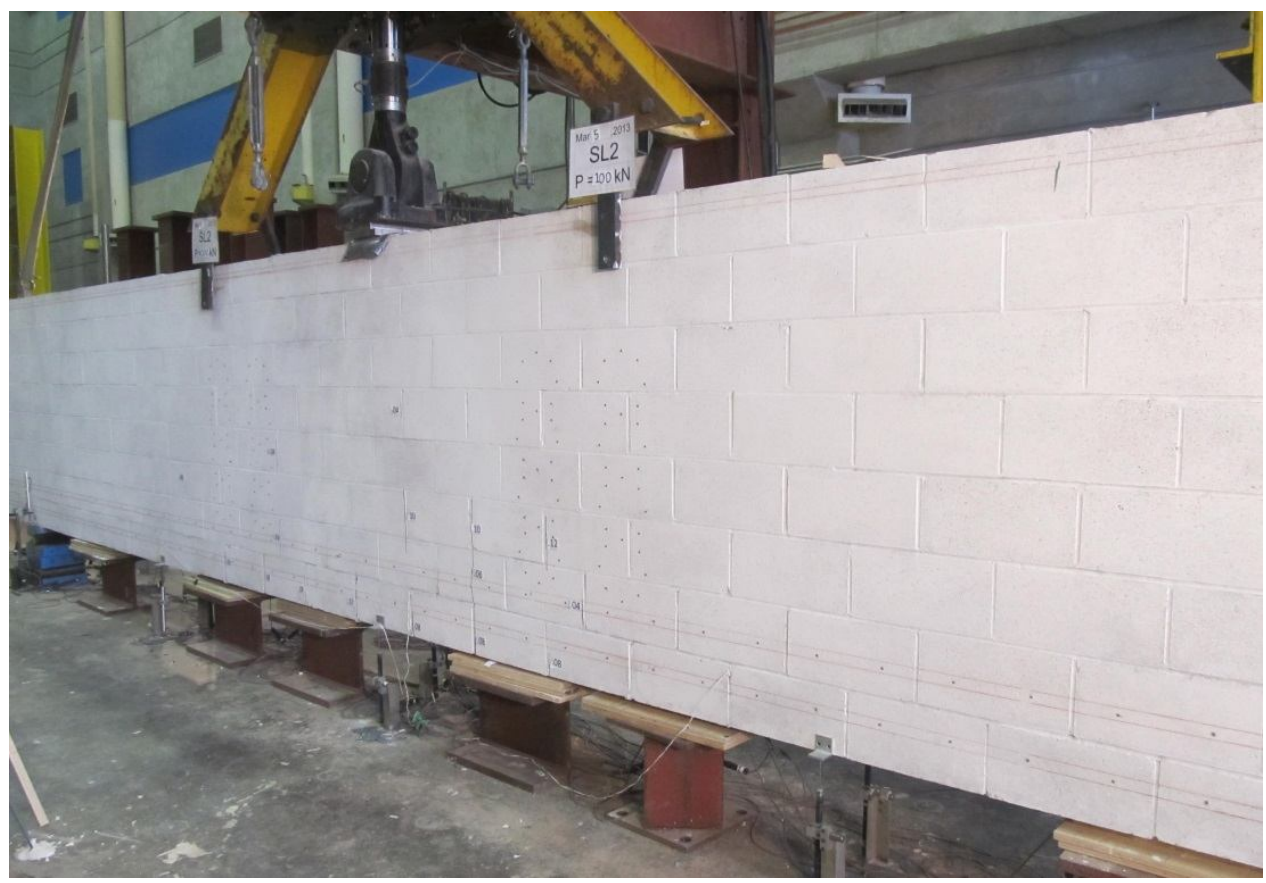

a) Test Setup for Beam SL2

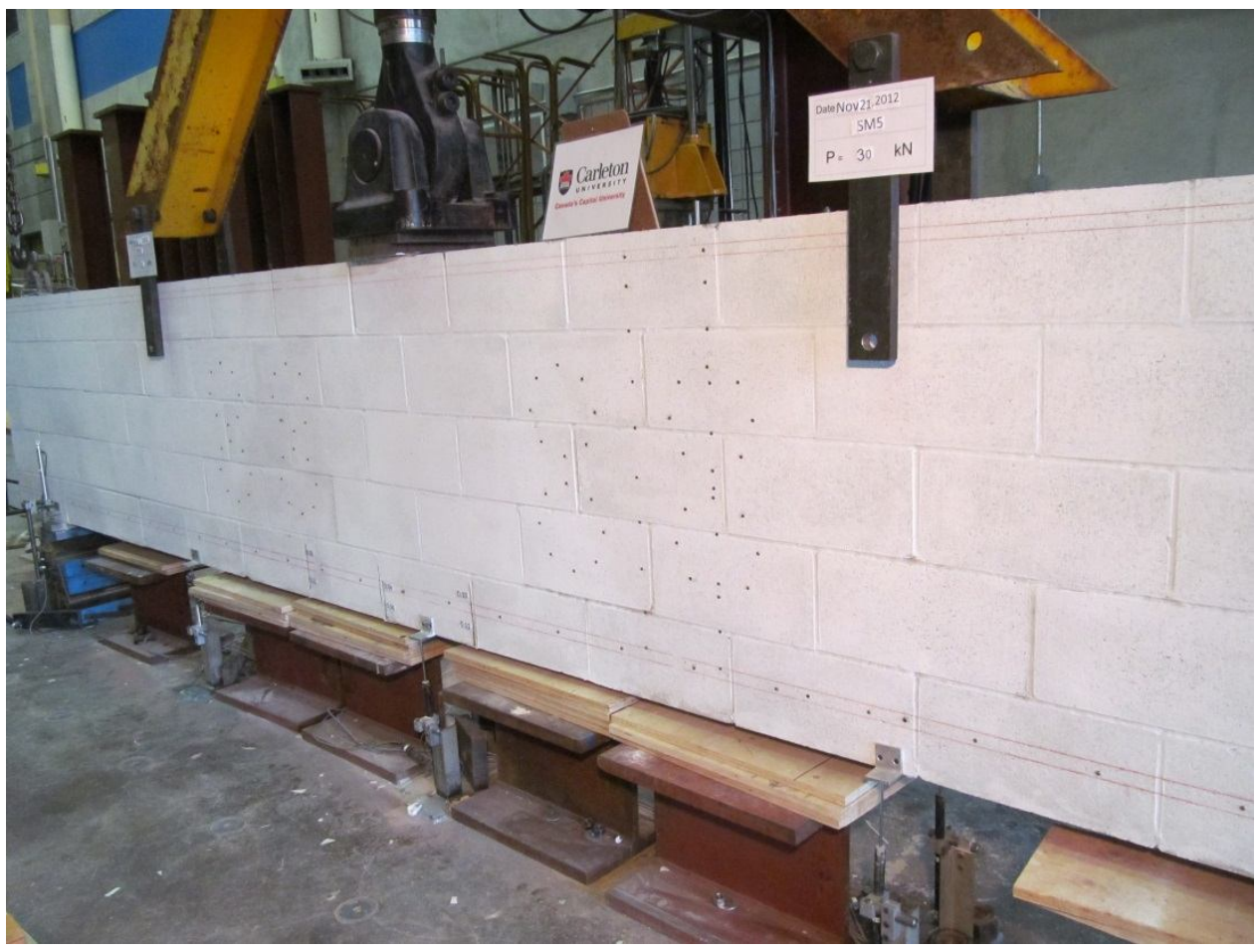

b) Test Setup for Beam SM5

Figure 3-30: Photos of the Test Set up of the of the Large and Medium Beams 


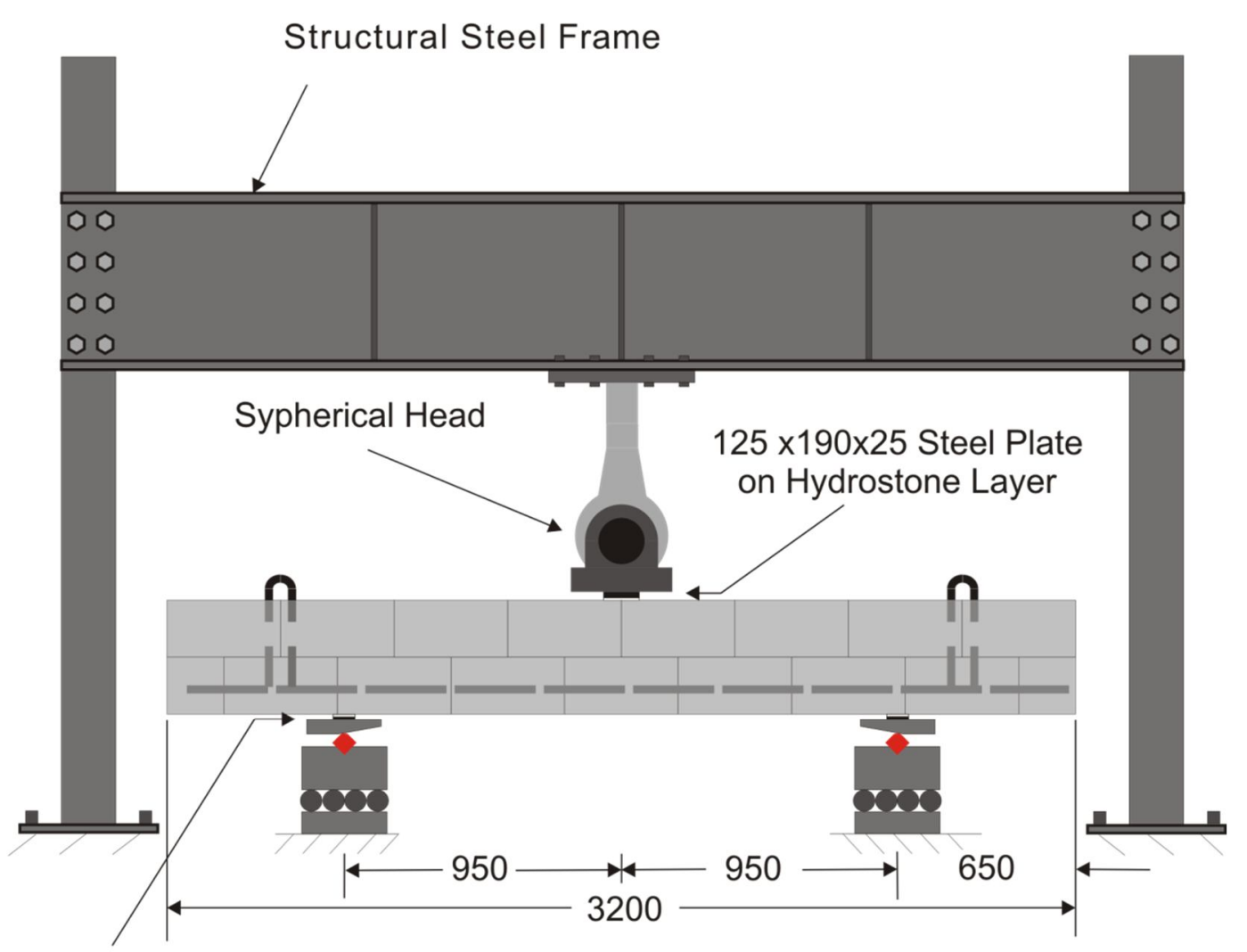

$75 \times 190 \times 25$ Steel Plate on Roller with

Hydrostone Layer

a) Test Setup of the Small Beams

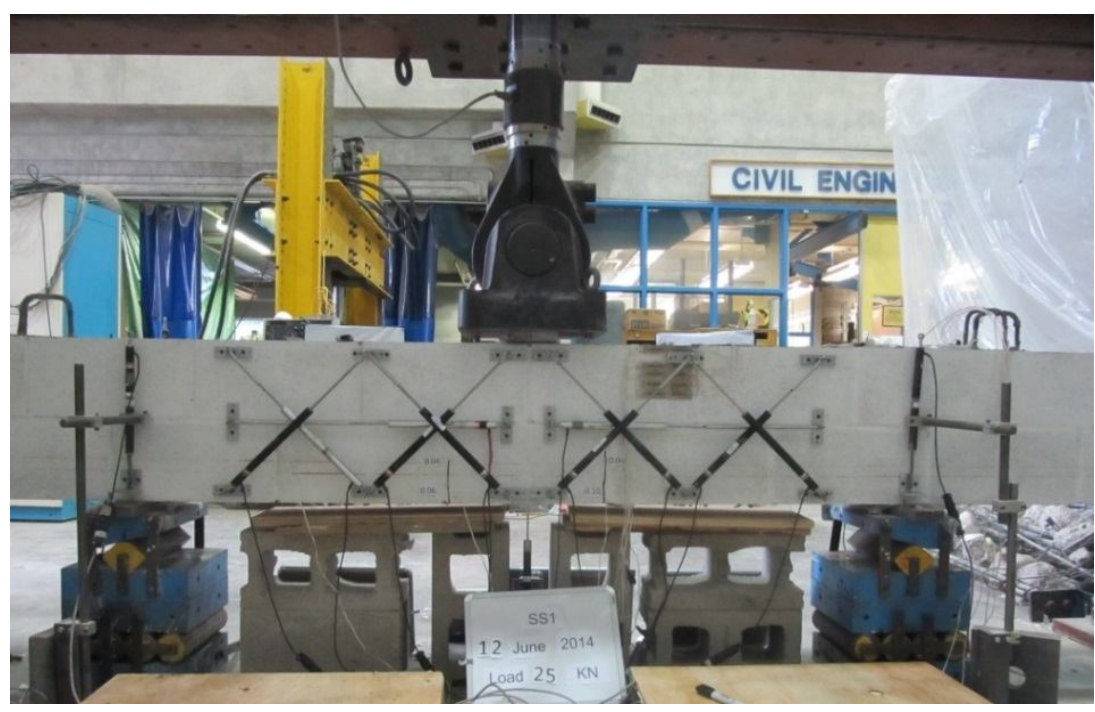

b) Test Setup of Beam SS1

Figure 3-31: Test Setup of the Small Beams 


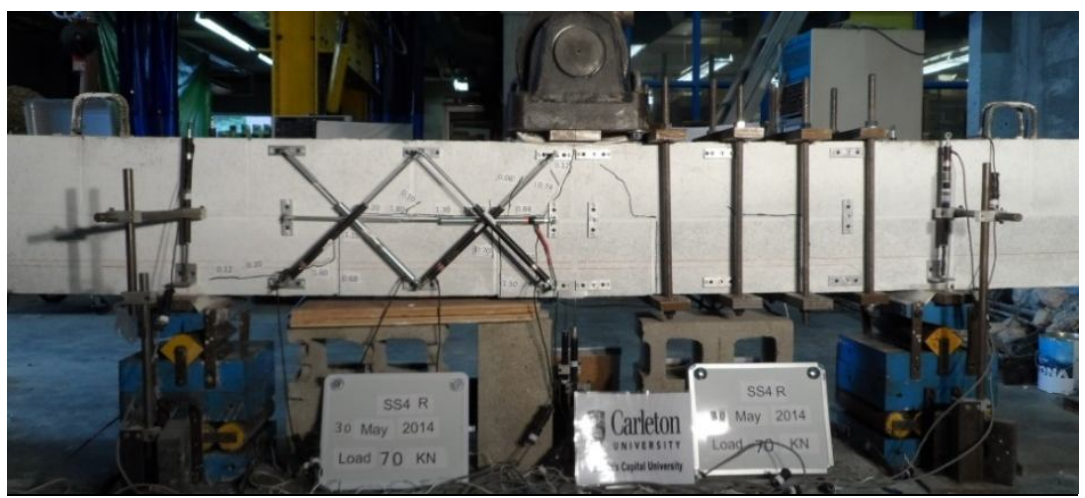

a) Small Beams

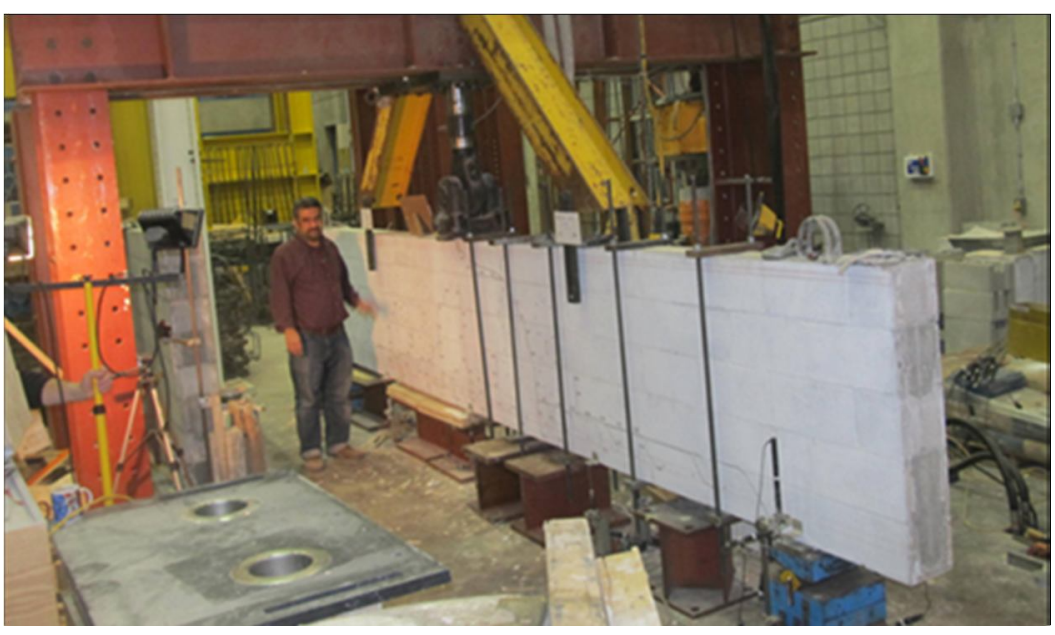

b) Medium Beams

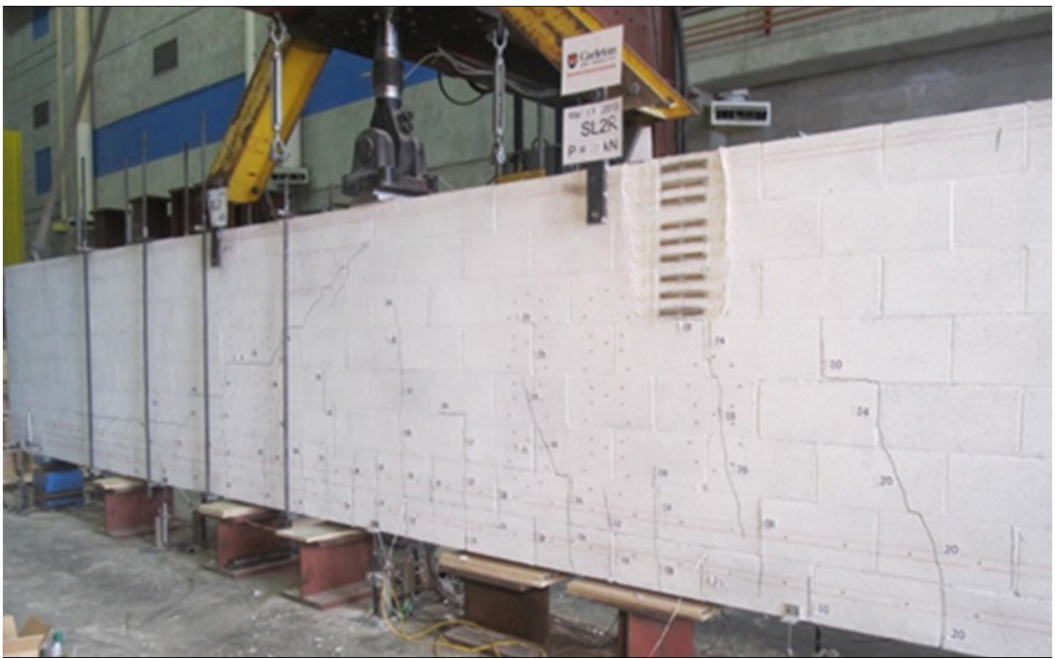

c) Large Beams

Figure 3-32: Testing of the Repeated Sides of the Beams 


\subsection{Testing of the Material Properties}

As discussed earlier, numerous separate specimens were built to measure material properties. The purpose of these specimens was to obtain the basic strength characteristic of the masonry. These specimens include: four unit high running bond masonry prisms loaded normal and parallel to bed joints, grout cylinders (Figure 3-18b), block moulded prisms and mortar cubes (see Figure 3-18a,c). A number of these specimens were test for each series of beams (large, medium and small beams). Several block units were tested for each series of beams as well.

\subsubsection{Masonry Prisms}

A key factor of masonry prism testing is the load transfer mechanism at the top and bottom faces of the prism. This includes providing flat bearing surfaces and thick loading plates to distribute the load uniformly to the prism (Drysdale and Hamid 2005). As shown in Figure 3-33, the bearing surfaces of the prisms were capped with thin layers of hydrostone in order to assure uniform stress distribution. A lightly greased glass plate was used to level the capping and the levelness of the capping was checked using a level placed on the glass plate. The first capped face was left to cure for one day before the second side was capped. A small wooden assembly was used to facilitate flipping the prisms to cap the opposite sides of the prisms (see Figure 3-33 e). A purpose-made moving device was used to move the prism into the testing machine, as shown in Figure 3-33f. 


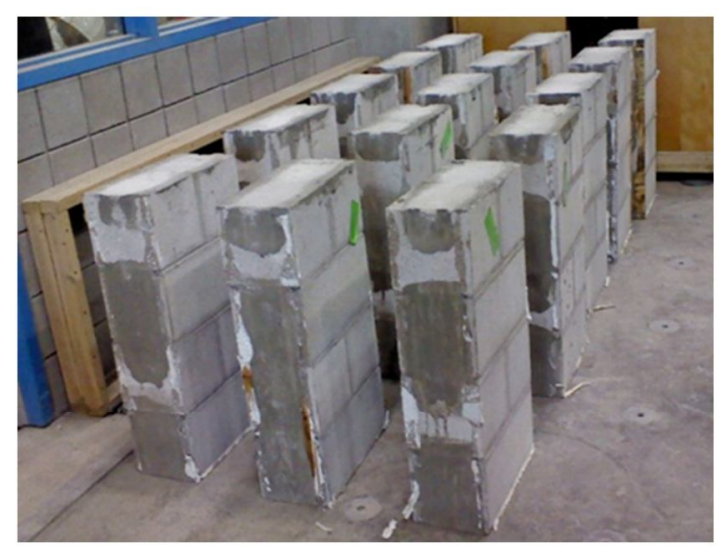

a) Glass Plate and Oil used for Capping

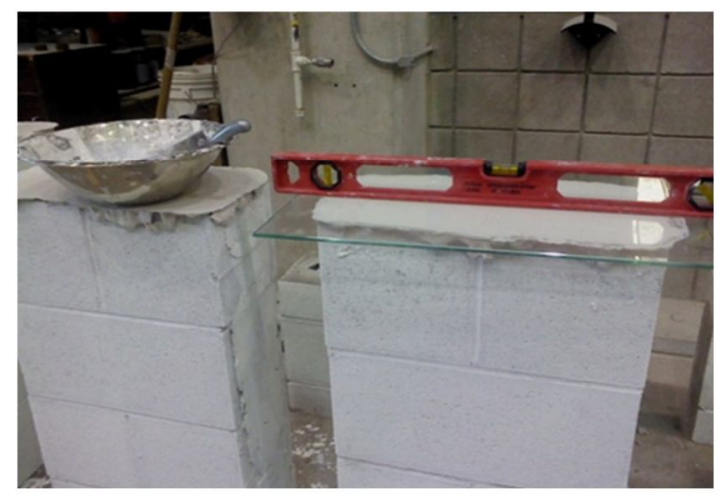

c) Capping of Prisms

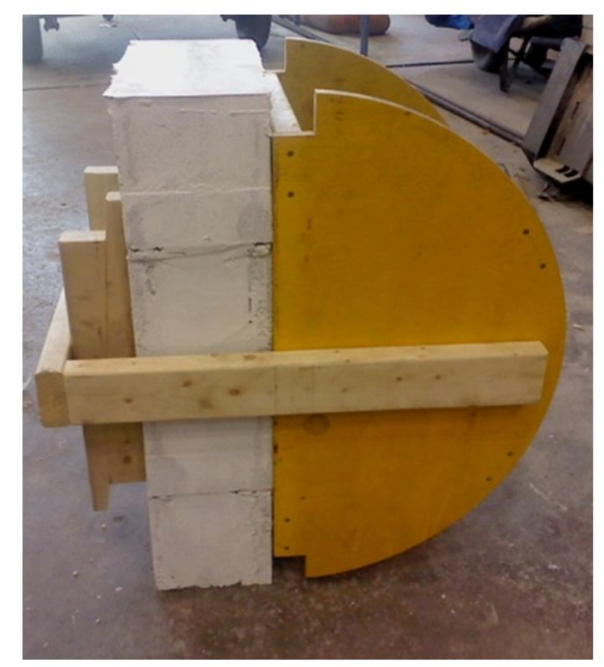

e) Wooden Flipping Assembly

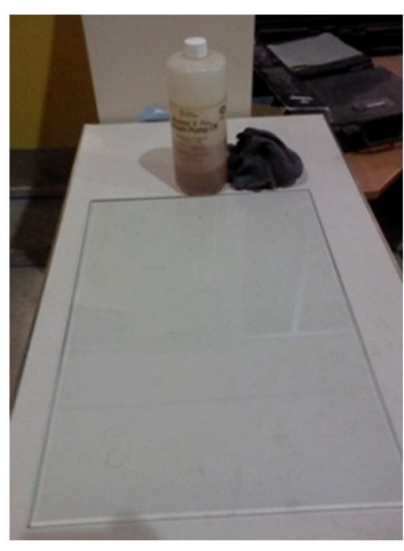

b) Glass Plate and Oil used for Capping

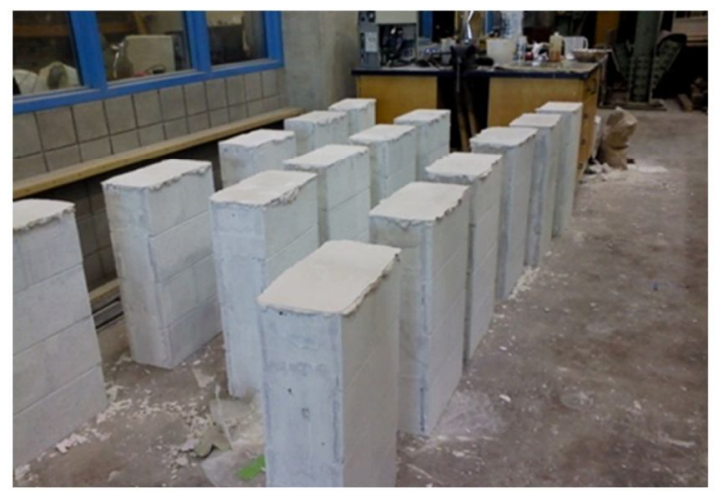

d) Prisms after Painting and Capping

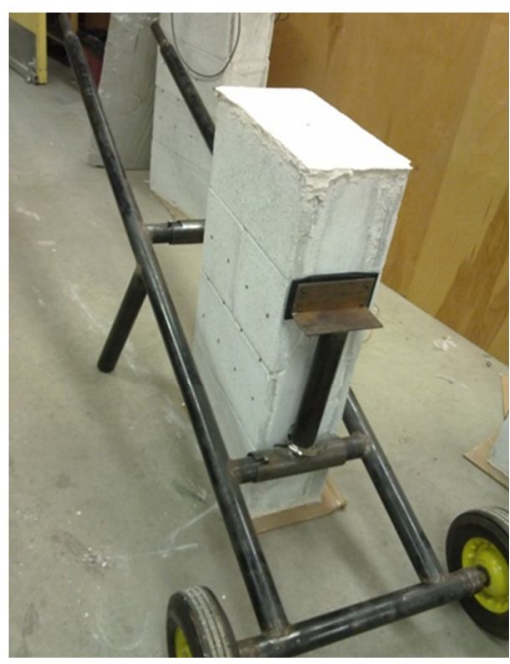

f) Prism Moving Device

Figure 3-33: Painting and Capping of the Prisms 
A $1840 \mathrm{kN}$ capacity testing machine was used to test the prisms at a displacement control rate of $0.1 \mathrm{~mm} / \mathrm{min}$. The machine has a test bed with sufficient area and stiffness to provide uniform load transfer. A 5 in. $(127 \mathrm{~mm})$ thick steel plate of was attached to the spherical top head of the testing machine to provide adequate stiffness at top of the prism. This thickness meets The CSA S304.1 requirements for testing prism testing. Figure 3-31 shows the selection of the additional steel plate. To measure the vertical displacement and the modulus of elasticity of the prisms, a specialized aluminum frame was constructed as shown in Figure 3-34. Some of the masonry prisms were installed with strain gauges (Figure 3-35).
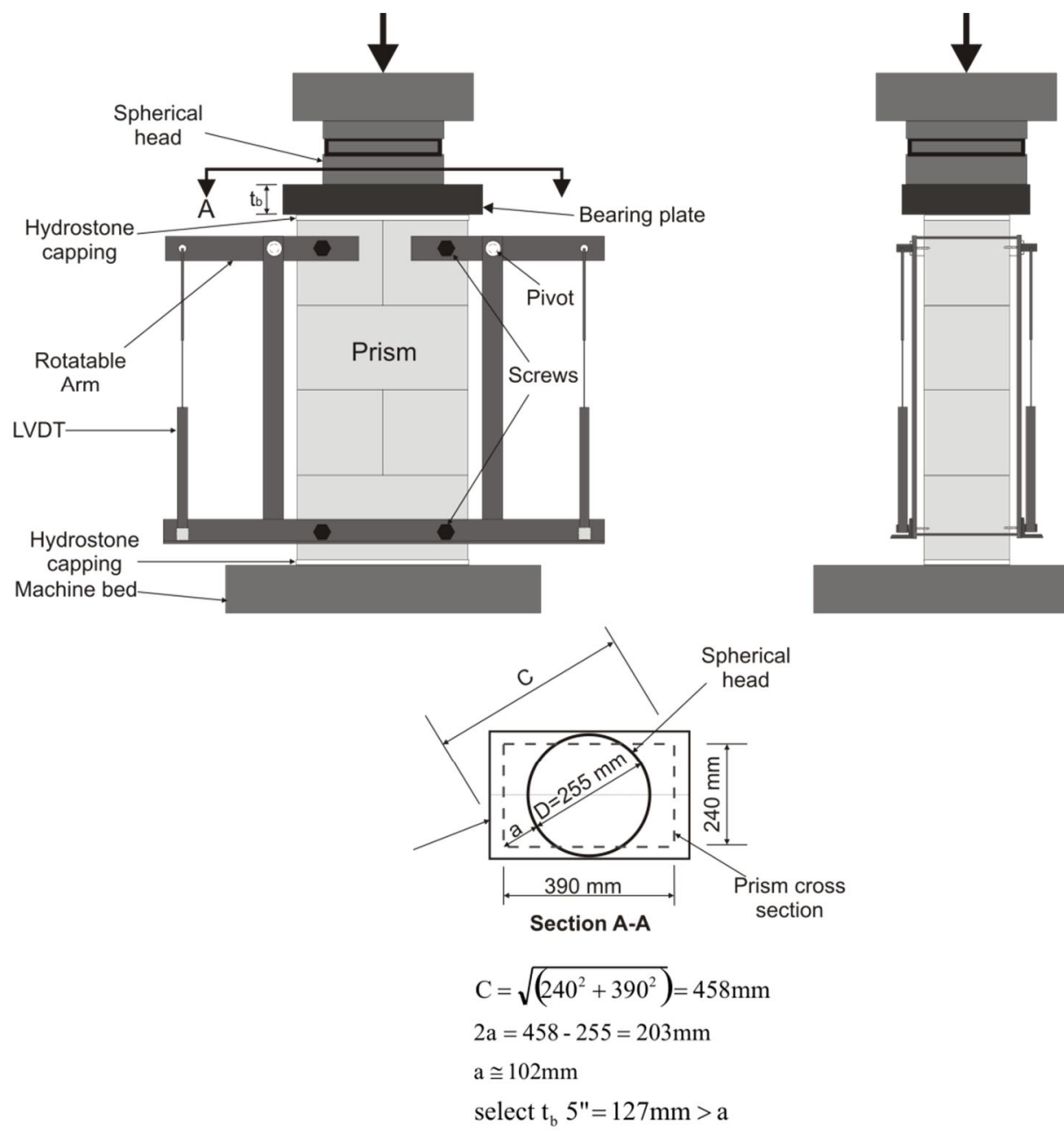

Figure 3-34: A Diagram Showing the Test Set up for the Prisms 


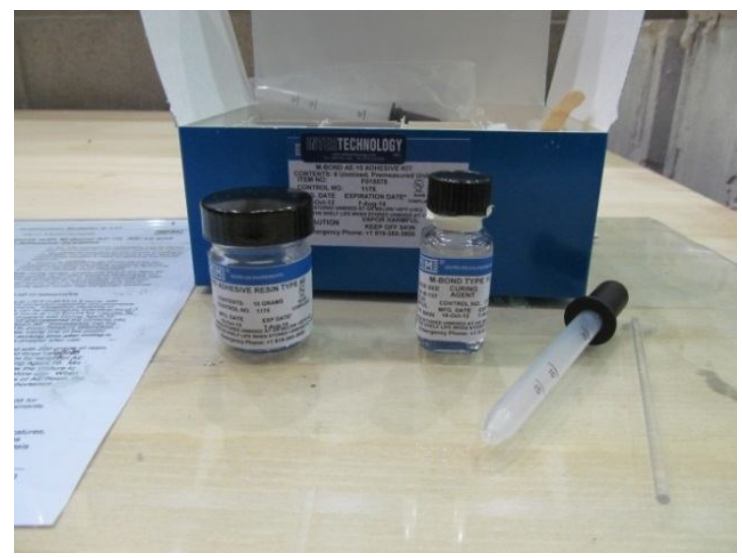

a) M-bond 10 adhesive

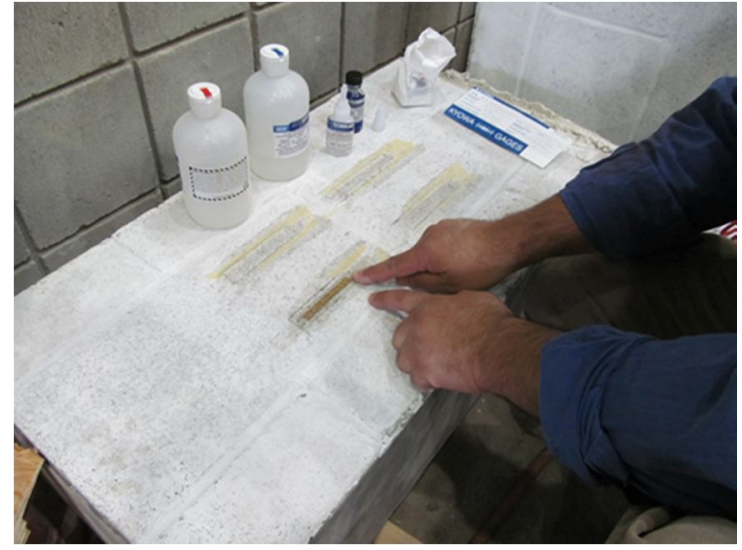

c) Installation of the Strain Gauges

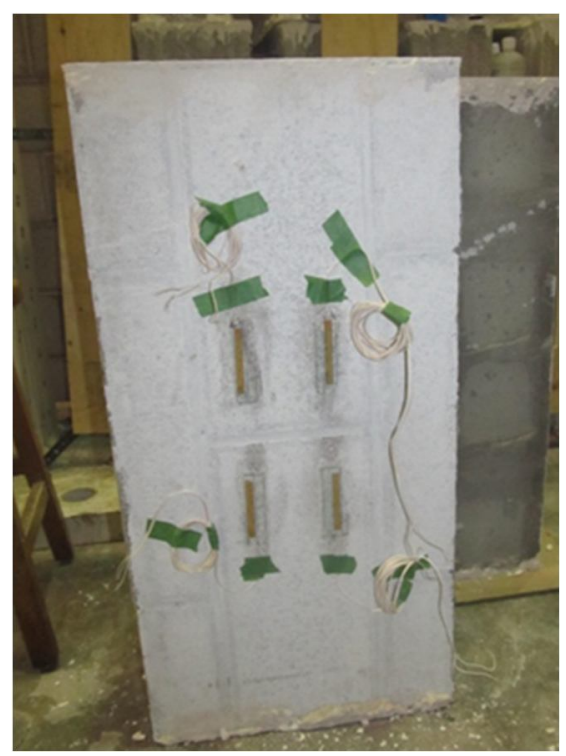

e) A prism Installed with Strain Gauges

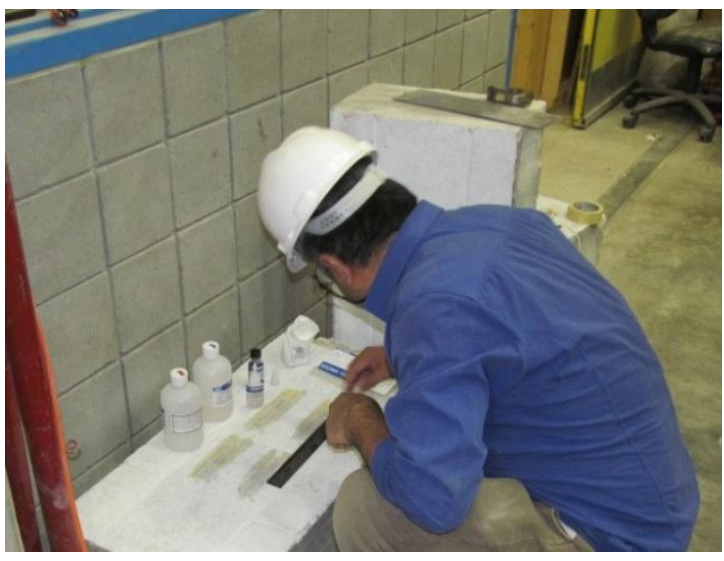

b) Surface Preparation

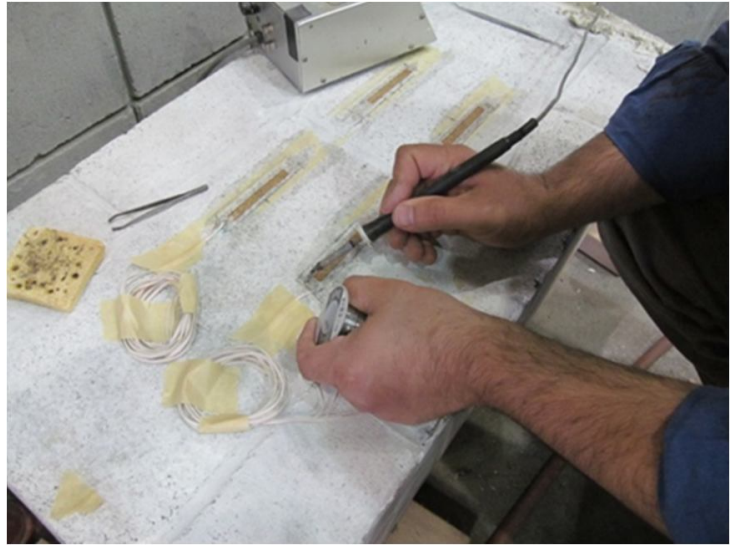

d) Installation of the Strain Gauges

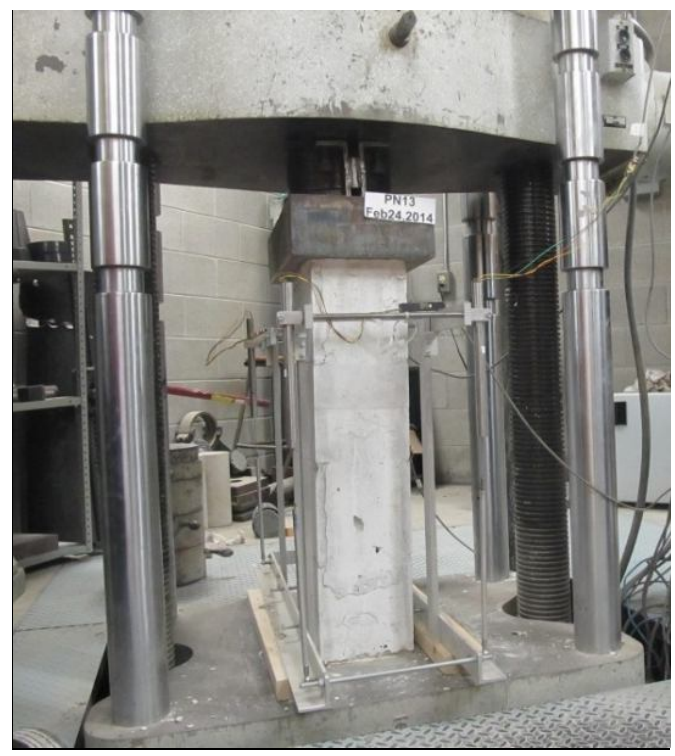

f) Testing the Masonry Prisms

Figure 3-35: Testing of the Masonry Prisms 


\subsubsection{Unit blocks}

The masonry units were delivered in pallets of 75 units. Three sets with a total of 23 unit blocks were chosen at random from the lot and were tested in compression in accordance with the requirements of CSA A165.1 (2004). The compressive test of the block unit was carried out at the same time as testing the beams. A displacement control rate of $0.01 \mathrm{~mm} / \mathrm{min}$ until failure was used in the testing of the units. The blocks were capped using hydrostone on top and bottom (see Figure 3-36a). Blocks were tested using the same machine as the prisms. Some of the tested blocks were instrumented with concrete strain gauges (see Figure 3-36b) to determine their behavior in compression and find their stress strain relationships.

\subsubsection{Mortar}

The testing of the $50 \mathrm{~mm}$ x $50 \mathrm{~mm}$ x $50 \mathrm{~mm}$ mortar cubes was conducted within one week of testing their corresponding beams and prisms. The testing was done using the same $1840 \mathrm{kN}$ testing machine and in accordance with CSA A165.1 (2004). Some of the mortar cubes were instrumented with $5 \mathrm{~mm}$ concrete strain gauges to determine their behavior in compression and find their stress strain relationships (see Figure 3-37a, b).

\subsubsection{Grout}

As mentioned before, two types of samples were used to measure the compressive strength of the grout: $100 \mathrm{~mm}$ x $200 \mathrm{~mm}$ non-absorbent plastic cylinders and $89 \mathrm{~mm}$ x $89 \mathrm{~mm}$ x175 mm block moulded prisms. These samples were tested within one week of testing their corresponding beams and prisms. A sulfur capping compound was used to ensure uniform bearing stresses (see Figure 3-37c, d). In the modulus of elasticity test, concrete cylinders were instrumented to 
record longitudinal deformations using two LVDT of a gauge length of $127 \mathrm{~mm}$ connected to a data acquisition system, as shown in Figure 3-33f. The LVDTs were placed on opposite sides of the cylinders, and the average of the two LVDTs was used as the cylinder deformation. The stress-strain relationship was plotted for each test and the secant modulus of elasticity.

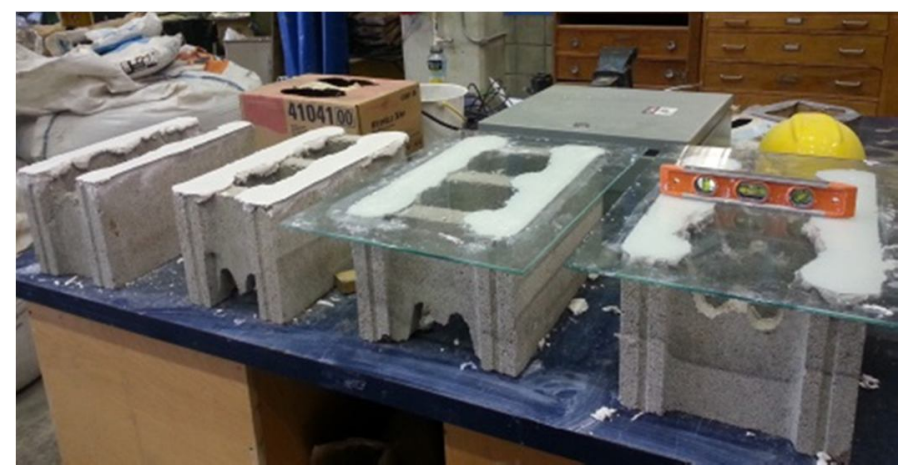

a) Capping the Block Units

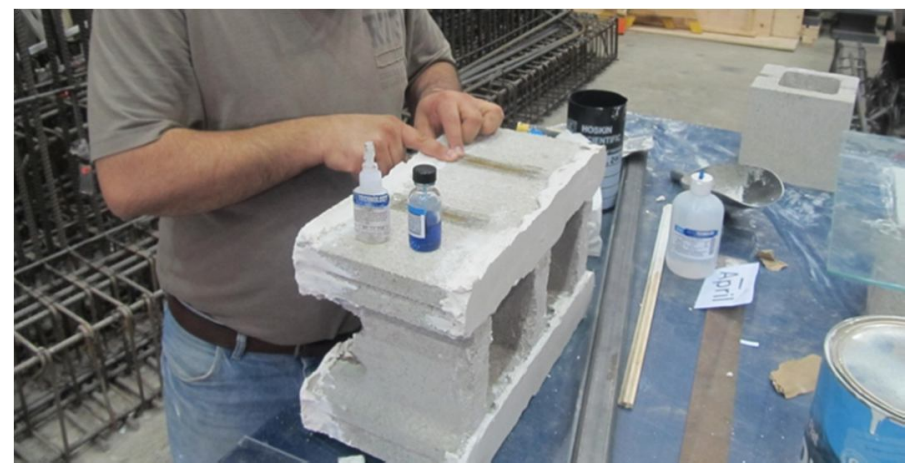

b) Installation of the Strain Gauges
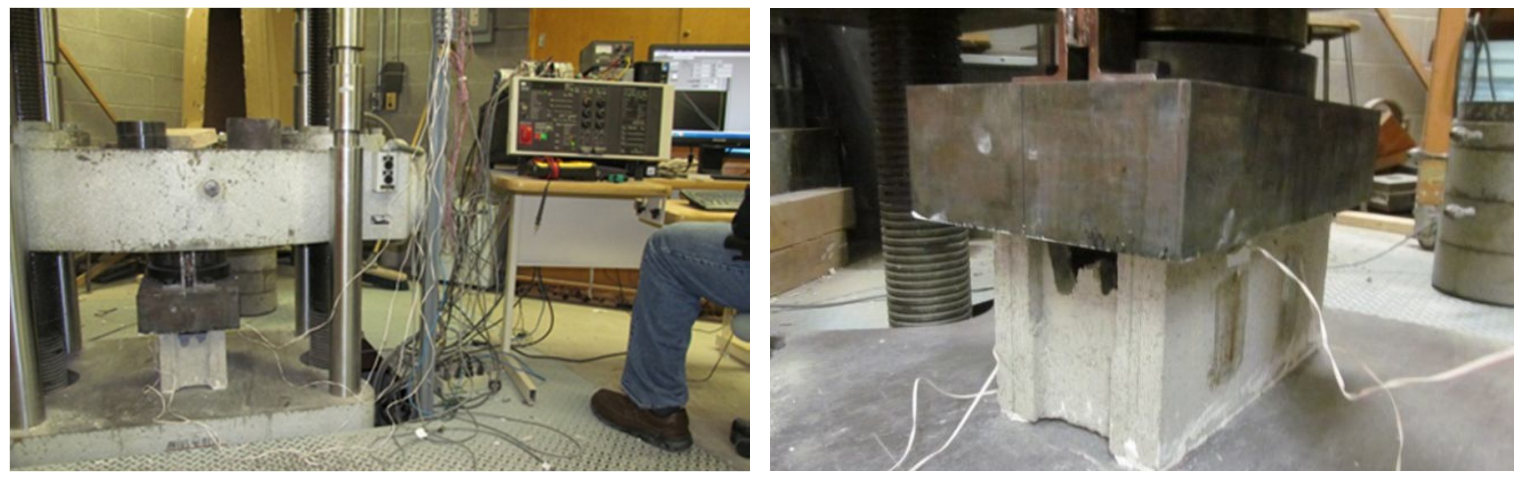

c) Testing the Block Units under Compression

Figure 3-36: Capping and Testing of the Unit Blocks 


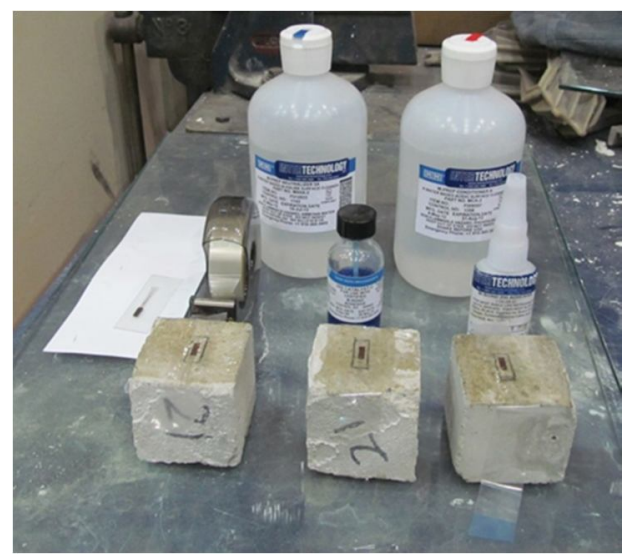

a) Installation of Stain Gages on the Mortar Cubes

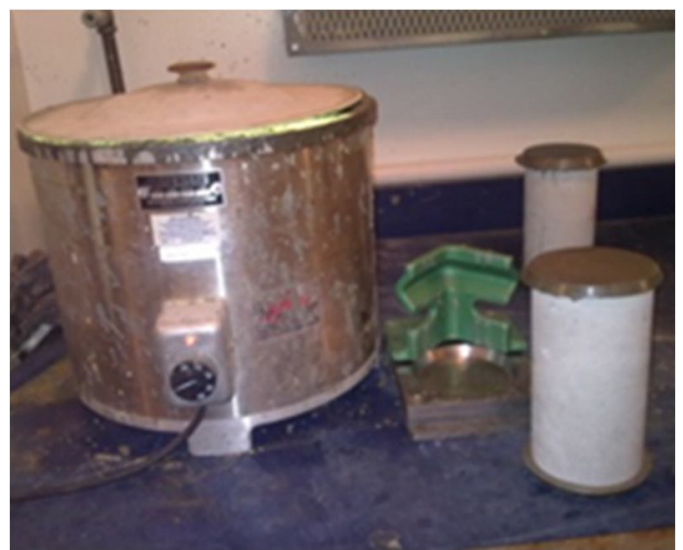

c) Capping the Grout Samples

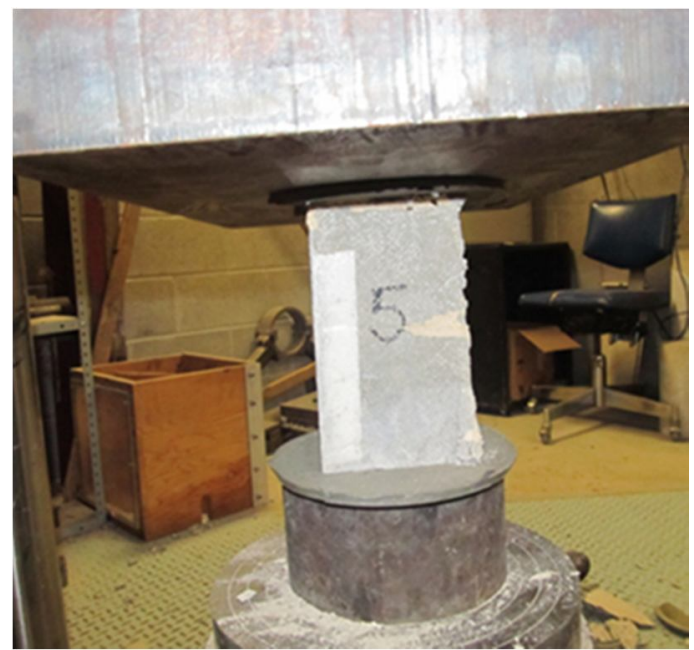

d) Testing the Block- Moulded Grout

Prisms

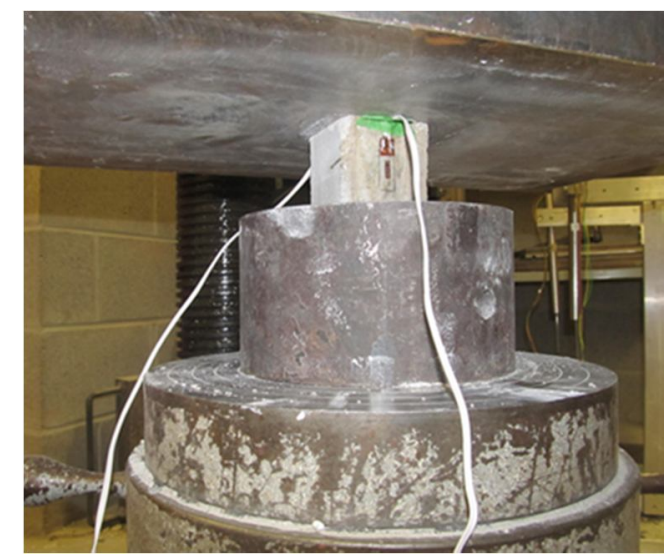

b) Testing the Mortar Cubes under Compression
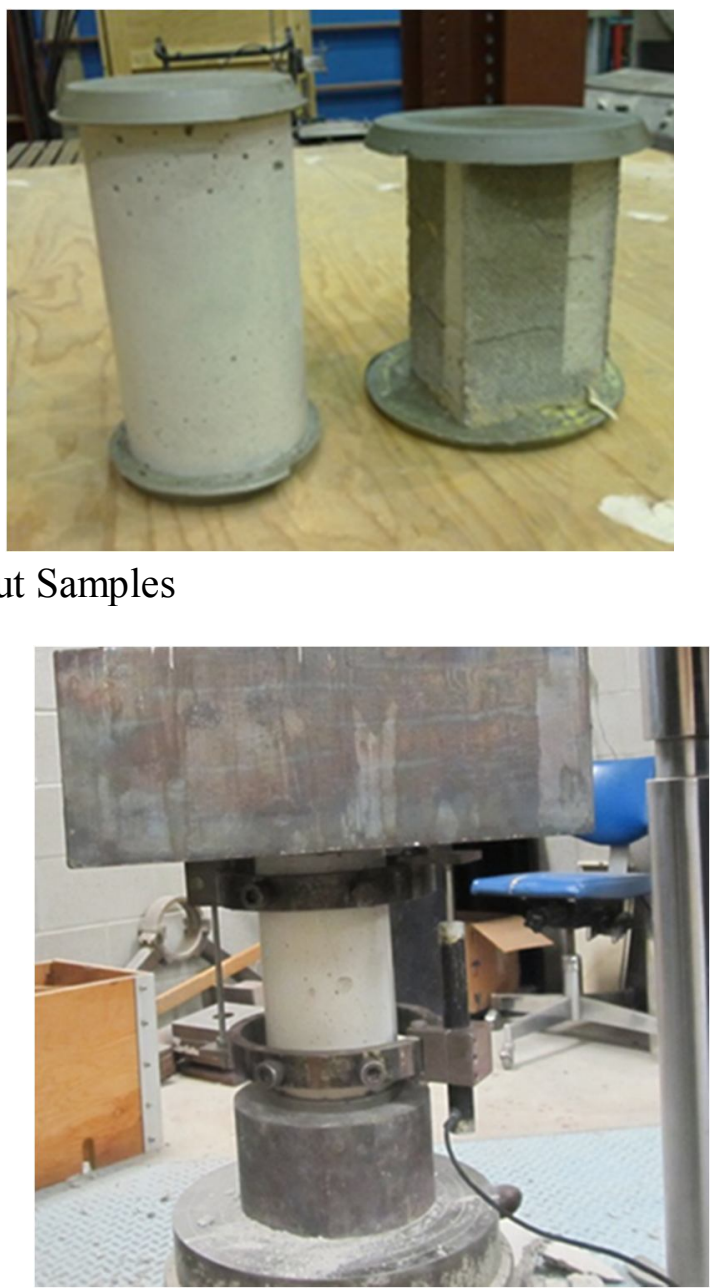

e) Testing the Grout Prisms Cylinder

Figure 3-37: Testing of the Mortar and Grout 


\subsubsection{Reinforcing Steel}

Pull tests were conducted according to ASTM A370 (2008) on the conventional steel rebars while the mechanical properties of the dywidag rebars and the GFRP rods were obtained from the manufacturers (DSI Canada for the dywidag rebars and Pultrull V-ROD Canada for the GFRP rods). A $1840 \mathrm{kN}$ capacity testing machine was used to test the $30 \mathrm{M}$ samples while the rest of the samples were tested in a $500 \mathrm{kN}$ MTS machine. The tensile loading was applied at a displacement control rate of $0.015 \mathrm{~mm} / \mathrm{min}$ until yielding and $0.1 \mathrm{~mm} / \mathrm{min}$ after that. Each of the 30M samples was instrumented with two strain gauges at the middle of the sample to measure the strain (see Figure 3-38a). The displacement for the rest of the samples was measured by a 5 in extensometer which was attached at the middle of the samples (as shown in Figure 3-38b).

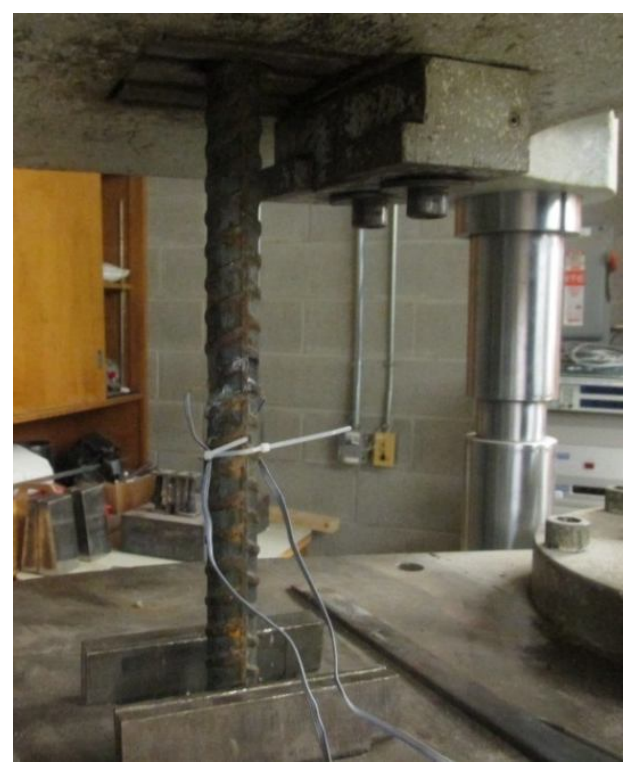

a) Pull test of a 30M rebar

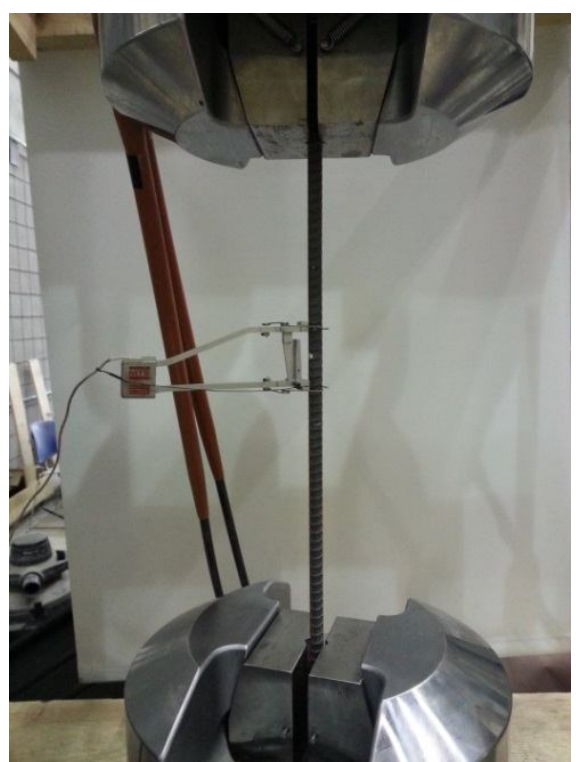

b) pull test of a $15 \mathrm{M}$ rebar

Figure 3-38: Pull Tests of the Steel Reinforcing Rebars 


\subsection{Digital Image Correlation}

One of the main objectives of this thesis is to conduct a detailed measurement and analysis of strains, cracks widths and spacing to studying how shear cracking and flexural- shear cracking affect shear capacity of reinforced masonry. Besides using LVDTs, steel strain gauges and concrete strain gauges, Digital Image Correlation (DIC) techniques were used as well. The DIC method is a non-contact, optical measurement technique that provides full-field displacements and strains by comparing the digital images of the test specimen's surface obtained before and after deformation (Cintrón and Saouma (2008), Citto et al. (2011)). The DIC technique relies on a contrasting speckle pattern on the surface of the test specimen. To achieve effective correlation, the pattern must be random, isotropic (i.e. must not exhibit a bias to one orientation), and highly contrasting (i.e. must show dark blacks and bright whites)

In general, the implementation of the DIC method included the following steps: specimen (beam or prism) preparation, recording images of the specimen's surface obtained before and after loading, and processing the acquired images of the surface of the specimen. The specimen`s surface (south surface of the beams) was first coated with a non-glare flat white paint and then random black dots were sprayed on the surface with a brush (see Figure 3-39). Recording the images of the small beams was made by two Canon cameras, an SX170 IS camera taking $16 \mathrm{MP}$ images and a SX150 IS camera taking 14.1 MP images. The cameras were positioned at distance of $3 \mathrm{~m}$ from the beams or prism. A professional flash lightning set was used to ensure that the specimen surface was brightly and also evenly illuminated (see Figure 3-39). On average, about 100 images per test were taken. Recording the images of the prism tests were done by a SX130 
IS Canon camera taking 12.1 MP images positioned at a distance of $1.6 \mathrm{~m}$ from the prism. When testing each specimen, a photo was taken at zero load and successive ones were taken at load stages as the load increased until failure. These photos were analyzed by the VIC-2D software. The obtained full-field displacements and strains in the south sides of the beams were compared with measurement of the vertical and side LVDTs attached on the north sides of the beams. For the prisms, the accuracy of DIC technique was verified by comparing its full-field strains with the measured strains from concrete strain gauges installed on the sides of the prisms. 


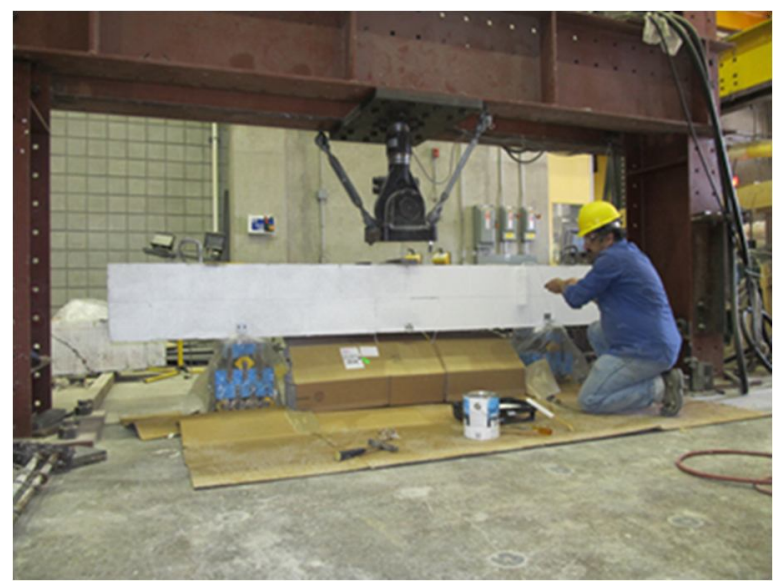

a) Painting the Beam Surface in White

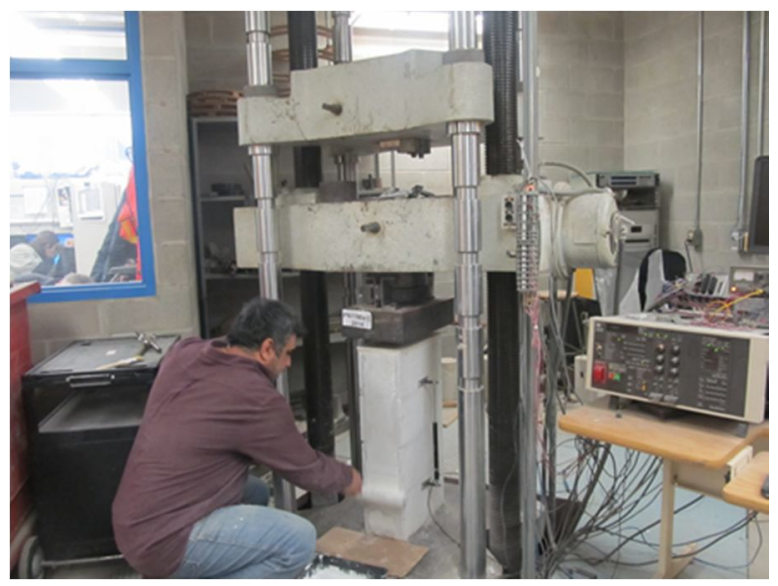

c) Painting the Prism Surface in White

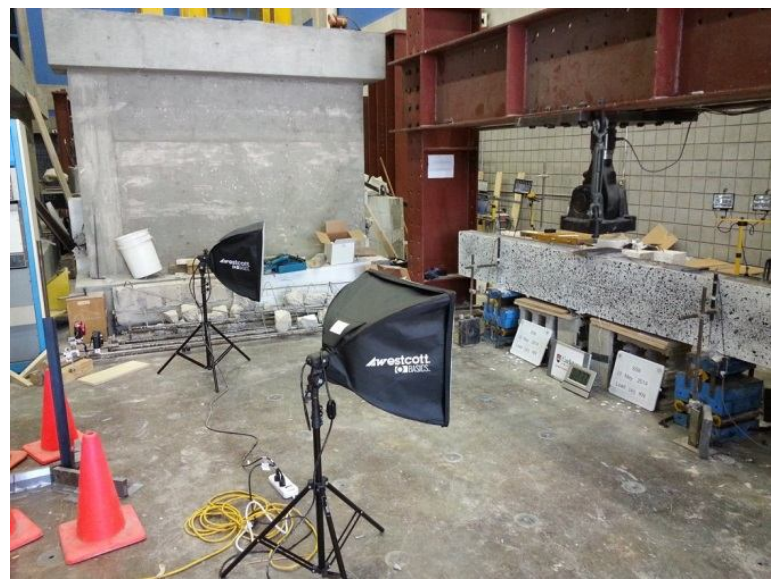

e) Test Setup for Small Beams

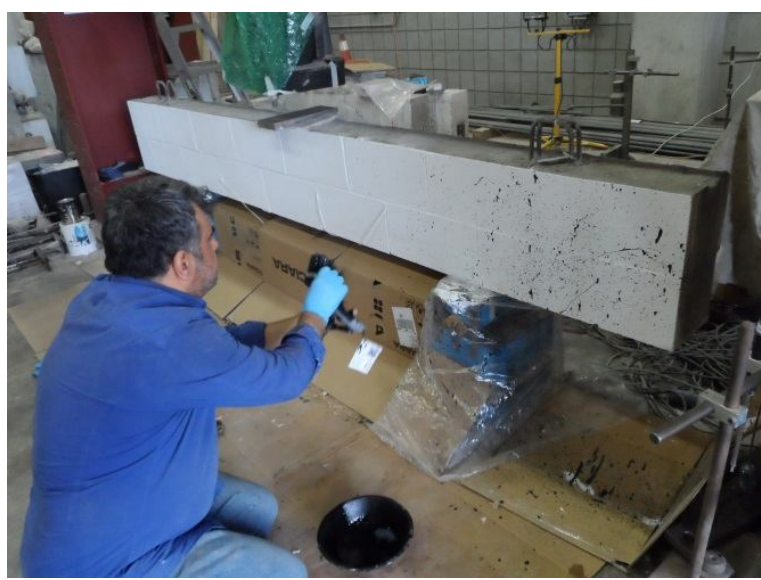

b) Spraying the Speckle Pattern on the Beam Surface

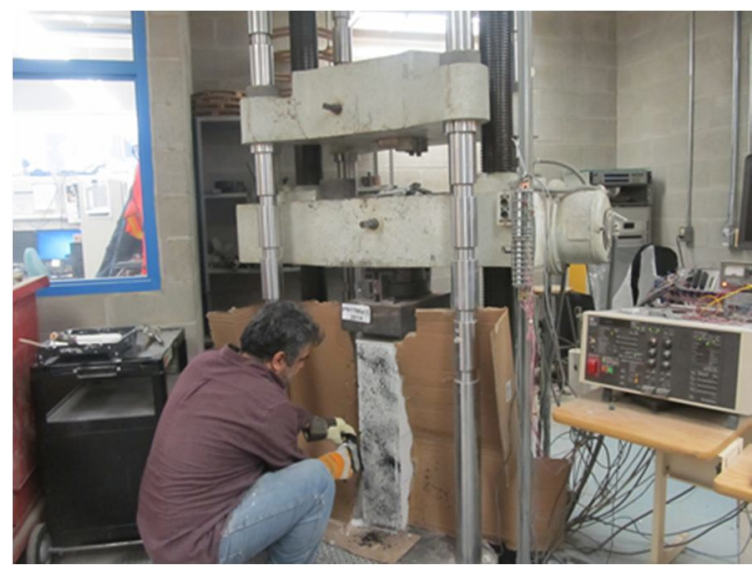

d ) Spraying the Speckle Pattern on the Prism Surface in White

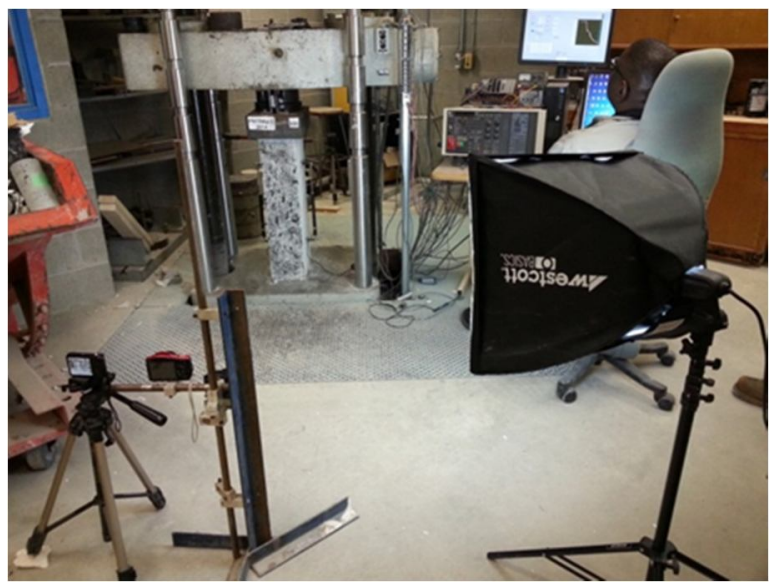

f) Test Setup for Prisms

Figure 3-39: Specimen Preparation for the DIC Measurement 


\section{CHAPTER 4: TEST RESULTS}

\subsection{General}

The purpose of this chapter is to report the results of the tests performed on the 15 reinforced masonry beams described in Chapter 3. This Chapter also presents the results of tests conducted on various material properties associated with these beams. The tests, as described in Chapter 3, included compressive tests of masonry prisms, blocks, mortar cubes, grout cylinders, grout prisms, as well as rebar coupon tests.

The experimental program included building and testing fifteen full scale reinforced masonry beams. For each beam or a group of beams, a set of separate specimens were built and tested. These separate specimens included: 23 unit blocks, 90 mortar cubes, 36 grout samples and 41 masonry prisms (see Table 4-1.) All the specimens (beams, unit blocks, mortar cubes, grout cylinders, block-moulded prisms and masonry prisms) were tested well past the conventional standard 28 days.

\subsection{Test Results of the Block Units}

A total of 1220 units were used in this experimental program, consisting of $628190 \mathrm{~mm}$ depressed web units, $382240 \mathrm{~mm}$ depressed web units, 160 lintel units and $50240 \mathrm{~mm}$ lintel units. Samples of the depressed web units were randomly held back during construction and were tested to determine the block strength, as summarized in Table 4-2. 
Table 4-1: The Matrix of the Experimental Program

\begin{tabular}{|c|c|c|c|c|c|c|c|}
\hline \multirow{2}{*}{ Beam ID } & \multirow{2}{*}{ Testing Date } & \multicolumn{2}{|c|}{ Masonry Prisms } & \multirow{2}{*}{ Mortar Cubes } & \multicolumn{2}{|c|}{ Grout Samples } & \multirow{2}{*}{ Unit Blocks } \\
\hline & & (Normal to bed joint) & (Parallel to bed joint) & & $\begin{array}{c}\text { Non-absorbent } \\
\text { Cylinders }\end{array}$ & $\begin{array}{c}\text { Block Moulded } \\
\text { Prisms }\end{array}$ & \\
\hline SM1,SM1R & July 6,26 2012 & PN1, PN2 and PN3 & PL1 and PL2 & MR1 $\rightarrow$ MR9 & $\mathrm{GRC} 1$ and $\mathrm{GRC} 2$ & GRP1 and GRP2 & \multirow{6}{*}{$190 \mathrm{~B} 1 \rightarrow 190 \mathrm{~B} 13$} \\
\hline SM6,SM6R & September 10,11 2012 & PN4, PN5 and PN6 & - & MR10 $\rightarrow$ MR15 & GRC 3 and GRC4 & GRP3 and GRP4 & \\
\hline SM4,SM4R & October 3,5 2012 & - & - & \multirow{2}{*}{ MR16 $\rightarrow$ MR27 } & - & - & \\
\hline $\mathrm{SM} 2, \mathrm{SM} 2 \mathrm{R}$ & $\begin{array}{c}\text { October } 292012 \\
\text { November } 012012\end{array}$ & - & - & & GRC5 and GRC6 & GRP5 and GRP6 & \\
\hline SM5 & December 1,5 2012 & PN7, PN8 and PN9 & $\begin{array}{l}\text { PL3 and PL4, } \\
\text { HPSM } 5^{*}\end{array}$ & MR28 $\rightarrow-$ MR33 & - & - & \\
\hline SM1D,SM1DR & December 17,19 2012 & PN10, PN11 and PN12 & PL5 and PL6, PLSG & $\mathrm{MR} 34 \rightarrow \mathrm{MR} 42$ & GRC7 and GRC8 & GRP7 and GRP8 & \\
\hline SL2, SL2R & March 5,6,11,18 2013 & \multirow{2}{*}{$\begin{array}{l}\text { PLN1, PLN2, PLN3, } \\
\text { PLN4, and PLN5 }\end{array}$} & \multirow{2}{*}{$\begin{array}{c}\text { PLL1 } \\
\text { HPSL1, HPSL2 }\end{array}$} & MR43 $\rightarrow$ MR57 & GRC9 and GRC10 & GRP9 and GRP10 & \multirow{2}{*}{$240 \mathrm{~B} 1 \rightarrow 240 \mathrm{~B} 6$} \\
\hline SL1, SL1R & $\begin{array}{c}\text { April } 2,3,4,9,11 \\
2103\end{array}$ & & & $\mathrm{MR} 58 \rightarrow \mathrm{MR} 72$ & GRC11 and GRC12 & GRP11 and GRP12 & \\
\hline SS6, SS6R & May 20, 212104 & \multirow{2}{*}{ PN13, PN14 and PN15 } & \multirow{2}{*}{ PL11 and PL12 } & \multirow{2}{*}{$\mathrm{MR} 73 \rightarrow 79$} & \multirow{2}{*}{ GRC13 and GRC14 } & \multirow{2}{*}{ GRP13 and GRP14 } & \multirow{7}{*}{ 190B14 $\rightarrow 190 \mathrm{~B} 18$} \\
\hline SS4, SS4R & May 29, 302104 & & & & & & \\
\hline $\mathrm{SS} 1, \mathrm{SS} 2 \mathrm{R}$ & June 122014 & \multirow{4}{*}{$\begin{array}{l}\text { PN16, PN17, PN18 } \\
\text { and PN19 }\end{array}$} & HPSS1 & \multirow{4}{*}{$\mathrm{MR} 80 \rightarrow \mathrm{MR} 84$} & \multirow{4}{*}{ GRC15 and GRC16 } & \multirow{4}{*}{ GRP15 and GRP16 } & \\
\hline $\mathrm{SS} 2, \mathrm{SS} 2 \mathrm{R}$ & June 18,20 2014 & & - & & & & \\
\hline $\mathrm{SS} 3, \mathrm{SS} 3 \mathrm{R}$ & June 24,25 2014 & & - & & & & \\
\hline SS5, SS5R & July 82014 & & HPSS5 & & & & \\
\hline SM3 & April 28,29 2015 and May 62015 & PL20, PL21 & - & MR85 $\rightarrow$ MR90 & GRC17 and GRC18 & GRP17 and GRP18 & \\
\hline
\end{tabular}


Table 4-2: Unit Test Matrix

\begin{tabular}{|c|c|c|c|c|c|c|c|c|c|c|}
\hline $\begin{array}{l}\text { Set } \\
\text { No. }\end{array}$ & $\begin{array}{c}\text { Block } \\
\text { Unit ID }\end{array}$ & Testing Date & $\begin{array}{c}\text { Load } \\
(\mathbf{k N})\end{array}$ & $\begin{array}{c}\mathbf{f}_{\mathrm{bl}} \\
\text { (Face-shell) } \\
(\mathrm{MPa})\end{array}$ & $\begin{array}{c}\mathbf{f}_{\mathrm{bl}} \\
\text { Average } \\
\text { (MPa) }\end{array}$ & STDV & $\begin{array}{c}\mathrm{COV} \\
(\%)\end{array}$ & $\begin{array}{c}\mathbf{f}_{\mathrm{bl}} * \\
\text { (net area) } \\
(\mathrm{MPa})\end{array}$ & Beam ID & Prism ID \\
\hline \multirow{13}{*}{1} & 190B-1 & \multirow{3}{*}{ December 192012} & 1644 & 52.7 & \multirow{13}{*}{47.9} & \multirow{13}{*}{5.2} & \multirow{13}{*}{10.9} & \multirow{13}{*}{36.3} & \multirow{13}{*}{$\begin{array}{c}\text { SM1, SM6, } \\
\text { SM4, SM2, } \\
\text { SM5 and } \\
\text { SM1D }\end{array}$} & \multirow{13}{*}{$\begin{array}{c}\text { Normal to Bed Joint } \\
\text { PN1, PN2, PN3, } \\
\text { PN4, PN5, PN6, } \\
\text { PN7, PN8, PN9, } \\
\text { PN10, PN11 and } \\
\text { PN12 } \\
\text { Parallel to Bed Joint } \\
\text { PL1, PL2, PL3, PL4, } \\
\text { PL5 and PL6 }\end{array}$} \\
\hline & 190B-2 & & 1642 & 52.6 & & & & & & \\
\hline & 190B-3 & & 1815 & 58.2 & & & & & & \\
\hline & 190B-4 & \multirow{2}{*}{ January 032013} & 1345 & 43.1 & & & & & & \\
\hline & 190B-5 & & 1446 & 46.3 & & & & & & \\
\hline & 190B-6 & \multirow{2}{*}{ January 042013} & 1604 & 51.4 & & & & & & \\
\hline & 190B-7 & & 1275 & 40.9 & & & & & & \\
\hline & 190B-8 & \multirow{5}{*}{ January 062013} & 1553 & 49.8 & & & & & & \\
\hline & 190B-9 & & 1360 & 43.6 & & & & & & \\
\hline & 190B-10 & & 1251 & 40.1 & & & & & & \\
\hline & 190B-11 & & 1528 & 49.0 & & & & & & \\
\hline & 190B-12 & & 1476 & 47.3 & & & & & & \\
\hline & 190B-13 & January 122013 & 1554 & 49.8 & & & & & & \\
\hline \multirow{5}{*}{2} & 240B-1 & \multirow{2}{*}{ March 252013} & 1450.0 & 43.2 & \multirow{5}{*}{41.1} & \multirow{5}{*}{2.9} & \multirow{5}{*}{7.0} & \multirow{5}{*}{29.8} & \multirow{5}{*}{$\begin{array}{l}\text { SL2 and } \\
\text { SL1 }\end{array}$} & \multirow{5}{*}{$\begin{array}{l}\frac{\text { Normal to Bed Joint }}{\text { PLN1, PLN2, PLN3, }} \\
\text { PLN4 and PLN5 } \\
\frac{\text { Parallel to Bed Joint }}{\text { PLL1, HPSL1 }}{ }^{*} \text { and } \\
\text { HPSL2 }^{*}\end{array}$} \\
\hline & 240B-2 & & 1226 & 36.6 & & & & & & \\
\hline & $240 \mathrm{~B}-3$ & \multirow{3}{*}{ April 242013} & 1411 & 42.1 & & & & & & \\
\hline & 240B-4 & & 1461 & 43.6 & & & & & & \\
\hline & 240B-5 & & 1344 & 40.1 & & & & & & \\
\hline \multirow{5}{*}{3} & 190B-14 & \multirow{5}{*}{ January 202014} & 1745 & 55.9 & \multirow{5}{*}{49.5} & \multirow{5}{*}{6.1} & \multirow{5}{*}{12.3} & \multirow{5}{*}{37.5} & \multirow{5}{*}{$\begin{array}{l}\text { SS6, SS4, } \\
\text { SS1, SS2, } \\
\text { SS3, SS6 } \\
\text { and SM3 }\end{array}$} & \multirow{5}{*}{$\begin{array}{c}\text { Normal to Bed Joint } \\
\text { PN13, PN14, PN15 } \\
\text { PN16, PN17, PN18, } \\
\text { PN19, PN20 and } \\
\text { PN21 } \\
\frac{\text { Parallel to Bed Joint }}{\text { PL11 and PL12 }}\end{array}$} \\
\hline & 190B-15 & & 1677 & 53.8 & & & & & & \\
\hline & 190B-16 & & 1426 & 45.7 & & & & & & \\
\hline & 190B-17 & & 1592 & 51.0 & & & & & & \\
\hline & 190B-18 & & 1280 & 41.0 & & & & & & \\
\hline
\end{tabular}

* Net area compressive strengths were obtained by dividing face shell strength by 1.32 and 1.38 for 190 mm and 240 units, respectively

The unit blocks were capped with hydrostone on top and bottom over the face shell areas when tested in compression. To calculate the compressive strength of the units, the failure load was divided by the effective capped area. Effective areas of $31200 \mathrm{~mm}^{2}$ and $37540 \mathrm{~mm}^{2}$ were used 
for $190 \mathrm{~mm}$ and $240 \mathrm{~mm}$ units, respectively. Figure $4-1$ shows the effective capped areas of the unit blocks.

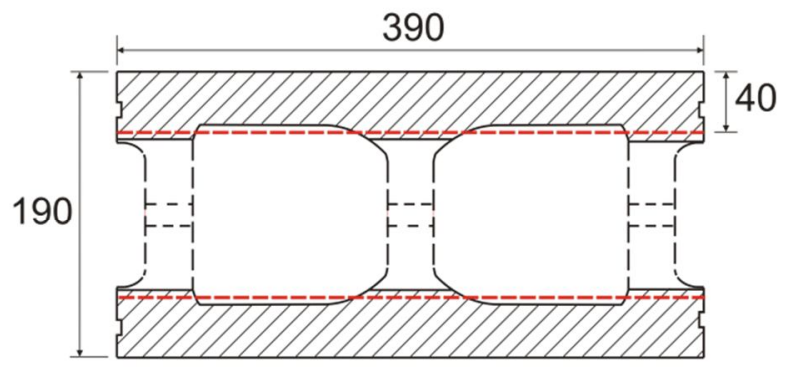

a) $190 \mathrm{~mm}$ Unit

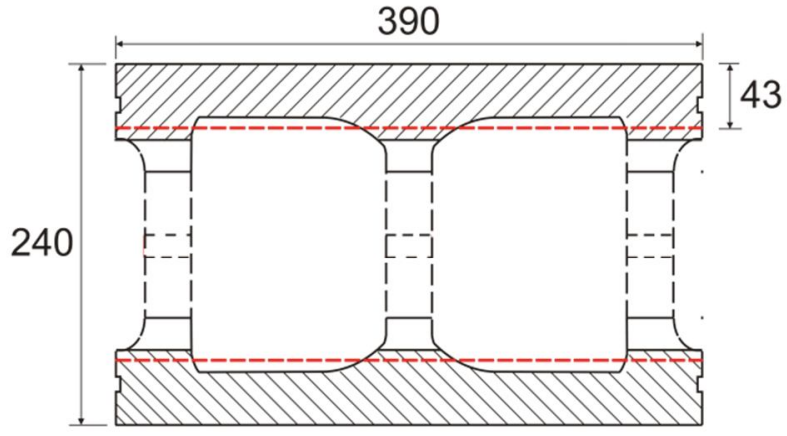

b) $240 \mathrm{~mm}$ Unit

Figure 4-1: Effective Capped Areas of the Unit Blocks

It can be seen form Table 4-2 that the compressive strengths of the $190 \mathrm{~mm}$ units in this first set ranged from 40.9 MPa to 58.2 MPa with an average strength of 47.9 $\mathrm{MPa}$ and a coefficient of variation of $10.9 \%$. The compressive strength of the $240 \mathrm{~mm}$ units ranged from $36.6 \mathrm{MPa}$ to 43.6 MPa with an average strength of $41.1 \mathrm{MPa}$ and a coefficient of variation of $7 \%$. Lastly, the compressive strengths of the $190 \mathrm{~mm}$ units in the third set varied between 41.0 MPa and 55.9 MPa with an average strength of $49.5 \mathrm{MPa}$ and a coefficient of variation of $12.3 \%$. Masonry design codes generally deal with unit compressive strengths based on net area rather than faceshell areas. The equivalent average net area compressive strength of the units in this project were calculated and presented in Table 4-2. Ratios of net to face shell area of 1.32 and 1.38 were used for the $190 \mathrm{~mm}$ and $240 \mathrm{~mm}$ units respectively. The equivalent average net area compressive strengths were $36.3 \mathrm{MPa}, 29.8 \mathrm{MPa}$ and $37.5 \mathrm{MPa}$ for the three sets in sequence. It is clear from Figure 4-2 that the unit blocks failed by web splitting with crack initiating in a zone of tensile 
stresses at top or bottom of all three webs of the unit. This pattern of failure was reported by other researchers (Shrive (1982), Becica and Harrison (1982) and Mina et al. (2012)).
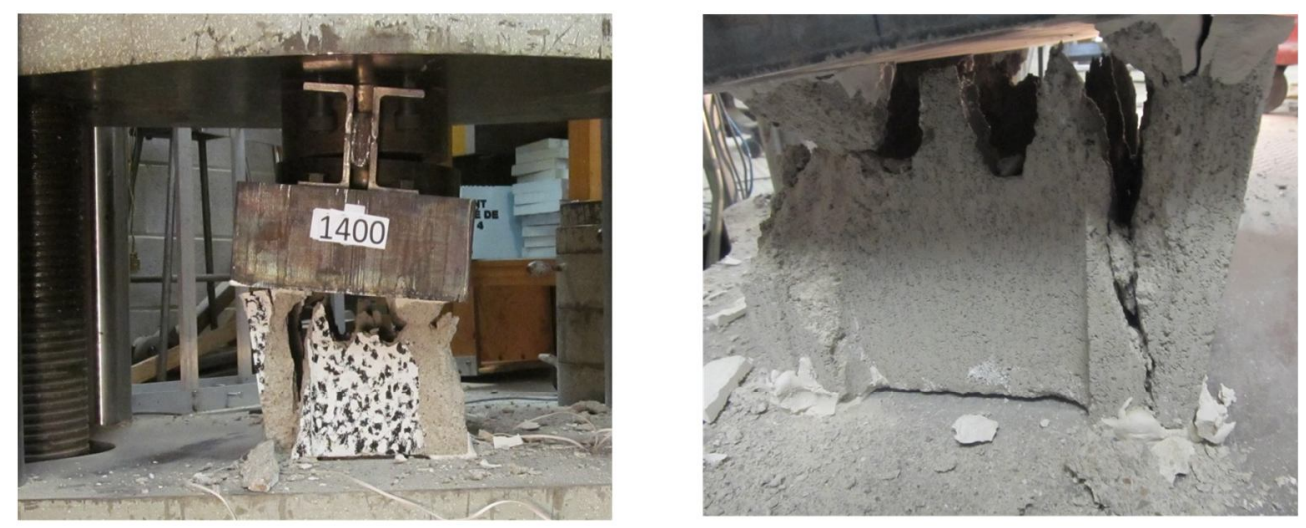

a) Failure Patterns of $240 \mathrm{~mm}$ Unit blocks
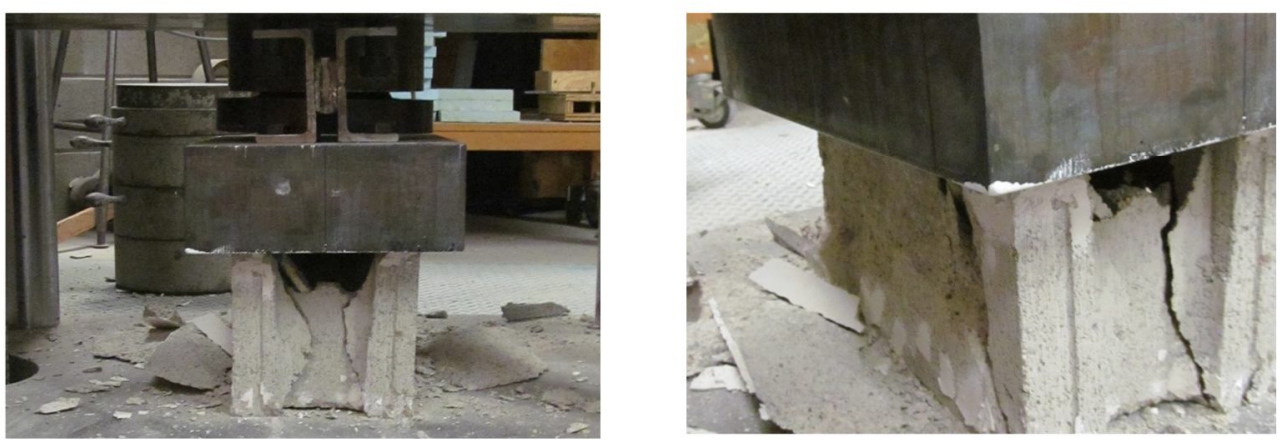

b) Failure Patterns of $190 \mathrm{~mm}$ Unit blocks

Figure 4-2: Failure Patterns of Unit Blocks Tested in Compression

Figure 4-3 shows the stress-strain curves for the $190 \mathrm{~mm}$ and $240 \mathrm{~mm}$ units under compression. It can be noted that these curve are similar to those of concrete. The non-linearity portion of the curve starts at around $50 \%$ of the peak compressive strength. The chord modulus of elasticity (between $5 \%$ and $33 \%$ of the strength) were calculated to be $452 \mathrm{f}_{\mathrm{bl}}$ for the $190 \mathrm{~mm}$ and $655 \mathrm{f}_{\mathrm{bl}}$ for the $240 \mathrm{~mm}$ unit. 


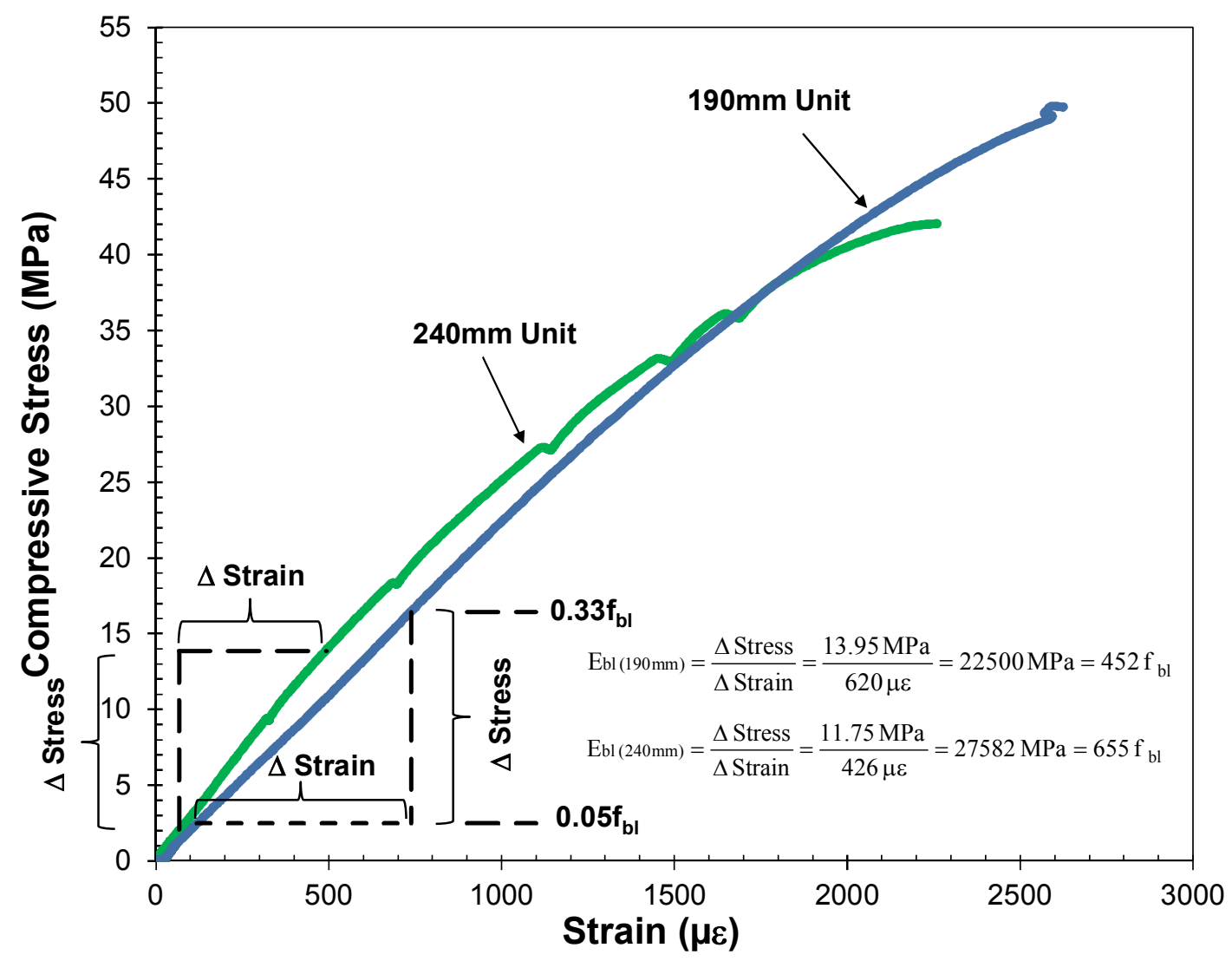

Figure 4-3: Stress- Strain Curves for the Masonry Units

\subsection{Test Results of the Mortar Cubes}

In this experimental program ten sets of mortar cubes totalling 90 cubes were tested in compression to determine the compressive strength of the mortar used in the masonry beams and prisms. Table 4-3 shows the mortar test results along with indications which beam or prism each set associated with. 
Table 4-3: Test Results of Mortars

\begin{tabular}{|c|c|c|c|c|c|c|c|c|c|c|}
\hline Set No. & Testing Date & Mortar Cube ID & Age (days) & Load $(k N)$ & $\mathbf{f}_{\mathrm{mr}}(\mathbf{M P a})$ & $\begin{array}{c}\mathbf{f}_{\mathrm{mr}} \\
\text { Average } \\
\text { (MPa) }\end{array}$ & STDV & $\operatorname{COV}(\%)$ & Beam ID & Prism ID \\
\hline \multirow{9}{*}{1} & \multirow{6}{*}{ July 112012} & MR1 & \multirow{6}{*}{442} & 57.2 & 22.9 & \multirow{9}{*}{24.1} & \multirow{9}{*}{1.8} & \multirow{9}{*}{7.6} & \multirow{9}{*}{ SM1 } & \\
\hline & & MR2 & & 61.9 & 24.8 & & & & & \\
\hline & & MR3 & & 59.2 & 23.7 & & & & & \\
\hline & & MR4 & & 63.1 & 25.2 & & & & & \\
\hline & & MR5 & & 61.1 & 24.4 & & & & & PN1, PN2, PN3, \\
\hline & & MR6 & & 65.9 & 26.4 & & & & & \\
\hline & & MR7 & & 65.6 & 26.2 & & & & & \\
\hline & August 92012 & MR8 & 471 & 52.7 & 21.1 & & & & & \\
\hline & & MR9 & & 55.1 & 22.0 & & & & & \\
\hline & & MR10 & & 63.2 & 25.3 & & & & & \\
\hline & & MR11 & & 59.8 & 23.9 & & & & & \\
\hline & September 14 & MR12 & & 68.3 & 27.3 & & & & & PN4, PN5 and \\
\hline 2 & 2012 & MR13 & 507 & 70.8 & 28.3 & 25.9 & 1.7 & 6.7 & SM6 & PN6 \\
\hline & & MR14 & & 60.8 & 24.3 & & & & & \\
\hline & & MR15 & & 66.3 & 26.5 & & & & & \\
\hline & & MR16 & & 70.1 & 28.0 & & & & & \\
\hline & & MR17 & & 60.3 & 24.1 & & & & & \\
\hline & & MR18 & & 60.1 & 24.0 & & & & & \\
\hline & & MR19 & & 59.6 & 23.8 & & & & & \\
\hline & November 8 & MR20 & & 65.0 & 26.0 & & & & & \\
\hline & 2012 & MR21 & 562 & 57.0 & 22.8 & & & & SM4 & \\
\hline 3 & & MR22 & & 77.3 & 30.9 & 26.3 & 2.9 & 10.9 & and & - \\
\hline & & MR23 & & 76.5 & 30.6 & & & & & \\
\hline & & MR24 & & 59.2 & 23.7 & & & & & \\
\hline & & MR25 & & 67.3 & 26.9 & & & & & \\
\hline & December 5 & MR26 & & 74.3 & 29.7 & & & & & \\
\hline & 2012 & MR27 & 585 & 63.3 & 25.3 & & & & & \\
\hline & & MR28 & & 74.3 & 29.7 & & & & & \\
\hline & & MR29 & & 78.5 & 31.4 & & & & & \\
\hline & December 5 & MR30 & & 70.3 & 28.1 & & & & & PN7, PN8, PN9, \\
\hline 4 & 2012 & MR31 & 585 & 64.6 & 25.8 & 27.4 & 2.9 & 10.5 & SM5 & $\begin{array}{c}\text { PL3, PL4, and } \\
\text { HPSM5 }\end{array}$ \\
\hline & & MR32 & & 64.2 & 25.7 & & & & & \\
\hline & & MR33 & & 59.2 & 23.7 & & & & & \\
\hline & & MR34 & & 78.1 & 31.2 & & & & & \\
\hline & & MR35 & & 70.6 & 28.2 & & & & & \\
\hline & December 18 & MR36 & 601 & 64.2 & 25.7 & & & & & \\
\hline & 2012 & MR37 & 601 & 54.3 & 21.7 & & & & & PN10, PN11, \\
\hline 5 & & MR38 & & 58.6 & 23.4 & 25.5 & 3.5 & 13.7 & SM1D & PN12 PL5, PL6 \\
\hline & & MR39 & & 54.0 & 21.6 & & & & & and PLSG \\
\hline & & MR40 & & 56.3 & 22.5 & & & & & \\
\hline & December 19 & MR41 & 602 & 64.8 & 25.9 & & & & & \\
\hline & & MR42 & & 73.2 & 29.3 & & & & & \\
\hline & & MR43 & & 57.6 & 23.0 & & & & & \\
\hline & & MR44 & & 83.3 & 33.3 & & & & & \\
\hline & & MR45 & & 78.2 & 31.3 & & & & & \\
\hline & February 7 & MR46 & & 77.0 & 30.8 & & & & & \\
\hline & 2013 & MR47 & 653 & 76.7 & 30.7 & & & & & \\
\hline & & MR48 & & 77.6 & 31.0 & & & & & \\
\hline & & MR49 & & 52.6 & 21.0 & & & & & \\
\hline 6 & & MR50 & & 54.1 & 21.6 & 28.3 & 3.9 & 13.8 & SL2 & \\
\hline & & MR51 & & 64.7 & 28.0 & & & & & \\
\hline & February 8 & MR52 & 654 & 72.3 & 31.1 & & & & & \\
\hline & & MR53 & & 61.4 & 24.6 & & & & & \\
\hline & & MR54 & & 70.2 & 28.1 & & & & & \\
\hline & & MR55 & & 77.7 & 31.1 & & & & & \\
\hline & April 192013 & MR56 & 723 & 76.3 & 30.5 & & & & & \\
\hline & & MR57 & & 71.3 & 28.5 & & & & & PLN3, PLN4, \\
\hline & & MR58 & & 68.2 & 27.3 & & & & & $\begin{array}{l}\text { PLNS, PLL1, } \\
\text { HPSL1 1 and }\end{array}$ \\
\hline & Anril 192013 & MR59 & 723 & 70.3 & 28.1 & & & & & $\begin{array}{l}\text { HPSL1 and } \\
\text { HPSL2 }\end{array}$ \\
\hline & Apr11 192013 & MR60 & 123 & 65.4 & 26.2 & & & & & \\
\hline & & MR61 & & 77.3 & 30.9 & & & & & \\
\hline & & MR62 & & 61.0 & 24.4 & & & & & \\
\hline & & MR63 & & 55.3 & 22.1 & & & & & \\
\hline & & MR64 & & 62.2 & 24.9 & & & & & \\
\hline 7 & & MR65 & & 51.5 & 20.6 & 27.1 & 3.5 & 13 & SL1 & \\
\hline & April 252103 & MR66 & 729 & 83.6 & 33.4 & & & & & \\
\hline & & MR67 & & 77.1 & 30.8 & & & & & \\
\hline & & MR68 & & 75.8 & 30.3 & & & & & \\
\hline & & MR69 & & 71.5 & 28.6 & & & & & \\
\hline & & MR70 & & 69.4 & 27.8 & & & & & \\
\hline & April 262103 & MR71 & 730 & 59.1 & 23.6 & & & & & \\
\hline & & MR72 & & 67.2 & 26.9 & & & & & \\
\hline
\end{tabular}


Continuation of Table 4-3

\begin{tabular}{|c|c|c|c|c|c|c|c|c|c|c|}
\hline \multirow{6}{*}{8} & \multirow{6}{*}{ June 112014} & MR73 & \multirow{6}{*}{1142} & 79.2 & 31.6 & \multirow{6}{*}{25.5} & \multirow{6}{*}{3.5} & \multirow{6}{*}{13.6} & \multirow{6}{*}{$\begin{array}{l}\text { SS6 and } \\
\text { SS4 }\end{array}$} & \multirow{6}{*}{$\begin{array}{l}\text { PN13, PN14, } \\
\text { PN15, PL11 and } \\
\text { PL12 }\end{array}$} \\
\hline & & MR74 & & 54.8 & 22 & & & & & \\
\hline & & MR75 & & 63.4 & 25.2 & & & & & \\
\hline & & MR76 & & 57.6 & 23.2 & & & & & \\
\hline & & MR77 & & 68.1 & 27.2 & & & & & \\
\hline & & MR78 & & 60 & 24 & & & & & \\
\hline \multirow{6}{*}{9} & \multirow{6}{*}{ June 262014} & MR79 & \multirow{6}{*}{1155} & 71.1 & 28.4 & \multirow{6}{*}{26.3} & \multirow{6}{*}{1.6} & \multirow{6}{*}{6.2} & \multirow{6}{*}{$\begin{array}{l}\text { SS1, SS2, } \\
\text { SS3 and } \\
\text { SS5 }\end{array}$} & \multirow{6}{*}{$\begin{array}{c}\text { PN16, PN17, } \\
\text { PN18, PN19, } \\
\text { HPSS1 and } \\
\text { HPSS5 }\end{array}$} \\
\hline & & MR80 & & 60.4 & 24 & & & & & \\
\hline & & MR81 & & 64.1 & 25.6 & & & & & \\
\hline & & MR82 & & 66.4 & 26.8 & & & & & \\
\hline & & MR83 & & 63.0 & 25.2 & & & & & \\
\hline & & MR84 & & 69.1 & 27.6 & & & & & \\
\hline \multirow{6}{*}{10} & \multirow{6}{*}{ June 92015} & MR85 & \multirow{6}{*}{1505} & 84.7 & 33.9 & \multirow{6}{*}{28.9} & \multirow{6}{*}{3.1} & \multirow{6}{*}{10.8} & \multirow{6}{*}{ SM3 } & \multirow{6}{*}{ PN20 and PN21 } \\
\hline & & MR86 & & 67.2 & 26.9 & & & & & \\
\hline & & MR87 & & 63.3 & 25.3 & & & & & \\
\hline & & MR88 & & 76.2 & 30.5 & & & & & \\
\hline & & MR89 & & 67.3 & 26.9 & & & & & \\
\hline & & MR90 & & 74.7 & 29.9 & & & & & \\
\hline
\end{tabular}

It can be seen in Table 4-4 that for each of the beams SM1 and SM1D, a single set of nine mortar cubes were tested. For each of beams SM3, SM5 and SM6, a single set of six mortar cubes was tested. Twelve mortar cubes were tested to determine the mortar strength of specimens SM2 and SM4. For each of the large beams SL1 and SL2, one set of fifteen mortar cubes was tested. A set of six mortar cubes was tested to determine the mortar strength of the small size beams SS4 and SS6. Finally, for beams SS1, SS2, SS3 and SS5 one set of six mortar cubes was tested. All the mortar cubes were tested at times similar to the beams they are associated with. The ages of the mortar cubes were calculated between the date of test and the date of construction (April 26-28, 2011).

The average compressive strengths of the mortar cube sets varied between 24.6 MPa and 28.9 MPa with coefficients of variation ranging from $6.2 \%$ to $13.8 \%$. The high values of COV can be attributed to the small batch size and hand mixing procedure utilized in the project. A typical failure of a pyramidal shape was noticed in all the tested cubes, as shown in Figure 4-4. 

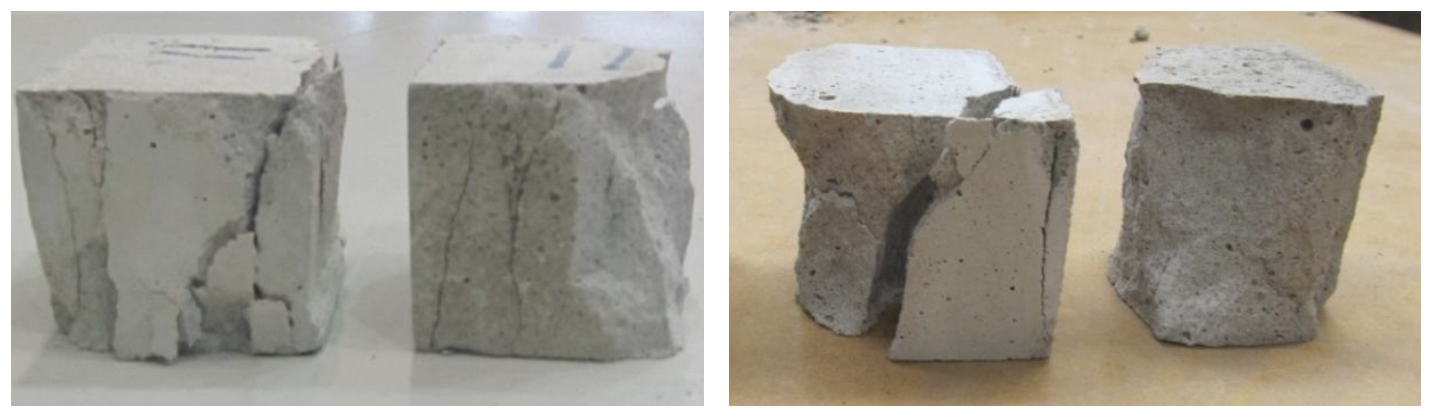

Figure 4-4: Failure Patterns of the Mortar Cubes

\subsection{Test Results of the Grout Samples}

Two types of grout samples were cast and tested in compression to determine grout compressive strengths: $100 \mathrm{~mm}$ x $200 \mathrm{~mm}$ non-absorbent cylinders and $89 \mathrm{~mm}$ x $89 \mathrm{~mm}$ x $170 \mathrm{~mm}$ blockmoulded prisms. Nine sets of grout samples were cast, four samples in each: two cylinders and two prisms. Table 4-5 summarizes the test results of the grout samples and references the associated beams and prisms.

All grout samples were tested in compression at a controlled displacement rate of $0.01 \mathrm{~mm} / \mathrm{min}$. The average compressive strength of the cylinder grouts varied from $18.3 \mathrm{MPa}$ to $23.8 \mathrm{MPa}$ While the average compressive strength of the grout prisms ranged from 18.7 MPa to 26.7 $\mathrm{MPa}$. It can be noted that the compressive strengths of the grout prisms increased slightly with time whereas the grout cylinder strengths did not appear to do so. This can be related to fact that these samples were tested well past 28 days. Knowing that the 28 days targeted strength of the grout was $15 \mathrm{MPa}$, it is expected that the strength will not increase significantly at a range of ages between 380 to 1445 days. All block moulded prisms exhibited a compression shear type failure while the cylinders failed in either shear or cone and shear types of failure (see Figure 4-5.) 
Table 4-4: Compressive Strength Results for the Grout Samples

\begin{tabular}{|c|c|c|c|c|c|c|c|c|c|c|c|c|c|}
\hline \multirow[b]{2}{*}{$\begin{array}{l}\text { Set } \\
\text { No. }\end{array}$} & \multirow[b]{2}{*}{ Testing Date } & \multirow[b]{2}{*}{$\begin{array}{c}\text { Age } \\
\text { (days) }\end{array}$} & \multicolumn{4}{|c|}{ Grout Cylinders (1) } & \multicolumn{5}{|c|}{ Block Moulded Grout Prisms (2) } & \multirow[b]{2}{*}{$\begin{array}{l}\text { Beam } \\
\text { ID }\end{array}$} & \multirow[b]{2}{*}{ Prism ID } \\
\hline & & & $\begin{array}{c}\text { Grout } \\
\text { Sample } \\
\text { ID } \\
\end{array}$ & $\begin{array}{r}\text { Load } \\
(\mathrm{kN})\end{array}$ & $\begin{array}{c}\mathbf{f}_{\mathrm{gr}} \\
(\mathbf{M P a})\end{array}$ & $\begin{array}{c}\mathbf{f}_{\mathrm{gr}} \\
\text { Average } \\
\text { (MPa) } \\
\end{array}$ & $\begin{array}{c}\text { Grout } \\
\text { Sample } \\
\text { ID } \\
\end{array}$ & $\begin{array}{c}\text { Load } \\
(\mathbf{k N})\end{array}$ & $\begin{array}{c}\mathbf{f}_{\mathrm{gr}} \\
(\mathbf{M P a})\end{array}$ & $\begin{array}{c}\mathbf{f}_{\mathrm{gr}} \\
\text { Average } \\
\text { (MPa) } \\
\end{array}$ & $\begin{array}{l}\text { Ratio of } \\
\text { (2)/ (1) }\end{array}$ & & \\
\hline \multirow{2}{*}{1} & \multirow{2}{*}{ July 112012} & \multirow{2}{*}{380} & GRC1 & 171.8 & 21.9 & \multirow{2}{*}{21.1} & GRP1 & 145.1 & 18.3 & \multirow{2}{*}{19.8} & \multirow{2}{*}{0.94} & \multirow{2}{*}{ SM1 } & \multirow{2}{*}{$\begin{array}{c}\text { PN1, PN2 and } \\
\text { PN3 } \\
\text { PL1 and PL2 }\end{array}$} \\
\hline & & & GRC2 & 160.5 & 20.4 & & GRP2 & 135.6 & 19.3 & & & & \\
\hline \multirow{2}{*}{2} & \multirow{2}{*}{ September 142012} & \multirow{2}{*}{444} & GRC3 & 142.1 & 18.1 & \multirow{2}{*}{18.6} & GRP3 & 162.8 & 20.6 & \multirow{2}{*}{21} & \multirow{2}{*}{1.13} & \multirow{2}{*}{ SM6 } & \multirow{2}{*}{$\begin{array}{c}\text { PN4, PN5 and } \\
\text { PN6 }\end{array}$} \\
\hline & & & GRC4 & 149.8 & 19.1 & & GRP4 & 130.0 & 21.4 & & & & \\
\hline- & October 3,5 2012 & - & - & - & - & $19.3^{*}$ & - & - & - & & - & SM4 & - \\
\hline \multirow[t]{2}{*}{3} & \multirow{2}{*}{ November 82012} & \multirow{2}{*}{499} & GRC5 & 162.9 & 20.7 & \multirow{2}{*}{20.7} & GRP5 & 191.7 & 24.2 & \multirow{2}{*}{23.3} & \multirow{2}{*}{1.13} & \multirow{2}{*}{ SM2 } & \multirow{2}{*}{ - } \\
\hline & & & GRC6 & 161.8 & 20.6 & & GRP6 & 177.3 & 22.4 & & & & \\
\hline - & December 1,5 2012 & - & - & - & - & $20.5^{*}$ & - & - & - & - & - & SM5 & $\begin{array}{l}\text { PN7, PN8, PN9 } \\
\text { PL3 and PL4 }\end{array}$ \\
\hline & & & GRC7 & 162.0 & 20.6 & & GRP7 & 147.1 & 18.6 & & & & PN10, PN11, \\
\hline & & & GRC8 & 159.6 & 20.3 & 20.0 & GRP8 & 157.0 & 19.8 & 10.2 & 0.84 & SIVID & \\
\hline 5 & 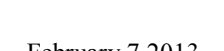 & 500 & GRC9 & 156.5 & 19.9 & 2 & GRP9 & 178.4 & 22.5 & 1 & $1 \rho 0$ & & \\
\hline & & & GRC10 & 194.7 & 24.8 & & GRP10 & 187.0 & 23.6 & & & & PLN3, PLN4, \\
\hline & & & GRC11 & 184 & 23.4 & & GRP11 & 189.3 & 23.9 & & & & HPSL $1^{*}$, and \\
\hline & & & GRC12 & 189.8 & 24.2 & & GRP12 & 226.8 & 28.6 & & & & \\
\hline & & & GRC13 & 139.1 & 17.7 & & GRP13 & 185.3 & 23.4 & & & SS6 & PN13, PN14, \\
\hline 7 & Fiay 252014 & 1000 & GRC14 & 168.6 & 21.5 & 1900 & GRP14 & 159.5 & 20.1 & & & SS4 & PL12 \\
\hline & Jum 26.2014 & 1004 & GRC15 & 129.0 & 16.4 & $10 ?$ & GRP15 & 139.0 & 17.5 & 107 & 100 & SS1, SS2 & PN16, PN17, PN18 \\
\hline 8 & & & GRC16 & 158.7 & 20.2 & & GRP16 & 158.0 & 19.9 & & & SS6 & and PN19 \\
\hline & J & 190 & GRC17 & 174.0 & 22.1 & & GRP17 & 223.7 & 28.2 & & & & \\
\hline 9 & & & GRC18 & 181.8 & 23.1 & & GRP18 & 199.4 & 25.2 & & & & \\
\hline
\end{tabular}




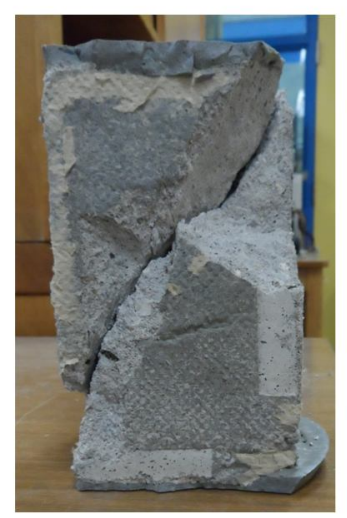

Block moulded Prism

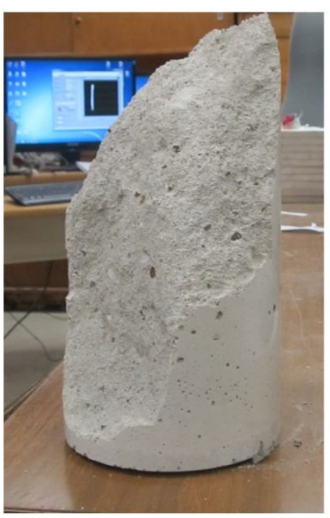

Cylinder

a) Shear Failure Pattern
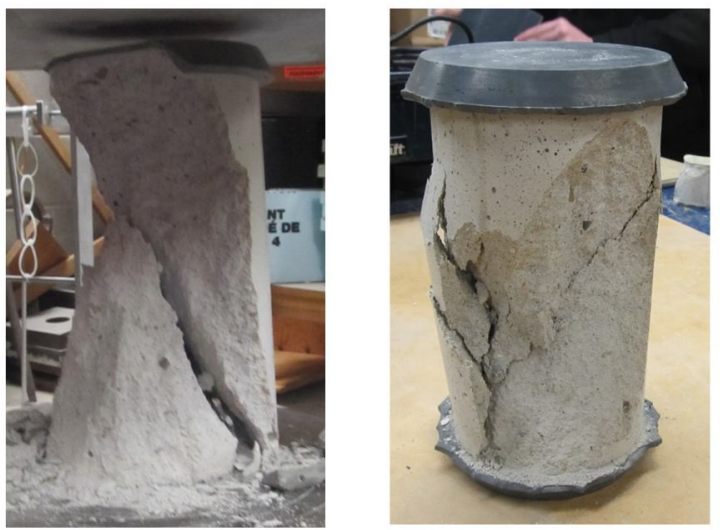

b) Shear Cone Failure Pattern in Cylinders

Figure 4-5: Failure Patterns of the Grout Samples

The stress-strain curves were recorded for various grout cylinder samples. Figure 4-6 presents the stress strain curve for sample GRC6. The nonlinearity of the curve started at $45 \%$ of the peak grout compressive stress due to micro-cracking in the interface zone between the aggregate and the cement paste (Drysdale and Hamid 2005). The chord modulus of elasticity of the cylinders ranged from $790 f_{\text {gr }}$ to $820 f_{\text {gr. }}$ 


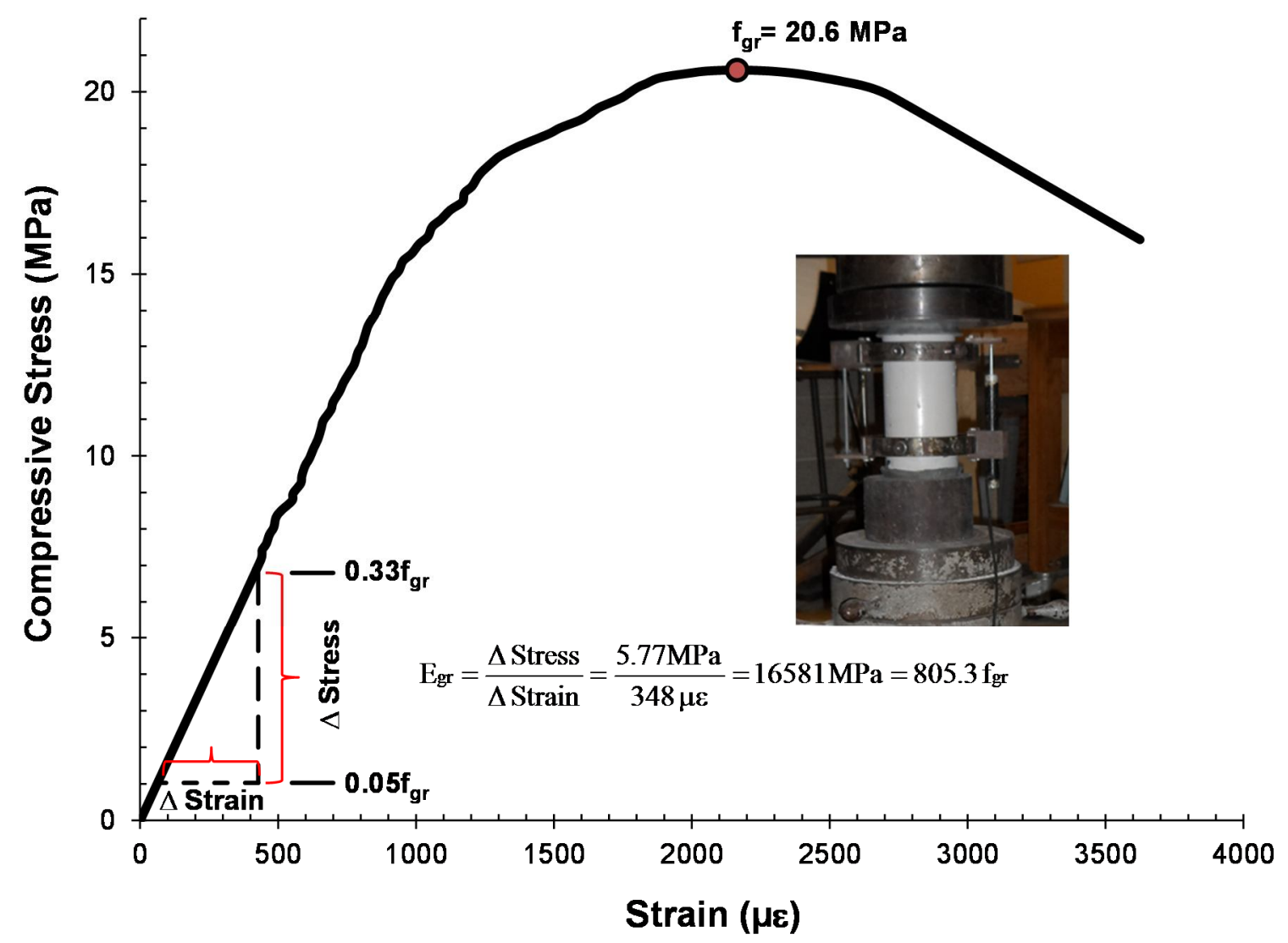

Figure 4-6: A Typical Stress-Strain Curve for the Cylinder Grout Samples

Block moulded grout prisms are often used (Drysdale and Hamid 2005) in research programs as a more accurate test of the in-situ compressive strength of the grout. This is because the block moulds moisture from the grout, unlike plastic cylinders. Test results by Scrivener and Baker (1988), on the other hand, have shown that the difference between the compressive strength of non-absorbent cylinders and block moulded samples was not significant. In the current investigation, the ratio between the compressive strength of the moulded prisms and the nonabsorbent cylinder were calculated for all the nine sets and presented in Table 4-4. This ratio varies from 0.94 to 1.23 with an average of 1.07. These results would seem to confirm Scrivener and Baker`s results. 


\subsection{Test Results of the Masonry Prisms}

As stated in Chapter 3, two types of prisms were constructed and tested under uniaxial compression: masonry prisms loaded normal to bed joints and masonry prisms loaded parallel to bed joints. Eight sets of prisms were constructed and tested in the investigation with a total of 41 masonry prisms: 26 prisms normal to bed joints and 15 parallel to bed joints. Table $4-5$ presents the masonry prism test matrix with references to the beams they are associated with. In order to understand Table 4-5 it is useful to recall the notation of the prisms. Prims built with $190 \mathrm{~mm}$ blocks have three letter names: the first term denotes that it is a prism $(\mathrm{P})$, the second term indicates the direction of the applied load ( $\mathrm{N}$ for normal to the bed joint and $\mathrm{P}$ for parallel to the bed joint) and the third term is a numerical designation (given in the order of their testing sequence). Prisms PN1 to PN12, PN20 and PN21 were associated with the middle size beams (built at the same time with the same materials as the beams). It is worth mentioning that no prisms were tested with beams SM2 and SM4 and that their compressive strengths were calculated by interpolation between the test results of the second and third sets. Prisms PN13 to PN19 were associated with the small size beams. Prisms PL1 to PL7 (tested parallel to bed joints) are associated with the middle size beam series while prisms PL11 and PL12 are associated with the small size beams. Prisms HPSM5, HPSS1 and HPSS5 were instrumented with strain gauges and tested parallel to bed joints in such a way that the obtained stress strain behaviour is similar to the stress strain behaviour of the uncracked compression zones of their reference beams SM5, SS1 and SS5. 
Table 4-5: Compressive Strength Results for the Masonry Prisms

\begin{tabular}{|c|c|c|c|c|c|c|c|c|c|c|c|c|c|c|}
\hline \multirow[b]{2}{*}{$\begin{array}{l}\text { Set } \\
\text { No. }\end{array}$} & \multicolumn{6}{|c|}{$\begin{array}{l}\text { Normal to Bed Joint Masonry Prisms } \\
\end{array}$} & \multicolumn{7}{|c|}{ Parallel to Bed Joint Masonry Prisms } & \multirow[b]{2}{*}{ Beam ID } \\
\hline & $\begin{array}{c}\text { Prism } \\
\text { ID }\end{array}$ & Testing Date & $\begin{array}{c}\text { Age } \\
\text { (days) }\end{array}$ & $\begin{array}{l}\text { Load } \\
(\mathbf{k N})\end{array}$ & $\underset{(\mathbf{M P a})}{f_{m}}$ & $\begin{array}{c}f_{m} \\
\text { Average } \\
(\mathrm{MPa}) \\
\end{array}$ & Prism ID & Testing Date & $\begin{array}{c}\text { Age } \\
\text { (days) }\end{array}$ & $\begin{array}{l}\text { Load } \\
(\mathrm{kN})\end{array}$ & $\underset{(\mathbf{M P a})}{\mathbf{f}_{\mathbf{m}}}$ & $\begin{array}{c}f_{m} \\
\text { Average } \\
\text { (MPa) } \\
\end{array}$ & $\begin{array}{c}\text { Ratio of } \\
\text { (Normal/Parallel) }\end{array}$ & \\
\hline \multirow{3}{*}{1} & PN1 & \multirow{3}{*}{ August 82012} & \multirow{3}{*}{407} & 1319.6 & 17.81 & \multirow{3}{*}{17.9} & PL1 & August 162012 & \multirow{3}{*}{415} & 1300 & 17.7 & \multirow{3}{*}{17.5} & \multirow{3}{*}{0.98} & \multirow{3}{*}{ SM1 } \\
\hline & PN2 & & & 1300.6 & 17.55 & & PL2 & August 162012 & & 1326 & 17.3 & & & \\
\hline & PN3 & & & 1348 & 18.19 & & - & & & - & - & & & \\
\hline \multirow{3}{*}{2} & PN4 & \multirow{3}{*}{ September 142012} & \multirow{3}{*}{444} & 1341 & 18.10 & \multirow{3}{*}{18.0} & \multirow{3}{*}{ - } & \multirow{3}{*}{ - } & \multirow{3}{*}{ - } & \multirow{3}{*}{ - } & \multirow{3}{*}{ - } & \multirow{3}{*}{ - } & \multirow{3}{*}{ - } & \multirow{3}{*}{ SM6 } \\
\hline & PN5 & & & 1303.4 & 17.59 & & & & & & & & & \\
\hline & PN6 & & & 1362.5 & 18.39 & & & & & & & & & \\
\hline \multirow{2}{*}{-} & - & October 3,52102 & & & & $18.5^{\prime \prime}$ & - & - & & - & - & - & - & SM4 \\
\hline & - & October 292102 & & - & - & $19.1^{\prime \prime}$ & - & - & & - & - & - & - & SM2 \\
\hline & PN7 & November 272012 & 518 & 1416.4 & 19.11 & \multirow{3}{*}{19.5} & PL3 & December 62012 & 527 & 1490 & 19.85 & \multirow{3}{*}{19.5} & & \\
\hline 3 & PN8 & November 282012 & 519 & 1536.2 & 20.73 & & PL4 & December 102012 & 531 & 1432 & 19.08 & & 1.0 & SM5 \\
\hline & PN9 & December 52012 & 526 & 1403 & 18.90 & & HPSM5 $^{*}$ (PL8) & & & 1452.1 & 19.4 & & & \\
\hline & PN10 & December 202012 & 541 & 1643.1 & 22.17 & & PL5 & Docomber 212012 & 542 & 1196.3 & 15.94 & & & \\
\hline 4 & PN11 & & & 1275.0 & 17.21 & 20.0 & PL6 & Detentiver 212012 & 542 & 1304 & 17.38 & - & 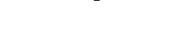 & SM1D \\
\hline & PN12 & December 212012 & 342 & 1643.5 & 22.18 & & $\mathrm{PL}^{* *}$ & May 032013 & 675 & 1170.8 & 15.6 & 16.7 & 0.84 & \\
\hline & PLN1 & May 62013 & 678 & 1710.0 & 18.27 & & PLL1 & May 062013 & 678 & 1628.6 & 17.4 & - & 0.93 & \\
\hline & PLN2 & & & 1688.9 & 18.04 & & HPSL2 $^{*}{ }^{*}$ (PLL2) & September 52013 & & & & - & - & \\
\hline 5 & PLN3 & March 192013 & 630 & 1821.2 & 19.46 & 18.9 & $\operatorname{HPSL1}^{*}{ }^{*}$ (PLL2) & August 82013 & & & & - & - & SL1 and SL2 \\
\hline & PLN4 & & & 1812.4 & 19.36 & & & & & & & & & \\
\hline & PLN5 & May 62013 & 678 & 1790.0 & 19.12 & & & & & & & & & \\
\hline & PN13 & February 242014 & 972 & 1331.8 & 17.97 & & PL11 & February 262014 & 974 & 1608.5 & 21.4 & $20.4-2$ & & \\
\hline 6 & PN14 & March 42014 & 980 & 1404.5 & 18.95 & 18.0 & PL12 & March 42014 & 980 & 1446.9 & 19.3 & 20.7 & 1.13 & SS6 and SS4 \\
\hline & PN15 & March 62014 & 982 & 1269.5 & 17.13 & & - & - & & - & - & - & & \\
\hline & PN16 & June 52014 & 1073 & 1507.6 & 20.35 & & HPSS $^{*}$ (PL9) & & & 1196.3 & 15.94 & & & \\
\hline 7 & PN17 & June 62014 & 1074 & 1233.3 & 16.64 & 17.5 & HPSS5 $^{*}$ (PL10) & & & 1304 & 17.38 & - & - & SS1, SS2, SS3 and \\
\hline & PN18 & June 262014 & 1094 & 1292.0 & 17.44 & & - & - & - & - & - & & & \\
\hline & PN19 & (1) & - & 1167.8 & 15.76 & & & 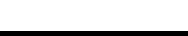 & 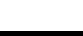 & & 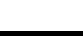 & & & \\
\hline 8 & PN20 & & & 1378.0 & 18.60 & & & & & & & & & \\
\hline 8 & PN21 & June 262015 & 1442 & 1166.7 & 15.74 & 17.2 & - & - & - & - & - & - & - & SM3 \\
\hline
\end{tabular}

" value calculated by interpolation

* tested under the same loading history of its reference beam

** tested well past other prisms in the set and its result is not included in the average value 
Prisms built with $240 \mathrm{~mm}$ blocks have four letter names: the first two terms denote that it is a large prism (PL), the third term indicates the direction of the applied load ( $\mathrm{N}$ for normal to the bed joint and L for parallel to the bed joint) and the fourth term is a number showing the order of their testing sequence. In this set, five normal to bed joint prisms and three parallel to bed joint prisms were built and tested. Prisms HPSL1, HPSL2 were instrumented with strain gauges and tested parallel to bed joint under with loading patterns that lead to stress strain behaviour that is the similar to the stress strain response of the uncracked compression zones of their reference beams SL1 and SL2.

\subsubsection{Masonry Prisms Loaded Normal to Bed Joints}

The test data from the prisms loaded normal to the bed joint were used to determine the compressive strength $\left(\mathrm{f}_{\mathrm{m}}\right)$ of the masonry beams. To calculate their compressive strengths, gross areas of $74100 \mathrm{~mm}^{2}$ and $93600 \mathrm{~mm}^{2}$ were used for the $190 \mathrm{~mm}$ prisms and $240 \mathrm{~mm}$ prisms, respectively, as shown in Figure 4-7.

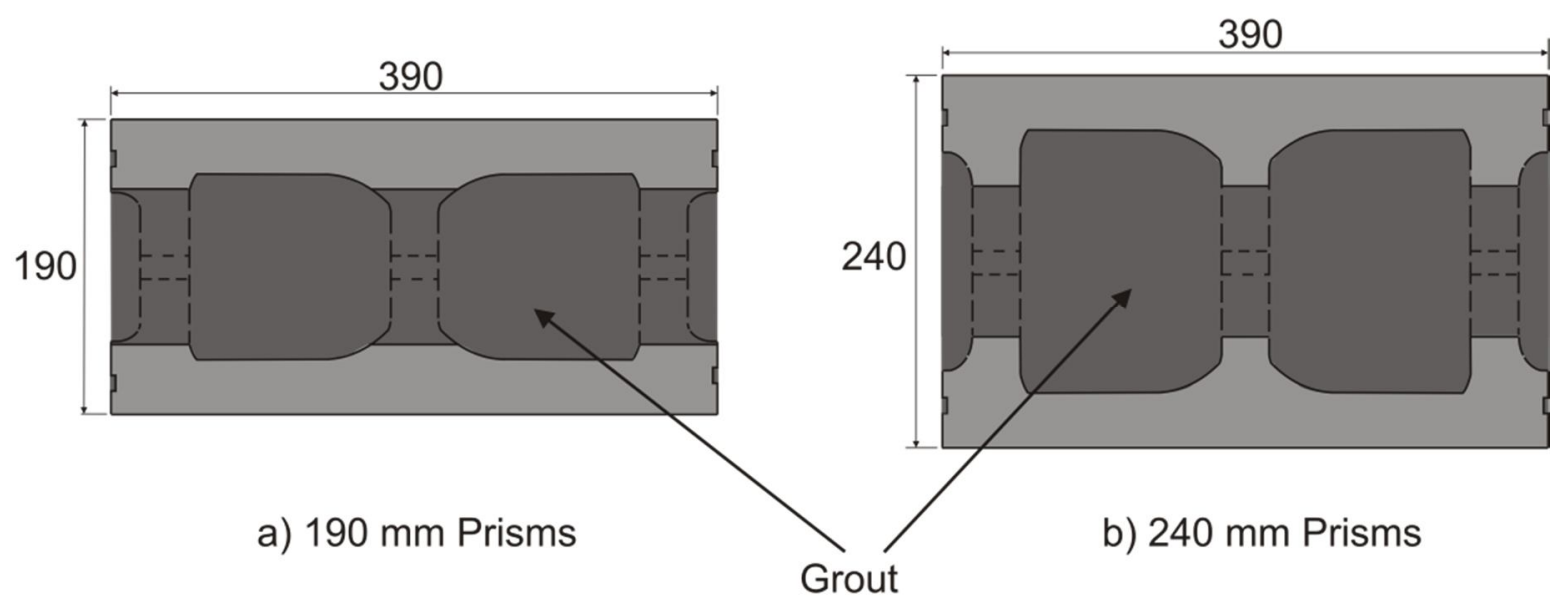

Figure 4-7: Gross Areas of the Normal to Bed Joint Prisms 
As indicated in Table 4-5, the average compressive strengths of the prisms tested normal to bed joints varied between 17.3 $\mathrm{MPa}$ to $20 \mathrm{MPa}$. There was an increase in compressive strength with time for $190 \mathrm{~mm}$ masonry prism from the first set to the fourth set (from ages 407 days to 542 days), however the average compressive strength showed a reduction trend in the sixth to the eighth sets. Although significant consistency was achieved in the construction and grouting of the beams and prisms, it is possible that some variation in the strengths of the grout used in the prisms occurred which was not observed in the strength of the grout samples. This was possibly due to the addition of superplasticizer to grout trucks many times during the grouting process to achieve the slump requirement $(240 \mathrm{~mm})$. As such, some prisms might have grouted just before the addition of the superplasticizer and others just after. The significant variation in the results of prisms in set seven (15.76 $\mathrm{MPa}$ to $20.53 \mathrm{MPa}$ ) and set eight (15.76 $\mathrm{MPa}$ to 18.9 $\mathrm{MPa}$ ) supports this justification.

It can be seen from Figures 4-8 and 4-9 that the failure mode in masonry prism loaded normal to bed joint is tensile splitting which initiates in the shells of the blocks in the middle courses. To explain this phenomenon, consider Figure 4-10 which show the stress-strain curves for the prism PN11 and its block unit and grout sample. Based on the principal of compatibility, it is reasonable to assume that at a given strain level of the prisms, the grout and block will undergo the same magnitude of strain. Consider the strain level of $1300 \mu \varepsilon$ which is close to the strain recorded at the maximum stress in prism PN9. This stresses associated with this strain level are 18.2 $\mathrm{MPa}$ in the grout and $29 \mathrm{MPa}$ in the block which are equal to $88 \%$ and $60 \%$ of the strengths of the grout and the block, respectively. At this level of stress, the grout undergoes large lateral expansions due to an increased Poisson's ratio near ultimate strength. These lateral expansions in 
turn create tension in the outer shells of the block as they tend to confine the grout. These lateral tensile stresses reduce the compressive strength of the block. As a result the block fails in tensile splitting while the grout columns remain mostly intact. At approximately $80 \%$ of the failure load, vertical cracks were visible along the webs as the face shells of the blocks were separated from the grouted cells. The grout cores were either intact as those in the failure of PN13 in Figure 4-8a and PLN4 in Figure 4-9, or lightly damaged as shown in the failure of PN13 in Figures 4-8b. 

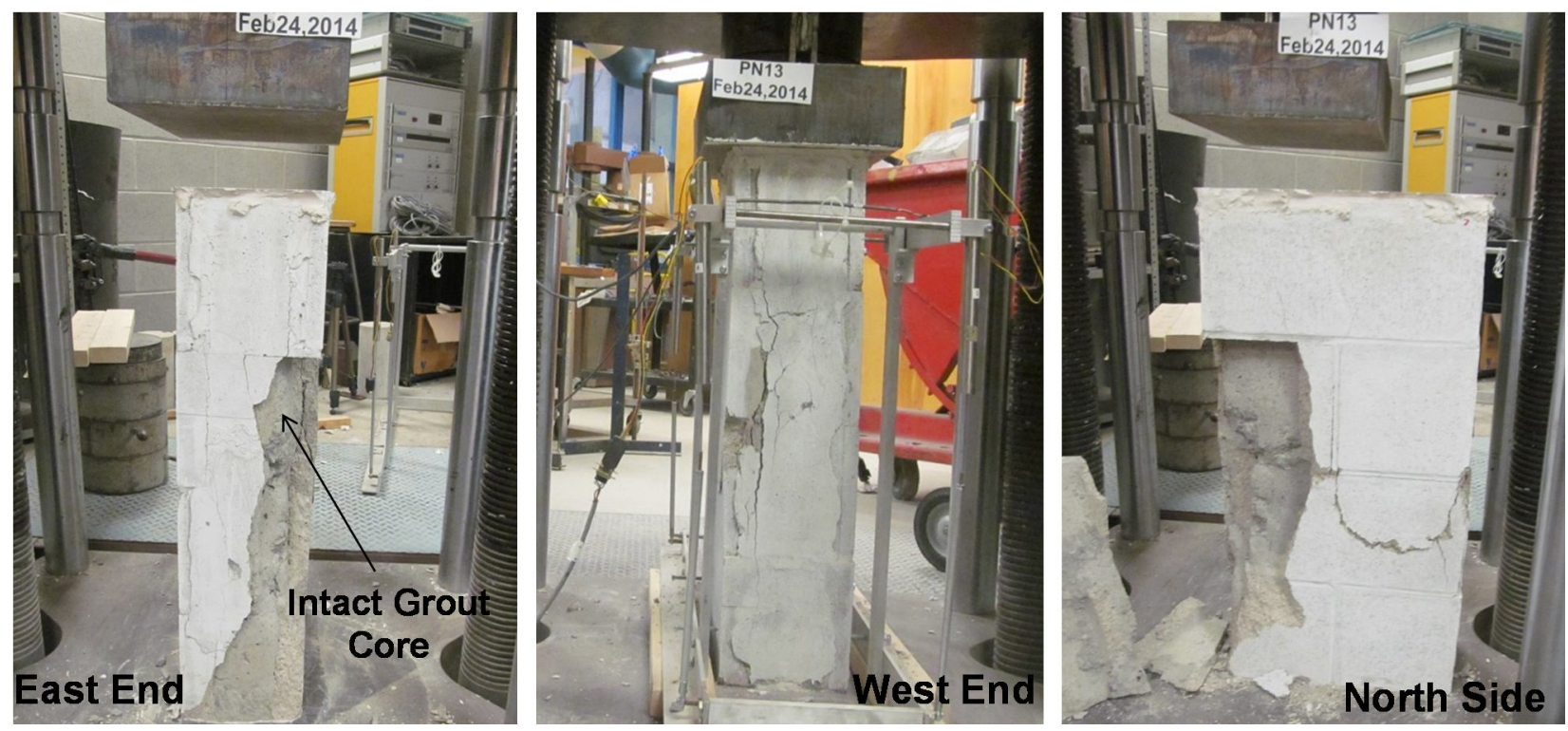

a) Failure Pattern of Prism PN13
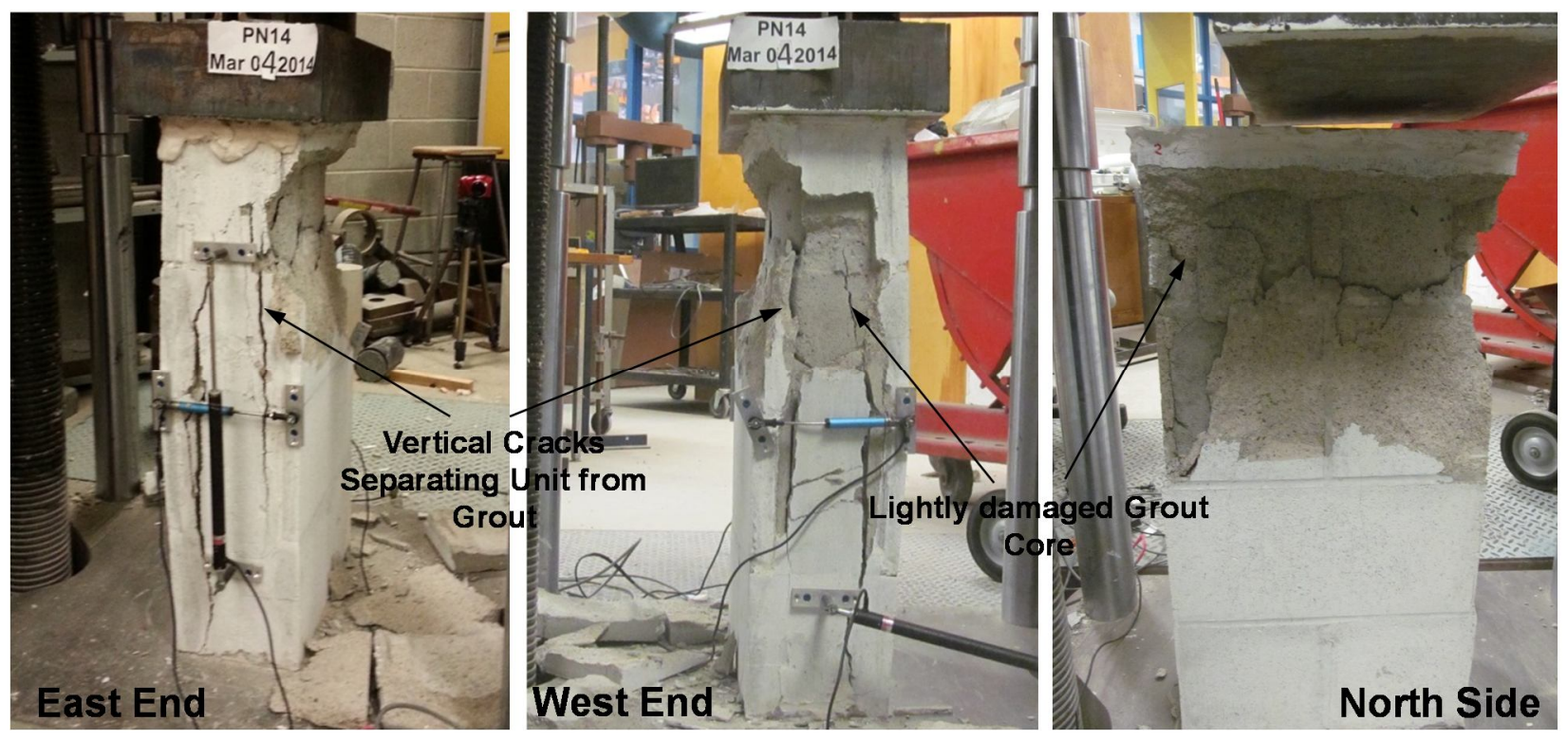

b) Failure Pattern of Prism PN14

Figure 4-8: Typical Failure Patterns of 190 mm Masonry Prisms Loaded Normal to the Bed Joint 

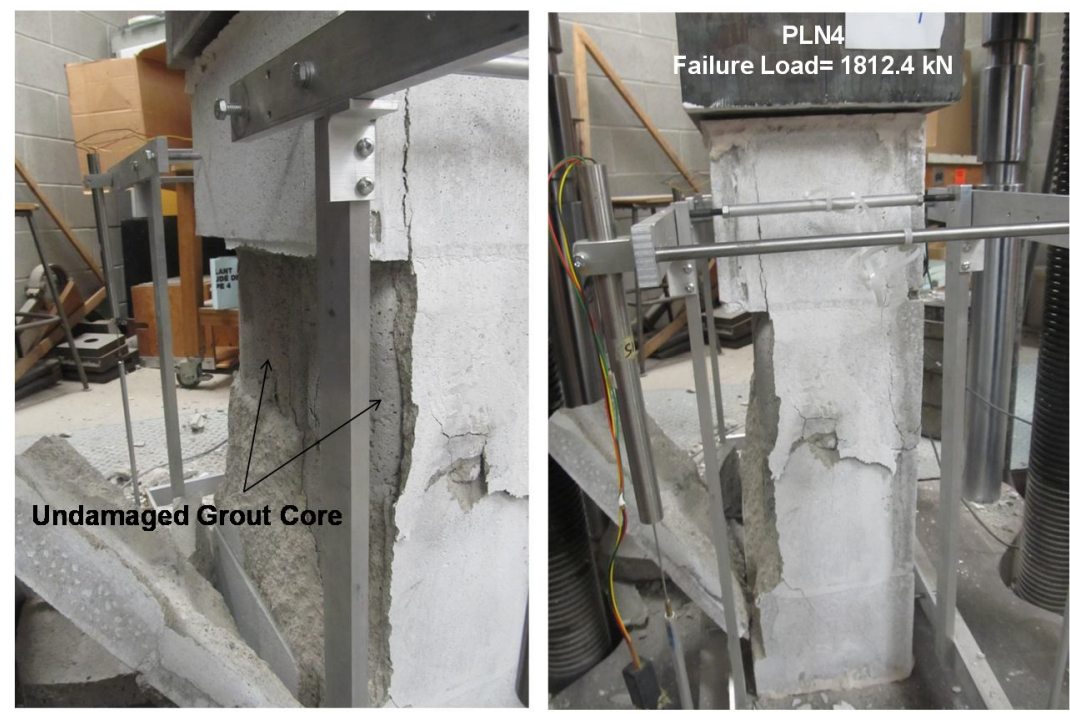

Figure 4-9: Typical Failure Patterns of 240 mm Masonry Prisms Loaded Normal to the Bed Joint

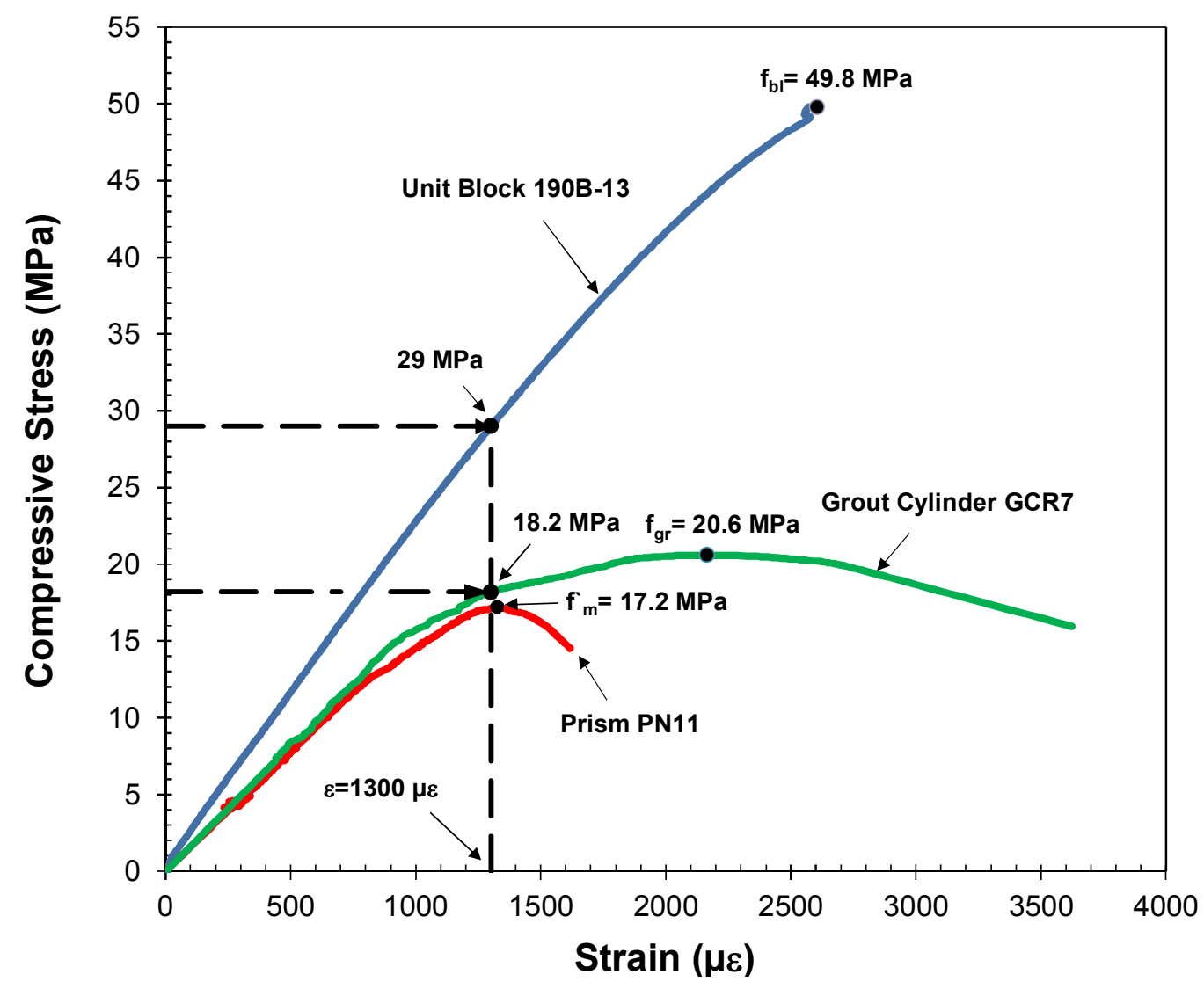

Figure 4-10: Stress-Strain Curves for Prism PN9 and its Block Unit and Grout Sample 
As masonry is a highly non-homogeneous material, local deformations may differ over the hight, length and width of a masonry structural element. As such, it is necessary to measure the strain over a considerable length to better repesent the average values (Drysdale and Hamid 2005.) In this investigation, different method were used to measure the strain in the masonry prisms. One of these methods was the jig described in Figure 3-31 and shown in Figures 4-8a and Figures 49. This jig measured the strain with four LVDTs rununing between the top and bottom corners over $600 \mathrm{~mm}$ hight that includes four courses and three bed joints. The strains of prisms PN11 (normal to bed joint) and PN5 (parallel to bed joint) measured by the jig were plotted versus the stress values of these prisms and presented in Figure 4-10. It can be seen form Figure 4-11 that nonolinear behaviour of PN11 started at about 70\% of the peak stress The existence of a desending brach is also evident. The strain at the peak stress was $0.00134 \mathrm{~mm} / \mathrm{mm}$ for prism PN11 and ranged between 0.0013 to 0.0016 for other prisms tested normal to bed joint in the current research. The modulus of elascity of PN11 was $937 \mathrm{f}_{\mathrm{m}}^{\prime}$ and varied from $930 \mathrm{f}_{\mathrm{m}}^{\prime}$ and 960 $f_{m}^{\prime}$ for other prisms normal to bed joint tested in this investigation. 


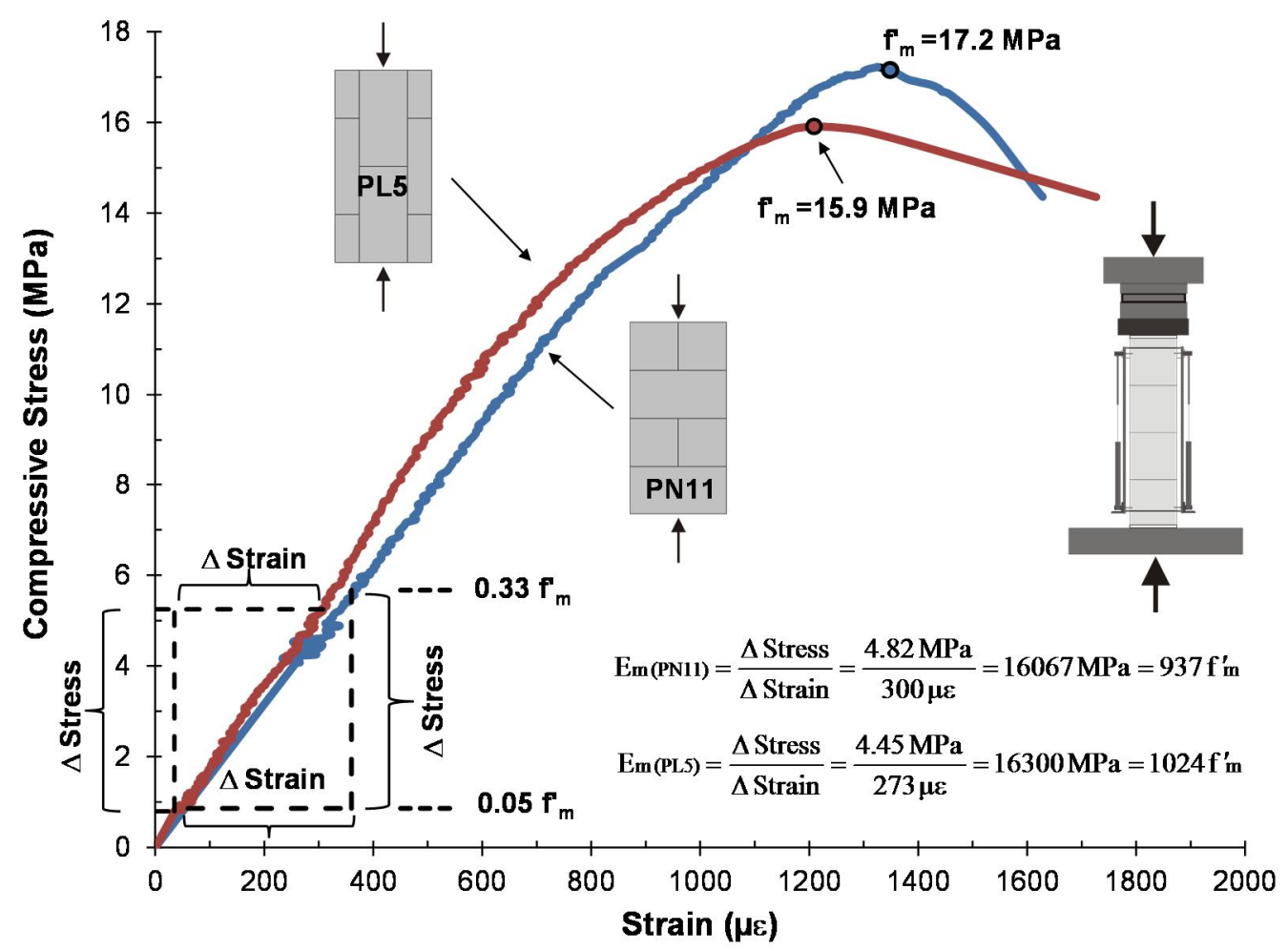

Figure 4-11 Typical Stress-Strain Curves of the Masonry Prisms Tested Normal and Parallel to the Bed Joint

The digital image correlation (DIC) process was conducted on one end face of a $190 \mathrm{~mm}$ block masonry prisms tested normal to the bed joint. Figure 4-12 shows the axial and lateral strain contours for different load stages measured by VIC-2D. It can be seen in Figure 4-12a that when the load reached $65 \%$ of the failure load the lateral strains in the upper middle block (second from top) started to increase noticeably at the interface between the face shell of the block and the grout. With the increase of the load the lateral strains increased significantly along the interface zones of the two top blocks causing two visible vertical cracks. The imminence of failure and its mode can be observed in the last photo captured before failure. This behaviour exactly reflects the failure patterns observed in Figures 4-8 and 4-9. 


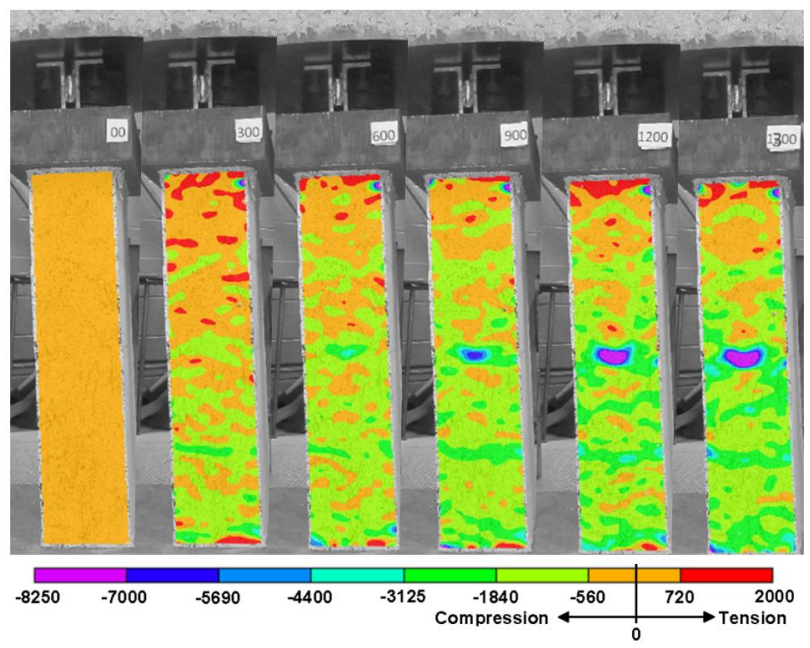

Axial Strain $(\mu \varepsilon)$

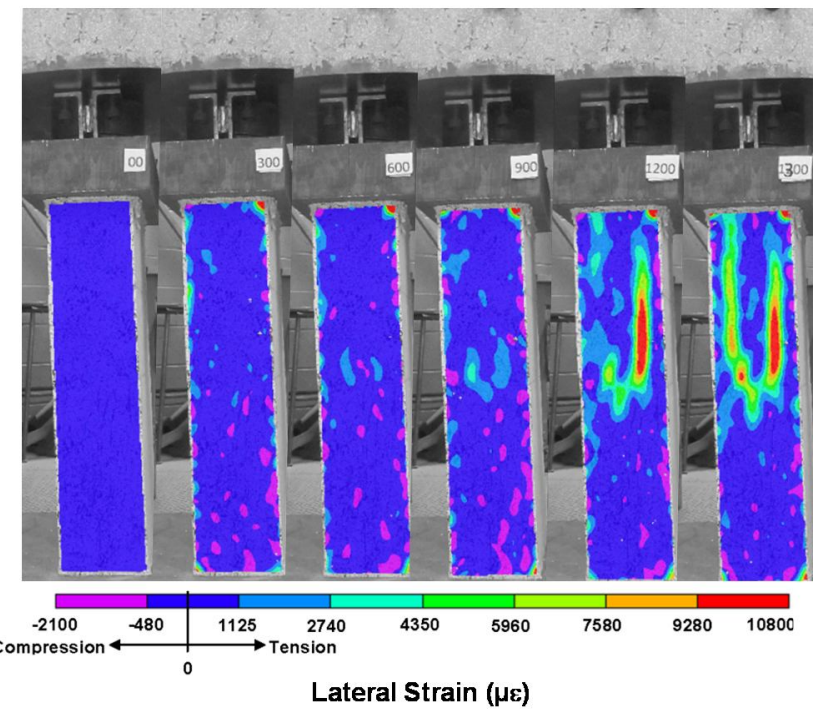

a) Axial and Lateral Strain

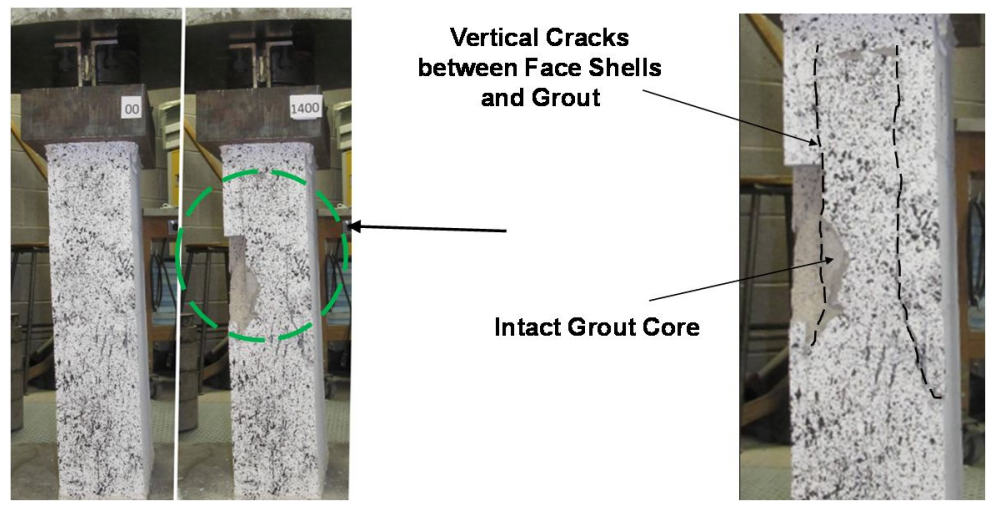

b) A close up of the Failure Pattern

Figure 4-12: The VIC-2D Analysis for a Masonry Prism Tested Normal to the Bed Joints 
The values of axial strains at different stress levels were estimated from the strain contours and were used to construct the stress strain curve for the masonry prism PN9. See Figure 4-13, in which the stress-strain curve established by using VIC-2D software for specimen PN9 is compared to that measured by strain gauges installed on the sides of the prism. The accuracy of VIC-2D in measuring the axial strains was compared with the measured strains from concrete strain gauges installed on the sides of the prisms. Figure 4-13 shows that VIC-2D can be reasonably accurately construct the stress strain curve for the masonry prism. The values of strain measured by VIC-2D are slightly higher than those measured by the strain gauges and this is expected as the strain gauges were put on the face shells of block which is known to be strained less than the webs of the masonry (due to the bowing effect) where the VIC-2D was used to measure the strains.

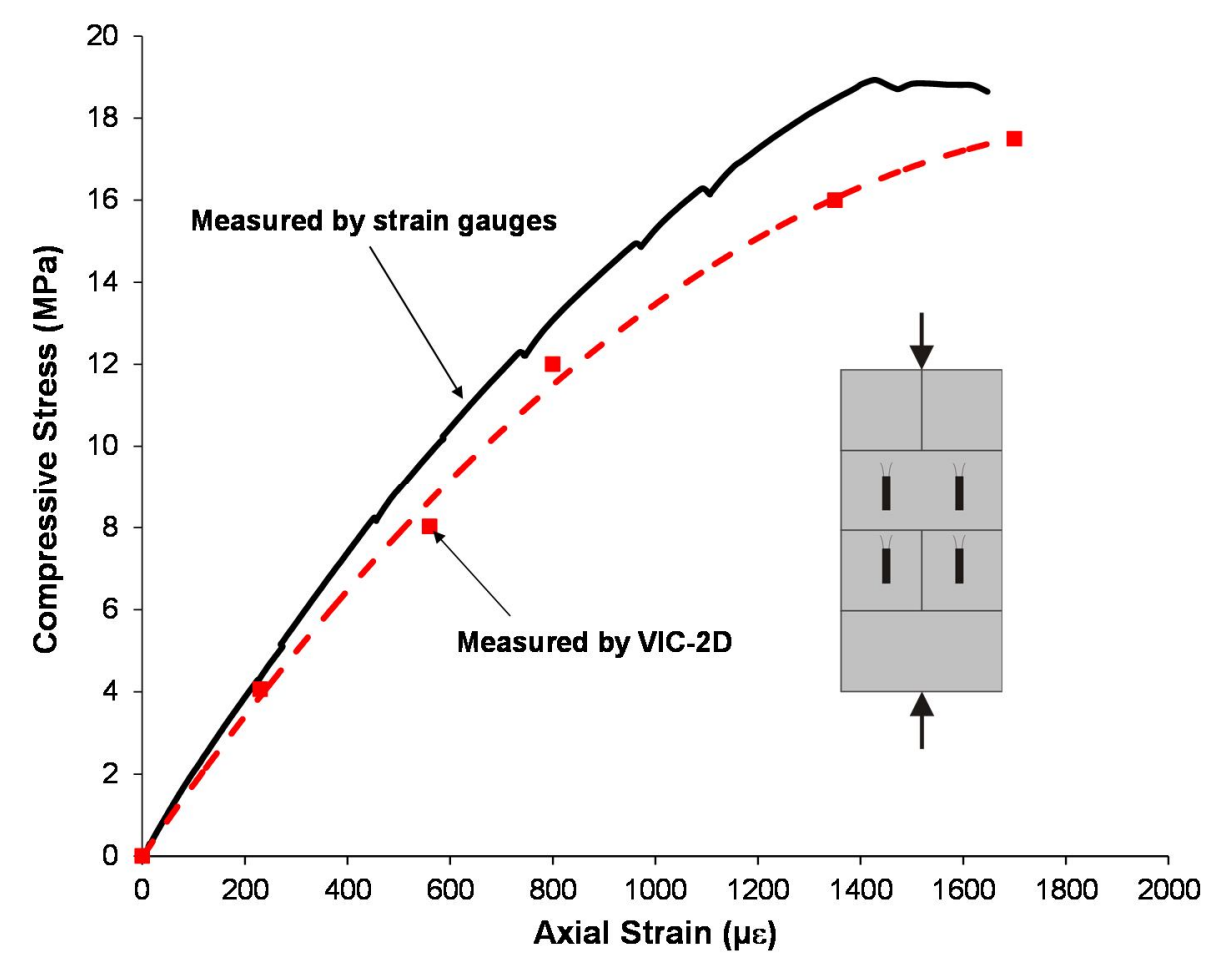

Figure 4-13: Stress-Strain Curve for Masonry Prism (PN9) Tested Normal to the Bed Joint 


\subsubsection{Masonry Prisms Loaded Parallel to Bed Joint}

There were two goals behind the decision to build and test masonry prisms parallel to bed joints. The first goal was to measure the strains and the modulus of elasticity in masonry in the direction parallel to bed joint in a manner which resembles the compression zone in reinforced masonry beams. The second goal was to determine the ratio of the prism strength parallel to the bed joint to that normal to the bed joint. These ratios of the strength of parallel to bed joint to that of normal to bed joint are reported in Table 4-5. It is important to note that the compressive strength of parallel to bed joint prisms was calculate based on gross areas of $75,050 \mathrm{~mm}^{2}$ for prisms made with $190 \mathrm{~mm}$ units and $94,800 \mathrm{~mm}^{2}$ for prisms made with $240 \mathrm{~mm}$ units. Figure 414 shows the gross areas of the prisms loaded parallel to the bed joint. The results and discussion of these prisms will be presented in Chapter 5 .

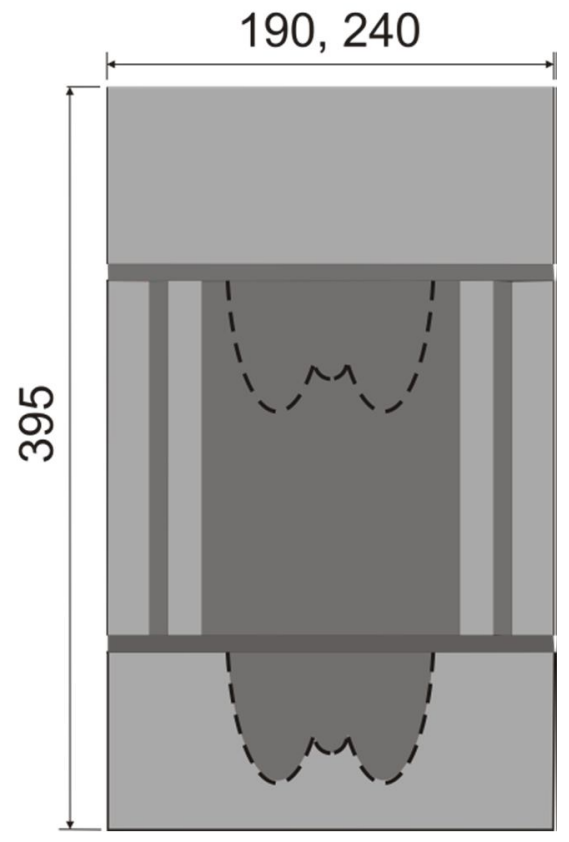

Figure 4-14: Gross Areas of Prisms Loaded Parallel to the Bed Joints 
Some masonry design codes specify different compressive strengths for masonry depending on whether it is loaded normal or parallel to bed joints. The CSA S304.1 code, for example, provides $\chi$ factor to account for this effect. For compression normal to the bed joint, where continuous vertical columns of grout can be provided, $\chi$ is set equal to 1.0. For compression parallel to the bed joint $\chi$ is 0.5 for standard concrete block units (the grout is interrupted by the webs) and $\chi$ is 0.7 for units in which the grout is partially continuous, such as depressed web units, knock-out units and lintel units. It can be seen in Table 4-5 that compressive strengths parallel to the bed joints ranged from 0.84 to 1.13 of the compressive strength normal to bed joints. The average ratio of compressive strength parallel to normal bed joint is 0.98 which considerably larger than the value of 0.7 set by the Canadian code. These results match those of Ring (2009).

The failure of the masonry prisms loaded parallel to the bed joints occurred by web cracking (upper web or lower web or both of them) followed by shearing and lateral deflection of the block face shells. Vertical cracks were visible at the plates and between the masonry unit and the grout (see Figures 4-15 and 4-16). This can be attributed to the differences in deformational characteristic of the grout and unit. At high strains grout undergoes high lateral expansions due to Poisson`s effect. These large lateral expansions create tension in the block shells. The grout cores remained intact after failure in most of the prisms tested parallel to bed joint in this investigation. 

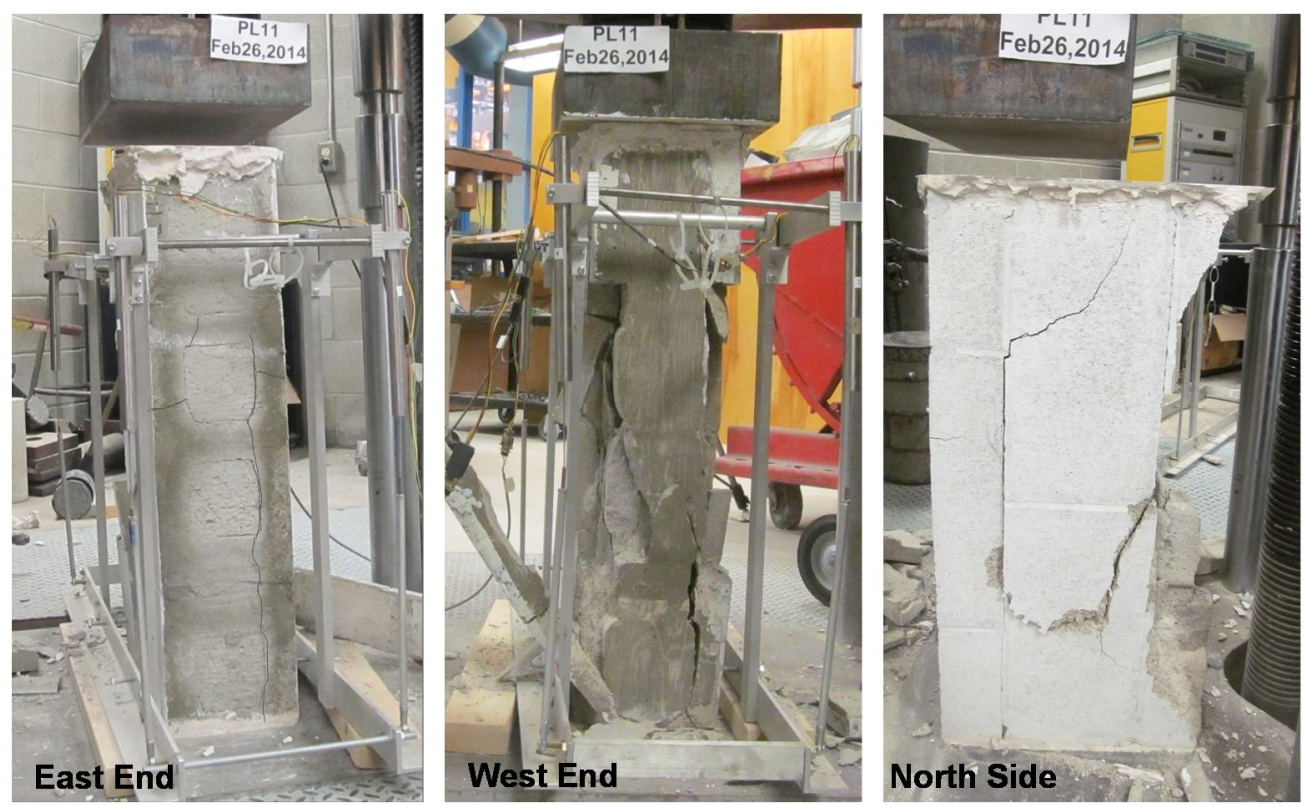

a) Failure Pattern of Prism PL11
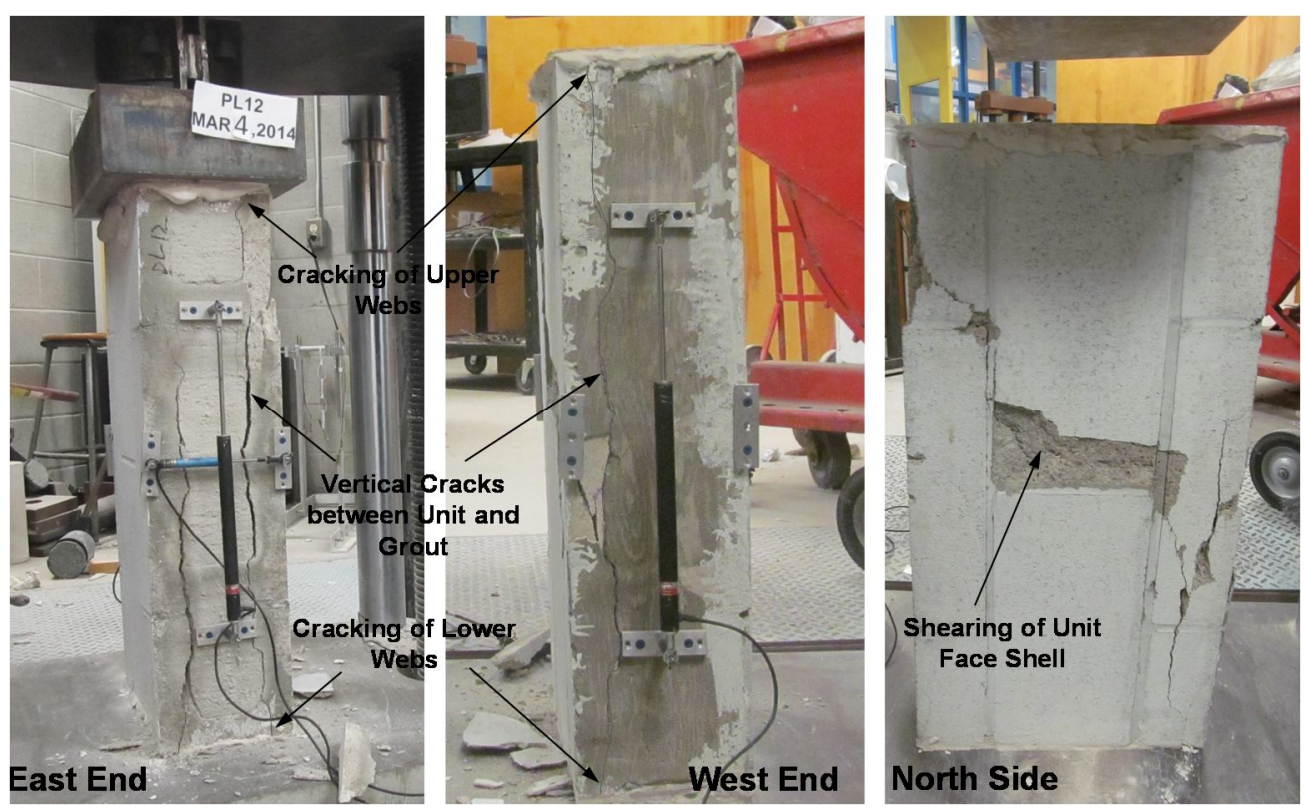

b) Failure Pattern of Prism PL12

Figure 4-15: Typical Failure Patterns of 190 mm Masonry Prisms Loaded Parallel to the Bed Joint 


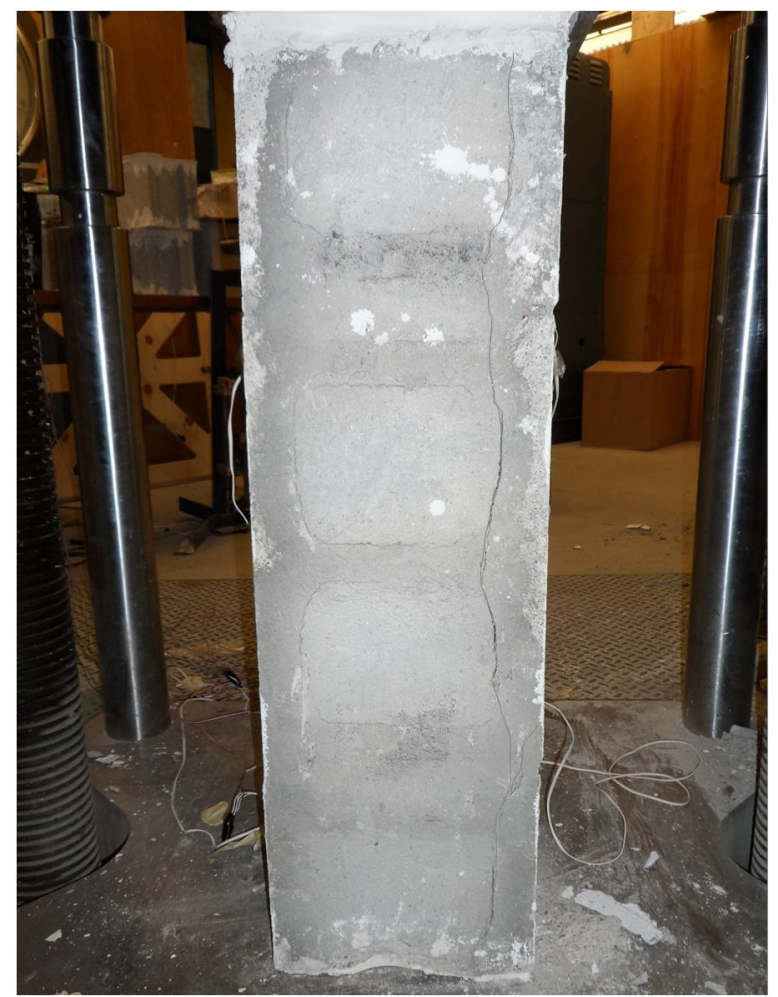

a) Failure Pattern of Prism PLL1

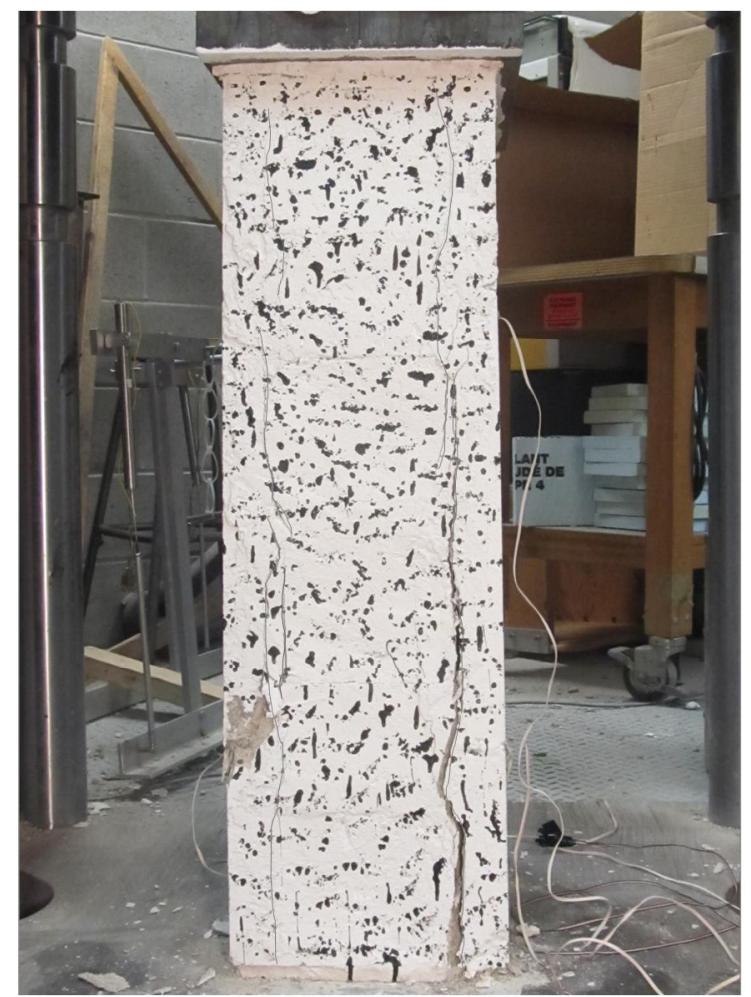

b) Failure Pattern of Prism PLL1

Figure 4-16: Typical Failure Patterns of $240 \mathrm{~mm}$ Masonry Prisms Loaded Parallel to the Bed Joint

A typical stress-strain curve for the masonry prisms loaded parallel to bed joints tested is presented in Figure 4-11. It can be seen in Figure 4-11 that relatively smaller strains were recorded for this parallel to bed joint prism compared to those of normal to bed joint prism PN11 from the same set. The stain at the peak stress for PL5 was 0.00124 . For other prisms tested parallel to bed joint in the current investigation, the stain at the peak stress ranged from 0.0013 to 0.0015. The modulus of elasticity of these prisms varied between $950 \mathrm{f}_{\mathrm{m}}^{\prime}$ and $1040 \mathrm{f}_{\mathrm{m}}^{\prime}$. 


\subsection{Reinforcement Mechanical Properties}

Three types of reinforcing steel were used in the masonry beams: conventional steel reinforcement, high strength steel (Dywidag rebars) and glass fiber reinforced polymer (GFRP) rods. Pull tests were conducted on four $650 \mathrm{~mm}$ long specimens for each bar size of the conventional steel rebars while the mechanical properties of the dywidag rebars and the GFRP rods were obtained from the manufacturers. A typical failure of the rebars is presented in Figure $4-17$.

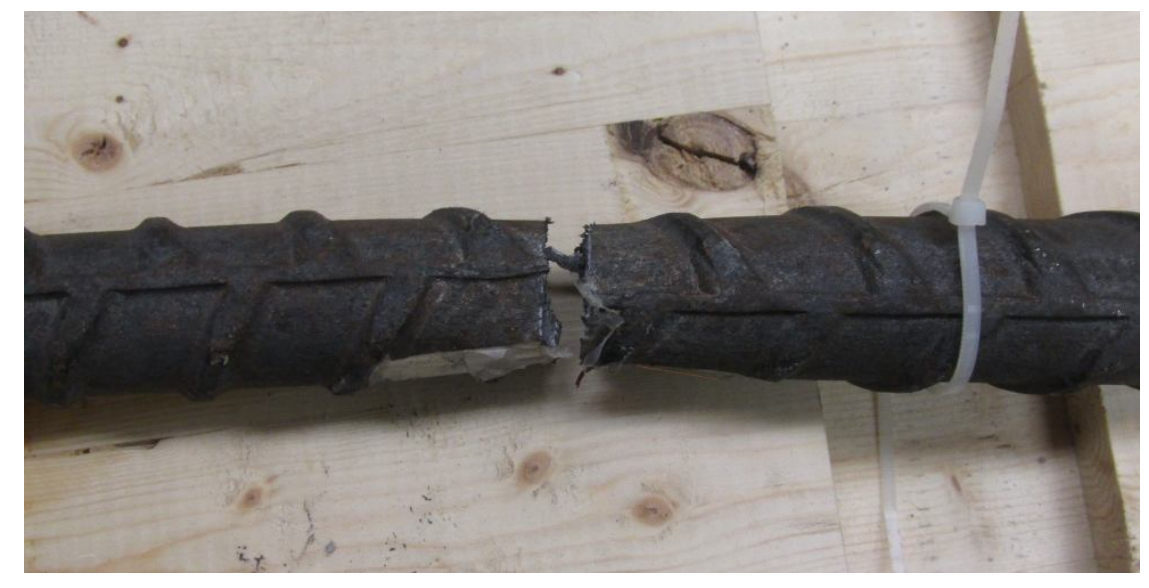

Figure 4-17: Typical tensile failure of steel rebar

The mechanical properties of the different steel types used in this investigation are summarised in Table 4-6 along with purpose of using each type or size of the steel. The values of the conventional steels are the average of results of four samples. The modulus of elasticity (E) was calculated from the stress-strain curves as will be shown later in this section. The values of $\mathrm{E}$ for the conventional steel are all about 200,000 MPa. 
Table 4-6: The Summary of Reinforcement Properties

\begin{tabular}{|c|c|c|c|c|c|c|c|c|}
\hline Rebar & $\begin{array}{c}\text { Reinforcement } \\
\text { Type }\end{array}$ & $\begin{array}{l}\text { Nominal } \\
\text { Diameter } \\
(\mathbf{m m})\end{array}$ & $\begin{array}{c}\mathrm{As}_{\mathrm{S}} \\
\left(\mathrm{mm}^{2}\right)\end{array}$ & $\begin{array}{c}\text { Yield } \\
\text { Strength } \\
\mathbf{f}_{\mathbf{y}} \\
(\mathbf{M P a})\end{array}$ & $\begin{array}{l}\text { Yield } \\
\text { strain } \\
(\%)\end{array}$ & $\begin{array}{c}\text { Ultimate } \\
\text { Strength } \\
\mathbf{f}_{\mathrm{u}} \\
(\mathrm{MPa})\end{array}$ & $\begin{array}{c}\mathbf{E} \\
(\mathrm{GPa})\end{array}$ & Usage \\
\hline $\begin{array}{l}\# 5 / 16^{\prime \prime} \\
\text { Smooth }\end{array}$ & $\begin{array}{l}\text { Conventional } \\
\text { Steel }\end{array}$ & 8 & 50 & 525 & 0.45 & 630 & 200 & Stirrups in SS3 \\
\hline $10 \mathrm{M}$ & $\begin{array}{l}\text { Conventional } \\
\text { Steel }\end{array}$ & 11.3 & 100 & 415 & 0.26 & 660 & 200 & $\begin{array}{c}\text { Stirrups in SM3, Compression steel } \\
\text { in SS3 }\end{array}$ \\
\hline $15 \mathrm{M}$ & $\begin{array}{l}\text { Conventional } \\
\text { Steel }\end{array}$ & 16 & 200 & 450 & 0.44 & 670 & 200 & Horizontally distributed steel in SM6 \\
\hline $20 \mathrm{M}$ & $\begin{array}{l}\text { Conventional } \\
\text { Steel }\end{array}$ & 19.5 & 300 & 400 & 0.25 & 640 & 200 & $\begin{array}{c}\text { Compression steel in SM and SL } \\
\text { series }\end{array}$ \\
\hline $25 \mathrm{M}$ & $\begin{array}{l}\text { Conventional } \\
\text { Steel }\end{array}$ & 25.2 & 500 & 405 & 0.25 & 650 & 200 & Main reinforcement in SS1 and SS2 \\
\hline $30 \mathrm{M}$ & $\begin{array}{l}\text { Conventional } \\
\text { Steel }\end{array}$ & 29.9 & 700 & 440 & 0.28 & 730 & 200 & $\begin{array}{l}\text { Main reinforcement in SS6, SM1, } \\
\text { SM1D, SM2, SM6, SM3, SL1 and } \\
\text { SL2 }\end{array}$ \\
\hline $5 / 8$ in & $\begin{array}{l}\text { High Strength } \\
\text { Steel }\end{array}$ & 15 & 177 & 900 & - & 1100 & 205 & Main reinforcement in SS4 \\
\hline 1 in & $\begin{array}{l}\text { High Strength } \\
\text { Steel }\end{array}$ & 26 & 548 & 830 & - & 1035 & 205 & Main reinforcement in SM4 \\
\hline$\# 5$ & GFRP & 15.8 & 197 & 656 & 1.56 & - & 48.2 & Main reinforcement in SS5 \\
\hline
\end{tabular}

Figures 4-18 and 4-19 show samples of the stress-strain profiles created from the pull tests. From these profiles, the yield strength, yield strain, ultimate strength and the modulus of elasticity of the steel can be determined. It can be seen in Figure 4-19 that the 5/16 in. smooth rebar and the $15 \mathrm{M}$ rebar did not show a distinctive yield stress. The yield strengths of these rebars were determined based on the $0.2 \%$ offset method. A line with same slope of the linear part of the curve was drawn from the strain value of $0.2 \%$ from the origin. The $0.2 \%$ offset yield strength is the stress at which the constructed line intersects the stress-strain curve. Close ups of the elastic regions of the profiles of 5/16 in. and 15M rebars are in shown in Figure 4-19. 

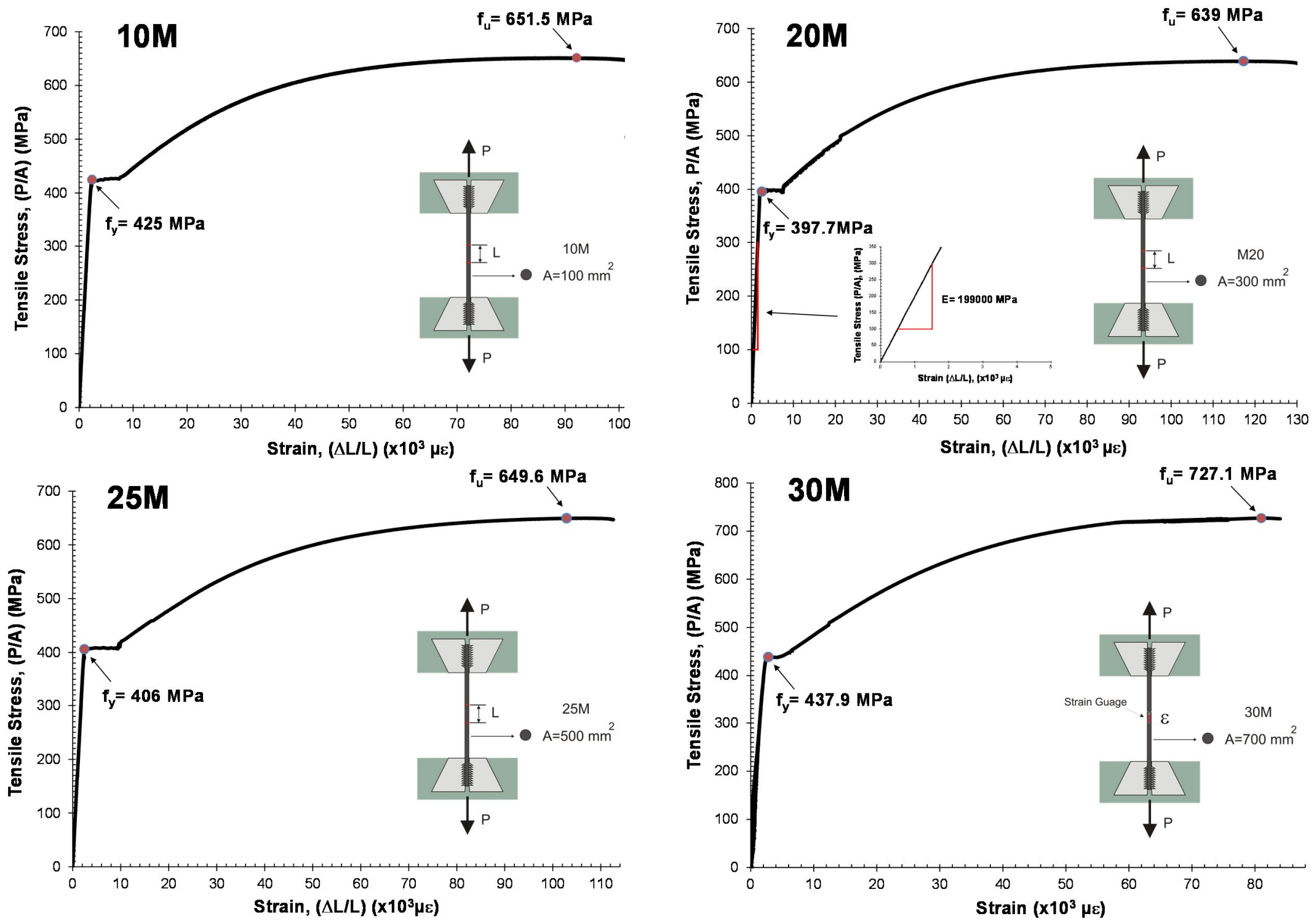

Figure 4-18 Typical Stress-Strain Curves for the 10M, 20M, 25M and 30M rebars 

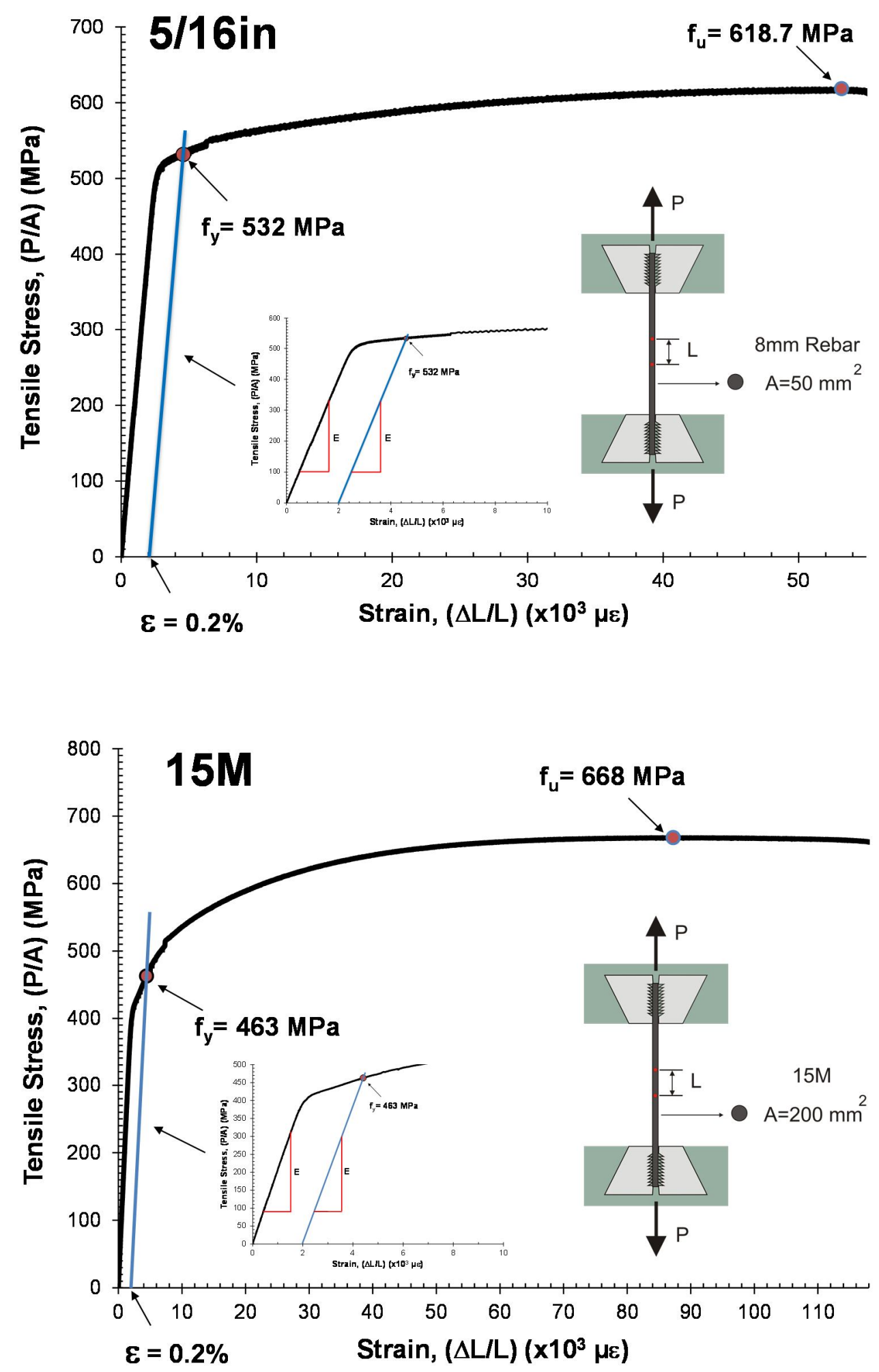

Figure 4-19 Typical Stress-Strain Curves for the 5/16in and 15M rebars 


\subsection{Experimental Results of the Reinforced Masonry Beams}

Only the experimental test results of the reinforced masonry beams at failure are presented in this chapter. The whole test results throughout the loading stages are presented in Appendix A. The analysis of the results will be presented in Chapter 5 (size effect) and Chapter 6 (strain effect.)

\subsubsection{Results of the Initial Tests}

This section presents the results for initial tests of the beams. The test results of the repeated sides will be presented in the following section. To better understand the test results of the beams it is useful to define these results. Figures 4-20 to 4-22 show schematic diagrams for the main experimental results values for different beams tested in this investigation. For the first tests of the beams the following key test results are summarized in Tables 4-7 and 4-8:

$\mathrm{P}_{\text {exp }}$-experimental failure load;

$\mathrm{V}_{\text {exp }}$-experimental failure shear calculated at $\mathrm{d}$ from face of loading plate;

$\Delta$ - midspan deflection

$\Delta / 0.5 \mathrm{~L}$-ratio of midspan deflection to one-half of the span length;

$\gamma$ - shear strain;

$\varepsilon_{x^{-}}$longitudinal strain at mid-depth of the beam; and

$\varepsilon_{\mathrm{s}, \max }$-midspan longitudinal steel strain

The majority of the beams (except for SMID and SM5) failed in shear due to breakdown of beam action prior to reaching their flexural capacity. The modes of failure for the first (initial) tests of these beams were clear diagonal tension failures. It is worth mentioning that the breakdown of aggregate interlock capacity was the most common mechanism for shear failure in most of the 
beams (as will be shown later in chapter 5 and 6). In specimens SMID and SM5, the initial breakdowns of aggregate interlock were followed by the engagement of strut and tie actions and the formation of shear keys at corners of masonry units that permitted shear transfer by interlocking of adjacent blocks. Specimens SMID and SM5 failed due to combinations of strut and tie failures and breakdowns of shear keys. In specimens SS2, SS4, SS6, and SM1 and SM2 the initial breakdowns of aggregate interlock occurred in one of the shear spans and the ultimate failure (due to diagonal tension) occurred in the opposite shear span. The engagements of strut and tie actions and the formation of shear keys led to larger deflections, steel strains, longitudinal strains and shear strains than those associated with the breakdown of the aggregate interlock. Likewise, the engagement of these mechanisms led to higher final shear strengths. For these beams (in which shear keys were formed and strut and tie actions were engaged), final test results were reported in Tables 4-7 and 4-8 along with results at the initial breakdown of aggregate interlock capacity.

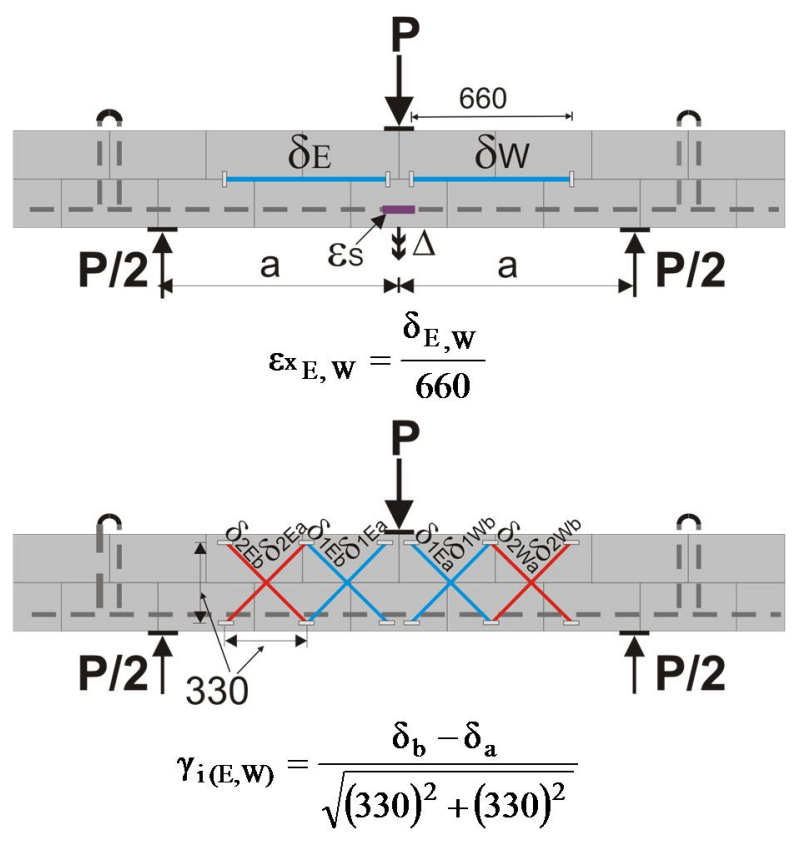

Figure 4-20: A schematic Diagram for the Key Experimental Results for the Small Beams 


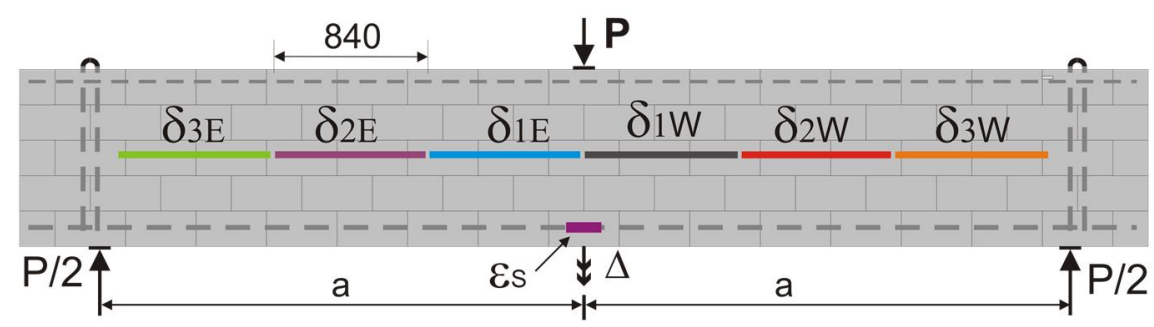

$$
\varepsilon \times \mathrm{Ex}_{\mathrm{E}, \mathrm{W}}=\frac{\delta_{\mathrm{E}, \mathrm{W}}}{840}
$$

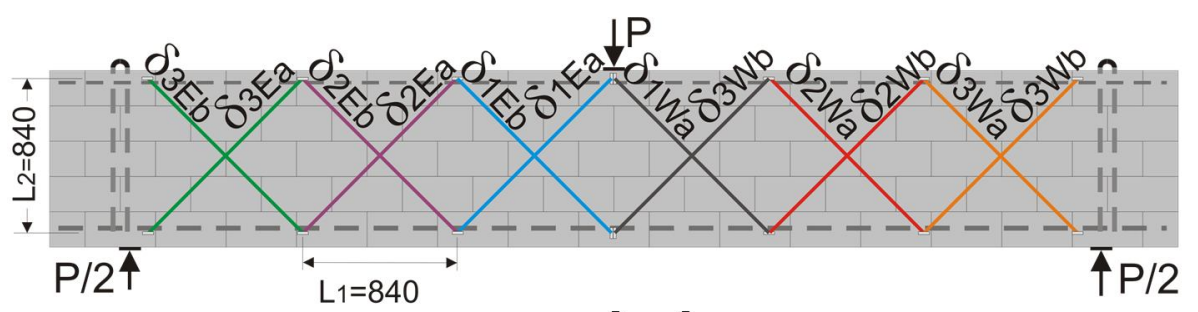

$$
\gamma_{\mathrm{i}(\mathrm{E}, \mathrm{W})}=\frac{\delta_{\mathrm{b}}-\delta_{\mathrm{a}}}{\sqrt{(840)^{2}+(840)^{2}}}
$$

Figure 4-21: A Schematic Diagram for the Key Experimental Results for the Medium Beams
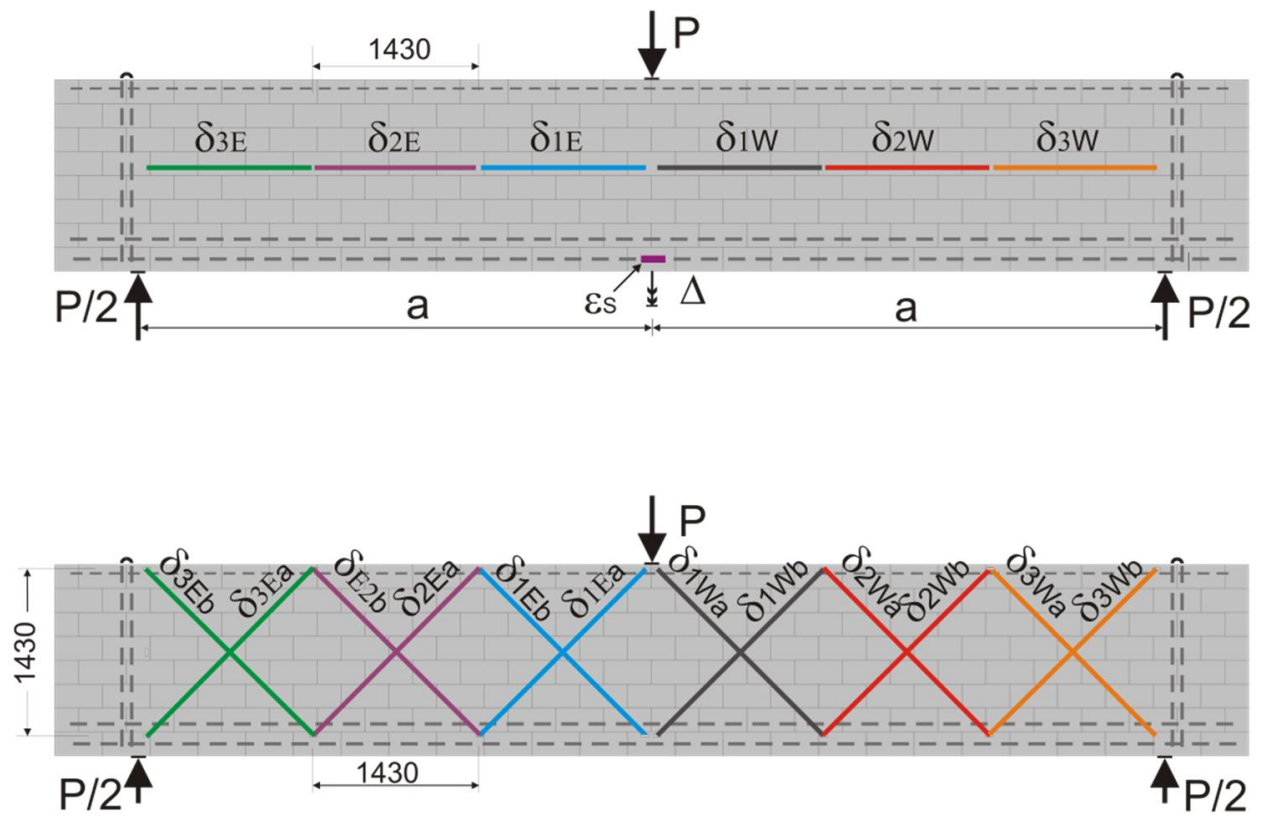

Figure 4-22: A Schematic Diagram for the Key Experimental Results for the Large Beams 
Table 4-7: Summary of Experimental Observations for the Initial Tests of the Masonry Beams

\begin{tabular}{|c|c|c|c|c|c|c|c|c|c|c|c|c|c|c|c|c|c|c|c|}
\hline \multirow[b]{2}{*}{ 曷 } & \multirow[b]{2}{*}{$\begin{array}{c}\text { Age } \\
\text { (Days) }\end{array}$} & \multicolumn{7}{|c|}{ Geometry and Reinforcement } & \multicolumn{5}{|c|}{ Material Properties } & \multicolumn{5}{|c|}{ Experimental Observations of the First Failed Sides } & \multirow[b]{2}{*}{ 竞 } \\
\hline & & $\underset{(\mathrm{mm})}{\mathrm{a}}$ & $\underset{(\mathrm{mm})}{\mathrm{d}}$ & $\mathbf{a} / \mathbf{d}$ & $\begin{array}{c}\mathbf{b}_{\mathrm{w}} \\
(\mathbf{m m})\end{array}$ & $\begin{array}{c}\rho \\
(\%)\end{array}$ & $\frac{A_{v} f_{y}}{b_{w} s}$ & $\begin{array}{c}\text { Crack } \\
\text { control } \\
\text { steel }\end{array}$ & $\begin{array}{c}\mathrm{fbl} \\
\text { (MPa) }\end{array}$ & $\begin{array}{c}\mathrm{fmr} \\
(\mathbf{M P a})\end{array}$ & $\begin{array}{c}\mathrm{fgr} \\
\text { (MPa) }\end{array}$ & $\begin{array}{c}\mathrm{f}^{\prime} \mathrm{m} \\
\text { (MPa) }\end{array}$ & $\begin{array}{l}P_{\text {exp }} \\
(\mathbf{k N})\end{array}$ & $\begin{array}{l}\mathbf{V}_{\text {exp }}^{+} \\
(\mathbf{k N})\end{array}$ & $\begin{array}{c}v^{++} \\
(\mathrm{MPa})\end{array}$ & $\begin{array}{c}\Delta^{\#} \\
(\mathbf{m m})\end{array}$ & $\begin{array}{c}\Delta /(\mathbf{H} / \mathbf{2}) \\
\left(\mathbf{x} 10^{-3}\right)\end{array}$ & $\begin{array}{c}\varepsilon_{\mathrm{smax}}^{\#} \\
(\mu \varepsilon)\end{array}$ & \\
\hline SS1 & 1081 & 950 & 300 & 3.17 & 190 & 0.88 & - & - & 49.5 & 26.3 & 18.3 & 17.5 & 80.5 & 40.8 & 0.72 & 3.54 & 3.72 & 1300 & $\mathrm{DT}^{* *}$ \\
\hline SS2 & 1087 & 950 & 305 & 3.11 & 190 & 1.72 & - & - & 49.5 & 26.3 & 18.3 & 17.5 & 140.2 & 70.5 & 1.22 & $\begin{array}{l}7.72 \\
(4.0)^{*}\end{array}$ & $\begin{array}{c}8.12 \\
(4.21)^{*}\end{array}$ & $\begin{array}{c}1346 \\
(1190)^{*}\end{array}$ & DT \\
\hline SS4 & 1067 & 950 & 307 & 3.10 & 190 & 0.30 & - & - & 49.5 & 25.5 & 19.6 & 18.0 & 72.6 & 36.8 & 0.63 & 9.27 & 9.76 & 3754 & DT \\
\hline SS5 & 1107 & 950 & 303 & 3.14 & 190 & 0.34 & - & - & 49.5 & 26.3 & 18.3 & 17.5 & 43.1 & 22.1 & 0.38 & 14.68 & 15.45 & 4535 & DT \\
\hline SS6 & 1058 & 950 & 305 & 3.11 & 190 & 2.42 & - & - & 49.5 & 25.5 & 19.6 & 18.0 & 143.2 & 72.1 & 1.24 & $\begin{array}{c}7.39 \\
(2.18)^{*}\end{array}$ & $\begin{array}{l}7.78 \\
(2.3)^{*}\end{array}$ & $\begin{array}{c}1363 \\
(717)\end{array}$ & DT \\
\hline SM1 & 375 & 2700 & 885 & 3.05 & 190 & 0.83 & - & - & 47.9 & 24.6 & 21.1 & 17.9 & 189.8 & 98.40 & 0.59 & $\begin{array}{c}9.65 \\
(6.4)^{*}\end{array}$ & $\begin{array}{c}3.58 \\
(2.36)\end{array}$ & $\begin{array}{r}1349 \\
(1287)^{*}\end{array}$ & DT \\
\hline SM1D & 539 & 2780 & 885 & 3.14 & 190 & 0.83 & - & - & 47.9 & 25.3 & 20.5 & 20.0 & 173.4 & 90.20 & 0.54 & $\begin{array}{l}10.36 \\
(5.4)^{*}\end{array}$ & $\begin{array}{c}3.73 \\
(1.93)^{*}\end{array}$ & $\begin{array}{c}1256 \\
(1149)\end{array}{ }^{*}$ & $\begin{array}{c}\text { Strut and Tie } \\
+ \\
\text { Shear Key }\end{array}$ \\
\hline SM2 & 490 & 2780 & 875 & 3.18 & 190 & 1.68 & - & - & 47.9 & 26.1 & 20.7 & 19.1 & 228.6 & 117.8 & 0.71 & $\begin{array}{c}6.71 \\
(4.5)^{*}\end{array}$ & $\begin{array}{c}2.41 \\
(1.62)^{*}\end{array}$ & $\begin{array}{c}770 \\
(742)\end{array}$ * & DT \\
\hline SM3 & 1409 & 2730 & 868 & 3.15 & 190 & 1.70 & 0.52 & - & 49.5 & 28.9 & 22.6 & 17.3 & 424.4 & 215.7 & 1.31 & 19.73 & 7.18 & 1810 & DT \\
\hline SM4 & 464 & 2780 & 880 & 3.16 & 190 & 0.33 & - & - & 47.9 & 26.1 & 19.3 & 18.5 & 130.8 & 68.5 & 0.41 & 10.23 & 3.68 & 1834 & DT \\
\hline SM5 & 527 & 2750 & 880 & 3.13 & 190 & 0.30 & - & - & 47.9 & 27.4 & 20.5 & 19.5 & 93.2 & 50.1 & 0.3 & $\begin{array}{c}74.1 \\
(38)\end{array}$ & $\begin{array}{c}26.6 \\
(9.6)^{*}\end{array}$ & $\begin{array}{c}7775 \\
(6377)\end{array} *$ & $\begin{array}{c}\text { Shear Key } \\
+ \\
\text { Strut and Tie } \\
\end{array}$ \\
\hline SM6 & 441 & 2780 & 880 & 3.16 & 190 & 0.84 & - & $\begin{array}{l}\text { No.15 } \\
@ 200\end{array}$ & 47.9 & 25.9 & 18.6 & 18.0 & 212.9 & 110 & 0.66 & 7.98 & 2.89 & 1180 & DT \\
\hline SL1 & 652 & 4300 & 1420 & 3.02 & 240 & 0.82 & - & - & 40.1 & 26.9 & 22.4 & 18.9 & 319.4 & 171 & 0.50 & 8.58 & 1.99 & 1050 & DT \\
\hline SL2 & 623 & 4300 & 1422 & 3.02 & 240 & 0.82 & - & - & 40.1 & 27.9 & 23.8 & 18.9 & 340.8 & 181.7 & 0.53 & 9.41 & 2.19 & 1268 & DT \\
\hline
\end{tabular}

$V_{\exp }=\frac{\text { Pexp }}{2}+V @ d$ from point load (due to self weight ${ }^{++} v=\frac{V_{\exp }}{b_{w} d}$

${ }^{\#}$ Values at ultimate failure

${ }^{*}$ Values at the initial breakdown of aggregate interlock capacity, ${ }^{* *}$ Diagonal tension failure 
Table 4-8: Summary of Longitudinal Strains $\varepsilon_{\mathrm{x}}$ and Shear strains $\gamma_{\mathrm{xy}}$ for the Initial Tests of the Masonry Beams

\begin{tabular}{|c|c|c|c|c|c|c|c|c|c|c|c|c|c|c|c|c|c|c|c|}
\hline \multirow{3}{*}{$\underset{\Xi}{\Xi}$} & \multicolumn{7}{|c|}{ Geometry and Reinforcement } & \multicolumn{12}{|c|}{ Experimental Observations of the First Test } \\
\hline & \multirow[b]{2}{*}{$\mathbf{a} / \mathbf{d}$} & \multirow{2}{*}{$\underset{(\mathrm{mm})}{\mathrm{d}}$} & \multirow{2}{*}{$\begin{array}{c}\mathbf{b}_{\mathrm{w}} \\
(\mathbf{m m})\end{array}$} & \multirow[b]{2}{*}{$\rho(\%)$} & \multirow{2}{*}{$\begin{array}{l}\text { Main } \\
\text { Steel } \\
\text { Type }\end{array}$} & \multirow{2}{*}{$\frac{A_{v} f_{y}}{b_{w} s}$} & \multirow{2}{*}{$\begin{array}{c}\text { Crack } \\
\text { contr } \\
\text { ol } \\
\text { steel }\end{array}$} & \multicolumn{6}{|c|}{ Ultimate Shear Strains, $\gamma_{\mathrm{xy}}\left(\mathrm{x} \mathrm{O}^{-3}\right)$} & \multicolumn{6}{|c|}{ Longitudinal Strains, $\varepsilon_{\mathrm{x}}\left(\mathrm{x}^{-3} 0^{-3}\right)$} \\
\hline & & & & & & & & $\gamma_{\mathrm{E} 1}$ & $\gamma_{\mathrm{E} 2}$ & $\gamma_{\mathrm{E} 3}$ & $\gamma_{w 1}$ & $\gamma_{w_{2}}$ & $\gamma_{\mathrm{w} 3}$ & $\varepsilon_{\mathrm{XE} 1}$ & $\varepsilon_{\mathrm{XE} 2}$ & $\varepsilon_{\mathrm{XE} 3}$ & $\varepsilon_{\mathrm{xw1}}$ & $\varepsilon_{\mathrm{xW} 2}$ & $\varepsilon_{\mathrm{xW} 3}$ \\
\hline SS1 & 3.17 & 300 & 190 & 0.88 & Steel & - & - & 1.0 & 0.19 & - & 0.57 & 0.20 & - & 0.48 & - & - & 0.44 & - & - \\
\hline SS2 & 3.11 & 305 & 190 & 1.72 & Steel & - & - & $\begin{array}{c}2.82 \\
(1.89)\end{array}{ }^{*}$ & $\begin{array}{c}4.16{ }^{*} \\
(2.59)^{*}\end{array}$ & - & $\begin{array}{c}3.82 \\
(0.43)\end{array}{ }^{*}$ & $\begin{array}{c}6.0 \\
(0.11)^{*}\end{array}$ & - & $\begin{array}{c}0.93 \\
(0.63)^{*}\end{array}$ & - & - & $\begin{array}{c}1.07 \\
(0.28)^{*}\end{array}$ & - & - \\
\hline SS3 & 3.11 & 305 & 190 & 1.72 & Steel & 0.67 & - & 5.44 & 5.17 & - & 7.8 & 7.1 & - & & - & - & 0.21 & - & - \\
\hline SS4 & 3.10 & 307 & 190 & 0.30 & Steel & - & - & 4.9 & 4.14 & - & 1.30 & 0.62 & - & 2.51 & - & - & 0.99 & - & - \\
\hline SS5 & 3.10 & 303 & 190 & 0.34 & GFRP & - & - & 10.5 & 8.10 & - & 3.12 & 1.09 & - & 4.35 & - & - & 2.39 & - & - \\
\hline SS6 & 3.11 & 305 & 190 & 2.42 & Steel & - & - & $\begin{array}{c}2.34 \\
(0.31)\end{array}{ }^{*}$ & $\begin{array}{r}3.75 \\
(0.15)^{*} \\
\end{array}$ & - & $\begin{array}{c}6.11 \\
(0.20)\end{array}{ }^{*}$ & $\begin{array}{c}8.79 \\
(0.03)^{*} \\
\end{array}$ & - & $\begin{array}{c}0.42 \\
(0.11)^{*}\end{array}$ & - & - & $\begin{array}{c}0.99 \\
(0.11)^{*}\end{array}$ & - & - \\
\hline SM1 & 3.05 & 885 & 190 & 0.83 & Steel & - & - & $\begin{array}{c}0.23 \\
(0.20)\end{array}$ * & $\begin{array}{c}0.17 \\
(0.12)^{*}\end{array}$ & $\begin{array}{c}0.0 \\
(0.0)^{*}\end{array}$ & $\begin{array}{c}2.71 \\
(0.98)\end{array}$ & $\begin{array}{c}3.29 \\
(1.12)^{*}\end{array}$ & $\begin{array}{r}2.62 \\
(0.01)\end{array}$ & $\begin{array}{c}0.33 \\
(0.28)^{*}\end{array}$ & $\begin{array}{c}0.02 \\
(0.02)\end{array}{ }^{*}$ & $\begin{array}{c}0.02 \\
(0.02)^{*}\end{array}$ & $\begin{array}{c}2.04 \\
(0.78)\end{array}{ }^{*}$ & $\begin{array}{c}-0.07 \\
(0.02)\end{array}$ & $\begin{array}{l}-0.09 \\
(0.0)\end{array}$ \\
\hline SM1D & 3.14 & 885 & 190 & 0.83 & Steel & - & - & $\begin{array}{c}0.59 \\
(0.0)^{*}\end{array}$ & $\begin{array}{r}0.67 \\
(0.11)^{*} \\
\end{array}$ & $\begin{array}{r}2.72 \\
(0.06) \\
\end{array}$ & $\begin{array}{c}0.49 \\
(0.36)\end{array}{ }^{*}$ & $\begin{array}{r}0.49 \\
(0.28) \\
\end{array}$ & $\begin{array}{c}0.10 \\
(0.01)^{*}\end{array}$ & $\begin{array}{c}2.0 \\
(0.54) \\
\end{array}$ & $\begin{array}{l}-0.12 \\
(0.0)^{*}\end{array}$ & $\begin{array}{c}-0.11 \\
(0.01)^{*} \\
\end{array}$ & $\begin{array}{c}0.38 \\
(0.26)^{*}\end{array}$ & $\begin{array}{r}0.12 \\
(0.11) \\
\end{array}$ & $\begin{array}{c}0 \\
(0.0)^{*}\end{array}$ \\
\hline SM2 & 3.18 & 875 & 190 & 1.68 & Steel & - & - & $\begin{array}{c}0.13 \\
(0.11)\end{array}{ }^{*}$ & $\begin{array}{c}0.10 \\
(0.07)\end{array}$ & $\begin{array}{c}0.07 \\
(0.07)\end{array}$ & $\begin{array}{c}1.27 \\
(0.26)\end{array}{ }^{*}$ & $\begin{array}{c}1.7 \\
(0.26)^{*}\end{array}$ & $\begin{array}{c}1.17 \\
(0.07)\end{array}$ & $\begin{array}{c}0.06 \\
(0.05) \\
\end{array}$ & $\begin{array}{c}0.04 \\
(0.03) \\
\end{array}$ & $\begin{array}{c}-0.05 \\
(-0.05) \\
\end{array}$ & $\begin{array}{c}0.83 \\
(0.17) \\
\end{array}$ & $\begin{array}{c}-0.14 \\
(-0.03)\end{array}$ & $\begin{array}{c}-0.12 \\
(-0.04)\end{array}$ \\
\hline SM3 & 3.15 & 868 & 190 & 1.70 & Steel & 0.52 & - & 2.77 & 0.41 & 3.26 & 1.81 & 3.49 & 1.12 & 0.24 & -0.16 & 1.5 & 1.03 & 0.06 & -0.21 \\
\hline SM4 & 3.16 & 880 & 190 & 0.33 & Steel & - & - & 0.74 & 0.76 & 0.06 & 1.28 & 1.31 & 0.03 & 0.83 & 0.56 & 0.01 & 1.24 & 0 & 0 \\
\hline SM5 & 3.13 & 880 & 190 & 0.30 & GFRP & - & - & $\begin{array}{c}22.78{ }^{*} \\
(7.82)\end{array}$ & $\begin{array}{c}19.89 \\
(8.31)^{*} \\
\end{array}$ & $\begin{array}{c}18.75 \\
(3.39)^{*} \\
\end{array}$ & $\begin{array}{c}7.93 \\
(5.27)\end{array}{ }^{*}$ & $\begin{array}{c}11.4 \\
(6.21)\end{array}{ }^{*}$ & $\begin{array}{c}2.14 \\
(0.08)\end{array}{ }^{*}$ & $\begin{array}{c}7.75 \\
(5.35)\end{array}{ }^{*}$ & $\begin{array}{c}-0.11 \\
(-0.1)^{*}\end{array}$ & $\begin{array}{c}-0.12 \\
(-0.1)\end{array}{ }^{*}$ & $\begin{array}{c}5.48 \\
(2.94)\end{array}{ }^{*}$ & $\begin{array}{c}-0.11 \\
(0.08)\end{array}{ }^{*}$ & $\begin{array}{c}-0.10 \\
(0.06)\end{array}$ * \\
\hline SM6 & 3.16 & 880 & 190 & 0.84 & Steel & - & $\begin{array}{l}\text { M15 } \\
@ 200\end{array}$ & 1.0 & 1.1 & 0 & 0.55 & 0.57 & 0.11 & 0.75 & 0.04 & 0 & 0.47 & 0.04 & 0 \\
\hline SL1 & 3.02 & 1420 & 240 & 0.82 & Steel & - & - & 0.13 & 0.26 & 0.07 & 0.22 & 0.12 & 0.02 & 0.34 & 0.043 & 0.006 & 0.29 & 0.11 & 0.01 \\
\hline SL2 & 3.02 & 1422 & 240 & 0.82 & Steel & - & - & 0.21 & 0.16 & 0.06 & 0.27 & 0.23 & 0.02 & 0.39 & 0.13 & -0.01 & 0.38 & 0.04 & 0.01 \\
\hline
\end{tabular}

${ }^{\#}$ Values at ultimate failure

*Values at the breakdown of aggregate interlock capacity 


\subsubsection{Results of the Repeated Tests}

The damage in the beams SM3 and SM5 following the initial tests was such that it was not possible to clamp the failed sides to conduct the repeated tests. The majority of beams (except for beams SS3R, SM1R, SMIDR, SM2R and SM4R) in the repeated tests failed in an obvious diagonal tension failure, either by breakdown of aggregate interlock (such as SS2R, SS4R, SS5R, SS6R, SL1R and SL2R) or breakdown of shear keys (SS1R). Specimens SMIDR and SM2R failed in clear strut and tie modes of failure. The breakdown of beam action in theses beams was followed by engagement of shallow struts extending from the point load to the support. SMIDR failed due to splitting at the level of the main steel while SM2R suffered anchorage failure. Both failures were brittle. Specimens SMIR and SM4R failed due to combinations of strut and tie failures and breakdowns of shear keys. The test results of the repeated tests are presented in Table 4-9. For the repeated tests the following key results were

reported: $\mathrm{P}_{\exp }, \mathrm{V}_{\exp }, \Delta, \Delta / 0.5 \mathrm{~L}$ and $\gamma$. The crack patterns and widths of these beams throughout the loading stages along with other test results are presented in Appendix A. 
Table 4-9: Summary of Experimental Observations for the Repeated Tests of the Masonry Beams

\begin{tabular}{|c|c|c|c|c|c|c|c|c|c|c|c|c|c|c|c|c|c|c|}
\hline \multirow[b]{2}{*}{ 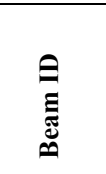 } & \multirow[b]{2}{*}{$\begin{array}{l}\text { Age } \\
\text { (Days) }\end{array}$} & \multicolumn{7}{|c|}{ Geometry and Reinforcement } & \multicolumn{9}{|c|}{ Material Properties and Experimental Observations } & \multirow[b]{2}{*}{ Failure Mode } \\
\hline & & $\mathbf{a} / \mathbf{d}$ & $\underset{(\mathbf{m m})}{\mathrm{d}}$ & $\begin{array}{c}\mathbf{b}_{\mathrm{w}} \\
(\mathbf{m m})\end{array}$ & $\begin{array}{l}\text { Main } \\
\text { Steel } \\
\text { Type }\end{array}$ & $\begin{array}{c}\rho \\
(\%)\end{array}$ & $\frac{A_{v} f_{y}}{b_{w} s}$ & $\begin{array}{c}\text { Crack } \\
\text { control } \\
\text { steel }\end{array}$ & $\begin{array}{c}\mathrm{f}_{\mathrm{m}}^{\prime} \\
\text { (MPa) }\end{array}$ & $\begin{array}{l}P_{\text {exp }} \\
(\mathbf{k N})\end{array}$ & $\begin{array}{l}\mathbf{V}_{\text {exp }}^{+} \\
(\mathbf{k N})\end{array}$ & $\begin{array}{c}v^{++} \\
\text {(MPa) }\end{array}$ & $\underset{(\mathbf{m m})}{\Delta}$ & $\begin{array}{l}\Delta /(\mathbf{L} / 2) \\
\left(\mathbf{x 1 0 ^ { - 3 }}\right)\end{array}$ & $\gamma_{1}$ & $\gamma_{2}$ & $\gamma_{3}$ & \\
\hline SS1R & 1081 & 3.17 & 300 & 190 & Steel & 0.88 & - & - & 17.5 & 98.4 & 49.7 & 0.87 & $\begin{array}{c}7.3 \\
(4.8)^{*} \\
\end{array}$ & $\begin{array}{c}7.68 \\
(5.1)^{*} \\
\end{array}$ & $\begin{array}{r}4.51 \\
(0.93)^{*} \\
\end{array}$ & $\begin{array}{c}4.99 \\
(0.03)^{*} \\
\end{array}$ & - & $\mathrm{DT}^{! !}+$Shear Key \\
\hline $\mathrm{SS} 2 \mathrm{R}$ & 1089 & 3.11 & 305 & 190 & Steel & 1.72 & - & - & 17.5 & 130.2 & 65.6 & 1.22 & 8.76 & 9.2 & 5.7 & 10.2 & - & DT \\
\hline SS3R & 1094 & 3.11 & 305 & 190 & Steel & 1.72 & 0.67 & - & 17.5 & 189 & 95 & 1.76 & 8.54 & - & - & - & - & $\mathrm{F}^{\#}$ \\
\hline SS4R & 1068 & 3.10 & 307 & 190 & Steel & 0.30 & - & - & 18 & 74.6 & 36.7 & 0.63 & 8.54 & 9 & 4.58 & 3.45 & - & DT \\
\hline SS5R & 1107 & 3.10 & 303 & 190 & GFRP & 0.34 & - & - & 17.5 & 49 & 25.0 & 0.63 & 14.25 & 15 & 7.38 & 4.38 & - & DT \\
\hline SS6R & 1059 & 3.11 & 305 & 190 & Steel & 2.42 & - & - & 18 & 151.8 & 76.4 & 0.63 & 7.64 & 8.5 & 5.78 & 8.13 & - & DT \\
\hline SM1R & 395 & 3.05 & 885 & 190 & Steel & 0.83 & - & - & 17.9 & 231.9 & 119.5 & 0.71 & 12.56 & 4.65 & 3.45 & 4.22 & 2.95 & $\begin{array}{c}\text { Strut and Tie" } \\
+ \text { Shear Key }\end{array}$ \\
\hline SM1DR & 541 & 3.14 & 885 & 190 & Steel & 0.83 & - & - & 20 & 287.1 & 147.1 & 0.87 & $\begin{array}{c}10.7 \\
(5.1)^{*} \\
\end{array}$ & $\begin{array}{c}3.85 \\
(1.83)^{*} \\
\end{array}$ & $\begin{array}{c}3.25 \\
(0.57)^{*} \\
\end{array}$ & $\begin{array}{c}3.67 \\
(0.54)^{*} \\
\end{array}$ & $\begin{array}{c}5.36 \\
(0.06)^{*} \\
\end{array}$ & Strut and Tie ${ }^{* *}$ \\
\hline $\mathrm{SM} 2 \mathrm{R}$ & 493 & 3.18 & 875 & 190 & Steel & 1.68 & - & - & 19.1 & 245.6 & 117.8 & 0.71 & - & - & - & - & - & Strut and Tie ${ }^{* * *}$ \\
\hline SM4R & 466 & 3.16 & 880 & 190 & Steel & 0.33 & - & - & 18.5 & 168.5 & 87.8 & 0.52 & $\begin{array}{c}18.5 \\
(11.5)^{*} \\
\end{array}$ & $\begin{array}{r}6.65 \\
(4.14)^{*} \\
\end{array}$ & $\begin{array}{r}4.77 \\
(1.32)^{*} \\
\end{array}$ & $\begin{array}{c}2.8 \\
(1.68)^{*}\end{array}$ & $\begin{array}{c}7.45 \\
(0.77)^{*} \\
\end{array}$ & $\begin{array}{c}\text { Strut and Tie }^{* *} \\
+ \text { Shear Key } \\
\end{array}$ \\
\hline SM6R & 442 & 3.16 & 880 & 190 & Steel & 0.84 & - & $\begin{array}{c}\text { No.15@ } \\
200\end{array}$ & 18 & 207.9 & 107.5 & 0.64 & 7.44 & 2.68 & 2.71 & 2.84 & 2.95 & DT \\
\hline SL1R & 654 & 3.02 & 1420 & 240 & Steel & 0.82 & - & - & 18.9 & 336.2 & 179.4 & 0.53 & 9.62 & 2.24 & 0.17 . & 0.11 & 0.02 & DT \\
\hline SL2R & 630 & 3.02 & 1422 & 240 & Steel & 0.82 & - & - & 18.9 & 378 & 200.3 & 0.59 & 10.11 & 2.35 & 0.35 & 0.23 & 0.09 & DT \\
\hline
\end{tabular}

${ }^{+} V_{\exp }=\frac{\text { Pexp }}{2}+\mathrm{V} @ \mathrm{~d}$ frompointload $\left(\right.$ dueto self weigh), ${ }^{++} v=\frac{V_{\exp }}{b_{\mathrm{w}} \mathrm{d}}$

" Diagonal tension failure, ${ }^{\#}$ Flexural Failure

${ }^{*}$ Values at the breakdown of aggregate interlock

" Strut and Tie failure by crushing of the compression zone

** Strut and Tie failure by splitting at the level of steel

${ }^{* * *}$ Strut and Tie failure by anchorage failure 


\section{CHAPTER 5: SIZE EFFECT IN REINFORCED MASONRY}

\subsection{General}

This chapter discusses the results of the experimental program described in chapters 3 and 4 in the context of the size effect in shear is the main theme. The objective of the chapter is to answer key questions raised in chapters 1 and 2. The first question is "Is the size effect real and significant in reinforced masonry"; and will be answered by analyzing the results a series of small, medium and large reinforced beams reinforced with the same main reinforcement ratio ( $\rho=0.83 \%$ ) but with three different effective depths $(300 \mathrm{~mm}, 885 \mathrm{~mm}$ to $1420 \mathrm{~mm}$ ). The existence of size effect in reinforced masonry will also be explored in additional series of geometrically identical medium and small beams: one series reinforced with conventional steel ( $\rho=1.68 \%$ ) with two effective depths $(305 \mathrm{~mm}$ and $875 \mathrm{~mm}$ ), one series reinforced with dywidag bars $(\rho=0.32 \%)$ with two effective depths $(307 \mathrm{~mm}$ and $880 \mathrm{~mm})$ and one series reinforced with GFRP bars $(\rho=0.32 \%$ ) with two effective depths $(307 \mathrm{~mm}$ and $880 \mathrm{~mm})$. Furthermore, the effects of stirrups and crack control reinforcement on the size effect in reinforced masonry beams will be discussed.

The second question that will be answered is "Do masonry design codes give accurate predictions of the failure shear stress of large masonry beams?" Two masonry design codes will be considered in this regards: TMS 402 (US) and CSA S304.1 (Canada). A third set of shear design provisions was chosen -the general method of shear design from the CSA A23.3-04 code for reinforced concrete. Suggestions to improve the predictive ability of the Canadian masonry code to account for size effect will be provided in this section. 
The third question that will be addressed in this chapter is "what are the shear transfer mechanisms in reinforced masonry?" To explore the shear transfer mechanisms in reinforced masonry, the results of four beams instrumented with strain gauges in their uncracked compression zone at the heads of dominant shear cracks will be analyzed to measure the shear carried in the compression zone.

\subsection{Size Effect in RM Beam Series with $\rho=0.83 \%$}

The existence of the size effect in reinforced masonry can be investigated by studying specimens SS1, SM1, SMD1, SL1 and SL2. These beams have similar values of a/d, $\rho$ and $\mathrm{f}_{\mathrm{m}}$, but they have different depths.

\subsubsection{Failure Mechanisms and Load-Deflection Behaviour}

All specimens in this series exhibited an obvious diagonal shear failure (breakdown of beam action) before reaching their flexural capacity for the initial tests. The failures for SS1, SL1, and SL2 were very brittle due to the breakdown of beam action mechanism, while in SM1 and SM1D initial breakdowns of aggregate interlock were followed by slight engagements of arch action leading to failure loads higher (by $4 \%$ and $9 \%$ respectively) than those which caused the breakdown of aggregate interlock. Thus SM1 and SM1D beams exhibited large deflections prior to failure. In SM1 the initial breakdown of beam action in the west span was followed by the formation of strut and tie action. The final failure of SM1 occurred due to the breakdown of aggregate interlock in the east span. In SM1D the initial breakdown of beam action and the final

failure occurred in the east span. In both specimens SM1 and SM1D the initial breakdown of 
beam action were also followed by shear keys between masonry units that permitted some shear transfer by interlocking of adjacent blocks. No significant post-peak response was noticed for all beams. The load vs. mid-span deflection curves are presented in Figure 5-1.

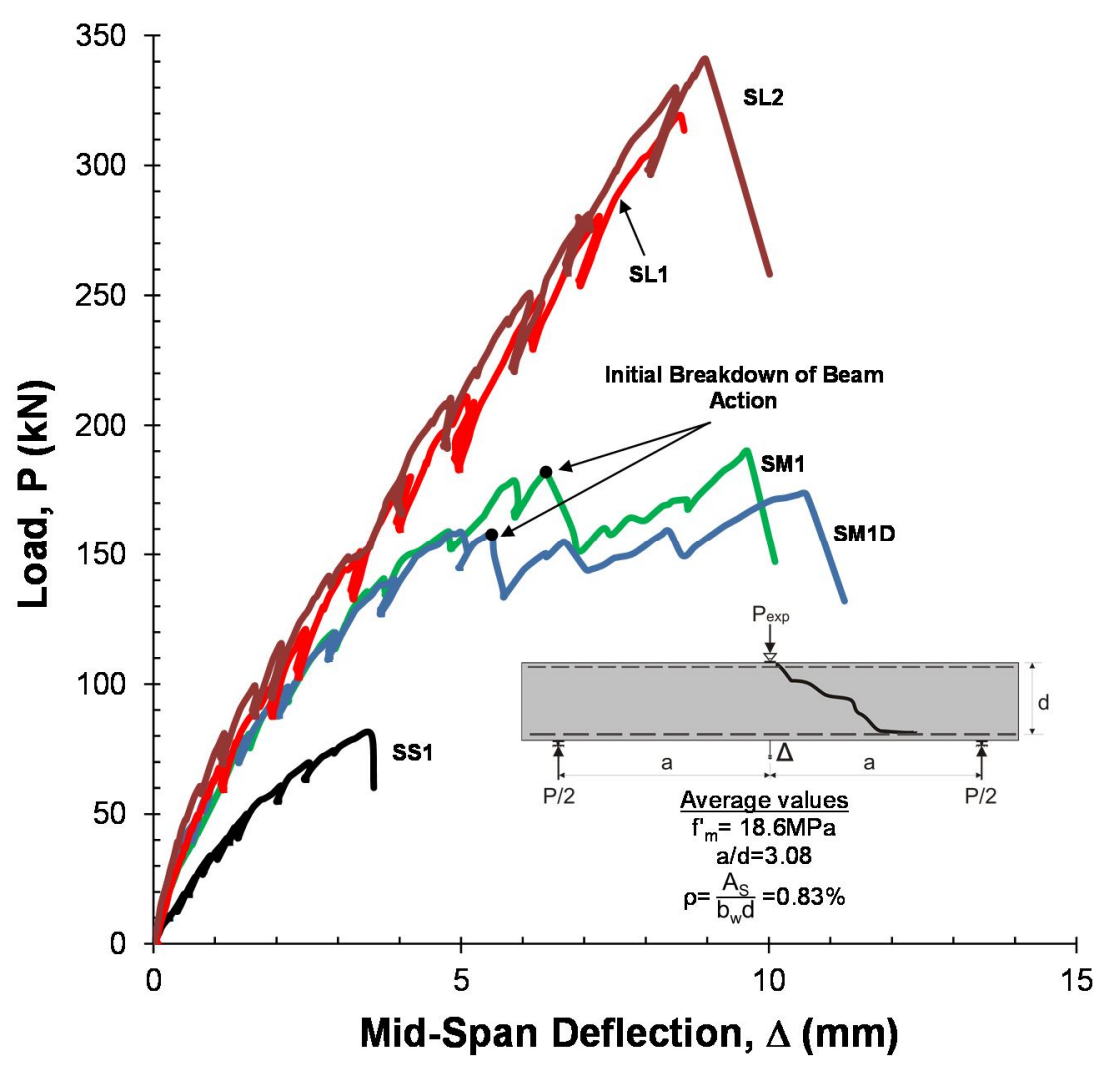

Figure 5-1: Load-Deflections Curves of Specimens SS1, SM1, SM1D, SL1 and SL2

It is clearly shown that both the large and the small specimens exhibited very brittle behaviour, though the large specimens were more brittle than the small specimen. Figure 5-2 shows that the relative displacements at failure in large specimens were less than half of those in the small specimen. The small specimen SS1 failed at an average deflection of 1/490th of the span, while the large specimen SL2 failed at an average deflection of only 1/1150th of the span. Also, reflecting the lower failure shear stresses, measured shear strains reduced considerably as the depth increases (see Figure 5-3). 


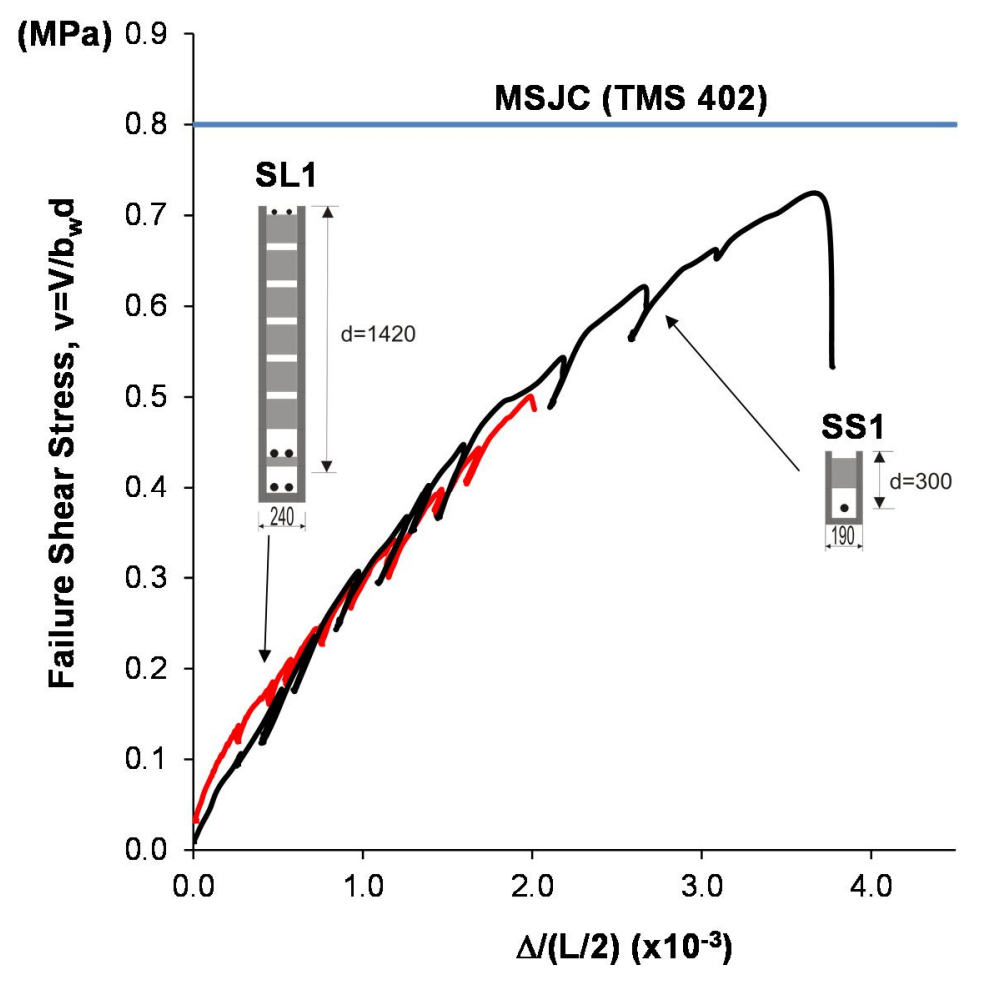

Figure 5-2: Relative Deflections of Specimens SS1 and SL1

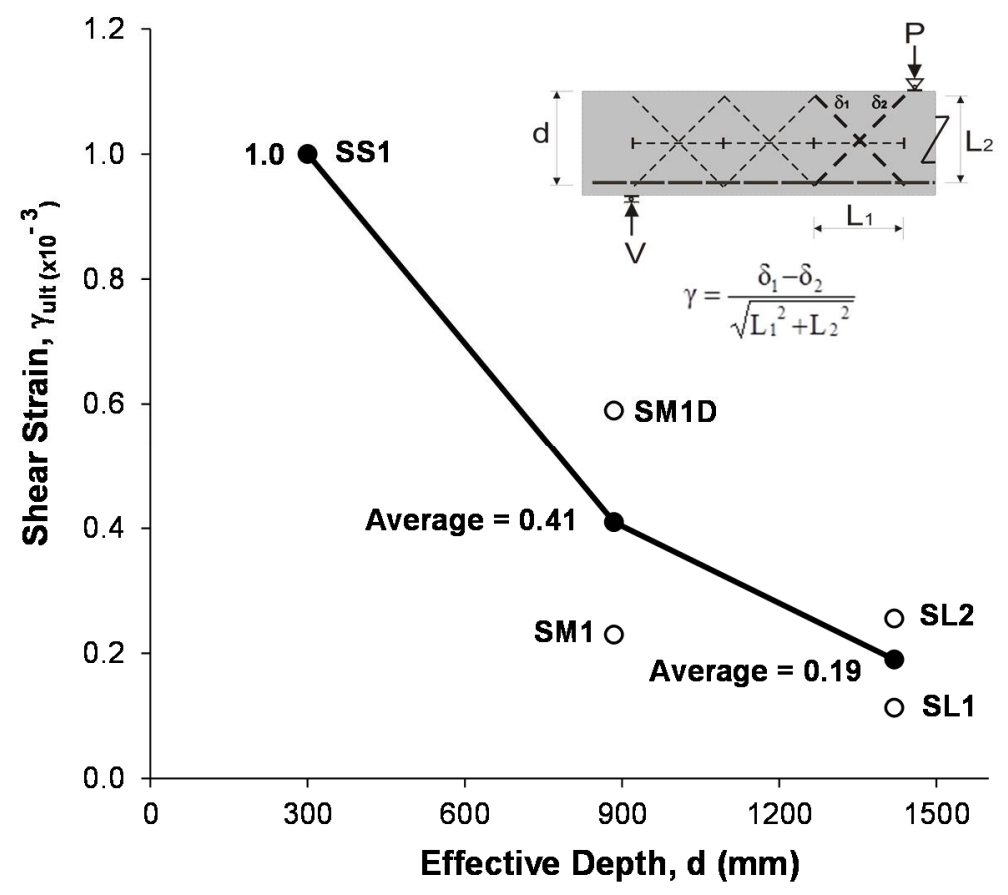

Figure 5-3: Ultimate Shear Strain in first failed Sides of Specimens SS1, SM1, SM1D, SL1 and SL2 


\subsubsection{The Progression of Shear Failure in RMB Series with $\rho=0.83 \%$}

\section{Specimen SS1}

The progression of shear failure in specimen SS1 is presented in Figure 5-4. At early stages of loading, flexural cracks began to appear in the mortar head joints in the bottom course at the mid span of the beam. With more load, flexural-shear cracks (far from the point load) appeared through the head joints and extended up toward the second course in each span. As the load increased, the crack close to the point load in the east side of the beam (left side in Figure 5-4) travelled horizontally along the bed joint and diagonally towards the load. This was followed by the far flexural-shear crack in the east side reaching the second course and turning slightly toward the load joint forming a clear masonry tooth. After reaching $88 \%$ of the failure load, the far flexural-shear crack of the masonry tooth (the dominant crack) travelled horizontally through the bed joint towards the point load. One difference between reinforced masonry and reinforced concrete is that this crack would propagate diagonally towards the point load if it was in reinforced concrete. The existence of the bed joints in reinforced masonry creates planes of weakness which will be sought by cracks to travel through. Shortly after the peak load was reached, the dominant crack in the east side of the beam propagated horizontally through the bed joint connecting to the diagonal portion of the crack close to the point load and diagonally backwards towards the support. The failure happened due to breakdown of aggregate interlock through the jagged diagonal crack. This can be identified by the extensive increase in the width of the failure crack after failure $(\mathrm{load}=80.5 \mathrm{kN})$ compared to that at the last load stage before failure $($ load $=70 \mathrm{kN})$. Reflecting the extensive increase in the crack width, Figure 5-5 shows that the shear strains in the east side (the failure side) increased significantly after the failure load while the shear strains in the west side exhibited only marginal increases. 


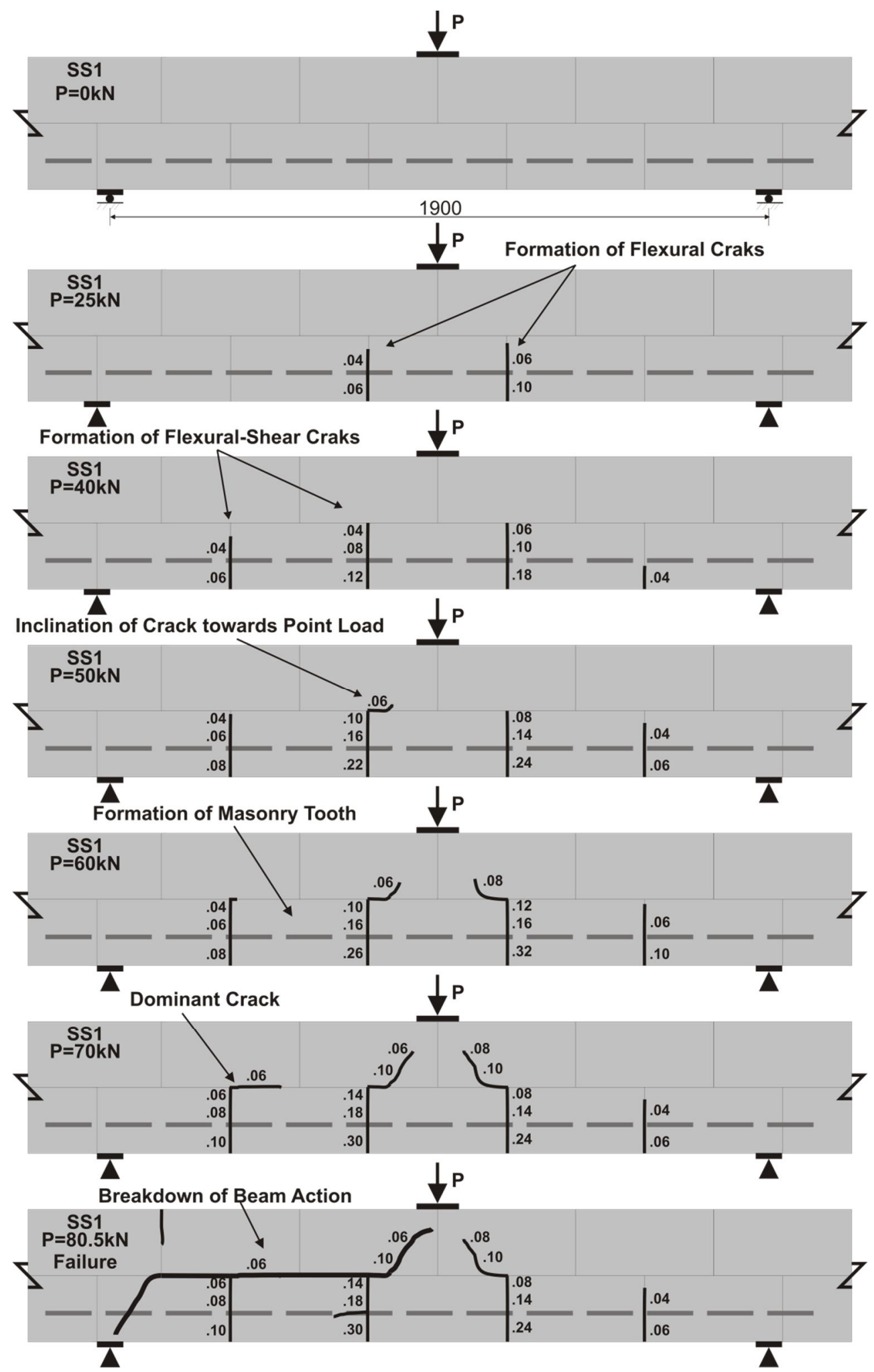

Figure 5-4: Crack Patterns for Specimen SS1 


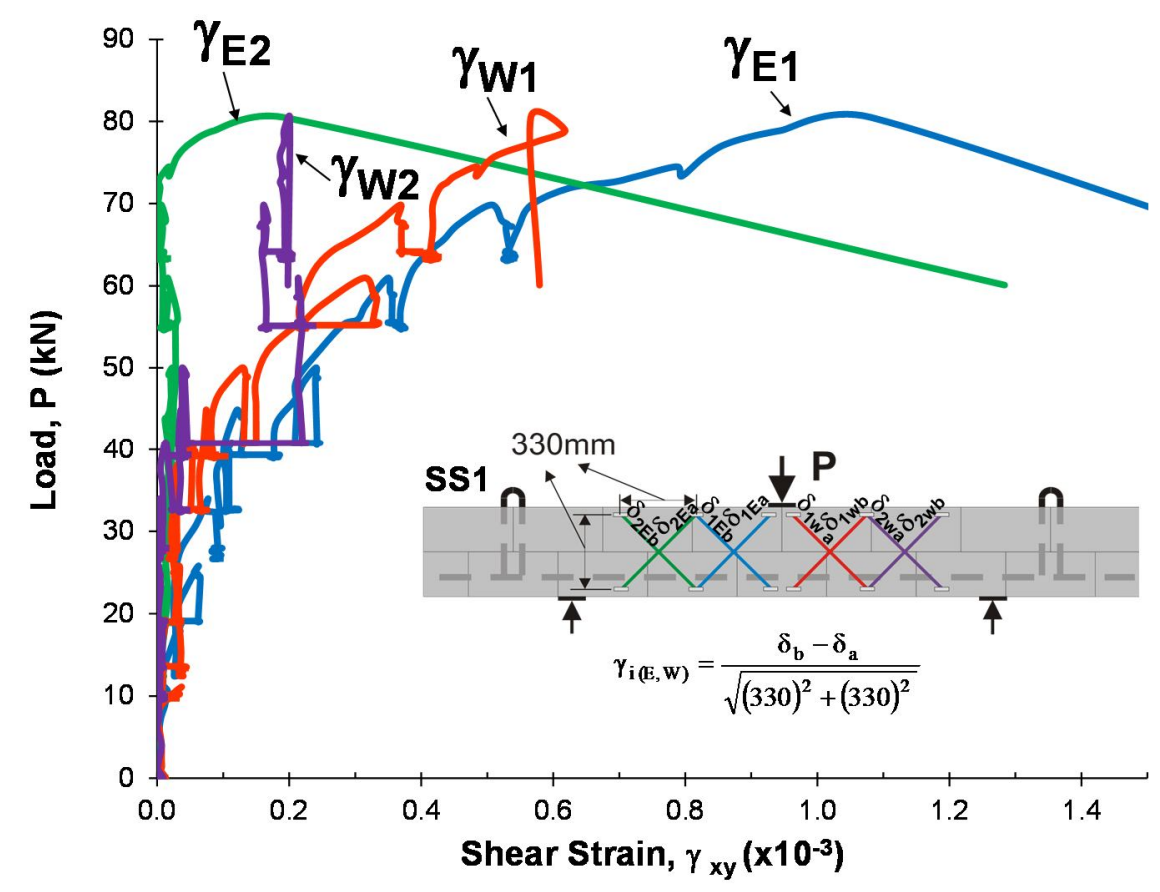

Figure 5-5: Shear Strains in Specimen SS1

\section{Specimen SM1}

In specimen SM1, flexural cracks appeared at early load stages in the head joints of the bottom course. This was followed by formation of shear flexural-shear cracks in both shear spans. At a load of $70 \%$ of the failure load, these cracks reached the middle of the third course (mid-depth of the beam) forming masonry teeth in both shear spans. At a load of $182 \mathrm{kN}$ (equivalent to $96 \%$ of the failure load), the dominant flexural shear crack in the west shear span started to widen noticeably and extended diagonally to the top course, and backward towards the western support through the bottom bed joint. This phenomenon was identified as an initial breakdown of beam action since it was associated with a significant drop in the applied load accompanied by a sudden significant increase in the shear strains measured in the west span (see Figure 5-7). 


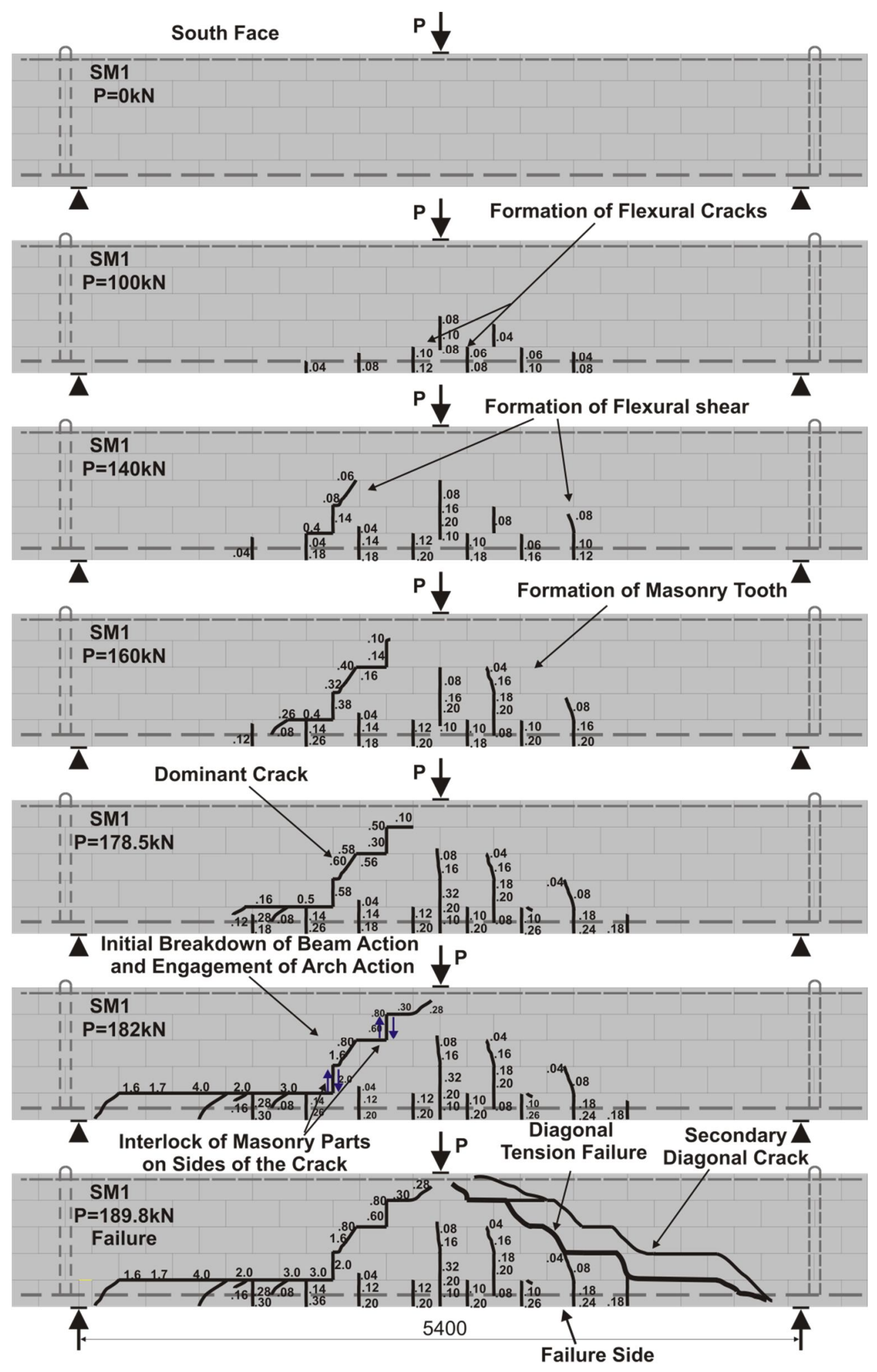

Figure 5-6: Crack Patterns for Specimen SM1 


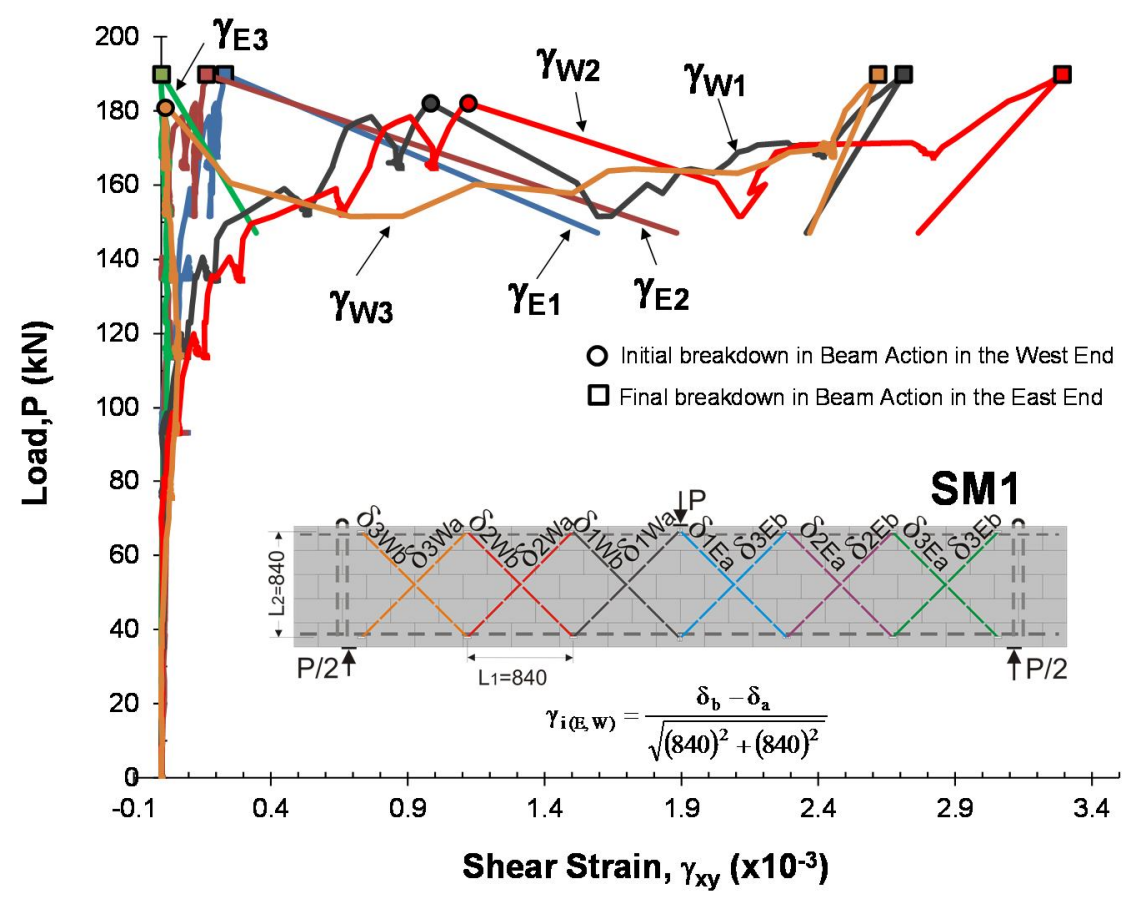

Figure 5-7: Shear Strains in Specimen SS1

The initial breakdown of beam action in the west shear span was followed by engagement of arch action and by formation of shear keys permitting shear transfer by interlocking of adjacent blocks as shown in Figure 5-6. The engagement of arch action in the west shear span is confirmed by Figure 5-8 which shows that the steel strain at the quarter span increased significantly and became almost equal to the steel strain at the mid span of the beam. Suddenly after reaching the failure load of $189.9 \mathrm{kN}$ (only $4 \%$ higher than the load caused the initial breakdown of beam action in the west span), one of the flexural shear cracks in the east shear span propagated diagonally towards the loading point and backwards towards the support leading through the bottom bed joint along the length of the reinforcement. This failure is a clear diagonal tension failure similar to the typical shear failure of reinforced concrete beams. Also a secondary diagonal crack formed simultaneously with the final failure of SM1. The horizontal 
cracking at the level of the reinforcement and the formation of the secondary crack in SM1 were post-peak phenomena (see Figure 5-4).

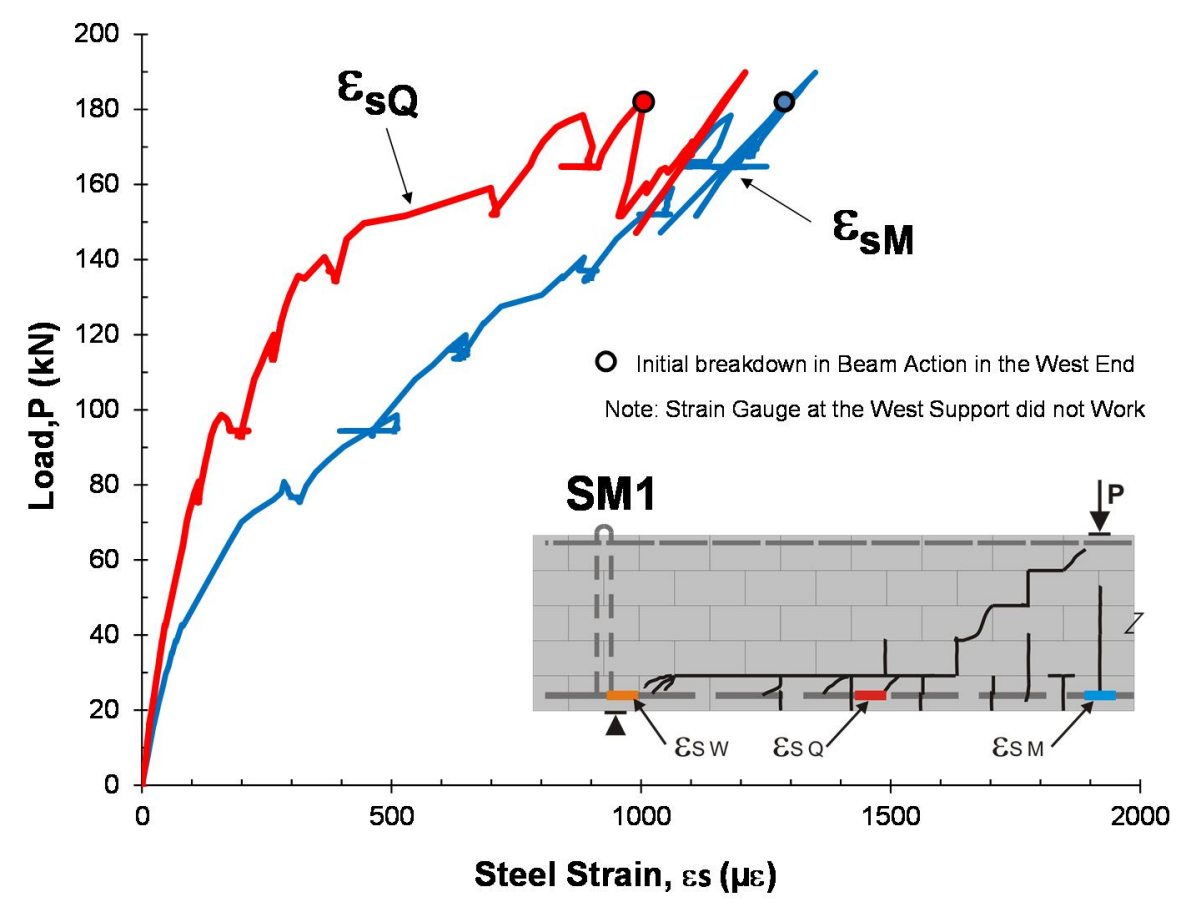

Figure 5-8: Steel strains in the West Span of Specimen SM1

\section{Specimen SM1D}

The cracking behavior of specimen SM1D was similar to SM1 until the formation of the masonry teeth as shown in Figure 5-9. At a load of $160 \mathrm{kN}$ (corresponding to $92 \%$ of the failure load) the dominant crack in the east span (left side in Figure 5-9) propagated upward diagonally toward the loading point and backwards horizontally through the bottom bed joint. The propagation of the crack was associated with a significant drop in the applied load and noticeable increases in mid-span deflection and the shear strains measured in the east span as shown in Figures 5-10 and 5-11. This marked an initial breakdown of beam action which was followed by a slight engagement of arch action and the formation of shear keys. At a load of 173.4 specimens SM1D failed in a combination of strut and tie failure (crushing of the compression zone) and the breakdown of the additional interlocking across the crack (shear keys). 


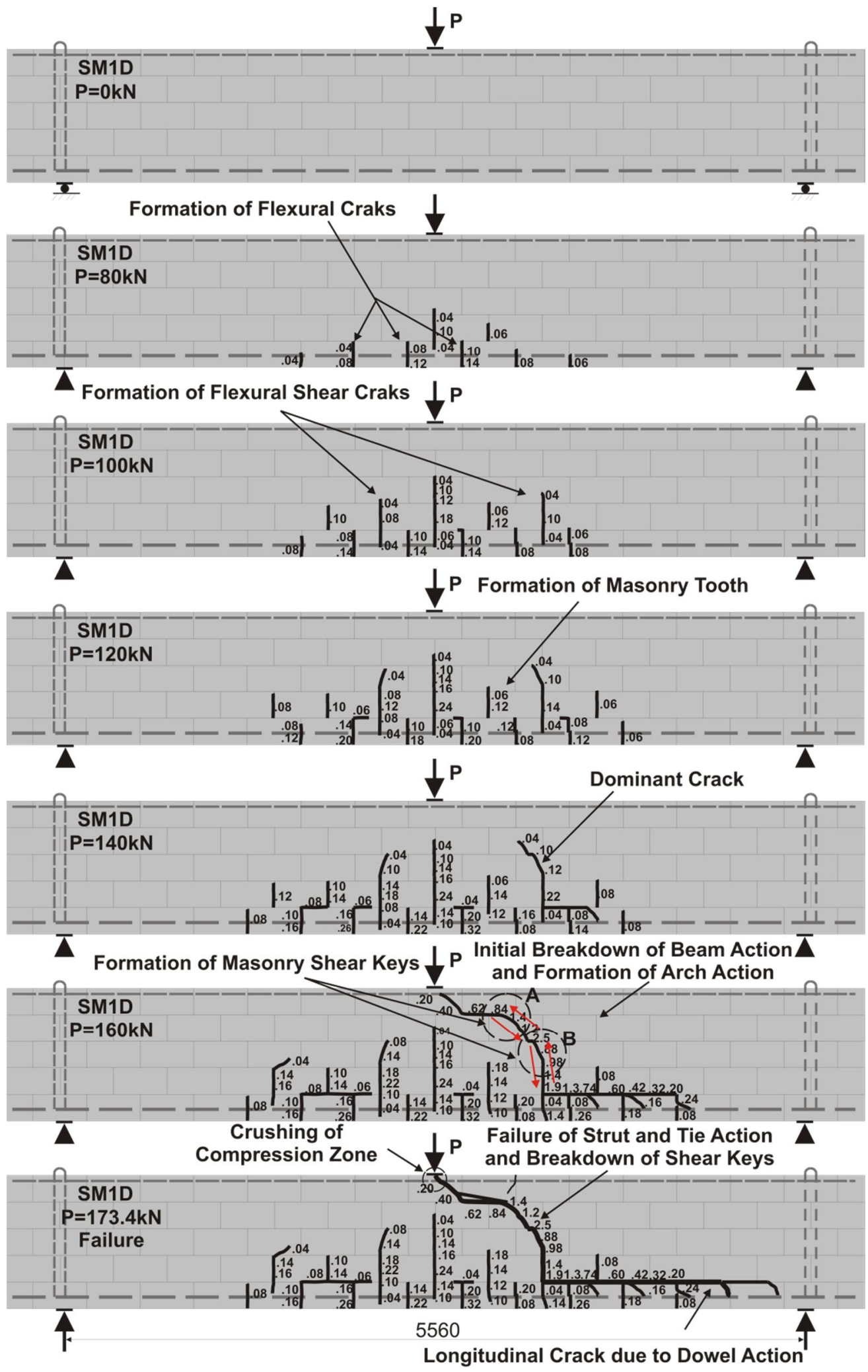

Figure 5-9: Crack Patterns for Specimen SM1D 


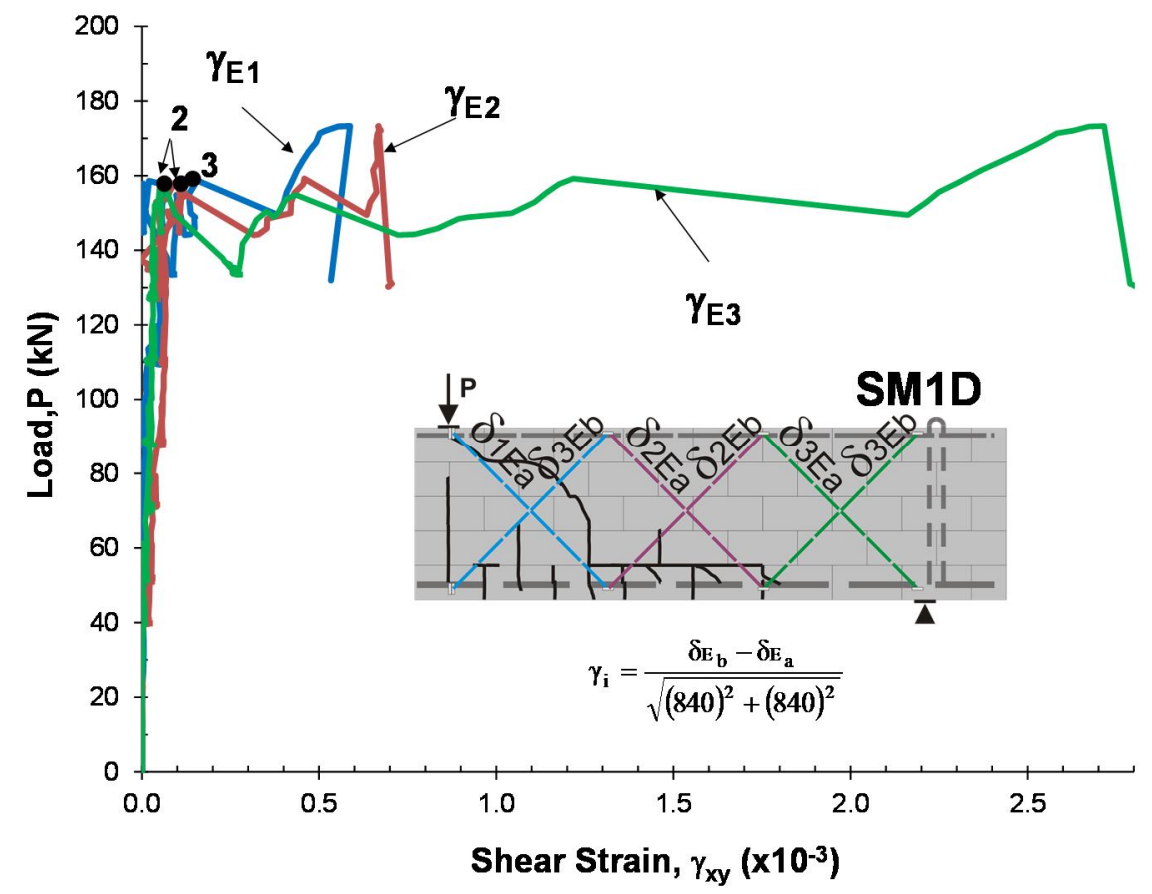

Figure 5-10: Shear Strains Measured in the East Span of Specimen SM1D

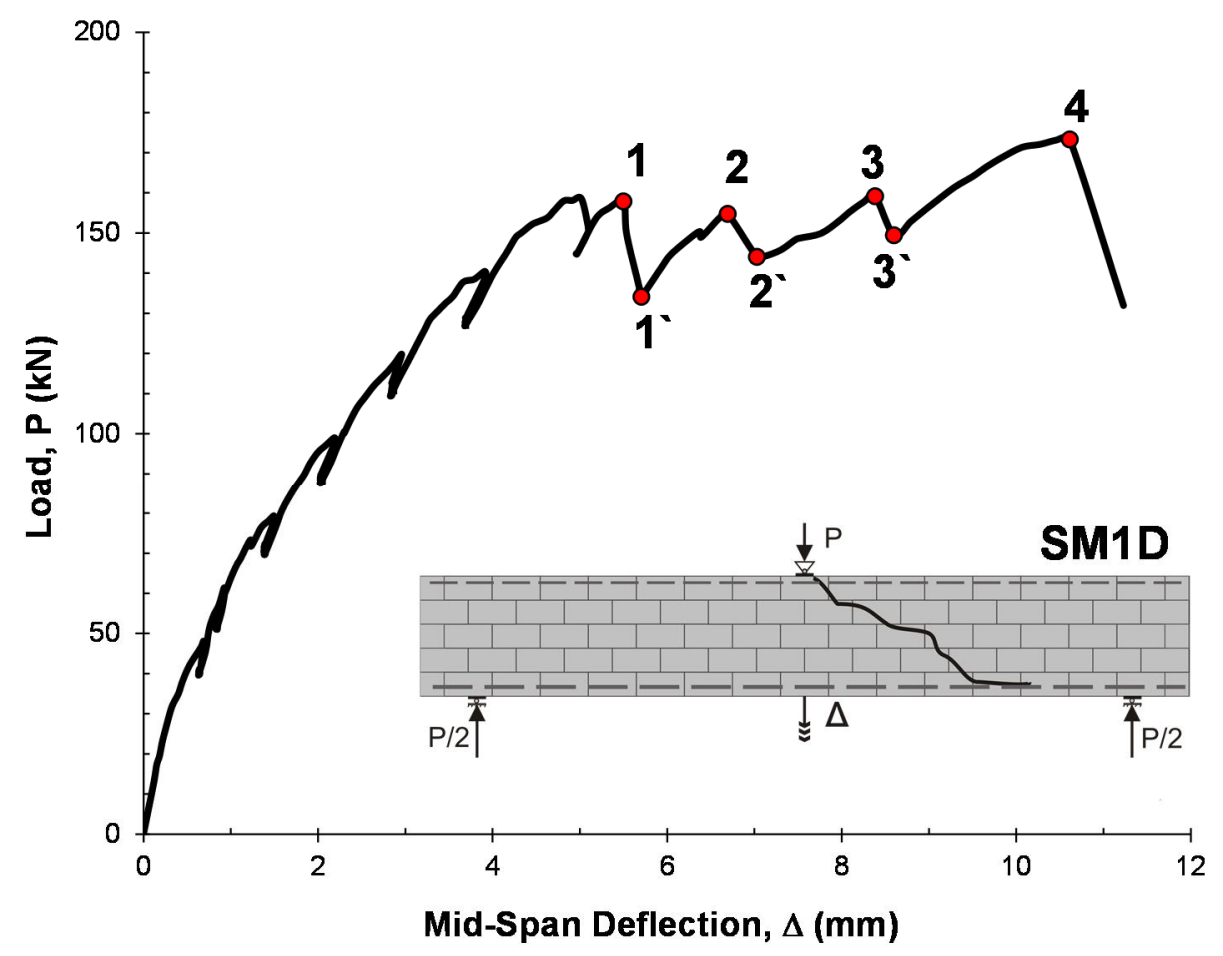

Figure 5-11: Load-Deflection of Specimen SM1D 
The possibility of arch action engagement in the east span of specimen SM1D was depicted in Figure 5-12. It is clear that the formed strut is cut by the diagonal crack. To have a strut that is not cut by the diagonal crack; its effective compression depth should be $10 \mathrm{~mm}$. Such strut is not an efficient strut and cannot considerably increase the shear strength of the beam beyond the breakdown of beam action. The cracking of SM1D was videotaped and figures from the video of the dominant crack are presented in Figure 5-13. This figure shows that after the initial breakdown of the beam action interlock mechanism across the crack was still active in two locations: the interlocking of the adjacent blocks at the shear key (Detail A in Figure 5-9 and 513) and some remaining interlock across the crack (Detail B in Figure 5-9 and 5-13).

Furthermore, while it is well acknowledged in reinforced concrete that no more interlock mechanisms is maintained by the diagonal shear crack when arch action is engaged, this is not the case in specimen SM1D as some interlocks were noticed between the masonry parts on the sides of the crack at these two locations.

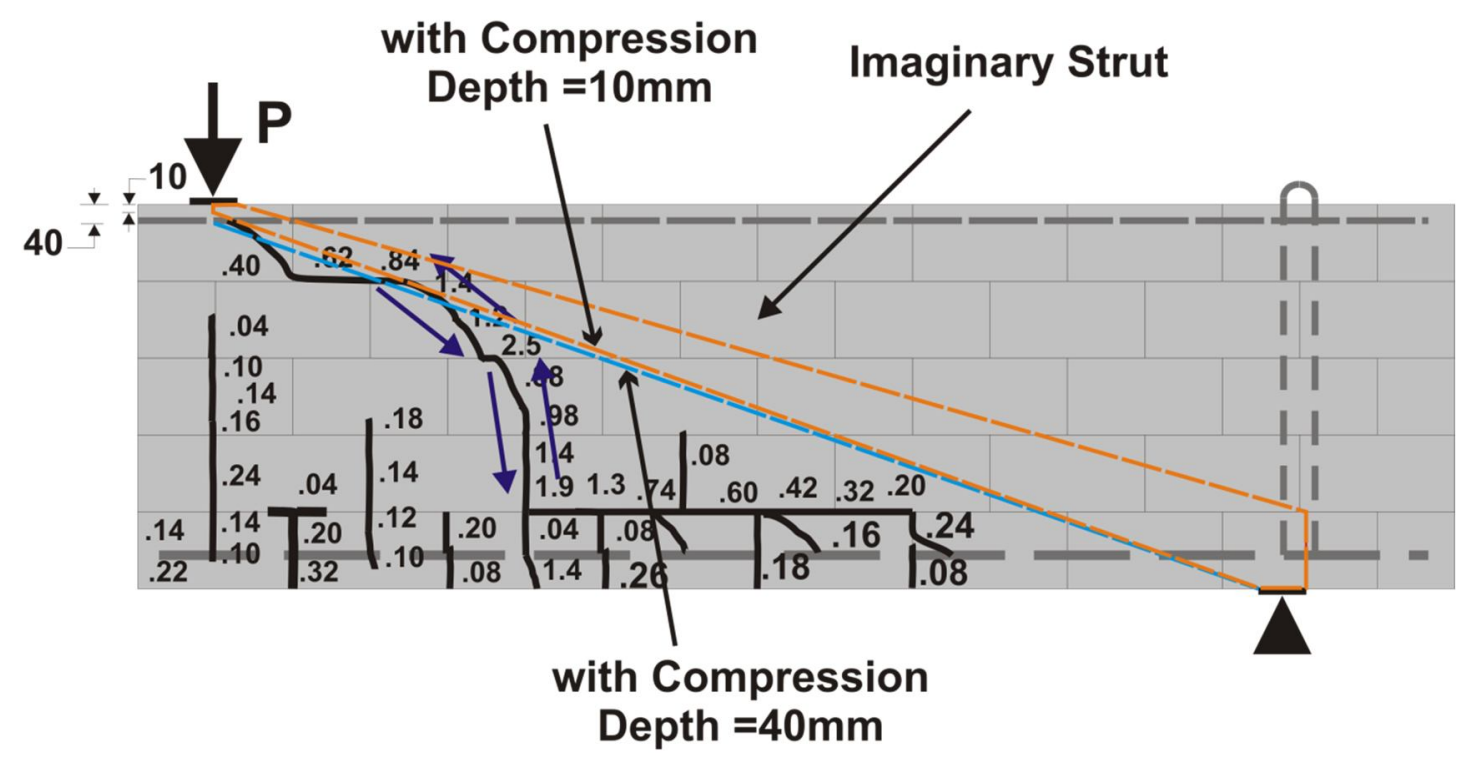

Figure 5-12: An assumed Strut and Tie Model for Specimen SM1D 

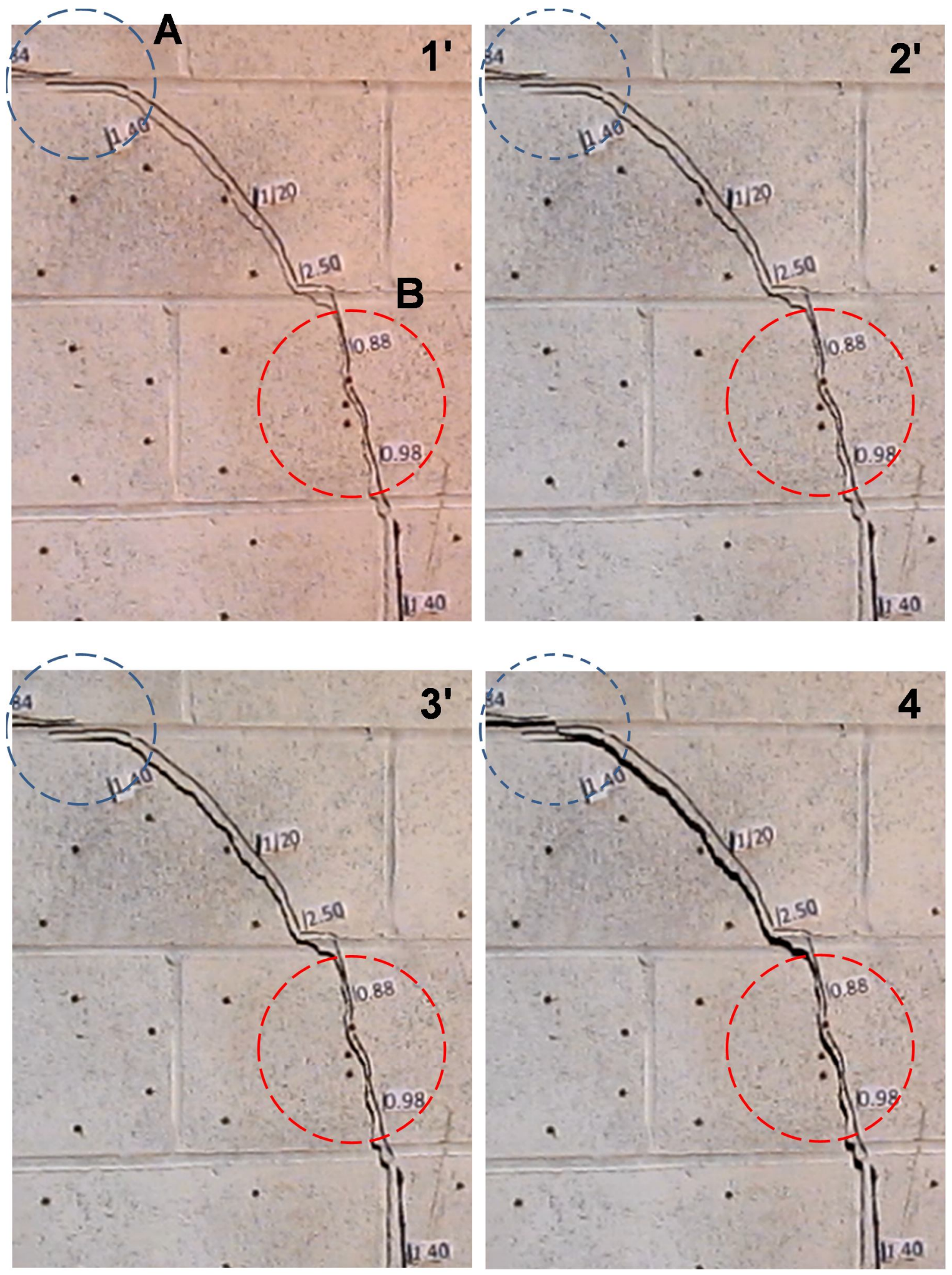

Figure 5-13: Interlocking across the Crack in Specimen SM1D after an Initial Breakdown of Beam Action 
Figure 5-14 shows that the initial breakdown of beam action was associated with increases in the steel strains in the middle of the east shear span and at the east support. This confirms the formation of the strut and tie action. However, the steel strains at these locations were still smaller than the strain at the center of the beam. This means that some of shear stresses were resisted through the interlock mechanism across the crack.

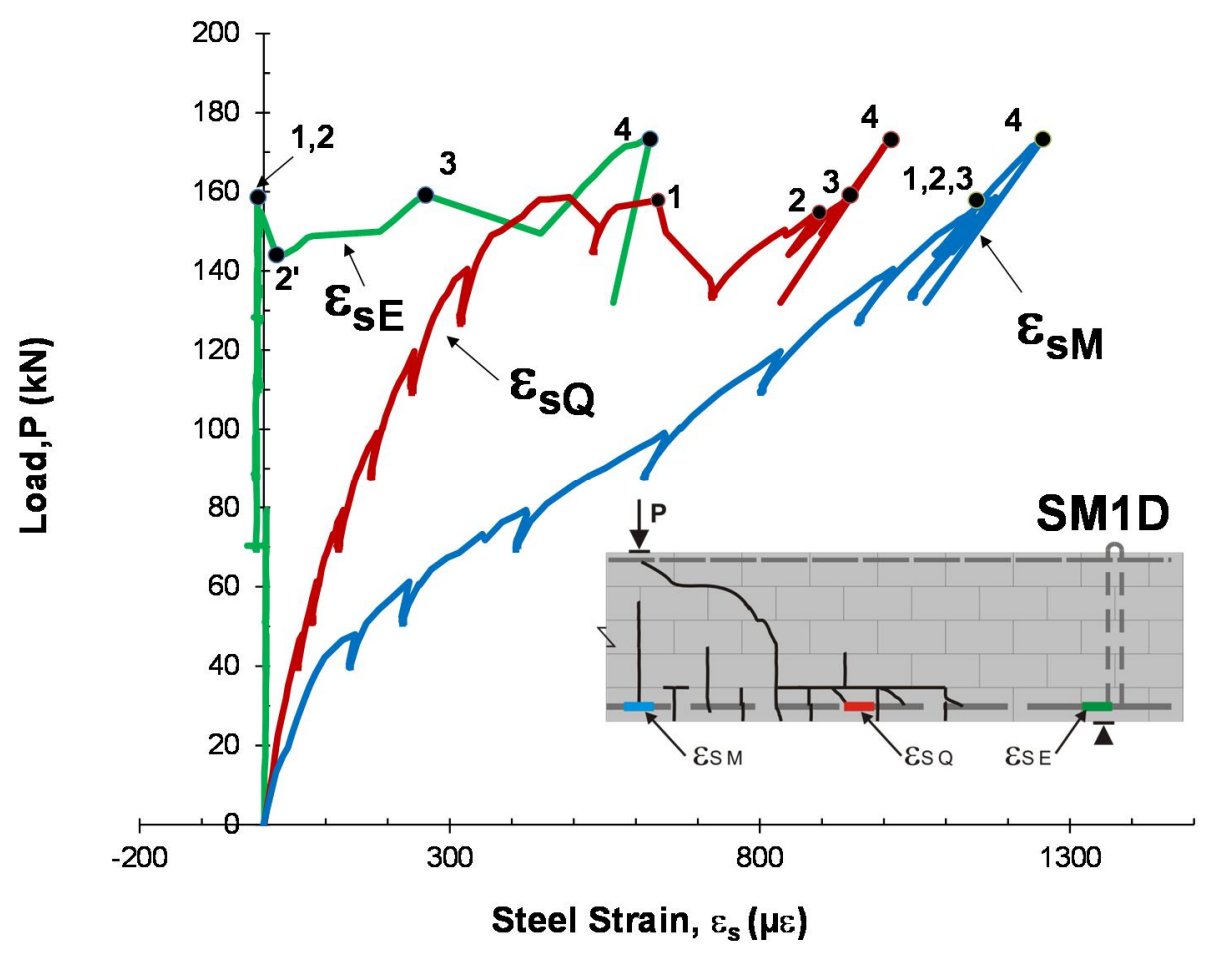

Figure 5-14: Steel Strains in the East Span of Specimen SM1D

\section{Specimen SL2}

Specimens SL1 and SL2 exhibited similar cracking behavior at early stages of loading to those of small and medium size beams. It can be seen in Figure 5-15 that when flexural shear cracks reached the mid-depth of specimen SL2, they were more widely spaced than those in small and medium size beams. Also, more numerous and larger masonry teeth formed in the shear zones at 
lower shear stresses compared to those in medium and small beams. Both SL1 and SL2 failed in obvious diagonal tension failures which happened more suddenly than those in the small and medium beams. This failure occurred due to breakdown of aggregate interlock which was identified by a significant increase in the shear strains in the sides where the failure happened right after reaching the failure load (see Figure 5-16). No shear keys were formed in SL1 and SL2 after the breakdown of aggregate interlock mechanism.

The behavior of the large masonry beams far more closely resembles the behavior of reinforced concrete beams than does the behavior of the small and medium beams. Furthermore, the crack patterns in the large beams more closely resembles those observed in similar reinforced concrete beams. The closer spacing of the joints relative to the overall height in the large beams means that the cracks can form in such a way that they resemble reinforced concrete with only a minor jagged appearance. 


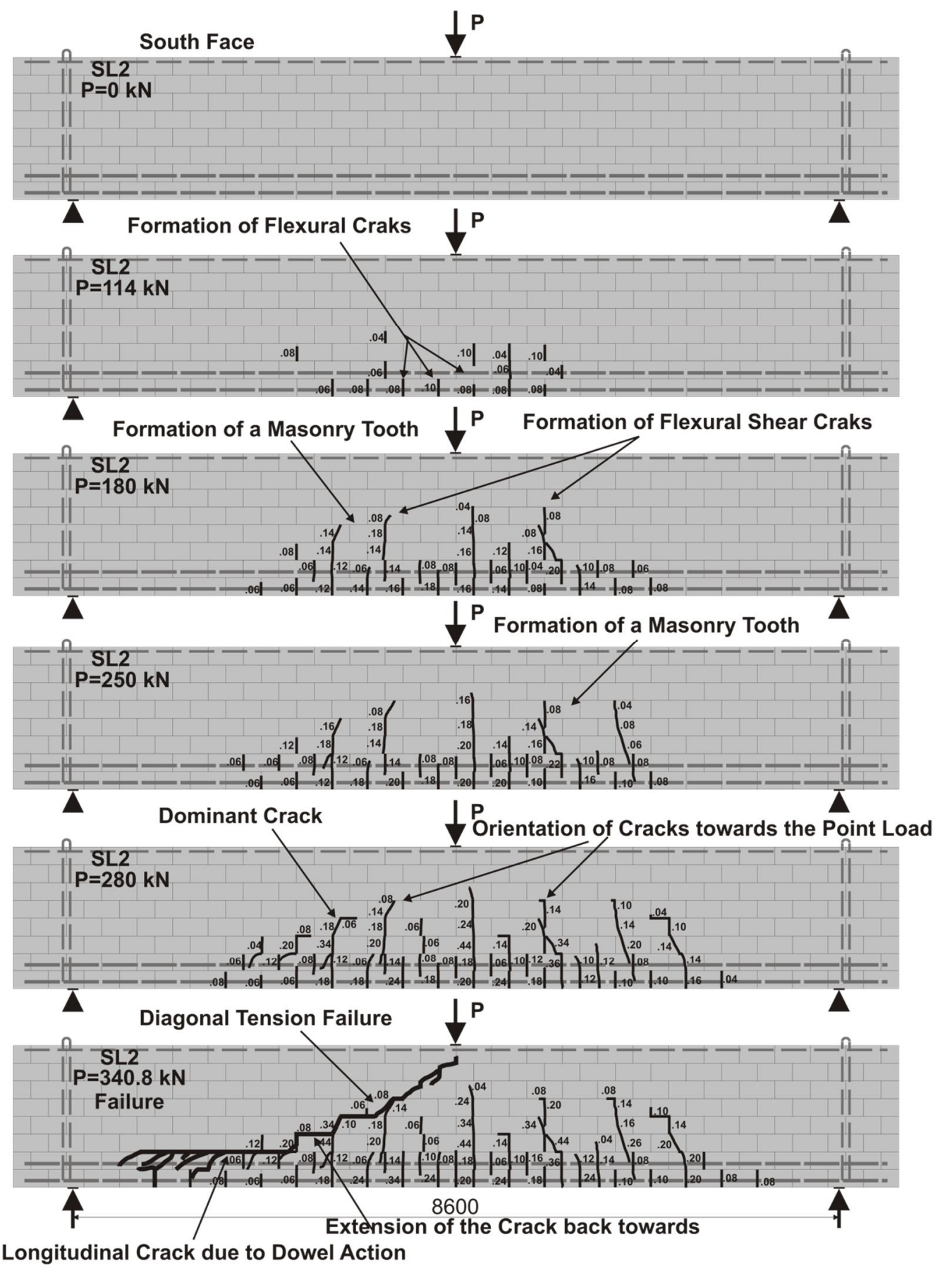

Figure 5-15: Crack Patterns for Specimen SL2 


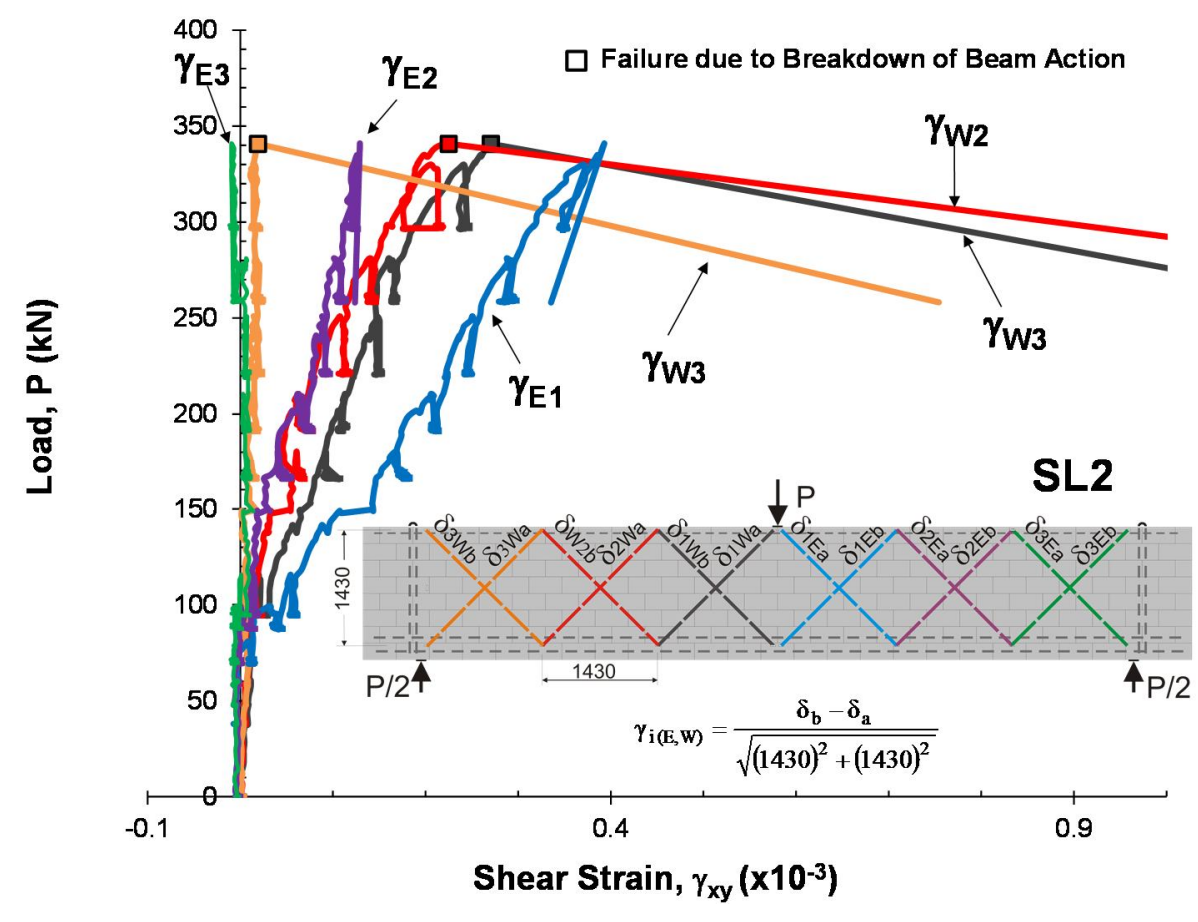

Figure 5-16: Shear Strains in Specimen SL2

It can be seen in Figure 5-17 that the mode of failure of the reinforced masonry beams in this series was diagonal tension failure. As in reinforced concrete beams, with increasing applied load flexural shear cracks form teeth where the major shear resistance mechanism is the aggregate interlock. A major difference in cracking behavior of reinforced masonry than reinforced concrete is the jagged appearance of the cracks due to predefined weak mortar joints.

The breakdown of aggregate interlock in reinforced masonry can be followed by the engagement of strut and tie actions and the formation of shear keys between masonry units that permitted shear transfer by interlocking of adjacent blocks leading to higher failure shear stresses and deflections than those associated with the breakdowns of aggregate interlock. However, these mechanisms cannot be considered to be reliable as they did not develop in all the beams and even when they were engaged it led in most cases to only marginal increases in failure shear stresses. 


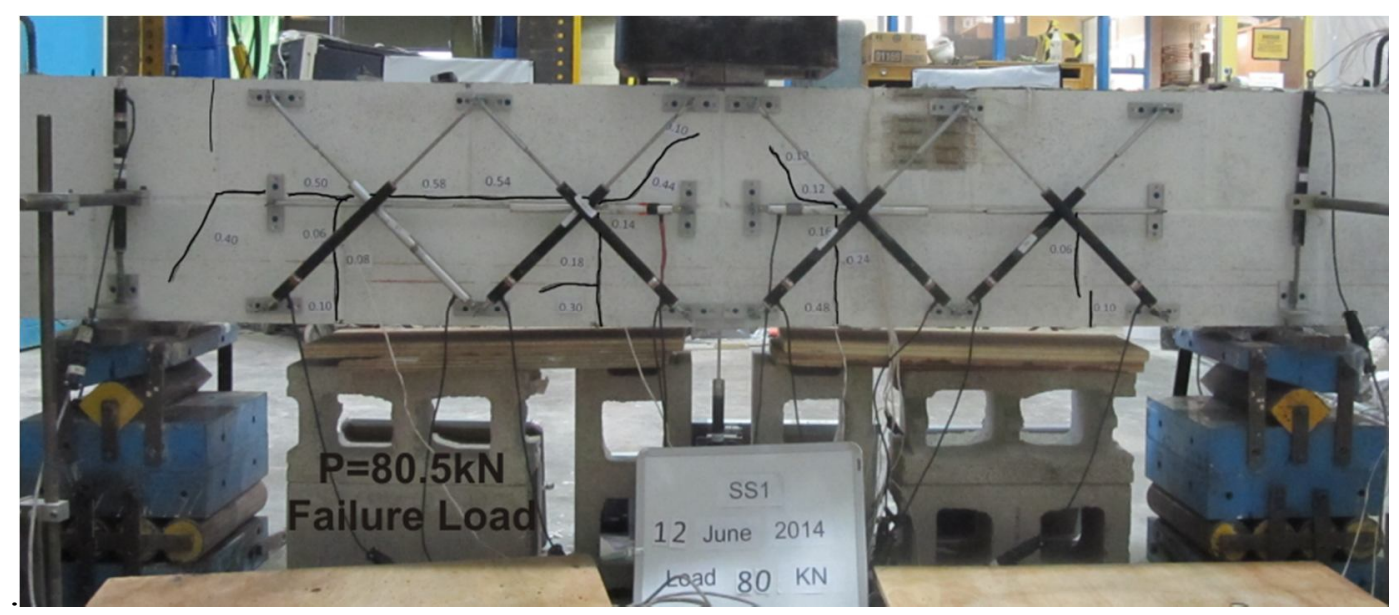

a) Failure mode of beam SS1

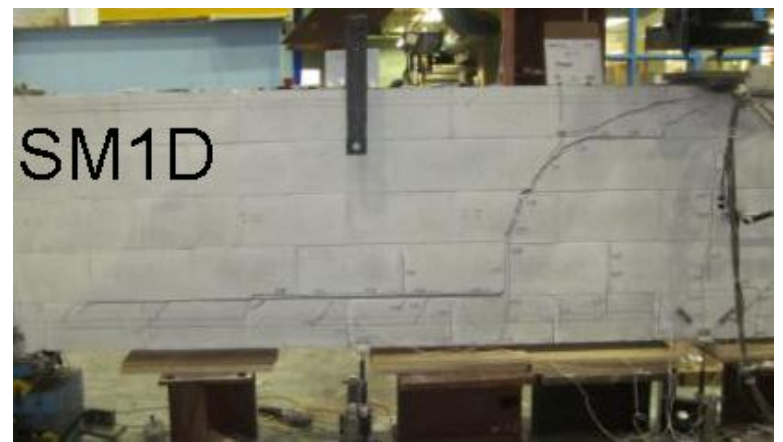

b) Failure mode of beam SM1D

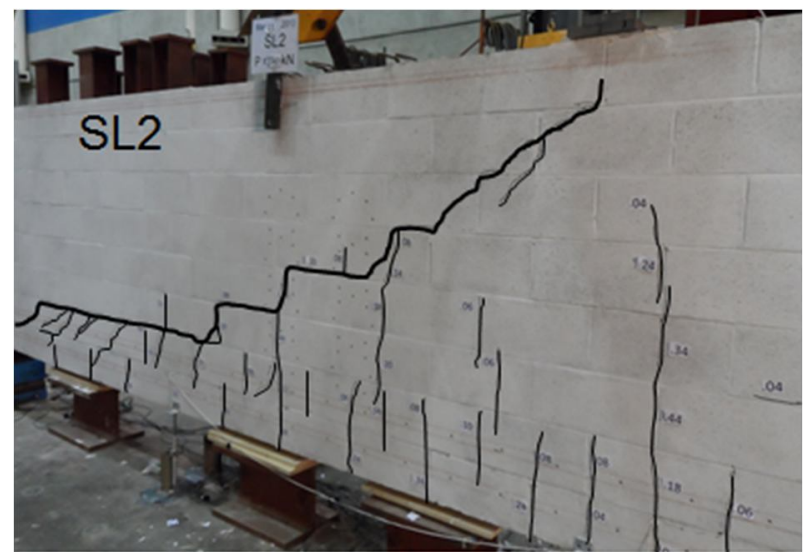

d) Failure mode of beam SL2

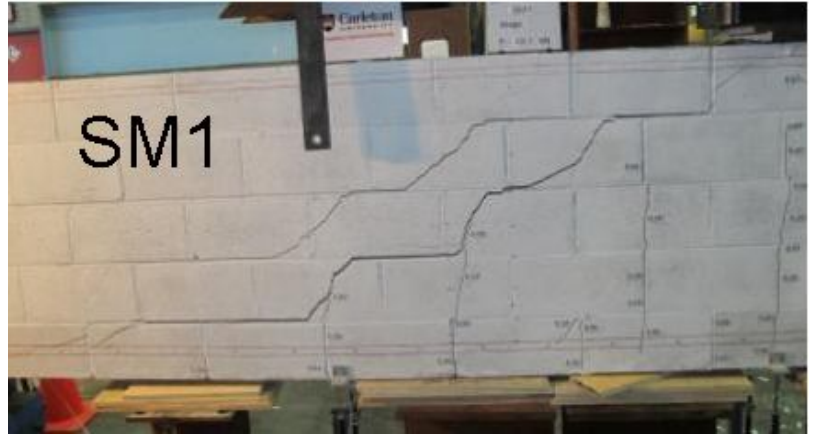

c) Failure mode of beam SM1

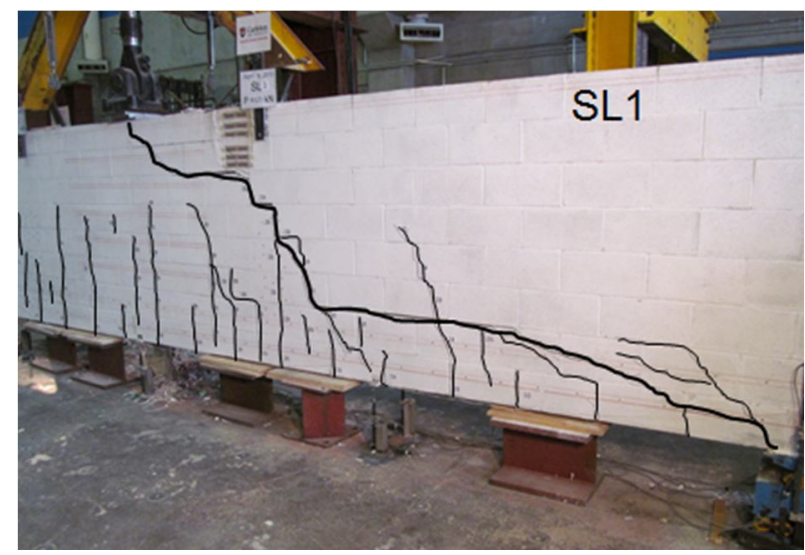

e) Failure mode of beam SL1

Figure 5-17: Failure Pattern of SS1, SM1, SMD1, SL1 and SL2 Beams 


\subsubsection{Crack Spacing and Crack Widths}

The effect of increasing the member depth on cracking behaviour of reinforced masonry beams can be studied by considering Figures 5-18 and 5-19 which show the crack patterns in South and North faces of beam SS1, SM1 and SL1 at a shear stress 0.51 MPa. Note that these specimens have been drawn in these figures such that the effective depths of the three beams are the same size on the page. Average crack spacings at mid-depth of the specimens have been presented in Figures 5-20 and 5-21. It can be seen that the spacing of cracks in both shear spans of specimen SS1 was governed primarily by the distance between head joints in the bottom course. Thus distance is $400 \mathrm{~mm}$, which is equivalent to $1.33 \mathrm{~d}$. However, above mid-depth under the point load the spacing between the cracks reduced to $160 \mathrm{~mm}(0.53 \mathrm{~d})$ and $220 \mathrm{~mm}(0.73 \mathrm{~d})$ in the north and south faces, respectively. Theses spacings considerably exceeds the average crack spacing observed by Shioya (1989) and Sherwood et al. (2007) in reinforced concrete. The average crack spacing at mid-depth of specimen SM1 (d=885 mm) was $555 \mathrm{~mm}(0.63 \mathrm{~d})$, whereas in SL2 $(d=1422 \mathrm{~mm})$ it was $750 \mathrm{~mm}(0.53 \mathrm{~d})$. It can thus be seen that as the effective depth increases, the crack spacing approach those observed in reinforced concrete.

It is also interesting to note that the crack spacing at mid-depth of SL2 and SM1was considerably greater than that at the level of steel. This has been repeatedly observed in similar reinforced concrete beams and occurs due reduced crack control as the distance from the steel increases. In the small beams the reduction in crack spacing between mid-depth and the level of the steel was as great. This is reflective of the shorter distance to the steel and the predefined cracks at joints. 

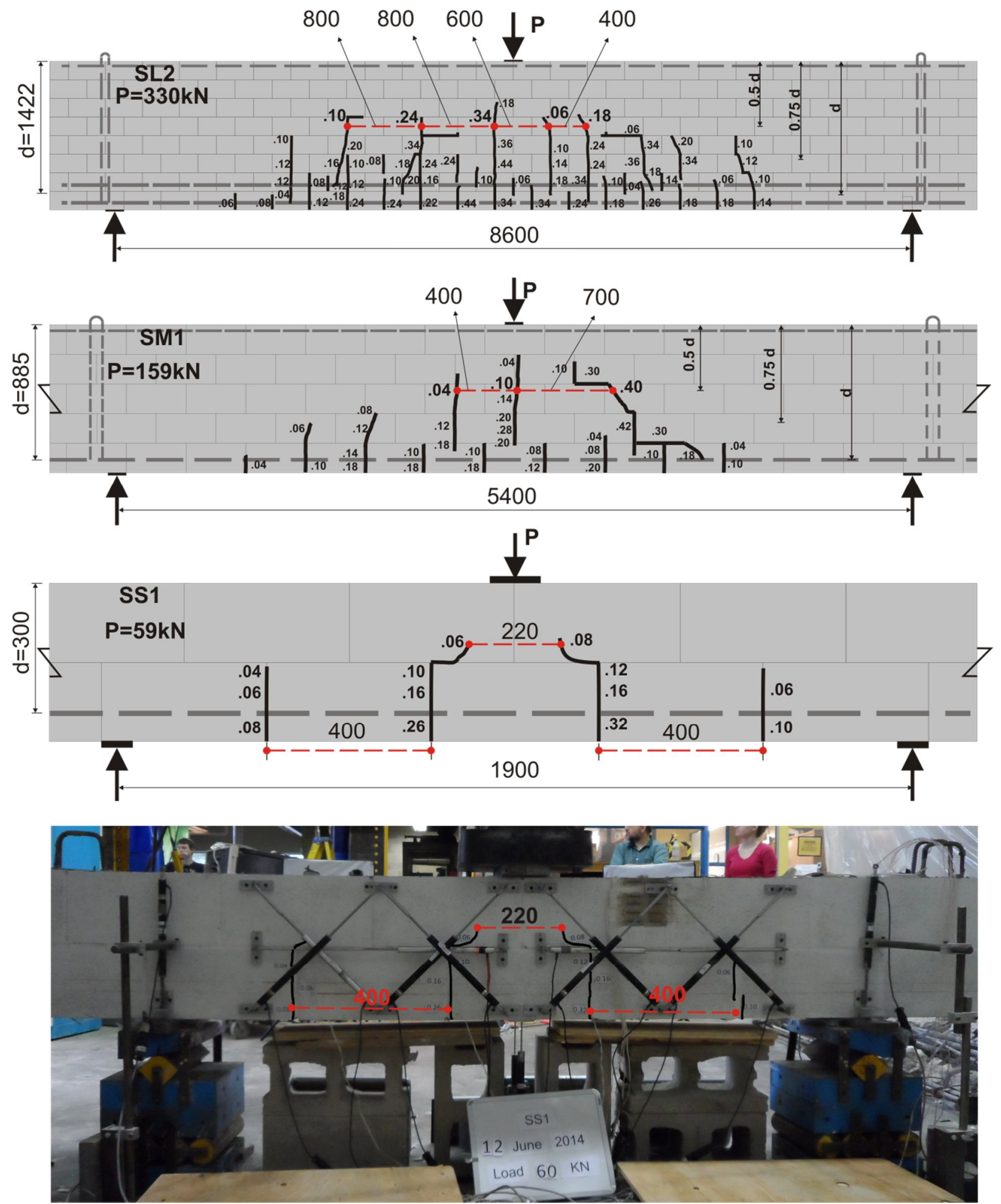

Figure 5-18: Crack Patterns in North Face of SS1, SM1 and SL2 at Shear Stress of 0.51 MPa 

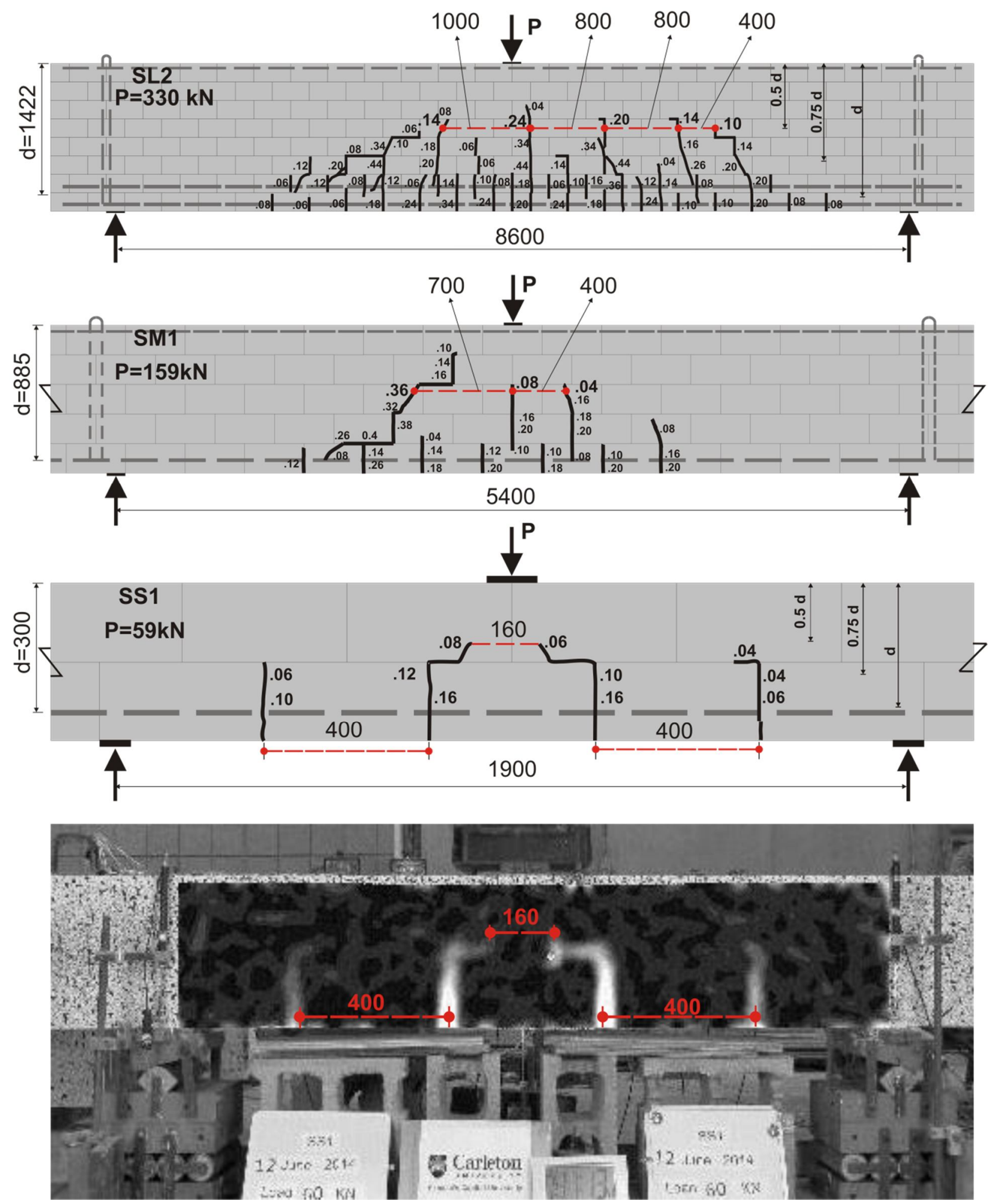

Figure 5-19: Crack Patterns in South Faces of SS1, SM1 and SL2 at Shear Stress of 0.51 MPa 


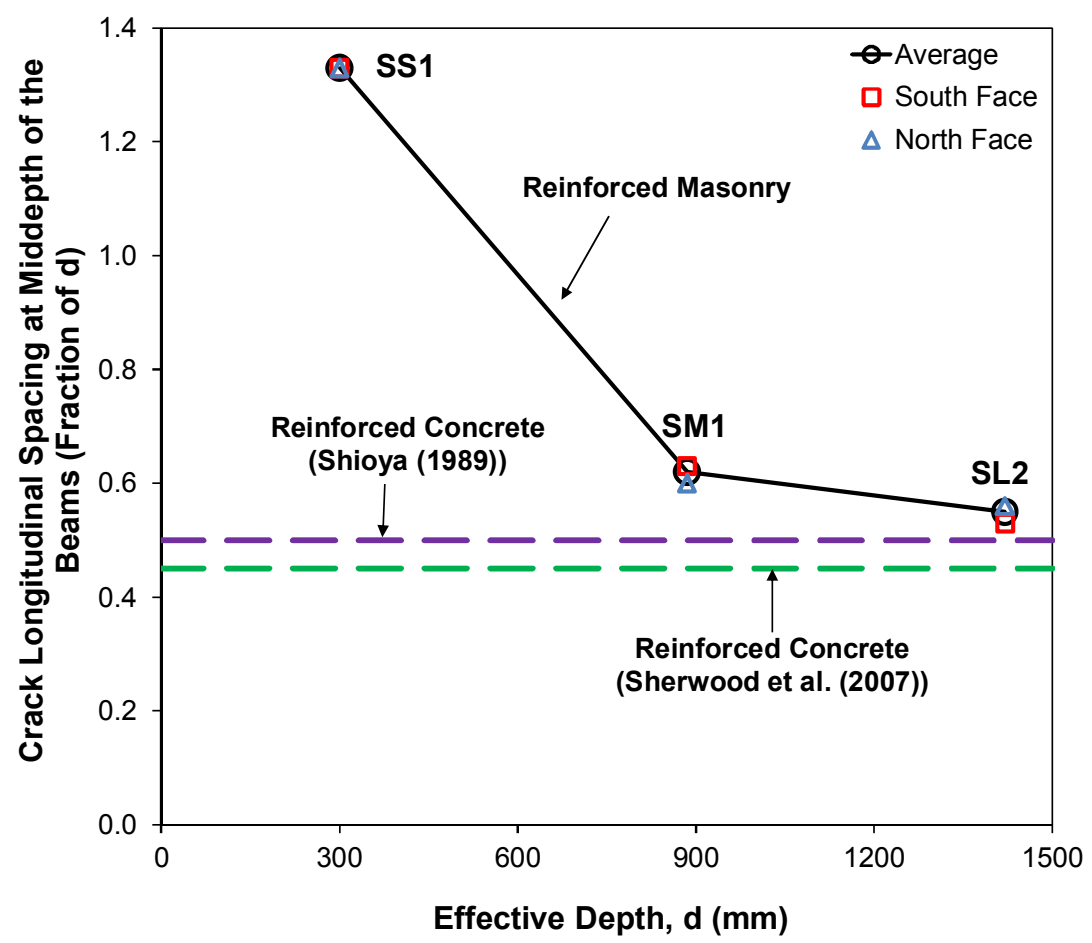

Figure 5-20: Crack Spacing at Mid-depth of SS1, SM1 and SL2 Beams as a Function of d at $\mathrm{v}=0.51 \mathrm{MPa}$

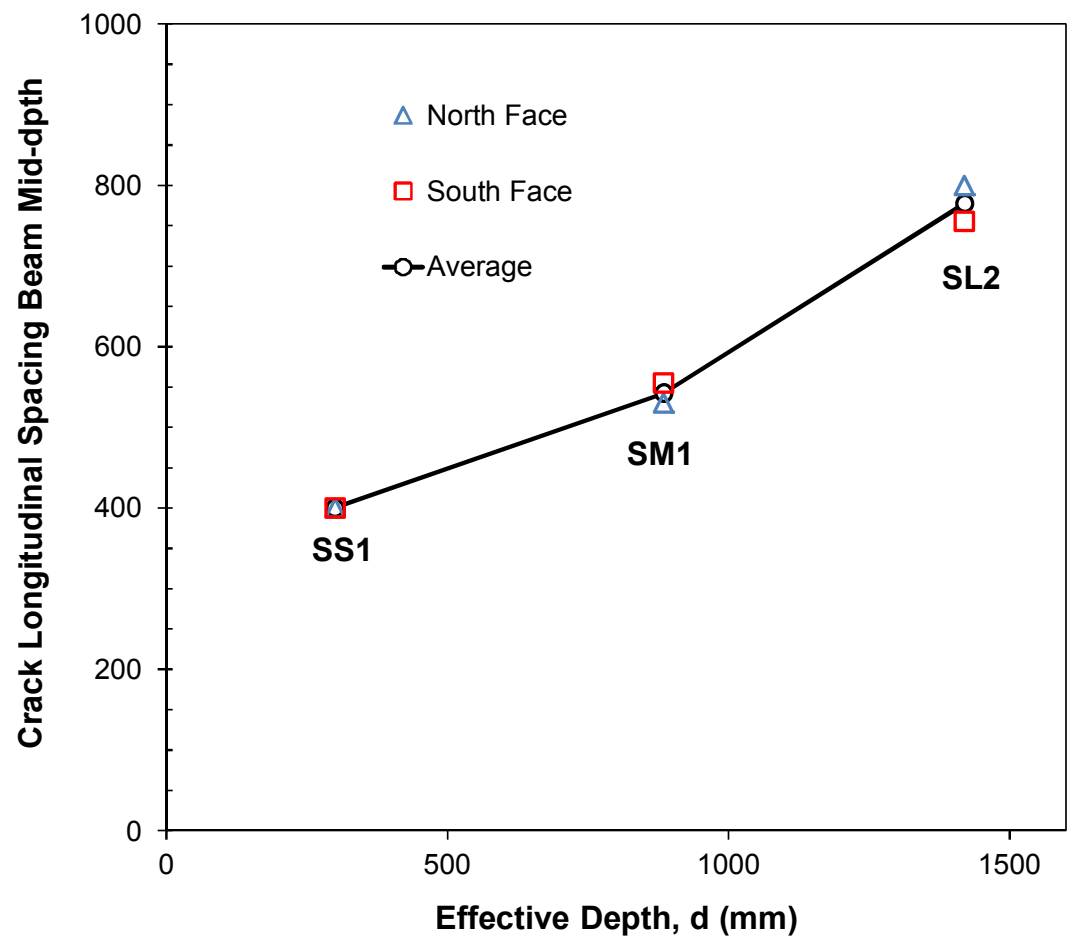

Figure 5-21: Crack Spacing at Mid-Depth of SS1, SM1 and SL2 Beams at v=0.51 MPa 
The increases in the crack spacing at mid-depth established in Figure 5-21 of the beams were associated with increases in crack widths. This can be seen in Figure 5-22, wherein it is shown that wider cracks were observed in the larger beams. Furthermore, prior to failure, the crack width at mid-height in the medium and large specimens were 2.6 and 2.14 times the crack widths in the equivalent small specimens. This is a significant finding in the field of masonry research, as it offers an explanation for the size effect that is similar to that for the size effect in reinforced concrete. Namely, that increasing the effective depth results in increased crack spacing and increased crack widths. These wider crack widths then precipitate shear failure at a lower shear stress due to reduced aggregate interlock capacity.

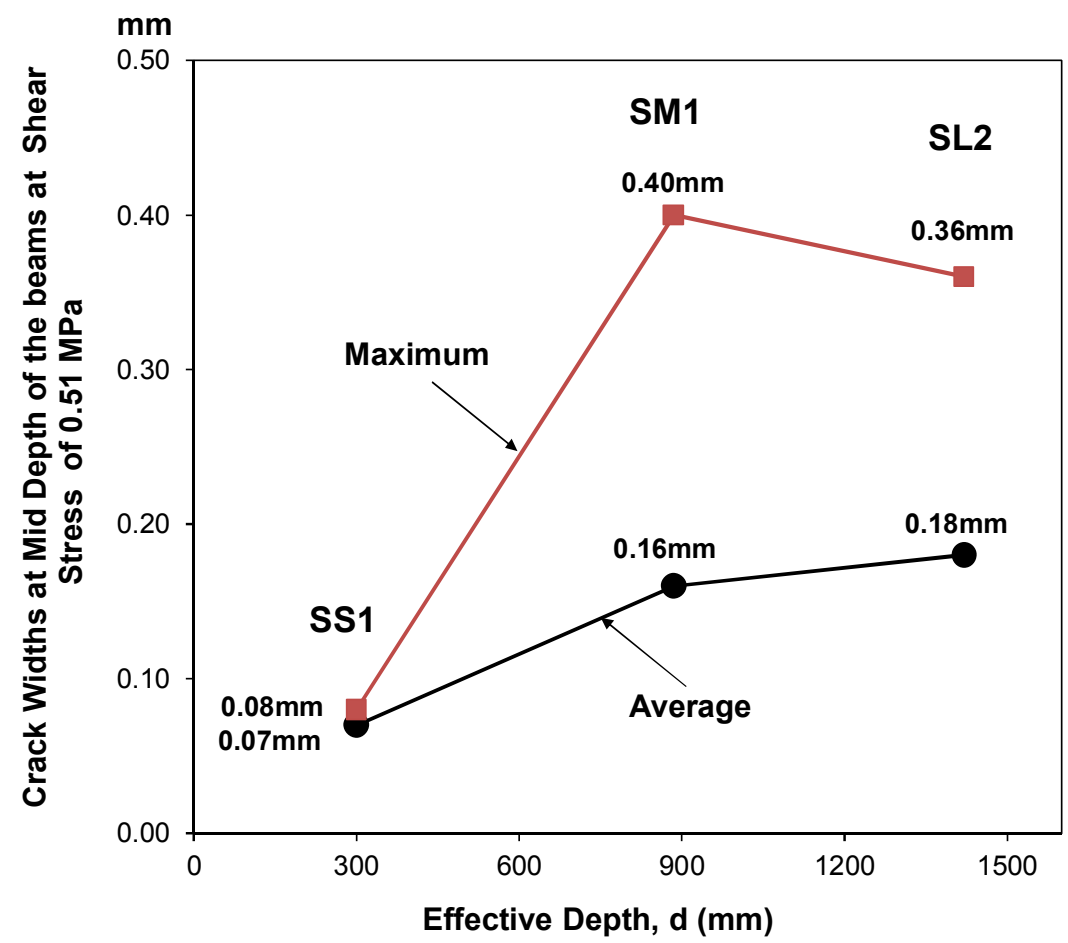

Figure 5-22: Average and Maximum Crack Widths at Mid-Depth of SS1, SM1 and SL2 Beams at Shear Stress of 0.51 MPa

Based on the observation that the cracks were spaced wider in the medium and large specimens than they were in the small specimens, it is useful to recall the diagram shown in Figure 2-12 in 
Chapter 2 for reinforced concrete. The longitudinal strain at mid-depth, $\varepsilon_{x}$, is a function solely of the crack width and the crack spacing. Therefore, any action that serves to increase the crack spacing is predicted to increase the crack width. Shear stresses are transferred across diagonal cracks by aggregate interlock, and the capacity of these cracks to transfer shear is thus a function of the crack width. As such, it is reasonable to conclude that any action that serves to increase $\varepsilon_{\mathrm{x}}$, or the crack spacing, will also cause a reduction in failure shear stress due to reduced aggregate interlock capacity of the wider cracks. The results of this size effect series suggests that reinforced concrete masonry behaves roughly in a similar fashion to reinforced concrete when subjected to shear and that wider cracks in deeper beams can explain the size effect in reinforced masonry.

\subsection{Predictions of Failure Shear Stresses}

Table 5-1 shows the geometrical dimensions, reinforcement details and basic experimental observations of the twelve beams included in the size effect series. Only the results and behaviour of the initial tests will be reported in this section. It can be noted that the normalized failure shear stress (values for term $\beta$ ) decreased as the depth increases. It can also be seen that the TMS MSJC code overestimates by a considerable margin the shear strength of the RCM beams with average of $\mathrm{V}_{\text {exp }} / \mathrm{V}_{\text {pred }}$ of 0.85 and COV of $33 \%$. Beam SL1 (d=1420mm), for example, failed at shear stress of $67 \%$ that of specimen SS1 $(\mathrm{d}=300 \mathrm{~mm})$. The TMS 402 code (Equation (2-18)) predicts SL1 to fail at a shear force of $277 \mathrm{kN}$. In fact, SL2 failed at $171 \mathrm{kN}$ which is equal to $62 \%$ of the predicted load by the TMS 402 . This overestimation can be attributed to the fact that it does not account for size effect in shear. Although the CSA S304.1 code accounts for size effect, it still exhibited a high coefficient of variation. Interestingly, the 
General Method can predict the variation in failure shear stresses of the RCM beams very well (an average of $\mathrm{V}_{\text {exp }} / \mathrm{V}_{\text {pred }}$ of 1.19) while giving the least variation (with a COV of 14\%).

Normalized failure shear stresses for specimens SS1, SM1, SM1D, SL1 and SL2 are plotted in Figure 5-23 versus their effective depths (d). It is quite clear that the size effect exists in reinforced masonry. It can be further seen that the General Method can accurately and safely capture the variation in failure shear stresses of the beams. The inability of masonry design codes to account for the size effect may lead to a high risk of sudden failure of large masonry beams and girders (such as those in Figures 1-5 to 1-7) at lower loads than designed for by these codes. These codes need to be revisited to account for size effect. In this study, it was found that the shear strength of RCM beams can be more accurately and safely calculated using the CSA A23.3 code for concrete than current masonry codes. In fact, the results presented in this thesis were used to justify the use of the CSA A23.3 as a base to revise the shear provision in of CSA S304 masonry codes in its 2014 version. 
Table 5-1: Experimental Observation of the Initial Tests of the Size Effect Series Beams with North American Codes Predictions

\begin{tabular}{|c|c|c|c|c|c|c|c|c|c|c|c|c|c|c|c|c|c|c|c|}
\hline \multirow{3}{*}{ 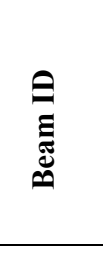 } & \multicolumn{6}{|c|}{ Geometry } & \multicolumn{5}{|c|}{ Experimental Observation } & \multicolumn{8}{|c|}{ Predictions } \\
\hline & \multirow[b]{2}{*}{$\mathrm{a} / \mathrm{d}$} & \multirow[b]{2}{*}{$\underset{(\mathrm{mm})}{\mathrm{d}}$} & \multirow[b]{2}{*}{$\begin{array}{c}\mathrm{b}_{\mathrm{w}} \\
(\mathrm{mm})\end{array}$} & \multirow[b]{2}{*}{$\rho(\%)$} & \multirow[b]{2}{*}{$\frac{A_{v} f_{y}}{b_{w} s}$} & \multirow[b]{2}{*}{$\begin{array}{c}\text { Crack } \\
\text { control } \\
\text { steel }\end{array}$} & \multirow[b]{2}{*}{$\begin{array}{c}\mathrm{f}_{\mathrm{m}}^{\mathrm{n}} \\
(\mathrm{MPa})\end{array}$} & \multirow[b]{2}{*}{$\begin{array}{l}P_{\exp } \\
(k N)\end{array}$} & \multirow[b]{2}{*}{$\begin{array}{l}\mathrm{V}_{\text {exp }}^{*} \\
(\mathrm{kN})\end{array}$} & \multirow[b]{2}{*}{$\begin{array}{c}v^{* *} \\
(\mathrm{MPa})\end{array}$} & \multirow[b]{2}{*}{$\beta^{* *}$} & \multicolumn{2}{|c|}{ CSA S304.1 } & \multicolumn{2}{|c|}{ TMS 402} & \multicolumn{2}{|c|}{ CSA A23.3 } & \multicolumn{2}{|c|}{ Hoult et al. } \\
\hline & & & & & & & & & & & & 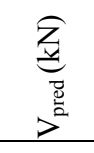 & $>^{\vec{s}}>^{\vec{d}}$ & 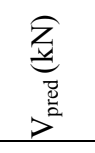 & $>^{2}$ & 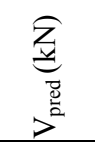 & 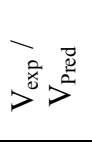 & 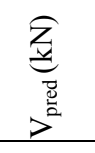 & $>^{\circ}$ \\
\hline $\mathrm{SS} 1$ & 3.17 & 300 & 190 & 0.88 & - & - & 17.5 & 80.5 & 40.8 & 0.72 & 0.171 & 38.2 & 1.07 & 44.6 & 0.92 & 37.8 & 1.08 & 40.5 & 1.01 \\
\hline $\mathrm{SS} 2$ & 3.11 & 305 & 190 & 1.72 & - & - & 17.5 & 140.2 & 70.5 & 1.22 & 0.291 & 39.4 & 1.79 & 46.0 & 1.53 & 47.5 & 1.48 & 48.9 & 1.44 \\
\hline $\mathrm{SS} 3$ & 3.11 & 305 & 190 & 1.72 & 0.67 & - & 17.5 & 202.8 & 101.9 & 1.76 & 0.42 & 78.6 & 1.30 & 65.9 & 1.55 & 90.8 & 1.14 & 93.8 & 1.09 \\
\hline SS4 & 3.10 & 307 & 190 & 0.30 & - & - & 18.0 & 72.4 & 36.7 & 0.63 & 0.149 & 46.3 & 0.79 & 46.3 & 0.79 & 26.5 & 1.39 & 30.6 & 1.20 \\
\hline SM1 & 3.05 & 885 & 190 & 0.83 & - & - & 17.9 & 189.8 & 98.4 & 0.59 & 0.138 & 86.2 & 1.14 & 133.0 & 0.74 & 80.5 & 1.22 & 83.8 & 1.17 \\
\hline SM1D & 3.14 & 885 & 190 & 0.83 & - & - & 20.0 & 173.4 & 90.2 & 0.54 & 0.120 & 91.1 & 0.99 & 140.6 & 0.64 & 82.9 & 1.09 & 86.8 & 1.04 \\
\hline SM2 & 3.18 & 875 & 190 & 1.68 & - & - & 19.1 & 228.6 & 117.8 & 0.71 & 0.163 & 88.6 & 1.33 & 135.9 & 0.87 & 98.2 & 1.20 & 99.4 & 1.19 \\
\hline SM3 & 3.15 & 868 & 190 & 1.70 & 0.52 & - & 17.2 & 424.4 & 215.7 & 1.31 & 0.319 & 169.7 & 1.27 & 173.2 & 1.25 & 237.1 & 0.91 & 243.4 & 0.89 \\
\hline SM4 & 3.16 & 880 & 190 & 0.33 & - & - & 18.5 & 130.8 & 68.5 & 0.41 & 0.095 & 87.5 & 0.78 & 134.5 & 0.51 & 58.1 & 1.18 & 64.6 & 1.06 \\
\hline SM6 & 3.16 & 880 & 190 & 0.84 & - & $\begin{array}{l}\text { No.15 } \\
@, 200\end{array}$ & 18.0 & 213.0 & 110 & 0.66 & 0.155 & 86.3 & 1.27 & 132.7 & 0.83 & 113.5 & $0.97^{+}$ & 126.8 & $0.90^{+}$ \\
\hline SL1 & 3.02 & 1420 & 240 & 0.82 & - & - & 18.9 & 319.4 & 171 & 0.50 & 0.115 & 116.2 & 1.47 & 277.1 & 0.62 & 132.5 & 1.29 & 136.7 & 1.25 \\
\hline SL2 & 3.02 & 1422 & 240 & 0.82 & - & - & 18.9 & 340.8 & 181.7 & 0.53 & 0.122 & 116.0 & 1.57 & 277.4 & 0.65 & 132.9 & 1.37 & 136.8 & 1.33 \\
\hline & & & & & & & & & & & & Mean & 1.22 & & 0.91 & & 1.19 & & 1.13 \\
\hline & & & & & & & & & & & & STDV & 0.33 & & 0.35 & & 0.17 & & 0.17 \\
\hline & & & & & & & & & & & & $\mathrm{V}(\%)$ & 27 & & 39 & & 14 & & 15 \\
\hline
\end{tabular}

* $\quad V_{\exp }=\frac{P \exp }{2}+\mathrm{V} @ \mathrm{~d}$ from point load (due to self weight), $* * \quad v=\frac{\mathrm{Vexp}}{\mathrm{b}_{\mathrm{w}} \mathrm{d}}, \beta=\frac{\mathrm{V} \text { exp }}{\mathrm{b}_{\mathrm{w}} \mathrm{d} \sqrt{\mathrm{f}_{\mathrm{m}}^{\prime}}},{ }^{+}$based on d=851mm (centroid of steel below mid-height of the beam) 


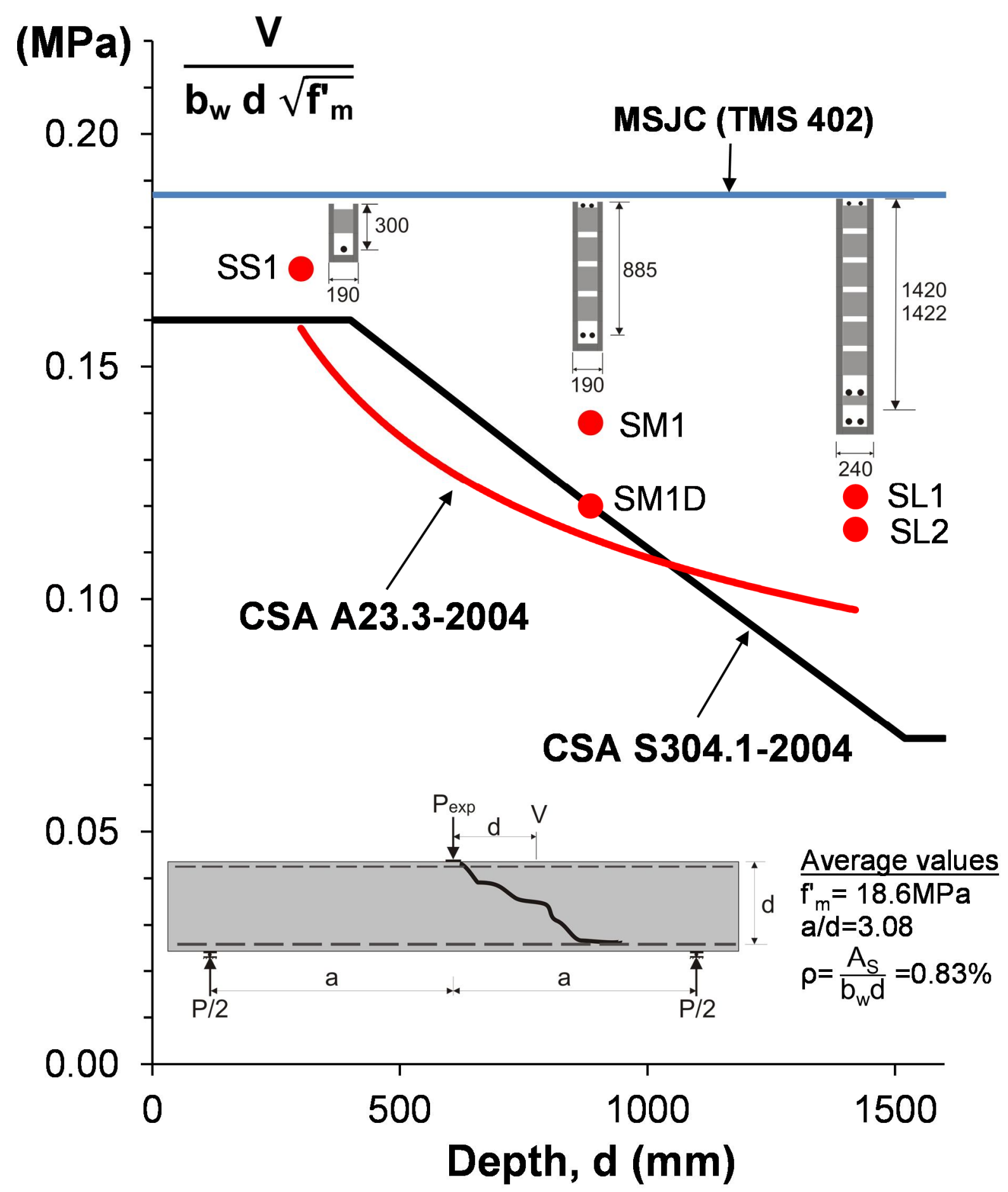

Figure 5-23: Failure Shear Stress for RMC Beams with Different Depths 
Table 5-2 presents shear predictions of BS5628 and AS3700 codes along with predictions of the empirical models proposed by Li et al., Feriege and Dhanasekar et al. It can be seen in Table 5-2 that while the BS5628 considerably overestimates the shear strengths of the medium and large beams, it gives reasonable predictions for the small size beams. The AS3700 code, on the other hand, gives reasonable prediction for the medium and large beams while underestimating the shear strengths of the small beams. It is interesting to note the wide variations in predicting shear strengths provided by different building codes. Besides being complicated, the empirical model proposed by Li et al. (Equation (2-20)) gives the most non-conservative predictions with an average of $\mathrm{V}_{\text {exp }} / \mathrm{V}_{\text {pred }}$ of 0.56 and COV of $42 \%$. It can be noted in Table 5-2 that Feriege`s model gives the highest COV value of $43 \%$ and the second lowest average $V_{\text {exp }} / V_{\text {pred }}$ of 0.62 . It is worth mentioning that Ferieg developed his model based on the test results of his own investigation which did not include the effect of $d$ on shear strength of RM beams. Furthermore, Ferieg`s test results showed that $\rho$ has no effect on shear strength of RM beams. As both $d$ and $\rho$ are the main parameters in the current investigation and since both have been proven to be very influential on shear strength of RM beams, it is not a surprise that Ferige`s model gives such high variation. Although Dhanasekar et al.`s model accounts for most of the influential factors that affects shear strength of RM beams, it yielded the third highest COV of $41 \%$. Dhanasekar et al.`s model highly overestimated the shear strength of small size beams. This can be attributed to the fact that this model was developed based on statistical analysis of a large database which mostly included tests results of single course RM beams and two-course stack-bonded RM beams. Generally, both types of beams had high shear strengths. As such, it is accepted for such model to overestimate the shear strength of running-bonded two course beam such as the small size series of the current investigations. 
Table 5-2: Shear Strength Predictions by the BS5628 and AS 3700 Codes and Empirical Models by Li et al., Feriege and Dhanasekar et al.

\begin{tabular}{|c|c|c|c|c|c|c|c|c|c|c|c|c|c|c|c|c|c|c|c|}
\hline \multirow{3}{*}{ 国 } & \multicolumn{9}{|c|}{ Geometry and test results } & \multicolumn{10}{|c|}{ Predictions } \\
\hline & \multirow[b]{2}{*}{$\begin{array}{c}\mathrm{h} \\
(\mathrm{mm})\end{array}$} & \multirow[b]{2}{*}{$\mathrm{a} / \mathrm{d}$} & \multirow[b]{2}{*}{$\underset{(\mathrm{mm})}{\mathrm{d}}$} & \multirow[b]{2}{*}{$\begin{array}{c}\mathrm{b}_{\mathrm{w}} \\
(\mathrm{mm})\end{array}$} & \multirow[b]{2}{*}{$\rho(\%)$} & \multirow[b]{2}{*}{$\begin{array}{c}\mathrm{f}_{\mathrm{y}} \\
(\mathrm{MPa})\end{array}$} & \multirow[b]{2}{*}{$\begin{array}{c}\mathrm{f}_{\mathrm{m}}^{\mathrm{n}} \\
(\mathrm{MPa})\end{array}$} & \multirow[b]{2}{*}{$\begin{array}{l}\mathrm{P}_{\exp } \\
(\mathrm{kN})\end{array}$} & \multirow[b]{2}{*}{$\begin{array}{l}\mathrm{V}_{\exp }^{*} \\
(\mathrm{kN})\end{array}$} & \multicolumn{2}{|c|}{ BS 5628} & \multicolumn{2}{|c|}{ AS 3700} & \multicolumn{2}{|c|}{ Li et al. } & \multicolumn{2}{|c|}{ Ferieg } & \multicolumn{2}{|c|}{ Dhanasekar et al. } \\
\hline & & & & & & & & & & 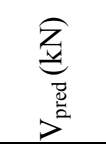 & $>^{2}$ & 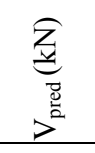 & $>^{2}$ & 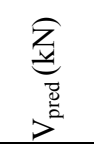 & 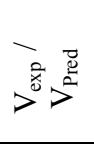 & 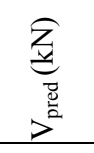 & $>^{\vec{x} 0}$ & 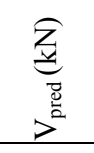 & $>^{0}$ \\
\hline SS1 & 388 & 3.17 & 300 & 190 & 0.88 & 405 & 17.5 & 80.5 & 40.8 & 49.1 & 0.83 & 28.7 & 1.42 & 81.9 & 0.50 & 64.0 & 0.64 & 83.1 & 0.49 \\
\hline $\mathrm{SS} 2$ & 390 & 3.11 & 305 & 190 & 1.72 & 405 & 17.5 & 140.2 & 70.5 & 65.0 & 1.08 & 37.7 & 1.87 & 93.0 & 0.76 & 65.2 & 1.08 & 118.9 & 0.59 \\
\hline $\mathrm{SS} 4$ & 390 & 3.10 & 307 & 190 & 0.30 & 900 & 18.0 & 72.4 & 36.7 & 40.7 & 0.90 & 23.6 & 1.56 & - & - & 66.6 & 0.55 & $-*$ & $-*$ \\
\hline SS6 & 390 & 3.11 & 303 & 190 & 2.42 & 440 & 18.0 & 143.2 & 72.1 & 76.7 & 0.94 & 44.5 & 1.62 & 85.1 & 0.85 & 65.7 & 1.10 & 142.0 & 0.51 \\
\hline SM1 & 990 & 3.05 & 885 & 190 & 0.83 & 440 & 17.9 & 189.8 & 98.4 & 144.7 & 0.68 & 83.3 & 1.18 & 257.0 & 0.38 & 191.7 & 0.51 & 96.6 & 1.02 \\
\hline SM1D & 990 & 3.14 & 885 & 190 & 0.83 & 440 & 20.0 & 173.4 & 90.2 & 142.8 & 0.63 & 83.3 & 1.08 & 266.9 & 0.34 & 202.0 & 0.45 & 100.3 & 0.90 \\
\hline SM2 & 990 & 3.18 & 875 & 190 & 1.68 & 440 & 19.1 & 228.6 & 117.8 & 182.5 & 0.65 & 107.1 & 1.10 & 276.8 & 0.43 & 194.9 & 0.60 & 136.8 & 0.86 \\
\hline SM4 & 990 & 3.16 & 880 & 190 & 0.33 & 830 & 18.5 & 130.8 & 68.5 & 116.1 & 0.59 & 67.9 & 1.01 & - & - & 193.0 & 0.35 & $-*$ & $-*$ \\
\hline SL1 & 1597 & 3.02 & 1420 & 240 & 0.82 & 440 & 18.9 & 319.4 & 171.0 & 293.5 & 0.58 & 168.2 & 1.02 & 544.4 & 0.31 & 399.7 & 0.43 & 124.7 & 1.37 \\
\hline SL2 & 1598 & 3.02 & 1422 & 240 & 0.82 & 440 & 18.9 & 340.8 & 181.7 & 293.9 & 0.62 & 168.4 & 1.08 & 545.2 & 0.33 & 400.3 & 0.45 & 124.8 & 1.46 \\
\hline & & & & & & & & & & Mean & 0.75 & & 1.29 & & 0.49 & & 0.62 & & 0.90 \\
\hline & & & & & & & & & & STDV & 0.18 & & 0.30 & & 0.20 & & 0.26 & & 0.37 \\
\hline & & & & & & & & & & $\mathrm{OV}(\%)$ & 23 & & 23 & & 42 & & 43 & & 41 \\
\hline
\end{tabular}

* Shear strength predictions were not calcultaed since models prposed by Li et al. and Dhanasekar and Wong account for fy in the range of $400 \mathrm{Mpa}$. 
In Tables 5-1 and 5-2, the predictions of failure shear stresses by various masonry design codes were made based on the masonry compressive strength obtained from testing the associated prisms of each beam. In practice, building and testing masonry prisms is typically not practical due to time, cost, the lack of local availability of high capacity testing machines and the complexities of transporting the samples. As such, masonry design codes allow the use of tabulated characteristic $\mathrm{f}^{\prime} \mathrm{m}$ values which are typically given for different characteristic compressive strength of the block. These tabulated values have been frequently reported to be conservative. A question can be raised as to how the predictions of the masonry design codes would be if $\mathrm{f}_{\mathrm{m}}$ values were based on tabulated characteristic values. For this purpose, Table 5-3 was constructed where the failure shear stress predictions for each of CSA S304.1 and TMS 402 codes were based on $\mathrm{f}_{\mathrm{m}}{ }_{\mathrm{m}}$ determined from their tabulated values.

Consider the failure shear stress of specimen SM1 which failed at a shear force of $98.4 \mathrm{kN}$. TMS 402 predicts the beam to fail at $133 \mathrm{kN}$ based on prism tests (corresponding to a $\mathrm{V}_{\text {exp }} / \mathrm{V}_{\text {pred }}$ of 0.74 ) and to fail at $143 \mathrm{kN}$ based on tabulated $\mathrm{f}_{\mathrm{m}}$ (making a $\mathrm{V}_{\text {exp }} / \mathrm{V}_{\text {pred }}$ value of 0.69). Thus, the TMS 402 code gives even more non-conservative predictions when using tabulated characteristic $\mathrm{f}_{\mathrm{m}}$ values. This is obvious from Table 5-4 which presents the average values $\mathrm{V}_{\text {exp }} / \mathrm{V}_{\text {pred }}$ of the considered codes based on $\mathrm{f}_{\mathrm{m}}$ from prism tests or tabulated values. It is clear from Table 5-4 that the CSA S304.1 becomes more conservative when tabulated $\mathrm{f}_{\mathrm{m}}{ }_{\mathrm{m}}$ are used in predicting the failure shear stresses. Although the CSA A23.3 code becomes more conservative as well, it is still less conservative than CSA S304.1. As such CSA A23.3 can serve as the base for any revisions of shear provisions of reinforced masonry in the CSA S304.1 code. 
Table 5-3: North American Codes Predictions Based on the Specified Masonry Compressive Strength

\begin{tabular}{|c|c|c|c|c|c|c|c|c|c|c|c|c|c|c|c|c|c|c|c|c|}
\hline \multirow[b]{3}{*}{ 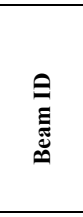 } & \multicolumn{8}{|c|}{ Geometry and Experimental Observation } & \multicolumn{12}{|c|}{ Predictions } \\
\hline & \multirow[b]{2}{*}{$\mathrm{a} / \mathrm{d}$} & \multirow[b]{2}{*}{$\underset{(\mathrm{mm})}{\mathrm{d}}$} & \multirow[b]{2}{*}{$\begin{array}{c}\mathrm{b}_{\mathrm{w}} \\
(\mathrm{mm})\end{array}$} & \multirow[b]{2}{*}{$\rho(\%)$} & \multirow[b]{2}{*}{$\frac{\mathrm{A}, \mathrm{f}_{\mathrm{f}}}{\mathrm{b} \mathrm{s}}$} & \multirow[b]{2}{*}{$\begin{array}{c}\text { Crack } \\
\text { control } \\
\text { steel }\end{array}$} & \multirow[b]{2}{*}{$\begin{array}{c}P_{\exp } \\
(\mathrm{kN})\end{array}$} & \multirow[b]{2}{*}{$\begin{array}{l}\mathrm{V}_{\exp }{ }^{*} \\
(\mathrm{kN})\end{array}$} & \multicolumn{4}{|c|}{ CSA S304.1 } & \multicolumn{2}{|c|}{ CSA A23.3 } & \multicolumn{2}{|c|}{ Hoult et al. } & \multicolumn{4}{|c|}{ TMS 402} \\
\hline & & & & & & & & & $\begin{array}{l}f_{\mathrm{bl} \text { I pecified }} \\
(\mathrm{MPa})\end{array}$ & $\begin{array}{l}\mathrm{f}_{\mathrm{m} \text { Specified }} \\
\text { (MPa) }\end{array}$ & 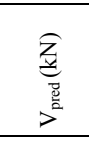 & 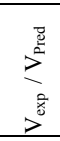 & 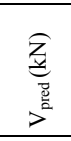 & ${\stackrel{p}{p^{2}}}^{\overrightarrow{8}}$ & 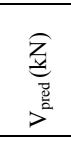 & $\begin{array}{l}\sum^{\vec{d}} \\
p^{\frac{8}{5}} \\
\end{array}$ & $\begin{array}{c}f_{b l} \\
\text { Specified } \\
\text { (MPa) }\end{array}$ & $\begin{array}{l}f_{m \text { Specified }} \\
(\mathrm{MPa})\end{array}$ & 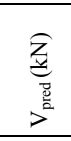 & $\sum_{>^{\frac{8}{5}}}^{p^{\frac{8}{2}}}$ \\
\hline SS1 & 3.17 & 300 & 190 & 0.88 & - & - & 80.5 & 40.8 & 30.0 & 13.5 & 33.5 & 1.22 & 34.6 & 1.18 & 36.8 & 1.11 & 37.5 & 20.7 & 48.5 & 0.84 \\
\hline SS2 & 3.11 & 305 & 190 & 1.72 & - & - & 140.2 & 70.5 & 30.0 & 13.5 & 34.1 & 2.07 & 43.1 & 1.64 & 44.1 & 1.60 & 37.5 & 20.7 & 49.3 & 1.43 \\
\hline SS3 & 3.11 & 305 & 190 & 1.72 & 0.67 & - & 202.8 & 101.9 & 30.0 & 13.5 & 74.6 & 1.37 & 89.1 & 1.14 & 92.4 & 1.10 & 37.5 & 20.7 & 69.9 & 1.46 \\
\hline SS4 & 3.10 & 307 & 190 & 0.30 & - & - & 72.4 & 36.7 & 30.0 & 13.5 & 34.3 & 1.07 & 24.2 & 1.51 & 27.7 & 1.33 & 37.5 & 20.7 & 49.6 & 0.74 \\
\hline SS6 & 3.11 & 305 & 190 & 2.42 & - & - & 143.2 & 72.1 & 30.0 & 13.5 & 34.1 & 2.12 & 46.7 & 1.54 & 47.1 & 1.53 & 37.5 & 20.7 & 49.3 & 1.46 \\
\hline SM1 & 3.05 & 885 & 190 & 0.83 & - & - & 189.8 & 98.40 & 29.9 & 13.5 & 74.88 & 1.31 & 72.7 & 1.35 & 75.3 & 1.31 & 36.3 & 20.7 & 143.0 & 0.69 \\
\hline SM1D & 3.14 & 885 & 190 & 0.83 & - & - & 173.4 & 90.20 & 29.9 & 13.5 & 74.88 & 1.20 & 72.1 & 1.25 & 74.7 & 1.21 & 36.3 & 20.7 & 143.0 & 0.63 \\
\hline SM2 & 3.18 & 875 & 190 & 1.68 & - & - & 228.6 & 117.8 & 29.9 & 13.5 & 74.52 & 1.58 & 85.8 & 1.37 & 86.4 & 1.21 & 36.3 & 20.7 & 141.4 & 0.83 \\
\hline SM3 & 3.15 & 868 & 190 & 1.70 & 0.52 & - & 424.4 & 215.7 & 30 & 13.5 & 164.54 & 1.31 & 227.0 & 0.95 & 236.6 & 0.91 & 36.3 & 20.7 & 185.5 & 1.16 \\
\hline SM4 & 3.16 & 880 & 190 & 0.33 & - & - & 130.8 & 68.5 & 29.9 & 13.5 & 74.70 & 0.92 & 52.4 & 1.31 & 57.6 & 1.19 & 36.3 & 20.7 & 142.2 & 0.48 \\
\hline SM6 & 3.16 & 880 & 190 & 0.84 & - & $\begin{array}{l}\text { No. } 15 \\
@ 200\end{array}$ & 213 & 110 & 29.9 & 13.5 & 74.70 & 1.47 & 103.1 & 1.07 & 110.3 & 1.00 & 36.3 & 20.7 & 142.2 & 0.77 \\
\hline SL1 & 3.02 & 1420 & 240 & 0.82 & - & - & 319.4 & 171 & 25 & 11.8 & 93.46 & 1.83 & 111.2 & 1.54 & 113.3 & 1.51 & 29.8 & 19.2 & 279.2 & 0.61 \\
\hline SL2 & 3.02 & 1422 & 240 & 0.82 & - & - & 340.8 & 181.7 & 25 & 11.8 & 93.59 & 1.94 & 111.2 & 1.63 & 113.4 & 1.60 & 29.8 & 19.2 & 279.6 & 0.65 \\
\hline & & & & & & & & & & & Mean & 1.49 & & 1.34 & & 1.27 & & & & 0.90 \\
\hline & & & & & & & & & & & STDV & 0.39 & & 0.23 & & 0.23 & & & & 0.35 \\
\hline & & & & & & & & & & & $\operatorname{COV}(\%)$ & 26 & & 17 & & 18 & & & & 39 \\
\hline
\end{tabular}

* Vexp $=\frac{\text { Pexp }}{2}+\mathrm{V} @ \mathrm{~d}$ from point load (due to self weight $)$ 
Table 5-4: Comparisons of Predictions of North American Codes Based on the Specified Masonry Compressive Strength and the Prisms Compressive Strength

\begin{tabular}{|c|c|c|c|c|c|c|c|c|}
\hline \multirow{2}{*}{\begin{tabular}{|c|} 
VExp \\
\hline VPred
\end{tabular}} & \multicolumn{9}{|c|}{ Codes } \\
\cline { 2 - 9 } & $\begin{array}{c}\text { CSA S304.1 } \\
\mathrm{f}_{\mathrm{m}} \\
\text { prism tests }\end{array}$ & $\begin{array}{c}\mathrm{f}_{\mathrm{m}} \\
\text { tabulated } \\
\text { values }\end{array}$ & $\begin{array}{c}\mathrm{f}_{\mathrm{m}} \\
\text { prism tests }\end{array}$ & $\begin{array}{c}\mathrm{f}_{\mathrm{m}} \\
\text { tabulated } \\
\text { values }\end{array}$ & $\begin{array}{c}\mathrm{f}_{\mathrm{m}} \\
\text { prism tests }\end{array}$ & $\begin{array}{c}\mathrm{f}_{\mathrm{m}} \\
\text { tabulated } \\
\text { values }\end{array}$ & $\begin{array}{c}\mathrm{f}_{\mathrm{m}} \\
\text { prism tests }\end{array}$ & $\begin{array}{c}\mathrm{f}_{\mathrm{m}} \\
\text { tabulated } \\
\text { values }\end{array}$ \\
\hline Mean & 1.22 & 1.49 & 1.19 & 1.34 & 1.13 & 1.27 & 0.91 & 0.90 \\
\hline STDV & 0.33 & 0.39 & 0.17 & 0.23 & 0.17 & 0.23 & 0.35 & 0.35 \\
\hline $\operatorname{COV(\% )}$ & 27 & 26 & 14 & 17 & 15 & 18 & 39 & 39 \\
\hline
\end{tabular}

\subsection{Size Effect in RMB Series with $\rho=1.68 \%$ and $\rho=0.32 \%$}

To show that size effect is real and significant in reinforced masonry at different reinforcement ratios, it was decided to compare the results of SS2 with SM2 $(\rho=1.68 \%)$ and SS4 with SM4 $(\rho=0.32 \%)$.

\subsubsection{Test Results of SS2 and SM2}

\section{Load deflection Response}

It can be seen in Figure 5-24 that SM2 failed a shear stress that is 58\% lower than that of specimen SS2. This reduction in failure shear stress was associated by a significant reduction in ductility. Specimen SM2 failed at a deflection of 1/830th of the span compared to specimen SS2 which failed at a deflection of 1/246th of the span. 


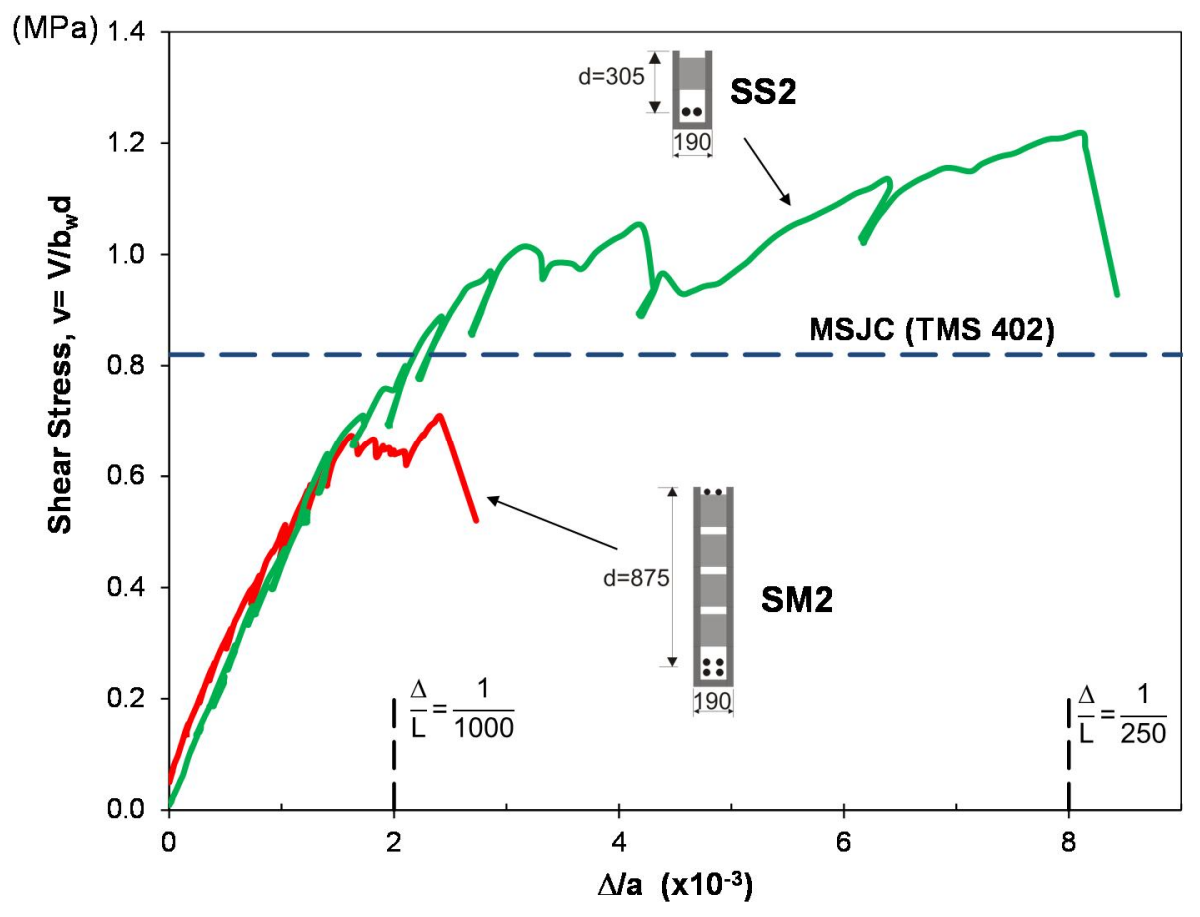

Figure 5-24: Relative Deflections of Beams SS2 and SM2

\section{Failure Progression of SS2 and SM2}

\section{Specimen SS2}

Figure 5-25 shows the crack patterns of specimen SS2 through the test. The progression of failure of SS2 is similar to that of specimen SS1 until the formation of the masonry teeth in the shear spans. At a load of $116.6 \mathrm{kN}$ (corresponding to $83 \%$ of the failure load) the far crack in the east span travelled horizontally through the bed joint joining the crack close to the point load which in turn extended diagonally towards the point load. The far crack also extended diagonally backward towards the east support. This was identified as an initial breakdown in beam action in the east span as it was associated with a significant increase in the shear strains following a sudden drop in load after this initial breakdown in beam action as shown in Figure 5-26. Following this initial breakdown in beam action a shear key was formed in the east span allowing shear stresses to be resisted by the interlock of the adjacent masonry units as shown in 
Figure 5-25. Aggregate interlock was still active at this stage particularly in the diagonal portions of the crack. Similarly, an initial breakdown in beam action occurred in the west span followed by formation of a shear key as well. At a load of $132 \mathrm{kN}$ (equivalent to $94 \%$ of the failure load) a new diagonal portion of the dominant crack branched from the bed joint and extended upward through the top course towards the point load.. At a load of $140.3 \mathrm{kN}$, the diagonal crack widened extensively causing specimen SS2 to fail due to breakdowns in the shear key and aggregate interlock.

To explore whether arch action was engaged after the initial breakdown of beam action, consider Figure 5-27 which shows the crack pattern of the east span of specimen SS2 prior to failure. It can be seen that it is impossible to have a strut that is cut by the horizontal and vertical cracks of the corner (A) of the shear key even if a prismatic strut with a compression depth of zero is assumed. If a strut is formed, then the continuity of the compressive stresses within corner (A) is kept by interlocking the masonry units meeting at the corner which means that it is the shear key mechanism that is resisting the shear rather than the arch action. One more proof that arch action was not engaged is the formation of the diagonal crack and the failure of the beam due to the widening of the crack and the breakdown of the shear key at corner (A). This failure is fundamentally different than a typical arch action type failure. 


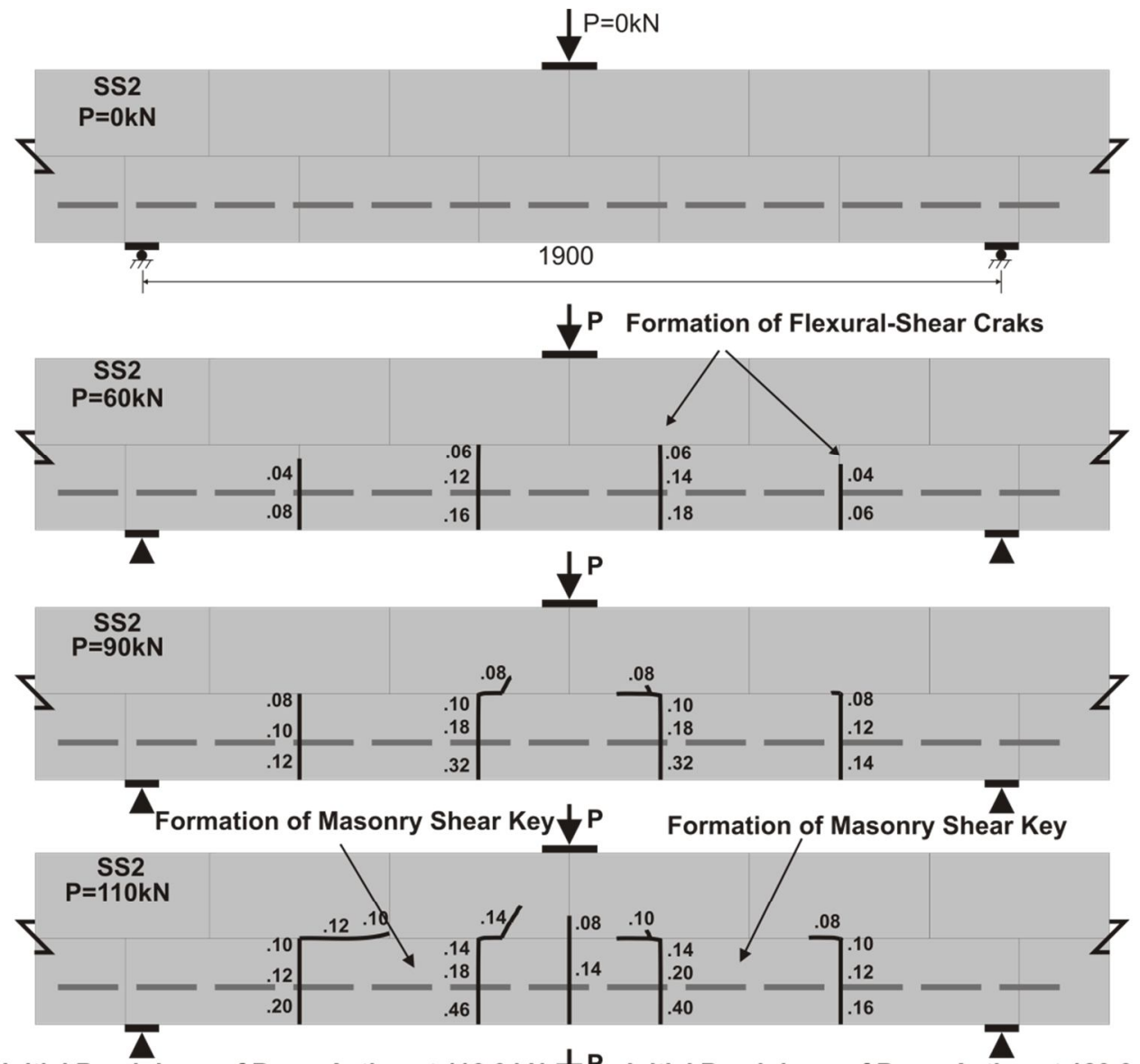

Initial Breakdown of Beam Action at $116.6 \mathrm{kN} \downarrow P \quad$ Initial Breakdown of Beam Action at 120.6

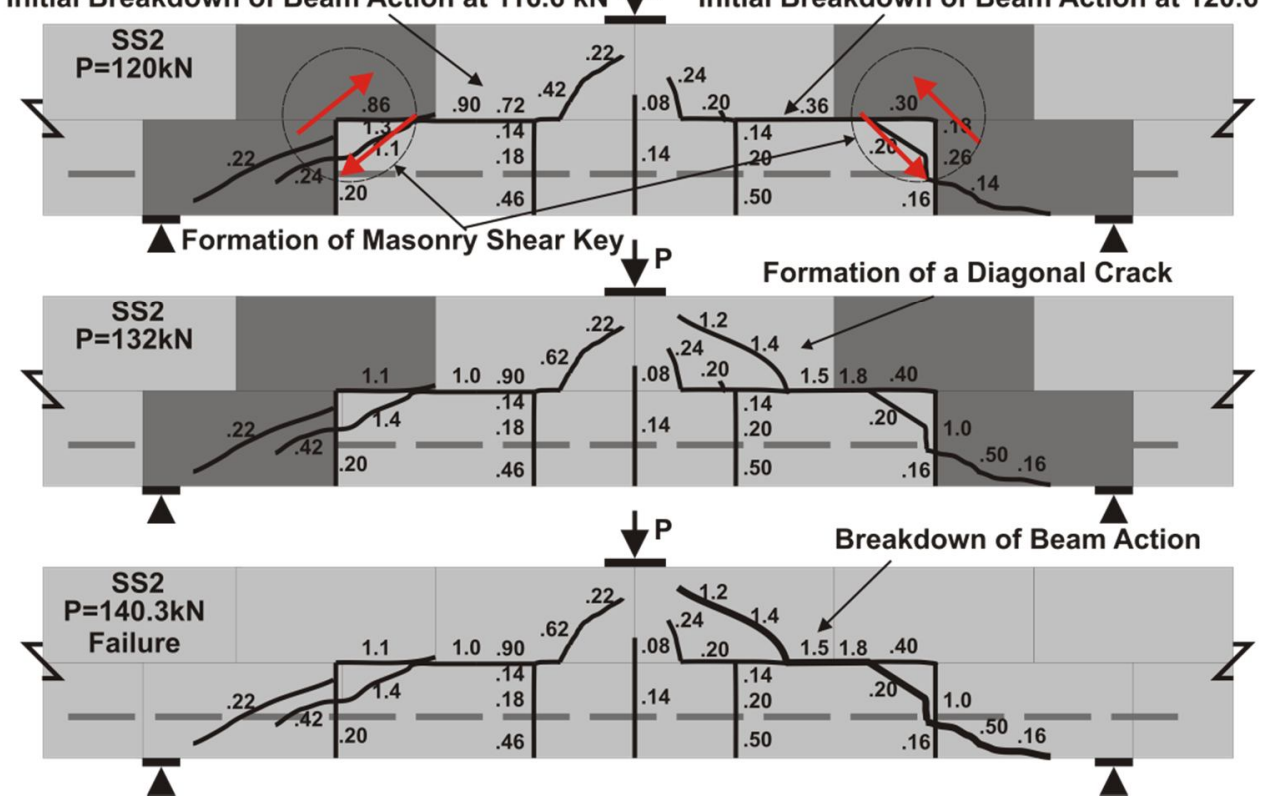

Figure 5-25: Crack Patterns for Specimen SS2 


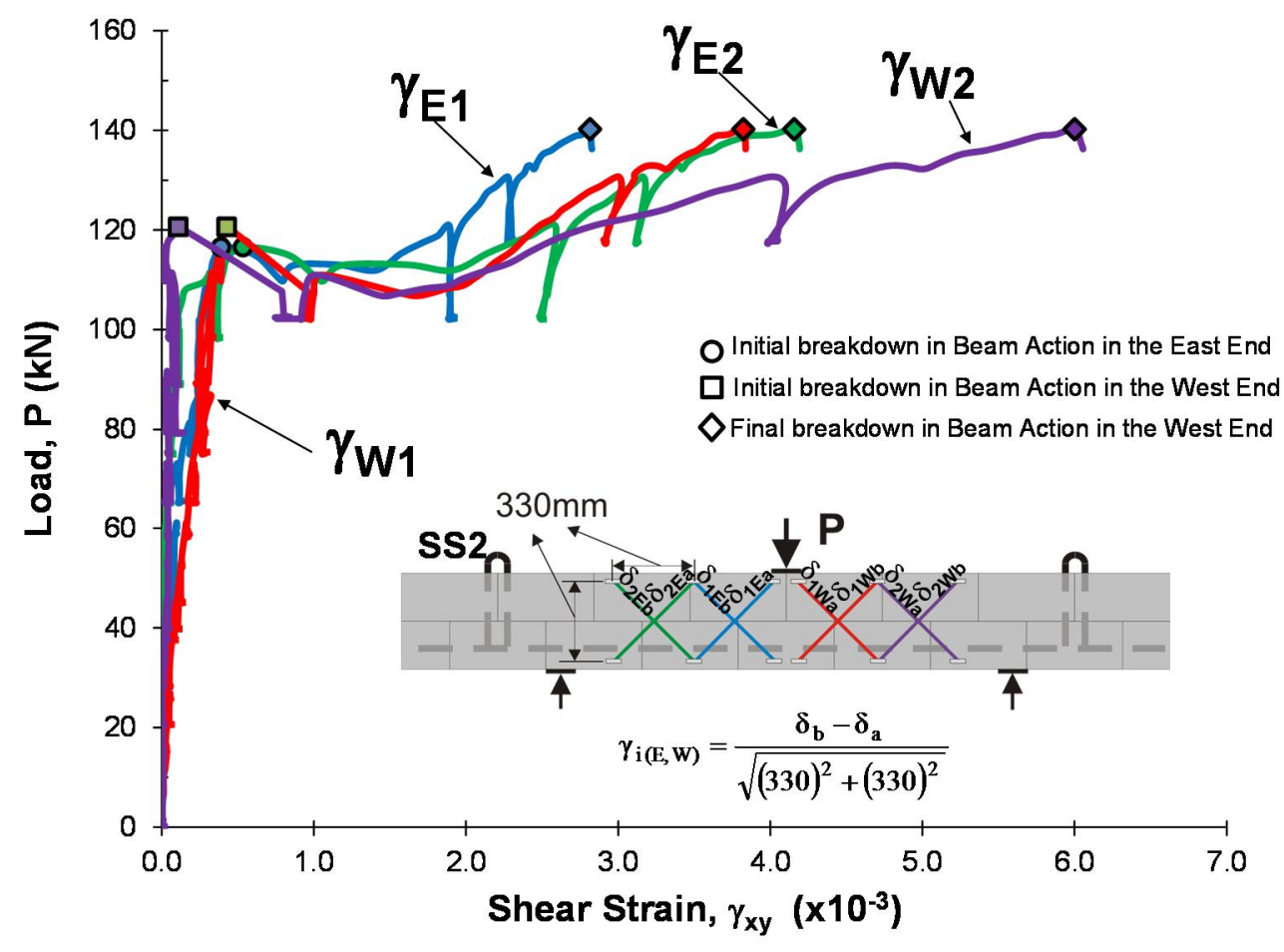

Figure 5-26: Shear Strains in Specimen SS2
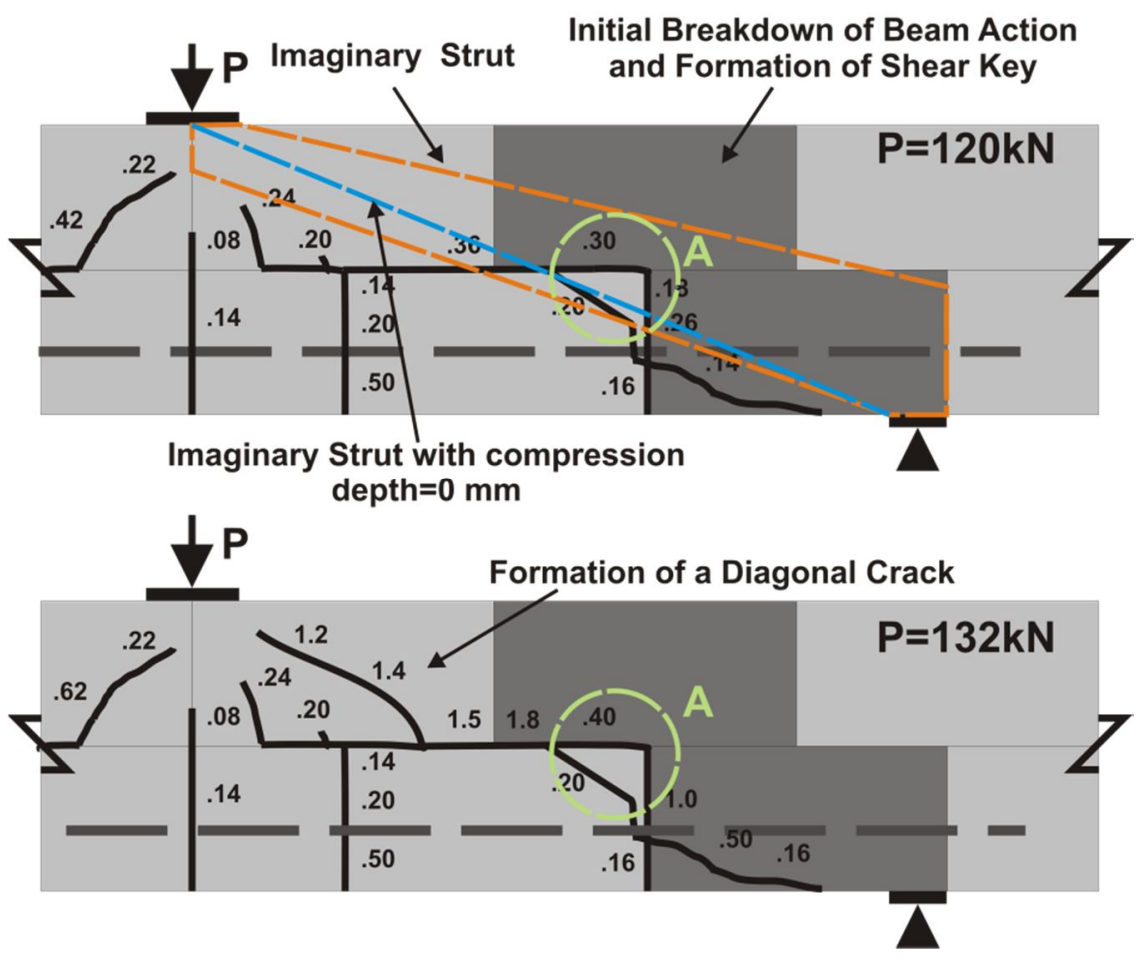

Figure 5-27: Shear Strains in Specimen SS2 


\section{Specimen SM2}

Figure 5-28 shows the crack patterns of specimen SM2 through different load stages until failure. It can be observed that the cracking sequence of specimen SM2 is similar to that of specimen SM1 until the initial of the breakdown of beam action in the west span. This initial breakdown in beam action occurred at a load of $217 \mathrm{kN}$ (equivalent to $95 \%$ of the failure load) and was marked by a significant increases in shear strains in the west shear span (see Figure 5-29). However, while a shear key was developed in SM1, it is more likely that arch action was engaged since the dominant crack was close to the loading point leaving a large un-cracked portion of the beam in which an effective strut can form extending from the point load towards the support. Although the assumed strut is cut by horizontal crack near the support (Detail A in Figure 2-28), the width of the this crack is less the $0.5 \mathrm{~mm}$ and it is possible that the grout column is intact or lightly cracked allowing a continuous path for compressive stresses in the strut. A sudden increase in the steel strains at the quarter and end of the west span (see Figure 530) were noticed. Furthermore, no shear keys were identified in the west span. At a load of 229 $\mathrm{kN}$, a major crack developed suddenly in the east span and propagated towards the point load and backward towards the east support causing an obvious diagonal tension failure due to the breakdown in aggregate interlock mechanism. This crack passed diagonally the masonry unit, horizontally through bed joint and vertically through the head joints. Significant increases in the shear strains in the west span were measured following the failure as shown in Figure 5-29. . 


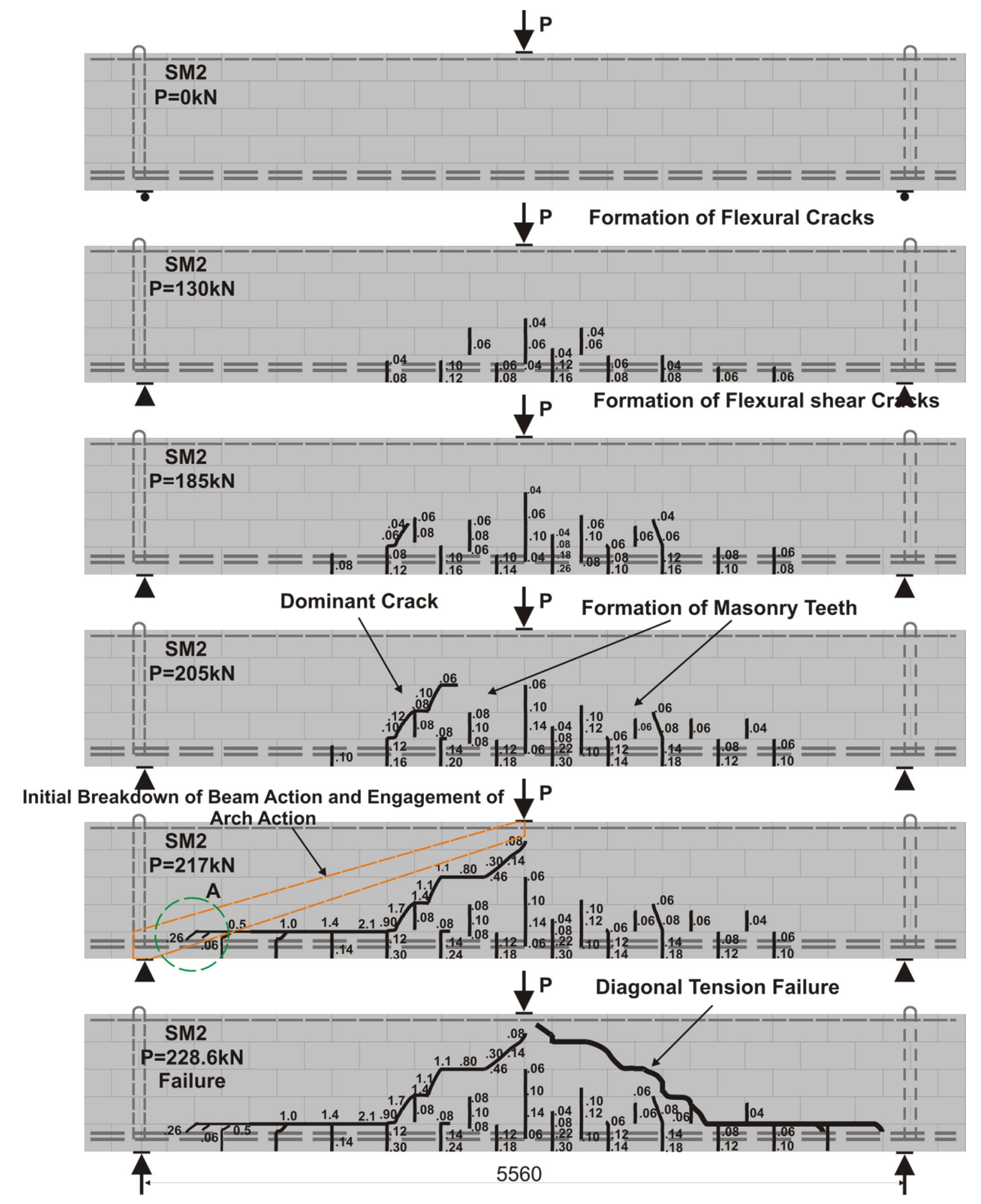

Figure 5-28: Crack Patterns for Specimen SM2 


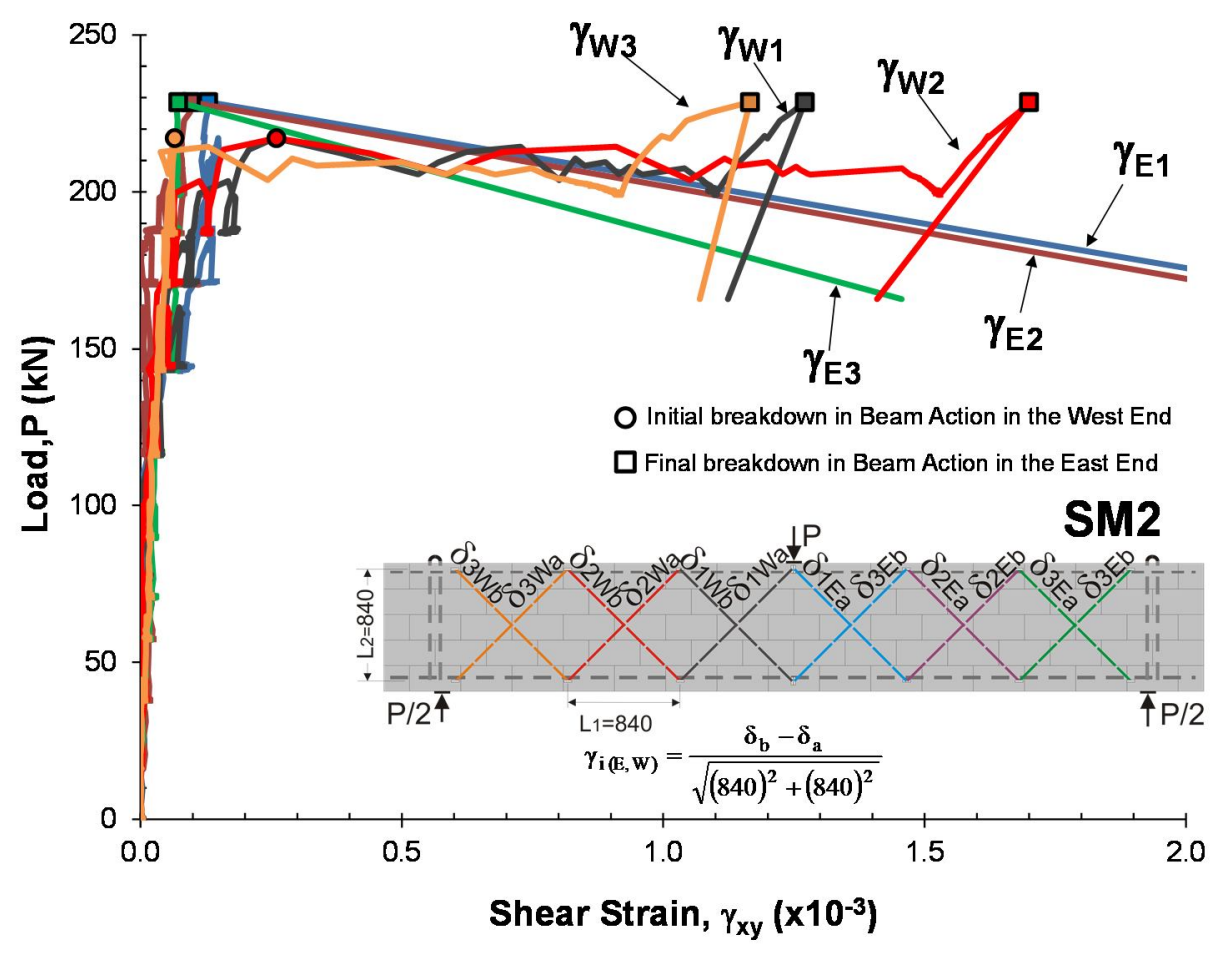

Figure 5-29: Shear Strains in Specimen SS2

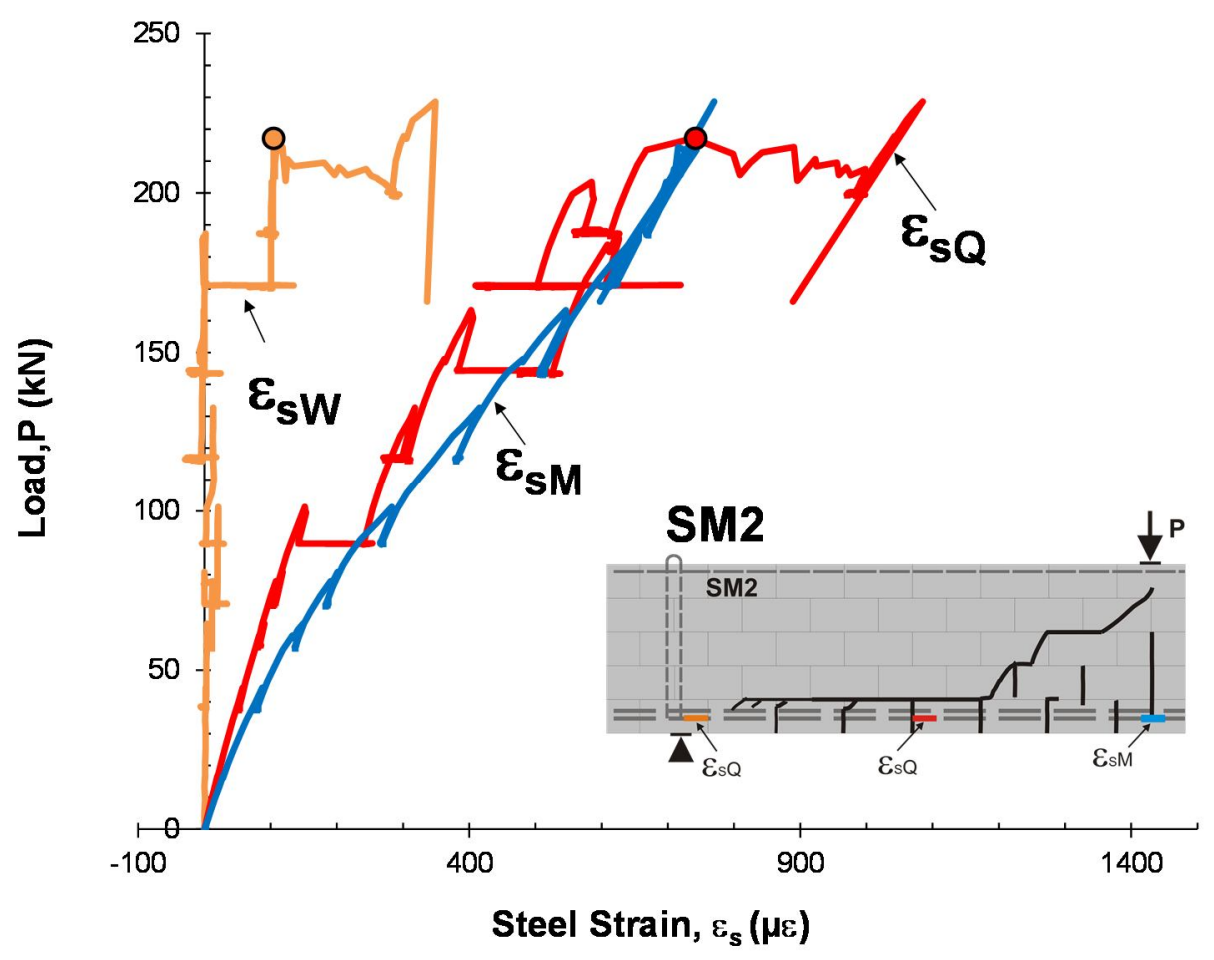

Figure 5-30: Steel Strains in the West Span of Specimen SM2 


\section{Crack Spacing and Crack Widths of SS2 and SM2}

Figure 5-31 shows the crack patterns of SS2 and SM2 at shear stress of $0.68 \mathrm{MPa}$. The average crack spacing at mid-depth of specimen SS2 was $400 \mathrm{~mm}$ (equivalent to 1.33d). This supports the observation made in specimen SS1 that the crack spacing in small beans is a function of the distance between the head joints. The average crack spacing in SM2 was $465 \mathrm{~mm}$. This is equivalent to $0.53 \mathrm{~d}$, which is similar to that observed in reinforced concrete. This clearly proves that the crack spacing in the five-course beam series is a function of the effective depth of the beam in a similar fashion to reinforced concrete beams. However, despite this small increase in average crack spacing at mid-depth from the small to the medium beams, the crack widths increased significantly. It is clear from Figure 5-31 the shear stress of 0.68 MPa was critical enough to form a wide diagonal crack in the west span of SM2 beam due an initial breakdown in beam action. Specimen SM2 could only sustain an increase in load of 5\% beyond this stage. It can also be noted from Figures 5-31 and 5-32 that although the crack spacing at $0.75 \mathrm{~d}$ was constant at $400 \mathrm{~mm}$, the crack widths at this level in SM2 were larger than those in SS2. This can be related to the reduced ability of steel to control the cracks as the effective of beam increases. The average crack widths at the level of main steel exhibited only small increases from the small to medium beam. 

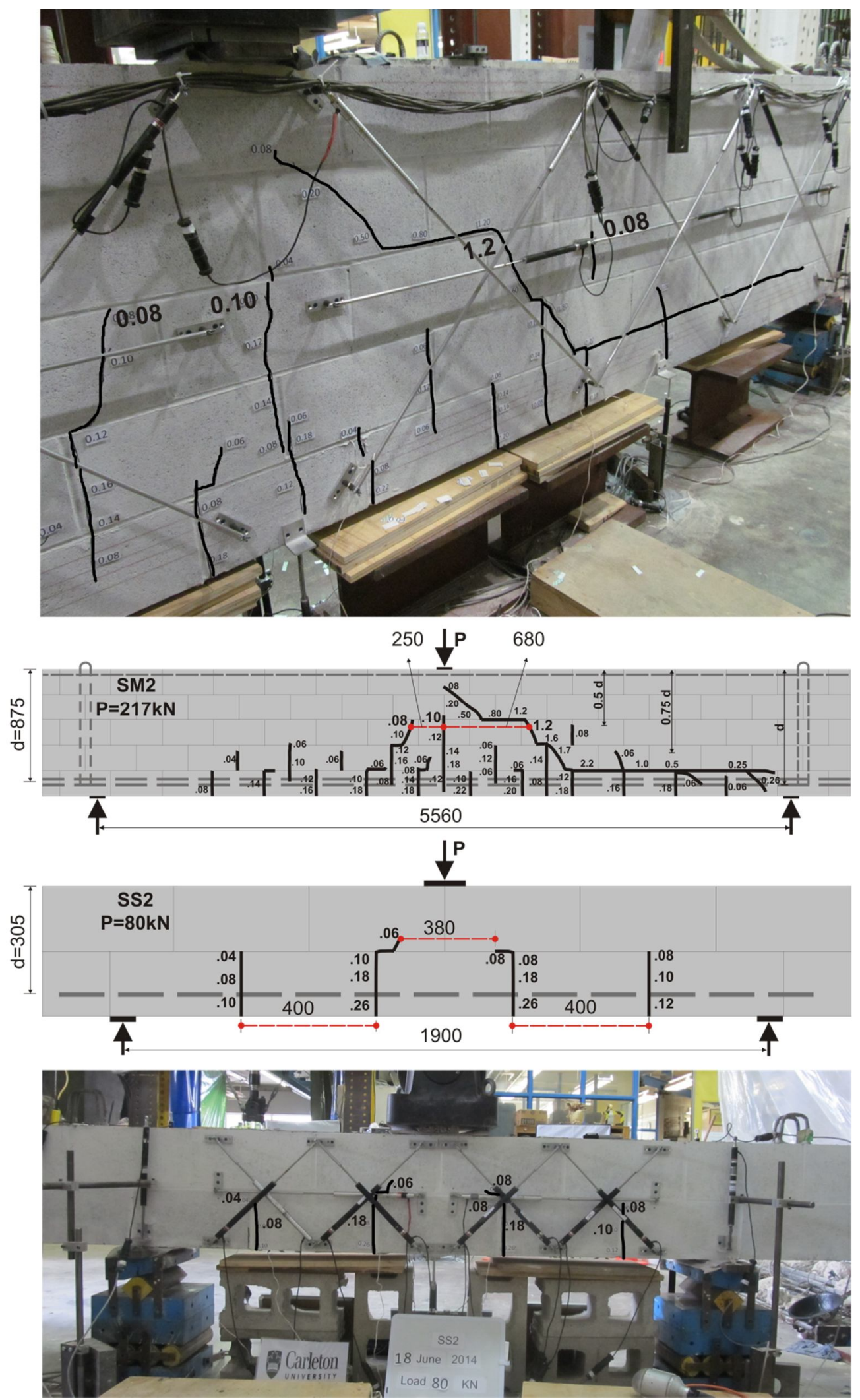

Figure 5-31: Crack Patterns in South Faces of SS2 and SM2 at Shear Stress of 0.68 MPa 

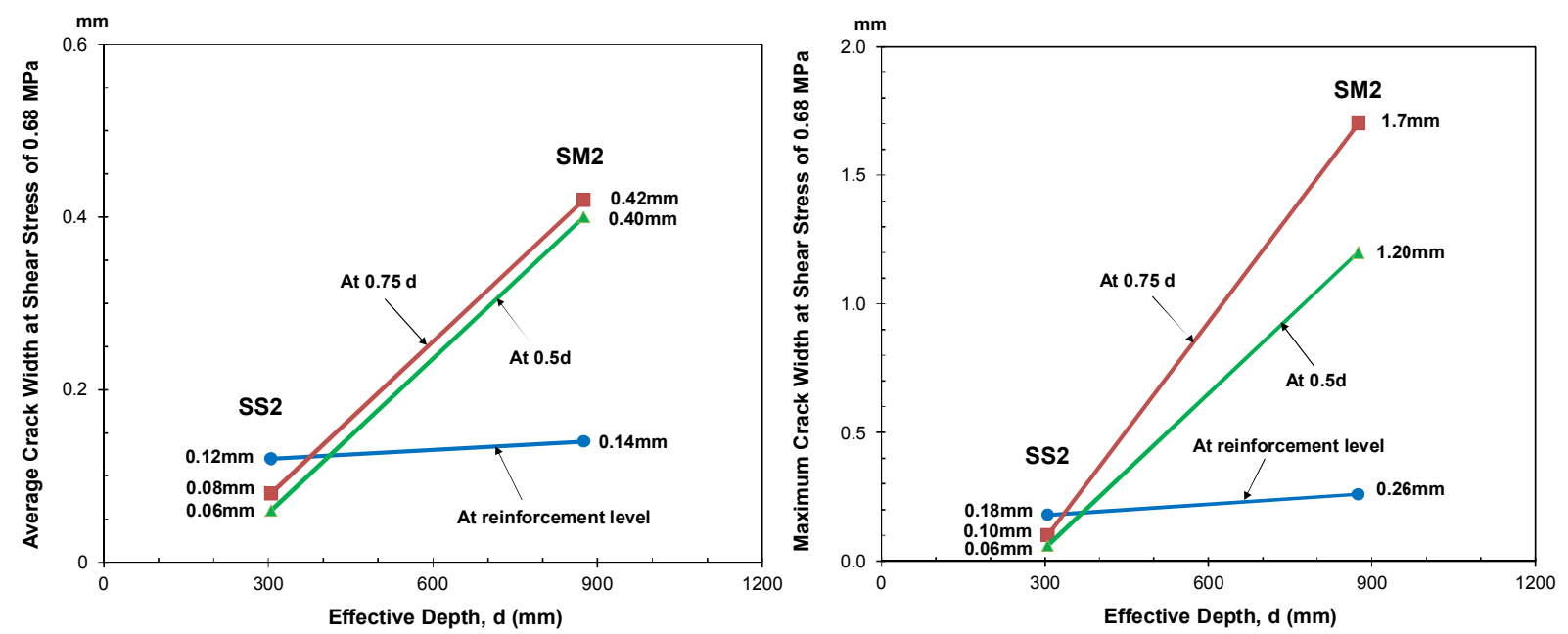

Figure 5-32: Average and Maximum Crack Widths in SS2 and SM2 Beams at a Shear Stress of $0.68 \mathrm{MPa}$

\subsubsection{Test Results of SS4 and SM4}

Specimen SS4 and SM4 are approximately identical but with different effective depths, $307 \mathrm{~mm}$ for SS4 and $880 \mathrm{~mm}$ for SM4.

\section{Load deflection Response}

Specimen SM4 $(d=880 \mathrm{~mm})$ failed at a shear stress of $65 \%$ of that of specimen SS4 $(d=307 \mathrm{~mm})$. Figure 5-33 shows the relative displacement responses of specimens SS4 and SM4. It can be seen in the figure that the relative displacement at failure in specimen SM4 was less than half of those in specimen SS4. The small specimen SS4 failed at an average deflection of 1/200th of the span, while specimen SM4 failed at deflection of only 1/580th of the span. 


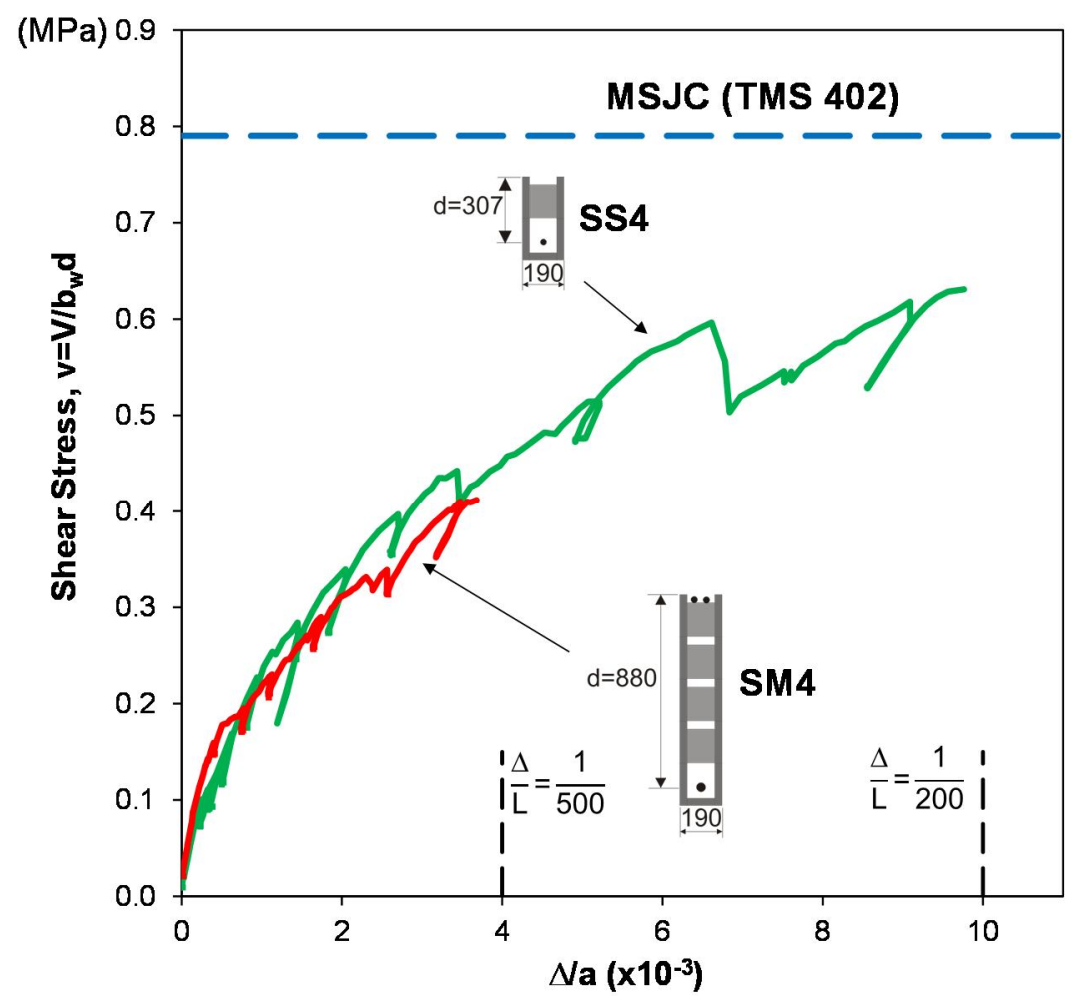

Figure 5-33: Relative Deflections of Beams SS4 and SM4

\section{Failure Progression of SS4 and SM4}

\section{Specimen SS4}

The cracking behavior of specimen SS4 was similar to those of beams SS1 and SS2 until the formation of masonry teeth in the shear spans (see Figure 5-34). At a load of $68.6 \mathrm{kN}(94 \%$ of the failure load) an initial breakdown in beam action occurred and was followed by the formation of a shear key in the eastern span as the far flexural shear crack in this span travelled through the bed joint and connected to the crack close to point load. At a load of $72.6 \mathrm{kN}$, the far crack in the western span of the beam extended upward through the head joint and the diagonally to the point load causing a clear diagonal tension failure in a similar fashion to reinforced concrete beams. The shear strains in the west span increased significantly indicating that shear stresses can no longer be transferred by aggregate interlock (see Figure 5-35). 

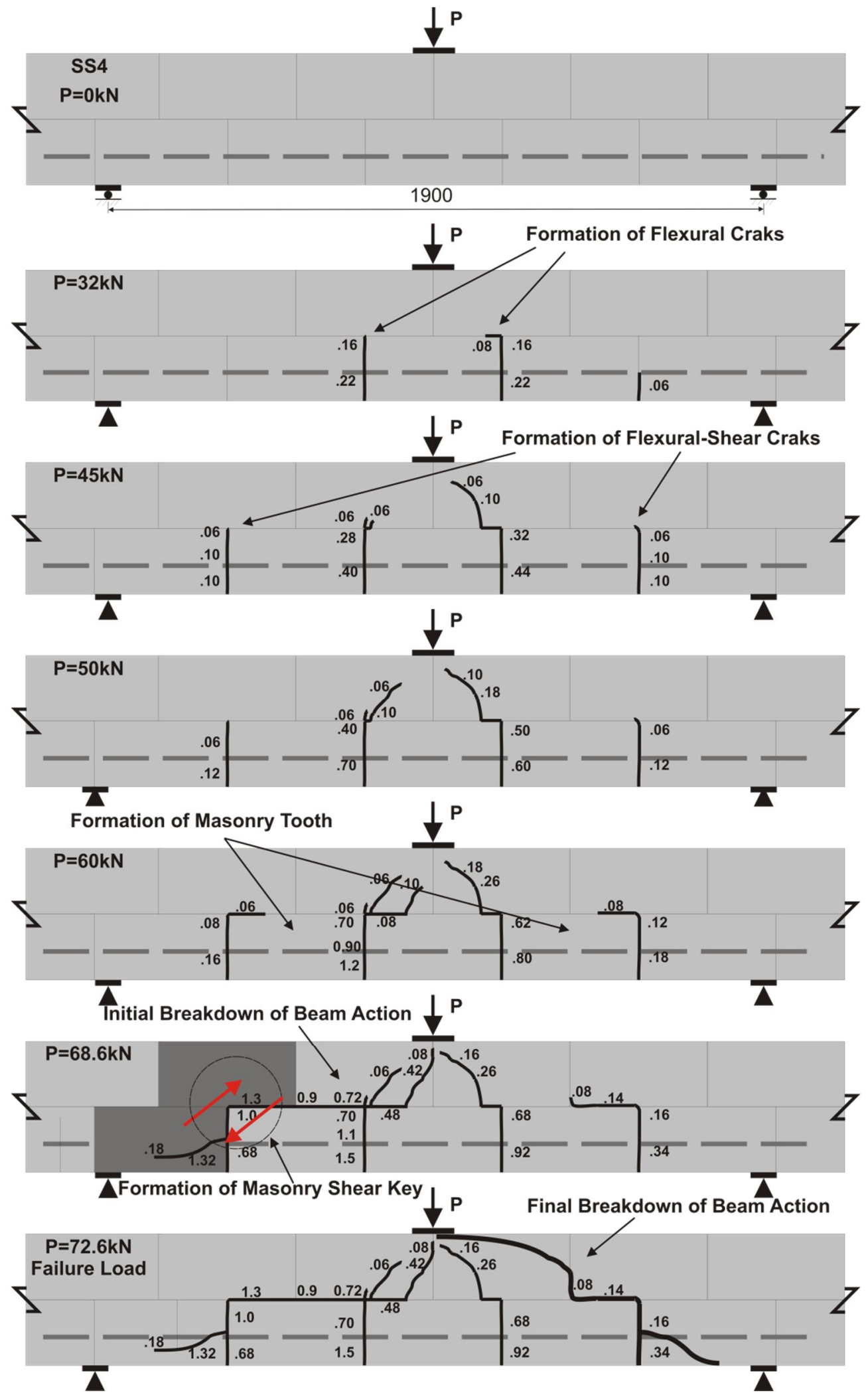

Figure 5-34: Crack Patterns for Specimen SS4 


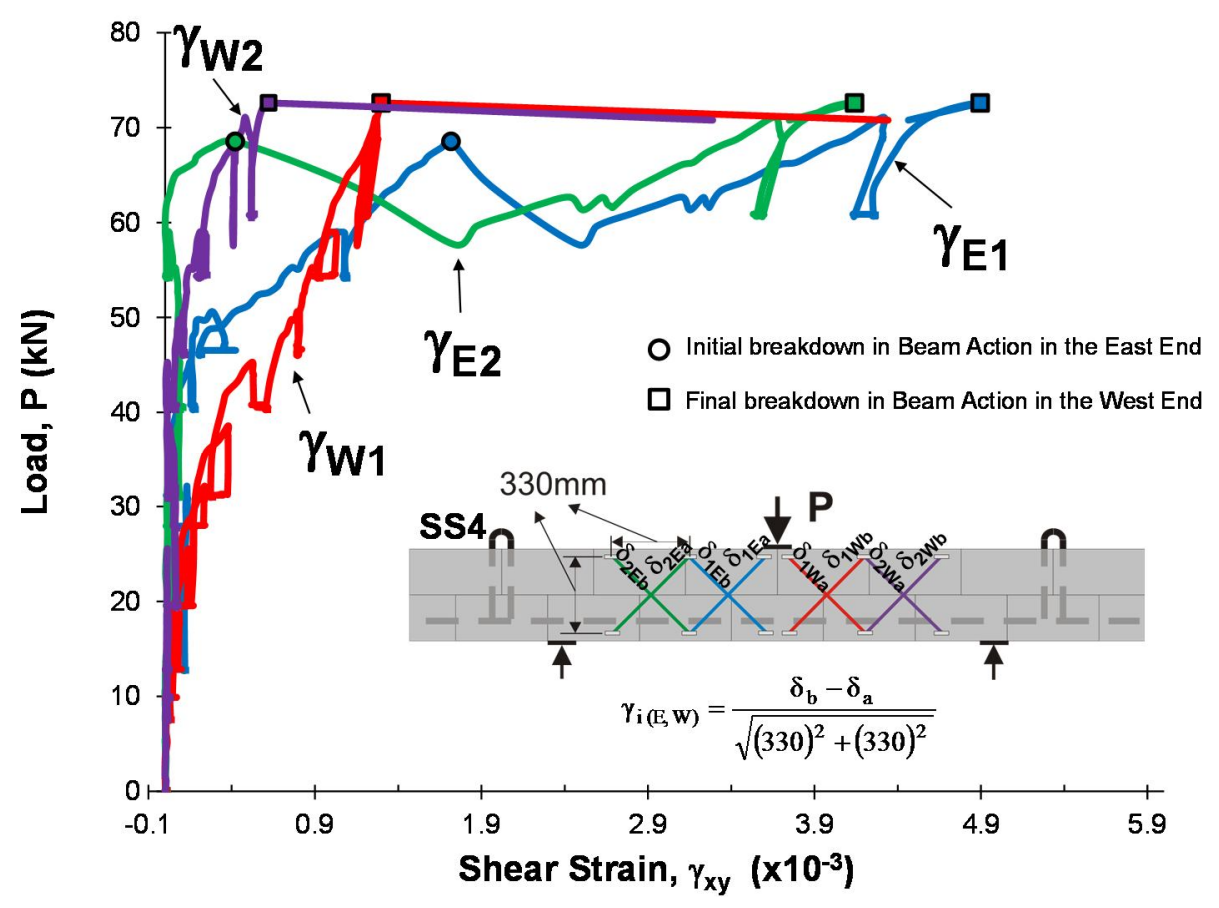

Figure 5-35: Shear Strains in Specimen SS4

\section{Specimen SM4}

The progression of failure in specimen SM4 is presented in Figure 5-36. The cracking sequence of SM4 in the early stages of loading formation of masonry teeth in the shear span is similar to those of other medium size beams. At a load of $90 \mathrm{kN}$ (equivalent to $70 \%$ of the failure load) two masonry teeth formed in the east span of SM4. Simultaneously, only one flexural shear crack formed in the west span (left span in Figure 5-36). At load of $106 \mathrm{kN}$ (corresponding to $80 \%$ of the failure load) the cracks close to the point load in both spans propagated upward towards the point load with the one in the west span additionally extended backward the bottom bed.

Suddenly at a load of $130.8 \mathrm{kN}$ a diagonal tension crack formed in the east span causing failure. This crack travelled upward horizontally through the upper bed joint (right at the top of the masonry teeth in that span) then diagonally through the upper masonry unit and backward 
diagonally through the second and third courses then horizontally through the bottom bed joint towards the east span.

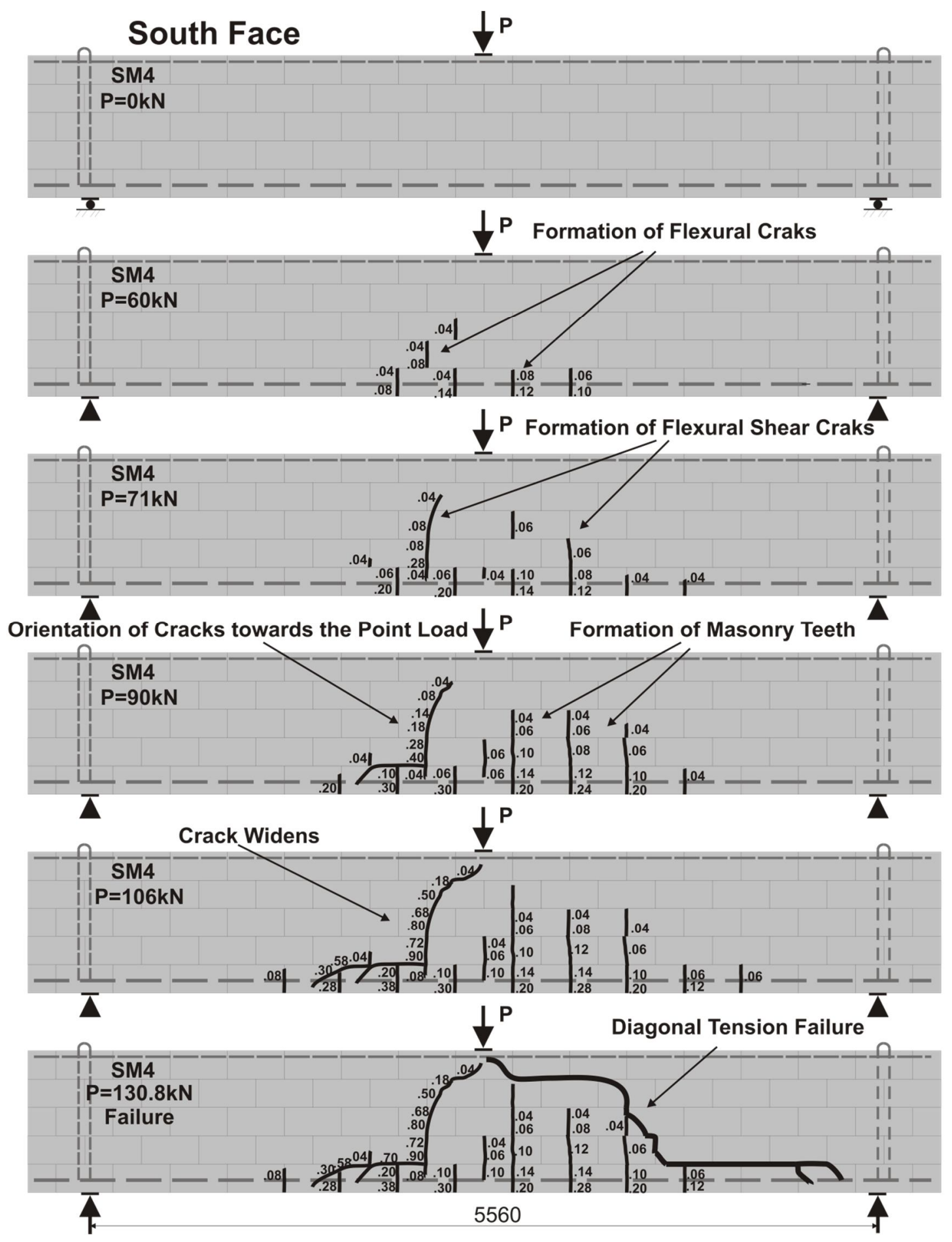

Figure 5-36: Crack Patterns for Specimen SM4 


\section{Crack Spacing and Crack Widths of SS4 and SM4}

The crack patterns of both beams at shear stress of $0.34 \mathrm{MPa}$ are presented in Figure 5-37. It can be observed that the crack spacing at mid-depth increased slightly with the increase in $d$. The average longitudinal crack spacing increased from $400 \mathrm{~mm}$ in SS4 to $453 \mathrm{~mm}$ in SM4. However, this marginal increase in crack spacing was associated with a significantly increased crack width. Figure 5-38 shows that the average crack with at mid-depth of the section in SM4 is 4 times that in SS4 while the maximum crack width in SM4 is 8 times larger than that in SS4. Similarly, the crack widths at $0.75 \mathrm{~d}$ of SM 4 were greater than those in SS4. The average and maximum crack widths at the level of main steel exhibits a small increase from SS4 to SM4 (see Figure 5-38). 


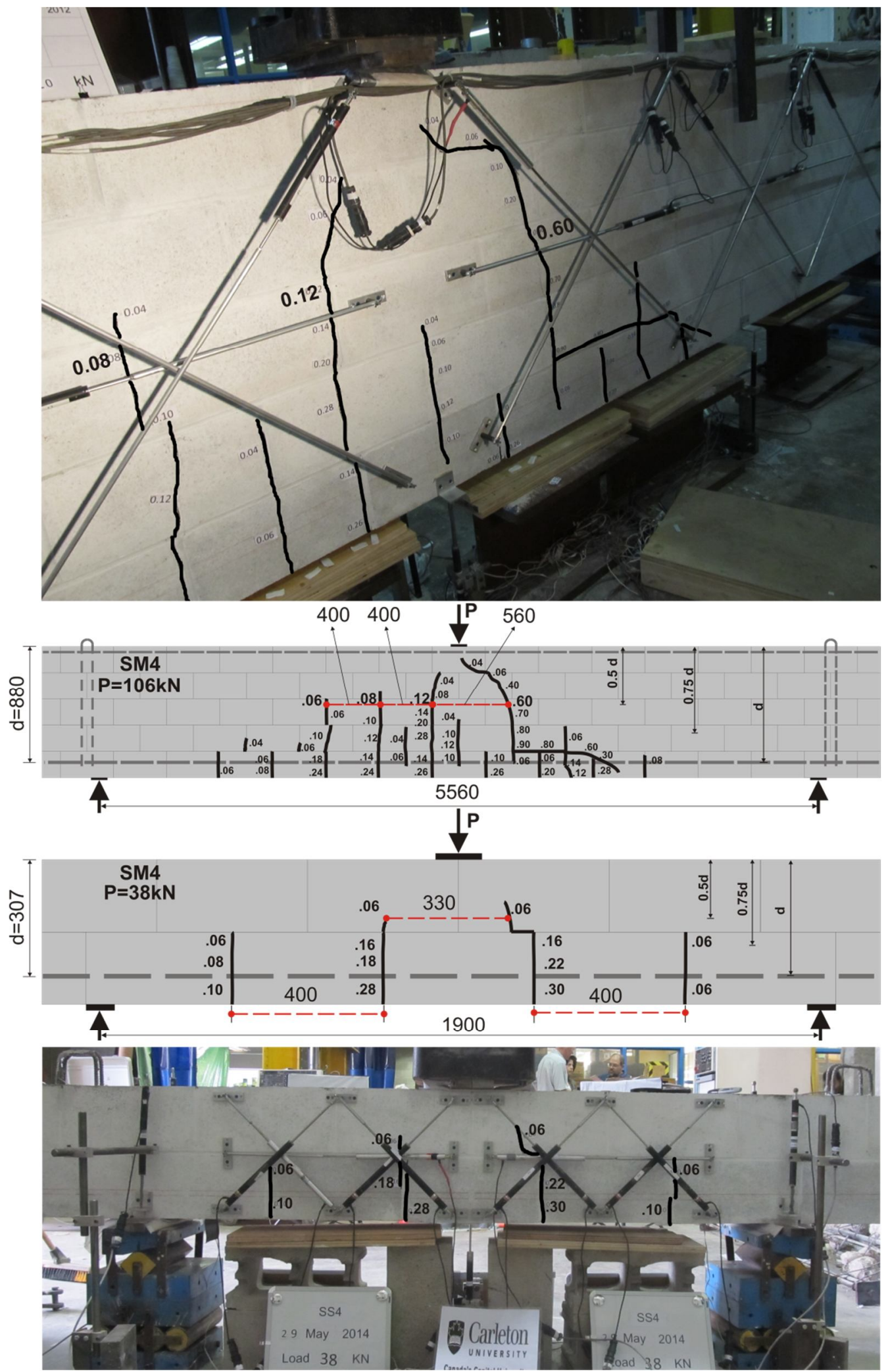

Figure 5-37: Crack Patterns in South Faces of SS4 and SM4 at Shear Stress of 0.34 MPa 

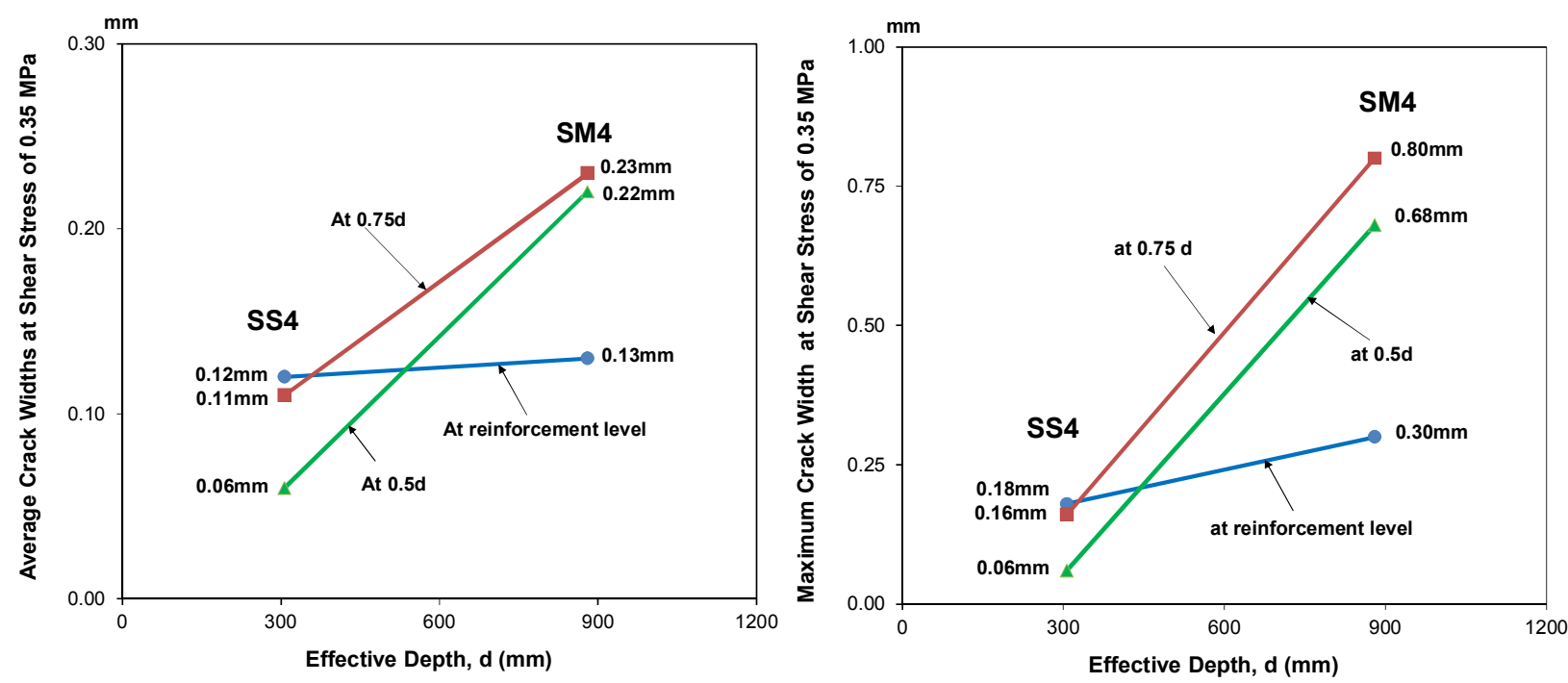

Figure 5-38: Average and Maximum Crack Widths in SS4 and SM4 at Shear Stress of 0.34 MPa

\subsubsection{Deformations at Failure}

It is important to note that as the effective depth of masonry beams without stirrups increases, the shear failures became more brittle. As discussed previously, the ratios of $\Delta / \mathrm{L}$ at failure decreased from $1 / 146$ to $1 / 830$ as the depth was increased from $305 \mathrm{~mm}$ to $875 \mathrm{~mm}$ at an average $\rho=1.70 \%$. Likewise, $\Delta / \mathrm{L}$ at failure decreased from $1 / 200$ to $1 / 580$ as the depth was increased from $307 \mathrm{~mm}$ to $880 \mathrm{~mm}$ at $\rho=1.68 \%$. The decreased in brittleness was also observed in the measured shear strains and steel strains. Specimens SM2 and SM4 failed at significantly lower shear strains than those in SS2 and SS4 respectively (see Figure 5-39). Finally, Figure 5-40 shows that measured maximum steel strains in SM2 and SM4 at failed were considerably lower than those in SS2 and SS4. 


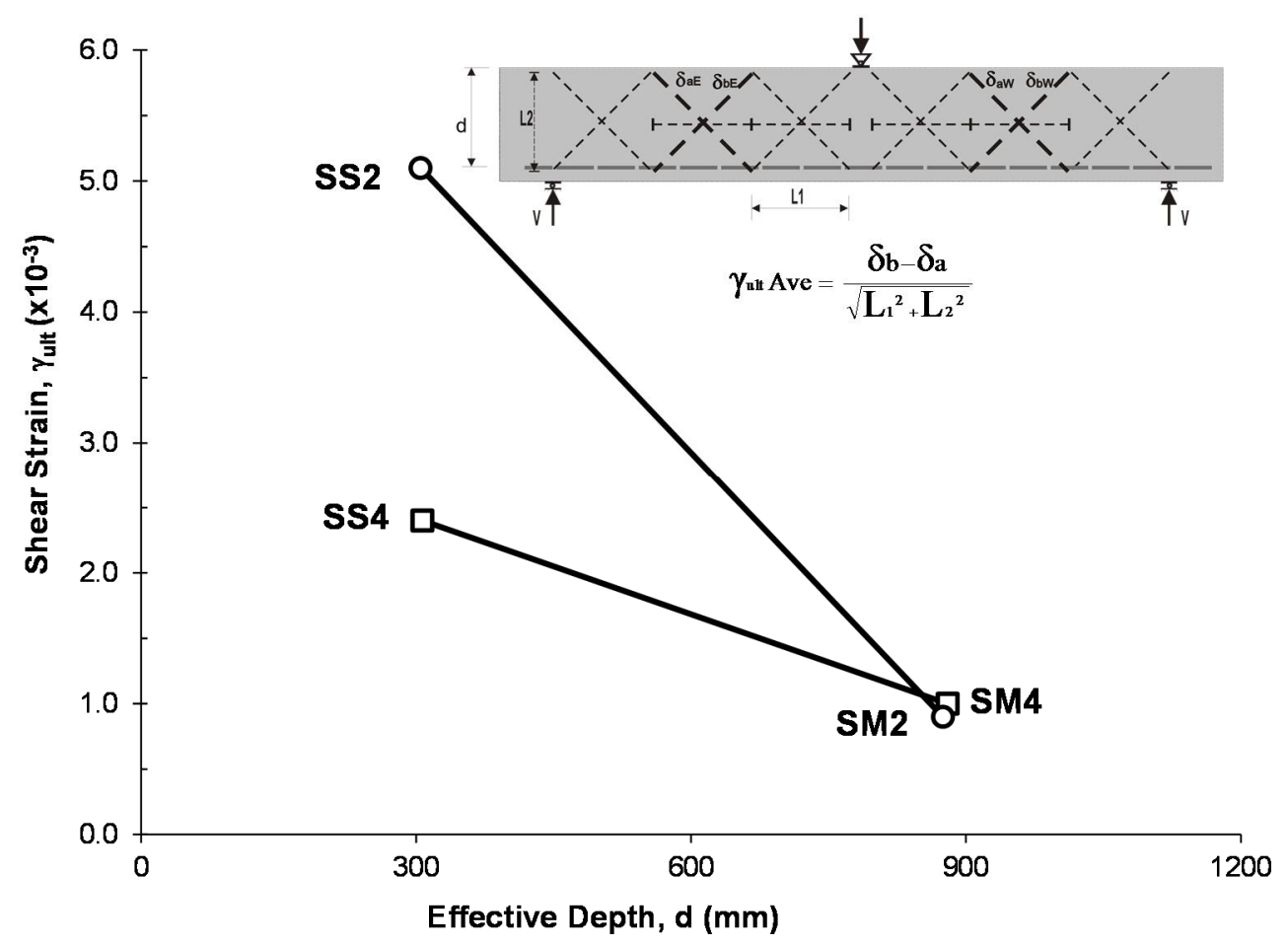

Figure 5-39: Ultimate Shear Strain in first failed Spans of Specimens SS2, SM2, SS4 and SM4.

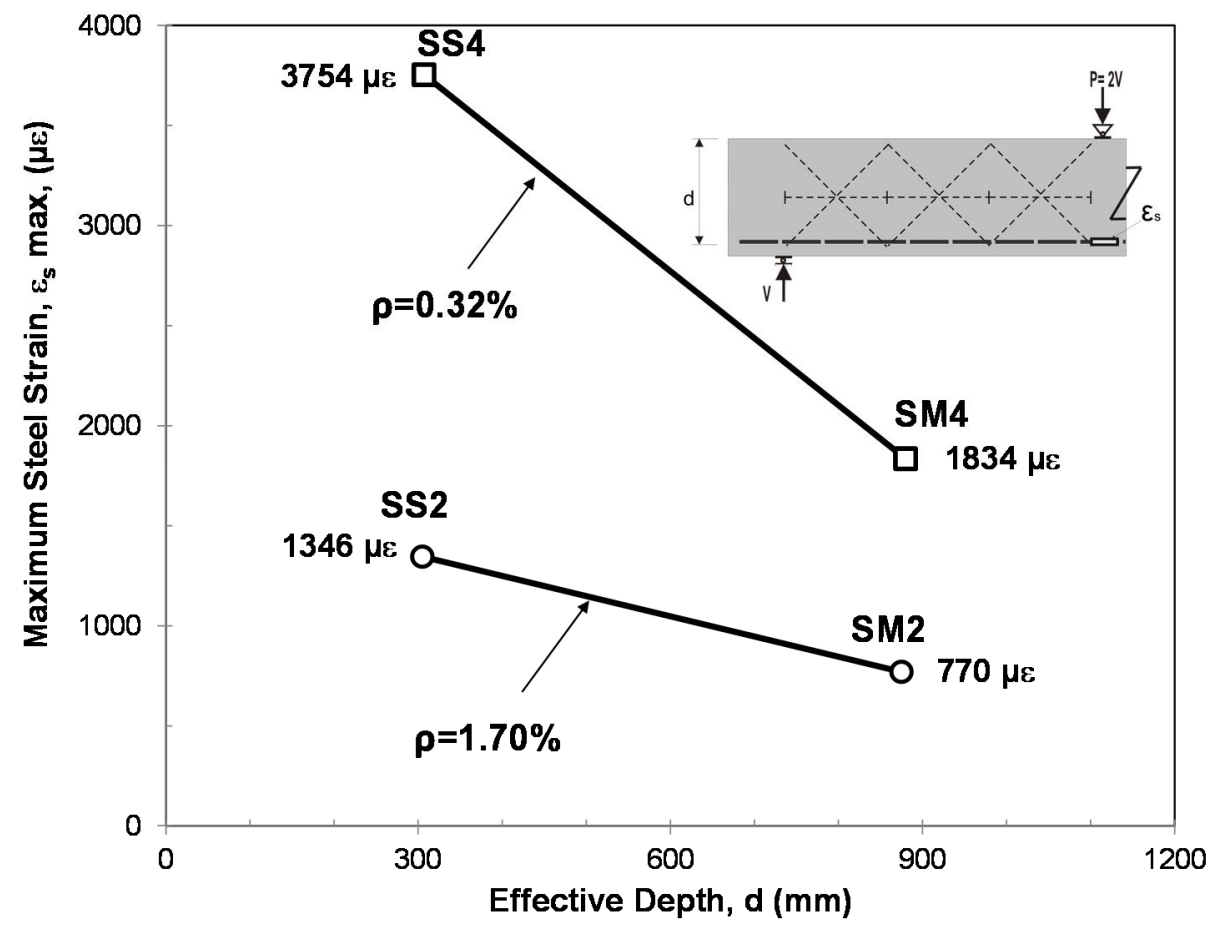

Figure 5-40: Maximum Steel Strains in Specimens SS2 and SM2 SS4 and SM4 


\subsubsection{Code Predictions}

Table 5-1 and Figure 5-41 show that the TMS 402 code gives non conservative predictions for shear strengths of SM2 and SM4 while the CSA A23.3 was able to safely and accurately predict the shear strengths of both medium size beams (SM2 and SM4) and small size beams (SS2 and SS4). The CSA S304.1, on the other hand, yielded safe predictions but with high variations. The results of SM2 show that size effect in masonry is significant even for beams with high

reinforcement ratios. Such is the case in reinforced concrete beams with high $\rho$ tested by Kani (1969). 


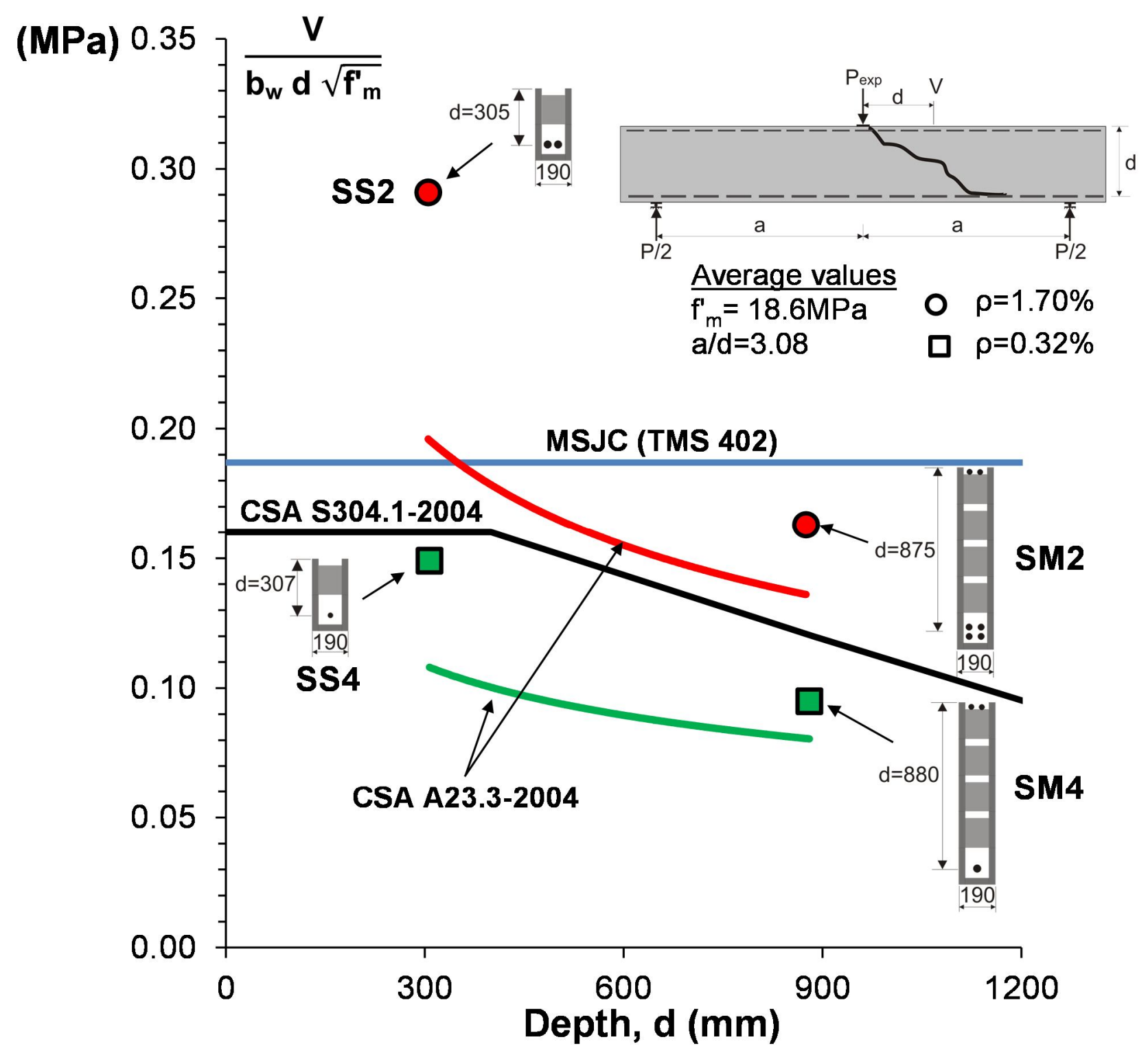

Figure 5-41: Failure Shear Stress for Specimens SS2, SM2, SS4 and SM4 


\subsection{The Effect of Crack Control Reinforcement}

It has been shown that the use of horizontally distributed steel (also known as crack control reinforcement) along the height of reinforced concrete beams increases the shear strength of these beams (Collins and Kuchman (1996), Sherwood (2008)). It has also been shown that if this steel is provided in a sufficiently large quantity that the failure shear stress is related to the vertical spacing between the layers of steel, rather than the effective depth. The CSA S304.12004 code requires that for RMB with heights exceed $600 \mathrm{~mm}$, longitudinal reinforcement should be provided. This code suggest using a single No. 15 bar for beams of up to $240 \mathrm{~mm}$ wide, and two No. 15 bars for wider beams, at $400 \mathrm{~mm}$ vertical spacing. For a RM beam with a width of $190 \mathrm{~mm}$, this ratio is approximately twice the minimum quantity required by the CSA A23.3 code which is $0.003 \mathrm{~b}_{\mathrm{w}} \mathrm{s}_{\mathrm{z}}$.

In the current investigation it was decided to study the behavior reinforced masonry beams reinforced with crack control steel. Specimen SM6 is reinforced with a single No. 15 bar in every course (200 $\mathrm{mm}$ between the layers) from the second to the forth course. This arrangement meets the CSA A23.3 minimum requirement of $0.003 b_{w} s_{z}$ and is twice the requirement by the CSA S304.1 code. The results of specimen SM6 will be compared with its identical reference beam without crack control steel, specimen SMID. Both beams have approximately the same dimensions and main reinforcement ratio. To evaluate the effectiveness of crack control steel in eliminating the size effect in reinforced masonry, comparison will be performed between specimens SS1, SM1D and SM6. 


\subsubsection{Failure Shear Stresses}

The presence of crack control steel had a major effect on shear strength (see Figure 5-42). Specimen SM6 failed at a shear stress of 0.66 MPa, whereas SM1D failed at a shear stress of $0.54 \mathrm{MPa}$. This corresponds to an increase of $23 \%$. Likewise, the ratio $\Delta /(\mathrm{L} / 2)$ at failure increased from 1/500 to 1/350. These findings echo those of Sherwood (2008) and Collins and Kuchman (1996) who found similar major enhancements in shear strength of reinforced concrete beams when crack control steel was added. Furthermore, these results represent the first experimental evidence showing a similar beneficial effect in masonry.

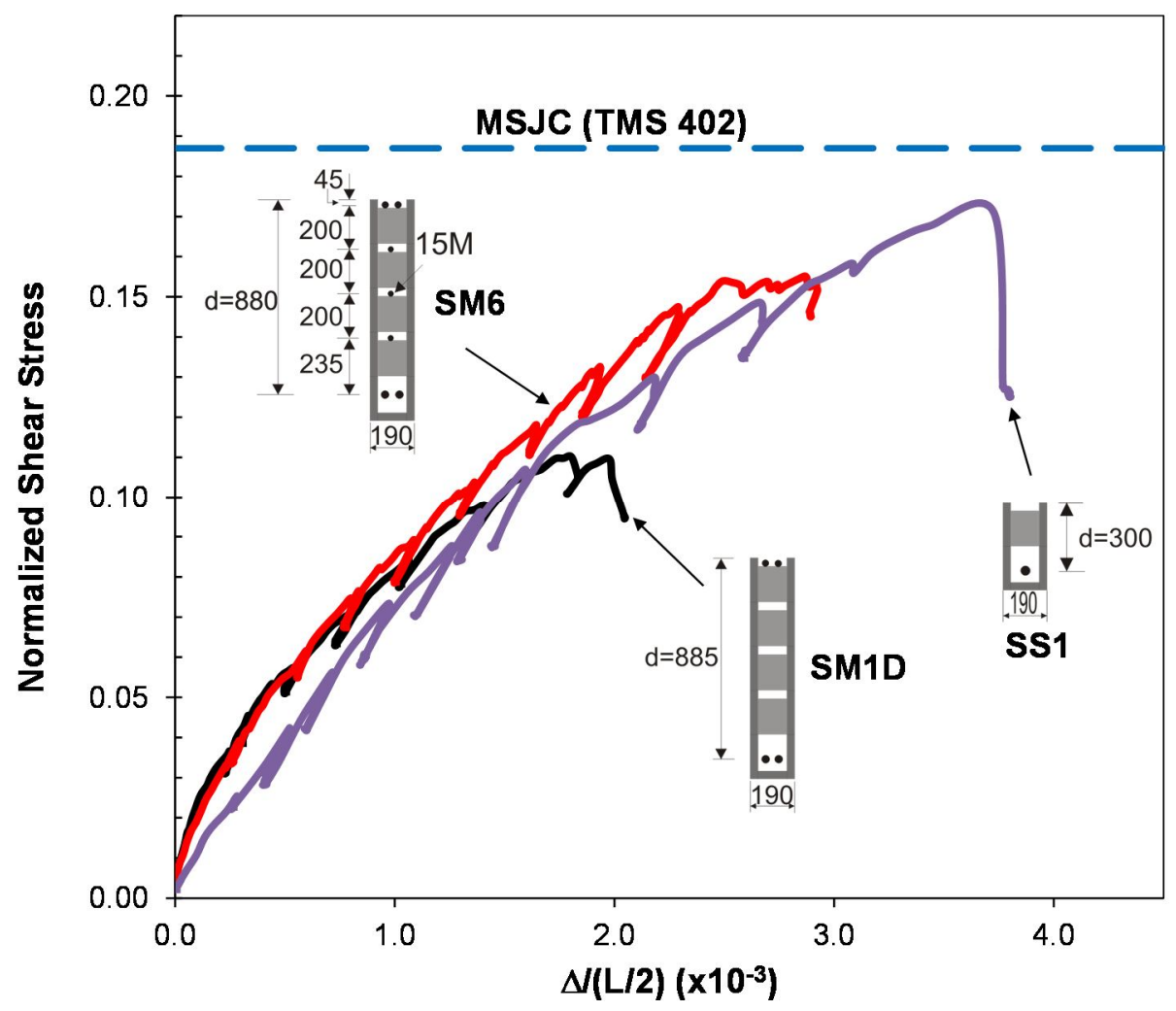

Figure 5-42: Relative Displacements in SS1, SM1D and SM6 


\subsubsection{Cracking Behavior}

Crack patterns of specimens SM1D and SM6 at shear stress of 0.5 MPa are presented in Figure 5-43. It can be seen that the longitudinal crack spacing averaged $550 \mathrm{~mm}$ in SM1D, whereas it was only $365 \mathrm{~mm}$ in SM6. Average crack spacing at $0.75 \mathrm{~d}$ and $\mathrm{d}$ were similar in both specimens. As such, the crack control steel reduced crack spacings by one third. Furthermore, cracks were consistently narrower in SM6 than in SMID (see Figure 5-44).

The shear stress of 0.5 MPa was critical stress for specimen SM1D as a major wide diagonal crack formed width a width up to $2.5 \mathrm{~mm}$ mid-height. Crack widths in SM6, on the other hand, did not exceed $0.1 \mathrm{~mm}$ near mid-height. Specimen SM1D could sustain a shear stress only $8 \%$ greater than that represented in Figure 5-43, whereas SM6 could sustain a shear stress of 30\% greater. Furthermore, specimen SM6 could sustain a greater amount of cracks prior to failure (see Figure 5-45). It seems clear that the crack control steel had a major beneficial effect. 


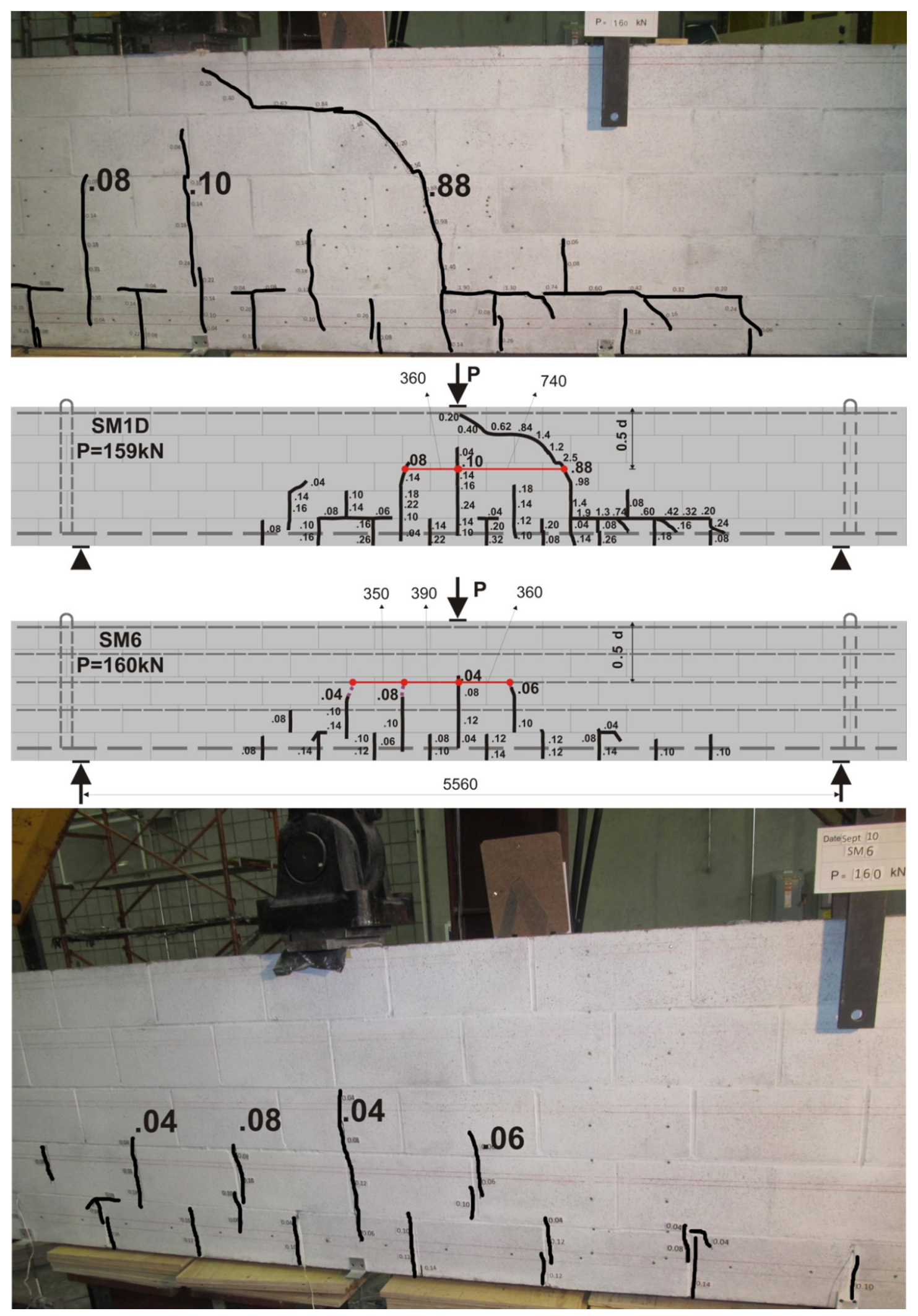

Figure 5-43: Crack Patterns in SM1D and SM6 at Shear Stress of 0.50 MPa 

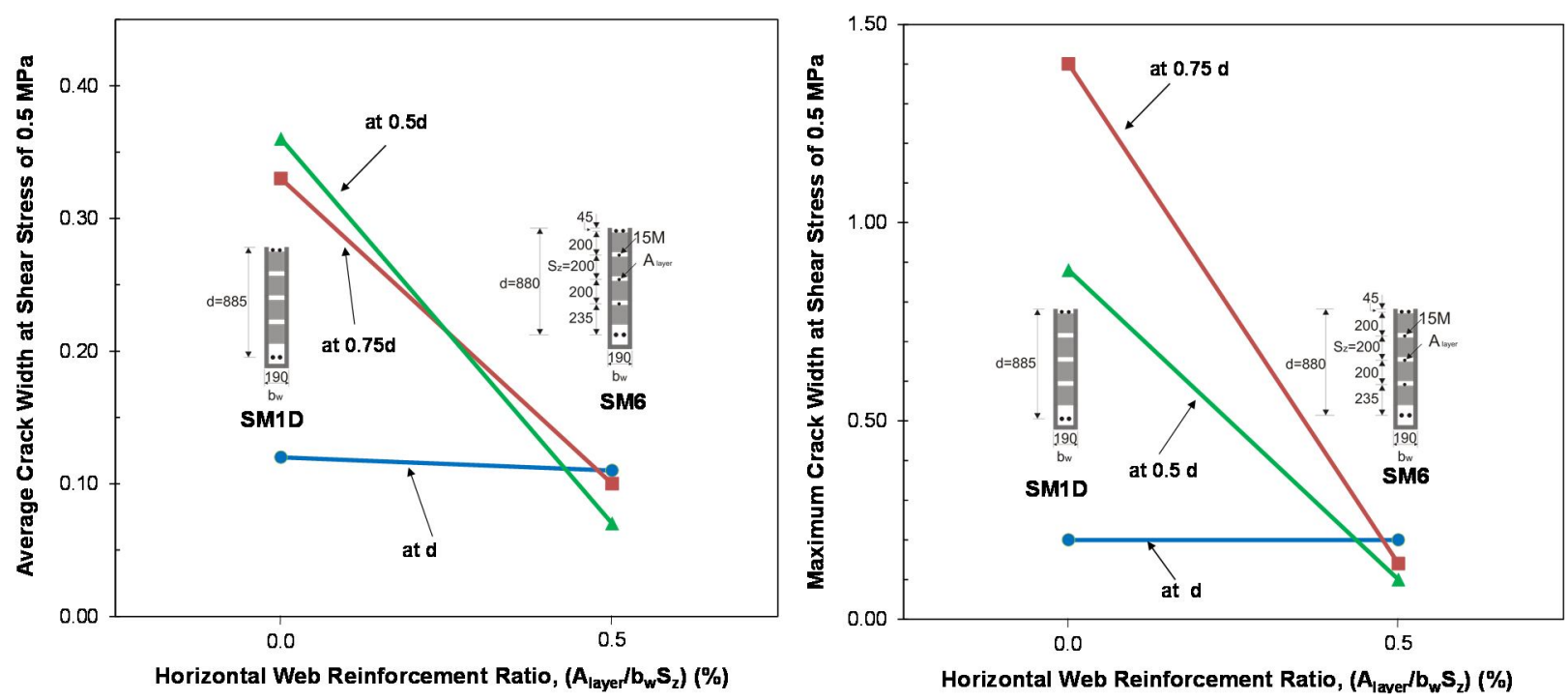

Figure 5-44: Maximum and Average Crack widths in SM1D and SM6 at 0.5 MPa

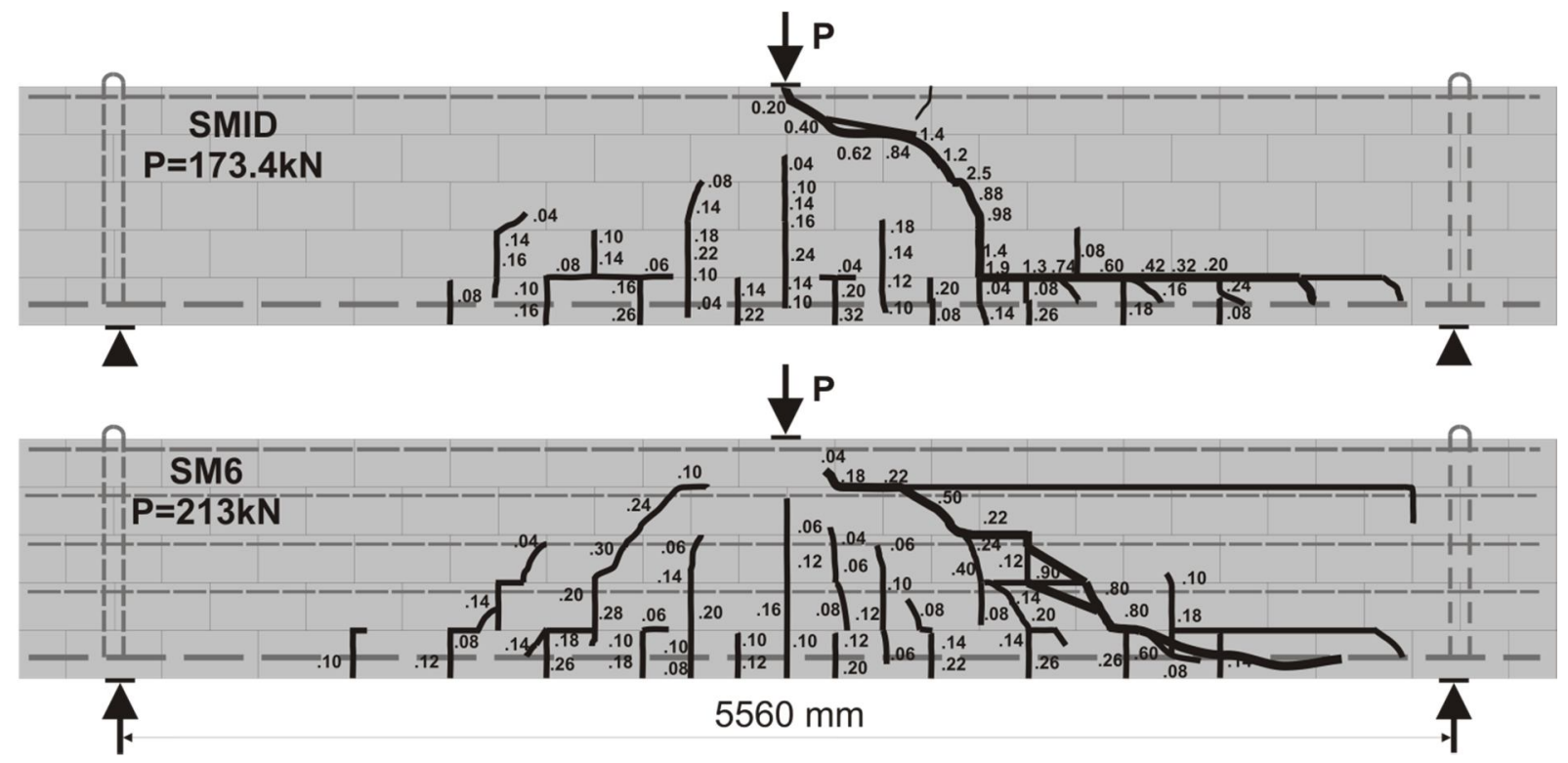

Figure 5-45: Failure Crack Patterns of SM1D and SM6 (Crack Widths Are for the Last Load stage Before Failure)

\subsubsection{Code predictions}

Failure shear stress predictions from the CSA S304.1, TMS 402 and CSA A23.3 are presented in

Figure 5-46. Note that in the case of CSA A23.3, the prediction is based on an effective depth of $851 \mathrm{~mm}$, which is the distance to the centroid of steel in the bottom $\mathrm{h} / 2$ of the beam. This 
approach matches that code`s approach to calculated, and corresponds to a reinforcement ratio of $((2 \times 700+300) /(190 \times 851))$ of $0.99 \%$.

It can be noted that CSA S304.1 and TMS 402 masonry codes are not sensitive to the use of crack control steel. The CSA A23.3, on the other hand, predicts the use of crack steel quite well. The ratios of $V_{\text {exp }} / V_{\text {pred }}$ are $0.83,1.27$ and 0.97 , respectively (Table 5-1). The CSA A23.3 prediction is based on crack spacing parameter, $\mathrm{s}_{\mathrm{x}}\left(\mathrm{s}_{\mathrm{z}}\right)$, of $200 \mathrm{~mm}$ which is the distance between the layers of the crack control steel. However, the distance between the main flexural steel and the bottom crack control bar was $235 \mathrm{~mm}$ (see Figure 3-2). Using $\mathrm{s}_{\mathrm{z}}=235 \mathrm{~mm}$ results in a predicted failure stress of $0.659 \mathrm{MPa}$ and an improved $\mathrm{V}_{\text {exp }} / \mathrm{V}_{\text {pred }}$ of 1.0 .

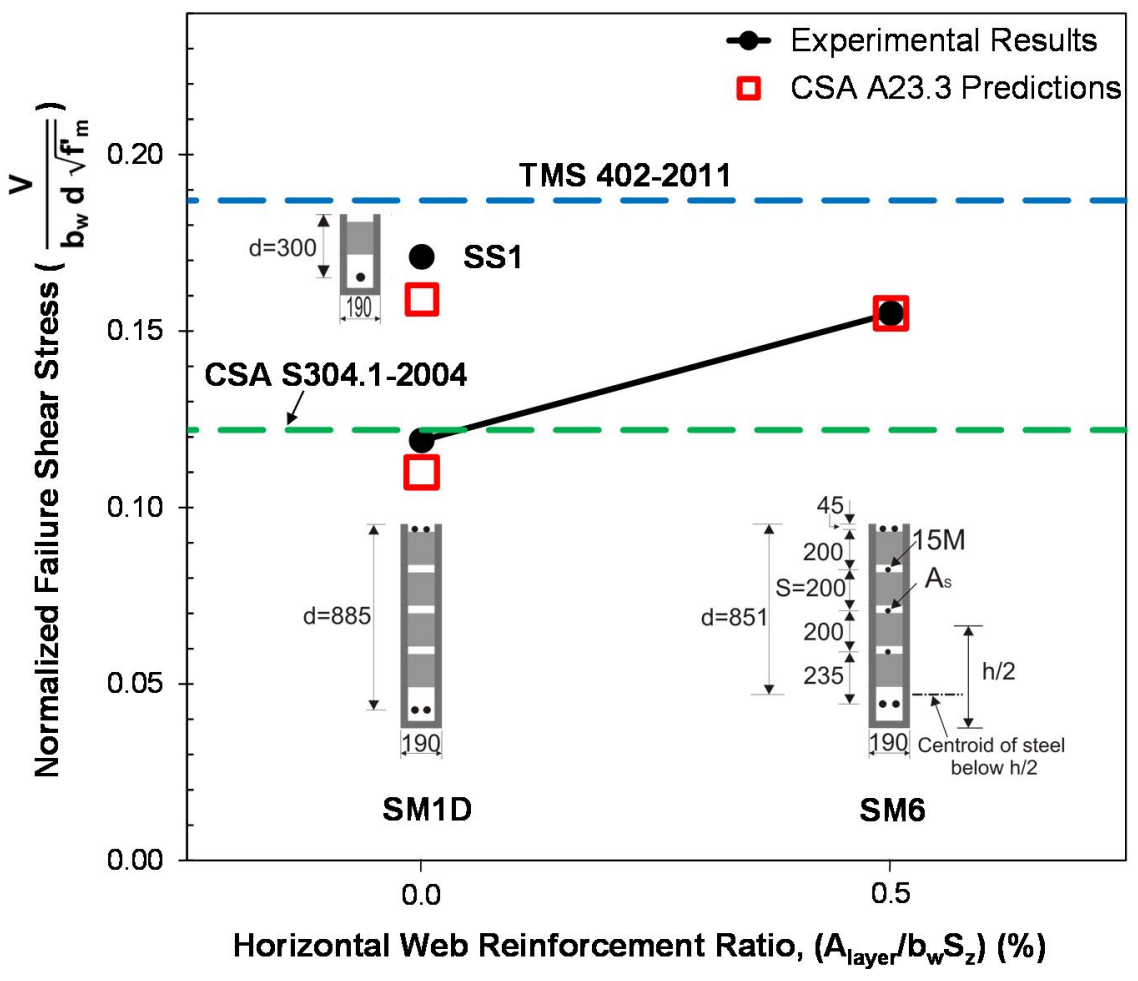

Figure 5-46: Failure Shear Stresses of SS1, SM1D and SM6 


\subsubsection{The Size Effect}

The presence of crack control steel almost eliminated the size effect, but did not completely do so. Specimen SS1, with effective depth of $300 \mathrm{~mm}$, failed at a shear stress of $0.72 \mathrm{MPa}$. Specimen SM6, with effective of $880 \mathrm{~mm}$ and $\rho$ of $0.84 \%$, failed at a shear stress of $0.66 \mathrm{MPa}$. This represents a decrease of $8 \%$. Given that SM6 had an effective crack spacing factor, sz, of $200 \mathrm{~mm}$ and SS1 had an effective crack spacing of $279 \mathrm{~mm}$ ( $0.72 \mathrm{~h}$ which is larger than $0.9 \mathrm{~d})$, the CSA A23.3 code would predict a small increase in failure shear stress, which was not observed.

\subsection{The Effect of Vertical Web Reinforcement (Stirrups)}

\subsubsection{General}

It is well known that using stirrup reinforcement in masonry beams is a difficult and time consuming task. As such it is preferable to design reinforced masonry with as few stirrups as possible (Dhanasker and Wong 2001). However, most masonry design codes require the use of a minimum shear reinforcement ratio. CSA S304.1-2004, for example, suggests using a minimum area of shear reinforcement $\left(\frac{A_{v} f_{y}}{b_{w} s}=0.35 \mathrm{MPa}\right)$ in all region of beams where the factored shear force, $\mathrm{V}_{\mathrm{F}}$, exceeds half of the masonry shear resistance contribution, $\mathrm{V}_{\mathrm{m}}$.

In this section the effectiveness of stirrups on the shear behaviour of reinforced masonry beams will be explored through the results of two specimens reinforced with stirrups. While the intention was to reinforce specimens SS3 and SM3 with the minimum stirrup requirement of the CSA A23.3 code, this was not possible due to the requirement that stirrups be spaced at multiples 
of $200 \mathrm{~mm}$ due to the spacing of cells in units. Specimen SM3 (d=868 mm) was reinforced with stirrups at a ratio of $\frac{A_{v} f_{y}}{b_{w} s}=0.53 \mathrm{MPa}$ which is twice the minimum requirement of the CSA

A23.3 code. Specimen SS3 $(d=305 \mathrm{~mm})$ was reinforced with a nominal ratio $\frac{A_{v} f_{y}}{b_{w} \mathrm{~S}}=0.53 \mathrm{MPa}$ based on an assumed yield stress of $\mathrm{f}_{\mathrm{y}}=400 \mathrm{MPa}$, for the $8 \mathrm{~mm}$ bars. The actual yield stress of the $8 \mathrm{~mm}$ was $540 \mathrm{MPa}$ giving an as-built $\frac{A_{v} f_{y}}{b_{w} s}$ of 0.67 MPa. Test results of SM3 and SS3 will be compared to their reference specimens SM2 and SS2 to evaluate the effect of stirrups on shear strength of reinforced masonry beams. It is worthwhile to mention that specimens SM3, SS3, SM2 and SS2 were constructed with main reinforcement ratio of $1.68 \%$ to ensure a shear failure rather than flexural failure. To examine the ability of stirrups to eliminate the size effect, comparison will be made between SM3, SM2, and SS2.

\subsubsection{Load-Displacement Response of Specimens SS2 and SS3}

Figure 5-47 shows the load vs. displacement graph for specimen SS2 and SS3. It is clear from the figure that SS3 failed at higher shear strength than specimen SS2 with a significantly greater ductility. This considerable improvement in shear strength and ductility can be attributed to the presence of stirrups. 


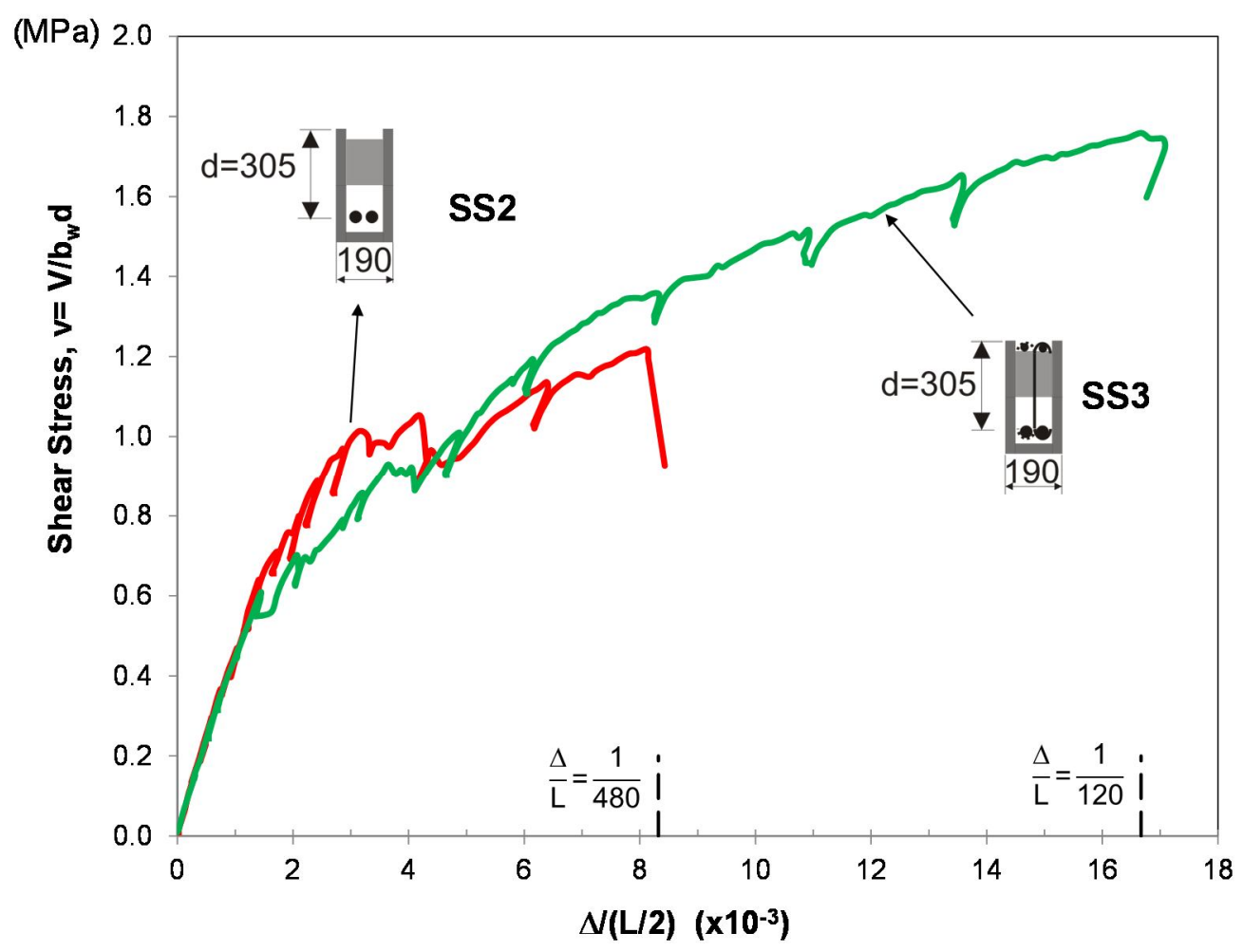

Figure 5-47: Load vs Displacements of Specimens SS3 and SS2

\subsubsection{Cracking Behavior of specimen SS3}

The crack pattern observed in SS3 at a shear stress of $1.15 \mathrm{MPa}$ is shown in Figure 5-48, along with the pattern in SS2 at a similar stress. It can be seen that the stirrups had a major effect on the widths of the horizontal and diagonal cracks. On the left side, for example the crack ranged from 0.9 to $1.1 \mathrm{~mm}$ in SS2, whereas it was only 0.34 to $0.84 \mathrm{~mm}$ in SS3. Likewise, diagonal cracks near the point load and near the support were narrower in SS3. Specimen SS2 failed at a shear stress that was only 6\% higher than that depicted in Figure 5-48, whereas SS3 failed at a load $50 \%$ greater. The stirrups were clearly effective in reducing crack widths and enhancing shear strength. 


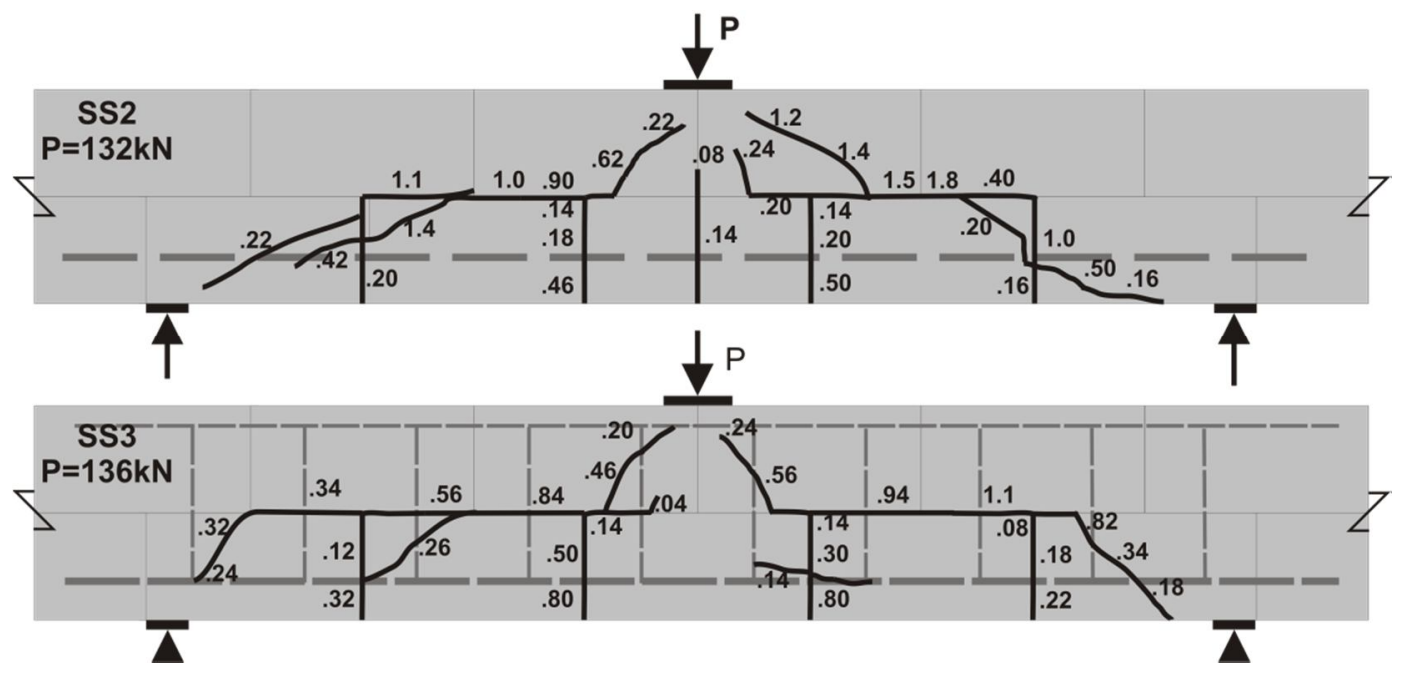

Figure 5-48: Crack Patterns of Specimens SS3 and SS2 Prior to Failure

It interesting to note that prior to failure cracks in specimen SS3 were wider than they were in SS2 (see Figure 5-49), The average crack width at mid-depth of SS3 was $2.1 \mathrm{~mm}$ compared to $0.58 \mathrm{~mm}$ in specimen SS2. The widest crack width in SS3 was $2.3 \mathrm{~mm}$ versus $1.4 \mathrm{~mm}$ in SS2. It is certainly appears that the use of stirrups permitted wider cracks to form and high shear strains to be attained before failure, indicative of far more ductile behavior.

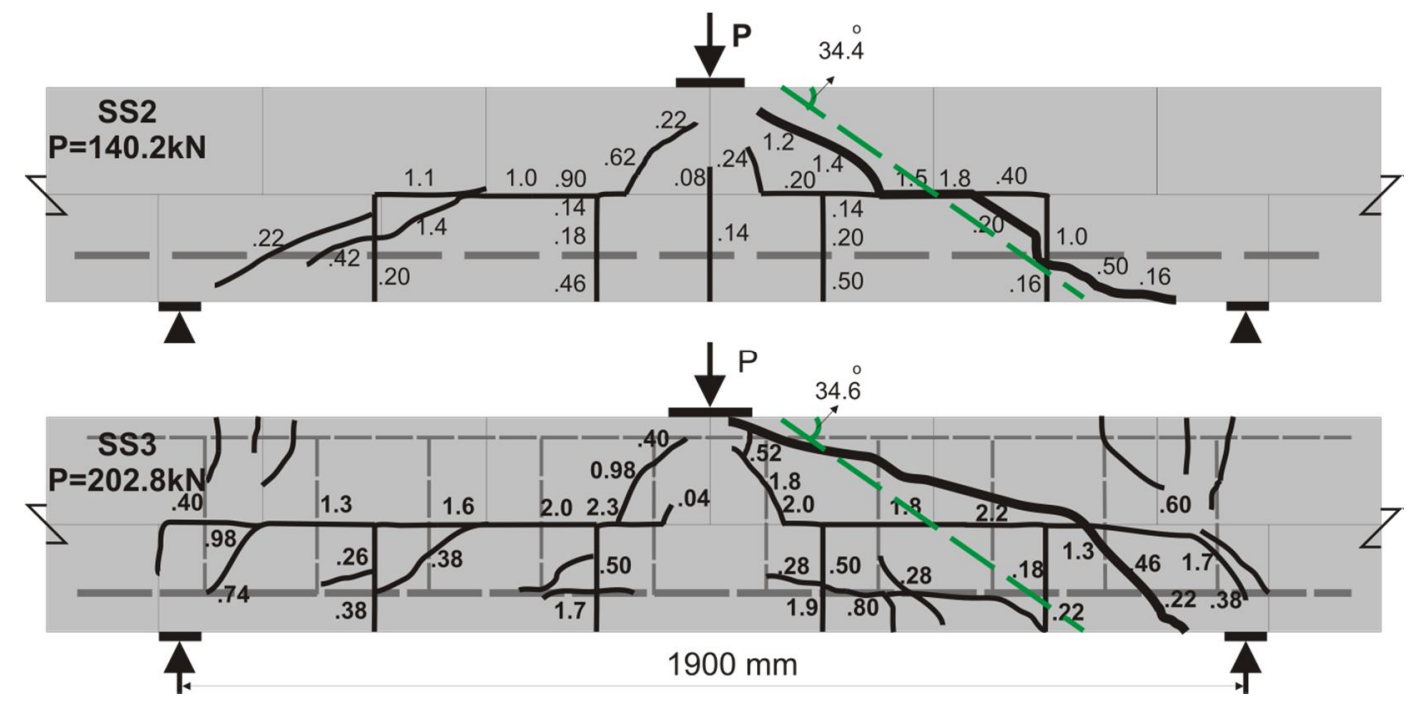

Figure 5-49: Failure Crack Patterns of Specimens SS3 and SS2 (Crack Widths Measured at Last Load Stage before Failure) 
Figure 5-50 presents the contours of horizontal displacements and shear strains for specimens SS2 and SS3 prior to failure using image correlation analysis. The slip on the horizontal crack can be calculated as the difference between the horizontal movement $\mathrm{s}$ above and below the crack. The average slip in SS2 was $0.65 \mathrm{~mm}$, whereas it was $3.0 \mathrm{~mm}$ in SS3. Likewise, much higher shear strains were sustained in the beam with stirrups. The beneficial effects of stirrups on the deformations of SS3 are clear in these figures.

\subsubsection{Load-Displacement Response of Specimen SM3}

Figures 5-51 shows the load deformation response of specimen SM3 relative to equivalent beams without stirrups. It can be seen in Figure 5-51 that SM3 (reinforced with stirrups) exhibited more ductility than SM2. The relative displacement of SM3 was 3 times greater than that of SM2. Furthermore, as the failure shear stress of SM3 was 1.85 times that of SM2 and 1.07 times that of SS2, it certainly appears that the use of sufficient quantity of stirrups essentially led to the elimination of the size effect entirely. This finding opposes the conclusion made by $\mathrm{Yu}$ et al. (2011) through a theoretical study that stirrups cannot suppress the size effect completely regardless of the stirrup ratio. The current finding supports the experimental results of Sherwood et al. (2007) which showed the size effect can be largely eliminated by using stirrups. 


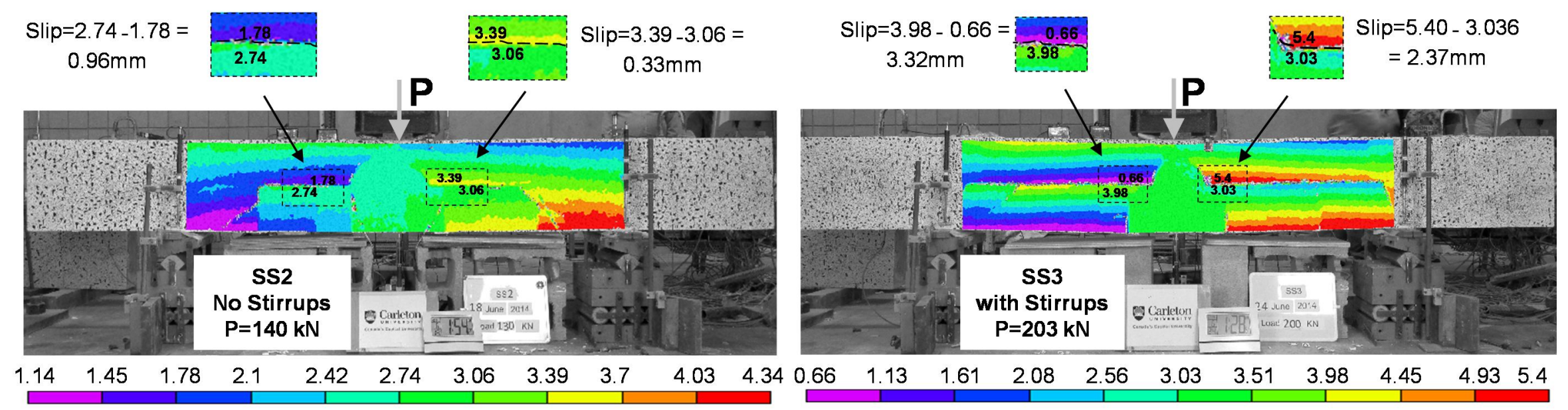

\section{Horizontal Displacement (mm)}
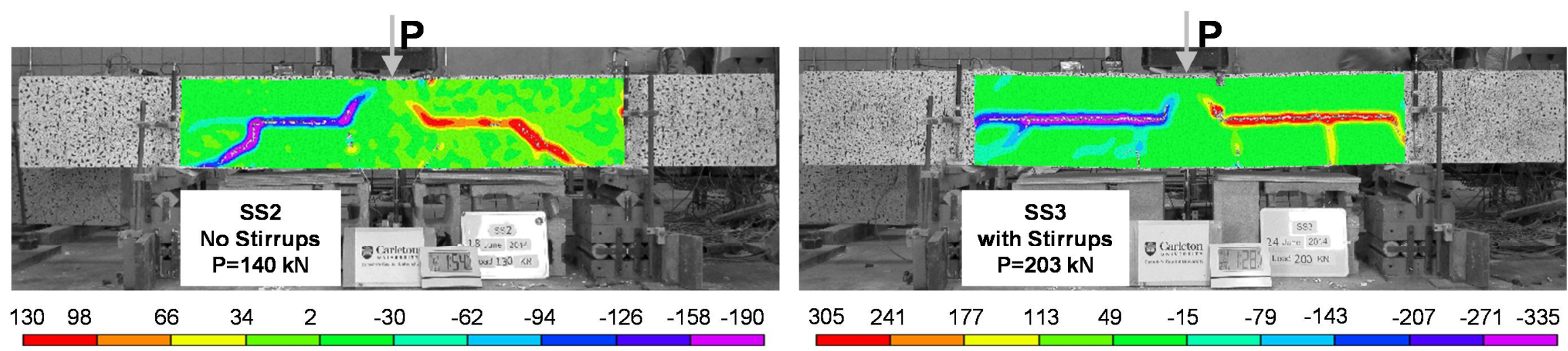

\section{Shear Strain $\times 10^{2}(\mu \varepsilon)$}

Figure 5-50: Contours of Horizontal Displacements and Shear Strains in Specimens SS2 and SS3 using Image Correlation Analysis (Photos Taken at Last Load Stage Prior to Failure) 


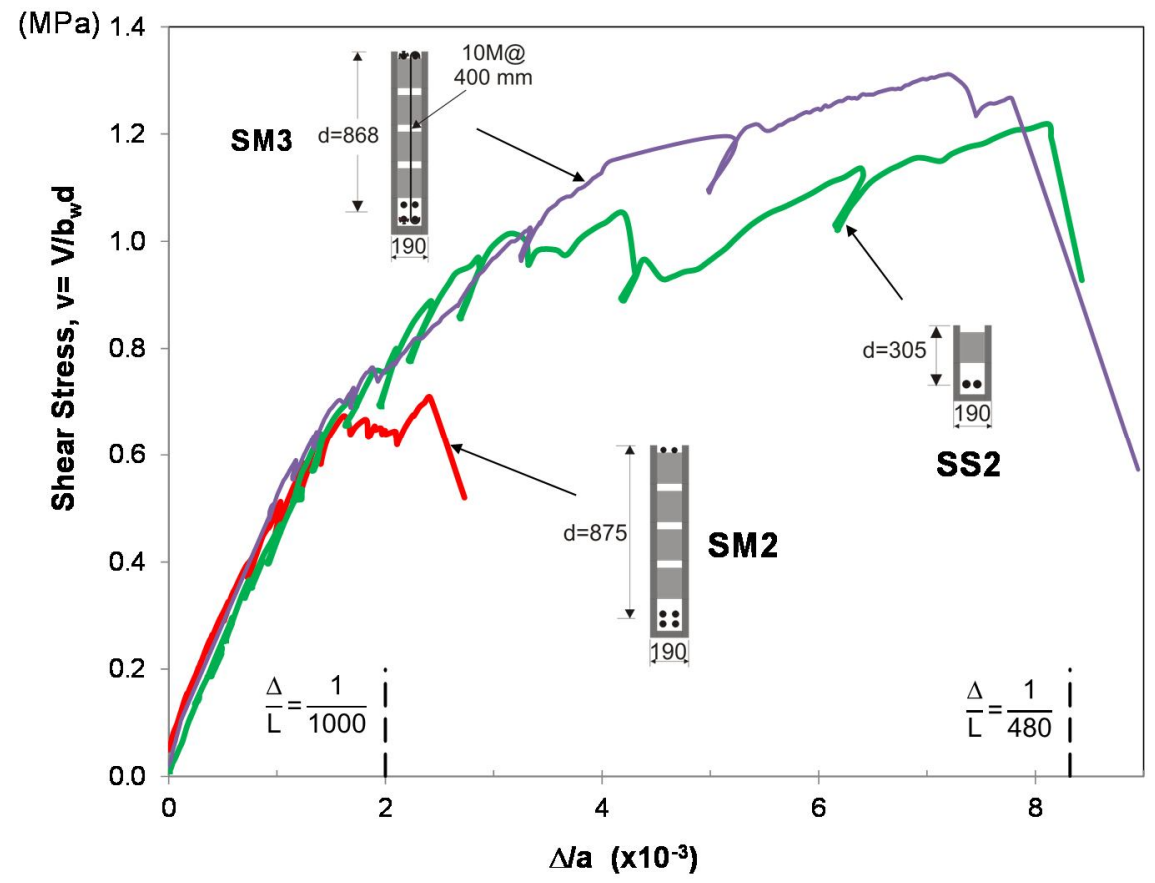

Figure 5-51: Relative Displacements of Specimens SS2, SM2 and SM3

\subsubsection{Cracking Behavior of Specimen SM3}

Due to the jagged nature of cracks in reinforced masonry, the average horizontal crack spacing shows no significant differences between SM2 and SM3. However, the average crack spacing measured perpendicular to the angle of inclination gave more reasonable indications about the benefits of using stirrups. Prior to failure (at a load of $384 \mathrm{kN}$ ) there were six wide diagonal cracks that passed the mid-depth of the beam. Figure 5-52 shows that the average crack spacing measured perpendicular to the angle of inclination (determined according to the CSA A23.3 code at distance $\mathrm{d}$ from the point load) was $318 \mathrm{~mm}$. The average crack width at mid-depth was 0.56 $\mathrm{mm}$ and the widest crack width was $1.6 \mathrm{~mm}$. SM3 was able to sustain a load $10 \%$ higher than this load stage. 
In specimen SM2, prior to failure there were only three cracks that passed the mid-depth of the beam, one under the load and one in each span. The average crack spacing was $415 \mathrm{~mm}$ (equivalent to $0.48 \mathrm{~d}$ ). The crack in the east end of the beam reached mid-depth of the beam in the north face only with a crack width of $0.08 \mathrm{~mm}$. The crack in the west end of the beam was quite wide, (1.2 mm at mid-depth of the section) and it passed the mid-depth and inclined towards the point load. This wide crack was formed due to an initial breakdown of beam action in the east end of specimen SM2. Although this crack was narrower than that in SM3, specimen SM2 could not sustain more than a 5\% increase beyond this load. This highlights the effectiveness of providing sufficient quantity of stirrups in allowing multiple wide cracks to form and high shear stresses reached before the breakdown of beam action.

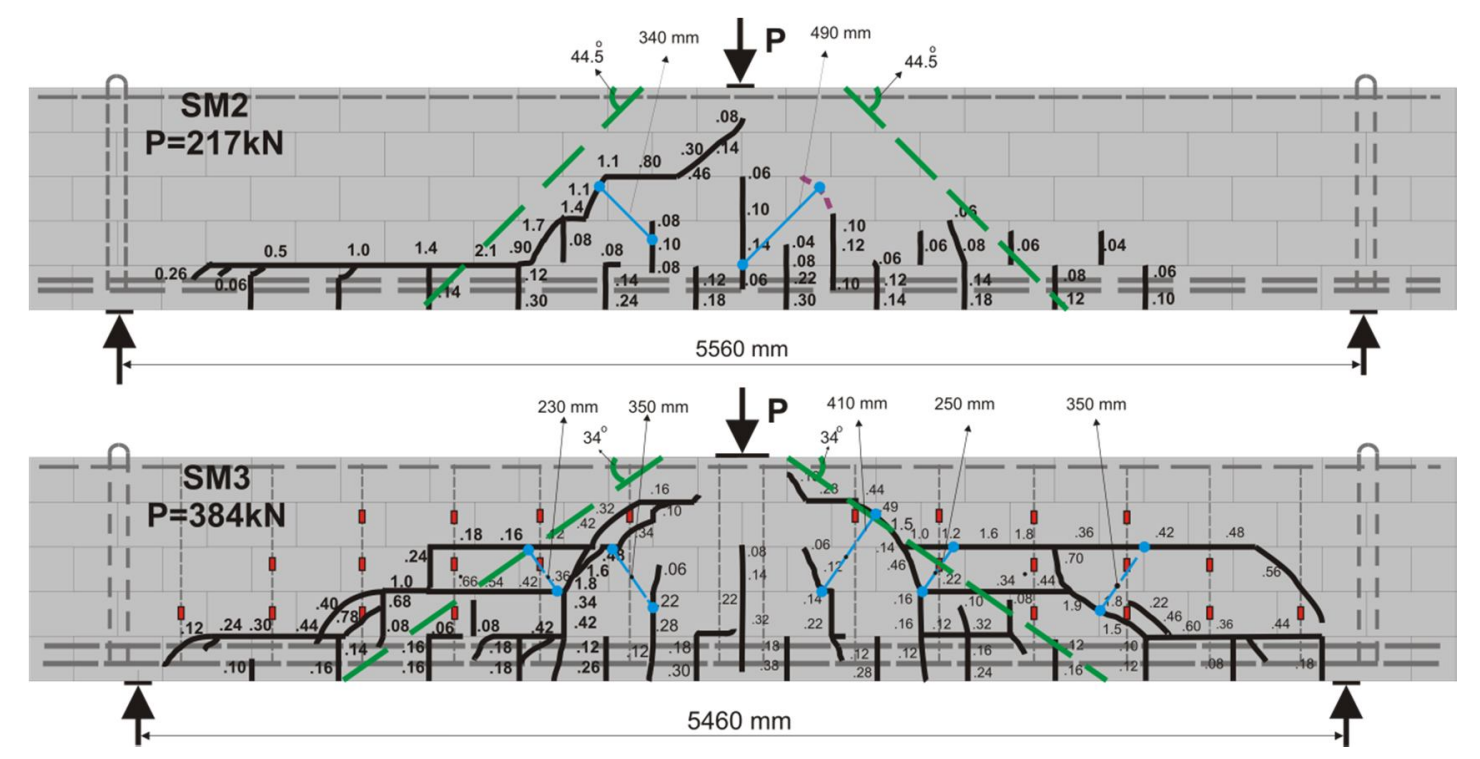

Figure 5-52: Crack Patterns of Specimens SM2 and SM3 Prior to Failure

The failure crack patterns of beams SM2 and SM3 are shown in Figure 5-53. It can be noted that the cracks were numerous and wider at mid-height of SM3 than SM2. Likewise, the shear strains at failure (Figure 5-54) were considerably greater in SM3 than in SM2. It is quite clear that the beam with stirrups exhibited a much more ductile response than that without stirrups. 


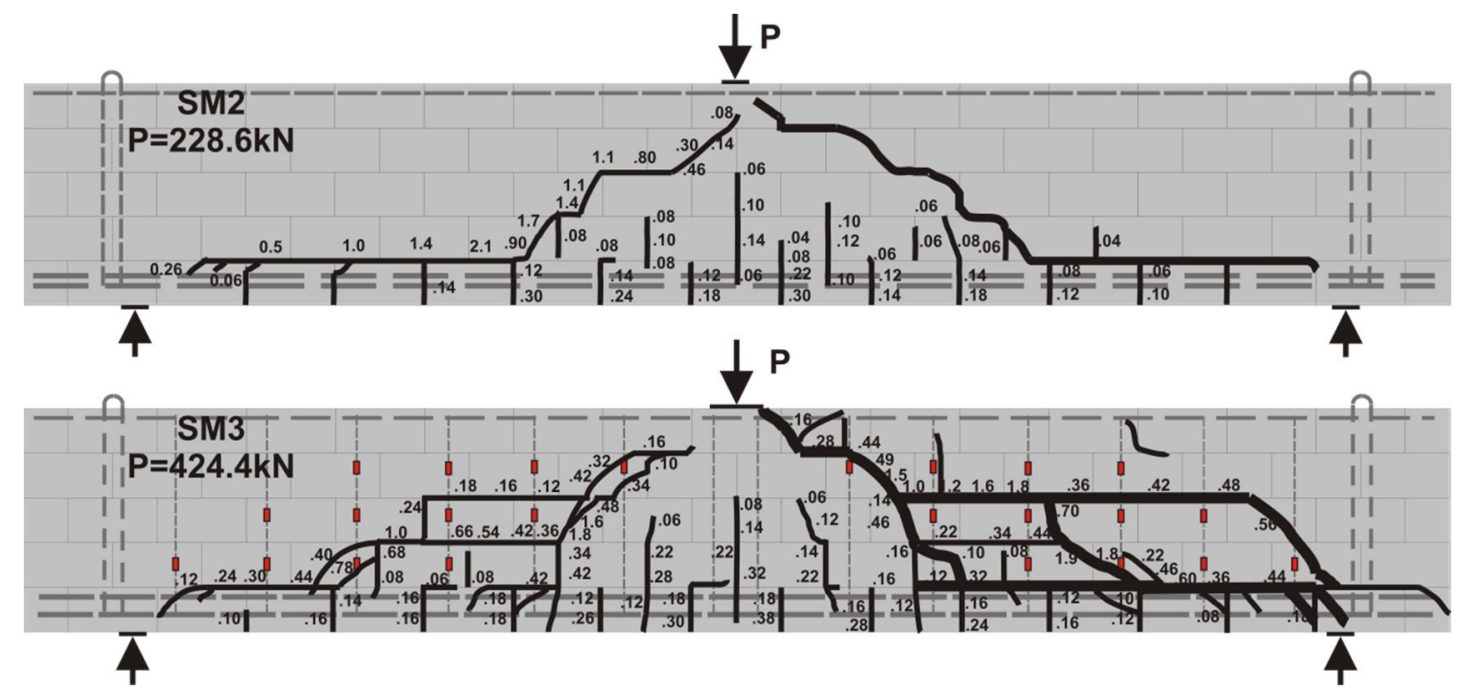

Figure 5-53: Failure Crack Patterns of Specimens SM2 and SM3

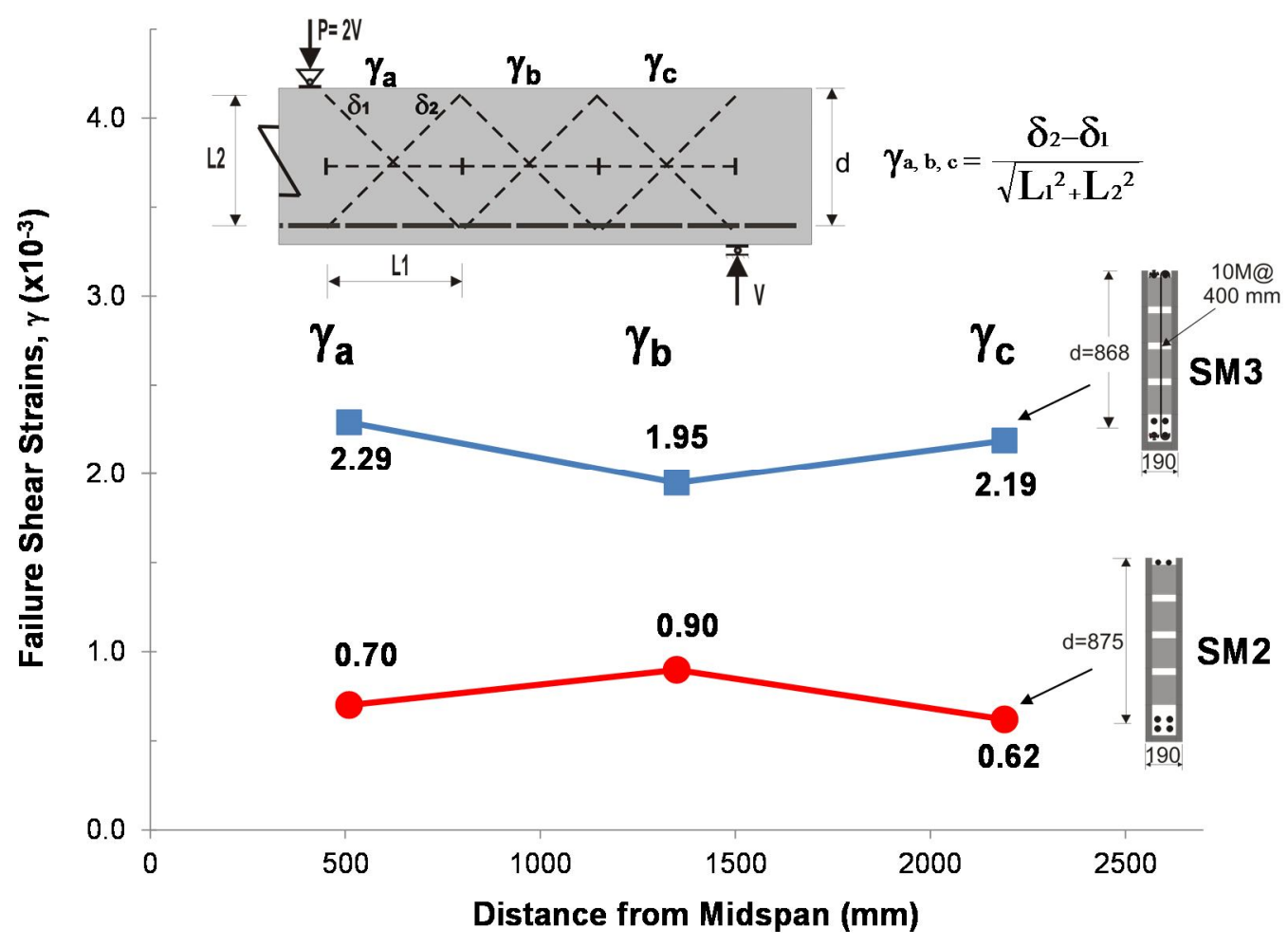

Figure 5-54: Failure Shear Strains of Specimens SM2 and SM3 


\subsubsection{Stirrups Strains}

The contribution of stirrups to shear resistance is based on the assumption that stirrups yield when crossed by the cracks. Figure 5-55 shows the measured stirrup stresses in the west span of specimen SM3 at different load stages along with crack patterns at these load stages. The line corresponding to a stress $\geq 417 \mathrm{MPa}$ represents the yielding of stirrups. When the stirrup strain is equal to or higher than the yielding strain the point is put on the line. It is interesting to note the gradual increases in stirrup stress as the load increased. At load stage of $204 \mathrm{kN}$, only two stirrups were slightly activated while prior to failure $(384 \mathrm{kN})$ all the six stirrups were activated and four of them experienced yielding as they were crossed by wide cracks. At failure, five stirrups yielded, showing significant ductility compared to specimen SM2 without stirrups. It can also be seen from Figure 5-54 that stirrup stress increased with increase of the crack width crossed by the stirrups showing the effectiveness of stirrups in bridging the cracks and allow higher load to be reached and higher ductility to be achieved.

\subsubsection{The effectiveness of Stirrups}

It can be seen in Table 5-1 and Figure 5-56 that the CSA A23.3 and CSA S304.1 codes are capable of predicting the failure shear stresses of reinforced masonry beams with stirrups with reasonable accuracy. The TMS 402 code, on the hand seems to underestimate failure shear stresses of these beams. This can be attributed to the fact that TMS 402 uses only half of the theoretical contributions of stirrups in determination of the failure shear stress of masonry beams (see Equation (2-25) in Chapter 2). The stirrups in specimens SS3 and SM3 were more effective than what the TMS 402 code expects. To further explain the underestimation of TMS 402 for stirrup contribution, consider Figure 5-57 which shows the ratio of the $\mathrm{V}_{\mathrm{s} \text { Exp }} / \mathrm{V}_{\mathrm{s}}$ Pred for the 
North American codes considered in the current investigation. It can be seen that the experimental contribution of the stirrups was on average twice the contribution expected by TMS 402. CSA A23.3 code slightly overestimated the contribution of the stirrups and this can be attributed the nature of crack propagation in reinforced masonry beams which is different than reinforced concrete.

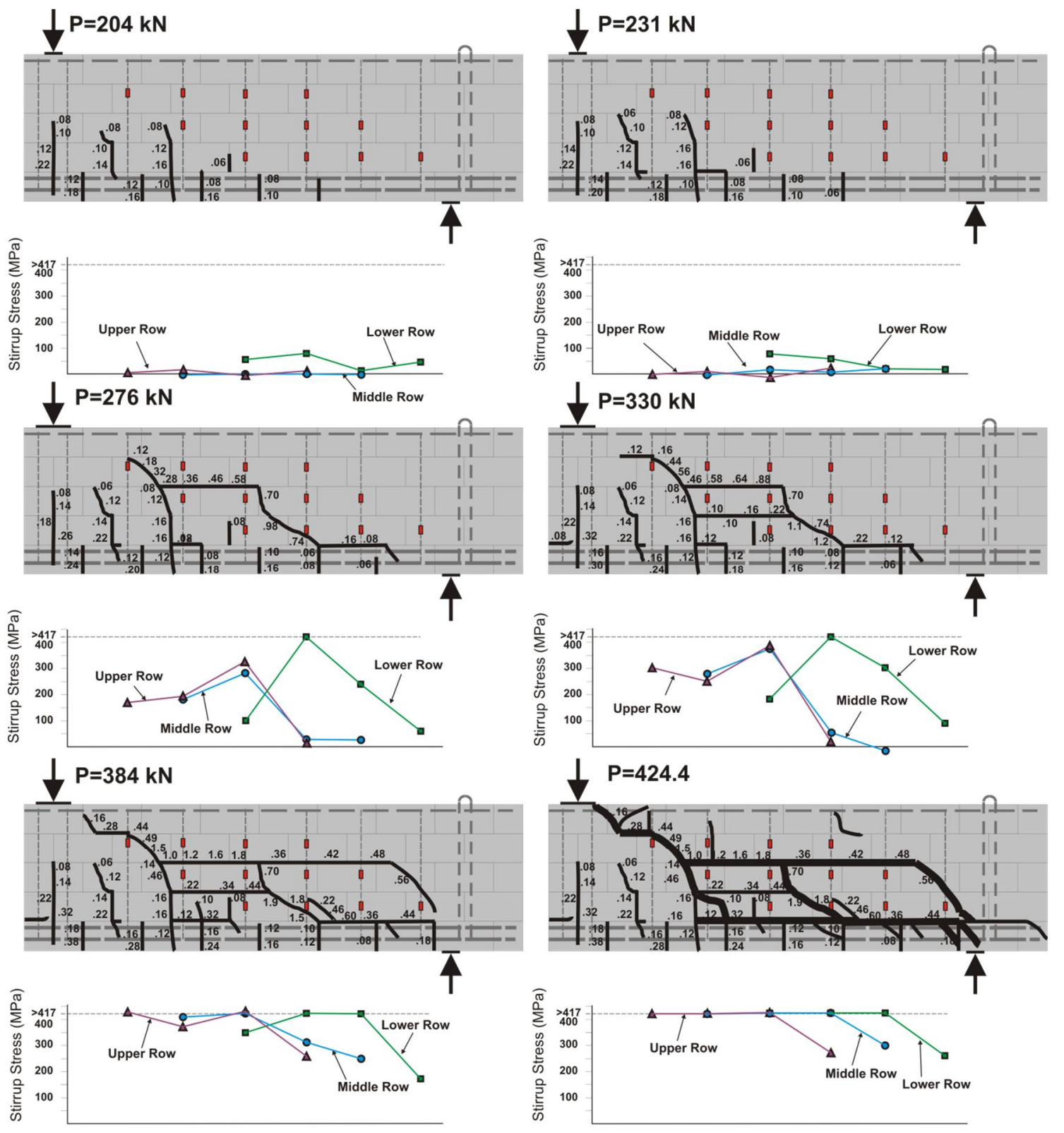

Figure 5-55: Stirrup Strains at Different Load Stages 


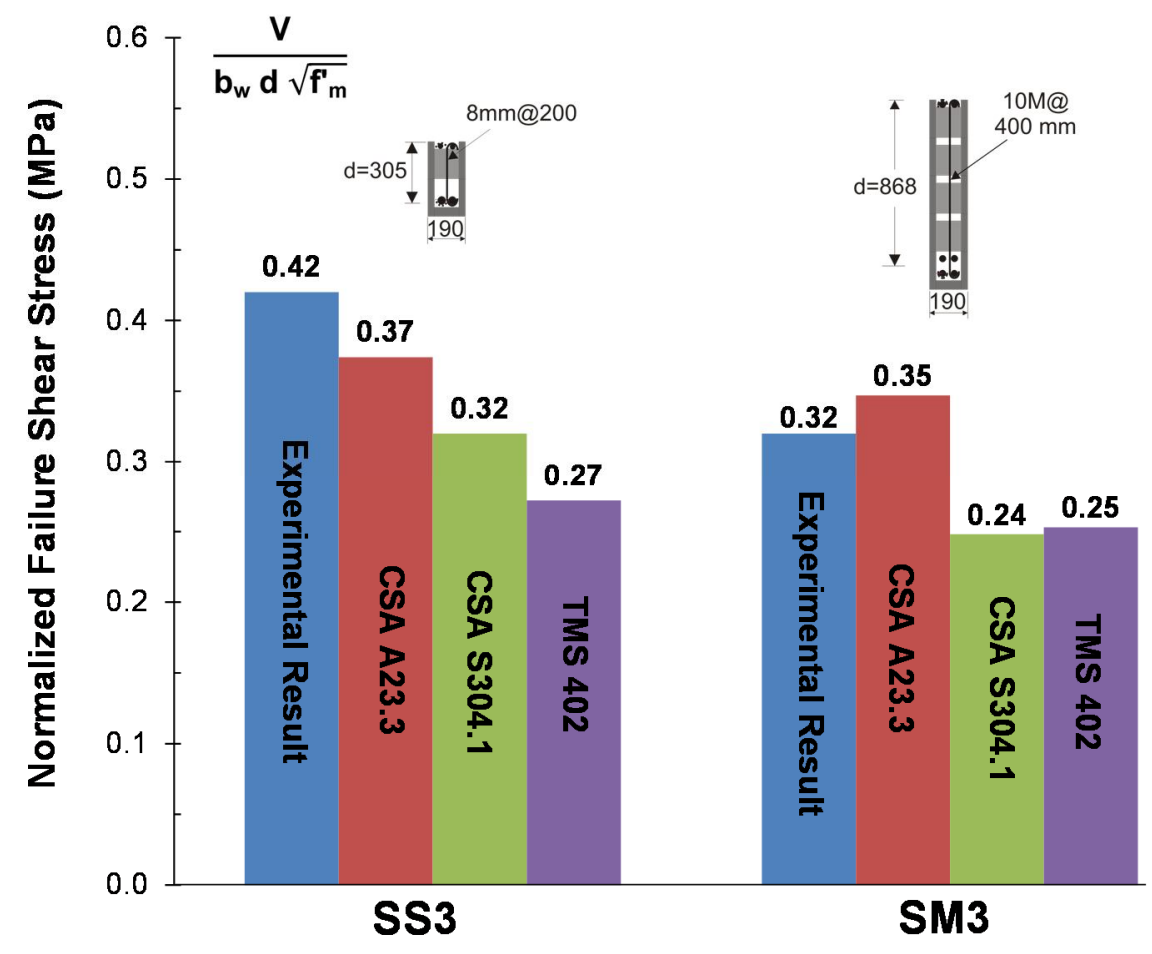

Figure 5-56: Failure Shear Stress Predictions for RM Beams Reinforced with Stirrup

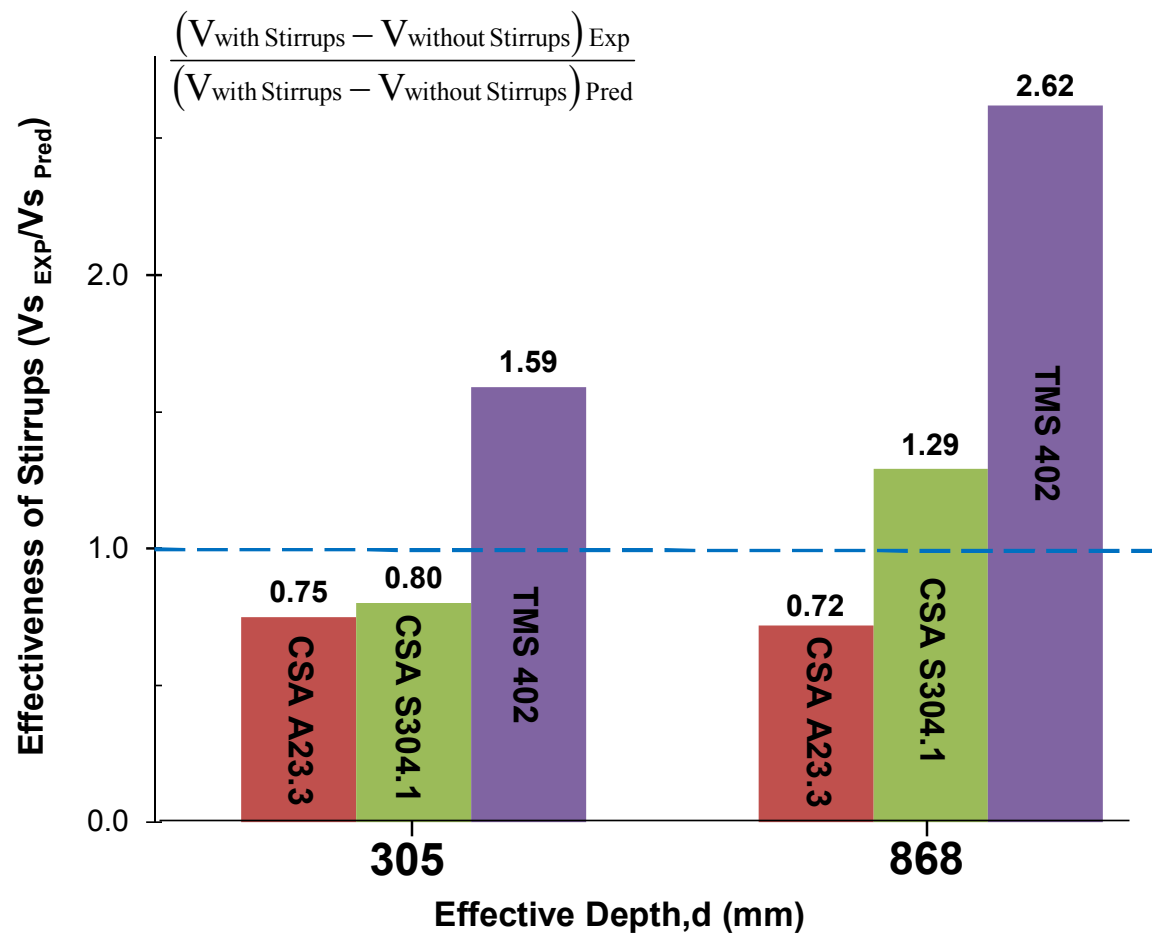

Figure 5-57: Effectiveness of Stirrups 


\subsection{The Effective Crack Spacing Term}

The results presented in this chapter have shown that the effective depth, d, has a significant influence on the failure shear stress of reinforced masonry beams. This effect appears to be related to the aggregate interlock capacity of cracks. Deeper members are associated with more widely spaced cracks, and in two geometrically similar beams with the same main reinforcement ratio, the section with a larger effective depth will exhibit wider cracks with reduced aggregate interlock capacity. The variable that accounts for the effect of effective depth in the general method in CSA A23.3 code is $\mathrm{s}_{\mathrm{xe}}$, which accounts for the crack spacing (through the use of the crack spacing parameter, $\mathrm{s}_{\mathrm{x}}$ ) and the maximum aggregate size, $\mathrm{a}_{\mathrm{g}}$. To investigate the applicability of this general method to reinforced masonry, a graph showing the size effect term as a function of $s_{x e}$ for the specimens tested in this investigation is presented in Figure 5-58 along with the experimental data points.

In this experimental study, a wide range of effective crack spacings, from $470 \mathrm{~mm}$ to $2240 \mathrm{~mm}$, was investigated by varying the effective depth, $\mathrm{d}$ from 300 to $1420 \mathrm{~mm}$. The experimental points for the specimens with the stirrups are shown by diamond symbols at $s_{x e}=300 \mathrm{~mm}$. This figure shows that the size effect factor can accurately model the shear strength of reinforced masonry sections over a wide range of depths. The CSAA23.3 size effect term can offer an accurate prediction of the shear strength of masonry beams with a wide range of effective crack spacings. Furthermore, the method offers considerable evidence in support of the concept of the equivalent crack spacing parameter in reinforced masonry. 


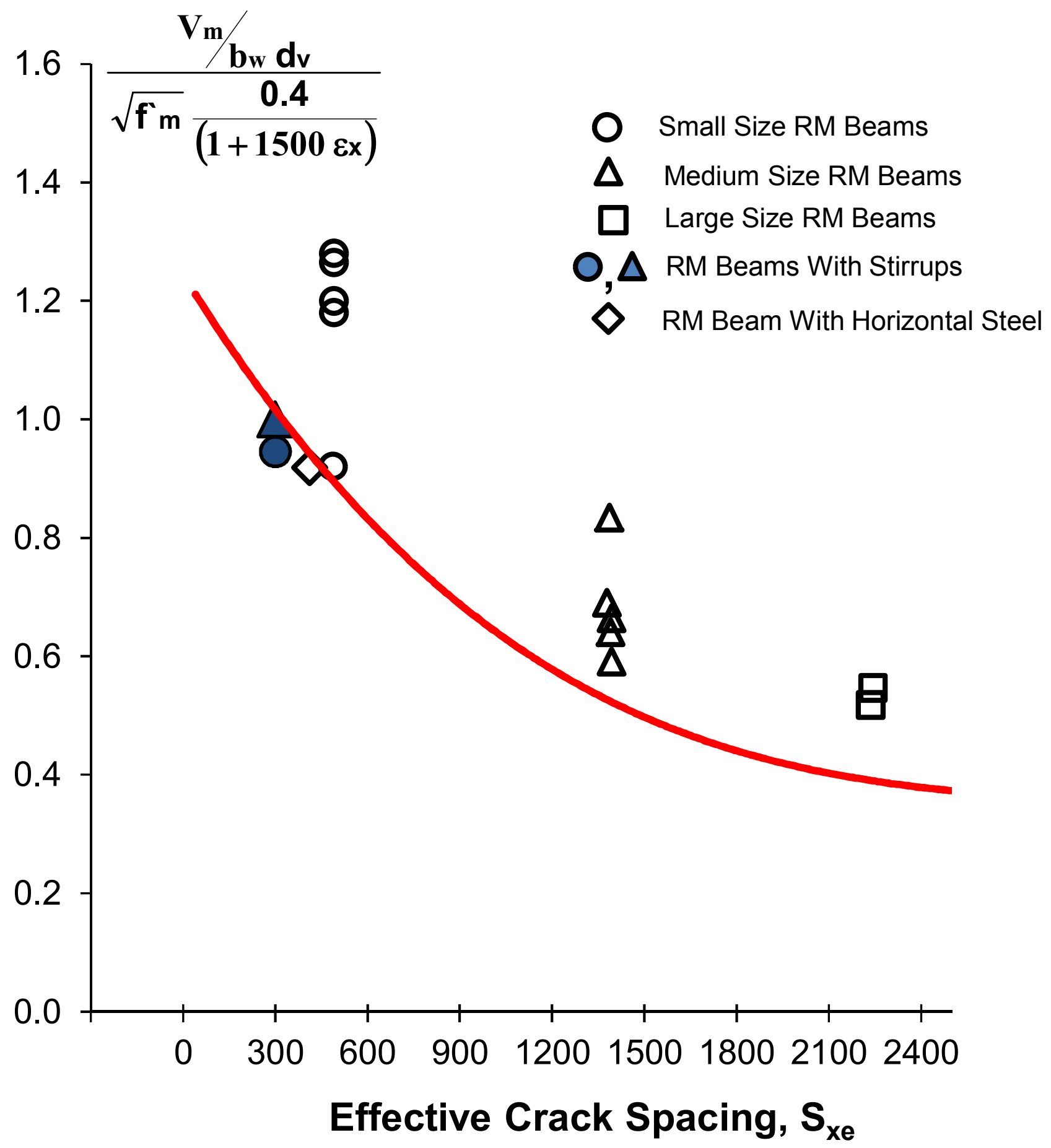

Figure 5-58: The CSA 2004 Size Effect Term 
It is worth mentioning that the values of $s_{x e}$ in Tables 5-1 and Figure 5-58 are based on a value of $\mathrm{a}_{\mathrm{g}}=5 \mathrm{~mm}$ to reflect the equivalent aggregate sizes used in grout, mortar and masonry units. To explore this choice, consider Figure 5-59 which show the crack pattern in the east side of beam SM2 along with profile of the major diagonal crack in SM2. It can be seen in Figure 5-59 that an inclined crack passed through three regions: diagonally through the units (type a), the bed joint (type b) and the head joint (type c). 

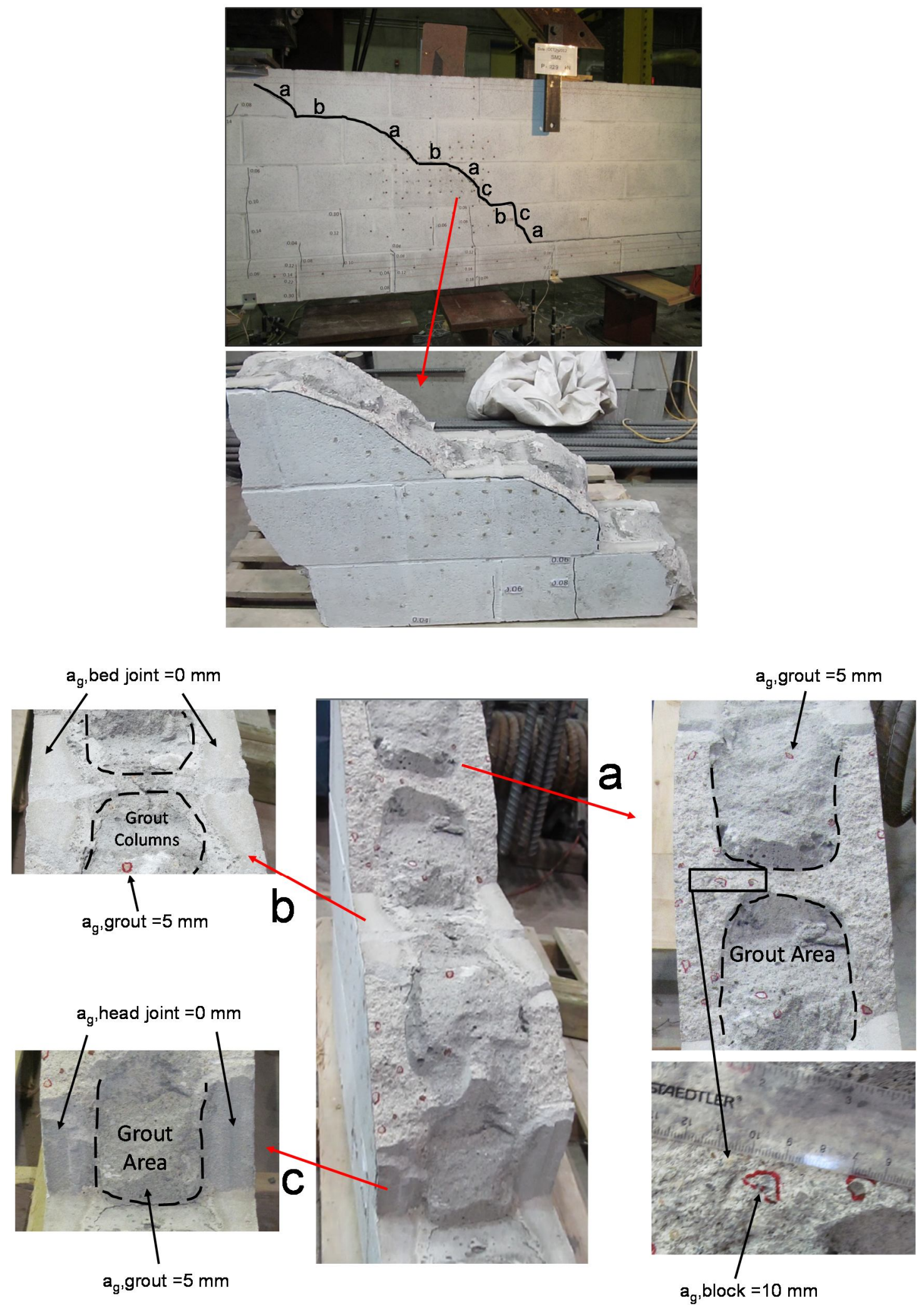

Figure 5-59: Maximum Aggregate Size in Specimen SM2 
It can be seen in Figure 5-59 that when the crack passes through grouted masonry units, aggregate interlock occur through the unit $\left(a_{g}=10 \mathrm{~mm}\right)$ and in the grout $\left(a_{g}=5 \mathrm{~mm}\right.$ for fine grout). When the crack passes through head or the bed joints, friction occurs between the mortar and the unit $\left(\mathrm{a}_{\mathrm{g}}=0 \mathrm{~mm}\right)$ and aggregate interlock occurs through the grout $\left(\mathrm{a}_{\mathrm{g}}=5 \mathrm{~mm}\right)$. In all these cases, the grouted area is roughly 50\% of the crack cross section area. Figure 5-60 shows the calculations for the equivalent $\mathrm{a}_{\mathrm{g}}$ in three beams with different sizes. In beam SS1, for example, the failure crack passed diagonally through the unit for $330 \mathrm{~mm}\left(50 \%\right.$ of $\mathrm{a}_{\mathrm{g}}=10 \mathrm{~mm}$ and $50 \%$ of $\left.\mathrm{a}_{\mathrm{g}}=5 \mathrm{~mm}\right)$ and horizontally through the smooth bed joint for $650 \mathrm{~mm}\left(50 \%\right.$ of $\mathrm{a}_{\mathrm{g}}=5 \mathrm{~mm}$ and $50 \%$ of $\left.\mathrm{a}_{\mathrm{g}}=0 \mathrm{~mm}\right)$. The equivalent $\mathrm{a}_{\mathrm{g}}$ in specimen $\mathrm{SS} 1$ is equal to $4.3 \mathrm{~mm}$. Similarly, the equivalent $\mathrm{a}_{\mathrm{g}}$ in specimen SM2and SL2 were calculated to be equal to $4.9 \mathrm{~mm}$ and $5.0 \mathrm{~mm}$ respectively. Therefore it reasonable to use the maximum aggregate size of the fine grout as $a_{g}$ in equation (2-18). As discussed in Chapter 3, the maximum aggregate size used in the grout was $5 \mathrm{~mm}$.

Figure 5-61 shows photos of specimen SL2 following failure. Figure 5-61 reveals excellent grout quality for the larger beams. No honeycombs were noticed and grout fully filled out the bottom courses of the beams achieving perfect bond with the main steel. Thus, the lower shear strength of these beams cannot be related to inadequate or incomplete grouting. 


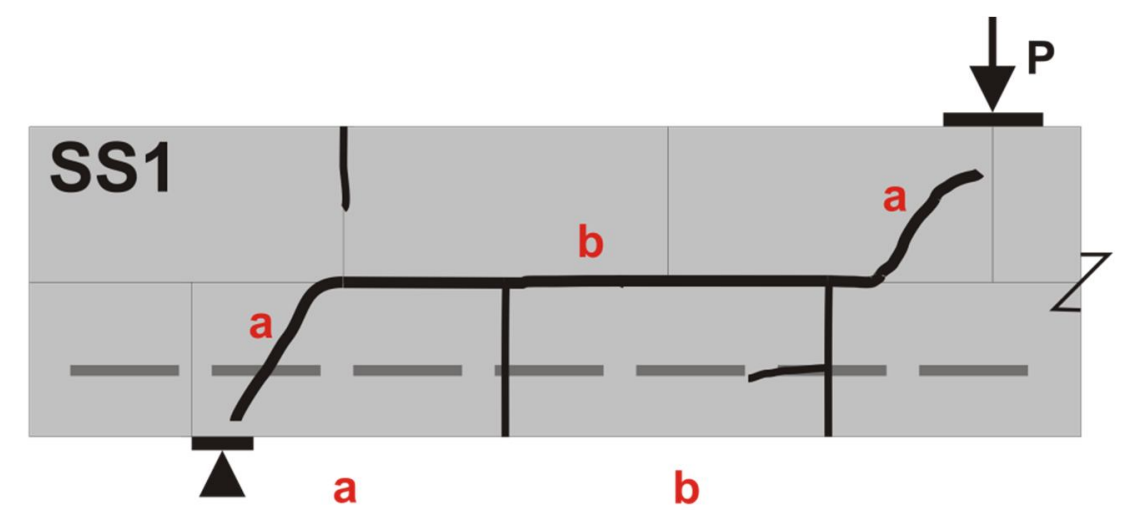

Effective $a_{g}=330(0.5 \times 10+0.5 \times 5)+650(0.5 \times 5+0.5 \times 0) /(330+650)=4.3 \mathrm{~mm}$

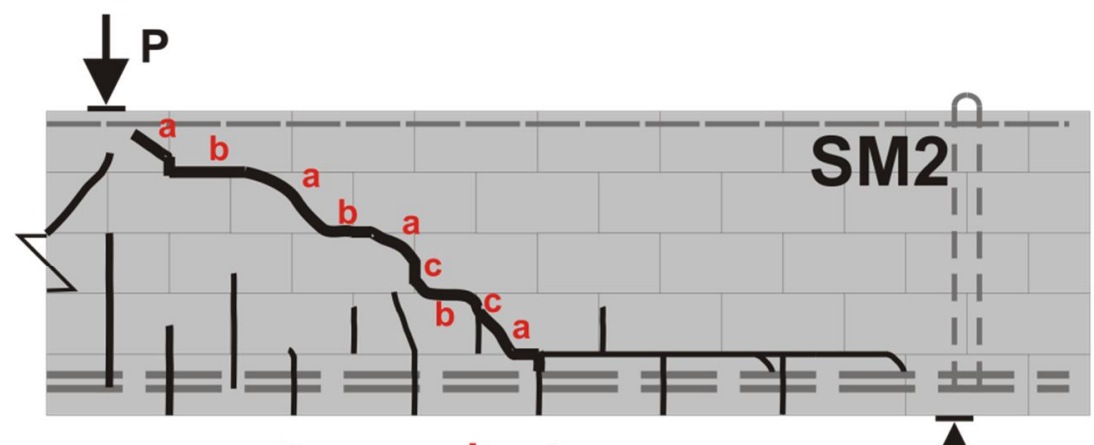

a b c

Effective $a_{g}=700(0.5 \times 10+0.5 \times 5)+(570+133)(0.5 \times 5+0.5 \times 0) /(700+570+133)=5 \mathrm{~mm}$

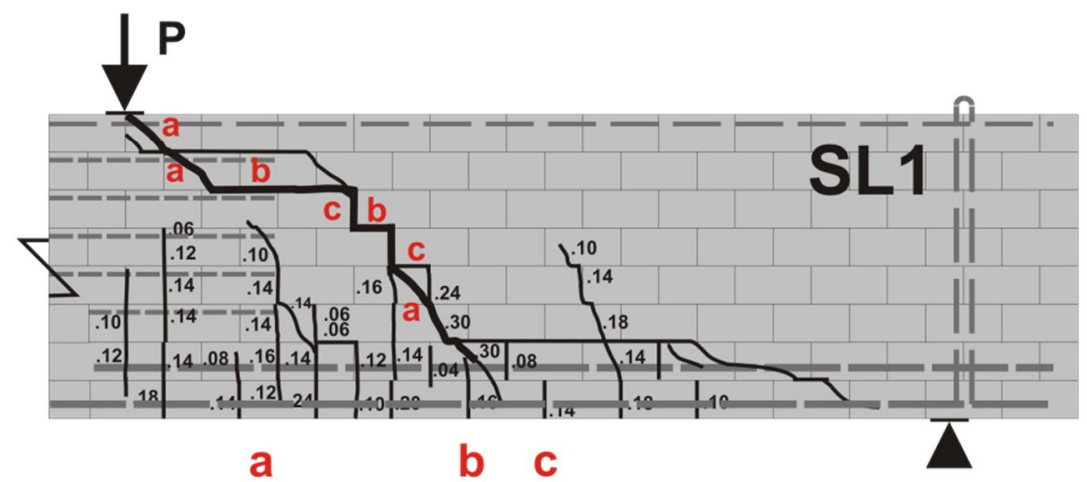

Effective $a_{g}=1260(0.5 \times 10+0.5 \times 5)+(950+400)(0.5 \times 5+0.5 \times 0) /(1260+950+400)=4.9 \mathrm{~mm}$

Figure 5-60 Calculations of Equivalent Aggregate Size for the CSA A23.3 Prediction of the Reinforced Masonry Beams 

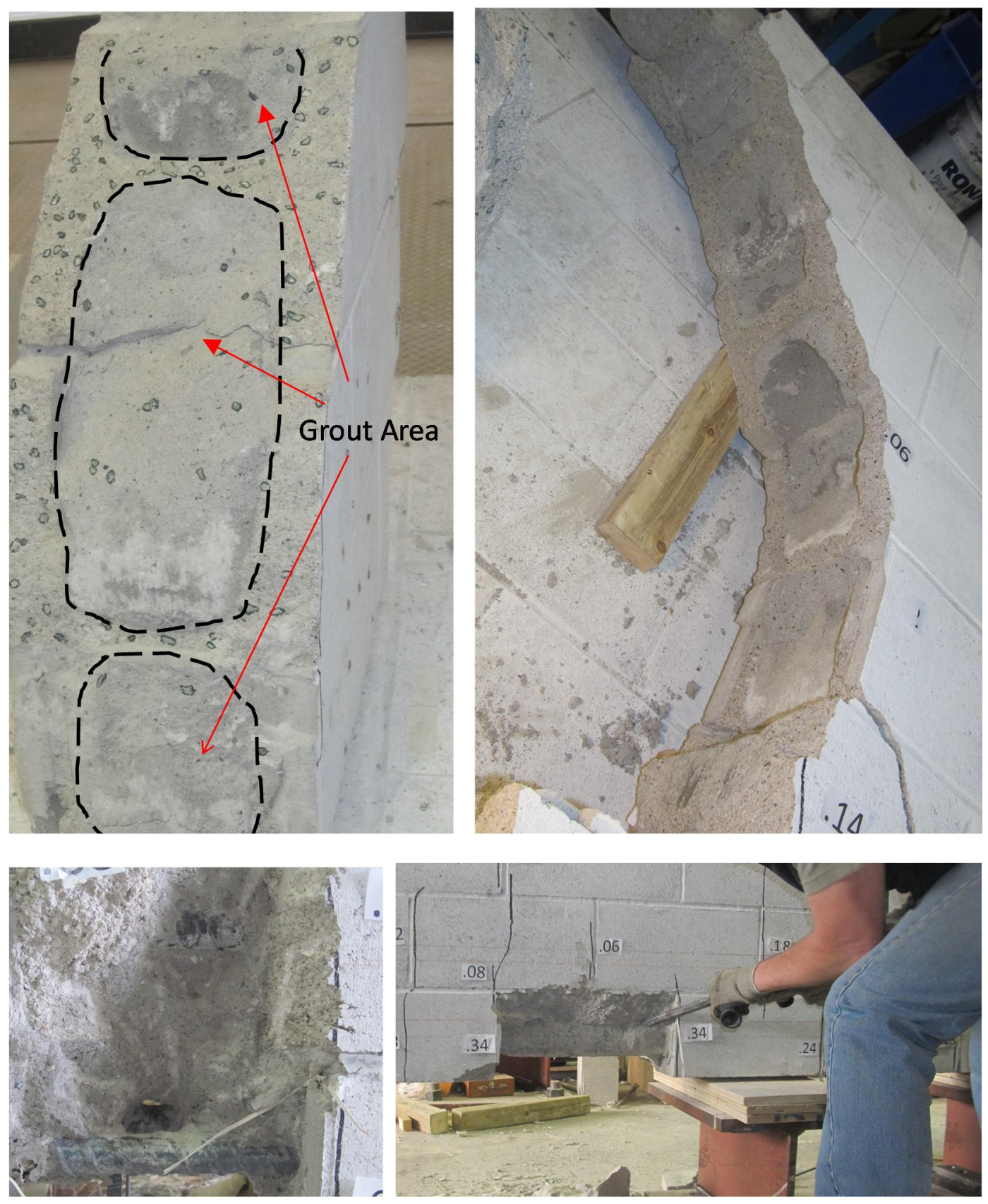

Figure 5-61: Surface of Major Diagonal Crack in Beam SL2 


\subsection{Size Effect in the Repeated Tests}

This section is devoted to exploring the existence of size effect in the repeated tests. Generally, the repeated tests of the specimens yielded higher shear strengths than the initial tests. The size effect was still evident in these tests.

\subsubsection{Size Effect in Series Reinforced with $\rho=0.83 \%$}

Figure 5-62 shows the load-displacement responses of specimens SS1R, SM1R and SL2R. It is clear that the failure shear stress decreased significantly with the increase in effective depth. Specimen SL2 failed at shear stress of $0.59 \mathrm{MPa}$ which is $68 \%$ of the failure shear stress of SS1R. This decrease in failure shear stresses was associated with major reductions in ductility. The relative displacement at failure in the large specimens SL2R was only $25 \%$ of that in the small specimen SS1R.

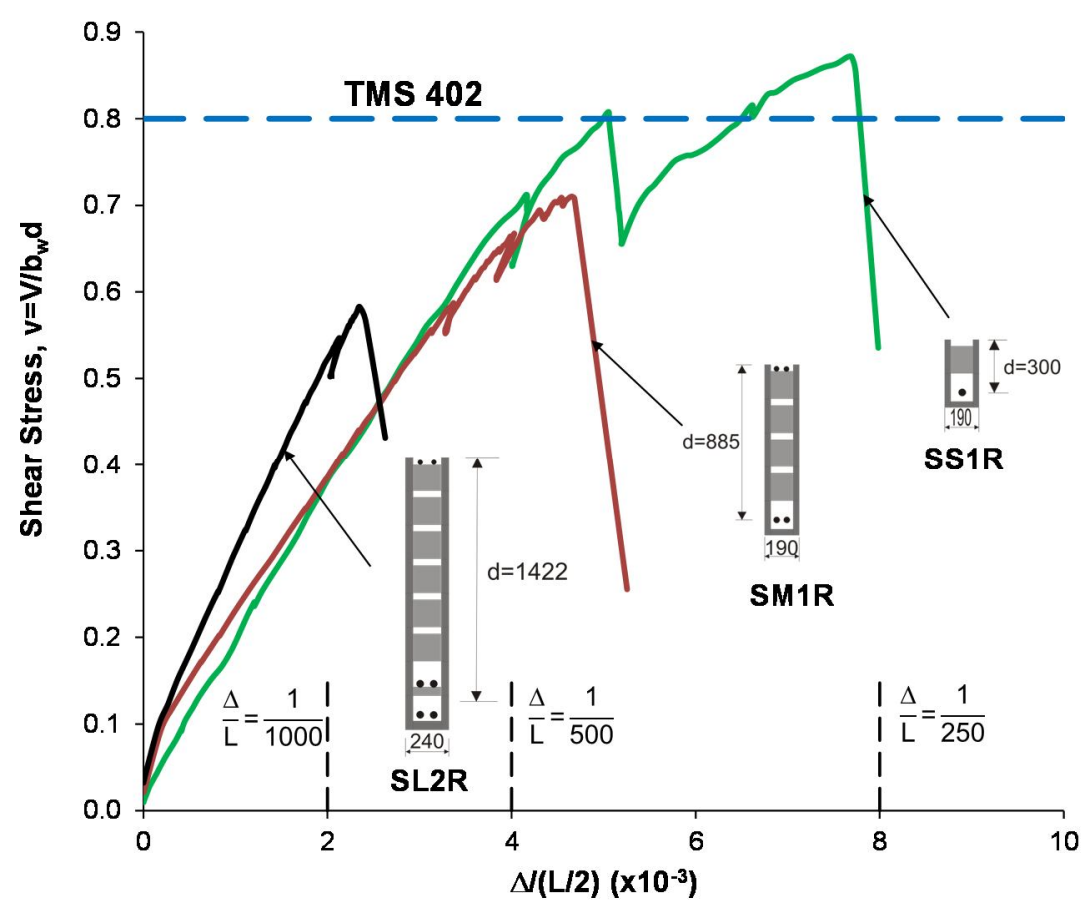

Figure 5-62: Relative Displacements of SS1R, SM1R and SL2R 


\subsubsection{Cracking Behaviour of Repeated Test Series with $\rho=0.83 \%$}

Generally, no new major shear cracks formed during these repeated tests of this series. A stabilized cracking phase was recognized in all the beams of this series where the existing cracks widened with the increase in the applied load.

\section{SS1R}

Figure 5-63 shows the crack patterns of specimen SS1R. It can be seen that at a load of $90 \mathrm{kN}$ (corresponding to $91 \%$ of the failure load) the far crack in the west side of the beam extended horizontally through the bed joint connecting the crack close to the point load and it also extended diagonally backward towards the support. The extension of this crack was associated with a significant drop in the load and increase in the shear strain measured in the shear span (see 5-64). This can be identified as an initial breakdown of aggregate interlock (especially along the bed joint) which was probably followed by formation of a shear key. It is worth mentioning that the aggregate interlock mechanism was still active at this stage especially in the diagonal parts of the crack. At a load of $98.4 \mathrm{kN}$ the beam SS1R failed due to the breakdown of beam action. The crack widened so extensively that they could not maintain resisting shear stresses through aggregate interlock or shear key mechanisms. Figure 5-63 shows that shear strains increased significantly with the drop in load after failure. 

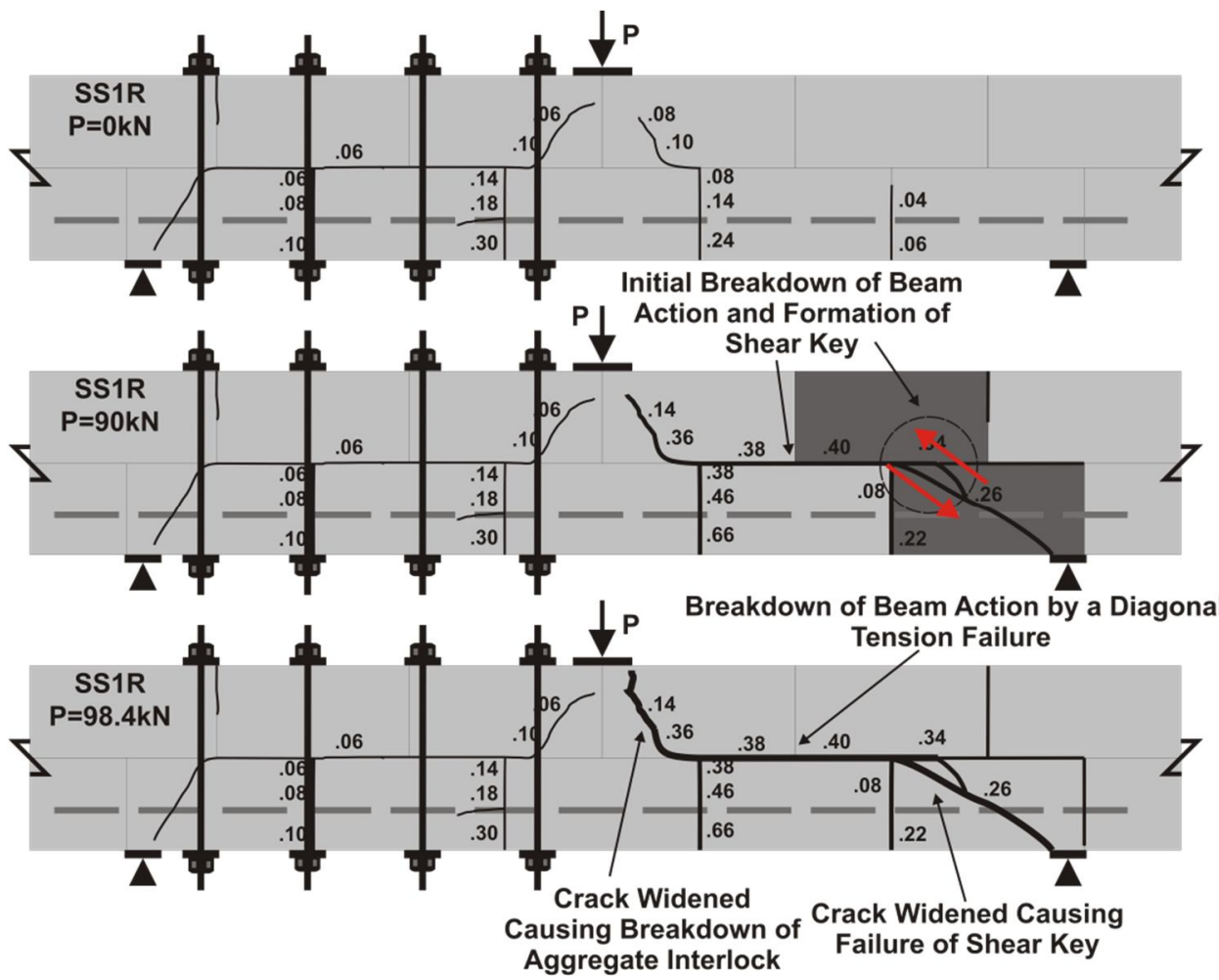

Figure 5-63: Crack Patterns of Specimen SS1R

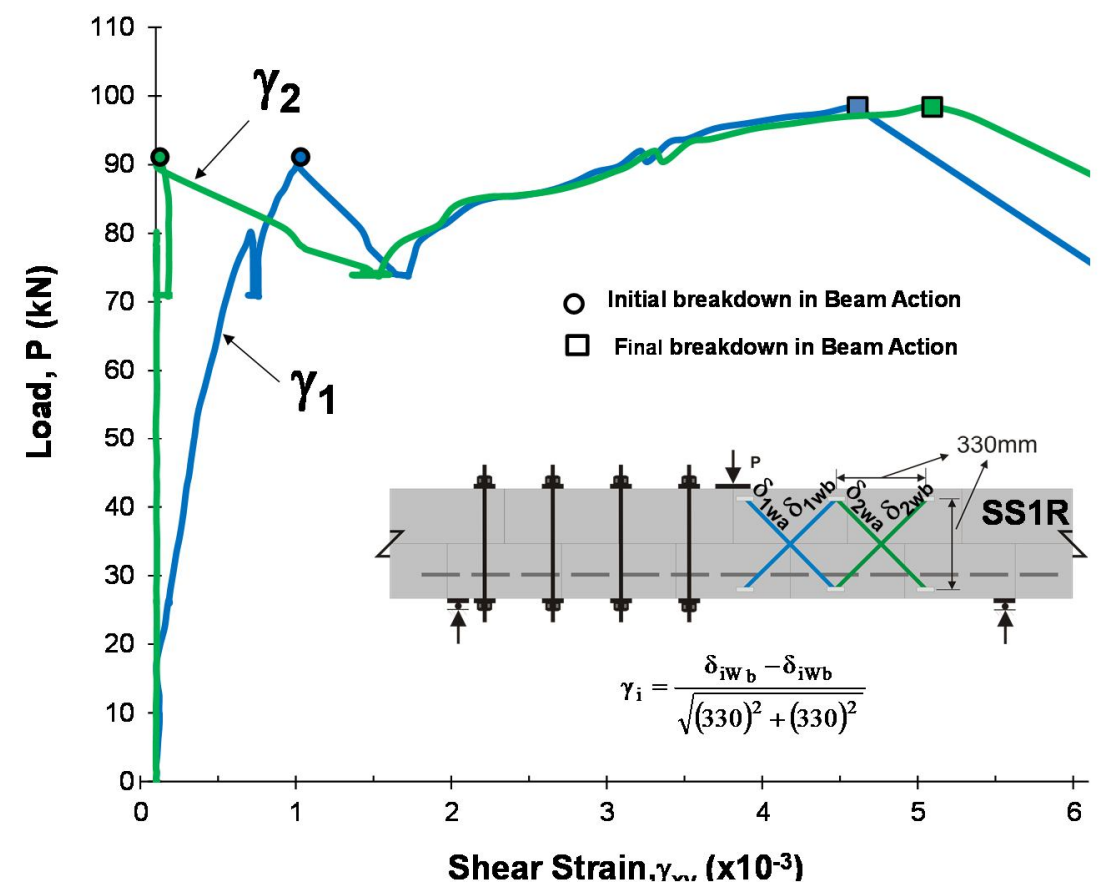

Figure 5-64: Shear Strains in SS1R 


\section{SM1R}

The crack patterns of specimen SM1R are depicted in Figure 5-65. As it was discussed in the initial test of the beam, an initial breakdown of beam action occurred in the west span and was followed by the engagement of strut and tie action and the formation of a shear key. In the repeated test, considerable interlocking was observed in the shear key area and around two head joints. At a load of $231.9 \mathrm{kN}$ the beam failed due to the crushing of compression zone and the breakdown of the shear key. The diagonal crack branched at the shear key area and extended diagonally toward the loading point though the top course (see Figure 5-66). A wedge-shaped masonry part was observed at the shear key after being cut by the diagonal crack.

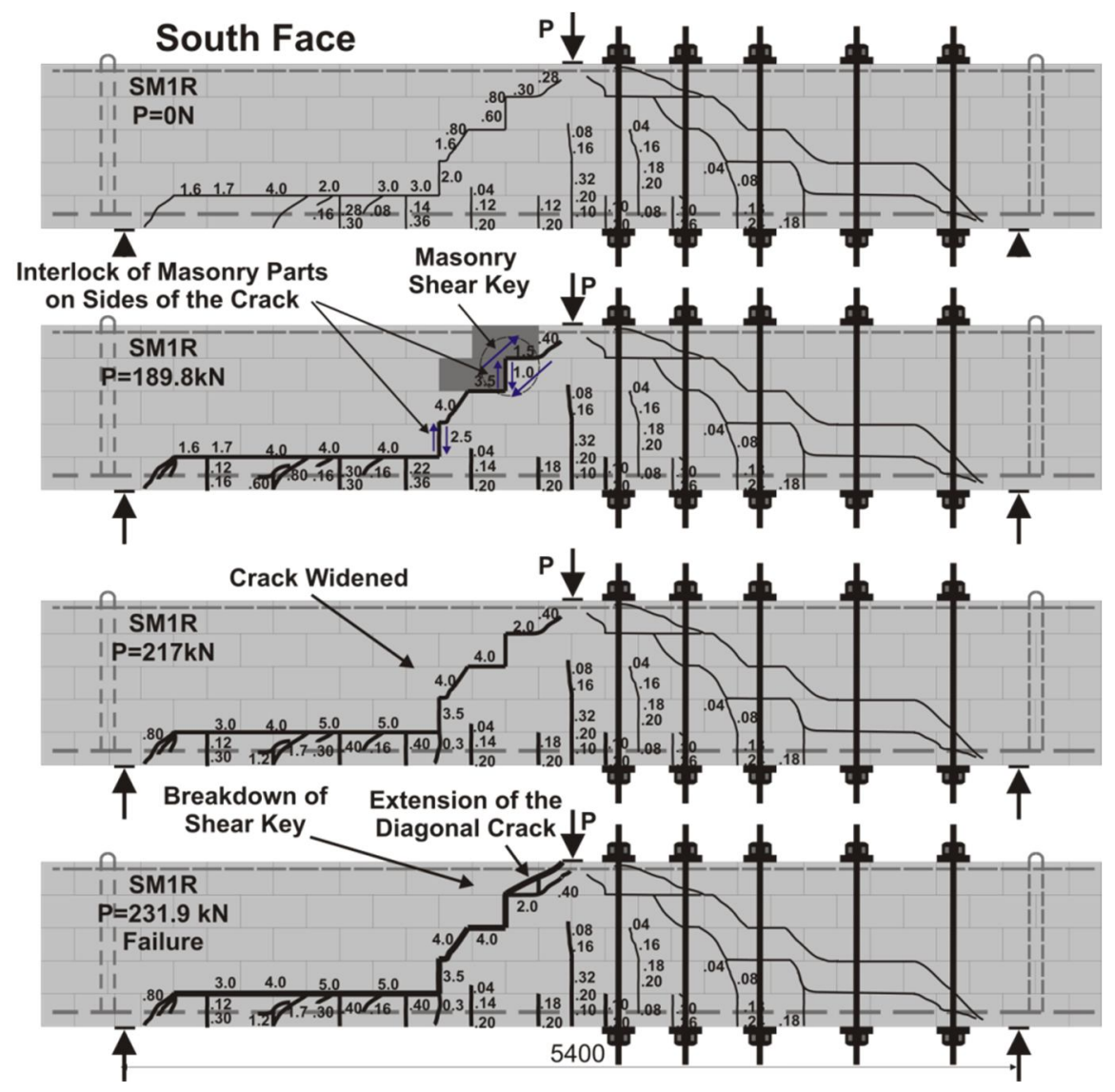

Figure 5-65: Crack Patterns of SM1R 

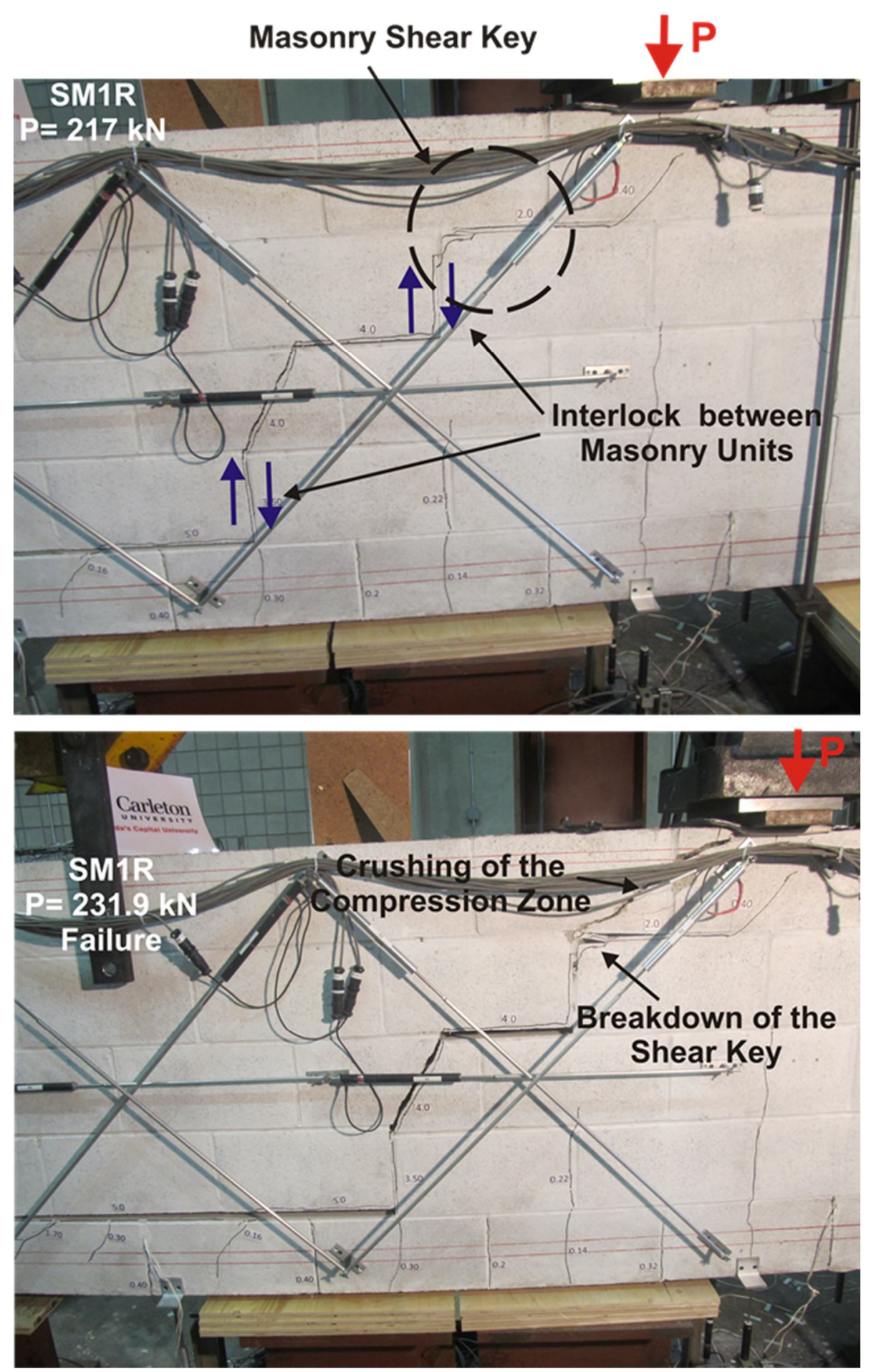

Figure 5-66: Failure of SM1R 


\section{$S L 2 R$}

In the repeated test of specimens SL1 and SL2, no new cracks were formed. The existing cracks widened and grew with increases in the applied load. Figure 5-67 shows the crack patterns of beam SL2R. At a load of $350 \mathrm{kN}$ (corresponding to $93 \%$ of the failure load) the far crack in the first masonry tooth (close to the point load) started to widen and inclined toward the point load travelling through the head and bed joints. At a load of $378 \mathrm{kN}$ the dominant crack widened extensively causing the breakdown of aggregate interlock. The failure of the beams was followed by a significant increase in the shear strain which was associated the drop in the applied load (see Figure 5-68). The failure of SL1R was similar to that of SL2R.

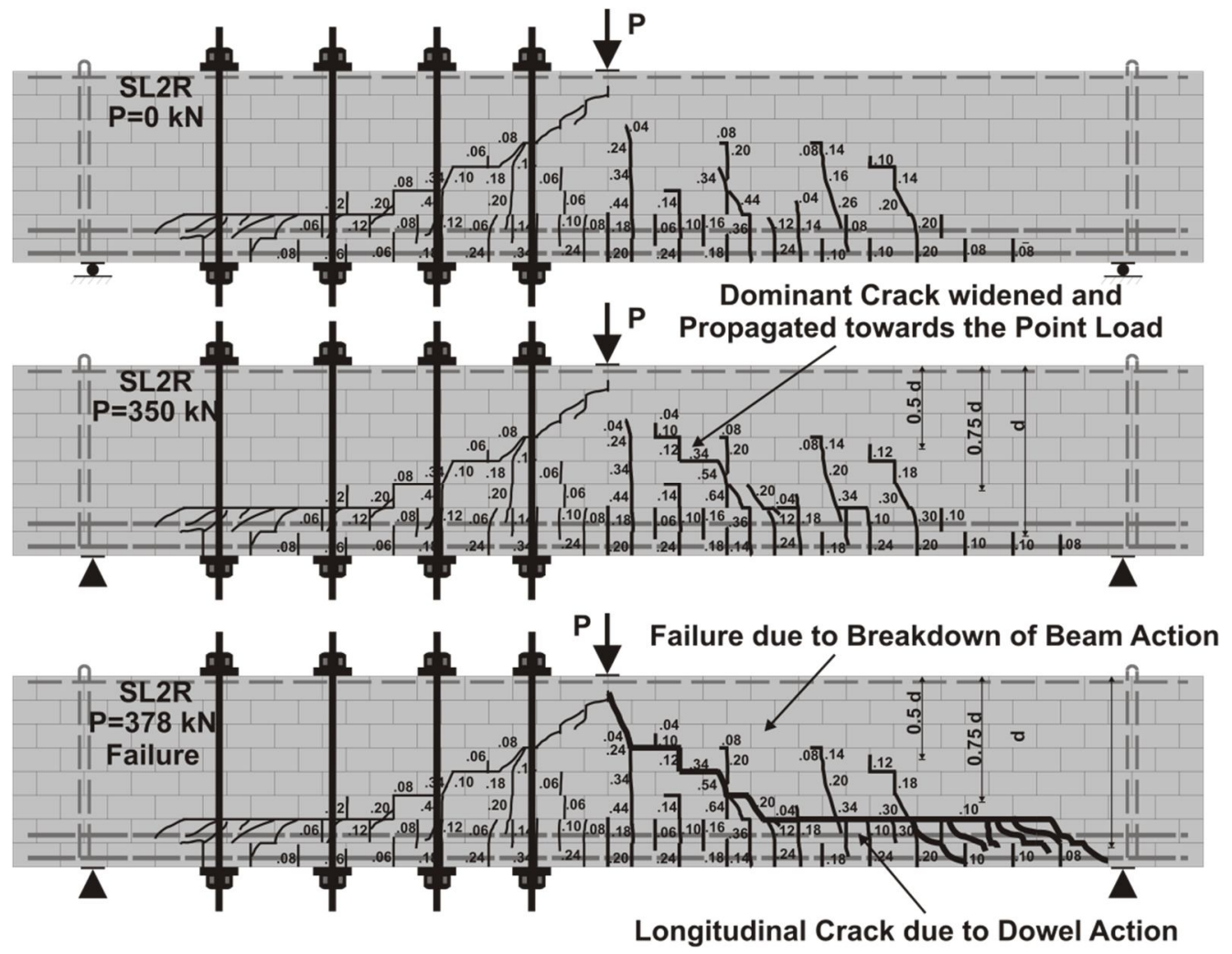

Figure 5-67: Crack Patterns of SL2R 


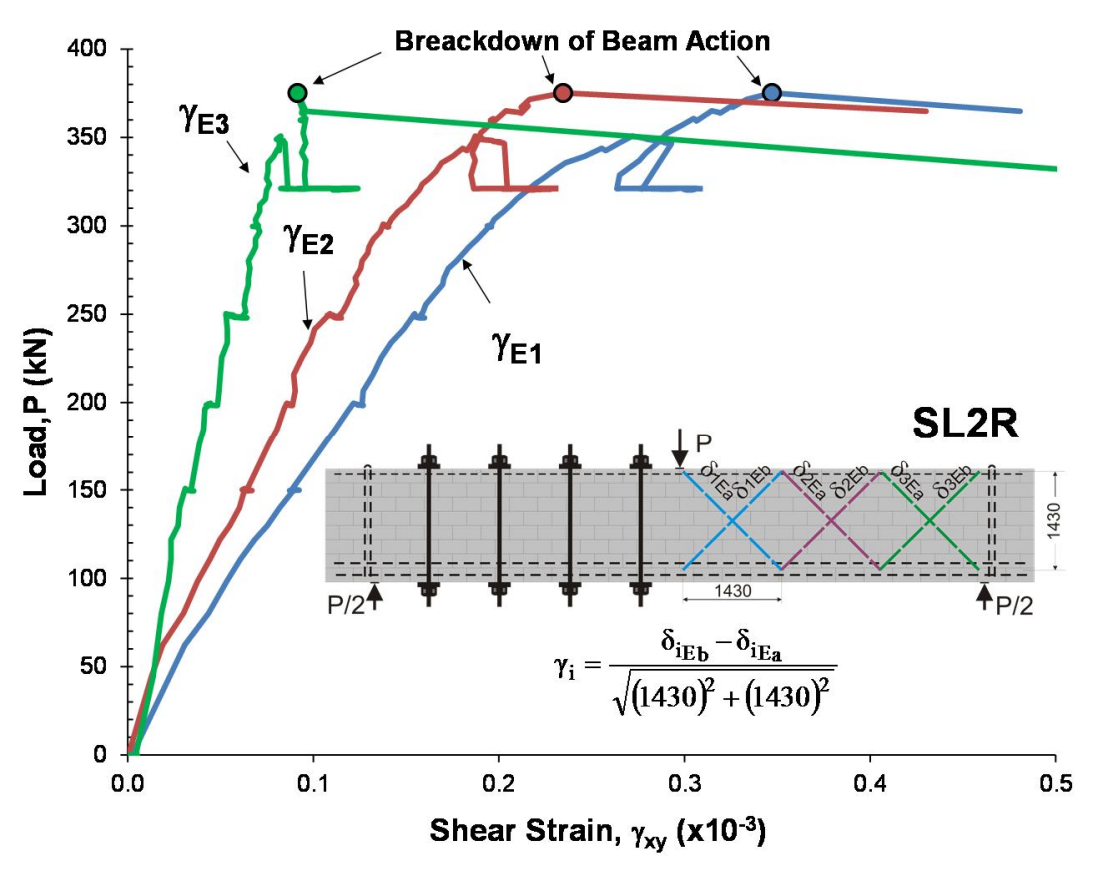

Figure 5-68: Shear Strains in SL2R

\section{SM1DR}

Figure 5-69 shows the crack patterns of SM1DR. It can be seen that loading the beam until 180 $\mathrm{kN}$ caused only widening and extension of the existing cracks, particularly a diagonal crack close to the point load (the dominant crack in the west span). At a load of $184 \mathrm{kN}$ this dominant crack grew upward toward the point load and backward horizontally along the bottom bed joint toward the support. This can be identified as a breakdown in beam action as it was associated with a significant drop in the applied load and considerable increases in the shear strains as shown in Figure 5-70. It can also be seen in Figure 5-70 that the steel strains at midspan and at the west support exhibited significant increases marking a switch from beam action to strut and tie. Having a large un-cracked portion of the beam extending from the point load towards the support helped the formation of an efficient strut. The horizontal crack near the support (Detail A in Figure 569) was narrow and it did not break up the continuity of the compressive stresses in the strut. No shear keys were formed and no interlocking was observed between the masonry parts around the 
crack. At a load of $287.1 \mathrm{kN}$ the beam failed due to extensive cracking in the bed joint above the steel level and at the level of steel near the support. It is worth mentioning that Specimen SM2R had similar strut and tie behavior and it failed due anchorage failure at the support (see Appendix A).

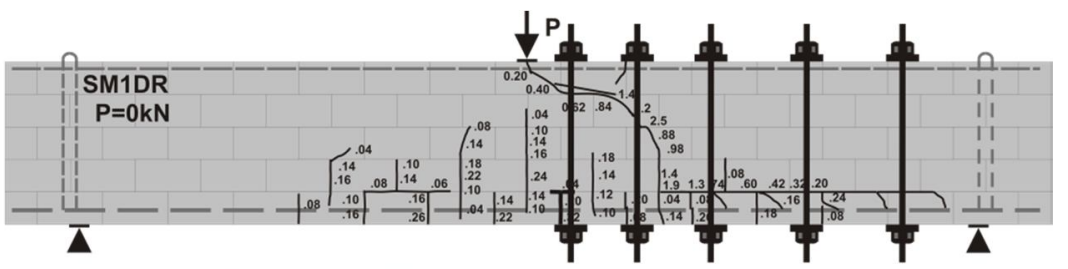

Existing Cracks Grow and Widen

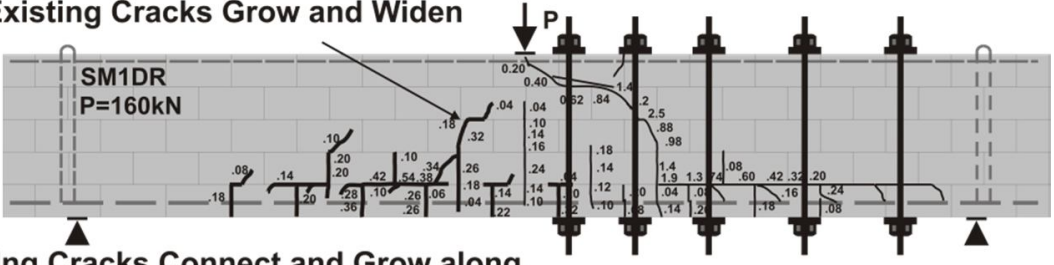

Existing Cracks Connect and Grow along

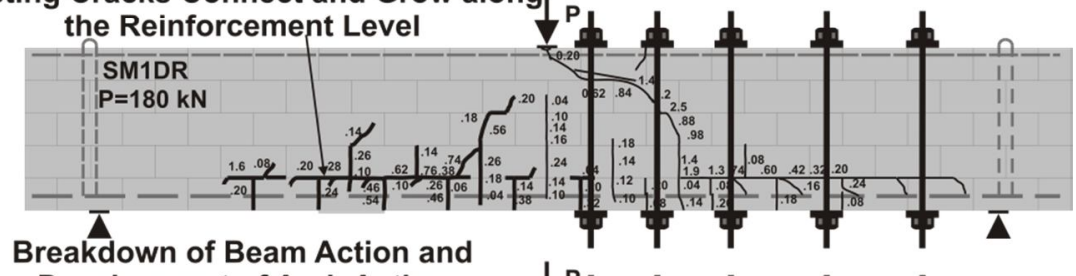

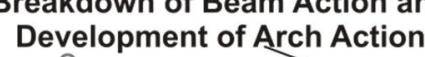
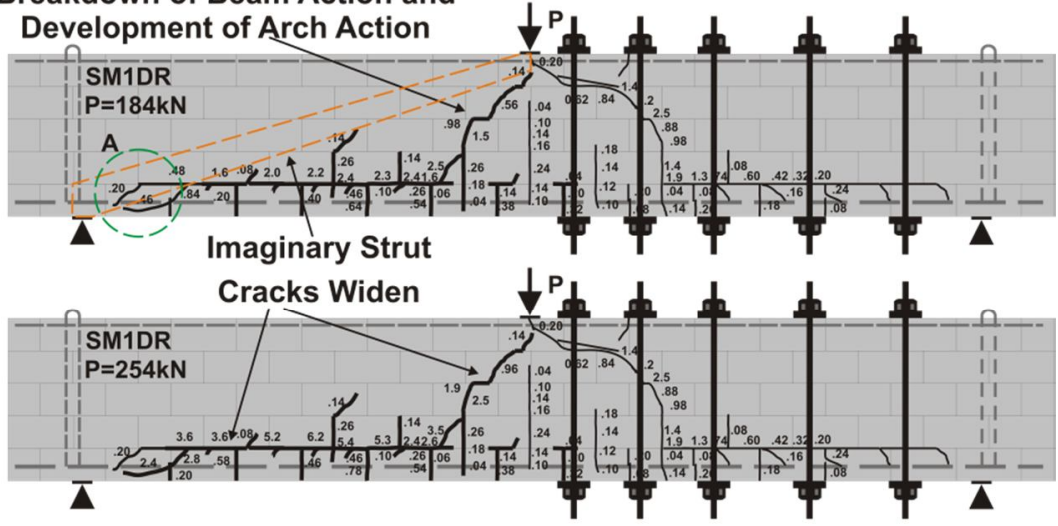

Failure by Splitting at the Level of Steel

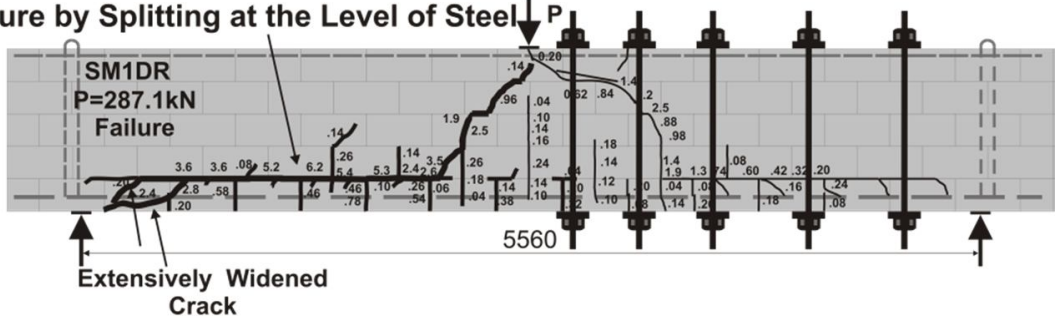

Figure 5-69: Crack Patterns of SM1DR 


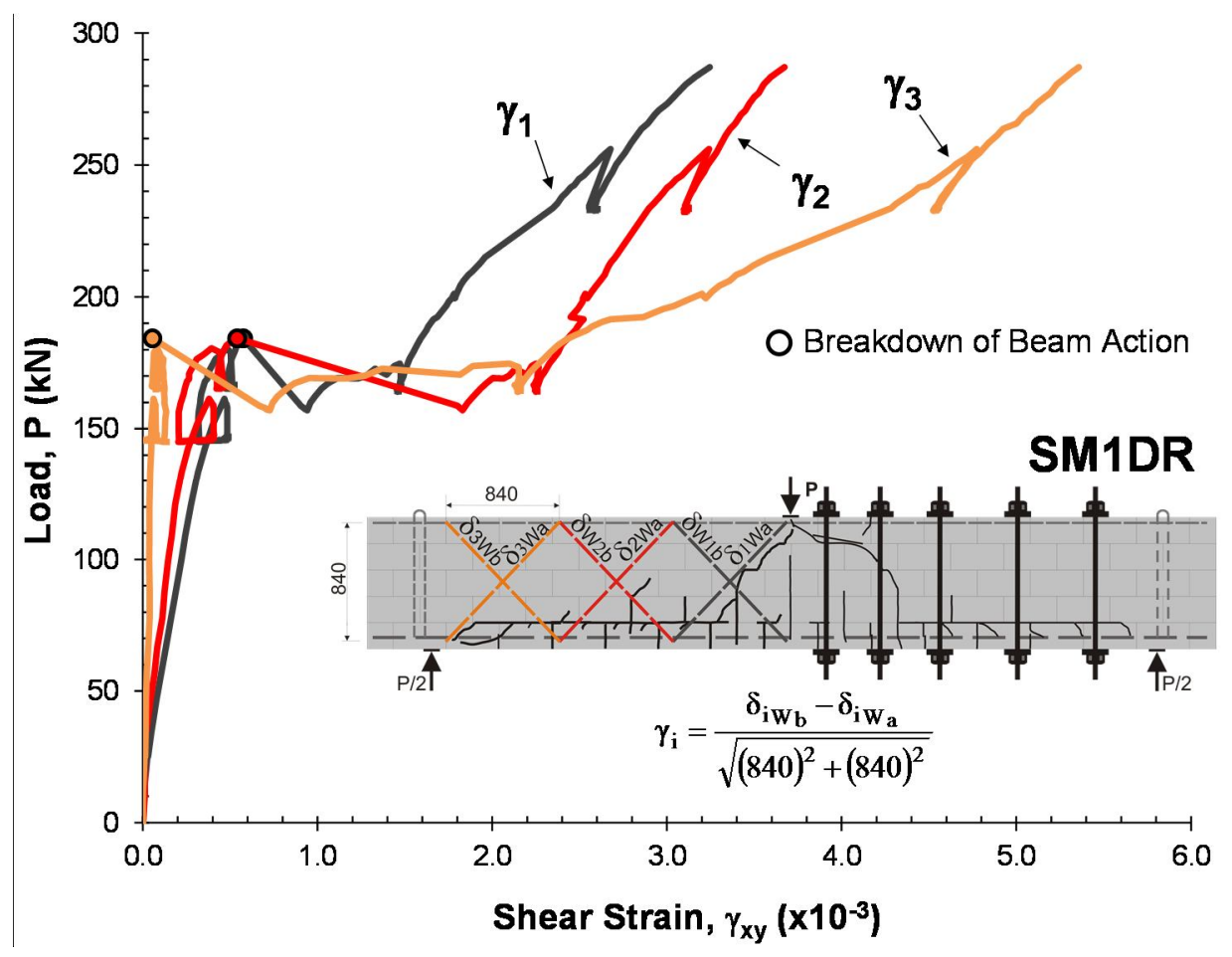

Figure 5-70: Shear Strains in SM1DR

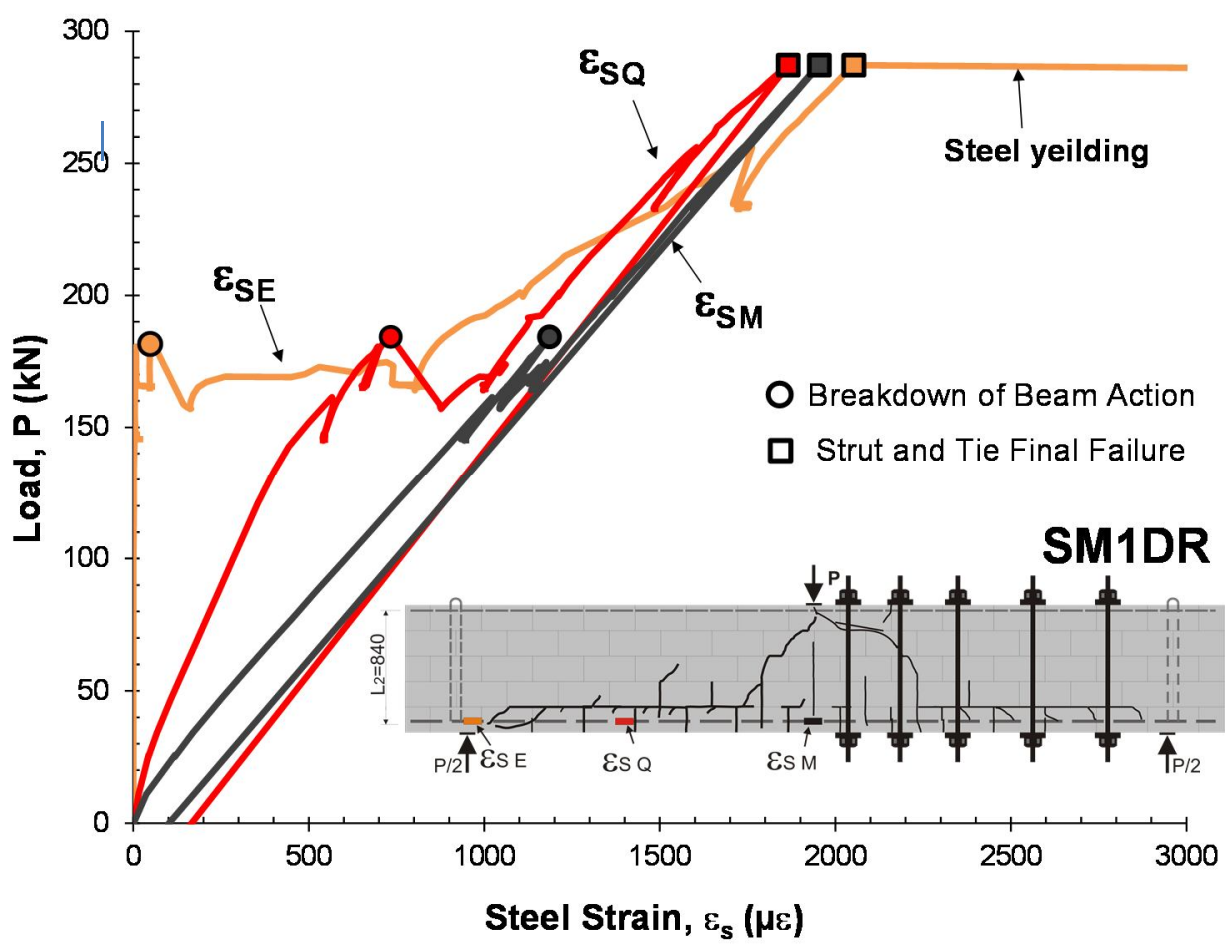

Figure 5-71: Steel Strains in SM1DR 


\subsubsection{Size Effect in the Repeated Tests of Series with $\rho=0.32 \%$}

Figure 5-72 presents the relative displacement responses of specimens SS4R and SM4R. It is clear that increasing the effective $\mathrm{d}$ from $307 \mathrm{~mm}$ in SS4R to $880 \mathrm{~mm}$ in specimen SM4R resulted in reduction of failure shear stress by $20 \%$. SS4R failed at a relative displacement of $1 / 200$ th of the compared 1/340th of the span for SM4R.

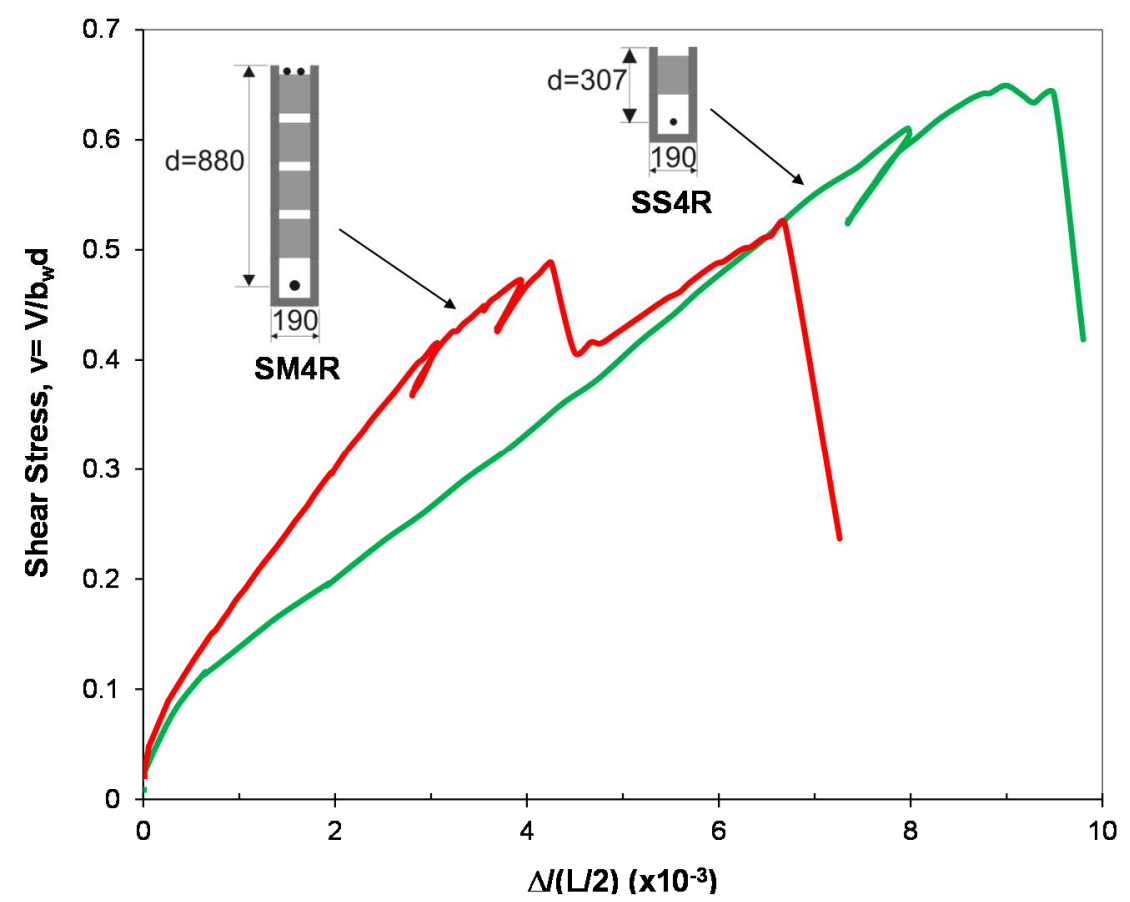

Figure 5-72: Relative Displacements of SS1R, SM1R and SL2R

\subsubsection{Cracking Behaviour of Repeated Test Series with $\rho=0.32 \%$}

SS4R

Figure 5-73 shows the crack patterns of specimen SS4R. It is clear from the figure that loading SS4R up to $70 \mathrm{kN}$ (equivalent to $96 \%$ of the failure load) resulted only in widening and extension of the existing cracks. No new cracks were formed. In this stage the interlock between 
the adjacent blocks at the shear key formed and aggregate interlock across the diagonal portions of the crack was in effect with the other mechanisms (dowel action and uncracked compression zone) in resisting the shear stresses. At a load of $74.8 \mathrm{kN}$ the dominant crack widened significantly causing failure due to breakdown of the shear key and aggregate interlock.

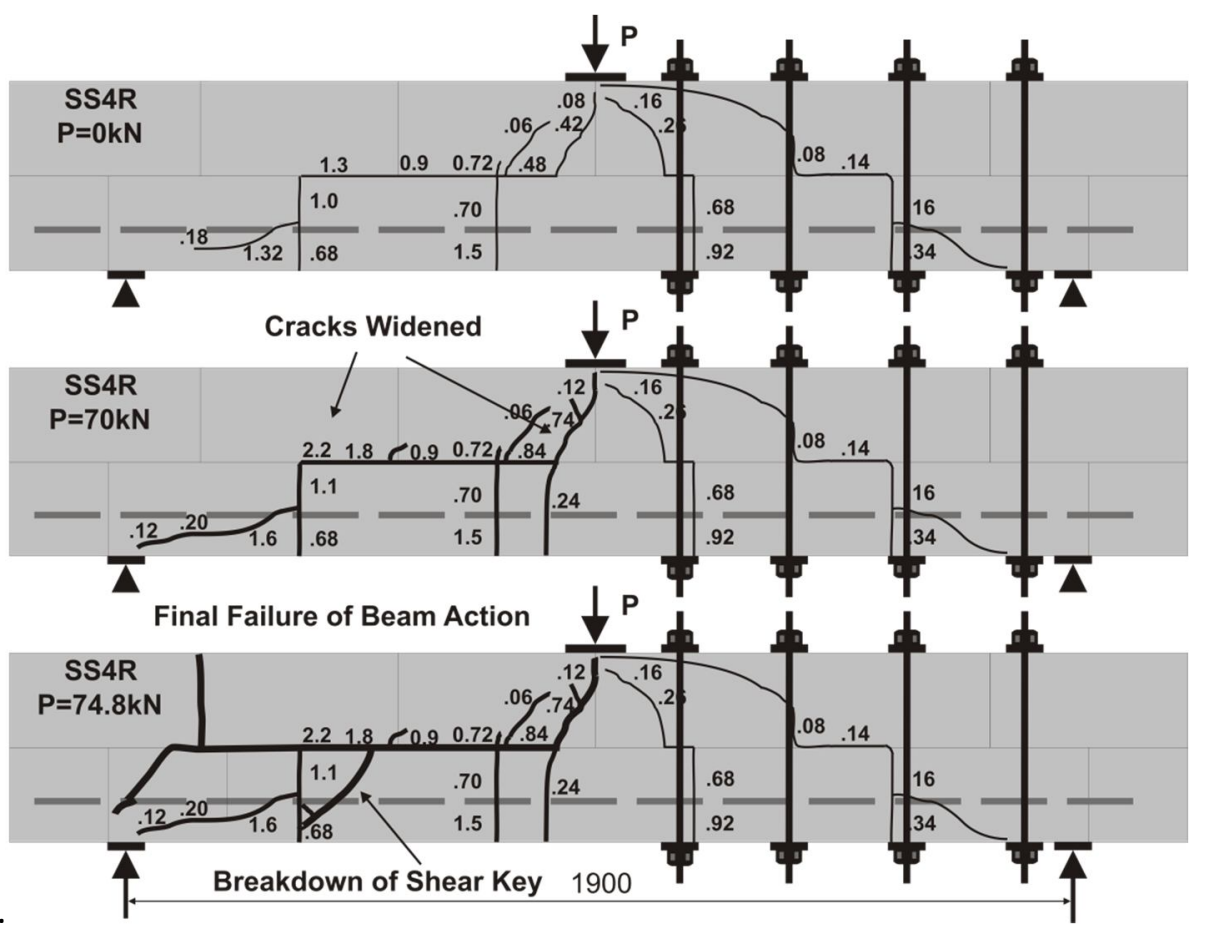

Figure 5-73: Crack Patterns of SS4R

\section{SM4R}

The crack patterns of SM4R are depicted in Figure 5-74. At a load of $151 \mathrm{kN}$ a new flexural shear crack developed in the middle of the shear span forming with the existing crack a wide masonry tooth. At a load of $156 \mathrm{kN}$ (corresponding to $93 \%$ of the failure load) this new crack travelled horizontally along the bed joint toward the loading point causing a sudden drop in the applied load associated with a significant increases in the shear strains (see Figure 5-75). This can be considered as an initial breakdown of beam action which was followed by the 
engagement of strut and tie model and the formation a shear key. At a load $168.5 \mathrm{kN}$, specimen SM4R failed in a combination of strut and tie failure and breakdown of the shear key.
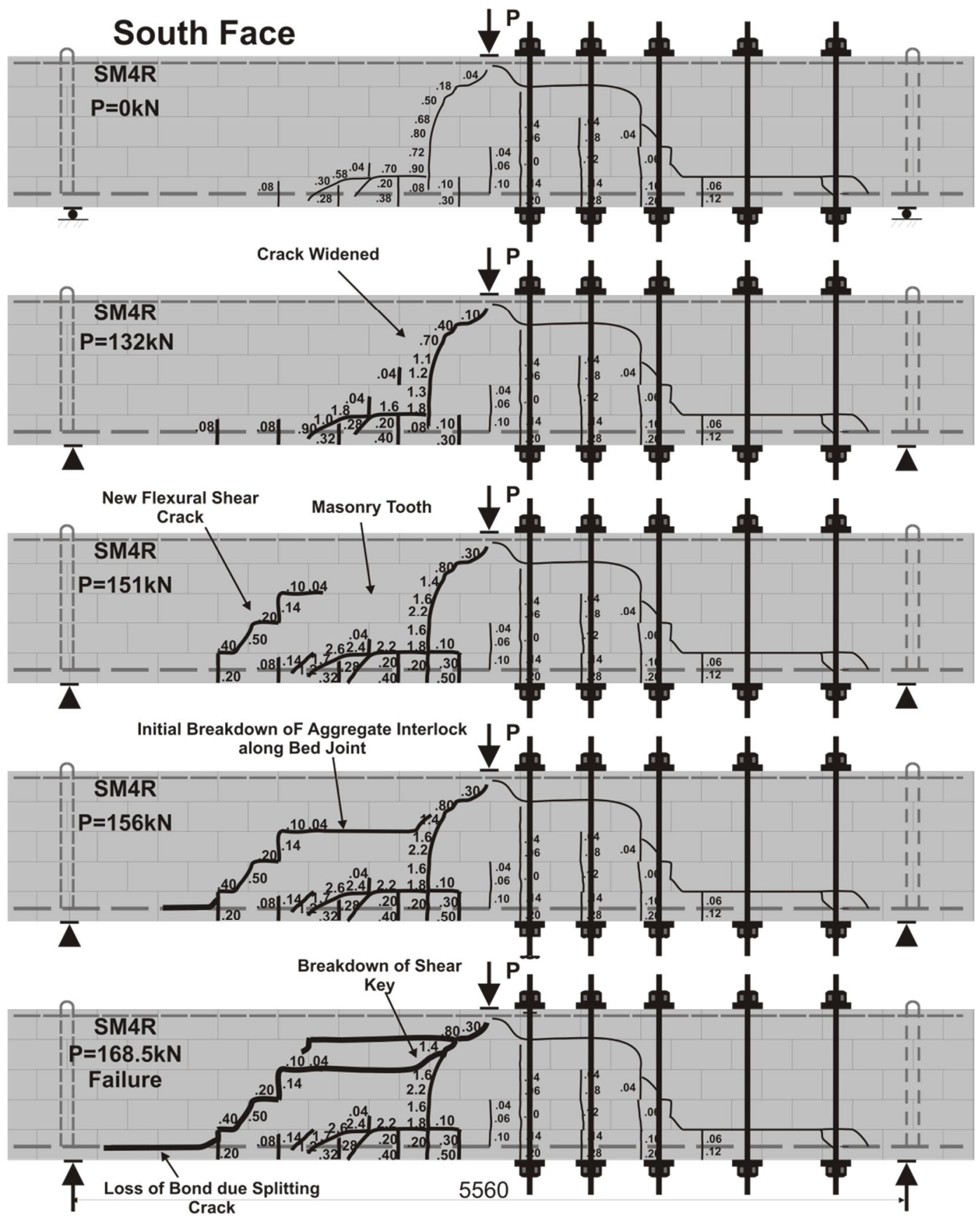

Figure 5-74: Crack Patterns of SM4R 


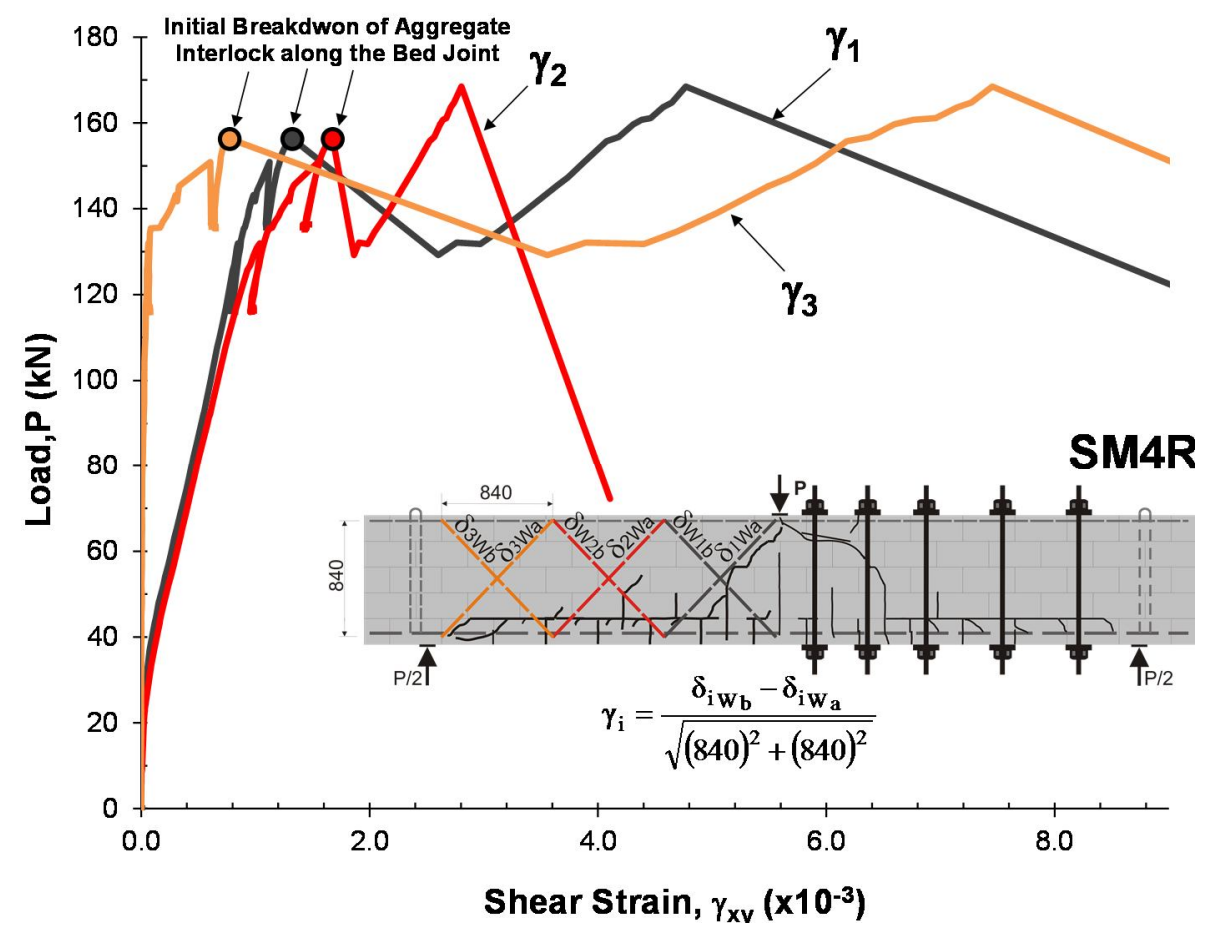

Figure 5-75: Shear Strains in SM4R

\subsubsection{Failure Shear Stress Predictions of the Repeated Tests}

The failure shear stresses of the repeated tests with the code predictions are presented in Table 55 and Figures 5-76 and 5-77. It can be seen that the size effect was significant in the repeated specimens. It can also be observed that although the repeated tests exhibited higher shear stresses than the initial tests, the TMS 402 code still gives unsafe predictions for the medium and large specimens. This non-conservative estimation by TMS 402 code is associated with the highest variation (COV is 31\%). The CSA S304.1 gives safe predictions but with high variation. The CSA A23.3 and Hoult et al. expression were able to safely and accurately predict the failure shear stresses of the repeated tests. The CSA A23.3 code exhibited the smallest value of COV of $15 \%$. 
Table 5-5: Experimental Observation of the Repeated Tests of the Size Effect Series Beams with North American Codes Predictions

\begin{tabular}{|c|c|c|c|c|c|c|c|c|c|c|c|c|c|c|c|c|c|c|c|}
\hline \multirow[b]{2}{*}{ 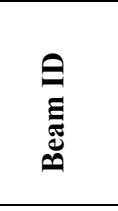 } & \multicolumn{6}{|c|}{ Geometry } & \multicolumn{5}{|c|}{ Experimental Observation } & \multicolumn{2}{|c|}{ CSA S304.1 } & \multicolumn{2}{|c|}{ TMS 402} & \multicolumn{2}{|c|}{ CSA A23.3 } & \multicolumn{2}{|c|}{ Hoult et al. } \\
\hline & $\mathrm{a} / \mathrm{d}$ & $\mathrm{d}(\mathrm{mm})$ & bw(mm) & $\rho(\%)$ & $\frac{A_{v} f_{y}}{b_{w} s}$ & $\begin{array}{c}\text { Crack } \\
\text { Control } \\
\text { Steel }\end{array}$ & $\begin{array}{c}\mathrm{f}_{\mathrm{m}} \\
(\mathrm{MPa})\end{array}$ & $\begin{array}{l}\text { Pexp } \\
(\mathrm{kN})\end{array}$ & $\begin{array}{c}\mathrm{Vexp}^{*} \\
(\mathrm{kN})\end{array}$ & $\begin{array}{c}v^{* *} \\
(\mathrm{MPa})\end{array}$ & $\beta^{* *}$ & 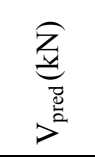 & $\frac{p^{\frac{\vec{g}}{n^{2}}}}{p^{\tilde{z}}}$ & 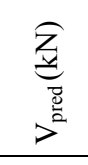 & $\frac{\sum^{\frac{\vec{g}}{2}}}{p^{2}}$ & 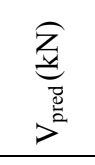 & 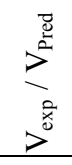 & $\underset{\substack{z \\
\frac{d}{2}}}{>^{2}}$ & $\frac{\sum^{\frac{\vec{g}}{2}}}{p^{\frac{\tilde{x}}{0}}}$ \\
\hline SS1R & 3.17 & 300 & 190 & 0.88 & - & - & 17.5 & 98 & 49.5 & 0.87 & 0.21 & 38.2 & 1.30 & 44.6 & 1.11 & 37.8 & 1.31 & 40.5 & 1.23 \\
\hline SS2R & 3.11 & 305 & 190 & 1.72 & - & - & 17.5 & 130.2 & 65.6 & 1.13 & 0.27 & 39.4 & 1.66 & 45.3 & 1.45 & 47.5 & 1.38 & 48.9 & 1.34 \\
\hline SS4R & 3.10 & 307 & 190 & 0.30 & - & - & 18 & 74.6 & 36.7 & 0.63 & 0.15 & 46.3 & 0.79 & 46.3 & 0.79 & 26.5 & 1.39 & 30.6 & 1.20 \\
\hline SM1R & 3.05 & 885 & 190 & 0.83 & - & - & 17.9 & 231 & 119 & 0.71 & 0.17 & 86.22 & 1.38 & 133.0 & 0.89 & 80.5 & 1.48 & 83.8 & 1.42 \\
\hline SM1DR & 3.14 & 885 & 190 & 0.83 & - & - & 20 & 289 & 148 & 0.88 & 0.20 & 91.14 & 1.62 & 140.6 & 1.05 & 82.9 & 1.79 & 86.8 & 1.71 \\
\hline SM4R & 3.16 & 880 & 190 & 0.33 & - & - & 18.5 & 168 & 87.5 & 0.52 & 0.12 & 87.45 & 1.00 & 134.5 & 0.65 & 58.1 & 1.51 & 64.6 & 1.35 \\
\hline SM6R & 3.16 & 880 & 190 & 0.84 & - & No.15@200 & 18 & 213 & 110 & 0.66 & 0.16 & 86.3 & 1.27 & 132.7 & 0.83 & 117.5 & 0.97 & 126.8 & 0.90 \\
\hline SL1R & 3.02 & 1420 & 240 & 0.82 & - & - & 18.9 & 378 & 200 & 0.59 & 0.13 & 116.2 & 1.72 & 277.1 & 0.72 & 132.5 & 1.51 & 136.7 & 1.46 \\
\hline SL2R & 3.02 & 1422 & 240 & 0.82 & - & - & 18.9 & 342 & 181.7 & 0.53 & 0.12 & 116 & 1.57 & 277.4 & 0.65 & 132.9 & 1.37 & 136.8 & 1.33 \\
\hline & & & & & & & & & & & & Mean & 1.37 & & 0.91 & & 1.41 & & 1.33 \\
\hline & & & & & & & & & & & & STDV & 0.32 & & 0.26 & & 0.22 & & 0.22 \\
\hline & & & & & & & & & & & & $V(\%)$ & 23 & & 29 & & 15 & & 16 \\
\hline
\end{tabular}

* Vexp $=\frac{P \exp }{2}+\mathrm{V} @ \mathrm{~d}$ from point load (due to self weight)

** $\quad v=\frac{\text { Vexp }}{b_{w} d}, \beta=\frac{V}{b_{w} d \sqrt{f^{\prime} m}}$ 


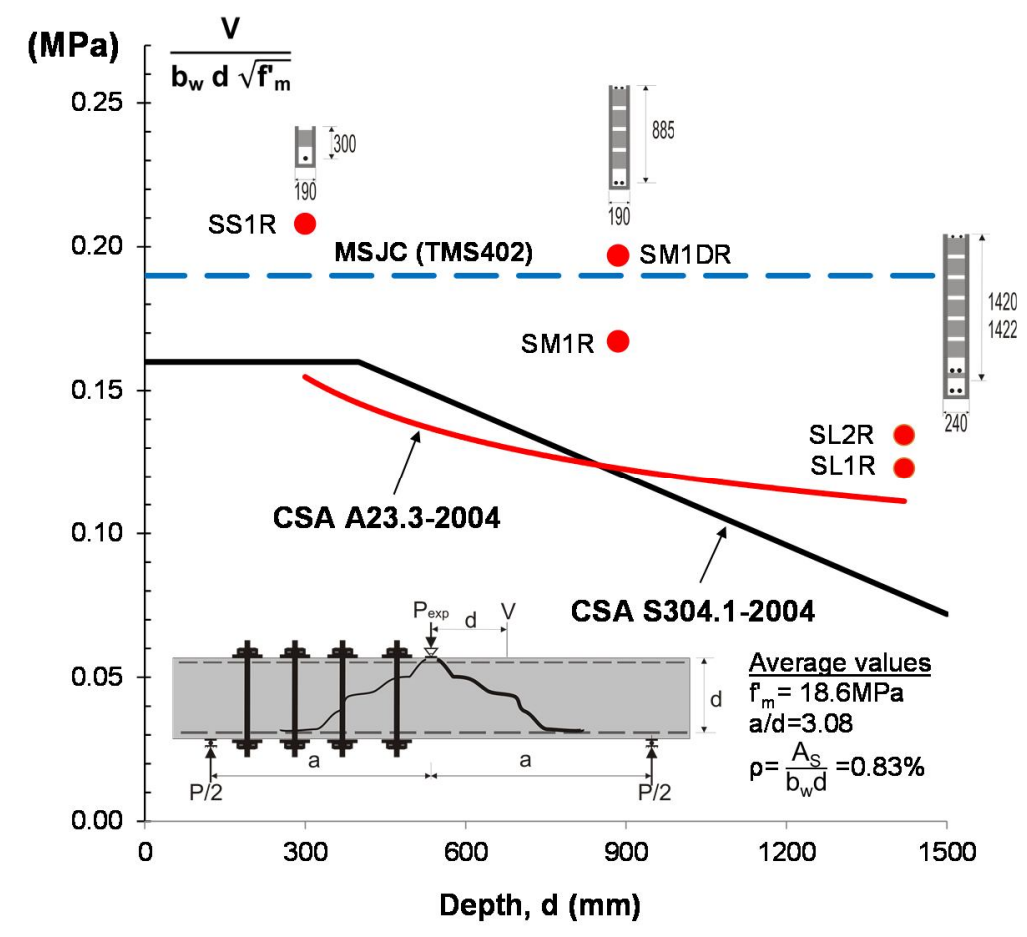

Figure 5-76: Failure Shear Stresses of Specimens SS1R, SM1DR, SM1D, SL1 and SL2

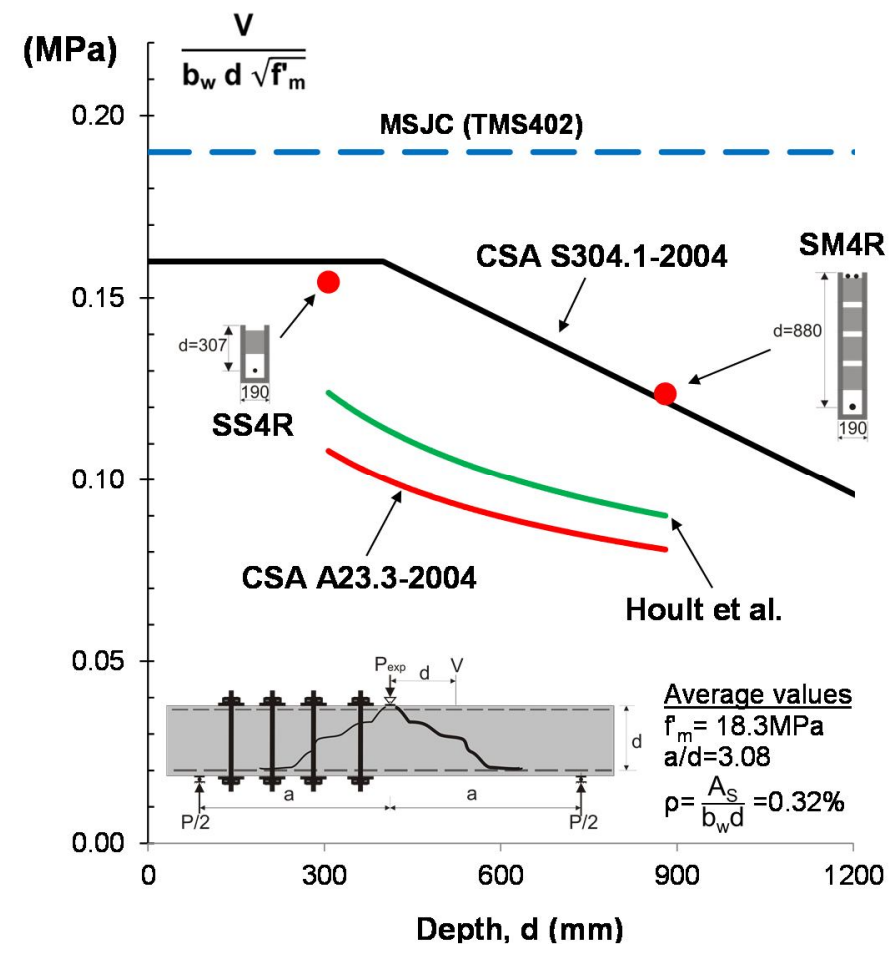

Figure 5-77: Failure Shear Stresses of Specimens SS4R and SM4R 


\subsection{Size Effect in RMB Series Reinforced with FRP Bars}

In this section, the existence of size effect in RMB reinforced with FPR rebars will be examined.

It can be noted from Table 5-6 that a larger effective depth in specimen SM5 as compared to specimen SS2 was associated a significant drop in failure shear stress. Beam SM5 failed at shear stress of $74 \%$ that of the failure shear stress of SS5.

Table 5-6 Experimental Observations of the RMB Reinforced with GFRP Bars with North American Codes Predictions

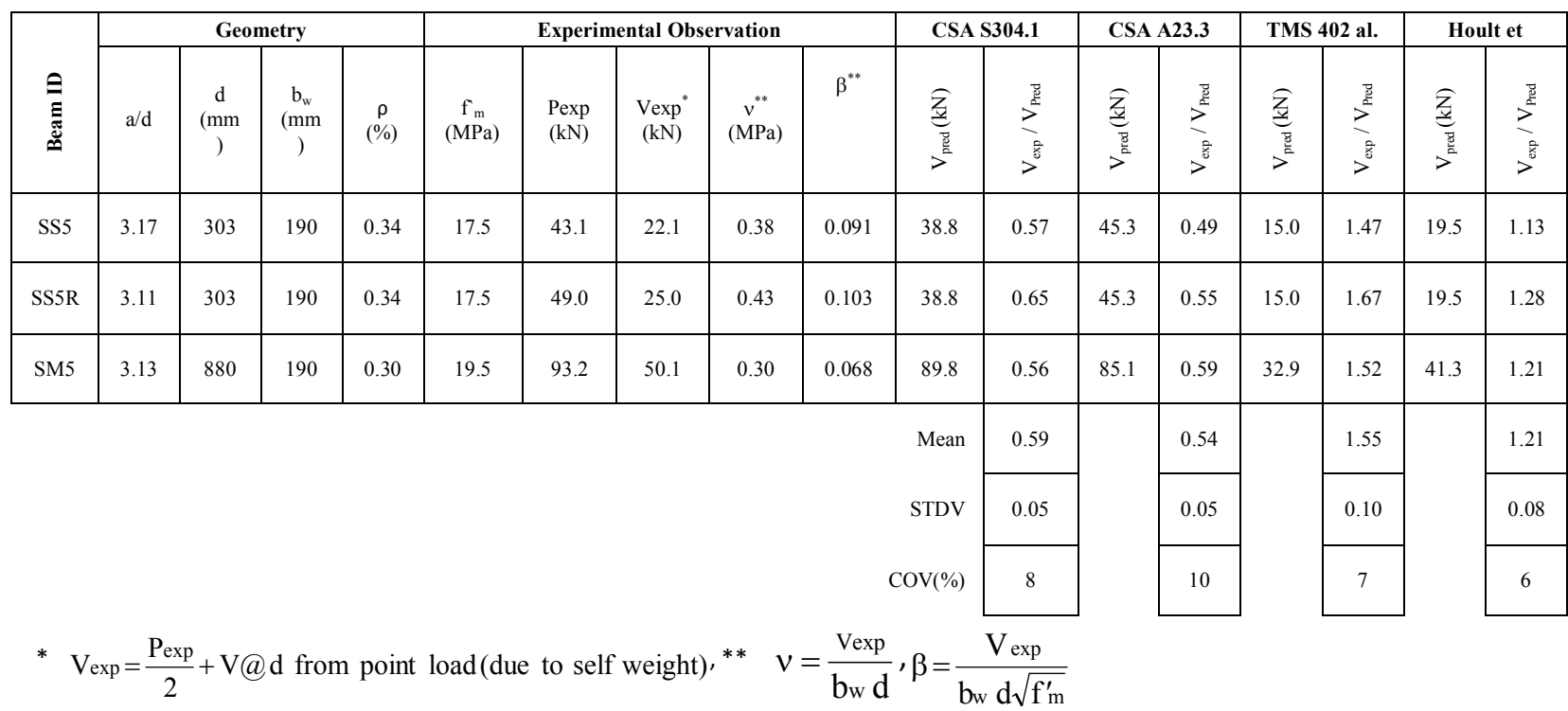

The crack patterns of SS5 and SM5 specimens at an average shear stress of $0.21 \mathrm{MPa}$ are drawn in Fig. 5-78. The average crack spacing at mid-depth of SS5 is $370 \mathrm{~mm}$ (equivalent to $1.22 \mathrm{~d}$ ) compared to $465 \mathrm{~mm}$ (equivalent to $0.53 \mathrm{~d}$ ) in SM5. As discussed earlier in this chapter, the crack spacing in small RM beams is governed by the distance between the predefined crack paths (head joints) in the bottom course (400mm in this case) while crack spacing at mid-depth of the five-course beams is a function of effective depth (about $0.50 \mathrm{~d}$ ) which is similar to reinforced 
concrete beams. The crack spacings at $0.75 \mathrm{~d}$ and reinforcement levels were $400 \mathrm{~mm}$ regardless of the effective depth.
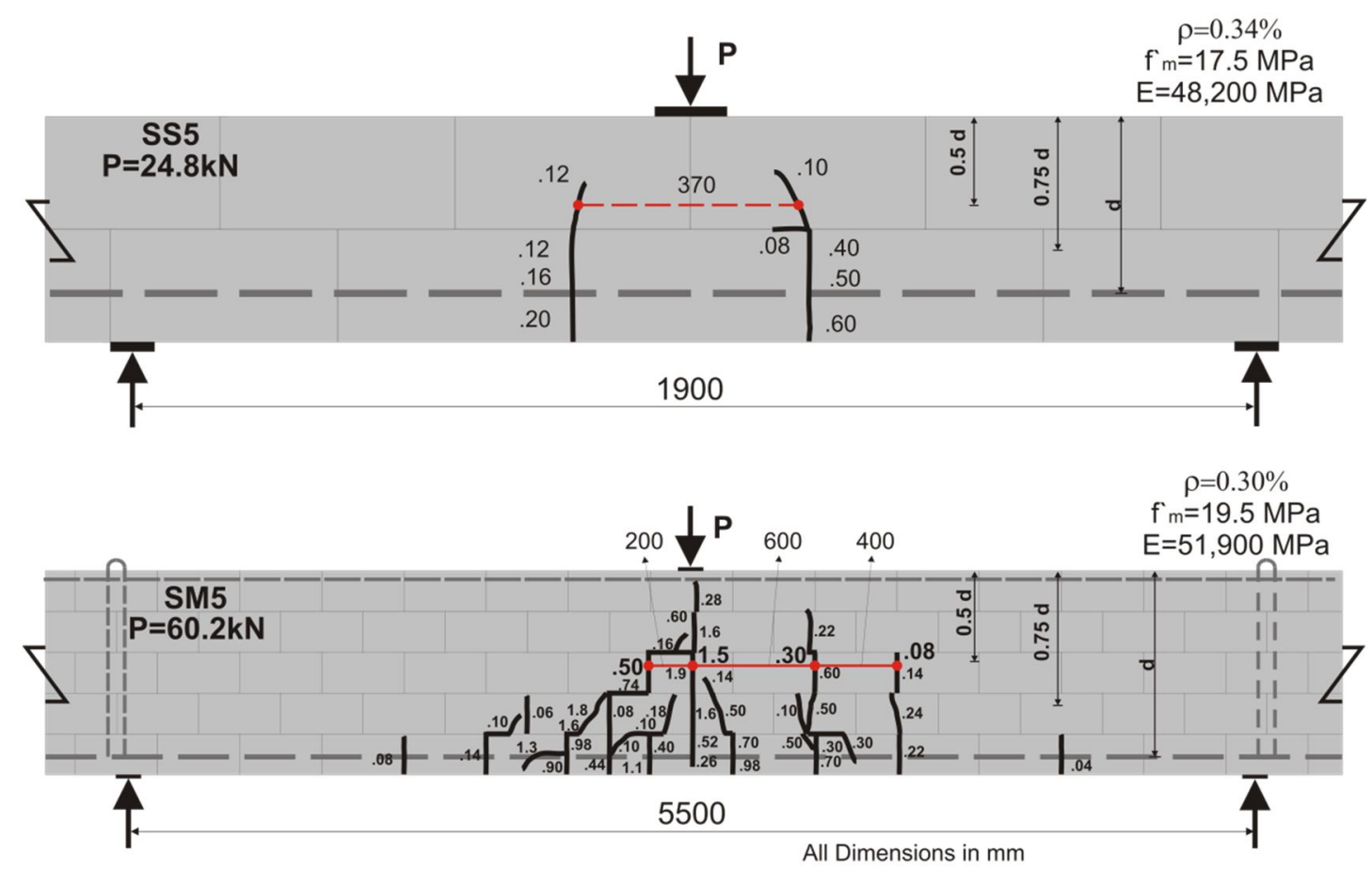

Figure 5-78: Crack Patterns in SS5 and SM5 at Shear Stress of 0.21 MPa

It is clear from Figure 5-79 that wider crack widths were measured in specimen SM5 than in specimen SS5. The average crack width at the mid-depth of the section in SM5 is 5 times larger than that in SS5. The widest crack in SM5 was 3.6 times greater than that in specimen SS5. These wider cracks appear to have caused SM5 to fail at a lower shear stress due to reduced capacity of these cracks to transfer shear stress. 

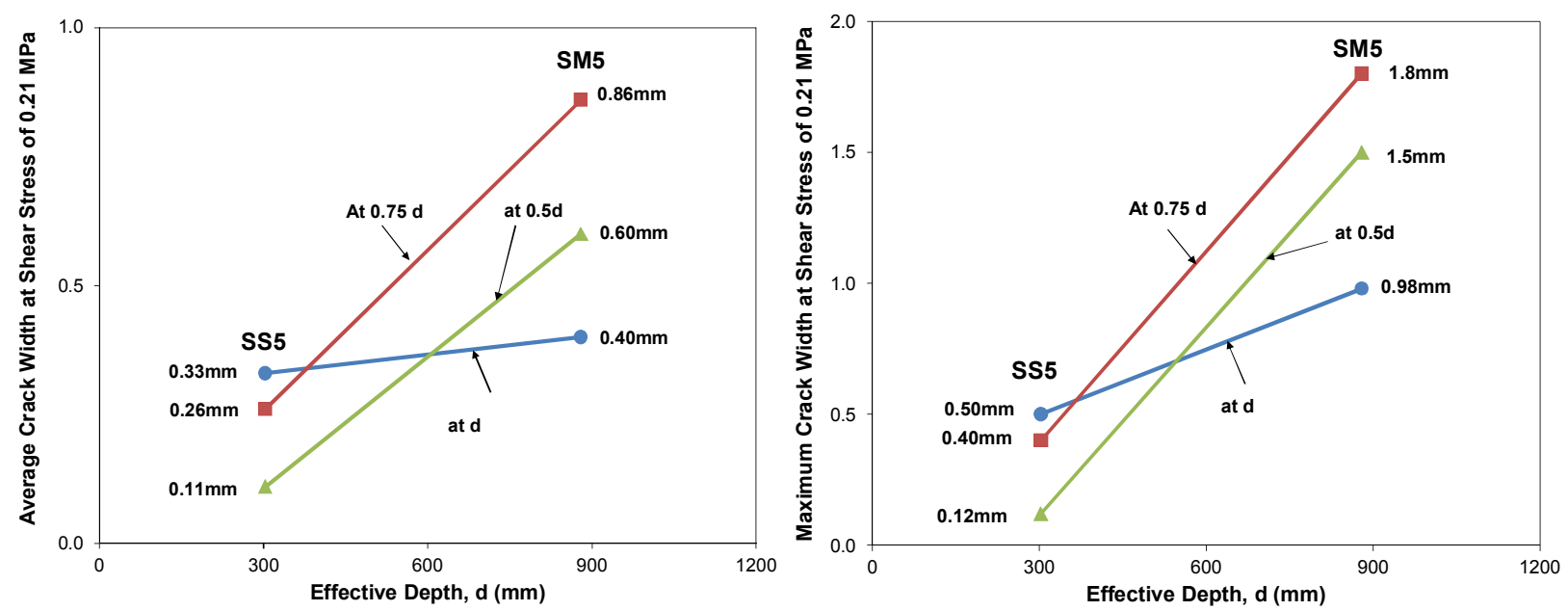

Figure 5-79: Average and Maximum Crack Widths in SS5 and SM5 Beams at Shear Stress of $0.21 \mathrm{MPa}$

The experimental failure shear stress for SM5, SS5 and SS5R are plotted in Figure 5-80 along with the predicted failure shears by CSA S304.1, TMS 402, CSA A23.3 and Hoult et al. In this figure it can be observed that both the TMS 402 and CSA S304.1 codes are extremely nonconservative when predicting the shear strength of specimen SS5 and SM5 beams, while CSA A23.3 and Hoult et al. safely predict their strengths with the latter being more accurate. This accuracy can be attributed to the fact that the Hoult et al. (2006) method was specifically derived for reinforced concrete members with high strains, such as members reinforced with FRP rebars. 


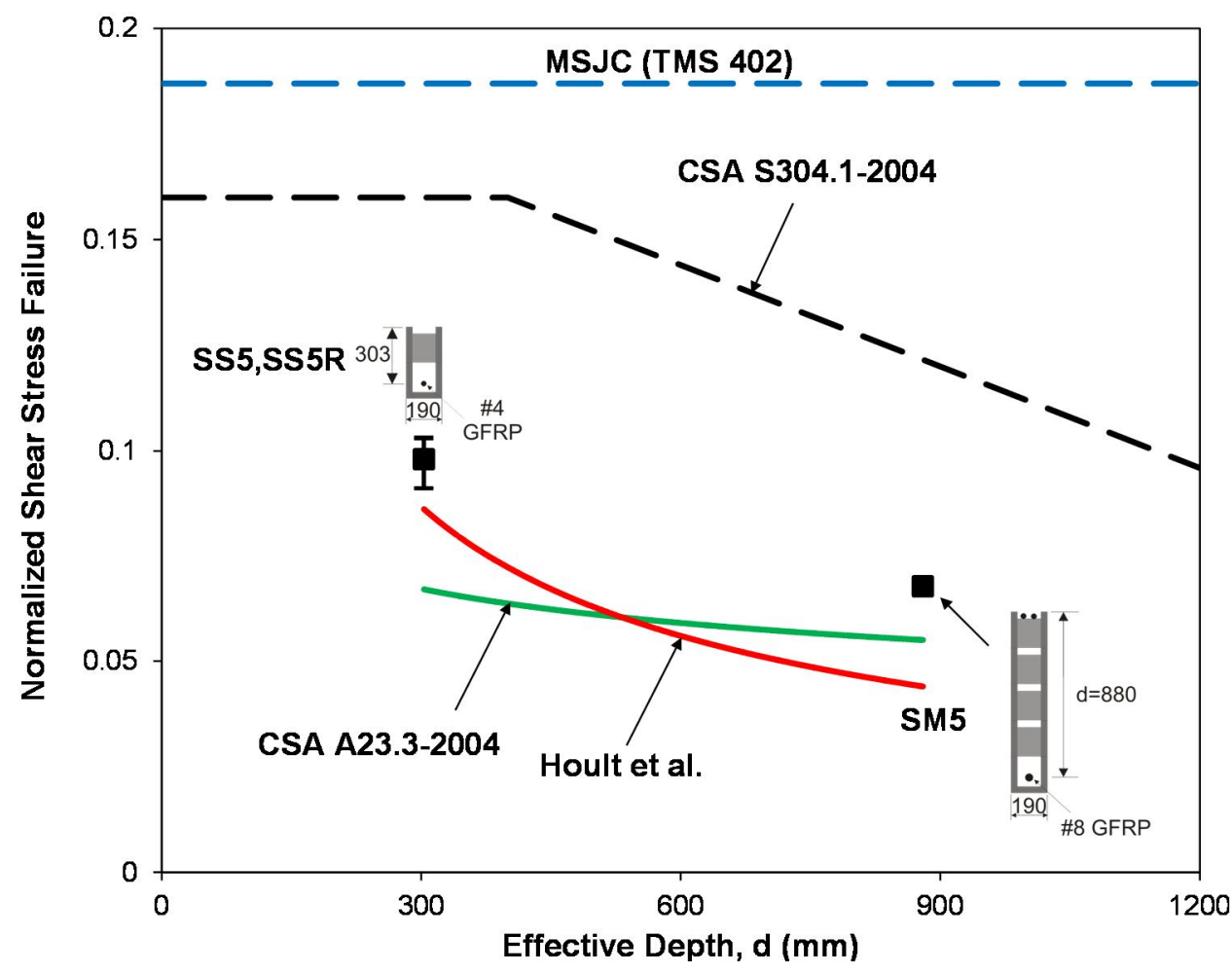

Figure 5-80: Failure Shear Stresses in RMB reinforced with GFRP bars

\subsection{Shear Stress Transmitted in Compression Zone}

As discussed in Chapter 2, the shear design provisions in masonry design codes are empirically derived based on the assumption that all the vertical shear force in reinforced masonry without shear reinforcement is carried on by the un-cracked compression zone. These codes do not consider the role played by aggregate interlock despite the fact that numerous tests in reinforced concrete (Fenwick and Paulay (1968) and Taylor (1970), Kani et. al. (1979) and Sherwood et al (2008)) have showed that significant shear stresses are transferred by aggregate interlock. In these tests, the contribution of aggregate interlock to the shear resistance was evaluated through careful instrumentation of cracked beams or other elements in a way that allowed the 
quantification of shear resistance by aggregate interlock mechanism. To explore the shear transfer mechanisms in reinforced masonry, it was therefore decided to instrument the uncracked compression zone at the heads of dominant shear cracks in several of the specimens using concrete strain gauges to measure the vertical shear carried in the compression zone.

In specimen SL2, the applied load was reduced to zero after a load of $280 \mathrm{kN}$ was applied, and two columns of horizontal strain gauges were applied at the head of one of the cracks in the east span of the south face of the beam. The load was then reapplied and the resulting longitudinal strains in these gauges recorded (see Figure 5-81). The longitudinal concrete strains were converted to longitudinal concrete stresses using a stress-strain curve constructed for a companion masonry prism tested under compression parallel to the bed joints (see Figures 5-82 and 5-83) following a similar load history as beam SL2.

The shear stress distribution in the compression zone can then be determined from the masonry longitudinal stress profiles by considering horizontal equilibrium using the basic formula of ( $v=\mathrm{VQ} / \mathrm{Ib}$ ) developed by Jourawski (1856). By integrating the resulting shear stress distribution, it was found that the uncracked compression zone carries only $28 \%$ of the total shear applied by the load, leaving the majority of the vertical shear in SL2 to be carried by aggregate interlock shear stresses in the web of the beam $\left(v_{\text {agg }}\right)$ and dowel action $\left(\mathrm{V}_{\mathrm{d}}\right)$. As it has been shown that dowel action accounts for a small portion of the vertical shear (Kani (1970), Gregely (1969), Taylor (1970)), it can thus be concluded that the majority of the vertical shear at these section was transferred by aggregate interlock. 

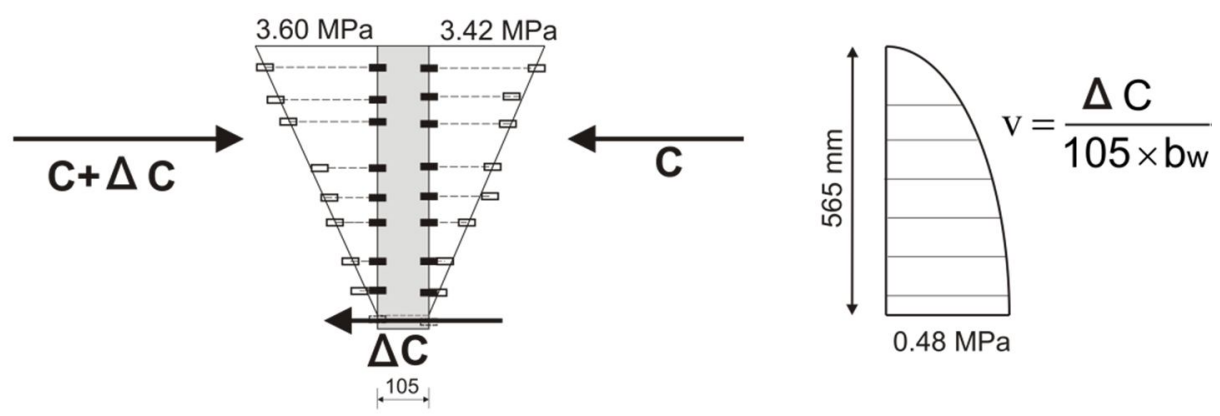

Vertical shear @ section 153.40 kN

Vertical shear in compression zone $=\mathrm{Vcz}=43.4 \mathrm{kN}$

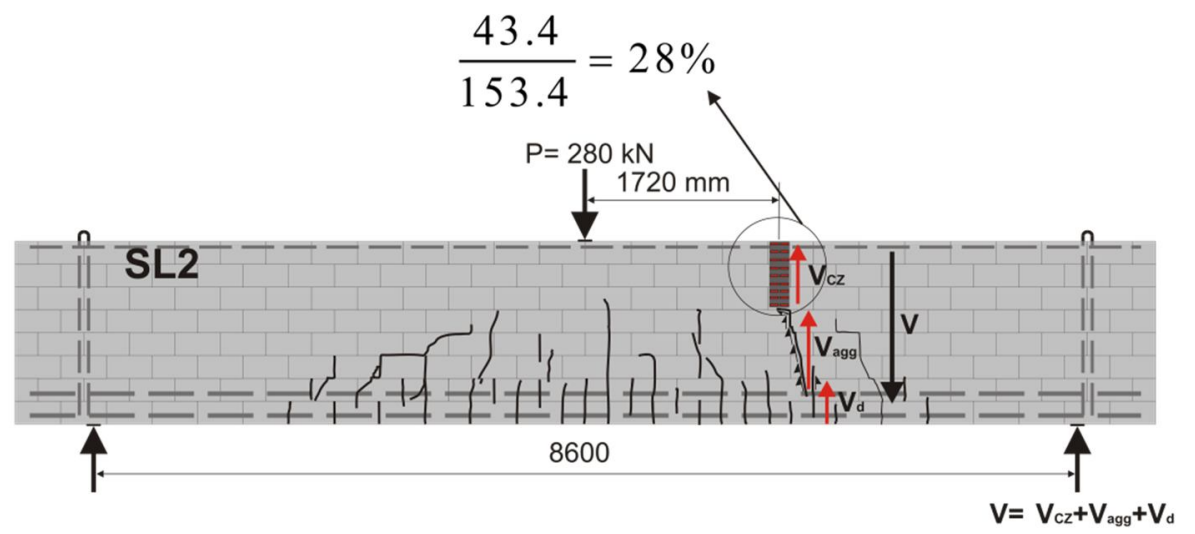

Figure 5-81 Measurement of Shear Transfer Portion by Compression Zone in Specimen SL2
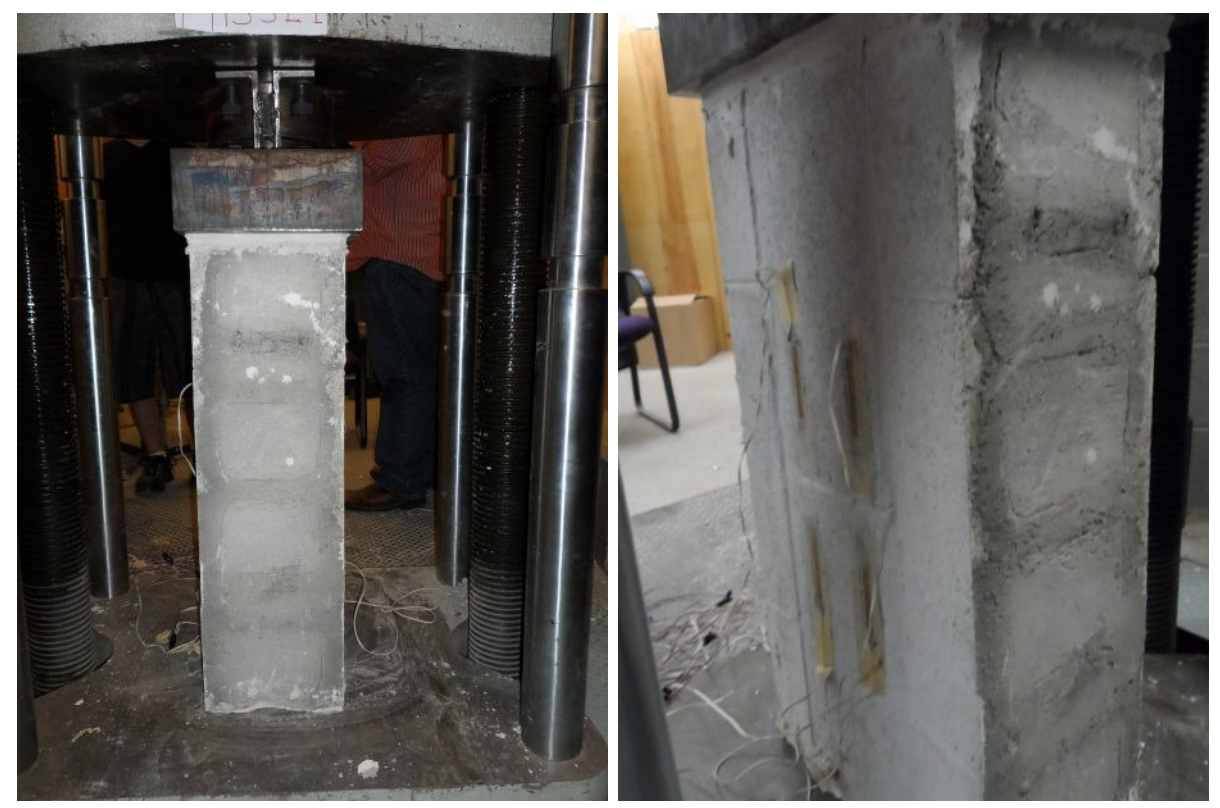

Figure 5-82: A Masonry Prism Instrumented with Strain Gauges and Tested Parallel to Bed Joints 
a) Stress-Strain Curve

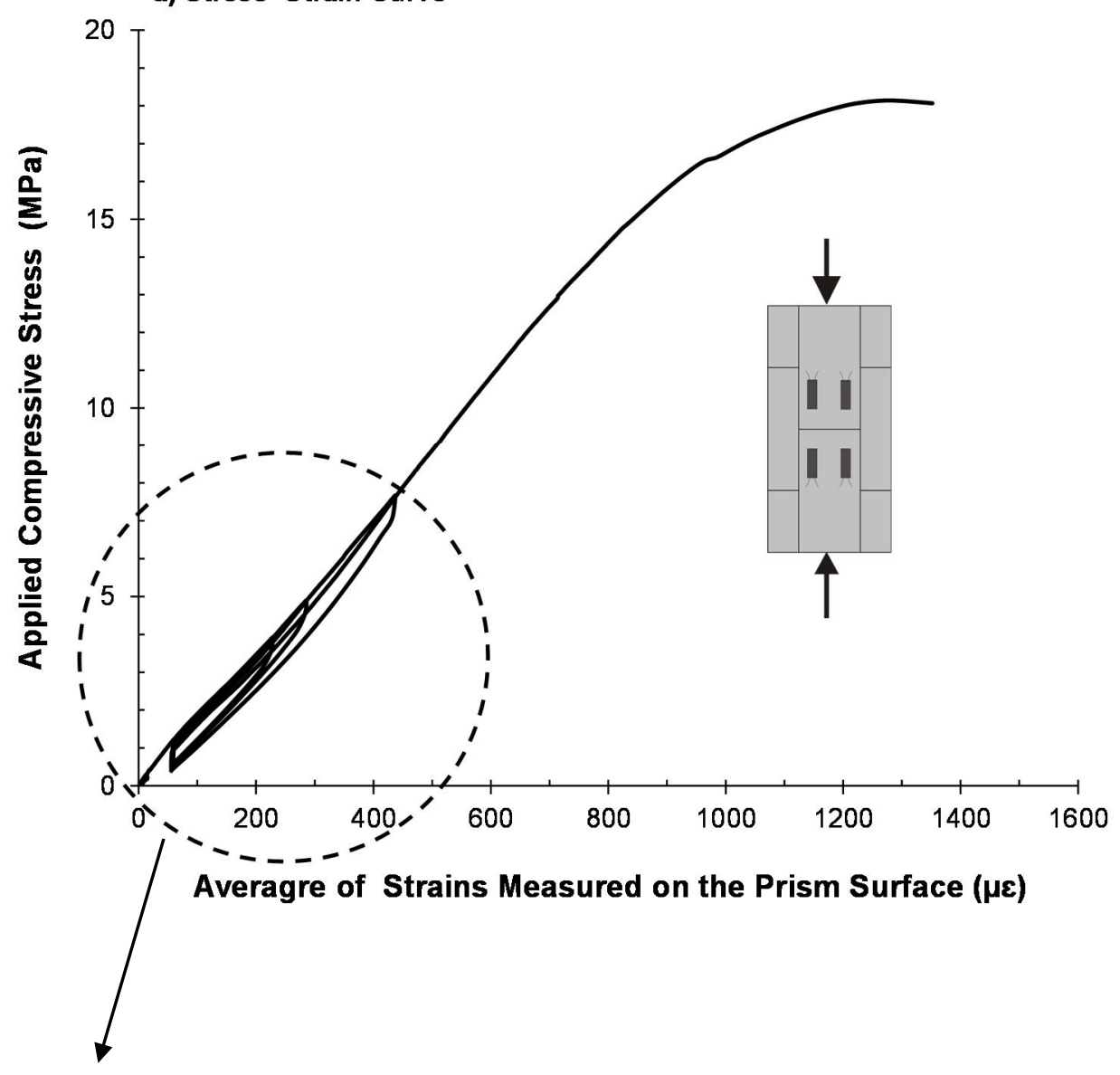

b) Close-up of curve in (a)

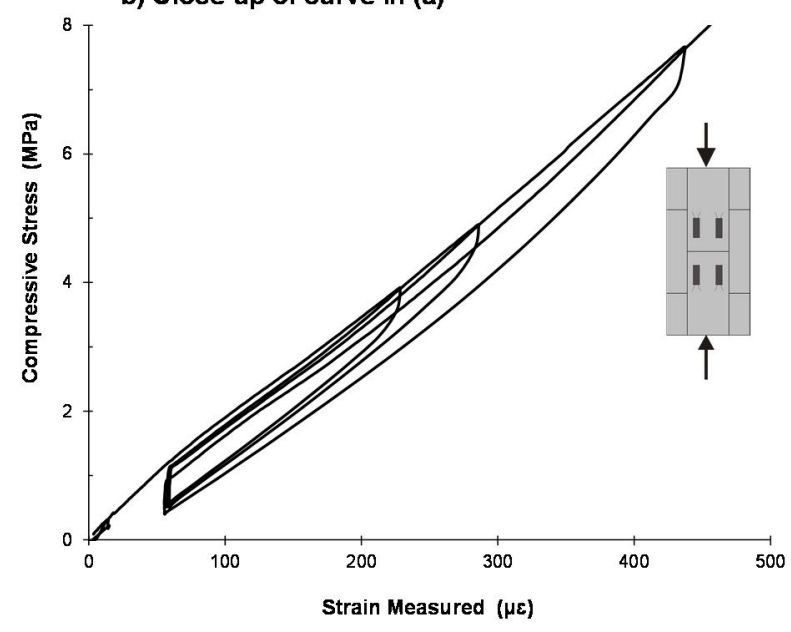

c) Load-Deflection Curve of Specimen SL2

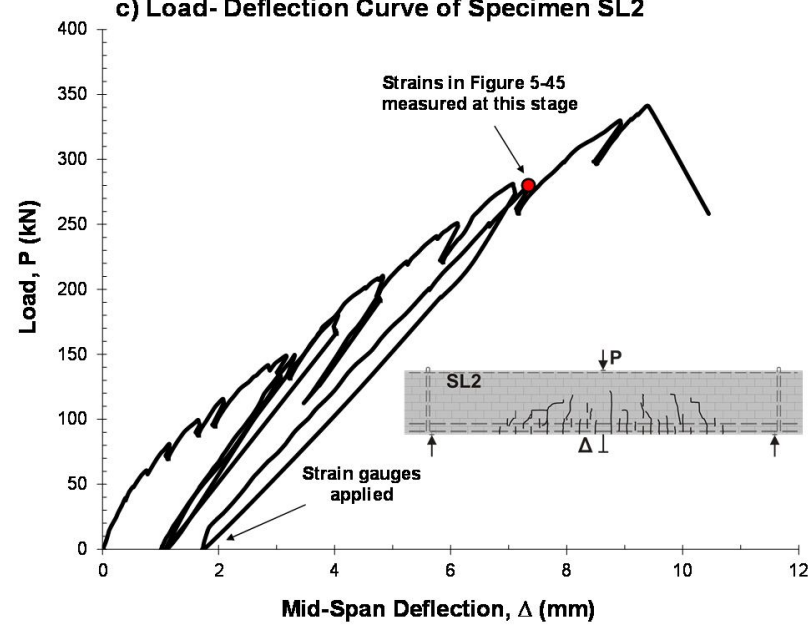

Figure 5-83: Stress -Strain Curve of the Companion Prism and Load-Deflection Curve of Specimen SL2 
Figure 5-84 describes the surface strain gauge instrumentation at the tip of a major flexural-shear crack in SL1 to determine the shear force transmitted by the uncracked compression zone. When the applied load on this specimen reached $300 \mathrm{kN}$ (corresponding to $94 \%$ of the final failure load), the flexural compressive stress profiles at the head of the crack were calculated by converting measured strains to stresses based on the masonry prism response under compression parallel to bed joints following a similar load-history for specimen SL1. Integrating the resulting shear stress distribution, we can see that the uncracked compression zone carries $35 \mathrm{kN}$ of shear force, which is just $24 \%$ of the total shear applied by the load.

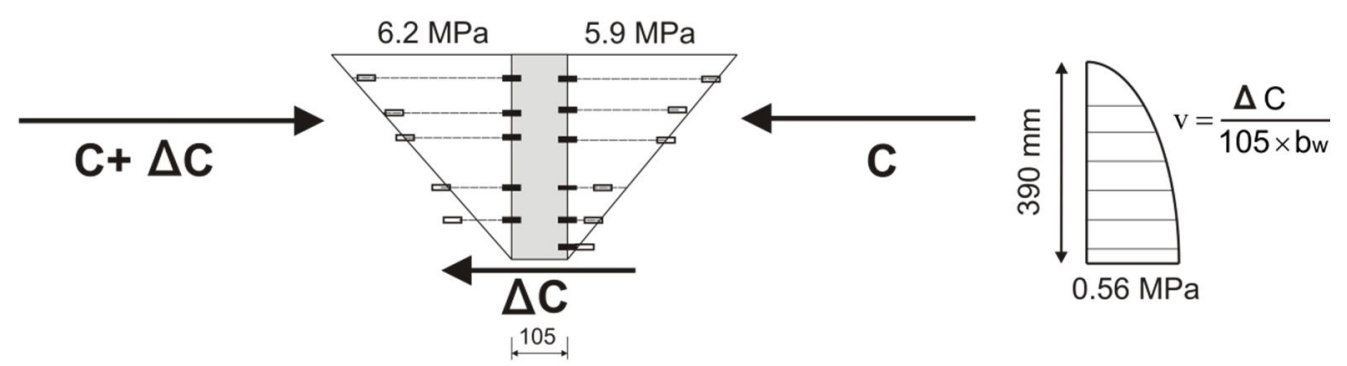

Vertical shear@ section 142.3 kN

Vertical shear in compression zone $=\mathrm{Vcz}=35.0 \mathrm{kN}$

$$
\frac{35.0}{142.3}=25 \%
$$

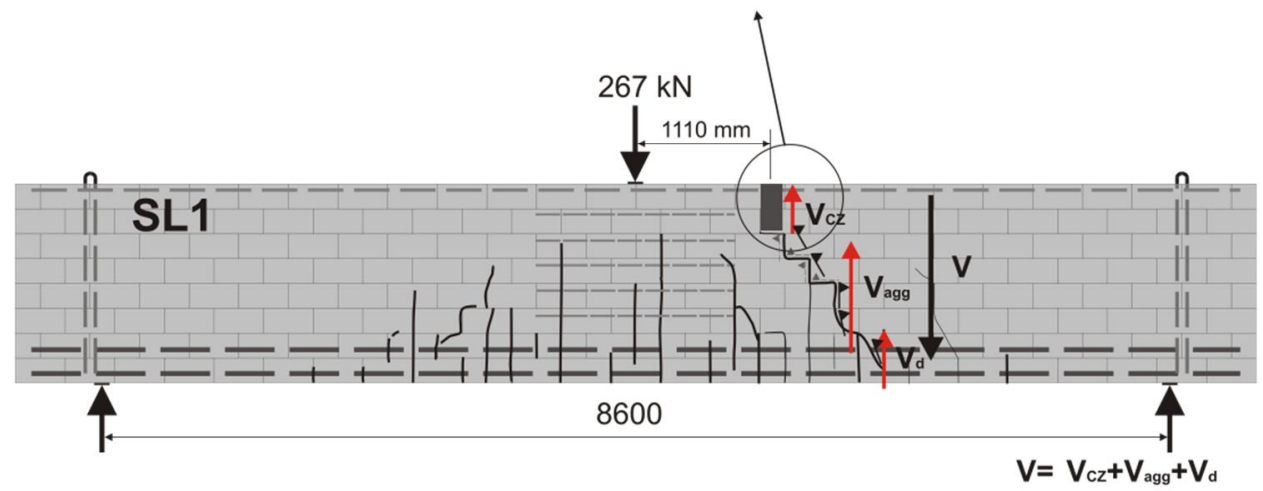

Figure 5-84 Measurement of Compression Zone Contribution to Shear Resistance in Specimen SL1 
A similar procedure was followed for specimen SM5 (medium size). Figure 5-85 shows the measurement of shear forces transmitted by the uncracked compression zone in SM5. It can be seen from the figure that the contribution of the compression zone was only $29 \%$.

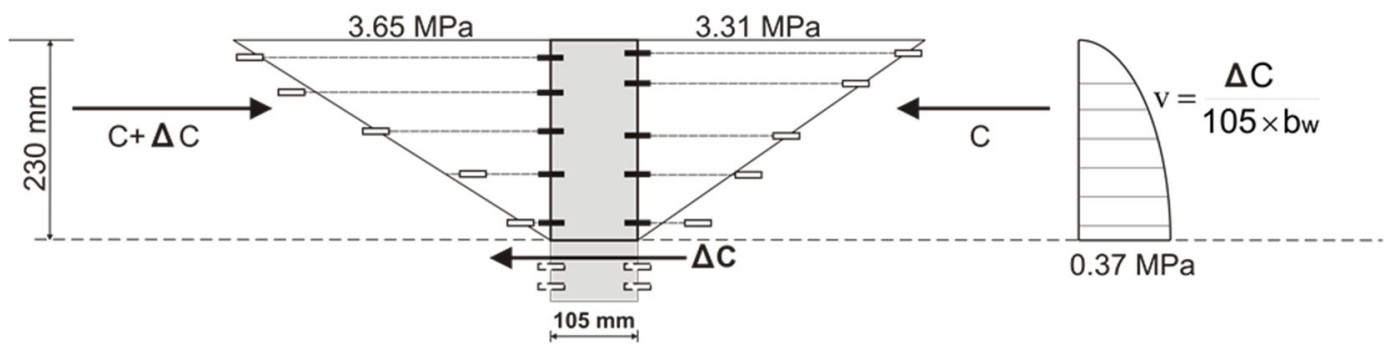

Vertical shear @ section 37.2 kN

Vertical shear in compression zone $=\mathrm{V} c z=10.78 \mathrm{kN}$

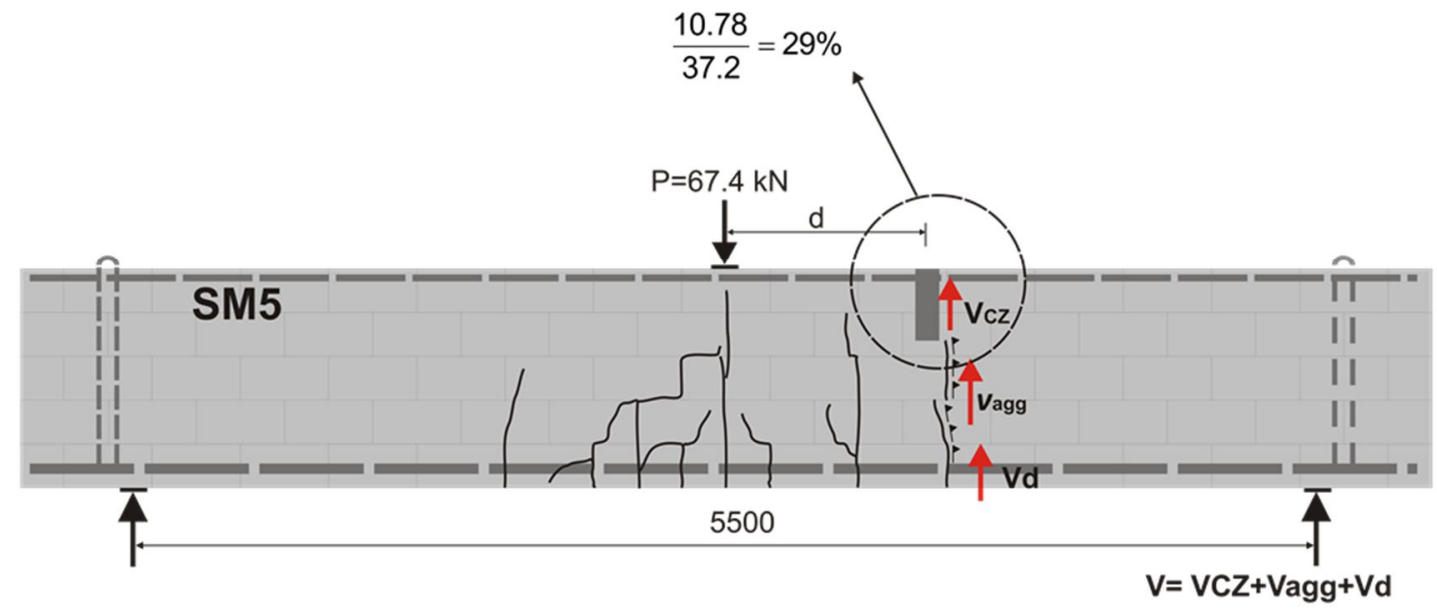

Figure 5-85: Measurement of Shear Transfer Portion by Compression Zone in Specimen SM5

Two columns of strain gauges were affixed to specimen SS5 to evaluate the contribution of the compression zone to the shear resistance of small reinforced masonry beams. The bottom strain gauge in each column did not yield logical readings and thus they were discarded. As summarized in Figure 5-86, the vertical shear in the uncracked compression zone corresponding to only a small portion $(26 \%)$ of the total shear at the sections. 


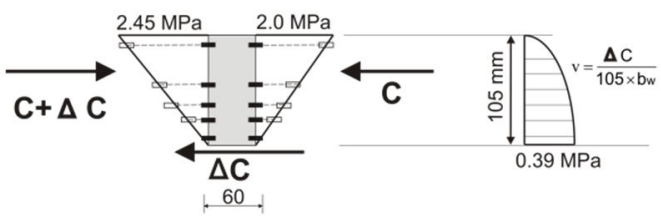

Vertical shear@ section 22.5 kN

Vertical shear in compression zone $=\mathrm{Vcz}=5.4 \mathrm{kN}$
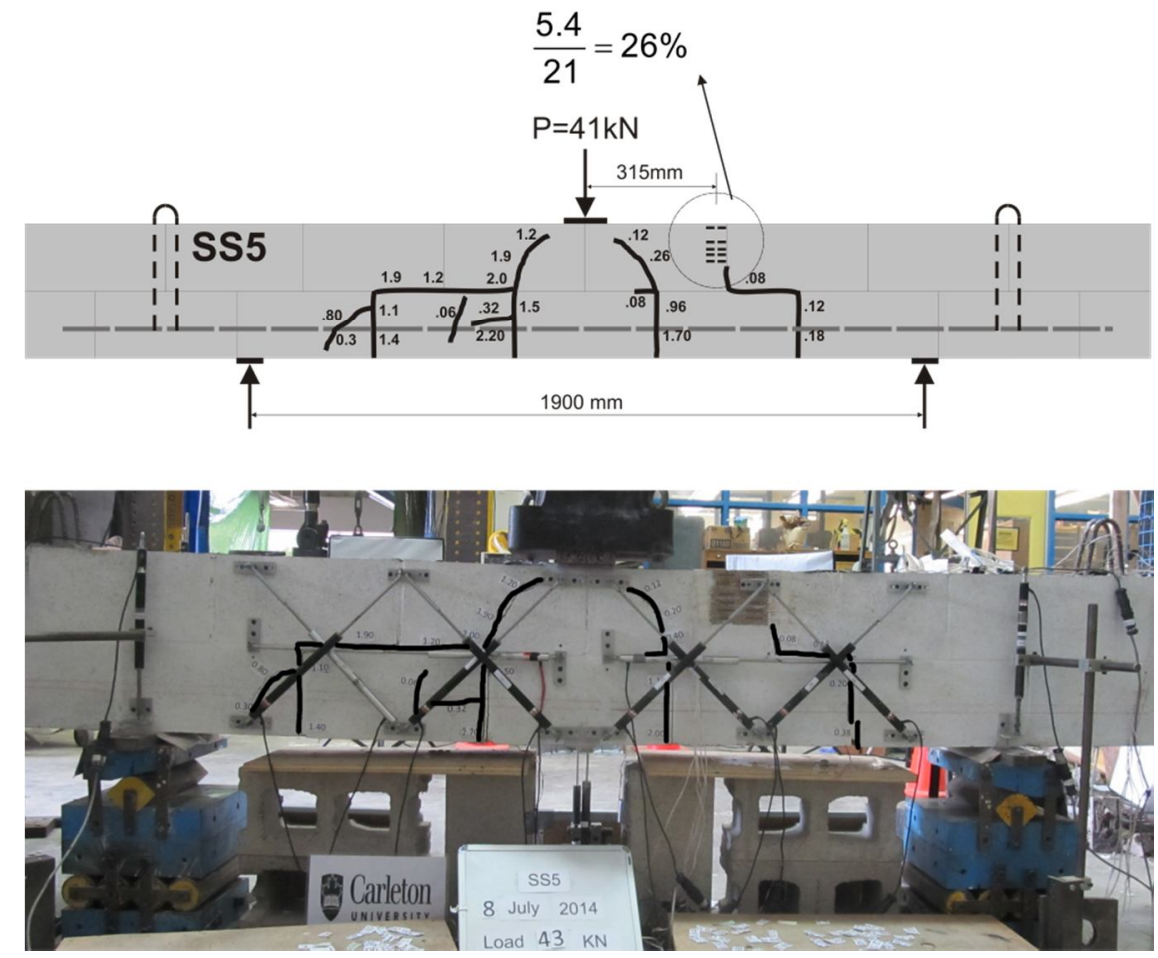

Figure 5-86: Measurement of Shear Transfer Contribution by Compression Zone in Specimen SS5

It thus appears that aggregate interlock was the dominant mechanism of shear transfer in each of the small, medium and large specimens. The uncracked compression zone can account only for a small proportion (ranging from $25 \%$ to $29 \%$ ) of the total shear resisted by the reinforced masonry section.

\subsection{Distribution of Strain in Longitudinal Steel}

Figure 5-87 shows the strains measured using the Demec points at the level of the longitudinal steel in specimens SM1 and SM1D at a load of $159 \mathrm{kN}$. The data shown is the 
average of both the east and west sides of specimens SM1 and SMID. The "x" data points represent strains measured by strain gauges placed on the reinforcement. This figure shows that the reinforcement strain depends not only on the moment, but the shear as well. Thus, shifting the rebar strain diagram to account for the effect of shear leads to more accurate predictions at the critical location, located about $\mathrm{d}$ from the load.

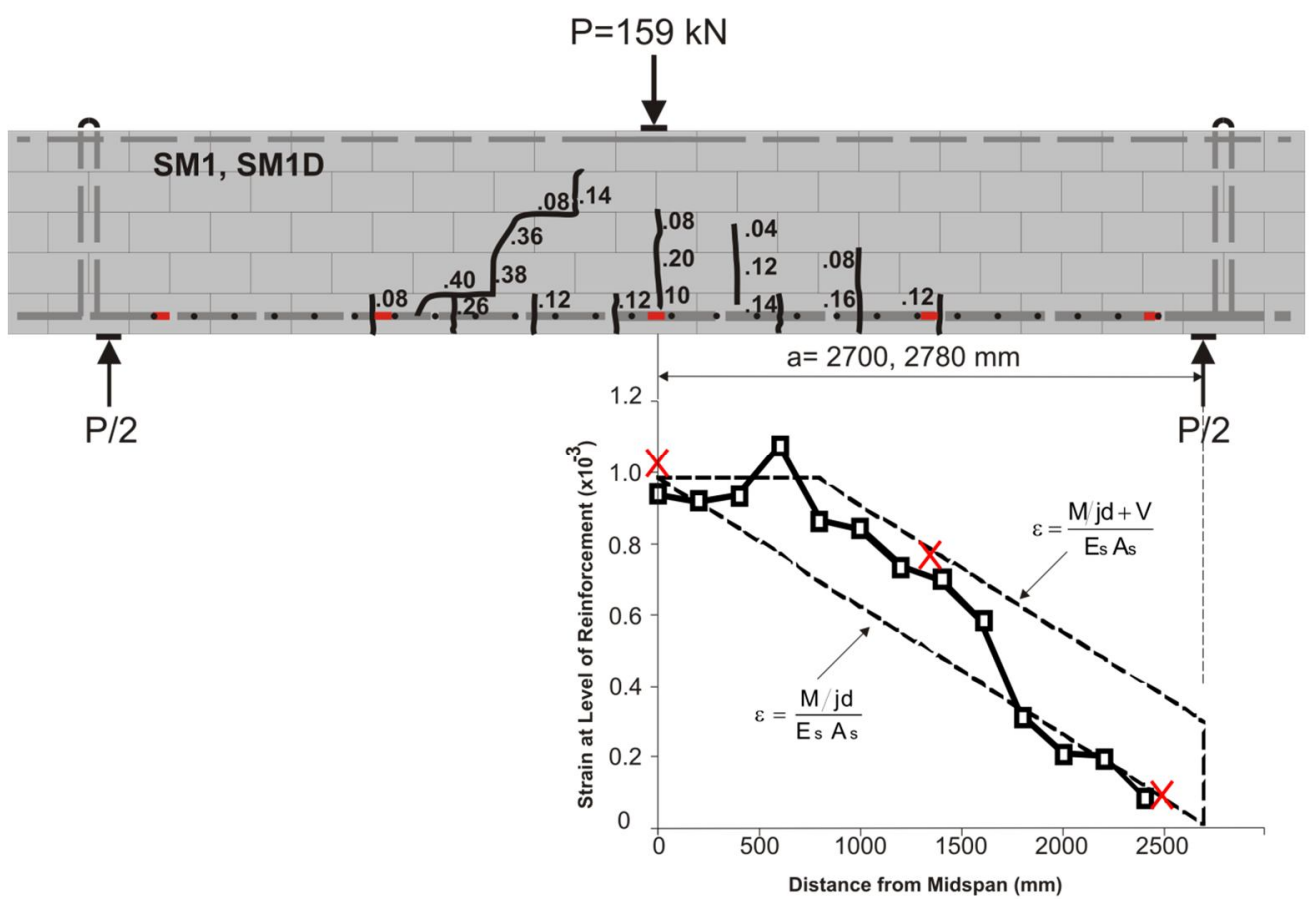

Figure 5-87: Strains at Level of Longitudinal Steel in Specimens SM1 and SM1D

Similarly, strains measured by Demec points at the level of the main steel in the large specimens (SL1 and SL2) show that the accuracy of stresses in the main reinforcement can be more accurately calculated as $(\mathrm{M} / \mathrm{jd}+\mathrm{V})$ (see Figure 5-88). Finally the strain measured by stain gauges placed on the main reinforcement in SM4 proves the applicability of this concept in small beams as well (as shown in Figure 5-89). 


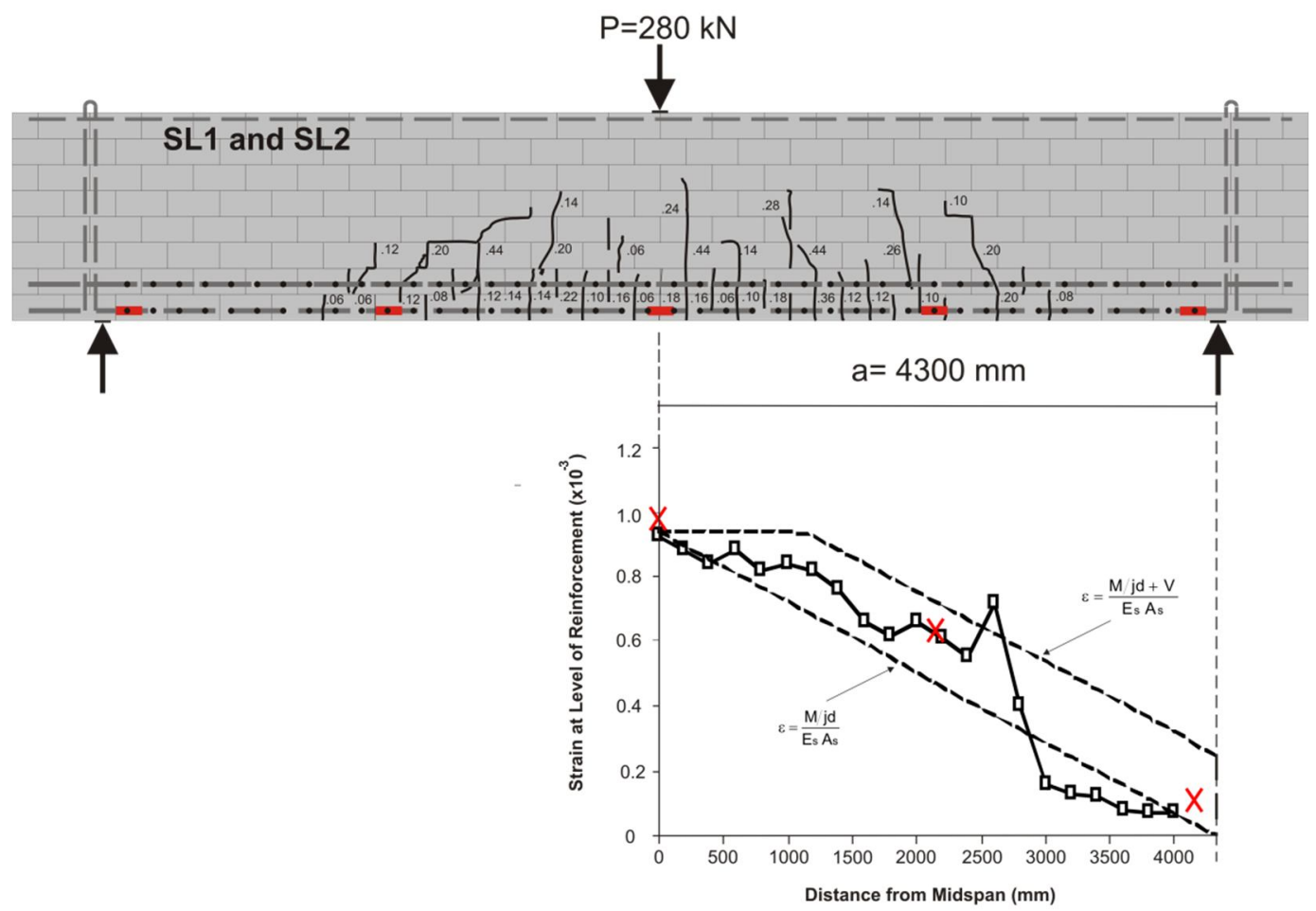

Figure 5-88: Strains at Level of Longitudinal Steel in Specimens SL1 and SL2

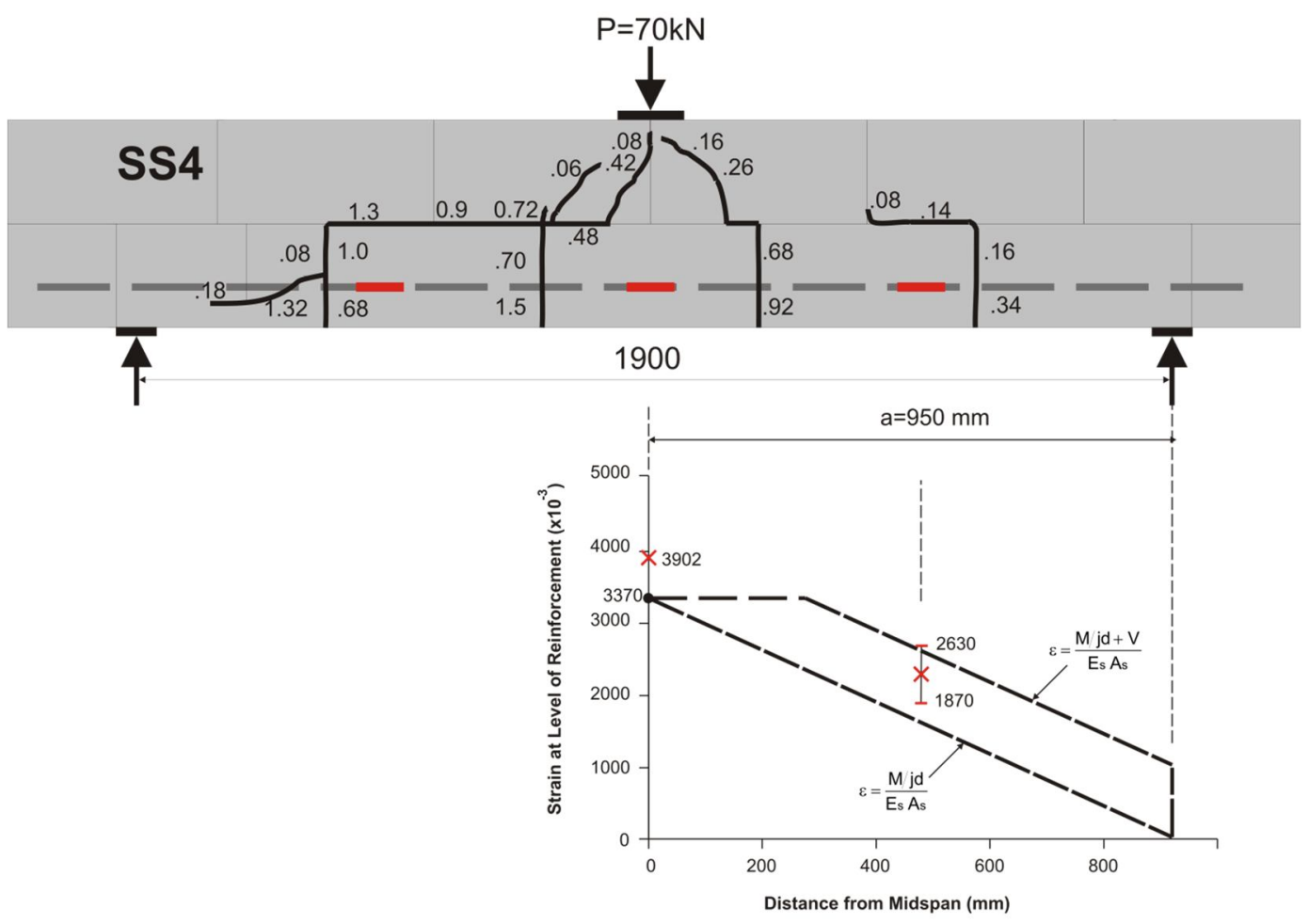

Figure 5-89: Strains at Level of Longitudinal Steel in Specimens SS4 


\subsection{Analysis of a Masonry Tooth}

It has been shown in this chapter that aggregate interlock is the main method of shear transfer in reinforced masonry. As such, it is useful to offer a simplified, logical explanation of shear failure based on aggregate interlock mechanism such as that reported by Moe (1962). Consider specimen SL1 in Figure 5-90. It can be seen that a series of so-called masonry teeth formed as the test progressed. The crack pattern prior to failure (at a load of $280 \mathrm{kN}$ ) in Figure 5-89 is reproduced in Figure 5-91, with an idealized set of stresses and forces that contributes to shear failure. It was shown in the previous section that the force in the reinforcement can be accurately predicted to be $(\mathrm{M} / \mathrm{jd}+\mathrm{V})$. This requires the steel stress to be higher at left face of the tooth $(\mathrm{T}+\Delta \mathrm{T}=471 \mathrm{kN})$ than that at right face $(\mathrm{T}=413.8 \mathrm{kN})$. Thus the masonry tooth (highlighted in Figures 5-90 and 5-91) is loaded by a force of $\Delta \mathrm{T}$ at the of the tension steel.

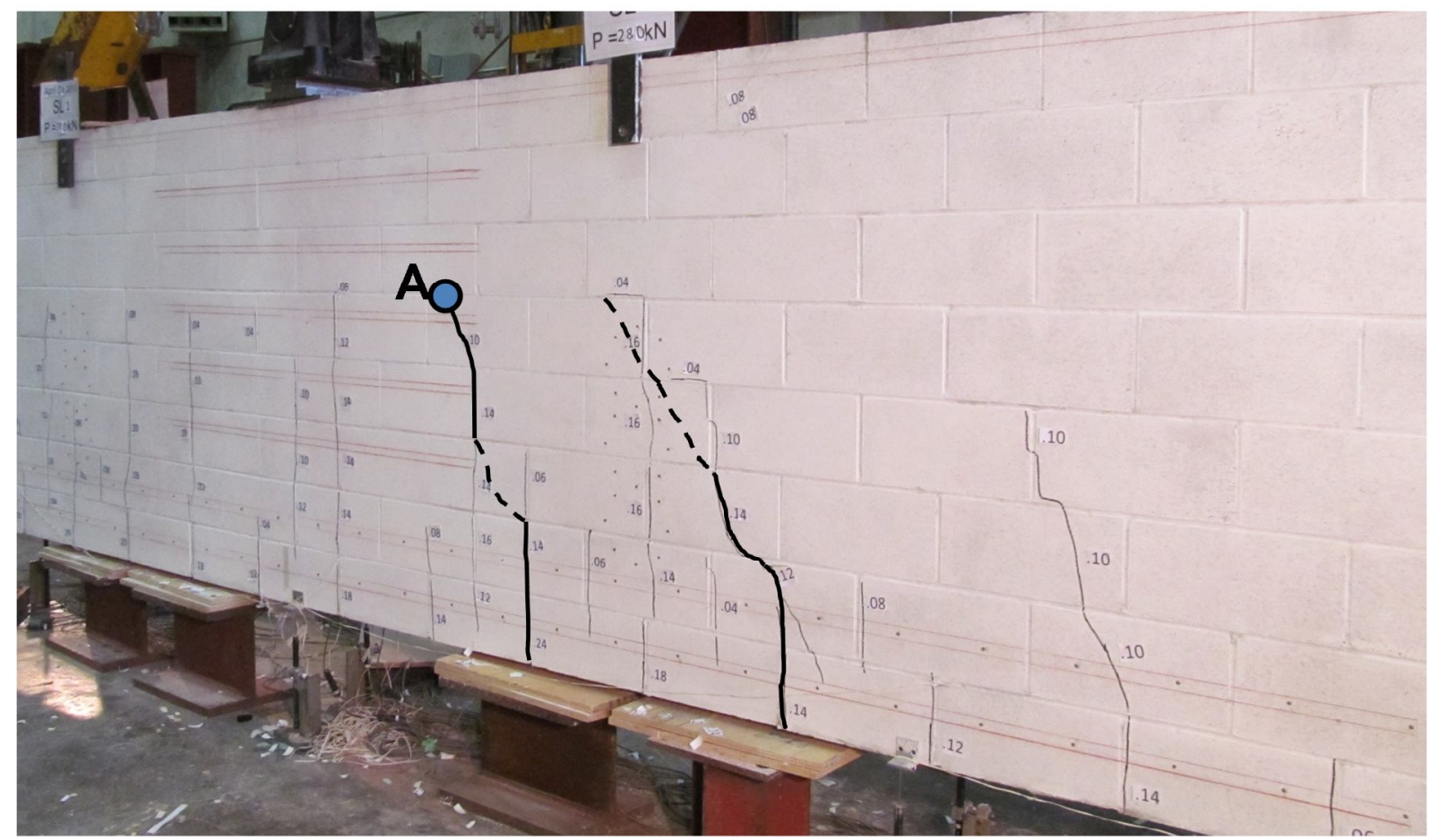

Figure 5-90: A Masonry Tooth in Specimen SL1 

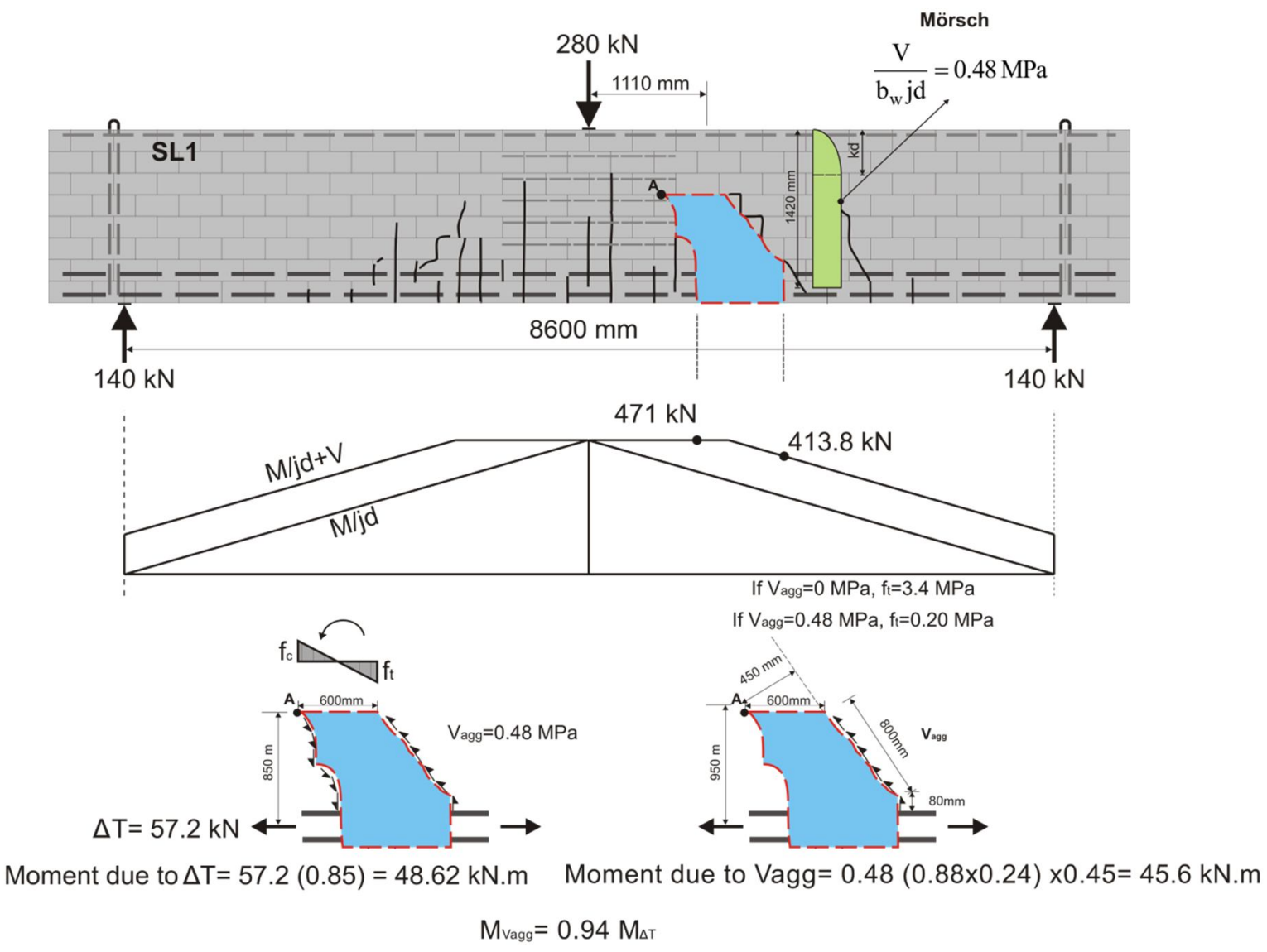

Figure 5-91: Analysis of a Masonry Tooth in Specimen SL1

The masonry tooth in Figure 5-91 can be represented by a vertical cantilever anchored in the compression zone and subjected to a horizontal point load of $\Delta \mathrm{T}$ at its tip $(950 \mathrm{~mm}$ from the base). This point load cause a clockwise moment $(\Delta \mathrm{T} x 850 \mathrm{~mm}=48.62 \mathrm{kN})$ about the root of the tooth. This moment induces vertical flexural stresses $\left(\mathrm{f}_{\mathrm{c}}\right.$ and $\left.\mathrm{ft}\right)$ at the root of the tooth. In the case of neglecting the aggregate interlock shear stress (assuming $\mathrm{v}_{\mathrm{agg}}=0$ ), the moment due to $\Delta \mathrm{T}$ must be resisted by bending at the root of the tooth. In this case $\mathrm{fc}_{\mathrm{c}}$ and $\mathrm{ft}_{\mathrm{t}}$ will be equal to $3.4 \mathrm{MPa}$. While this value is considerably less than the compressive strength of masonry, it is greater than five times the flexural tensile strength of masonry $(\mathrm{f} f=0.65 \mathrm{MPa}$ according to CSA S304.1 code Table 5). As result, The cantilever would have failed at a load considerably less than $280 \mathrm{kN}$. 
Thus aggregate interlock shear stresses ( $\mathrm{v}_{\text {agg }}$ ) must act on the faces of the masonry tooth forming a counter clockwise moment about the root of the tooth that balances the moment caused by $\Delta \mathrm{T}$. If the shear stress predicted by Mörsh is acting on the faces of the tooth, then this counteracting moment will be equal to $94 \%$ of the moment caused by $\Delta \mathrm{T}$. Hence flexural stress are not required to maintain the equilibrium and the entire moment caused by $\Delta \mathrm{T}$ can be resisted by the shear stress transferred across the cracks by aggregate interlock. The shear failure in this specimen SL1 at $320 \mathrm{kN}$ due to the widening of the cracks which resulted in reduction of aggregate interlock. This placed additional demand on the flexural tensile stresses causing the failure of the root of the cantilever (see Figure 5-92).

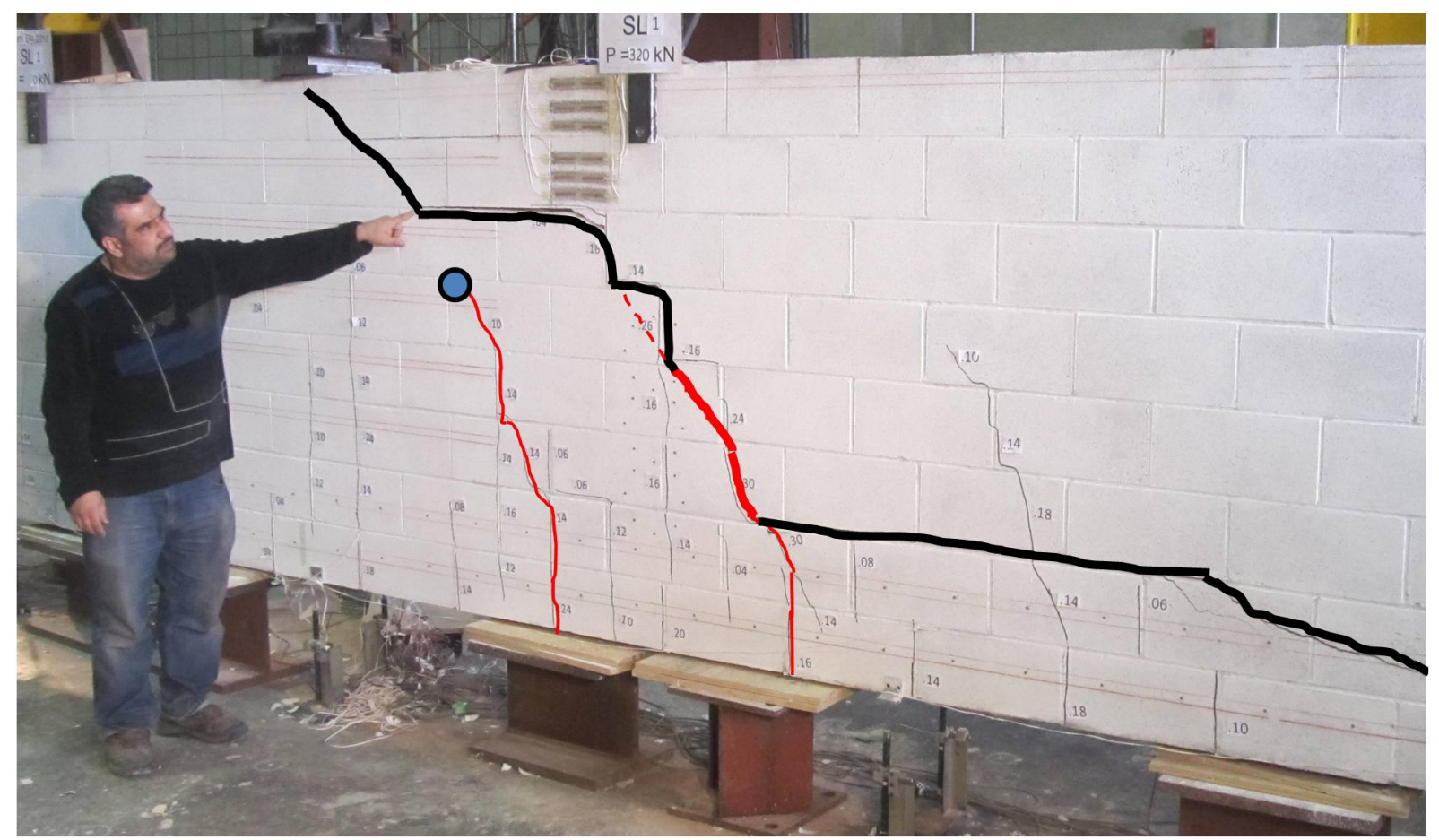

Figure 5-92: Shear Failure in Specimen SL1 due to Breakdown in Aggregate Interlock 


\subsection{Slipping of Cracks}

For cracks to transfer shear stress by aggregate interlock their sides need to slide on each other. Sherwood (2008) used high-speed cameras to prove the occurrence of slipping in shear cracks. In this investigation it was attempted to prove the crack slipping by using Demec points in the form of strain rosettes along the major shear cracks. In specimen SL2, for example, after reaching a load of $280 \mathrm{kN}$ multiple shear cracks were formed. The applied load was reduced to zero and Demec points were attached to the surface of the masonry with adhesive. Figure 5-93 shows one of these strain rosette placed on one of the shear cracks in the East end of specimen SL2. The inclination of the line perpendicular to the crack at this rosette was $20^{\circ}$. The initial readings of the strain rosette were taken. The load was then reapplied and the strains were measure using a Demec points strain gauge at three load stages $280 \mathrm{kN}$ and $330 \mathrm{kN}$ (in SL2) and $350 \mathrm{kN}$ (in the repeated test SL2R).

Figure 5-93 shows that the Demec points readings can be used to measure strain in the horizontal direction, $\varepsilon_{\mathrm{x}}$, vertical direction, $\varepsilon_{\mathrm{y}}$ and diagonal direction, $\varepsilon_{\mathrm{b}}$. These measured strains can be used to draw Mohr's circle and find the orientation of principal strain, $\varepsilon_{1}$. Figure5-93 shows that the orientation of the principal strain in each of the load stages was different and higher than the orientation of the line perpendicular to the crack $\left(20^{\circ}\right)$. The only explanation of this difference in the orientations is that there was shearing occurring along the crack. This shearing is associated with aggregate interlock stresses. This shows that shear crack opening in reinforced masonry is associated with shear crack sliding (or slipping) along the shear cracks which creates shear transferred by aggregate interlock. 


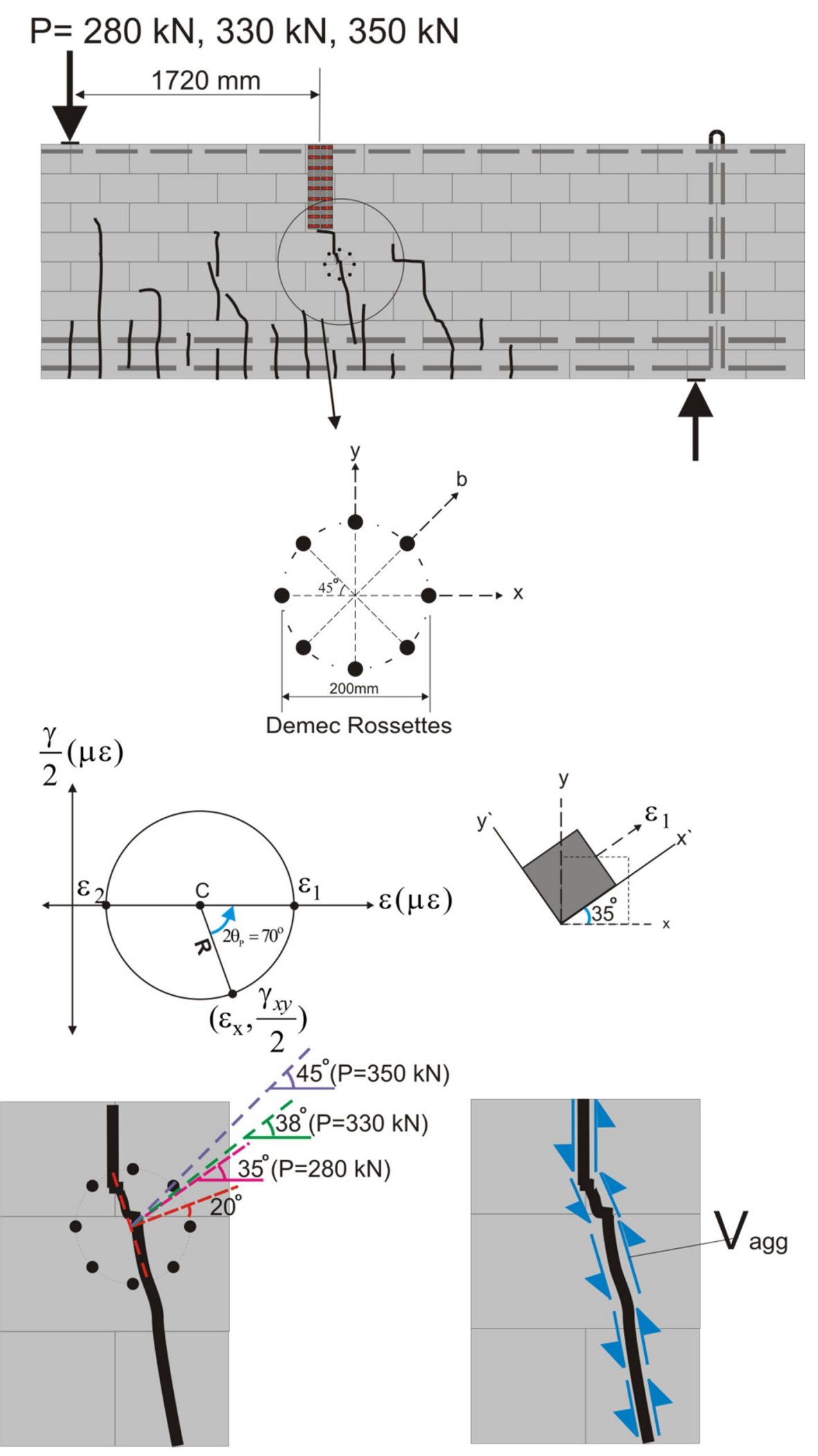

Figure 5-93: Slippage along One of the Major Shear Cracks in Specimen SL2 


\section{5-14 Concluding Remarks}

The test results discussed in this chapter reveals that the size effect in reinforced masonry is significant. It is shown that as the effective depth increases, the longitudinal crack width and spacing at mid-depth increase as well. These wider cracks initiate shear failure at a lower shear stress due to reduced aggregate interlock capacity. In some of the small and medium beams the breakdowns of aggregate interlock were followed by the engagement of strut and tie actions formation of shear keys between masonry units leading to higher failure shear stresses and deflections than those associated with the breakdowns of beam action. These mechanisms cannot be considered reliable as they did not develop in all the beams and even when they were engaged they led in most cases to only marginal increases in failure shear stresses.

It is shown that the TMS 402 masonry design code gives non-conservative predictions of the shear strength of large masonry beams. The inability of some masonry design codes to account for this factor could lead to a high risk of sudden failure of large masonry beams and girders at lower loads than they designed for by these codes. The most accurate prediction of the size effect in masonry is given by the General Method of shear design from the CSA A23.3-04 code. The test results described in this chapter highlights the necessity to revise masonry design codes to address the size effect and specifically supports the adoption of shear design provisions based on the modified compression field theory in the 2014 update of the CSA S304.1 code. 
The experiments described in this chapter have shown multiple benefits of using stirrups in reinforced masonry beams. The specimens reinforced with stirrups exhibited significantly higher strengths, larger deformations, wider crack widths and closer crack spacings than equivalent members without stirrups. There was considerable warning of imminent shear failure. The use of a sufficient quantity of stirrups was able to eliminate the size effect. Finally, the study on the shear strength of reinforced masonry beams with crack control steel has shown that shear strength can be enhanced through the use of the minimum quantity of distributed longitudinal steel required by the CSA A23.3 for large members. However this quantity was not quite sufficient to eliminate the size effect in reinforced masonry beams. 


\section{CHAPTER 6: THE STRAIN EFFECT IN REINFORCED MASONRY}

\subsection{General}

It was seen Chapter 5 that cracks in reinforced masonry can widen due to increased spacing and that these wider cracks can precipitate shear failure at lower shear stresses. It was shown that this phenomenon, like in reinforced concrete, could explain the size effect in shear. The purpose of chapter is to investigate the related phenomenon termed the strain effect. It has been shown in reinforced concrete that actions which cause the longitudinal strain at mid-depth of the section, $\varepsilon_{\mathrm{x}}$, to increase will increase crack width and thus initiate shear failures at a lower shear stress. These actions can include: reducing $\rho$, using low stiffness reinforcement such as FRP rebars, and the presence of axial tension. On the contrary, presence of axial compression and prestressing will increase shear strength by causing narrower cracks to form. This chapter will investigate the applicability of strain effect principle in reinforced masonry. Two aspects of the strain effect will be studied in this chapter, the effect of main reinforcement ratio $(\rho)$ and type of reinforcement (steel versus FRP). Each factor will be studied in the two-course series (small size) and fivecourse series (medium size) of beams.

As discussed in Chapter 2, the North American masonry design codes (TMS 402 and CSA S304.1) do not account for strain effect factors. Other international masonry design codes account for some of the strain effect factors, such as BS 5628 (both of $\rho$ and a/d) and the AS 3700 code (accounts for $\rho$ only). The results of the strain effect series in this investigation will be used to assess the predictive ability of these codes. As the general method of CSA A23.3 has given promising results in accounting for the size effect in reinforced masonry, the applicability 
of this method to account for strain effect in reinforced masonry will be assessed too. Other topics, such as the application of image correlation analysis for reinforced masonry and the effect of horizontal reinforcement on flexural cracks, will be addressed in this chapter as well.

\subsection{Effect of $\rho$ on Shear Strength of Reinforced Masonry}

In this section two series of beams will be utilized to study the effect of main reinforcement ratio on shear strength of RMB. The first series consists of four two-course beams (SS4, SS1, SS2 and SS6). These beams are approximately identical (average values of $d=300 \mathrm{~mm}, \mathrm{a} / \mathrm{d}=3.1$ and $\mathrm{f}^{\prime}{ }_{\mathrm{m}}=17.9 \mathrm{MPa}$ ) except for the main reinforcement ratio that ranges from $0.30 \%$ to 2.4 . The second series encompasses four five-course beams (SM4, SM1, SM1D and SM2). These beams have approximately constant values of $\mathrm{d}$ of $880 \mathrm{~mm}, \mathrm{a} / \mathrm{d}$ of 3.1 and $\mathrm{f}_{\mathrm{m}}{ }^{\prime}=18.9 \mathrm{MPa}$, but with different main reinforcement ratios that ranges from $0.31 \%$ to $1.68 \%$.

\subsubsection{Effect of $\rho$ on Shear Strength of Small Size Series}

\section{Load-Deflection Response and Failure Mechanisms}

All specimens of this series: SS4 $(\rho=0.30 \%), \operatorname{SS} 1(\rho=0.88 \%), \operatorname{SS} 2(\rho=1.72 \%)$ and SS6 $(\rho=2.4 \%)$ failed in shear before reaching their flexural capacity. Figure 6-1 shows the load-deflection for these beams. It can be seen in Figure 6-1 that the maximum loads reached in these beams increased with increasing $\rho$. It is clear from this figure that the post-cracking stiffness increased with increasing $\rho$. While specimens SS4 $(\rho=0.30 \%)$ and SS1 $(\rho=0.88 \%)$ failed in a brittle way, the breakdown in beam action in specimens SS2 $(\rho=1.72 \%)$ and SS6 $(\rho=2.4 \%)$ was followed by formation of shear keys (as discussed in (Chapter 5) leading to large deflections and crack widths at failure. 


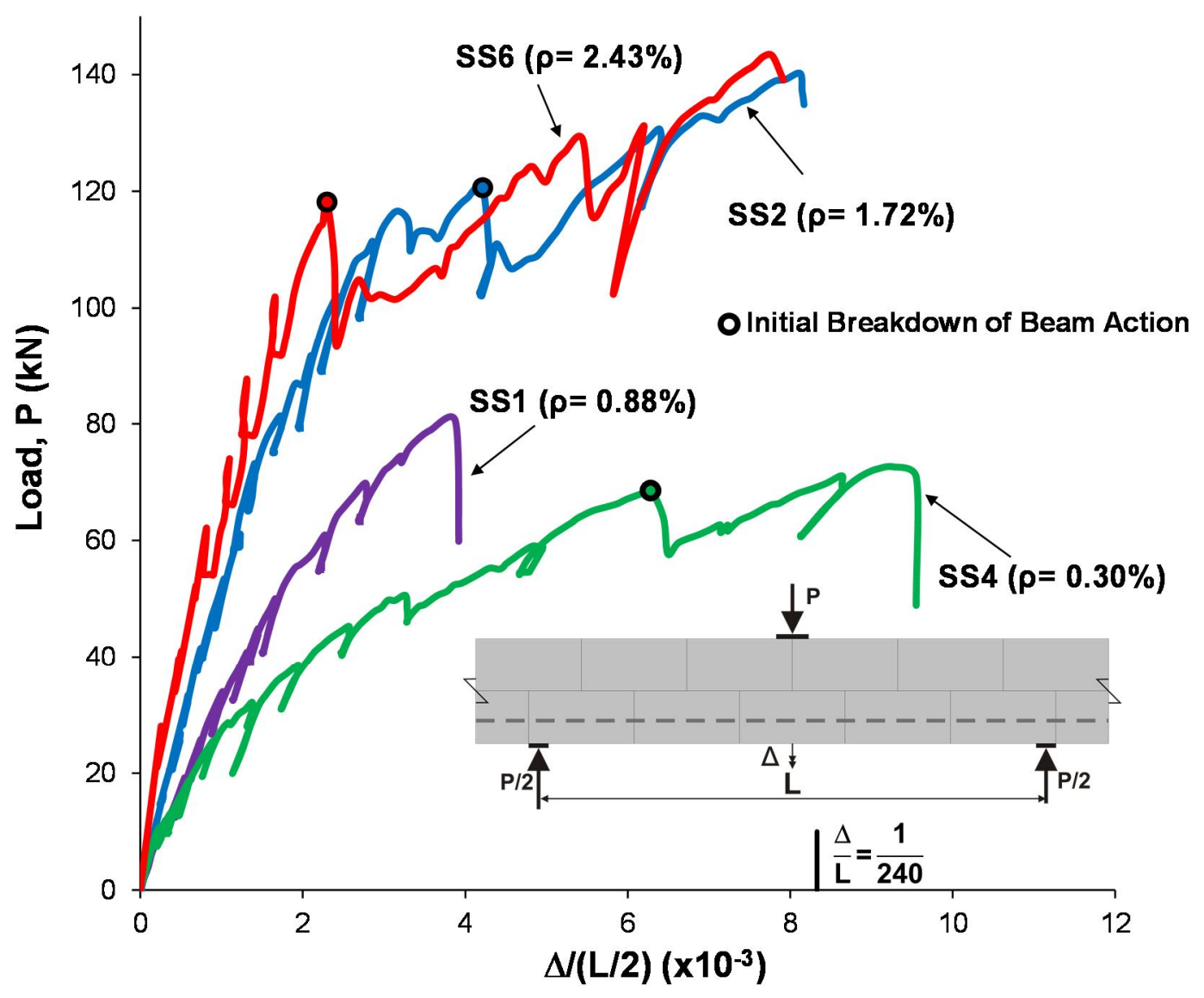

Figure 6-1: Relative Displacement with Different Reinforcement Ratios in Specimens SS1, SS2, and SS4and SS6

\section{Crack Spacing and Widths}

To offer an explanation as to why the shear strength of RM beams tested in this series increased with increasing $\rho$, consider Figure 6-2 which shows the crack patterns of the specimens in this series at an approximately constant applied load of $70 \mathrm{kN}$ (corresponding to a shear stress of 0.62 $\mathrm{MPa}$ ). It is clear that crack spacings did not vary between the beams. In all specimens the crack spacing was governed by the distance between the head joints $(400 \mathrm{~mm})$. It can also be seen that while some cracks in specimens SS4 $(\rho=0.30 \%)$ and SS1 $(\rho=0.88 \%)$ extended upward passing the mid-depth of the beam and orienting towards the point load, the cracks in SS2 $(\rho=1.72 \%)$ and SS6 $(\rho=2.4 \%)$ could barely reach the bed joint. Figures 6-2 and 6-3 show that the crack widths at 
different levels decreased considerably with increasing $\rho$. This reduction in crack widths with increasing $\rho$ can be attributed to the enhanced crack control provided by the increased main reinforcement. This finding is supported by Figure 6-4 which shows that strains measured at mid-span of the beams at this load stage decreased with increasing $\rho$. The reductions in the steel strains were associated with considerable reductions in the longitudinal strain, $\varepsilon_{\mathrm{x}}$, which in turn led to narrower cracks (see Figure 6-5). The load stage of $70 \mathrm{kN}$ was very critical in specimens SS4 $(\rho=0.30 \%)$ and SS1 $(\rho=0.88 \%)$ as both beams failed suddenly in shear at loads that were higher only by $2 \%$ and $15 \%$, respectively, than $70 \mathrm{kN}$. Specimens SS2 $(\rho=1.72 \%)$ and SS6 $(\rho=2.4 \%)$ were able to carry loads that were approximately $100 \%$ higher than $70 \mathrm{kN}$.

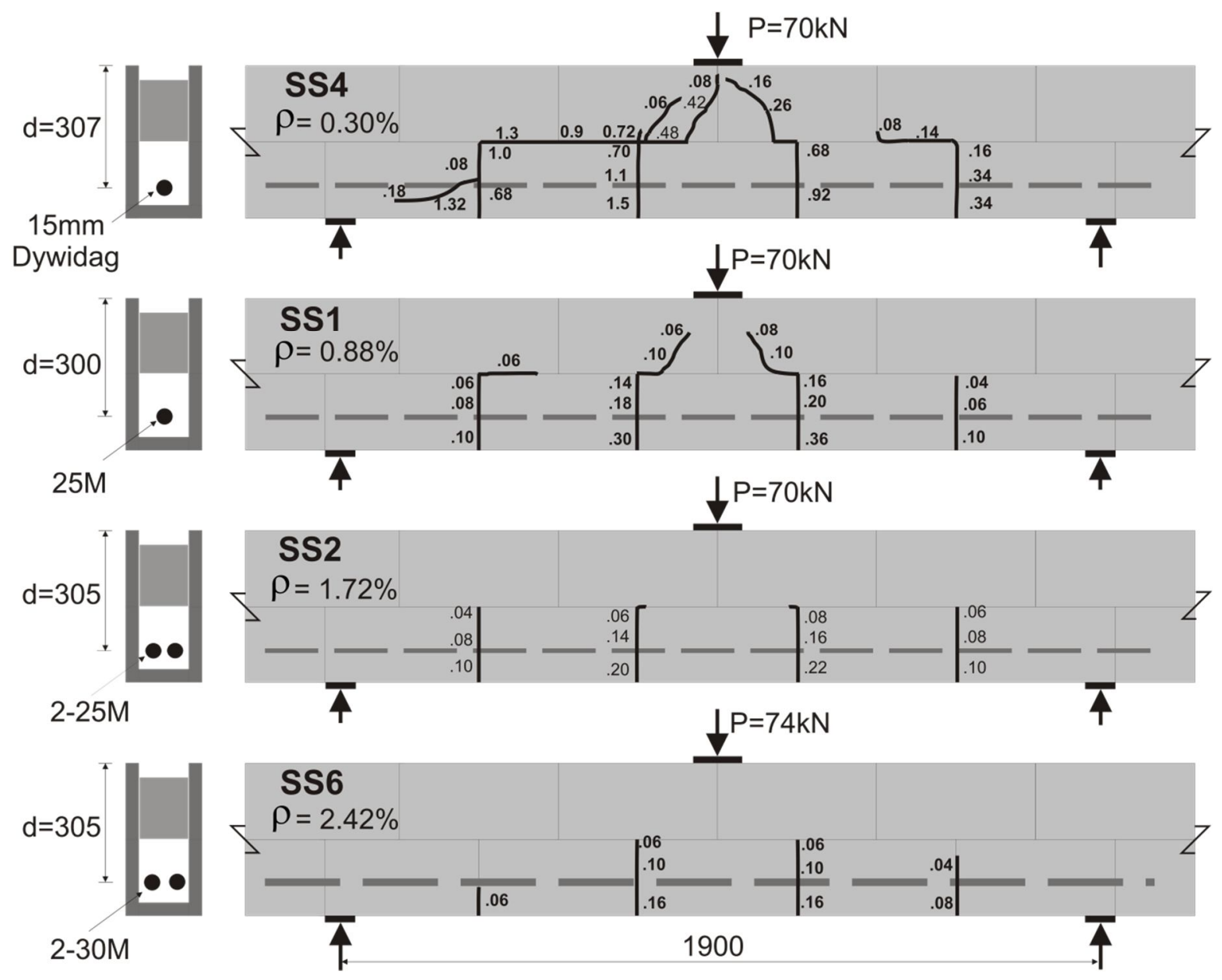

Figure 6-2: Crack Patterns of Specimens SS1, SS4, SS2 and SS6 


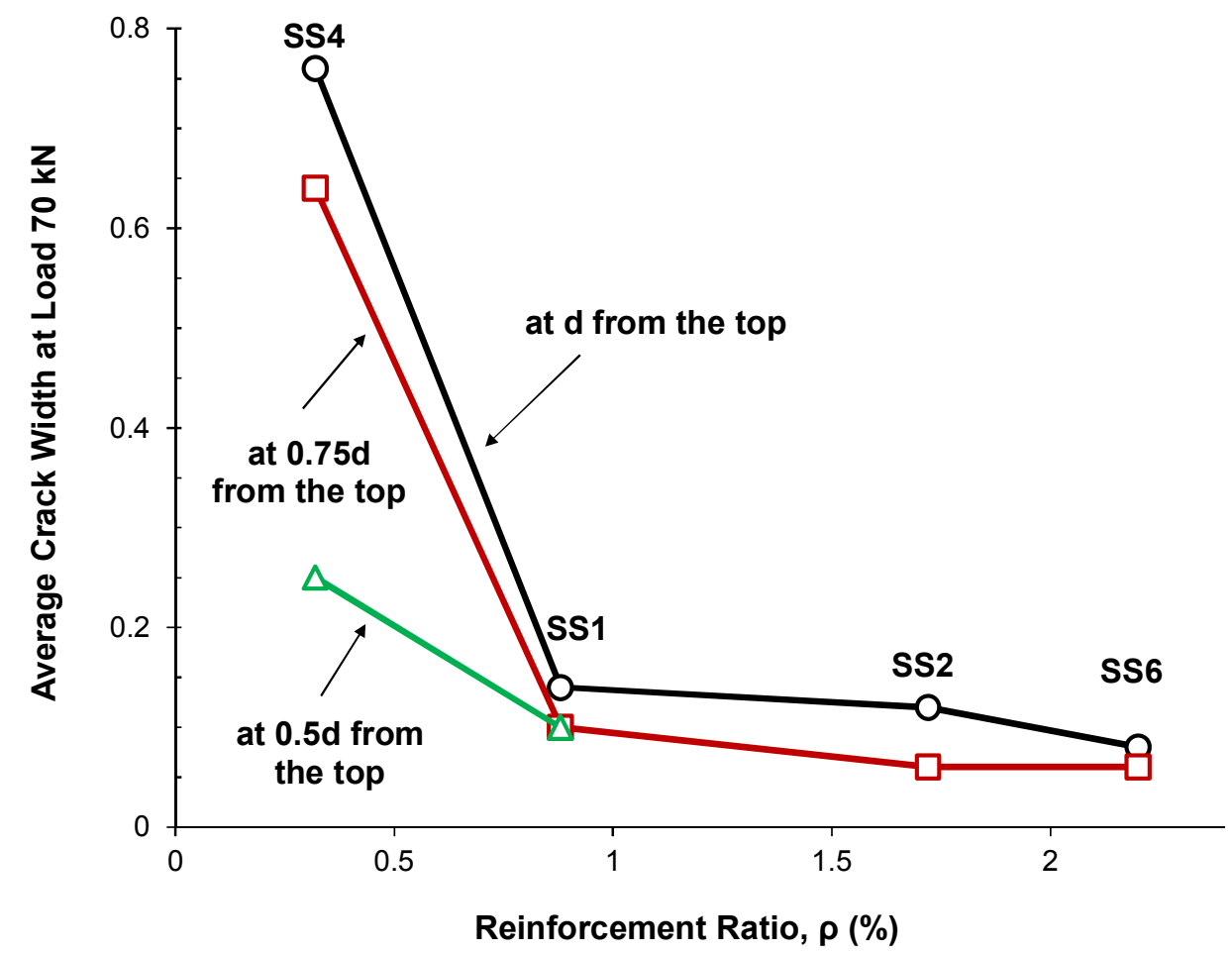

Figure 6-3: Average Crack Widths at $\mathrm{P}=70 \mathrm{kN}$ in Specimen SS1, SS2, SS4 and SS6

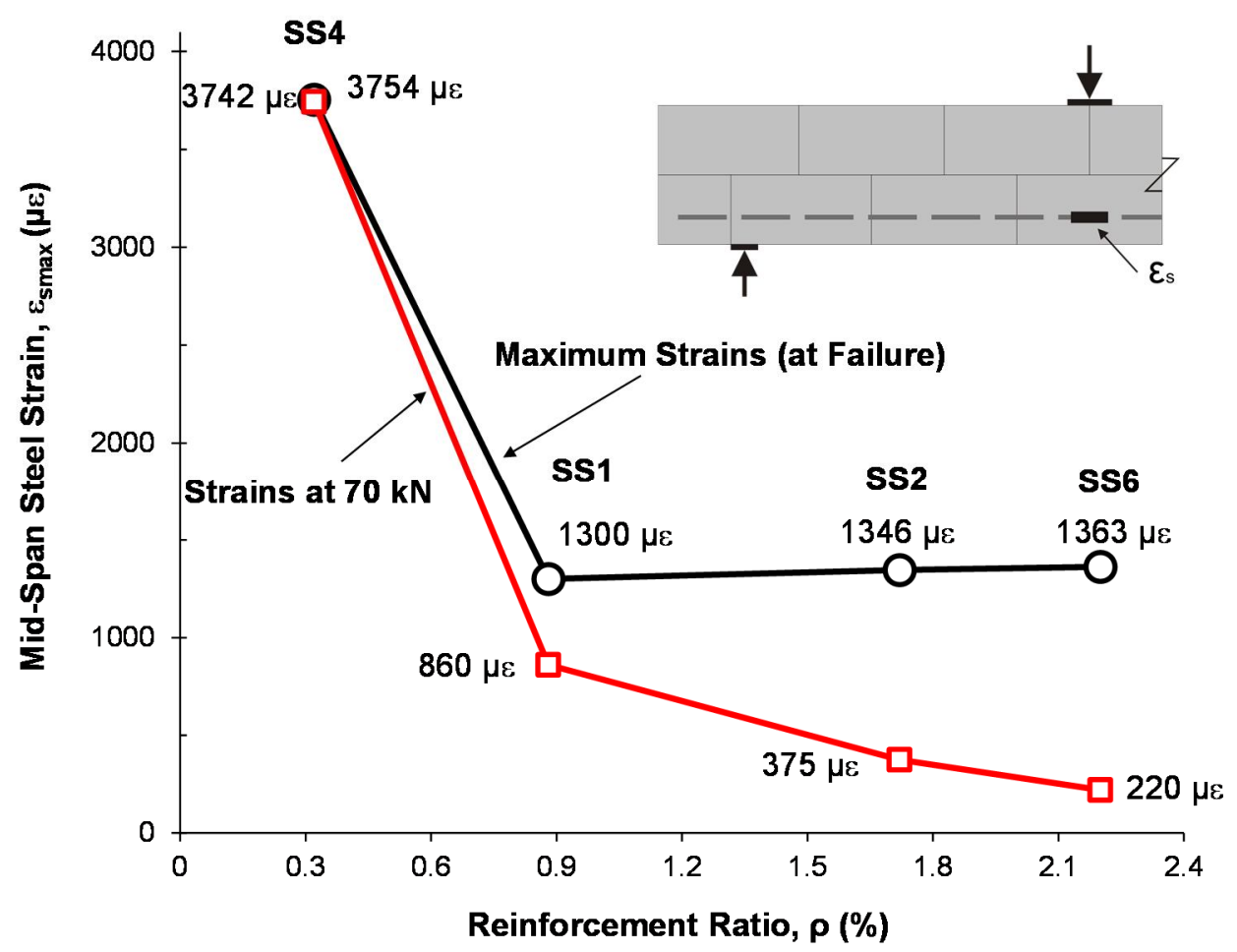

Figure 6-4: Steel Strains at Mid-Span of Specimens SS1, SS2, SS4 and SS6 


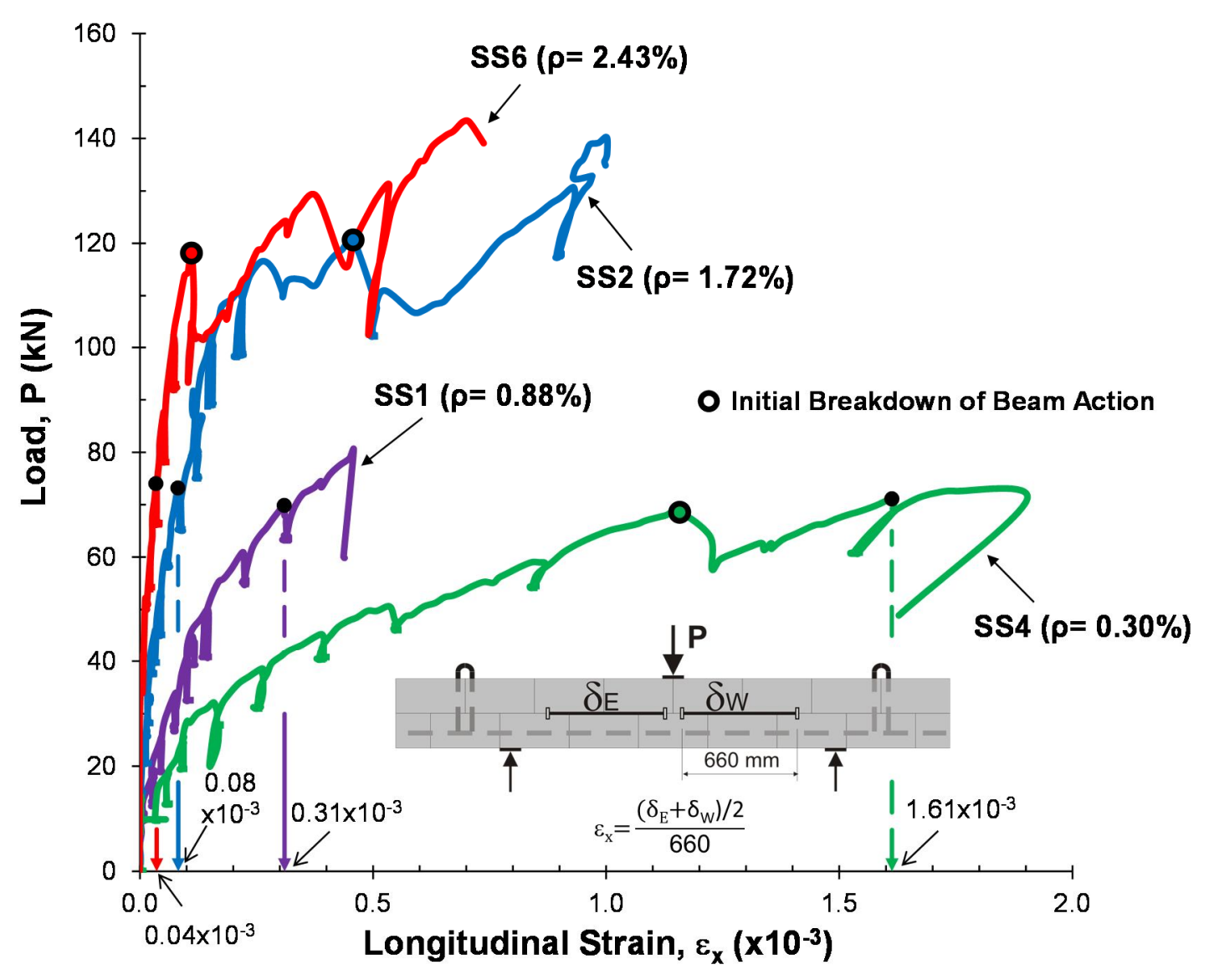

Figure 6-5: Longitudinal Strains, $\varepsilon_{\mathrm{x}}$, in Specimens SS1, SS2, SS4 and SS6

Image correlation analysis conducted on the south faces of the specimens in this series showed that longitudinal strains decreased significantly with the increase of the main reinforcement ratio. In Figure 6-6 meshes were used to establish the average value of the longitudinal strains (mainly concentrated at the head joints) at mid-depths of the east sides of the specimens. The averages of strain contours in the meshes were $1730 \mu \varepsilon, 430 \mu \varepsilon, 220 \mu \varepsilon$ and $190 \mu \varepsilon$ for specimen SS4 $(\rho=0.30 \%), \operatorname{SS} 1(\rho=0.88 \%), \operatorname{SS} 2(\rho=1.72 \%)$ and SS6 $(\rho=2.42 \%)$, respectively. This confirms the results observed in Figure 6-5. 


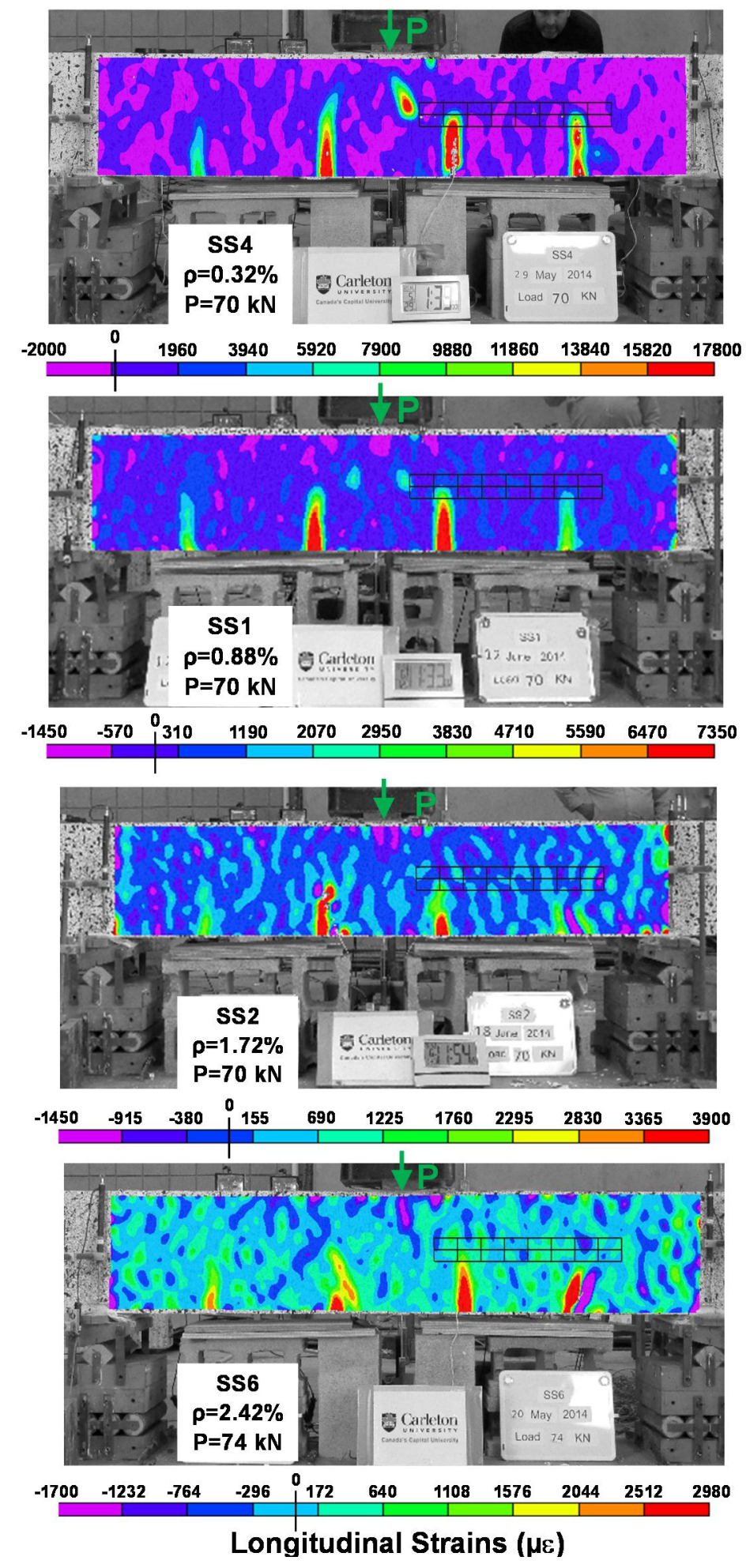

Figure 6-6: Steel Strains at Mid-Span of Specimens SS1, SS2, SS4 and SS6 
In Figure 6-7 three meshes were used to evaluate the average value of the longitudinal strains at various levels: top, mid-depth and steel levels at section A-A in specimen SS1. It is interesting to note that a roughly linear variation in strain is observed, indicating that plane stresses are remaining plane.

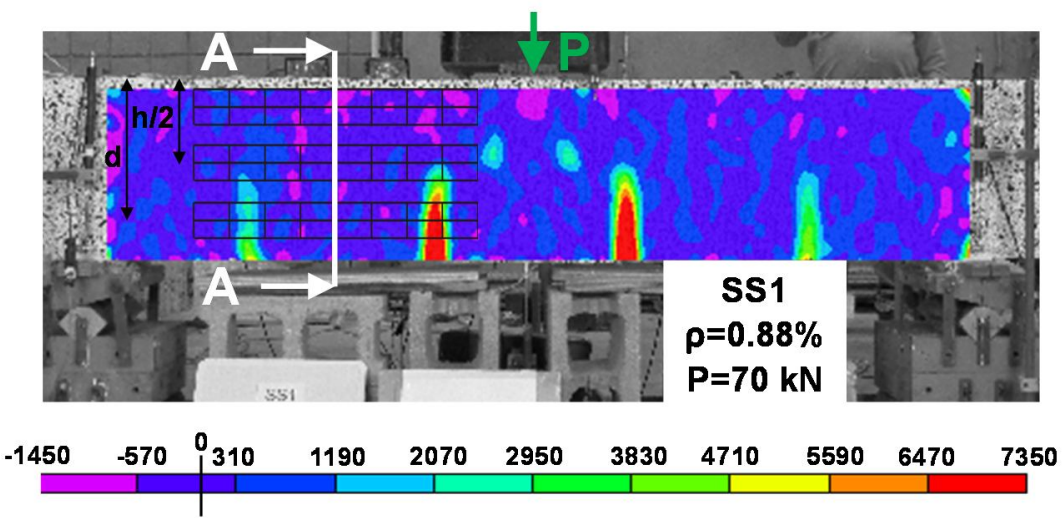

\section{Longitudinal Strains $(\mu \varepsilon)$}

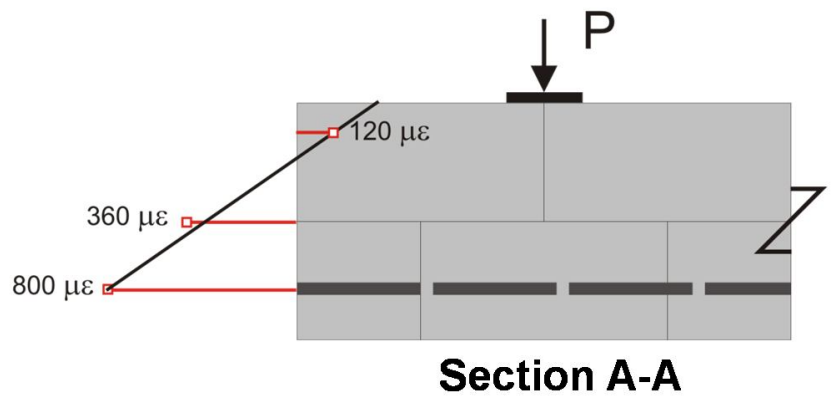

Figure 6-7: Longitudinal Strains at Various Levels in Specimens SS1

As it was noted earlier that the breakdown of aggregate interlock in specimens SS1 caused a sudden shear failure while the breakdowns of aggregate interlock in specimens SS2, SS4 and SS6 were followed by formation of masonry shear keys leading to higher failure shear stresses and strains than those associated with breakdowns of aggregate interlock. It was decided to compare the crack patterns of these beams at the last load stage prior to the breakdown of aggregate interlock (see Figure 6-8). It is clear that as the steel ratio increased the average and maximum crack widths decreased. 

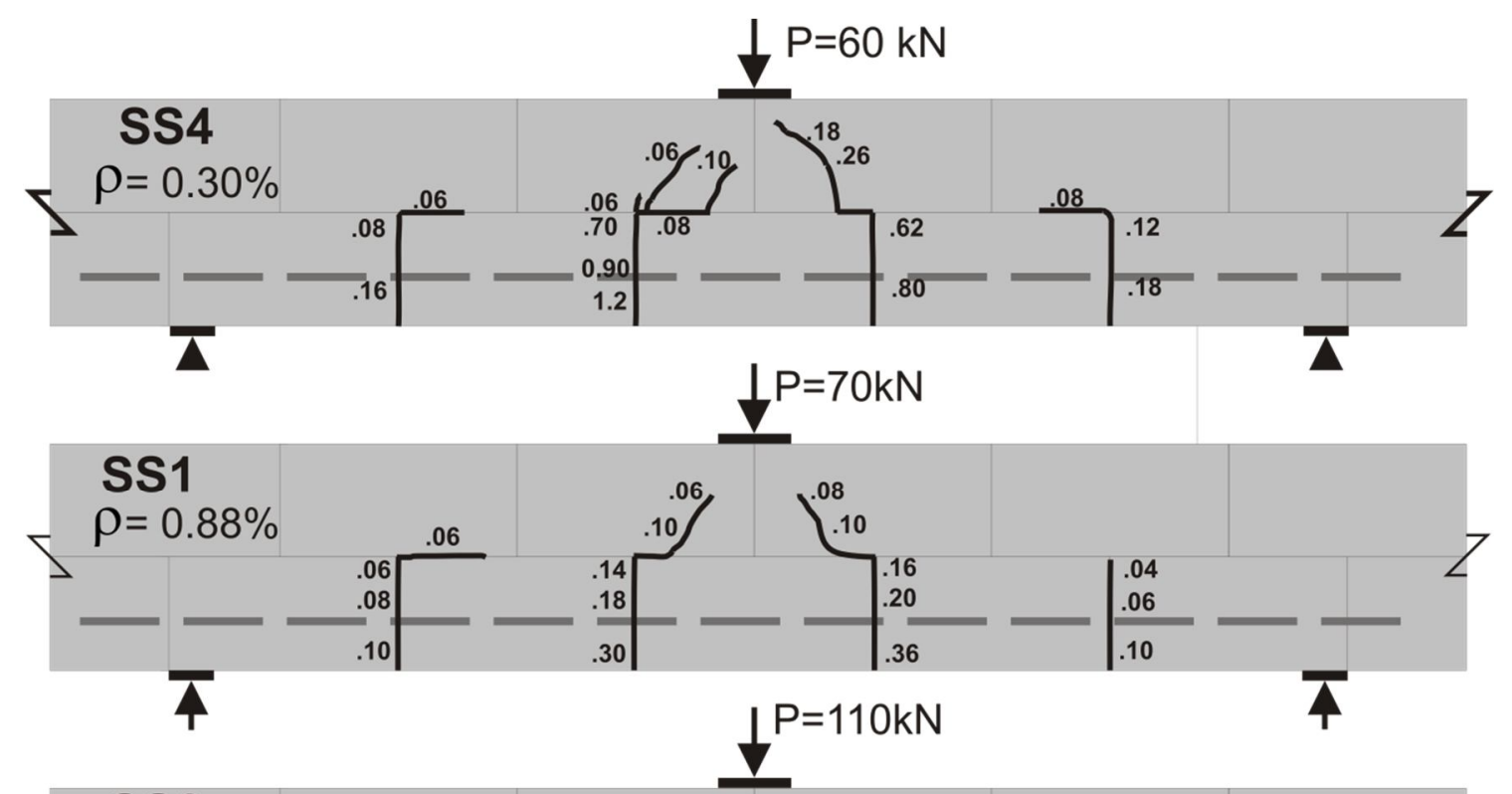

\section{SS2}

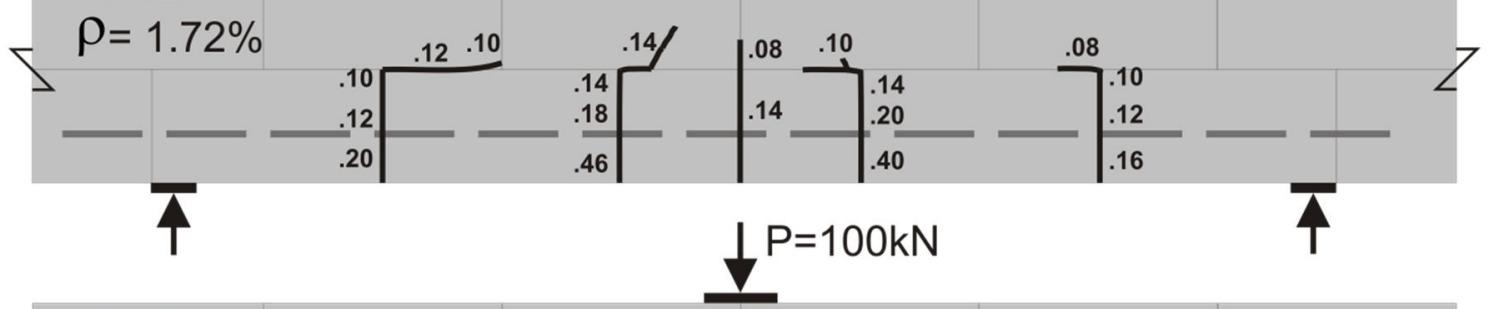

SS6

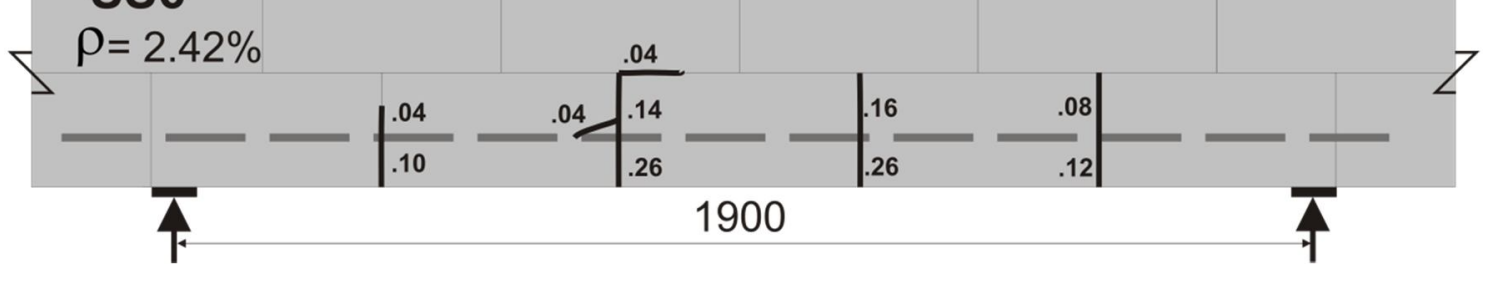

Figure 6-8: Crack Patterns of Specimens SS1, SS2, SS4 and SS6 Prior to initial Breakdown of Beam Action

Figure 6-9 show the final crack patterns of the beams in this series. It is clear from Figure 6-8 that the failures of these beams are diagonal tension failures which happen due to the breakdown of beam action. Increasing $\rho$ from $0.30 \%$ to $0.88 \%$ and $1.72 \%$ and $2.42 \%$, resulted in enhancements of shear strength by $15 \%, 90 \%$ and $98 \%$ respectively. Even in specimens SS2, SS4 and SS6 where breakdowns of aggregate interlock were followed by formation of shear keys, it was observed that shear strength increased with the increase of $\rho$. The test results of this 
investigation agrees well with tests results of Suter and Li et al who found that $\rho$ has a considerable effect on shear strength of RM beams. The results of this series contradict the test results by Feriege (1994) who found that $\rho$ have only marginal effect on shear strength.

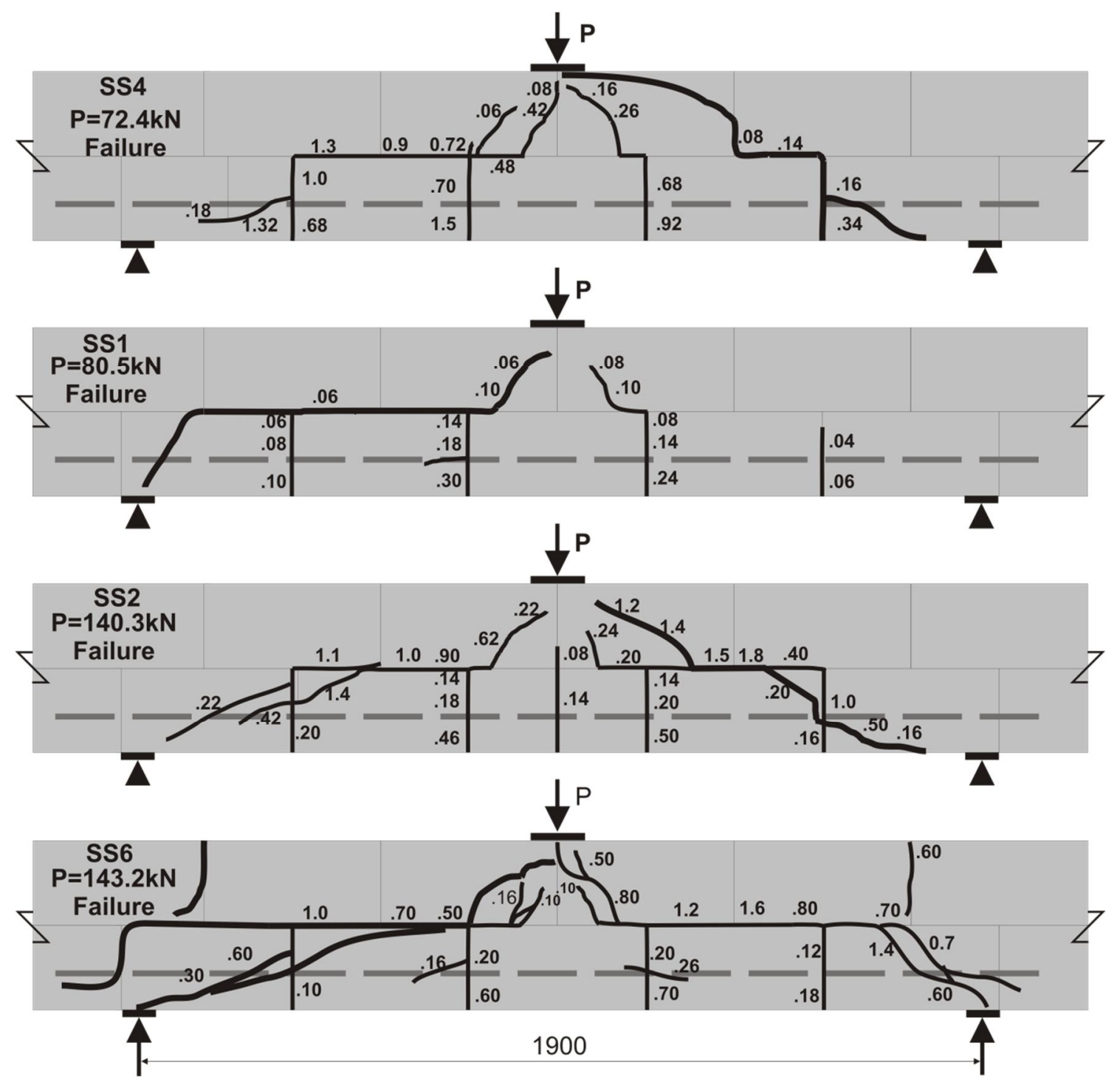

Figure 6-9: Failure Crack Patterns of Specimens SS1, SS2, SS4 and SS6 


\section{Repeated tests of Specimens SS1, SS2, SS4 and SS6}

The repeated tests of the specimens in this series yielded higher shear strengths than those of the initial tests (with the exception of SS2). Generally, no new major shear cracks formed during these repeated tests indicating that a stabilized cracking pattern had formed. The cracking process in these tests can be considered as a stabilized cracking phase where existing cracks are widening with the increase in the applied load. The failure occurred when these cracks were so wide that they cannot resist shear stresses through aggregate interlock or shear key mechanisms. The trend of increasing failure shear stresses with the increase of main reinforcement ratio is still strongly observed. The breakdown of aggregate interlock in the repeated side of specimen SS1R was followed by the formation of a shear key leading to higher deflections (see Figure 6-10) However, this had only marginal effects on failure shear stress (an $8 \%$ increases in load beyond the initial breakdown of beam action).

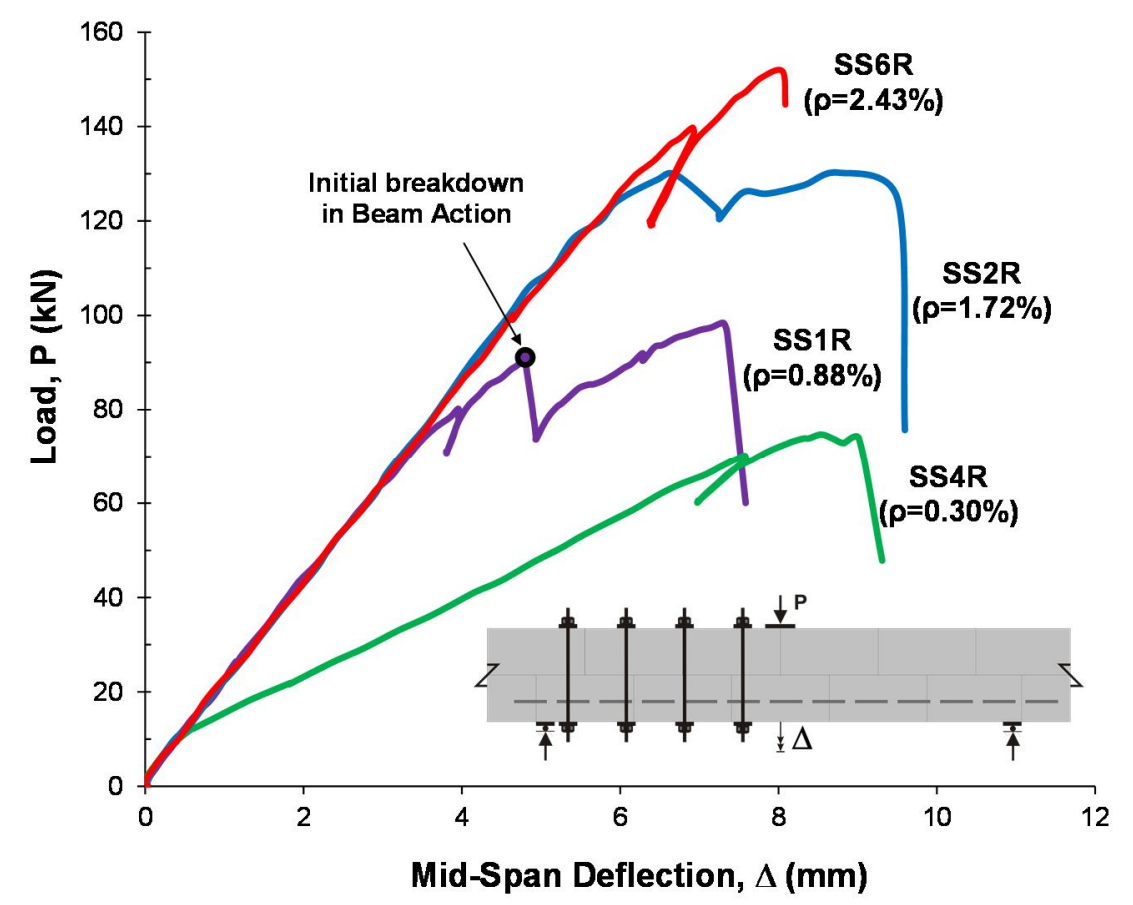

Figure 6-10: Load-Deflection Responses for Specimens SS1R, SS2R, SS4R and SS6R 


\section{Failure Shear Stress of Specimens SS4, SS1, SS2 and SS6}

Failure shear stresses of SS1, SS1R, SS2, SS2R, SS4, SS4R, SS6 and SS6R are plotted in Figure 6-11 versus $\rho$. Also presented are the predictions by the major masonry design codes along with the CSA A23.3 code and Hoult et al. It can be seen in Figure 6-11 that the North American codes (TMS 402 and CSA S304.1 codes) are not sensitive to the effect of $\rho$. These two codes highly underestimate the failure shear stresses for RM beams with high $\rho$. Both codes give constant predicted failure shear stresses that do not match the experimental behaviour, with CSA S304.1 being more conservative than TMS 402 code. The BS 5628 code, on the other hand, gives reasonable predictions for RM beams with high $\rho$ (specimens SS4 and SS1) but overestimates the failure shear stresses of RM beams with low $\rho$ (specimens SS2 and SS6). Although the Australian Code (AS 3700) accounts for the effect of $\rho$, it yielded highly conservative predictions. It is clear that the CSA A23.3 code and the Hoult et al. method were able to predict the variation in failure shear stress for RM beams with different $\rho$ very well. Both codes gave safe and accurate predictions. 


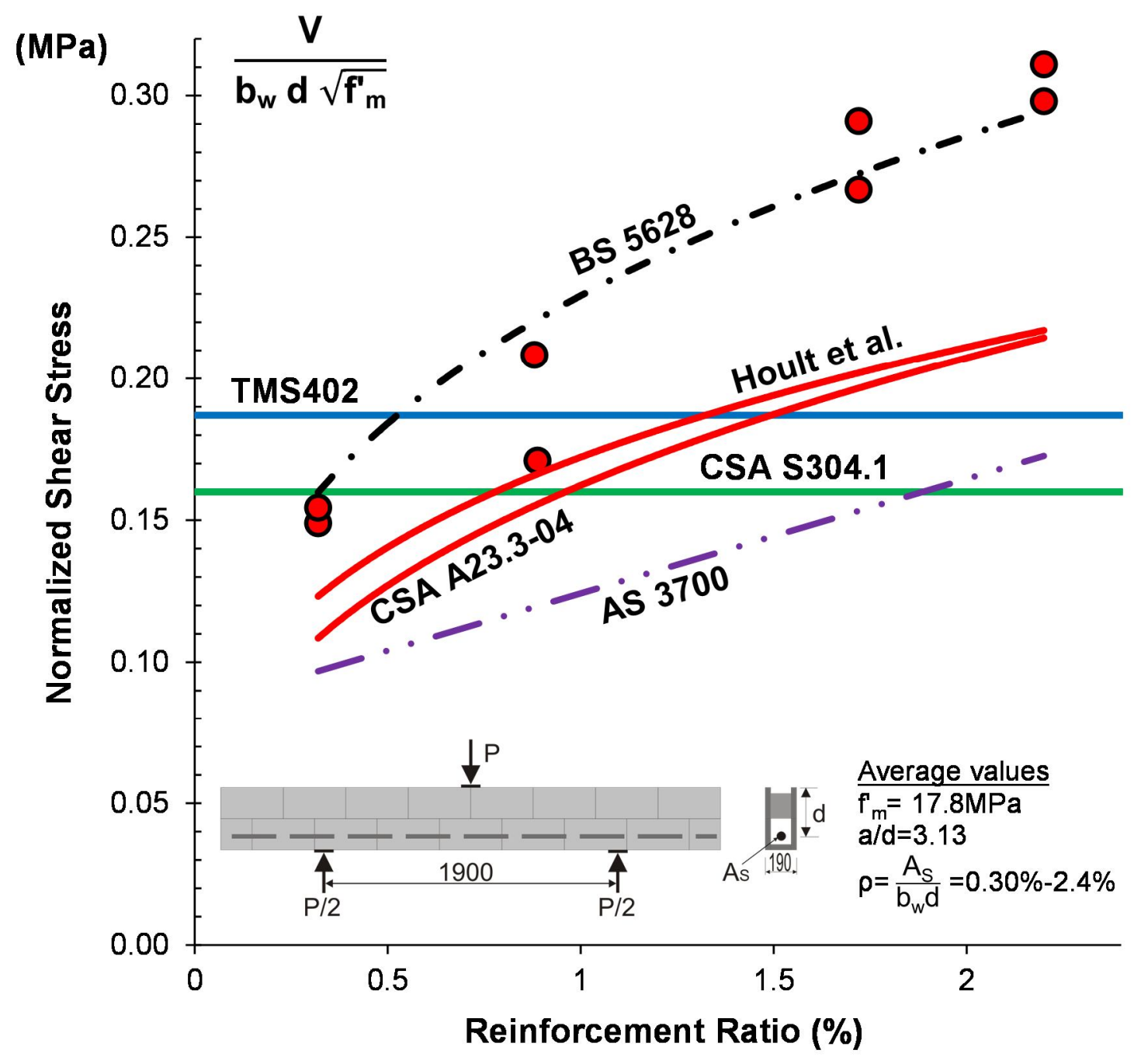

Figure 6-11: Failure Shear Stresses for Small Reinforced Masonry Beams with Different $\rho$

\subsubsection{Effect of $\rho$ on Shear Strength of Medium Size Series}

As discussed in Chapter 2, several investigations have been conducted on the effect of $\rho$ on shear strength of reinforced masonry beams (Suter 1980 and 1984, Li et al.1994 and Feriege 1994.) Besides yielding conflicting results, these investigations were conducted on small-scale beams, consisting of either one or two courses. In this investigation, a series of five-course beams (with an average effective depth of $880 \mathrm{~mm}$ ) were used to study the effect of $\rho$ on the shear behaviour 
of larger RMB. This series consists of specimens SM4 $(\rho=0.33 \%)$, SM1, SM1D $(\rho=0.83 \%)$ and $\operatorname{SM} 2(\rho=1.68 \%)$.

\section{Load-Deflection Response and Failure Mechanisms}

Figure 6-12 shows that increasing $\rho$ led to higher post-cracking stiffness and higher shear strength. While specimen SM4 failed suddenly due to an obvious breakdown of beam action, the initial breakdowns of aggregate interlock in SMI, SM1D and SM2 were followed by formation of shear keys and strut and tie actions leading to higher deflections at failure. It can be noted in Figure 6-12 that specimen SM1 and SM1D failed at higher shear load than SM4 but approximately at equal deflections of $(\Delta / \mathrm{L})=1 / 130$.

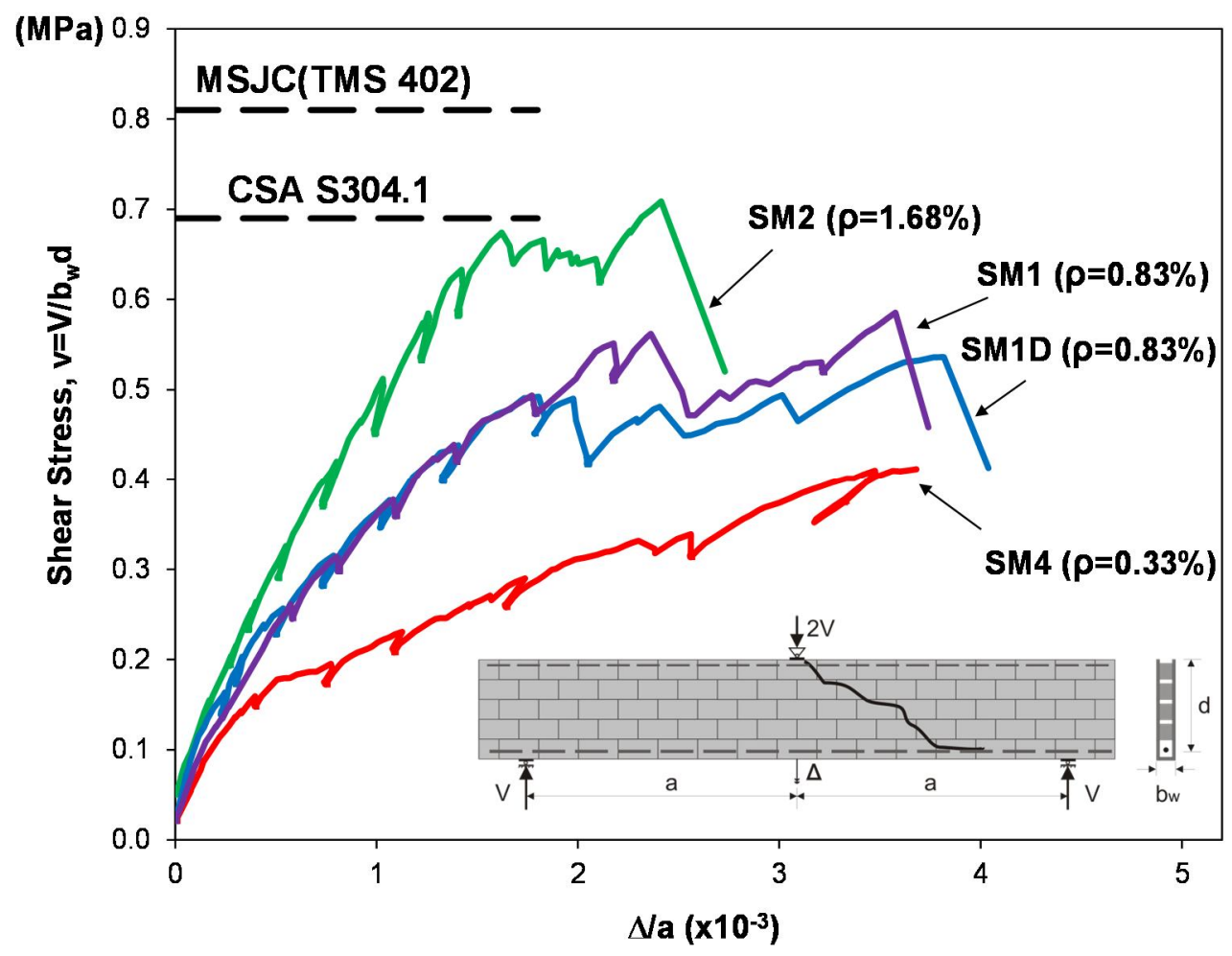

Figure 6-12: Load-Deflection Curves of Specimens SM1, SM1D, SM2 and SM4 


\section{Crack Spacing and Widths}

To further explore the observed increase in shear strength with increasing $\rho$, consider Figure 613 which shows the crack patterns in specimens SM1, SM1D, SM2 and SM4 at an applied load of $100 \mathrm{kN}$ (equivalent to a shear stress of $0.32 \mathrm{MPa}$ ). It is clear from Figure 6-13 that at this load stage four major cracks in specimen SM4 $(\rho=0.33 \%)$ reached beyond the mid-depth of beam versus only two cracks in specimen SM1D $(\rho=0.83 \%)$. Furthermore, SM2 $(\rho=1.68 \%)$ was very lightly cracked, with cracks barely reaching the first bed joint. The crack spacing in all specimens of this series at the reinforcement level was $400 \mathrm{~mm}$. The crack spacing at the $0.75 \mathrm{~d}$ and $0.5 \mathrm{~d}$ levels in SM4 and SM1D was approximately $0.5 \mathrm{~d}$, however, the maximum and average crack widths were significantly higher in SM4 $(\rho=0.33 \%)$ than those in SM1D $(\rho=0.83 \%)$. This reduction in crack widths with increasing $\rho$ can be primarily related to the enhancement in crack control ability provided by the extra steel. Figure 6-14 shows that steel strains measured at midspan of the beams of this series at $100 \mathrm{kN}$ decreased with the increase in $\rho$. 


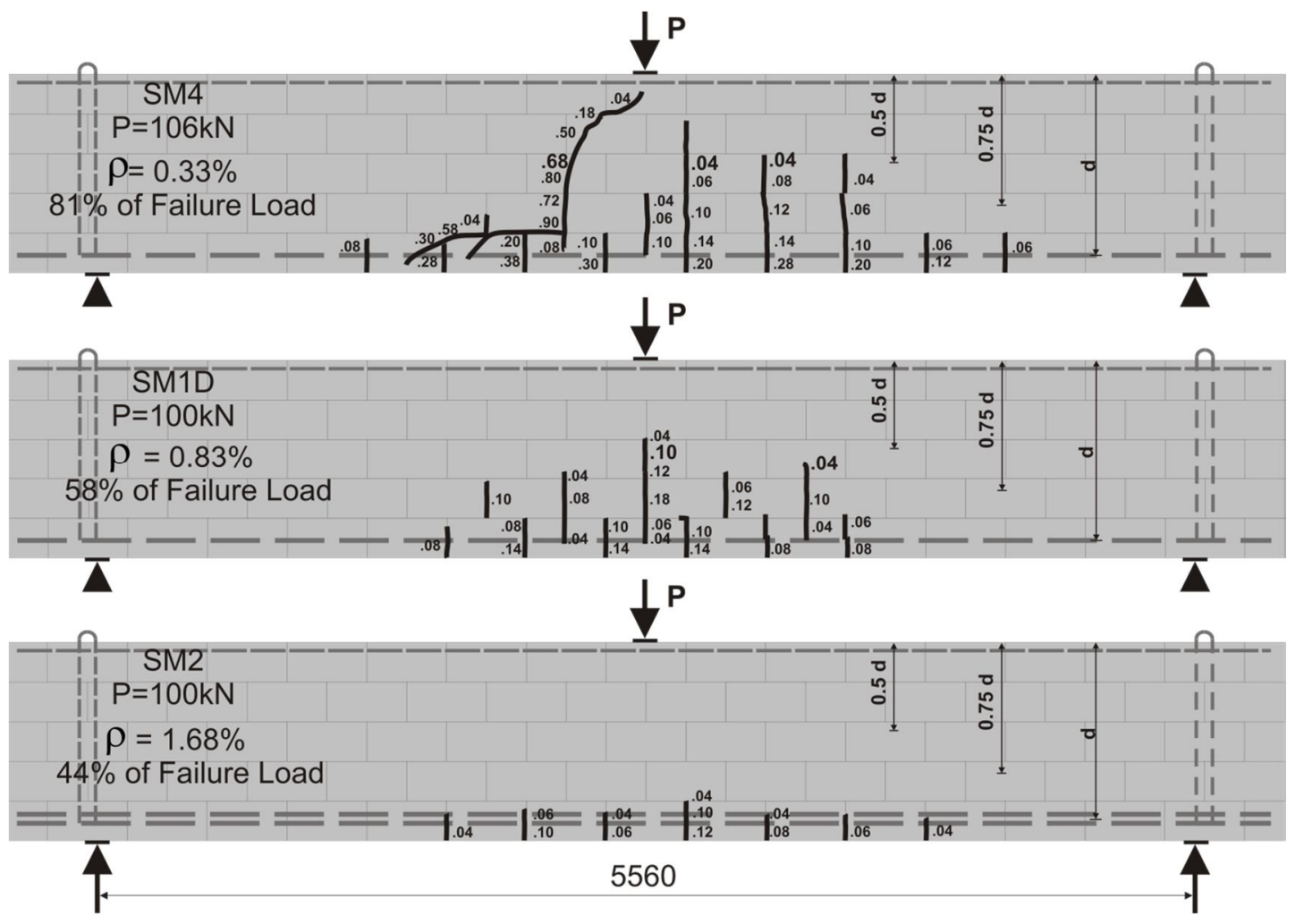

Figure 6-13: Crack Patterns in specimens SM1D, SM2 and SM4 at an applied load of $100 \mathrm{kN}$

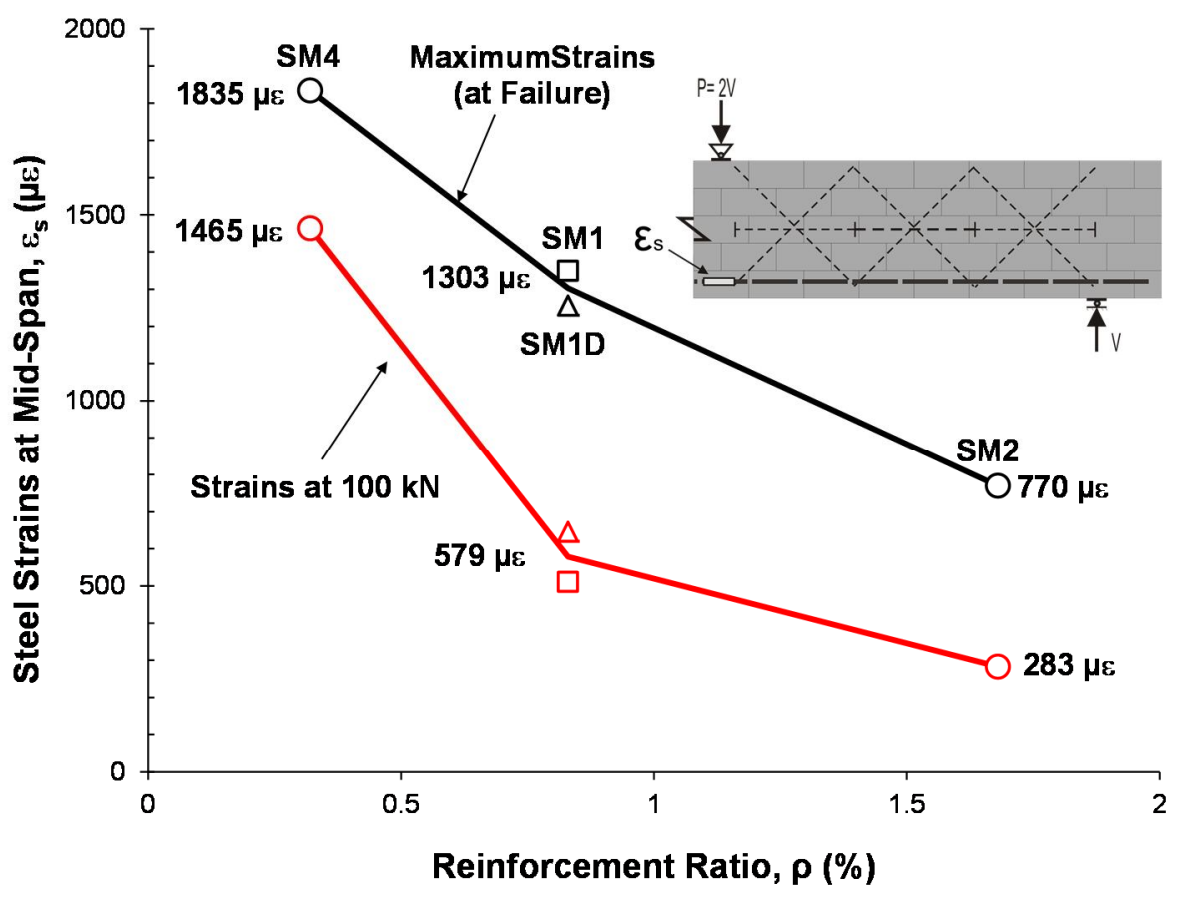

Figure 6-14: Mid-Height Steel Strains in Specimens SM1, SM1D, SM2 and SM4 
The reduction of the steel strain was associated with reductions in the longitudinal strains at middepth of beams. This can clearly be seen In Figure 6-15 which shows the measured longitudinal strains at mid-height of specimens SM1, SMID, SM2 and SM4. It can be noted that at a given applied load the longitudinal strain at the mid-height decreases as $\rho$ increases. This reduction in the longitudinal strains led to narrower cracks as $\rho$ increased from $0.33 \%$ to $0.83 \%$ and $1.68 \%$.

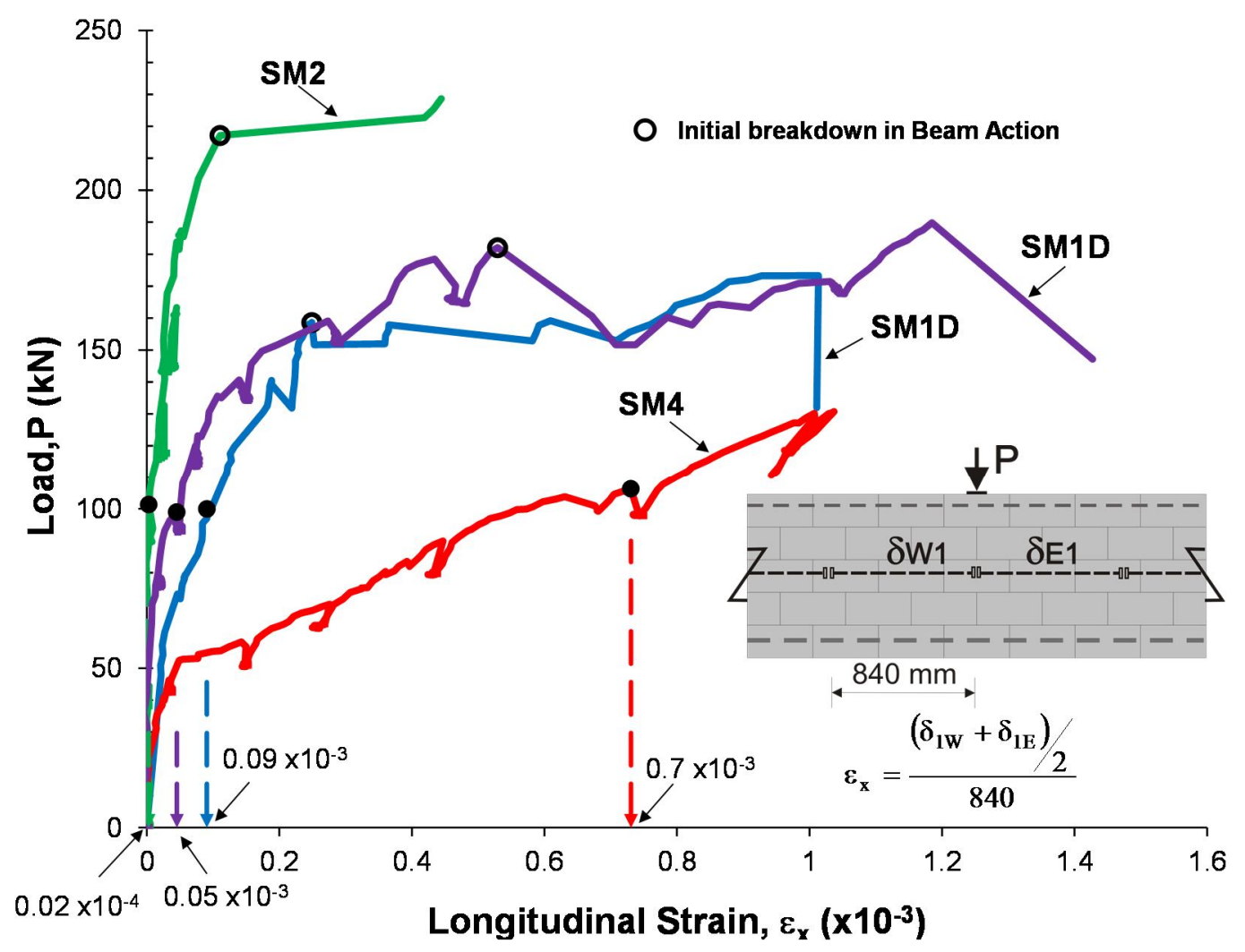

Figure 6-15: Mid-height Longitudinal Strains in Specimens SM1, SM1D, SM2 and SM4

The improvement in crack control due to the increase in $\rho$ became more evident prior to the breakdown of beam action (see Figure 6-16). It can be noticed that changing $\rho$ did not significantly affect the crack spacings at these load stages. Rather, the maximum and average crack widths decreased considerably with increasing $\rho$. These reductions can be related to the significant decreases in steel strains and $\varepsilon_{\mathrm{x}}$ with increasing $\rho$ as shown in Figure 6-14 and 6-15 


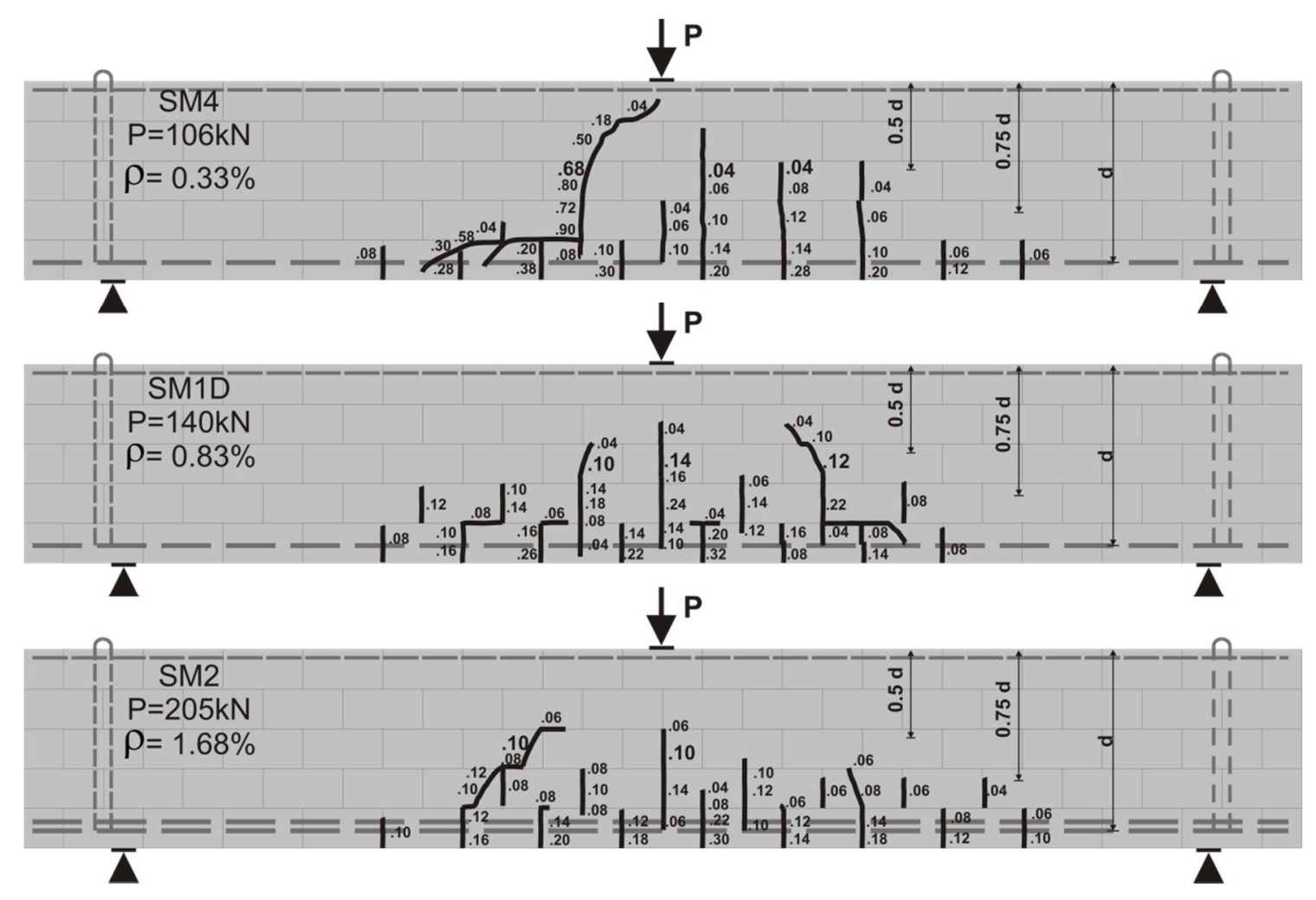

Figure 6-16: Crack Patterns in Specimens SM1D, SM2 and SM4 and Prior to Breakdown of Beam Action

Increasing $\rho$ from $0.33 \%$ to $0.83 \%$ and $1.68 \%$ resulted in enhancements of shear strength by $38 \%$ to $75 \%$ respectively. These results are valuable since that it is the first time the effect of $\rho$ on shear strength of masonry beams has been studied on beams of this size. Figure 6-17 shows the final crack patterns of the specimens in this series. It can be seen in figure that failures of these beams are characterized by a tooth failure type in similar fashion to failure in reinforced concrete beams. It is also interesting to note that the cracks in SM4 $(\rho=0.33 \%)$ were almost vertical (oriented at $\left.90^{\circ}\right)$ while the cracks in SM2 $(\rho=1.68 \%)$ were steeper and oriented towards the point load. Like reinforced concrete, then, the crack orientation in reinforced masonry is a function of the longitudinal strain. With increased longitudinal strains steeper cracks are formed. 


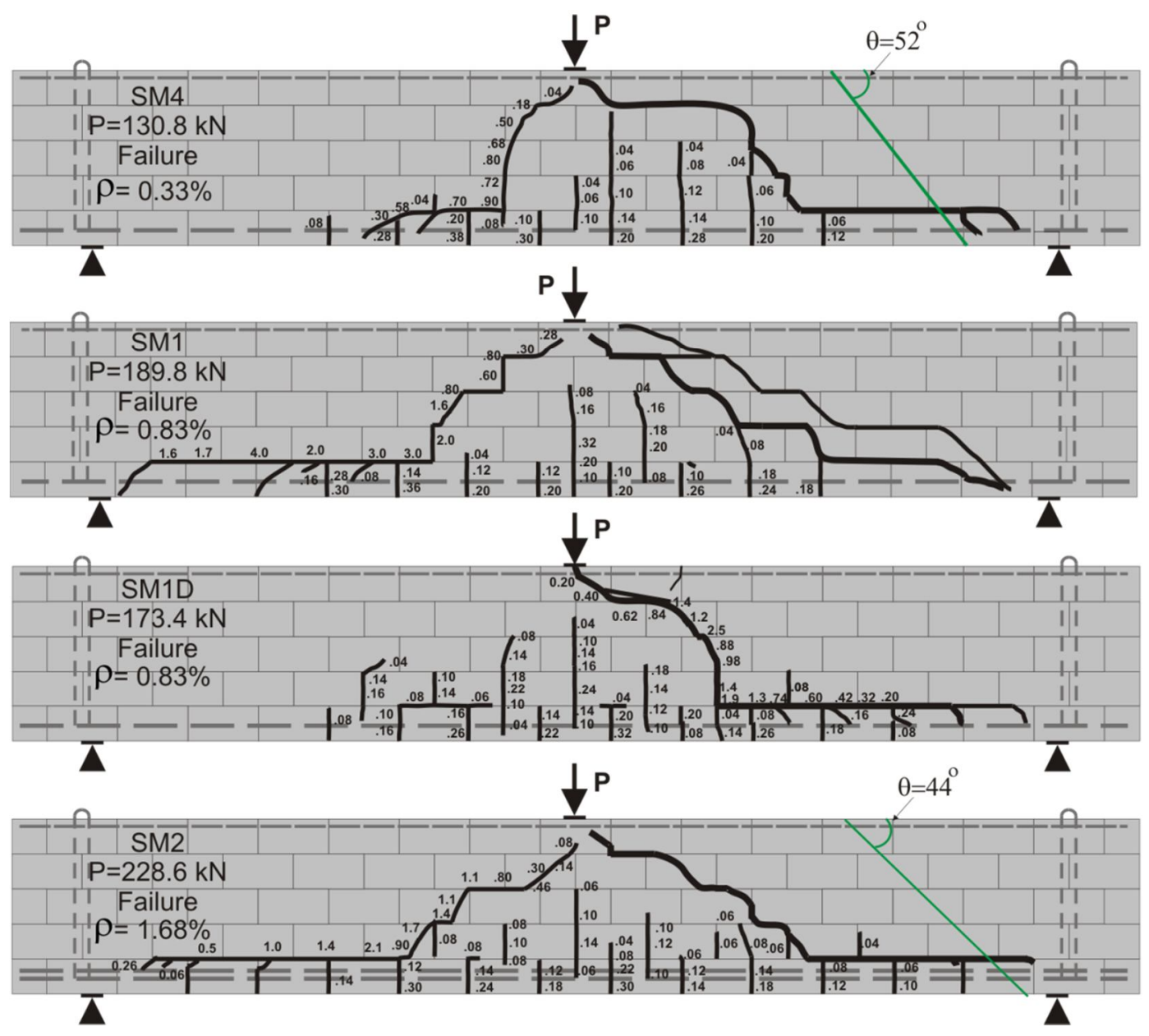

Figure 6-17: Failure Crack Patterns on south faces of Specimens SM1, SM1D, SM2 and SM4

\section{Failure Shear Stresses of SM4, SM1, SM1D and SM2}

In Figure 6-18 the normalized failure shear stress of specimens SM4, SM1, SM1D and SM2 are plotted versus $\rho$ along with the predictions of various code equations. Also, Table 6-1 summarizes the average ratios of tested to predicted strengths, the standard deviations, and COV values of these codes. It is clear from Figure 6-18 that the general method of the CSA A23.3 and the Hoult et al. method were able to capture the effects of varying $\rho$, giving accurate and safe 
predictions. It can be seen in Table 6-1 that these two methods exhibited the smallest value of COV (12\%). The TMS 402 code considerably overestimates the shear strength of specimens in this series. This overestimation is associated with a significantly high variation (a COV of $42 \%$ ) and can be attributed to two reasons: first the TMS 402 code does not account for effect of $\rho$, secondly it does not account for the size effect. While not accounting for strain effect parameters, CSA S304.1 gives more accurate predictions for specimens in this series. This is due to the fact that CSA S304.1 code accounts for the size effect. However, when the results of the small size series are included, CSA S304.1 exhibits a high COV of 32\% as shown in Table 6-1. Unlike its conservatism with regards to the small beams in the experimental series, the Australian code gave safe and accurate predictions for the failure shear stresses of the specimens in this series. This accuracy can be related to the fact that AS 3700 accounts for the effect of $\rho$. Although it gave accurate predictions for shear strengths of small size beams with different $\rho$ ratios, BS 5628 code extremely overestimated the failure shear stresses of the medium size beams. Both the AS 3700 and BS 5628 codes exhibited high variations (COV of $22 \%$ and $23 \%$ respectively). This high variation requires a very low material strength reduction factor in order to apply these codes safely (as discussed in Chapter 2). The accuracy and consistency of the CSA A23.3 in predicting the shear strength of RMB with wide range of $\rho$ ratios demonstrates that masonry design codes could improve the accuracy of their shear strength prediction by adopting design methods based on the MCFT. 


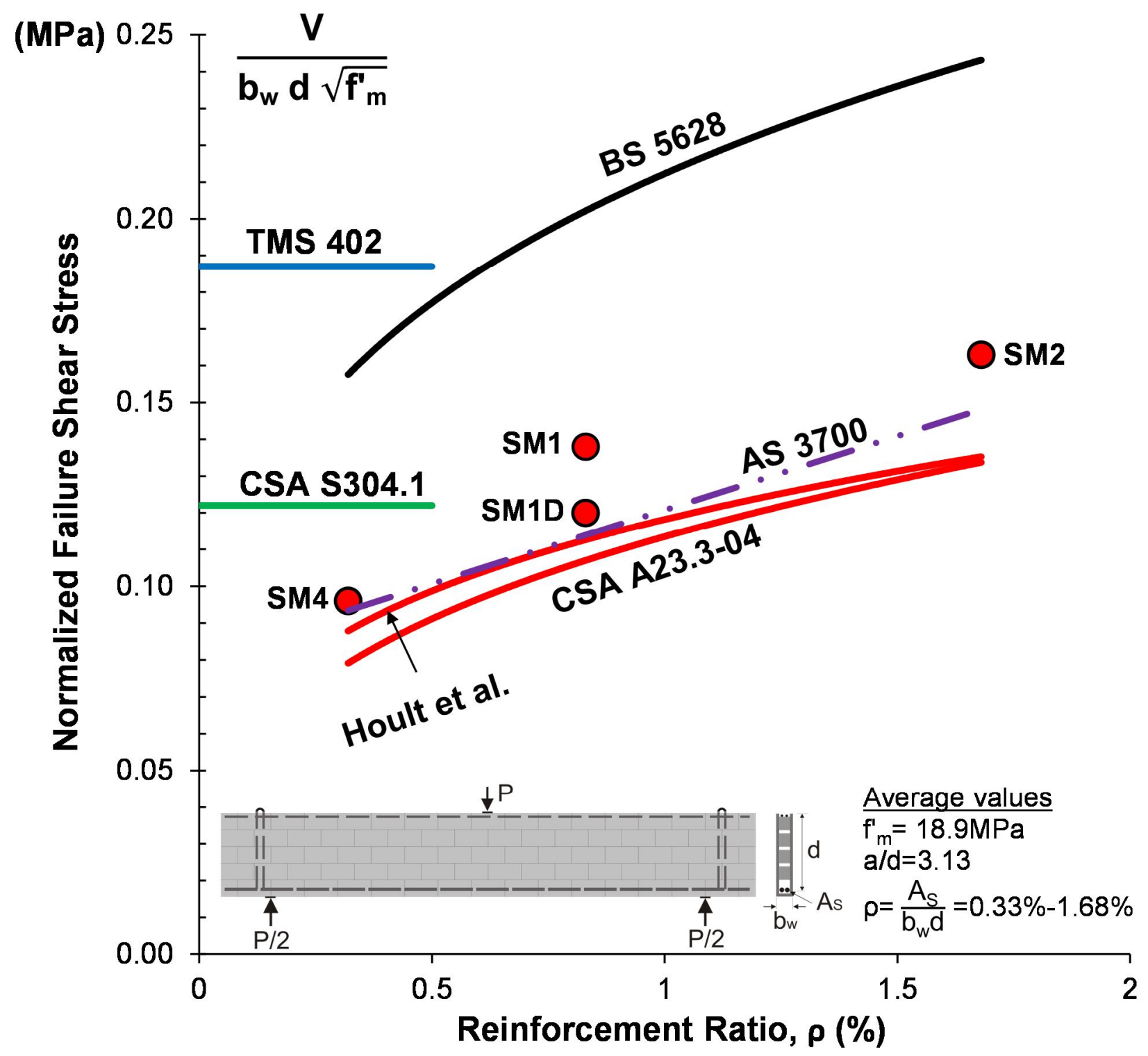

Figure 6-18: Failure Shear Stresses of specimens SM1, SM1D, SM2 and SM4 
Table 6-1: Experimental Observation of the Initial Tests of $\rho$ Effect Series with Codes Predictions

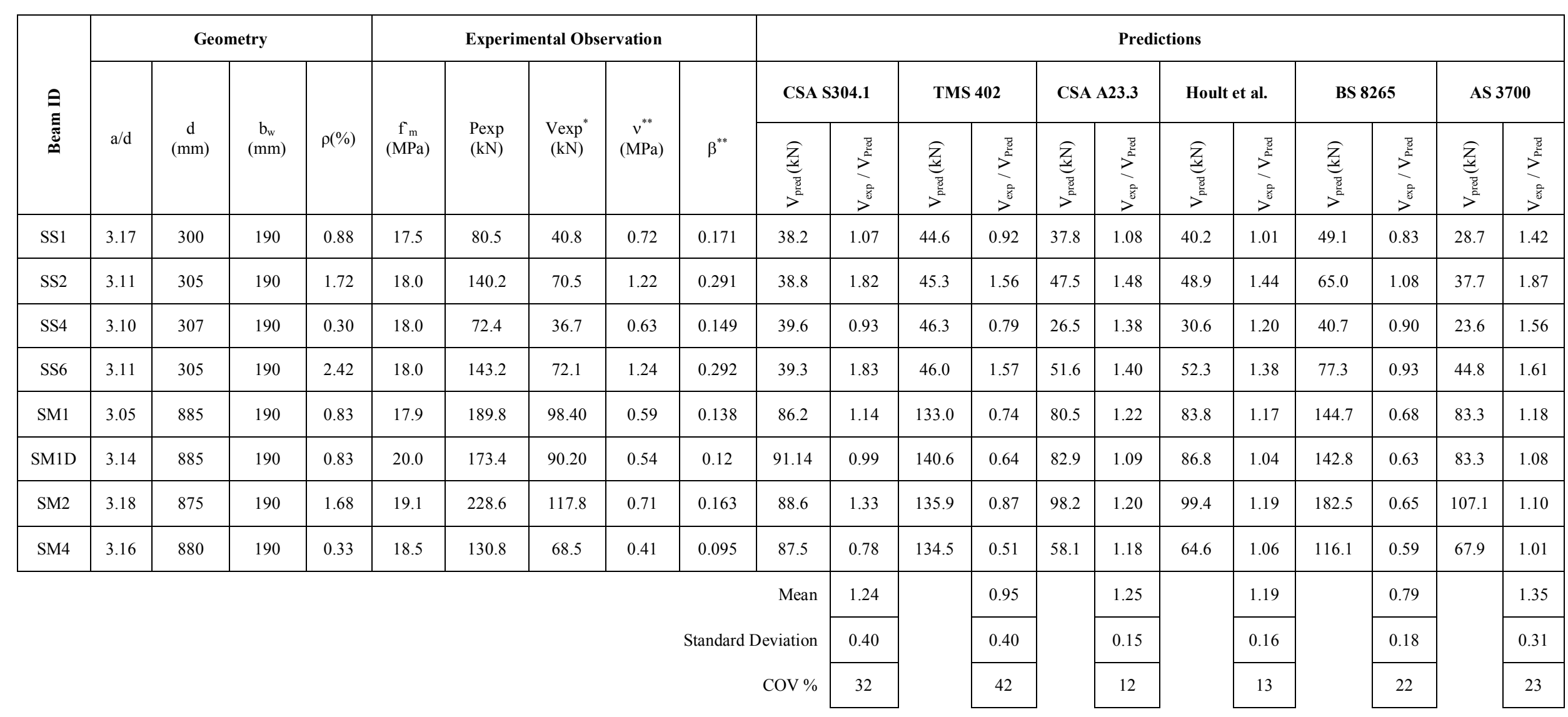

${ }^{*} V_{\exp }=\frac{P \exp }{2}+V @ d$ from point load(due toself weight), ${ }^{* *} v=\frac{V_{\exp }}{b_{\mathrm{w}} d}, \beta=\frac{V}{b_{w} d \sqrt{f_{m}^{\prime}}}$ 
To further highlight the applicability of the strain effect principle in reinforced masonry, consider Figure 6-34 which shows the cracking patterns of SM1D $(\rho=0.83 \%)$ and SM2 $(\rho=1.68 \%)$ at the same longitudinal strain (calculated using Equation (2-15b)). It can be seen from Figure 6-19 that the crack patterns and average crack spacing between these cracks in SM1D and SM2 are similar. Likewise, the average crack widths at various depths varied only slightly between the specimens. Interestingly, Figure 6-20 shows that at this level of $\varepsilon_{\mathrm{x},}$, the steel strains in mid-span of both SM1D and SM2 were approximately the same. Likewise the longitudinal strains measured by the side-mounted LVDTs in both beams were approximately the same (See Figure 6-21). The similarity in the crack patterns, and steel strain of SM1D and SM2 indicates that the longitudinal strain, $\varepsilon_{\mathrm{x}}$ controls the cracking behaviour reinforced masonry. 

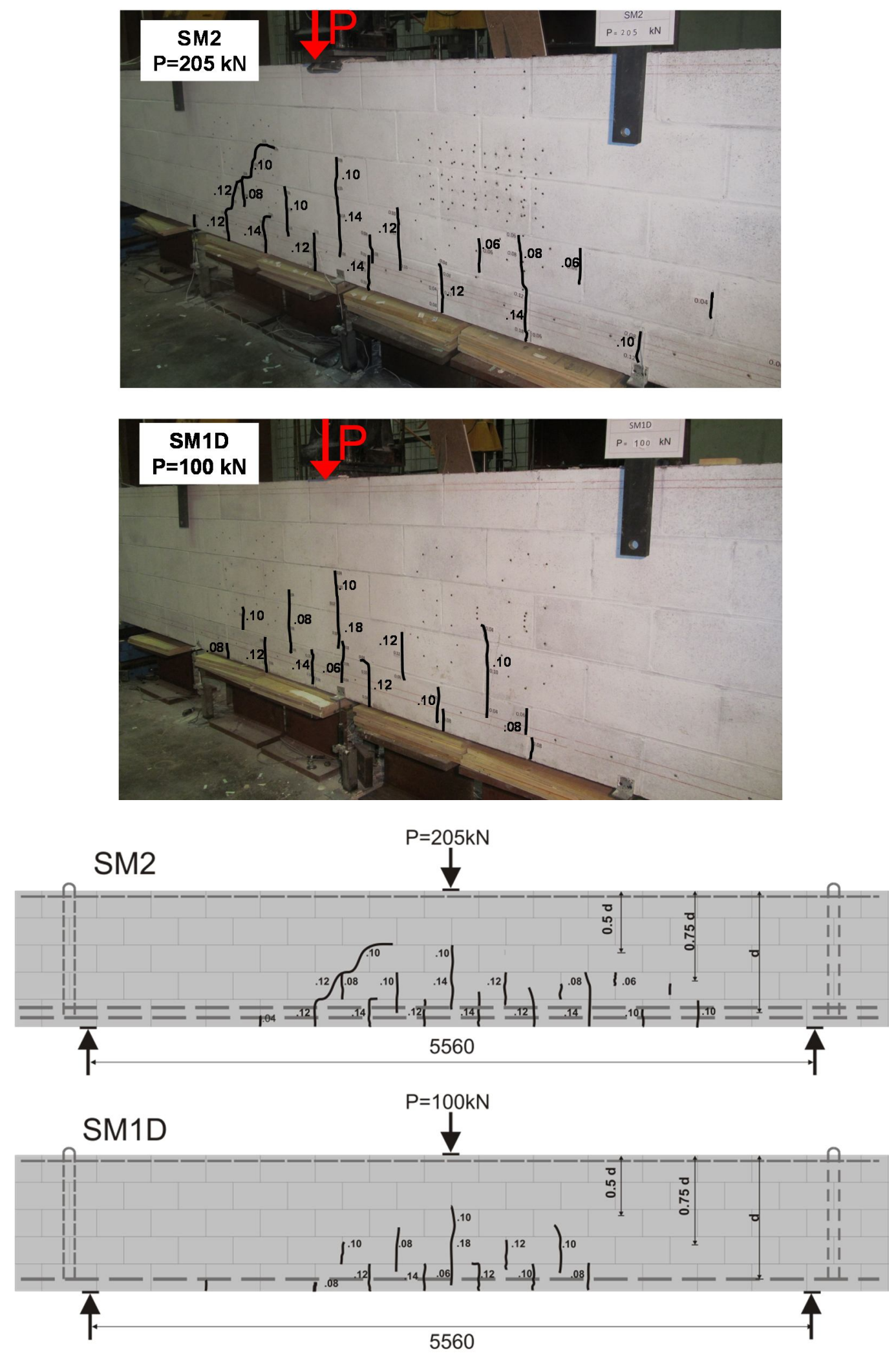

Figure 6-19: Crack Patterns of Specimens SM1D and SM2 at the Same Longitudinal Strain 


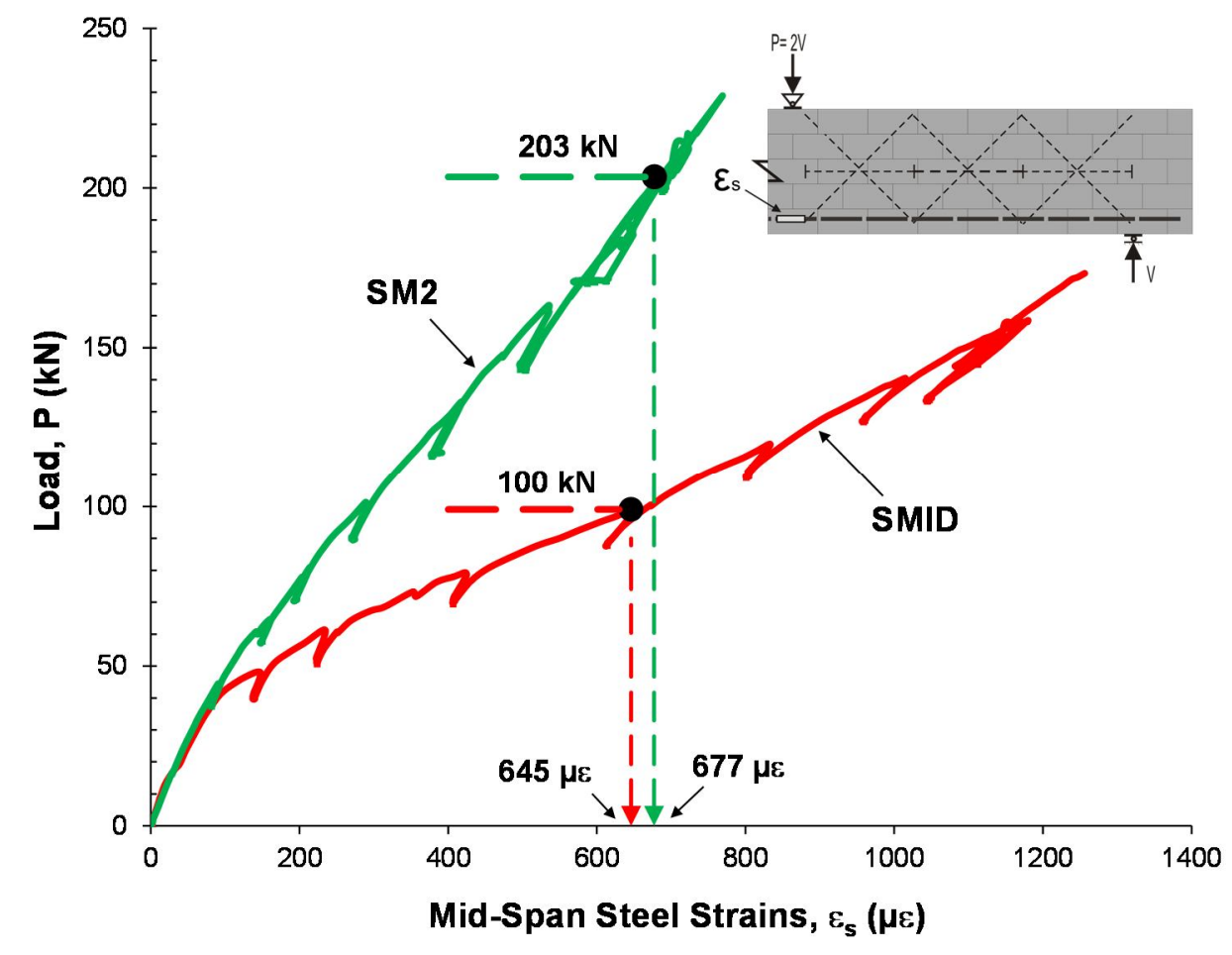

Figure 6-20: Mid-Span Steel Strains in SM1D and SM2

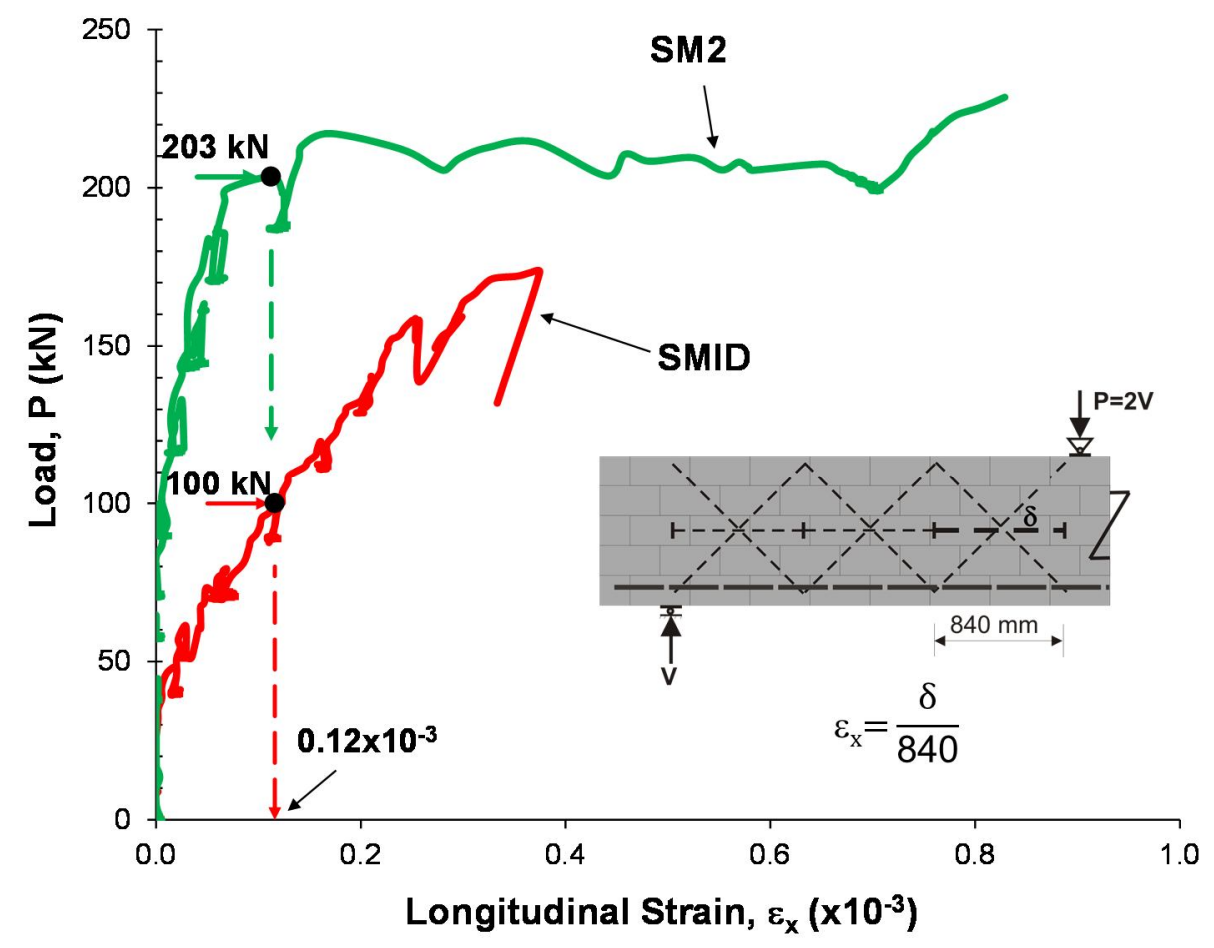

Figure 6-21: Longitudinal Strains, $\varepsilon_{\mathrm{x}}$, in Specimens SM1D and SM2 


\subsection{The Effect of Reinforcement Stiffness, E, on Shear Strength of Reinforced Masonry}

It is well established that the Young`s modulus of the flexural reinforcement has a significant effect on shear strength of reinforced concrete beams. In this section, the effect of using GFRP reinforcing bars on shear strength of reinforced masonry beams will be examined. The results of two sets of specimens (each set consisting of two beams) will be discussed in this section. The first set consisting of specimens SS4 and SS5. These beams are approximately identical (average $d=305$ and $\rho=0.32 \%$ ) except for the type of reinforcing steel. SS5 was reinforced with \#4 GFRP rebars and SS5 was reinforced with $15 \mathrm{~mm}$ high-strength steel rebar. The second set encompasses specimens SM4 and SM5. These beams had an effective depth of $880 \mathrm{~mm}$ and $\rho$ of $0.32 \%$. Specimen SM5 was reinforced with \#8 GFRP rebar while SM5 is reinforced with 25mm highstrength steel rebar.

\subsubsection{Specimens SS4 and SS5}

\section{Load-Deflection Response}

Load-deflection responses of SS4 and SS5 are presented in Figure 6-22. It can be seen that while the uncracked stiffness of both beams match very closely, specimen SS5 (reinforced with GFRP) exhibited a considerably reduced post-cracking stiffness compared to specimen SS4 (reinforced with high-strength steel). Specimen SS4 exhibited a brittle response failing at a $\Delta / \mathrm{L}$ of $1 / 204$ compared to $1 / 130$ exhibited by specimen SS5. Of primary importance, however, is the fact that the use of GFRP rebars $(E=48,200 \mathrm{MPa})$ in $\mathrm{SS} 5$ resulted in a reduction of $40 \%$ in shear strength compared to specimen SS4 reinforced with high-strength steel (E=200,000 MPa). 


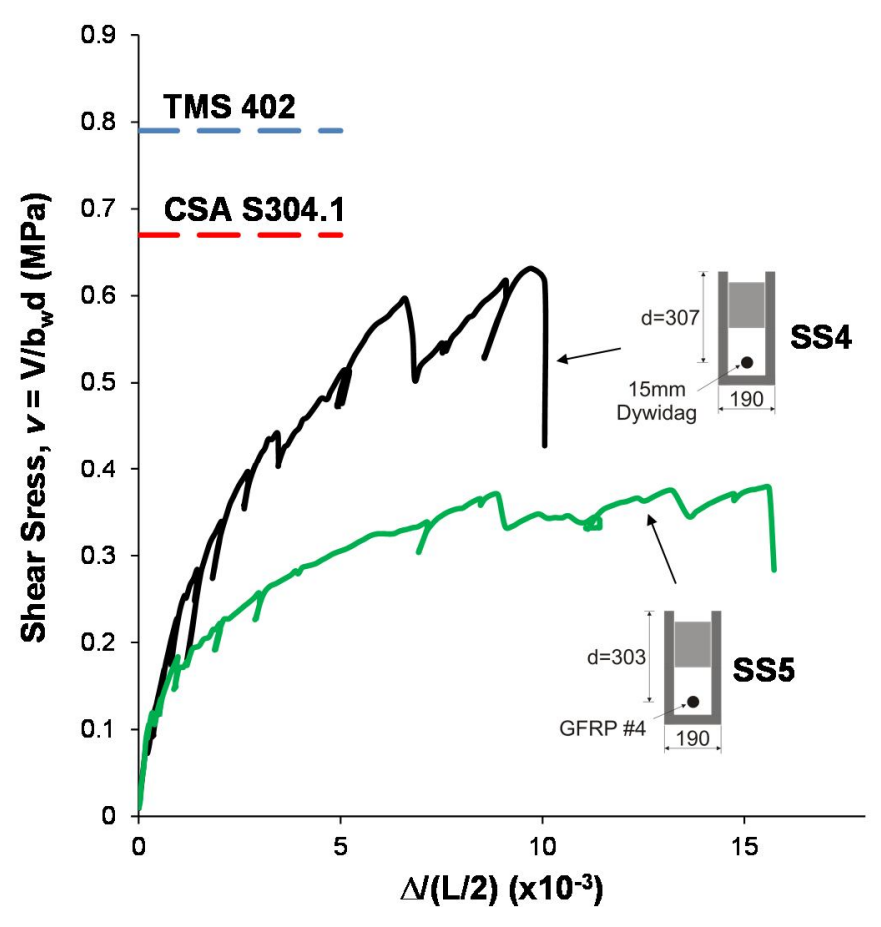

Figure 6-22: Load-Deflection Curves of Specimens SS4 and SS5

\section{Crack Spacing and Widths}

To investigate the reduction in shear strength due to the use of low stiffness reinforcement, consider Figure 6-23 which shows the crack patterns in specimens SS4 and SS5 at an applied load of $38.5 \mathrm{kN}$ (equivalent to a shear stress of $0.34 \mathrm{MPa}$ ). It is clear that crack spacings in both beams are similar; four major flexural- shear cracks developed through the vertical joints. In specimen SS5, two major cracks near the point load (one from each side) propagated upward and diagonally beyond the mid-depth of the beam. The other two cracks in specimen SS5 (far from point load) reached to the bed joint and inclined horizontally through the bed joint towards the load point. In specimen SS4 and at same 0.34 MPa shear stress, on the other hand, only one crack reached the mid-depth in the west side near the point load. The other three cracks could barely reach the bed joint. It can be seen from Figure 6-23 that crack widths at different depths in SS5 were considerably higher than those in SS4. This can be explained through the help of Figures 6-24 and 6-25. 

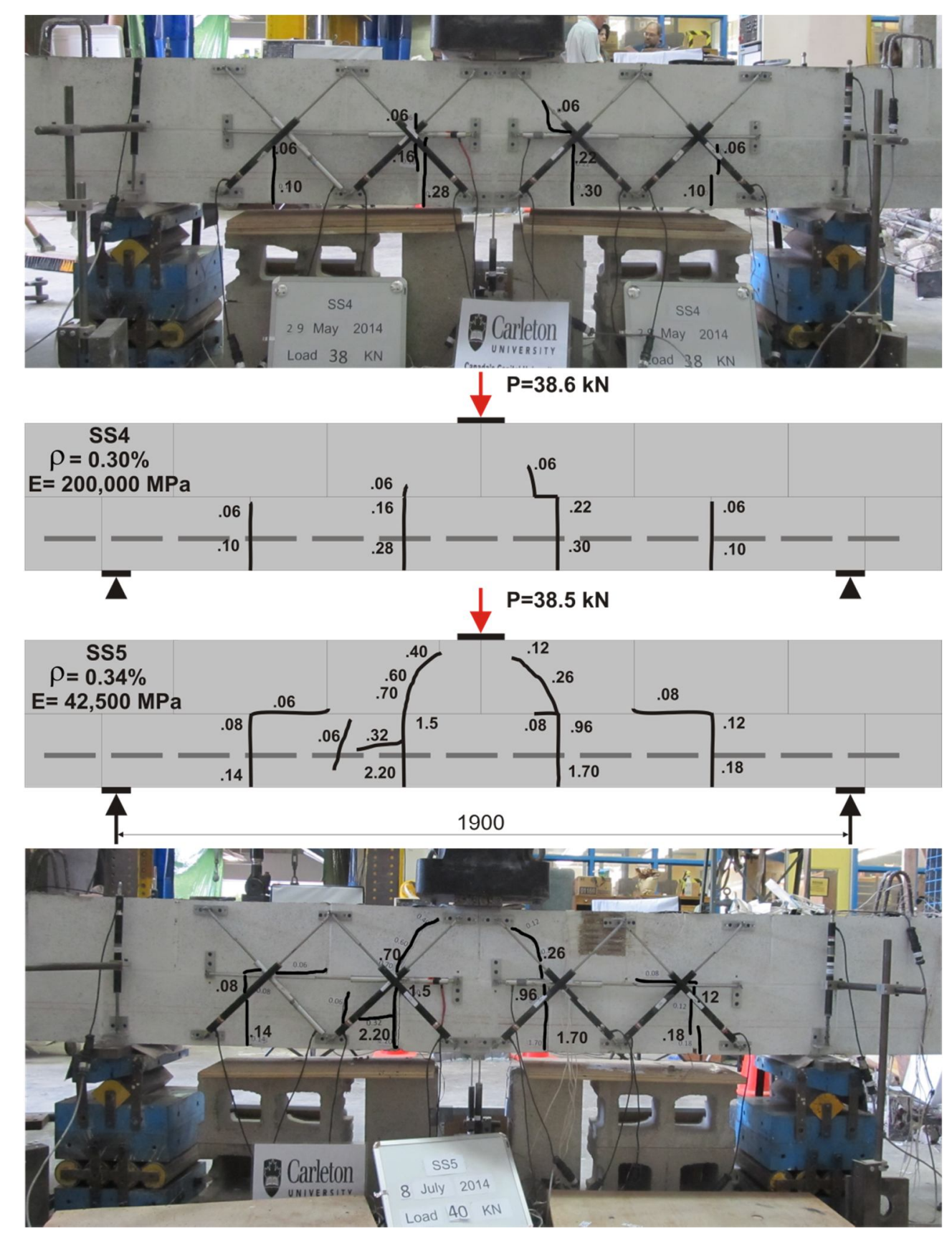

Figure 6-23: Crack Patterns of Specimens SS4 and SS5 at shear Stress of 0.34 MPa

It can be seen in Figure 6-24 that application of the load of $38.5 \mathrm{kN}$ caused a mid-span steel strain of $3608 \mu \varepsilon$ in SS5 versus only $1386 \mu \varepsilon$ in SS4. Given that both beams have similar reinforcement ratios, the wider cracks in SS5 appear to be primarily the result of using low- 
stiffness steel (GFRP) which resulted in reduced longitudinal stiffness to control crack widths. This increase in reinforcement strain in SS5 was associated with increased longitudinal strain at mid-depth of the beam (as shown in Figure 6-25) leading to wider cracks. This increased longitudinal strain was the result of wider cracks, given the similar crack spacings at mid-depth.

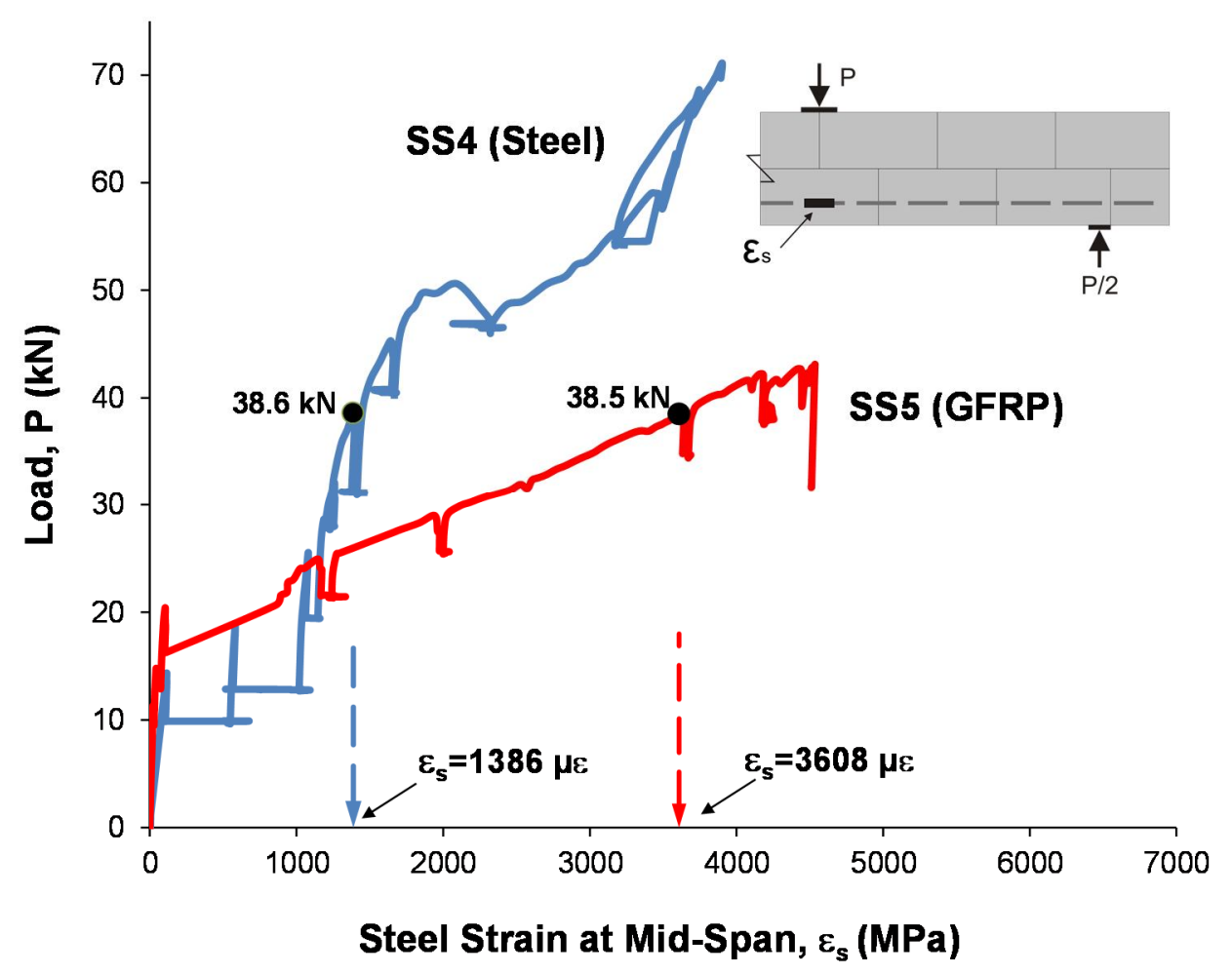

Figure 6-24: Mid-Span Steel Strains of Specimens SS4 and SS5

Image correlation analysis of the south faces of specimens SS4 and SS5 at this load stage shows that longitudinal strains, $\varepsilon_{\mathrm{x}}$, at mid-depth of SS5 were significantly higher than those of SS4 (see Figure 6-26). The averages of strain contours in the meshes located at mid-depth of the beams are $1508 \mu \varepsilon$ in specimen SS5 versus $300 \mu \varepsilon$ in specimen SS4. This confirms the trend observed in Figure 6-25. 


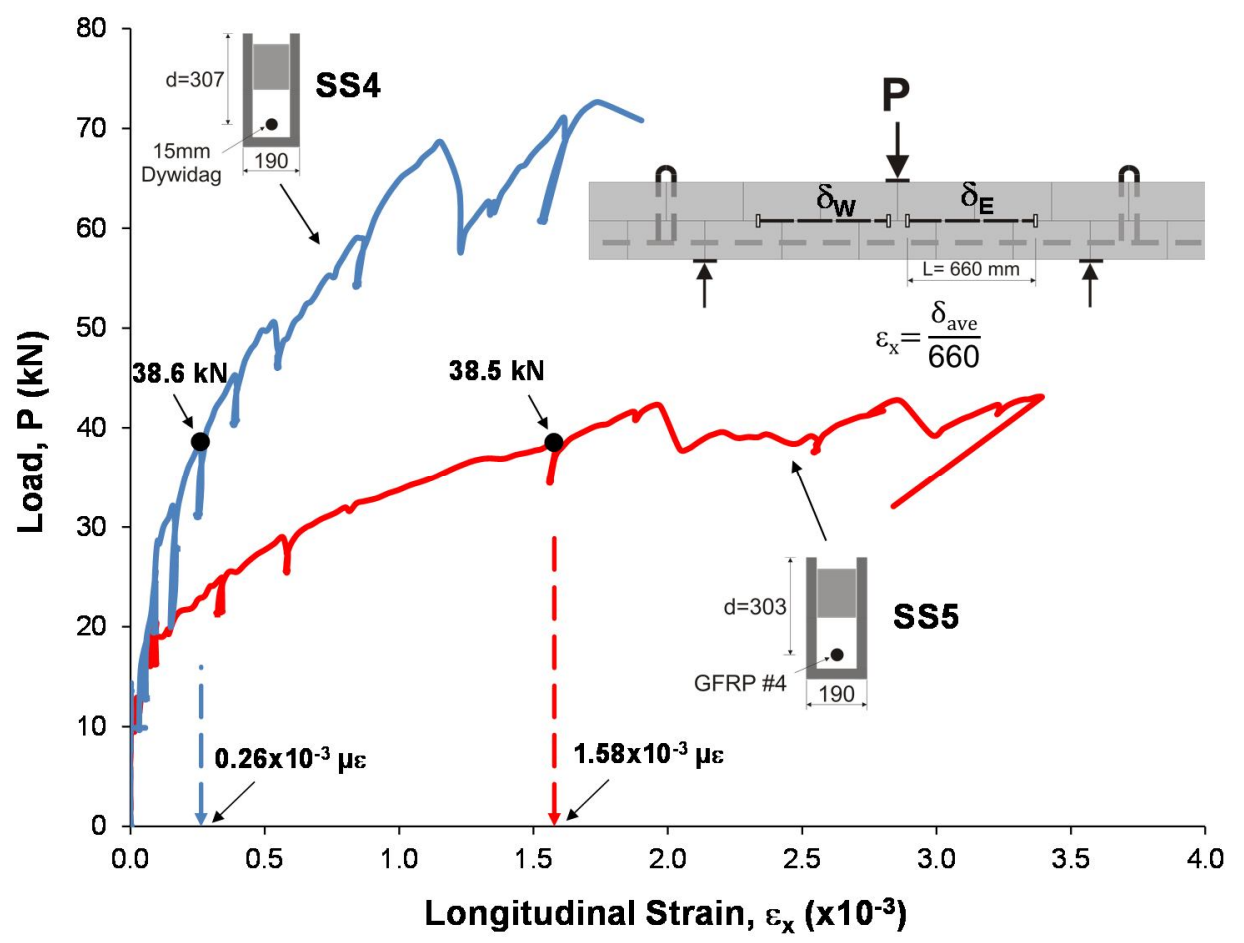

Figure 6-25: Longitudinal Strains at mid-depths of Specimens SS4 and SS5

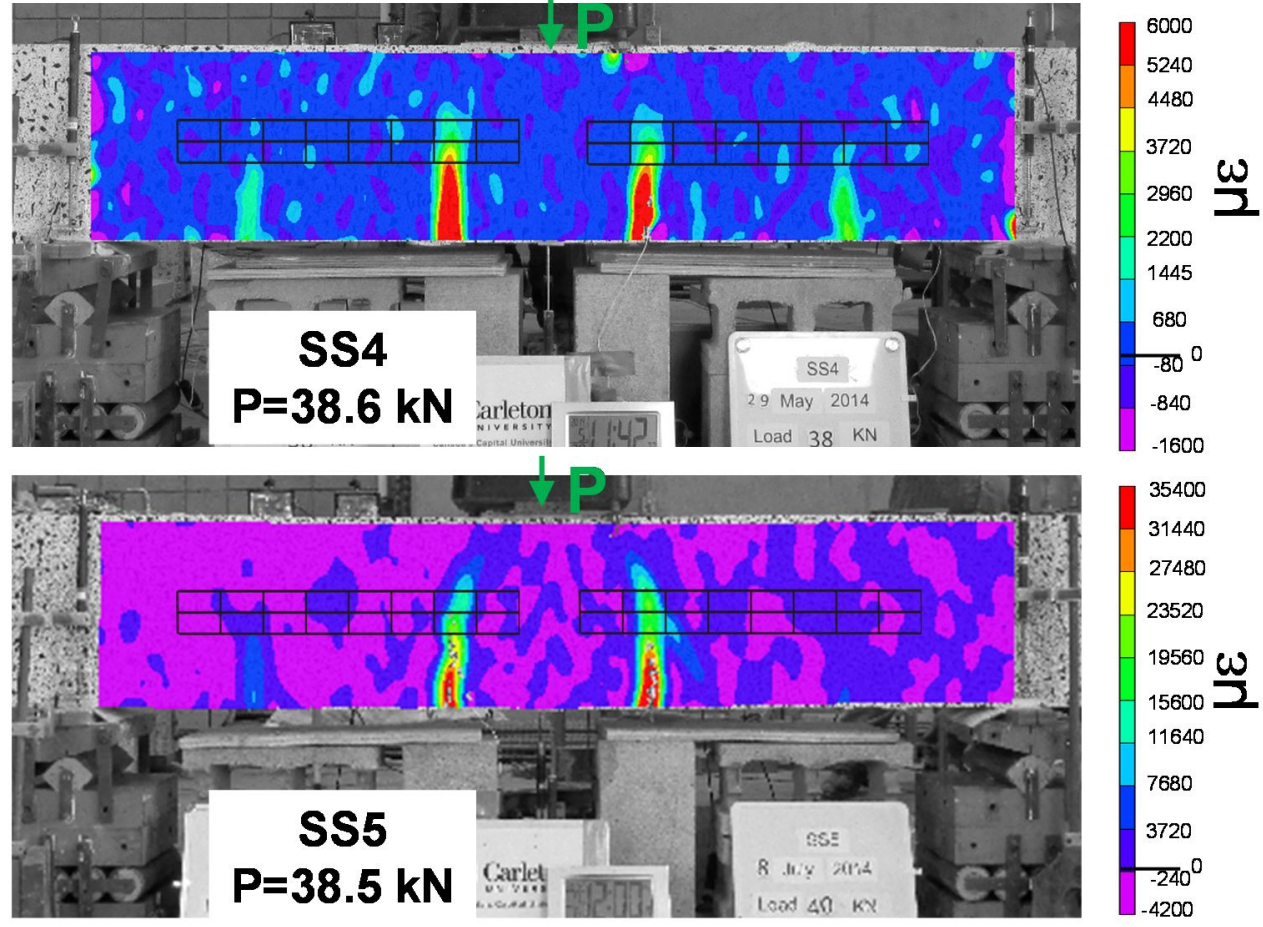

Figure 6-26: Longitudinal Strains $(\mu \varepsilon)$ in Specimens SS4 and SS5 using Image Correlation Analysis 
It can be seen in Figure 6-27 that the average and maximum crack widths at the reinforcement level, $0.75 \mathrm{~d}$ and $0.5 \mathrm{~d}$ in specimen SS5 are larger than those of SS4 at all shear stress levels.

These increases in cracks widths were caused by higher mid-depth strains, $\varepsilon_{\mathrm{x}}$, associated with reduced longitudinal stiffness. Increasing the widths of the cracks limited their ability to resist shear stresses through aggregate interlock capacity, causing SS5 to fail at load of $43.12 \mathrm{kN}$ which is equivalent to $60 \%$ of the failure load of specimen SS4 (see Figure 6-28).
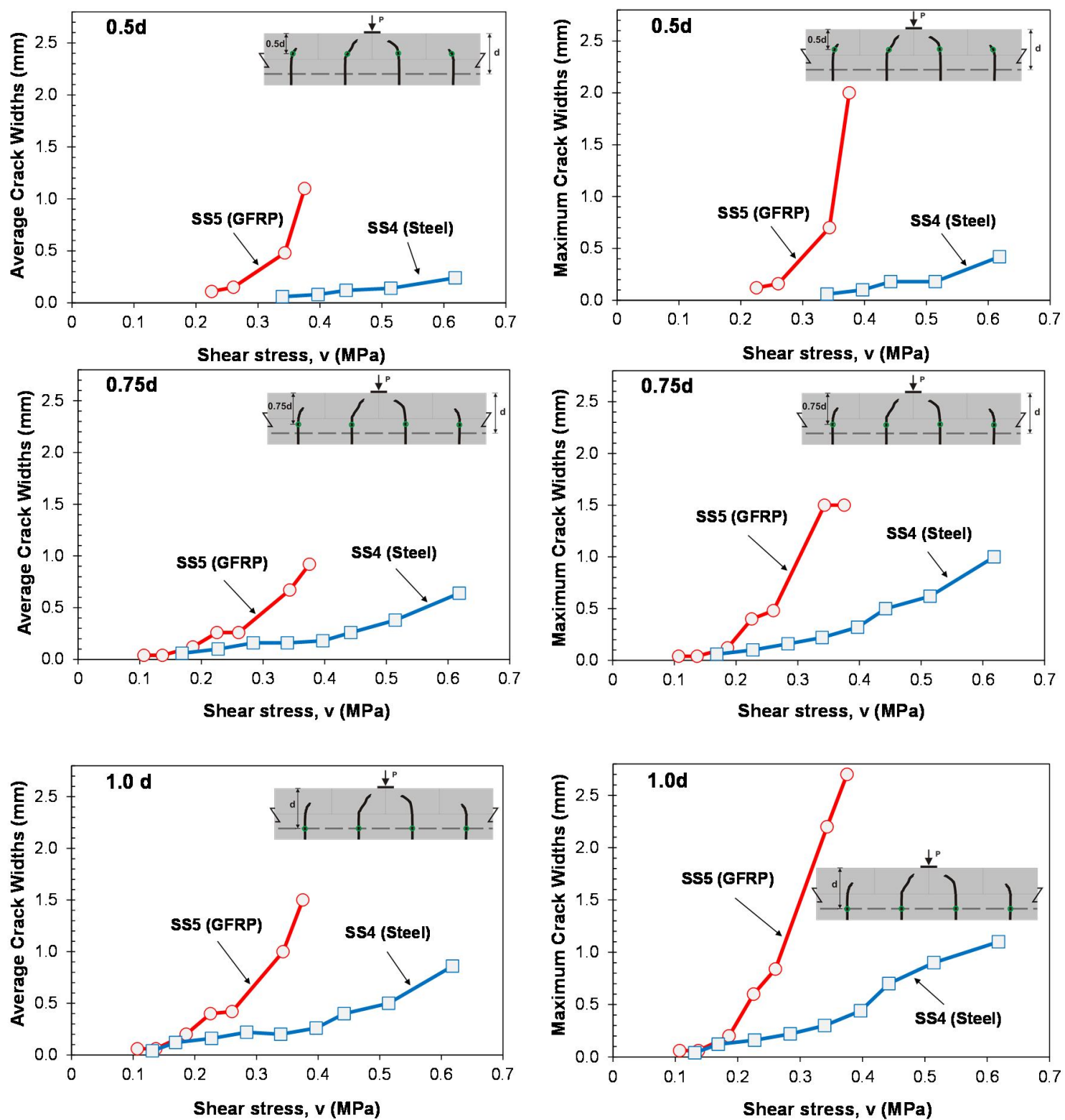

Figure 6-27: The Average and Maximum Crack Widths at Different Depths in SS4 and SS5 


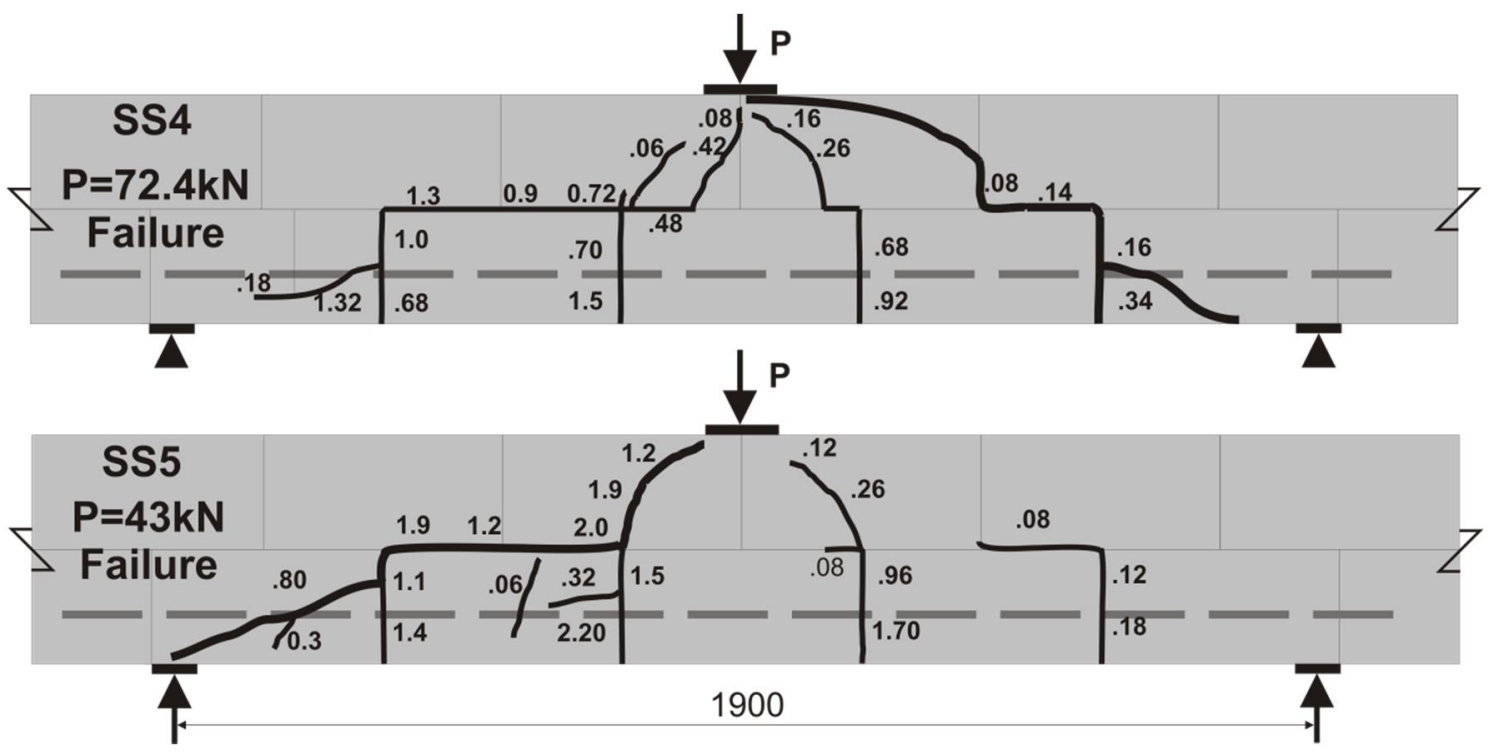

Figure 6-28: Failure Crack Patterns of Specimens SS4 and SS5 (Crack Widths Measured at Load Stage Prior to Failure)

\section{Repeated tests of SS4 and SS5}

In both beams the repeated failure shear stresses were higher than those of the first failed sides. Figure 6-29 shows that SS4R (reinforced with high strength steel) had higher cracking stiffness than that of SS5R (reinforced with GFRP rebars). No new major cracks developed in the repeated tests of both beams. It can be seen in Figure 6-30 that prior to failure, wider cracks were observed in SS5R than those in SS4R. These wide cracks caused SS5R to a fail at a load of 49.0 $\mathrm{kN}$ versus $74.8 \mathrm{kN}$ for SS4R. This can be related to the reduction in cracks ability to transfer shear stresses by aggregate interlock. 


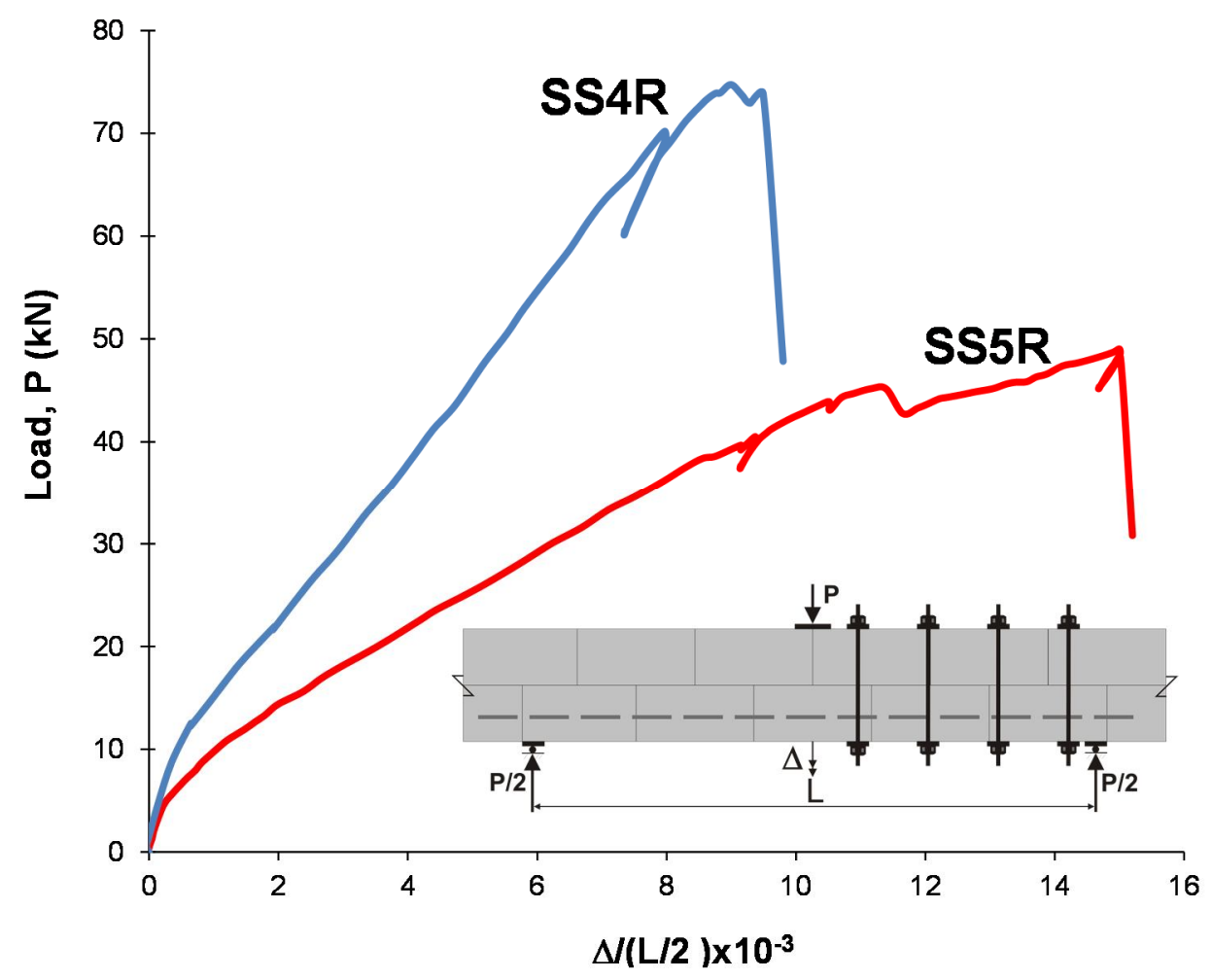

Figure 6-29: Load-Deflection Curves of Specimens SS4 and SS5
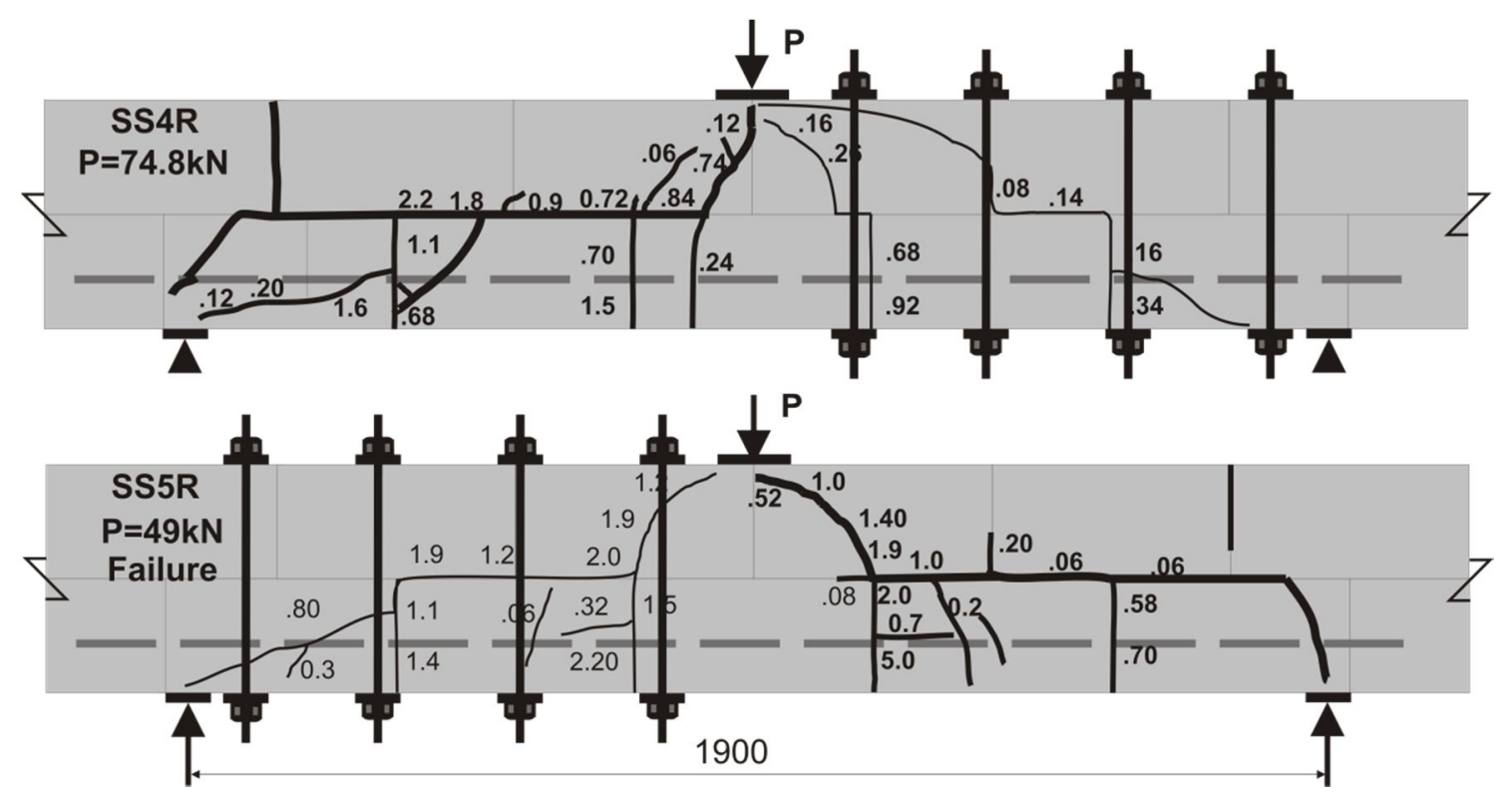

Figure 6-30: Crack Patterns of Specimens SS4R and SS5R prior to Failure 


\subsubsection{Specimens SM4 and SM5}

Specimens SM4 and SM5 are approximately identical $(d=880 \mathrm{~mm}$ and $\rho=0.32 \%)$ except for the type of reinforcement. Specimen SM4 was reinforced with a single \# 8 GFRP rebar $(E=51,900$ $\mathrm{MPa})$ while specimen SM5 was reinforced with a single $25 \mathrm{~mm}$ high-strength steel rebar $(\mathrm{E}=$ 200,000 MPa). The load deflection graph for these beams is shown in Figure 6-31. There were many similarities in relative behaviours of these specimens and specimens SS4 and SS5.

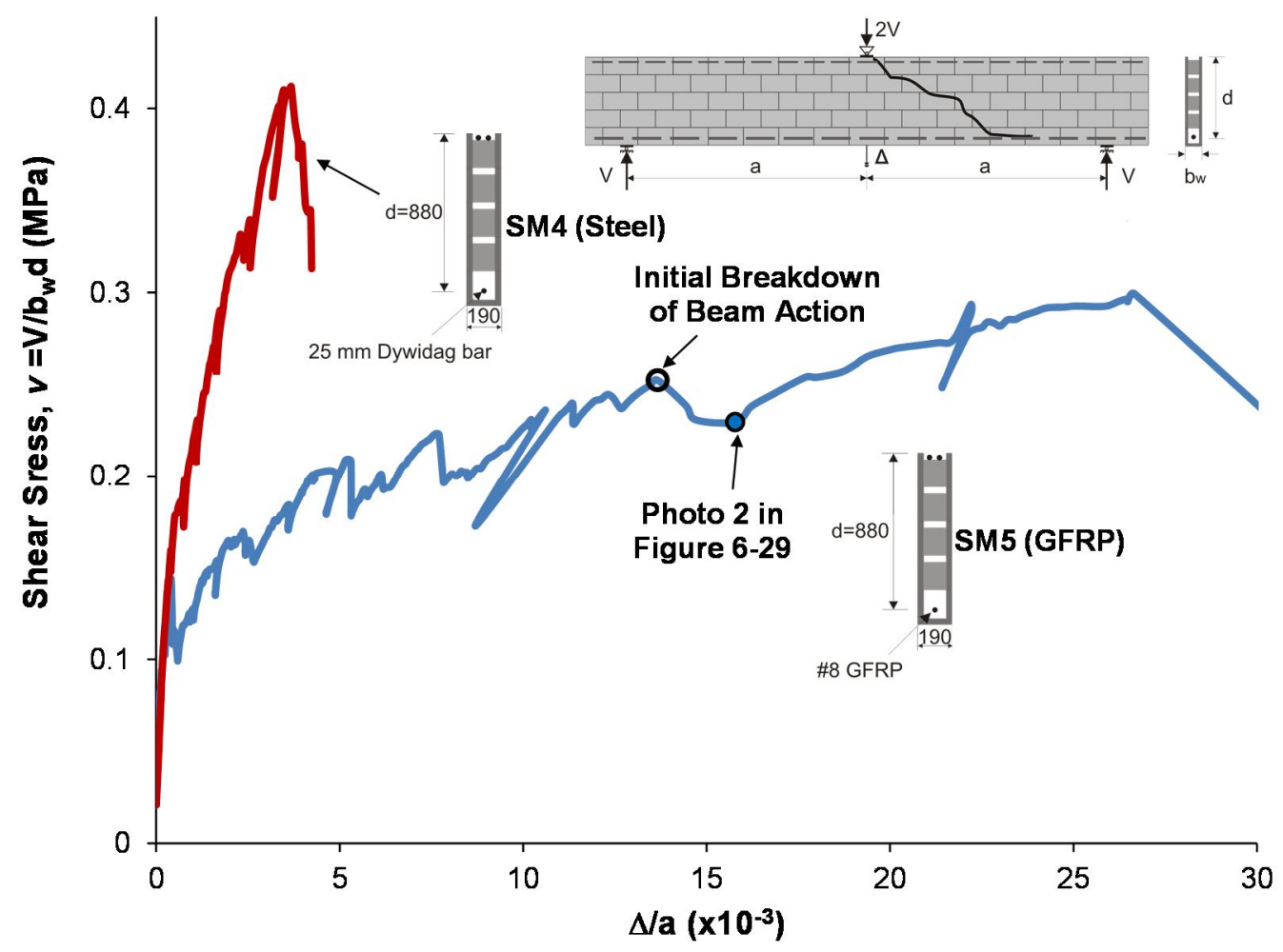

Figure 6-31: Load-Deflection Curves of Specimens SS4 and SS5

In Figure 6-31 it is clear that specimen SM4 (reinforced with high-strength steel) showed higher post-cracking stiffness than that of SM5 (reinforced with GFRP). Furthermore, the use of GFRP in SM5 resulted in a reduction of 30\% in shear strength compared to specimen SM4 reinforced with high-strength steel. Specimen SM4 failed in a brittle manner (at $(\Delta / \mathrm{L})$ of $1 / 270)$ due to breakdown in beam action through a major diagonal tension crack in the east end. The failure in 
specimen SM5, however, was characterized by a far more gradual mechanism. An initial breakdown of beam action at a load of $77 \mathrm{kN}$ (equivalent to $80 \%$ of the failure load) was followed by formation of shear keys between the two sides of the major diagonal crack in the east end of the beam. The failure progression failure of SM5 was videotaped and presented as snapshots in Figure 6-29. Photo 1 was taken before the initial breakdown of beam action at a load of $77 \mathrm{kN}$ while the rest of photos were taken afterwards. It can be seen in Figure that interlock between the two sides around the vertical part of the diagonal cracks (see area (a) in Figure 6-32) provided a substantial shear resistance mechanism. The gradual extension and widening of the crack along the lowest bed joint suggests that a shear resistance mechanism was also engaged along the bottom bed joint (see detail (b) in Figure 6-32). It can be noted in Figure 6-32 that the compression zone above the major diagonal crack was very thin(less than $20 \mathrm{~mm}$ ). As such the compression zone did not contributed much to resisting shear force across the section.. The possibility of arch action engagement after the initial breakdown of beam action was discussed in Figure 6-33. It can be noted in the figure that it is impossible to construct a strut that is not cut and disintegrated by the diagonal crack even if a compression depth of $0 \mathrm{~mm}$ is assumed. Figure 6-34 shows that the steel strain in the east support exhibited a considerable increase after the initial breakdown of the beam action. However, the steel strain at the support was less than $50 \%$ of that at mid-span indicating that strut and tie action was slightly engaged. Finally, Figure 6-35 shows that the majority of shear resistance occurred by the shear key formed at the vertical part of the diagonal crack. Despite the engagement of shear key mechanism, SM5 failed at significantly lower load compared to that of Specimen SM4. 

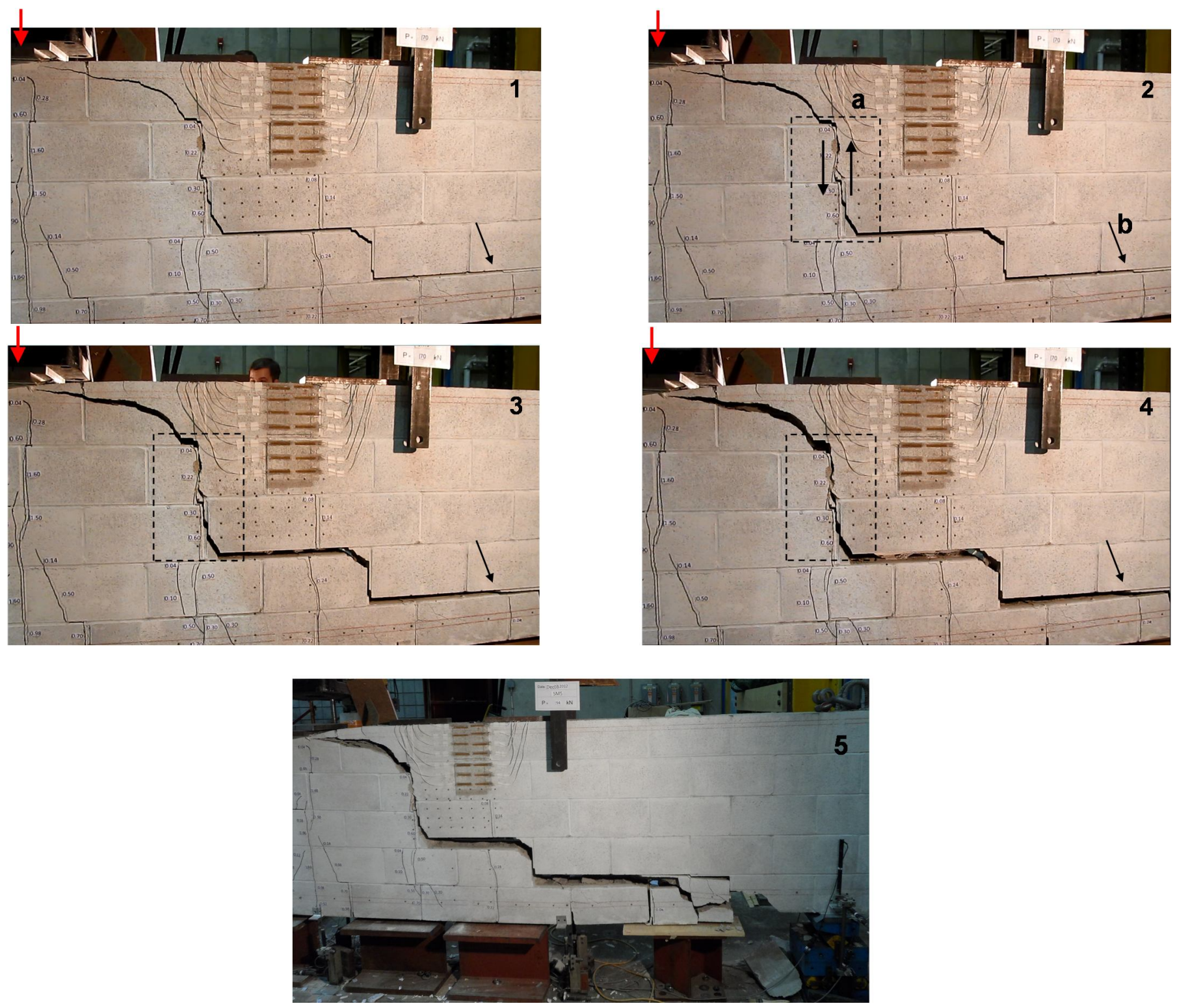

Figure 6-32: The Failure Progression of Specimen SM5 


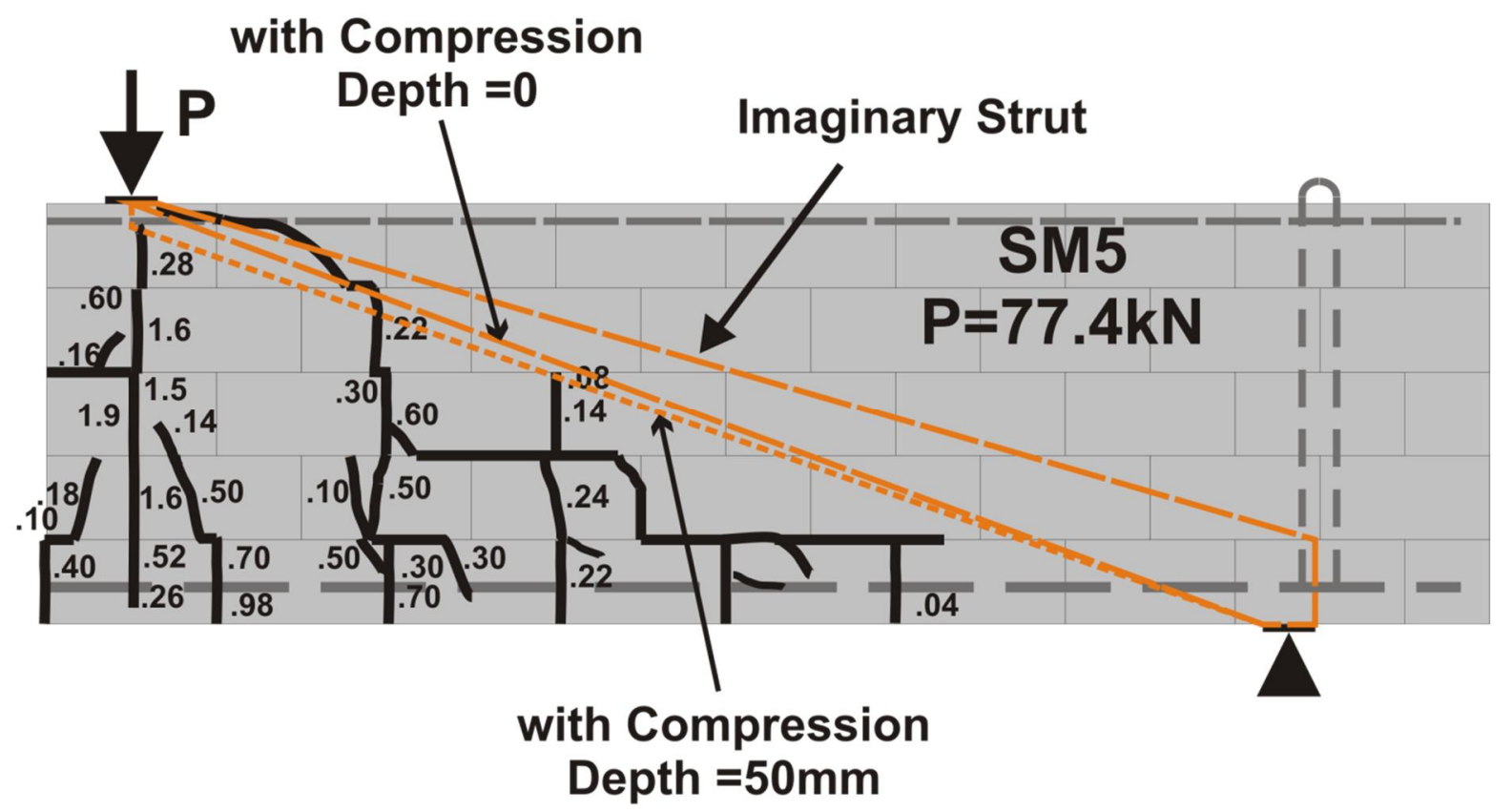

Figure 6-33: The Inspection of Possible Arch Action Engagement in Specimen SM5

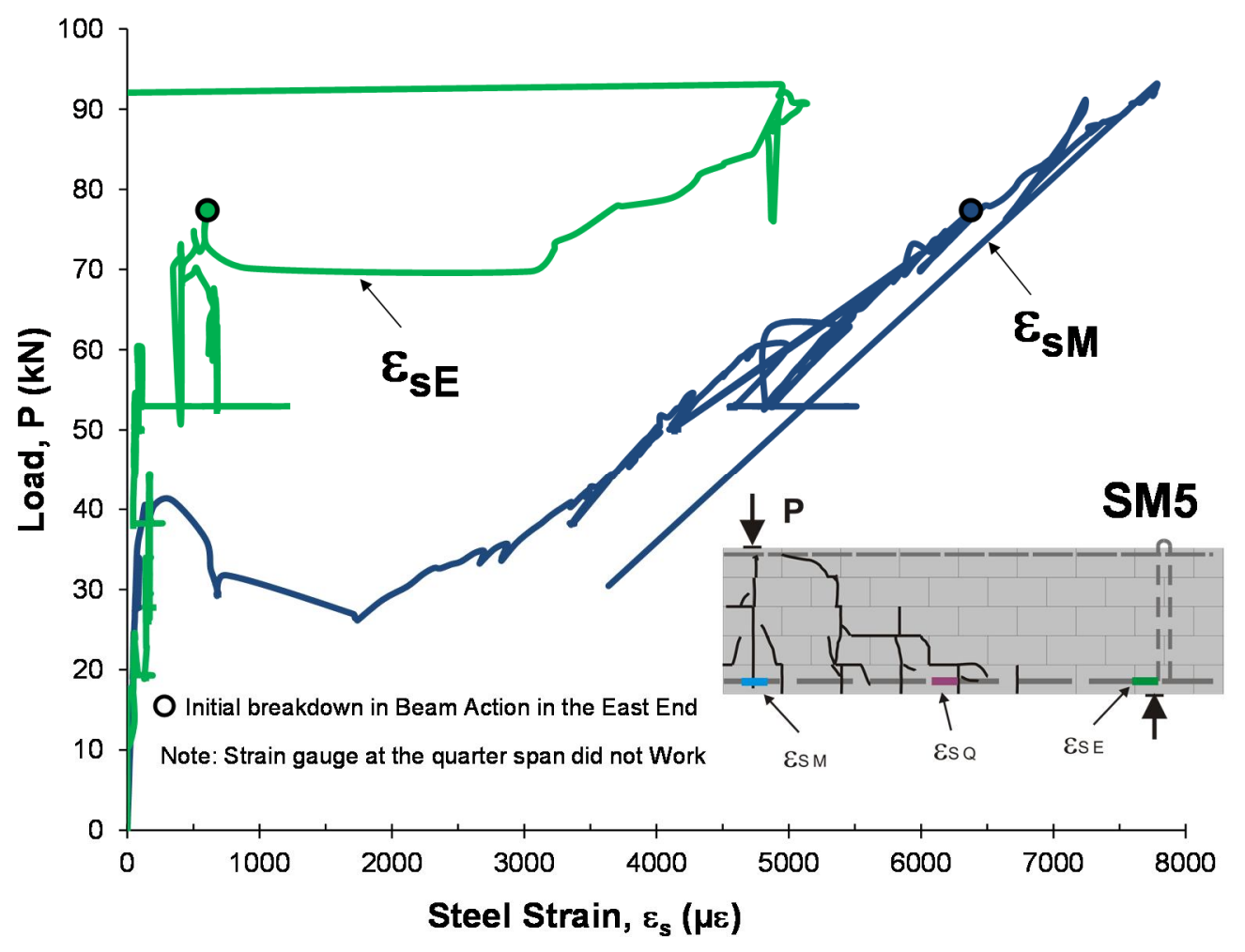

Figure 6-34: Steel Strains in the East Side of Specimen SM5 


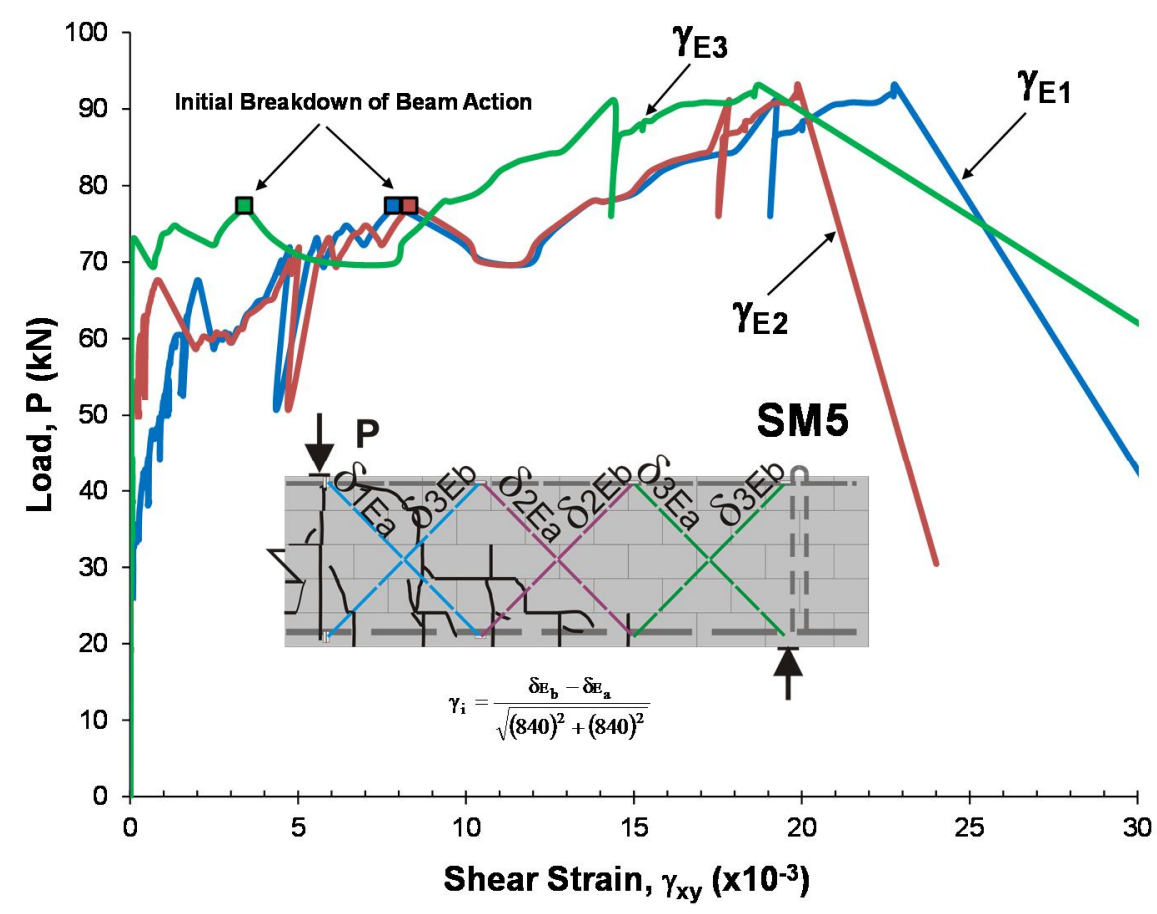

Figure 6-35: Shear Strain in the East Side of Specimen SM5

To investigate as to why the breakdown of beam action occurred at a lower load in SM5 than that in SM4, consider Figure 6-36 which shows crack patterns of both specimens at an applied of $60 \mathrm{kN}$. It is clear that this load caused the formation of major flexural cracking under the point load and three wide flexural-shear cracks in SM5 (two in the east end and one in the west end). All these cracks extended beyond the mid-depth of the beam with the crack in the east end inclined to the centre of the beam in a jagged manner through the bed and head joints. On the contrary, only minor cracking was visible in SM4, whereby cracks extended to the second lowest bed joint at this load. This can be attributed to the fact the use of low stiffness reinforcement in SM5 resulted in increasing the in the mid-depth causing numerous wider cracks. Figure 637shows that the longitudinal strain in SM5 was six times that in SM4 at this load stage. The widening of cracks reduces their ability to resist shear stresses through aggregate interlock. This can explain why the failure of SM5 was initiated by breakdown of beam action at lower load 
than that of SM5. The failure crack patterns of specimens SM4 and SM5 are presented in Figure 6-38. It can be seen in the figure that both beams experienced a tooth failure type. It is also that the maximum crack width prior to failure in SM5 was as twice as large as that in SM4.

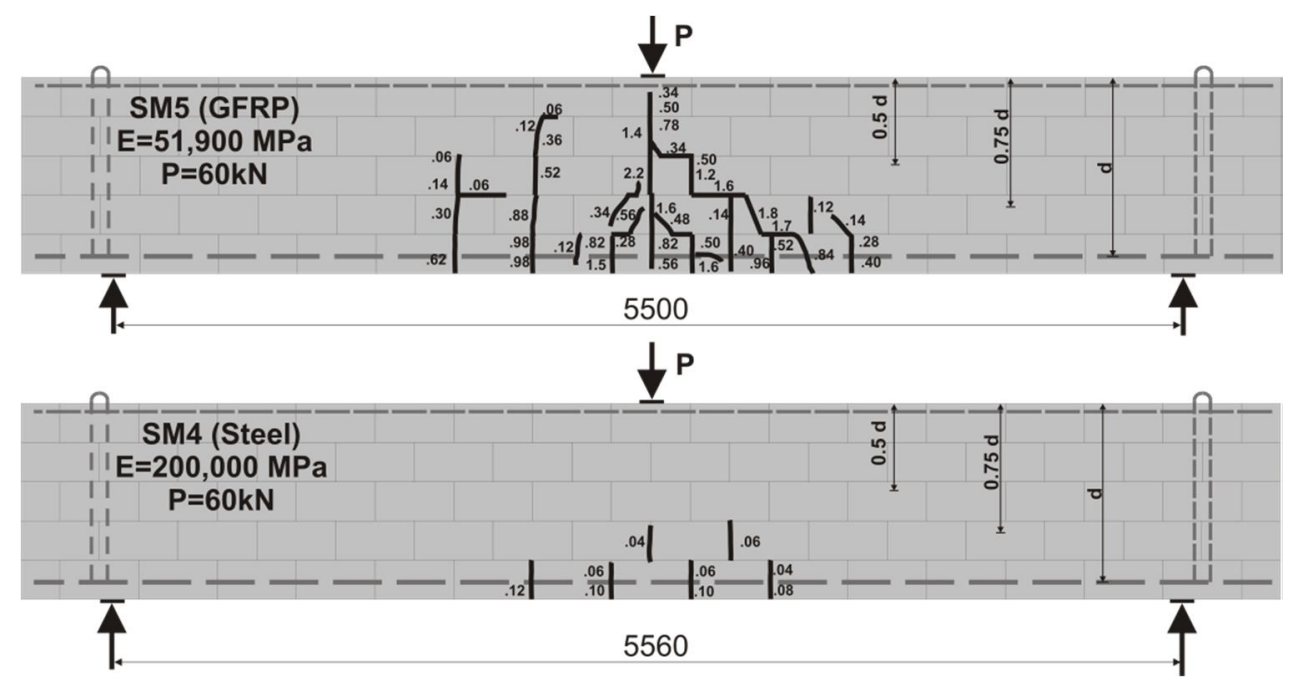

Figure 6-36: Crack Patterns of Specimens SM4 and SM5 at an Applied of 60kN

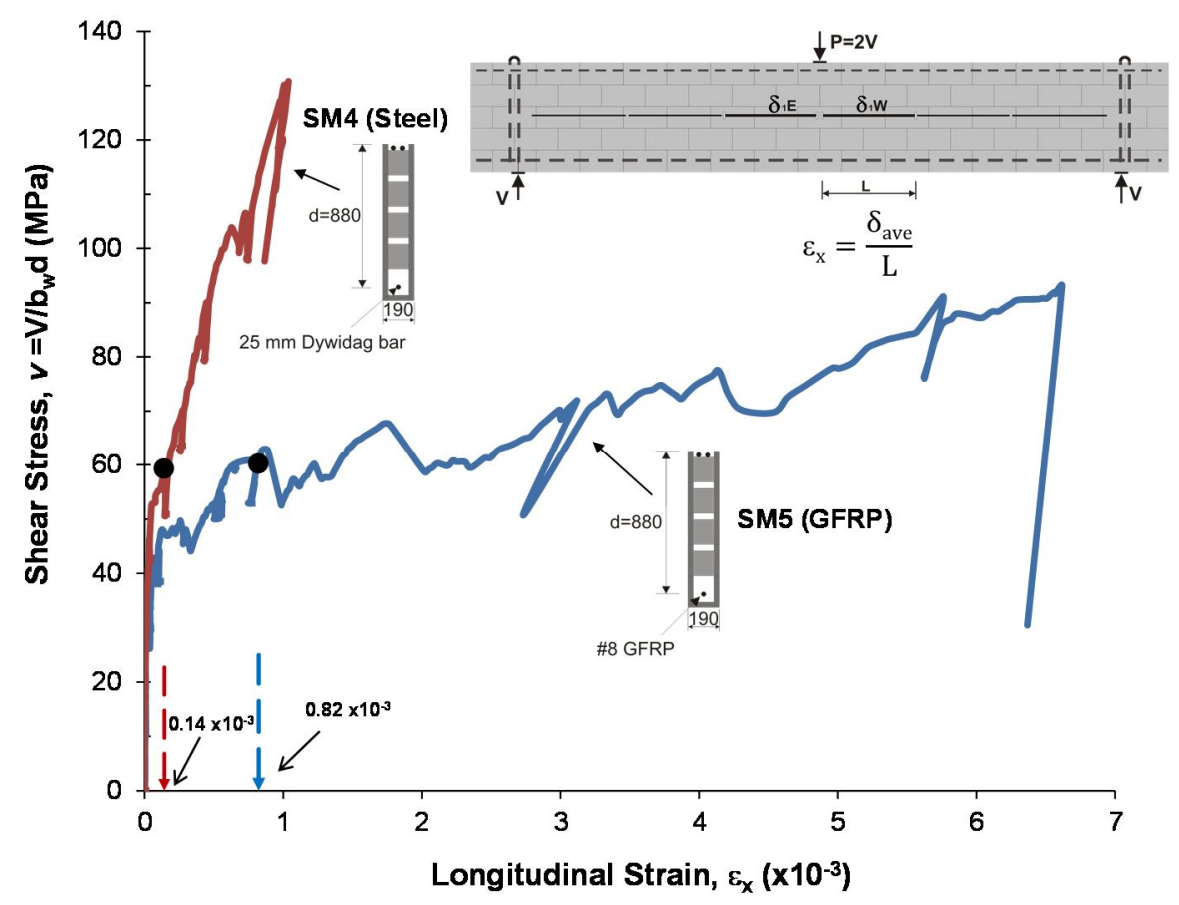

Figure 6-37: Longitudinal Strains, $\varepsilon_{\mathrm{x}}$, in specimens SM4 and SM5 


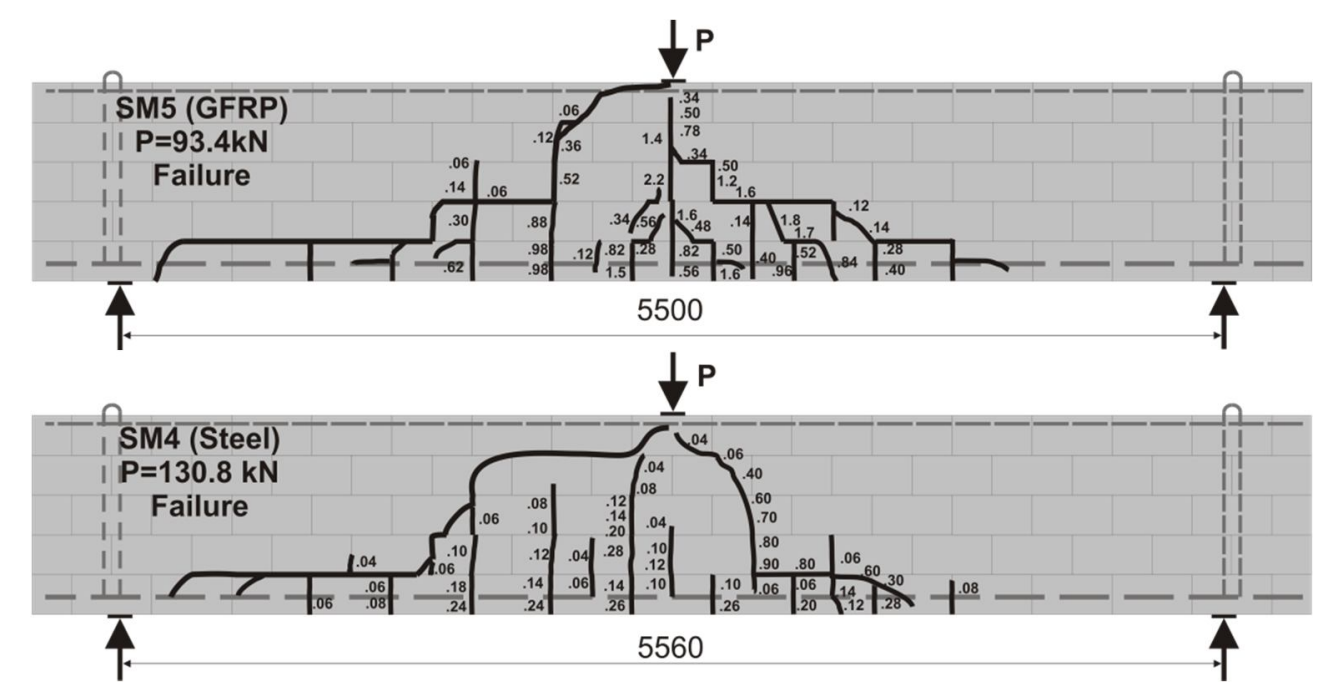

Figure 6-38: Failure Crack Patterns of Specimens SM4 and SM5 (Crack Widths Measured at Load Stage Prior to Failure)

\section{Codes Predictions}

The normalized failure shear stresses of specimens SS4, SS5, SM4 and SM5 are plotted versus the reinforcement stiffness (E) in Figure 6-39 along with the predictions of the codes considered in this thesis. It can be seen that the masonry design codes (TMS402 and CSA S304.1) are not sensitive to the change in the reinforcement type. The CSA A23.3 and Hoult et al. methods, on the other hand, were able to safely and accurately capture the variations in the shear strength of RM beams with different reinforcement types with the Hoult et al. method giving more accurate predictions since it was derived specifically to deal with high strains, which is the case for RMB reinforced with FRP rods. The CSA A23.3 code is the only design code that accounts for the stiffness of the main reinforcement. The results of this section highlight the necessity to revise masonry design codes to address the strain effect on shear strength. The general method of shear design for reinforced concrete can serve as a basis for this revision. 


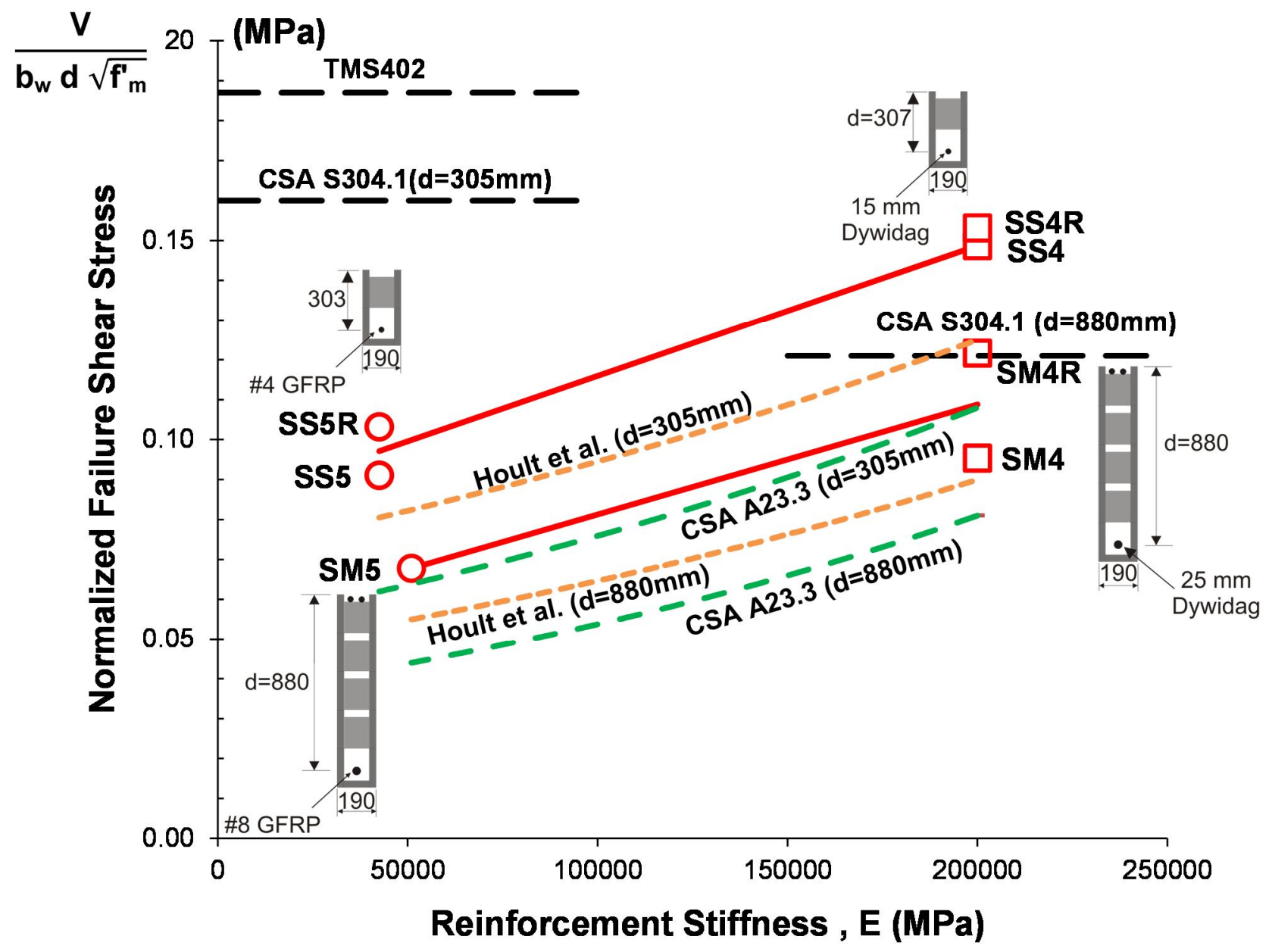

Figure 6-39: Failure Shear Stresses of RMB with Different Reinforcement Types

\subsection{The Strain Effect Term}

To further show the applicability of the strain effect principle in reinforced masonry, Figure 6-40 was constructed to show $\varepsilon_{\mathrm{x}}$ (calculated at $\mathrm{d}$ from point load) for the specimens tested in this investigation along with the experimentally measured values. In this experimental study, a wide range of $\varepsilon_{\mathrm{x}}$ values was investigated by varying $\rho$ and steel type. Two series are highlighted in 
Figure 6-40, a series of identical beams with different $\rho$ and a series of identical beams with different reinforcement (GFRP versus steel).

Figure 6-39 shows that the CSA A23.3 strain effect term can accurately and safely model the shear strength of reinforced masonry sections over a wide range of $\rho$ and for different types of steels. For example, it is clear in Figure 6-39 that CSA A23.3 was able to model the reduction in failure shear stresses due to decreasing the main reinforcement ratio from $2.4 \%$ to $0.30 \%$ (in the small size series). This modelling was done by accounting for $\varepsilon_{\mathrm{x}}$ which increased with the decrease of $\rho$ resulting in wider cracks. The widening of cracks reduces their ability to transfer shear stresses through aggregate interlock. Similarly, CSA A23.3 code was sensitive to the reduction in shear strength due to the change in the reinforcement type (GFRP versus steel). The accuracy of the general method in accounting for the strain effect in reinforced masonry suggests the opportunity to revise masonry design codes to be able to account for this effect. The results of this investigation agree with Banting and El-Dakhakhni (2012) in recognizing strain effect in reinforced masonry walls. 


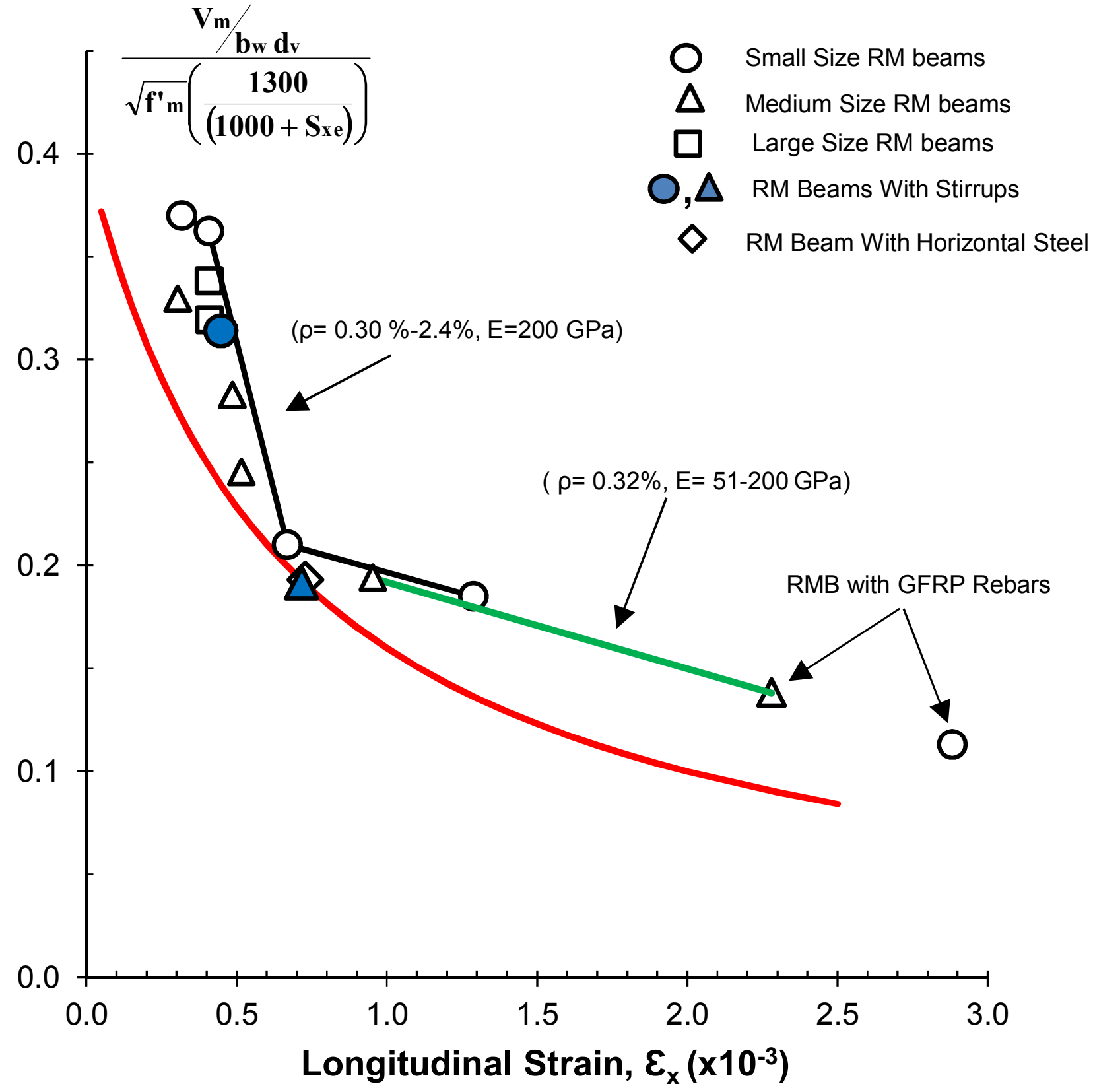

Figure 6-40: The CSA 2004 Strain Effect Term 


\subsection{Additional Topics}

\subsubsection{The Effect of Crack Control Reinforcement on Flexural Cracks}

The effect of the skin reinforcement on flexural crack widths in reinforced masonry will be studied in this section. Five 20M steel rebars (one in each course from the third to seventh courses) were added to the middle $1600 \mathrm{~mm}$ of the south face in specimens SL1. These rebars were put on the webs of the blocks with clear cover of $60 \mathrm{~mm}$. The crack widths in the middle $1600 \mathrm{~mm}$ of specimen were measured at various stages using a crack comparator gauge with a precision of $0.05 \mathrm{~mm}$. These cracks were compared with those in Specimen SL2 which was identical to SL1 but without skin reinforcement in the mid-span region. In this comparison only cracks located inside the mid-span region were considered.

Figure 6-41 shows the crack patterns on the south faces of specimens SL1 and SL2. Four cracks formed in the mid-span region of Specimen SL1 and extended upward beyond mid-depth level versus only a single crack in Specimen SL2. It is also noted that Specimen SL2, without skin reinforcement, exhibited wider flexural cracks than Specimen SL1 (reinforced with skin reinforcement). Maximum crack widths at $0.5 \mathrm{~d}$ and $0.75 \mathrm{~d}$ levels on the south faces of the specimens SL1 and SL2 are presented in Figure 6-42 for mid-span steel stresses ranging between 112-224 MPa. These stresses are equivalent $28-56 \%$ of the specified yield stress (400 MPa), and thus represent a possible service load stresses. The steel stresses $\left(f_{s}\right)$ were calculated based the simple formula of $\left(f_{s}=\frac{\text { Mmidspan }}{j d \text { As }}\right)$ with $j$ set at 0.88 . 


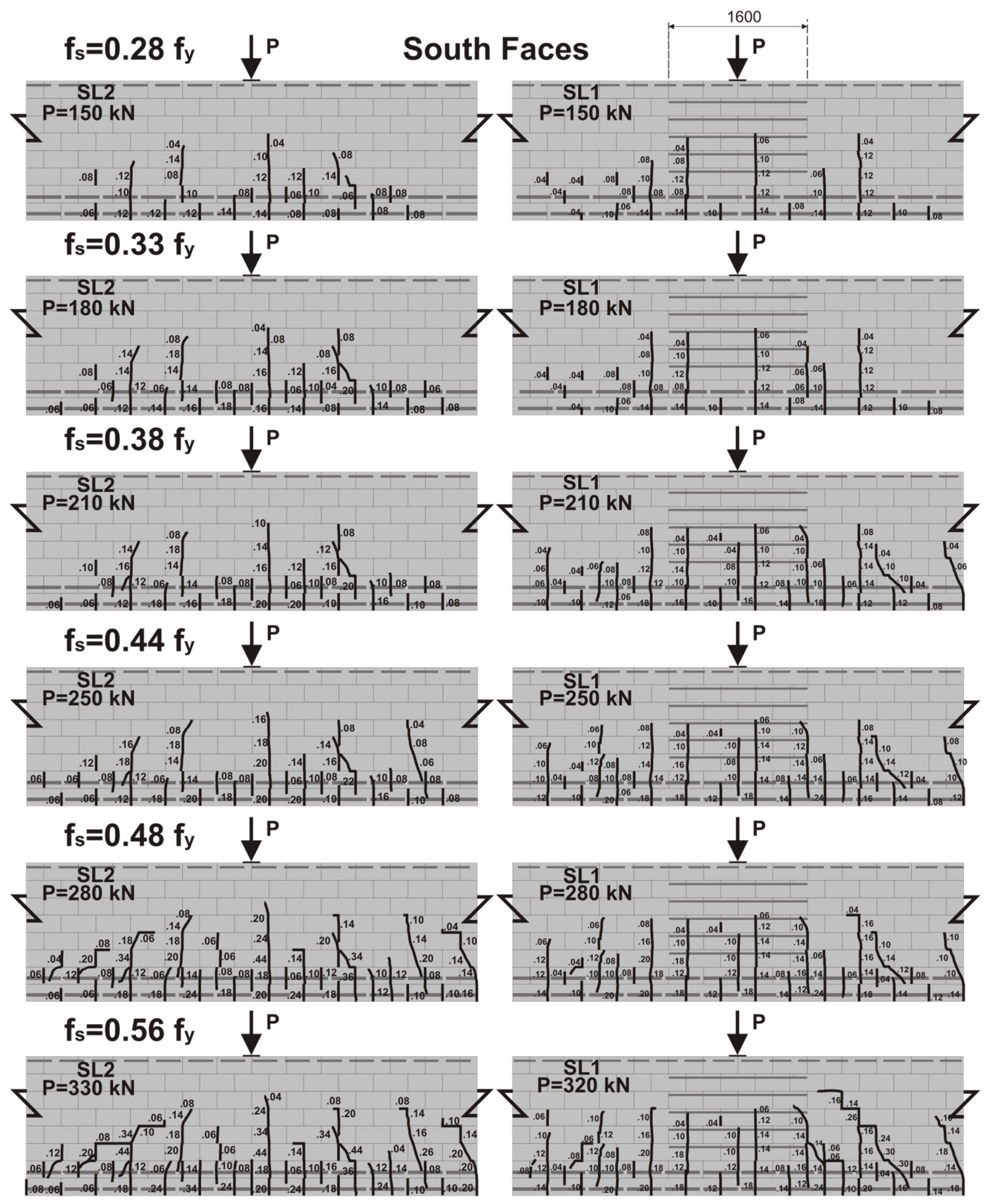

Figure 6-41: Crack Patterns on the South Faces of Specimen SL1 and SL2 

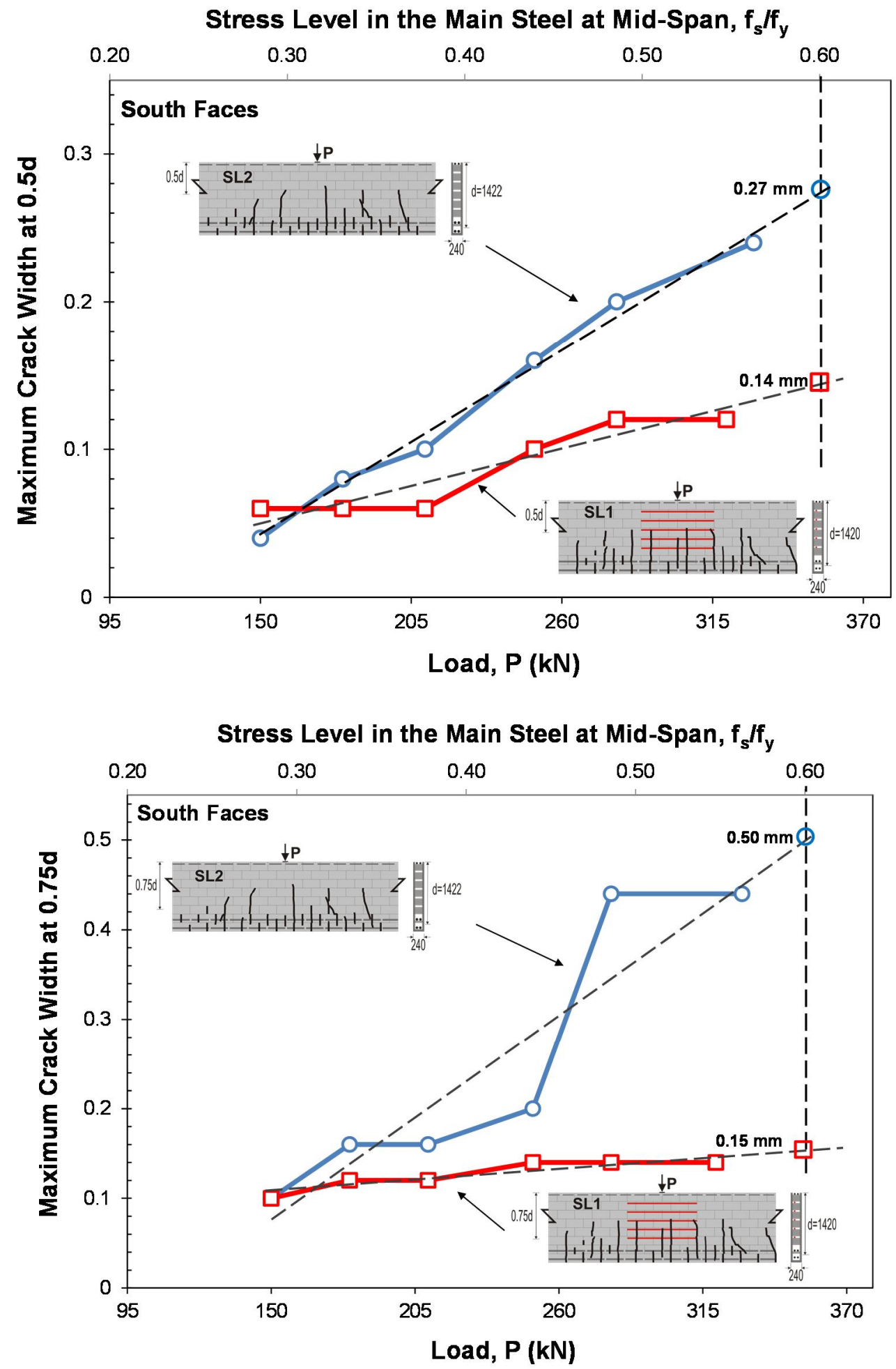

Figure 6-42: Maximum Crack Widths on the South Faces of Specimen SL1 and SL2 
Since specimens SL1 and SL2 failed at loads below those corresponding to a steel stress of maximum service load $\left(0.6 f_{y}\right)$, it is necessary to estimate the crack widths at the maximum service load $\mathrm{f}_{\mathrm{s}}=0.6 \mathrm{fy}$ (CSA S304.1). The estimated crack widths in SL2 at the $0.5 \mathrm{~d}$ and $0.75 \mathrm{~d}$ levels at steel stress of $0.6 \mathrm{f}_{\mathrm{y}}$ would be about $0.27 \mathrm{~mm}$ and $0.50 \mathrm{~mm}$. The addition of crack control reinforcement in the mid-span region in SL1 led to considerable reduction in the maximum cracks widths on the south face. At a steel stress of $0.6 f_{y}$ the estimated crack widths at the $0.5 \mathrm{~d}$ and $0.75 \mathrm{~d}$ levels are only $0.14 \mathrm{~mm}$ and $0.15 \mathrm{~mm}$. These are equivalent to reductions of $48-70 \%$. Thus, it is necessary that members of this depth are provided with additional reinforcement to control crack widths at service loads.

Although the crack control reinforcement was provided only in the south face of SL1, it was decided to investigate if it has any positive effect of reducing the crack widths on the north face. It is clear in Figure 6-43 that the existence of crack control reinforcement in the mid-span region in SL1 resulted in narrower cracks than those in SL2 (without crack control). At a steel stress of $0.6 \mathrm{f}_{\mathrm{y}}$, the maximum crack widths at the $0.5 \mathrm{~d}$ and $0.75 \mathrm{~d}$ levels were only $0.12 \mathrm{~mm}$ and $0.18 \mathrm{~mm}$ in north face of SL1 versus $0.39 \mathrm{~mm}$ and $0.49 \mathrm{~mm}$ in SL2, representing a decrease in maximum crack width of about $65-70 \%$ versus no skin reinforcement (see Figure 6-44). This clearly shows the effectiveness of crack control reinforcement in reducing the flexural crack widths. 


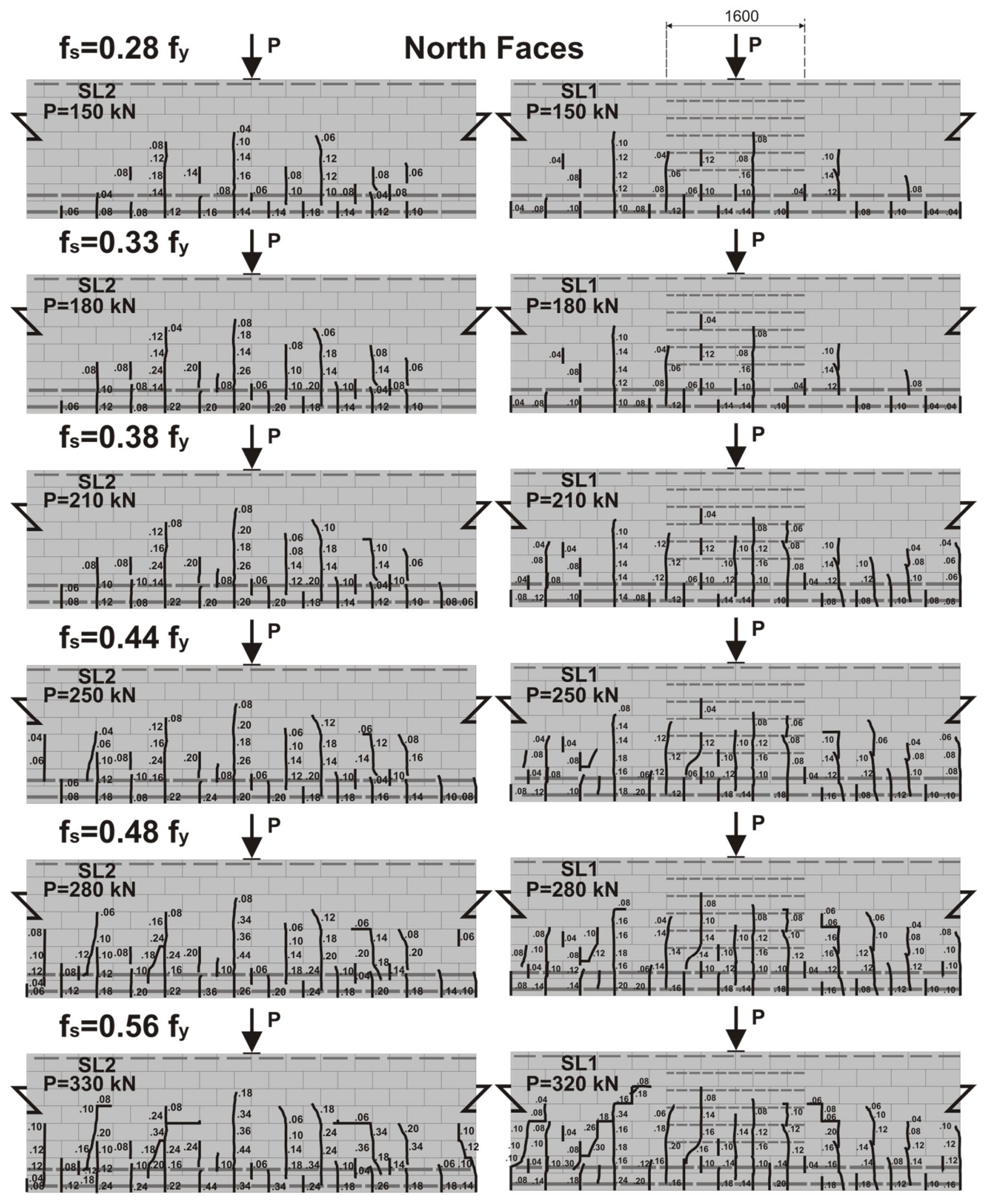

Figure 6-43: Crack Patterns on the North Faces of Specimen SL1 and SL2 

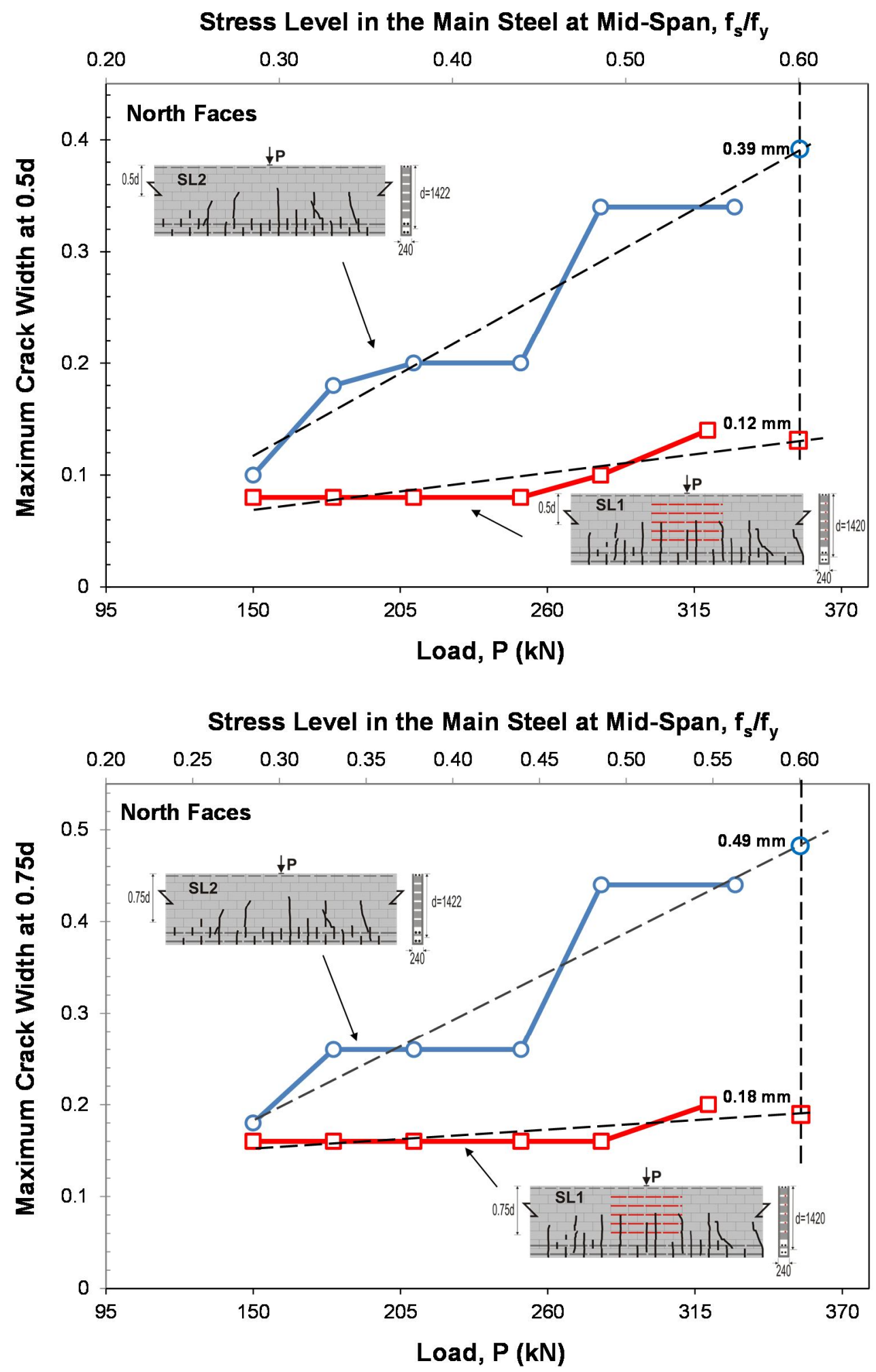

Figure 6-44: Maximum Crack Widths on the North Faces of Specimen SL1 and SL2 


\subsubsection{Accuracy of Image Correlation Analysis in Reinforced Masonry}

One of the objectives of this research program is to study the cracking behaviour of reinforced masonry using Digital Image Correlation (DIC). The DIC process was conducted on the south faces of the small size beam series. For each beam, a photo was taken at zero load and successive ones were taken at load stages as the load increased. The data acquisition takes readings at every 10 seconds while the cameras record the time of taking the photos in minutes. To avoid any lag, a digital clock was installed beside the beams; and the time of the clock was set to match time of the data acquisition. Hundreds of photos were taken and an extensive analysis was conducted using VIC-2D. However, only select examples are presented in this dissertation due to size limitations. In these examples the DIC analysis was used to: compare the horizontal displacements and shear strains of RM beams with and without stirrups (Figures 5-30) and compare the longitudinal strain contours for RM beams with different reinforcement ratios or reinforcement types (Figures 6-6 and 6-26). These examples showed that digital image correlation offers valuable information that allows for improved understanding of shear behaviour of reinforced masonry.

Many investigations (Citto et al. (2011), Ghiassi et al. (2013), Guerrero et al. (2013) and Salmanpour and Mojsilović (2013)) have been conducted on the use of DIC technique to understand the behavior of reinforced concrete. In all these investigations the outcomes of DIC analysis were not compared to experimentally measured strains and displacements. In the current investigation, side mounted LVDTs on the North faces of beams were used to measure the longitudinal strains at mid depth and the shear strains in the shear spans. Also, LVDTs were used underneath the beams to measure vertical displacement. The accuracy of the DIC analysis 
can thus be examined by direct comparison of the maximum vertical displacements measured by DIC and that measured by the LVDT instrumented at the south center of the beams. In Figure 645 , these maximums displacements were plotted for specimen SS5 at different load stages. It is clear that the differences between the two methods are marginal and can possibly be attributed to the vibration of the camera.

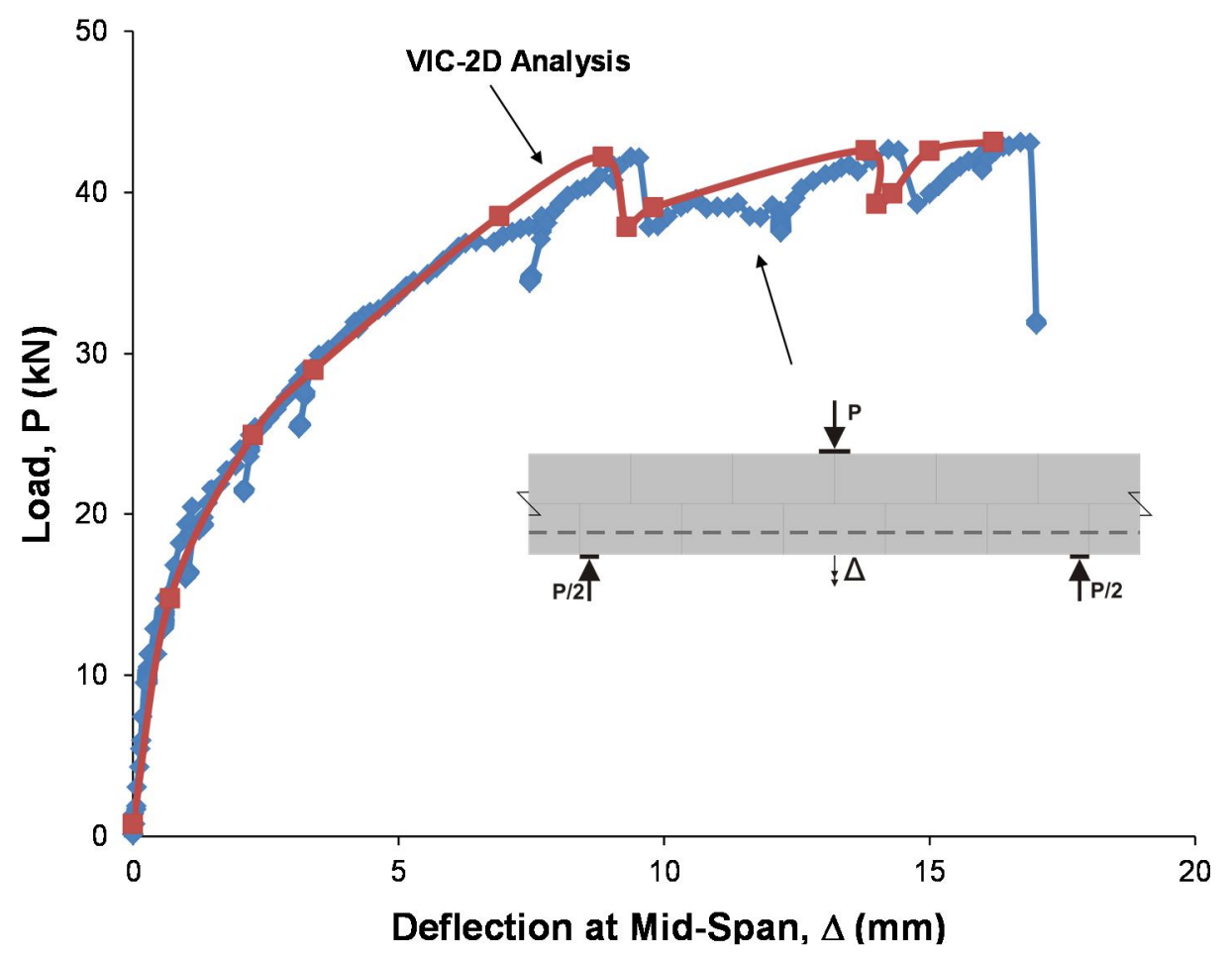

Figure 6-45: Load- Deflection Curve of Specimen SS5

The contours of vertical displacements in specimen SS5 at different load stages are shown in Figure 6-46. It can be seen that at every load stage the contour of vertical deflection is reasonable; it is symmetric, very small deflections were measured at the supports; larger downward deflections were measured at mid-span. 

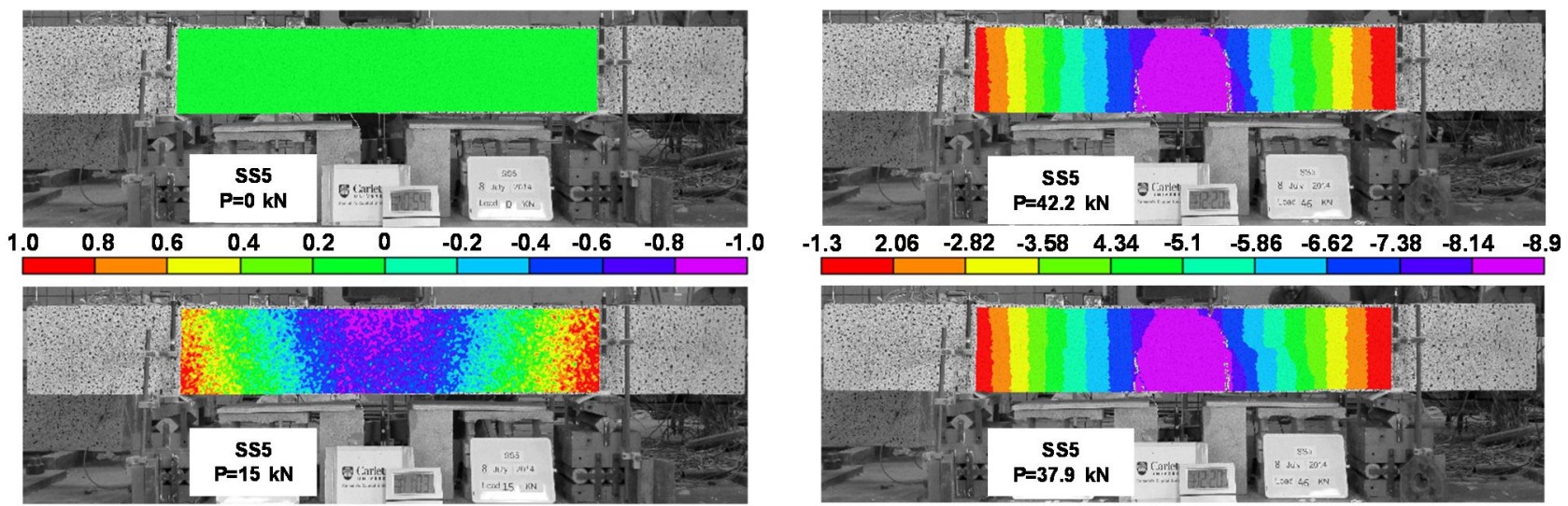

$\begin{array}{lllllllllll}-0.34 & -0.40 & -0.44 & -0.49 & -0.54 & -0.59 & -0.63 & -0.68 & -0.73 & -0.78 & -0.83\end{array}$

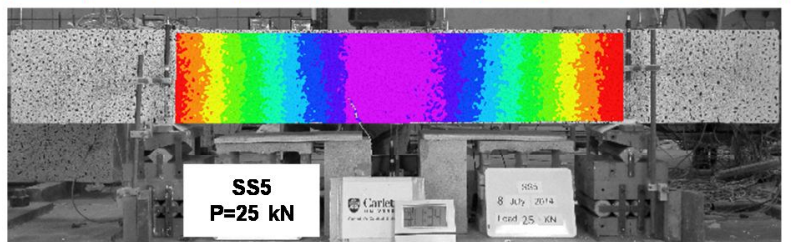

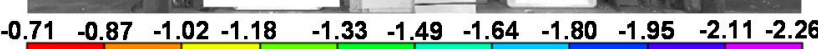
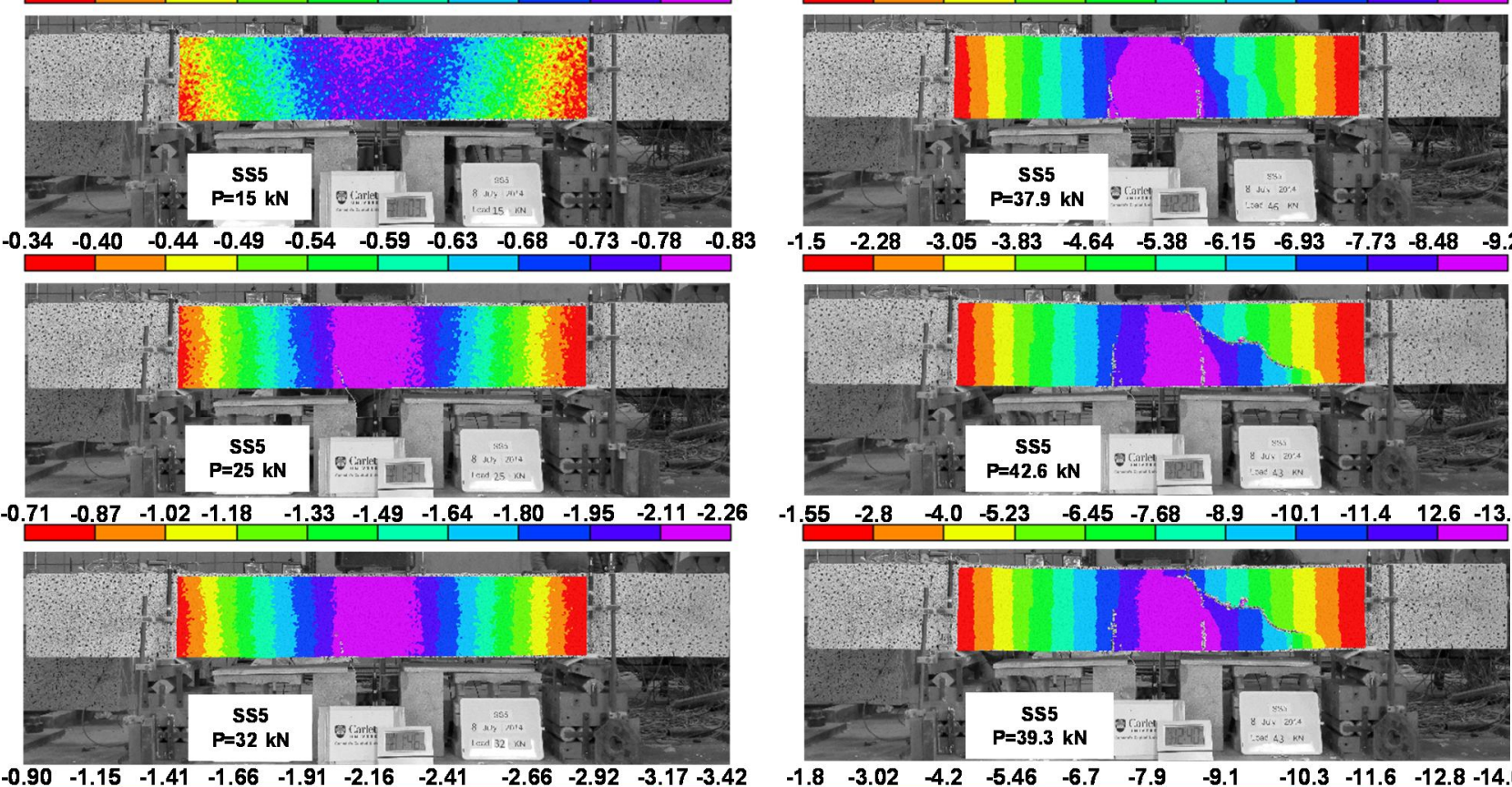

$\begin{array}{llllllllllll}-1.5 & -2.28 & -3.05 & -3.83 & -4.64 & -5.38 & -6.15 & -6.93 & -7.73 & -8.48 & -9.25\end{array}$

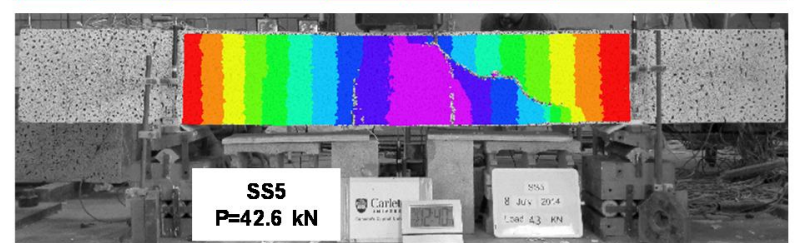

$\begin{array}{lllllllllll}-1.55 & -2.8 & -4.0 & -5.23 & -6.45 & -7.68 & -8.9 & -10.1 & -11.4 & 12.6 & -13.8\end{array}$
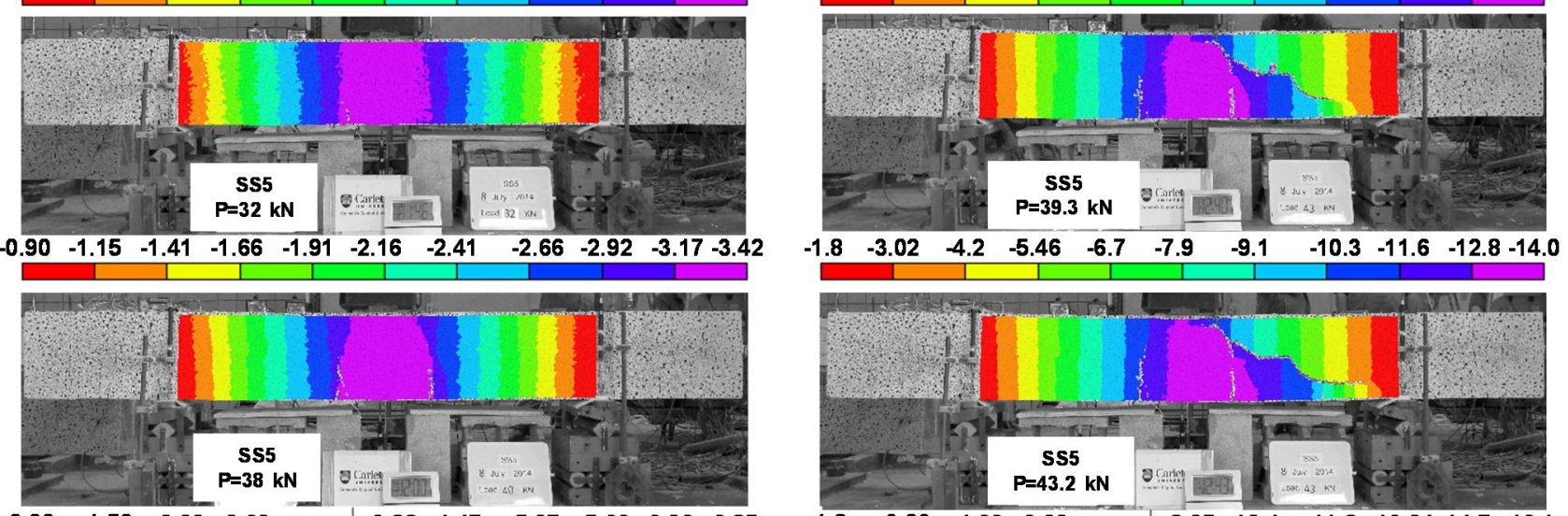

\begin{tabular}{lllll|llllll}
-0.90 & -1.50 & -2.09 & -2.69 & -3.28 & -3.88 & -4.47 & -5.07 & -5.66 & -6.26 & -6.85
\end{tabular}

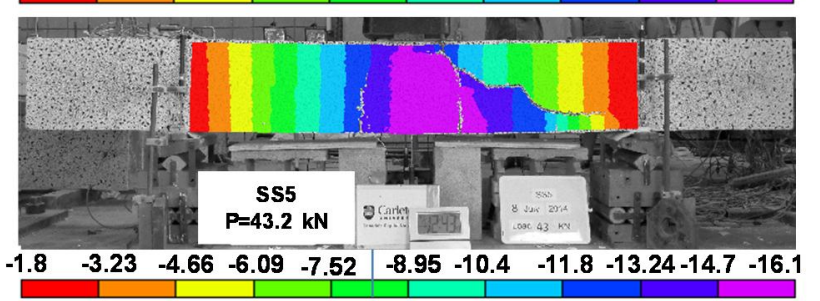

Figure 6-46: Vertical Displacement Contours of Specimens SS5 at Various Load Stages 


\subsection{Concluding Remarks}

The experiments described in this chapter have shown the existence and significance of the strain effect in reinforced masonry. It was also shown that the concept of strain effect from reinforced concrete research applies to reinforced masonry. In this effect the shear strength is related to the ability of cracks to transfer shear stresses through aggregate interlock. The crack widths are controlled by the longitudinal strain at mid-depth, $\varepsilon_{x}$, of the section. Any actions that serve to increase $\varepsilon_{\mathrm{x}}$ will increase the width of cracks which in turn will decrease the failure stress by decreasing the aggregate interlock capacity.

The test results showed that the reinforcement ratio has a significant effect on the shear strength of RM beams. Increasing $\rho$ resulted in enhancing the shear strength due to the increased aggregate interlock capacity. Analysis of crack patterns demonstrated the crack widths decreased significantly as $\rho$ increased permitting higher shear stresses to be transferred through aggregate interlock. Even in the beams where breakdown of aggregate interlock was followed by formation of shear keys, it was observed that beams with high $\rho$ had higher shear strength than those with low $\rho$. It was also shown in this chapter that RM beams reinforced with GFRP failed significantly lower shear stresses than the equivalent beams reinforced with steel. This was due

to the increase in crack widths with the decrease in the stiffness (E) of the reinforcement which led to limiting the ability of cracks to transfer shear stresses through aggregate interlock. 
It is shown that the TMS 402 and CSA S304.1 codes produce predicted failure shear stresses that do not match the experimental behaviour of the RM beams tested in this investigation. It was shown that BS 5628 and AS 3700 produced inconsistent predictions for the range of the main variables considered in this investigation. The CSA A23.3 code and the Hoult et al., on the other hand, were able to safely and accurately predict the variation in failure shear stress for RM beams with different $\rho$ or E very well. 


\section{CHAPTER 7: PREDICTION OF COMPRESSIVE STRENGTH OF HOLLOW CONCRETE BLOCK MASONRY}

\subsection{General}

The purpose of this part of the thesis is to assemble an experimental database of compressive tests of ungrouted and grouted hollow concrete block masonry prisms to develop accurate empirical formulae to predict the masonry compressive strength $\left(\mathrm{f}_{\mathrm{m}}\right)$. This chapter of the thesis presents the development of simple, accurate formulae to predict $\mathrm{f}^{\prime}{ }_{\mathrm{m}}$ for ungrouted and grouted hollow concrete block masonry. A large database of compressive test results on masonry prisms reported in the literature was assembled for this purpose. The database was analyzed to determine the main factors that affect the compressive strength of masonry prisms and regression analyses were conducted to predict the formulae. The predictive capabilities of the proposed formulae were compared to those of five major international masonry design codes. The five masonry codes considered include: AS 3700-2001 (Australia), BS 5628-2005 (UK), CSA S304.1-04 (Canada), Eurocode 6 (European Commission), and the TMS 402-11 (US).

\subsection{Background}

The masonry compressive strength $\left(\mathrm{f}_{\mathrm{m}}\right)$ is one of the most important characteristic that governs the structural performance of concrete masonry structures. However, determining $\mathrm{f}_{\mathrm{m}}$ is not an easy task due to the complex and highly non-uniform nature of masonry construction. Masonry design codes generally suggest two methods to determine the compressive strength of masonry. One method is to test small masonry assemblages built with site representative materials, usually 2 to 5 units in height (either prisms or wallets), as shown in Figure 7-1. The measured 
compressive strengths from these tests are then correlated to the strength of the masonry structure by factors that account for the height to thickness ratio of the tested samples. This method has certain practical limitations in terms of cost, time and the complexities of transporting samples to testing facilities. Furthermore, the capacity and size of available testing machines can cause additional constraints.

The second method, known as the unit strength method, involves testing individual samples of masonry units and mortar. In this approach, the compressive strength of masonry is estimated from tabulated values based on block strength and mortar type. The tables in various codes have been developed through empirical relationships between $\mathrm{f}^{\prime} \mathrm{m}$ and the unit compressive strength and the mortar strength or type. Generally, however, the data used to develop these tables have been limited, and have not been based on a full dataset of all available compressive tests. Table 2 of TMS402-2011 for example, was developed based on test results of only 51 average data points of ungrouted prisms and 11 average data points of grouted prisms. Furthermore, it is widely acknowledged that tabulated values of $\mathrm{f}_{\mathrm{m}}{ }_{\mathrm{m}}$ in design codes are conservative (Drysdale and Hamid (20050, Korany and Glanville (2005), and Gaynor and Korany (2011)). As more test results become available, it is worthwhile to re-evaluate the tabulated values of $\mathrm{f}_{\mathrm{m}}$ with a goal of increasing both the predictive ability and reliability of these tables. 

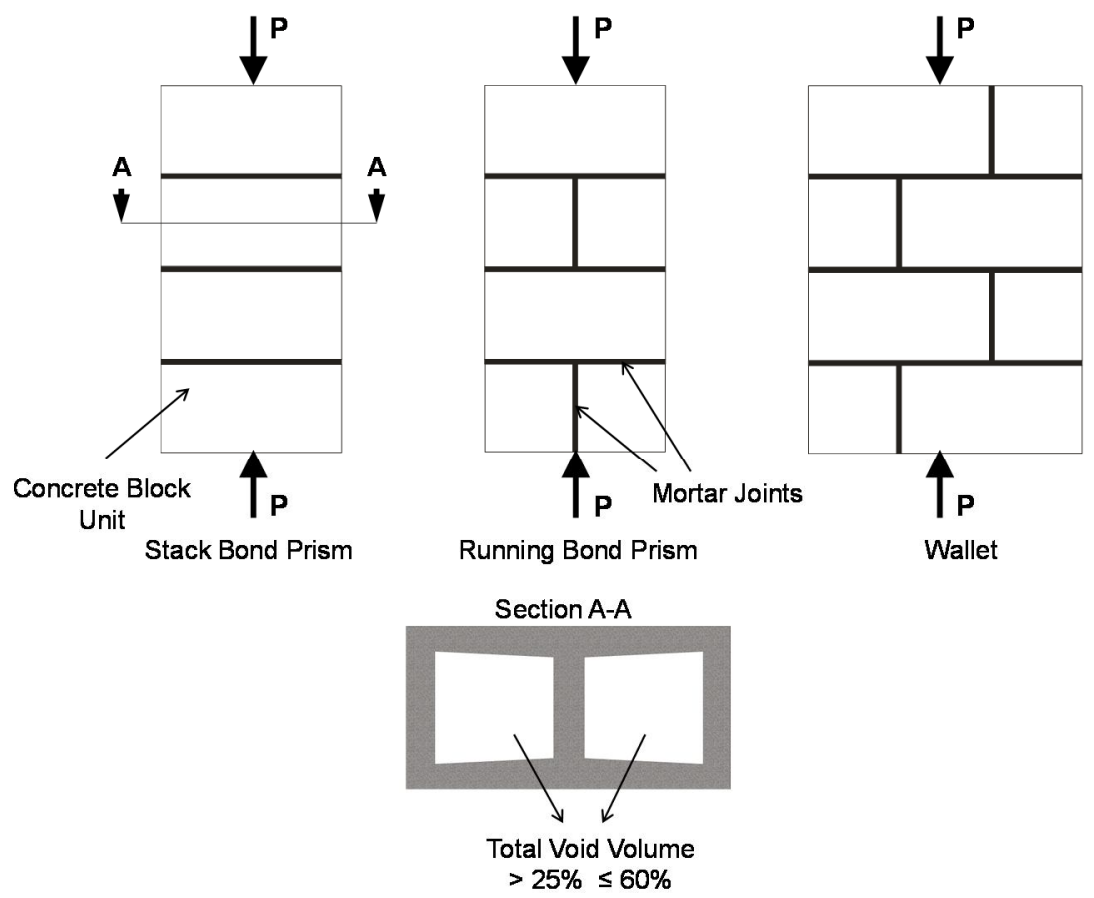

a) Configurations of Hollow Concrete Block Masonry Prisms

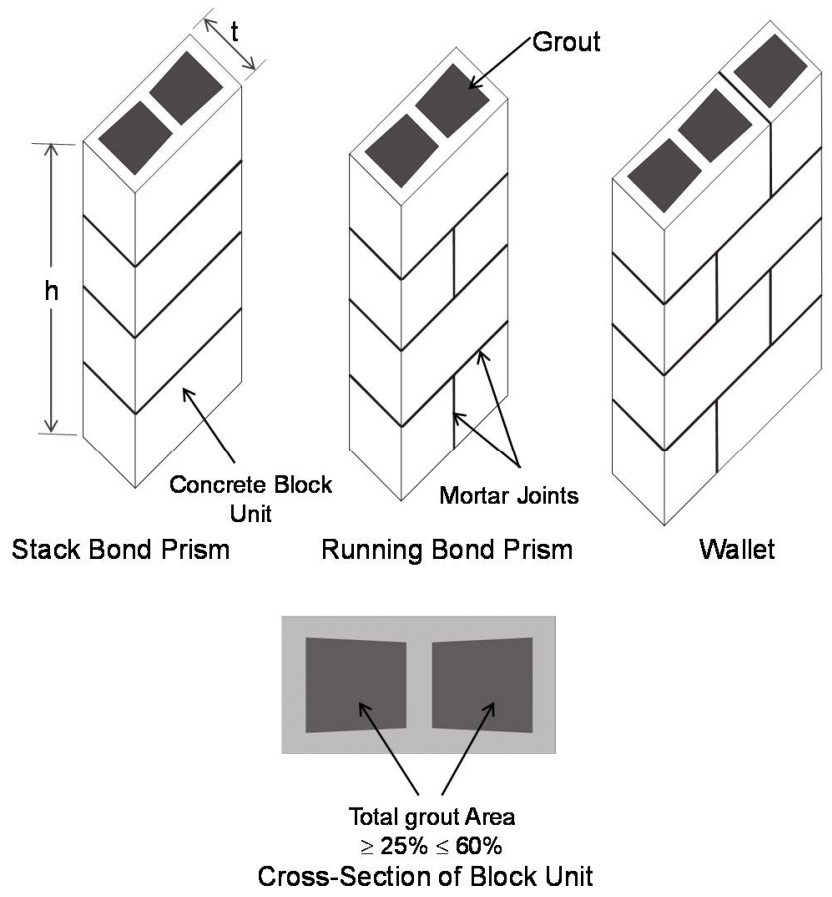

b) Configurations of Hollow Concrete Block Masonry Prisms

Figure 7-1: Configurations of Hollow Concrete Block Masonry Prisms 


\subsection{Prediction of Compressive Strength of Ungrouted Masonry}

A large database of compressive tests on ungrouted concrete block masonry prisms and wallets was collected from available literature (see Table 7-1). A total of 248 average masonry compressive strength data points, representing the test results of 1092 individual prisms, was assembled (see Appendix C). The gathered database covers masonry prisms and wallets made with hollow concrete blocks that have two or three vertical voids (passing completely through the block) with a solid area ranging from $40 \%$ to $75 \%$ of the gross area. These are "Group 2" blocks as per Eurocode 6 and "Hollow" blocks as per CSA A165. It is not the scope of this paper to study the compressive strength of prisms made with the following: solid blocks, semisolid block (solid ratio $>75 \%$ ), blocks with a solid ratio of less than $40 \%$, cellular concrete blocks that have cavities which do not pass right through the block, or concrete blocks with horizontal voids.

The selection of data was based on the following criteria: a) only test results reported and published in journal papers, conferences proceedings or published institutional reports were included in the database (test results reported in academic dissertations were not included); b) prisms constructed with more than six courses were excluded; c) where there was a choice of otherwise identical specimens within a test set, prisms with soft capping were excluded and those with hard capping were included; and d) prisms made out of block with compressive strengths in excess of $50 \mathrm{MPa}$ or less than $9 \mathrm{MPa}$ were excluded so as to represent as close as possible typical construction practice. Table 7-2 shows the ranges of values for different parameters covered in the database. 
Table 7-1 Summary of the Experimental Investigations Conducted on the Main Factors Affecting the Compressive Strength of Ungrouted Hollow Concrete Block Masonry

\begin{tabular}{|c|c|c|c|c|c|c|c|c|c|c|c|c|c|c|c|}
\hline \multirow{3}{*}{ 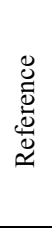 } & \multirow[b]{3}{*}{ Authors } & \multirow[b]{3}{*}{ Year } & \multicolumn{13}{|c|}{ Experimentally Studied Factors } \\
\hline & & & \multicolumn{2}{|c|}{ Unit } & \multicolumn{2}{|c|}{ Mortar } & \multicolumn{9}{|c|}{ Prism } \\
\hline & & & $\begin{array}{l}\vec{\Xi} \\
\stackrel{\Xi}{0} \\
\stackrel{0}{0}\end{array}$ & 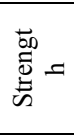 & 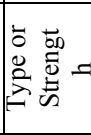 & 咅咅 & $\stackrel{\tilde{N}}{\mathrm{~N}}$ & \pm & 离 吾 & 吾 & مo & 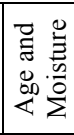 & 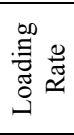 & 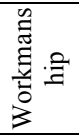 & 离 \\
\hline 1 & Copeland and Timms & 1932 & & $\sqrt{ }$ & $\sqrt{ }$ & & & & & & & & & & \\
\hline 2 & Richart et al. & 1932 & & $\sqrt{ }$ & $\sqrt{ }$ & & & & $\sqrt{ }$ & & & & & & \\
\hline 3 & Roberts & 1973 & & $\sqrt{ }$ & $\sqrt{ }$ & $\sqrt{ }$ & & & & & $\sqrt{ }$ & & & & \\
\hline 4 & Redmond and Allen, & 1975 & & $\sqrt{ }$ & $\sqrt{ }$ & & & $\sqrt{ }$ & & & & & & & \\
\hline 5 & Drysdale and Hamid & 1979 & $\sqrt{ }$ & $\sqrt{ }$ & $\sqrt{ }$ & $\sqrt{ }$ & $\sqrt{ }$ & & & & & & & & \\
\hline 6 & Maurenbrecher, A.H.P & 1980 & & $\sqrt{ }$ & & & & $\sqrt{ }$ & $\sqrt{ }$ & & $\sqrt{ }$ & & $\sqrt{ }$ & & \\
\hline 7 & Drysdale and Hamid & 1983 & $\sqrt{ }$ & $\sqrt{ }$ & & & & & & & & & & & \\
\hline 8 & Maurenbrecher, A.H.P & 1985 & & & & & & $\sqrt{ }$ & & & $\sqrt{ }$ & $\sqrt{ }$ & & $\sqrt{ }$ & \\
\hline 9 & Wong and Drysdale & 1985 & $\sqrt{ }$ & & & & & $\sqrt{ }$ & $\sqrt{ }$ & & $\sqrt{ }$ & & & & \\
\hline 10 & Gaynor et al. & 1987 & & $\sqrt{ }$ & $\sqrt{ }$ & & & & $\sqrt{ }$ & & & & & & \\
\hline 11 & Chahine and Drysdale & 1988 & $\sqrt{ }$ & $\sqrt{ }$ & & & & $\sqrt{ }$ & & & & & & & \\
\hline 12 & Xie, et al. & 1992 & $\sqrt{ }$ & & & & & $\sqrt{ }$ & $\sqrt{ }$ & & & & & & \\
\hline 13 & Khalaf et al. & 1994 & & $\sqrt{ }$ & & $\sqrt{ }$ & $\sqrt{ }$ & & & & & & & & \\
\hline 14 & Steadman et al. & 1995 & $\sqrt{ }$ & $\sqrt{ }$ & & & & & & & & & & & \\
\hline 15 & Khalaf & 1996 & & $\sqrt{ }$ & & $\sqrt{ }$ & $\sqrt{ }$ & $\sqrt{ }$ & & & & & & & \\
\hline 16 & Ramamurthy et al. & 2000 & $\sqrt{ }$ & $\sqrt{ }$ & $\sqrt{ }$ & $\sqrt{ }$ & & & $\sqrt{ }$ & & & & & & \\
\hline 17 & Roman and Romagna & 2002 & & $\sqrt{ }$ & $\sqrt{ }$ & & & & & & & & & & \\
\hline 18 & Mohamad et al. & 2007 & & $\sqrt{ }$ & $\sqrt{ }$ & & & & & & & & & & \\
\hline 19 & Andolfato et al. & 2007 & & $\sqrt{ }$ & $\sqrt{ }$ & & & & & & & & & & \\
\hline 20 & Barbosa, et al. & 2010 & & $\sqrt{ }$ & $\sqrt{ }$ & & & & & & & & & & \\
\hline 21 & NCMA & 2012 & & $\sqrt{ }$ & $\sqrt{ }$ & & & & & & & & & & \\
\hline 22 & Mina et al. & 2012 & & $\sqrt{ }$ & $\sqrt{ }$ & & & & & & & & & & \\
\hline 23 & Das et al. & 2013 & & & & & & $\sqrt{ }$ & $\sqrt{ }$ & $\sqrt{ }$ & & & & & \\
\hline 32 & Hegmier, et al. & 1977 & & & & & & & & & & & & & $\sqrt{ }$ \\
\hline 33 & Self, M.W & 1975 & & & & & & & & & & & & & $\sqrt{ }$ \\
\hline 34 & Mauenbrecher, A.H.P & 1983 & & & & & & & & & & & & & $\sqrt{ }$ \\
\hline 35 & Cheema and Klingner & 1986 & & & & & & & & & & & & & $\sqrt{ }$ \\
\hline 36 & Olatunji et al. & 1986 & & & & & & & & & & & & & $\sqrt{ }$ \\
\hline 37 & Scrivener and Baker & 1988 & & & & & & & & & & & & & $\sqrt{ }$ \\
\hline 38 & Page and Shrive & 1990 & & & & & & & & & & & & & $\sqrt{ }$ \\
\hline 39 & Thomas and Scolforo & 1995 & & & & & & & & & & & & & $\sqrt{ }$ \\
\hline 40 & Hawk et al. & 1997 & & & & & & & & & & & & & $\sqrt{ }$ \\
\hline
\end{tabular}


Table 7-2 Ranges of the Values of the Main Factors Affecting the Compressive Strength of Ungrouted Masonry Covered in the Assembled Database

\begin{tabular}{|l|c|}
\hline \multicolumn{1}{|c|}{ Parameter } & Range of the Parameter \\
\hline Unit compressive strength (MPa) & $8.9-45.6$ \\
\hline Unit thickness (mm) & $100-240$ \\
\hline Unit net area (\%) & $51-74$ \\
\hline Void ratio (\%) & $26-49$ \\
\hline Mortar compressive strength (MPa) & $3.65-26.90$ \\
\hline h/t ratio & $1.81-6.25$ \\
\hline No. of prism sets & 248 \\
\hline Total No. of prisms & 1092 \\
\hline No. of N-mortar prism sets & 97 \\
\hline No. of S-mortar prism sets & 151 \\
\hline No. of full-bedded prism sets & 150 \\
\hline No. of face- shell bedded prism sets & 98 \\
\hline
\end{tabular}

The collected database was used for three purposes. Firstly, the data was reviewed to explore the main factors that influence $\mathrm{f}^{\prime}$ m of ungrouted concrete block masonry. Secondly, the database was used to develop an accurate formula to estimate the compressive strength of ungrouted concrete block masonry. Finally the database was utilized to assess the predictive ability of the proposed formula compared to those of the international masonry codes.

\subsubsection{Factors Affecting $\mathrm{f}_{\mathrm{m}}$ of Ungrouted Masonry}

The review of the collected database shows that that various parameters, at both material and experimental levels, affect the compressive behavior of ungrouted masonry prisms. Among these factors, the unit strength, the mortar strength, the bedding type and the height to thickness ratio are the most influential factors. 


\section{Effect of unit compressive strength $\left(f_{b l}\right)$}

Multiple researchers (Andolfato et. al (2007), Barbosa et. al (2010), Chahine and Drysdale (1989), Copeland and Timms (1932), Das et. al (2013), Drysdale and Hamid (1979, 1983), Gayed et al. (2004), Gaynor et. al (1987), Khalaf (1996), Khalaf et. al (1994), Maurenbrecher (1980), Mohamad et. al (2007), NCMA (2012), Ramamurthy et al. (2000), Redmond and Allen (1975), Richart et.al (1932), Roberts (1973), Romagna and Roman (2002) and Steadman et. al (1995)) have shown that the compressive strength of masonry prisms increases with increasing compressive strength of the unit $\left(f_{b l}\right)$ (see Figure 7-2). It would appear that within the range of common block strengths (10-30 MPa) the relationship between prism strength and block strength is roughly linear. This matches findings reported by Drysdale and Hamid (2005). However, this linear trend does not extend to higher block strengths within the database where the relationship appears to become slightly non-linear. Drysdale and Hamid (1979) noted that compressive failure of prisms such as those shown in Figure7-1 is associated with vertical cracking in the prism. In the case of face-shell bedding, vertical cracks are observed in the webs, and have been explained using deep-beam analysis (Shrive (1982)). Since the tensile strength of concrete is related in a non-linear fashion to compressive strength, it is not surprising a slightly non-linear relationship between prism strength and block strength is observed, given that prism compressive failure is associated with tensile cracking in the prism. 


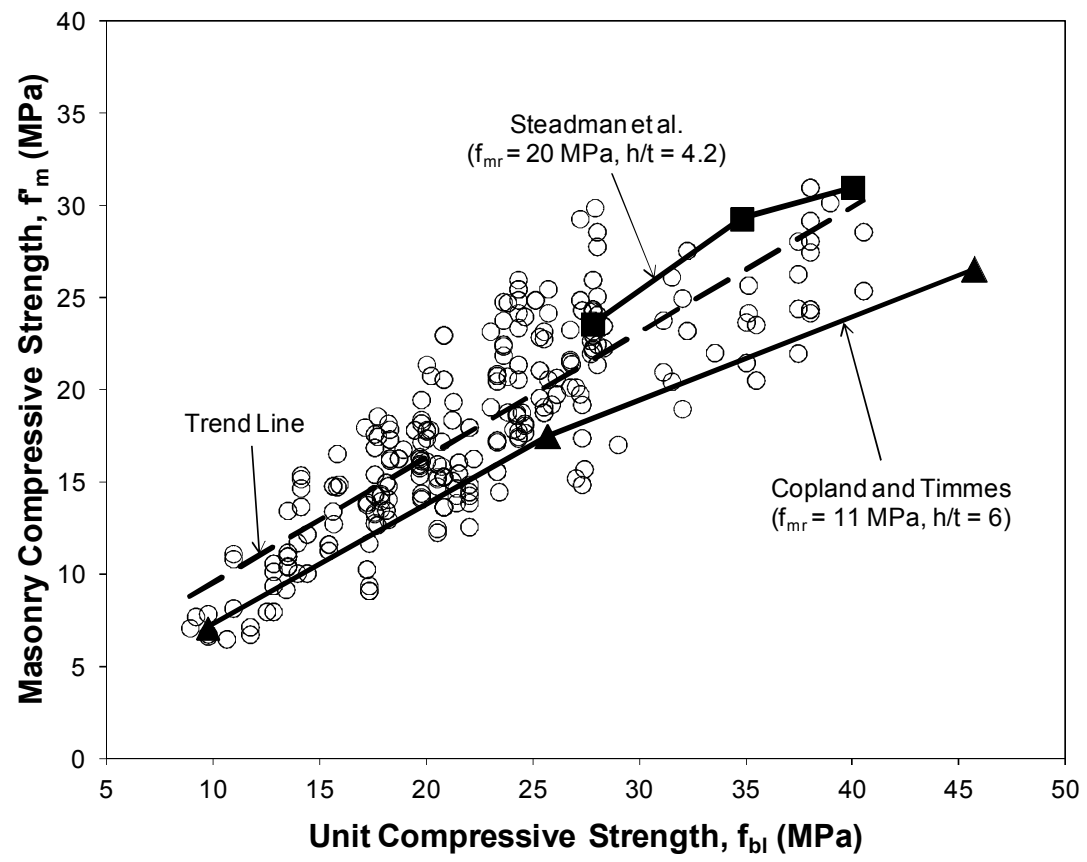

Figure 7-2: Effect of Unit Strength on Compressive Strength of Ungrouted Concrete Block Masonry

\section{Effect of mortar strength $\left(f_{m r}\right)$}

Numerous tests (Copeland and Timms (1932), Richart et al. 1932, Roberts (1973), Redmond and Allen (1975), Drysdale and Hamid (1979)) have indicated that the mortar strength ( $\left.f_{\text {mr }}\right)$ and type affect $\mathrm{f}_{\mathrm{m}}$. Higher mortar strength leads to less induced lateral tensile prisms which is the main cause of the masonry prism failure (Khalaf et al. (1994), Drysdale and Hamid (1979)). It can be seen in Figure 7-3 that there is considerable scatter in the data when mortar strength is plotted versus $\mathrm{f}_{\mathrm{m}}$, though the general trend is an increase in $\mathrm{f}_{\mathrm{m}}$ with the mortar strength. 


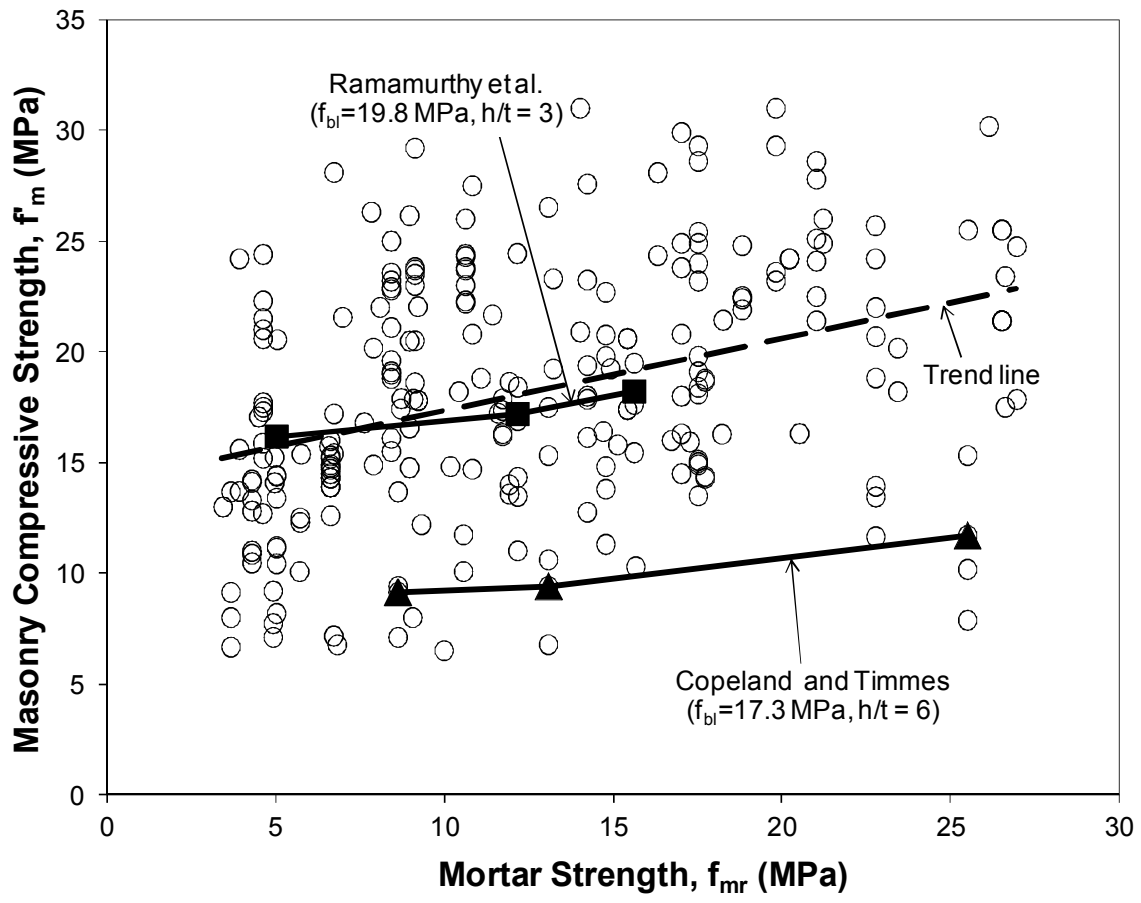

Figure 7-3: Effect of Mortar Strength on Compressive Strength of Ungrouted Concrete Block Masonry

\section{Effect of mortar bedding}

Worldwide, masonry construction practice varies widely. For example, face-shell bedding is a typical practice in North America and Australia (Page and Shrive (1988)), whereas full bedding is often used elsewhere (see Figure 7-4). The difference in construction practice is significant as it directly affects the capacity and failure modes of masonry when loaded in axial compression (Maurenbrecher (1980), Gaynor et al. (1987), Nacus (1980)). That is, investigations (Maurenbrecher (1980), Gaynor et al. (1987), Nacus (1980)) have shown that masonry prisms made with face-shell mortar bedding fail at significantly higher compressive stresses than those made with full mortar beddings. Ratios of strength of fully bedded to face shell bedded prisms have been reported to range from 0.84 to 0.91 with a weighted average ratio of about 0.89 (Colville and Wolde-Tinsae (1991)) Note that in these ratios, the strengths of fully- bedded 
prisms are based on the net area of the units, whereas the strengths of face shell bedded prisms are based on the net area of the face shells only.

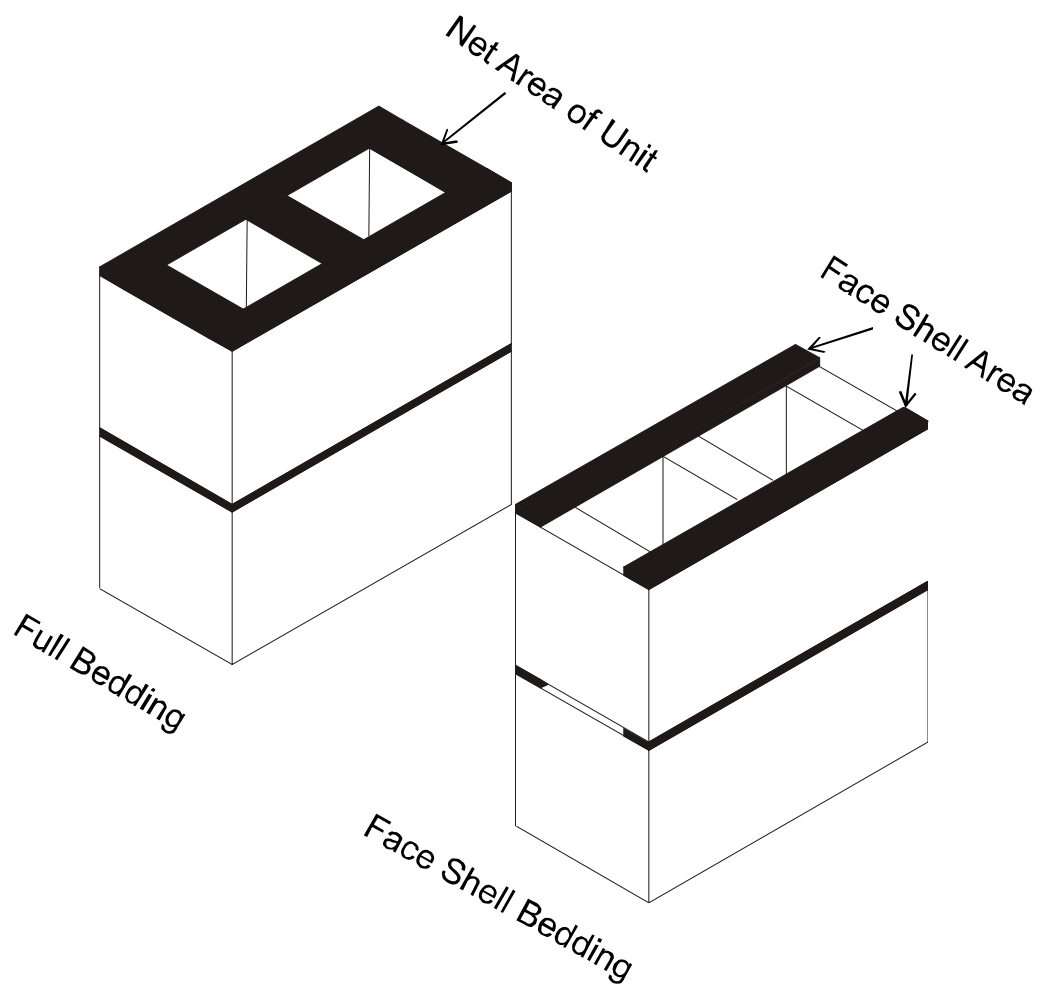

Figure 7-4: Bedding Types in Concrete Masonry

\section{Effect of $h / t$}

It is well known that the ratio of a prism's height to its thickness $(\mathrm{h} / \mathrm{t})$ affects its compressive strength. Many researchers (Maurenbrecher (1980), Wong and Drysdale (1985), Khalaf(1996), Das et al. (2013), Drysdaleand Hamid (2005), Kingsley et al. (1986)) have shown that the measured compressive strength decreases as $\mathrm{h} / \mathrm{t}$ increases, though above a certain height, the effect of $\mathrm{h} / \mathrm{t}$ becomes marginal. This decrease in strength can be attributed to the decreasing influence of platen restraint (Das et al. (2013), Drysdale and Hamid (2005)), though Maurenbrecher (1980) and Page and Shrive (1988) report that the effect of $h / t$ depends upon 
whether full or face shell bedding is used in construction of the prism. Other researchers (Das et al. (2013), Wong and Drysdale (1985)), on the other hand, report that when using high strength capping, the compressive strength of ungrouted masonry prisms decrease with increasing the $\mathrm{h} / \mathrm{t}$ ratio regardless of the bedding type.

In Figure 5-6, the compressive strength of ungrouted prisms is plotted against the values of $\mathrm{h} / \mathrm{t}$. The general trend is linear with about a $5 \%$ reduction in compressive strength with each unit increase in $\mathrm{h} / \mathrm{t}$ ratio. This $5 \%$ reduction was used in the proposed model. Test series by Khalaf (1996) and Das et al. (2013) are highlighted to indicate the effect of the $h / t$ ratio. The effect of $h / t$ is reflected in various masonry codes through the use of correction factors to convert $\mathrm{f}_{\mathrm{m}}$ calculated using prisms of a certain $\mathrm{h} / \mathrm{t}$ to a standard $\mathrm{h} / \mathrm{t}$. The TMS 402 code considers an $\mathrm{h} / \mathrm{t}$ of 2 as the standard for determining $\mathrm{f}_{\mathrm{m}}$ and applies a correction factor varying from $0.75 \mathrm{for} h / \mathrm{t}=1.3$ to 1.22 for $\mathrm{h} / \mathrm{t}=5$. Other codes use an $\mathrm{h} / \mathrm{t}$ of 5 as the standard based on the philosophy that taller prisms provide more representative test strengths of in-situ masonry. Therefore, they apply a reduction factor to $\mathrm{f}_{\mathrm{m}}$ values established by tests on prisms where $\mathrm{h} / \mathrm{t}$ is less than 5 . It is interesting that the CSA code only applies a correction factor for an $\mathrm{h} / \mathrm{t}$ value of 2 . This is quite different from the other codes (see Figure 7-6) and does not appear to match the experimental data summarized in Figure 7-5. 


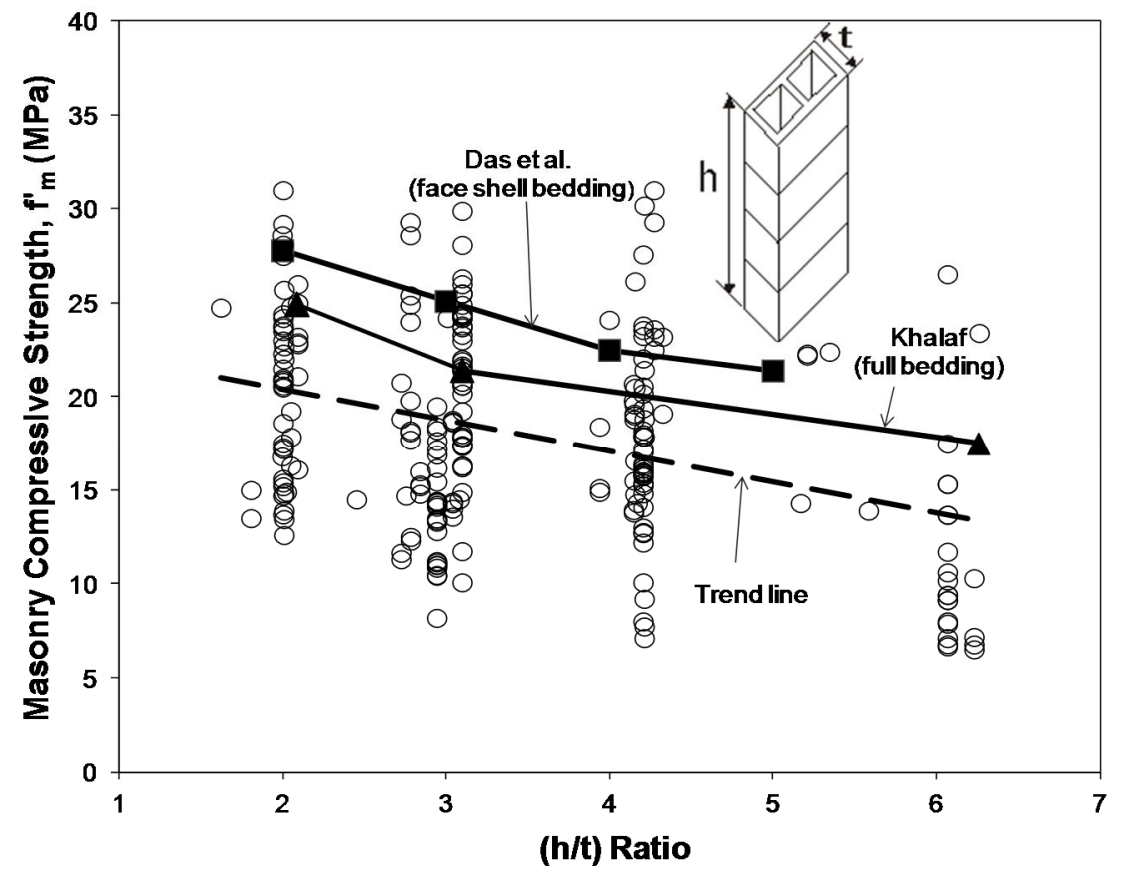

Figure 7-5: Effect of h/t Ratio on the Compressive Strength of Ungrouted Concrete Block Masonry Prisms

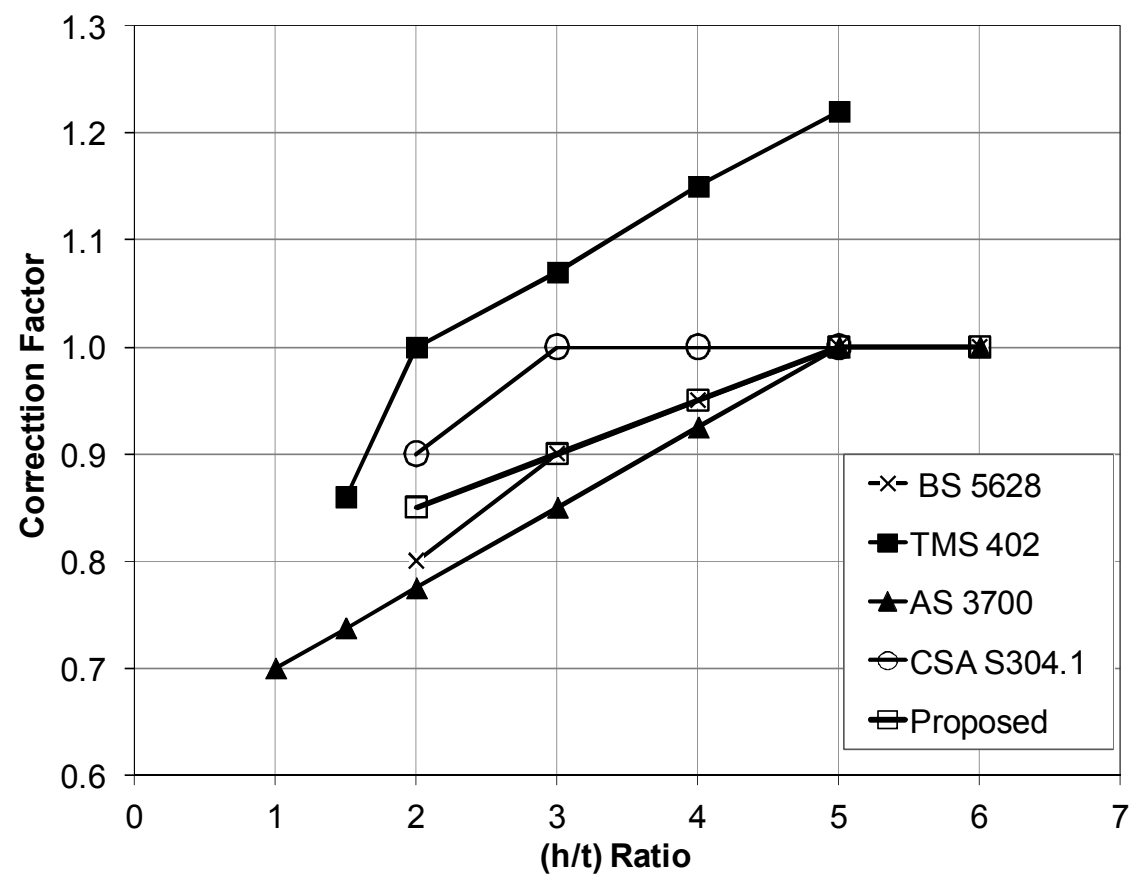

Figure 7-6: Correction Factors for $\mathrm{h} / \mathrm{t}$ Ratios of Ungrouted Concrete Block Masonry Prisms in Various Masonry Design Codes 


\subsubsection{Data Analysis}

Different procedures were used in testing the units, mortar and prisms and in reporting the results in the experimental investigations covered in the database. For example, unit compressive strengths $\left(f_{b l}\right)$ were reported in terms of either net or gross areas, while the database was unified to be expressed in terms of net area of the unit (Figure 7-4). Also, mortar compressive strengths were measured by testing either cubes or cylinders. To unify the database, mortar compressive strengths $\left(f_{m r}\right)$ were expressed in terms of cube compressive strength. A factor of $1 / 0.85$ was used to convert reported cylinder compressive strengths to cube compressive strengths (Singh (1988)).

Mortar bedded area was used for computing the prism strength to enter into the database. Strength values for prisms constructed with face-shell bedded mortar, but reported based on the net area, were adjusted by multiplying by a factor equal to the net area of block divided by the area of face shells. To account for the effect of bedding type on the compressive strength of ungrouted masonry, the reported experimental compressive strengths of fully-bedded prisms were increased by a factor of (1.1). This factor reflects the research work done by Maurenbrecher $(1980,1986)$ who found that face shell bedded prisms have $10 \%$ higher compressive strength than similar fully-bedded prisms. Gayed and Korany (2011) have used the same factor.

The proposed formulas adopt the CSA S304.1-04, AS 3700-2001 and BS 5628-2:2005 standard $\mathrm{h} / \mathrm{t}$ ratio of 5 . As such, the reported experimental strengths of the prisms were normalized by multiplying by the factor $(1-0.05(5-\mathrm{h} / \mathrm{t}))$ reflecting the average reduction in compressive 
strength with each unit increase in $\mathrm{h} / \mathrm{t}$ ratio illustrated in Figure 7-5. A similar reduction factor was recommended by Drysdale and Hamid (2005).

\subsubsection{Regression Analysis}

The majority of the experimental results were reported without variation values (i.e. standard deviations or coefficient of variations) for either one or all of the unit, mortar and prism's strengths. Hence, the derivation of the proposed formula was based on experimental average test results of the prisms and the average strengths of masonry components (unit and mortar). Regression analysis was used to develop the proposed formula. The dependent variable was the compressive strength of masonry prisms, $\mathrm{f}_{\mathrm{m}}^{\prime}$ (adjusted for bedding type and $\mathrm{h} / \mathrm{t}$ ratio), whereas the independent variables were block strength, $\mathrm{f}_{\mathrm{bl}}$ and mortar cube strength, $\mathrm{f}_{\mathrm{mr}}$. Different linear, power and multiple linear regression models were analyzed to obtain representative formulae, and the adequacy of these models was verified based on the following checks (Montgomery (2012)): coefficient of multiple determinations $\left(\mathrm{R}^{2}\right)$, test for significance of regression, tests on individual regression coefficients and residual analysis on normal probability plots of residuals and residual versus predicted values.

Table 7-3 shows formulae resulting from different regression models with their values of

analysis multiple determinations $\left(\mathrm{R}^{2}\right)$. It can be seen that correlating the masonry compressive strength to the unit compressive strength as the only dependent factor lead to formulae with less representation (lower coefficient of determination). The multiple power model (Equation (7-1)) exhibited the highest coefficient of determination at $82 \%$, meaning that this model can explain $82 \%$ of the total variation between observed and predicted values of $\mathrm{f}_{\mathrm{m}}$. This model gives an 
average ratio of experimental $f_{m}^{\prime}$ to predicted $f_{m}^{\prime}\left(f_{m} f_{\text {Exp }} / f_{m \text { Pred }}^{\prime}\right)$ of 1.0 for the entire database with a coefficient of variation of $12.5 \%$.

$\mathrm{f}^{\prime} \mathrm{m}=1.107(\mathrm{fbl})^{0.75}(\mathrm{fmr})^{0.18}$

Table 7-3: The Coefficients of Multiple Determination Factor for Different Statistical Model of Strength Prediction of Ungrouted Prisms

\begin{tabular}{|c|c|}
\hline Statistical Models & Coefficient of Multiple Determination $\left(\mathbf{R}^{2}\right)$ \\
\hline$f^{\prime} m=0.61 \mathrm{fbl}+3.723$ & 0.70 \\
\hline $\mathrm{f}^{\prime} \mathrm{m}=1.552(\mathrm{fbl})^{0.781}$ & 0.71 \\
\hline $\mathrm{f}^{\prime} \mathrm{m}=0.011(\mathrm{fbl})^{2}+1.181(\mathrm{fbl})-2.734$ & 0.72 \\
\hline $\mathrm{f}^{\prime} \mathrm{m}=0.583 \mathrm{fbl}+0.257 \mathrm{fmr}+1.141$ & 0.80 \\
\hline $\mathrm{f}^{\prime} \mathrm{m}=1.107(\mathrm{fbl})^{0.75}(\mathrm{fmr})^{0.18}$ & 0.82 \\
\hline
\end{tabular}

The adequacy of Equation (7-1) is illustrated in Figure 7-7. When the experimental values of $\mathrm{f}_{\mathrm{m}}$ are plotted against the predicted values (Figure 7-7a), the data points are consistently distributed around the line of equality. Figure $7-7 \mathrm{~b}$ presents the residuals for Equation (7-1) versus the block strength. The trend line is horizontal, thus residuals neither increase nor decrease with $\mathrm{f}_{\mathrm{bl}}$. This indicates that the slightly non-linear relationship between $\mathrm{f}_{\mathrm{m}}$ and block strength shown in Figure 7-2 is accounted for by Equation (7-1). 

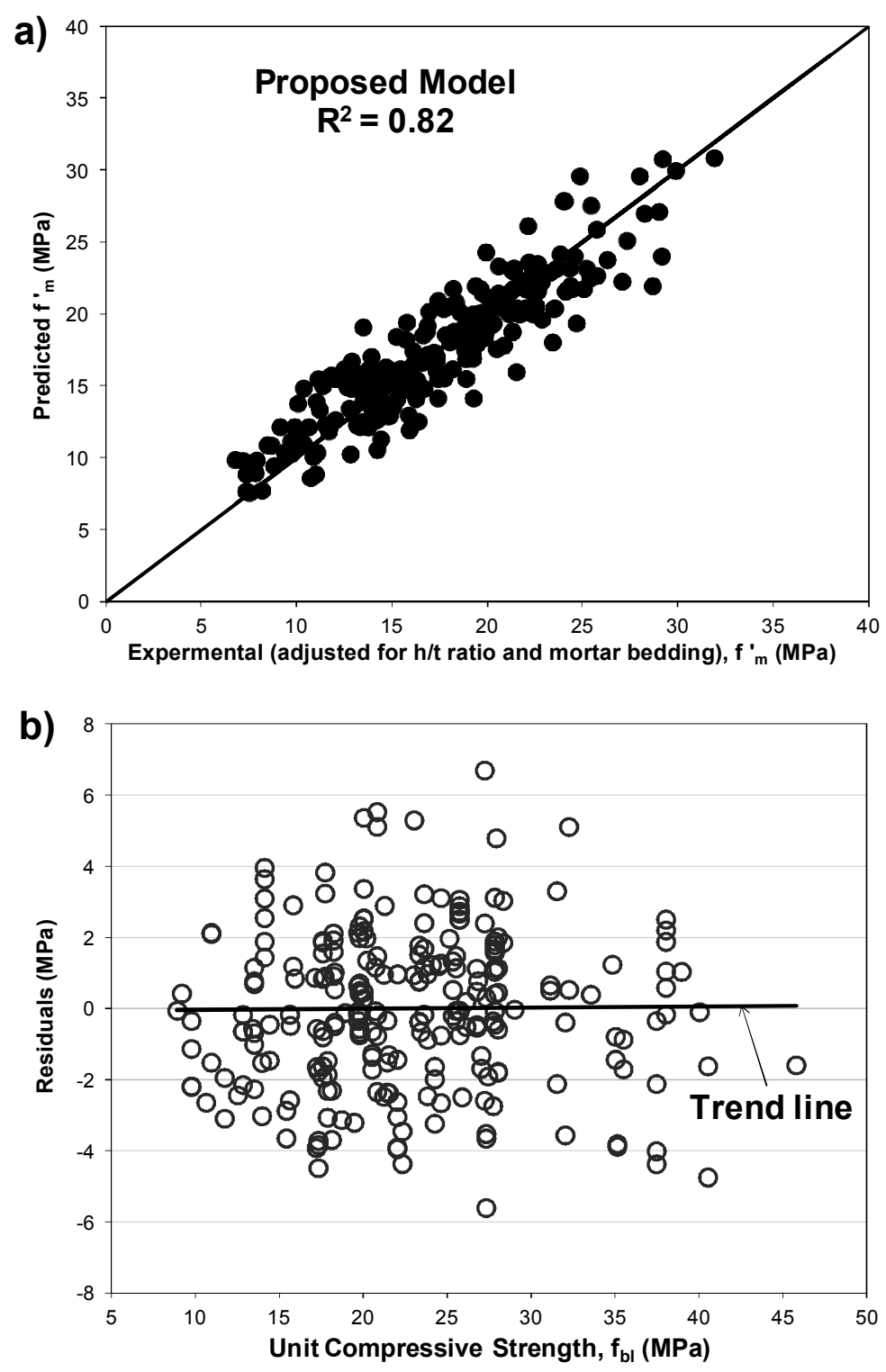

Figure 7-7: Predictive Ability of Equation (7-1): a) the Coefficient of Determination and b) Distribution of Residuals Plotted Against $f_{b l}$

As Equation (7-1) was developed based on $\mathrm{f}^{\prime}{ }_{\mathrm{m}}$ adjusted for bedding type and $\mathrm{h} / \mathrm{t}$ ratio, it can be modified to account for these two factors as shown below:-

$\mathrm{f}_{\mathrm{m}}^{\prime}=1.107 \mathrm{CbCh}(\mathrm{fbl})^{0.75}(\mathrm{fmr})^{0.18}$

Where: 
$\mathrm{C}_{\mathrm{b}}=\mathrm{a}$ factor to account for the mortar bedding type taken as 1.0 for face shell bedding and 0.91 for full bedding, and

$\mathrm{C}_{\mathrm{h}}=\mathrm{a}$ factor to account for the $(\mathrm{h} / \mathrm{t})$ ratio taken as:

$$
\begin{array}{ll}
\mathrm{Ch}_{\mathrm{h}}=\frac{1}{(1-0.05(5-\mathrm{h} / \mathrm{t}))} & \text { for } \mathrm{h} / \mathrm{t}<5 \\
\mathrm{Ch}_{\mathrm{h}}=1 & \text { for } \mathrm{h} / \mathrm{t} \geq 5
\end{array}
$$

Equation (7-2) accounts for the four major factors affecting the compressive strength of ungrouted masonry prisms, namely the unit strength, mortar strength, $\mathrm{h} / \mathrm{t}$ ratio and bedding type.

\subsubsection{The Proposed Model}

When used for design purposes, the proposed model needs to be associated with a margin of safety through setting a confidence lower limit. The proposed model follows the approach of Annex C of CSA S304.1 to determining the specified compressive strength from prism tests, where the $95 \%$ confidence lower limit is used. Assuming the $f_{m}^{\prime} \operatorname{Exp}^{\prime} / f_{m}$ Pred ratios to be normally distributed, the $95 \%$ confidence lower limit can be calculated by subtracting $1.64 \sigma$ from the arithmetic mean, where $\sigma$ is the standard deviation. The confidence lower limit for a mean of 1.0 and a standard deviation of 0.125 can thus be calculated to be 0.8 , and the application of this limit means that we can be confident by $95 \%$ that the $\mathrm{f}_{\mathrm{m} \text { Exp }} / \mathrm{f}_{\mathrm{m} \text { Pred }}$ ratio will be equal to or greater than 1.0 (see Figure 7- 8). Equation (7-2) can thus be rendered appropriate for design purposes by rewriting it as follows:

$$
\mathrm{f}^{\prime} \mathrm{m}=0.8\left\{1.107 \mathrm{CbCh}(\mathrm{fbl})^{0.75}(\mathrm{fmr})^{0.18}\right\}
$$




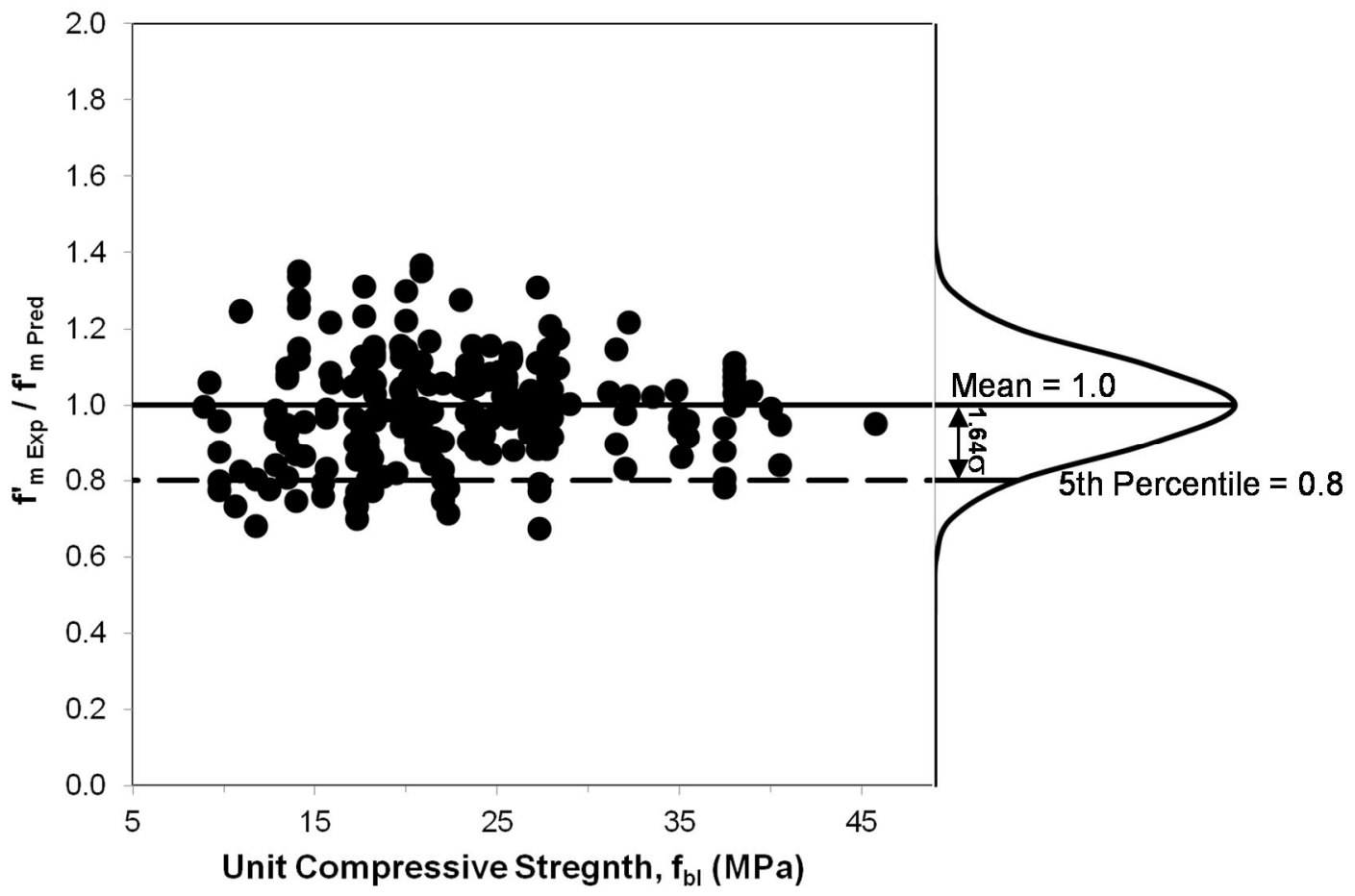

Figure 7-8: Application of the 95\% Confidence Lower Limit to the Proposed Model for Ungrouted Masonry Prism

Equation (7-4) can be simplified for prisms with h/t equal to 5 for both fully-bedded and faceshell bedded masonry by setting $\mathrm{C}_{\mathrm{h}}$ and $\mathrm{C}_{\mathrm{b}}$ equal to 1.0 .

$\mathrm{f}^{\prime} \mathrm{m}=0.886(\mathrm{fbl})^{0.75}(\mathrm{fmr})^{0.18}$

As mortar strength is traditionally classified by different types rather than strength, Equation (7-

5) can be further simplified by using typical mortar compressive strength values for each mortar type. Using characteristic strengths of 5 and $12.5 \mathrm{MPa}$ for types $\mathrm{N}$ and $\mathrm{S}$ mortars respectively (as North American codes suggest) will lead to the proposed model Equation (7-6):

$$
\begin{array}{ll}
\mathrm{f}^{\prime} \mathrm{m}=1.18(\mathrm{fbl})^{0.75} & \text { for Type N mortar masonry } \\
\mathrm{f}^{\prime} \mathrm{m}=1.40(\mathrm{fbl})^{0.75} & \text { for Type S mortar masonry }
\end{array}
$$


The proposed formula (Equation (7-6)) is valid for the range of block strengths (based on net area) of 9 to $50 \mathrm{MPa}$. Figure 7- 9 represents a graphical form of Equation (7-6) and it shows that this model can safely and accurately predict $\mathrm{f}_{\mathrm{m}}$ for the entire database.

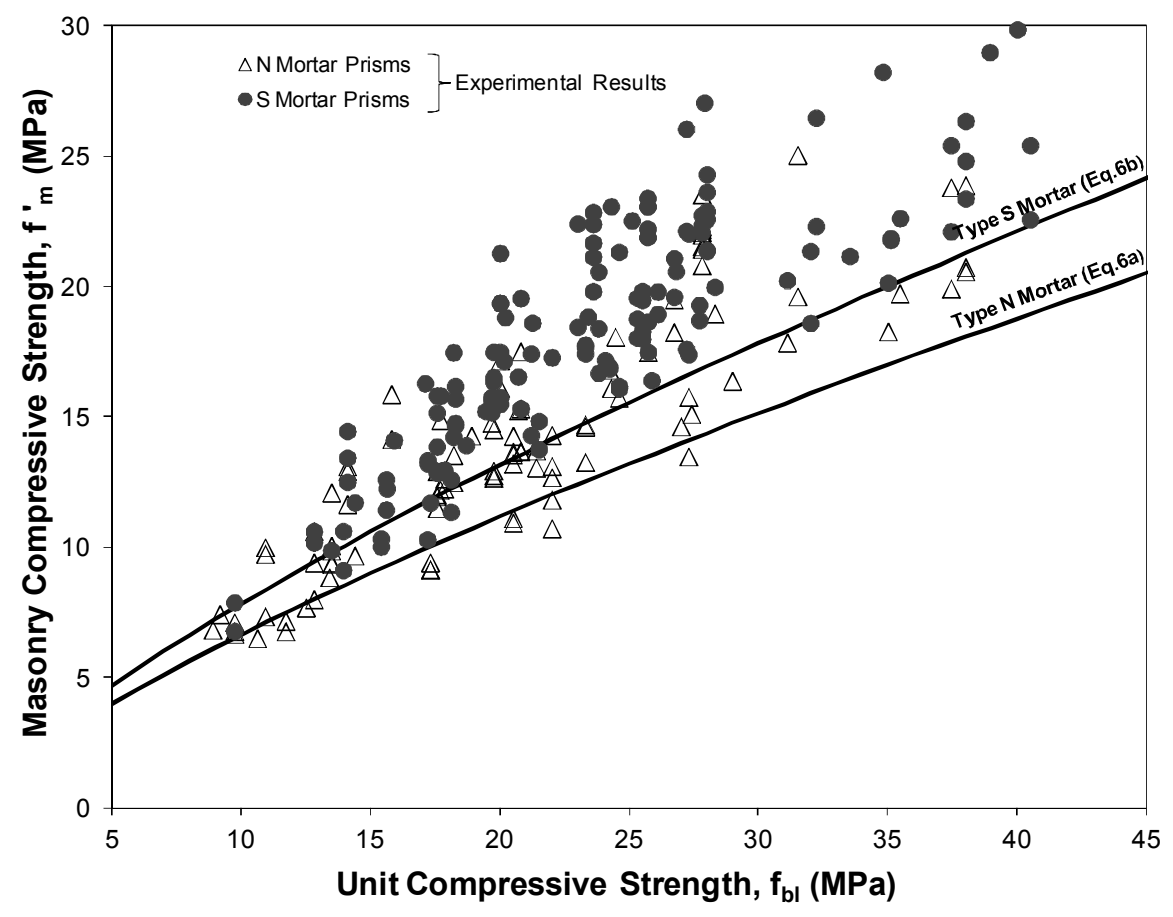

Figure 7-9: Graphical Form of Equation (7-6)

\subsubsection{Results and Discussion}

The predicted compressive strengths of the tested prisms covered in the database were calculated using the proposed model (Equation (7-6)) and five international masonry design codes, and the ratios of $\left(\mathrm{f}_{\mathrm{m}} \mathrm{Exp} / \mathrm{f}_{\mathrm{m} \text { Pred }}\right)$ were determined for each data point in the database (see Table 7-4 for a sample of calculations). The $\mathrm{f}_{\mathrm{m} \text { Exp }} / \mathrm{f}_{\mathrm{m}}$ Pred ratios, standard deviations, coefficients of variation $(\mathrm{COV} \%)$ and the integral absolute errors (IAE \%) for each code were calculated and summarized in Table 7-5. Also, comparisons were made between the codes and the proposed. 
Table 7.4: Sample of Calculations for Determination of $\mathrm{f}^{\prime}{ }_{\mathrm{m}}$ for Ungrouted Masonry

Khalaf (15) tested a set of 3 ungrouted fully bedded masonry prisms with (h/t) ratio of 3.1. The average unit (190x190x390 mm) compressive strength was $20 \mathrm{MPa}$ with a standard deviation of $2.1 \mathrm{MPa}$. The prisms were built with $\mathrm{S}$ mortar of an average cube compressive strength of 15.4 MPa. The average compressive strength of the tested prisms was $17.4 \mathrm{MPa}$ with a standard deviation of $0.9 \mathrm{MPa}$

\begin{tabular}{|c|c|c|}
\hline AS 3700-2001 & CSA S304.1-04 & TMS 402-11 \\
\hline $\begin{array}{l}\text { Correction facto for }(\mathrm{h} / \mathrm{t}) \text { ratio }=0.86 \text { by } \\
\text { interpolation }(\text { Appendix C of AS } 3700) \\
\text { The average corrected strength }=17.4 \times 0.86=14.96 \\
\mathrm{MPa} \\
\text { From equation }(2) \text { in the current paper } \\
\mathrm{f}^{\prime} \mathrm{m}=(1.3 \times 1.4 \sqrt{20})=8.14 \mathrm{MPa} \\
\text { Or from table in AS } 3700-2001 \\
\mathrm{f}_{\mathrm{m} \text { Exp }}^{\prime} / \mathrm{f}_{\mathrm{m} \text { Pred }}=14.96 / 8.14=1.84\end{array}$ & $\begin{array}{l}\text { Correction facto for }(\mathrm{h} / \mathrm{t}) \text { ratio= } 1 \text { (Annex D of CSA } \\
\text { S304.1) } \\
\text { The average corrected strength }=17.4 \times 1=17.4 \mathrm{MPa} \\
\text { From Table } 3 \text { in CSA S304.1-04, for } \mathrm{f}_{\mathrm{bl}}=20 \mathrm{MPa} \text { and } \\
\mathrm{S} \text { mortar } \\
\mathrm{f}_{\mathrm{m}}=13 \mathrm{MPa} \\
\mathrm{f}_{\mathrm{mExp}} / \mathrm{f}_{\mathrm{m} \text { Pred }}=17.4 / 13=1.31\end{array}$ & $\begin{array}{l}\text { Correction facto for }(\mathrm{h} / \mathrm{t}) \text { ratio }=1.08 \text { by interpolation } \\
(\text { ASTM C 1314-02a) } \\
\text { The average corrected strength }=17.4 \times 1.08=18.8 \mathrm{MPa} \\
\text { From Table } 2 \text { in TMS } 402-11 \text {, for } \mathrm{f}_{\mathrm{bl}}=20 \mathrm{MPa} \text { and } \mathrm{S} \\
\text { mortar } \\
\mathrm{f}^{\prime} \mathrm{m}=13.79+\frac{(20-19.31)}{(25.68-19.31)} \cdot(17.24-13.79)=14.16 \mathrm{MPa} \\
\mathrm{f}_{\mathrm{m} \text { Exp }}^{\prime} / \mathrm{f}_{\mathrm{m} \text { Pred }}^{\prime}=18.8 / 14.16=1.32\end{array}$ \\
\hline BS 5628:2005 & Eurocode & Proposed \\
\hline 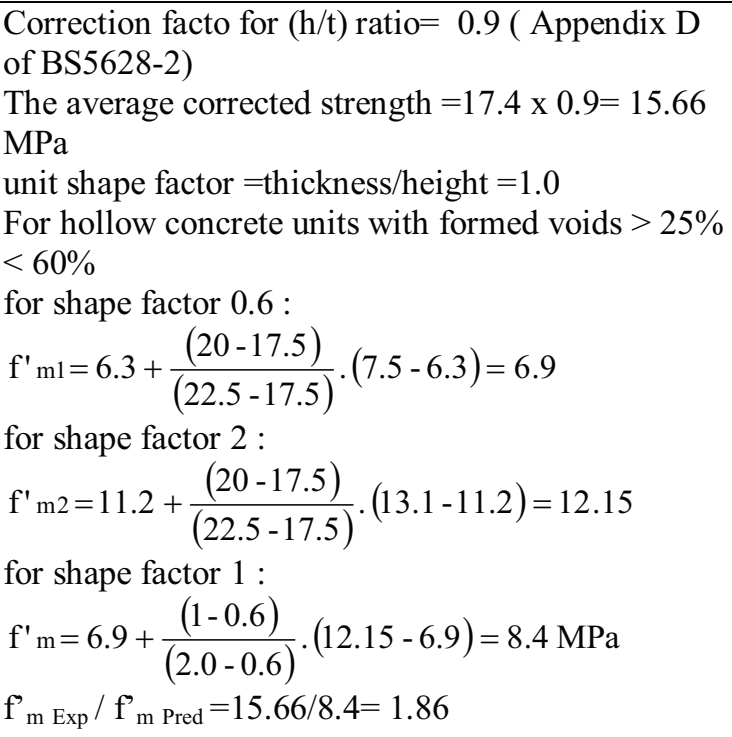 & $\begin{array}{l}\text { Correction facto for }(\mathrm{h} / \mathrm{t}) \text { ratio }=0.9(\text { National } \\
\text { Appendix D of BS5628-2) } \\
\text { The average corrected strength }=17.3 \times 0.9=15.66 \\
\mathrm{MPa} \\
\text { Normalized conversion factor }=1.14(\mathrm{BS} \text { EN } 772-1) \\
\text { Normalized block strength }=1.14 \times 20=22.8 \mathrm{MPa} \\
\text { Mortar strength according to Eurocode } 6 \\
=1.28 \times 15.4=19.71 \mathrm{MPa} \\
\text { For hollow concrete units with formed voids }>25 \% \\
<60 \% \text { (group } 2) \\
\mathrm{f}^{\prime} \text { m }=0.52(22.8)^{0.7}(19.71)^{0.3}=11.35 \mathrm{MPa} \\
\mathrm{f}_{\mathrm{m} \text { Exp }}^{\prime} / \mathrm{f}_{\mathrm{m} \text { Pred }}^{\prime}=15.66 / 11.35=1.38\end{array}$ & $\begin{array}{l}\text { Correction facto for }(\mathrm{h} / \mathrm{t}) \text { ratio }=1-0.05(5-3.1)=0.91 \\
\text { The average corrected strength }=17.4 \times 0.91=15.83 \\
\mathrm{MPa} \\
\text { From Equation }(7-6 \mathrm{~b}) \text { in the current study: } \\
\mathrm{f}^{\prime} \mathrm{m}=1.4(20)^{0.75}=13.24 \mathrm{MPa} \\
\text { Or from figure } 9 \text { for unit strength of } 20 \mathrm{MPa} \text { and type S } \\
\text { mortar } \\
\mathrm{f}_{\mathrm{m}}=13.25 \mathrm{MPa}\end{array}$ \\
\hline
\end{tabular}


Table 7-5: Values of Mean (f'm Exp/ f'm Pred), Standard Deviation, Coefficient of Variation and IAE for the Proposed Formula and Major International Masonry Codes

\begin{tabular}{|c|c|c|c|c|c|c|c|c|c|c|c|c|c|c|c|c|c|c|c|c|}
\hline & \multicolumn{4}{|c|}{ All the database } & \multicolumn{4}{|c|}{ Type N mortar prisms } & \multicolumn{4}{|c|}{ Type $\mathrm{S}$ mortar prisms } & \multicolumn{4}{|c|}{ Face-Shell Bedded prisms } & \multicolumn{4}{|c|}{ Full Bedded prisms } \\
\hline & \multicolumn{3}{|c|}{$\left(\mathrm{f}_{\mathrm{m} \text { Exp }} / \mathrm{f}_{\mathrm{m} \text { Pred }}\right)$} & \multirow[b]{2}{*}{$\begin{array}{l}\partial^{\circ} \\
\text { प1 } \\
\vdots\end{array}$} & \multicolumn{3}{|c|}{$\left(\mathrm{f}_{\mathrm{m} \text { Exp }} / \mathrm{f}_{\mathrm{m} \text { Pred }}\right)$} & \multirow[b]{2}{*}{$\begin{array}{l}\stackrel{0}{\circ} \\
\text { 띯 }\end{array}$} & \multicolumn{3}{|c|}{$\left(\mathrm{f}_{\mathrm{m} \text { Exp }} / \mathrm{f}_{\mathrm{m} \text { Pred }}\right)$} & \multirow[b]{2}{*}{$\begin{array}{l}\stackrel{\circ}{0}^{\circ} \\
\text { ஸा }\end{array}$} & \multicolumn{3}{|c|}{$\left(\mathrm{f}_{\mathrm{m} \text { Exp }} / \mathrm{f}_{\mathrm{m} \text { Pred }}\right)$} & \multirow[b]{2}{*}{ 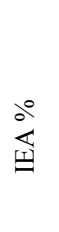 } & \multicolumn{3}{|c|}{$\left(\mathrm{f}_{\mathrm{m} \text { Exp }} / \mathrm{f}_{\mathrm{m} \text { Pred }}\right)$} & \multirow[b]{2}{*}{$\begin{array}{l}\stackrel{\circ}{\circ} \\
\stackrel{1}{\leq}\end{array}$} \\
\hline & 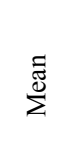 & 弇 & $\begin{array}{l}d^{\circ} \\
\dot{0} \\
0\end{array}$ & & 丞 & 点 & $\begin{array}{l}0^{\circ} \\
0 \\
0\end{array}$ & & $\stackrel{\Xi \Xi}{\Sigma}$ & 忩 & $\begin{array}{l}0^{\circ} \\
0 \\
0\end{array}$ & & $\sum^{\tilde{\Xi}}$ & 党 & $\begin{array}{l}d^{\circ} \\
\overrightarrow{0}\end{array}$ & & $\stackrel{\bar{\Xi}}{\stackrel{\Xi}{\Sigma}}$ & 党 & $\begin{array}{l}d^{\circ} \\
\overrightarrow{0}\end{array}$ & \\
\hline CSA S304.1-04 & 1.41 & 0.24 & 17 & 29 & 1.51 & 0.28 & 19 & 35 & 1.35 & 0.18 & 14 & 28 & 1.47 & 0.26 & 18 & 30 & 1.37 & 0.21 & 15 & 27 \\
\hline TMS 402-11 & 1.31 & 0.20 & 15 & 25 & 1.23 & 0.19 & 16 & 20 & 1.37 & 0.18 & 13 & 28 & 1.34 & $0 . .19$ & 15 & 25 & 1.30 & 0.21 & 16 & 24 \\
\hline AS 3700-2001 & 1.81 & 0.34 & 19 & 46 & 1.61 & 0.29 & 18 & 39 & 1.94 & 0.30 & 15 & 49 & 1.88 & 0.35 & 18 & 46 & 1.77 & 0.32 & 18 & 44 \\
\hline BS 5628:2005 & 1.81 & 0.32 & 17 & 45 & 1.77 & 0.34 & 19 & 44 & 1.84 & 0.30 & 16 & 45 & $1 . .90$ & 0.32 & 17 & 47 & 1.75 & 0.30 & 17 & 43 \\
\hline Eurocode 6 & 1.44 & 0.22 & 15 & 30 & 1.53 & 0.24 & 16 & 35 & 1.39 & 0.19 & 14 & 28 & 1.50 & 0.18 & 12 & 34 & 1.40 & 0.24 & 17 & 28 \\
\hline Equation 7-2 & 1.17 & 0.15 & 13 & 16 & 1.17 & 0.17 & 15 & 20 & 1.17 & 0.14 & 12 & 16 & 1.19 & 0.14 & 12 & 17 & 1.15 & 0.16 & 14 & 15 \\
\hline $\begin{array}{c}\text { Proposed } \\
\text { (Equation 7-6) }\end{array}$ & 1.21 & 0.16 & 13 & 18 & 1.21 & 0.18 & 15 & 19 & 1.21 & 0.14 & 12 & 18 & 1.24 & 0.16 & 13 & 18 & 1.19 & 0.16 & 13 & 17 \\
\hline
\end{tabular}


The IAE index has been used by others (Oluokun 1991, Arıglu et. al 2006) to evaluate the goodness of fit of proposed relationships for reinforced concrete structures, and it can be computed from Equation (7-7):

$\operatorname{IAE}(\%)=\sum \frac{\left(\left(f_{m}^{\prime} \text { Exp }-f_{m P r e d}^{\prime}\right)^{2}\right)^{1 / 2}}{\sum f_{m E x p}^{\prime}} .100$

The IAE measures the relative deviations of data from the regression equation. The model having the smallest value of the IAE can thus be judged to be the most reliable.

The AS 3700, CSA S304.1 and TMS 402 codes use tabulated values based on block strength and mortar type to estimate the compressive strength of ungrouted masonry. The Eurocode 6 code suggests using the following formula to determine the compressive strength of masonry:

$\mathrm{f}^{\prime} \mathrm{m}=\mathrm{K}\left(\mathrm{f}_{\mathrm{bln}}\right)^{\alpha}\left(\mathrm{f}_{\mathrm{mr}}\right)^{\beta}$

Where $\mathrm{K}, \alpha$ and $\beta$ are constants given in the national Annex for a particular country. The values of these constants in the UK are 0.52 (for hollow concrete block which have more than $25 \%$ but less than $60 \%$ of formed vertical voids or cavities, which pass completely through the block [31]), 0.7 and 0.3 respectively (Edgell et al. 2002). The term $\left(f_{b l n}\right)$ in Equation (7-8) is the normalised compressive strength of 100x100 units (BS EN 1015-11(1999)). The method of measurement for mortar in Eurocode 6 is done in accordance with BS EN1015-11where the compressive strength is determined on the broken parts of a flexural strength specimen. Ferguson (1995) demonstrated that on average the mean strength of such prisms is 1.28 times 
that of mortar cubes. As such, the $\mathrm{f}_{\mathrm{mr}}$ values used in Equation (7-8) to predict $\mathrm{f}_{\mathrm{m}}$ were the mortar cube strength increased by a factor of 1.28 .

The AS 3700 code uses the following formula to calculate $\mathrm{f}_{\mathrm{m}}^{\prime}$

$f^{\prime} m=K_{h} K_{m} \sqrt{f b l}$

Where:

$\mathrm{k}_{\mathrm{h}}=\mathrm{a}$ factor that accounts for the ratio of unit height to mortar joint thickness (for blocks of $190 \mathrm{~mm}$ high blocks and mortar joints with $10 \mathrm{~mm}$ thickness, $\mathrm{K}_{\mathrm{h}}$ is 1.3 ), and $\mathrm{k}_{\mathrm{m}}=\mathrm{a}$ factor that accounts for bedding type ( 1.4 for full bedding and 1.6 for face-shell bedding)

Table 7-5 summarizes the predictive ability for the considered masonry codes along with the proposed model. It can be noted that the proposed model gives the lowest average $f_{m}^{\prime}$ Exp $/ f_{m \text { Pred }}^{\prime}$ ratio, coefficient of variation and IAE for the entire database or any individual subset of the data (i.e., type $\mathrm{N}$ mortar, type $\mathrm{S}$ mortar, fully bedded, or face shell bedded). Figure 7-10 shows comparisons of the predictive abilities of the proposed model, CSA S304.1-04, TMS 402 and the AS 3700-2001 codes. It can be seen that the CSA S304.1 and AS 3700 codes significantly underestimate $\mathrm{f}_{\mathrm{m}}^{\prime}$ with high variations, whereas the proposed model and the TMS 402 code predict $\mathrm{f}_{\mathrm{m}}$ quite well.

As face shell bedding is the common practice in North America and Australia, it is worthwhile to compare the proposed model to North American codes and the Australian code for face shell bedded prisms (see Figure 7-11). Table 4 shows that the proposed model gives the lowest mean $\mathrm{f}_{\mathrm{m} \text { Exp }} / \mathrm{f}_{\mathrm{m} \text { Pred }}$ ratio at 1.24. It is also has the lowest COV at $13 \%$ and the lowest value of IAE at 
$18 \%$. The CSA code, on the other hand, has a mean $\mathrm{f}_{\mathrm{m} \text { Exp }} / \mathrm{f}_{\mathrm{m} \text { Pred }}$ ratio of 1.47 with a COV of $18 \%$ and IAE of $30 \%$. Since face shell bedding is the main practice in Canada, this underestimation shows the need to update CSA S304.1. It is clear from Figure 7-11 that AS 3700-2001 considerably underestimates $\mathrm{f}_{\mathrm{m}}$ for face shell bedded concrete masonry with a mean $\mathrm{f}_{\mathrm{m} \text { Exp }} / \mathrm{f}_{\mathrm{m} \text { Pred }}$ ratio of $1.88, \mathrm{COV}$ of $18 \%$ and IAE of $46 \%$.
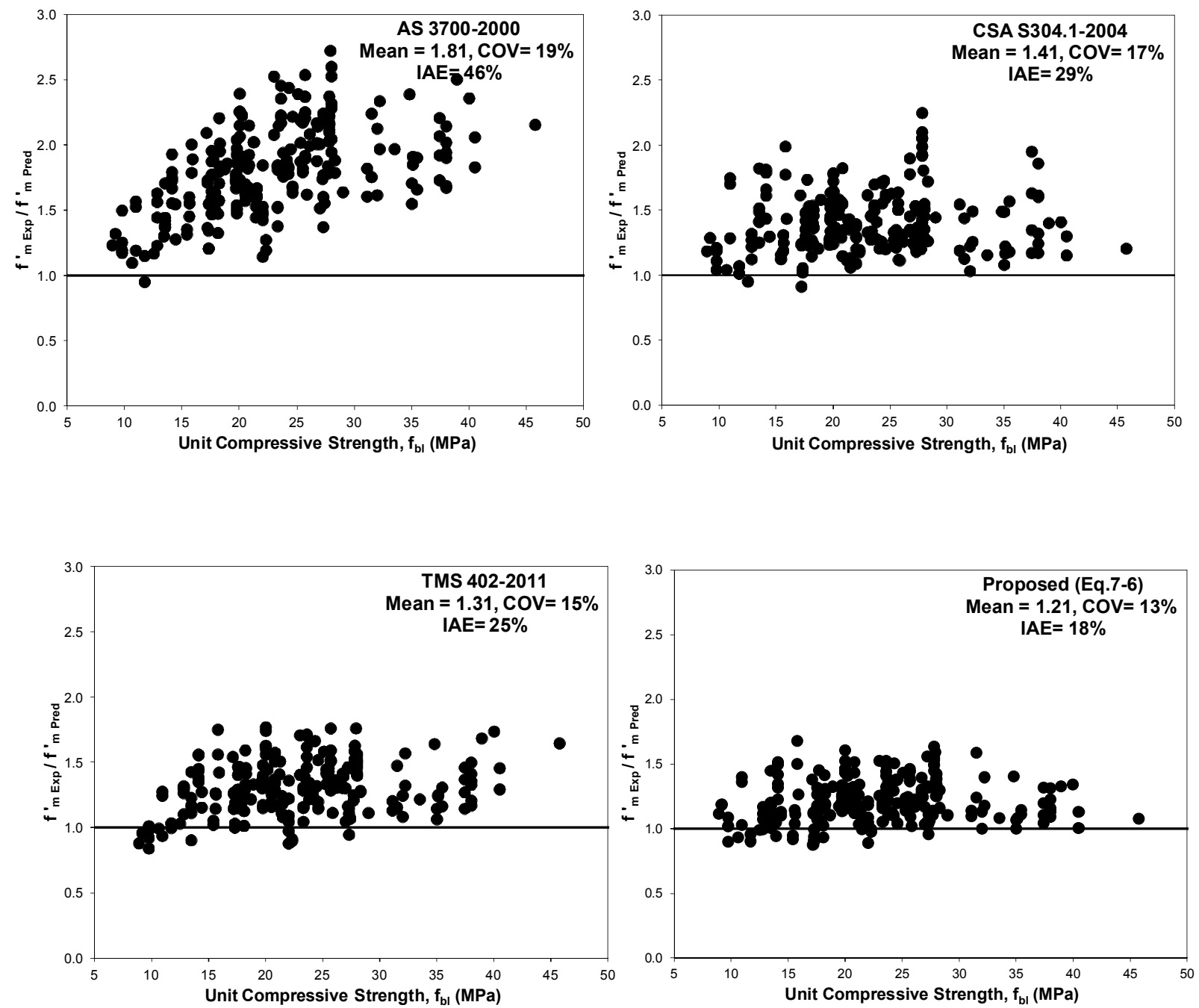

Figure 7-10: Comparison of Predictive Abilities of the AS 3700, CSA S304.1, TMS 402 Codes and Equation (7-6) for the Entire Database of Ungrouted Prisms 

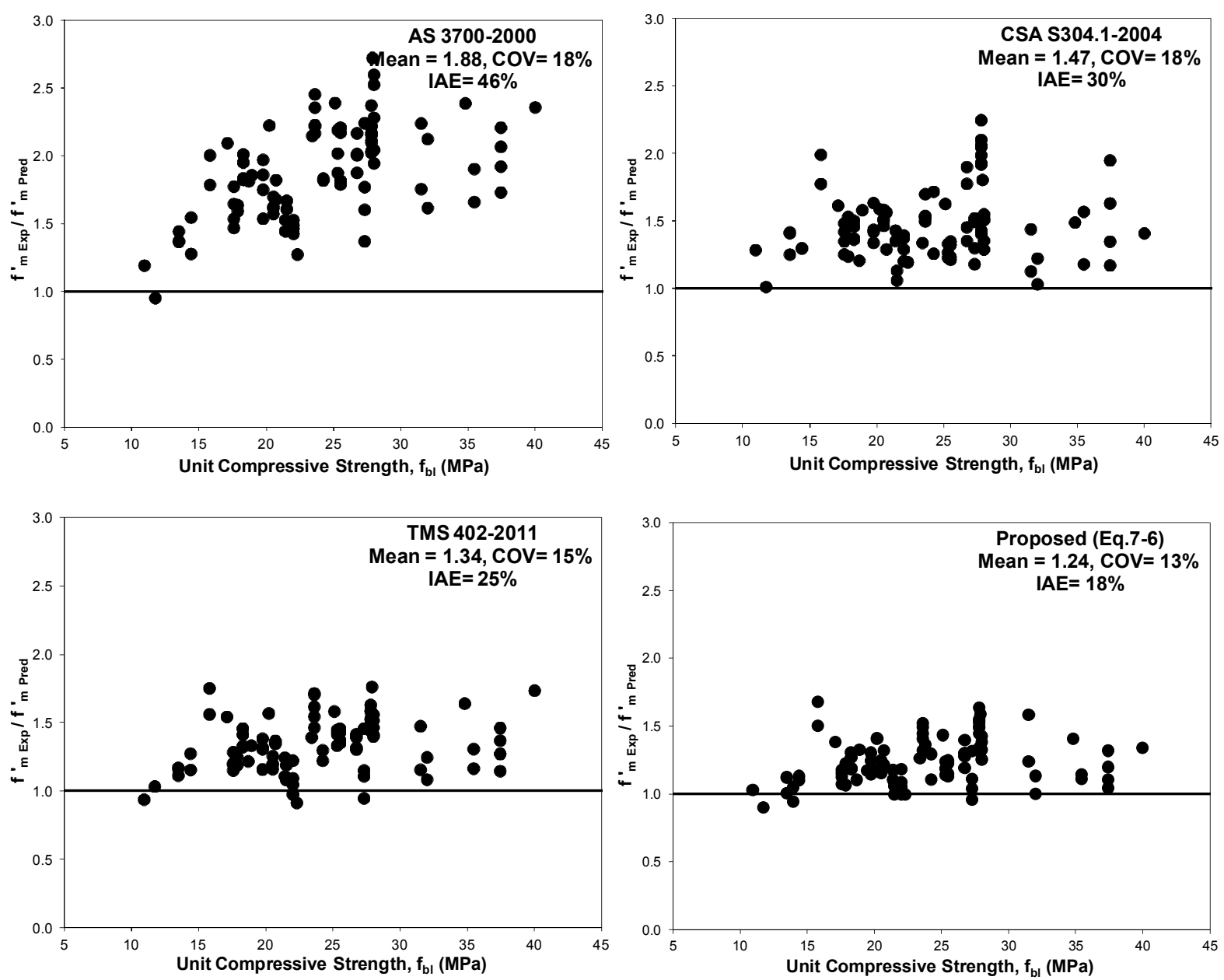

Figure 7-11: Comparison of Predictive Abilities of the AS 3700, CSA S304.1, TMS 402 Codes and Equation (7-6) for Face-shell Bedded Ungrouted Masonry

The British and the European masonry design codes consider full mortar bedding as the common practice with face-shell bedding as an alternative technique. Hence, it worthwhile to compare the predictive abilities of BS 5628 and Eurocode 6 to that of the proposed model using the fully bedded prisms in the database (see Figure 7-12). Despite the fact that its tabulated compressive strength values were derived based on correlation of fully bedded prisms, BS 5628-2 considerably underestimates of the compressive strength of the fully bedded prisms in the database with high variation. The BS 5628 has a mean $\mathrm{f}_{\mathrm{m} \text { Exp }} / \mathrm{f}_{\mathrm{m} \text { Pred }}$ ratio of $1.75, \mathrm{COV}$ of $17 \%$ 
and IAE of $43 \%$. Predictions by Eurocode 6 and the proposed model are more accurate and exhibit less variation with the proposed model having the lowest mean $\mathrm{f}_{\mathrm{m}}^{\prime}$ Exp $/ \mathrm{f}_{\mathrm{m} \text { Pred }}$ ratio, COV and IAE.
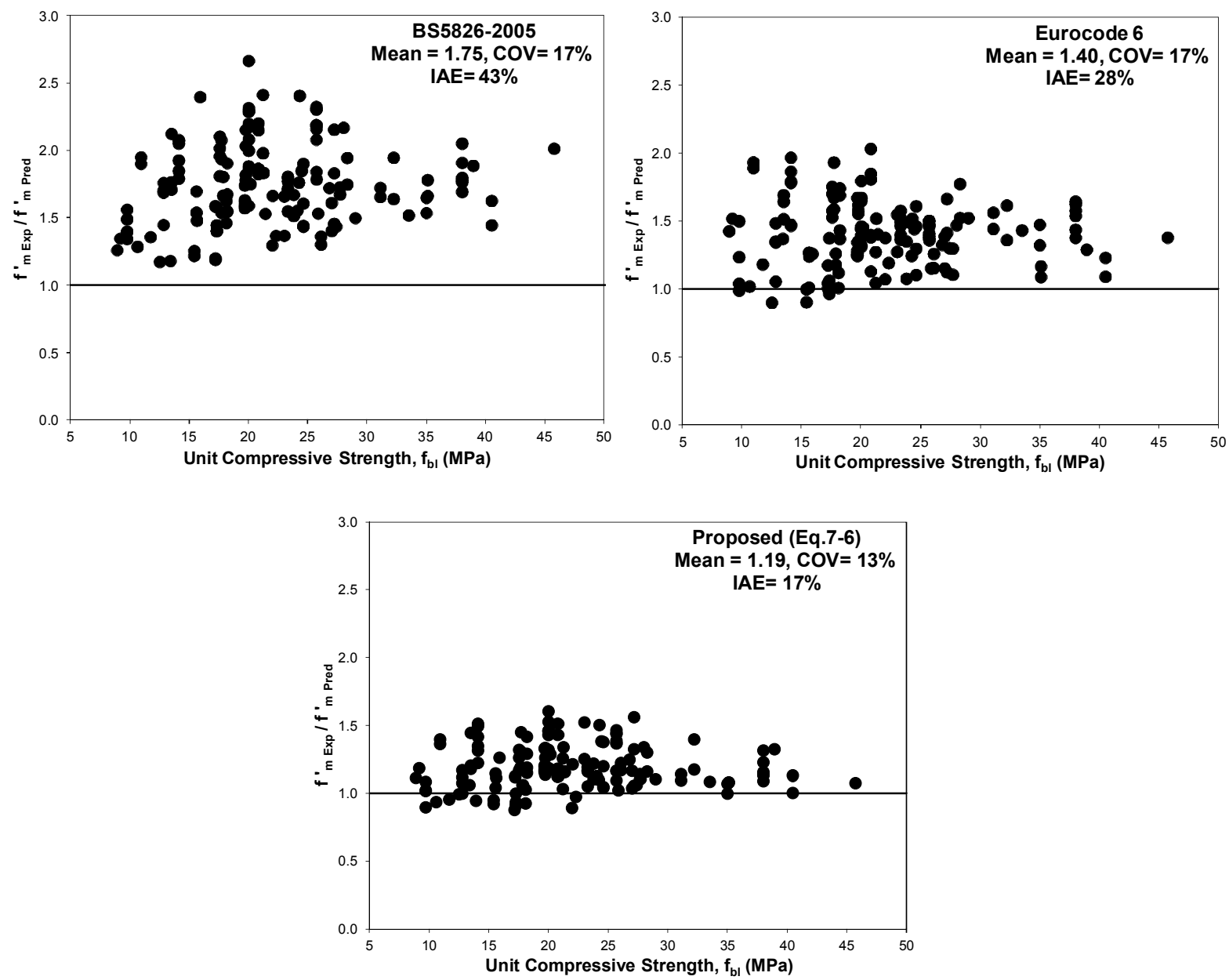

Figure 7-12: Comparison of Predictive Abilities of the BS5826-2, Eurocode 6 and Equation (7-6) for Fully Bedded Ungrouted Masonry

The breakdown of the database to prisms constructed with different mortar types shows that the CSA S304.1 code is overly conservative when predicting the compressive strength of masonry prisms constructed with type $\mathrm{N}$ mortar. The CSA S304.1 code gives a mean $\mathrm{f}_{\mathrm{m} \text { Exp }} / \mathrm{f}_{\mathrm{m}}$ Pred ratio of 1.51 with a COV of $19 \%$ and IAE of $35 \%$ for type $\mathrm{N}$ mortar prisms. Figure $7-13$ shows that 
the proposed formula gives consistently accurate predictions for both types of mortar. Any revision of the CSA S304.1 tabulated masonry strength values should target ungrouted masonry using type $\mathrm{N}$ mortar. As this type of prism makes up less than $39 \%$ of the database, more experimental work is needed for prisms constructed with type $\mathrm{N}$ mortar, particularly for high strength units.
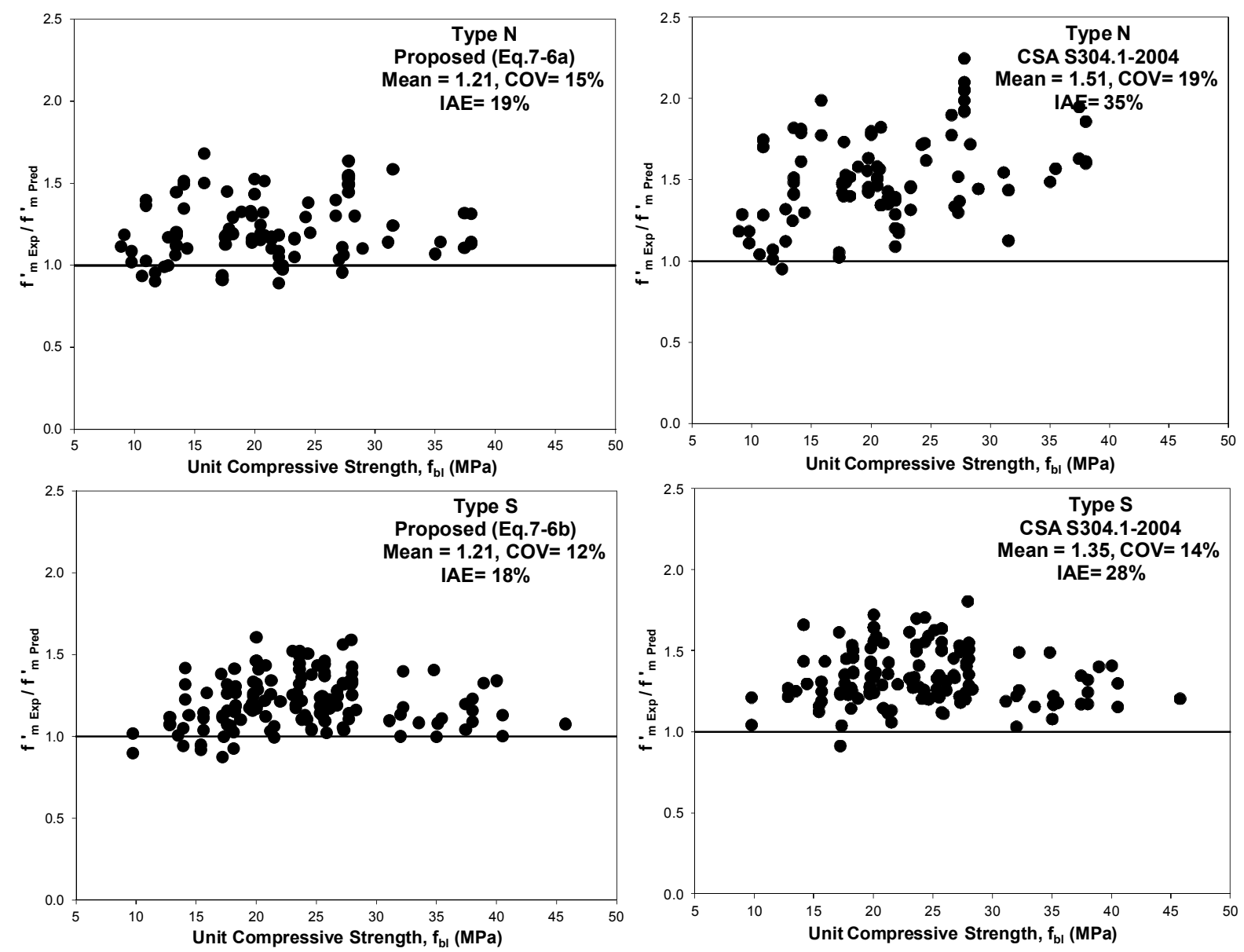

Figure 7-13: Comparison of Predictive Abilities of the CSA S304.1-2004 Code and Equation (76) For N Type Mortar and S Type Mortar Ungrouted Prisms 
Most masonry design codes deals with the specified (or characteristic) compressive strength rather than the average prism strength, where the specified strength is derived from a statistical analysis of multiple prism tests. Furthermore, tabulated specified masonry compressive strengths in design codes are typically based on the specified (or characteristic) compressive strength of the block. As the proposed model was derived based on average block strength and average prism strengths, Figure 7-14 was prepared to investigate the applicability of the model to predict specified $\mathrm{f}_{\mathrm{m}}$ values. In this figure, specified strength of unit and prisms were calculated by subtracting $1.64 \sigma$ from the mean strengths as per Annex C of CSA S304.1. The deviation was taken as the higher of the reported value or $10 \%$. If the reference did not report a standard deviation, $\sigma$ was taken to be $10 \%$. It can be clearly seen that the proposed model can accurately predict specified masonry strengths based on specified unit strengths with a degree of accuracy and reliability that exceeds CSA S304.1. On average specified masonry strengths are $14 \%$ higher using the proposed model than specified strengths obtained from CSA S304.1.
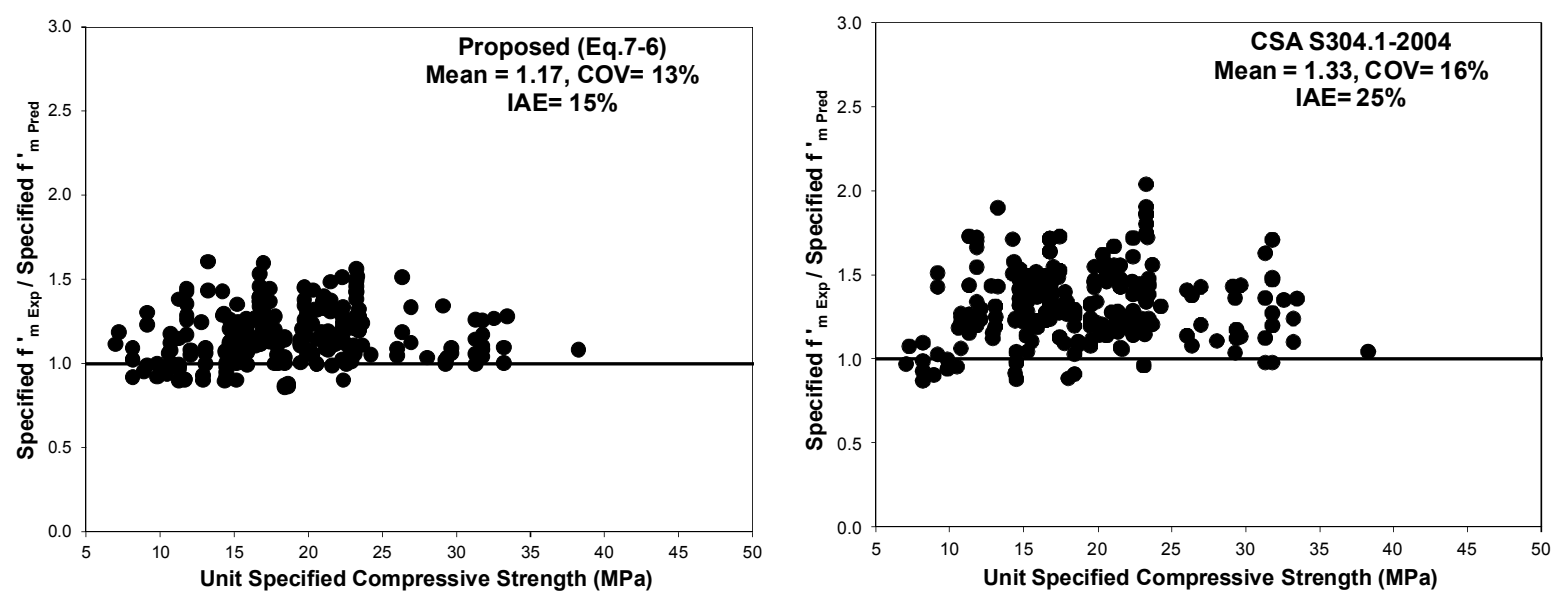

Figure 7-14: Comparison of Predictive Ability of Equation (7-6) and CSA S304.1-2004 Based on Specified Compressive Strength of Ungrouted Prisms 


\subsection{Prediction of Compressive Strength of Grouted Masonry}

\subsubsection{Experimental Database}

A large number of results of compressive tests on grouted concrete block masonry prisms were assembled from published literature (Drysdale and Hamid (1979, 1983), Boult (1979), Hamid et al. (1978), Drysdale and Hamid (1983), Romagna and Roman (1988), NCMA (1988, 2012), Scrivener and Baker (1988), Kingsley et al. (1989), Khalaf et al. (1994), Steadman et al. (1995), Baba and Senbu (1986), Khalaf (1996), Thompson et al. (2002), NCMA (2012), Hegmier et al. (1977), Cheema and Klingner (1984), Sakr and Neis (1989), Bexten et al. (1989), Olatunji et al. (1986), Guo (1991), Thomas and Scolforo (1995), Yao (1989), Ross et al. (2012), Das et al. (2014), and Foreste et al. (2014) ) (see Table 7-6). A total of 171 average masonry compressive strength data points, representing the test results of 624 individual prisms, was collected (see Appendix D for a full list of the gathered data points and the references).

The data was selected based the following criteria: a) where there was a choice of otherwise identical specimens within a test set, prisms with soft capping were excluded and those with hard capping were included; and b) prisms made out of block or grout with compressive strengths in excess of $50 \mathrm{MPa}$ or less than $10 \mathrm{MPa}$ were excluded so as to reasonably represent typical North American construction practice Table 7-7 shows the ranges of values for different parameters covered in the database. 
Table 7-6: Summary of Experimental Investigations Conducted on the Main Factors Affecting the Compressive Strength of Grouted Hollow Concrete Block Masonry

\begin{tabular}{|c|c|c|c|c|c|c|c|c|c|c|c|c|c|}
\hline \multirow[b]{3}{*}{ 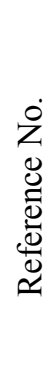 } & \multirow[b]{3}{*}{ Author } & \multirow[b]{3}{*}{ Year } & \multicolumn{11}{|c|}{ Experimentally Studied Factors } \\
\hline & & & \multicolumn{2}{|c|}{ Unit } & \multicolumn{2}{|c|}{ Mortar } & \multirow[b]{2}{*}{ 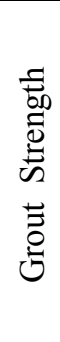 } & \multicolumn{6}{|c|}{ Prism } \\
\hline & & & $\begin{array}{l}\vec{E} \\
0 \\
0 \\
0 \\
0\end{array}$ & 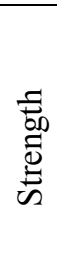 & 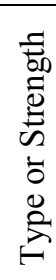 & 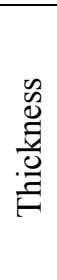 & & 孞 & \pm & 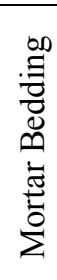 & 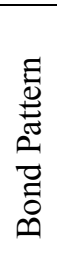 & 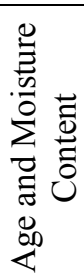 & $\begin{array}{l}\overline{\mathbf{s}} \\
\bar{\Xi}\end{array}$ \\
\hline 1 & Drysdale and Hamid & 1979 & $\sqrt{ }$ & & & $\sqrt{ }$ & $\sqrt{ }$ & & & & & & \\
\hline 2 & Boult & 1979 & & $\sqrt{ }$ & & & & & $\sqrt{ }$ & & & & \\
\hline 3 & Hamid et al. & 1979 & & & $\sqrt{ }$ & & $\sqrt{ }$ & & & $\sqrt{ }$ & & & \\
\hline 4 & Drysdale and Hamid & 1983 & & $\sqrt{ }$ & & & $\sqrt{ }$ & & & & & & \\
\hline 5 & Wong and Drysdale & 1985 & $\sqrt{ }$ & & & & $\sqrt{ }$ & & $\sqrt{ }$ & $\sqrt{ }$ & & & \\
\hline 6 & Romagna and Roman & 1988 & & $\sqrt{ }$ & $\sqrt{ }$ & & $\sqrt{ }$ & & & & & & \\
\hline 7 & NCMA Tests & 1988 & & $\sqrt{ }$ & $\sqrt{ }$ & & $\sqrt{ }$ & & & & & & \\
\hline 8 & Scrivener and Baker & 1988 & & $\sqrt{ }$ & $\sqrt{ }$ & & $\sqrt{ }$ & & & $\sqrt{ }$ & $\sqrt{ }$ & & \\
\hline 9 & Kingsley \& Noland & 1989 & & $\sqrt{ }$ & & & & & $\sqrt{ }$ & & & & \\
\hline 10 & Yao & 1989 & & & $\sqrt{ }$ & $\sqrt{ }$ & $\sqrt{ }$ & & & $\sqrt{ }$ & & & \\
\hline 11 & Khalaf et al. & 1994 & & $\sqrt{ }$ & & $\sqrt{ }$ & $\sqrt{ }$ & $\sqrt{ }$ & & & & & \\
\hline 12 & Steadman et al. & 1995 & & $\sqrt{ }$ & & & $\sqrt{ }$ & & & & & & \\
\hline 13 & Baba and Senbu & 1995 & & $\sqrt{ }$ & & & $\sqrt{ }$ & & & & & & \\
\hline 14 & Khalaf & 1996 & & $\sqrt{ }$ & $\sqrt{ }$ & $\sqrt{ }$ & $\sqrt{ }$ & $\sqrt{ }$ & $\sqrt{ }$ & & & & \\
\hline 15 & Thompson et al. & 2002 & & & & & & & & & & $\sqrt{ }$ & \\
\hline 16 & Dunkon & 2008 & & & & & $\sqrt{ }$ & & & & & & \\
\hline 17 & NCMA Tests & 2012 & & $\sqrt{ }$ & $\sqrt{ }$ & & $\sqrt{ }$ & & & & & & \\
\hline 18 & Ross et al. & 2012 & & $\sqrt{ }$ & & & & & & & & & \\
\hline 19 & Das et al. & 2014 & & & & & & & $\sqrt{ }$ & & & & \\
\hline 20 & Foreste et al. & 2014 & & $\sqrt{ }$ & $\sqrt{ }$ & & $\sqrt{ }$ & & & & & & \\
\hline 21 & Hegmier et al. & 1977 & & & & & & & & & $\sqrt{ }$ & & $\sqrt{ }$ \\
\hline 22 & Cheema and Klingner & 1984 & & & & & & & & & & & $\sqrt{ }$ \\
\hline 23 & Sakr and Neis & 1989 & & & & & & & & & & & $\sqrt{ }$ \\
\hline 24 & Baxtin et al. & 1989 & & & & & & & & & & & $\sqrt{ }$ \\
\hline 25 & Olatunji et al. & 1986 & & & & & & & & & & & $\sqrt{ }$ \\
\hline 26 & Guo & 1991 & & & & & $\sqrt{ }$ & & & & & & $\sqrt{ }$ \\
\hline 27 & Thomas and Scolforo & 1995 & & & & & & & & & & & $\sqrt{ }$ \\
\hline
\end{tabular}


Table 7-7: Ranges of the Values of the Main Factors Affecting $\mathrm{f}_{\mathrm{m}}^{\prime}$ of Grouted Masonry Covered in the Assembled Database

\begin{tabular}{|c|c|}
\hline Parameter & Range of the Parameter \\
\hline Unit compressive strength, MPa & $12.5-41.6$ \\
\hline Unit thickness, $\mathrm{t}$ mm & $140-240$ \\
\hline Unit solid ratio (\%) & $51-75$ \\
\hline Grouted area ratio (\%) & $25-49$ \\
\hline Grout compressive strength, MPa & $6.3-47.3$ \\
\hline Mortar joint thickness (mm) & $5-20$ \\
\hline Mortar compressive strength, MPa & $3.8-26.8$ \\
\hline h/t ratio & $1.81-6.25$ \\
\hline No. of prism sets & 171 \\
\hline Total No. of prisms & 624 \\
\hline No. of sets using Type N mortar & 42 \\
\hline No. of sets using Type S mortar & 129 \\
\hline
\end{tabular}

\subsubsection{Factors Influencing $\mathrm{f}_{\mathrm{m}}$ of Grouted Concrete Block Masonry}

A review of the database showed that a multitude of parameters affect the compressive strength of masonry prisms. Among these parameters, the unit strength, the mortar strength, the grout strength and the height to thickness ratio are the most influential factors.

\section{Influence of $h / t$}

Many researchers (Boult (1979), Wong and Drysdale (1985), Kingsley et al. (1989) and Khalaf (1996)) have shown that the measured compressive strength decreases as the ratio of a prism's height to its thickness $(\mathrm{h} / \mathrm{t})$ increases, though above a certain height the effect of $\mathrm{h} / \mathrm{t}$ becomes negligible (Kingsley et al. (1989)). This reduction is due primarily to the effect of reduced platen restraint (Wong and Drysdale (1985), Kingsley et al. (1989)), as h/t increases. The reported 
compressive strengths of 171 prism sets included in the database are plotted in Figure 7-15 versus the prism $\mathrm{h} / \mathrm{t}$ ratio. The general trend is linear, with about a $7.5 \%$ reduction in measured compressive strength with each unit increase in $\mathrm{h} / \mathrm{t}$ ratio.

Masonry design codes account for the effect of $\mathrm{h} / \mathrm{t}$ through the use of correction factors to convert $f_{m}$ measured using prisms of a certain $h / t$ to a standard $h / t$ (see Figure 7-16). These codes have different philosophies regarding the standard $\mathrm{h} / \mathrm{t}$ that should be used to determine $\mathrm{f}^{\prime} \mathrm{m}$. The TMS MSJC code considers an $\mathrm{h} / \mathrm{t}$ of 2 as the standard for determining $\mathrm{f}_{\mathrm{m}}^{\prime}$ and applies a correction factor varying from 0.75 for $h / t=1.3$ to 1.22 for $h / t=5$. Other codes use an $h / t$ of 5 as the standard based on the assumption that taller prisms are more representative of in-situ masonry. As such, they apply a reduction factor to $\mathrm{f}_{\mathrm{m}}$ values established by tests on prisms where $\mathrm{h} / \mathrm{t}$ is less than 5 .

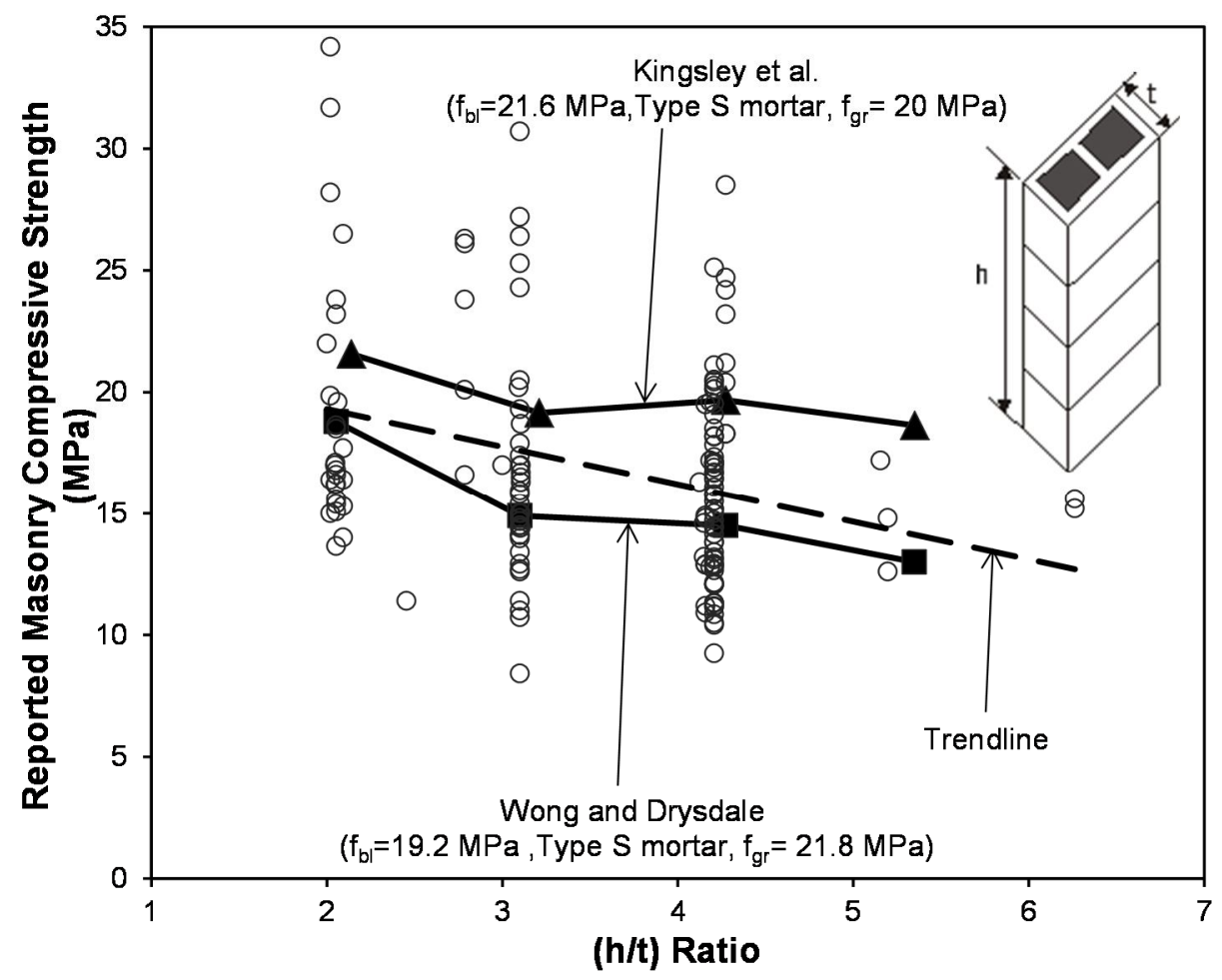

Figure 7-15: Effect of h/t Ratio on the Compressive Strength of Grouted Concrete Block Masonry 
The proposed formula adopts the CSA S304.1-04, AS 3700-2001 and BS 5628-2:2005 standard prism $\mathrm{h} / \mathrm{t}$ ratio of 5. As such, the reported compressive strengths plotted in Figure 7-15 were normalized in the database by multiplying them by the factor $(1-0.075(5-\mathrm{h} / \mathrm{t}))$ reflecting the linear trend observed in Figure 7-15. Reported compressive strengths that have been normalized for the $\mathrm{h} / \mathrm{t}$ ratio are identified as $\mathrm{f}_{\mathrm{m}}$ values in all subsequent figures and discussions.

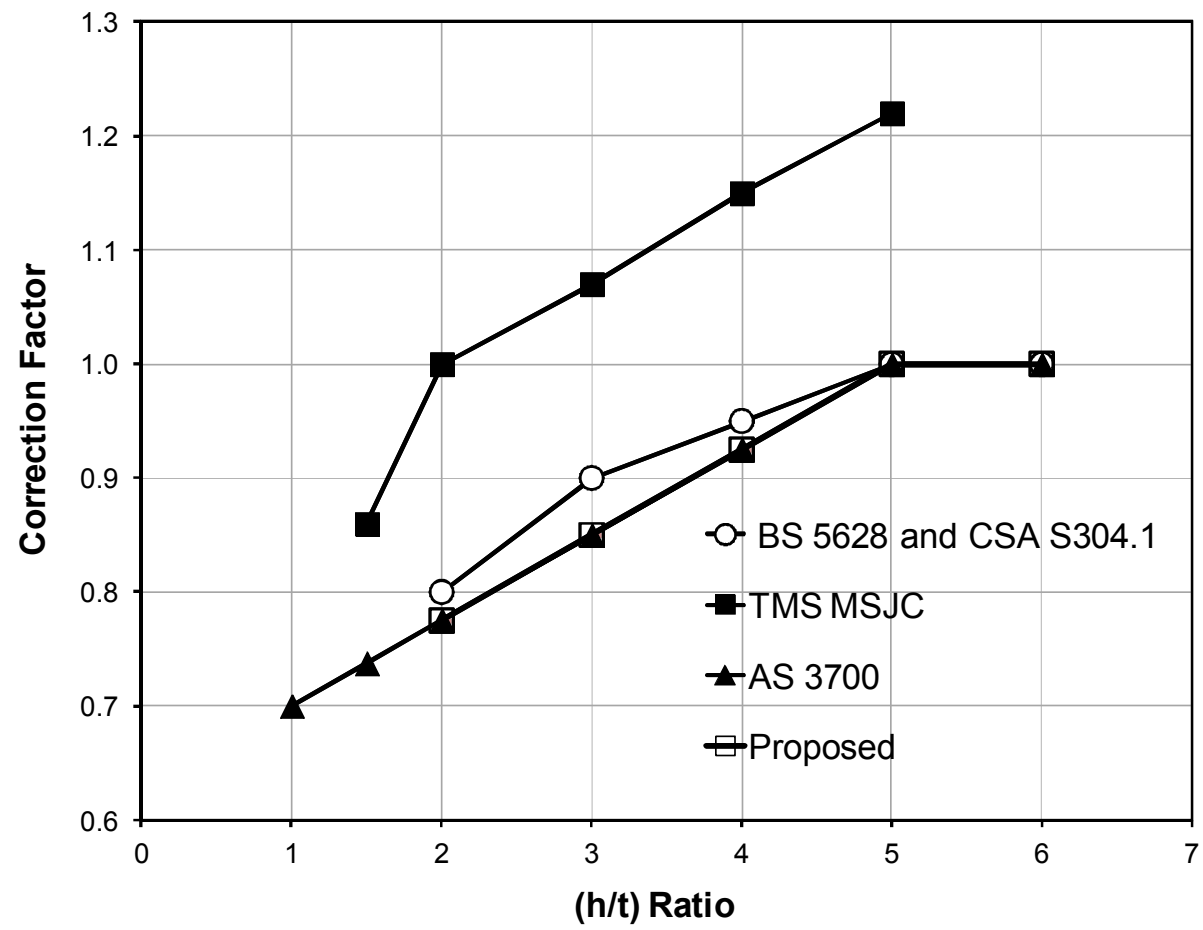

Figure 7-16: Correction Factors for h/t Ratios of Grouted Concrete Block Masonry in Different International Masonry Design Codes

\section{Influence of unit compressive strength $\left(f_{b l}\right)$}

Numerous tests (Boult (1979), Drysdale and Hamid (1983), Romagna and Roman (1988),

NCMA (1988), Scrivener and Baker (1988), Kingsley et al. (1989), Steadman et al. (1995), Baba and Senbu (1986), Khalaf (1996) and NCMA 2012)) have revealed that the compressive strength of grouted masonry prisms increases with an increase in compressive strength of the unit $\left(f_{b l}\right)$ 
(see Figure 7-17). Compressive failure of a grouted prism is associated with vertical tensile cracking in the unit followed by splitting of the unit, often with the grout cores left largely intact. This failure mechanism occurs due to differences between the Poisson's ratios and stiffnesses of the grout and unit leading to the unit failing prior to the grout (Drysdale and Hamid (1979)). Given that compressive failure of a prism is thus partly related to the tensile strength of the concrete used in the block, it would be expected that a non-linear relationship exists between block strength and prism strength. While there is some evidence of such a relationship in Figure 7-17 when results from individual test series are identified (Romagna and Roman (1988)), it is apparent that within the range of common block strengths the relationship between prism strength and block strength is roughly linear. It must be noted that unit compressive strengths reported in the references used in the database were expressed either in terms of net or gross areas. To unify the database, $\mathrm{f}_{\mathrm{bl}}$ was expressed in the database in terms of net area.

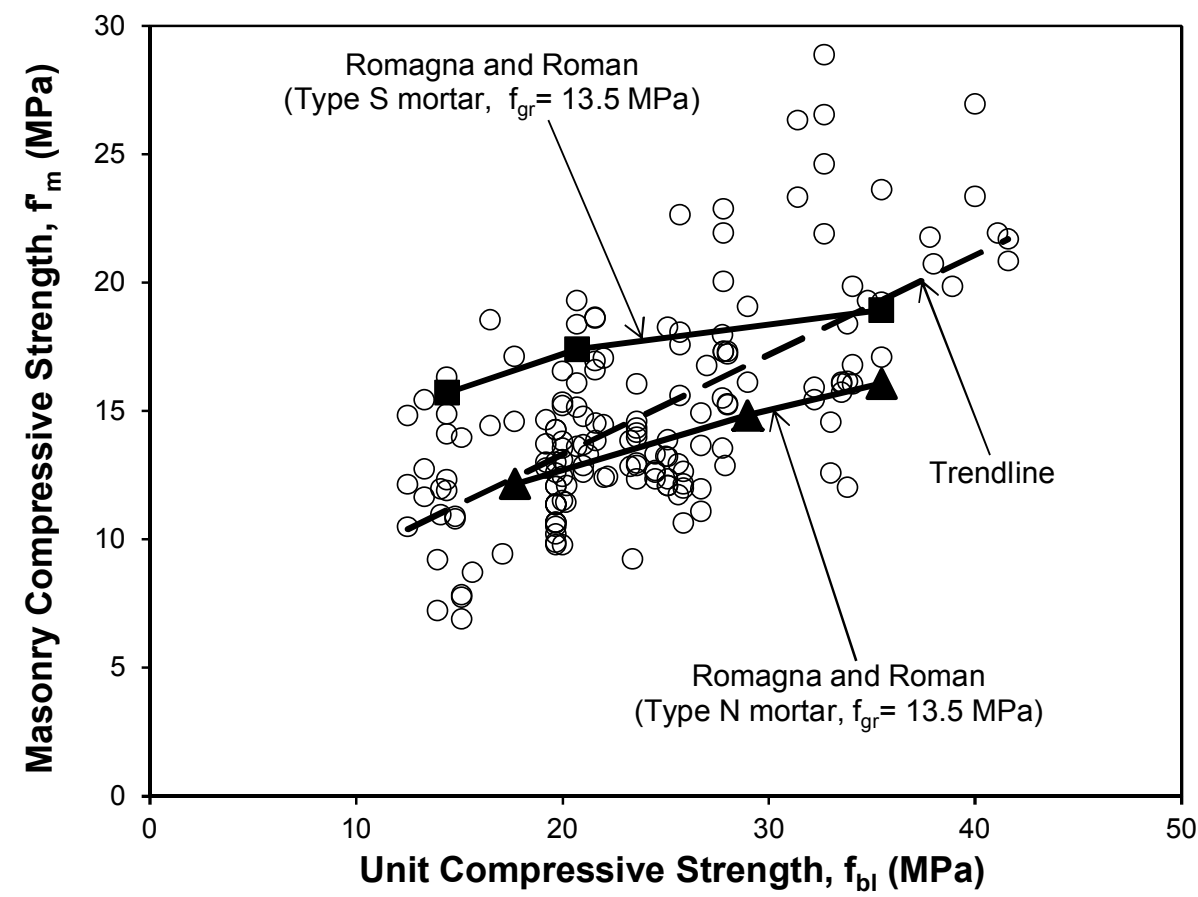

Figure 7-17: Effect of Unit strength on the Compressive Strength of Grouted Concrete Block Masonry 


\section{Influence of mortar strength $\left(f_{m r}\right)$}

Multiple researchers (Hamid et al. (1978), Romagna and Roman (1988), NCMA (1988), Scrivener and Baker (1988), Khalaf (1996), Thompson et al. (2002) and NCMA (2012)) have shown that mortar compressive strength $\left(f_{\mathrm{mr}}\right)$ affects prism strength, though the compressive strength of grouted masonry is less influenced by mortar properties than that of ungrouted masonry due to the presence of grout and its major role in the carrying compressive loads (Drysdale and Hamid (1979), Khalaf (1996)). Indeed, considerable scatter is observed in Figure 7-18, wherein $\mathrm{f}_{\mathrm{m}}$ is plotted versus the mortar strength. Despite the scatter, a general trend that $\mathrm{f}_{\mathrm{m}}$ increases when mortar strength increases can be observed.

It must be noted that mortar compressive strengths reported in the references covered in the database were measured by testing either cubes or cylinders. The database was unified by expressing mortar strength $\left(f_{\mathrm{mr}}\right)$ in terms of cube strength. A factor of $1 / 0.85$ was used to convert reported cylinder compressive strengths to cube compressive strengths (Singh (1988)), and Figure 7-18 expresses $f_{m r}$ in terms of the cube strength. 


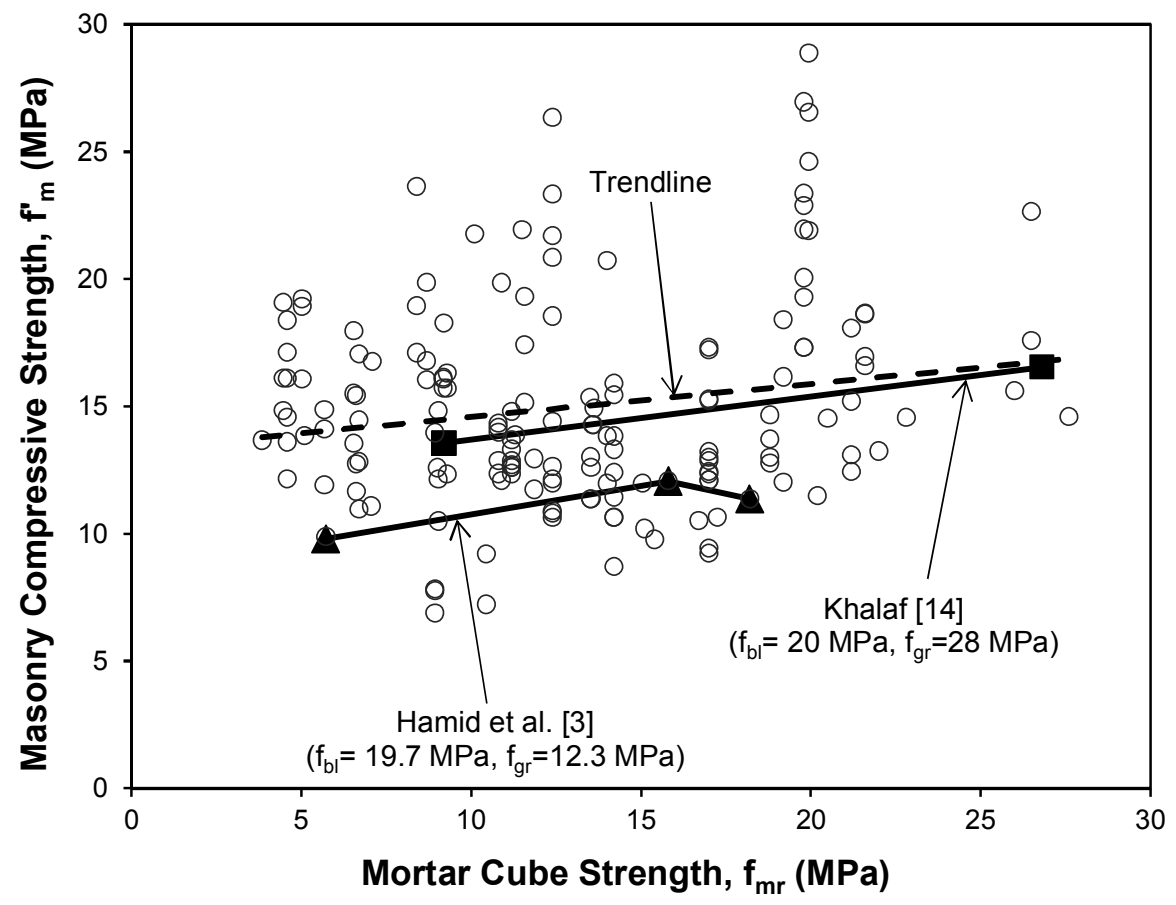

Figure 7-18: Effect of Mortar Strength on the Compressive Strength of Grouted Concrete Block Masonry

\section{Influence of grout strength $\left(f_{g r}\right)$}

Many researchers (Drysdale and Hamid (1979), Hamid et al. (1978), Drysdale and Hamid (1983), Wong and Drysdale (1985), Romagna and Roman (1988), NCMA (1988), Scrivener and Baker (1988), Khalaf et al. (1994), Steadman et al. (1995), Baba and Senbu (1986), Khalaf (1996) and NCMA (2012)) have studied the effect of grout strength on $\mathrm{f}_{\mathrm{m}}$. The general trend is that increasing grout strength results in increasing prism strength for all different block strengths (see Figure 7-19), so long as the grout is adequately consolidated. However, only a portion of the grout strength is effective in the determination of the prism strength given that prism failure is characterized by block crushing rather than grout crushing. Several investigations ((Drysdale and Hamid (1979), Romagna and Roman (1988), Khalaf (1996) and Fortes et al. (2014)) have revealed that the best compressive strength results can be achieved when the deformation 
characteristics of the grout (such as stiffness and Poisson's ratio) matches those of the concrete block. It has been found that this can be achieved by using a grout compressive strength that is 1.5 times that of the concrete block ((Drysdale and Hamid (1979), Khalaf(1996) and Fortes et al. (2014))

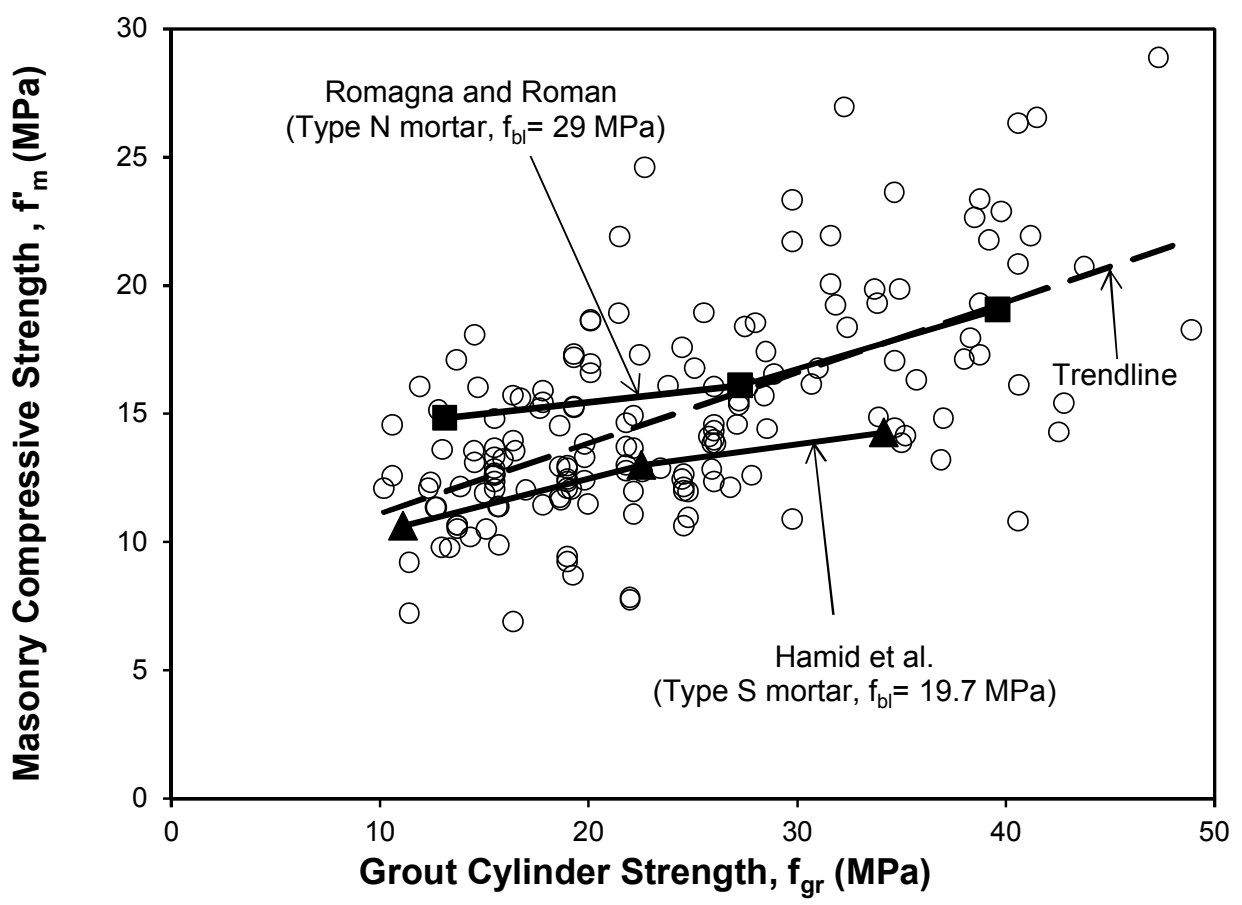

Figure 7-19: Effect of Grout Strength on the Compressive Strength of Grouted Concrete Block Masonry

Grout strengths in the references were determined by testing different types of specimens: cubes, cylinders or absorbent block moulded prisms. The grout compressive strength is unified based on the cylinder strength, with a height to diameters ratio of 2 . A factor of 0.85 was used to convert cube compressive strength to equivalent cylinder compressive strength. To convert grout compressive strength of block moulded prisms to equivalent cylinder compressive strength, the empirical formula developed by Neville (1966) and adopted by Hamid et al. (1980) was used: 


$$
\frac{f_{g r}}{P_{g}}=\frac{0.85}{\left(0.56+\frac{0.697}{\left(\frac{V 1}{6 h_{g} d_{g}}+\frac{h_{g}}{d_{g}}\right)}\right)} \quad\left(\mathrm{V} 1, h_{g} \text { and } d_{g} \text { in }(\mathrm{mm})\right)
$$

Where:

$\mathrm{f}_{\mathrm{gr}}=$ Grout cylinder compressive strength

$\mathrm{P}_{\mathrm{g}} \quad=$ Grout prism compressive strength

$\mathrm{d}_{\mathrm{g}} \quad=$ Maximum lateral dimension of the grout prism

$\mathrm{h}_{\mathrm{g}} \quad=$ Height of the grout prism

$\mathrm{Vl}=$ Volume of the grout prism

\subsubsection{Regression Analysis}

Since the majority of the experimental results were reported without variation values (standard deviation or coefficient of variation) for either one or all of the unit, mortar, grout and prism strengths, the derivation of the proposed model was based on the average strength of the prisms, unit, mortar and grout. A regression analysis based on the least squares method was conducted with the compressive strength of the masonry prisms (normalized for $h / t$ ), $\mathrm{f}_{\mathrm{m}}$, considered to be a dependent variable and block strength, $\mathrm{f}_{\mathrm{bl}}$, mortar cube strength, $\mathrm{f}_{\mathrm{mr}}$, and grout cylinder strength, $\mathrm{f}_{\mathrm{gr}}$, considered to be the independent variables. Various linear, power and multiple linear regression models were examined to obtain the most representative formula. Note that models (g) to (j) were formulated as a portion of the ungrouted strength plus a contribution from the grout. In these models, the ungrouted strength is taken as equal to $\left(1.107 \mathrm{fbl}^{0.75} \mathrm{fmr}^{0.18}\right)$ as in 
Equation (7-1). The goodness of fit of these regression models was verified based on the following checks (Montgomery (2012)): coefficient of multiple determinations $\left(\mathrm{R}^{2}\right)$, test for significance of regression, and tests on individual regression coefficients. Further tests were performed on residuals such as residual analysis on normal probability plots and residuals versus predicted values. Table 7-7 summarizes the models considered in this analysis with their values of multiple determinations $\left(\mathrm{R}^{2}\right)$. The multiple linear model (model (e)) exhibited the highest coefficient of determination at $72 \%$, meaning that this model can explain $72 \%$ of the variation between experimentally observed and predicted values of $\mathrm{f}_{\mathrm{m}}$. This model (Equation (7-11)) gives an average ratio of experimentally determined $\mathrm{f}_{\mathrm{m}}$ to predicted $\mathrm{f}_{\mathrm{m}}\left(\mathrm{f}_{\mathrm{m}} \mathrm{fxp}_{\mathrm{Exp}} / \mathrm{f}_{\mathrm{m}}\right.$ Pred $)$ of 1.0 with a coefficient of variation of $15 \%$.

$\mathrm{f}^{\prime} \mathrm{m}=0.29 \mathrm{fbl}+0.10 \mathrm{fmr}+0.21 \mathrm{fgr}+1.51$

The adequacy of Equation (7-11) is illustrated in Figure 7-20a. When the experimental values of $\mathrm{f}_{\mathrm{m}}$ are plotted against the predicted values predicted by Equation (7-11), the data points are consistently distributed around the line of equality. It can be further seen from Table 7-8 and Figure 5-20b that correlating the compressive strength of grouted prisms to only the unit compressive strength and the mortar type (as is done in various masonry codes) leads to formulae with poor representation. Another indication of the adequacy of Equation (7-11) is presented in Figure 7-21, wherein the residuals for Equation (7-11) are plotted against the block strength. The trend line is horizontal and located at zero, thus residuals neither increase nor decrease with $\mathrm{f}_{\mathrm{bl}}$. 
Table 7-8: Coefficients of Multiple Determination for Different Statistical Models of Grouted Prisms

\begin{tabular}{|c|c|c|}
\hline \multicolumn{2}{|r|}{ Statistical Models } & Coefficient of Multiple \\
\hline a & $f^{\prime} \mathrm{m}=0.375 \mathrm{fbl}+5.88$ & 0.42 \\
\hline b & $\mathrm{f}^{\prime} \mathrm{m}=2.14(\mathrm{fbl})^{0.61}$ & 0.41 \\
\hline c & $f^{\prime} m=0.008(\mathrm{fbl})^{0.61}-0.054(\mathrm{fbl})+11.01$ & 0.43 \\
\hline \multirow{2}{*}{ d } & $\begin{array}{c}\text { N Type Mortar } \\
\mathrm{f}^{\prime} \mathrm{m}=3.872(\mathrm{fbl})^{0.406}\end{array}$ & 0.23 \\
\hline & $\begin{array}{c}\text { S Type Mortar } \\
\mathrm{f}^{\prime} \mathrm{m}=1.734(\mathrm{fbl})^{0.677}\end{array}$ & 0.40 \\
\hline e & $\mathrm{f}^{\prime} \mathrm{m}=0.29 \mathrm{fbl}+0.10 \mathrm{fmr}+0.21 \mathrm{fgr}+1.51$ & 0.72 \\
\hline$f$ & $\mathrm{f}^{\prime} \mathrm{m}=0.28 \mathrm{fbl}+0.06 \mathrm{fmr}+1.55 \sqrt{\mathrm{fgr}}+1.21$ & 0.51 \\
\hline $\mathrm{g}$ & $f^{\prime} m=0.47\left(1.107 \mathrm{fbl}^{0.75} \mathrm{fmr}^{0.18}\right)^{*}+0.22 \mathrm{fgr}+0.84$ & 0.64 \\
\hline h & $\mathrm{f}^{\prime} \mathrm{m}=0.48\left(1.107 \mathrm{fbl} \mathrm{fmr}^{0.75} \mathrm{fm}^{0.18}+2.14 \sqrt{\mathrm{fgr}}-4.33\right.$ & 0.64 \\
\hline $\mathrm{i}$ & $\mathrm{f}^{\prime} \mathrm{m}=0.92 \mathrm{An}\left(1.107 \mathrm{fbl}{ }^{0.75} \mathrm{fmr}{ }^{0.18}\right)^{*}+0.22(1-\mathrm{An}) \mathrm{fgr}+0.64$ & 0.62 \\
\hline${ }^{j}$ & $\mathrm{f}^{\prime} \mathrm{m}=\mathrm{An}\left(1.107 \mathrm{fbl}^{0.75} \mathrm{fmr}^{0.18}\right)^{*}+3.43(1-\mathrm{An}) \sqrt{\mathrm{fgr}_{\mathrm{gr}}}-2.93$ & 0.59 \\
\hline
\end{tabular}

$\mathrm{f}^{\prime}{ }_{\mathrm{m}}$ of ungrouted masonry (Equation (7-1)) 
a)

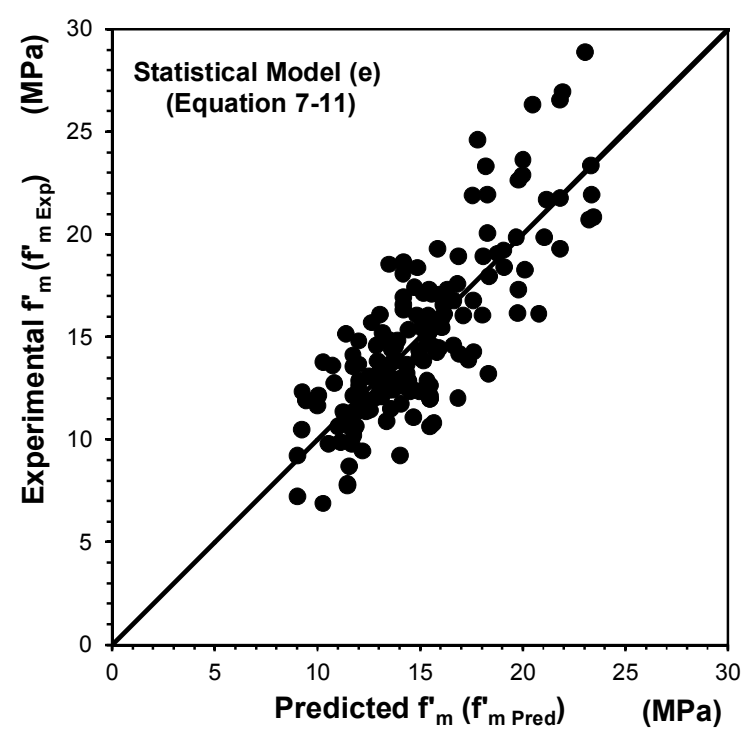

b)

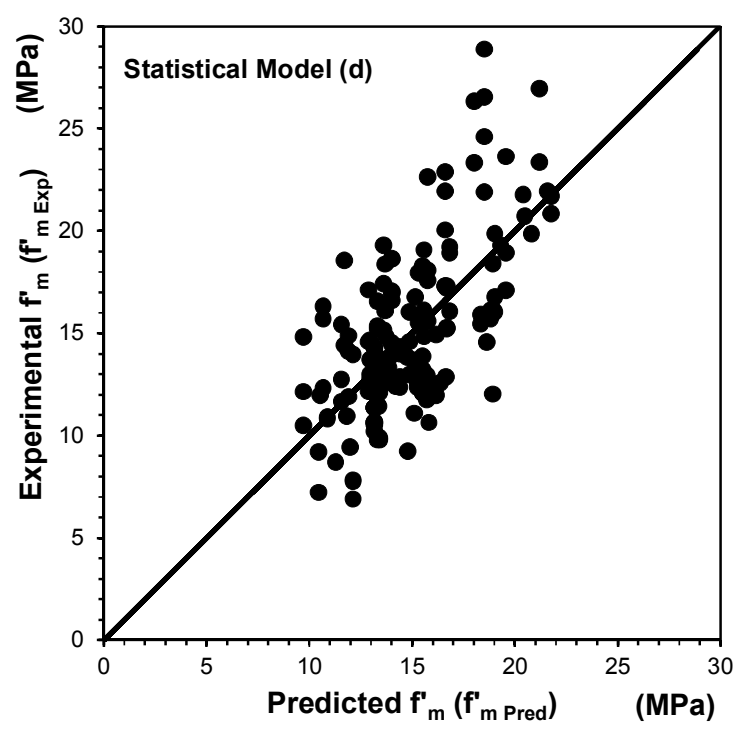

Figure 7-20: Adequacy of Equation (7-11) Compared to the Unit Strength Model

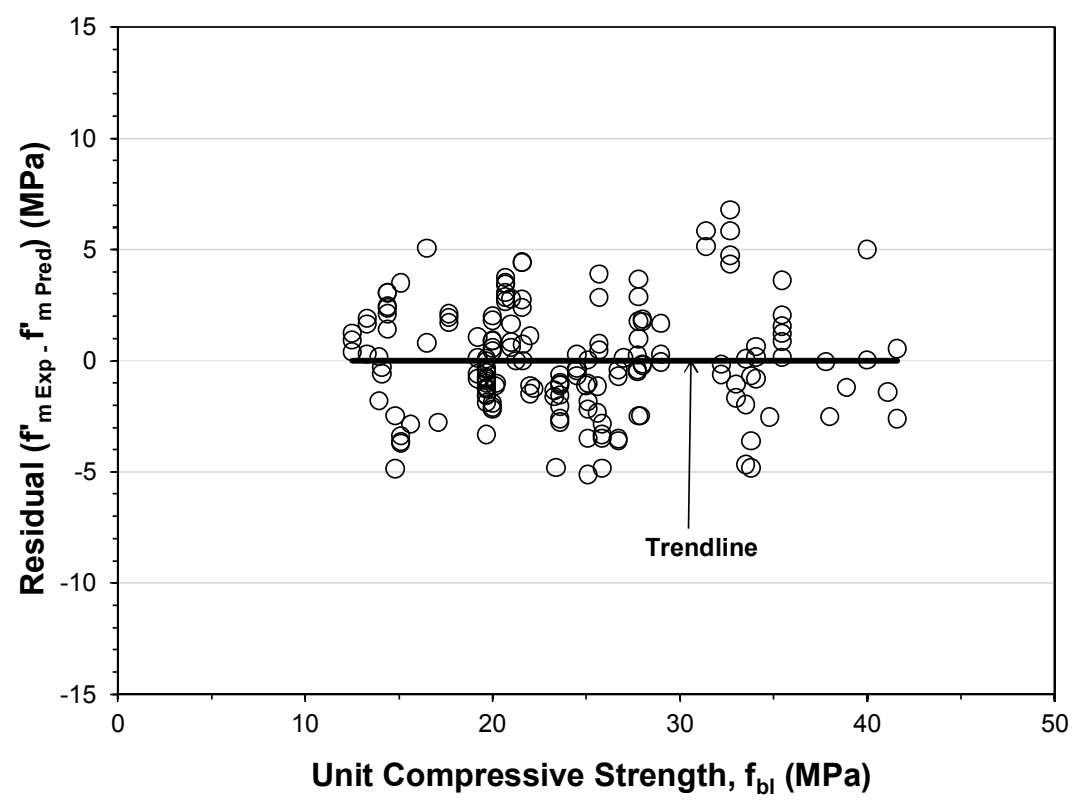

Figure 7-21: Distribution of Residuals of Equation (7-11) Plotted Against $\mathrm{f}_{\mathrm{bl}}$

\subsubsection{The Proposed Model}

When used for design purposes, the proposed model needs to be associated with a margin of safety through setting a confidence lower limit. The CSA S304.1 code, Gayed and Korany 
(2011) and Ross and Korany (2012), for instance, used reduction factors to ensure that $90 \%$ of the predicted prism strengths exceeded the experimentally determined values. In the current study, it was decided to use this $90 \%$ confidence limit. Assuming the $\mathrm{f}_{\mathrm{m}} \mathrm{Exp}^{\prime} / \mathrm{f}_{\mathrm{m}}^{\prime}$ Pred ratios to be normally distributed, the $90 \%$ confidence limit can be calculated by subtracting 1.28 standard deviations from the arithmetic mean. For a mean of 1.0 and a standard deviation of 0.15 the confidence lower limit is 0.81 , and the application of this limit means that we can be confident by $90 \%$ that the $f_{m \text { Exp }} / f_{m}$ Pred ratio will be equal to or greater than 1.0 (see Figure 7-22). Thus the proposed formula (Equation (7-11)) can be re-written as follows:

$\mathrm{f}^{\prime} \mathrm{m}=0.81\{0.29 \mathrm{fbl}+0.10 \mathrm{fmr}+0.21 \mathrm{fgr}+1.51\}$

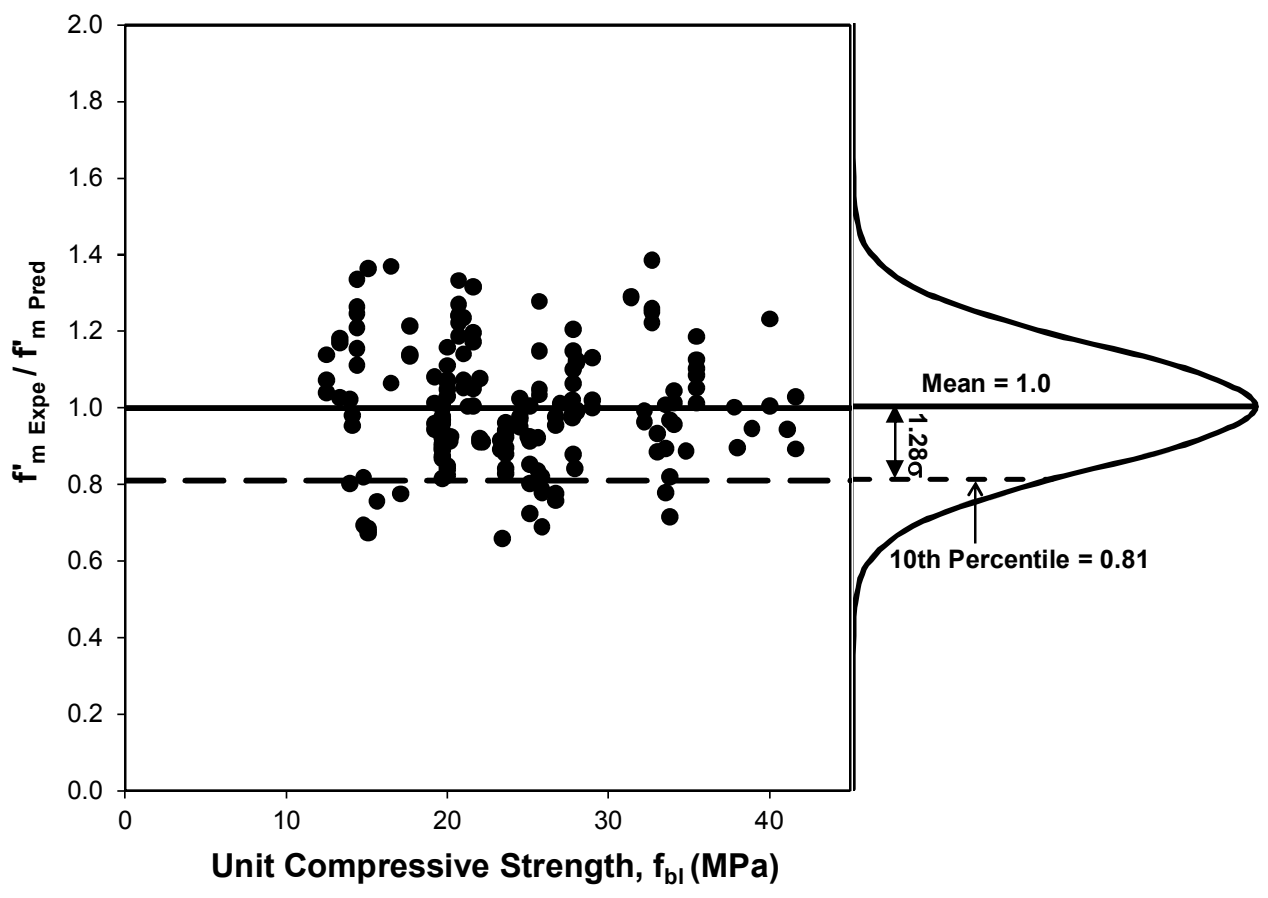

Figure 7-22: Application of the $90 \%$ confidence lower limit to the proposed model 
The proposed formula (Equation (7-12)) is valid for the range of : a) grouted prisms made out of hollow concrete blocks having a An ratio of 0.4 to $0.75, \mathrm{~b}$ ) block strengths (based on net area) of 10 to $50 \mathrm{MPa}, \mathrm{c})$ cylinder grout strength of 10 to $50 \mathrm{MPa}$. Furthermore, the grout strength used in the proposed model is limited to a maximum of 1.5 times the block strength, as recommended by Fortes et al. (2014), and d) mortar cube strength of less than 30MPa.

A graphical form of Equation (7-12) is presented in Figure 7-23, and this can be used to simplify the determination of $\mathrm{f}_{\mathrm{m}} \mathrm{using}$ Equation (7-12). For example, for a set of grouted masonry prisms (tested by NCMA (2012)) made out of 14.1 MPa blocks, type N mortar with strength of 6.7 $\mathrm{MPa}$ and grout with strength of $24.8 \mathrm{MPa}$. As the grout strength is greater than 1.5 times of the block strength, its value will be limited to $1.5 \times 14.1 \mathrm{MPa}=21.2 \mathrm{MPa}$. Figure 7-23 can be used to determine that $\mathrm{f}_{\mathrm{m}}=\mathrm{A}+\mathrm{B}+\mathrm{C}=4.5+3.6+0.6=8.7 \mathrm{MPa}$. The experimentally measured $\mathrm{f}_{\mathrm{m}}$ (normalized for a $\mathrm{h} / \mathrm{t}$ ratio of 5) was $10.92 \mathrm{MPa}$ leading to $\mathrm{f}_{\mathrm{m} \text { Exp }} / \mathrm{f}_{\mathrm{m}}$ Pred ratio of 1.25. CSA S304 code significantly underestimates the compressive strength of this set of prisms and gives $\mathrm{f}_{\mathrm{m} \text { Exp }} /$ $\mathrm{f}_{\mathrm{m} \text { Pred }}$ ratio of 2.1 


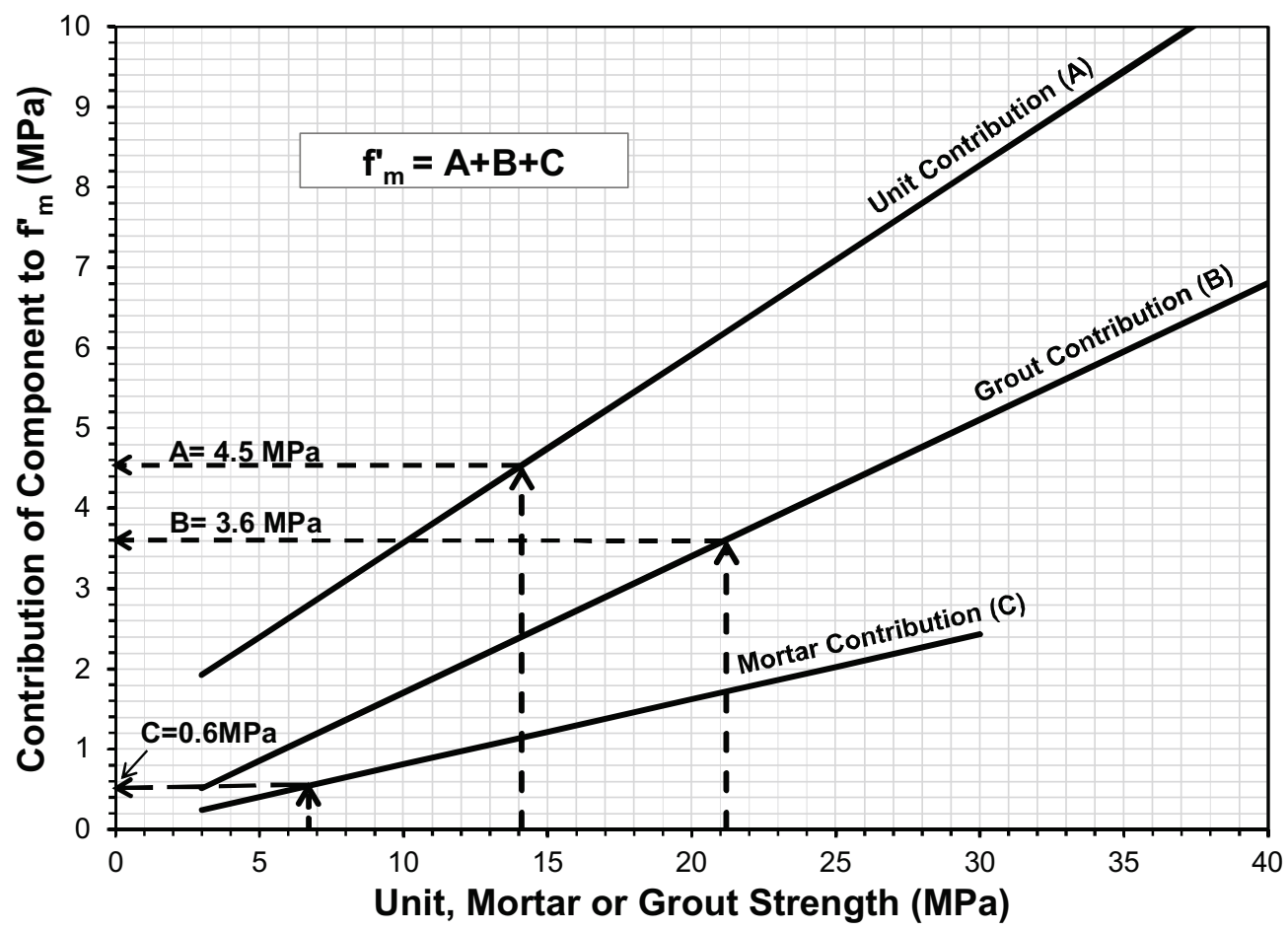

Figure 7-23: Graphical Form for the Proposed Formula

For grouted masonry prisms built with $\mathrm{h} / \mathrm{t}$ other than $5, \mathrm{f}_{\mathrm{m}} \mathrm{can}$ be predicted by applying a correction factor, $\mathrm{C}_{\mathrm{hg}}$, to Equation (7-12) as indicated in Equation (7-13).

$$
f^{\prime} m=0.81 C h g\{0.29 f b l+0.10 f m r+0.21 f g r+1.51\}
$$

Where $\mathrm{C}_{\mathrm{hg}}$ is a factor to account for the $\mathrm{h} / \mathrm{t}$ ratio which can be taken as:

$$
\begin{array}{ll}
\mathrm{Chg}_{\mathrm{hg}}=\frac{1}{(1-0.075(5-\mathrm{h} / \mathrm{t}))} & \text { for } \mathrm{h} / \mathrm{t}<5 \\
\mathrm{Chg}_{\mathrm{h}}=1 & \text { for } \mathrm{h} / \mathrm{t} \geq 5
\end{array}
$$




\subsubsection{Results and Discussions}

The predicted compressive strengths of the prisms included in the database were generated using Khalaf et al.'s model [11] and the five international masonry design codes along with the proposed model (Equation (7-12)), and the ratios of $\mathrm{f}_{\mathrm{m} \text { Exp }} / \mathrm{f}_{\mathrm{m}}$ Pred were calculated for each data point (a sample of calculations is presented in Table 7-9). The mean $\mathrm{f}_{\mathrm{m} \text { Exp }} / \mathrm{f}_{\mathrm{m}}^{\prime}$ Pred ratios, standard deviations, coefficients of variation (COV \%), number and percentage of overpredicted data $\left(\mathrm{f}_{\mathrm{m}}\right.$ Exp $/ \mathrm{f}_{\mathrm{m}}$ Pred ratio with value less than 1.0) and the integral absolute errors (IAE \%) for each model were calculated and summarized in Table 7-10. Comparisons were made between the different methods and discussion will be presented in this section. .

The BS 5628-2, CSA S304.1, CSA S304 and the TMS 402 code predictions were calculated using tabulated values presented in the codes. Linear Interpolation for intermediate values between tabulated values was used. The AS3700 predictions were generated using Equation (715), which is reproduced from the code:

$$
f^{\prime} m=(1.3 \times 1.4 \sqrt{\mathrm{fbl}}) \mathrm{An}_{n}+1.4(1-\mathrm{An}) \sqrt{\frac{\mathrm{fgr}}{1.3}}
$$

Where: $A_{n}=$ unit solid ratio 
Table 7-9: Sample of Calculations for determination of $\mathrm{f}_{\mathrm{m}}$ for grouted masonry CNMA [2012] tested a set of three grouted masonry prisms with $(\mathrm{h} / \mathrm{t})$ ratio of 2.1. The prisms were built of hollow concrete blocks with net compressive strength of $14.1 \mathrm{MPa}$ and $\mathrm{COV}$ of $6.6 \%$, type $\mathrm{N}$ mortar with cube compressive strength of $6.7 \mathrm{MPa} \mathrm{COV}$ of $6.6 \%$ and a grout mix with cylinder compressive strength of 24.8 MPa. The average compressive strength of the tested prisms was $14 \mathrm{MPa}$ with COV of $4 \%$.

\begin{tabular}{|c|c|c|}
\hline AS 3700-2001 & BS 5628-2:2005 & CSA S304.1-04 \\
\hline $\begin{array}{l}\text { Correction facto for }(\mathrm{h} / \mathrm{t}) \text { ratio }=0.78 \mathrm{By} \\
\text { interpolation (Appendix C of AS } 3700) \\
\text { The average normalized strength }=14 \times 0.78= \\
10.92 \mathrm{MPa} \\
\mathrm{f}^{\prime} \text { m ungrouted }=(1.3 \times 1.4 \sqrt{14.1})=6.83 \mathrm{MPa} \\
\text { Grout contr. }=\left(1.4 \sqrt{\frac{24.8}{1.3}}\right)=6.11 \mathrm{MPa} \\
\text { An }=0.52 \\
\mathrm{f}_{\mathrm{m}}^{\prime}=6.83 \mathrm{x} \text { An }+6.11 \times(1-\mathrm{An})=6.48 \mathrm{MPa} \\
\mathrm{f}_{\mathrm{m} \text { Exp }}^{\prime} / \mathrm{f}_{\mathrm{m} \text { Pred }}^{\prime}=10.92 / 6.48=1.68\end{array}$ & $\begin{array}{l}\text { Correction facto for }(\mathrm{h} / \mathrm{t}) \text { ratio }=0.8(\text { Appendix } \mathrm{D} \text { of } \\
\text { BS5628-2) } \\
\text { The average normalized strength }=14 \times 0.8=11.2 \mathrm{MPa} \\
\mathrm{f}_{\mathrm{gr}}>\mathrm{fbl} \text {, hence use } \mathrm{f}_{\mathrm{bl}} \\
\text { unit shape factor }=\text { thickness/height }=1 \\
\text { for shape factor } 0.6 \text { table } 2 \text { for solid concrete unit } \\
\qquad \mathrm{f}^{\prime} \mathrm{m} 1=4.2+\frac{(14.1-10.4)}{(17.5-10.4)} \cdot(5.5-4.2)=4.89 \\
\text { for shape factor } 2.0 \text { table } 2 \text { for solid concrete unit } \\
\qquad \mathrm{f}^{\prime} \mathrm{m} 2=8.4+\frac{(14.1-10.4)}{(17.5-10.4)} \cdot(11.1-8.4)=9.81 \\
\text { For shape factor }=1 \\
\qquad \mathrm{f}^{\prime} \mathrm{m}=4.89+\frac{(1-0.6)}{(2.0-0.6)} \cdot(9.81-4.89)=6.29 \\
\mathrm{f}_{\mathrm{m} \text { Exp }}^{\prime} / \mathrm{f}_{\mathrm{m} \text { Pred }}^{\prime}=11.2 / 6.29=1.78\end{array}$ & $\begin{array}{l}\text { Correction facto for }(\mathrm{h} / \mathrm{t}) \text { ratio }=0.8(\text { Annex D of CSA S304.1) } \\
\text { The average normalized strength }=14 \text { x } 0.8=11.2 \mathrm{MPa} \\
\text { From Table } 3 \text { in CSA S304.1-04, for } \mathrm{f}_{\mathrm{bl}}=14.1 \mathrm{MPa} \text { and type N } \\
\text { mortar } \\
\mathrm{f}^{\prime} \mathrm{m}=4.5+\frac{(14.1-10)}{(15-10)} \cdot(6-4.5)=5.73 \mathrm{MPa} \\
\mathrm{f}_{\mathrm{m} \text { Exp }}^{\prime} / \mathrm{f}_{\mathrm{m} \text { Pred }}^{\prime}=11.2 / 5.73=1.96\end{array}$ \\
\hline TMS $402-11$ & $\begin{array}{l}\text { Khalaf et al. } \\
\end{array}$ & Proposed \\
\hline $\begin{array}{l}\text { Correction facto for }(\mathrm{h} / \mathrm{t}) \text { ratio }=1.0(\text { ASTM C } \\
1314-02 a) \\
\text { The average normalized strength }=14.0 \times 1.0= \\
14.0 \mathrm{MPa} \\
\text { From Table } 2 \text { in TMS } 402-11 \text {, for } \mathrm{f}_{\mathrm{bl}}=14.1 \mathrm{MPa} \\
\text { and type } \mathrm{N} \text { mortar } \\
\mathrm{f}^{\prime} \mathrm{m}=9.3+\frac{(14.1-13.1)}{(14.82-13.1)} \cdot(10.34-9.31)=9.9 \mathrm{MPa} \\
\mathrm{f}_{\mathrm{m} \text { Exp }}^{\prime} / \mathrm{f}_{\mathrm{m} \text { Pred }}^{\prime}=14.0 / 9.91=1.41\end{array}$ & $\begin{array}{l}\text { for } \mathrm{f}_{\mathrm{b}} \mathrm{l}=19.2 \mathrm{MPa}, \mathrm{f}_{\mathrm{mr}}=18.8 \mathrm{MPa} \text { and } \mathrm{f}_{\mathrm{gr}}=26.65 \mathrm{MPa} \\
\text { (cube strength) } \\
\mathrm{f}^{\prime} \mathrm{m}=(0.3(19.2)+0.20(18.8)+0.25(26.65)+1.3)=17.8 \mathrm{MPa} \\
\mathrm{f}_{\mathrm{m} \text { Exp }}^{\prime} / \mathrm{f}_{\mathrm{m} \text { Pred }}^{\prime}=14.9 / 17.48=0.85\end{array}$ & $\begin{array}{l}\text { Correction facto for }(\mathrm{h} / \mathrm{t}) \text { ratio }=1-0.075 \times(5-2.1)=0.78 \\
\text { The average normalized strength }=14 \times 0.78=10.92 \mathrm{MPa} \\
\mathrm{f}_{\mathrm{gr}}=24.8>1.5 \times \mathrm{f}_{\mathrm{bl}}=21.2 \text {, hence use } \mathrm{f}_{\mathrm{gr}}=21.2 \mathrm{MPa} \\
\text { From Equation } 7-12 \text { in the current study: } \\
\mathrm{f}^{\prime} \mathrm{m}=0.81(0.291(4.1)+0.10(6.7)+0.21(21.2)+1.51)=8.68 \mathrm{MPa} \\
\text { Or from figure } 7-23 \\
\text { Unit, grout, and mortar contributions }=4.5,3.6,0.6 \mathrm{MPa}, \text { respectively } \\
\mathrm{f}^{\prime} \mathrm{m}=4.5+3.6+0.6=8.7 \mathrm{MPa} \\
\mathrm{f}_{\mathrm{m}}^{\prime} \text { Exp } / \mathrm{f}_{\mathrm{m} \text { Pred }}=10.92 / 8.68=1.26\end{array}$ \\
\hline
\end{tabular}


Table 7-10: Values of mean ( $\mathrm{f}_{\mathrm{m} \text { Exp }} / \mathrm{f}_{\mathrm{m}}$ Pred $)$, standard deviation, coefficient of variation, IAE, number and percentage of overpredicted data for the proposed formula and major international masonry codes

\begin{tabular}{|c|c|c|c|c|c|c|c|c|c|c|c|c|c|c|c|c|c|c|}
\hline \multirow{3}{*}{ Masonry Design Code } & \multicolumn{6}{|c|}{ All the database } & \multicolumn{6}{|c|}{ Type N mortar prisms } & \multicolumn{6}{|c|}{ Type $\mathrm{S}$ mortar prisms } \\
\hline & \multicolumn{5}{|c|}{$\left(f_{m \text { Exp }} / f_{m \text { Pred }}^{\prime}\right)$} & \multirow{2}{*}{$\begin{array}{c}\text { IAE } \\
\%\end{array}$} & \multicolumn{5}{|c|}{$\left(\mathrm{f}_{\mathrm{m} \text { Exp }} / \mathrm{f}_{\mathrm{m} \text { Pred }}\right)$} & \multirow{2}{*}{$\begin{array}{c}\text { IAE } \\
\%\end{array}$} & \multicolumn{5}{|c|}{$\left(\mathrm{f}_{\mathrm{m} \text { Exp }} / \mathrm{f}_{\mathrm{m} \text { Pred }}\right)$} & \multirow{2}{*}{$\begin{array}{c}\text { IAE } \\
\%\end{array}$} \\
\hline & Mean & STDV & $\begin{array}{c}\mathrm{COV} \\
\%\end{array}$ & $\begin{array}{l}\text { \# of } \\
<1.0\end{array}$ & $\begin{array}{l}\% \text { of } \\
<1.0\end{array}$ & & Mean & STDV & $\begin{array}{c}\mathrm{COV} \\
\%\end{array}$ & $\begin{array}{l}\text { \# of } \\
<1.0\end{array}$ & $\begin{array}{l}\begin{array}{l}\% \text { of } \\
<1.0\end{array}\end{array}$ & & Mean & STDV & $\begin{array}{c}\mathrm{COV} \\
\%\end{array}$ & $\begin{array}{l}\text { \# of } \\
<1.0\end{array}$ & $\begin{array}{l}\% \text { of } \\
<1.0\end{array}$ & \\
\hline CSA S304.1-2004 & 1.52 & 0.41 & 27 & 3 & 1.7 & 32 & 1.96 & 0.33 & 17 & 0 & 0 & 48 & 1.39 & 0.33 & 23 & 3 & 2.3 & 28 \\
\hline BS 5628-2:2005 & 1.63 & 0.37 & 23 & 1 & 0.6 & 37 & 1.83 & 0.37 & 20 & 0 & 0 & 40 & 1.56 & 0.35 & 22 & 1 & 0.8 & 35 \\
\hline TMS $402-2011$ & 1.21 & 0.28 & 23 & 44 & 25.7 & 20 & 1.28 & 0.28 & 22 & 6 & 14.3 & 22 & 1.19 & 0.28 & 24 & 38 & 29.5 & 19 \\
\hline AS $3700-2001$ & 1.96 & 0.35 & 18 & 0 & 0 & 49 & 1.91 & 0.23 & 12 & 0 & 0 & 48 & 1.98 & 0.38 & 19 & 0 & 0 & 50 \\
\hline Proposed (Eq. 7-12) & 1.24 & 0.20 & 16 & 12 & 7 & 20 & 1.28 & 0.17 & 13 & 1 & 2.4 & 22 & 1.22 & 0.19 & 15 & 11 & 8.5 & 20 \\
\hline Equation (Eq. 7-11) & 1.00 & 0.15 & 15 & 81 & 47.4 & 12 & 1.01 & 0.14 & 17 & 18 & 42.8 & 11 & 1.00 & 0.15 & 15 & 63 & 48.8 & 13 \\
\hline Khalaf et al. (Eq. 7-16) & 0.93 & 0.16 & 17 & 112 & 65.5 & 15 & 0.98 & 0.17 & 18 & 23 & 54.8 & 10 & 0.93 & 0.17 & 18 & 89 & 69 & 16 \\
\hline
\end{tabular}


Based on their test results of grouted masonry prisms, Khalaf et al. suggested the following equation:

$$
f^{\prime} m=0.3 \mathrm{fbl}+0.2 \mathrm{fmr}+0.25 \mathrm{fgr}+1.3
$$

Where $f_{b l}$ is based on net area and $f_{m r}$ and $f_{g r}$ are in terms of the cube compressive strength. It is worth mentioning that Khalaf et al derived the last two terms $\left(0.25 \mathrm{f}_{\mathrm{gr}}+1.3\right)$ from the best fitting line passing through the results of grouted prisms with polystyrene joints (no mortar was used) having varying grout strengths. The gradient of the line 0.25 was considered to be the contribution factor or the grout strength while the constant of 1.3 was related to the strength of the block unit. The contributions of the block and mortar $\left(0.3 f_{b l}+0.2 f_{m r}\right)$ were derived based on test results of ungrouted prisms.

It can be noted that the proposed model gives the lowest coefficient of variation, the second lowest mean $\mathrm{f}_{\mathrm{m} \text { Exp }} / \mathrm{f}_{\mathrm{m} \text { Pred }}$ ratio and the second lowest IAE value for the entire database or any individual subset of the data (for example, type $\mathrm{N}$ mortar and type $\mathrm{S}$ mortar). Figure 7-24 shows that the AS3700, BS 5628-2, and CSA S304.1 codes underestimate $\mathrm{f}_{\mathrm{m}}$ by considerable margins. This underestimation of $\mathrm{f}_{\mathrm{m}}$ is likewise associated with high COV and IAE values. It can also be seen that although the TMS MSJC model exhibited a low $\mathrm{f}_{\mathrm{m} \text { Exp }} / \mathrm{f}_{\mathrm{m} \text { Pred }}$ ratio, it has a high COV of $23 \%$ and it gives non-conservative predictions ( $f_{m} \operatorname{Exp} / f_{m}$ Pred of less than 1.0) for more than $30 \%$ of the database. 

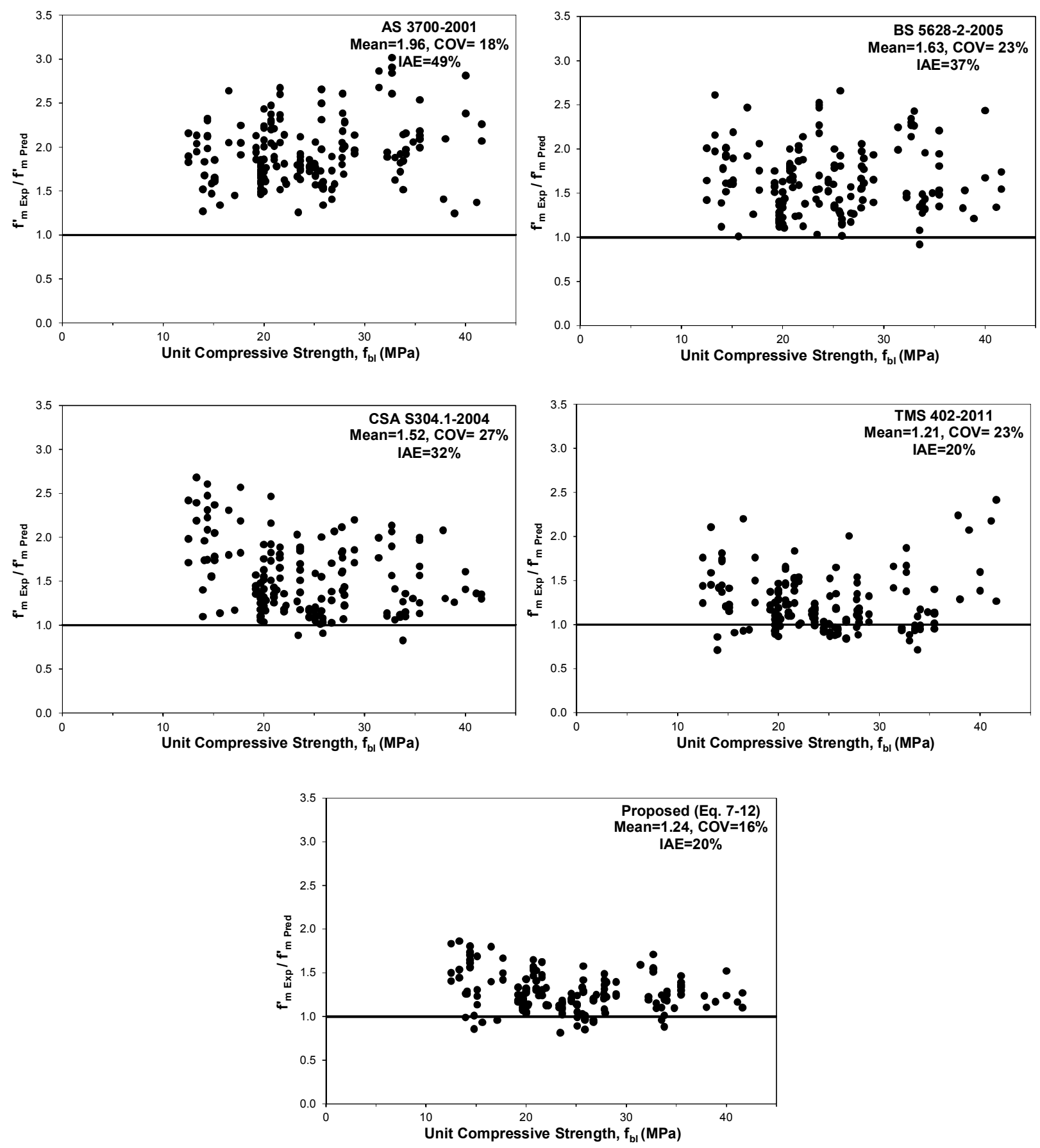

Figure 7-24: Comparison of Predictive Abilities of the AS 3700, CSA S304.1, TMS 402 Codes and Equation (7-12) for the Entire Database of Grouted Prisms 
It is interesting to note that both Khalaf et al.'s model (derived based on one experimental program) and Equation (7-11) (derived independently based on a large database) suggest that the contributions of block and grout to $\mathrm{f}_{\mathrm{m}}$ are about $30 \%$ and $25 \%$ of their strengths respectively. However, It can be seen from Figure 7-25 that Equation (7-11) gives better predictions with less variations (COV and IAE) and less number of overpredicted data points. This can be attributed partly to the fact that the proposed formula predicts that the mortar strength contributes less to prism strength than does Khalaf et al.'s equation.
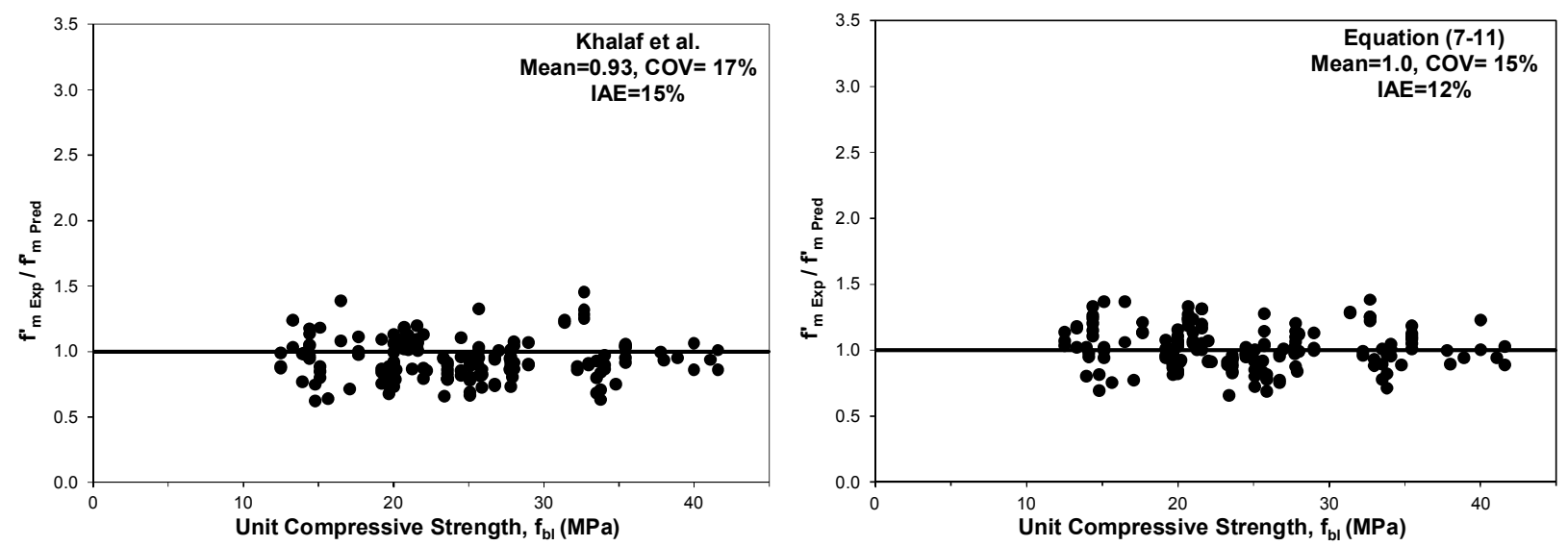

Figure 7-25: Comparison of Predictive Performance for Equation (7-11) and Khalaf et al.'s Model

Figure 7-26 shows that the CSA code underestimates the compressive strength of type N mortar prisms more than those of type $\mathrm{S}$ mortar prisms. The CSA S304.1 code gives a mean $\mathrm{f}_{\mathrm{m} \text { Exp }} / \mathrm{f}_{\mathrm{m}}$ Pred ratio of 1.96 with a COV of $17 \%$ and IAE of $48 \%$. The proposed model, on the other hand, gives consistently accurate predictions for prisms made with both types of mortar. Any revision of the CSA S304.1 tabulated masonry strength values should target grouted masonry with type N mortar. Moreover, as type $\mathrm{N}$ mortar prisms make up only $25 \%$ of the database, more experimental work is needed for prisms with this type of mortar, particularly for prisms made with high strength units. 

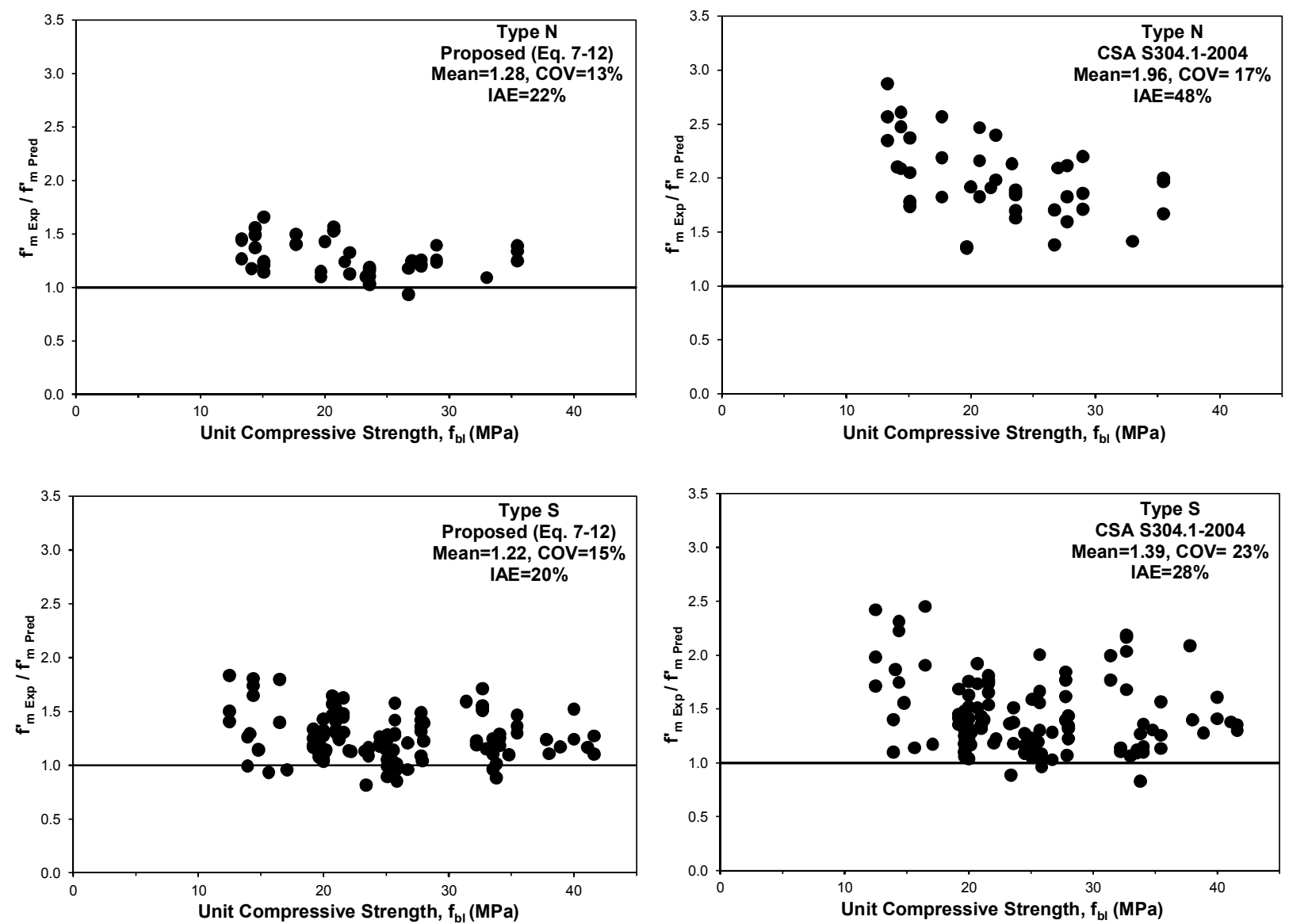

Figure 7-26: Comparison of Predictive Abilities of the CSA S304.1-2004 Code and Equation (712) For N Type Mortar and S Type Mortar grouted Prisms

With the exception of AS 3700, the masonry codes do not account for the effect of grout strength on $\mathrm{f}^{\prime}{ }_{\mathrm{m}}$. However, the AS 3700 code significantly underestimates $\mathrm{f}_{\mathrm{m}}$ for the entire range of grout strengths covered in the database (see Figure (7-27)). Conversely, the TMS MSJC code tends to significantly overestimate $\mathrm{f}_{\mathrm{m}}$ for grout strengths of less than about $15 \mathrm{MPa}$. This overestimation at lower grout strengths may need to be investigated further to ensure the adequacy of the TMS MSJC approach to calculating $\mathrm{f}^{\prime} \mathrm{m}$, particularly given the trend to use low strength grouts in masonry construction. Figure 7-27 shows that the proposed model gives more consistent predictions for the entire range of grout strengths covered in the database. 

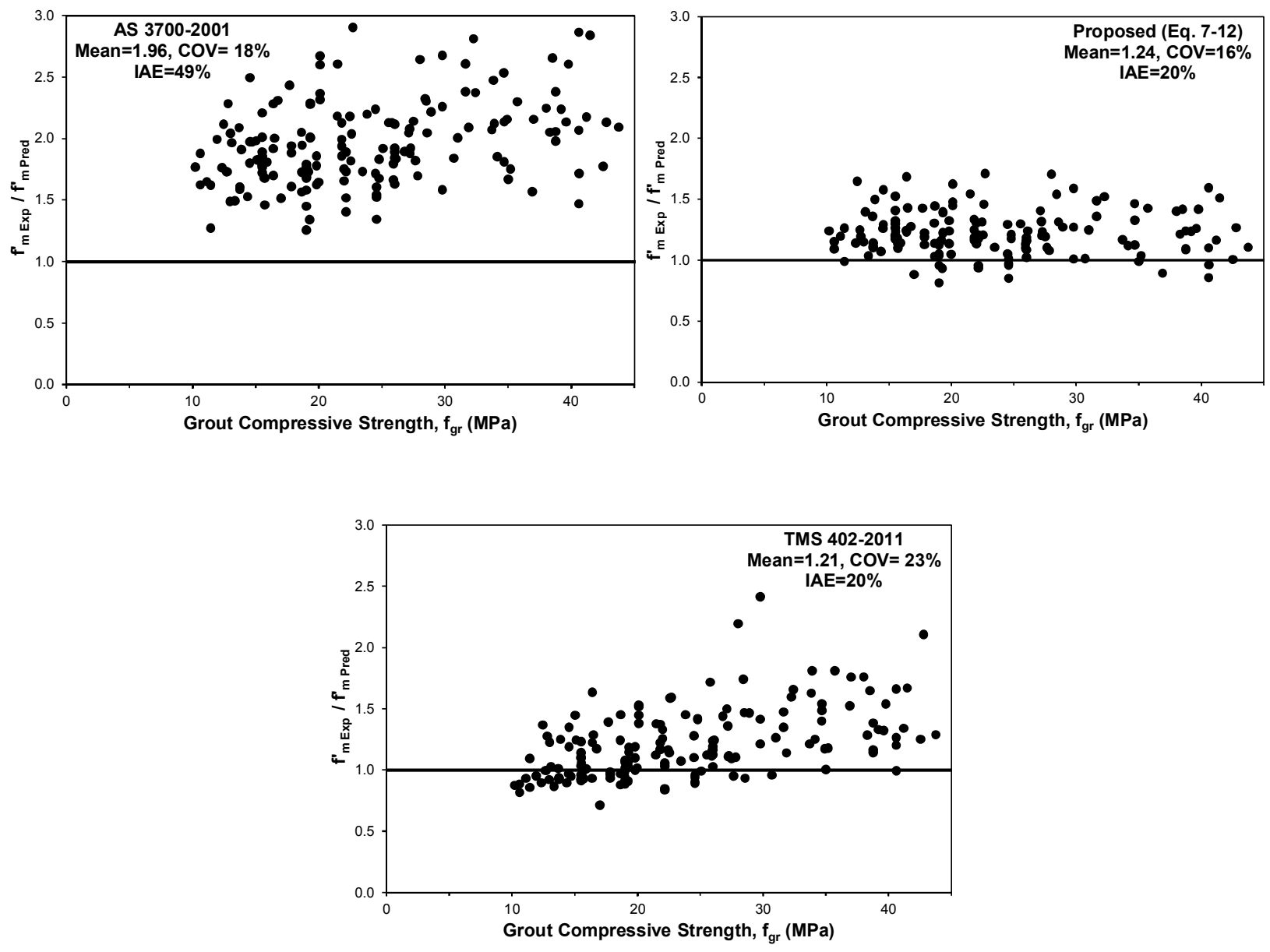

Figure 7-27: Comparison of Predictive Performance for the Proposed Model, AS 3700 and TMS 402 Codes for the Range of Grout Strength

In Figure 7-28, specified strengths of units, mortar, grout and prisms were calculated by subtracting 1.64 standard deviations from the mean strengths as per Annex C of CSA S304.1, with the standard deviation taken as the higher of the reported value or $10 \%$. If the reference did not report a standard deviation, it was taken to be $10 \%$. It can be clearly seen that the proposed model can accurately predict specified masonry strengths based on specified component strengths with a degree of accuracy and reliability that exceeds CSA S304.1. On average, specified masonry strengths are $25 \%$ higher using the proposed model than specified strengths obtained from CSA S304.1. 

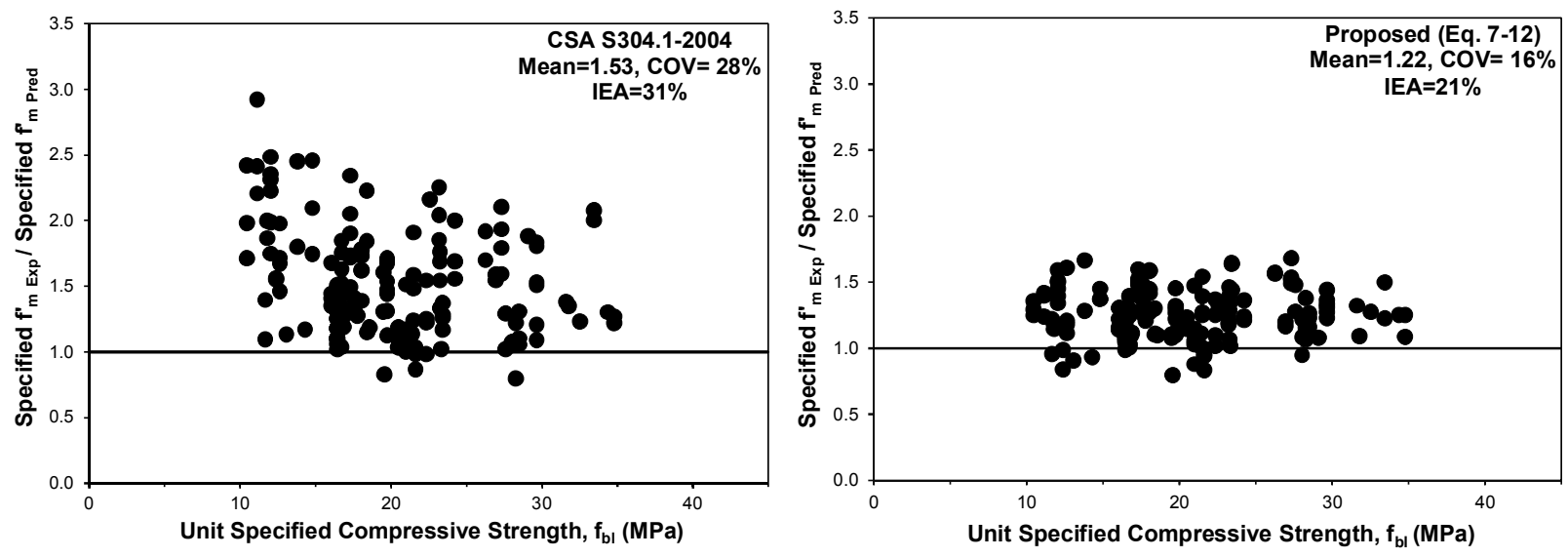

Figure 7-28: Comparison of Predictive Ability of Equation (7-12) and CSA S304.1-2004 Based on Specified Compressive Strength of grouted Prisms

\subsubsection{Prediction the Strengths of Prisms Tested in the Current Investigation}

Testing of compressive strength of masonry control prisms was a substantial part of the experimental program described. Eight sets with a total of 26 grouted masonry prisms were tested normal to the bed joint to determine the compressive strength of the masonry beams with which they associate. To check the ability of the proposed model (Equation (7-12)) to accurately predict the compressive strength of the tested masonry prisms in, Table 7-11 was constructed. It can be seen in this table that the proposed model was able to safely and accurately predict the compressive strength of the masonry prism with an average $f_{m \text { Exp }} / f_{m}$ Pred of 1.12 and a COV of $6 \%$. 
Table 7-11: Results of the Masonry Prisms Tested Normal to Bed Joint in the Current Investigation with the Predictions of the Proposed Equation (7-12)

\begin{tabular}{|c|c|c|c|c|c|c|c|c|c|c|}
\hline $\begin{array}{l}\text { Set } \\
\text { No. }\end{array}$ & $\begin{array}{l}\text { Individual } \\
\text { Prism IDs }\end{array}$ & $\begin{array}{c}\text { Prism } \\
\text { dimensions } \\
(\text { hxwxt })\end{array}$ & $\begin{array}{c}\mathrm{h} / \mathrm{t} \\
\text { ratio }\end{array}$ & $\begin{array}{c}\mathrm{f}_{\mathrm{bl}} \\
(\mathrm{MPa})\end{array}$ & $\begin{array}{c}\mathrm{f}_{\mathrm{mr}} \\
(\mathrm{MPa})\end{array}$ & $\begin{array}{c}\mathrm{f}_{\mathrm{gr}} \\
(\mathrm{MPa})\end{array}$ & $\begin{array}{l}\mathrm{f}_{\mathrm{m} \text { Exp }}^{\prime} \\
(\mathrm{MPa})\end{array}$ & $\begin{array}{c}\mathrm{f}_{\mathrm{m} \text { Exp }}^{*} \\
\text { Corrected } \\
\text { for } \mathrm{h} / \mathrm{t}\end{array}$ & $\begin{array}{l}\mathrm{f}_{\mathrm{m} \text { Pred }} \\
(\mathrm{MPa})\end{array}$ & $\mathrm{f}_{\mathrm{mExp} /}^{n} \mathrm{f}_{\mathrm{m}}^{n}$ \\
\hline 1 & $\begin{array}{l}\text { PN1,PN2 } \\
\text { and PN3 }\end{array}$ & $790 \times 390 \times 190$ & 4.17 & 36.3 & 24.1 & 21.1 & 17.9 & 16.78 & 15.3 & 1.1 \\
\hline 2 & $\begin{array}{l}\text { PN4,PN5 } \\
\text { and PN6 }\end{array}$ & $790 \times 390 \times 190$ & 4.17 & 36.3 & 25.9 & 18.6 & 18 & 16.87 & 15.0 & 1.13 \\
\hline 3 & $\begin{array}{l}\text { PN7,PN8 } \\
\text { and PN9 }\end{array}$ & $790 \times 390 \times 190$ & 4.17 & 36.3 & 26.3 & 20.5 & 19.5 & 18.28 & 15.4 & 1.19 \\
\hline 4 & $\begin{array}{c}\text { PN10,PN11 } \\
\text { and PN12 }\end{array}$ & $790 \times 390 \times 190$ & 4.17 & 36.3 & 25.5 & 20.5 & 20 & 18.75 & 15.3 & 1.23 \\
\hline 5 & $\begin{array}{c}\text { PLN1,PLN2 } \\
\text {, PLN3, } \\
\text { PLN4 and } \\
\text { PLN5 }\end{array}$ & $790 \times 390 \times 240$ & 3.3 & 29.8 & 27.7 & 22.4 & 18.9 & 16.07 & 14.3 & 1.13 \\
\hline 6 & $\begin{array}{c}\text { PN13,PN14 } \\
\text { and PN15 }\end{array}$ & $790 \times 390 \times 190$ & 4.17 & 37.5 & 25.5 & 19.6 & 18 & 16.87 & 15.4 & 1.09 \\
\hline 7 & $\begin{array}{c}\text { PN16,PN17 } \\
\text { PN18 and } \\
\text { PN19 }\end{array}$ & $790 \times 390 \times 190$ & 4.17 & 37.5 & 26.3 & 18.3 & 17.5 & 16.4 & 15.3 & 1.07 \\
\hline 8 & PN20,PN21 & $790 \times 390 \times 190$ & 4.17 & 37.5 & 28.9 & 22.6 & 17.3 & 16.2 & 16.2 & 1.00 \\
\hline \multirow{3}{*}{\multicolumn{9}{|c|}{${ }^{*}$ Values were obtained by the multiplication of the $\mathrm{f}_{\mathrm{m} \text { Exp }}$ by correction factors from Equation $(7-4)$}} & Mean & 1.12 \\
\hline & & & & & & & & & STDV & 0.07 \\
\hline & & & & & & & & & $\operatorname{COV}(\%)$ & 6.4 \\
\hline
\end{tabular}




\subsection{Concluding Remarks}

An extensive experimental database of ungrouted and grouted hollow concrete block masonry prisms was assembled. Regression analyses were conducted on the collected database and led to the development of simple and accurate formulae to predict $\mathrm{f}_{\mathrm{m}}$ of ungrouted and grouted hollow concrete block masonry based on the contributions of its individual components. The predictive abilities of the proposed models were compared to those of five international masonry codes (AS 3700-2001 (Australia), BS 5628-2005 (UK), CSA S304.1-04 (Canada), Eurocode 6 (European Commission), and the TMS 402-11 (US)). The proposed models gave mean $f_{m}^{\prime}$ Exp $/ f_{m}^{\prime}$ Pred ratios, coefficients of variation and IAE that are considerably lower than those of major international masonry codes. The supremacy of the proposed model over the masonry design codes is valid for predictions of $\mathrm{f}_{\mathrm{m}}$ based on both average and specified compressive strength. It was also proven that the proposed model can accurately and safely predict $f_{m}$ of ungrouted and grouted masonry for various combinations of material properties. The proposed formula can replace the conservative tabulated masonry compressive strength values in design codes. These efforts will enhance the economic competitiveness of masonry as a choice for structural engineers. 


\section{CHAPTER 8: CONCLUDING REMARKS}

\subsection{General}

This thesis has presented the results of an extensive series of tests designed to investigate the size effect and strain effect in reinforced masonry beams. Experimental variables have included 1) member depth, 2) the main reinforcement ratio, 3) the reinforcement stiffness, 4) the use of stirrups, 5) the use of crack control longitudinal reinforcement. While each chapter has included a section of concluding remarks, this chapter summarizes the results of the entire thesis.

\subsection{The Size Effect}

Chapter 5 presents the results of four series of tests in which the beams in each series were approximately identical (have similar a/d and $\rho$ ratios) except for the effective depth. Two of the series included RM beams reinforced with conventional steel at two different $\rho$ ratios $(0.83 \%$ for the first series and $1.68 \%$ for the second series). The third series was reinforced with highstrength steel while the last series was reinforced with GFRP rebars. In the first series three different effective depth were studied, 300mm (small), $885 \mathrm{~mm}$ (medium), and 1420mm (large) while only two effective depth values $(305 \mathrm{~mm}$ and $880 \mathrm{~mm})$ were studied in the rest of the series.

The test results showed that the size effect in reinforced masonry is real and significant. The existence of the size effect in shear was confirmed in reinforced masonry beams reinforced with different $\rho$ and different type of reinforcement (conventional steel, high strength steel and GFRP). It was found that the failure shear stress decreased considerably as the effective depth increased. Increasing the effective depth from $300 \mathrm{~mm}$ to $885 \mathrm{~mm}$ and $1420 \mathrm{~mm}$ in the first series 
resulted in the reduction of failure shear stresses by $25 \%$ and $31 \%$ respectively. Specimen SL1 (with an effective depth $1422 \mathrm{~mm}$ ) failed at a shear that was $62 \%$ of the TMS 402 predicted shear strength. Similarly, increasing the effective depth from $305 \mathrm{~mm}$ to $875 \mathrm{~mm}$ in the second series led to a reduction in failure shear stresses of $46 \%$. In the third series a decrease of $36 \%$ was noticed when the effective depth increased from $307 \mathrm{~mm}$ to $880 \mathrm{~mm}$. Specimen SM4 reinforced with high strength steel failed at a shear that was $50 \%$ of the TMS 402 predicted shear strength. Finally, increasing the effective depth from $303 \mathrm{~mm}$ to $880 \mathrm{~mm}$ in the fourth series reinforced with GFRP resulted in 23\% reduction in the failure shear stress.

Analysis of crack patterns indicated that the horizontal crack spacing at midheight in the small beams (effective depth $300 \mathrm{~mm}$ ) was governed by the distance between the head joints $(400 \mathrm{~mm}$ in this case) as these joints offer predefined paths for cracks to propagate through. In the medium and large beams, on the other hand, the crack spacings at midheight were proportional to the effective depth (i.e., a function of d). This trend is similar to the trend observed in crack spacings at midheight of reinforced concrete beams. Despite this inconsistency in the crack spacing trend between the small and the large, the crack spacing increased as the effective increased. These increases in crack spacings were associated with a significant increases in crack widths. As the capacity of cracks to transfer shear stress decreases as the crack width increases, it appears that the reduced aggregate interlock capacity in the larger specimens was the primary cause of the reduced shear strengths, and hence the cause of the size effect in shear.

In some of the small and medium beams the breakdowns of aggregate interlock were followed by the engagements of strut and tie actions and the formation of shear keys between masonry 
units that permitted shear transfer by interlocking of adjacent blocks leading to higher failure shear stresses and deflections than those associated with the breakdowns of aggregate interlock. This mechanism cannot be considered to be reliable as it did not develop in all the beams and even when it was engaged it led in most cases to only marginal increases in failure shear stresses. It is suggested that once beam action breaks down in slender reinforced masonry beams $(a / d>2.5)$, they should be considered to have failed in shear.

The test results showed that the major mechanism of shear transfer in reinforced masonry without shear reinforcement is aggregate interlock. Based on detailed measurements of the strains and stresses in uncracked masonry at the tips of critical shear cracks in four masonry beams with different sizes, the contribution of the uncracked compression zone to total shear resistance was limited (25-29\% of the total shear at the section). Tests reported in reinforced concrete literature have found that about $15-25 \%$ of the vertical shear is carried by dowel action. Thus, it can be concluded that at least $50 \%$ of the vertical shear is carried by aggregate interlock.

The test results showed that the TMS 402 code can produce unsafe predictions for large reinforced masonry beams constructed without stirrups. The inability of the TMS 402 code to account for this factor could lead to a high risk of sudden failure of large masonry beams and girders (like those in Figures 1-5 to 1-7) at lower loads than designed for by this code. Although the CSA S304.1 code accounts for size effect, it still exhibited high coefficient of variation. On the other hand, the CSA A23.3 code, which is based on the Simplified Modified Compression 
Field Theory, yielded safe and accurate predictions of the shear strengths at different depths with the least mean of $\mathrm{V}_{\mathrm{Exp}} / \mathrm{V}_{\text {Pred }}$ and the least variation (COV).

\subsection{The Effect of Stirrups}

Two sets of specimens, two beams in each set, were used to explore the effect of stirrups on shear strength of RM beams. In the first set, there were two beams with constant effective depth of $305 \mathrm{~mm}$ and reinforced ratio of $1.7 \%$ with one beam additionally reinforced with stirrup at a

ratio $\left(\frac{A_{v} f_{y}}{b_{w} s}\right)$ of $0.67 \mathrm{MPa}$ which is twice the minimum requirement of the CSA A23.3 code. In the second set, there were two beams with approximately constant effective depths of $870 \mathrm{~mm}$ and reinforced ratio of $1.68 \%$ with one beam additionally reinforced with stirrups at a ratio ( $\frac{A_{v} f_{y}}{b_{w} s}$ ) of $0.52 \mathrm{MPa}$. It was found that the use of stirrups greatly enhanced the shear strength, and resulted in increased crack widths and deflections at failure. The cracks at mid-depth of specimens reinforced with stirrups were spaced more closely than the ones without stirrups. It was noted that the TMS 402 underestimates the contribution of stirrups leading to overly conservative predictions. It is recommended that the reduction factor of 0.5 used to lower the contribution of stirrups in the TMS 402 be eliminated. CSA A23.3 and CSA S304.1 codes, on the other hand, gave more accurate predictions of shear strength of RM with stirrups.

\subsection{The Effect of Crack Control Reinforcement}

The effect of crack control reinforcement on shear strength of RM beams was examined by comparing the results of two five-course beams that were approximately identical except that one 
of the beams was additionally reinforced with a single No. 15 bar in every course ( $200 \mathrm{~mm}$ between the layers) from the second to the forth course.

It was found that the medium specimen with crack control steel failed at a shear stress that was $30 \%$ higher than in equivalent specimens without crack control steel. The benefits of using crack control steel was not limited to the strength, but included other aspects, such as ductility and crack spacing and widths. It was found that narrower cracks formed at closer spacing in the beam reinforced with crack control steel compared to the specimen without crack control steel. Despite these improvements in strength and deformation characteristics, it was shown that the use of minimum crack control steel could not entirely eliminate the size effect. It is worth mentioning that while masonry codes are not sensitive to the improvement in shear strength due to the use of crack control steel, the CSA A23.3 code demonstrated an accurate prediction with a reasonable $\mathrm{V}_{\exp } / \mathrm{V}_{\text {pred }}$ of 0.97 .

\subsection{The Strain Effect}

The results presented in this chapter have shown that the strain effect in reinforced masonry exists and can be explained using concepts from reinforced concrete research. This effect is related to the ability of cracks to resist shear stresses through aggregate interlock. The crack width is dependent upon the longitudinal strain at mid-depth, $\varepsilon_{\mathrm{x}}$, of the section. Any action that causes $\varepsilon_{\mathrm{x}}$ to increase (such as using low reinforcement ratio or using GFRP instead of steel) will lead to wider cracks which in turn will result in lower shear stresses transferred by cracks through aggregate interlock. In this research two aspects of strain effect were studied: the effect of longitudinal reinforcement ratio and the effect of reinforcement stiffness. 


\subsubsection{The Effect of Longitudinal Reinforcement Ratio}

Two series of RM beams were used to study the effect of longitudinal reinforcement ration shear strength of reinforced masonry. In the first series the average effective depth was kept approximately constant at $305 \mathrm{~mm}$ for all the beams while four different $\rho$ were used ranging from $0.34 \%$ to $2.43 \%$. In the second series, the effective depth was approximately constant at $880 \mathrm{~mm}$ and three different $\rho(0.31,0.83$ and $1.68 \%)$ were used.

The test results showed that the shear strength increased considerably as the reinforcement ratio increased. Analysis of crack patterns demonstrated the crack widths decreased significantly as the reinforcement ratio increased. The crack spacing at mid-depth, on the other hand, did not change considerably. The increased in the shear strength was primarily due to the increased aggregate interlock capacity. Even in the beams where breakdown of aggregate interlock was followed by formation of shear keys, it was noticed that beams with high $\rho$ had higher shear strength than those with low $\rho$.

The North American codes (TMS 402 and CSA S304.1) do not account for the effect of $\rho$. Both codes exhibited the highest COV values. BS 5628 code did not accurately capture the effect of changing $\rho$ despite the fact that this code accounts directly for $\rho$. AS 3700 code gave safe predictions for the shear strength of beams with varying $\rho$, however this was associated with high values of and COV. The CSA A23.3 and Hoult et al. (2008) were able to safely and accurately predict the effect of $\rho$ with least and COV. 


\subsubsection{The Effect of Reinforcement Stiffness (E)}

Two sets of RM beams were tested to study the effect of using GFRP reinforcing bars versus high-strength steel on shear strength of RM beams. In each set, the average depth and the reinforcement ratio were kept constant and the only variable was the reinforcement type (GFRP versus steel). The beams reinforced with GFRP failed significantly lower shear stresses than the equivalent beams reinforced with steel. Decreasing the stiffness (E) of the reinforcement resulted in wider cracks at mid-depth of the section. Increasing the widths of the cracks limited their ability to transfer shear stresses through aggregate interlock. None of the masonry design codes account for the effect of (E). The CSA A23.3 and Hoult et al. (2008) were able to predict the variation in the shear strength of RM beams with different reinforcement types.

\subsection{Recommended Updates on the CSA S304.1}

It was shown that the CSA A23.3 code, intended for reinforced concrete, can accurately and safely account for the effects of a wide range of variables, such as the size effect, $\rho, E$, the existence of stirrups and the use of crack control steel. The CSA A23.3 code exhibited the lowest average $\mathrm{V}_{\mathrm{Exp}} / \mathrm{V}_{\text {Pred }}$ and the smallest COV for the RM beams tested in the current investigation. The accuracy of the CSA A23.3 code was not only evident for beams included in this study, but also for other RM beams reported in the literature. A database of 117 shear tests reported in the literature on reinforced masonry beams was assembled and presented in Chapter 2. The study showed that the average $\mathrm{V}_{\text {Exp }} / \mathrm{V}_{\text {Pred }}$ ratios for the masonry codes ranged from 1.05 to 1.54 . However, high coefficients of variation for all four masonry codes indicated that low material strength reduction factors are required in order to apply the design codes with appropriate safety. 
The CSA A23.3 general method had a low average ratio of tested to predicted strength, and the lowest coefficient of variation of all five codes.

It was concluded that reinforced masonry beams exhibited similar behaviour in shear as reinforced concrete beams, and that their shear strengths can be more accurately predicted using the CSA A23.3 code for concrete than current masonry codes. As such it is recommended that shear provisions in masonry design codes be revisited making use of the shear provisions in CSA A23.3. In fact, one of the main contributions of the current investigation that its test results were used to justify the use of the CSA A23.3 as a base to revise the shear provisions in of CSA S304 masonry codes in its 2014 version.

\subsection{The Prediction of Compressive Strength of Masonry}

In this thesis a large database of compressive test results on ungrouted and grouted concrete block masonry prisms was assembled from published literature. This database was critically reviewed to study different factors influencing the compressive strength $\left(\mathrm{f}^{\prime} \mathrm{m}\right)$ of masonry. Furthermore, the collected database was statistically analyzed to derive an accurate empirical formula to estimate $\mathrm{f}_{\mathrm{m}} \mathrm{m}$ of ungrouted and grouted masonry. The predictive performance of the proposed models at calculating $\mathrm{f}_{\mathrm{m}} \mathrm{m}$ were compared to those of major international masonry design codes.

\subsubsection{The Compressive Strength of Ungrouted Masonry}

The statistical analysis led to the development of an accurate formula that gives a mean $\mathrm{f}_{\mathrm{m}}$ Exp $/$ $\mathrm{f}_{\mathrm{m}}^{\prime}$ Pred ratio, coefficient of variation and IAE that are considerably lower than major international 
masonry codes. The supremacy of the proposed model over the masonry design codes is valid for predictions of $\mathrm{f}_{\mathrm{m}}$ based on both average and specified compressive strength. The proposed formula can explain $82 \%$ of the total variation between the observed and predicted $\mathrm{f}^{\prime}{ }_{\mathrm{m}}$ values and achieves a safe confidence margin of $95 \%$ for the 248 data points included in the assembled database. The study showed that the proposed formula gives the lowest coefficient of variation and the second lowest average ratio of experimental $f_{m}^{\prime}$ to predicted $f_{m}^{\prime}\left(f_{m}^{\prime} \operatorname{Exp}^{\prime} / f_{m \text { Pred }}\right)$.

The international masonry design codes considered in this study, particularly the BS 5628-22005 and the AS3700-2001 codes, significantly underestimate $\mathrm{f}_{\mathrm{m}}$ for ungrouted masonry and are associated with high variation for the entire range of unit compressive strengths covered in the database. The tabulated masonry strength values of the international codes considered in the current study should be revised to overcome considerable conservatism when predicting $\mathrm{f}^{\prime}{ }_{\mathrm{m}}$ for ungrouted masonry.

\subsubsection{The Compressive Strength of Grouted Masonry}

A regression analysis was conducted on the collected database and led to the development of an accurate model to predict $\mathrm{f}_{\mathrm{m}}$ of grouted hollow concrete block masonry based on the contributions of its individual components. This model gives the lowest coefficient of variation and the second lowest mean of $\mathrm{f}_{\mathrm{m} \text { Exp }} / \mathrm{f}_{\mathrm{m}}^{\prime}$ Pred and the second lowest IAE value for the assembled database. It was also proven that the proposed model can accurately and safely predict $\mathrm{f}_{\mathrm{m}}$ of grouted masonry for various combinations of material properties. The superiority of the proposed model over the masonry design codes is verified for predictions of $\mathrm{f}_{\mathrm{m}}$ based on both average and characteristic compressive strength. The proposed formula can replace the conservative tabulated masonry compressive strength values in design codes. The characteristic 
masonry strengths are $25 \%$ higher using the proposed model than characteristic strengths obtained from CSA S304. This effort can contribute to advance the effective use of masonry as a competitive building material.

The BS 5628-2, the AS 3700 and CSA S304.1 codes significantly underestimate $\mathrm{f}_{\mathrm{m}}$ for grouted masonry, and do so with high variations. The CSA S304-2014 code underestimates f' ${ }_{m}$ of type $\mathrm{N}$ mortar prisms while the TMS 402-2013 code, on the other hand, significantly overestimates $\mathrm{f}_{\mathrm{m}}$ of prisms with grout strength of $20 \mathrm{MPa}$ or less. The overestimation of $\mathrm{f}_{\mathrm{m}}$ by the TMS 402 code requires further investigation.

\subsection{Future Work}

The tests results described in this thesis showed that the aggregate interlock is the major shear resistance mechanism in reinforced masonry. To the author`s knowledge, no research has been devoted to study the effect aggregate size (especially in the grout) on shear strength of masonry. Suter and Keller (1980) studied this parameter indirectly through the slump of grout materials: lean concrete or mortar. They concluded that concrete grouted masonry has higher shear strength than mortar grouted masonry regardless of the slump. The importance of the aggregate size parameter is obvious from the field of masonry practice in using three types of grout: mortar grout, fine concrete grout and coarse concrete grout. As such it is recommended that an experimental program be conducted to study the effect of using different type of grout (made with different aggregate sizes) on the shear strength of reinforced masonry.

The behaviour and design of deep reinforced beams have not been studied thoroughly especially for large beams. Several researchers have shown that strut-and-tie modeling can be a practical method for designing masonry shear walls ((Roca 2004, Voon and Ingham 2008, Mojsilovi'c 
2011, Nolph 2010), however, no guiding principles has been developed for implementing the strut-and-tie in reinforced masonry. The CSA S304.1, for example, recommend that designer can follow practices used in reinforced concrete with rationally integrate the principle for masonry behaviour and design. It is recommended that a series of tests be conducted to study the behaviour of reinforced masonry beams with a/d ratio of less than 2.5. Efforts need to be intensified to develop strut-and-tie modeling guidelines for reinforced masonry structures.

As using stirrup reinforcement is a difficult and time consuming task, reinforced masonry beams either constructed without stirrups or with as few as possible stirrups. Steel fibers, on the hand, is well known to enhance the shear strength of reinforced concrete beams reinforced as it offers extra tensile strength that aggregate interlock on wide cracks. It is recommended that a series of tests be conducted to investigate the viability of using steel fibers in the grout to fully or partially replace the stirrups. The use of fiber grouted reinforced masonry may be a cost-effective alternative to using stirrups in reinforced masonry. However, it is important to design the fibre grout mix so it can achieve adequate workability and grouting quality. Various parameters that would need to be studied would be the mix proportions, fiber type (straight, intended or hooked ended), fiber length and volume fraction. 


\section{References}

ACI Committee 318 (2005) "Building Code Requirements for Reinforced Concrete (ACI 31805) and Commentary ACI 318 R-05,” American Concrete Institute, Detroit, 430 pp.

ACI-ASCE Committee 326 (1962) "Shear and Diagonal Tension," Journal of the American Concrete Institute, Proceedings, V. 59, No. 1, 2, 3, January pp. 1-30, February pp. 277-334, March pp. 352-396,

American Association of State Highway Transportation Officials (2004) AASHTO LRFD Bridge Design Specifications and Commentary, Third Ed., Washington, 1264 pp.

Anderson, B.G. (1957), "Rigid Frame Failures,” ACI Journal, Vol. 53, No. 1, Jan, pp. 625-636.

Andolfato, R. P., Camacho, J. S., and Ramalho, M. A., "Brazilian Results on Structural Masonry Concrete Blocks," ACI Materials Journal, Vol. 104, No. 1, 2007, pp. 33-39.

Arıglu, N.Z., Girgin, C. and Arıglu, E., "Evaluation of Ratio between Splitting Tensile Strength and Compressive Strength for Concretes up to $120 \mathrm{MPa}$ and its Application in Strength Criterion," ACI Materials Journal, Vol. 103, No. 1, 2006, pp. 18-24.

AS Committee 3700-2001. Masonry Structures. Australian Standard Association, Sydney, 2001, $197 \mathrm{pp}$.

Baba, A., and Senbu, O., "Influencing Factors on Prism Strength of Grouted Masonry and Fracture Mechanism under Uniaxial Loading," Proceedings of the 4th Canadian Masonry Symposium, Vol. 2, Frediction, New Brunswick, 1986, pp. 1068-1074.

Banting, B. , El-Dakhakhni, W. "Modified Compression Field Theory (MCFT) for Shear Strength Predictions of Reinforced Masonry Shear Walls" 15th International Brick and Block Masonry Conference, Florianópolis , Brazil, June 2012, Paper 86, on CD-ROM.

Barbosa, C. S., Lourenco, P. B. and Hanai, J. B. "On the compressive strength prediction for concrete masonry prisms,” Materials and Structures, Vol. 43, No .3, 2010, pp. 331-344.

Becica, I.J., Harris, H.G., "Ultimate Strength Behavior of Hollow Concrete Masonry Prisms Under Axial Load and Bending," Proceedings of the 2nd North American Masonry Conference, pp. 3-1 to 3-20, Longmont, Colorado, 1982

Bentz, E.C. and Collins, M.P. (2005) "Development of the 2004 CSA A23.3 Shear Provisions for Reinforced Concrete," Canadian Journal of Civil Engineering, Vol. 33, No. 5, May, pp. 521534 
Bentz, E.C., Vecchio, F.J. and Collins, M.P. (2006) "Simplified Modified Compression Field Theory for Calculating Shear Strength of Reinforced Concrete Elements," ACI Structural Journal, Vol. 103, No. 4, pp. 614-624

Bexten K, Tedros M, Horton R., "Compression Strength of Masonry," Proceedings of the 5th Canadian Masonry Symposium, Vancouver, B.C., Canada, 1989, pp. 629-639.

BIA Technical Note No.17B 1999: BIA Technical Note No.17B . Reinforced Brick Masonry. Brick Industry Association, Reston, VA, 1999.

BIA Technical Note No.17M 1988: BIA Technical Note No.17M . Reinforced Brick Masonry Girders - Examples. Brick Industry Association, Reston, VA, 1988.

Boult, B. F., "Concrete Masonry Prism Testing,” ACI Journal, Vol. 76, No. 4, 1979, pp. 513535 .

Bresler, B. and Pister, K.S. (1958) "Strength of Concrete Under Combined Stresses," Journal of the American Concrete Institute, Vol. 30, No. 3, Proceedings Vol. 55, pp. 321-345

Bresler, B. and Scordelis, A.C. (1963) "Shear Strength of Reinforced Concrete Beams," Journal of the American Concrete Institute, Proceedings, Vol. 60, No. 1, pp. 51-74

BS Committee 5628-2. Code of Practice for the use of Masonry - Part 2: Structural Use of Reinforced and Prestressed Masonry. London, United Kingdom, 2005, 68 pp.

BS EN 1015-11-1999. Methods of Test for Mortar for Masonry. Part II : Determination of Flexural and Compressive Strength of Hardened Mortar, British Standards Institution, 12pp.

BS EN 1996: Eurocode 6. Design of Masonry Structures. British Standard Institution, 128 pp.

BS EN 772-1-2000. Methods of test for Masonry Units. Part 1: Determination of Compressive Strength, British Standards Institution, 14 pp.

CAN/CSA-A165. CSA standards on concrete masonry units. CSA, Mississauga, ON; 2004. 78pp.

CEN. Eurocode 6. Design of masonry structure- Part 1- Common rules for reinforced and unreinforced masonry structures. BS EN-1996-1-1, 2005, 128pp.

Chahine, G. N., and Drysdale, R. G., "Influence of Test Conditions on the Compressive Strength and Behaviour of Face Shell Mortar bedded Concrete Block Prisms," 5Th Canadian Masonry Symposium, Vancouver, B.C., Canada, 1989, pp. 651-660.

Cheema, T. S. and Klingner, R. E. (1986) "Compressive Strength of Concrete Masonry Prisms," ACI Journal, Vol. 83, No. 1, 1986, pp. 88-97. 
Cintrón, R. and Saouma, V. (2008). "Strain measurements with digital image correlation system Vic-2D.” Report Cu-NEES-08-06, University of Colorado, U.S.A.

Citto, C., Wo, S. and Willam, K. (2011). "Image correlation diagnostics of masonry assemblies." Proc., 11th North American Masonry Conference, Minneapolis, Minnesota, Paper \#6.02-1.

Collins, M.P., Bentz, E.C and Sherwood, E.G. (2007) "Where is Shear Reinforcement Required?" A Review of Research Results and Design Procedures," ACI Structural Journal, Vol. 105, Issue 5, pp. 590-600.

Collins, M.P., Mitchell, D., Adebar, P., and Vecchio, F. J. (1996) "A General Shear Design Method,"ACI Structural Journal, Vol. 93, No. 1, pp. 36-45.

Colville, J., and Wolde-Tinsae, A. (1991) "Compressive Strength of Hollow Concrete Masonry," TMS Journal, Vol. 9, No. 2, 1991, pp. 81-93.

Copeland, R.E., and Timms, A.G.( 1932) "Effect of Mortar Strength and Strength of Unit on the Strength of Concrete Masonry Walls" ACI Journal, Vol. 28, 1932, pp. 551-562.

CSA Committee S304.1, "Design of Masonry Structures, CSA S304.1-04," Canadian Standards Association, Toronto, Ontario, 2004, 148 pp.

Das, S., Liu, J., El Sayed, M. and Kenno, S. "Effect of Height-to-Thickness Ratio on Compressive Strength of Masonry." TMS Journal, Vol. 32, No. 1, 2014, pp. 1-9.

Das, S., Liu, J., El Sayed, M. and Sturgeon, G., "Effect of Height-to-Thickness Ratio on Compressive Strength of Hollow Concrete Masonry," 12th Canadian Masonry Symposium, Vancouver, B.C., 2013.

Drysdale, R. and Hamid, A. Masonry Structures: Behavior and Design. Canada Masonry Design Centre, 2005, 895 pp.

Drysdale, R. G., and Hamid, A. A., "Behavior of Concrete Block Masonry under Axial Compression," ACI Journal, Vol. 76, No. 6, June 1979, pp. 707-721.

Drysdale, R. G., and Hamid, A. A., "Capacity of Concrete Block Masonry Prisms Under Eccentric Compressive Loading," ACI Journal, Vol. 80, No. 2, 1983, pp. 102-108.

Duncan L. Effect of Block Face Shell Geometry and Grouting on the Compressive Strength of Concrete Block Masonry. MSc Thesis. University of Windsor ,2008, 136pp.

Edgell G.J., Bright N.J. and Heath M., "Characteristic Compressive Strength of U.K. Masonry: A Review," 6th International Masonry Conference, London, Nov. 2002, pp. 109-120.

Fenwick, R.C. and Paulay, T. (1964) Discussion of Kani (1964), Journal of the American Concrete Institute, Proceedings Vol. 61, No. 12, pp. 1590-1595 (1964) 
Fenwick, R.C. and Paulay, T. (1968) "Mechanisms of Shear Resistance of Concrete Beams," Journal of the Structural Division, ASCE, Vol. 94, No. ST10, pp. 2235-2350 (Y)

Ferguson, WA. A Comparison between the Compressive Strength of Mortar Obtained from $70.7 \mathrm{~mm}$ Mortar Cubes and 40mm x 40mm x 160mm Prisms. Report to Masonry Research Advisory Committee, July 1995, 10 pp.

Forssell, C. (1954), "Tests of Shear Strength and Shear Reinforcement of Concrete Beams," Transactions, Swedish Cement and Concrete Research Institute at the Royal Institute of Technology, Stockholm, Sweden, No. 78

Fortes, E., Parsekian, G., and Fonseca, F. "Relationship between the Compressive Strength of Concrete Masonry and the Compressive Strength of Concrete Masonry Units." J. Mater. Civ. Eng., 2014, pp. 1-12.

Gayed, M., Korany, Y., "Concrete Compressive Strength Using the Unit Strength Method," Masonry Chair Report No.102-2011, May 2011, 22 pp.

Gayed, M., Korany, Y., Sturgeon, G., "Examination of the Prescribed Concrete Block Masonry Compressive Strengths in the Canadian Masonry Design Standard, CSA S304.1-2004," 15 th International Brick and Block Masonry Conference, Florianopolis, Brazil, 2012.

Gayed, M., Korany, Yand Nazief, M. "Effect of Test Conditions on the Compressive Strength of Hollow Concrete Masonry Units," TMS Journal, Vol. 30, No. 1, 2012, pp. 21-33.

Gaynor, P., Woodward, K., Scribner, C. "Influence of Mortar Bedding on Masonry Prism Behavior," U.S. Department of Commerce, National Bureau of Standards, Report NBSIR 863467, 1987, 69 pp.

Gergely, P. (1969) "Splitting Cracks Along the Main Reinforcement in Concrete Members," Report to Bureau of Public Roads, U.S. Department of Transportation, Cornell University, Ithaca, New York, April 1969

Gergely, P. and Lutz, L.A. (1968) "Maximum Crack Width in Reinforced Concrete Flexural Members," Causes, Mechanisms and Control of Cracking in Concrete, SP-20, American Concrete Institute, Farmington Hills, Michigan, pp. 87-117

Grant B. J., McMillian D. and Klayman J. (2009) “Alper Audi at the Meadows" Masonry Magazine, The Masonry Institute of St. Louis, Vol.15, Issue 3, pp. 8-9.

Guo, P. Investigation and Modeling of the Mechanical Properties of Masonry. Doctoral thesis. McMaster University, 1991, 388pp. 
Hamid, A. A.; Drysdale, R. G.; and Heidebrecht, A.C., "Effect of Grouting on the Strength Characteristics of Concrete Block Masonry," Proceedings of the North American Masonry Conference, Boulder, Colorado, 1978, pp. 11-1 to 11-17.

Hanson, J.A. (1958) "Shear Strength of Lightweight Reinforced Concrete Beams," Journal of the American Concrete Institute, Vol. 30, No. 3, Proceedings Vol. 55, pp. 387-403

Hawk, S. W., Mclean, D. L. and Young, T. C. "Compressive behavior of insulated concrete masonry prisms," TMS Journal, Vol. 15, No. 2, 1997, pp. 53-60.

Hegmier, G. A.; Krishnmoorthy, G. ; Nunn, R. O. ; and Moorthy, T. V., "Prism Tests for the Compressive Strength of Concrete Masonry," Report No. AMES-NSF-77-1, University of California, San Diego, 1977, 100 pp.

Hoult N. A., Sherwood, E. G., Bentz, E. C. and Collins, M. P. "Does the Use of FRP Reinforcement Change the One-Way Shear Behavior of Reinforced Concrete Slabs? "Journal of Composites for Construction, Vol. 12, No. 2, April 1, 2008.

Jourawski, D.J. (1858) "Sur le résistance d'un corps prismatique et d'une Piece Composée en Bois ou on Tôle de Fer à une Force Perpendiculaire à leur Longeur," Annales des Ponts et Chausees, Memoires and Documents, 3rd Series, V. 12, Part 2, pp. 328-351

Kani, G.N.J. (1964) "The Riddle of Shear Failure and its Solution," Journal of the American Concrete Institute, Proceedings, Vol. 61, No. 4, pp. 441-466

Kani, G.N.J. (1967) "How Safe are Our Large Reinforced Concrete Beams?" Journal of the American Concrete Institute, Proceedings, Vol. 64, No. 3, pp. 128-141

Kani, M.W., Huggins, M.W. and Wittkopp, R.R. (1979) "Kani on Shear in Reinforced Concrete," University of Toronto Press, Toronto, Canada, 225pp.

Khalaf, F. M., "Factors Influencing Compressive Strength of Concrete Masonry Prisms," Magazine of Concrete Research, Vol. 48, No. 175, 1996, pp. 95-101.

Khalaf, F.M., Hendry, A.W., and Fairbairn, D.R. (1994). "Study of the Compressive Strength of Blockwork Masonry,” ACI Structural Journal, Vol. 91, No. 4, 1994, pp. 367-376.

Kingsley, G. R., Atkinson, R. H., Noland, J. L. and Hart, G. C., "The effect of Height on StressStrain Measurements of Grouted Concrete Masonry Prisms," 5th Canadian Masonry Symposium, Vancouver, B.C., Canada, 1986, pp. 587-598.

Korany Y. and Glanville, J., "Comparing Masonry Compressive Strength in Various Codes," Concrete International, July 2005, pp. 35-39. 
MacGregor, J.G. and Walters, J.R.V. (1967) "Analysis of Inclined Cracking Shear in Slender Reinforced Concrete Beams," ACI Journal, Proceedings, Vol. 64, No. 10, October 1967, pp. 644- 653

Masonry Standards Joint Committee. (2011). "Building code requirements for masonry structures (TMS 402-11/ACI 530-11/ASCE 5-11).” The Masonry Society, Boulder, CO, 2011, $236 \mathrm{pp}$.

Mauenbrecher, A.H.P., "Compressive Strength of Eccentrically Loaded Masonry Prisms," 3rd Canadian Masonry Symposium. Edmonton, AB, Canada, 1983, pp. 10 (1-13).

Maurenbrecher, A. H. P. "Axial Compression Tests on Masonry Walls and Prisms," Third North American Masonry Conference, University of Texas at Arlington, 1985, pp. 1901-1914.

Maurenbrecher, A. H. P., "Compressive Strength of Hollow Concrete Blockwork," 4Th Canadian Masonry Symposium, Fredericton, N.B., Canada, 1986, pp. 997-1009.

Maurenbrecher, A. H. P., "Compressive Strength of Hollow Concrete Blockwork," Proceedings of the 4Th Canadian Masonry Symposium, Fredericton, N.B., Canada, 1986, pp. 997-1009.

Maurenbrecher, A. H. P., "Effect of Test Procedures on Compressive Strength of Masonry Prisms," Proceedings, 2nd Canadian Masonry Symposium, Carleton University, Ottawa, June 1980, pp. 119-132.

Miller, S.C., El-Dakhakhni, W.W. and Drysdale, R.G. "Experimental Evaluation of the Shear Capacity of Reinforced Masonry Shear Walls" 10th Canadian Masonry Symposium, Banff, Alberta, Canada, June 2005, on CD-ROM.

Moe, J. (1962) Discussion of ACI-ASCE Committee 326 (1962), Journal of the American Concrete Institute, Proceedings, Vol. 59, No. 9, pp. 1334-1339

Mohamad, G., Lourenco, P. B. and Humberto Roman R., "Mechanics of Hollow Concrete Block Masonry Prisms under Compression: Review and Prospects," Cement and Concrete Composites, Vol. 29, No. 3, 2007, pp.181-192.

Mojsilovi'c, N., "Strength of masonry subjected to in-plane loading: A contribution," International Journal of Solids and Structures, 482011 p. 865-873.

Montgomery, D.C. (2012). Design and Analysis of Experiments. John Wiley \& Sons, New York, 752pp.

Mörsch, E. (1909) Concrete-Steel Construction, (Der Eisenbetonbau), English translation of the 3rd German Edition, McGraw-Hill Book Company, New York, 368pp. 
Nacus, C. J. “Comparison of Fully Bedded and Face-Shell Bedded Concrete Block," Report CE495, Colorado State University, November, 1980, 50 pp.

National Concrete Masonry Association 2012, "Recalibration of the Unit Strength Method for Verifying Compliance with the Specified Compressive Strength of Concrete Masonry," 2012, 98 pp.

National Concrete Masonry Association, "Research Investigation of the Properties of Masonry Grout in Concrete Masonry," 1988, 39pp.

Neville, A.M. "A general relation for strengths of concrete specimens of different shapes and sizes,” ACI Journal, Vol. 63, No. 52, 1966, pp. 1095-1109.

Nolph, S. M., In-Plane Shear Performance of Partially Grouted Masonry Shear Walls. Master's thesis, Washington State University, Pullman, WA, 2010.

Olatunji, T.M., Warwaruk, J. and Longworth, J. "Behaviour and Strength of Masonry Wall/Slab Joints," Report No. 139, University of Alberta, 1986, 228 pp.

Oluokun, F. "Prediction of Concrete Tensile Strength from its Compressive Strength: an Evaluation of Existing Relations for Normal Weight Concrete," ACI Materials Journal, Vol. 88, No. 3, 1991, pp. 302-309.

Page, A. W., and Shrive, N. G. "A critical Assessment of Compression Tests for Hollow Block Masonry," Masonry International Journal, Vol. 2, 1988, pp. 64-70.

Page, A.W., Shrive, N.G., "Concentrated Loads on Hollow Concrete Masonry," ACI Structural Journal, Vol. 87, No. 4, 1990, pp. 436-444.

Parmalee, R.A. (1961) "A Study of the Ultimate Strength of Reinforced Concrete Beams," Structural Engineering and Structural Mechanics Report \#61-11, University of California, Berkely, California, Jan., 1961, 66pp.

Ramamurthy, K., Sathish, V. and Ambalavanan, R., "Compressive Strength Prediction of Hollow Concrete Block Masonry Prisms," ACI Structural Journal, Vol. 91, No. 1, 2000, pp. 6167.

Redmond, T.B., and Allen, M.H. "Compressive strength of composite brick and concrete masonry walls," Masonry: Past and Present, ASTM, STP 589, 1975, pp. 195-232.

Richart, F.E., Moorman, R.B., and Woodworth, P.M. Strength and stability of concrete Masonry Walls. University of Illinois, Bulletin 251, 1932, 38 pp.

Ritter, W. (1899) "Die Bauweise Hennebique (Construction Techniques of Hennebique)", Schweizerische Bauzeitung, Zürich, Vol. 33, No. 7, pp. 59-61 
Roberts, J. J., "The Effect of Different Test Procedures upon the Indicated Strength of Concrete Blocks in Compression," Magazine of Concrete Research, Vol. 25, No. 83, June 1973, pp. 8798.

Roca, P., "Simplified Methods for Assessment of Masonry Shear Walls," Proceedings of 6th Congresso Nacional de Sismologia e Engenharia S'1smica, Guimarªes, Portugal, 2004 p.101117.

Romagna, R. H., Roman, H. R., "Compressive Strength of Grouted and Ungrouted Concrete Block Masonry," Proceedings of the British Masonry Society, Vol. 9, 2002, pp. 399-404.

Ross, M., and Korany, Y., "Concrete Masonry Compressive Strength Using the Unit Strength Method for Grouted Masonry,” Masonry Chair Report No.105-2012, May 2012, 17 pp.

Ross, M., Korany, Y., and Sturgeon, G. "Recalibration of the unit strength method in the Canadian masonry design standard, CSA S304.1-04 for grouted masonry." 12th Canadian Masonry Symp., Univ. of British Columbia, BC, Canada, 2013.

Sakr, K. and Neis, V., "Some Studies on the Stress Strain Behaviour of Grouted Masonry Block Units," Proceedings of the 5th Canadian Masonry Symposium, Vancouver, B.C., Canada, 1989, pp. 619-628.

Scrivener, J. C. and Baker, L.R., "Factors Influencing Grouted Masonry Prism Compressive Strength," Brick and Block Masonry, Vol. 2, 1988, pp. 874-883.

Self, M.W., "Structural Properties of Load Bearing Concrete Masonry," Masonry: Past and Present, ASTM, STP 589, 1975, pp. 233-254.

ShenCao (2001), "Size Effect and the Influence of Longitudinal Reinforcement on the Shear Response of Large Reinforced Concrete Members," MAsc. Thesis, Department of Civil Engineering, University of Toronto, Toronto, Ontario

Sherwood, E.G., Bentz, E.C. and Collins, M.P. (2007) "Effect of Aggregate Size on Beam Shear Strength of Thick Slabs,” ACI Structural Journal, Vol. 104, No. 2, pp. 180-190

Shioya, T. (1989) "Shear Properties of Large Reinforced Concrete Member," Special Report of Institute of Technology, Shimizu Corporation, No. 25, 1989, 198 pp. (in Japanese)

Shioya, T., Iguro, M., Nojiri, Y., Akiyama, H., and Okada, T. (1989) "Shear Strength of Large Reinforced Concrete Beams" Fracture Mechanics: Application to Concrete," SP 118, American Concrete Institute, Detroit, 309 pp.

Shrive, N. G., "The Failure Mechanism of Face-Shell Bedded (ungrouted and unreinforced) Masonry," The International Journal of Masonry Construction, Vol. 3, No. 2, 1982, pp. 
Singh, R. "Evaluation of Masonry Mortar Properties and Relationship between Compressive Strength of 2," cube and 2" x 3" cylinder," M.Sc Thesis, University of Texas, May 1988, 137 pp.

Steadman M. ; Drysdale R. G; and Khattab, M. M., "Influence of Block Geometry and Grout Type on Compressive Strength of Block Masonry," Proceedings of the 7th Canadian Masonry Symposium, Hamilton, Canada, 1995, pp. 1116-1127.

Taylor, H.P.J. (1970) "Investigation of Forces Carried across Cracks in Reinforced Concrete Beams by Interlock of Aggregates," TRA 42.447, Cement and Concrete Association, London, 22 pp.

Taylor, H.P.J. (1970) "The Fundamental Behaviour of Reinforced Concrete Beams in Bending and Shear," Shear in Reinforced Concrete, ACI SP-42, paper 3, pp. 43-77

Thomas, R. D., and Scolforo, M. J., "Evaluation of the compressive strength of masonry by prism sampling," TMS Journal, Vol. 13, No. 2, 1995, pp. 65-67.

Thompson, J.; Walloch, C.; and Thomas, R., "Predicting Grouted Concrete Masonry Prism Strength," Masonry Opportunities in the 21st Century, STP 1432, ASTM International, 2002, pp. 170-185.

TMS Committee 402, 2011. Building Code Requirements and Specification for Masonry Structures and Related Commentaries. 2011, 236 pp.

Vecchio, F.J. and Collins, M.P. (1986) "The Modified Compression Field Theory for Reinforced Concrete Elements Subjected to Shear," ACI Journal, Vol. 83, No. 2, pp. 219-231.

Voon, K. C., J. M. Ingham, "Experimental In-Plane Investigation of Reinforced Concrete Masonry Walls with Openings," Journal of Structural Engineering, 134(5), 2008 p. 758-768.

Walraven, J.C. (1981) "Fundamental Analysis of Aggregate Interlock," Journal of the Structural Division, ASCE, Vol. 107, No. 11, pp. 2245-2270

Walther, R. (1962) "Calculation of the Shear Strength of Reinforced and Prestressed Concrete Beams by the Shear Failure Theory," Translation 110, Cement and Concrete Association, originally in Beton-und Stahlbetonbau, Vol. 57, No. 11, pp. 261-271

Williams, A. (1986) "Tests on Large Reinforced Concrete Elements Subjected to Direct Tension," Technical Report No. 562, Cement and Concrete Association, Wexham Springs, UK, April, 56pp.

Wong, H. E, and Drysdale R. G., "Compression Characteristics of Concrete Block Masonry Prisms," Masonry, Research, Application, and Problems, ASTM STP 871, 1985, pp.167-177. 
Xie, H., Page, A. W., and Kleeman, P. W., "An Investigation of the Compressive Failure Mechanism For Face-Shell Bedded Hollow Masonry," 6th Canadian Masonry Symposium, Saskatoon, SK., Canada, 1992, pp. 97-108.

Yao C. Failure Mechanisms of Concrete Masonry. Doctoral thesis. University of British Columbia, 1989, 238pp.

Yoshida, Y. (2000) "Shear Reinforcement for Large, Lightly-Reinforced Concrete Members," M.A.Sc. Thesis, Department of Civil Engineering, University of Toronto

Yu, Q. and Bažant, Z. (2011). "Can Stirrups Suppress Size Effect on Shear Strength of RC Beams?." J. Struct. Eng., 10.1061/(ASCE)

Zwoyer, E.M. and Siess, C.P. (1954) "Ultimate Strength of Simply-Supported Prestressed Concrete Beams without Web Reinforcement," Journal of the American Concrete Institute, Vol. 29, No. 2, Proceedings Vol. 51, pp. 181-200. 


\section{Appendices}




\section{Appendix A}

\section{Tests Results of the Reinforced Masonry Beams}




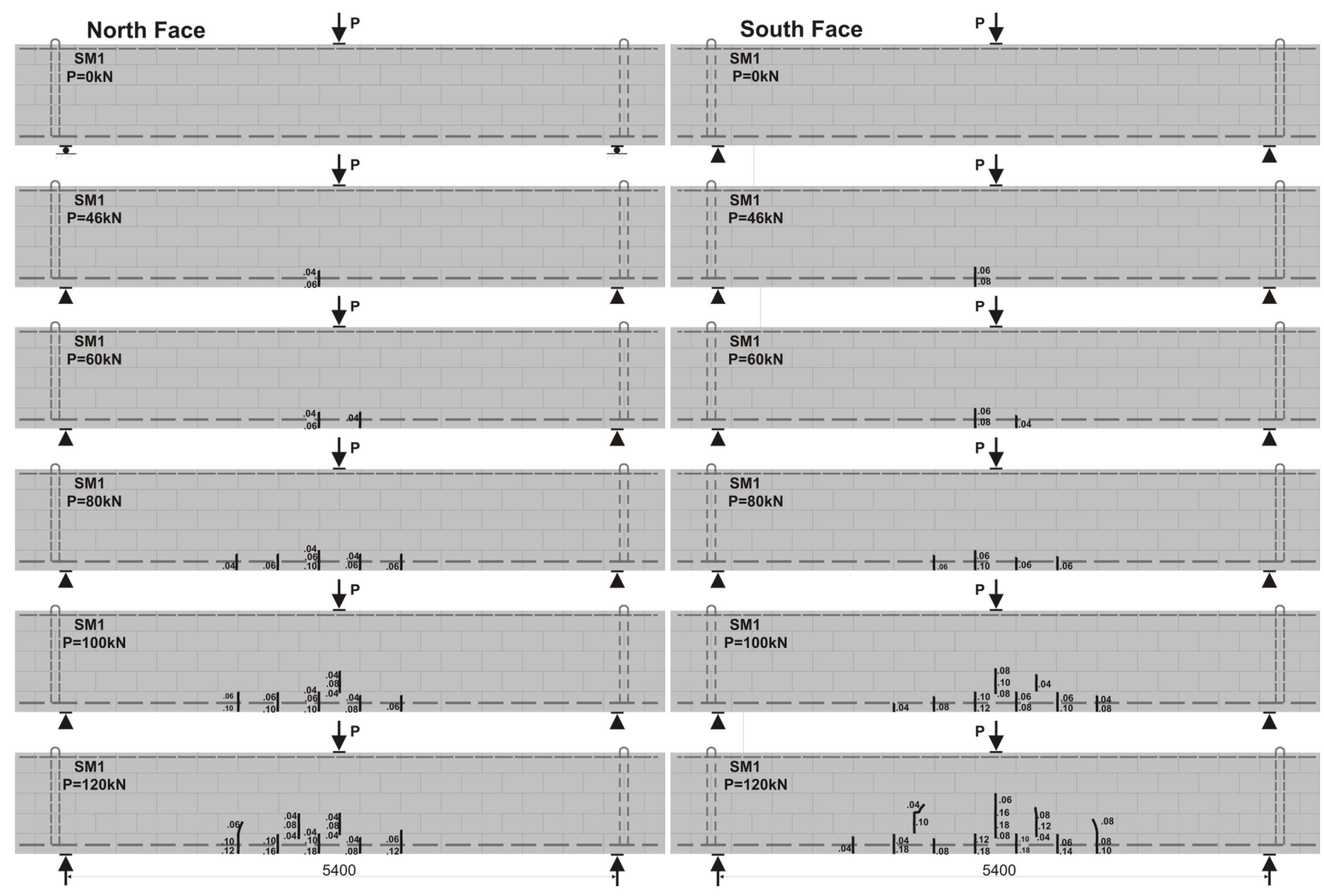




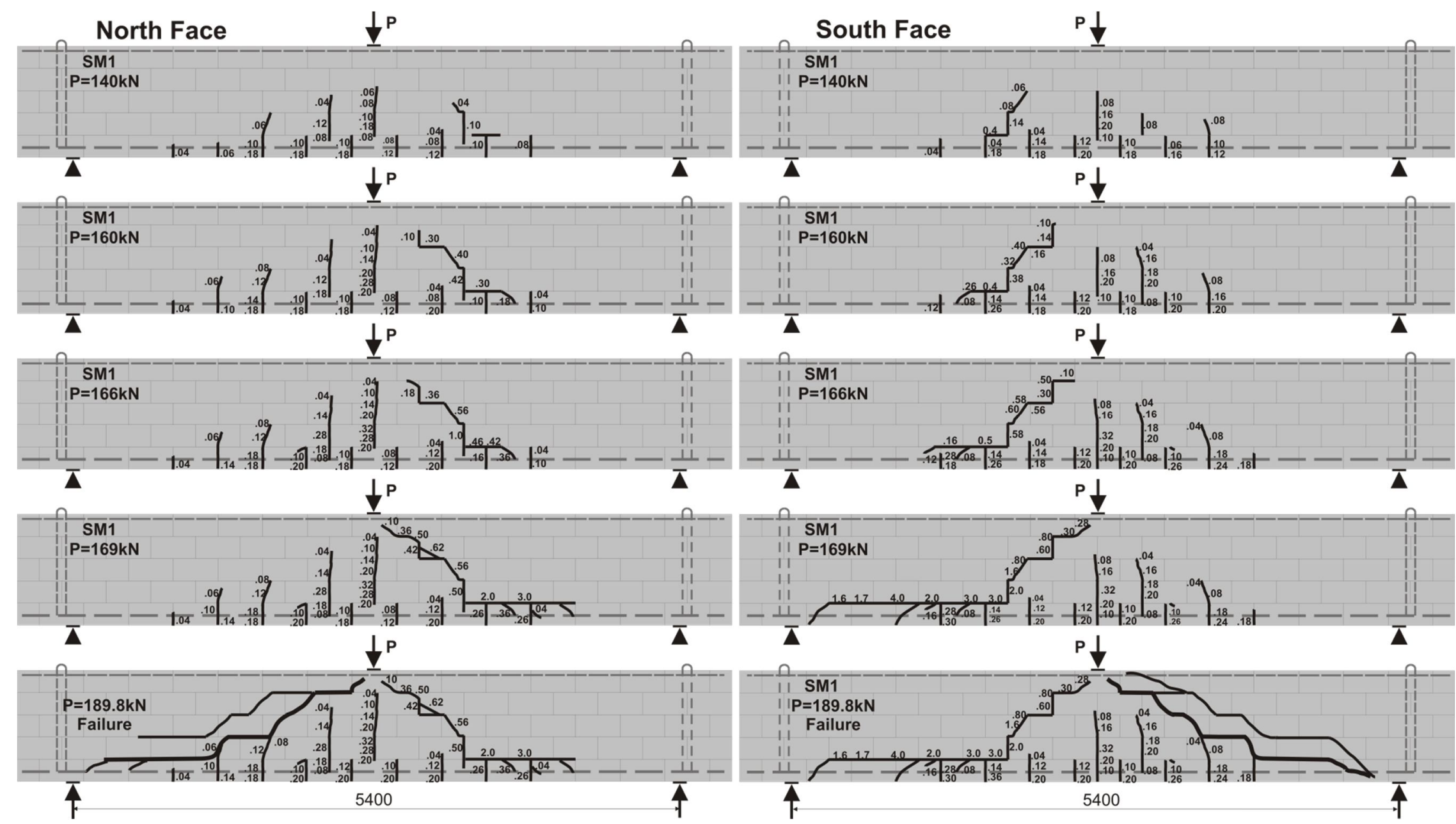



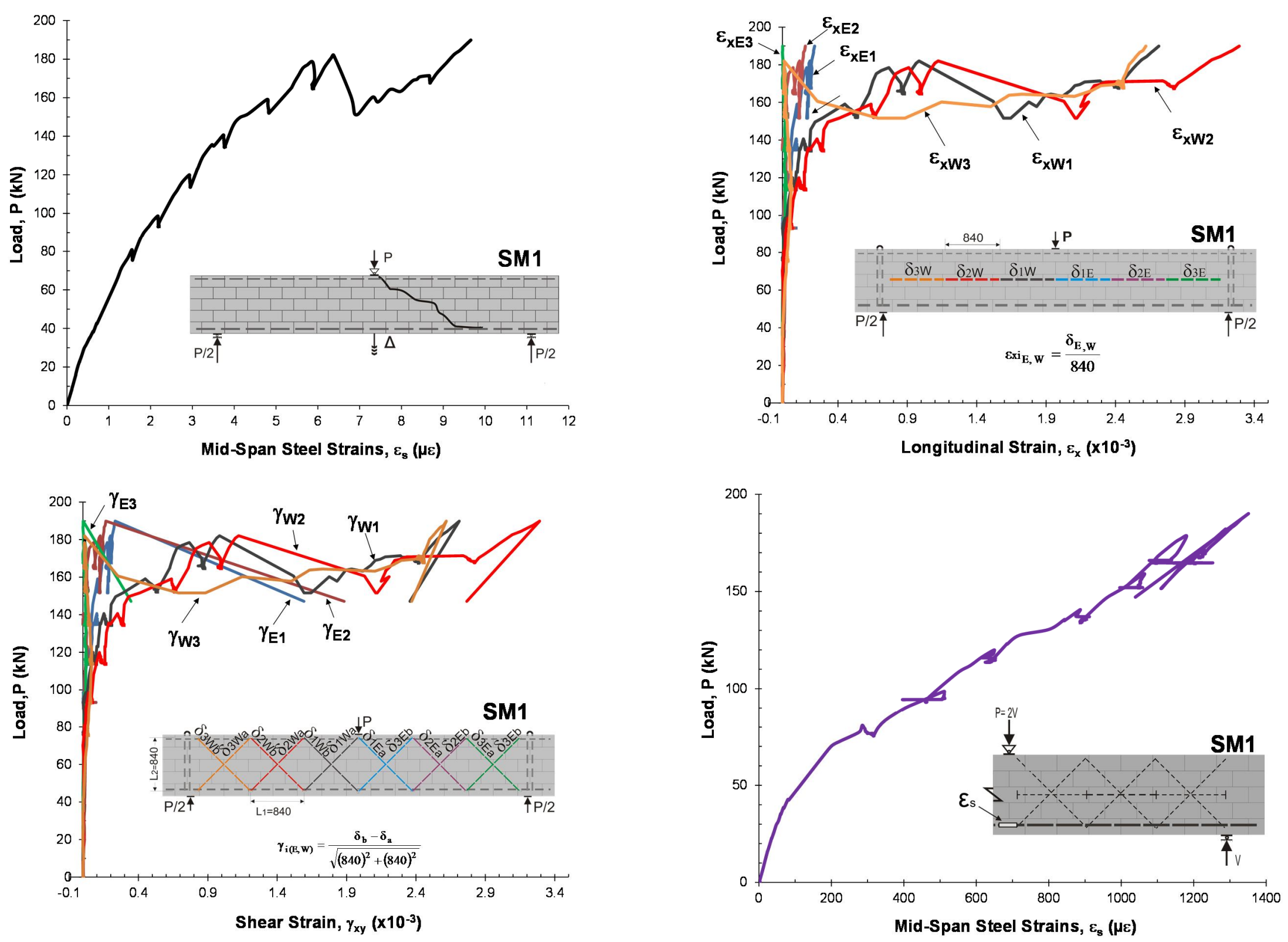

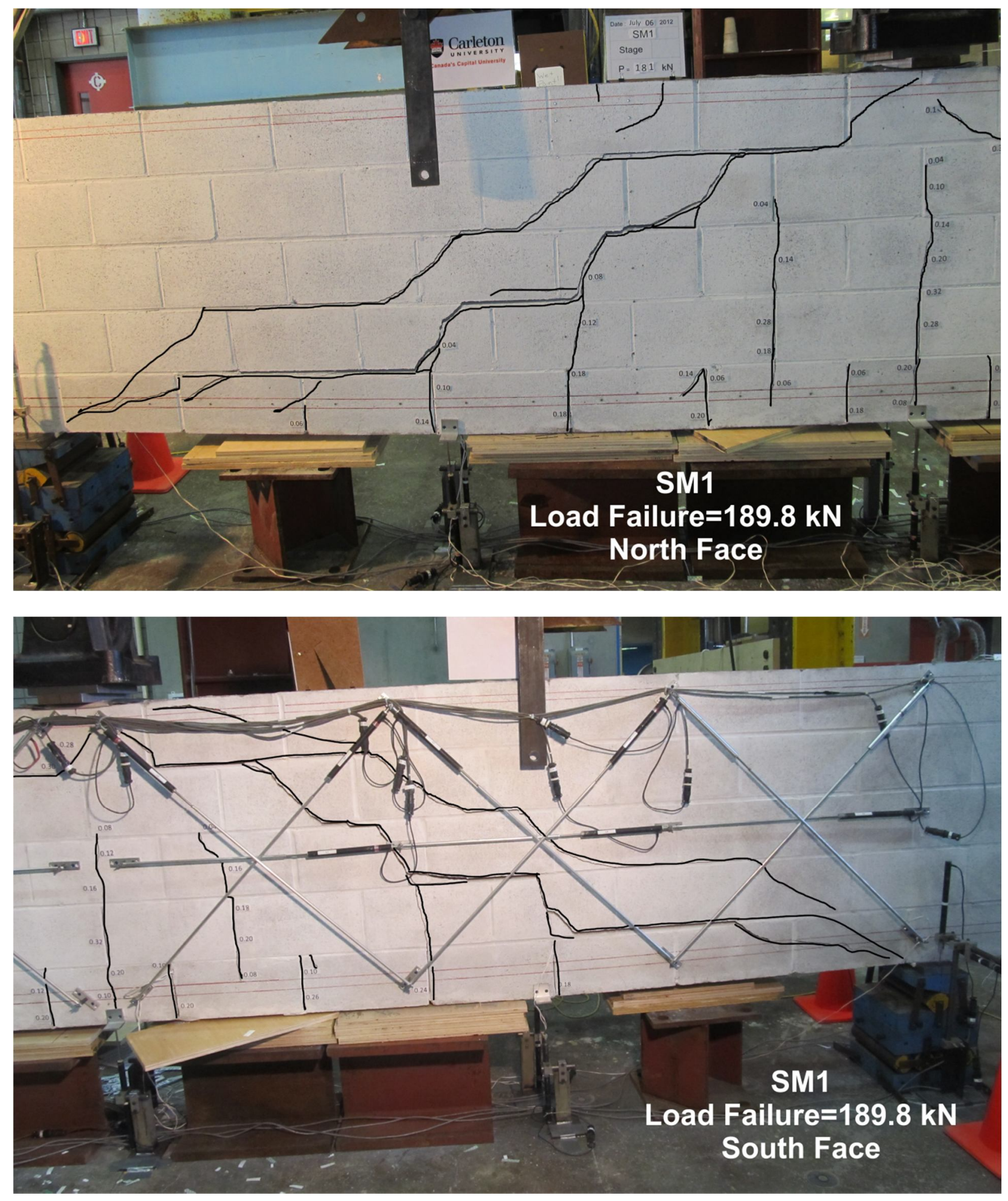

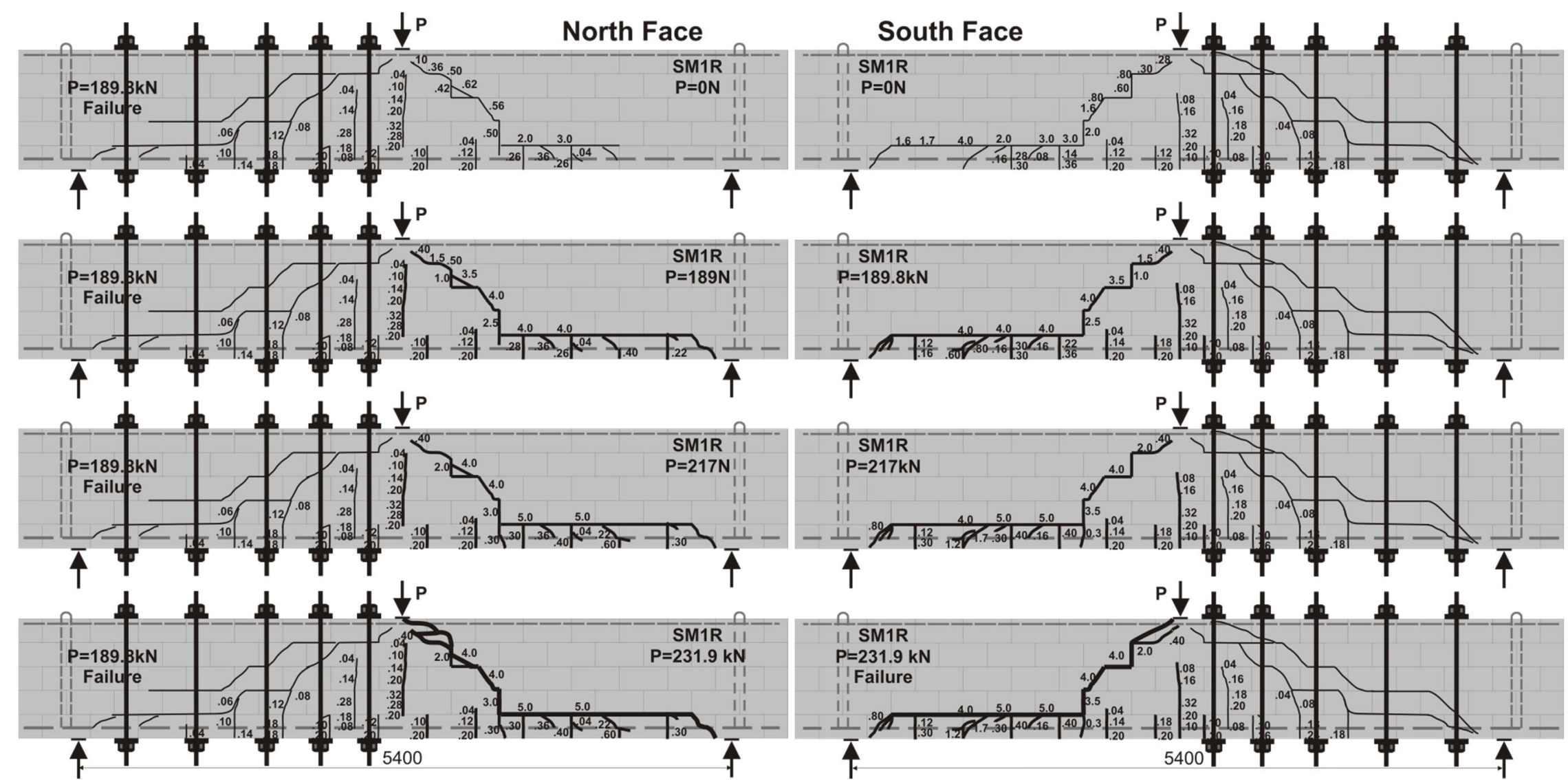

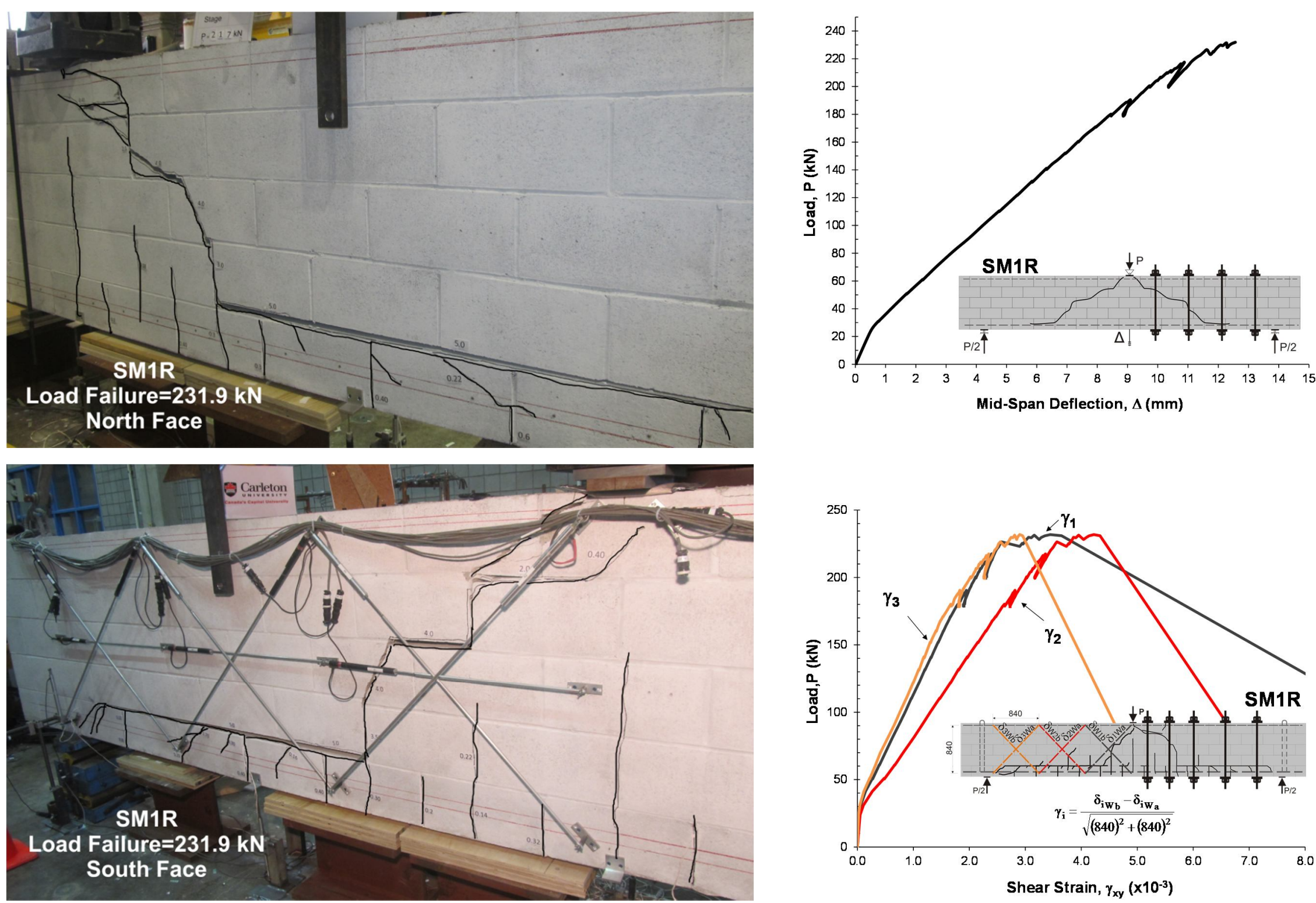


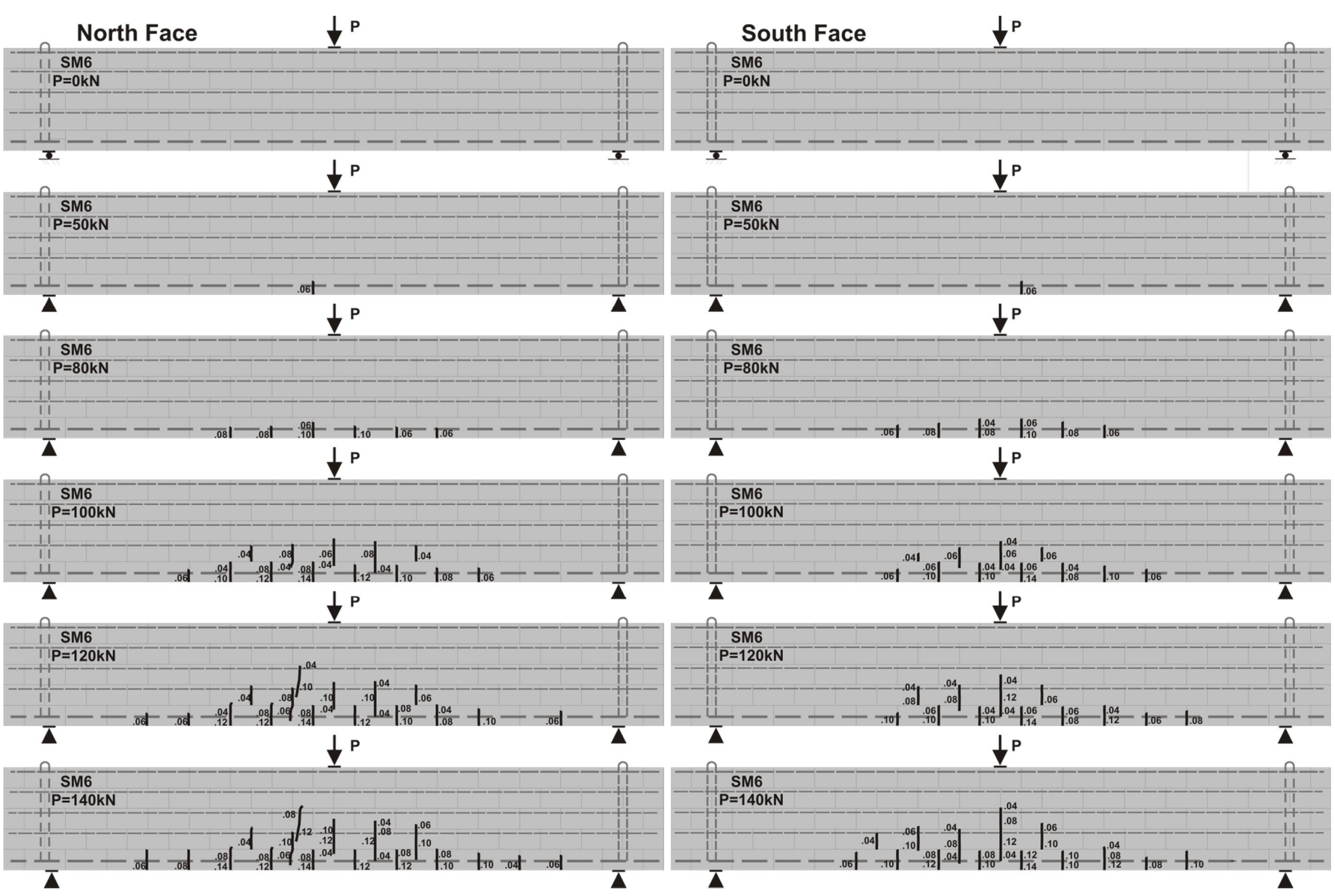




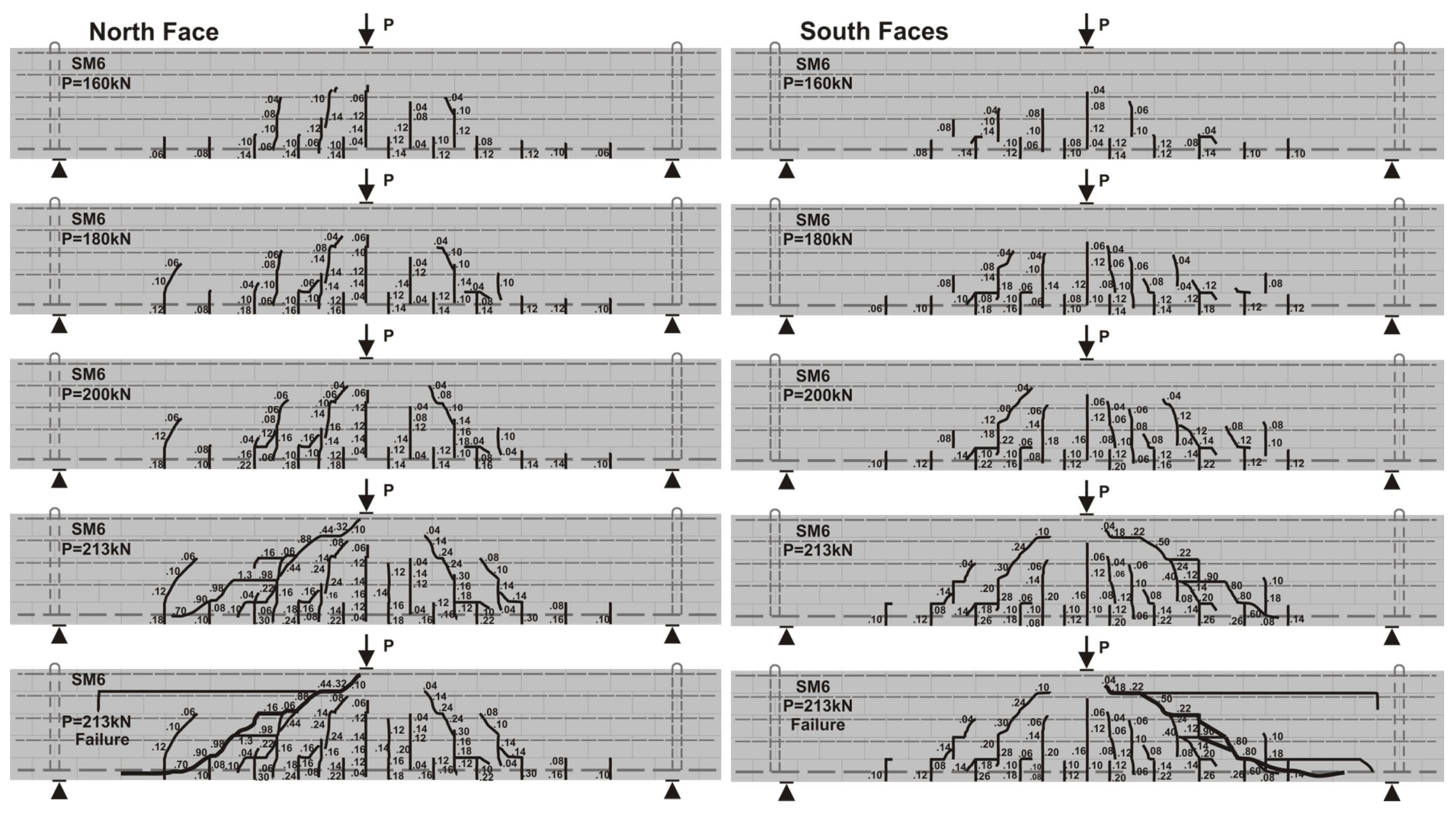



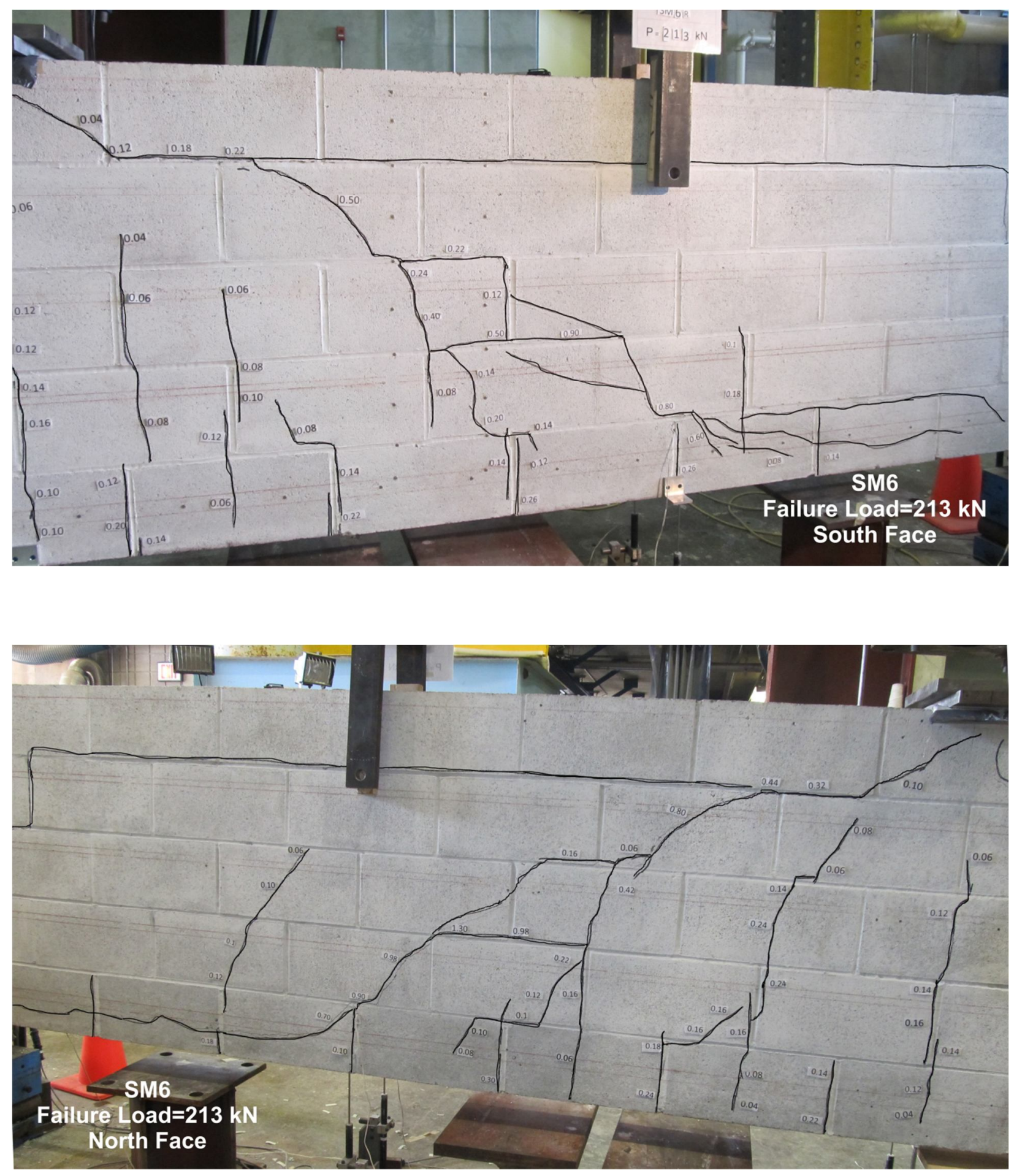

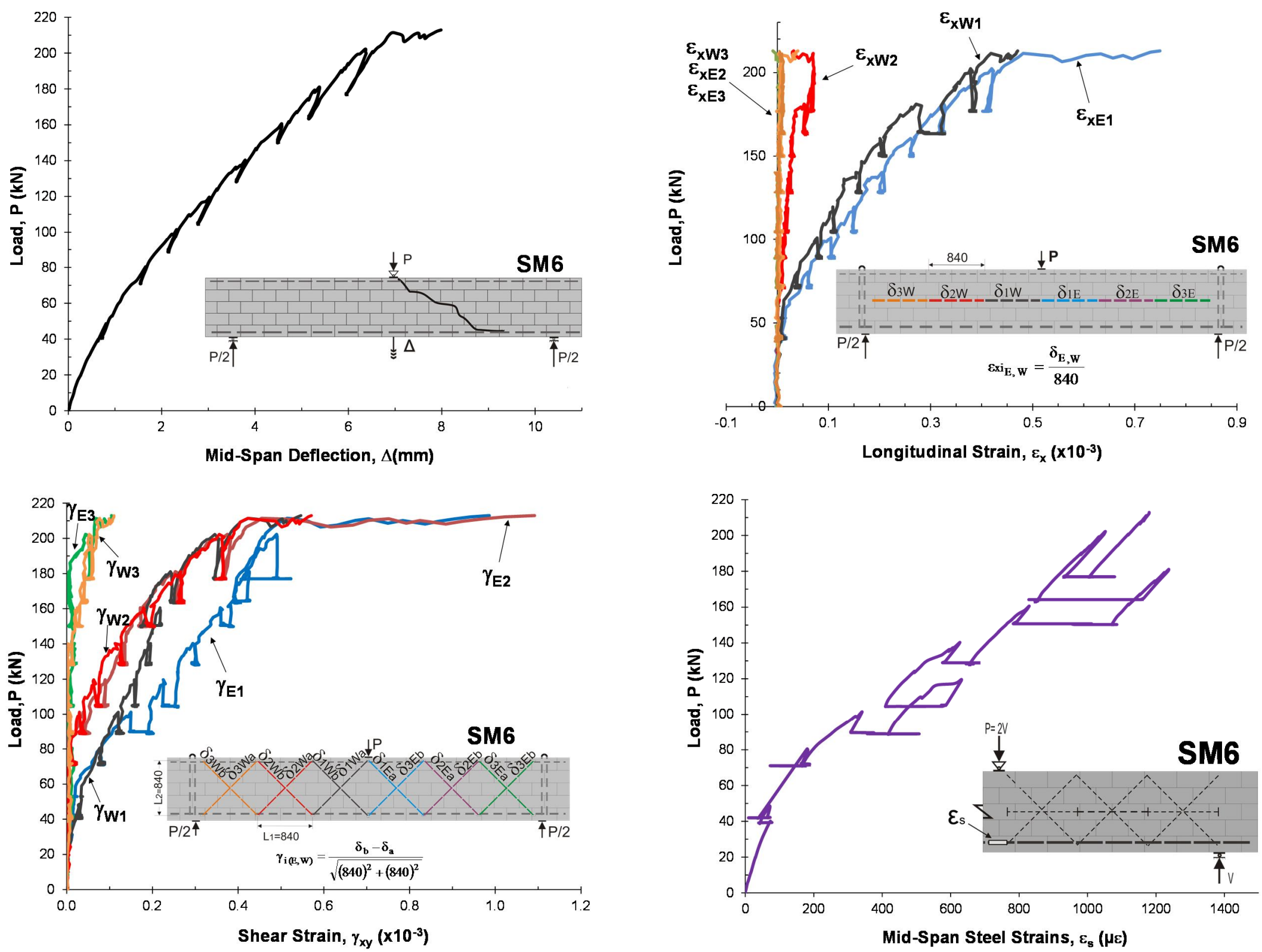

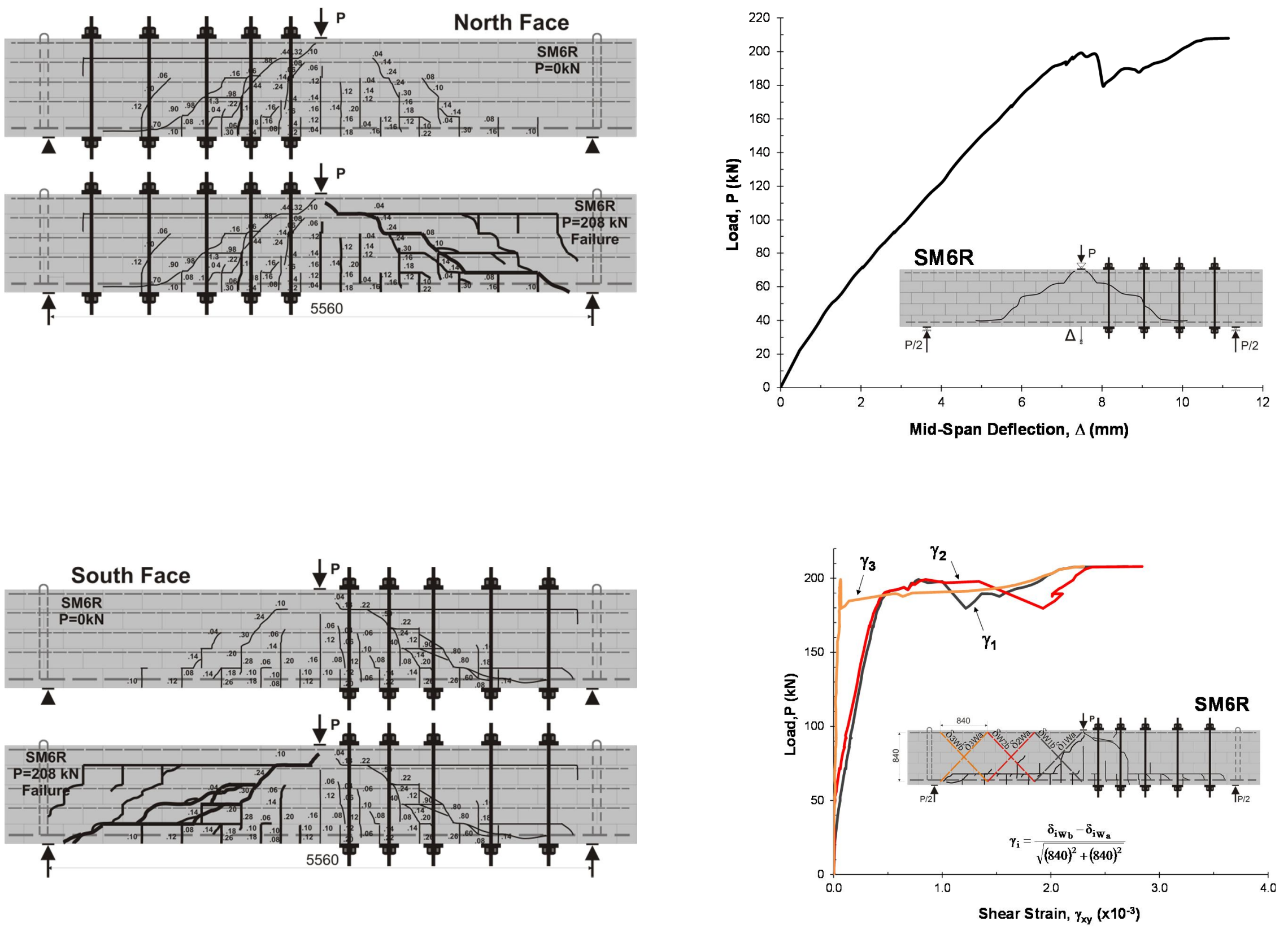

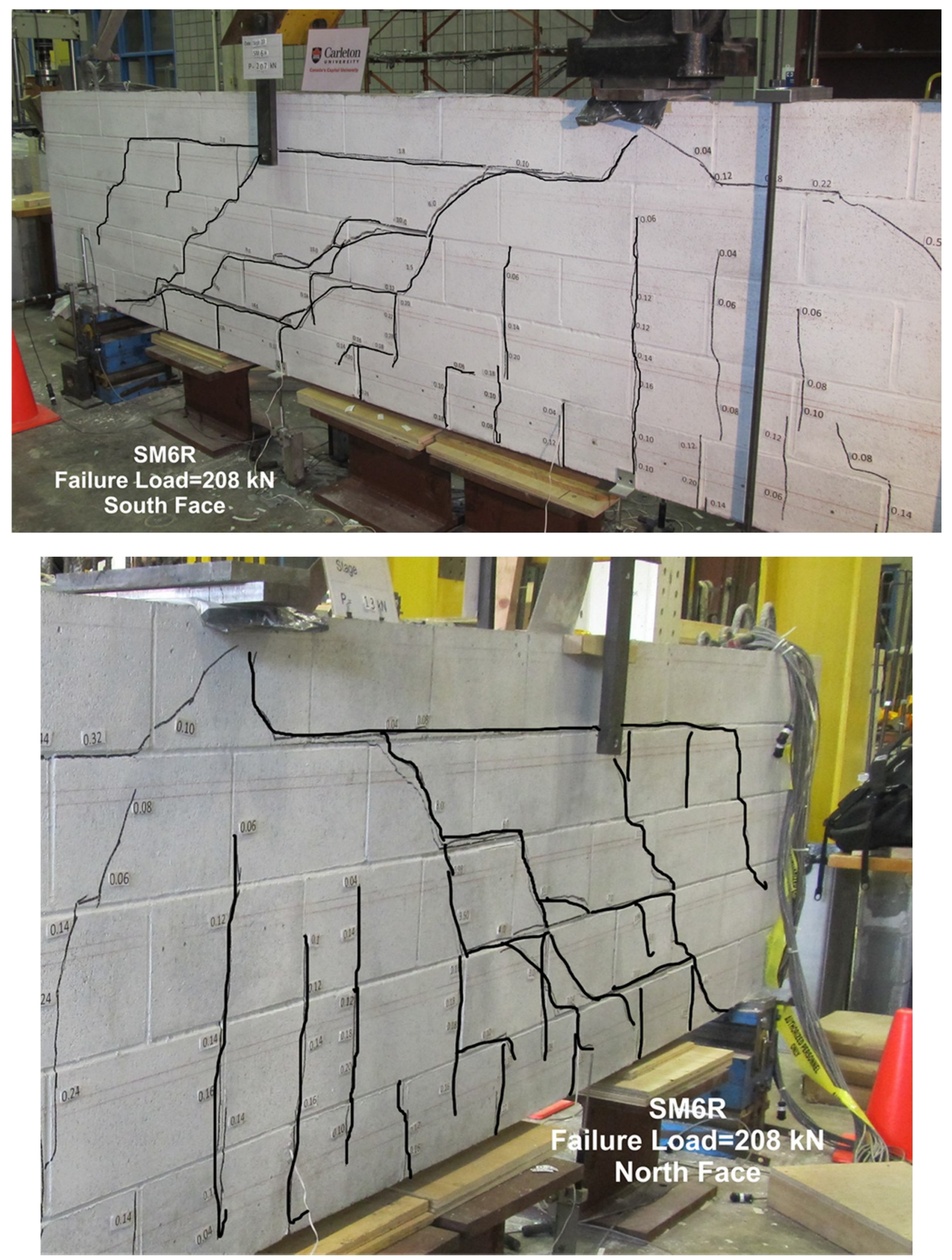


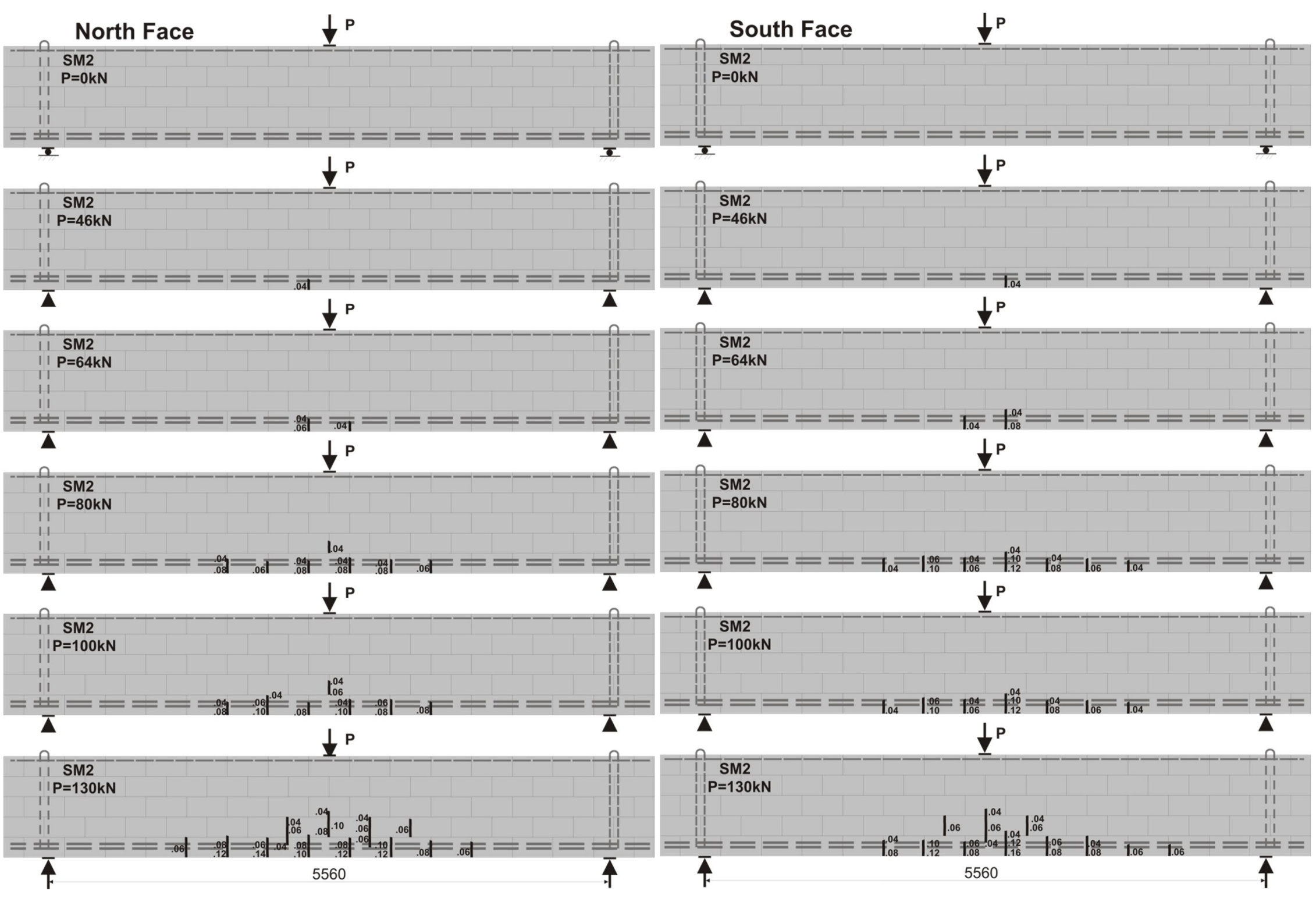




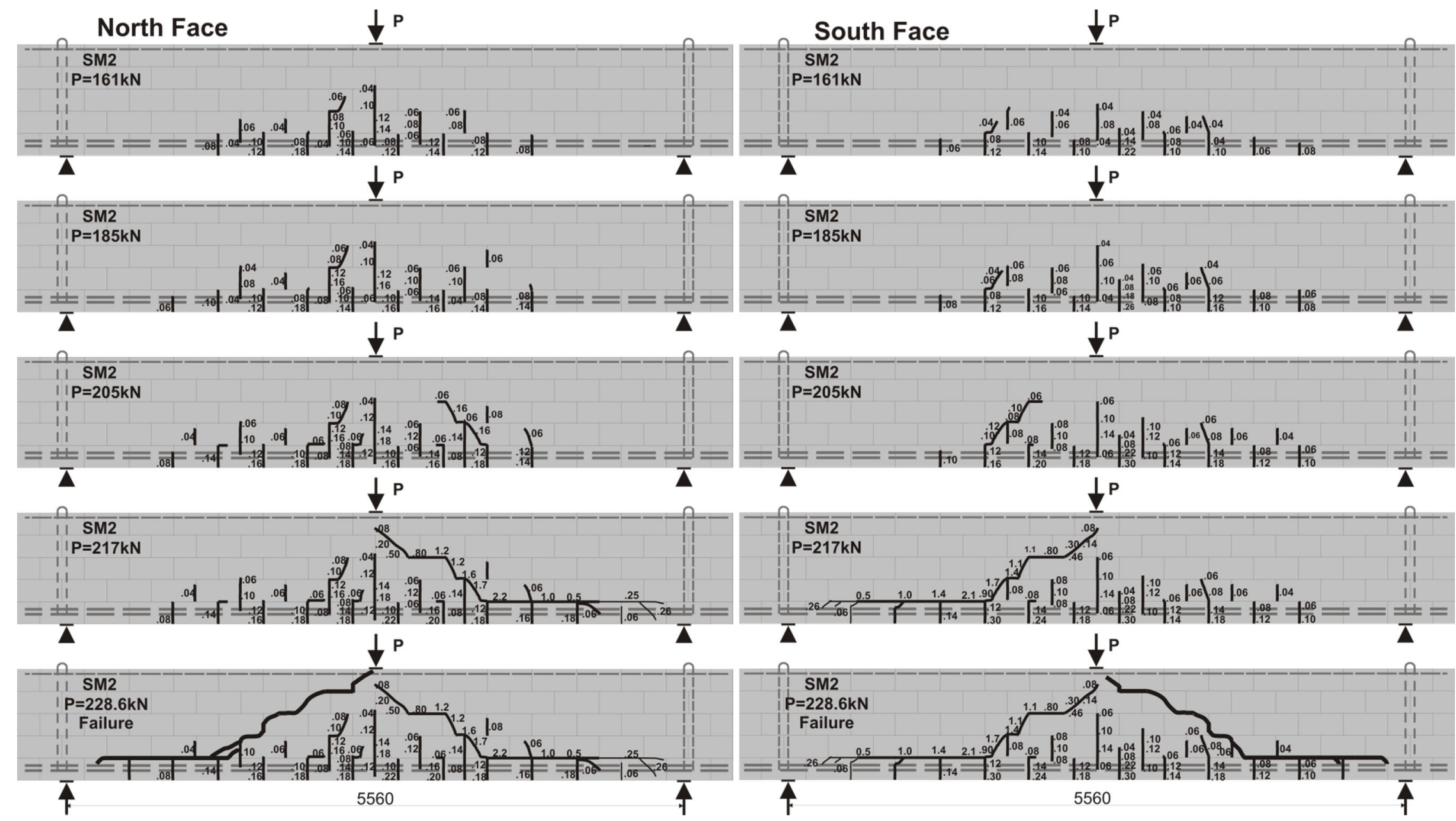



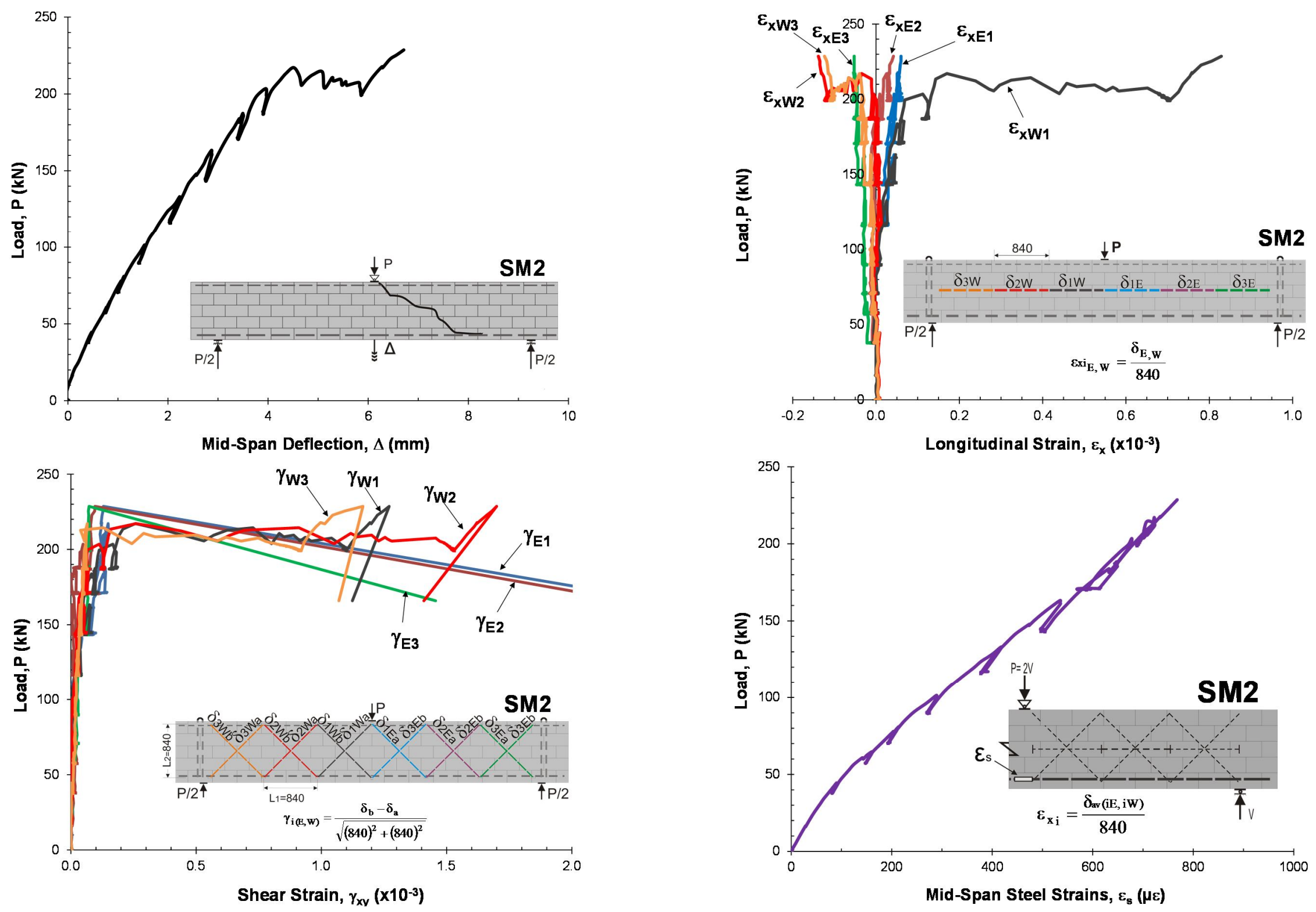

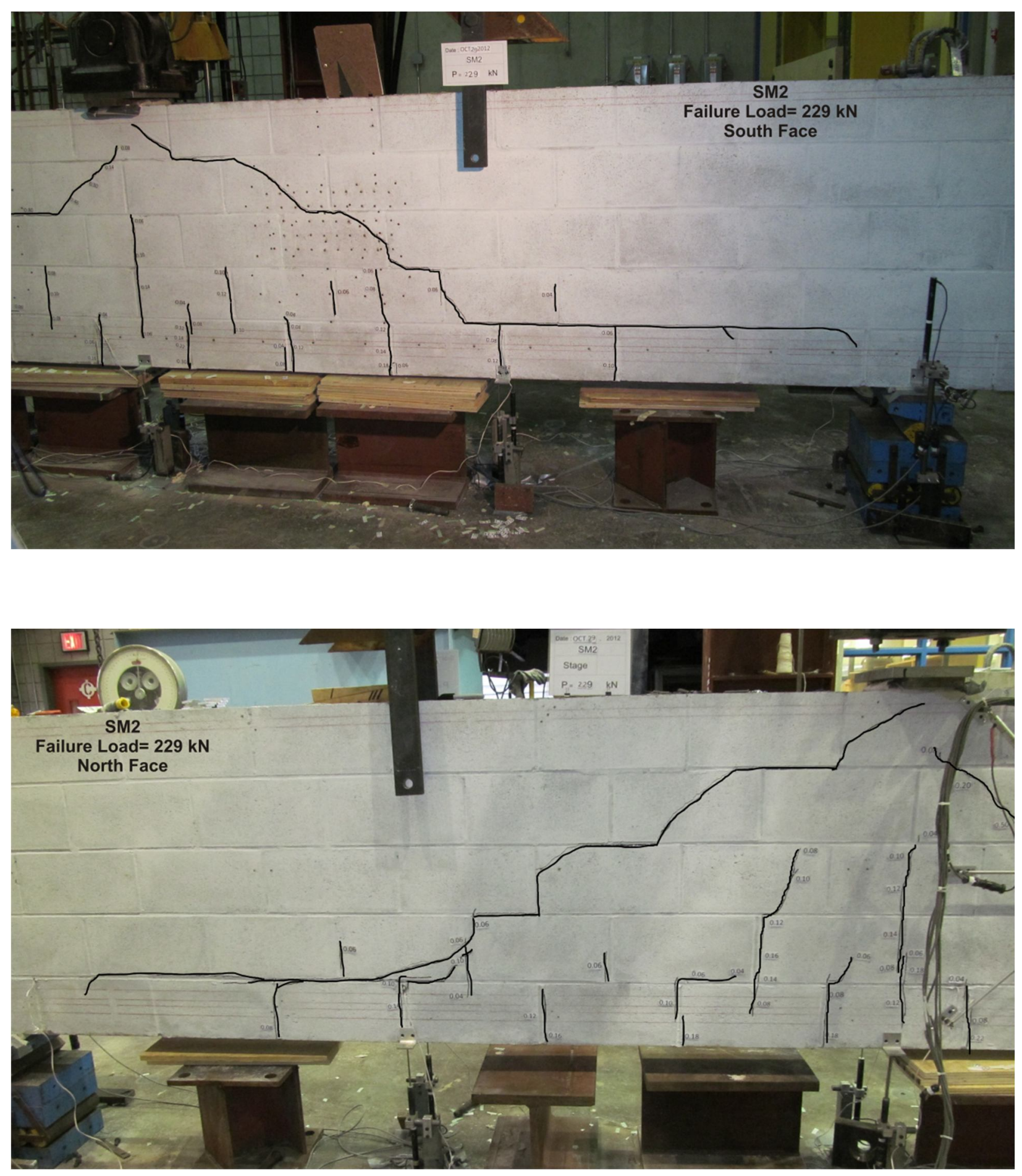

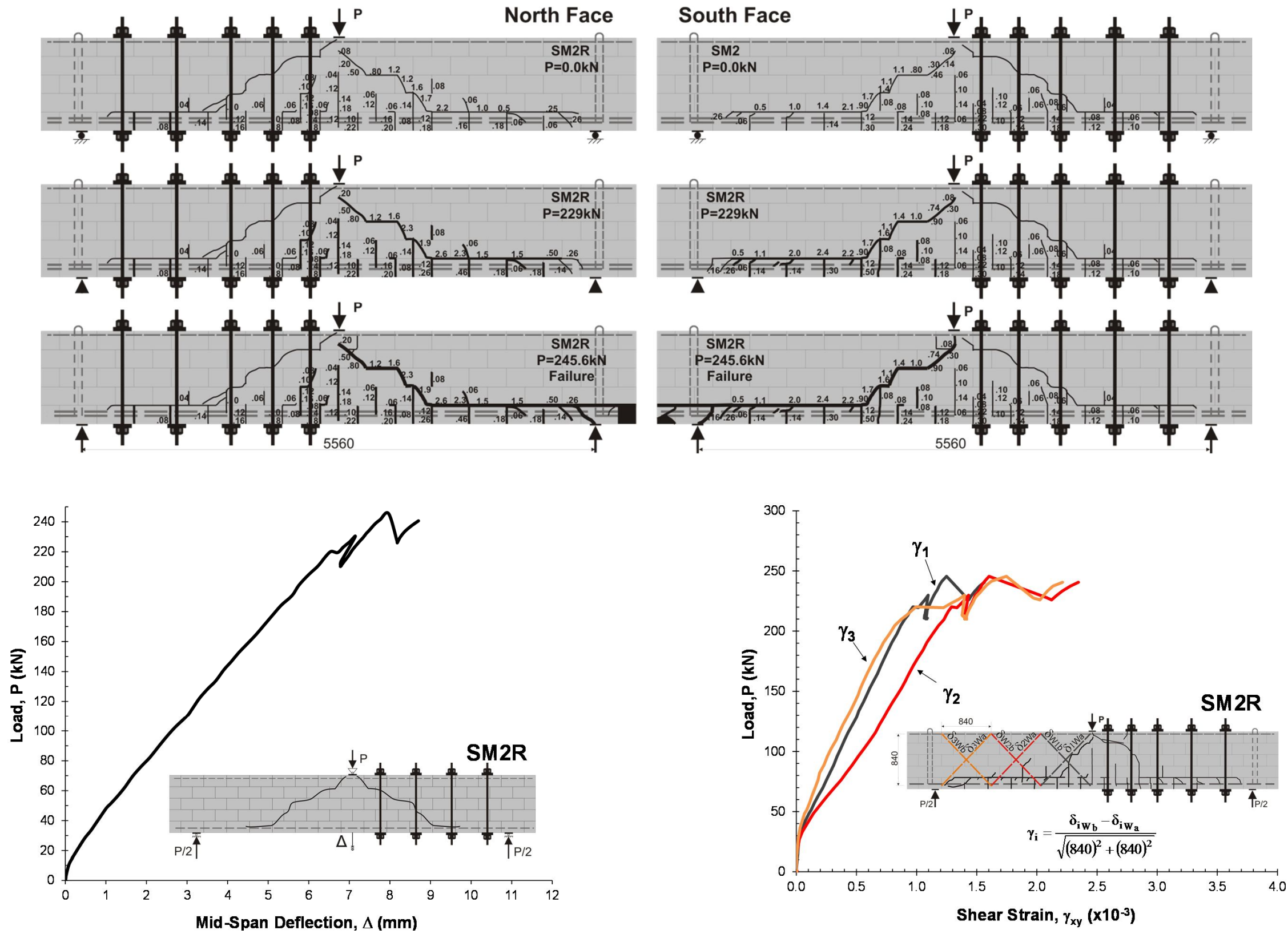

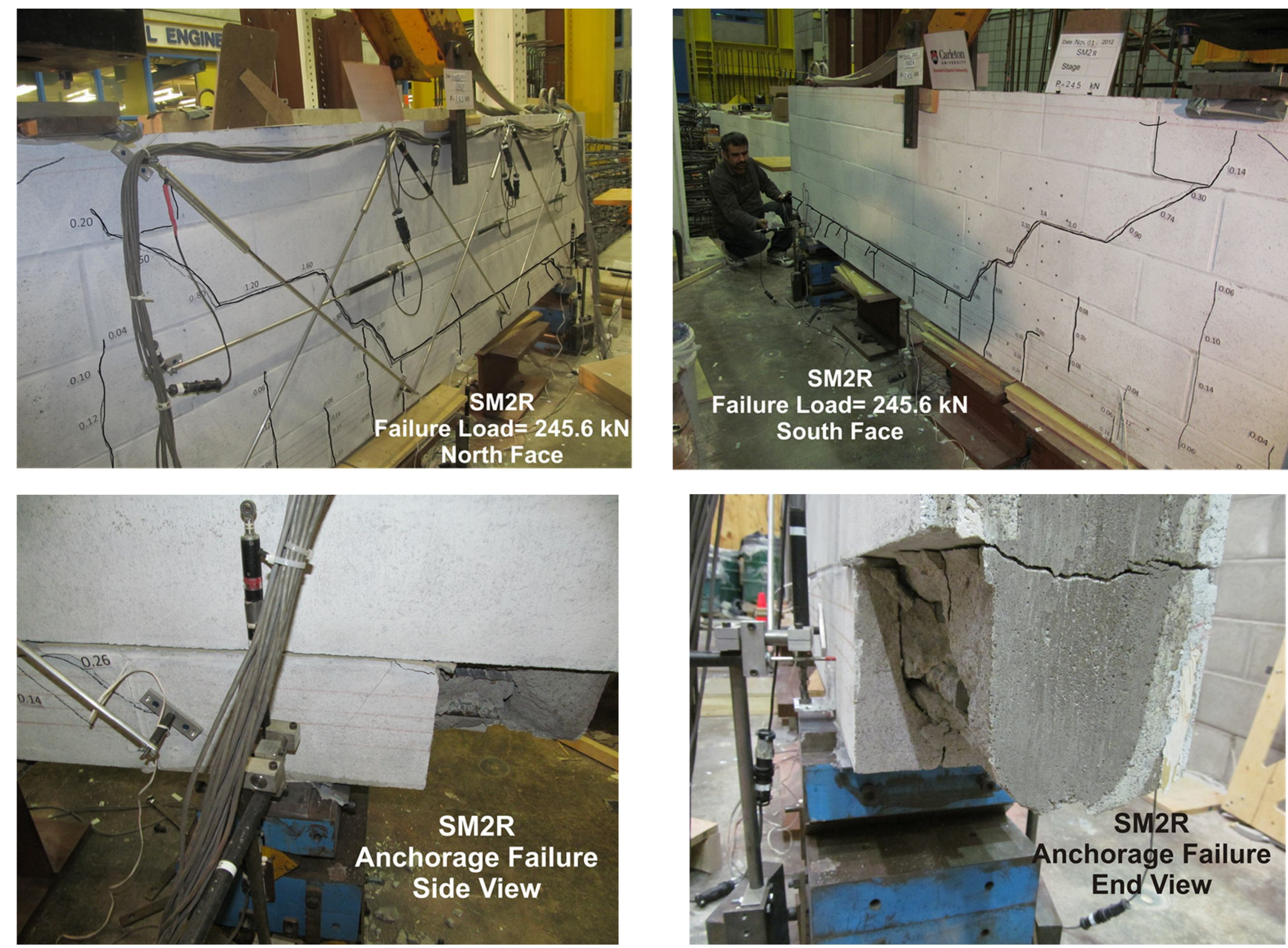


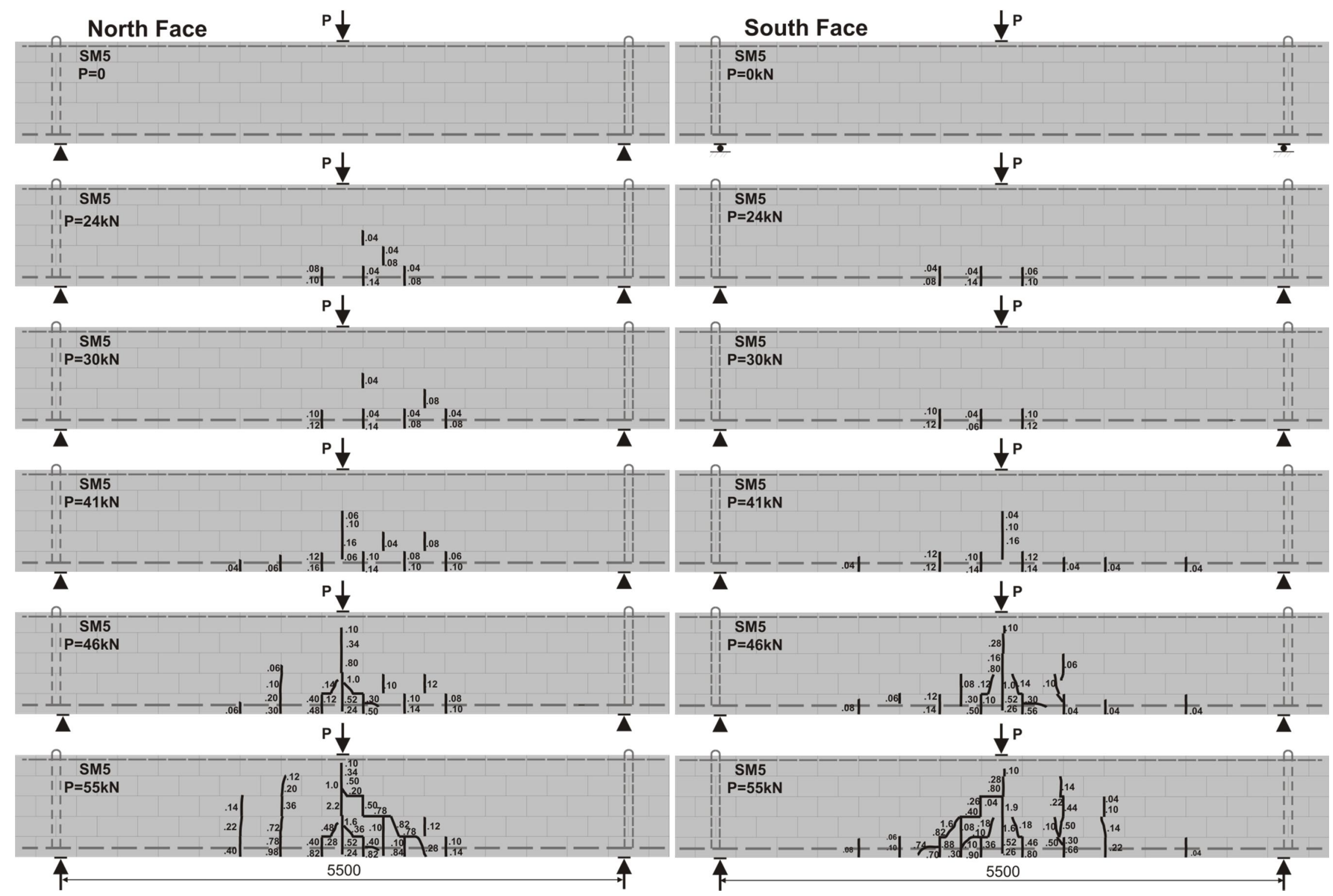



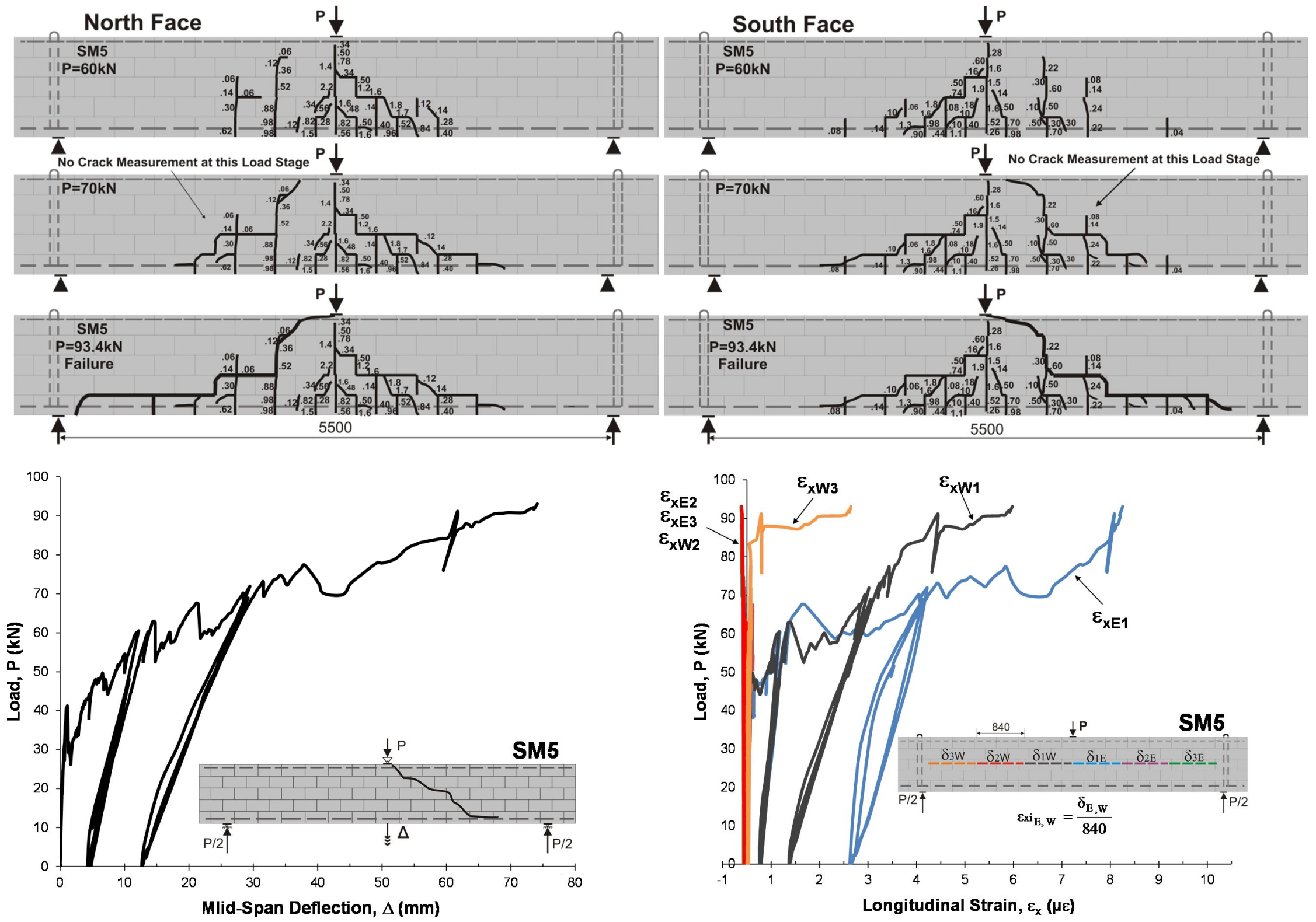

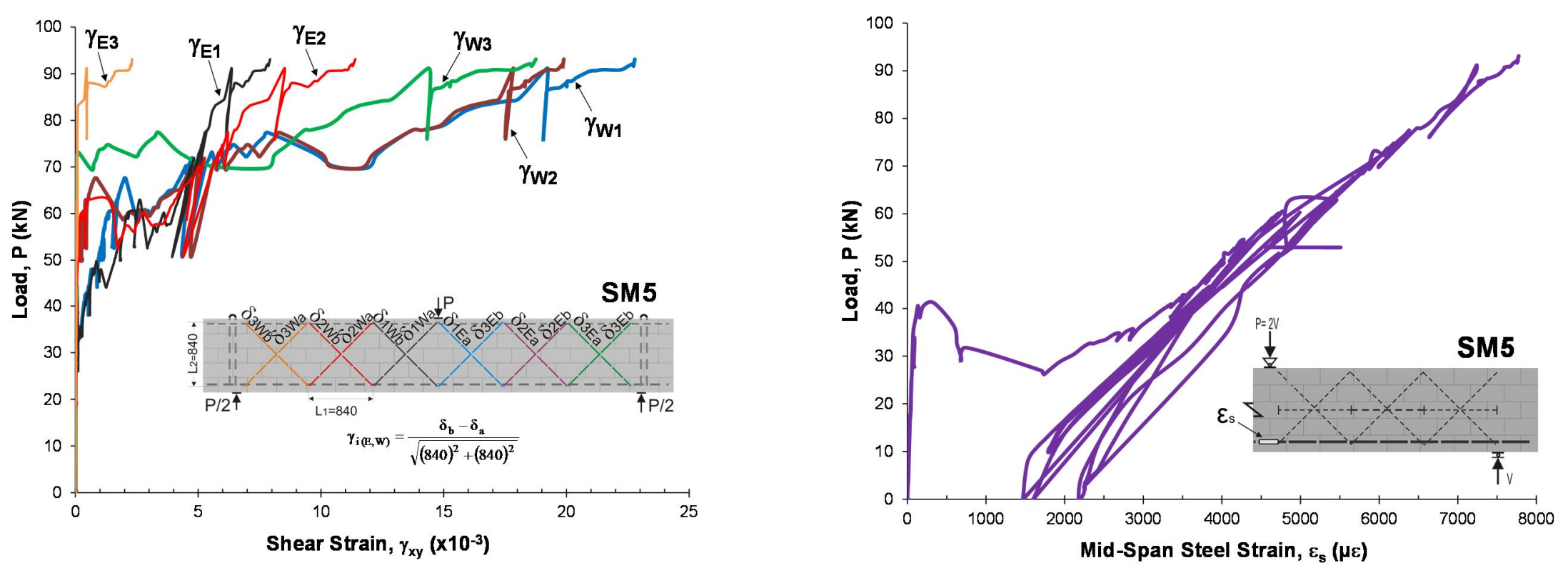

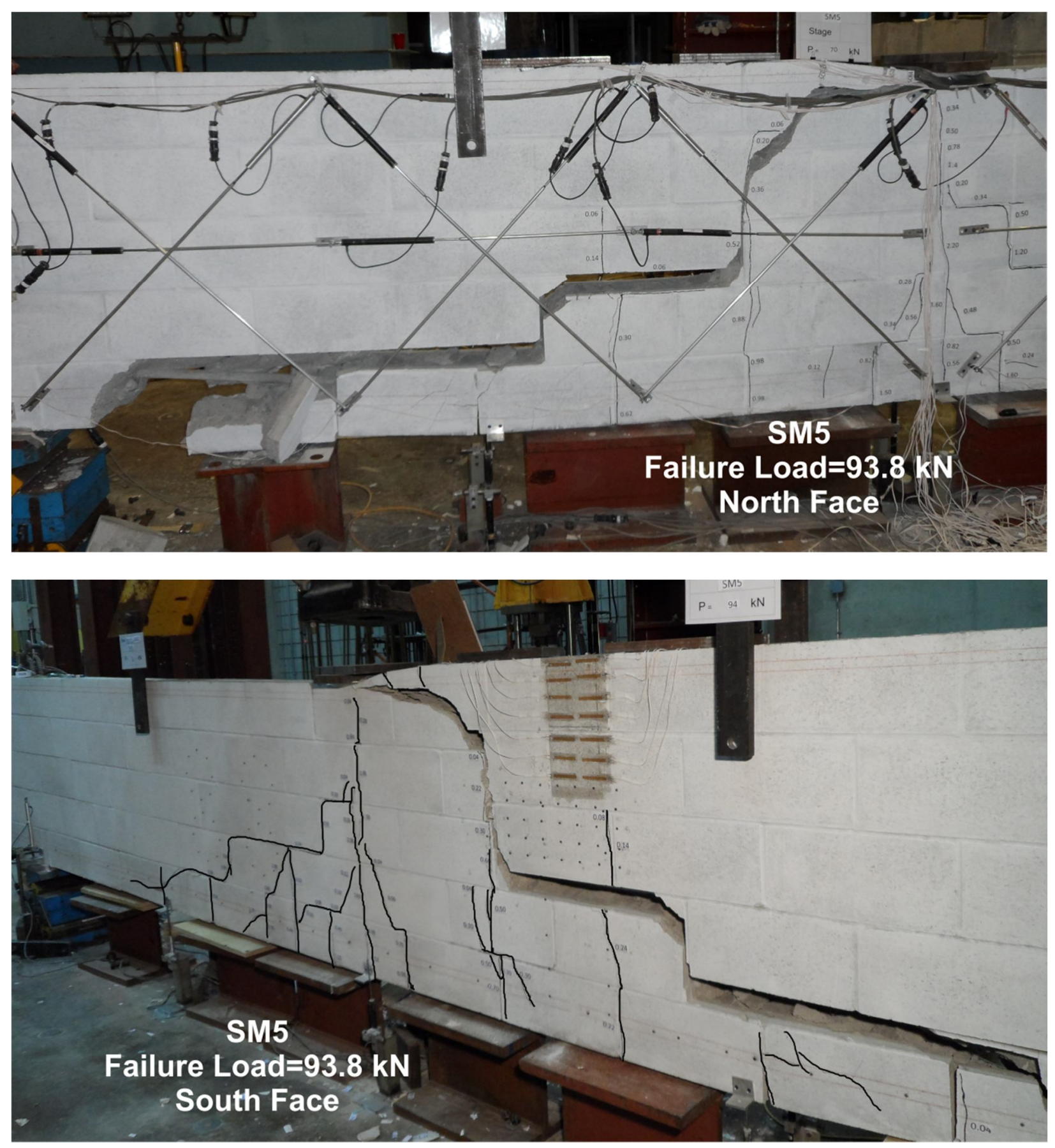


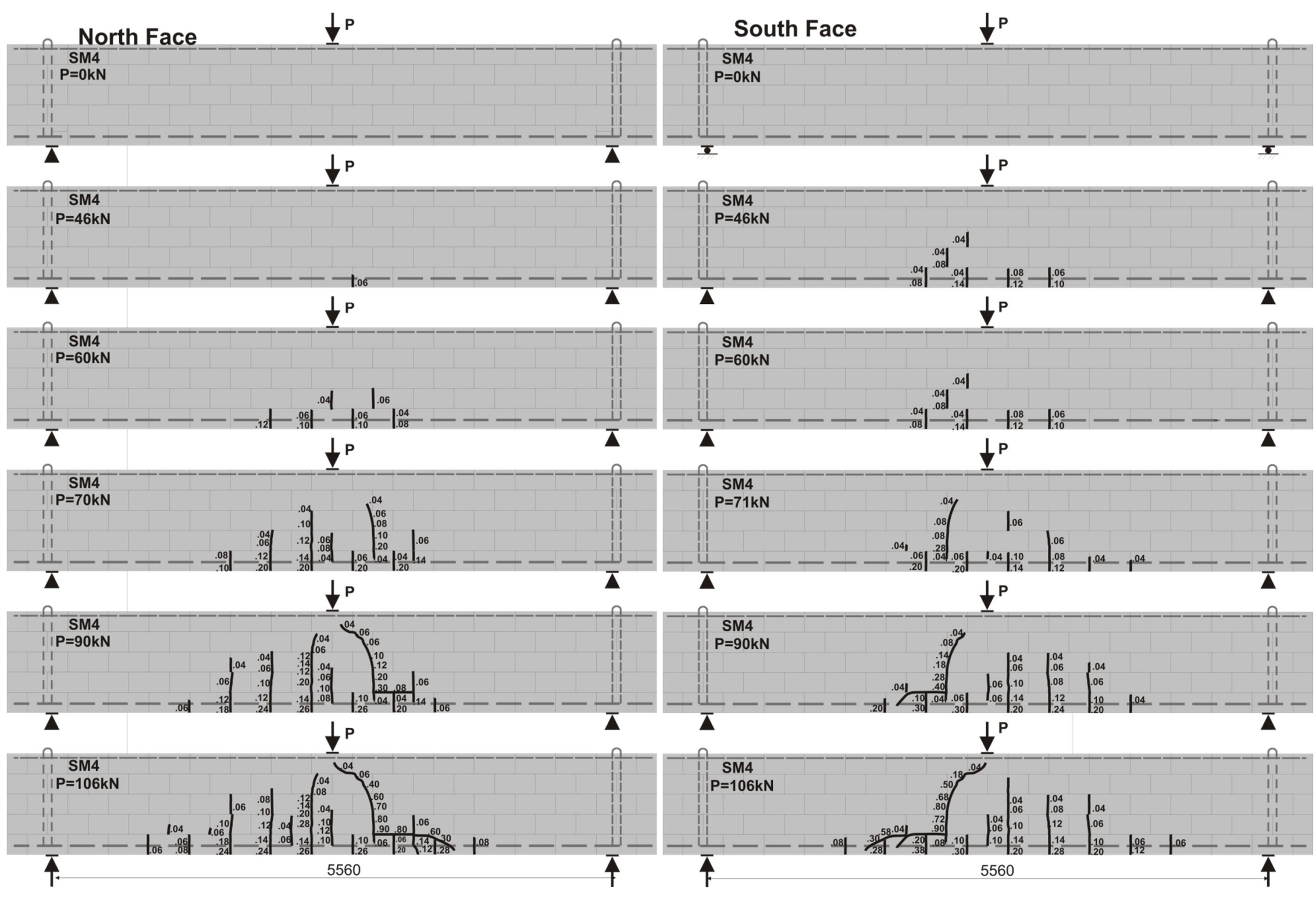



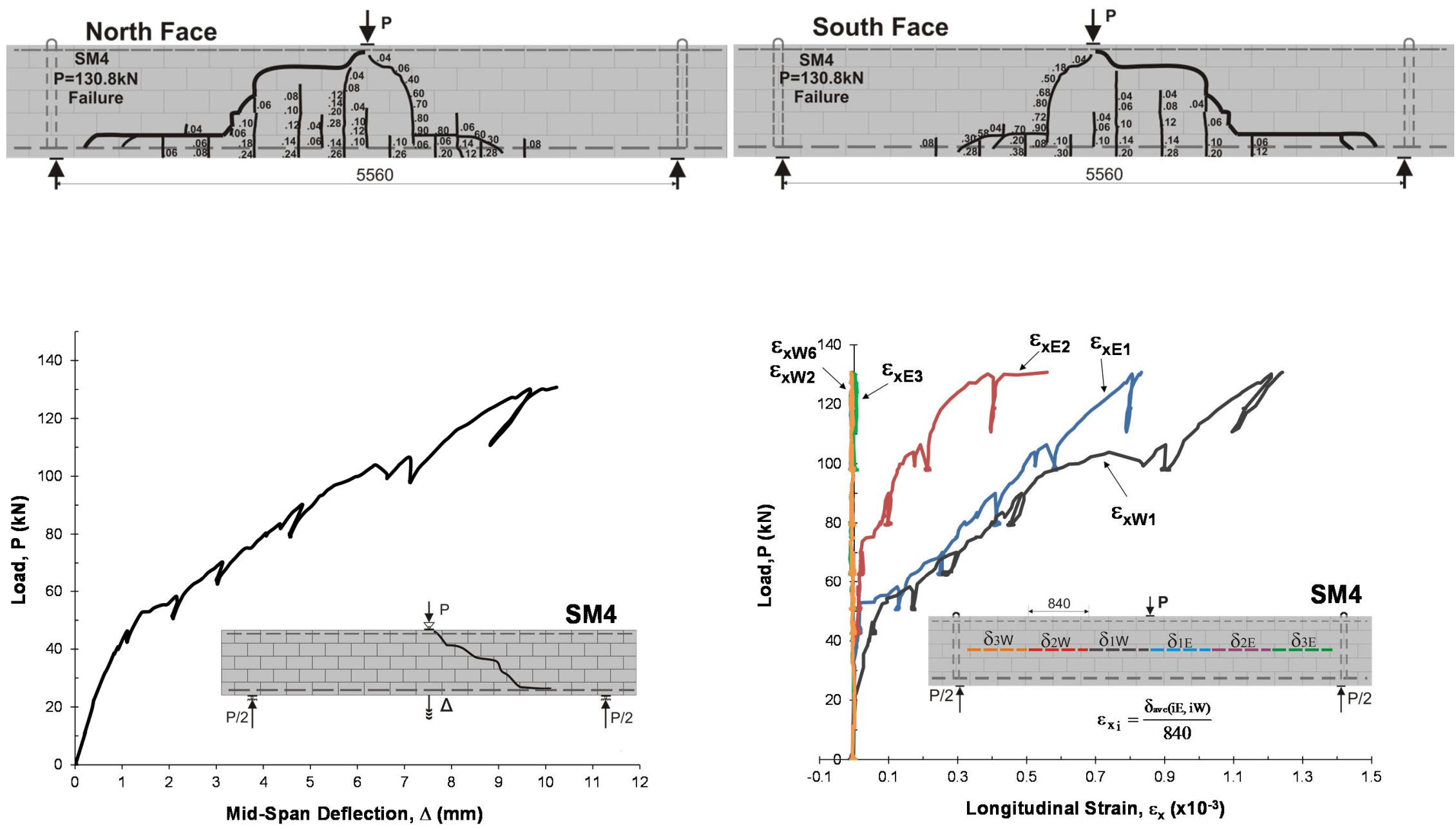

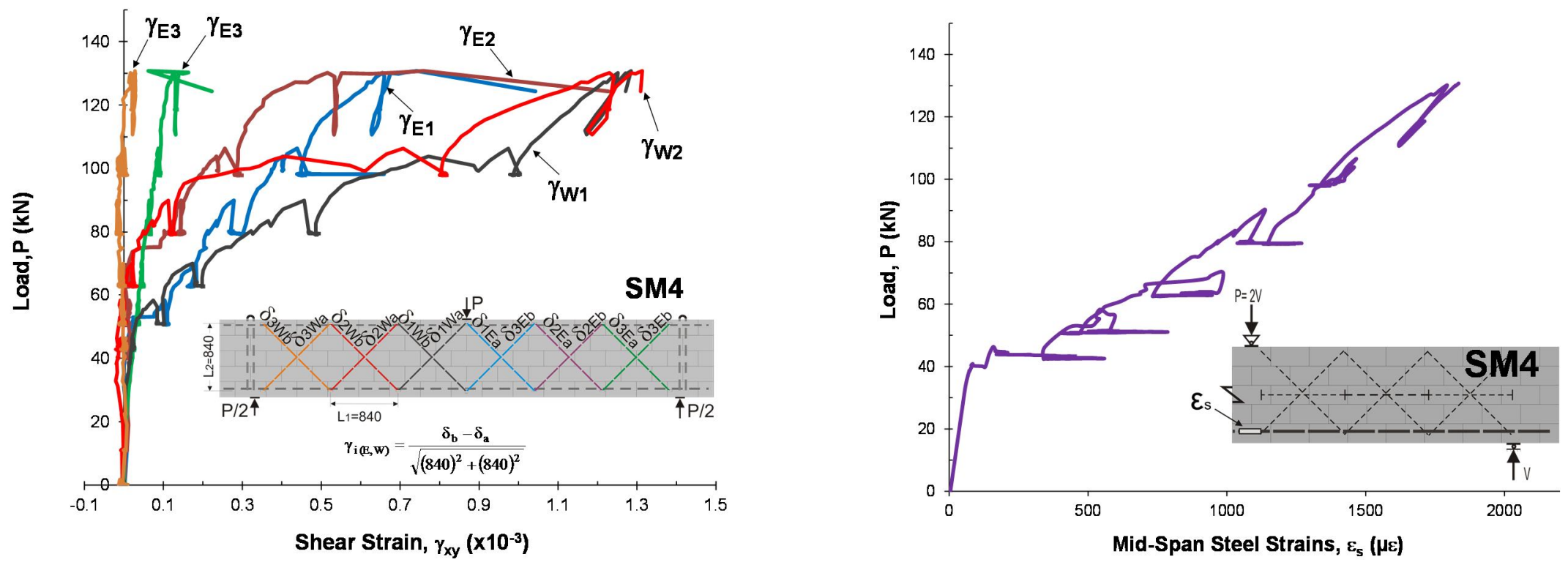

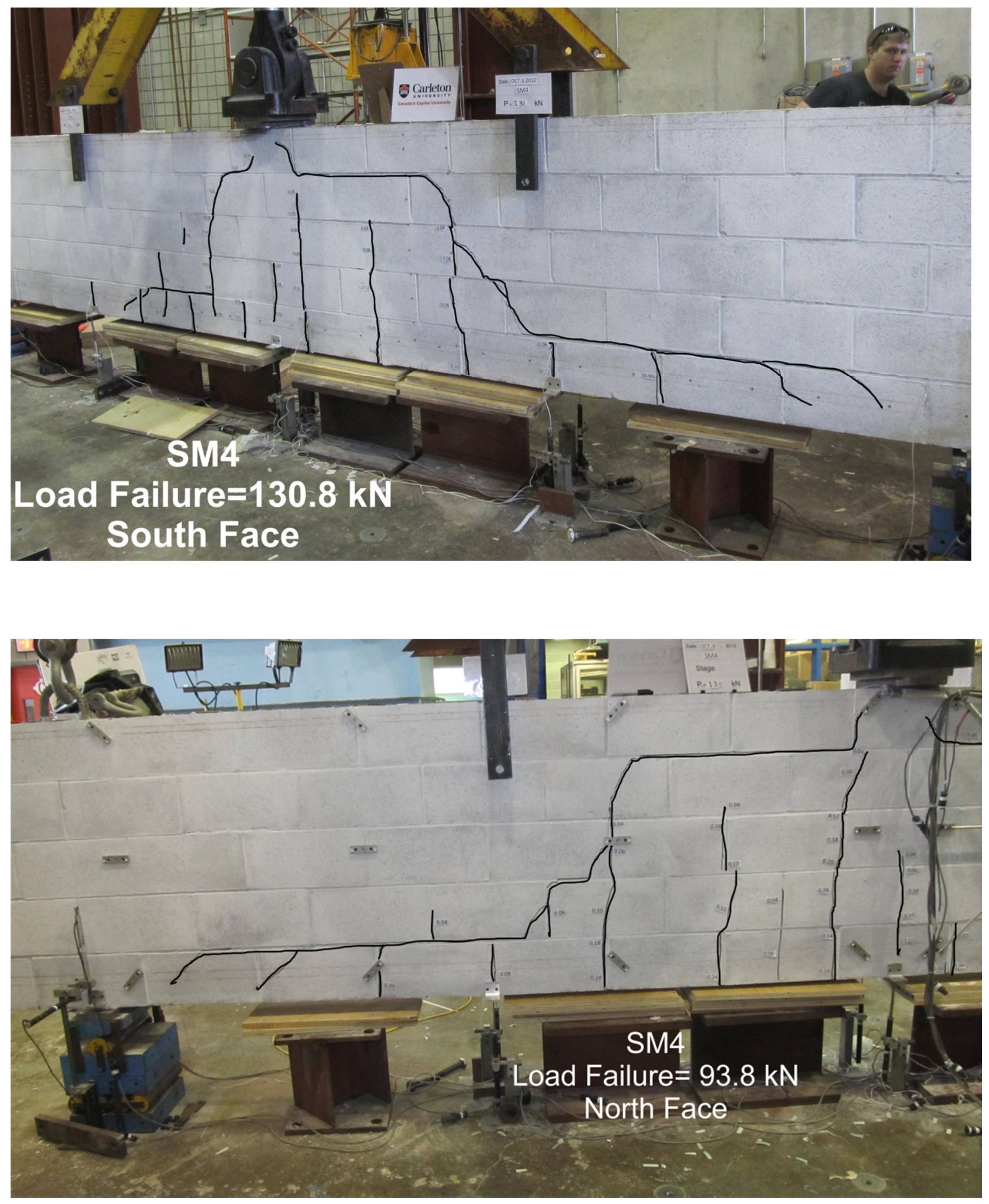

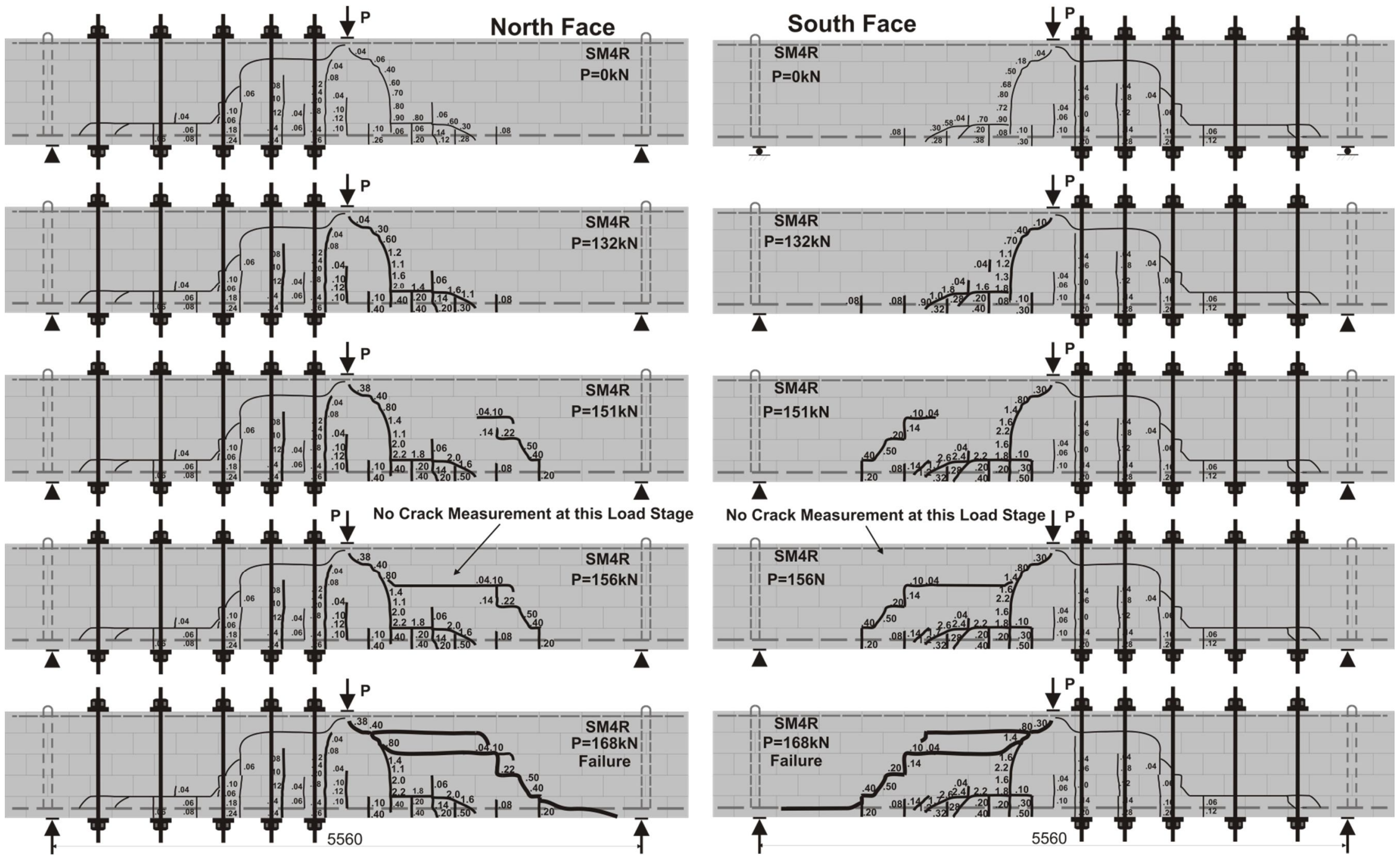

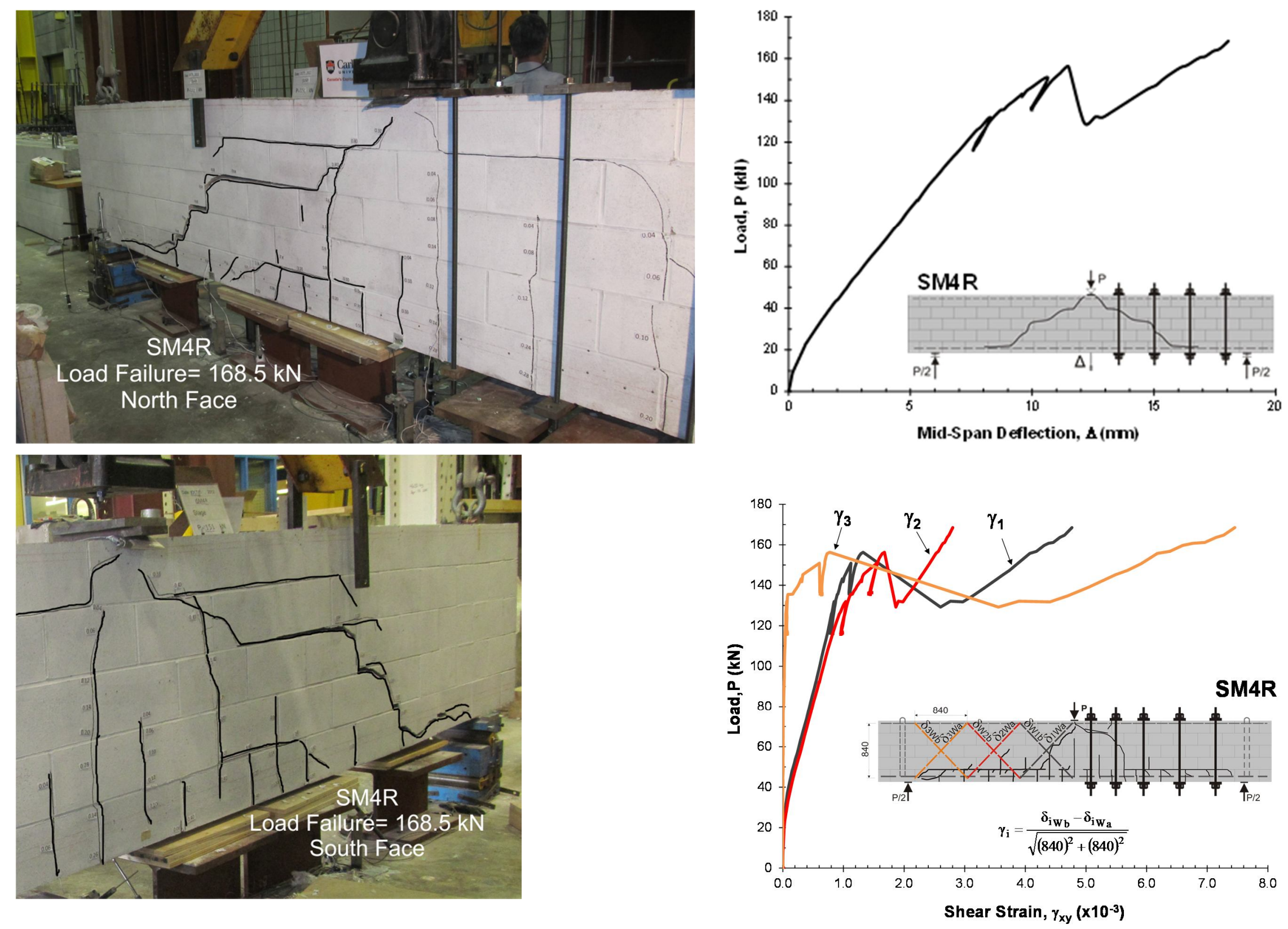


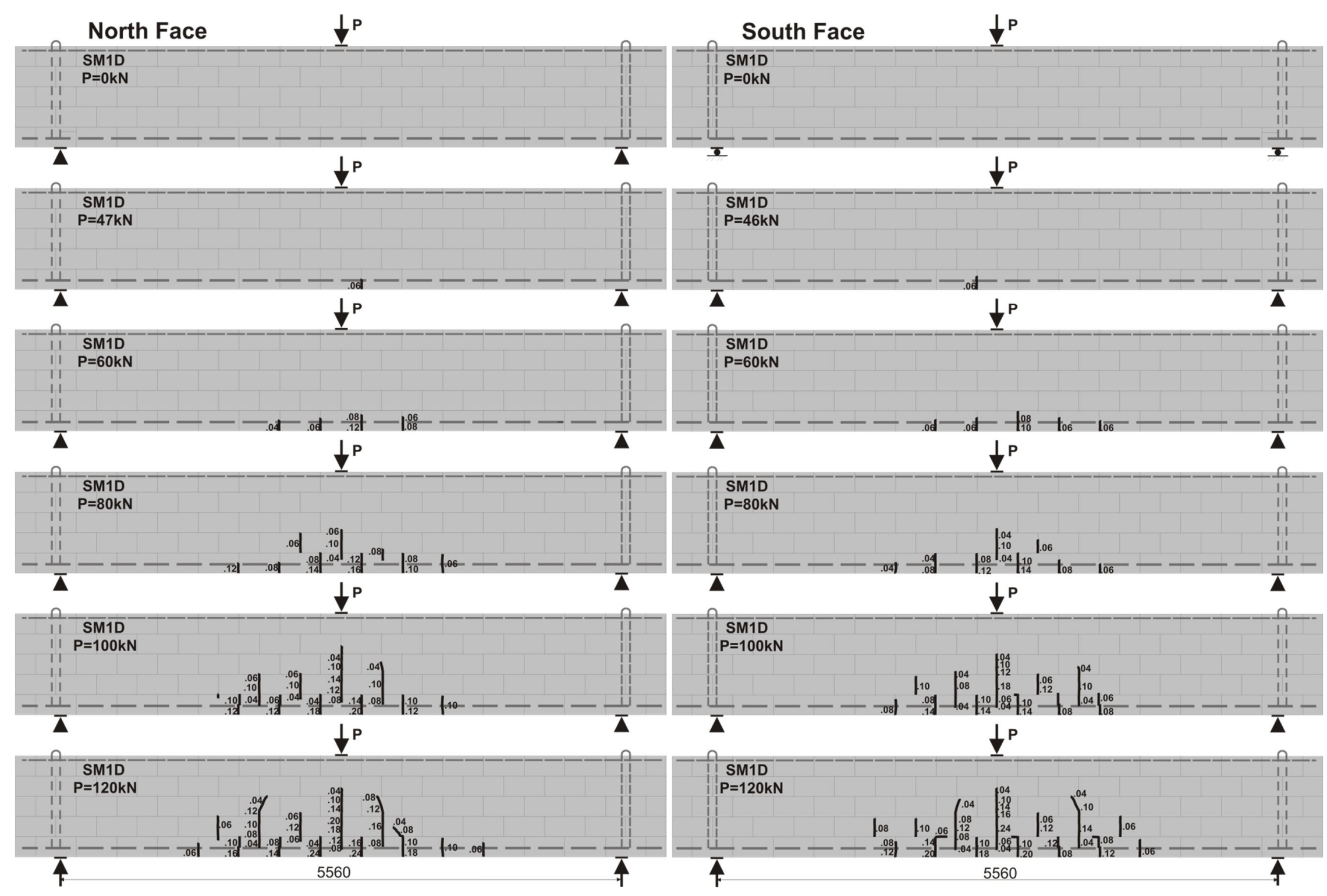




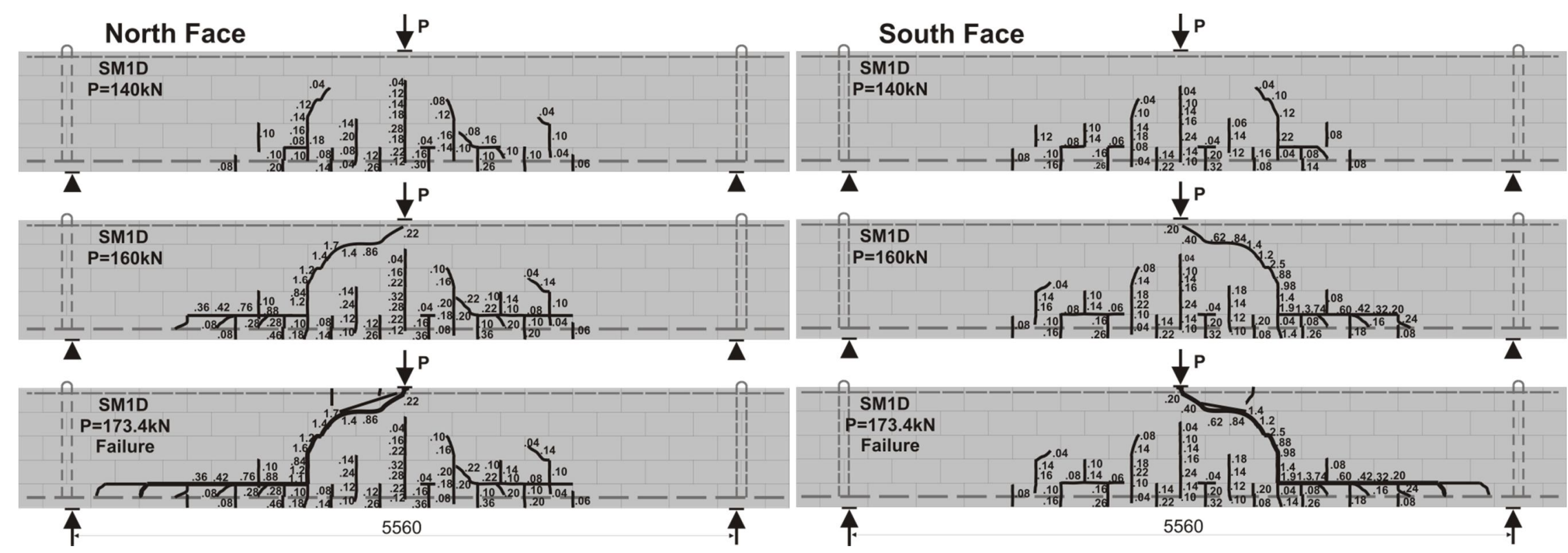



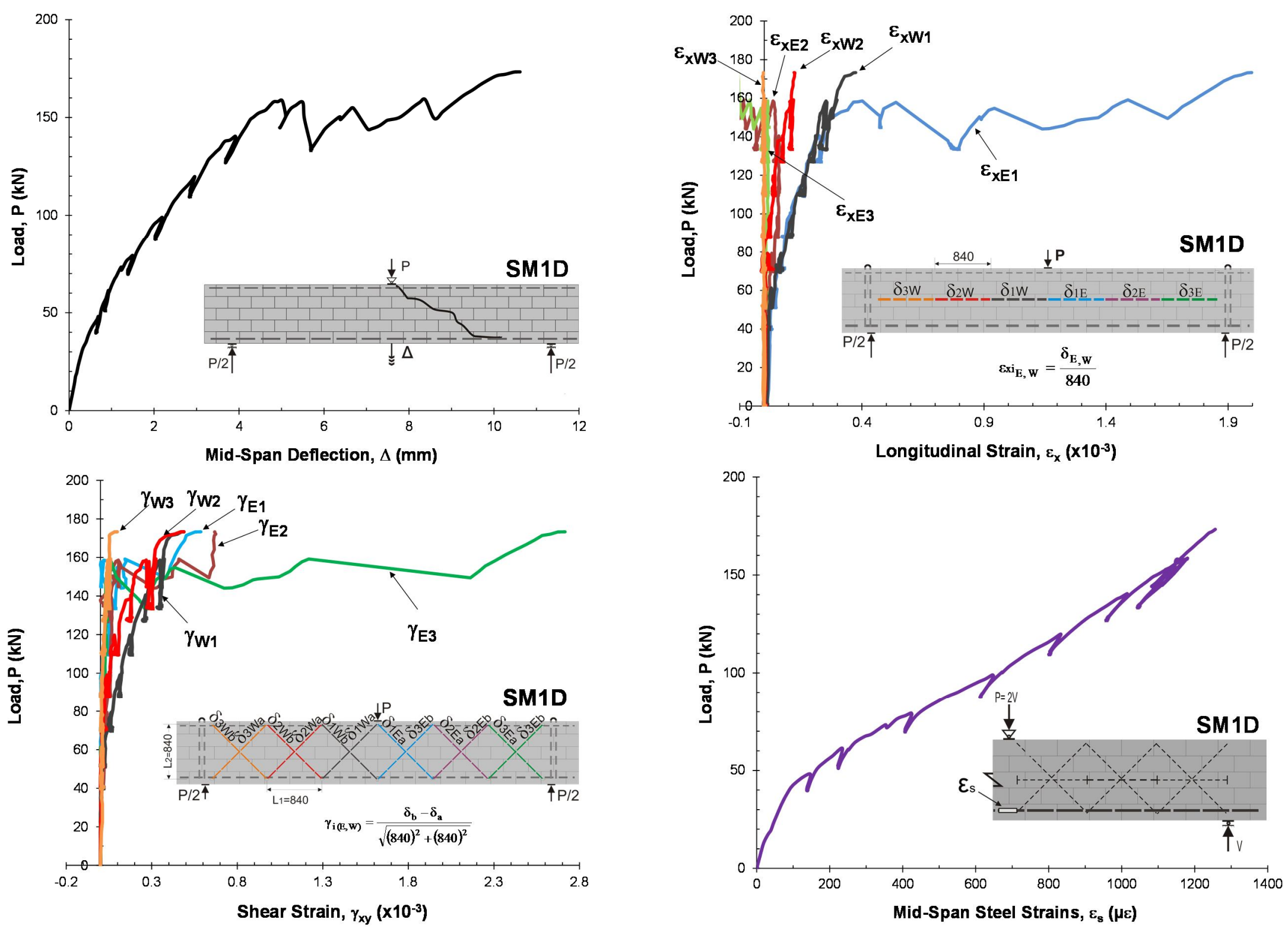

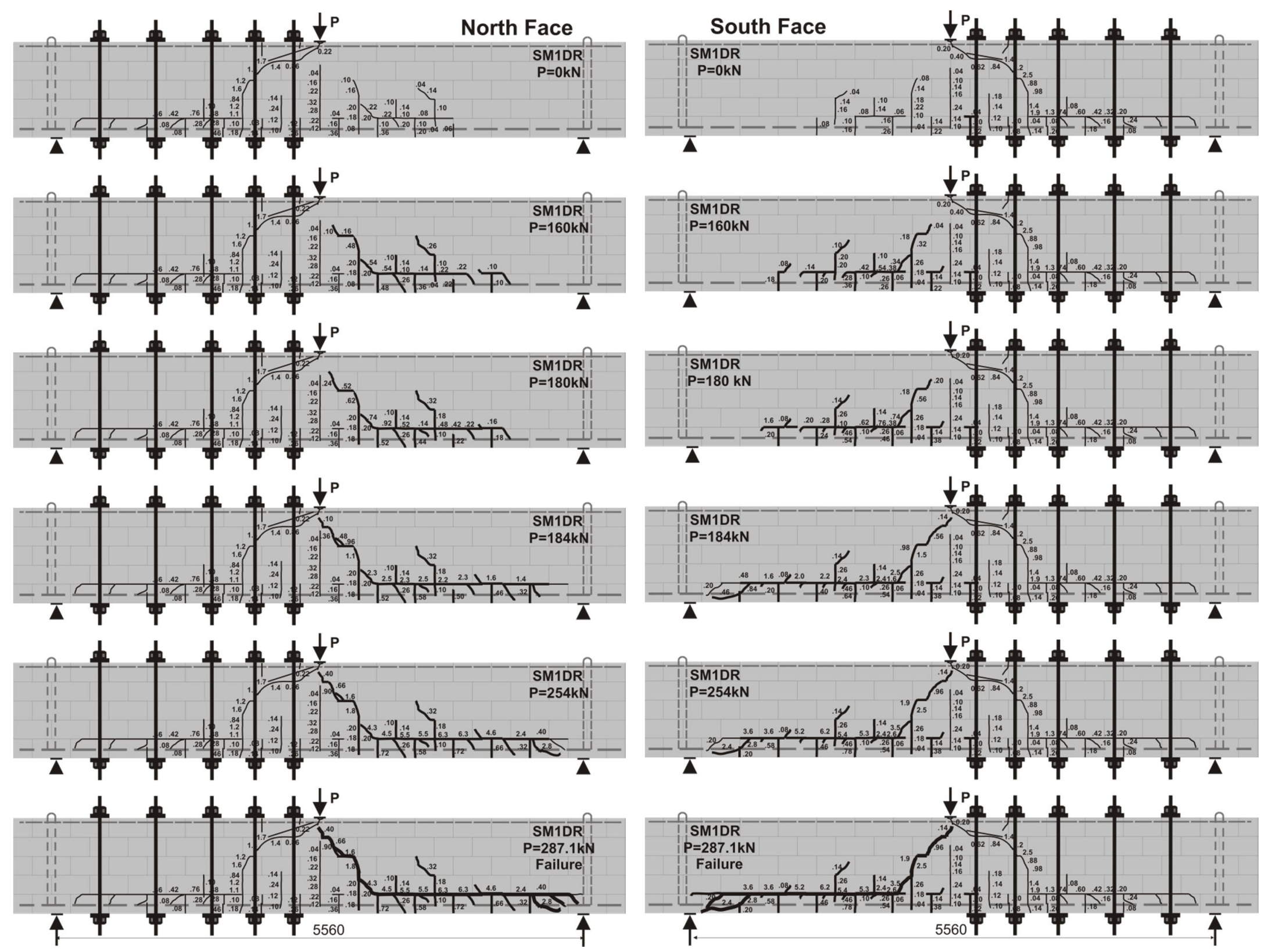

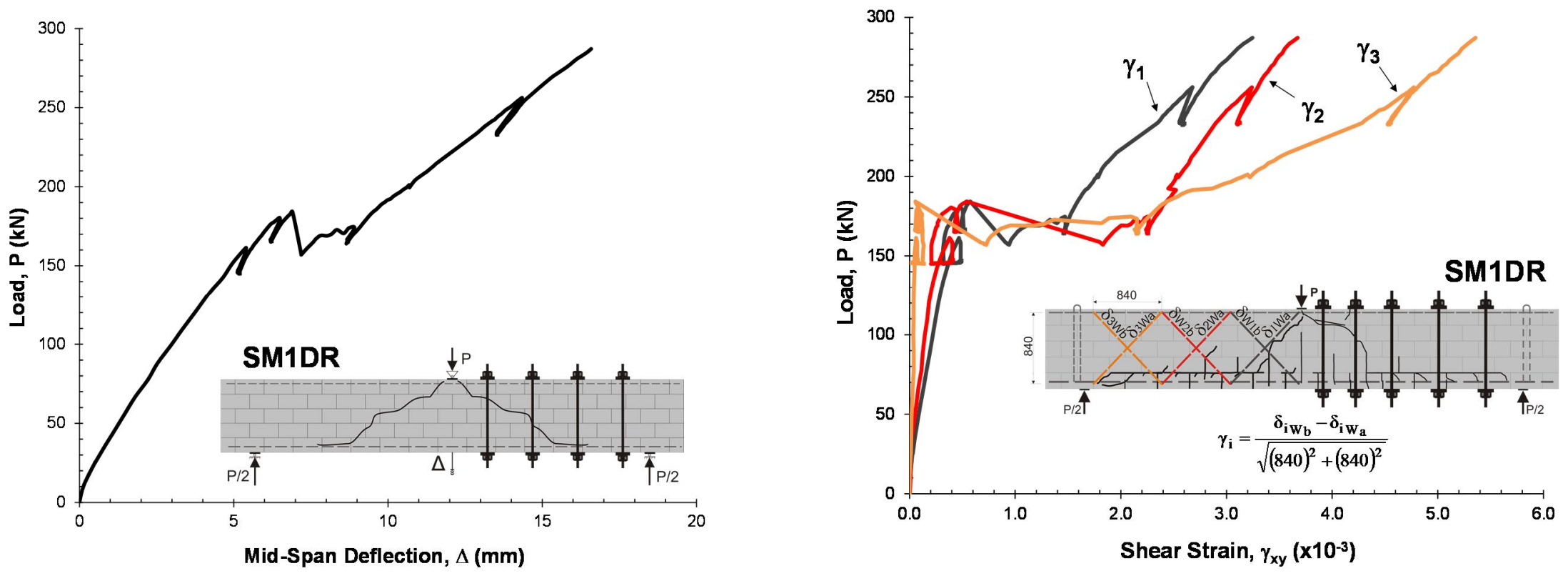

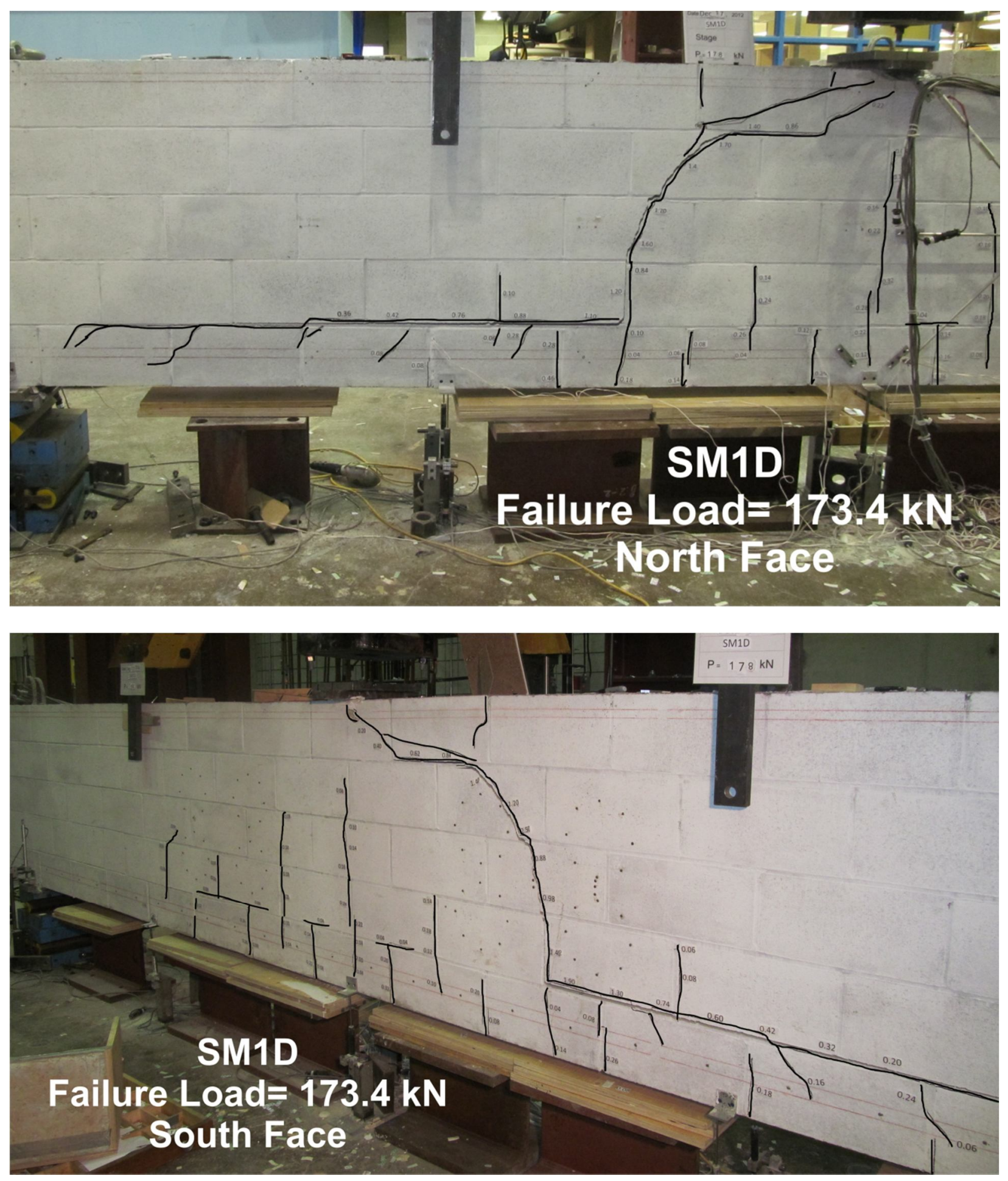

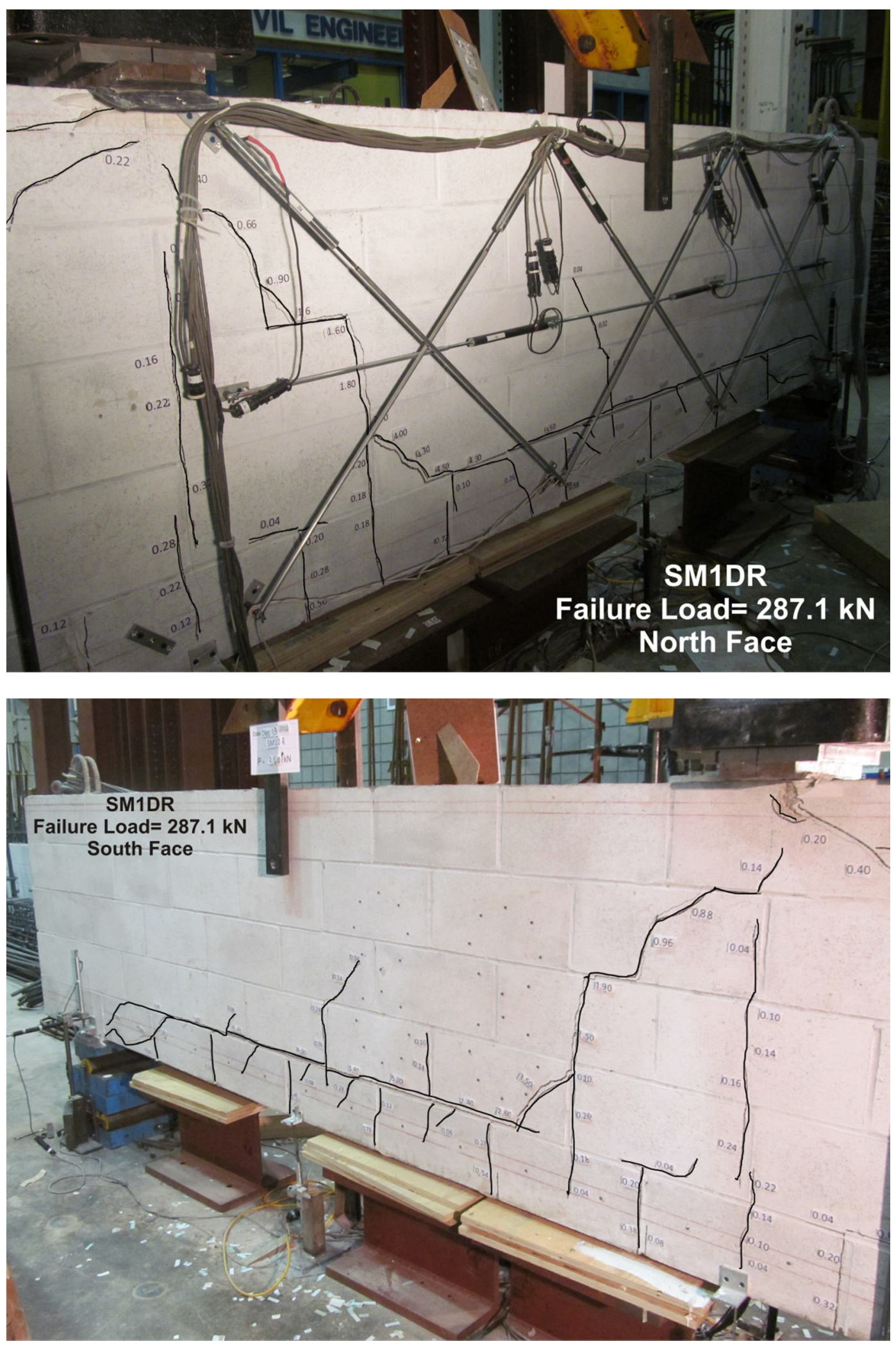


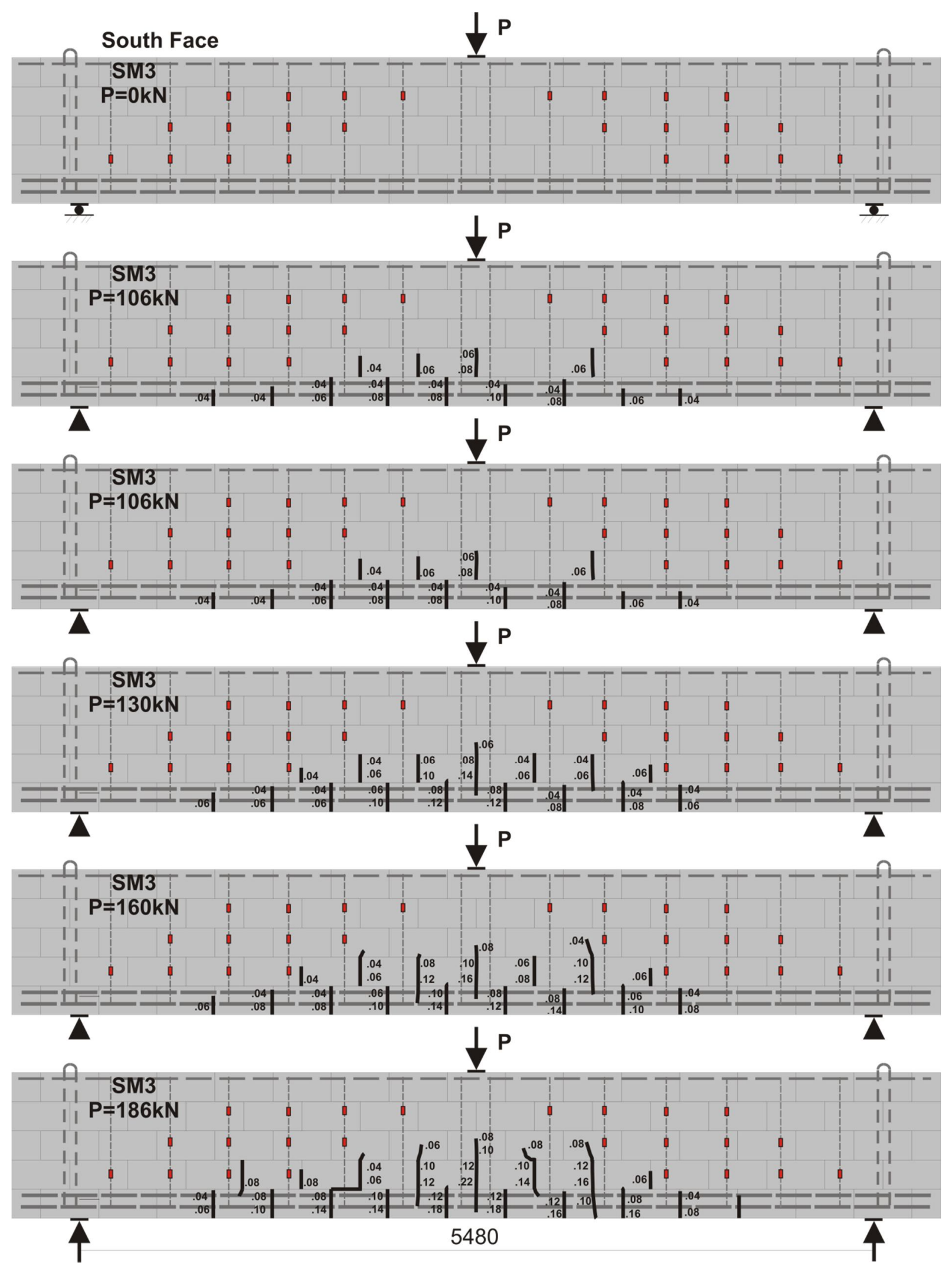




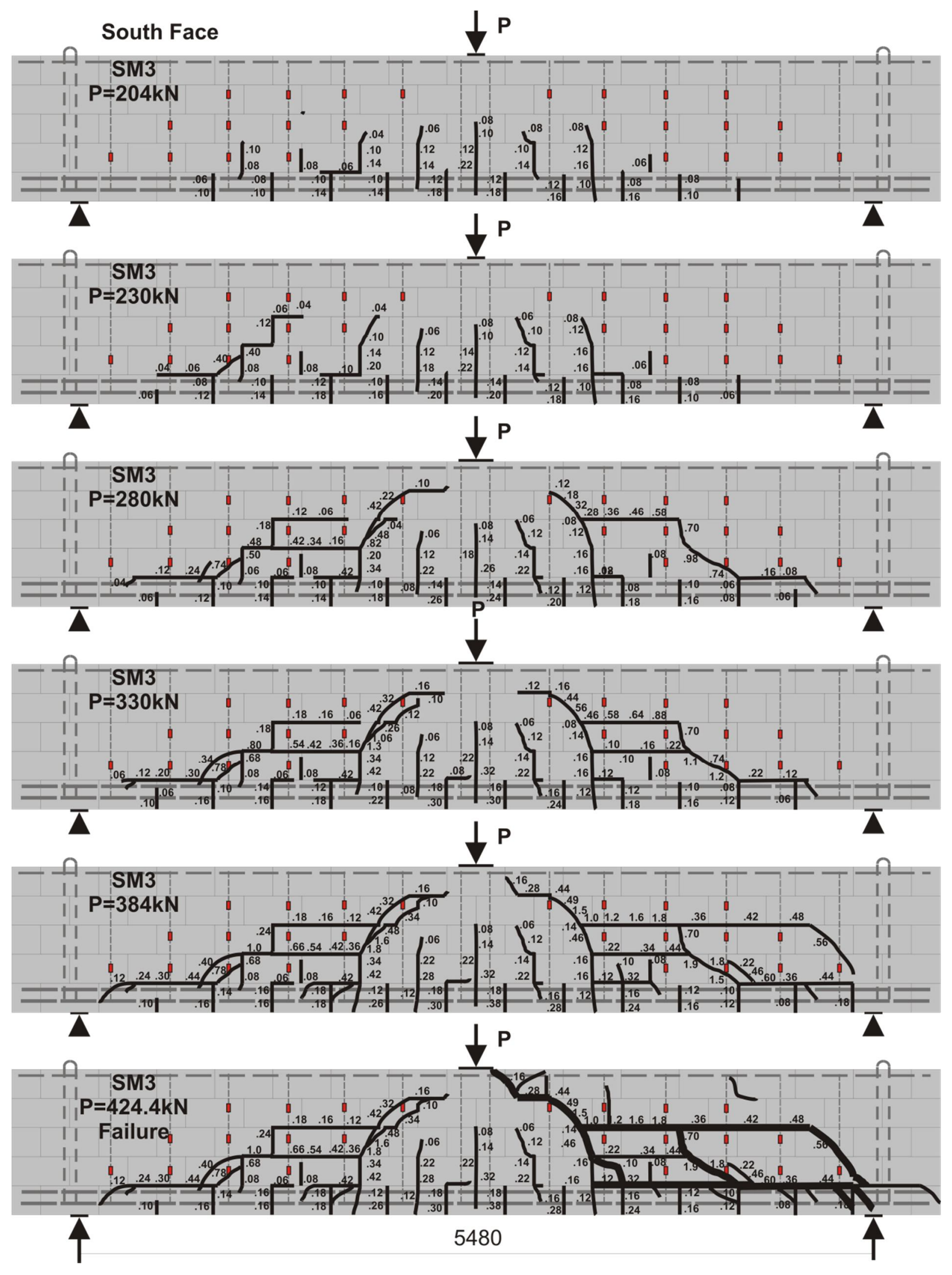



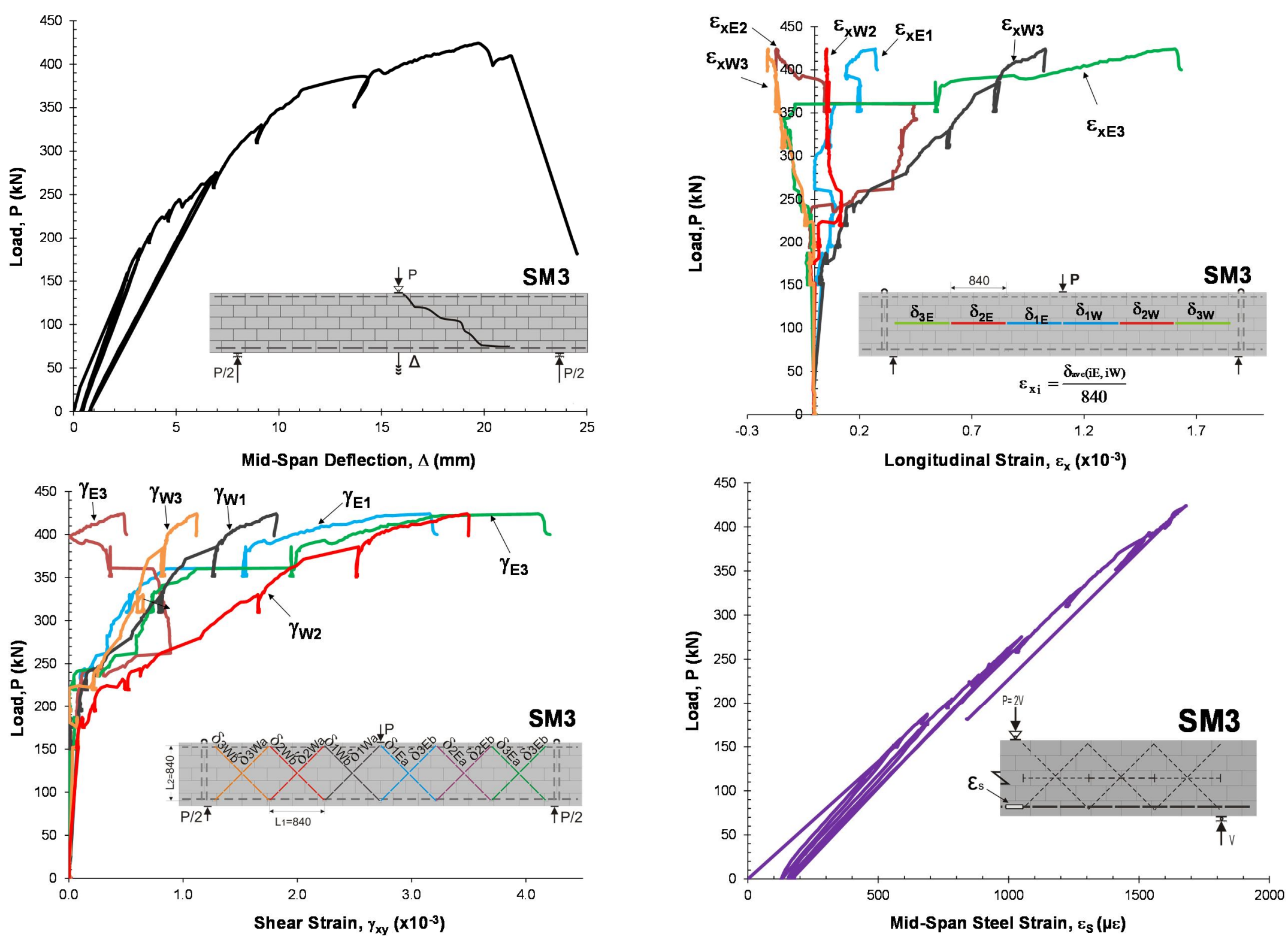


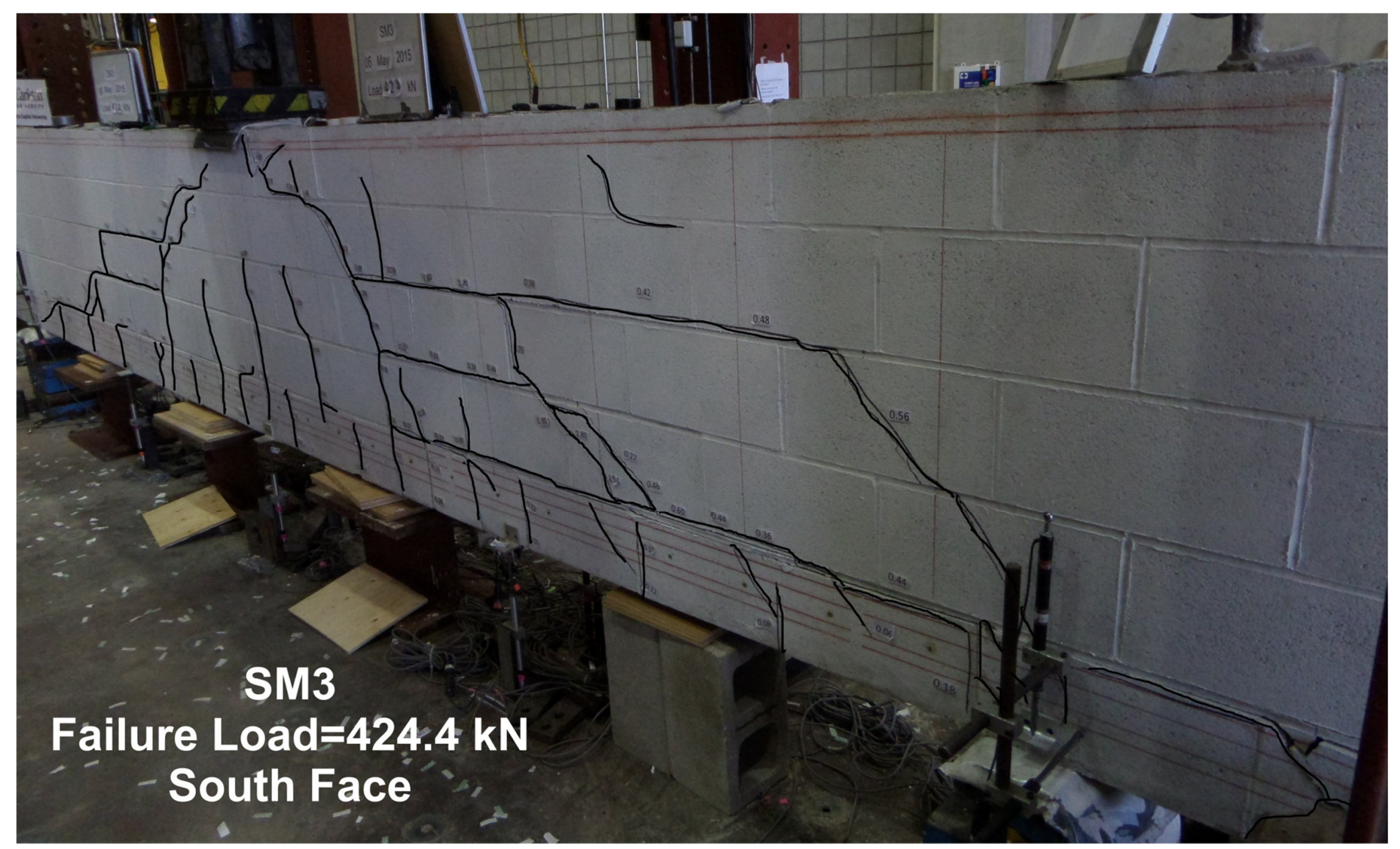




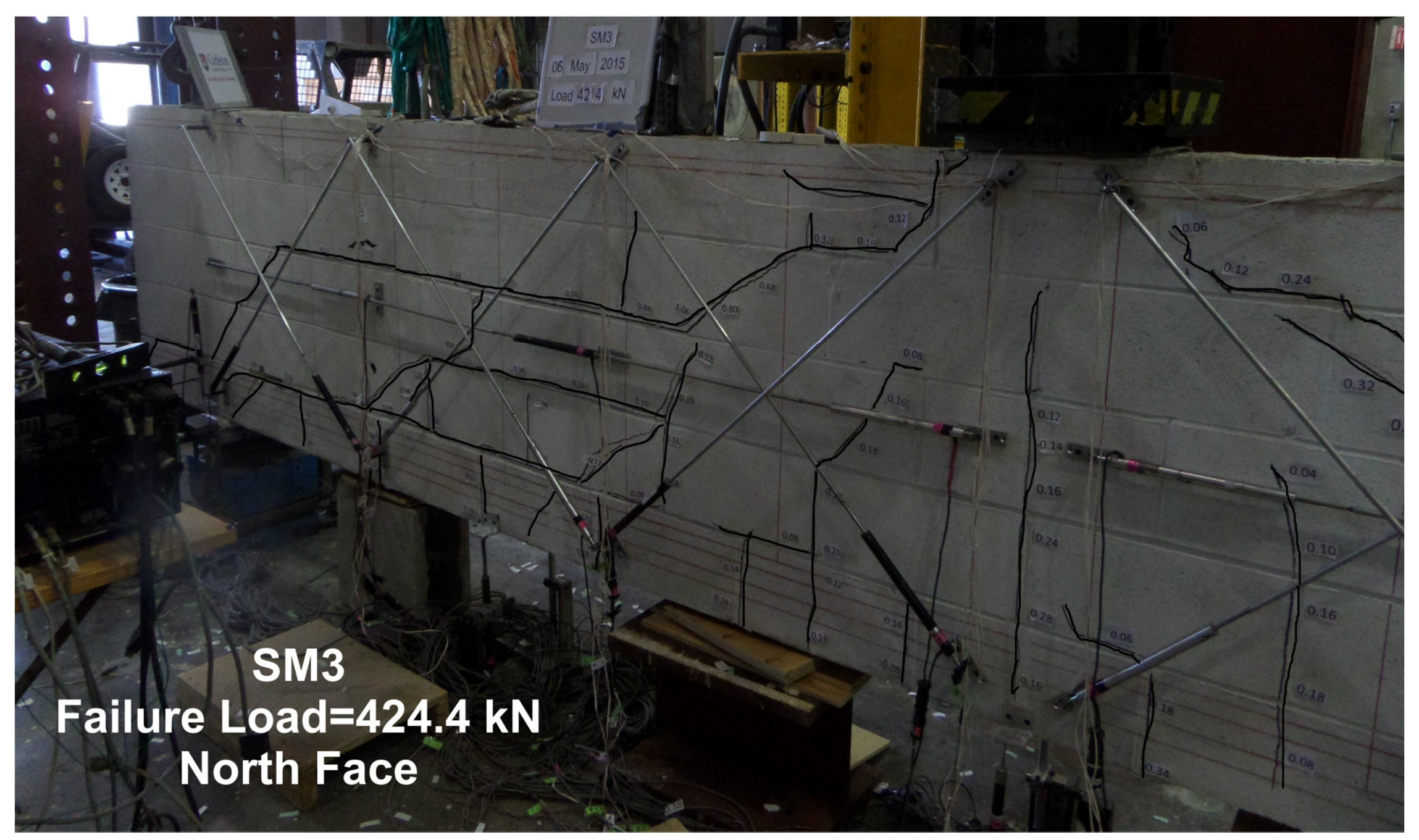




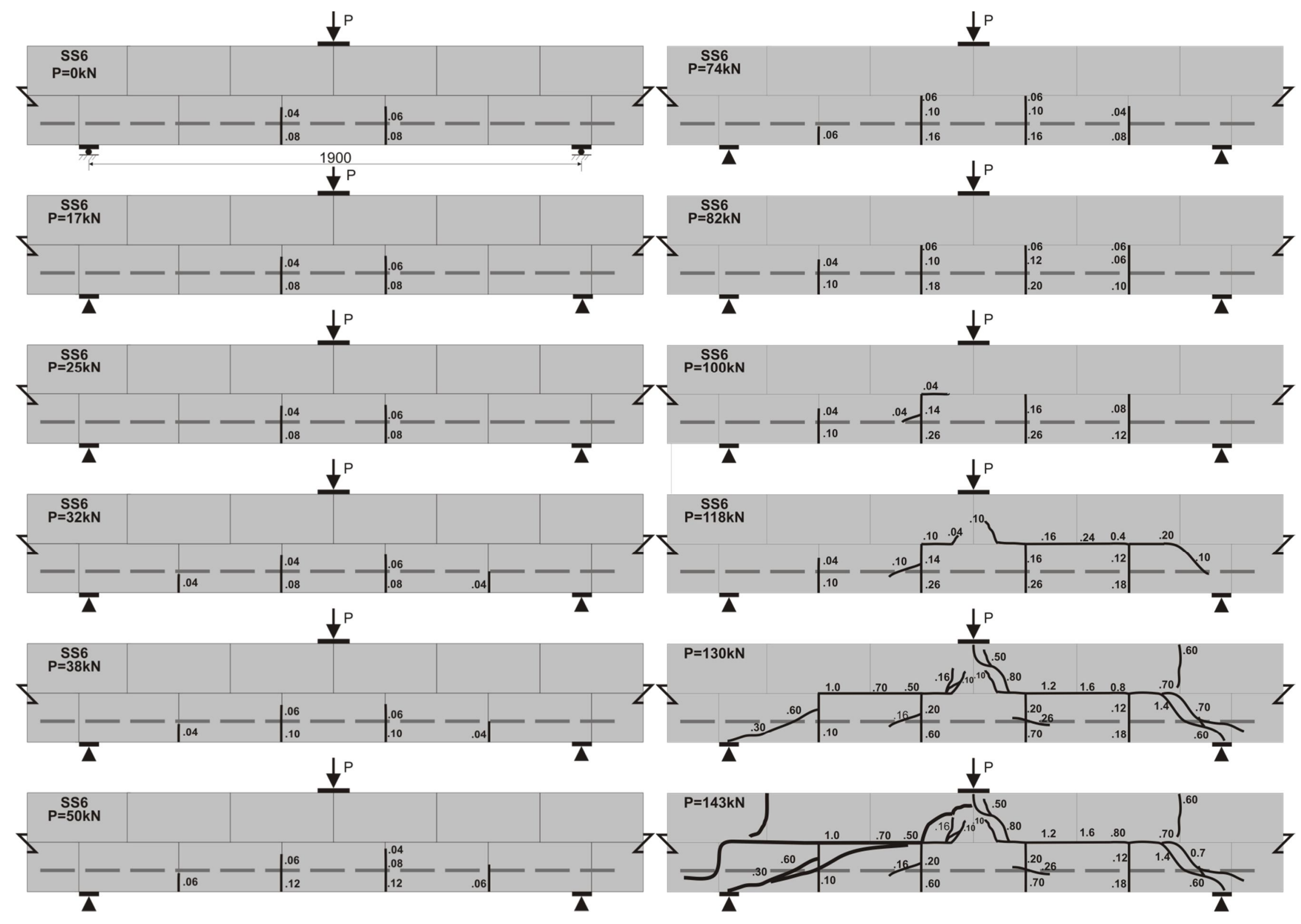



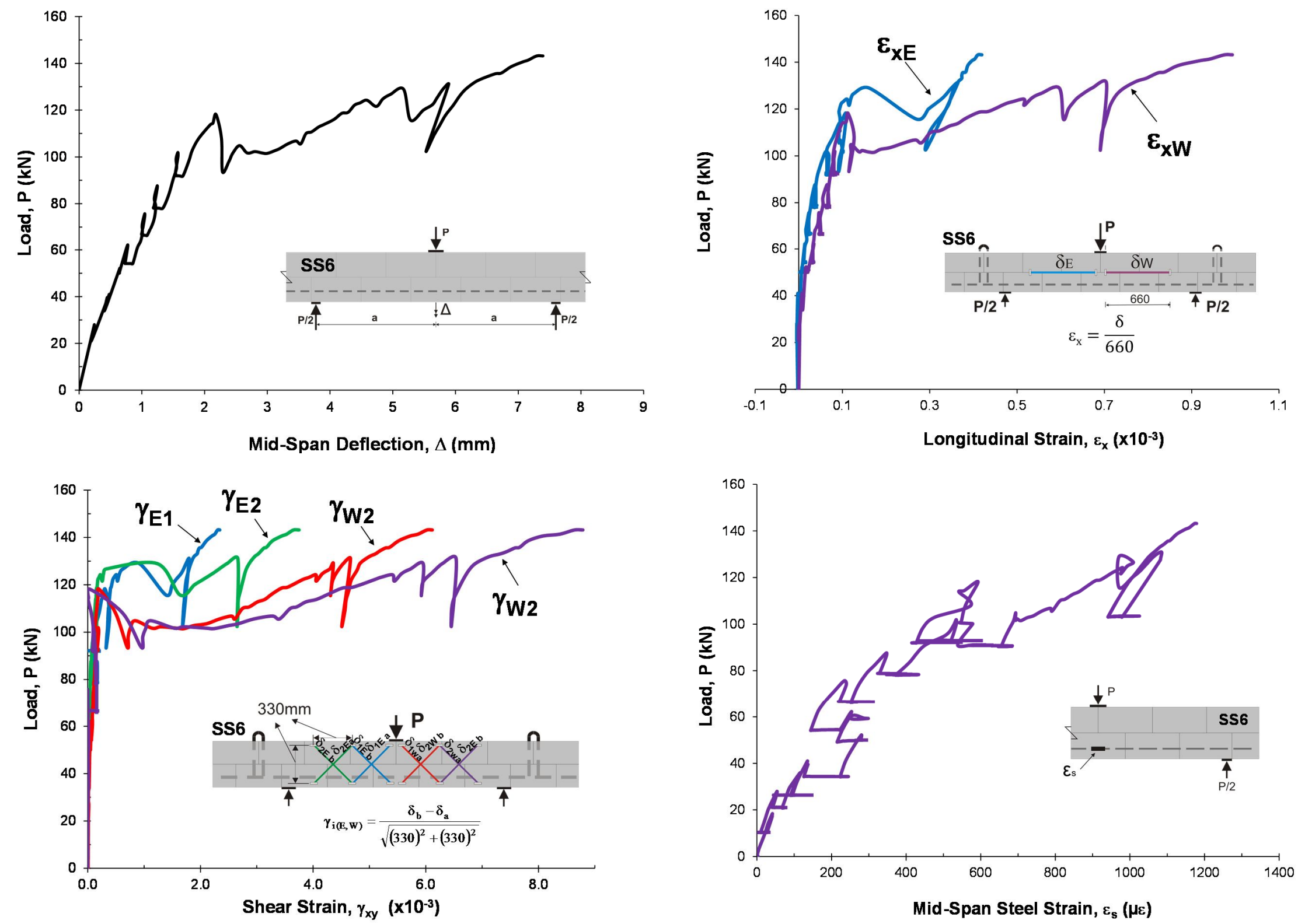

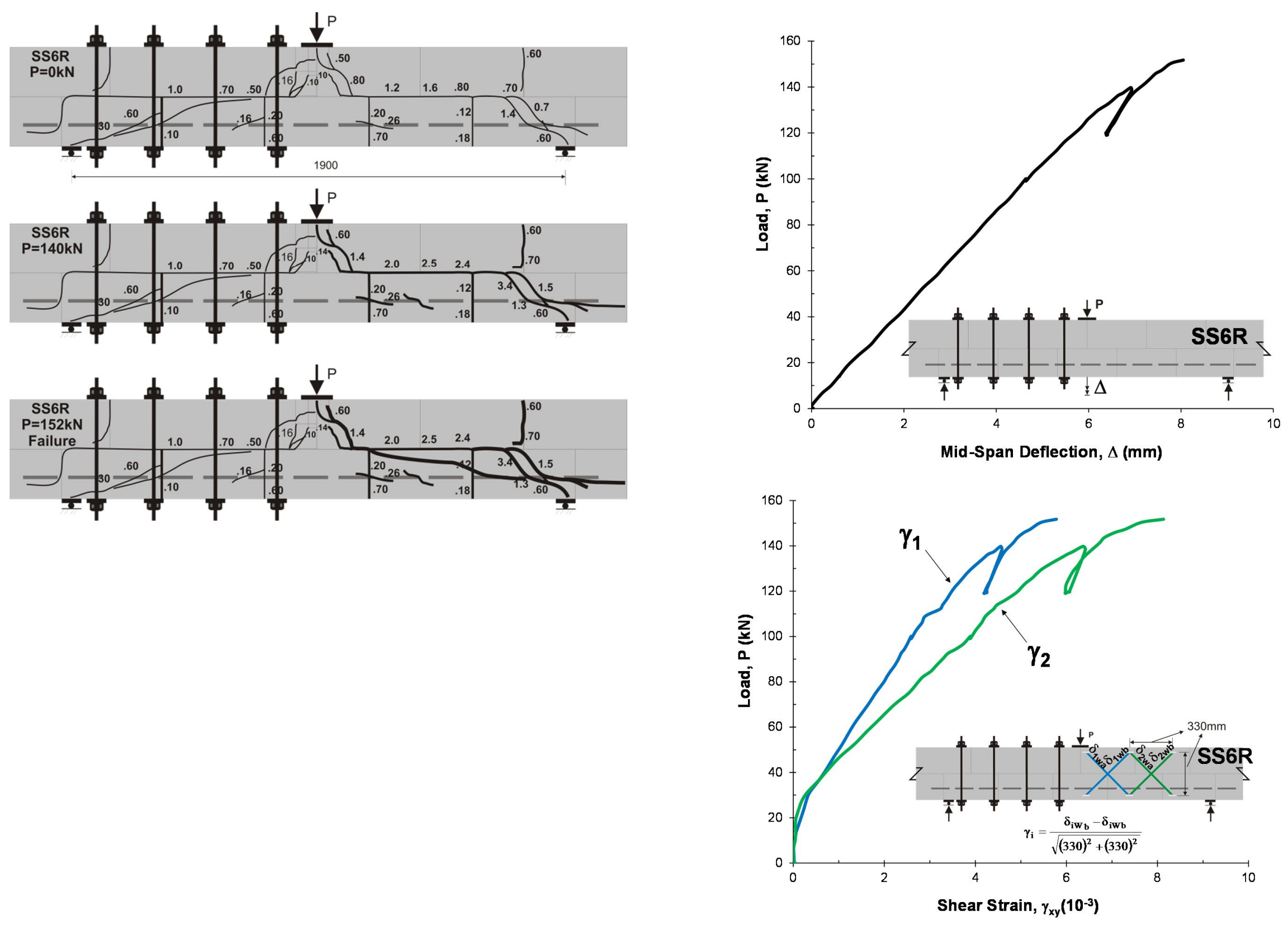

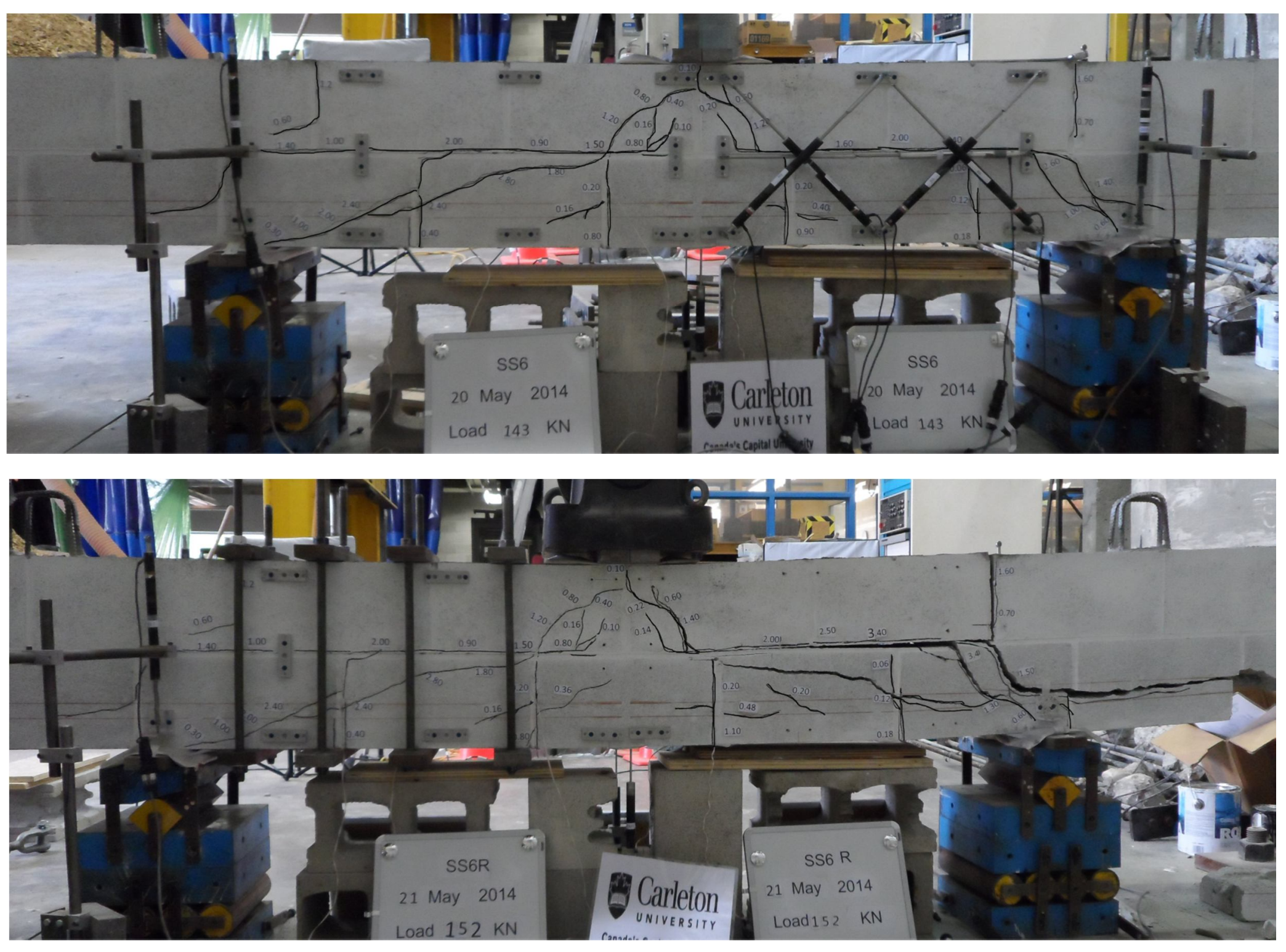


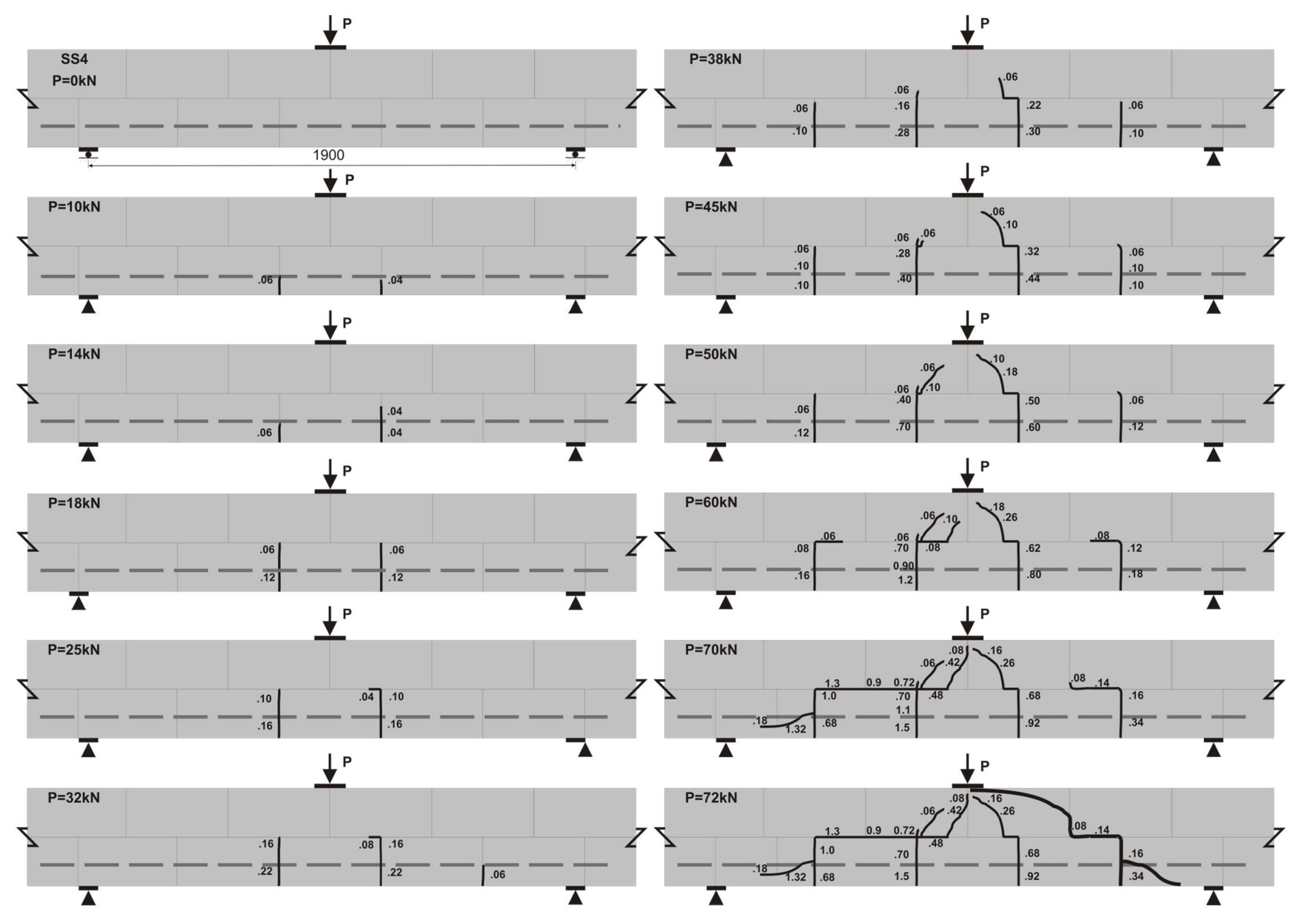



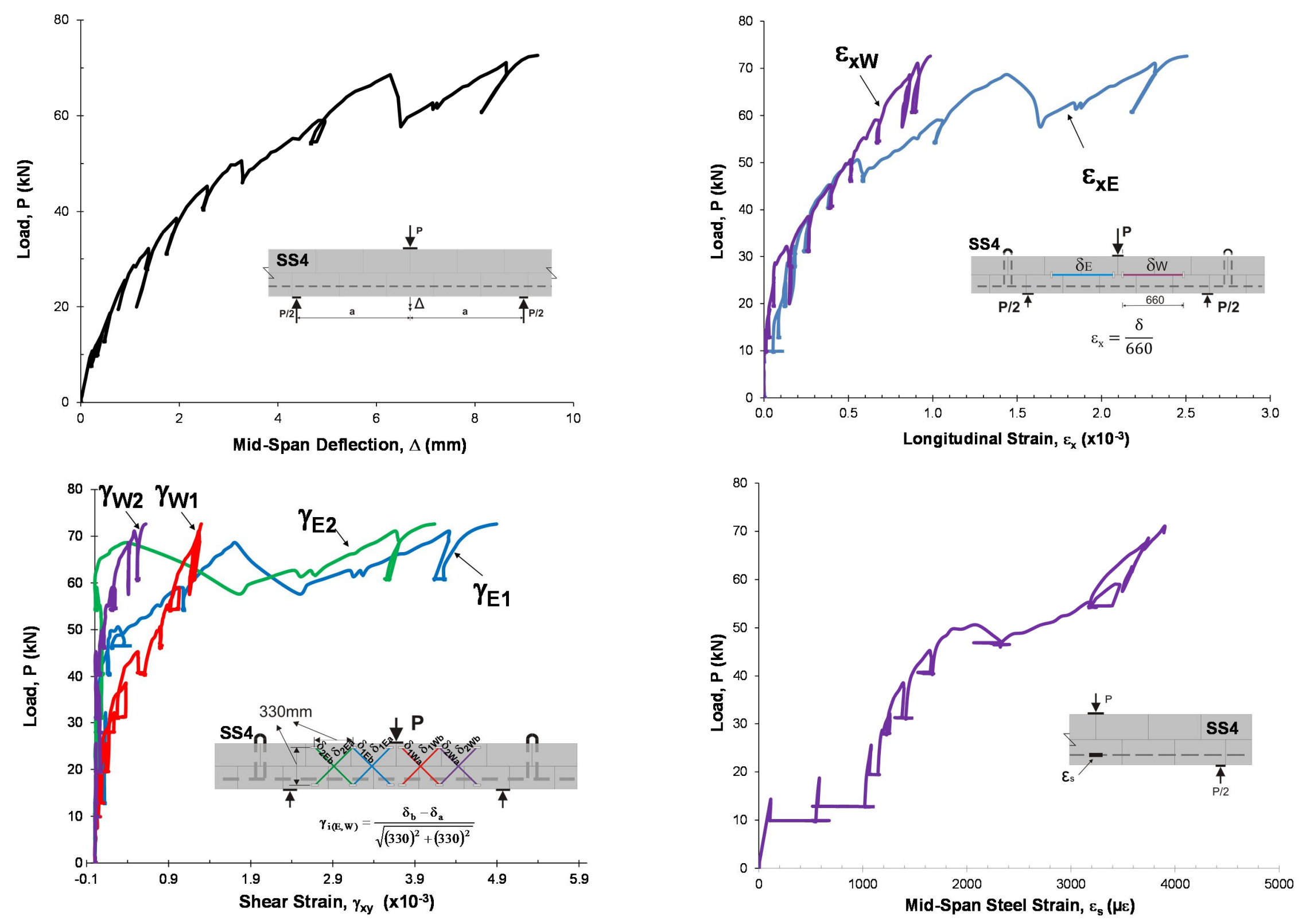

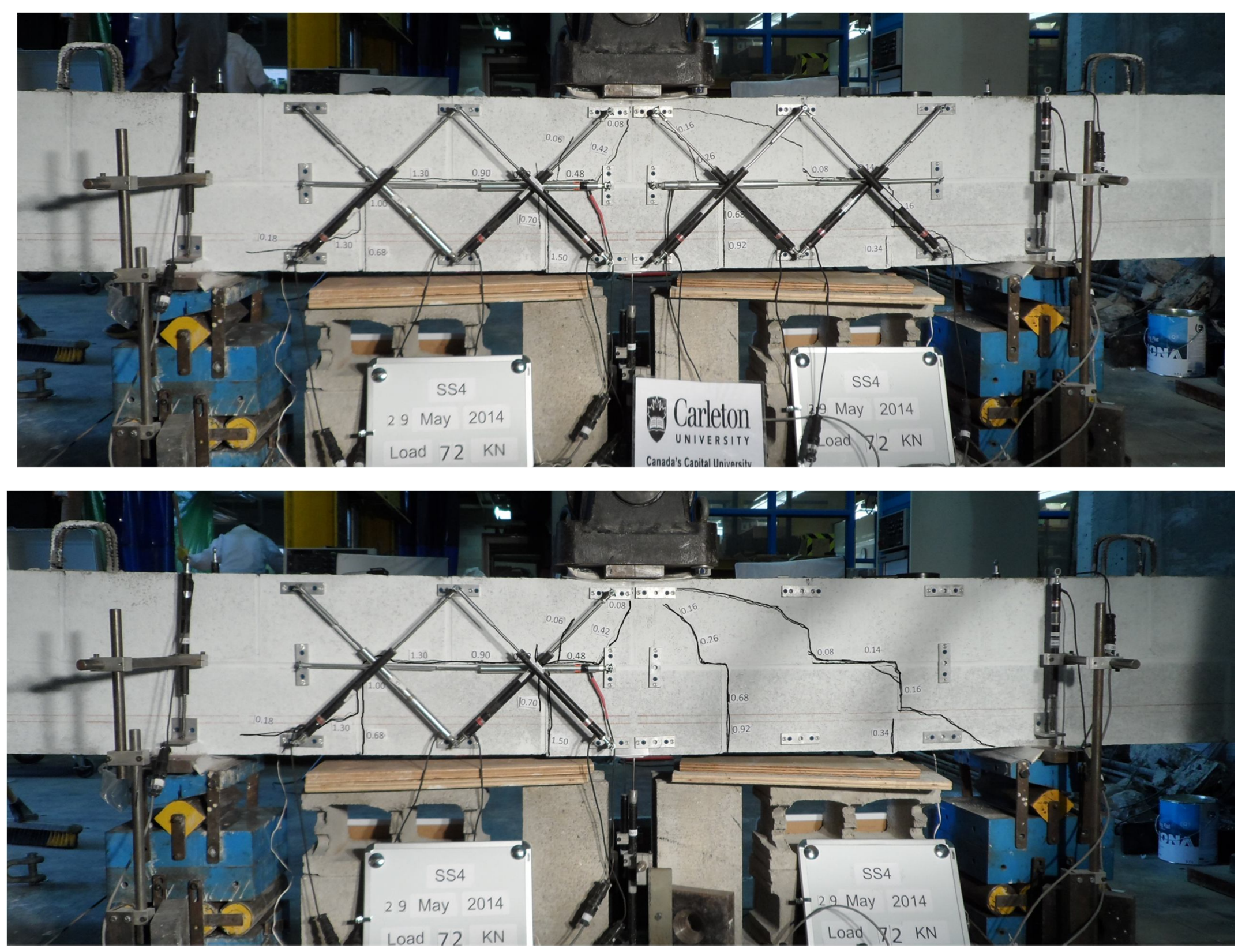

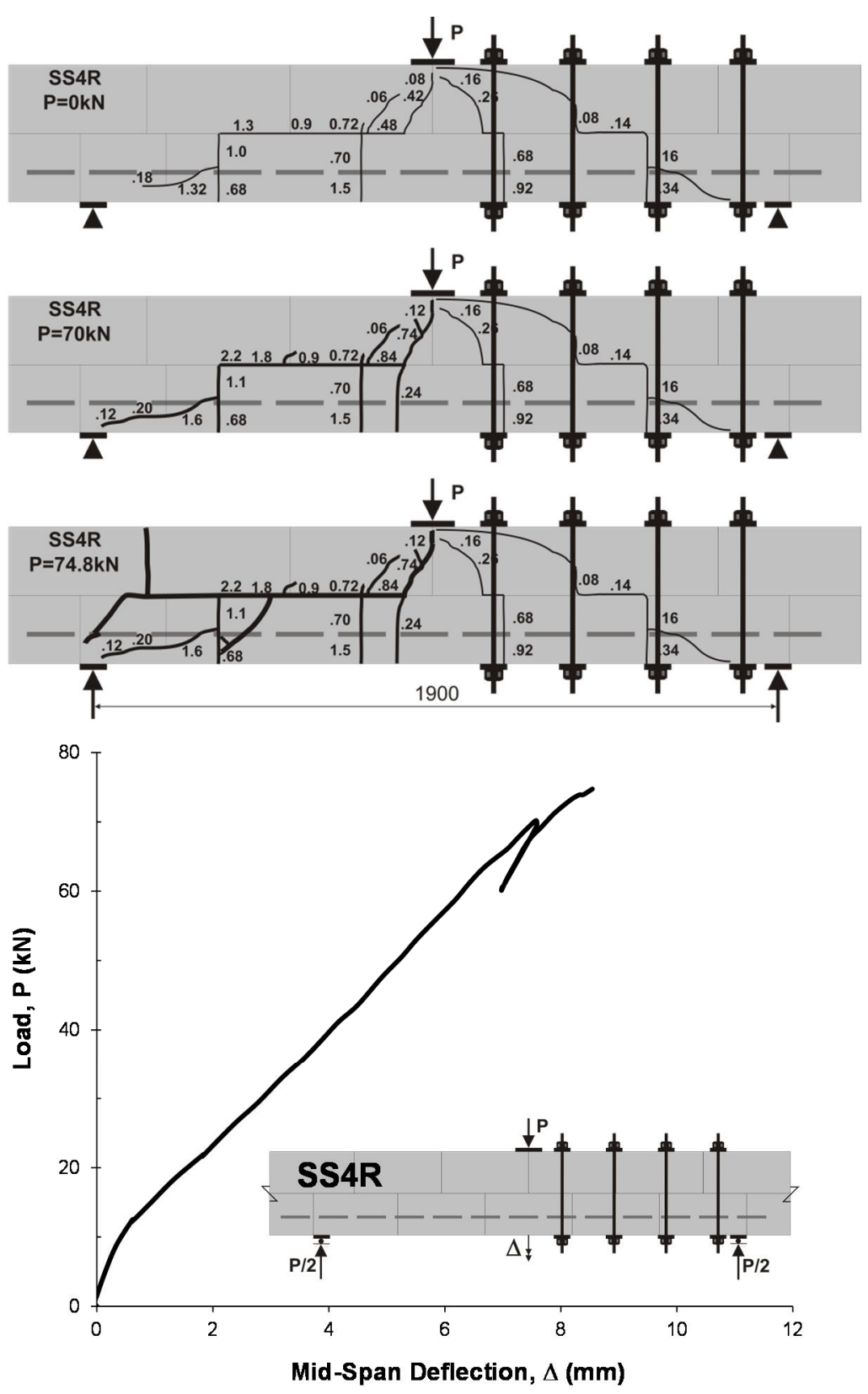
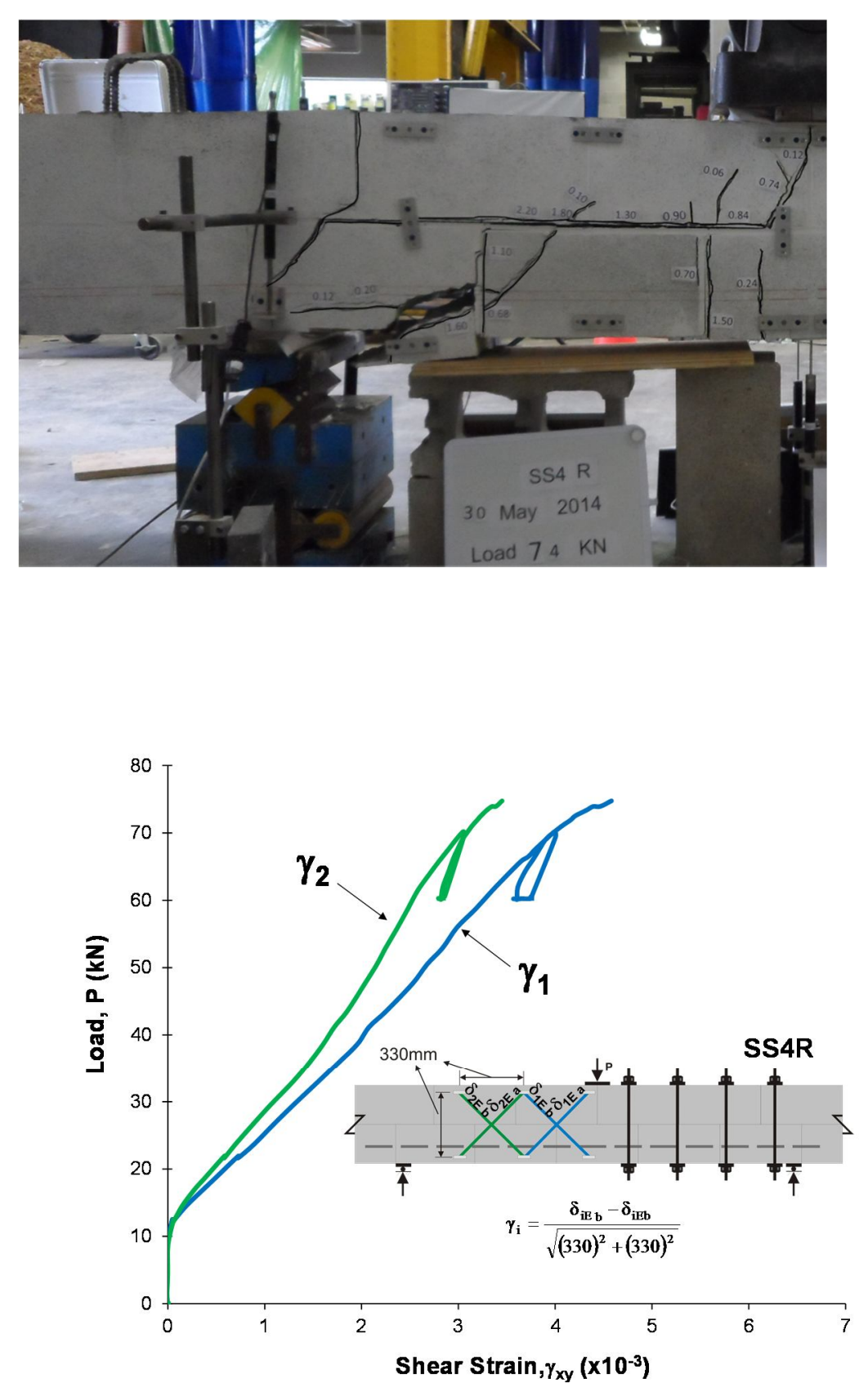


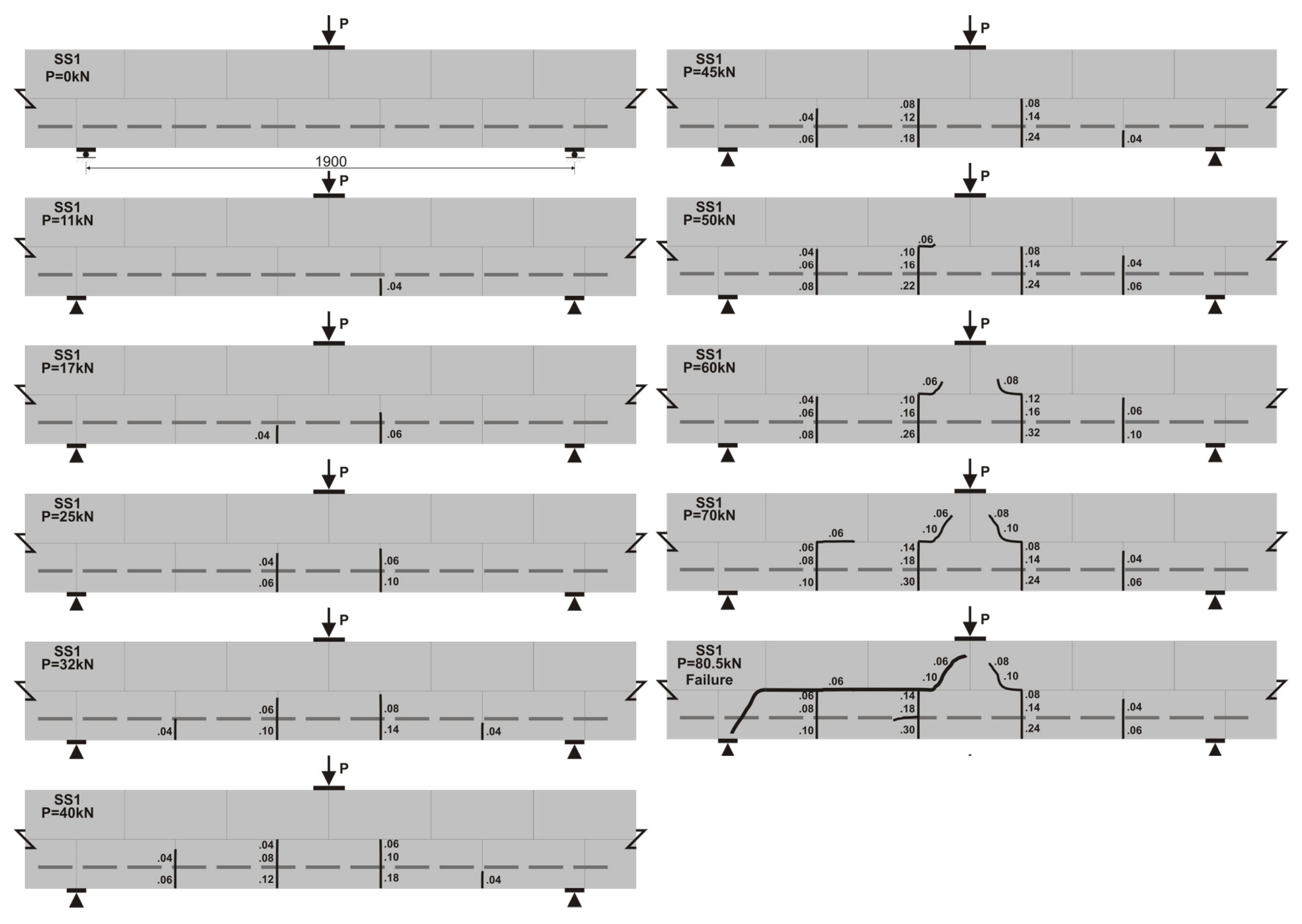



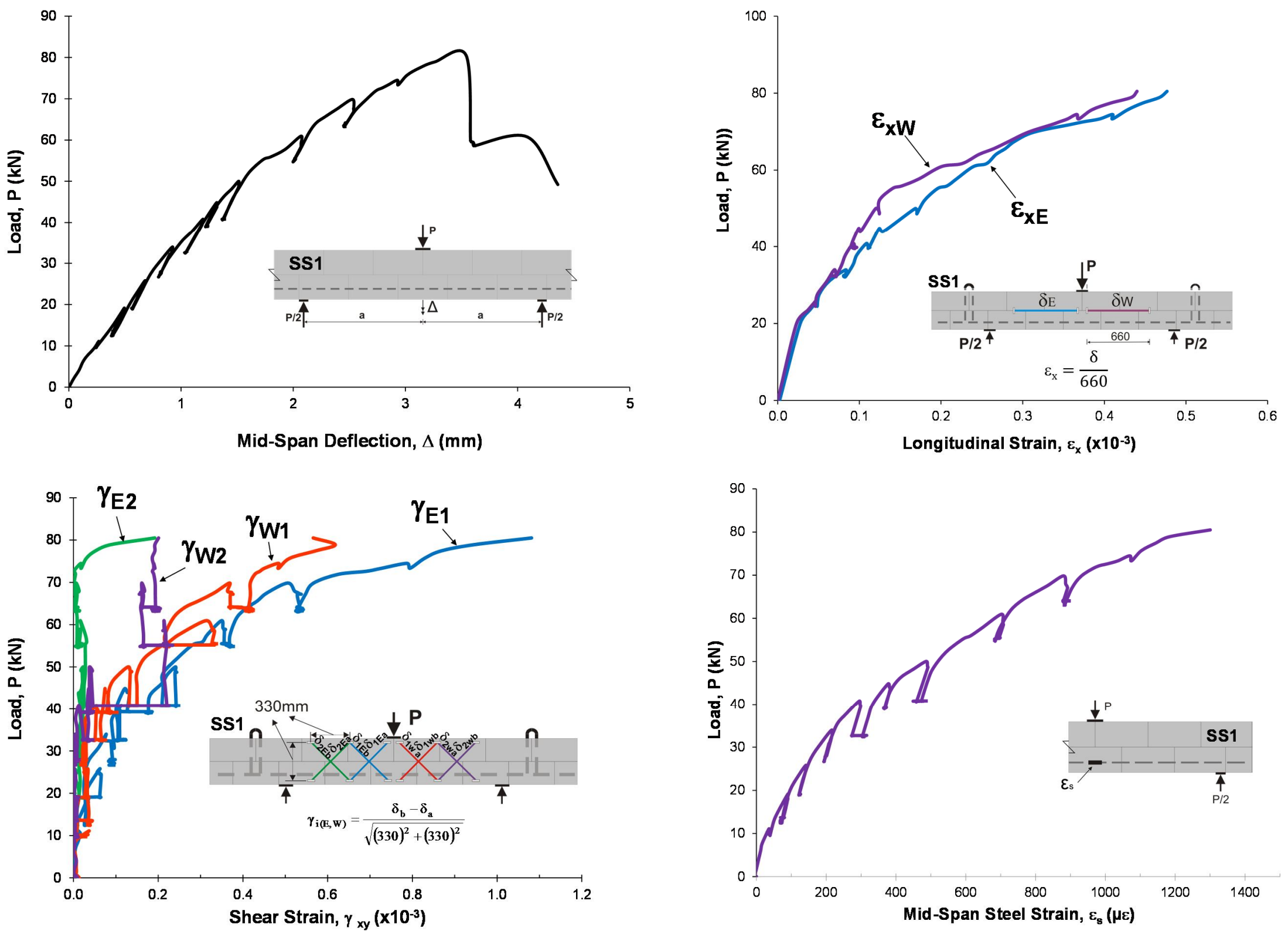

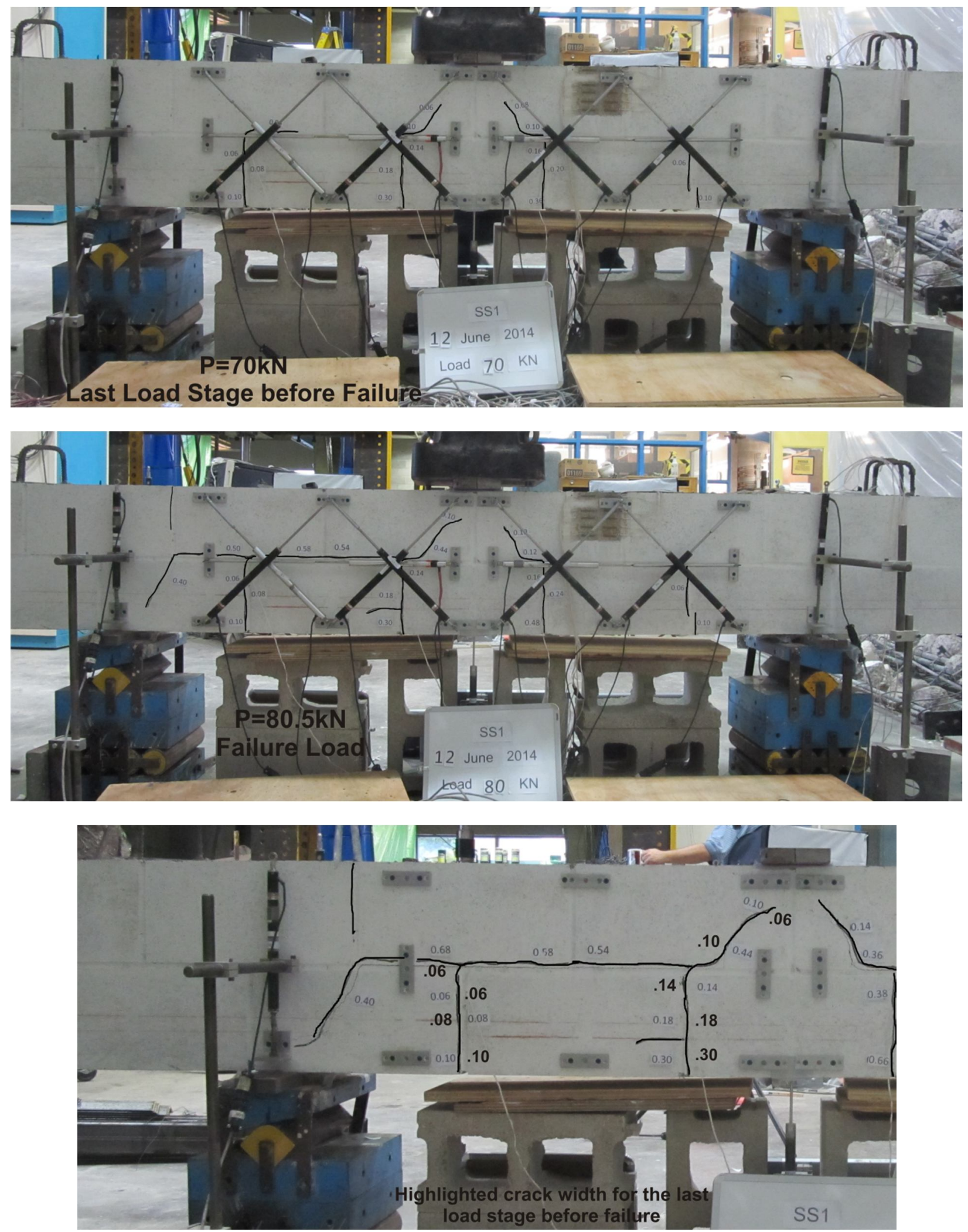

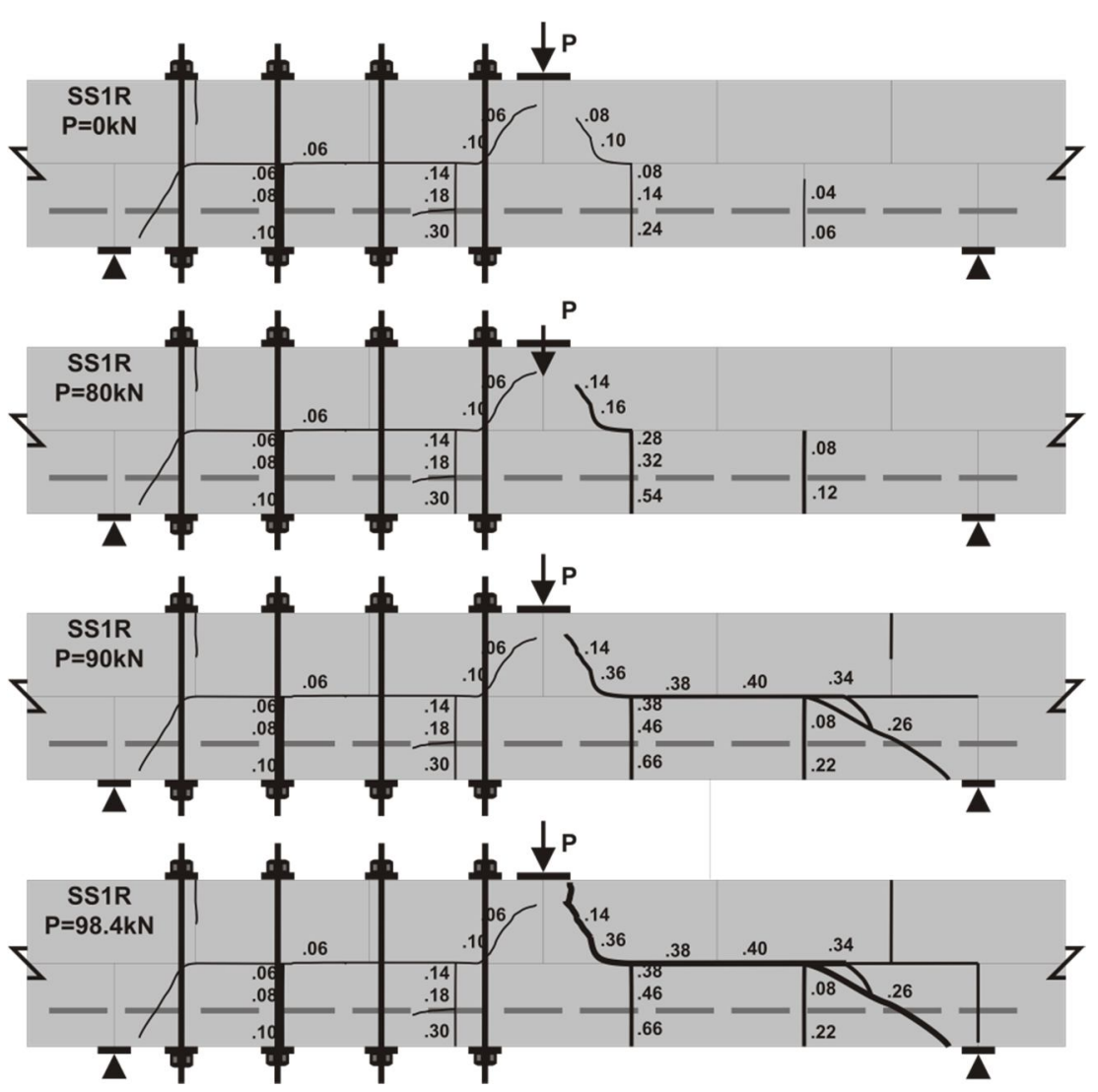
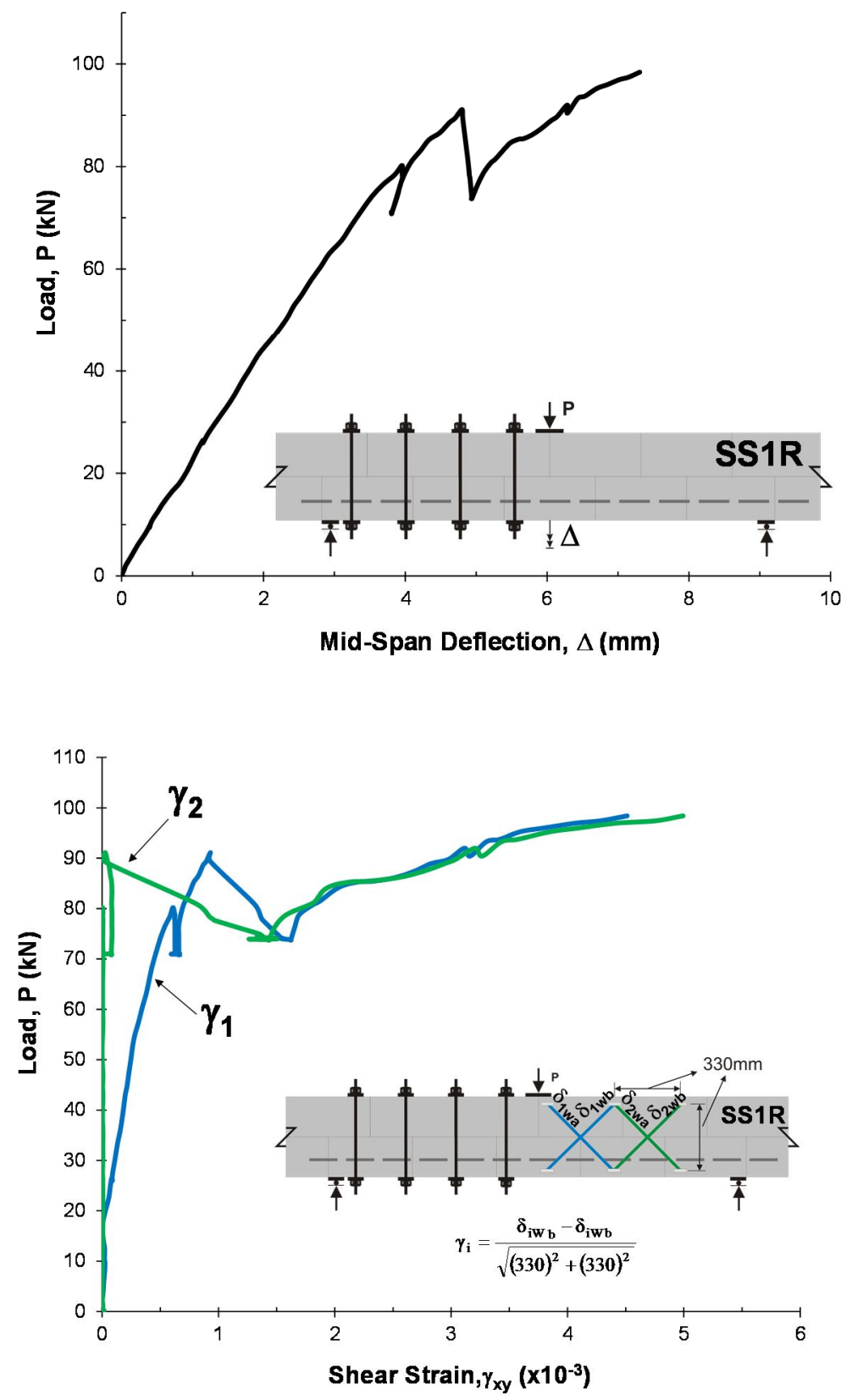

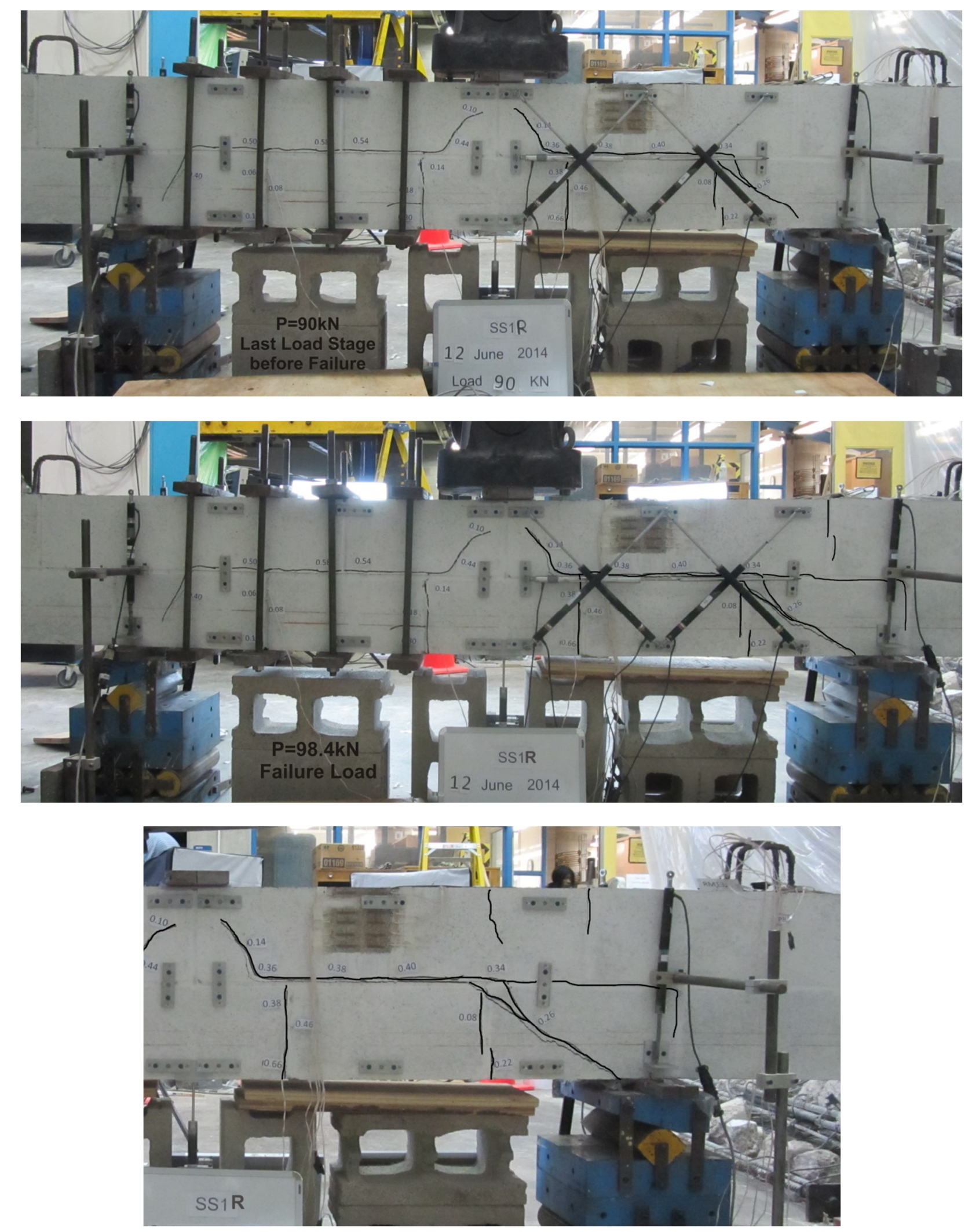


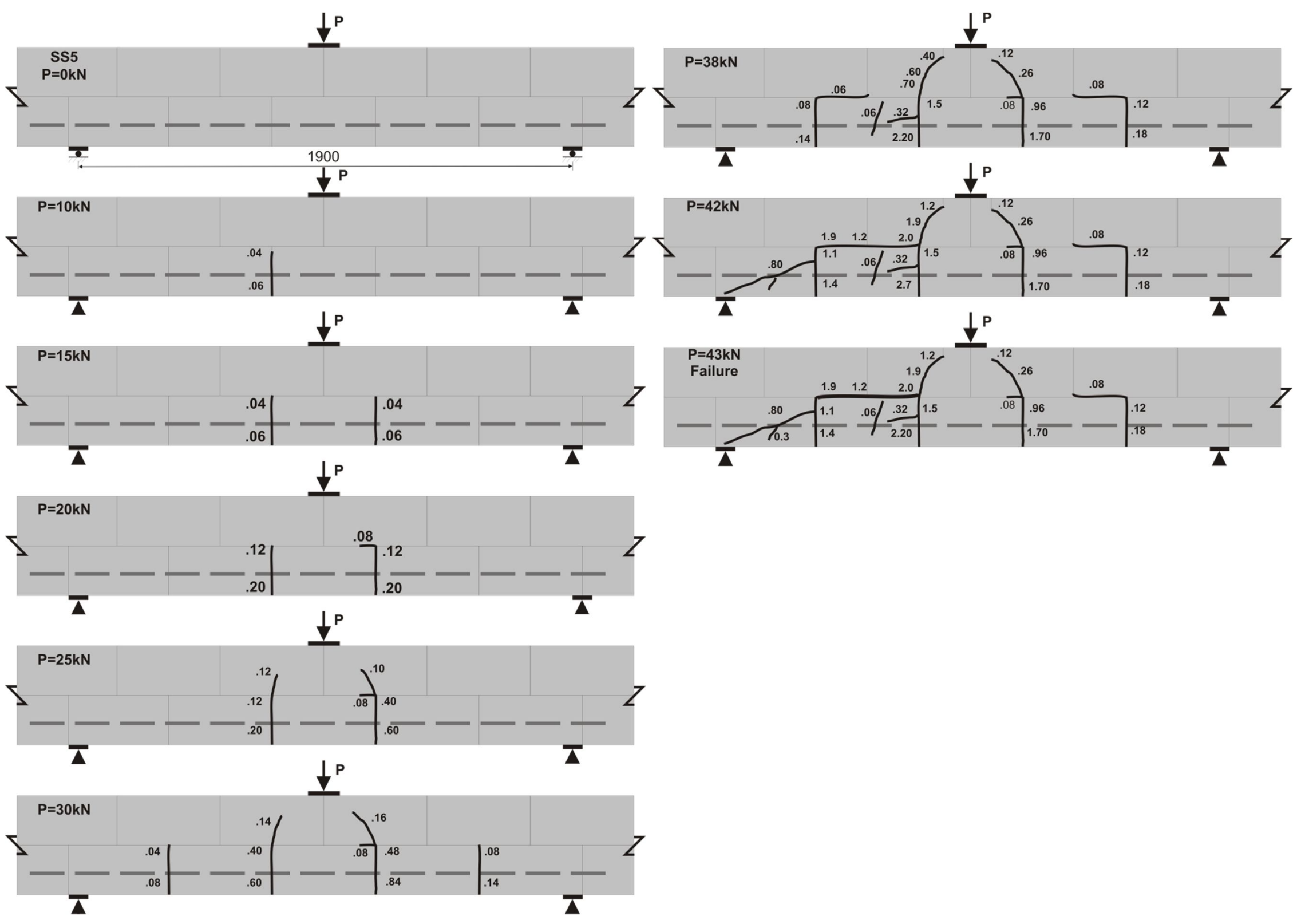



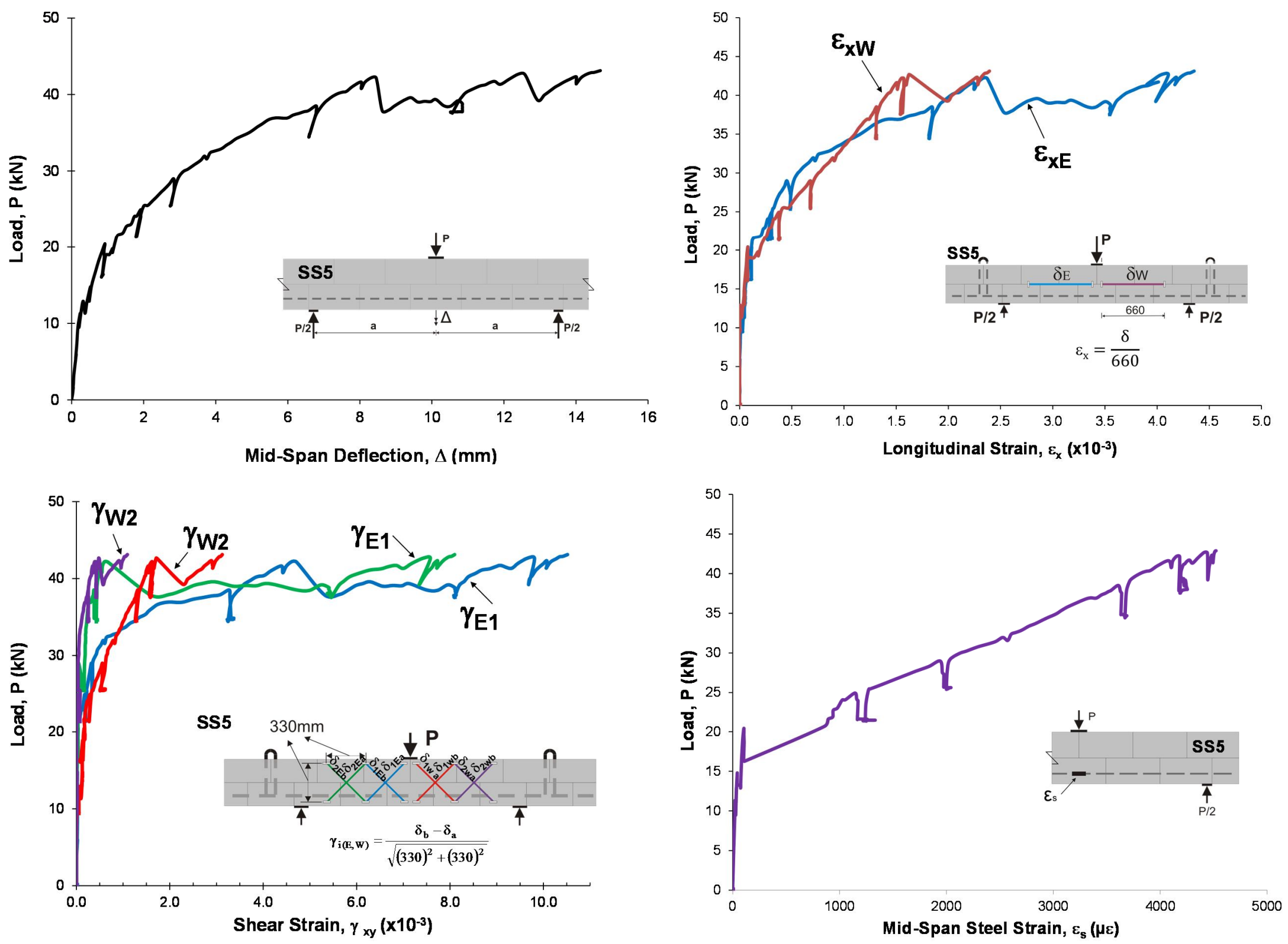

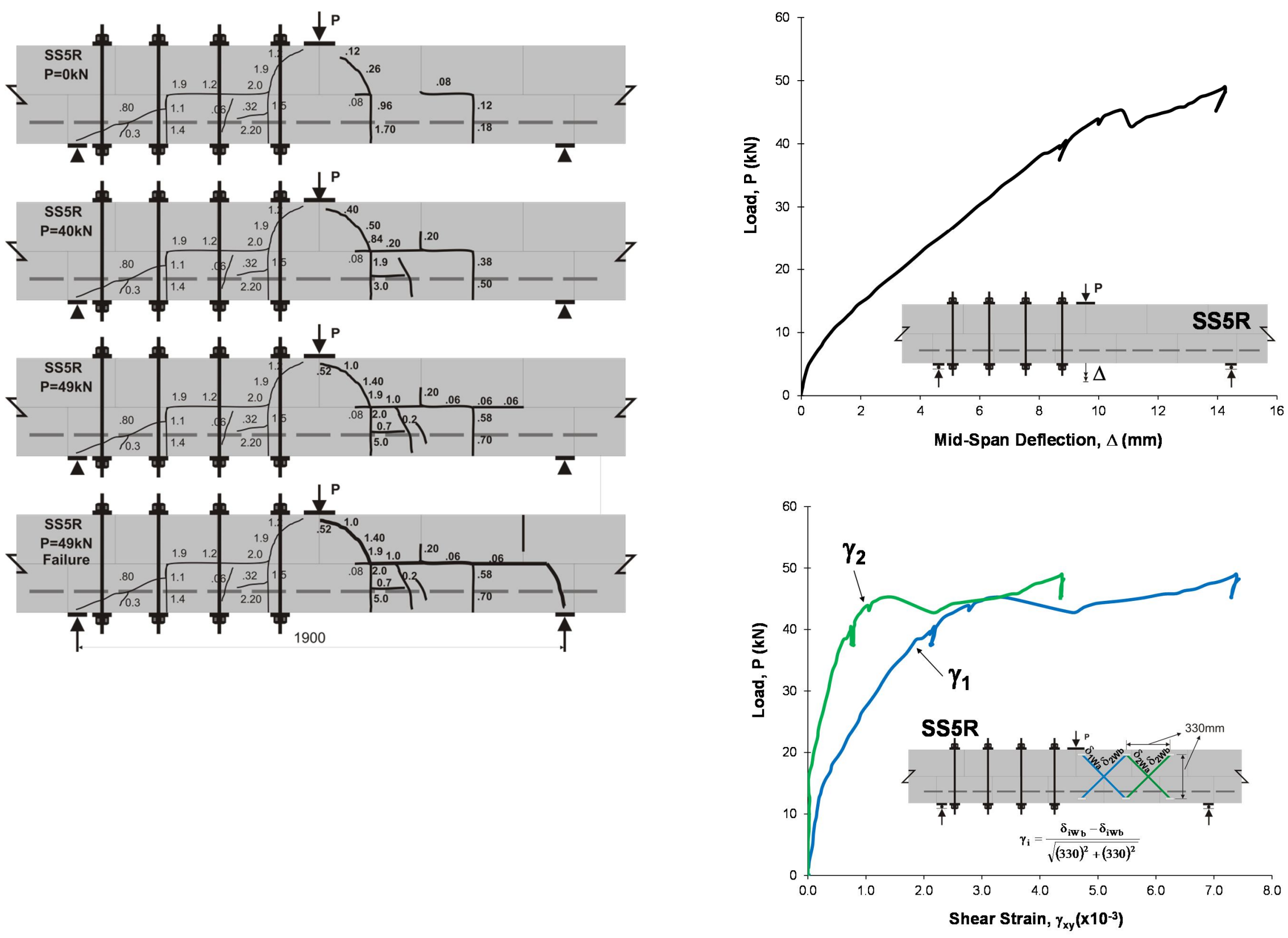

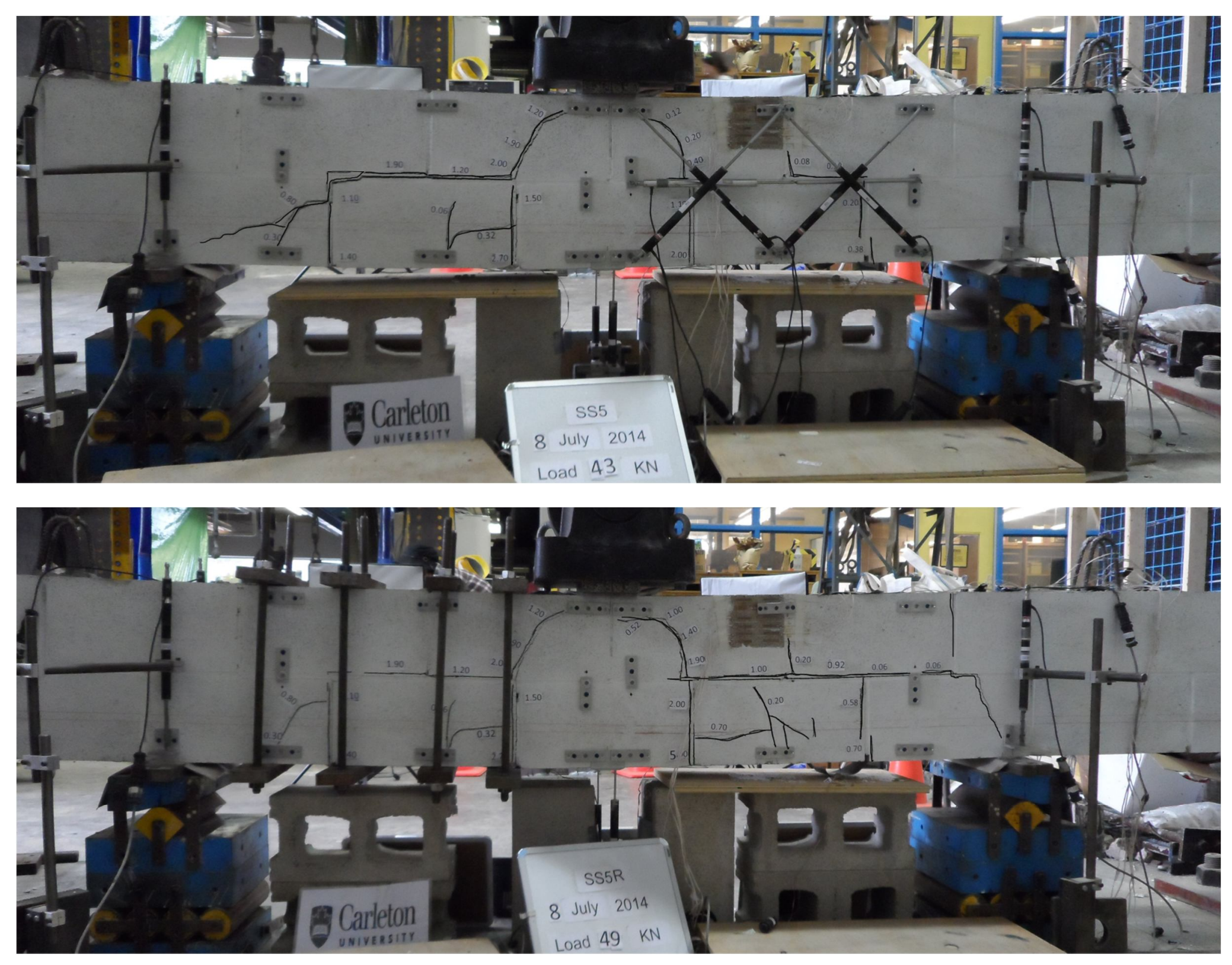


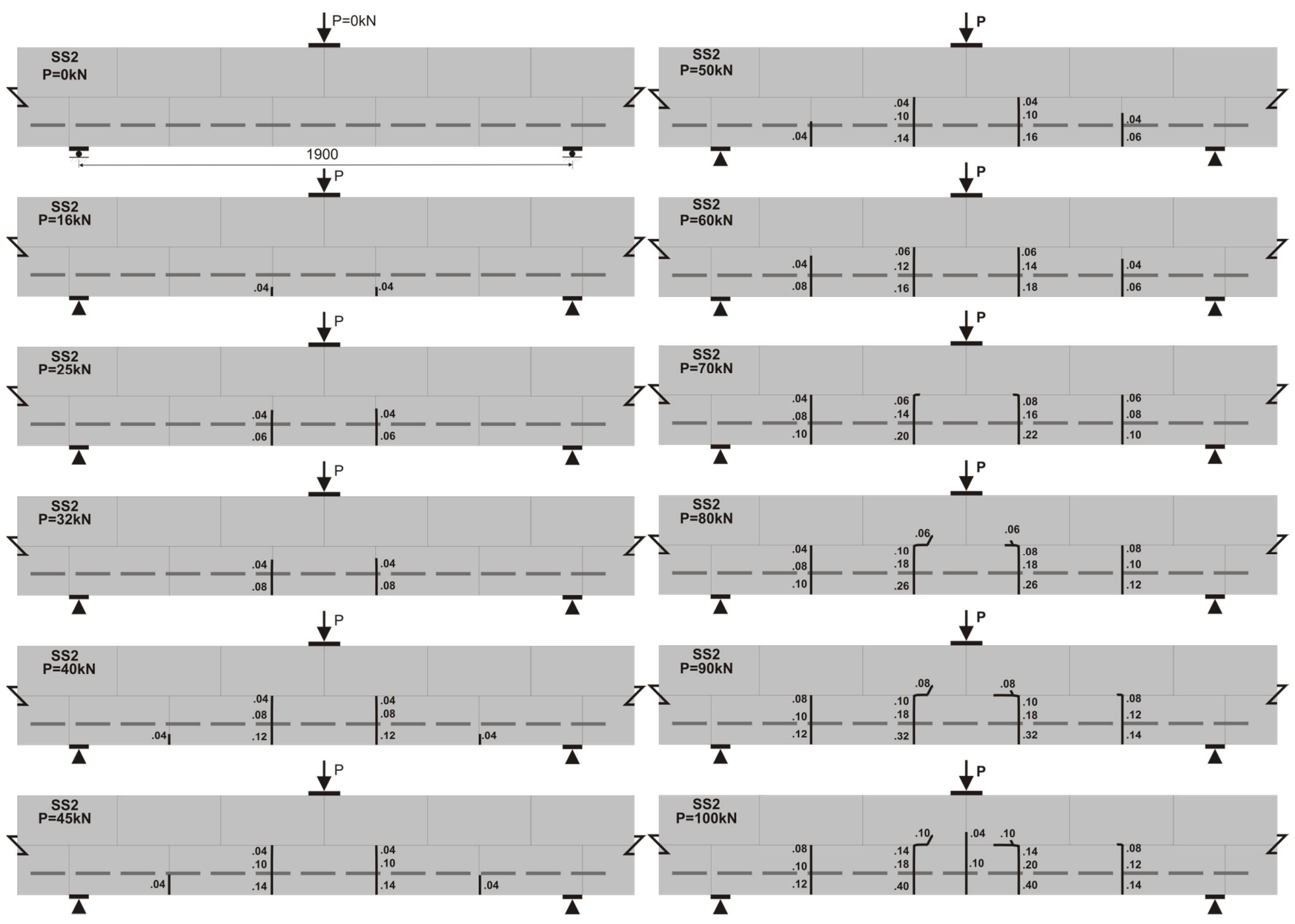




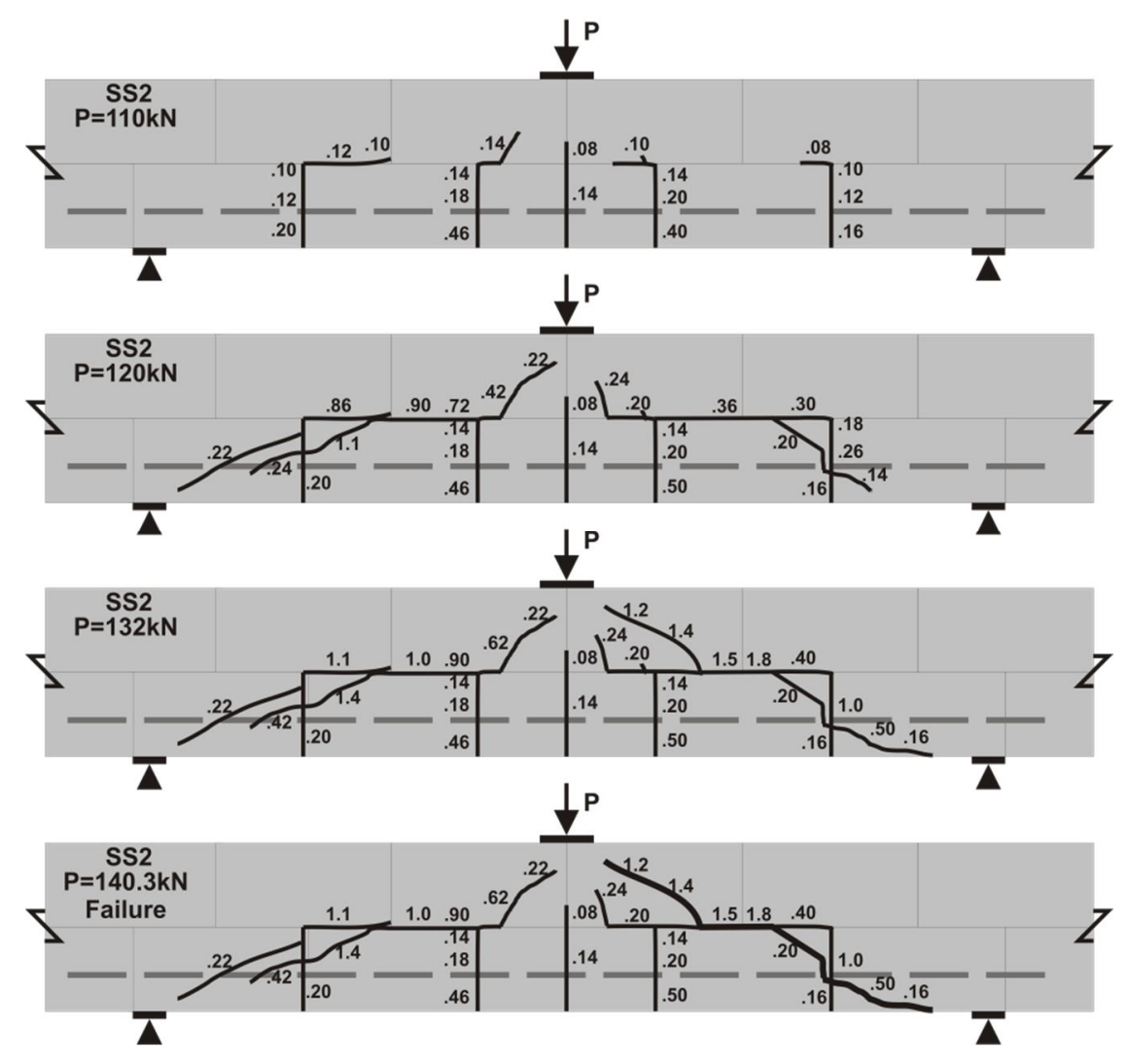



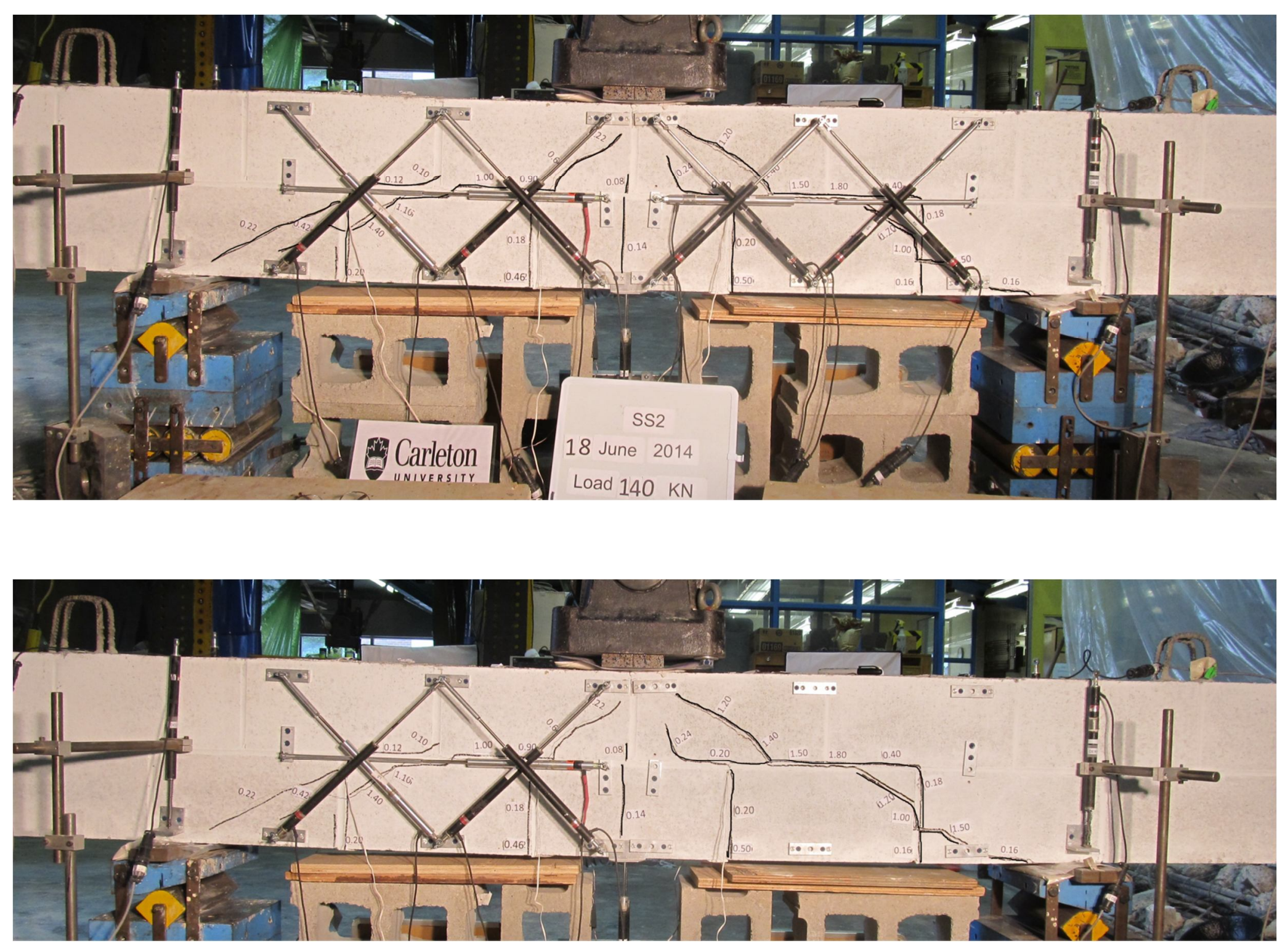

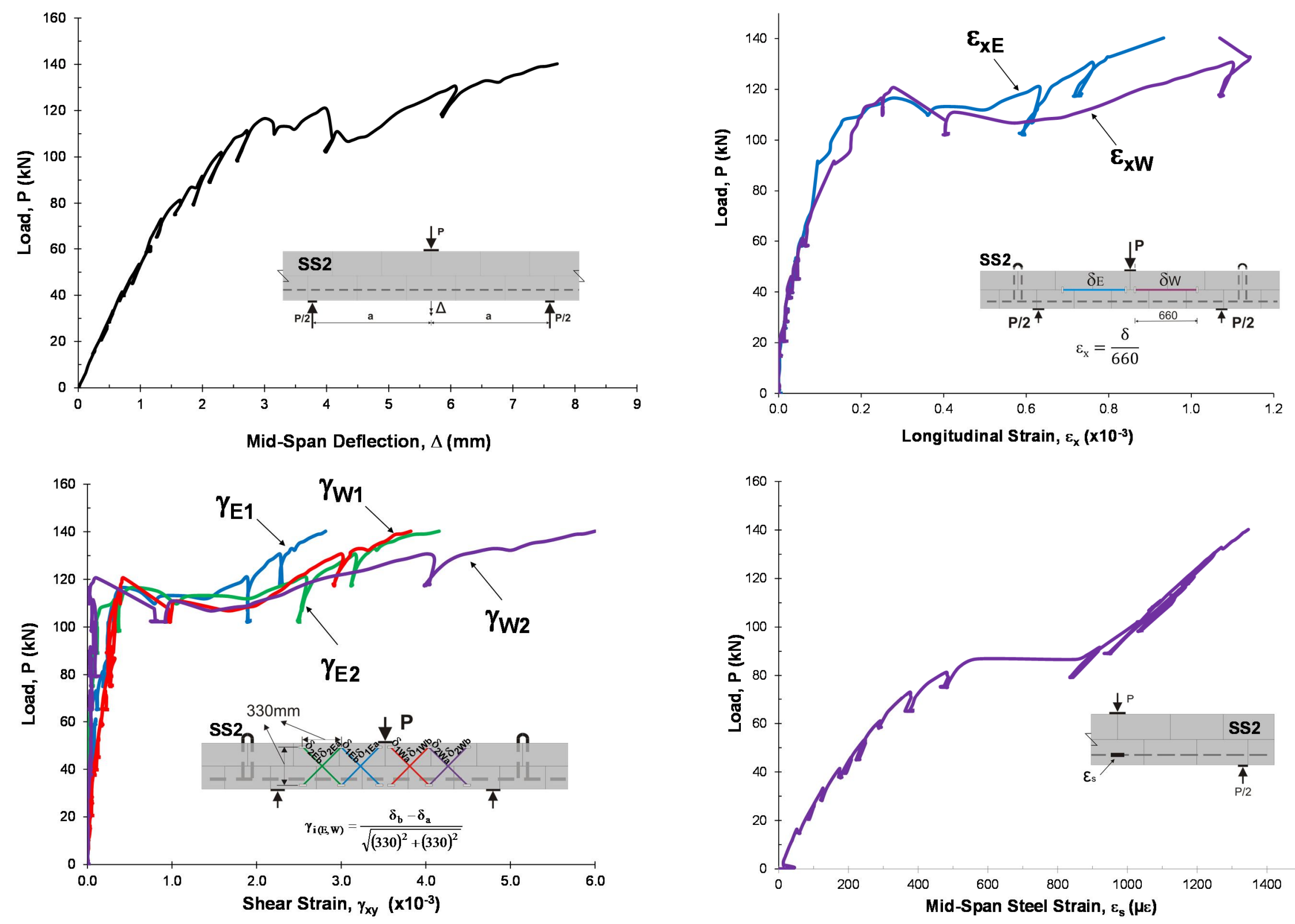

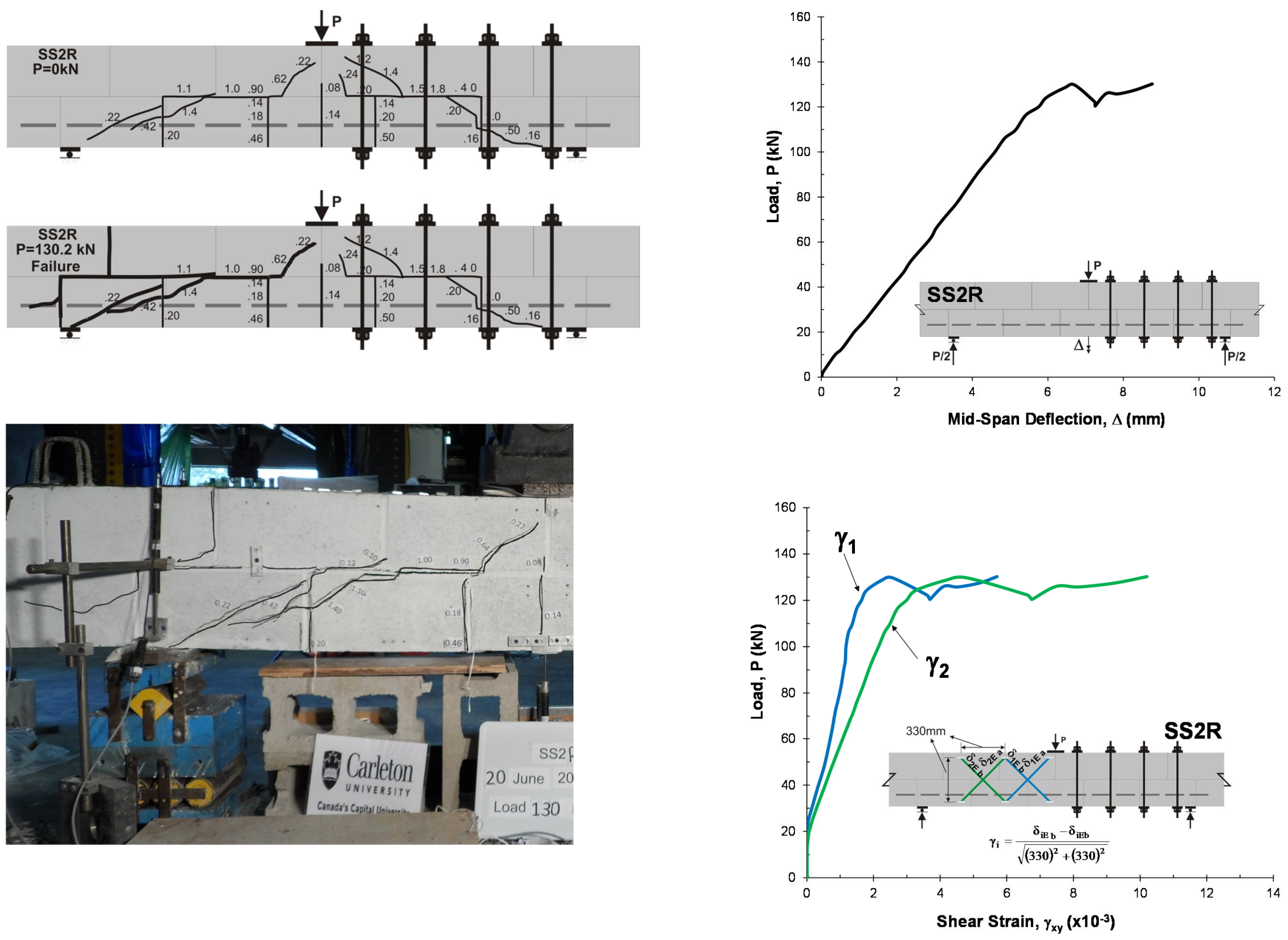


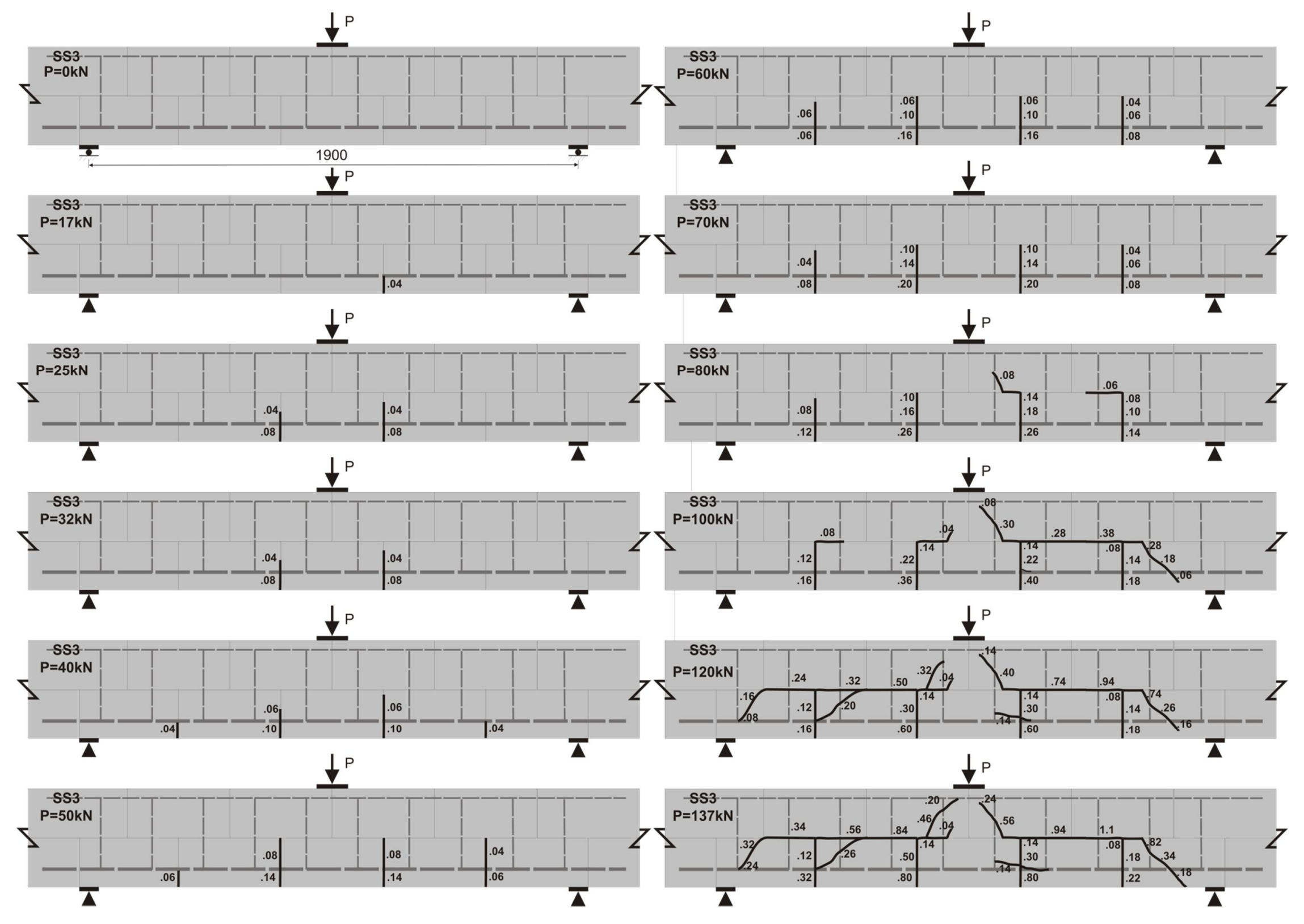




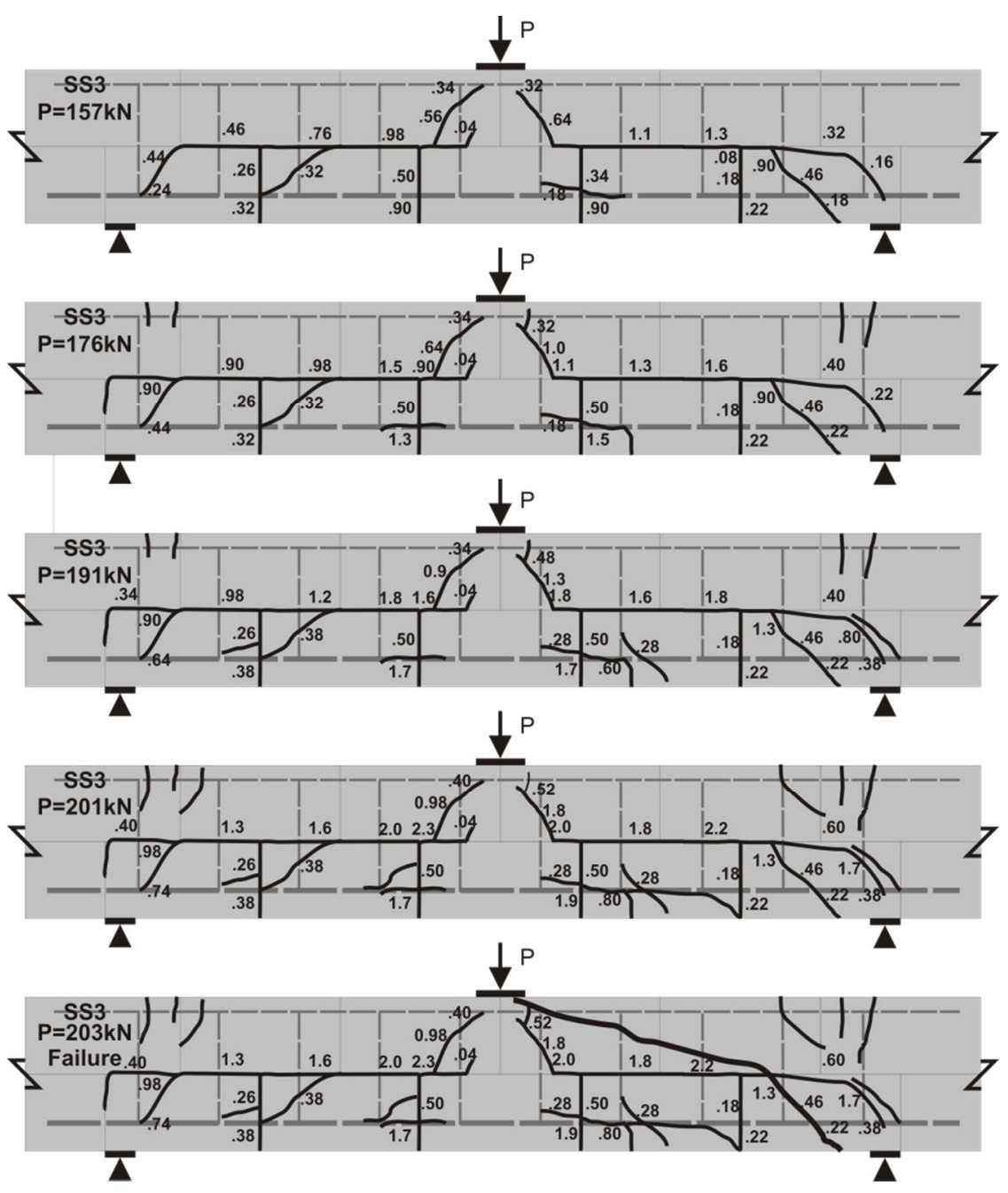



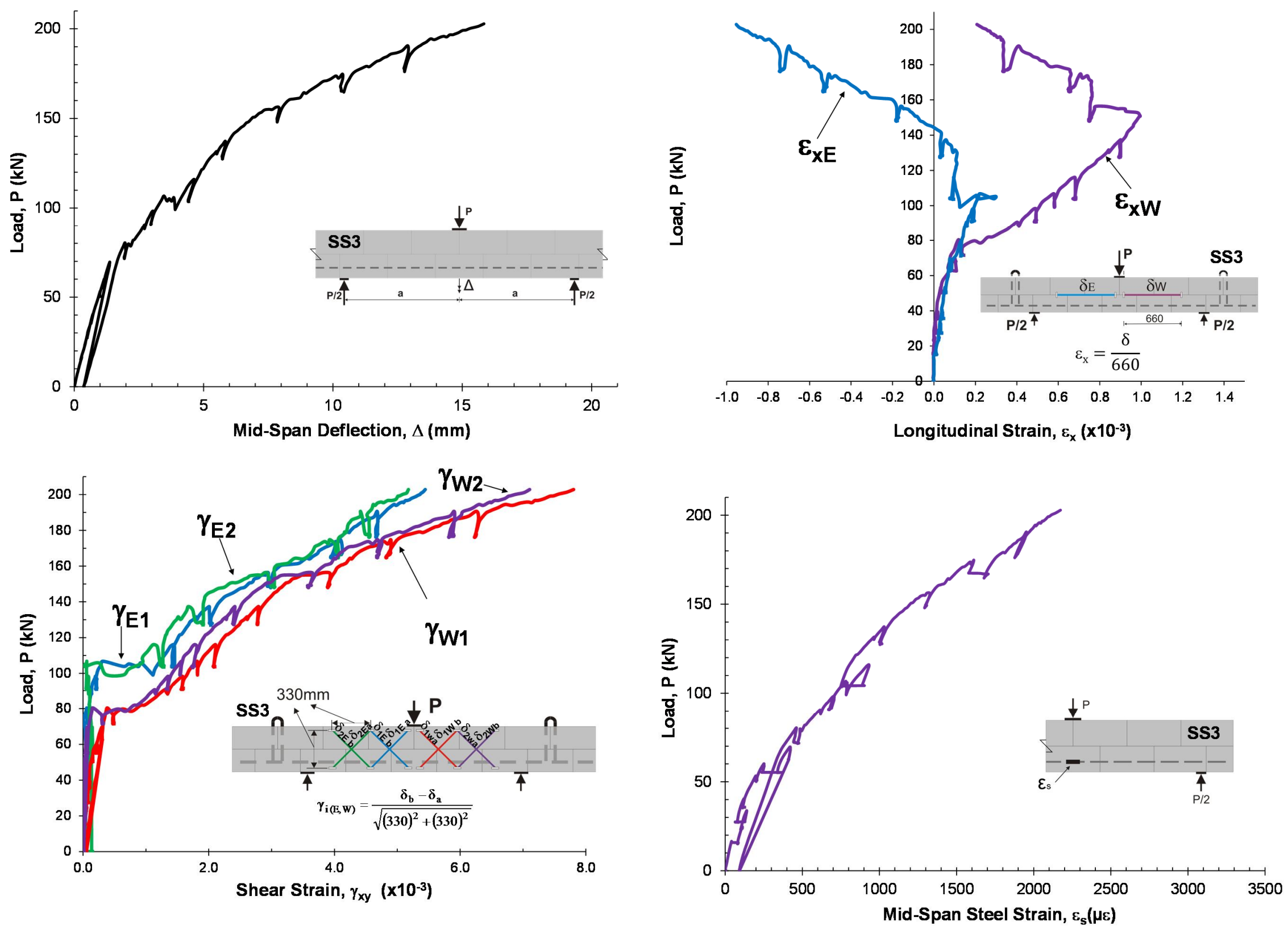

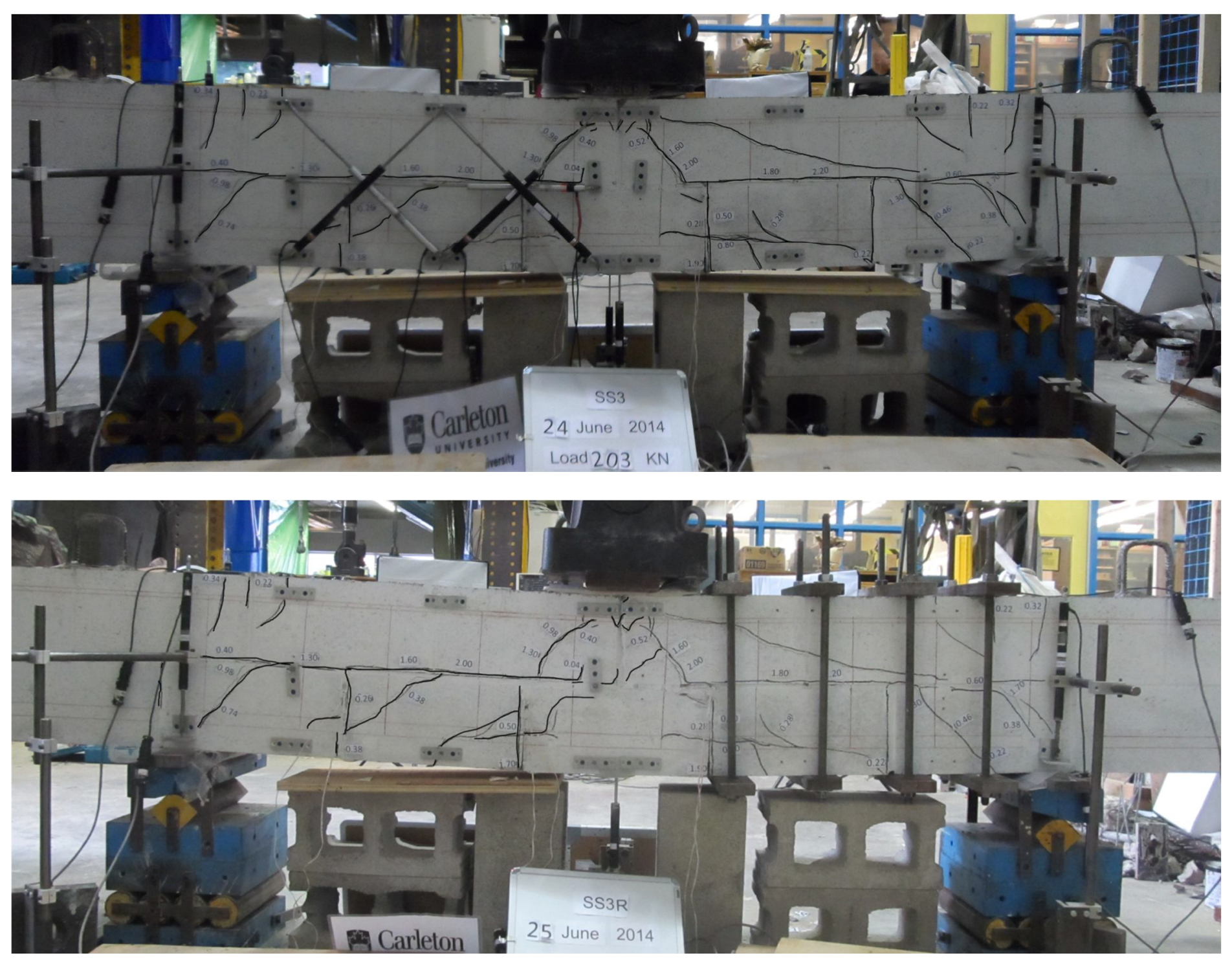

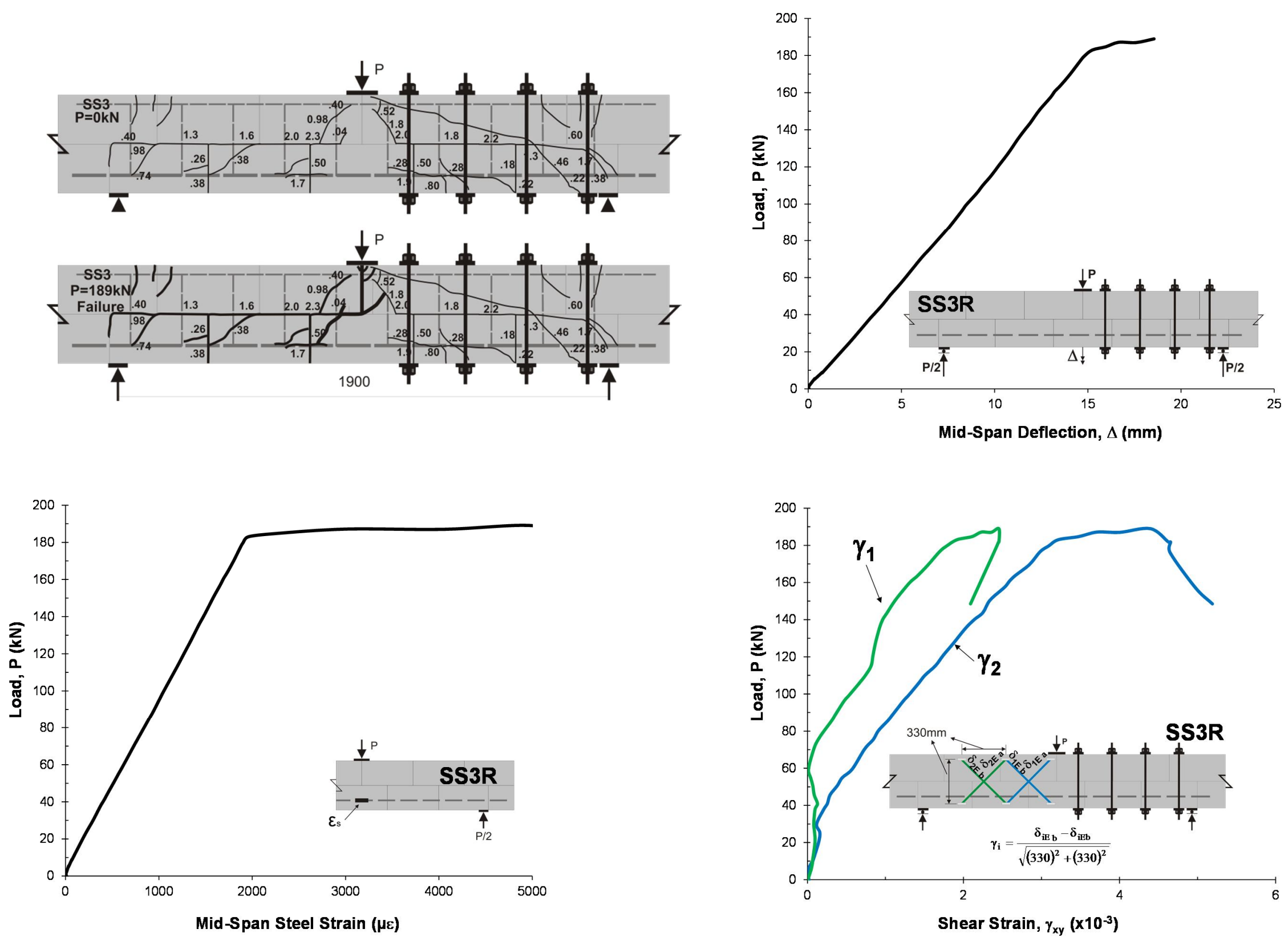


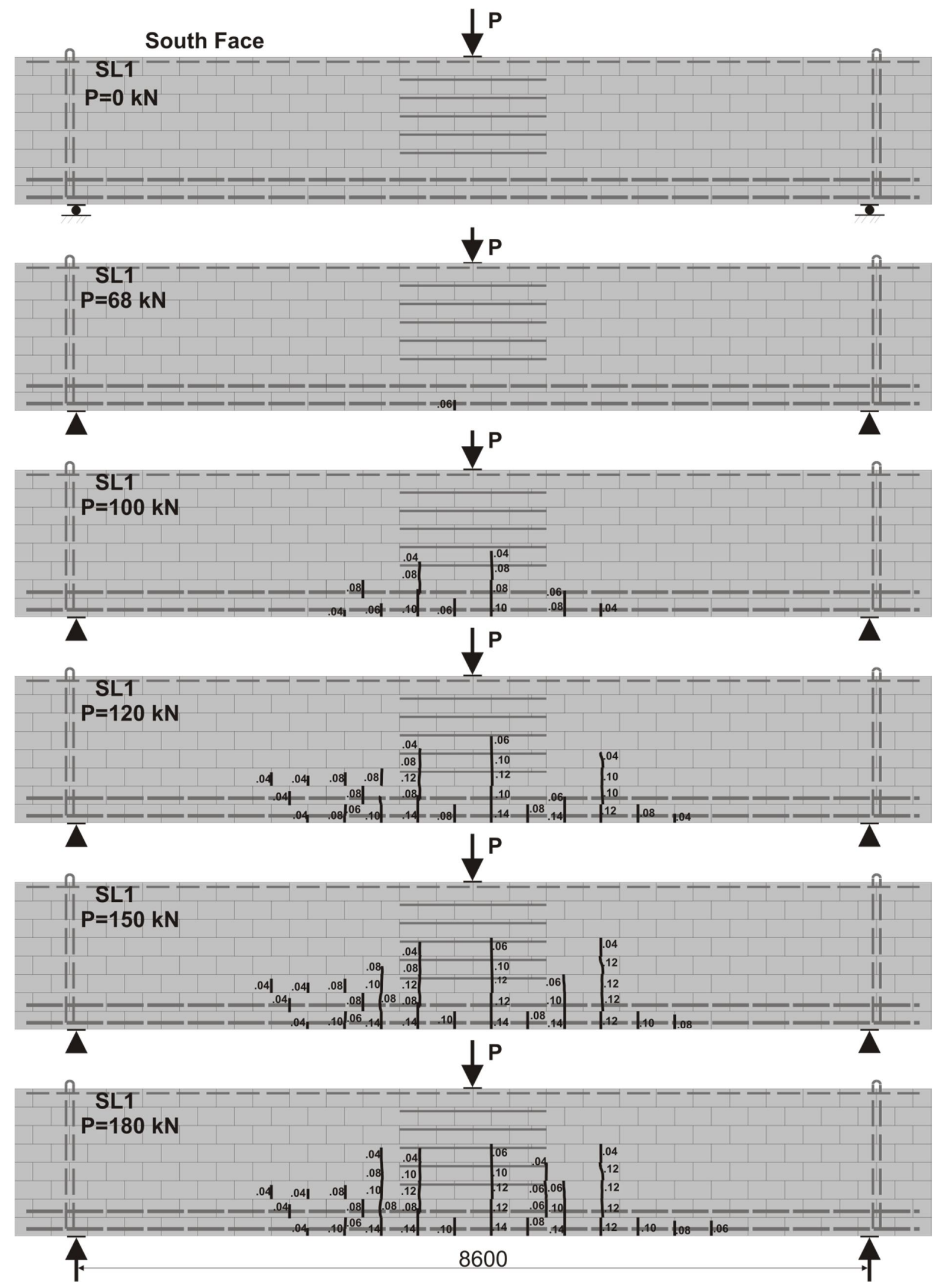




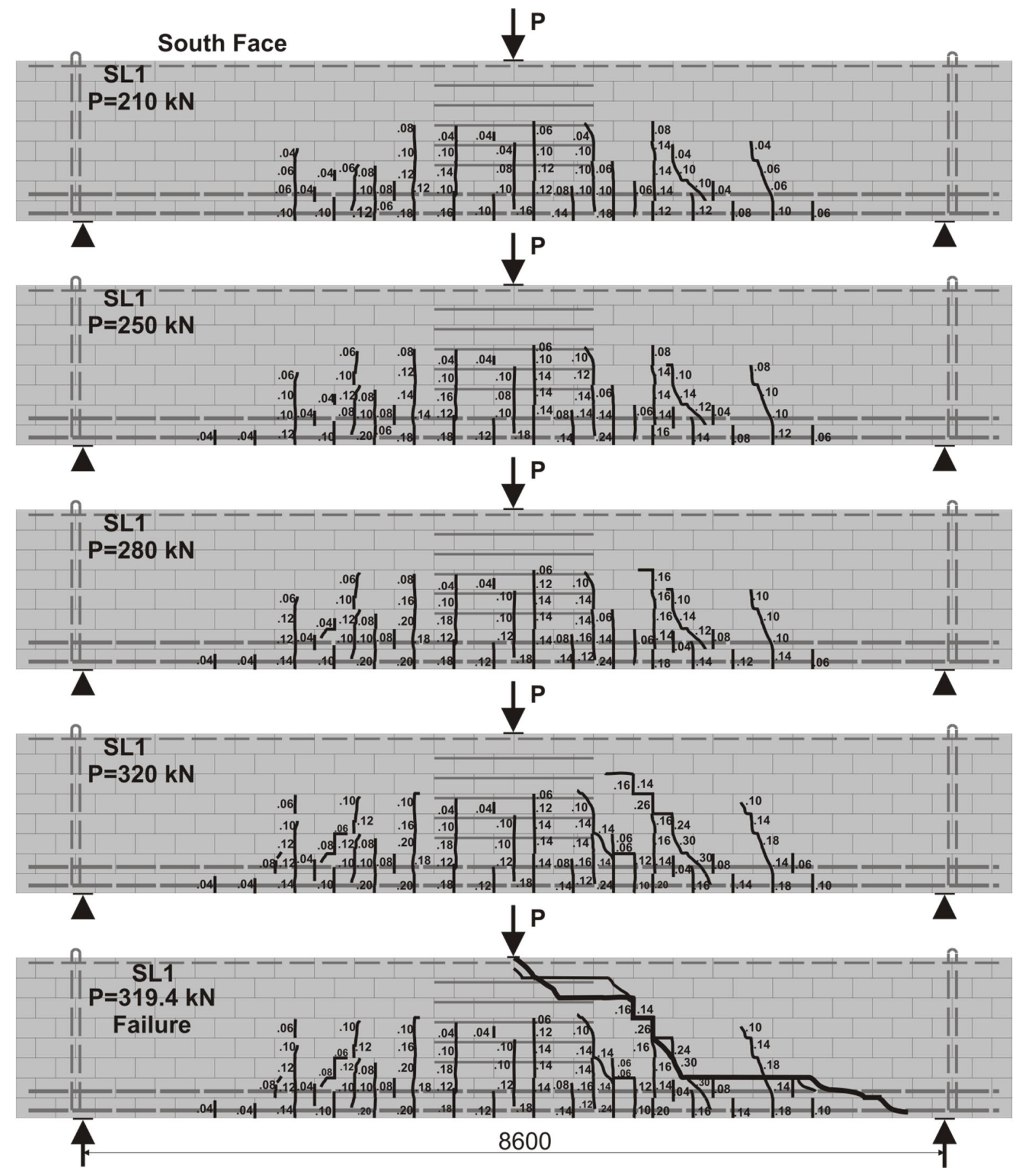




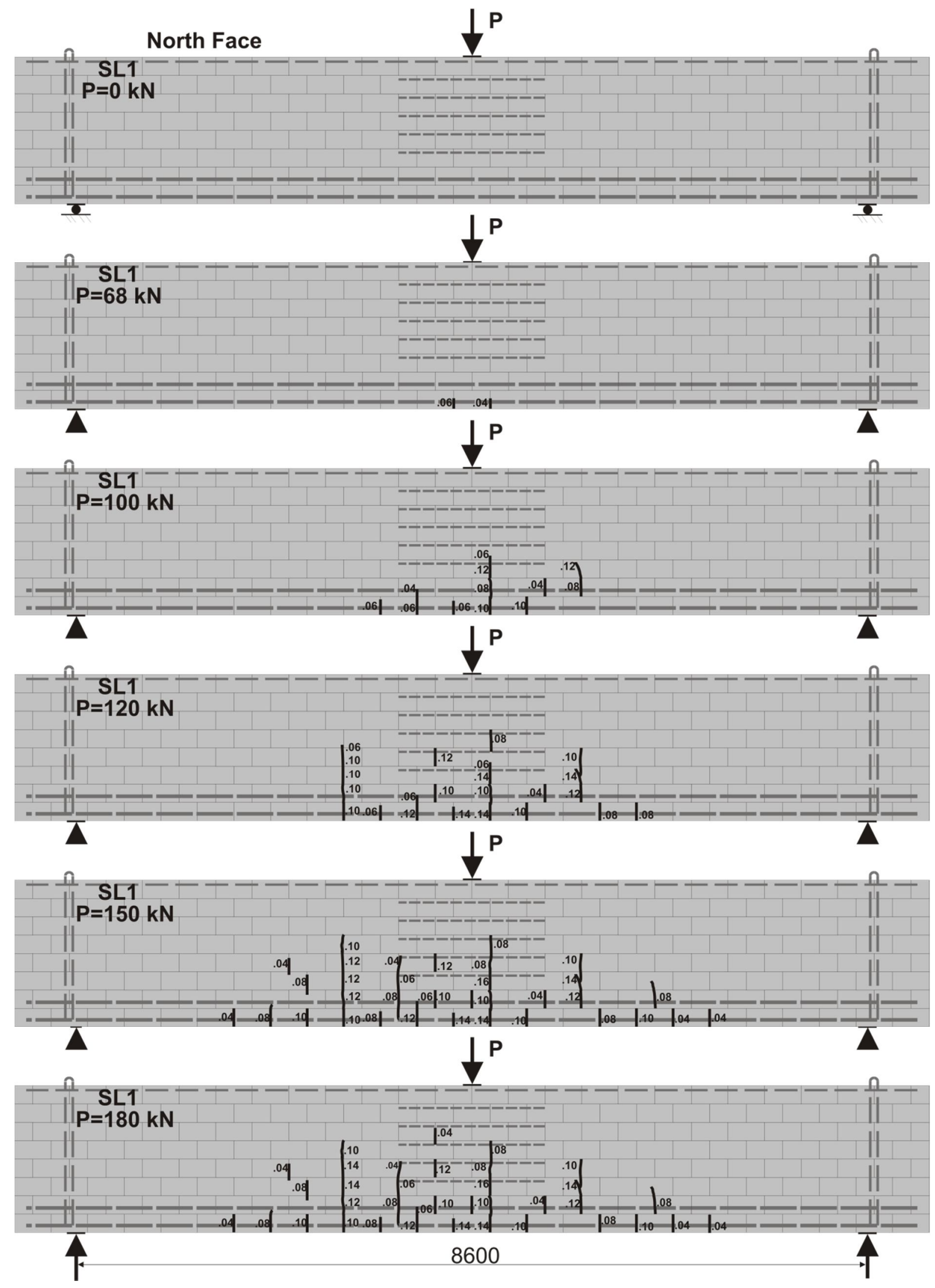




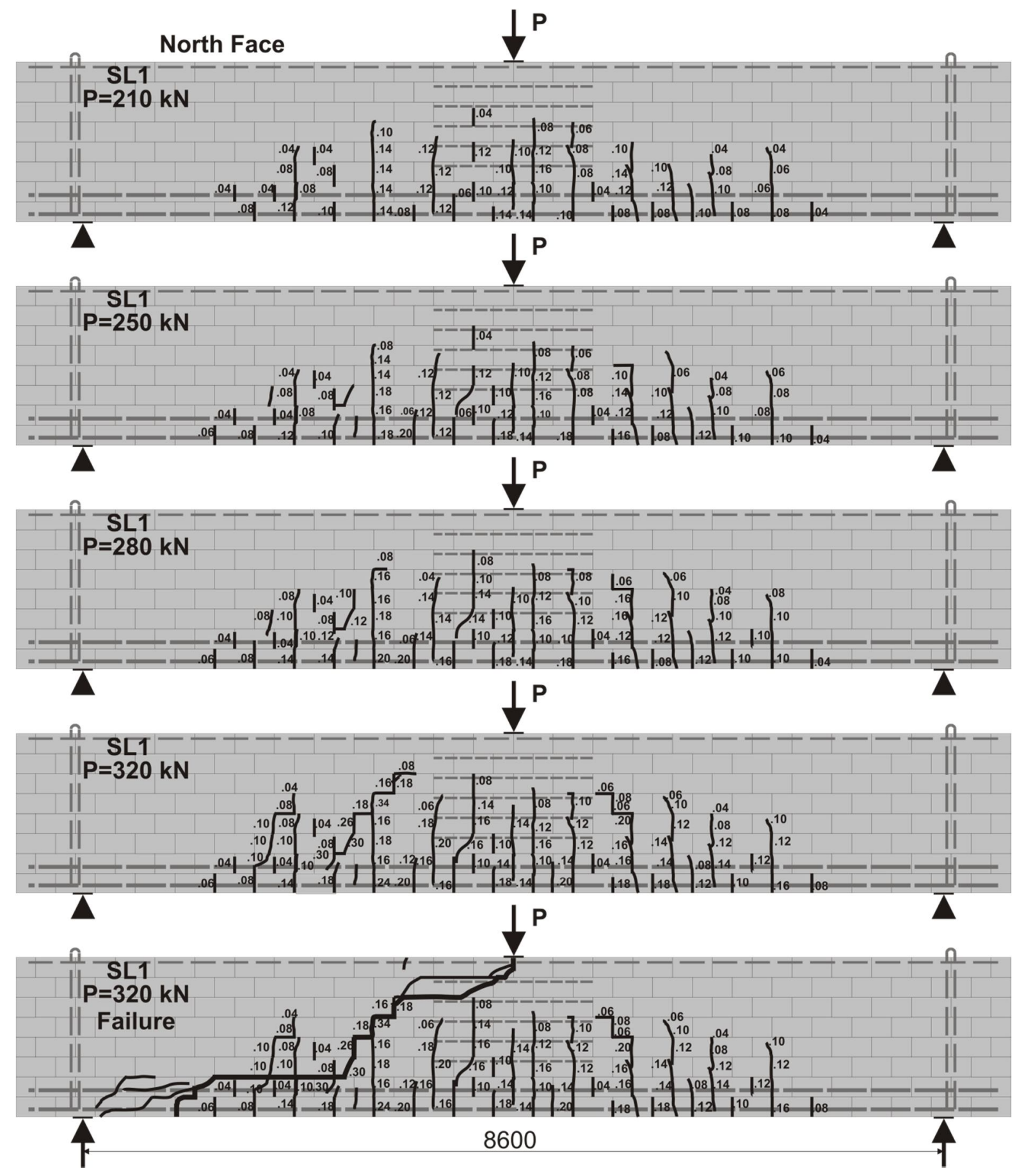



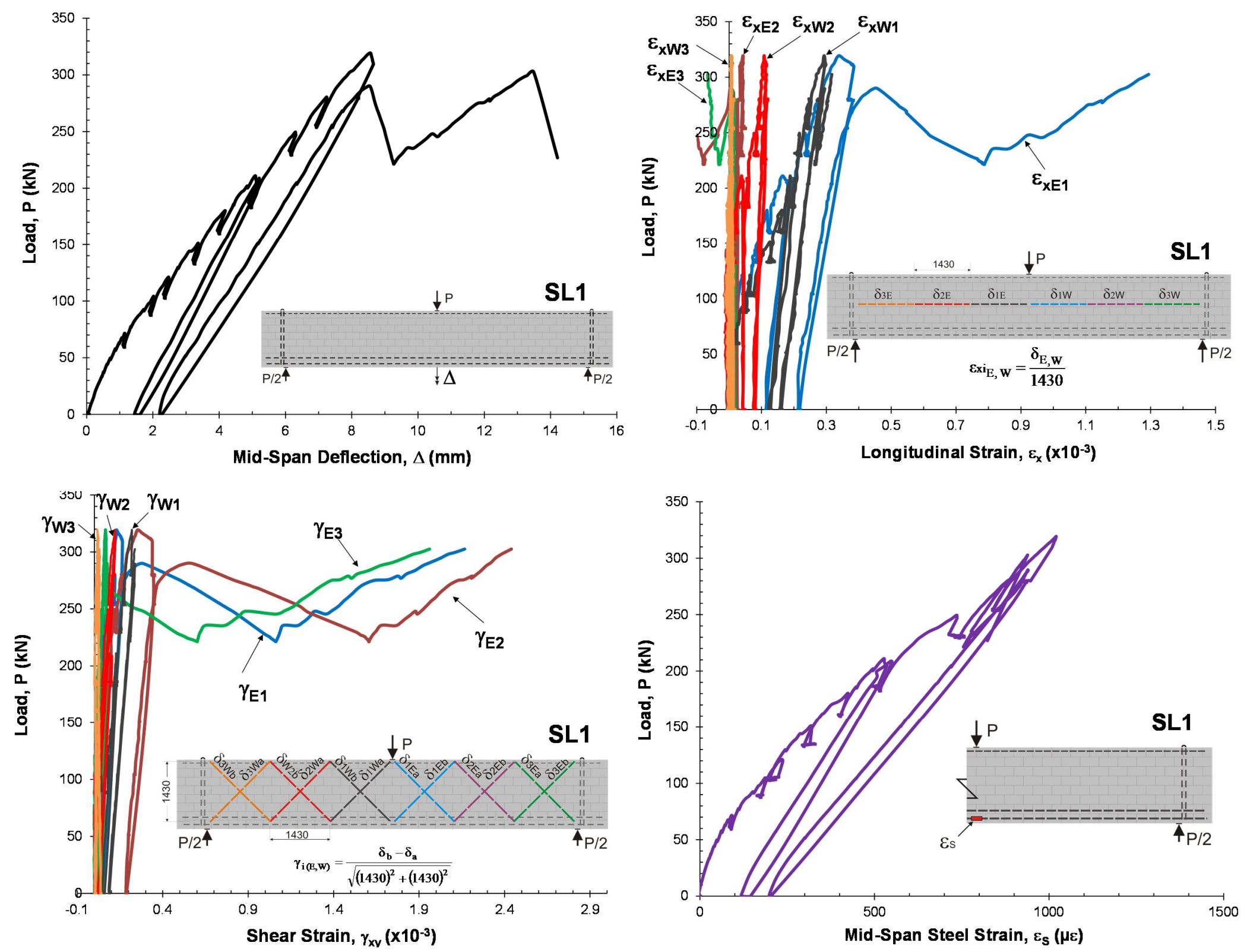


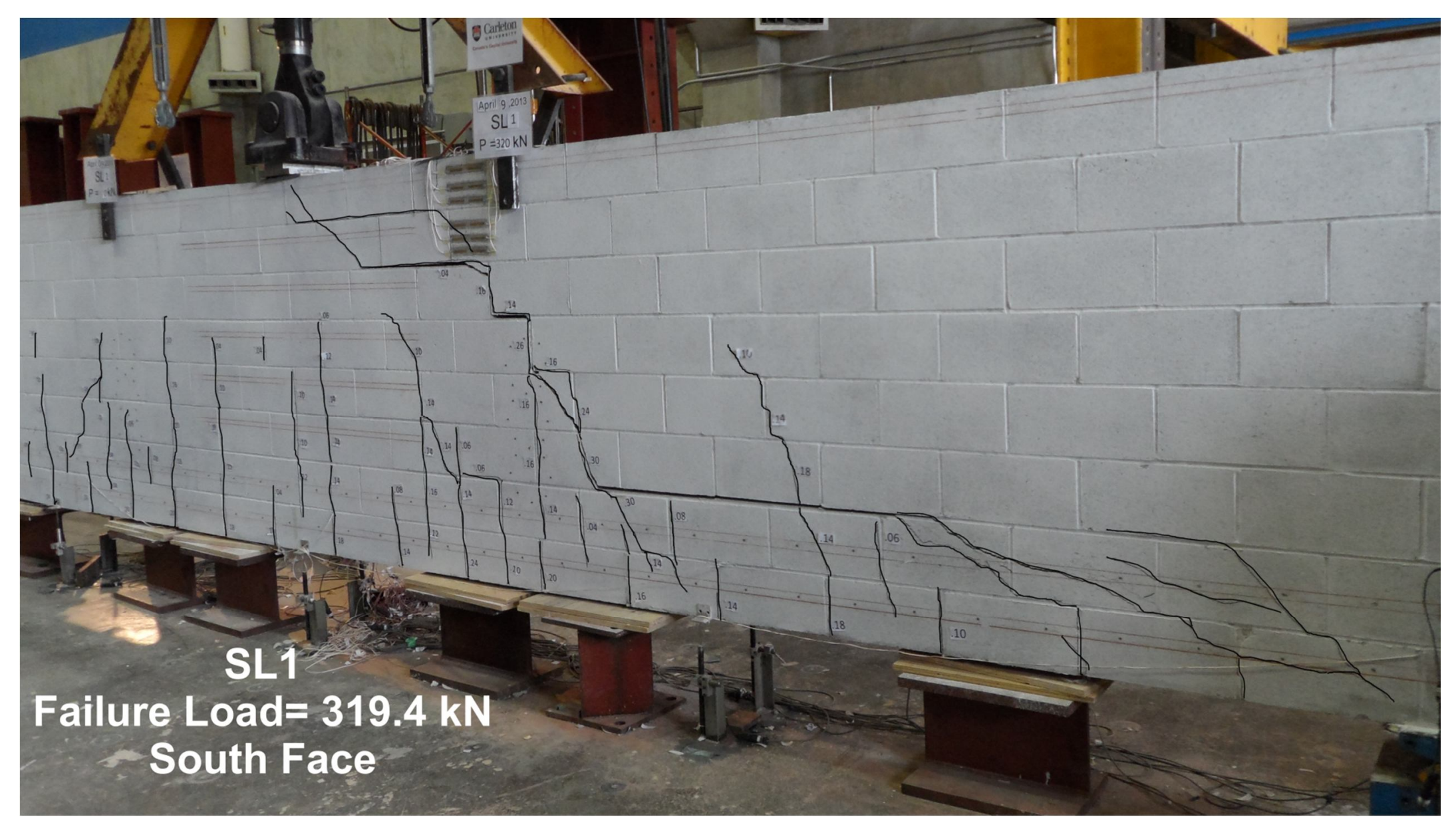




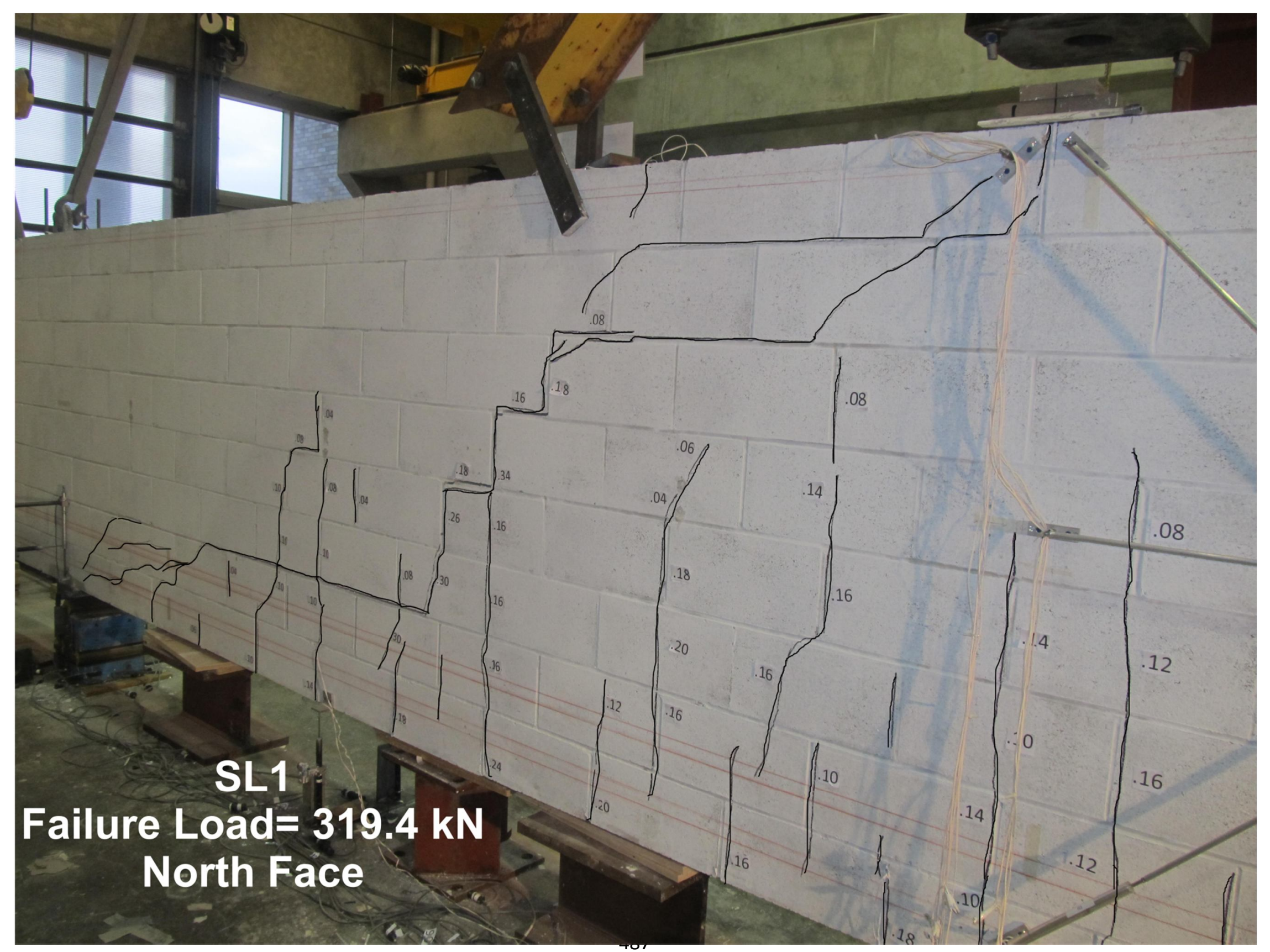



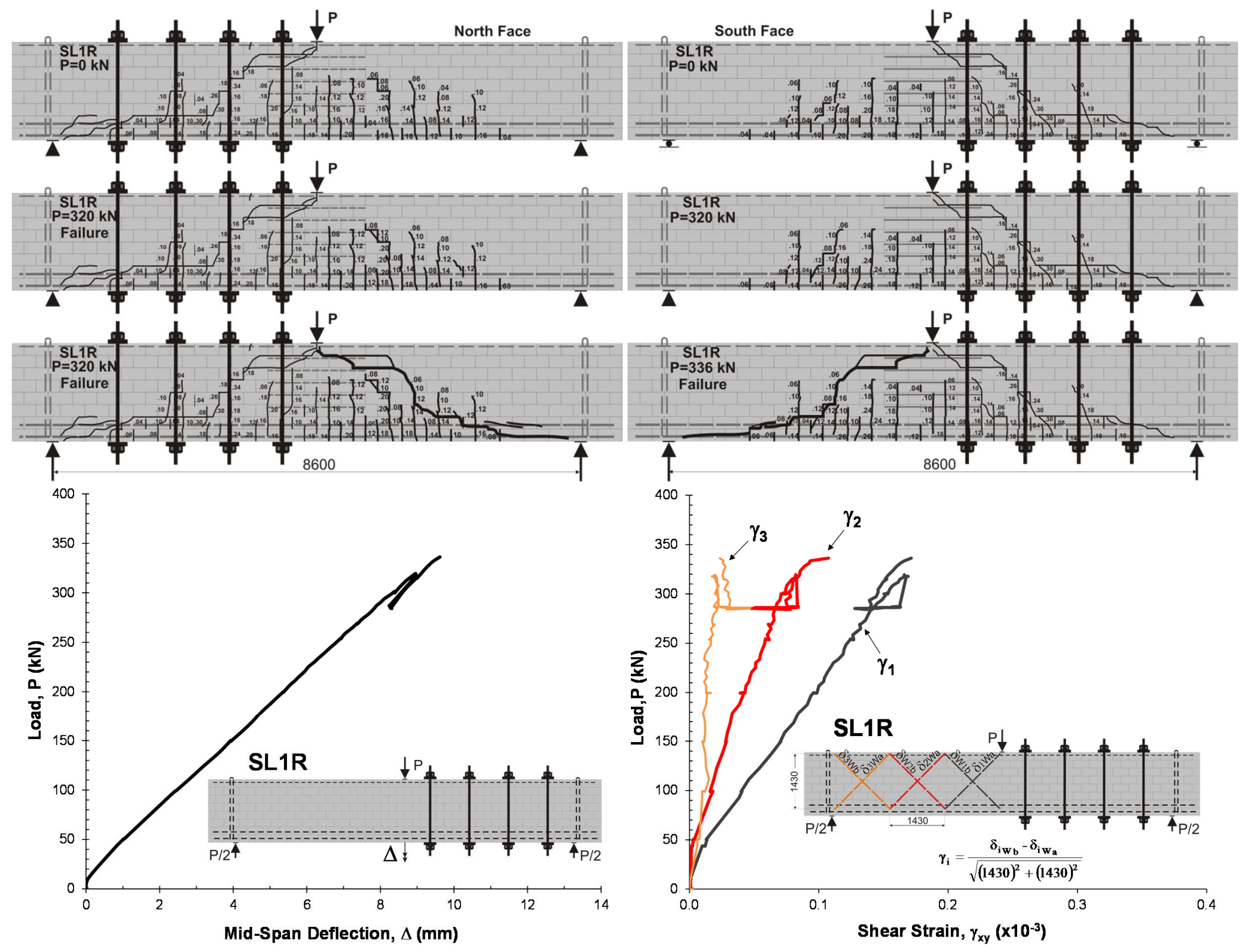


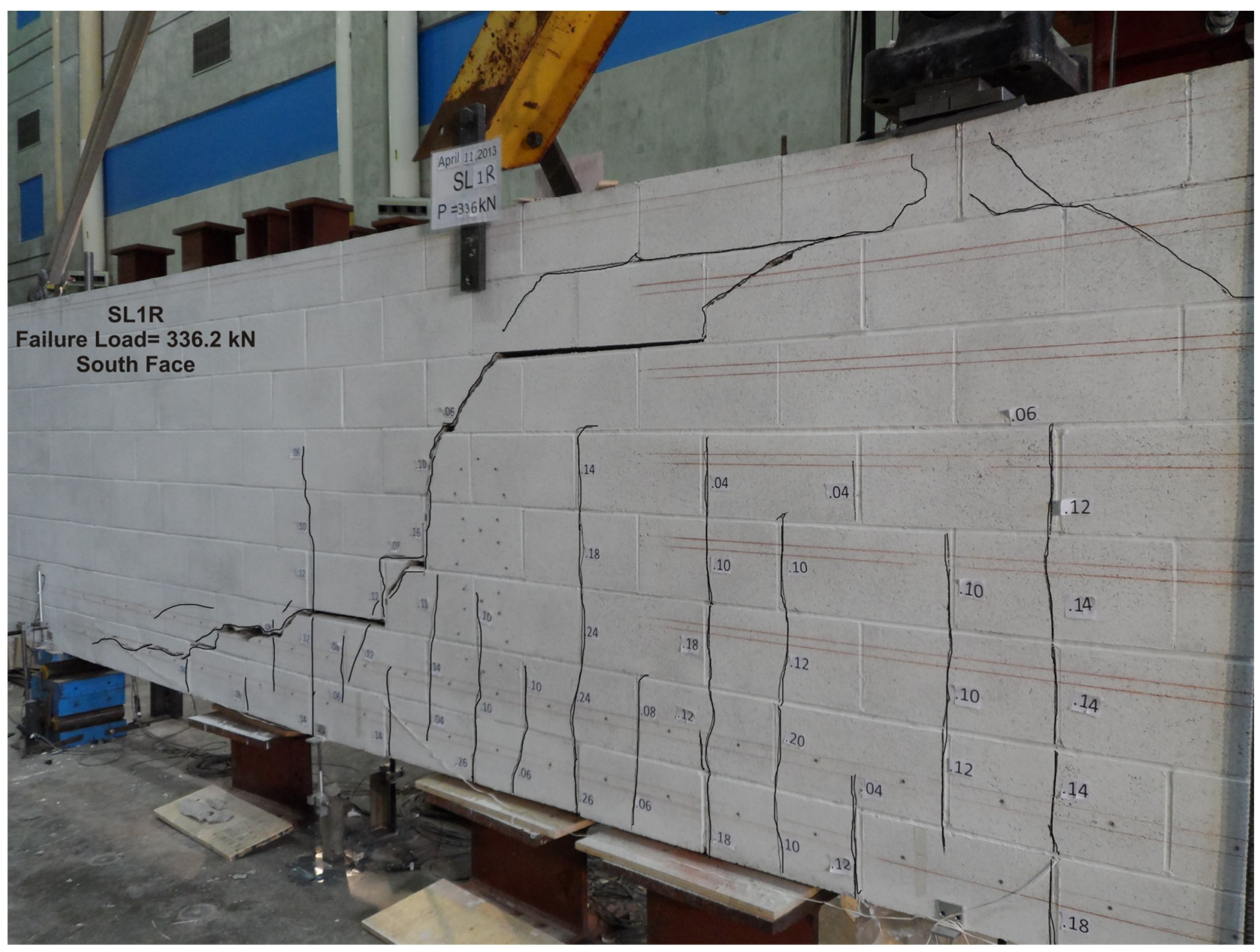




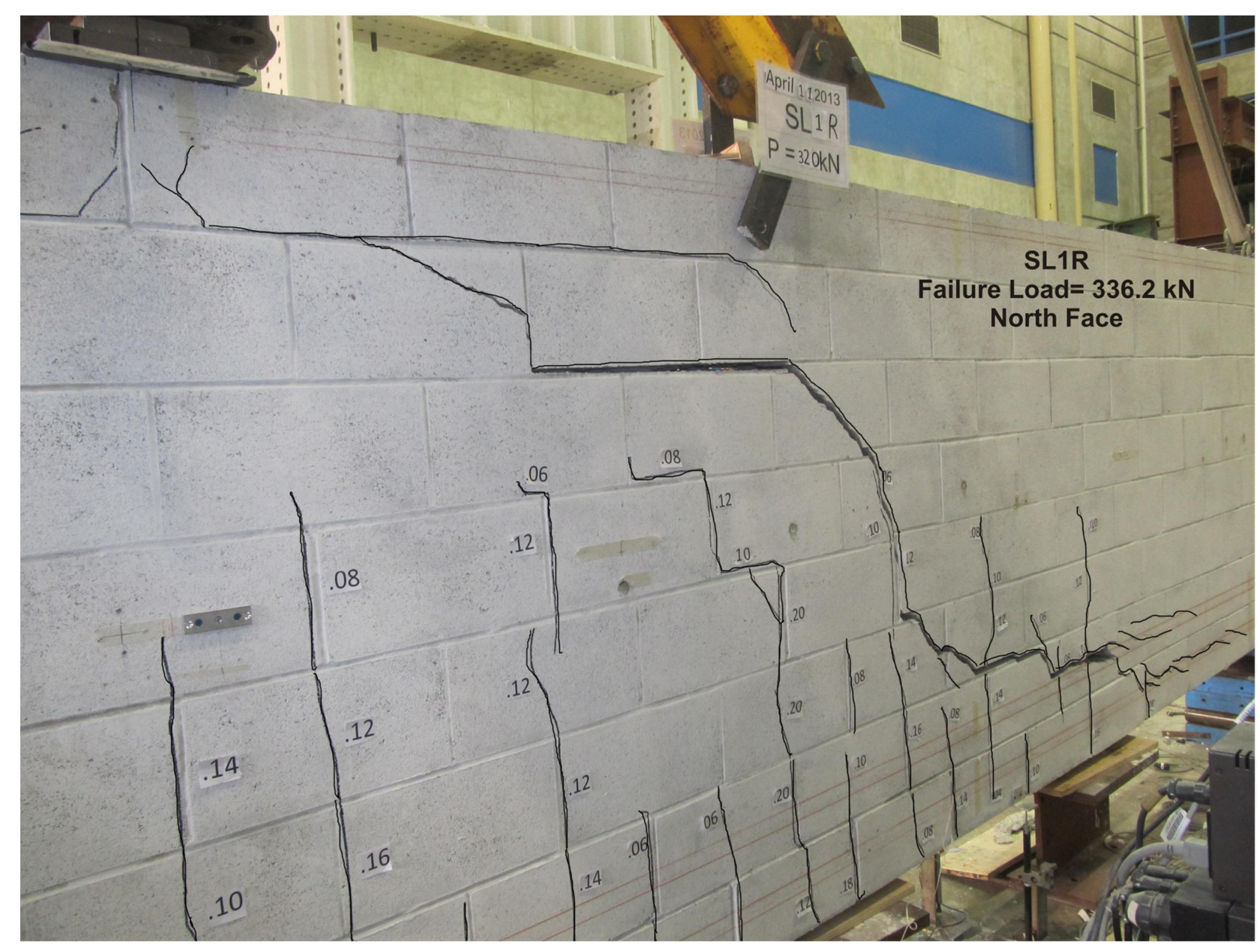




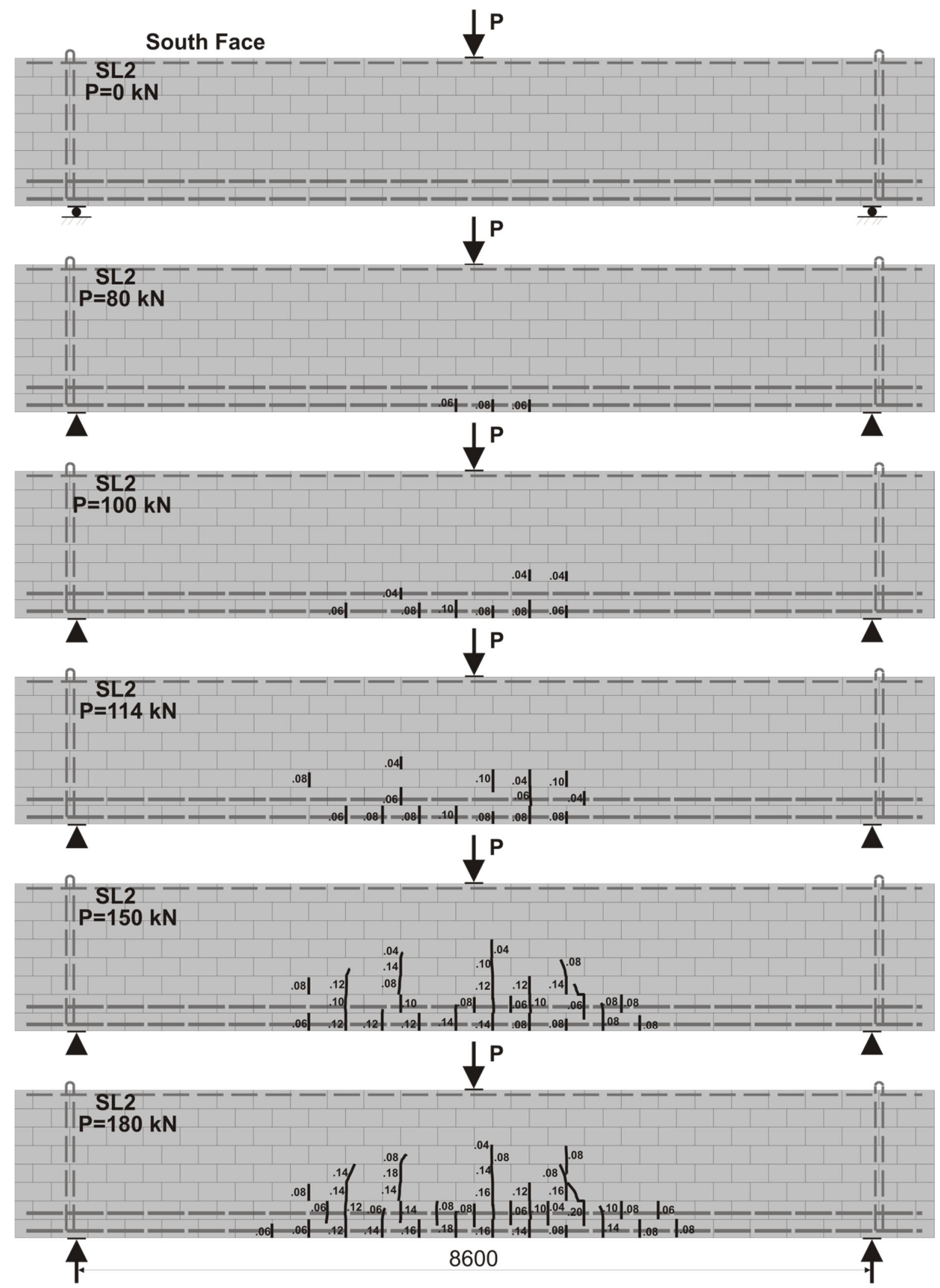




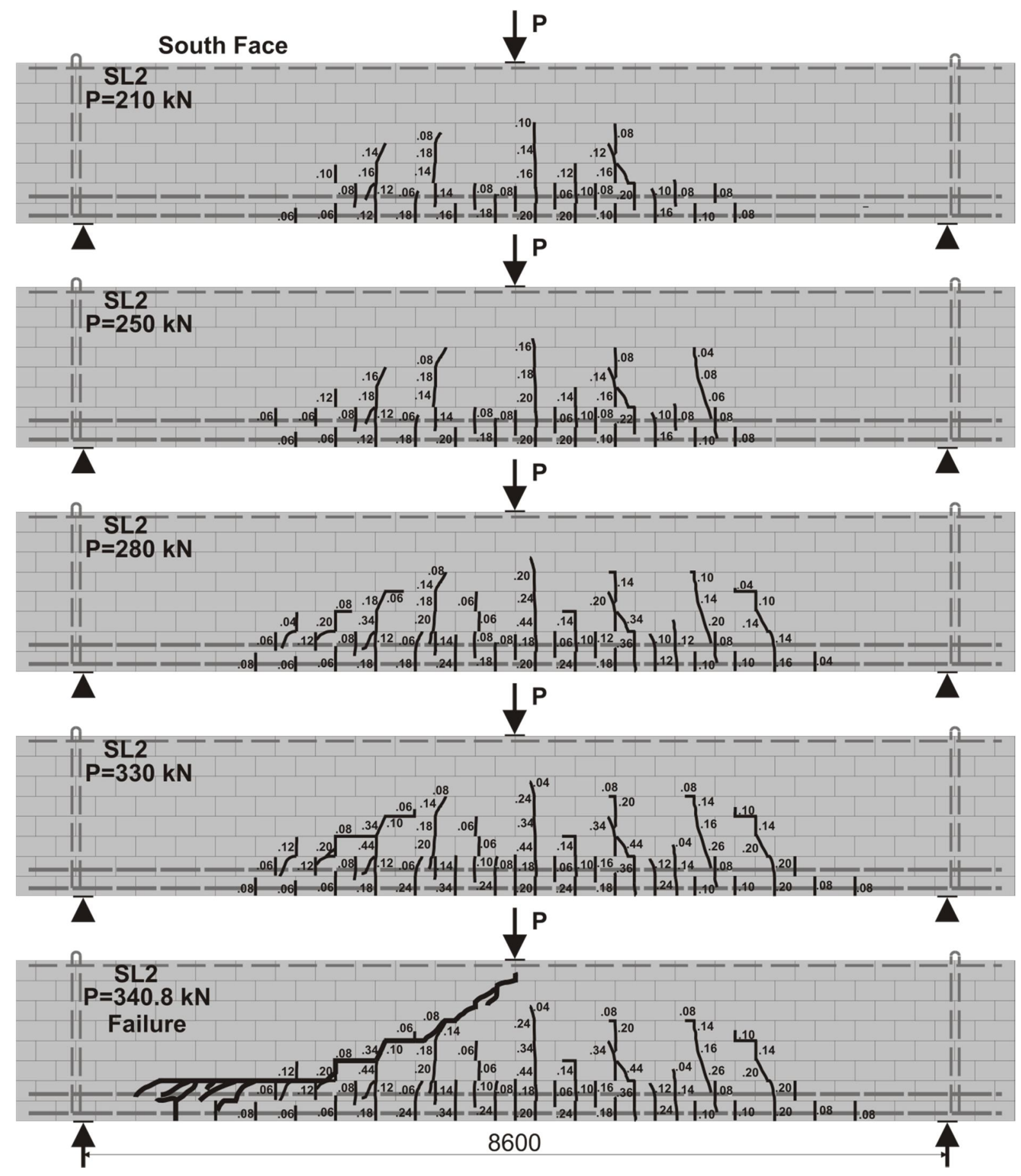




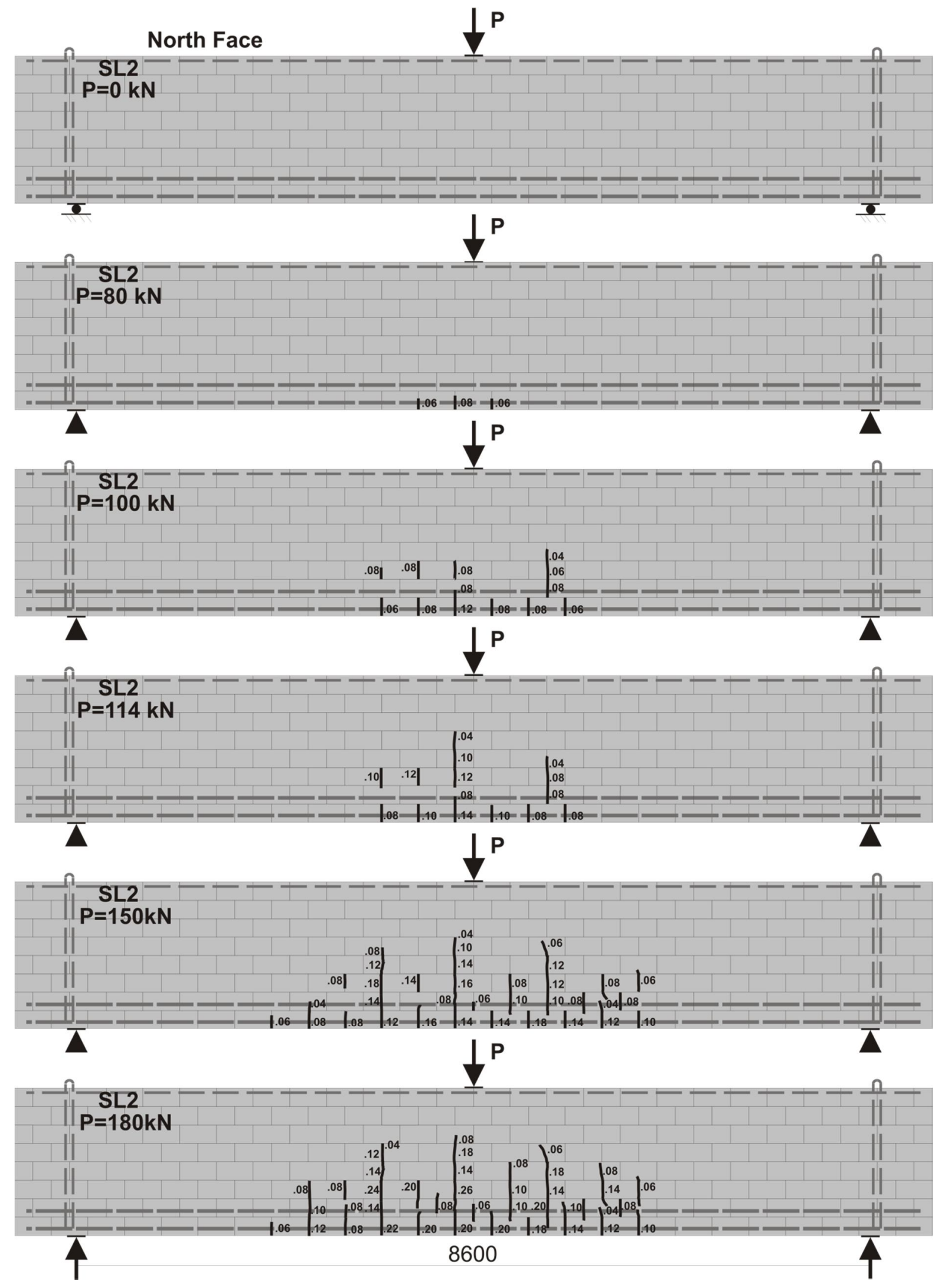




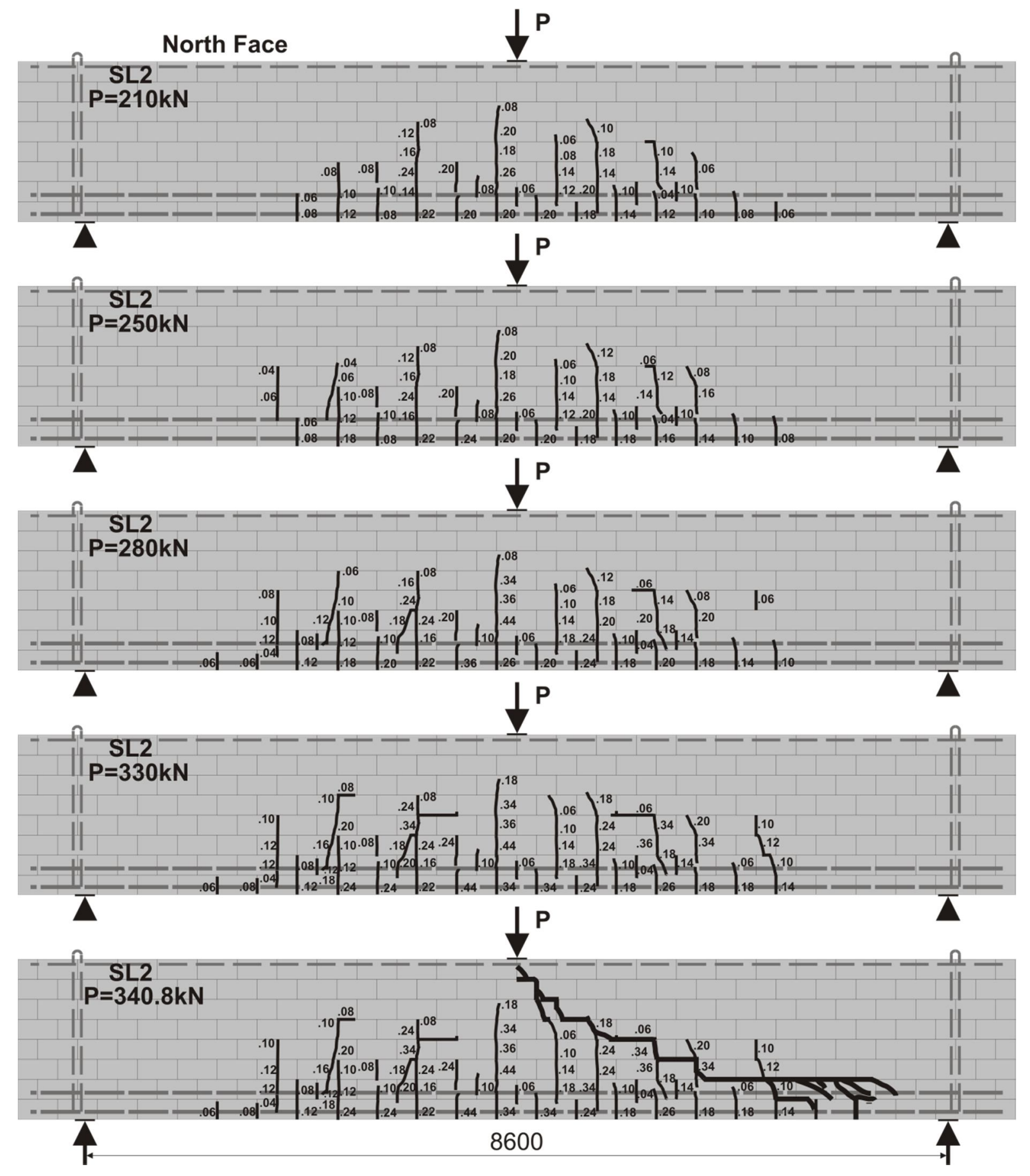



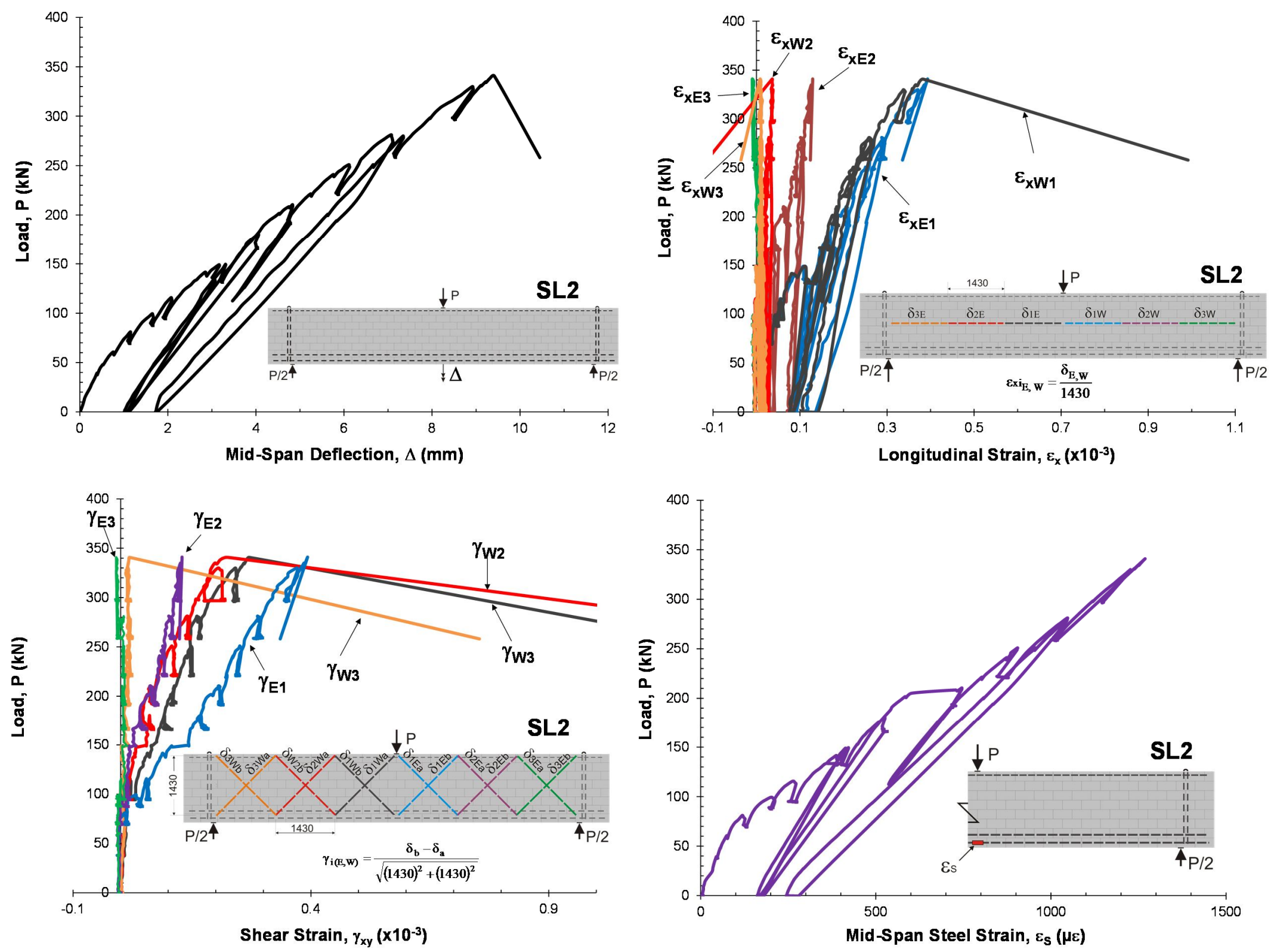


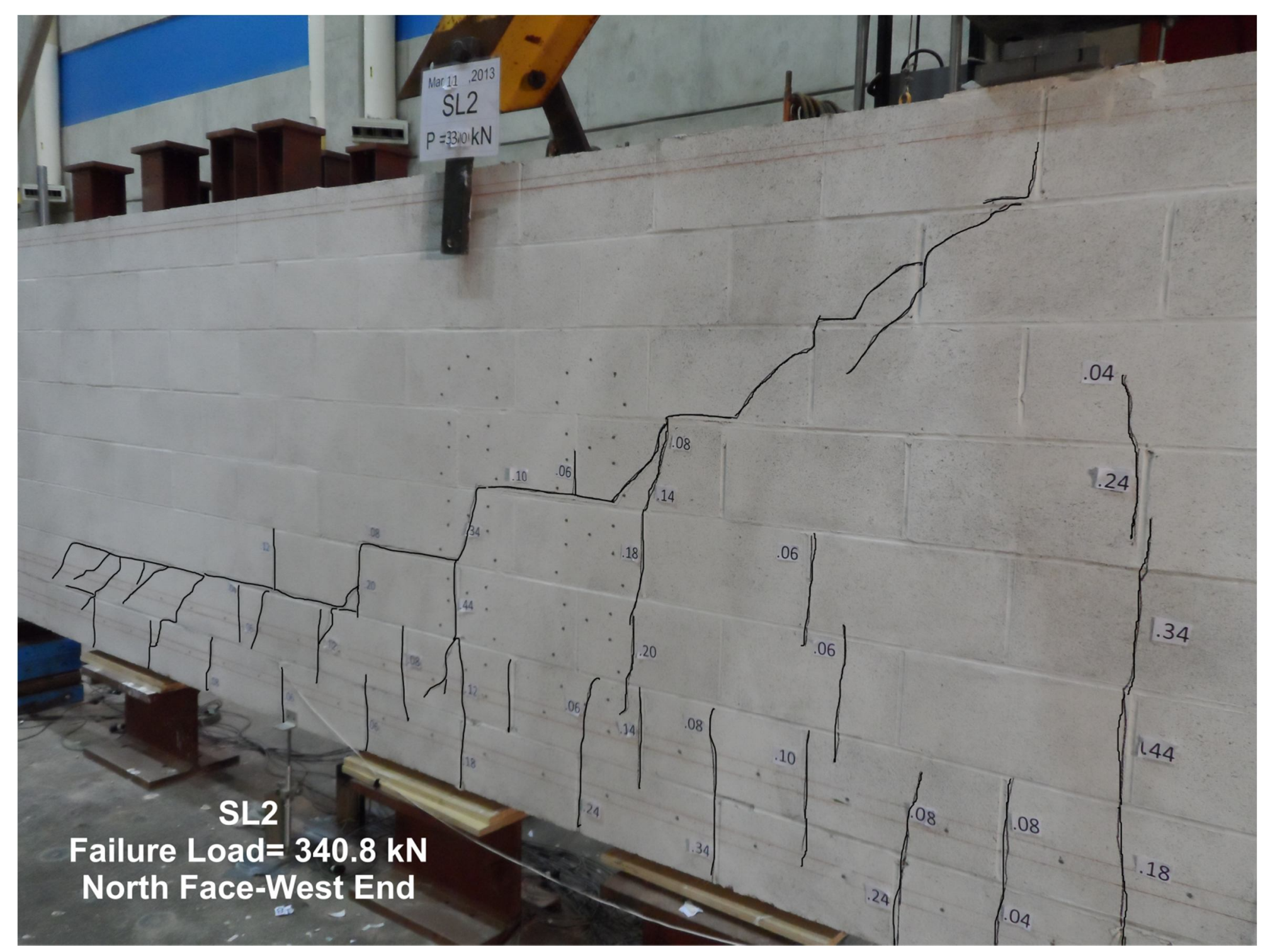




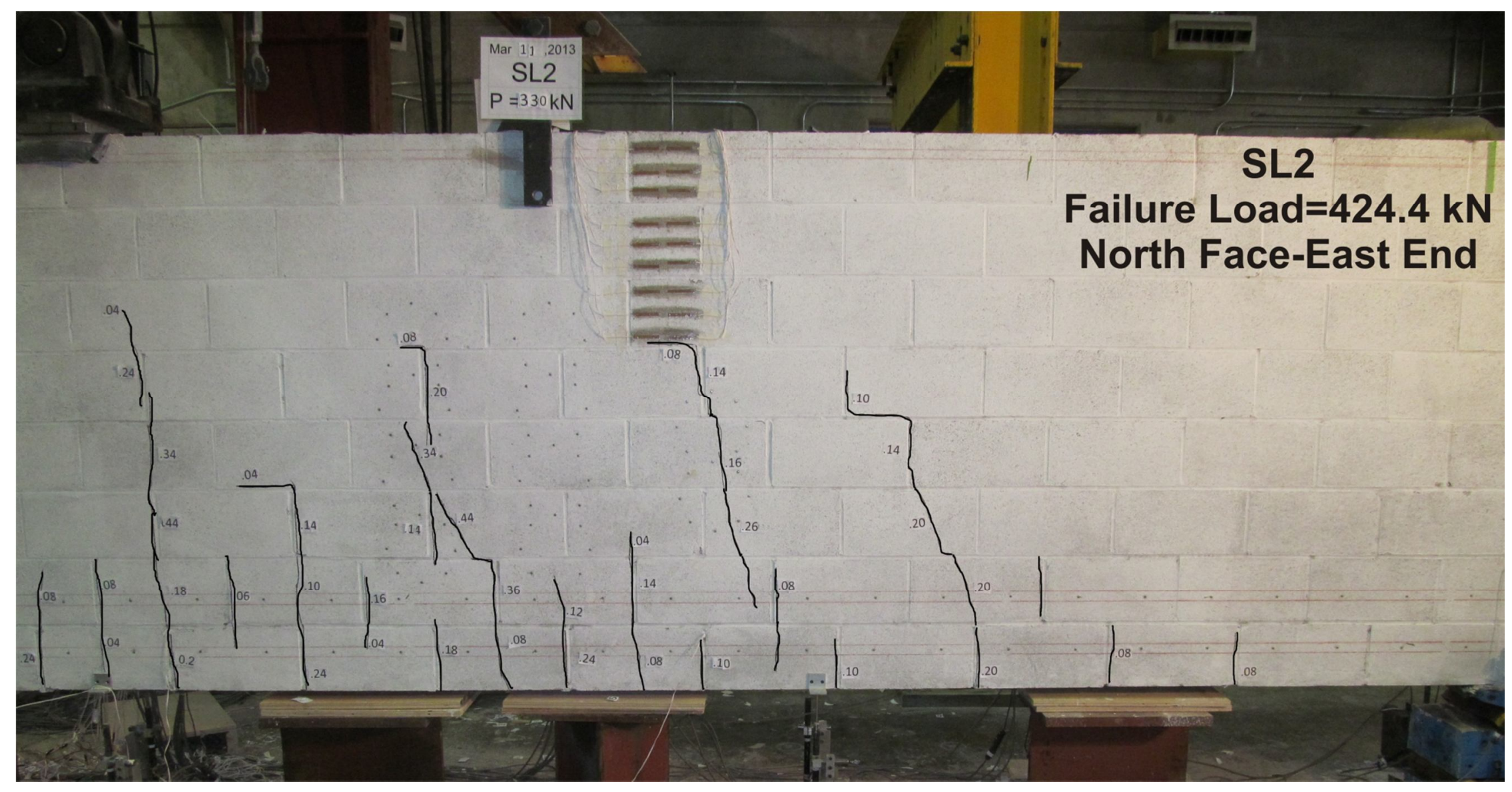



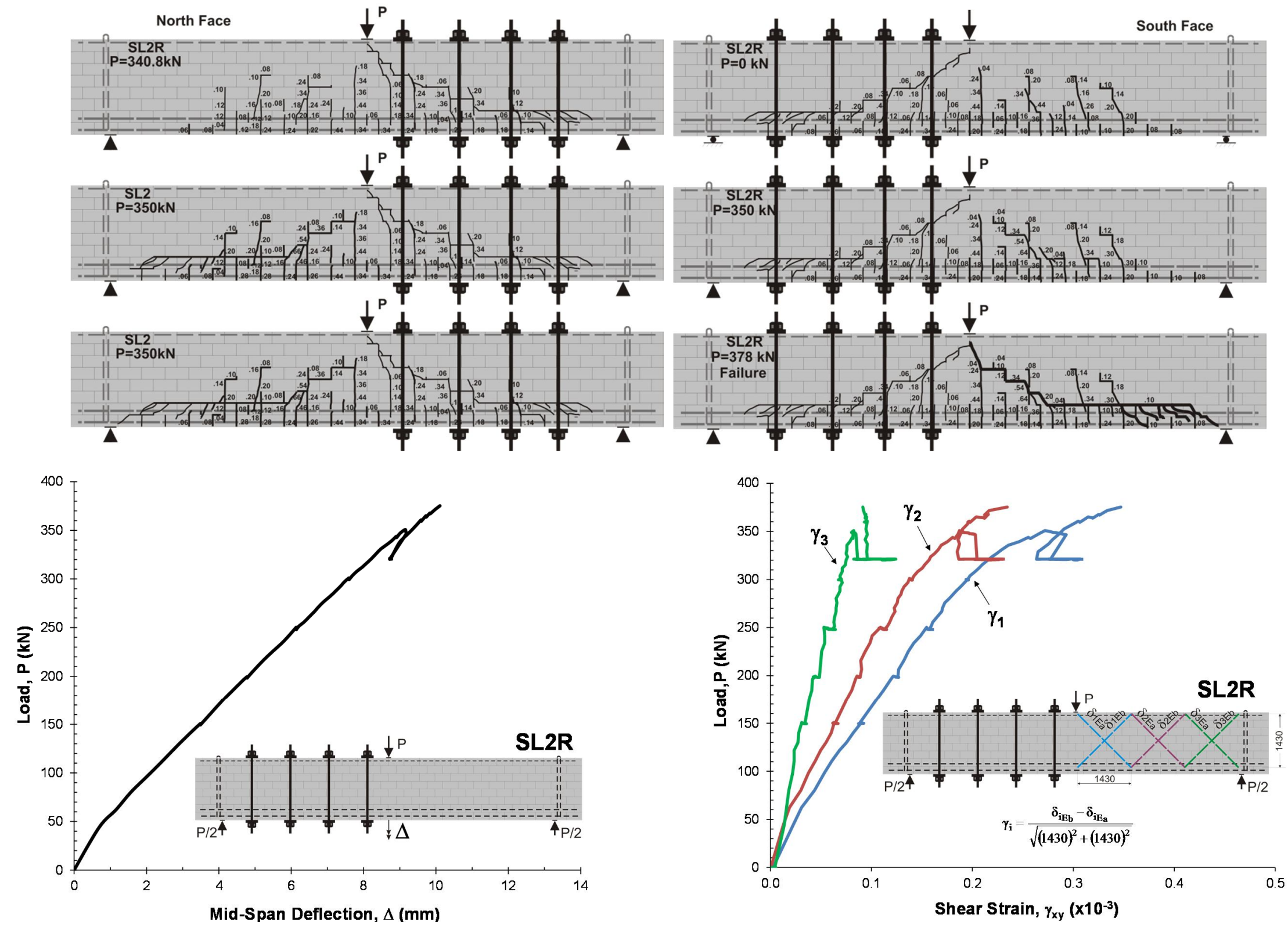


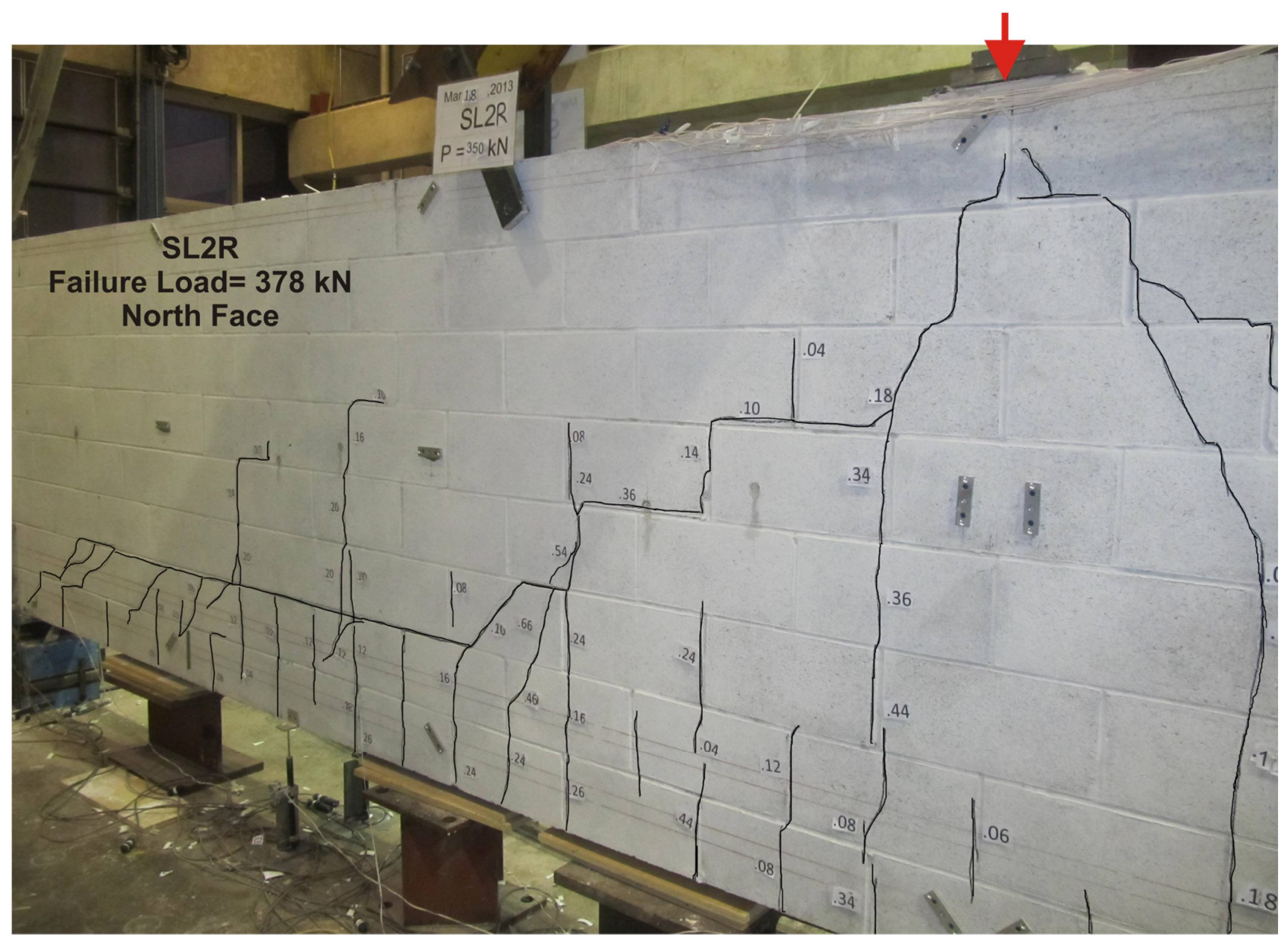




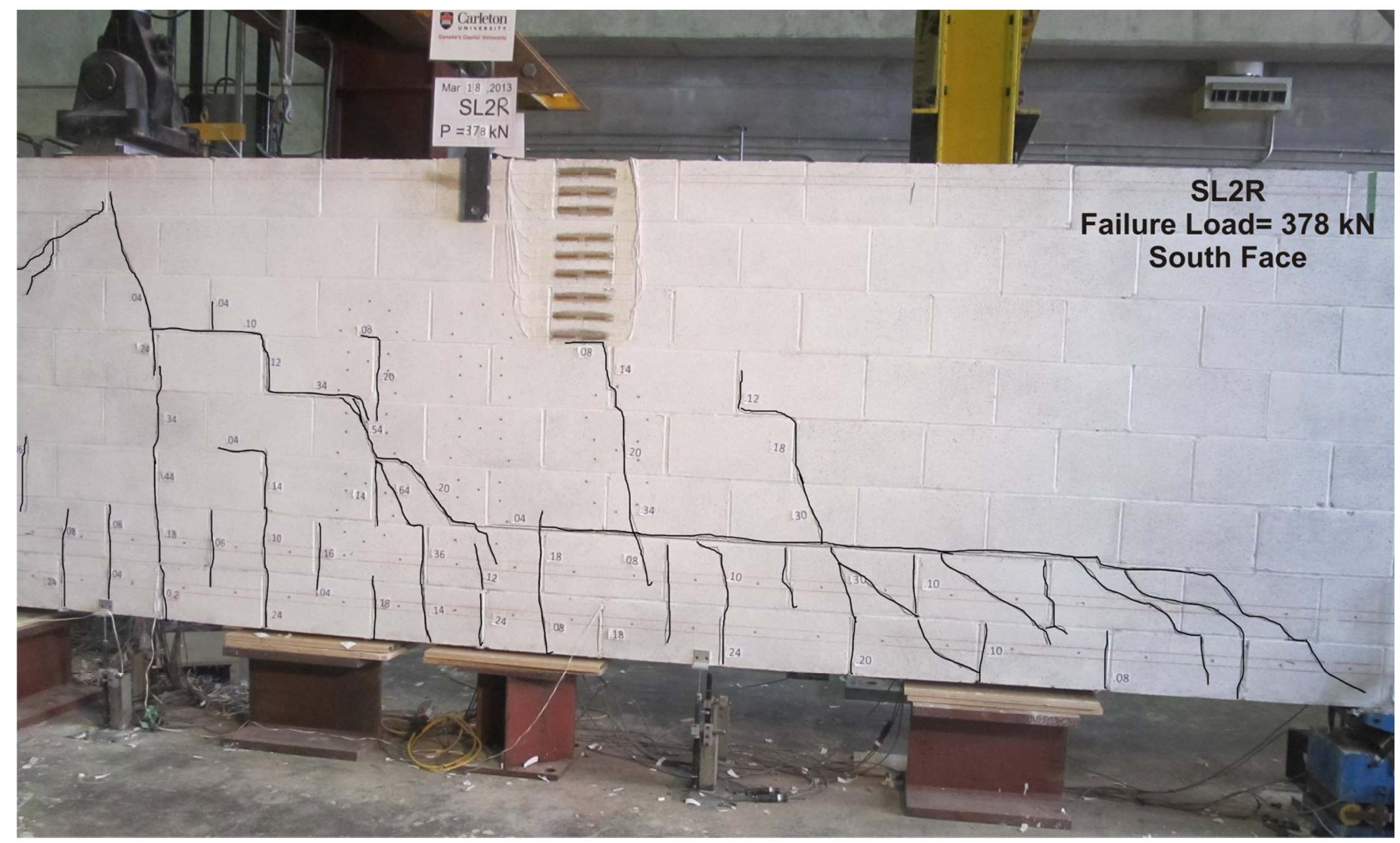




\section{Appendix B}

\section{Sample of Calculations for the Shear Strength Prediction of a Reinforced Masonry Beams}


Shear Strength Calculations of Specimen SM1

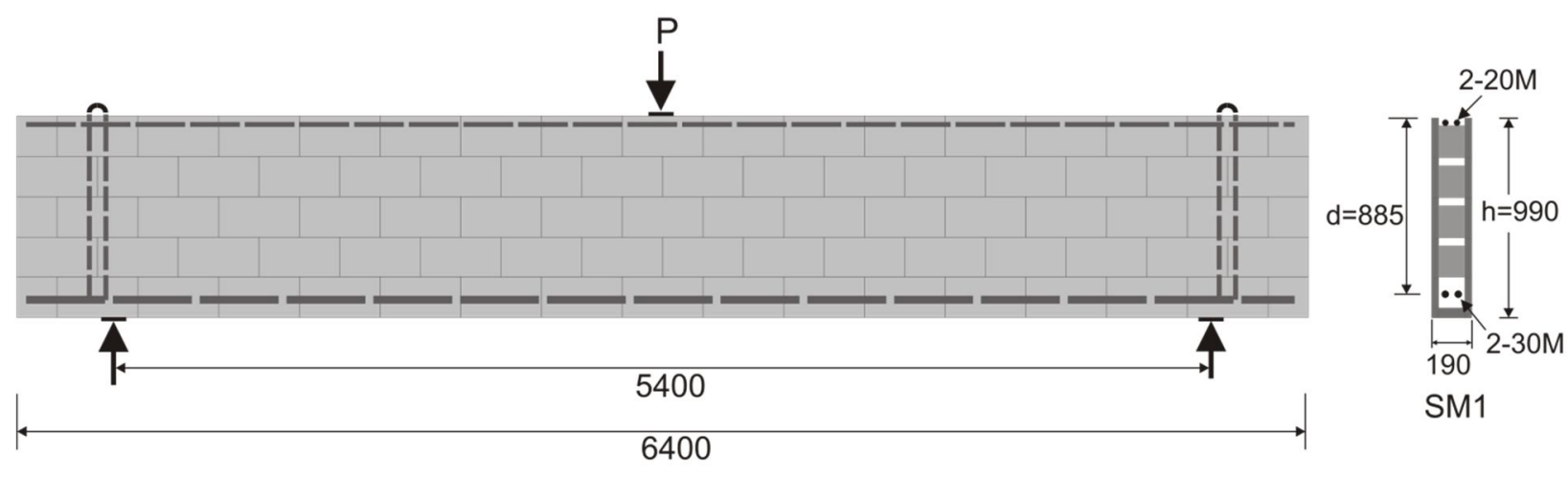

$\mathrm{f}_{\mathrm{m}}=17.9 \mathrm{MPa}$

$\mathrm{a}=2700 \mathrm{~mm}$

$\mathrm{L}=2 \mathrm{a}=5400 \mathrm{~mm}$

$\mathrm{d}=885 \mathrm{~mm}, \quad \mathrm{a} / \mathrm{d}=3.05$

$\mathrm{b}_{\mathrm{w}}=190 \mathrm{~mm}$

As $=1400 \mathrm{~mm}^{2}, \rho=0.83 \%$

$P_{\text {exp }}=189.87 \mathrm{kN}$

$\mathrm{V} \exp =\frac{\mathrm{P} \exp }{2}+\mathrm{V} @ \mathrm{~d}$ frompointload(self weight $)$

Self-weight $=2100 \mathrm{kN} / \mathrm{m}^{3}$ (measured in the lab) $\times 0.99 \times 0.19=3.95 \mathrm{kN} / \mathrm{m}$

Shear force at critical section $=3.95 \times 0.885=3.49 \mathrm{kN}$

$$
\mathrm{V}_{\exp }=\frac{189.87}{2}+3.50=98.4 \mathrm{kN}
$$

\section{TMS 402-2011}

$$
\begin{aligned}
& \mathrm{V}_{\mathrm{m}}=0.187 \sqrt{\mathrm{f}^{\prime} \mathrm{m}} b_{\mathrm{w}} \mathrm{d} \\
& \mathrm{Vm}_{\mathrm{m}}=0.187 \sqrt{17.9}(190)(885) / 1000=133 \mathrm{kN} \\
& \frac{\mathrm{V}_{\text {exp }}}{\mathrm{V}_{\text {pred }}}=\frac{98.4}{133}=0.74
\end{aligned}
$$




\section{AS 3700-2001}

$$
\begin{aligned}
& \mathrm{V}_{\mathrm{m}}=\mathrm{f}_{\mathrm{vm}}^{\prime} b_{\mathrm{w}} \mathrm{d}+\mathrm{f}_{\mathrm{vs}} \mathrm{A}_{\mathrm{s}} \\
& \mathrm{V}_{\mathrm{m}}=(0.35(190)(885)+17.5(1400)) / 1000=83.3 \mathrm{kN} \\
& \frac{\mathrm{V}_{\text {exp }}}{\mathrm{V}_{\text {pred }}}=\frac{98.4}{83.3}=1.08
\end{aligned}
$$

\section{CSA S304.1-2004}

$$
\begin{aligned}
& \mathrm{V}_{\mathrm{m}}=0.16 \sqrt{\mathrm{f}_{\mathrm{m}}}\left(1.0-\frac{\mathrm{d}-400}{2000}\right) \mathrm{b}_{\mathrm{w}} \mathrm{d} \\
& \mathrm{V}_{\mathrm{m}}=0.16 \sqrt{17.9}\left(1.0-\frac{885-400}{2000}\right)(190)(885) / 1000=86.2 \mathrm{kN} \\
& \frac{\mathrm{V}_{\exp }}{\mathrm{V}_{\text {pred }}}=\frac{98.4}{86.2}=1.14
\end{aligned}
$$

\section{$\underline{\text { 4. BS 5628-2:2005 }}$}

$$
\begin{aligned}
& \mathrm{Vm}_{\mathrm{m}}=\left(0.35+17.5 \mathrm{As} / \mathrm{b}_{\mathrm{wd}}\right) \cdot(2.5-0.25 \mathrm{a} / \mathrm{d}) \mathrm{b}_{\mathrm{wd}} \\
& \mathrm{V}_{\mathrm{m}}=(0.35+17.5(0.0083) \cdot(2.5-0.25(3.05)(190)(885) / 100 \theta 14448 \mathrm{kN} \\
& \frac{\mathrm{V}_{\text {exp }}}{\mathrm{V}_{\text {pred }}}=\frac{98.4}{144.48}=0.68
\end{aligned}
$$

\section{CSA A23.3-04 General Method}

Crack spacing parameter $\left(\mathrm{s}_{\mathrm{x}}\right)=0.9 \times 885=796.5 \geq 0.72 \times 990=712.8$

Equivalent crack spacing factor, $\mathrm{sxe}=\frac{35 \mathrm{sx}}{15+\mathrm{ag}} \geq 0.85 \mathrm{sx}$

$$
\mathrm{Sxe}=\frac{35(796.5)}{15+\mathrm{ag}}=1394 \geq 0.85(796.5)=677
$$

Size effect term $=\frac{1300}{(1000+\text { Sxe })}$

Size effect term $=\frac{1300}{(1000+1394)}=0.543$ 
Consider critical section at $\mathrm{d}$ from point load

Moment $($ self- at critical section $)=12.85$ kN.m

- Guess $\quad \varepsilon_{\mathrm{X}}=0.5 \times 10^{-3} \quad$ (first iteration)

a) Strain effect term $=\frac{0.4}{\left(1+1500 \varepsilon_{x}\right)}$

Strain effect term $=\frac{0.4}{\left(1+1500\left(0.5 \times 10^{-3}\right)\right)}=0.229$

$\beta=($ Strain effect term $) \cdot($ Size effect term $)$

b) $\beta=0.229 \times 0.543=0.1241$

$\mathrm{Vm}_{\mathrm{m}}=\beta \sqrt{\mathrm{f}^{\mathrm{m}}} \mathrm{b}_{\mathrm{w}} \mathrm{d}_{\mathrm{v}}$

c) $\mathrm{Vm}_{\mathrm{m}}=0.124 \sqrt{17.9}(190)(0.9 \times 885)=79.47 \mathrm{kN}$

d) $\mathrm{V}$ due to load $=79.47-3.5=75.97 \mathrm{kN}$

Check $\varepsilon_{x}=\frac{M f / d_{v}+V_{f}}{2 E_{s} A_{s}}$

e) $\varepsilon_{x}=\frac{(75.97(\mathrm{a}-\mathrm{d})+12.85) / 0.796+79.47}{2(200000)(1400)}=0.48 \times 10^{-3}$

f) New $\varepsilon_{\mathrm{x}}=((0.5+0.48)) / 2=0.49 \times 10^{-3}$

Repeat steps a to f until getting good convergence

$\varepsilon_{\mathrm{x}}=0.49 \times 10^{-3}$ (2nd iteration), Strain effect term $=0.230, \beta=0.230 \times 0.543=0.1252, \mathrm{~V}_{\mathrm{m}}=80.17$ $\mathrm{kN}, \mathrm{V}$ due to load $=76.67 \mathrm{kN}$, Check $\varepsilon_{\mathrm{x}}=0.484 \times 10^{-3}$

New $\varepsilon_{\mathrm{X}}=((0.49+0.484)) / 2=0.487 \times 10^{-3}, \varepsilon_{\mathrm{X}}=0.487 \times 10^{-3}$ (3rd iteration), Strain effect term $=0.231, \beta=0.2311 \times 0.543=0.1255, \mathrm{~V}_{\mathrm{m}}=80.37 \mathrm{kN}, \mathrm{V}$ due to load $=76.88 \mathrm{kN}$, Check $\varepsilon_{\mathrm{x}}$ $=0.485 \times 10^{-3}$ 
New $\varepsilon_{\mathrm{x}}=((0.487+0.485)) / 2=0.486 \times 10^{-3}, \varepsilon_{\mathrm{x}}=0.486 \times 10^{-3}$ (4th iteration), Strain effect term $=0.2313, \beta=0.231 \times 0.543=0.1256, \mathrm{~V}_{\mathrm{m}}=80.44 \mathrm{kN}, \mathrm{V}$ due to load $=76.96 \mathrm{kN}$, Check $\varepsilon_{\mathrm{x}}$ $=0.486 \times 10^{-3}$ Good convergence, $\quad$ Vpredicted $=76.96+3.5=80.46 \mathrm{kN}$

$$
\frac{\mathrm{V} \exp }{\mathrm{V} \text { pred }}=\frac{98.4}{80.46}=1.22
$$

\section{Li et al.}

$$
\begin{aligned}
& \mathrm{V}_{\mathrm{m}}=\left[1.996-0.994 \ln \left(\frac{\mathrm{a}}{\mathrm{d}}\right)\right]\left[0.173+0.056 \ln \left(\frac{\mathrm{As}_{\mathrm{s}}}{\mathrm{f}_{\mathrm{m}}^{\prime} \mathrm{b}_{\mathrm{w}} \mathrm{d}}\right)\right] \mathrm{f}_{\mathrm{m}}^{\prime} \mathrm{b}_{\mathrm{w}} \mathrm{d} \\
& \mathrm{V}_{\mathrm{m}}=[1.996-0.994 \ln (3.05)]\left[0.173+0.056 \ln \left(\frac{1400 \mathrm{x} 400}{17.9 \mathrm{x} 190 \mathrm{x} 885}\right)\right] \times 17.9(190)(885) / 1000=257.0 \mathrm{kN} \\
& \frac{\mathrm{V}_{\text {exp }}}{\mathrm{V}_{\text {pred }}}=\frac{98.4}{257}=0.38
\end{aligned}
$$

\section{Fereige}

$$
\begin{aligned}
& \mathrm{V}_{\mathrm{m}}=\frac{1}{12}\left[3.6-0.12\left(\frac{\mathrm{a}}{\mathrm{d}}\right)\right] \sqrt{\mathrm{f}^{\prime} \mathrm{m}} \mathrm{b}_{\mathrm{w}} \mathrm{d} \\
& \mathrm{V}_{\mathrm{m}}=\frac{1}{12}[3.6-0.12(3.05)] \sqrt{17.9}(190)(885) / 1000=191.72 \mathrm{kN} \\
& \frac{\mathrm{V} \text { exp }}{\mathrm{V}_{\text {pred }}}=\frac{98.4}{191.7}=0.51
\end{aligned}
$$

\section{Dhanasekar and Wong}

$$
\begin{aligned}
& \mathrm{Vm}=\left(1.2\left[\frac{\mathrm{a}}{\mathrm{d}}\right]-0.8\left[\sqrt{\frac{\mathrm{Le}}{\mathrm{d}}} \times \sqrt{\frac{\mathrm{ag}}{\mathrm{h}}} \times \sqrt[4]{\mathrm{f}_{\mathrm{y}} \times \rho \times \mathrm{f}_{\mathrm{m}}^{\prime}}\right]\right)^{2} \\
& \mathrm{Vm}=\left(1.2(3.05)-0.8\left[\sqrt{\frac{5400}{885}} \times \sqrt{\frac{5}{990}} \times \sqrt[4]{400 \times 0.83 \times 17.9}\right]\right)^{2}=96.6 \mathrm{kN} \\
& \frac{\mathrm{V}_{\text {exp }}}{\mathrm{V}_{\text {pred }}}=\frac{98.4}{96.6}=1.02
\end{aligned}
$$




\section{Appendix C}

\section{Database of the Compressive Tests for Ungrouted Hollow Block Masonry Prisms}




\begin{tabular}{|c|c|c|c|c|c|c|c|c|c|c|c|c|c|c|c|c|c|c|c|c|c|}
\hline \multirow{3}{*}{ No. } & \multirow{3}{*}{ Author. } & \multicolumn{6}{|c|}{ Unit } & \multicolumn{4}{|c|}{ Mortar } & \multicolumn{10}{|c|}{ Prism } \\
\hline & & \multicolumn{3}{|c|}{ Dimensions } & \multirow[b]{2}{*}{$\frac{5}{<}$} & \multirow{2}{*}{ 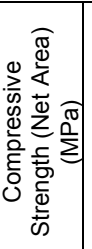 } & \multirow[b]{2}{*}{$\stackrel{\circ}{\circ}$} & \multirow[b]{2}{*}{$\stackrel{\Perp}{\stackrel{0}{\gtrless}}$} & \multirow{2}{*}{$\begin{array}{l}0 \\
\frac{0}{0} \\
0 \\
0 \\
\frac{0}{0} \\
\frac{0}{0} \\
\frac{.}{\lambda} \\
0\end{array}$} & \multirow{2}{*}{ 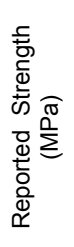 } & \multirow[b]{2}{*}{$\begin{array}{l}\circ \\
\text { oे } \\
0\end{array}$} & \multirow{2}{*}{ 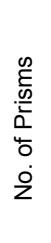 } & \multicolumn{3}{|c|}{ Dimensions } & \multirow{2}{*}{ 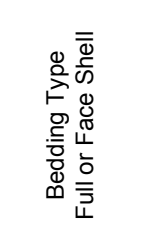 } & \multirow{2}{*}{ 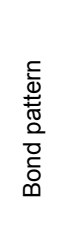 } & \multirow{2}{*}{$\begin{array}{l}0 \\
0 \\
0 \\
\stackrel{0}{7} \\
0 \\
\dot{0} \\
\dot{0} \\
\dot{0}\end{array}$} & \multirow[b]{2}{*}{$\stackrel{t}{\Sigma}$} & \multirow{2}{*}{ 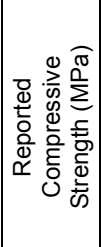 } & \multirow[b]{2}{*}{$\begin{array}{l}\circ \\
\text { ठे } \\
0\end{array}$} \\
\hline & & L & $\mathrm{T}$ & $\mathrm{H}$ & & & & & & & & & L & $\mathrm{T}$ & $\mathrm{H}$ & & & & & & \\
\hline 1 & \multirow{18}{*}{ Copeland \& Timms } & \multirow{18}{*}{400} & \multirow{18}{*}{203} & \multirow{18}{*}{197} & \multirow{18}{*}{0.63} & 20.8 & & 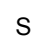 & & 21.7 & & 2 & & & & & & & & 15.32 & \\
\hline 2 & & & & & & 20.8 & & $s$ & & 11.1 & & 2 & & & & & & & & 15.32 & \\
\hline 3 & & & & & & 20.8 & & $\mathrm{~N}$ & & 7.3 & & 2 & & & & & & & & 13.68 & \\
\hline 4 & & & & & & 20.8 & & $N$ & & 3.1 & & 2 & & & & & & & & 13.68 & \\
\hline 5 & & & & & & 17.3 & & $\mathrm{~N}$ & & 7.3 & & 2 & & & & & & & & 9.14 & \\
\hline 6 & & & & & & 17.3 & & $\mathrm{~N}$ & & 3.1 & & 2 & & & & & & & & 9.14 & \\
\hline 7 & & & & & & 17.3 & & $s$ & & 11.1 & & 2 & & & & & & & & 9.41 & \\
\hline 8 & & & & & & 17.3 & & $s$ & & 21.7 & & 2 & & & & & & & & 11.71 & \\
\hline 9 & & & & & & 9.7 & - & $\mathrm{s}$ & $\frac{\mathscr{\infty}}{\frac{\omega}{0}}$ & 11.1 & - & 2 & 000 & 101 & $120<$ & 产 & . & 0 & 0.1 & 6.78 & - \\
\hline 10 & & & & & & 9.7 & & $\mathrm{~N}$ & 产 & 7.3 & & 2 & & & & $\stackrel{\infty}{\bar{J}}$ & $\stackrel{\complement}{\widetilde{\Upsilon}}$ & & & 7.11 & \\
\hline 11 & & & & & & 9.7 & & $\mathrm{~N}$ & & 3.1 & & 2 & & & & & & & & 6.67 & \\
\hline 12 & & & & & & 9.7 & & $S$ & & 21.7 & & 2 & & & & & & & & 7.88 & \\
\hline 13 & & & & & & 12.8 & & $s$ & & 21.7 & & 2 & & & & & & & & 10.18 & \\
\hline 14 & & & & & & 12.8 & & $s$ & & 11.1 & & 2 & & & & & & & & 10.61 & \\
\hline 15 & & & & & & 12.8 & & $\mathrm{~N}$ & & 7.3 & & 2 & & & & & & & & 9.41 & \\
\hline 16 & & & & & & 12.8 & & $\mathrm{~N}$ & & 3.1 & & 2 & & & & & & & & 8.00 & \\
\hline 17 & & & & & & 25.7 & & $S$ & & 11.1 & & 2 & & & & & & & & 17.49 & \\
\hline 18 & & & & & & 45.8 & & $s$ & & 11.1 & & 2 & 400 & (10) & $120<$ & & & 0 & 0.1 & 26.53 & \\
\hline 19 & & & & & & 11.7 & & $N$ & & 5.7 & & 2 & & & & Full Bedding & & & & 16.0 & \\
\hline 20 & & & & & & 11.7 & & $\mathrm{~N}$ & $\frac{\mathscr{2}}{\omega}$ & 5.8 & & 2 & & & & Full Bedding & $\stackrel{\mathscr{D}}{\leftrightarrows}$ & & & 15.9 & \\
\hline 21 & Ricnart et al. & 400 & 203 & 203 & 0.63 & 10.6 & - & $\mathrm{N}$ & $\frac{\sqrt{\frac{5}{3}}}{\mathrm{~d}}$ & 8.5 & - & 2 & 812 & 203 & 1268 & FS & $\stackrel{\vec{z}}{\vec{x}}$ & 0 & 0.2 & 15.4 & - \\
\hline 22 & & & & & & 17.2 & & $s$ & & 13.3 & & 2 & & & & Full Bedding & & & & 16.4 & \\
\hline
\end{tabular}




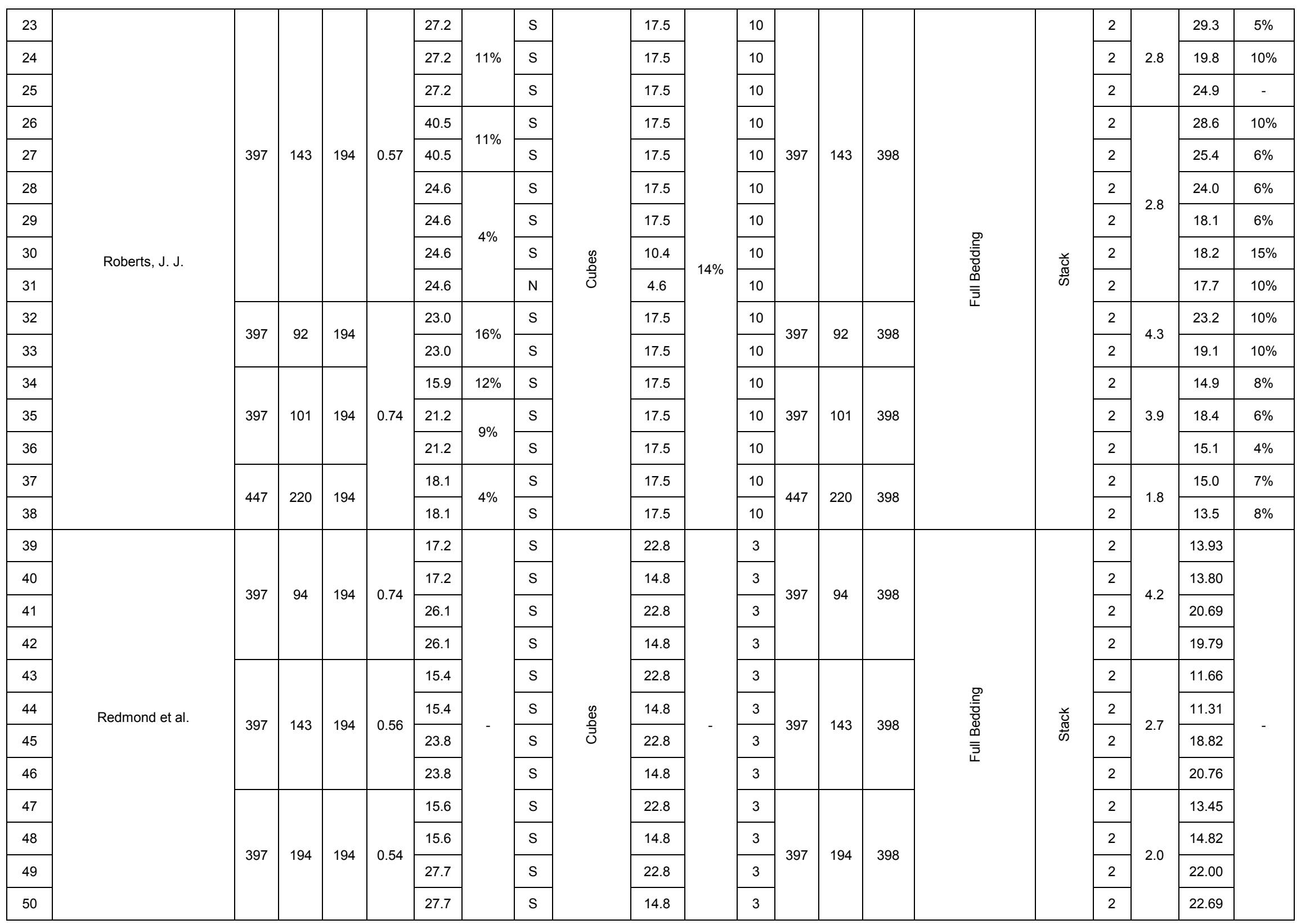




\begin{tabular}{|c|c|c|c|c|c|c|c|c|c|c|c|c|c|c|c|c|c|c|c|c|c|}
\hline 51 & \multirow{13}{*}{ Drysdale \&Hamid (1979) } & \multirow{13}{*}{390} & \multirow{13}{*}{140} & \multirow{13}{*}{190} & \multirow{6}{*}{0.59} & 19.7 & $0 \%$ & $S$ & \multirow{13}{*}{ 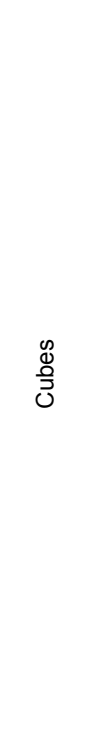 } & 15.1 & & 3 & \multirow{13}{*}{195} & \multirow{13}{*}{140} & \multirow{13}{*}{589} & \multirow{13}{*}{ 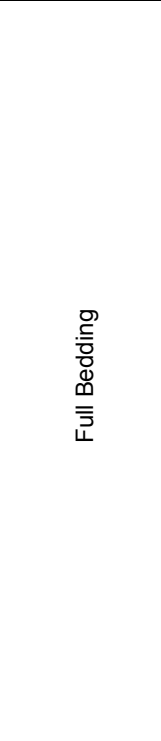 } & Stack & 3 & 4.2 & 15.8 & $4.2 \%$ \\
\hline 52 & & & & & & 19.7 & $4 \%$ & $s$ & & 16.7 & & 3 & & & & & Runn. & 3 & 4.2 & 16.0 & $7.5 \%$ \\
\hline 53 & & & & & & 19.7 & $4 \%$ & $s$ & & 17.2 & & 3 & & & & & \multirow{11}{*}{$\begin{array}{l}\frac{.}{\tilde{J}} \\
\stackrel{\Phi}{\omega}\end{array}$} & 3 & 4.2 & 15.93 & $3.3 \%$ \\
\hline 54 & & & & & & 19.7 & $4 \%$ & $\mathrm{~N}$ & & 5.7 & & 3 & & & & & & 3 & 4.2 & 15.38 & $5.5 \%$ \\
\hline 55 & & & & & & 19.7 & $4 \%$ & $\mathrm{~s}$ & & 14.7 & & 3 & & & & & & 3 & 4.2 & 16.4 & $3.6 \%$ \\
\hline 56 & & & & & & 19.7 & $4 \%$ & $s$ & & 18.2 & & 3 & & & & & & 3 & 4.2 & 16.28 & $3.3 \%$ \\
\hline 57 & & & & & \multirow{2}{*}{0.58} & 32.2 & $7 \%$ & $s$ & & 14.2 & - & 3 & & & & & & 3 & 4.2 & 27.58 & $4.9 \%$ \\
\hline 58 & & & & & & 32.2 & $7 \%$ & $s$ & & 14.2 & & 3 & & & & & & 3 & 4.2 & 23.24 & $1.1 \%$ \\
\hline 59 & & & & & 0.70 & 22.0 & $4 \%$ & $S$ & & 14.2 & & 3 & & & & & & 3 & 4.2 & 18.0 & $1.7 \%$ \\
\hline 60 & & & & & 0.69 & 21.3 & $6 \%$ & $S$ & & 14.2 & & 3 & & & & & & 3 & 4.2 & 19.38 & $1.5 \%$ \\
\hline 61 & & & & & 0.64 & 20.2 & $5 \%$ & $s$ & & 14.2 & & 3 & & & & & & 3 & 4.2 & 17.86 & $5.1 \%$ \\
\hline 62 & & & & & 0.74 & 20.0 & $6 \%$ & $s$ & & 14.2 & & 3 & & & & & & 3 & 4.2 & 16.14 & $6.9 \%$ \\
\hline 63 & & & & & 0.61 & 15.6 & $8 \%$ & $S$ & & 14.2 & & 3 & & & & & & 3 & 4.2 & 12.76 & $8.4 \%$ \\
\hline 64 & \multirow{8}{*}{$\begin{array}{c}\text { Maurenbrecher, A.H.P. } \\
\text { (1980) }\end{array}$} & \multirow{4}{*}{397} & \multirow{4}{*}{194} & \multirow{4}{*}{194} & \multirow{4}{*}{0.55} & 22.0 & \multirow{4}{*}{$8 \%$} & $N$ & \multirow{8}{*}{$\begin{array}{l}\mathscr{0} \\
\mathbb{0} \\
\stackrel{\Xi}{3}\end{array}$} & \multirow{8}{*}{6.6} & \multirow{8}{*}{ - } & 12 & \multirow{4}{*}{397} & \multirow{4}{*}{194} & 398 & \multirow{5}{*}{ 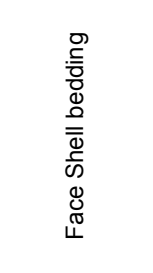 } & & 2 & 2.0 & 14.90 & $3.6 \%$ \\
\hline 65 & & & & & & 22.0 & & $N$ & & & & 12 & & & 602 & & & 3 & 3.1 & 14.50 & $5.4 \%$ \\
\hline 66 & & & & & & 22.0 & & $\mathrm{~N}$ & & & & 10 & & & 1010 & & & 5 & 5.2 & 14.30 & $3.9 \%$ \\
\hline 67 & & & & & & 22.0 & & $\mathrm{~N}$ & & & & 14 & & & 398 & & 응 & 2 & 2.0 & 13.90 & $14 \%$ \\
\hline 68 & & & & & & 21.4 & & $\mathrm{~N}$ & & & & 10 & & & 386 & & $\ddot{\omega}$ & 2 & 2.8 & 14.70 & $4.8 \%$ \\
\hline 69 & & 397 & 140 & 188 & 0.57 & 21.4 & $4 \%$ & $\mathrm{~N}$ & & & & 10 & 397 & 140 & 584 & Full Bedding & & 3 & 4.2 & 14.30 & $3 \%$ \\
\hline 70 & & & & & & 21.4 & & $\mathrm{~N}$ & & & & 10 & & & 782 & Face Shell & & 4 & 5.6 & 13.90 & $4.3 \%$ \\
\hline 71 & & 397 & 194 & 194 & 0.55 & 22.0 & $8 \%$ & $N$ & & & & 10 & 397 & 194 & 398 & Full Bedding & & 2 & 2.0 & 12.60 & $10 \%$ \\
\hline 72 & & & & & & 25.1 & & $s$ & & 17 & & 5 & & & & & & 3 & 3.1 & 24.90 & $3.3 \%$ \\
\hline 73 & & 390 & 190 & 190 & & 17.1 & & $S$ & & 17 & & 4 & 195 & 190 & 590 & 임 & & 3 & 3.1 & 18.00 & $11 \%$ \\
\hline 74 & Drysdale \&Hamid (1983) & & & & & 20.2 & & $S$ & $\mathscr{\infty}$ & 17 & & 3 & & & & $\stackrel{0}{0}$ & 兑 & 3 & 3.1 & 20.80 & $16 \%$ \\
\hline 75 & & 390 & 140 & 190 & 0.00 & 23.6 & & $S$ & $\bar{J}$ & 17 & & 4 & 195 & 140 & 590 & $\frac{\Phi}{\omega}$ & $\ddot{\omega}$ & 3 & 4.2 & 23.80 & $2.3 \%$ \\
\hline 76 & & 390 & 190 & 190 & & 27.9 & & $s$ & & 17 & & 3 & 195 & 190 & 590 & $\begin{array}{l}\tilde{\mathscr{\sigma}} \\
\stackrel{\leftarrow}{\leftarrow}\end{array}$ & & 3 & 3.1 & 29.9 & $7.4 \%$ \\
\hline 77 & & 390 & 240 & 190 & & 23.4 & & $S$ & & 17 & & 3 & 195 & 240 & 590 & & & 3 & 2.45 & 21.60 & $4.5 \%$ \\
\hline 78 & $\begin{array}{c}\text { Maurenbrecher, A.H.P. } \\
\text { (1985) }\end{array}$ & 390 & 140 & 190 & 0.57 & 20.5 & $11 \%$ & $\mathrm{~N}$ & Cubes & 6.6 & - & 20 & 390 & 140 & 390 & Face Shell & Stack & 2 & 2.8 & 15.30 & $6.7 \%$ \\
\hline
\end{tabular}




\begin{tabular}{|c|c|c|c|c|c|c|c|c|c|c|c|c|c|c|c|c|c|c|c|c|c|}
\hline 79 & \multirow{3}{*}{$\begin{array}{c}\text { Maurenbrecher , A.H.P. } \\
\text { (1985) }\end{array}$} & \multirow{3}{*}{390} & \multirow{3}{*}{140} & \multirow{3}{*}{190} & \multirow{3}{*}{0.57} & 20.5 & \multirow{3}{*}{$11 \%$} & $\mathrm{~N}$ & \multirow{3}{*}{ Cubes } & \multirow{3}{*}{6.6} & \multirow{3}{*}{ - } & 12 & \multirow{3}{*}{390} & \multirow{3}{*}{140} & \multirow{3}{*}{390} & \multirow{3}{*}{ Face Shell } & \multirow{3}{*}{ Stack } & 2 & 2.8 & 16.00 & $12 \%$ \\
\hline 80 & & & & & & 20.5 & & $\mathrm{~N}$ & & & & 10 & & & & & & 2 & 2.8 & 14.80 & $9.2 \%$ \\
\hline 81 & & & & & & 20.5 & & $\mathrm{~N}$ & & & & 10 & & & & & & 2 & 2.8 & 15.20 & $8.8 \%$ \\
\hline 82 & \multirow{4}{*}{ Wong and Drysdale } & \multirow{4}{*}{390} & \multirow{4}{*}{190} & \multirow{4}{*}{190} & \multirow{4}{*}{0.51} & 19.2 & \multirow{4}{*}{-} & $s$ & \multirow{4}{*}{$\begin{array}{l}\mathscr{0} \\
\mathbb{0} \\
\text { J }\end{array}$} & 18.8 & \multirow{4}{*}{$14 \%$} & 3 & \multirow{4}{*}{390} & \multirow{4}{*}{194} & 390 & & & 2 & 2.1 & 24.80 & $10 \%$ \\
\hline 83 & & & & & & 19.2 & & $s$ & & 18.8 & & 3 & & & 589 & $\begin{array}{l}\overline{\bar{\Phi}} \\
\frac{\bar{\omega}}{\omega}\end{array}$ & 긍 & 3 & 3.1 & 21.90 & $6 \%$ \\
\hline 84 & & & & & & 19.2 & & $S$ & & 18.8 & & 3 & & & 812 & 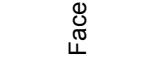 & $\omega$ & 4 & 4.3 & 22.50 & $6 \%$ \\
\hline 85 & & & & & & 19.2 & & $s$ & & 18.8 & & 3 & & & 1016 & & & 5 & 5.3 & 22.40 & $5 \%$ \\
\hline 86 & & & & & & 24.2 & & $s$ & & 17.7 & & 3 & & & & Face Shell & Runn. & 3 & 3.0 & 18.77 & $7 \%$ \\
\hline 87 & & & & & & 24.2 & & $s$ & & 17.7 & 10 & 3 & & & & Full Bedding & Stack & 3 & 3.0 & 18.68 & $5 \%$ \\
\hline 88 & & & & & & 24.2 & & $\mathrm{~N}$ & & 11.9 & $10 \%$ & 3 & & & & Face Shell & & 3 & 3.0 & 18.63 & $5 \%$ \\
\hline 89 & Gaynor et al. & 397 & 194 & 194 & 0.52 & 17.9 & - & $S$ & $\frac{\Phi}{3}$ & 17.7 & & 3 & 397 & 194 & 590 & Face Shell & & 3 & 3.0 & 14.38 & $6 \%$ \\
\hline 90 & & & & & & 17.9 & & $S$ & & 17.7 & & 3 & & & & Full Bedding & $\begin{array}{l}\overline{0} \\
\frac{\pi}{00}\end{array}$ & 3 & 3.0 & 14.29 & $4 \%$ \\
\hline 91 & & & & & & 17.9 & & $\mathrm{~N}$ & & 11.9 & 1000 & 3 & & & & Face Shell & & 3 & 3.0 & 14.00 & $4 \%$ \\
\hline 92 & & & & & & 17.9 & & $\mathrm{~N}$ & & 11.9 & To & 3 & & & & Full Bedding & & 3 & 3.0 & 13.58 & $3 \%$ \\
\hline 93 & & & & & & 25.5 & & $s$ & & 8.4 & & 5 & & & & & & 2 & 2.1 & 22.80 & $4.4 \%$ \\
\hline 94 & & & & & & 25.5 & J/0 & $s$ & & 8.4 & & 5 & & & & & & 2 & 2.1 & 23.20 & $2.4 \%$ \\
\hline 95 & & & & & & 32.0 & $17 \%$ & $s$ & & 8.4 & & 5 & & & 200 & & & 2 & 2.1 & 25.00 & $4.1 \%$ \\
\hline 96 & & & & & & 21.5 & $9 \%$ & $S$ & & 8.4 & & 5 & & & & $\stackrel{D}{\subseteq}$ & & 2 & 2.1 & 16.10 & $4.2 \%$ \\
\hline 97 & Chahine and Drycdale & & & & & 25.3 & 00 & $s$ & $\infty$ & 8.4 & & 5 & & & & ప్ర & $\stackrel{D}{\leftrightarrows}$ & 2 & 2.1 & 22.90 & $1.8 \%$ \\
\hline 98 & & 390 & 190 & 190 & 0.52 & 25.3 & $5 / 0$ & $s$ & $\stackrel{0}{3}$ & 8.4 & - & 5 & 390 & 190 & & $\begin{array}{l}\overline{\bar{\Phi}} \\
\frac{\bar{\omega}}{\omega}\end{array}$ & 莺 & 2 & 2.1 & 21.10 & $3.7 \%$ \\
\hline 99 & & & & & & 25.5 & $5 \%$ & $s$ & & 8.4 & & 5 & & & & 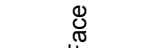 & & 4 & 4.2 & 18.80 & $4.8 \%$ \\
\hline 100 & & & & & & 25.5 & $5 \%$ & $s$ & & 8.4 & & 5 & & & & & & 4 & 4.2 & 19.10 & $1.6 \%$ \\
\hline 101 & & & & & & 32.0 & $17 \%$ & $S$ & & 8.4 & & 5 & & & 789 & & & 4 & 4.2 & 19.00 & $8.4 \%$ \\
\hline 102 & & & & & & 21.5 & $15 \%$ & $s$ & & 8.4 & & 5 & & & & & & 4 & 4.2 & 15.50 & $6.4 \%$ \\
\hline 103 & & & & & & 25.3 & $9 \%$ & $S$ & & 8.4 & & 5 & & & & & & 4 & 4.2 & 19.60 & $3 \%$ \\
\hline 104 & & & & & & 27.8 & & $\mathrm{~N}$ & & 10.6 & & 5 & & & & & & 3 & 3.1 & 24.40 & $2 \%$ \\
\hline 105 & at & 000 & 100 & 100 & 0 ? & 27.8 & -5 & $\mathrm{~N}$ & $\mathscr{\infty}$ & 10.6 & $\%$ & 5 & 300 & 100 & 580 & $\begin{array}{l}\overline{\bar{d}} \\
\bar{\infty} \cdot \frac{D}{\bar{c}}\end{array}$ & 일 & 3 & 3.1 & 26.00 & $1 \%$ \\
\hline 106 & Xle et al. & 390 & 190 & 190 & 0.52 & 27.8 & $5 \%$ & $\mathrm{~N}$ & U & 10.6 & $6 \%$ & 5 & 390 & 190 & 589 & $\begin{array}{l}0 \\
0 \\
\pi\end{array}$ & 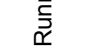 & 3 & 3.1 & 23.80 & $4 \%$ \\
\hline 107 & & & & & & 27.8 & & $N$ & & 10.6 & & 5 & & & & & & 3 & 3.1 & 24.30 & $2 \%$ \\
\hline
\end{tabular}




\begin{tabular}{|c|c|c|c|c|c|c|c|c|c|c|c|c|c|c|c|c|c|c|c|c|c|}
\hline 108 & \multirow{4}{*}{ Xie et al. } & \multirow{4}{*}{390} & \multirow{4}{*}{190} & \multirow{4}{*}{190} & \multirow{4}{*}{0.52} & 27.8 & \multirow{4}{*}{$5 \%$} & $\mathrm{~N}$ & \multirow{4}{*}{ Cubes } & 10.6 & \multirow{4}{*}{$6 \%$} & 2 & \multirow{4}{*}{390} & \multirow{4}{*}{190} & 589 & \multirow{4}{*}{$\begin{array}{c}\text { Face Shell } \\
\text { bedding }\end{array}$} & \multirow{4}{*}{ 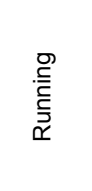 } & 3 & 3.1 & 23.00 & \multirow{4}{*}{ - } \\
\hline 109 & & & & & & 27.8 & & $\mathrm{~N}$ & & 10.6 & & 2 & & & 589 & & & 3 & 3.1 & 23.70 & \\
\hline 110 & & & & & & 27.8 & & $N$ & & 10.6 & & 2 & & & 990 & & & 5 & 5.2 & 22.20 & \\
\hline 111 & & & & & & 27.8 & & $\mathrm{~N}$ & & 10.6 & & 2 & & & 990 & & & 5 & 5.2 & 22.30 & \\
\hline 112 & \multirow{6}{*}{ Khalaf et al.(1994) } & \multirow{6}{*}{390} & \multirow{6}{*}{190} & \multirow{6}{*}{190} & \multirow{6}{*}{0.52} & 20.0 & $10 \%$ & $\mathrm{~N}$ & \multirow{6}{*}{\begin{tabular}{l}
$\mathscr{0}$ \\
$\mathbb{0}$ \\
\multirow{3}{3}{} \\
0
\end{tabular}} & 9.2 & & 3 & \multirow{2}{*}{390} & \multirow{2}{*}{190} & \multirow{2}{*}{598} & & & 3 & 3.1 & 17.80 & $6 \%$ \\
\hline 113 & & & & & & 20.0 & $10 \%$ & $s$ & & 15.4 & & 3 & & & & & & 3 & 3.1 & 17.40 & $5 \%$ \\
\hline 114 & & & & & & 25.7 & $11 \%$ & $s$ & & 15.4 & & 3 & & & & $\frac{5}{\overline{0}}$ & 응 & 3 & 3.1 & 20.60 & $13 \%$ \\
\hline 115 & & & & & & 25.7 & $11 \%$ & $S$ & & 20.2 & - & 3 & 190 & 190 & 598 & $\stackrel{\infty}{=}$ & $\ddot{\omega}$ & 3 & 3.1 & 24.20 & $3 \%$ \\
\hline 116 & & & & & & 25.7 & $11 \%$ & $S$ & & 25.5 & & 3 & & & & & & 3 & 3.1 & 25.50 & $3 \%$ \\
\hline 117 & & & & & & 20.0 & $10 \%$ & $S$ & & 26.5 & & 3 & 390 & 190 & 598 & & & 3 & 3.1 & 21.40 & $2 \%$ \\
\hline 118 & & & & & & 27.8 & & $S$ & & 19.8 & & 3 & & & & & Runn. & 4 & 4.3 & 23.6 & \\
\hline 119 & Ctondmon & 300 & 100 & 100 & 056 & 27.8 & & $S$ & $\mathscr{\infty}$ & 19.8 & & 2 & 200 & 100 & 012 & Face Shell & Stack & 4 & 4.3 & 23.2 & \\
\hline 120 & Stedurnali el al. & 390 & 190 & 190 & 0.50 & 40.0 & - & $S$ & $\vec{J}$ & 19.8 & - & 3 & 390 & 190 & 012 & bedding & Runn. & 4 & 4.3 & 31.0 & - \\
\hline 121 & & & & & & 34.8 & & $S$ & & 19.8 & & 3 & & & & & Runn. & 4 & 4.3 & 29.3 & \\
\hline 122 & & & & & & 25.7 & $11 \%$ & $S$ & & 20.2 & & 3 & 190 & & & & & 3 & 3.1 & 24.2 & $3 \%$ \\
\hline 123 & & & & & & 20 & & $\mathrm{~N}$ & & 9.2 & & 3 & & & & & & 3 & 3.1 & 17.8 & $6 \%$ \\
\hline 124 & & & & & & 20 & $10 \%$ & $s$ & & 21.2 & & 3 & 390 & & & & & 3 & 3.1 & 19.2 & $14 \%$ \\
\hline 125 & & & & & & 20 & & $S$ & & 21.2 & & 3 & & & & & & 3 & 3.1 & 23.3 & $7 \%$ \\
\hline 126 & & & & & & 25.7 & $11 \%$ & $s$ & & 15.4 & & 3 & 100 & & 509 & & & 3 & 3.1 & 20.6 & $13 \%$ \\
\hline 127 & Kholef 1000 & 200 & 100 & 100 & 050 & 25.7 & $11 \%$ & $s$ & 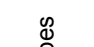 & 26.5 & & 3 & 190 & 100 & & $\frac{-5}{\overline{7}}$ & 弟 & 3 & 3.1 & 25.5 & $3 \%$ \\
\hline 128 & Analal (1996) & 390 & 190 & 190 & 0.50 & 20 & & $s$ & 范 & 21.2 & & 3 & & 190 & & $\stackrel{\infty}{=}$ & $\ddot{\omega}$ & 2 & 2.1 & 24.9 & $7 \%$ \\
\hline 129 & & & & & & 20 & $10 \%$ & $s$ & & 26.5 & & 3 & 390 & & & एँ & & 3 & 3.1 & 21.4 & $2 \%$ \\
\hline 130 & & & & & & 20 & & $S$ & & 26.6 & & 3 & & & 1190 & & & 6 & 6.3 & 17.5 & $3 \%$ \\
\hline 131 & & & & & & 25.7 & $11 \%$ & $s$ & & 21.2 & & 3 & & & 398 & & & 2 & 2.1 & 26.0 & $1.5 \%$ \\
\hline 132 & & & & & & 25.7 & $11 \%$ & $S$ & & 26.5 & & 3 & 190 & & 589 & & & 3 & 3.1 & 25.5 & $1.5 \%$ \\
\hline 133 & & & & & & 25.7 & $11 \%$ & $S$ & & 26.6 & & 3 & & & 1190 & & & 6 & 6.3 & 23.4 & $3 \%$ \\
\hline 134 & & & & & & 19.8 & & $S$ & & 15.6 & $6 \%$ & 3 & & & & & & & & 18.22 & $9 \%$ \\
\hline 135 & & & & & & 19.8 & 1001 & $s$ & & 12.2 & $8 \%$ & 3 & & & & 吾 & & & & 17.20 & $14 \%$ \\
\hline 136 & Ramamurthy et al. & 300 & 200 & 100 & 050 & 19.8 & $12 \%$ & $\mathrm{~N}$ & $\mathscr{E}$ & 5 & $15 \%$ & 3 & 300 & 200 & 580 & $\stackrel{=}{=}$ & 胥 & 3 & 20 & 16.18 & $14 \%$ \\
\hline 137 & & 390 & 200 & 190 & 0.59 & 19.8 & & $\mathrm{~N}$ & 吾 & 4.3 & $12 \%$ & 3 & 390 & 200 & 589 & $\frac{\bar{\Phi}}{\omega}$ & 产 & 3 & 2.9 & 14.21 & $17 \%$ \\
\hline 138 & & & & & & 17.6 & $20 \%$ & $\mathrm{~s}$ & & 15.6 & $6 \%$ & 3 & & & & 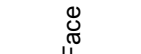 & & & & 15.45 & $11 \%$ \\
\hline 139 & & & & & & 17.6 & $0 \%$ & $s$ & & 12.2 & $8 \%$ & 3 & & & & & & & & 14.33 & $9 \%$ \\
\hline
\end{tabular}




\begin{tabular}{|c|c|c|c|c|c|c|c|c|c|c|c|c|c|c|c|c|c|c|c|c|c|}
\hline 140 & \multirow{19}{*}{ Ramamurthy et al. } & \multirow{19}{*}{390} & \multirow{19}{*}{200} & \multirow{19}{*}{190} & \multirow{6}{*}{0.59} & 17.6 & \multirow{2}{*}{$8 \%$} & $\mathrm{~N}$ & \multirow{19}{*}{$\begin{array}{l}\mathscr{0} \\
\mathbb{0} \\
0 \\
0 \\
0\end{array}$} & 5 & $15 \%$ & 3 & \multirow{19}{*}{390} & \multirow{19}{*}{200} & \multirow{19}{*}{589} & \multirow{6}{*}{ 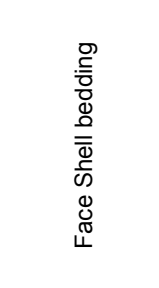 } & \multirow{19}{*}{ 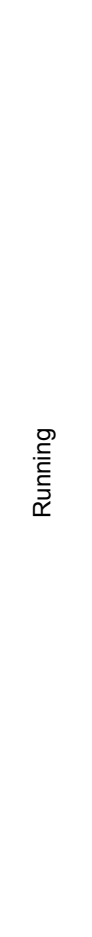 } & \multirow{19}{*}{3} & \multirow{19}{*}{2.9} & 13.40 & $10 \%$ \\
\hline 141 & & & & & & 17.6 & & $\mathrm{~N}$ & & 4.3 & $12 \%$ & 3 & & & & & & & & 12.81 & $10 \%$ \\
\hline 142 & & & & & & 13.5 & \multirow{3}{*}{$10 \%$} & $\mathrm{~s}$ & & 12.2 & $8 \%$ & 3 & & & & & & & & 11.02 & $14 \%$ \\
\hline 143 & & & & & & 13.5 & & $\mathrm{~N}$ & & 5 & $15 \%$ & 3 & & & & & & & & 10.43 & $15 \%$ \\
\hline 144 & & & & & & 13.5 & & $\mathrm{~N}$ & & 4.3 & $12 \%$ & 3 & & & & & & & & 10.47 & $13 \%$ \\
\hline 145 & & & & & & 10.9 & $12 \%$ & $\mathrm{~N}$ & & 5 & $15 \%$ & 3 & & & & & & & & 8.19 & $15 \%$ \\
\hline 146 & & & & & \multirow{13}{*}{0.60} & 19.8 & \multirow{4}{*}{$12 \%$} & $s$ & & 15.6 & $6 \%$ & 3 & & & & \multirow{13}{*}{ 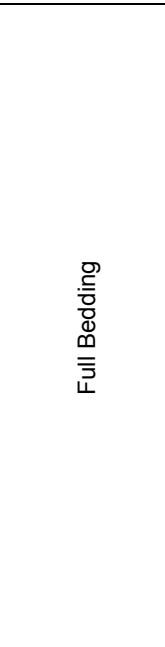 } & & & & 19.49 & $11.5 \%$ \\
\hline 147 & & & & & & 19.8 & & $S$ & & 12.2 & $8 \%$ & 3 & & & & & & & & 18.41 & $14.9 \%$ \\
\hline 148 & & & & & & 19.8 & & $\mathrm{~N}$ & & 5 & $15 \%$ & 3 & & & & & & & & 14.42 & $6.4 \%$ \\
\hline 149 & & & & & & 19.8 & & $\mathrm{~N}$ & & 4.3 & $12 \%$ & 3 & & & & & & & & 14.11 & $7.9 \%$ \\
\hline 150 & & & & & & 17.6 & \multirow{4}{*}{$8 \%$} & $S$ & & 15.6 & $6 \%$ & 3 & & & & & & & & 17.63 & $9.4 \%$ \\
\hline 151 & & & & & & 17.6 & & $S$ & & 12.3 & $8 \%$ & 3 & & & & & & & & 16.90 & $8.1 \%$ \\
\hline 152 & & & & & & 17.6 & & $\mathrm{~N}$ & & 5 & $15 \%$ & 3 & & & & & & & & 14.39 & $9.2 \%$ \\
\hline 153 & & & & & & 17.6 & & $\mathrm{~N}$ & & 4.3 & $12 \%$ & 3 & & & & & & & & 13.31 & $9.5 \%$ \\
\hline 154 & & & & & & 13.5 & \multirow{3}{*}{$10 \%$} & $\mathrm{~N}$ & & 12.2 & $8 \%$ & 3 & & & & & & & & 13.48 & $7.1 \%$ \\
\hline 155 & & & & & & 13.5 & & $\mathrm{~N}$ & & 5 & $15 \%$ & 3 & & & & & & & & 11.21 & $8.7 \%$ \\
\hline 156 & & & & & & 13.5 & & $\mathrm{~N}$ & & 4.3 & $12 \%$ & 3 & & & & & & & & 11.00 & $17.2 \%$ \\
\hline 157 & & & & & & 10.9 & \multirow{2}{*}{$12 \%$} & $\mathrm{~N}$ & & 5 & $15 \%$ & 3 & & & & & & & & 11.14 & $13.8 \%$ \\
\hline 158 & & & & & & 10.9 & & $\mathrm{~N}$ & & 4.3 & $12 \%$ & 3 & & & & & & & & 10.86 & $8.7 \%$ \\
\hline 159 & \multirow{12}{*}{ Roman\& Romagna } & & & & & 17.7 & & $\mathrm{~N}$ & & 3.9 & & 3 & & & & & & 3 & 4.2 & 12.7 & \\
\hline 160 & & & & & & 27.4 & & $\mathrm{~N}$ & & 5.6 & & 3 & & & & $\stackrel{\text { D }}{\underline{\bar{n}}}$ & & 3 & 4.2 & 15.73 & \\
\hline 161 & & & & & & 29.0 & & $\mathrm{~N}$ & & 3.8 & & 3 & & & & 离 & & 3 & 4.2 & 17.06 & \\
\hline 162 & & & & & & 24.1 & & $S$ & & 7.4 & & 3 & & & & $\overline{\bar{u}}$ & & 3 & 4.2 & 17.89 & \\
\hline 163 & & & & & & 33.5 & & $\mathrm{~s}$ & & 7.8 & & 3 & & & & & & 3 & 4.2 & 22.04 & \\
\hline 164 & & 390 & 140 & 190 & 058 & 14.4 & 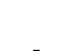 & $\mathrm{N}$ & $\frac{\infty}{\frac{\omega}{0}}$ & 4.8 & 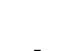 & 3 & 390 & 140 & 589 & & 并 & 3 & 4.2 & 10.08 & 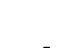 \\
\hline 165 & & 390 & 140 & 190 & 0.58 & 20.7 & - & $N$ & $\frac{\sqrt[5]{7}}{3}$ & 3.9 & - & 3 & 390 & 140 & 589 & 管 & $\ddot{\omega}$ & 3 & 4.2 & 15.88 & - \\
\hline 166 & & & & & & 35.5 & & $\mathrm{~N}$ & & 4.3 & & 3 & & & & $\stackrel{\varnothing}{=}$ & & 3 & 4.2 & 20.55 & \\
\hline 167 & & & & & & 14.4 & & $\mathrm{~s}$ & & 7.9 & & 3 & & & & $\frac{\Phi}{\omega}$ & & 3 & 4.2 & 12.20 & \\
\hline 168 & & & & & & 20.7 & & $s$ & & 9.8 & & 3 & & & & $\stackrel{0}{0}$ & & 3 & 4.2 & 17.23 & \\
\hline 169 & & & & & & 35.5 & & $s$ & & 7.1 & & 3 & & & & & & 3 & 4.2 & 23.56 & \\
\hline 170 & & & & & & 12.5 & & $s$ & & 7.7 & & 3 & & & & Full Bedding & & 3 & 4.2 & 8.0 & \\
\hline 171 & Mohamad et al. & 390 & 140 & 190 & 0.58 & 18.2 & - & $s$ & Cylinders & 19.9 & - & 6 & 390 & 140 & 589 & Full Bedding & Stack & 3 & 4.2 & 18.2 & - \\
\hline
\end{tabular}




\begin{tabular}{|c|c|c|c|c|c|c|c|c|c|c|c|c|c|c|c|c|c|c|c|c|c|}
\hline 172 & \multirow{5}{*}{ Mohamad et al. } & \multirow{5}{*}{390} & \multirow{5}{*}{140} & \multirow{5}{*}{190} & \multirow{5}{*}{0.58} & 18.2 & & $s$ & \multirow{5}{*}{ Cylinders } & 8.63 & & 6 & \multirow{5}{*}{390} & \multirow{5}{*}{140} & \multirow{5}{*}{589} & \multirow{5}{*}{ 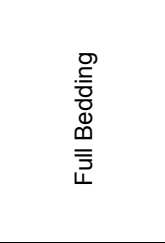 } & \multirow{5}{*}{ 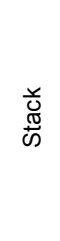 } & 3 & 4.2 & 14.82 & \multirow{5}{*}{ - } \\
\hline 173 & & & & & & 18.2 & & $\mathrm{~N}$ & & 4.2 & & 6 & & & & & & 3 & 4.2 & 14.09 & \\
\hline 174 & & & & & & 18.2 & - & $\mathrm{N}$ & & 2.9 & - & 6 & & & & & & 3 & 4.2 & 13.00 & \\
\hline 175 & & & & & & 27.0 & & $S$ & & 19.9 & & 6 & & & & & & 3 & 4.2 & 20.17 & \\
\hline 176 & & & & & & 27.0 & & $\mathrm{~N}$ & & 4.2 & & 6 & & & & & & 3 & 4.2 & 15.24 & \\
\hline 177 & \multirow{3}{*}{ Andolfato et al. } & \multirow{3}{*}{290} & \multirow{3}{*}{140} & \multirow{3}{*}{190} & \multirow{3}{*}{0.58} & 9.2 & $13 \%$ & $\mathrm{~N}$ & \multirow{3}{*}{ 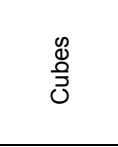 } & 4.9 & & 3 & \multirow{3}{*}{290} & \multirow{3}{*}{140} & \multirow{3}{*}{589} & FS & \multirow{3}{*}{ 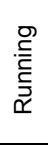 } & 3 & 4.2 & 7.73 & $9.8 \%$ \\
\hline 178 & & & & & & 9 & $13 \%$ & $\mathrm{~N}$ & & 4.9 & - & 3 & & & & Full Bedding & & 3 & 4.2 & 7.11 & $9.4 \%$ \\
\hline 179 & & & & & & 13.4 & $13 \%$ & $\mathrm{~N}$ & & 4.9 & & 3 & & & & Full Bedding & & 3 & 4.2 & 9.20 & $9.4 \%$ \\
\hline 180 & & & & & & 24.5 & $3 \%$ & $\mathrm{~N}$ & & 9.4 & $11 \%$ & 3 & & & & & & 3 & 4.2 & 18.81 & $2.0 \%$ \\
\hline 181 & Barbosa et al. & 390 & 140 & 190 & 0.56 & 20.0 & $4.5 \%$ & $\mathrm{~N}$ & $\frac{\omega}{0}$ & 7.7 & $14 \%$ & 3 & 390 & 140 & 589 & 흥 & 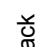 & 3 & 4.2 & 17.86 & $3.7 \%$ \\
\hline 182 & & (50) & 140 & 10 & 0.00 & 26.8 & $2.5 \%$ & $\mathrm{~s}$ & 紊 & 15.5 & $2 \%$ & 3 & (200 & 140 & . & $\frac{\varpi}{\bar{\Xi}}$ & $\omega$ & 3 & 4.2 & 21.43 & $4.8 \%$ \\
\hline 183 & & & & & & 38.9 & $2.5 \%$ & $M$ & & 22.2 & $7 \%$ & 3 & & & & & & 3 & 4.2 & 30.18 & $3.9 \%$ \\
\hline 184 & & & & & & 14.1 & $6 \in 0$ & $S$ & & 9.1 & $9 \%$ & 3 & & & & & & & & 17.0 & $5.9 \%$ \\
\hline 185 & & & & & & 14.1 & 0.07 & $S$ & & 14 & $2 \%$ & 3 & & & & & & & & 15.8 & $4.1 \%$ \\
\hline 186 & & & & & & 20.8 & $3 \%$ & $S$ & & 9.1 & & 3 & & & & & & & & 23.0 & $4.9 \%$ \\
\hline 187 & & & & & & 17.7 & $12 \%$ & $\mathrm{~s}$ & & 9.1 & & 3 & & & & & & & & 18.6 & $4.8 \%$ \\
\hline 188 & & & & & & 23.3 & $4.7 \%$ & $S$ & & 9.1 & & 3 & & & & & & & & 20.5 & $6.4 \%$ \\
\hline 189 & & & & & & 28.3 & $3 \%$ & $\mathrm{~s}$ & & 9.1 & $9 \%$ & 3 & & & & & & & & 23.5 & $5.0 \%$ \\
\hline 190 & & & & & & 31.1 & $3 \%$ & $S$ & & 9.1 & & 3 & & & & & & & & 23.8 & $4.2 \%$ \\
\hline 191 & & & & & & 35.0 & $3 \%$ & $\mathrm{~s}$ & & 9.1 & & 3 & & & & & & & & 23.7 & $1.7 \%$ \\
\hline 192 & & & & & & 38.0 & $2 \%$ & $S$ & & 9.1 & & 3 & & & & & & & & 29.2 & $3.7 \%$ \\
\hline 193 & NCMA & 394 & 194 & 194 & 0.52 & 14.1 & $6.6 \%$ & $\mathrm{~N}$ & $\mathscr{\&}$ & 4.6 & $18 \%$ & 3 & 219 & 194 & 389 & 흥 & 둥 & 2 & 2 & 15.2 & $6.6 \%$ \\
\hline 194 & 政 & 304 & 104 & 104 & 0.02 & 17.7 & $12 \%$ & $\mathrm{~N}$ & $\overline{\mathcal{U}}$ & 4.6 & $10 \%$ & 3 & 210 & 104 & 000 & $\stackrel{\varpi}{\bar{\Xi}}$ & $\tilde{\omega}$ & 2 & 2 & 17.5 & $3.5 \%$ \\
\hline 195 & & & & & & 20.8 & $3 \%$ & $\mathrm{~N}$ & & 4.6 & & 3 & & & & & & & & 20.6 & $3.0 \%$ \\
\hline 196 & & & & & & 23.3 & $4.7 \%$ & $\mathrm{~N}$ & & 4.6 & & 3 & & & & & & & & 17.3 & $7.0 \%$ \\
\hline 197 & & & & & & 28.3 & $3 \%$ & $\mathrm{~N}$ & & 4.6 & $18 \%$ & 3 & & & & & & & & 22.3 & $8.6 \%$ \\
\hline 198 & & & & & & 31.1 & $3 \%$ & $\mathrm{~N}$ & & 4.6 & 1070 & 3 & & & & & & & & 21.0 & $7.4 \%$ \\
\hline 199 & & & & & & 35.0 & $3 \%$ & $\mathrm{~N}$ & & 4.6 & & 3 & & & & & & & & 21.5 & $4.3 \%$ \\
\hline 200 & & & & & & 38.0 & $2 \%$ & $\mathrm{~N}$ & & 4.6 & & 3 & & & & & & & & 24.4 & $6.4 \%$ \\
\hline 201 & & & & & & 14.1 & $6.6 \%$ & $S$ & & 10.8 & & 3 & & & & & & & & 14.7 & $3.4 \%$ \\
\hline 202 & & & & & & 23.3 & $4.7 \%$ & $\mathrm{~S}$ & & 10.8 & $8 \%$ & 3 & & & & & & & & 20.8 & $5.6 \%$ \\
\hline 203 & & & & & & 38.0 & $2 \%$ & 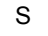 & & 10.8 & & 3 & & & & & & & & 27.5 & $5.8 \%$ \\
\hline
\end{tabular}




\begin{tabular}{|c|c|c|c|c|c|c|c|c|c|c|c|c|c|c|c|c|c|c|c|c|c|}
\hline 204 & \multirow{8}{*}{ NCMA } & \multirow{8}{*}{394} & \multirow{8}{*}{194} & \multirow{8}{*}{194} & \multirow{8}{*}{0.52} & 14.1 & $6.6 \%$ & $\mathrm{~N}$ & \multirow{8}{*}{ 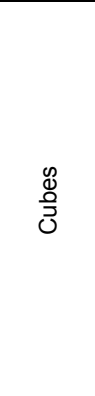 } & 3.9 & \multirow{3}{*}{$6.8 \%$} & 3 & \multirow{8}{*}{219} & \multirow{8}{*}{194} & \multirow{8}{*}{389} & \multirow{8}{*}{ 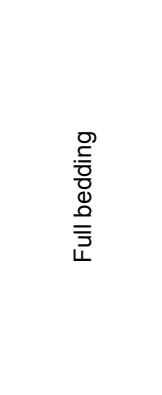 } & \multirow{8}{*}{$\begin{array}{l}\frac{r}{\tilde{J}} \\
\dot{m}\end{array}$} & \multirow{8}{*}{2} & \multirow{8}{*}{2} & 13.7 & $1.8 \%$ \\
\hline 205 & & & & & & 23.3 & $4.7 \%$ & $\mathrm{~N}$ & & 3.9 & & 3 & & & & & & & & 15.6 & $7.4 \%$ \\
\hline 206 & & & & & & 38.0 & $2 \%$ & $\mathrm{~N}$ & & 3.9 & & 3 & & & & & & & & 24.2 & $5.2 \%$ \\
\hline 207 & & & & & & 23.3 & $4.7 \%$ & $s$ & & 14 & \multirow{2}{*}{$2 \%$} & 3 & & & & & & & & 20.9 & $3.3 \%$ \\
\hline 208 & & & & & & 38.0 & $2 \%$ & $S$ & & 14 & & 3 & & & & & & & & 31.0 & $3.2 \%$ \\
\hline 209 & & & & & & 14.1 & $6.6 \%$ & $\mathrm{~N}$ & & 6.7 & \multirow{3}{*}{$5 \%$} & 3 & & & & & & & & 15.4 & $4.9 \%$ \\
\hline 210 & & & & & & 23.3 & $4.7 \%$ & $\mathrm{~N}$ & & 6.7 & & 3 & & & & & & & & 17.2 & $2.3 \%$ \\
\hline 211 & & & & & & 38.0 & $2 \%$ & $\mathrm{~N}$ & & 6.7 & & 3 & & & & & & & & 28.1 & $2.8 \%$ \\
\hline 212 & \multirow{12}{*}{ Mina et al. } & \multirow{12}{*}{390} & \multirow{12}{*}{190} & \multirow{12}{*}{190} & \multirow{12}{*}{0.52} & 37.4 & \multirow{4}{*}{$4 \%$} & $S$ & & 12.1 & $1.6 \%$ & 3 & & & & & & & & 24.44 & $8 \%$ \\
\hline 213 & & & & & & 37.4 & & $N$ & & 8.1 & $15 \%$ & 3 & & & & & & & & 22.01 & $8.7 \%$ \\
\hline 214 & & & & & & 37.4 & & $s$ & & 16.3 & $1.3 \%$ & 3 & & & & & & & & 28.09 & $7.4 \%$ \\
\hline 215 & & & & & & 37.4 & & $\mathrm{~N}$ & & 7.8 & $4.7 \%$ & 3 & & & & & & & & 26.31 & $13 \%$ \\
\hline 216 & & & & & & 26.7 & & $s$ & & 13.2 & $3.5 \%$ & 3 & & & & 产 & & & & 23.30 & $3.5 \%$ \\
\hline 217 & & & & & & 26.7 & $7 \%$ & $\mathrm{~N}$ & $\mathscr{E}$ & 7.9 & $12 \%$ & 3 & 390 & 100 & 580 & $\stackrel{\Xi}{=}$ & 弟 & 3 & 310 & 20.17 & $9 \%$ \\
\hline 218 & & & & & & 26.7 & $\%$ & $s$ & 永 & 11.4 & $4.8 \%$ & 3 & 390 & 190 & 589 & $\frac{\bar{\Phi}}{\omega}$ & $\frac{\pi}{\omega}$ & 3 & 3.10 & 21.67 & $7.7 \%$ \\
\hline 219 & & & & & & 26.7 & & $\mathrm{~N}$ & & 6.9 & $8.9 \%$ & 3 & & & & 造 & & & & 21.56 & $10 \%$ \\
\hline 220 & & & & & & 27.3 & & $S$ & & 13.2 & $3.5 \%$ & 3 & & & & & & & & 19.23 & $9.7 \%$ \\
\hline 221 & & & & & & 27.3 & 110 & $\mathrm{~N}$ & & 7.87 & $12 \%$ & 3 & & & & & & & & 14.89 & $7.4 \%$ \\
\hline 222 & & & & & & 27.3 & 1170 & $S$ & & 16.3 & $1.3 \%$ & 3 & & & & & & & & 24.35 & $12 \%$ \\
\hline 223 & & & & & & 27.3 & & $N$ & & 8.7 & $1.9 \%$ & 3 & & & & & & & & 17.42 & $2.4 \%$ \\
\hline 224 & & & & & & 28.0 & & $S$ & & 21 & & 5 & & & 389 & & & 2 & 2 & 27.8 & $6.6 \%$ \\
\hline 225 & & & & & & 28.0 & & $S$ & & 21 & & 5 & & & 589 & $\frac{\Phi}{\omega}$ & & 3 & 3 & 25.1 & $1.9 \%$ \\
\hline 226 & Das et al & דم & 10 & 10 & $0<0$ & 28.0 & 010 & $s$ & $\notin$ & 21 & 000 & 5 & ד07 & 10 & 789 & $\underset{\pi}{\mathscr{\sigma}}$ & 岳 & 4 & 4 & 22.5 & $7.5 \%$ \\
\hline 227 & & 391 & 194 & 194 & 0.02 & 28.0 & $2.1 \%$ & $S$ & $\bar{J}$ & 21 & $0.0 \%$ & 5 & 391 & 194 & 990 & & & 5 & 5 & 21.4 & $9.7 \%$ \\
\hline 228 & & & & & & 28.0 & & $S$ & & 21 & & 5 & & & 789 & Full Bedding & & 4 & 4 & 24.1 & $2.5 \%$ \\
\hline 229 & & & & & & 28.0 & & $\mathrm{~s}$ & & 21 & & 5 & & & 389 & Face Shell & Stack & 2 & 2 & 28.6 & $14 \%$ \\
\hline 230 & & & & & & 18.3 & & $s$ & & 11.7 & & 3 & & & & & & 3 & 3.1 & 16.31 & \\
\hline 231 & Hiaminres & 200 & 100 & 100 & (2) & 18.3 & & $s$ & $\mathscr{0}$ & 11.7 & & 3 & 300 & 100 & 500 & Face Shell & 임 & 3 & 3.1 & 17.88 & \\
\hline 232 & Higmier et al. & 390 & 190 & 190 & 0.52 & 18.3 & & $s$ & Ũ & 11.7 & - & 3 & 390 & 190 & 589 & Bedding & $\frac{\pi}{\omega}$ & 3 & 3.1 & 16.21 & - \\
\hline 233 & & & & & & 18.3 & & $s$ & & 11.7 & & 3 & & & & & & 3 & 3.1 & 17.35 & \\
\hline 234 & Colf M & 207 & 110 & 100 & (2) & 35.1 & 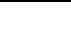 & $s$ & Ouhnot & 22.8 & 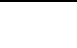 & 3 & 207 & 101 & 584 & ᄃ & Stor & 3 & 3.0 & 24.20 & 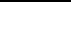 \\
\hline 235 & sen, IMl. vv. & 391 & 194 & 194 & 0.52 & 35.1 & & $\mathrm{~s}$ & cunes & 22.8 & & 3 & 391 & 194 & 390 & rull beading & Stack & 2 & 2.0 & 25.70 & - \\
\hline
\end{tabular}




\begin{tabular}{|c|c|c|c|c|c|c|c|c|c|c|c|c|c|c|c|c|c|c|c|c|c|}
\hline 236 & \multirow{2}{*}{$\begin{array}{c}\text { Maurenbrecher A.H.P. } \\
\text { (1983) }\end{array}$} & \multirow{2}{*}{390} & \multirow{2}{*}{140} & \multirow{2}{*}{190} & \multirow{2}{*}{0.61} & 22.3 & \multirow{2}{*}{$8 \%$} & $\mathrm{~N}$ & \multirow{2}{*}{ Cubes } & 5.7 & \multirow{2}{*}{ - } & 10 & \multirow{2}{*}{390} & \multirow{2}{*}{140} & \multirow{2}{*}{390} & Face Shell & Stack & 2 & 2.8 & 12.50 & $7 \%$ \\
\hline 237 & & & & & & 22.3 & & $\mathrm{~N}$ & & 5.7 & & 10 & & & & Full Bedding & Stack & 2 & 2.8 & 12.30 & $10 \%$ \\
\hline 238 & Cheema and Klingner & 390 & 190 & 190 & 0.52 & 25.9 & - & $S$ & Cubes & 14.9 & - & 3 & 390 & 190 & 390 & Full Bedding & Stack & 2 & 2.1 & 19.24 & $14 \%$ \\
\hline 239 & \multirow{2}{*}{ Olatunji et al. } & \multirow{2}{*}{390} & \multirow{2}{*}{190} & \multirow{2}{*}{190} & \multirow{2}{*}{0.56} & 13.9 & \multirow{2}{*}{ - } & $S$ & \multirow{2}{*}{ Cubes } & 10.5 & \multirow{2}{*}{ - } & 4 & 390 & 190 & 589 & Full Bedding & Stack & 2 & 3.1 & 11.74 & $20 \%$ \\
\hline 240 & & & & & & 13.9 & & $\mathrm{~s}$ & & 10.5 & & 4 & 589 & 190 & 589 & Full Bedding & Stack & 2 & 3.1 & 10.08 & $5 \%$ \\
\hline 241 & \multirow{4}{*}{ Scrivener and Baker } & \multirow{4}{*}{390} & \multirow{4}{*}{190} & \multirow{4}{*}{190} & \multirow{4}{*}{0.56} & 11.6 & $9 \%$ & $\mathrm{~N}$ & \multirow{4}{*}{ 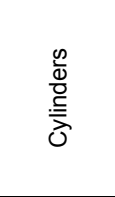 } & 7.6 & & 3 & \multirow{4}{*}{390} & \multirow{4}{*}{190} & \multirow{4}{*}{589} & \multirow{4}{*}{ 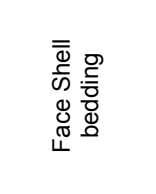 } & Runn. & 3 & \multirow{4}{*}{4.2} & 14.77 & \\
\hline 242 & & & & & & 23.2 & $8 \%$ & $\mathrm{~N}$ & & 7.6 & & 3 & & & & & Stack & 3 & & 26.15 & \\
\hline 243 & & & & & & 23.2 & $8 \%$ & $\mathrm{~N}$ & & 7.6 & - & 3 & & & & & Runn. & 3 & & 20.49 & \\
\hline 244 & & & & & & 11.6 & $9 \%$ & $\mathrm{~N}$ & & 7.6 & & 3 & & & & & Stack & 3 & & 16.57 & \\
\hline 245 & Page and Shrive & 400 & 200 & 200 & 0.56 & 18.9 & - & $\mathrm{N}$ & Cubes & 7.6 & - & 18 & 400 & 200 & 400 & Face Shell & Stack & 2 & 2.0 & 16.80 & - \\
\hline 246 & Thomas \& Scolforo & 390 & 190 & 190 & 0.56 & 18.7 & - & $S$ & Cubes & 20.5 & - & 30 & 390 & 190 & 390 & Face Shell & Stack & 2 & 2.1 & 16.31 & $6 \%$ \\
\hline 247 & \multirow{2}{*}{ Hawk et al. } & 390 & 240 & 190 & 0.56 & 23.8 & & $\mathrm{~s}$ & Cylinderc & 22.9 & & 3 & 390 & 240 & 390 & & Stack & 2 & 1.6 & 24.75 & \\
\hline 248 & & 390 & 190 & 190 & 0.56 & 19.4 & & $S$ & 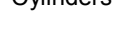 & 22.9 & & 3 & 390 & 190 & 390 & & Stack & 2 & 2.1 & 17.85 & - \\
\hline
\end{tabular}




\section{Appendix D}

\section{Database of the Compressive Tests for Grouted Hollow Block Masonry Prisms}




\begin{tabular}{|c|c|c|c|c|c|c|c|c|c|c|c|c|c|c|c|c|c|c|c|c|c|c|c|c|}
\hline \multirow{3}{*}{ No. } & \multirow{3}{*}{ Author } & \multicolumn{6}{|c|}{ Unit } & \multicolumn{4}{|c|}{ Mortar* } & \multicolumn{3}{|c|}{ Grout } & \multicolumn{10}{|c|}{ Prisms } \\
\hline & & \multicolumn{3}{|c|}{ Dimension (mm) } & \multirow[b]{2}{*}{$\frac{5}{4}$} & \multirow{2}{*}{ 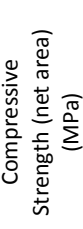 } & \multirow[b]{2}{*}{$\frac{\bar{o}}{\partial}$} & \multirow[b]{2}{*}{$\stackrel{\Perp}{\stackrel{2}{\gtrless}}$} & \multirow{2}{*}{ 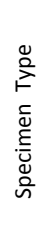 } & \multirow{2}{*}{ 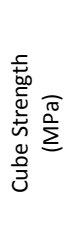 } & \multirow[b]{2}{*}{$\frac{\bar{o}}{\partial}$} & \multirow{2}{*}{ 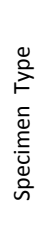 } & \multirow{2}{*}{ 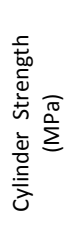 } & \multirow[b]{2}{*}{$\begin{array}{l}\bar{\alpha} \\
\text { ò }\end{array}$} & \multirow{2}{*}{ 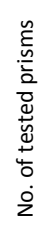 } & \multicolumn{3}{|c|}{ Dimension (mm) } & \multirow[b]{2}{*}{ 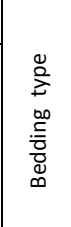 } & \multirow[b]{2}{*}{ 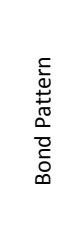 } & \multirow{2}{*}{ 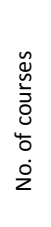 } & \multirow[b]{2}{*}{$\stackrel{t}{s}$} & \multirow{2}{*}{ 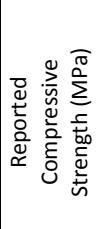 } & \multirow[b]{2}{*}{ ò } \\
\hline & & w & $\mathrm{T}$ & $\mathrm{H}$ & & & & & & & & & & & & $\mathrm{H}$ & w & T & & & & & & \\
\hline 1 & & 390 & 140 & 190 & 0.59 & 19.7 & 4.2 & $S$ & & 15.1 & & & 14.3 & & 5 & 589 & 390 & 140 & & Stack & 3 & 4.2 & 10.84 & 6.1 \\
\hline 2 & & 390 & 140 & 190 & 0.59 & 19.7 & 4.2 & $S$ & & 16.7 & & & 13.7 & & 5 & 589 & 390 & 140 & & Run. & 3 & 4.2 & 11.18 & 6.2 \\
\hline 3 & & 390 & 140 & 190 & 0.59 & 19.7 & 4.2 & s & & 17.3 & & & 13.7 & & 5 & 589 & 195 & 140 & & & 3 & 4.2 & 11.32 & 4.4 \\
\hline 4 & & 390 & 140 & 190 & 0.59 & 19.7 & 4.2 & $\mathrm{~N}$ & & 5.73 & & & 15.7 & & 4 & 589 & 195 & 140 & & & 3 & 4.2 & 10.50 & 3.3 \\
\hline 5 & & 390 & 140 & 190 & 0.59 & 19.7 & 4.2 & $S$ & & 14.2 & & & 13.7 & & 5 & 589 & 195 & 140 & & & 3 & 4.2 & 11.32 & 14 \\
\hline 6 & & 390 & 140 & 190 & 0.59 & 19.7 & 4.2 & $S$ & & 18.2 & & & 15.7 & & 4 & 589 & 195 & 140 & & & 3 & 4.2 & 12.08 & 3 \\
\hline 7 & & 390 & 140 & 190 & 0.59 & 19.7 & 4.2 & $S$ & & 15.8 & & $\varepsilon$ & 19.2 & & 5 & 589 & 195 & 140 & & & 3 & 4.2 & 12.83 & 6.4 \\
\hline 8 & & 390 & 140 & 190 & 0.59 & 19.7 & 4.2 & $S$ & & 13.5 & & 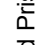 & 27.8 & & 4 & 589 & 195 & 140 & 흠 & & 3 & 4.2 & 13.39 & 7.2 \\
\hline 9 & $\begin{array}{l}\text { Drysdale and } \\
\text { Hamid (1979) }\end{array}$ & 390 & 140 & 190 & 0.59 & 19.7 & 4.2 & s & 通 & 13.5 & - & $\frac{0}{3}$ & 15.7 & - & 4 & 589 & 195 & 140 & $\overline{\bar{\omega}}$ & & 3 & 4.2 & 12.08 & 3 \\
\hline 10 & & 390 & 140 & 190 & 0.58 & 32.2 & 6.9 & $S$ & & 14.2 & & $\begin{array}{l}z \\
\text { i } \\
0\end{array}$ & 17.8 & & 4 & 589 & 195 & 140 & $\begin{array}{l}\infty \\
\Xi \\
0\end{array}$ & Stack & 3 & 4.2 & 16.91 & 2.3 \\
\hline 11 & & 390 & 140 & 190 & 0.58 & 32.2 & 6.9 & st & & 14.2 & & & 17.8 & & 4 & 589 & 195 & 140 & & & 3 & 4.2 & 16.42 & 5.2 \\
\hline 12 & & 390 & 140 & 190 & 0.70 & 22.0 & 4 & $S$ & & 14.2 & & & 19.8 & & 4 & 589 & 195 & 140 & & & 3 & 4.2 & 13.18 & 4.1 \\
\hline 13 & & 390 & 140 & 190 & 0.69 & 21.3 & 6 & $S$ & & 14.2 & & & 19.8 & & 4 & 589 & 195 & 140 & & & 3 & 4.2 & 14.15 & 4.7 \\
\hline 14 & & 390 & 140 & 190 & 0.64 & 20.2 & 5.4 & $S$ & & 14.2 & & & 17.8 & & 4 & 589 & 195 & 140 & & & 3 & 4.2 & 12.15 & 1.4 \\
\hline 15 & & 390 & 140 & 190 & 0.74 & 20.0 & 5.9 & $S$ & & 14.2 & & & 19.8 & & 4 & 589 & 195 & 140 & & & 3 & 4.2 & 14.70 & 9.2 \\
\hline 16 & & 390 & 140 & 190 & 0.61 & 15.6 & 8 & $S$ & & 14.2 & & & 19.3 & & 3 & 589 & 195 & 140 & & & 3 & 4.2 & 9.25 & 3.3 \\
\hline 17 & & 390 & 140 & 190 & 0.59 & 19.7 & 4 & $S$ & & 13.6 & & & 42.5 & & 4 & 589 & 195 & 140 & & & 3 & 4.2 & 15.18 & 6.9 \\
\hline 18 & & 406 & 203 & 203 & 0.56 & 21.0 & & $S$ & & 11.2 & & & 15.5 & & 3 & 416 & 406 & 203 & & & 2 & 2.0 & 16.20 & \\
\hline 19 & & 406 & 203 & 203 & 0.56 & 21.0 & & $S$ & बे & 11.2 & & $\frac{\grave{\phi}}{0}$ & 15.5 & & 3 & 629 & 406 & 203 & $\begin{array}{l}\overline{\bar{\Phi}} \\
\bar{\infty}\end{array}$ & - & 3 & 3.1 & 15.00 & \\
\hline 20 & & 406 & 203 & 203 & 0.56 & 21.0 & & $S$ & $\overline{\mathrm{J}}$ & 11.2 & & ত & 15.5 & & 3 & 842 & 406 & 203 & 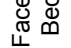 & के & 4 & 4.1 & 14.60 & \\
\hline 21 & & 406 & 203 & 203 & 0.56 & 21.0 & & $\mathrm{~s}$ & & 11.2 & & & 15.5 & & 3 & 1055 & 406 & 203 & & & 5 & 5.2 & 14.80 & \\
\hline
\end{tabular}




\begin{tabular}{|c|c|c|c|c|c|c|c|c|c|c|c|c|c|c|c|c|c|c|c|c|c|c|c|c|}
\hline 22 & \multirow{4}{*}{ Boult (1979) } & 406 & 203 & 203 & 0.56 & 24.5 & \multirow{4}{*}{-} & s & \multirow{4}{*}{ 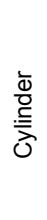 } & 11.2 & \multirow{4}{*}{-} & \multirow{4}{*}{ 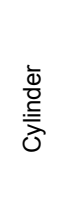 } & 15.5 & & 3 & 416 & 406 & 203 & \multirow{4}{*}{ 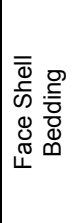 } & \multirow{4}{*}{ 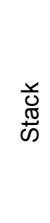 } & 2 & 2.0 & 17.10 & \\
\hline 23 & & 406 & 203 & 203 & 0.56 & 24.5 & & s & & 11.2 & & & 15.5 & \multirow{3}{*}{-} & 3 & 629 & 406 & 203 & & & 3 & 3.1 & 14.80 & \multirow{3}{*}{-} \\
\hline 24 & & 406 & 203 & 203 & 0.56 & 24.5 & & S & & 11.2 & & & 15.5 & & 3 & 842 & 406 & 203 & & & 4 & 4.1 & 13.20 & \\
\hline 25 & & 406 & 203 & 203 & 0.56 & 24.5 & & $s$ & & 11.2 & & & 15.5 & & 3 & 1055 & 406 & 203 & & & 5 & 5.2 & 12.60 & \\
\hline 26 & \multirow{7}{*}{ Hamid et al.(1979) } & \multirow{7}{*}{390} & \multirow{7}{*}{140} & \multirow{7}{*}{190} & \multirow{7}{*}{0.59} & 19.7 & \multirow{7}{*}{4.3} & $S$ & \multirow{7}{*}{$\begin{array}{l}0 \\
\stackrel{0}{J} \\
0\end{array}$} & 14.2 & \multirow{7}{*}{-} & \multirow{7}{*}{ 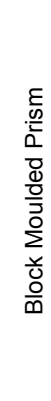 } & 11.1 & 9 & 5 & 589 & 195 & 140 & \multirow{7}{*}{ 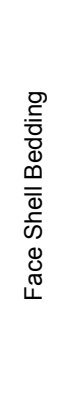 } & \multirow{7}{*}{$\begin{array}{l}\text { 总 } \\
\text { ci }\end{array}$} & 3 & 4.2 & 11.30 & 14 \\
\hline 27 & & & & & & 19.7 & & $\mathrm{~S}$ & & 18.2 & & & 12.7 & 9 & 5 & 589 & 195 & 140 & & & 3 & 4.2 & 12.07 & 3 \\
\hline 28 & & & & & & 19.7 & & $N$ & & 5.72 & & & 13.0 & 9 & 5 & 589 & 195 & 140 & & & 3 & 4.2 & 10.41 & 3.3 \\
\hline 29 & & & & & & 19.7 & & $\mathrm{~s}$ & & 15.8 & & & 15.5 & 4 & 5 & 589 & 195 & 140 & & & 3 & 4.2 & 12.83 & 6.4 \\
\hline 30 & & & & & & 19.7 & & $S$ & & 13.5 & & & 22.5 & 5 & 5 & 589 & 195 & 140 & & & 3 & 4.2 & 13.83 & 7.2 \\
\hline 31 & & & & & & 19.7 & & $S$ & & 13.5 & & & 12.7 & 8 & 5 & 589 & 195 & 140 & & & 3 & 4.2 & 12.07 & 3 \\
\hline 32 & & & & & & 19.7 & & $S$ & & 13.6 & & & 34.1 & 3 & 5 & 589 & 195 & 140 & & & 3 & 4.2 & 15.17 & 7 \\
\hline 33 & \multirow{9}{*}{$\begin{array}{l}\text { Drysdale and } \\
\text { Hamid (1983) }\end{array}$} & 390 & 190 & 190 & 0.53 & 25.1 & & $S$ & & 17 & & & 19.0 & & 5 & 589 & 390 & 190 & & & 3 & 3.1 & 14.40 & 3.3 \\
\hline 34 & & 390 & 190 & 190 & 0.53 & 25.1 & & $s$ & & 17 & & & 12.3 & & 4 & 589 & 390 & 190 & & & 3 & 3.1 & 14.10 & 11 \\
\hline 35 & & 390 & 190 & 190 & 0.53 & 17.1 & & $S$ & & 17 & & $\varepsilon$ & 19.0 & & 3 & 589 & 390 & 190 & & & 3 & 3.1 & 11.00 & 16 \\
\hline 36 & & 390 & 190 & 190 & 0.53 & 27.9 & & $S$ & & 17 & & $\frac{1}{2}$ & 19.0 & & 3 & 589 & 390 & 190 & 言 & & 3 & 3.1 & 15.00 & 7.2 \\
\hline 37 & & 390 & 190 & 190 & 0.53 & 20.2 & - & $\mathrm{s}$ & $\frac{0}{3}$ & 17 & - & $\frac{d}{3}$ & 19.0 & - & 4 & 589 & 390 & 190 & $\overline{\bar{\Phi}}$ & 兽 & 3 & 3.1 & 14.10 & 2.3 \\
\hline 38 & & 390 & 190 & 190 & 0.75 & 22.2 & & $S$ & & 17 & & $\sum_{i}$ & 19.0 & & 3 & 589 & 390 & 190 & ల & & 3 & 3.1 & 14.50 & 4.5 \\
\hline 39 & & 390 & 140 & 190 & 0.54 & 23.6 & & $S$ & & 17 & & & 19.0 & & 4 & 589 & 390 & 140 & & & 3 & 4.2 & 13.80 & 6.5 \\
\hline 40 & & 390 & 190 & 190 & 0.53 & 25.1 & & $S$ & & 17 & & & 36.9 & & 3 & 589 & 390 & 190 & & & 3 & 3.1 & 15.40 & 7.4 \\
\hline 41 & & 390 & 240 & 190 & 0.52 & 23.4 & & $S$ & & 17 & & & 19.0 & & 4 & 589 & 390 & 240 & & & 3 & 2.5 & 11.40 & 11 \\
\hline 42 & & 390 & 190 & 190 & 0.51 & 19.2 & & $S$ & & 18.8 & & & 21.8 & & 3 & 390 & 390 & 190 & & & 2 & 2.1 & 18.80 & 12 \\
\hline 43 & Wong and $D$ & 390 & 190 & 190 & 0.51 & 19.2 & & $S$ & $\otimes$ & 18.8 & & $\bar{\Phi}$ & 21.8 & - & 3 & 589 & 390 & 190 & $\mid \begin{array}{l}\overline{\overline{0}} \\
\bar{\infty}\end{array}$ & 궁 & 3 & 3.1 & 14.90 & 9.5 \\
\hline 44 & (19 & 390 & 190 & 190 & 0.51 & 19.2 & & $S$ & $\tilde{u}$ & 18.8 & & ত & 21.8 & & 3 & 812 & 390 & 190 & 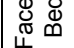 & ஸ゙ & 4 & 4.3 & 14.50 & 0.6 \\
\hline 45 & & 390 & 190 & 190 & 0.51 & 19.2 & & $S$ & & 18.8 & & & 21.8 & & 3 & 1016 & 390 & 190 & & & 5 & 5.3 & 13.00 & 3.5 \\
\hline 46 & & 390 & 140 & 190 & 0.58 & 17.7 & & $N$ & & 4.6 & & & 13.9 & & 3 & 589 & 390 & 140 & $\stackrel{9}{\subseteq}$ & & 3 & 4.2 & 12.92 & \\
\hline 47 & $\begin{array}{c}\text { Roman and } \\
\text { Romagna (1988) }\end{array}$ & 390 & 140 & 190 & 0.58 & 17.7 & - & $\mathrm{N}$ & $\frac{0}{3}$ & 4.6 & - & $\stackrel{0}{\frac{0}{7}}$ & 27.1 & - & 3 & 589 & 390 & 140 & 总 & $\begin{array}{l}\text { 离 } \\
\text { के }\end{array}$ & 3 & 4.2 & 15.50 & - \\
\hline 48 & & 390 & 140 & 190 & 0.58 & 17.7 & & $N$ & & 4.6 & & & 38.0 & & 3 & 589 & 390 & 140 & $\overline{\bar{u}}$ & & 3 & 4.2 & 18.20 & \\
\hline
\end{tabular}




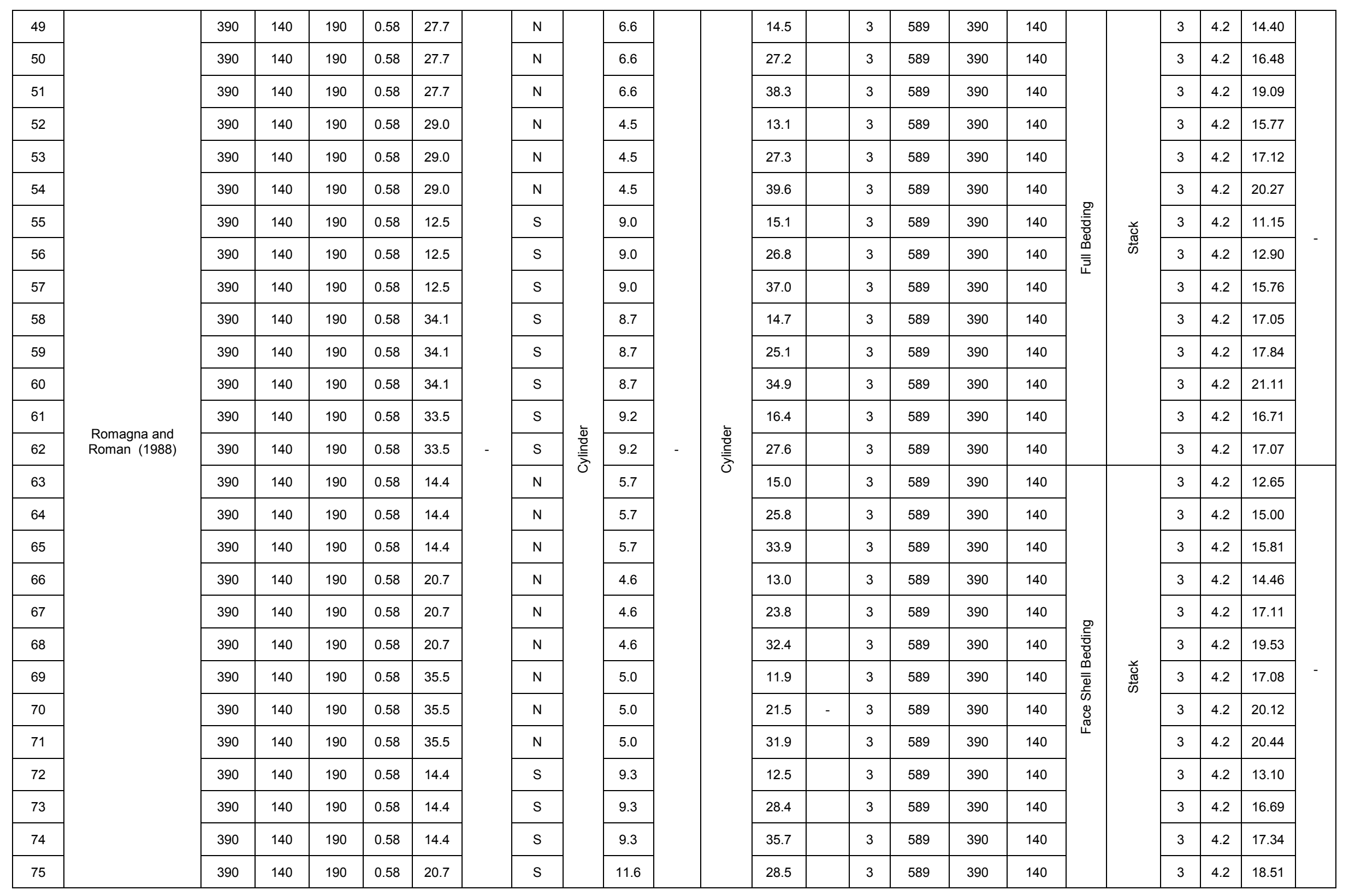




\begin{tabular}{|c|c|c|c|c|c|c|c|c|c|c|c|c|c|c|c|c|c|c|c|c|c|c|c|c|}
\hline 76 & \multirow{6}{*}{$\begin{array}{l}\text { Romagna and } \\
\text { Roman (1988) }\end{array}$} & 390 & 140 & 190 & 0.58 & 20.7 & & $S$ & \multirow{6}{*}{$\begin{array}{l}\frac{\bar{\phi}}{0} \\
\stackrel{\text { J }}{\mathrm{J}}\end{array}$} & 11.6 & \multirow{6}{*}{ - } & \multirow{6}{*}{$\begin{array}{l}\frac{\bar{d}}{0} \\
\text { 들 } \\
\text { d }\end{array}$} & 33.8 & & 3 & 589 & 390 & 140 & \multirow{5}{*}{ 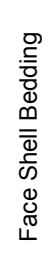 } & \multirow{6}{*}{$\begin{array}{l}\text { 弟 } \\
\text { के }\end{array}$} & 3 & 4.2 & 20.52 & \\
\hline 77 & & 390 & 140 & 190 & 0.58 & 35.5 & & $S$ & & 8.4 & & & 13.7 & & 3 & 589 & 390 & 140 & & & 3 & 4.2 & 18.18 & \\
\hline 78 & & 390 & 140 & 190 & 0.58 & 35.5 & & 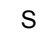 & & 8.4 & & & 25.5 & & 3 & 589 & 390 & 140 & & & 3 & 4.2 & 20.13 & \\
\hline 79 & & 390 & 140 & 190 & 0.58 & 35.5 & & $S$ & & 8.4 & & & 34.7 & & 3 & 589 & 390 & 140 & & & 3 & 4.2 & 25.12 & \\
\hline 80 & & 390 & 140 & 190 & 0.58 & 20.7 & & $S$ & & 11.6 & & & 12.8 & & 3 & 589 & 390 & 140 & & & 3 & 4.2 & 16.10 & \\
\hline 81 & & 390 & 140 & 190 & 0.58 & 33.5 & & $S$ & & 9.2 & & & 40.6 & & 3 & 589 & 390 & 140 & $\mathrm{FB}$ & & 3 & 4.2 & 17.14 & \\
\hline 82 & \multirow{7}{*}{ NCMA (1988) } & 397 & 193 & 193 & 0.51 & 13.3 & 2.5 & $\mathrm{~N}$ & \multirow{7}{*}{$\begin{array}{l}\mathscr{N} \\
\stackrel{0}{J} \\
\stackrel{0}{0}\end{array}$} & 6.62 & & \multirow{7}{*}{ 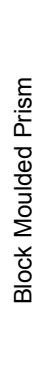 } & 18.7 & 16 & 3 & 396 & 397 & 193 & \multirow{7}{*}{ 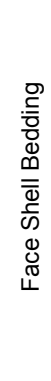 } & \multirow{7}{*}{$\begin{array}{l}\frac{r}{0} \\
\stackrel{\pi}{0}\end{array}$} & 2 & 2.0 & 15.00 & 3.0 \\
\hline 83 & & 397 & 193 & 193 & 0.51 & 13.3 & 2.5 & $\mathrm{~N}$ & & 6.62 & & & 22.6 & 2 & 3 & 396 & 397 & 193 & & & 2 & 2.0 & 16.40 & 2.5 \\
\hline 84 & & 397 & 193 & 193 & 0.57 & 32.7 & 1.6 & $S$ & & 19.9 & & & 41.5 & 6 & 3 & 396 & 397 & 193 & & & 2 & 2.0 & 34.18 & 6.6 \\
\hline 85 & & 397 & 193 & 193 & 0.57 & 32.7 & 1.6 & $S$ & & 19.9 & - & & 47.3 & 4 & 3 & 396 & 397 & 193 & & & 2 & 2.0 & 37.18 & 5.9 \\
\hline 86 & & 397 & 193 & 193 & 0.57 & 32.7 & 1.6 & $S$ & & 19.9 & & & 22.70 & 8 & 3 & 396 & 397 & 193 & & & 2 & 2.0 & 31.68 & 2.2 \\
\hline 87 & & 397 & 193 & 193 & 0.57 & 32.7 & 1.6 & $S$ & & 19.9 & & & 21.5 & 2 & 3 & 396 & 397 & 193 & & & 2 & 2.0 & 28.20 & 3.5 \\
\hline 88 & & 397 & 193 & 193 & 0.51 & 13.3 & 2.5 & $\mathrm{~N}$ & & 6.62 & & & 42.8 & 6 & 3 & 396 & 397 & 193 & & & 2 & 2.0 & 19.86 & 0.7 \\
\hline 89 & \multirow{4}{*}{$\begin{array}{l}\text { Scrivener and } \\
\text { Baker (1989) }\end{array}$} & 390 & 190 & 200 & 0.56 & 15.1 & 8 & $\mathrm{~N}$ & \multirow{4}{*}{$\begin{array}{l}\frac{\bar{\phi}}{0} \\
\frac{c}{\bar{J}}\end{array}$} & 8.9 & \multirow{4}{*}{ - } & \multirow{4}{*}{ 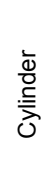 } & 16.4 & & 3 & 830 & 190 & 190 & \multirow{4}{*}{$\begin{array}{l}\overline{\bar{\Phi}} \\
\bar{\omega} \\
\mathbb{\Psi} \\
\tilde{\Psi} \\
\mathscr{\leftarrow}\end{array}$} & Stack & 4 & 4.4 & 14.7 & 12 \\
\hline 90 & & 390 & 190 & 200 & 0.56 & 15.1 & 8 & $\mathrm{~N}$ & & 8.9 & & & 16.4 & - & 3 & 830 & 190 & 190 & & Run & 4 & 4.4 & 11 & 13 \\
\hline 91 & & 390 & 190 & 200 & 0.56 & 15.1 & 8 & $\mathrm{~N}$ & & 8.9 & & & 22.0 & & 3 & 830 & 190 & 190 & & Stack & 4 & 4.4 & 12 & 19 \\
\hline 92 & & 390 & 190 & 200 & 0.56 & 15.1 & 8 & $\mathrm{~N}$ & & 8.9 & & & 22.0 & - & 3 & 830 & 190 & 190 & & Run & 4 & 4.2 & 11.3 & 11 \\
\hline 93 & \multirow{4}{*}{$\begin{array}{l}\text { Kingsley \& Noland } \\
\text { (1989) }\end{array}$} & 390 & 190 & 190 & 0.56 & 21.6 & & $S$ & \multirow{4}{*}{$\begin{array}{l}\mathscr{W} \\
0 \\
0 \\
0\end{array}$} & 21.6 & \multirow{4}{*}{-} & \multirow{4}{*}{$\begin{array}{l}\frac{\mathrm{d}}{0} \\
\frac{\mathrm{c}}{\mathrm{J}}\end{array}$} & 20.1 & & 2 & 407 & 390 & 190 & & & 2 & 2.1 & 21.57 & \\
\hline 94 & & 390 & 190 & 190 & 0.56 & 21.6 & & $\mathrm{~S}$ & & 21.6 & & & 20.1 & & 2 & 610 & 390 & 190 & $\frac{\Phi}{\omega}$ & 号 & 3 & 3.2 & 19.16 & \\
\hline 95 & & 390 & 190 & 190 & 0.56 & 21.6 & 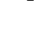 & $S$ & & 21.6 & & & 20.1 & & 2 & 812 & 390 & 190 & Ð & 亮 & 4 & 4.3 & 19.68 & 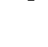 \\
\hline 96 & & 390 & 190 & 190 & 0.56 & 21.6 & & $S$ & & 21.6 & & & 20.1 & & 2 & 1016 & 390 & 190 & & & 5 & 5.3 & 18.64 & \\
\hline 97 & & 390 & 190 & 190 & 0.51 & 23.6 & 7 & $\mathrm{~s}$ & & 27.6 & 5 & & 25.5 & 5 & 3 & 590 & 390 & 190 & & & 3 & 3.1 & 17 & 8 \\
\hline 98 & & 390 & 190 & 190 & 0.51 & 23.6 & 7 & $\mathrm{~s}$ & & 32.3 & 7 & $\underset{\frac{E}{\omega}}{\varepsilon}$ & 25.5 & 5 & 3 & 590 & 390 & 190 & $\stackrel{\text { D }}{\text { : }}$ & & 3 & 3.1 & 18.7 & 3 \\
\hline 99 & & 390 & 190 & 190 & 0.51 & 23.6 & 7 & $\mathrm{~N}$ & & 10.8 & 9 & 8 & 34.5 & 6 & 3 & 590 & 390 & 190 & ల & (2) & 3 & 3.1 & 16.5 & 9 \\
\hline 100 & Yao(1989) & 390 & 190 & 190 & 0.51 & 23.6 & 7 & $\mathrm{~N}$ & 荨 & 10.8 & 9 & $\frac{\overline{0}}{\bar{z}}$ & 25.5 & 5 & 2 & 590 & 390 & 190 & $\overline{\overline{3}}$ & 产 & 3 & 3.1 & 16.3 & 17 \\
\hline 101 & & 390 & 190 & 190 & 0.51 & 23.6 & 7 & $\mathrm{~N}$ & & 10.8 & 9 & $x$ & 23 & 3 & 3 & 590 & 390 & 190 & & & 3 & 3.1 & 15 & 8 \\
\hline 102 & & 390 & 190 & 190 & 0.51 & 23.6 & 7 & $\mathrm{~N}$ & & 10.8 & 9 & $\frac{0}{m}$ & 25.5 & 5 & 3 & 590 & 390 & 190 & FS & & 3 & 3.1 & 14.4 & 3 \\
\hline 103 & & 390 & 190 & 190 & 0.51 & 23.6 & 7 & $\mathrm{~N}$ & & 10.8 & 9 & & 25.5 & 5 & 3 & 590 & 390 & 190 & FB & & 3 & 3.1 & 16.7 & 5 \\
\hline 104 & 1 & 390 & 190 & 190 & 0.56 & 20.0 & 10 & $\mathrm{~N}$ & $\mathrm{C}$ & 9.2 & & هి & 16.5 & & 3 & 589 & 390 & 190 & $R$ & Ctock & 3 & 3.1 & 15.80 & 13 \\
\hline 105 & 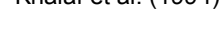 & 390 & 190 & 190 & 0.56 & 20.0 & To & $S$ & S & 13.5 & 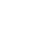 & $\mathcal{U}$ & 27.2 & 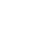 & 3 & 589 & 390 & 190 & T & Glavon & 3 & 3.1 & 17.90 & 4 \\
\hline
\end{tabular}




\begin{tabular}{|c|c|c|c|c|c|c|c|c|c|c|c|c|c|c|c|c|c|c|c|c|c|c|c|c|}
\hline 106 & \multirow{6}{*}{ Khalaf et al. (1994) } & 390 & 190 & 190 & 0.56 & 20.0 & \multirow{4}{*}{10} & $S$ & \multirow{6}{*}{$\begin{array}{l}\mathscr{E} \\
\stackrel{0}{J} \\
0\end{array}$} & 15.4 & & \multirow{6}{*}{$\begin{array}{l}0 \\
\stackrel{3}{3} \\
0\end{array}$} & 13.3 & & 3 & 589 & 390 & 190 & \multirow{6}{*}{ 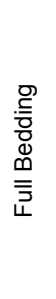 } & \multirow{6}{*}{ Stack } & 3 & 3.1 & 11.40 & 2 \\
\hline 107 & & 390 & 190 & 190 & 0.56 & 20.0 & & $S$ & & 20.2 & & & 20.0 & & 3 & 589 & 390 & 190 & & & 3 & 3.1 & 13.40 & 8 \\
\hline 108 & & 390 & 190 & 190 & 0.56 & 20.0 & & $S$ & & 26.8 & & & 28.9 & & 3 & 589 & 390 & 190 & & & 3 & 3.1 & 19.30 & 8 \\
\hline 109 & & 390 & 190 & 190 & 0.56 & 20.0 & & $S$ & & 26.5 & & & 24.5 & & 3 & 589 & 390 & 190 & & & 3 & 3.1 & 14.50 & 14 \\
\hline 110 & & 390 & 190 & 190 & 0.56 & 25.7 & \multirow{2}{*}{11} & $S$ & & 26.5 & \multirow{2}{*}{-} & & 24.5 & & 3 & 589 & 195 & 190 & & & 3 & 3.1 & 20.50 & 5 \\
\hline 111 & & 390 & 190 & 190 & 0.56 & 25.7 & & $S$ & & 26.5 & & & 38.5 & & 3 & 589 & 195 & 190 & & & 3 & 3.1 & 26.40 & 3 \\
\hline 112 & \multirow{8}{*}{$\begin{array}{l}\text { Steadman and } \\
\text { Drysdale (1995) }\end{array}$} & 390 & 190 & 190 & 0.56 & 27.8 & \multirow{8}{*}{ - } & $S$ & \multirow{8}{*}{$\begin{array}{l}\mathscr{0} \\
\mathbb{0} \\
0 \\
0\end{array}$} & 19.8 & \multirow{8}{*}{ - } & \multirow{8}{*}{ 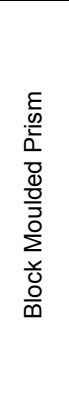 } & 38.8 & \multirow{8}{*}{-} & 3 & 812 & 390 & 190 & \multirow{8}{*}{ 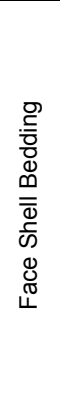 } & \multirow{4}{*}{ 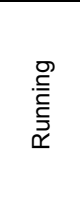 } & 4 & 4.3 & 18.30 & \multirow{8}{*}{ - } \\
\hline 113 & & 390 & 190 & 190 & 0.56 & 27.8 & & $s$ & & 19.8 & & & 22.4 & & 3 & 812 & 390 & 190 & & & 4 & 4.3 & 18.30 & \\
\hline 114 & & 390 & 190 & 190 & 0.56 & 27.8 & & $S$ & & 19.8 & & & 31.6 & & 2 & 812 & 390 & 190 & & & 4 & 4.3 & 21.20 & \\
\hline 115 & & 390 & 190 & 190 & 0.56 & 27.8 & & $S$ & & 19.8 & & & 39.8 & & 3 & 812 & 390 & 190 & & & 4 & 4.3 & 24.20 & \\
\hline 116 & & 390 & 190 & 190 & 0.56 & 27.8 & & $S$ & & 19.8 & & & 31.6 & & 3 & 812 & 390 & 190 & & Stack & 4 & 4.3 & 23.20 & \\
\hline 117 & & 390 & 190 & 190 & 0.56 & 40.0 & & $S$ & & 19.8 & & & 38.8 & & 2 & 812 & 390 & 190 & & \multirow{3}{*}{$\begin{array}{l}\text { O } \\
\text { 产 } \\
\text { 喜 }\end{array}$} & 4 & 4.3 & 24.70 & \\
\hline 118 & & 390 & 190 & 190 & 0.56 & 34.8 & & $S$ & & 19.8 & & & 38.8 & & 3 & 812 & 390 & 190 & & & 4 & 4.3 & 20.40 & \\
\hline 119 & & 390 & 190 & 190 & 0.56 & 40.0 & & $S$ & & 19.8 & & & 32.3 & & 3 & 812 & 390 & 190 & & & 4 & 4.3 & 28.50 & \\
\hline 120 & \multirow{6}{*}{$\begin{array}{l}\text { Baba and Senbu } \\
\quad(1986)\end{array}$} & 390 & 190 & 190 & 0.56 & 14.8 & \multirow{6}{*}{-} & $S$ & & 12.4 & & & 29.8 & & 1 & 589 & 190 & 190 & & & 3 & 3.1 & 12.70 & \\
\hline 121 & & 390 & 190 & 190 & 0.56 & 41.6 & & $S$ & & 12.4 & & क्ञ & 29.8 & & 1 & 589 & 190 & 190 & 을 & & 3 & 3.1 & 25.30 & \\
\hline 122 & & 390 & 190 & 190 & 0.56 & 41.6 & & $S$ & $\mathscr{E}$ & 12.4 & & 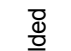 & 40.6 & & 1 & 589 & 190 & 190 & $\stackrel{\oplus}{=}$ & 이 & 3 & 3.1 & 24.30 & \\
\hline 123 & & 390 & 190 & 190 & 0.56 & 31.4 & & $S$ & $\vec{J}$ & 12.4 & & ${ }^{\overline{0}}$ & 29.8 & & 1 & 589 & 190 & 190 & $\begin{array}{l}\Phi \\
\text { ஸ }\end{array}$ & $\omega$ & 3 & 3.1 & 27.20 & \\
\hline 124 & & 390 & 190 & 190 & 0.56 & 31.4 & & $S$ & & 12.4 & & 흥 & 40.6 & & 1 & 589 & 190 & 190 & $\underset{ల}{0}$ & & 3 & 3.1 & 30.70 & \\
\hline 125 & & 390 & 190 & 190 & 0.56 & 14.8 & & $S$ & & 12.4 & & & 40.6 & & 1 & 589 & 190 & 190 & & & 3 & 3.1 & 12.60 & \\
\hline 126 & & 390 & 190 & 190 & 0.56 & 20.0 & 1 & $S$ & & 21.2 & & & 14.5 & & 3 & 390 & 390 & 190 & & & 2 & 2.1 & 16.8 & 6 \\
\hline 127 & & 390 & 190 & 190 & 0.56 & 20.0 & 10 & $S$ & & 26.6 & & & 17.7 & & 3 & 1190 & 390 & 190 & & & 6 & 6.3 & 15.20 & 6 \\
\hline 128 & 1 & 390 & 190 & 190 & 0.56 & 25.7 & 11 & $S$ & $\otimes$ & 26 & & 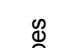 & 16.7 & & 3 & 1190 & 190 & 190 & 듬 & 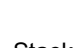 & 6 & 6.3 & 15.60 & 6 \\
\hline 129 & Knalar (1996) & 390 & 190 & 190 & 0.56 & 25.7 & 11 & $S$ & $\bar{J}$ & 21.2 & - & U & 14.5 & -- & 3 & 390 & 190 & 190 & $\begin{array}{l}\stackrel{\infty}{\equiv} \\
=\end{array}$ & Stack & 2 & 2.1 & 23.20 & 2 \\
\hline 130 & & 390 & 190 & 190 & 0.56 & 20.0 & 10 & S= & & 21.2 & & & 21.2 & & 3 & 589 & 390 & 190 & & & 3 & 3.1 & 14.5 & 8 \\
\hline 131 & & 390 & 190 & 190 & 0.56 & 20.0 & 10 & st & & 21.2 & & & 21.2 & & 3 & 589 & 390 & 190 & & & 3 & 3.1 & 12.8 & 8 \\
\hline 132 & $\begin{array}{l}\text { Thompson et } \\
\text { al.(2002) }\end{array}$ & 395 & 194 & 194 & 0.52 & 25.0 & - & $S$ & $\mathrm{Cu}$ & 22 & - & Сy & 15.9 & - & 5 & 397 & Stack & 194 & $\mathrm{FB}$ & Stack & 2 & 2.0 & 17.00 & 4.4 \\
\hline 133 & & 396 & 194 & 193 & 0.52 & & & & & & & & 17 & 12 & 5 & 802 & 396 & 194 & & & 4 & 4.1 & 12.8 & 4 \\
\hline 134 & Dunken (2008) & 396 & 194 & 193 & 0.52 & 33.8 & 4 & s & $\mathrm{Cu}$ & 19.2 & 13 & Cy & 30.7 & 8 & 5 & 802 & 396 & 194 & FS & Run. & 4 & 4.1 & 17.2 & 7 \\
\hline 135 & & 396 & 194 & 193 & 0.52 & & & & & & & & 27.5 & 11 & 5 & 802 & 396 & 194 & & & 4 & 4.1 & 19.6 & 9 \\
\hline 136 & CNMA (2012) & 394 & 194 & 194 & 0.52 & 14.1 & 6.6 & $S$ & $\mathrm{Cu}$ & 14 & 2 & BMP & 24.8 & 5 & 3 & 406 & 216 & 194 & $\mathrm{FB}$ & Stack & 2 & 2.1 & 15.3 & 2 \\
\hline
\end{tabular}




\begin{tabular}{|c|c|c|c|c|c|c|c|c|c|c|c|c|c|c|c|c|c|c|c|c|c|c|c|c|}
\hline 137 & \multirow{4}{*}{ CNMA (2012) } & 394 & 194 & 194 & 0.52 & 23.3 & 4.7 & $S$ & \multirow{4}{*}{$\begin{array}{l}\infty \\
\mathbb{8} \\
\stackrel{0}{7} \\
0\end{array}$} & 14 & \multirow{2}{*}{2} & \multirow{4}{*}{ 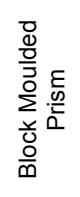 } & 25.9 & 1.5 & 3 & 406 & 216 & 194 & \multirow{4}{*}{ 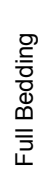 } & \multirow{4}{*}{ Stack } & 2 & 2.1 & 17.70 & 4 \\
\hline 138 & & 394 & 194 & 194 & 0.53 & 38.0 & 2 & $\mathrm{~s}$ & & 14 & & & 43.8 & 1.7 & 3 & 406 & 216 & 194 & & & 2 & 2.1 & 26.50 & 4 \\
\hline 139 & & 394 & 194 & 194 & 0.52 & 14.1 & 6.6 & $\mathrm{~N}$ & & 6.7 & \multirow{2}{*}{6} & & 24.8 & 5 & 3 & 406 & 216 & 194 & & & 2 & 2.1 & 14.00 & 4 \\
\hline 140 & & 394 & 194 & 194 & 0.52 & 23.3 & 4.7 & $N$ & & 6.7 & & & 25.9 & 1.5 & 3 & 406 & 216 & 194 & & & 2 & 2.1 & 16.40 & 3.6 \\
\hline 141 & \multirow{6}{*}{ Ross et al. (2013) } & 390 & 190 & 190 & 0.52 & 26.7 & 3 & $S$ & \multirow{6}{*}{ 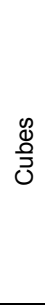 } & 15.1 & \multirow{6}{*}{-} & \multirow{6}{*}{ 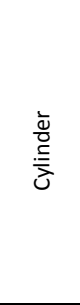 } & 22.16 & \multirow{6}{*}{ - } & 3 & 589 & 390 & 190 & \multirow{6}{*}{ 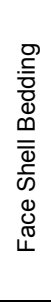 } & \multirow{6}{*}{ 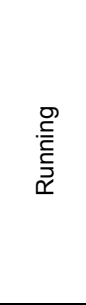 } & & 3.1 & 13.96 & \multirow{6}{*}{-} \\
\hline 142 & & 390 & 190 & 190 & 0.52 & 26.7 & 3 & $N$ & & 3.85 & & & 22.16 & & 3 & 589 & 390 & 190 & & & & 3.1 & 15.93 & \\
\hline 143 & & 390 & 190 & 190 & 0.52 & 26.7 & 3 & $s$ & & 13.6 & & & 22.16 & & 3 & 589 & 390 & 190 & & & & 3.1 & 17.4 & \\
\hline 144 & & 390 & 190 & 190 & 0.52 & 26.7 & 3 & $\mathrm{~N}$ & & 7.06 & & & 22.16 & & 3 & 589 & 390 & 190 & & & & 3.1 & 12.92 & \\
\hline 145 & & 390 & 190 & 190 & 0.52 & 33.0 & 13 & $s$ & & 22.8 & & & 10.60 & & 3 & 589 & 390 & 190 & & & & 3.1 & 16.98 & \\
\hline 146 & & 390 & 190 & 190 & 0.52 & 33.0 & 13 & $\mathrm{~N}$ & & 9.01 & & & 10.60 & & 3 & 589 & 390 & 190 & & & & 3.1 & 14.67 & \\
\hline 147 & \multirow{5}{*}{ Fortes et al.(2014) } & 390 & 140 & 190 & 0.58 & 21.6 & 14.3 & $N$ & \multirow{5}{*}{$\begin{array}{l}\stackrel{0}{0} \\
\stackrel{0}{J}\end{array}$} & 5.1 & 3.7 & \multirow{5}{*}{ 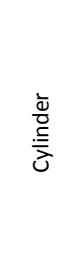 } & 26.1 & 12 & 5 & 390 & 390 & 140 & \multirow{5}{*}{ 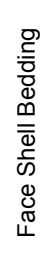 } & & 2 & 2.8 & 16.6 & 11 \\
\hline 148 & & 390 & 140 & 190 & 0.58 & 27 & 13.7 & $N$ & & 7.1 & 4.8 & & 31.0 & 6.8 & 5 & 390 & 390 & 140 & & Stack & 2 & 2.8 & 20.1 & 11 \\
\hline 149 & & 390 & 140 & 190 & 0.58 & 38.9 & 9.8 & $S$ & & 10.9 & 5.1 & & 33.7 & 4.6 & 5 & 390 & 390 & 140 & & & 2 & 2.8 & 23.8 & 7.4 \\
\hline 150 & & 390 & 140 & 190 & 0.58 & 37.8 & 8.1 & $S$ & & 10.1 & 3.2 & & 39.2 & 6.1 & 5 & 390 & 390 & 140 & & & 2 & 2.8 & 26.1 & 4.2 \\
\hline 151 & & 390 & 140 & 190 & 0.58 & 41.1 & 8.8 & $S$ & & 11.5 & 4 & & 41.2 & 7.7 & 5 & 390 & 390 & 140 & & & 2 & 2.8 & 26.3 & 2.9 \\
\hline 152 & & 397 & 194 & 194 & 0.52 & 28 & & $S$ & & & & & & & 5 & 400 & 397 & 194 & & & 2 & 2 & 19.6 & 2 \\
\hline 153 & Dome & 397 & 194 & 194 & 0.52 & 28 & 0 & $S$ & $\Phi$ & 17 & 7 & ষ্ঠ & $10 ?$ & 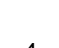 & 5 & 600 & 397 & 194 & & D) & 3 & 3 & 20.2 & 10 \\
\hline 154 & Das cial. (20 14) & 397 & 194 & 194 & 0.52 & 28 & 2 & $S$ & 0 & 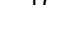 & & ১) & 10.0 & 4 & 5 & 800 & 397 & 194 & 10 & 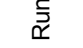 & 4 & 4 & 16.3 & 5 \\
\hline 155 & & 397 & 194 & 194 & 0.52 & 28 & & $S$ & & & & & & & 5 & 1000 & 397 & 194 & & & 5 & 5 & 17.2 & 9 \\
\hline 156 & Hegemier et al. & 394 & 190 & 194 & 0.56 & 25.6 & 11 & $S$ & 요 & 11.9 & - & & 18.6 & 4.2 & 3 & 390 & 390 & 190 & $F P$ & Ctonk & 2 & 2.1 & 16.61 & 9 \\
\hline 157 & (1991 & 394 & 190 & 194 & 0.56 & 25.6 & 11 & $S$ & 0 & 11.9 & & & 18.6 & 4.2 & 3 & 390 & 390 & 190 & rD & Slack & 2 & 2.1 & 15.07 & 16 \\
\hline 158 & & 390 & 190 & 190 & 0.56 & 25.9 & & $S$ & & 12.4 & & ర & 24.6 & & 5 & 390 & 390 & 190 & & & 2 & 2.1 & 15.59 & 7 \\
\hline 159 & Cheer & 390 & 190 & 190 & 0.56 & 25.9 & 18 & $S$ & ® & 12.4 & 13 & 흥 ह & 24.6 & 17 & 11 & 390 & 390 & 190 & 棓 & Stack & 2 & 2.1 & 15.39 & 11 \\
\hline 160 & Klinker (1984) & 390 & 190 & 190 & 0.56 & 25.9 & 10 & $S$ & $\overrightarrow{0}$ & 12.4 & 10 & $\frac{z}{0}$ & 24.6 & 10 & 7 & 390 & 390 & 190 & $\stackrel{\infty}{=}$ & Slack & 2 & 2.1 & 16.22 & 7 \\
\hline 161 & & 390 & 190 & 190 & 0.56 & 25.9 & & $S$ & & 12.4 & & & 24.6 & & 6 & 390 & 390 & 190 & & & 2 & 2.1 & 13.65 & 3 \\
\hline 162 & Sakr and Nies & 390 & 190 & 190 & 0.56 & 16.5 & & $S$ & $C_{1}$ & 12.4 & & 8 & 28.6 & - & 4 & 390 & 390 & 190 & $F P$ & Stont & 2 & 2.1 & 18.50 & \\
\hline 163 & (1989) & 390 & 190 & 190 & 0.56 & 16.5 & - & $S$ & Cu & 12.4 & -- & $\frac{\partial}{\bar{z}} \varepsilon$ & 28.6 & & 17 & 390 & 390 & 190 & rD & Slack & 2 & 2.1 & 23.80 & - \\
\hline 164 & Royton ot ol (1080) & 400 & 200 & 200 & 0.56 & 22 & & $\mathrm{~N}$ & $C_{1}$ & 6.7 & & 远 & 34.7 & - & 2 & 600 & 400 & 200 & ER & Stont & 3 & 3.0 & 17.00 & \\
\hline 165 & Daxtent El al.(1909) & 400 & 200 & 200 & 0.56 & 22 & - & $N$ & $\mathrm{Cu}$ & 6.7 & - & & 34.7 & & 2 & 400 & 400 & 200 & rD & Slack & 2 & 2.0 & 22.00 & - \\
\hline 166 & Olatunji et al.(1986) & 390 & 190 & 190 & 0.56 & 13.9 & - & $S$ & $\mathrm{Cu}$ & 10.5 & - & Cy & 11.42 & - & 3 & 589 & 390 & 190 & $\mathrm{FB}$ & Stack & 3 & 3.1 & 10.73 & - \\
\hline
\end{tabular}




\begin{tabular}{|c|c|c|c|c|c|c|c|c|c|c|c|c|c|c|c|c|c|c|c|c|c|c|c|c|}
\hline 167 & Olatunji et al.(1986) & 390 & 190 & 190 & 0.56 & 13.9 & - & $s$ & $\mathrm{Cu}$ & 10.5 & - & Cy & 11.42 & - & 3 & 589 & 589 & 190 & FB & Run & 3 & 3.1 & 8.42 & - \\
\hline 168 & \multirow{3}{*}{ Gou (1991) } & 390 & 190 & 190 & 0.56 & \multirow{3}{*}{25.1} & \multirow{3}{*}{5} & $S$ & \multirow{3}{*}{$\mathrm{Cu}$} & 10.9 & \multirow{3}{*}{ - } & \multirow{3}{*}{ Cy } & 10.2 & \multirow{3}{*}{-} & 5 & 790 & 390 & 190 & \multirow{3}{*}{ FS } & \multirow{3}{*}{ 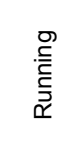 } & 4 & 4.1 & 12.9 & 5 \\
\hline 169 & & 390 & 190 & 190 & 0.56 & & & $S$ & & 11.3 & & & 35 & & 5 & 790 & 390 & 190 & & & 4 & 4.1 & 14.8 & 11 \\
\hline 170 & & 390 & 190 & 190 & 0.56 & & & $s$ & & 9.2 & & & 48.9 & & 5 & 790 & 390 & 190 & & & 4 & 4.1 & 19.5 & 5 \\
\hline 171 & $\begin{array}{c}\text { Thomas \& } \\
\text { Scolforo(1995) }\end{array}$ & 390 & 190 & 190 & 0.56 & 21.6 & - & $S$ & $\mathrm{Cu}$ & 20.5 & - & BMP & 19.0 & & 30 & 390 & 390 & 190 & $\mathrm{FB}$ & Stack & 2 & 2.1 & 18.64 & 5 \\
\hline
\end{tabular}

Notes:

* The mortar joint thickness is $10 \mathrm{~mm}$ unless otherwise stated

- The mortar joint thickness is $5 \mathrm{~mm}$

+ The mortar joint thickness is $20 \mathrm{~mm}$ 